\title{
Fauna of the Mediterranean Hydrozoa*
}

\author{
JEAN BOUILLON ${ }^{1}$, MARIA DOLORES MEDEL ${ }^{2}$, FRANCESC PAGÈS ${ }^{3}$, \\ JOSEP-MARIA GILI ${ }^{3}$, FERDINANDO BOERO ${ }^{4}$ and CINZIA GRAVILI ${ }^{4}$
}

\footnotetext{
${ }^{1}$ Laboratoire de Biologie Marine, Université Libre de Bruxelles, 50 Ave F. D. Roosevelt, 1050 Bruxelles, Belgium.

2 Departamento de Fisiología y Zoología, Facultad de Biologia, Universidad de Sevilla, Reina Mercedes 6 , 410121 Sevilla, Spain.

3 Institut de Ciències del Mar (CSIC) Passeig Marítim de la Barceloneta 37-49, 08003 Barcelona, Catalonia, Spain.

${ }^{4}$ Dipartimento di Scienze e Tecnologie Biologiche ed Ambientali, Stazione di Biologia Marina, Università di Lecce, 73100, Lecce, Italy.
}

\begin{abstract}
SUMMARY: This study provides a systematic account of the hydrozoan species collected up to now in the Mediterranean Sea. All species are described, illustrated and information on morphology and distribution is given for all of them. This work is the most complete fauna of hydrozoans made in the Mediterranean. The fauna includes planktonic hydromedusae, benthic polyps stages and the siphonophores. The Hydrozoa are taken as an example of inconspicuous taxa whose knowledge has greatly progressed in the last decades due to the scientific research of some specialists in the Mediterranean area. The number of species recorded in the Mediterranean almost doubled in the last thirty years and the number of new records is still increasing. The 457 species recorded in this study represents the $12 \%$ of the world known species. The fauna is completed with classification keys and a glossary of terms with the main purpose of facilitating the identification of all Meditrranean hydrozoan species.
\end{abstract}

Key words: Hydrozoa, hydromedusae, hydropolyps, siphonophores, taxonomy, systematics, fauna, Mediterranean.

RESUMEN: FAUNA DE HIDROZOOS DEL MEDITERRÁNEO. - Este estudio proporciona una relación sistemática de las especies de hidrozoos conocidas hasta la actualidad en el mar Mediterráneo. Se describen e ilustran todas las especies de las cuales se ofrece información sobre su morfología y distribución. Este trabajo es la fauna mas completa de hidrozoos hecha en el Mediterráneo. Esta fauna incluye las hidromedusas planctónicas, los estadios bentónicos de pólipos y los sifonóforos. Los Hydrozoa se han tomado como un ejemplo de taxones inconspicuos cuyo conocimiento ha progresado enormemente durante las últimas décadas gracias a la investigación de algunos especialistas en el area mediterránea. El número de especies citadas en el Mediterráneo se ha casi doblado en los últimos treinta años y el número de nuevos registros sigue incrementándose. Las 457 especies referenciadas en este estudio representan el 12\% del total mundial de especies. La fauna se complementa con claves de clasificación y un glosario de términos con el propósito de facilitar la identificación de todas las especies de hidrozoos del Mediterráneo.

Palabras clave: Hydrozoa, hidromedusas, hidropólipos, sifonóforos, taxonomía, sistemática, fauna, Mediterráneo.

\section{INTRODUCTION}

\section{The Mediterranean framework}

The Mediterranean Sea is located between Europe, Asia, and Africa. Excluding the Black Sea,

*Received June 24, 2004. Accepted July 15, 2004. it covers $2.542 .000 \mathrm{Km}^{2}$, with an average depth close to $1.500 \mathrm{~m}$ and a maximal depth of $5.121 \mathrm{~m}$ in the Ionian Sea. The Mediterranean Sea is an almost closed basin, connected with the Atlantic Ocean via the Strait of Gibraltar, with the Red Sea via the Suez Canal, and with the Black Sea via the Bosphorous and the Dardanelles Straits. Surface temperatures range between $11-13^{\circ} \mathrm{C}$ (with extremes of $4-5^{\circ} \mathrm{C}$ in 
the Gulf of Trieste) in winter and $25-30^{\circ} \mathrm{C}$ in summer, determining cold temperate to warm-temperate conditions in the cold season, and tropical conditions in the warm one. Deep-water temperature is about $13^{\circ} \mathrm{C}$ and, normally, this is also the surface temperature in winter, when the basin becomes homoeothermic. Summer thermoclines divide the variable surface waters from the more stable, deep waters. In the Mediterranean, evaporation exceeds both direct rainfall and the water input by rivers that, in general, drain rather arid countries. This balance explains the main properties of the sea. Water of relatively high salinity, an average of $37 \mathrm{psu}$, is formed by evaporative concentration and, being more dense, sinks to the bottom and falls across the Gibraltar sill into the Atlantic, at a level where Atlantic water has a lower density. The Mediterranean water pouring into the Atlantic sinks until it finds equal density, travelling northwards, along the Portuguese coast. The loss of deep Mediterranean water is over-compensated by a surface Atlantic current entering through Gibraltar Strait. These water exchange sums about $1,900 \mathrm{Km}^{3}$ per year, whereas the losses by evaporation could be of $1,300 \mathrm{Km}^{3}$ per year. This Mediterranean-Atlantic balance avoids excessive eutrophication (Margalef, 1985): the Mediterranean loses deep water, relatively rich with mineralised or recycled nutrients, and receives lownutrient surface Atlantic water.

The present-day situation is the result of a complex history. The Mediterranean Sea is a remnant of the once extensive Tethys Sea, a wedge-shaped, eastward-open equatorial water-body that was indenting Pangaea during the Triassic (Maldonado, 1985). In the Cretaceous, the Atlantic Ocean was formed and the Tethys connected it to the Indopacific Ocean, harbouring a highly diverse warm-water biota. In the Oligocene, a reduction in the surface of the Tethys Sea and a decrease of its warming influence on the world oceans caused cold water conditions elsewhere. Simultaneously, at the beginning of the Miocene (10 Ma), a biota extinction occurred outside the Tethys (Bianchi and Morri, 2000). During the Messinian crisis, about 5.5 Ma, the Mediterranean Sea became closed and evaporated almost completely, with just a few "pools" of water that allowed the survival of some paleoendemics, whereas the rest of the local biota went through a mass extinction. After the crisis, the present-day biota originated from a contingent that entered in the basal Pliocene (5.3 Ma) from the Atlantic Ocean through the newly opened Strait of Gibraltar. In spite of some relicts of the Tethys Sea (the IndopacificAtlantic connection of ancient times), most Mediterranean species are of Atlantic origin, having entered through Gibraltar from either the African or the European portion of the Atlantic. This made the Mediterranean biota an Atlantic province from a biogeographic point of view (Briggs, 1974). The alteration of the ice ages and warm interglacial periods during the Quaternary resulted in different immigration waves of Atlantic fauna of boreal or subtropical origin respectively (Bianchi and Morri, 2000). Considering the long and complex Mediterranean history, the present high species richness is probably due to both its evolutionary period through the Tertiary and the post-Pliocene diversity pump from the Atlantic Ocean.

Historical reasons are, however, just one side of the explanation of the rich Mediterranean biodiversity, the other side being strictly ecological: seasonality is the key for the coexistence of a high number of species (Coma et al. 2000). The same physical space, in fact, can widen its potential for life in another dimension, with the alternation of species in time.

The availability of proper conditions for both tropical and temperate species makes the Mediterranean a perfect sea for biological invasions (Boero, 2002). Species of cold affinity are thus pre-adapted to deep-waters and/or winter temperature conditions, whereas species of temperate affinity are preadapted to surface and/or summer conditions. Most Mediterranean life, in fact, is characterised by a sharp seasonality in its rhythms of activity, either in terms of actual presence (many species spend the adverse season as dormant or encysted stages) or in terms of sexual reproduction (Boero, 1994; Boero et al., 1996; Marcus and Boero, 1998). Biodiversity is not equally distributed throughout the basin (Arvanitridis et al., 2002). The Western Mediterranean is richer in species than the Eastern basin. Many explanations have been proposed for this pattern, including a low effort in biodiversity research. An historical-ecological reason might be that the Eastern basin is of greater tropical affinity that the Western basin and that the tropical species entering from Gibraltar found a temperate barrier that prevented them from reaching the portion of the basin with proper conditions for their establishment. The opening of the Suez Canal, in fact, allowed the entrance of Red Sea species that thrive now in the easternmost part (warmer in the winter than the rest of the basin) and can also widen their geographic range under partic- 
ularly favourable conditions. Very few Mediterranean species entered the Red Sea, since the more stable physical conditions have selected there a specialised biota that easily out compete the less focused Mediterranean species. The establishment of so many Lessepsian species in the Eastern Mediterranean led Por (1989) to propose a new biogeographical province: the Lessepsian Province. This establishment of many new species of tropical affinity suggests that the Eastern Mediterranean, after the opening of the Suez Canal, is fulfilling its potential of being inhabited by tropical species.

In addition to the entrance of new species from both Suez and Gibraltar (the Atlantic flow never stopped), the Mediterranean is experiencing also the transport of exotic species (Zaitsev and Öztürk, 2001) by ships, both in hulls' fouling and in the ballast waters of big cargoes. These release their ballast in the harbour of destination, and sail away with a load of goods. This pattern is particularly evident in the Black Sea, with the traffic of oil tankers that brought in ctenophores that impaired the yield of fisheries by feeding on fish larvae and on their food (CIESM, 2001, 2002). Another source of biological invasions is aquaculture. In addition, the growing number of allochtonous species recorded from the basin (e.g. the algal Caulerpa spp pool) can be surely due to unwanted (but very effective) humanmediated spreading. The recent natural history of the Mediterranean Sea is full of biological invasions, many poorly documented but inferable from the present observed distribution ranges of many species. After the waters of the Atlantic, however, that colonization process has always been regarded as a natural mechanism within the species' colonization strategies (Gili, 2000). For the past 200 years, the introduction of new species can no longer be regarded as natural, with mankind playing a major role. This historical process of migrations, colonisations, and invasions has been changing the marine ecosystem in the Mediterranean and has given rise to an underwater landscape that can be likened to a puzzle due to its high degree of heterogeneity.

A further impulse to the presence of alien species of tropical affinity is the undeniable temperature increase that characterises the Mediterranean surface waters since several years and that is probably due to a tendency towards global warming. The biological response to this trend is dramatic. Southern species are widening their geographical range; tropical species that enter the basin establish successful populations, like the Caulerpa spp., medusae like Rhopilema nomadica (Kideys and Gücü, 1995; Lotan et al., 1992; Avsar, 1999) and many fish species. Species of cold water affinity, furthermore, are affected by the deepening of surface thermocline and warm waters in the summer (Francour et al., 1994). Mass mortalities of gorgonians in the Ligurian Sea are most probably due to such impacts (Cerrano et al., 2000).

From all the above, it is evident that the Mediterranean biota are at the opposite extreme of IndoMalayan ones, characterised by an extremely long stability that yielded a very rich biodiversity that, in its turn, was exported to both nearby and distant zones. If seen in the framework of source and sink ecology (Pulliam, 1988), the Indo-Malayan region is a source and the Mediterranean is a sink.

As stressed by Maurer (1999), the extremely rich biodiversity of a given place might be an epi-phenomenon due to the immigration of species coming from different source populations. Applied to the Mediterranean, the problem is: are the newly formed populations liable of undergoing a separate evolution in respect to the source ones? Following the allopatric model of speciation, genetic bottlenecks and founder effects should affect the propagules originating new populations, leading to evolutionary novelties (or to dramatic failures) (Boero, 2002). Actually, the number of Mediterranean endemisms is very high (the most outstanding example is Posidonia oceanica, the trademark of the Mediterranean Sea) and accounts for the originality of the Mediterranean biota.

The natural experiment (enhanced by human activities) of species immigration is leading to an extraordinary blend of species that makes of the Mediterranean the ecological crossroad of the world ocean, with the fastest evolving biota in terms of both ecological and evolutionary time.

It is evident, from all this, that the Mediterranean has always been changing (both physically and biologically) and that the change of today is not the first revolution that the basin passed through. It is important, however, to distinguish human-generated changes from changes due to natural (or more global) forces.

The example of Caulerpa is paradigmatic. It might be possible, in fact, that $C$. taxifolia had been introduced in the basin by the careless management of some human enterprise (Meinesz, 1999), but the invasion by other species of the same genus, and their extraordinary success, calls for reconsideration 
of the causes of this phenomenon. Exotic Caulerpa species coul reach the Mediterranean many times in the past, but did not find proper conditions for development, whereas the present situation is conducive to their establishment.

\section{The Hydrozoa as an example of inconspicuous group}

The bulk of biodiversity, in terms of species numbers, is made of poorly known and inconspicuous species that, usually, can be noticed only by specialised taxonomists. Taxonomy, however, is disappearing from most scientific communities, and our appreciation of biodiversity is biased towards conspicuous groups. The Hydrozoa are an inconspicuous group whose knowledge greatly progressed in the last decades due to the presence of some specialists in the Mediterranean area. The number of species recorded from the Mediterranean almost doubled in thirty years and the number of new records is still increasing (Boero et al., 1997). The 457 species recorded in this fauna represent $12 \%$ of the world species described (Bouillon et al., in press). The ecological role of these animals, especially those represented also by a medusa stage, can be great due to their general ability to feed upon fish eggs and larvae and/or on the plankton that fish larvae feed upon, so acting as potential predators and/or competitors of commercial species. They might even be keystone predators, depressing potentially monopolising fish species, so leaving space for less competitive species (Piraino et al., 2002). Neglecting this apparently minor component of biodiversity might lead to ecological misunderstandings that, in their turn, might lead to misleading interpretations of the causes affecting the yield of fisheries. A worth-asking question is: are conspicuous groups sufficient to appreciate marine biodiversity and understand its functioning?.

The knowledge of the biogeography of Mediterranean Hydrozoa is far from being complete, not only due to the continuous recording of new species in the basin, but also due to insufficient or geographically too concentrated research efforts, so leading to inefficient coverage of distribution areas.

The case of the Hydrozoa shows that we are still very far from a proper evaluation of the structure of biodiversity, in terms of species presence and distribution, and that the understanding of biodiversity function, via the identification of species roles, is even less developed. The lack of specialists in almost every marine group will rapidly lead to the impossibility of pursuing this kind of studies, with the paradox that, in the era of biodiversity, biodiversity experts are disappearing, at least from Europe (Boero, 2001).

\section{The Hydrozoa of the Mediterranean Sea}

The study of Mediterranean Hydrozoa dates back to the dawn of modern zoology. Several Linnaean species thrive also in the Mediterranean and, in 1785, Cavolini reported on Eudendrium racemosum, probably the first species described as new to science from this Sea. Since the $19^{\text {th }}$ Century, oceanographic vessels explored seas and oceans far away from Europe and few expeditions surveyed the Mediterranean. The establishment of the Zoological Station of Naples in the same century, however, signed also the dawn of modern marine biology: people from all over the world came to the Mediterranean to study marine biology on a residential basis. Biological oceanography and marine biology stemmed from completely different approaches to marine science (oceanographic vessels Vs marine stations) but had the same original aim: the exploration of marine biodiversity. Oceanographers focused on distant parts of the world and/or to deep waters, whereas marine biologists focused on coastal areas that were particularly rich in biodiversity. Along with Naples, another possible location for a marine station was Messina, due to the strong currents of its Strait, which brought to the coast the unusual animals of deep waters. Metchnikoff (1886a, b) and Kölliker (1853a, b) worked extensively at Messina and gave important contributions to the knowledge of the Hydrozoa. The founders of Hydrozoan Zoology, with very few exceptions, were from Northern European Countries characterised by hostile climates and relatively poor faunas. They soon started to move towards the warmer and richer Mediterranean to perform their studies on living organisms. The pattern of activity of these non-residential researchers was dictated by climate and by their academic obligations. They usually worked in their home countries during the winter and moved towards the Mediterranean (mainly Naples) during the summer. This tendency marked sharply the type of Hydrozoan fauna that was going to be described because, as we have seen, the Mediterranean is a sharply seasonal sea. Other places where research on marine life became prominent were located in the Austro-Hungarian Empire at Trieste, Rovinj, Split,

\section{J. BOUILLON et al.}


and in France at Villefranche-sur-Mer, Endoume and Banyuls.

A very particular student of marine biology was Rupert Riedl. He went to Naples, and then to many other parts of the Mediterranean Sea, at the beginning of the Fifties and started the exploration of marine caves with SCUBA diving techniques. A new era of marine biology began, with the entrance of the scientist in the environment that was the object of his studies. Riedl (1959) studied the hydroids of marine caves and of rocky coasts in general, producing one of the first ecological papers on the group.

The new frontier of Hydrozoan studies originated in the first half of the $20^{\text {th }}$ Century, when the British school of Hydrozoan zoology, led by F.S. Russell and W.J. Rees, started to work at the building of a single classification for both hydroids and medusae. They opened a research project that is still far from being accomplished: reconstruct the life cycle of all species so to treat them as a single biological and taxonomical unit. In the Mediterranean, at the Naples Zoological Station, this project was the basis for a great enterprise that was expected to lead to the Hydrozoan Fauna of the Mediterranean. Bouillon, Brinckmann-Voss, Haeckel, Petersen, Stechow, Tardent, Vannucci, Uchida, Yamada and others amongst the most prominent researchers of Hydrozoa gathered at Naples and worked there for more than a decade. Unfortunately, the project was accomplished only in part and Brinckmann-Voss (1970) published just the first of a series of monographs that should have covered the Hydrozoa of the Mediterranean Sea. Another great contribution to the knowledge of Mediterranean Hydrozoa came from the work of Picard and a group of his pupils who, at the Endoume Marine Station, bridged taxonomy, phylogenetics and ecology. At the Zoological Station of Villefranche, a long series of papers mainly by Claude Carré and Danièle Carré gave a great contribution to the knowledge of the Siphonophora and of the Hydromedusae.

In 1985, at the Laboratory of Benthic Ecology of the Zoological Station of Naples, at Ischia, the Hydrozoan Society was founded, gathering most of the active students of the Hydrozoa from all over the world (Bouillon et. al. 1987). This gave new impulse to the study of the Hydrozoa and set the basis for a host of collaborations that has been increased with joint work and publications in following meetings of the Hydrozoan Society (Bouillon et al., 1992; Piraino et al., 1996; Mills et al., 2000).

\section{Origins of Mediterranean Hydromedusae: the case of the fauna of marine canyons}

The present Mediterranean hydrozoan fauna is composed of species referable to several biogeographic categories (Boero and Bouillon, 1993):

- Circumtropical species form the most abundant group with a temperate Atlantic-Mediterranean background.

- Cosmopolitan species, including panoceanic species occurring from the Polar seas to the Equator;

- Boreal Atlantic species, remnants of the iceages, especially of the Würm glacial.

- Tropical-Atlantic species which include interglacial remnants especially from the Tyrrhenian stage.

- Mediterranean-Atlantic species with eastern Atlantic migrants, specially into the Alborán Sea.

- Indo-Pacific species.

- Endemic species comprising both paleoendemics, of Tethyan origin, and neoendemics, mainly of Pliocene origin.

The origins, and the originality, of the fauna inhabiting the depths of the Mediterranean Sea are debated. The temperature there is constantly $13^{\circ} \mathrm{C}$, thus higher than that of the Atlantic, from where most of the Mediterranean fauna originated. The Gibraltar sill, moreover, is too shallow to permit the entrance of bathypelagic species in the Mediterranean after the Messinian crisis. Recent studies on Mediterranean submarine canyons provide important clues about some aspects of the origin of deep-sea biodiversity in the basin. Marine canyons are channels for the transport of large quantities of organic matter from the coastal region to the deep-sea via downwelling currents (Vetter and Dayton, 1998). They are systems with high production rates and hence locations capable of attaining high faunal richness. Submarine canyons, moreover, may strongly contribute to the biological production processes in many coastal regions via their upwelling currents (Della Tommasa et al., 2000). Furthermore, they may also play an important role in speciation processes affecting the deep-water fauna, as observed in the Foix, LacazeDuthiers, and Planier canyons, located in the western Mediterranean, where medusa species richness is high, with seven new species being found recently (38.8\% of the total) (Gili et al., 1998; Gili et al., 1999). This discovery raised the level of endemism in the deep-sea Mediterranean medusan fauna to $24 \%$. The species were collected by sediment traps located above the seabed at the $1000 \mathrm{~m}$ isobath in the 
canyons, a region inaccessible to conventional sampling methods.

The most important aspect of the discovery is the relationship between the number of individuals of endemic species and the ecological features of the submarine canyons. In the canyons, the number of individuals increased progressively as the total flux of organic matter reaching the interior of the canyons increased. In addition, canyons with close-together walls might increase isolation while attenuating hydrodynamic processes and are thus home to larger numbers of individuals. Furthermore, almost all the new species were endemic to one of the canyons, suggesting a high level of isolation inside. These canyons had ancestor paleocourses in the Messinian period (5 Ma ago), when the Mediterranean dried up nearly completely. Still, some areas, such as the deepest part of these canyons, were not completely dried up since Messinian evaporated deposits accumulated there (Hsü et al., 1978). This indicates that the deepest part of these canyons remained submerged during the Messinian times. The two new species of the genus Foersteria described in the Mediterranean ( $F$. antoni$a e$ in the Lacaze-Duthiers Canyon and $F$. araiae in the Foix Canyon) (Gili et al., 2000) have two congeneric species in the Pacific (F. purpurea) and Indian Oceans (F. bruuni). Probably, the common ancestor of both the Mediterranean species and the oceanic ones inhabited the Tethys Sea. That ancestral species underwent a process of allopatric speciation both worldwide, when the drying up of the Tethys Sea separated the Atlantic and the Pacific basins, and at a local scale, when the parallel canyons became separated as well. Indeed, the ecological differences between the canyons are probably responsible for generating the allopatric speciation found there.

The discovery of this singular medusan fauna is a key to investigate the origin of the Mediterranean deep-sea fauna. It also calls for the protection of marine biodiversity. Mediterranean submarine canyons incise the continental shelf and approach very close inshore. Mediterranean coastal regions are overpopulated and cause heavy environmental impacts that may be channelled through the submarine canyons and, consequently, that fauna is threatened and could disappear entirely even before it becomes fully known.

\section{Lists of Mediterranean Hydrozoa}

Picard (1958b) made a complete list of Mediterranean Antho- and Leptomedusae, summing up 191 species, to set the basis for a never to be made Faune de France volume on the group. Boero and Bouillon (1993) updated the work of Picard, treating all the Hydrozoa besides the Siphonophores, bringing the list to 346 records. Boero et al. (1997) further updated the list to 379 species. To these, the Siphonophora have to be added. Boero and Bouillon (1993) treated the life cycle patterns of the Hydrozoa and their bearing on the distribution of these organisms. They also defined zoogeographical regions having the Mediterranean as their centre, and made an analysis of the affinities of the fauna. These topics will not be treated further here.

A complete bibliographic database on the Hydrozoa is on line, and can be found at the following address: http://siba2.unile.it/ctle/hydro/index.php3.

\section{The records}

All species reported at least once from the Mediterranean are part of the list. Some records are old and need reconfirmation, but they were kept to help future workers that might find them again. As it happens for all groups, also in the Hydrozoa there are common and rare species. The history of records, however, indicates that the species contingent of the Mediterranean is going through great changes and that species that were not recorded in the past, presumably due to their rarity, are now common, whereas species that have been found in the past are not being reported anymore. Species records can be divided into the following categories:

a) "Evident" common species. These species are known since a long time and can be found in almost every sample from a proper environmental setting. Their list comprises popular species such as Eudendrium racemosum, E. glomeratum, Aglaophenia spp., Clytia hemisphaerica, Obelia dichotoma, $O$. geniculata, Dynamena disticha, Sertularella gaudichaudi and S. crassicaulis. The set of species inhabiting Posidonia leaves are part of this group, even though one of them, a Sertularella, is still to be described formally. Some common species, even of large size, can have been misidentified in the past, so that their names might be rather obscure. The most striking case is possibly Eudendrium armatum, a large species that can be invariably found on the roofs at the entrance of caves and crevices. Its general aspect resembles that of Eudendrium rameum and is possibly often reported with this name. Riedl (1959), in his monograph on the hydroids of Mediterranean caves, did not men- 
tion it, but recorded repeatedly $E$. rameum, even figuring it in his popular guides of the Adriatic and the Mediterranean flora and fauna. Confirmed records of Eudendrium rameum are very rare, whereas E. armatum is extremely common. Species very common in plankton communities along coastal waters mainly in spring-summer are the medusae Aglaura hemistoma and Rhopalonema velatum, and the siphonophore Muggiaea atlantica (e.g. Gili et al., 1988). Species more common in open waters, throughout the water column including deep layers are Solmissus albescens, Solmundella bitentaculata and the siphonophores Chelophyes appendiculata, Lensia conoidea and Abylopsis tetragona (Mills et al., 1996).

b) Cryptic species now collected more frequently due to increased sampling efficiency. Halocoryne epizoica, a species described by Hadzi in 1917 from the Adriatic Sea, was not found again until Picard reported it from the Ligurian Sea, fifty years later (see Piraino et al., 1992). The species was anyway so "rare" that Brinckmann-Voss (1970) could not find it while working at her monograph on capitate hydroids and medusae. Halocoryne epizoica is strictly symbiotic with the bryozoan Schizoporella sanguinea, a very abundant species in sea urchin barrens, at low depth. This type of environment is easily reachable by SCUBA diving techniques, but is not easy to sample from the surface with grabs and dredges. The yield of samplings, thus, can be biased by the employed techniques. This means that $H$. epizoica might have been common even in the past but that it passed unnoticed due to sampling difficulties. The same is true for Cytaeis schneideri (formerly referred to as Perarella schneideri), another specialist for symbiosis with bryozoans. Another example is the medusa Ptychogastria asteroides, previously found in two places in the Mediterranean but nowadays caught frequently by sediment traps located near the bottom of submarine canyons (Gili et al., 1999). The first casual records probably could indicate intrusion of waters from the deep sea to the continental shelf.

c) Species that are alternately rare and common. Paracoryne huvei became frequent and abundant for a relatively narrow time window. It cannot be missed or mistaken with anything else, since it lives in the infralittoral zone and is the only known Mediterranean hydroid that settles higher above the mean sea level. It forms large pink patches on black mussels and on bare rocks that can be seen while walking along the shore. Its polymorphic colonies are so different from those of any other species that Picard (1957), describing it as a new species, ascribed it to a new genus and a new family! It is almost impossible that such a species passed unnoticed to all the people who worked earlier on Mediterranean hydroids, if not for its extreme rarity. In the Seventies and Eighties Paracoryne huvei became common along the northern coasts of the Mediterranean and was repeatedly reported. Then it disappeared again and went back to rarity. The presence of resting stages in its cycle can be the reason why the species is able to disappear and reappear. Extra long diapause might be rather widespread in most species since all hydroids can become dormant while regressing to resting hydrorhizae. This pattern of presence makes it possible to be active during the favourable season, but might be also the way these animals can disappear for decades and be suddenly back again. This pattern is even more evident for their medusae! The second example refers to a species that was formerly very abundant and is now apparently rarer: Ectopleura crocea (=Tubularia crocea). Pierre Tardent worked extensively on populations of this species living in the Gulf of Naples. He chose it as experimental animal due to the ease of finding specimens in the harbour on every season. He went back to Naples after thirty years, considering the opportunity of performing more work but had to give up his project because he could not find a single specimen (personal communication to F.B.). It is possible that the period of commonness is rather long, as that of rarity. It is part of the ecology of all gelatinous plankton (and of its benthic counterpart) to be present with massive blooms or even outbreaks and to be absent even for decades thereafter. This is possible mainly due to the presence of benthic stages that can become encysted, so escaping most sampling efforts. Some holoplanktonic species follows high inter-annual bloom variation mainly in coastal waters. Over recent decades, man's expanding influence on the oceans has begun to cause real change and there is reason to think that, in some regions, new blooms of jellyfish are occurring in response to some of the cumulative effects of these impacts. Beyond that basic life cycle-driven seasonal change in numbers, several other kinds of events appear to be increasing the numbers of jellies present in some ecosystems (Mills, 2001). In the Mediterranean, the frequency of jellyfish blooms increased during the last decades causing important problems in the people that visit beaches during summer time. There are several hydrozoan species 
generating dense blooms that can be observed near the coast (e.g. Lizzia blondina, Velella velella).

d) Species that newly entered the basin. The study of Lessepsian migration from the Red Sea to the Mediterranean through the Suez Canal originated a wealth of information about Indo-Pacific species entering the basin (Por, 1978; Spanier and Galil, 1991). No such records regarding the Hydrozoa were noticed until recent times. Clytia gravieri, a nominal campanulariid species, however, was described from specimens coming from the Suez Canal by Billard (1938). Subsequently, it was considered as conspecific with Clytia linearis, a species first described from the Indo-Pacific. This species was first recorded from the Mediterranean in the Fifties and might be one of the first (and undetected as such) Lessepsian migrants. Now it is one of the commoner hydroids of shallow rocky Mediterranean coasts. Due to its branched habit, it is distinct from most other Clytia and it is highly improbable that in the past it was as abundant and frequent as it is now and that it simply passed unnoticed. Hydrozoan researchers found much more inconspicuous and relatively rare species than this one, so that they should have reported it frequently. Being a tropical species, it is probable that the recent tropicalisation of the Mediterranean favoured its success in the basin. Another way to enter the Mediterranean, of course, is through the Strait of Gibraltar. The study of the Hydrozoa of the Alborán Sea (Ramil and Vervoort, 1992; Medel and Vervoort, 1995; Medel et $a l ., 1998)$ is leading to many new records and this is evidently a hot spot of new entries from the Atlantic Ocean. A recent introduction is Clytia hummelincki. It was recorded in the Mediterranean for the first time in 1996, along the coasts of Calabria (Boero et al., 1997), almost in the centre of the basin. Being present both in the Atlantic and in the Pacific (with rare records) it is difficult to establish if it entered from Suez or from Gibraltar. At present, this species is very successful, forming a belt at $0.5-1 \mathrm{~m}$ depth in sea urchin barrens along the Apulian coast, where it is extremely common and abundant in the summer. Its distribution in the rest of the basin is unknown, probably because it can be mistaken with species of the genus Campanularia and only hydrozoan specialists can identify it properly. In the same period, Bitar and Bitar-Kouli (1995) recorded Macrorhynchia philippina from the coasts of Lebanon, undoubtedly a Lessepsian migrant. The area of Gibraltar still is a place where is easily to detect the presence of newly recorded species, such as the siphonophores Forskalia spp., which became more common in the entire occidental basin during the last years (Dallot et al., 1988). Another interesting species is the Antarctic anthomedusan Russellia mirabilis recently found in the Alboràn Sea (Pagès et al., 1999) and that arrived to the Mediterranean probably through a complex life cycle together with the transport role of Antarctic Intermediate and Bottom waters.

e) Species that are rare since their discovery. Rarity can be either soffusive, when a species is rare at many places but common at least at one, or diffusive, when a species is rare everywhere it occurs (Schoener, 1987). The number of records is not so great for most of rare species, and it is difficult to distinguish between the two types of rarity for any of them. Rarity, furthermore, can be geographical or ecological. Geographically rare species live in restricted areas, and are absent in other areas that, nevertheless, have the same features as the areas where they thrive. Ecologically rare species have very strict ecological requirements that are met just at few places; if their particular requirements are met, however, they are often present. For the Hydrozoa, furthermore, rarity can be also linked to seasonality, since some species can be present over a very short time window and become encysted (usually as hydrorhizae) for the rest of the year. The best example of this is Rhysia autumnalis, a species present only in autumn and that, furthermore, is strictly linked to serpulid tubes (Brinckmann, 1965b). Hydractinia inermis, on the contrary, is present for a short period in the spring, and disappears for the rest of the year. Information about rare species, though, is often insufficient to assign them to any particular category. The only Mediterranean hydrozoan that is mentioned in red lists is Errina aspera, probably due to its calcified skeleton, its resemblance to a coral and its restriction to the Strait of Messina (Zibrowius and Cairns, 1992) where, however, is very abundant, so being an example of soffusive rarity. A good example of rare species is Codonorchis octaedrus, described by Haeckel in 1879 from the Atlantic coast of France and never found again since Boero et al. (1997) reported its hydroid from a cave of the Ionian Sea, reconstructing its life cycle. In this case, however, rarity might be an artefact due to inconspicuousness of the hydroid and to the resemblance of the medusa to those of the genus Amphinema, so that the species might have been passed unnoticed as hydroid and misidentified as medusa. Some siphonophores 
(Rosacea villafrancae Carré, 1969) have not been recorded since their description probably because difficulties for taxonomic identification.

f) Declining species. This category is very elusive and might be included in that one comprising species that are alternately rare and common. The concern about species threatening and extinction invariably regards popular and conspicuous species, as the above-mentioned Errina aspera. This attitude is partly linked to the perception of species by the lay people, but has its foundation also in the attitude of researchers. If it is easy to recognise that a species has become abundant, in fact, it is more difficult to demonstrate that it has become rare, since absence is less evident than presence. In other words, researchers tend to stress what they find instead of what they do not find. To recognise decline we should be able to check the presence of species from the published records of all the researchers that worked on the group, comparing their results. A declining species might be one that is not found since fifty years, after having been found repeatedly during the previous fifty years, taking care of both the types of sampled environments and seasonality. If Eudendrium rameum is really a Mediterranean species and its records are not simply misidentifications of E. armatum, then this species is probably a declining one. One example of these declining species is also the siphohonophore Apolemia uvaria (Carré and Carré, 1994). It is important, thus, to reconstruct the history of the study of all species, so to have maps of their records and keep their "health" under control. At present, however, no hydrozoan species are sufficiently well known to deserve the status of either threatened or endangered. In this last case, it is important to mention the species that are continuously threatened and eliminated by trawlers. Lytocarpia myriophyllum, for instance, was very common on sandy and mud benthic shelf communities in the Mediterranean and is now much rarer than before (Gili et al., 1987).

\section{Seasonality and life cycles}

As stressed above, the Mediterranean is a markedly seasonal sea and its summer and winter faunas have different zoogeographical affinities and ecological requirements. The Hydrozoa, in particular, are mostly seasonal in occurrence and the possibility for the polyps to become encysted as resting hydrorhizae contributes to the presence of great differences in the species that can be found at a given place according to the season. Boero and Fresi (1986) studied the seasonality of nearly one hundred species of Antho- and Leptomedusan polyps at a single study site of the Ligurian Sea, showing the existence of two distinct hydroid faunas, characterising the warm and the cold season respectively. Boero et al. (1986) studied the seasonality of Eudendrium glomeratum, illustrating the sudden growth of its colonies and their equally sudden decline. The pattern of growth of most hydroids involves sudden colony appearance, production of gonophores (either fixed or as free medusae) and subsequent decline. The life of most medusae ranges between a few hours to one month, and the production of planulae, thus, takes place with such a delay from medusa liberation, whereas the colonies with fixed gonophores usually produce planulae directly. A reasonable expectation is that, after fertilisation and planula development, the population of hydroids will increase in number and density; instead, it usually suddenly declines. The obvious explanation is that either planulae or newly formed colonies are able to encyst and to wait for the following favourable season (or even successive ones) to produce noticeable and reproductive colonies.

Colonies, furthermore, can remain asexual for long times, without producing reproductive bodies (either medusae or fixed gonophores). This was stressed by Edwards (1973c) who observed that medusae of some species could be absent for years, being continuously present as hydroids only.

The gelatinous zooplankton species without benthic stages, however, can be sharply seasonal too, so generating doubts about their holoplanktonic way of life. Many plankters, in fact, have inconspicuous resting stages (see Boero et al., 1996; Marcus and Boero, 1998 for reviews) and easily escape detection. Many calanoid copepods, traditionally considered as holoplanktonic, spend the adverse season as benthic cysts, wrapped in a chitinous sheath. The perisarc of the Hydrozoa is made of chitin and the polyps easily form cysts with their hydrorhizae (Bouillon, 1995a).

The list of hydrozoan species from a given area, thus, cannot be the result of a single sample. Boero and Fresi (1986) reported two main seasons, having their centre in February and July, so that these two months might be sufficient to have an almost complete species list for a given locality. This, however, is not enough to find reproductive colonies, since gonophores can be produced for very short periods or, as we have seen, can be absent for several years, 
just as the whole colonies can, remaining present as dormant hydrorhizae. Carefully taken samples often give some novelties, even from the most explored coast, in terms of new records for the area, or of reproductive colonies of species with unknown life cycle, if not of species new to science. Boero et al. (1997), keeping a small substrate fragment in an aquarium, observed, in sequence, the appearance of Zanclea sp., Trichydra sp., Thecocodium brieni, Turritopsis nutricula and Codonorchis octaedrus. Evidently, these species coexisted as hydrorhizae on that small space and alternated in becoming active, a quite common behaviour for most hydroids.

Zooplankton studies in the northwestern Mediterranean showed seasonal changes in abundance for many medusae and siphonophores, such as the more common species, Aglaura hemistoma and Muggiaea atlantica, in consecutive years (Goy, 1985). This seasonal variation has been related to fluctuating local hydrographic conditions and primary production peaks (Gili et al., 1987). The maximum abundance of cnidarians in the plankton is observed when the water column is homogeneous, or when stratification begins, at the end of spring. Two main peaks have been described, the first one in April-May, dominated mainly by siphonophores in coastal waters. This siphonophore peak precedes the maximum abundance of medusae, which coincides with the yearly maximum of all zooplankton in the Mediterranean (Ribera d'Alcalá et al., 2004). The maximum siphonophore density is observed before that of the medusae and it could be explained because of the formation of polymorphic colonies with high growth rates (Purcell, 1982). The second period of siphonophore abundance, partly coming from the eudoxids produced during the first period, shows more marked peaks than that of medusae (Gili et al., 1987). The stability of the water column promotes the increase of zooplankton populations and, thus, of the gelatinous carnivore zooplankton, favoured by the availability of potential prey. Even the peaks of abundance of cnidarians are dominated by few species, their distribution and abundance will have a large influence on the whole community, allowing the presence of less competitive species at the end of the prevalence of the more abundant ones, such as $M$. atlantica and A. hemistoma. Seasonality and abundance are not independent. In general, significant differences in size among individuals of medusae and siphonophores have been observed in the same sample, but not in different periods of the year. This leads to explain that the cnidarian plank- tonic populations are continuously changing and that seasonal peaks of abundance show an increment of the total population but do not indicate a clear pattern of seasonal growth. Cnidarians perform daily migrations in the water column, with wider ranges in oceanic waters that near the coast. For almost all species, these vertical movements are closely related with the search of food (Mackie et al., 1987). In general, even though hydrodynamic conditions are important in determining spatial and temporal heterogeneity of cnidarians in the plankton, trophic relationships play a key role as well (Arai, 1988).

\section{The "role" of the Hydrozoa}

Ecological roles have been taken as a very important issue to emit judgement about the relevance of species, so to produce convincing evidence about the need for their protection (Piraino et al., 2002). This attitude, of course, implies that if a species has no recognised role, it is implicitly regarded as less important than a renowned species. This causes a great bias in the way we perceive biodiversity. We are attracted by conspicuous species. Our knowledge on the roles of species is so scant that we cannot consider any species as unimportant a priori. Only recently, for instance, it is generally perceived how phytoplankton is more important than (or at least as important as) tropical rain forests in maintaining the climate of the whole planet the way it is (Falkowski, 2002). Diatoms and flagellates are not as impressive as oaks and redwoods, just as copepods and small jellies are not as impressive as whales and sharks. Marine systems are based on microscopic life and, thus, are generally undervalued. Most conservation purposes are first biased in favour of terrestrial systems and, when the sea is considered, in favour of big, charismatic species, usually vertebrates and higher plants (with the sole exception of corals and some molluscs). The Hydrozoa are no exception and, thus, tend to be considered as "negligible" if compared to groups that are more "visible". This attitude is based on a naive way of conceiving ecology and is simply wrong. The case of Mnemiopsis lleydi, for instance, shows that a gelatinous predator can impair larval survival and subsequent recruitment of commercial fish, greatly impacting on human activities (see Boero and Briand, 2001). This ecological role might be played also by hydromedusae, since many species are of the right 
size to predate on fish eggs and larvae and, furthermore on their prey, so acting as both predators and competitors. The arrival of the already cited Clytia hummelincki in the Mediterranean, and its large hydroid populations, producing great numbers of relatively large medusae might play an important role in the success of fish recruitment, by removing eggs and larvae from the environment. The impact on biodiversity, however, might even be positive, since predation on the larvae of particularly successful fish species might decrease their abundance so to leave space for the development of previously outcompeted fish species, so enhancing fish diversity.

The difficulties of studying hydroids as part of the communities of hard substrates have limited appreciation of their importance in those communities. Most of the available knowledge comes from studies of artificial substrata placed in the sea for variable lengths of time (Boero, 1984; Gili and Hughes, 1995). Hydroids are often abundant in initial stages of colonization and in the later stages of community development by colonizing other organisms (Riedl, 1959). Once established, hydroids may prevent settlement by other colonizing species (Young and Chia, 1987). Obelia dichotoma inhibited settlement of other invertebrates, partly by eating their larvae (Standing, 1976), and the dense colonies of Hydractinia echinata prevented settlement and even overgrowth by other species by successfully defending the space (Sutherland and Karlson, 1977). The accumulation of sediment among and beneath the hydrocauli of Tubularia larynx may prevent settlement by the larvae of other species (Östman, 1977). Conversely, T. larynx may facilitate colonisation by other species, such as ascidians (Schmidt, 1983). While studies on artificial substrata may provide some idea of seasonal variations in species abundance within an area, it may be that only a small number of species colonise artificial substrata (Millard, 1959). In addition to their economic nuisance as members of the fouling community (Morri and Boero, 1986), hydroids may pose specific problems, for example in self-contained aquaculture systems, where they endure by developing resting stages capable of tolerating substantial changes in temperature and drying conditions (Sandifer and Smith 1979).

The hydroid polyps, furthermore, are also very important in the passage of energy from pelagic to benthic systems (Gili et al., 1998). The diet of most species studied, consisting largely of algal cells (e.g. Nemalecium lighti) and zooplankton (e.g. Eudendrium racemosum or Tubularia larynx). In some species, particulate organic matter (POM) also contributed a significant portion of the diet (e.g. Campanularia everta). Benthic organisms (e.g. nematodes or small bivalves) were found only occasionally. The diet of Silicularia rosea is almost exclusively benthic diatoms, captured when the bottom sediment is disturbed and resuspended. The results confirm that benthic hydroids can feed on a great variety of prey. Apart from zooplankton, they can feed on bacteria, protozoa, phytoplankton, detritus, and even on metabolites of algal origin or dissolved organic matter (Gili and Hughes, 1995). Hydrozoans account for a small fraction of total community biomass, and the amount of total energy they ingest is less than that recorded for dense populations of active suspension feeders such as bivalves. Nevertheless, the high capture rates recorded in all the species studied, and their often high densities, indicate that hydroids may play a significant role in energy transfer from the plankton to the benthos in shallow marine ecosystems as they capture up to $10^{5}$ prey items $\mathrm{m}^{-2} \mathrm{~d}^{-1}$ (Coma et al., 1995). The highest capture rates recorded were very similar to the rates observed in laboratory experiments in which feeding rates were maximal as food was not limiting (Gili and Hughes, 1995). Under natural conditions, colony growth rates may be very high, with duplication of colony biomass in less than a week (Hughes, 1983; Llobet et al., 1991), in which nearly $40 \%$ of energy consumption may be invested in growth during non-reproductive periods. In fact, hydroids are like plants they have indeterminate growth, the rate of which is determined by energy input, and will not grow at all, but will survive indefinitely, if energy is limiting (Gili and Hughes, 1995). Miglietta et al. (2000) reviewed on the ethology of both hydroids and medusae, revealing a great range of behavioural patterns.

\section{GENERAL CLASSIFICATION}

\section{Superclass HYDROZOA}

Definition: Cnidaria with either tetramerous, polymerous or, exceptionally, biradial symmetry; gastrovascular system simple, deprived of stomodeum (pharynx, actynopharynx), septa or gastric tentacles; mesoglea acellular; sexes generally separated; gametes, with few exceptions, ectodermal in origin (endodermal in the Polypodiozoa, Actinulidae, Nannocoryne mammylia, Pegantha 
clara and Solmaris flavescens), ripening usually in the ectoderm and shed directly to the outside, never into the gastrovascular cavity (except Polypodi$u m$ ?); medusae with velum (except Obelia), a muscular membrane projecting inwards from the umbrellar margin and partially occluding the umbrellar opening; polyps, when present, solitary or, most often, colonial, modular, with interconnected coelenterons, often polymorphic, with chitinous exoskeleton (perisarc), some secreting extensive calcium carbonate exoskeletons (coenosteum); cnidocysts of about 24 major categories, generally restricted to the ectoderm; atrichous isorhizas are the only cnidocyst type found throughout the Hydrozoa, never very common, but present at least in some species of all classes, they occur also in Anthozoa, Cubozoa and Scyphozoa; life cycles involving: 1) planulae developing directly of into medusae, or into intermediate "actinula"-like stages (Automedusa); 2) planulae developing indirectly into either solitary or modular, asexual polyps, generating planktonic, individual, sexual medusae usually by budding via a medusary nodule; 3 ) many paedomorphic species with various degrees of medusa reduction, reduced medusoids generally producing gametes without breaking away from polyp colony, sometimes functioning for the propulsion of planktonic colonies (Hydroidomedusa); 4) endocellular parasitic (polypoid?) stages producing free-living (medusoid?) tentacled stages (Polypodiozoa).

The Hydrozoa are a wide and heterogeneous group, comprising taxa that share few derived features, namely the velum, absent only in Obelia (see Boero et al., 1996 for a detailed treatment of the peculiarities of this medusa and on its possible origin), and the ectodermal "gonads". The superclass Hydrozoa comprises three classes: the Automedusa, the Hydroidomedusa and the Polypodiozoa (see Bouillon and Boero, 2000).

The Hydrozoa are important carnivores; they are among the strong planktonic and benthic predators, when abundant they are actually major consumers of crustaceans, fish larvae and other planktonic and epibenthic organisms. Some species may feed on bacteria, protozoans, phytoplankton and even dissolved organic matter, other species harbour symbiotic intracellular algae from which they may fix some nutrients. Hydromedusae have been used as biological indicators to predict movements of oceanic waters. Several species are known as indicators of upwelling systems.
Class AUTOMEDUSA Lameere, 1920 emend. (see Bouillon and Boero 2000).

(Actinulidae, Narcomedusae, Trachymedusae) (Figs. 1, 16A).

Hydrozoa with usually direct development and entirely pelagic life cycle, planulae never settle and acquire a benthic habit, each usually transforming into a single young medusa, except in parasitic forms; sexes separate; sex cells generally ripening in the ectoderm, each fertilised egg giving rise to a single medusa, except in some Narcomedusae where parasitic stages issue from the egg may give rise to several medusae by asexual budding; medusa formation without medusary nodule, subumbrellar cavity and velum formed by folding and deepening of the oral embryonic ectoderm, so being analogous to the subumbrellar cavity and velum of the Hydroidomedusa; primary marginal tentacles always formed before subumbrellar cavity and gastrovascular system; marginal tentacles deprived of tentacular bulbs (see peronia); sensory organs as ecto-endodermal statocysts, with an endodermal axis, growing out from circular canal, with sensory cells characterised by numerous kinocilium-lacking rootlets, surrounded by stereocilia, innervated by the upper nerve ring; lythocytes and statoliths of endodermal origin; asexual reproduction present only in "actinula"-like larvae and adults of Narcomedusae; frustules and cysts unknown.

Remarks: Intermediate tentaculated post-embryonic stages of Narcomedusae have been inappropriately called «actinulae», and considered identical with the Anthomedusae actinula. With the exception of the interstitial Actinulidae, the Automedusa are all oceanic, mainly represented by deep sea or open sea species. Their typically diploblastic "bauplan" limited their evolution so that, although having a very wide geographical distribution, the Automedusa show a limited generic and specific diversity. They may be considered as the most primitive of the recent Hydrozoa, similar to hypothetical ancestral Hydrozoa.

Class HYDROIDOMEDUSA Claus, 1877 emend. (Bouillon and Boero, 2000).

(Anthomedusae; Laingiomedusae; Leptomedusae; Limnomedusae; Siphonophorae)

(Figs. 2, 16B).

Hydrozoa usually undergoing indirect development through a succession of distinct stages. The 
"planula", a ciliated motile gastrula, typically developing into a benthic, modular, larval stage, the polyp (except in the Porpitidae, Margelopsis and Pelagohydra where the hydroid is floating). Polyps giving rise, by asexual budding, to planktonic, free-swimming and solitary hydromedusae, representing the sexual adult. Medusa often reduced to sporosacs (fixed gonophores), so that hydroids, by paedomorphosis, secondarily become the sexual stages. The Hydroidomedusa may also form pelagic swimming or floating, highly polymorphic modular colonies composed of several modified types of polyps and reduced medusae attached to a stolon supported by floating structures (pneumatophores and nectophores) (Siphonophorae).

Besides extreme cases of medusa reduction (e.g. Hydra and Rhysia), medusa budding occurs via a medusary nodule or entocodon, forming a coelomlike cavity, the subumbrellar cavity, lined by striated muscle cells; primary marginal tentacles always develop after subumbrellar cavity and gastro-vascular system. Both embryonic and larval stages, the planula and the polyp, typically diploblastic; adult sexual stages, the hydromedusae, acquiring a "triploblastic" kind of organisation during embryonic development (medusary nodule formation) (Boero et al., 1998).

Remarks: Hydroids can be solitary, but generally form modular colonies by simple budding. The colonies often produce polyps specialised for different functions, all having an interconnected coelenteron (defensive: dactylozooids, reproductive: gonozooids, nutritive: gastrozooids, etc.). The sense organs of pelagic hydroidomedusae, when present, are ocelli (Anthomedusae, some Leptomedusae), or statocysts (Leptomedusae, Limnomedusae); sometimes cordyli of unknown function are also present (Leptomedusae); siphonophores have no visible sense organs. Statocysts have different origins and structures: closed or open velar ectodermal statocysts are formed by the subumbrellar epithelium or velum epithelium (all Leptomedusae); ecto-endodermal closed statocysts are located in the mesoglea, near the ring canal or in the velum (Limnomedusae). The sensory cells of velar ectodermal statocysts are innervated by the lower nerve ring (= inner or subumbrellar) and, lacking stereocilia, are morphologically distinct from those of the sensory clubs of the Automedusa; lithocytes and statoliths are ectodermal in origin. Only the Limnomedusae, among the Hydroidomedusa, have ecto-endodermal statocysts, similar to those of the Automedusa. In both groups, statocysts are innervated by the upper nerve ring and also lithocytes and statoliths are of endodermal origin. The sensory cells of Limnomedusae statocysts are devoid of stereocilia. They present, thus, intermediate features between Leptomedusan and Automedusan statocysts. The presence of both a medusary nodule and of colonial modular hydroids suggests the inclusion of the Limnomedusae within the Hydroidomedusa.

The Hydroidomedusa have, with a few exceptions, separated sexes; the sex cells generally mature in the ectoderm. The fertilised oocytes give rise by gastrulation to typical planulae, which are very specialised contrary to Automedusa ones, containing (except in the Siphonophorae) cnidoblasts, different neural and glandular cell types and, often, interstitial cells. During the transformation of planulae into primary polyps, the embryonic neural and cementing glandular cells are destroyed. Hydroidomedusa are mostly marine, but some live in brackish or in freshwater, they are present at all latitudes and at all depths. Hydroidomedusae are frequently seasonal, the hydroid stage may develop several types of resting stages (frustules, propagules, cysts, dormant tissues in the stolon system) allowing them to overcome unfavourable ecological conditions.

\section{Class POLYPODIOZOA Raikova, 1988}

(Fig. 156)

Life cycle as a succession of a free-living stage and of a stage parasitizing the eggs of some Acipenseridae and Polyodontidae Pisces.

The earliest known stage is a binucleate cell, parasitizing previtellogenetic fish oocytes. Further development may last several years, leading to a convoluted didermic stolonal structure, with inverted germ layers, forming numerous inverted buds. Before fish spawning, eversion takes place and the germ layers take their normal position (ectoderm outside, endoderm inside). The stolon exits the egg and becomes fragmented into individual buds, each giving rise to a free creeping globular stage that multiplies by longitudinal fission. Globular stages can move and feed, having an oral mouth-cone and 24, 12 or 6 tentacles, according to season. Germ cells are endodermal. Socalled females with two kinds of "gonads", each with a gonoduct opening in the gastral cavity. So-called males deprived of gonoducts, their "gonads" forming gametophores carrying cnidocysts.

Remarks: It is not known how the parasites get into young previtellogenic fish oocytes. The free- 
living stages are presumably homologous to sexual medusae, the parasitic stages being considered as polypoid. By their stolonal parasitic budding stage and their cnidome, the Polypodiozoa seem to present some affinities with the Narcomedusae, to which they were previously assigned. This class comprises only Polypodium hydriforme Ussow, 1885 , which was till recently the only known metazoan adapted to an intracellular parasitic life.

For Siddall et al. (1995) the Myxozoa are related to Polypodium, and he proposed their demise as a phylum of protists and suggesting their inclusion in the Cnidaria, Hydrozoa, but for Okamura, Curry, Wood, and Canning (2002) the myxozoans are not Cnidaria but Bilateralia this based on significant differences between myxozoan Hox genes and cnidarian Cnox genes. On the other hand for Zrzavy and Hypsa (2003) Polypodium should not belong to the Cnidaria but together with the Myxozoa form a clade the Endocnidizoa that belongs to the Bilateralia clade. Pending more studies we tentatively retain the Polypodiozoa in the Cnidarians. The cnidocytes with their cnidocysts are one of the most complicated cellular structures of the animal kingdom and it is doubtful that they could have evolved twice in two very different clades one in the acoelomates, the Cnidaria and one in the Bilateralia the Endocnidozoa!

\section{GENERAL MORPHOLOGY OF HYDROIDS, MEDUSAE AND SIPHONOPHORES}

(see Thomas and Edwards 1991; Bouillon, 1995; Carré and Carré, 1995).

\section{Hydroids}

General appearance of colonies (Figs. 3 and 4)

Hydroids are generally colonial, bearing numerous individual polyps; some are solitary. Typically, they are permanently attached to their substrate but, exceptionally, they can be pelagic: Climacocodon, Margelopsis, Pelagohydra, and the Porpitidae. Solitary hydroids settling on hard substrates have a basal disc fixing them to their support, those settling on soft substrates have a pointed base and filamentous rootlets; both types of basal structures support a pedicel or hydrocaulus bearing a body, or hydranth, with an apical mouth normally surrounded by tentacles. In colonial forms, the basal area develops a system of hollow tubes, the stolons or hydrorhizae, which fix the colonies to the substrate and from which arise, from place to place, either sessile polyps, or polyps supported by a short pedicel, or large erect, often branched stems bearing numerous polyps, either sessile or pedicellate. Main stems and pedicels form the hydrocaulus; lateral branches bearing hydranths are the hydrocladia. Stolons, hydrocauli and hydrocladia are formed by ectoendodermal tubes surrounding a prolongation of hydranths' gastric cavities, enveloped by a protective chitinous layer, or perisarc. The living ectoendodermal part of the tubes is the coenosarc. It is by this common tubular system of coenosarc that all the hydranths making up a colony communicate with each other allowing, for instance, food circulation. The coenosarc represents the bulk of the living material of the colony.

New hydranths are always formed by asexual budding, this commonly leading to colony formation and growth. Hydranth budding rarely occurs on the hydranths, except in solitary forms, where lateral budding is a way of asexual reproduction leading to separate individuals. In colonial forms, budding usually occurs on stems and stolons. The medusae and their reduced equivalents bud off from hydranths, hydrorhizae, hydrocauli or hydrocladia.

Hydroidomedusae colonies have usually a reduced size most of them do not exceed a few centimetres to a few decimetres (i.e. Cladocarpus lignosus $70 \mathrm{~cm}$ ); the hydranths are usually very tenuous not exceeding a few millimetres, but there are exceptions (i.e. Hydrocoryne miurensis: $6 \mathrm{~cm}$; Corymorpha nutans: $12 \mathrm{~cm}$; Monocoryne gigantea: 40 $\mathrm{cm}$; Candelanbrum penola: $85 \mathrm{~cm}$; Branchiocerianthus imperator more than $2 \mathrm{~m}$ ).

\section{Morphology of polyps (Figs. 3, 5-9A,B)}

The hydranths (Figs. 5A: 1-8, 6),

The hydranth or feeding polyp, may have various shapes (urn-shaped, conical, club-shaped, cylindrical, etc.), with specialized zones:

Hypostome or proboscis. The apex of hydranths, above the tentacles when these are present, is differentiated into a hypostome or proboscis. Hypostomes are mostly either conical or dome shaped, rarely peduncled (Eudendriidae, Campanulariidae), always bearing a terminal mouth. The hypostome and the surrounding tentacles play an important role in feeding and in the first stages of prey ingestion. In the Cladonematidae the ectoderm of the hypostome is glandular and furrowed by a preoral cavity. A preo- 
ral cavity of very different origin is also observed in the Bonneviellidae, certain Tubulariidae and some Bimeria.

Gastric column. The gastric column is the main part of the hydranth. It is simple, internally not divided by septa, as it happens in the other cnidarian superclasses, but in certain species the endoderm may present folds and villosities increasing the absorption surface (i.e. Bonneviella, Candelabrum, Clava, and Koellikerina). It bears tentacles in some groups. Anthomedusae, Limnomedusae, and some Leptomedusae often differentiate medusary buds and gonophores at this level. The different steps of extracellular digestion and, according to species, intracellular digestion, take place in this zone too. In certain species, the contracted gastric column has a lateral expansion opposite the hydrocaulus (see Section below) forming the abcauline sac or abcauline caecum. In the Haleciidae, Plumulariidae, and Syntheciidae, the gastric endoderm is differentiated into two zones, the oral digestive one rich in glandular cells and digestive vacuoles, and the aboral nondigestive one.

Sphincter. The sphincter is a limited aboral portion of the hydranth. In the Anthomedusae polyps and in some Leptomedusan ones (e. g. Haleciidae, Eirenidae, etc.) the sphincter is usually represented by a zone at the base of the hydranth, deprived of tentacles, rich in muscular elements, whose endoderm, deprived of digestive inclusions, is formed by chordal cells. This region of reduced metabolic activity is interposed between the gastric column and the pedicel; its function is to isolate the column to the rest of the gastrovascular system so to allow localised digestion of prey and avoid the introduction of too large food items to the lumen of the stolonal system. In the Tubulariidae, a cushion of special endodermal cells projects into the basal part of the gastral cavity, functioning like a sphincter.

Tentacles. (Fig. 5A: 1-8, 7A) Tentacles are the most characteristic hydranth structures; they vary in type and structure according to the mode of distribution of cnidocysts on their surface.

The main types are:

-acnide: sensory tentacle deprived from cnidocysts (e.g. certain proximal tentacles of the Corynidae and Cladonematidae).

-capitate: tentacle or nematophore with a distinct large capitation (a knobbed end, or acrosphere), richly armed with cnidocysts (e.g. the Capitata).

-cateniform: tentacle with cnidocysts in a distinct large terminal capitation and with numerous small, spirally arranged cnidocyst clumps (e.g. Margelopsis and some Leptomedusae).

-filiform: thread-like straight tentacle, lacking prominent cnidocyst clusters, the cnidocysts appearing more or less evenly distributed (e.g. the Filifera and the majority of Leptomedusae polyps).

-monilifiliform: with dispersed small isolated clusters of cnidocysts on the adoral side of the tentacle and with a continuous band of cnidocysts along the aboral side (e.g. aboral tentacles of Tubulariidae)

-moniliform: with cnidocyts arranged in a terminal capitation and in rather regularly spaced conspicuous clumps or bands of tall epidermal cells bearing cnidocysts (e.g. Asyncoryne, Euphysa).

-pseudofiliform: tentacles with cnidocysts scattered in a relatively low epidermis along the adoral side and a concentration of cnidocysts in tall epidermis on the aboral side (e.g. oral tentacles of Tubulariidae) -ramified capitate: branched tentacles with a capitation on each branch (e.g. Cladocoryne).

-semifiliform: tentacle with a capitation stretched towards the aboral side (e.g. Pennaria, Paracoryne).

-semimoniliform: tentacle with a large capitation and numerous small cnidocyst clusters on the adoral side (e.g. Odessia).

A single polyp sometimes possesses different tentacle types (Cladonema, capitate and filiform; Euphysa, capitate and moniliform; Cladocoryne, capitate and ramified capitate; Pennaria, capitate and semifiliform).

Almost all hydranths have an oral tentacle circlet. Exceptions are atentacled hydranths (e.g. Craspedacusta, Limnocnida, Protohydra, Rhaptpagis) and those with a proboscis (e.g. Sphaerocoryne). Aboral tentacles, when present, can be either scattered or in one or several whorls. In exceptional cases tentacle arrangement is asymmetrical (e.g. Monobrachium, Proboscydactyla, Zanclella). The number of tentacles varies greatly, mostly oscillating between 8 and 50, sometimes less, exceptionally the number of tentacles is much higher, as in some solitary polyps (e.g. Monocoryne 110; Branchiocerianthus imperator 480; Candelabrum capensis 400 to 600; Candelabrum penola 330.000 !). In some Leptomedusan hydroids the bases of the tentacles are connected by an intertentacular web (or umbrellula).

Stolonal system (Fig. 3).

The hydrorhiza. Colonial forms are attached to the substrate by coenosarcal tubes usually contained in a perisarc sheath: the hydrorhiza. The stolonary gastric cavity is usually simple but is sometimes 
divided into several canalicules limited by endodermal cells (i.e. Asyncorynidae). The hydrorhizal stolons grow on the substrate, increasing the colony surface and, in many species, the medusary buds and the gonophores develop from their surface. Finally, under unfavourable conditions, the hydrorhizal tissues can become dormant, resorbing the rest of the colony. Hydrorhizae survive until proper conditions prevail again, then regenerating new colonies.

Some hydroid species are solitary and devoid of both sphincter and hydrorhizal system; they fix to substrates by an adhesive gelatinous or glandular disk (Hydra, Acaulis, Acauloides, etc.) or by an anchoring system of rootlets (Corymorpha, Candelabrum, Branchiocerianthus, etc.).

Colonies growing horizontally, with hydranths arising separately and directly from a common hydrorhiza, with or without a pedicel, are termed stolonal, or hydrorhizal. Erect colonies grow vertically, producing upright hydrocauli bearing more than one hydranth.

Hydrocaulus. (Figs. 3, 9A-B) The hydrocaulus is the main stem of a hydroid colony, arising from the hydrorhiza. It is simple (often called pedicel) in solitary or stolonal forms and in some unbranched colonies (e.g. Antennella); in most colonial forms, stems build up complex and varied colony forms: arborescent, bushy, cymose, flabellate, flexuose, pinnate (alternate or opposite), plumose, racemose, spiral, straight (biseriate or uniseriate), whorled or verticillate etc. Hydranths can be either on the hydrocaulus (cauline hydranths) and on all the branches, or exclusively on the branches, the most terminal ones being called hydrocladia. The hydrocaulus perisarc is usually divided into segments, or internodes, by partitions or nodes. In some Leptomedusae polyps, each internode may give origin to nematothecae and to one or two hydrothecae or hydrocladia with great regularity, each arising from a projection shoulder or apophysis. The hydrocaulus may be composed of a single coenosarcal tube (monosiphonic) or comprising two or more coenosarc tubes and form a composite stem structure, each tube retaining its perisarc (polysiphonic or fascicled). The coenosarcal cavity of the hydrocaulus is usually simple but it may be divided by endodermal canals in many Corymorphidae and Tubulariidae.

The form of erect colonies depends primarily on three main types of growth. (Figs. 9A, B).

- Monopodial growth with terminal hydranth (raceme). The first hydranth on the hydrocaulus is terminal. Below this hydranth there are a growthzone and a budding zone. Buds are formed in the budding zone and the hydrocaulus grows above them, so that the youngest bud is at the base of the stem and the oldest at the top. Each bud then grows in a similar manner and several degrees of branching may occur each branch topped by its oldest hydranth, e.g. most Anthomedusan colonies: Eudendrium, Bougainvillia, Pennaria.

- Monopodial growth with terminal growing point. There is no terminal hydranth, but the stem is topped by a growth-zone. Below the growth-zone is the budding zone, so that the oldest hydranth is at the base and the youngest one just below the tip, e.g. Plumulariidae, most Sertulariidae.

- Sympodial growth (cyme). The first hydranth is terminal, but it has no growth-zone and the stem does not elongate further. A budding zone below the hydranth produces a branch which grows beyond the first hydranth and is topped by the second hydranth. Continuation of this process produces a 'false axis' (the sympodium), which is in reality formed by successive branches (the podia), e.g. Haleciidae, Campanulinidae, Campanulariidae. Such a stem is usually zig-zag or geniculate.

\section{Perisarc: Stolons and stems}

The perisarc completely surrounds the stolonal system, the hydrocaulus and the hydrocladia of almost all hydroids, with the exception of some epizoic, parasitic or pelagic species, which are naked. Perisarcal structures are complex, being mainly composed of chitin and proteins; they are sometimes associated with calcareous elements (coenosteum). The perisarc serves for attachment, protection and support.

Generally present as distinct tubes running over the substrate, the stolons forming the hydrorhiza are sometimes fused or anastomosed in a complex and dense network covered with the common ectoderm of the colony. The perisarc covering the upper face of the stolons may even disappear, the hydrorhiza being then covered by naked coenosarc. The basal perisarc layer may produce spines which penetrate the coenosarc, reaching the surface (e.g. Hydractiniidae). The genera Hydrocorella and Janaria are similar to Hydractinia, but their skeleton is impregnated with calcium carbonate, as it is in the Milleporidae and Stylasteridae. In some erect flabellate species of Anthomedusan polyps, such as Solanderia and Pseudosolanderia, the perisarc forms a strong internal chitinous skeleton supporting the colonies. Pelagic hydroids (e.g. Margelopsis, 
Pelagohydra, Climacodon) are usually deprived from perisarc, however the Porpitidae have a chitinous float or pneumatocyte of perisarcal origin. The ectoderm sometimes gives rise to numerous digitations or villosities perforating the periderm and taking part in respiratory exchanges.

The chitinous perisarc of Anthomedusae polyps generally does not grow over the level of the hydranth sphincter, and the peduncle of medusa buds (except in Halitiara, Merona, Rhysia and Trichydra), but these are covered by a mucoproteinic periderm.

Hydrothecae (Figs. 4, 5A: 9-20, 5B: 1-11). In Leptomedusae polyps, the chitinous perisarc forms a solid theca around the hydranths (the hydrotheca), the reproductive organs (the gonotheca), and the protective polyps, or dactylozoids (the dactylotheca or nematotheca).

The hydrothecae usually have a chitinous diaphragm or an annular thickening at their base, isolating the inner space between the coenosarc and the perisarc from the outside water. The diaphragm is perforated, so to allow the passage of coenosarc. In the Syntheciidae, the Sertulariidae and the Plumulariidae the hydranth has a definite floor of perisarc with an asymmetrical or symmetrical hole or hydropore. The hydrothecae may be sessile or supported by a pedicel; sessile ones can be partly or wholly adnate to their support by their adcauline side, the abcauline one remaining free. The hydrothecal opening can be either unprotected or provided with either a single lid or an operculum, closing over the contracted hydranth. The operculum may be composed of several triangular flaps sharply or not sharply demarcated from hydrotheca. The hydrothecal rim may be cusped or even. The shape of cusps is often species-diagnostic. The hydrothecae often present internal cusps and one or more intrathecal septa. Hydrothecae may have alternate or opposite arrangement on stem and branches; single or in pairs, sometimes they are said subalternate or subopposite when there is an intermediate arrangement. Hydrothecae often regenerate, the new hydrotheca developing within the older one, repetition of this process is common in some families (e.g. Haleciidae, some Lafoeidae, some Sertulariidae).

The presence of a hydrotheca is a useful feature to identify Antho- and Leptomedusae polyps, respectively known as athecate and thecate. Such identification, however, is not always easy. On the one hand, some Anthomedusae polyps are provided with a pseudohydrotheca, not homologous to perisarcal hydrothecae but similar in function (Thamnostoma russelli, Bimeria vestita, Bougainvillia ramosa, Leuckartiara octona, Clathrozoella drygalskii etc.). On the other hand, many Leptomedusae polyps have very reduced thecae or even lack them (e.g. Halecium, Melicertum octocostatum, Eutima gracilis, Octorchis gegenbauri, Helgicirrha schulzei, Eugymnanthea, etc.).

In certain colonial forms (Limnocnida, Craspedacusta), the perisarc is reduced to the basal region, and is even lacking in some solitary species such as Hydra and Protohydra. In such cases, the hydranths are surrounded only by a mucoproteinic periderm.

Nematothecae. (Figs. 7C: 1-7, Fig. 8). The nematothecae contain the protective nematophores, they may be sessile or pedicellate, one-chambered (monothalamic) or two-chambered (bithalamic), movable or immovable. They are either irregularly arranged on the colony or grouped in a very distinct manner around the hydrothecae, as in the Aglaopheniidae, the Halopterididae, the Kirchenpaueriidae and the Plumulariidae. In these families, each hydrotheca has typically one basal (median inferior) nematotheca, and two lateral ones, one on each side. There may also be one or two nematothecae above the hydrotheca (superior nematothecae) and some on the hydrocaulus (cauline nematothecae) and on the hydrorhyza.

Gonothecae (Figs. 7B: 1-14, 8: A-D, H, I).The gonothecae are the chitinous structures surrounding the blastostyles or the gonophores, they are typically closed on top, until the developing embryos are ready to be released, they are often operculate. In some Leptomedusae with fixed gonophores the gonothecae have modified structures protecting the planulae until liberation, the "marsupium", formed by apical gonothecal expansions enveloping the planulae and forming an incubating chamber (e.g. some Diphasia and Thuiaria). The gonothecae may be simple or aggregated either into compound bodies "coppiniae", "glomulus" or "scapus", or protected by special outgrowths formed by the hydrocladia or modified hydrocladia: phylactocarps, corbulae. They often present a sexual dimorphism, the gonothecae being quite different in male or female gonangia.

\section{Polymorphism (Fig. 3)}

Hydroid colonies outstand by their polymorphism. In addition to the nutritive polyps (hydranths or gastrozooids) they often include: special sexual 
polyps, the gonozooids, bearing medusae or medusoids in various stages of regression; protective polyps usually lacking mouth and largely provided with cnidocysts, the dactylozooids or machozooids (of several types: tentaculozooids, spiralozooids, nematophores or sarcostyles); protective individuals not provided with cnidocysts, but constituting chitinous spines, the acanthozooids.

Medusae (Figs. 9C, 10-13).

The bell (Fig. 10A, B, 11A)

Hydrozoan medusae show essentially a tetramerous radial symmetry. Their main body, the swimming bell or umbrella, generally recalls the shape of a mushroom, a bell, a disk, a cone, a mitre etc., with considerable variation in form between species. The top of the umbrella is usually flattened, but some species may have a mesoglean thickening forming the apical projection or process, or may contain an apical canal (or umbilical canal) which is the remaining of the link between the gastric cavities of the mother hydroid and the medusa. The umbrella may also have exumbrellar cnidocyst patches, bands, or pouches (e.g. Zancleidae). Large hydromedusae can have a subumbrellar gelatinous projection (e.g. Aequorea). The umbrella of Hydroido- and Automedusae generally measures between $1 \mathrm{~mm}$ and $50 \mathrm{~mm}$, but in numerous species the size may be greater, reaching 100 to $200 \mathrm{~mm}$ (Aequorea) and even exceptionally $400 \mathrm{~mm}$ of diameter (Rhacostoma atlanticum). The main part of the umbrella volume is occupied by a gelatinous mass, the mesoglea, the jelly of the jellyfish, which confers form and buoyancy. The convex, upper (aboral) umbrellar surface is called the exumbrella; the concave, lower (oral) surface is termed the subumbrella; the space enclosed by the umbrella is the subumbrellar cavity.

\section{The velum (Figs. 10, 12, 13)}

The opening of the subumbrellar cavity is narrowed by a muscular horizontal marginal diaphragm, or velum, living only a central circular aperture, the velar opening. The velum plays an important role in medusan swimming; in certain medusae it is strongly developed and even hangs downwards like a curtain (some Trachymedusae); in Obelia it is absent. Two nerve rings are situated at the base of the velum, separated by the velar mesoglea.
The tentacles (Fig. 9C, 10, 12, 13)

The free rim of the umbrella usually bears marginal tentacles, often cirri of different kinds, usually associated with sensory cells and sense organs. In most medusae the tentacles are peripheral, in the Laingiomedusae and the Narcomedusae they are inserted on the exumbrellar surface. Tentacles show a great diversity in form and number. They are called solid, when their endoderm is formed by a core of single vacuolated cells (chordal cells); or hollow, when containing an extension of the circular canal (tentacular cavity) or when the endoderm is composed of several peripheral rows of cells coming in juxtaposition, the cavity being lost or only very partly retained at the tentacle base. Tentacle numbers may vary from zero to several hundreds (up to 640) according to species; their number does not necessarily equal the basic number of radial canals (4), or a multiple of it, but is usually not fixed, it may be even or uneven and is generally increasing with growth. Tentacles are armed with cnidocysts, formed either at the level of tentacular bulbs, or in a specialised marginal cnidocyst ring, when it exists. In species with marginal bulbs, the development of a tentacle is always preceded by the formation of a tentacular bulb.

There are different tentacle types according to the mode of distribution of the cnidocysts (see polyps and glossary). Cnidocysts may be disposed in a terminal button (capitate tentacles), in rings (moniliform tentacles), in spirals, or even irregularly along the tentacles (filiform tentacles). In some groups, tentacles bear specialized pedicellate and contractile stinging buttons, the cnidophores (e.g. Zancleidae). Tentacles are generally simple, but they can be bifurcated, one branch being armed with cnidocysts and the other one bearing adhesive organs (e.g. Cladonema, Eleutheria, and Staurocladia). When the tentacles are not in contact with the radial or circular canals they may present a tentacular endodermal root expanding in the umbrellar mesoglea (e.g. Blackfordia, many Narcomedusae).

Medusan species usually have tentacles of one kind; in a few species, however, two kind of marginal tentacles may be found (e.g. Liriope).

The bulbs (Figs. 12-13)

Tentacle bases are usually swollen into an enlargement, the tentacular bulbs; of various shape and size, they may be simple (bearing one tentacle) 
or compound (bearing two or more tentacles); sometimes they grow upwards, clasping the exumbrella with exumbrellar spurs; in some groups they may be absent (e.g. Calycopsidae, Limnomedusae, Trachymedusae). Not all marginal bulbs bear tentacles; some never do, they are called non-tentacular marginal bulbs, others will develop tentacles during growth (developing tentacular bulbs). Tentacular bulbs may carry ocelli, light-sensitive sense organs. In some species, tentacular bulbs have adaxial excretory pores, located or not at the apex of a papilla; sometimes the same structures can be found at the level of the circular canals. During development of species with more than 4 tentacles, the first tentacles to be formed are perradial, then interrardial, adradial and finally subradial; but after the adradial tentacles are formed the mode of tentacle appearance is often irregular.

\section{Marginal structures (Figs. 12-13)}

In addition to tentacles, the umbrellar margin may present other structures: marginal warts or swellings; sense organs like ocelli, different types of statocysts (open, closed, ectodermal, ecto-endodermal), and cordyli; small tentacular-like structures, or cirri, usually of two types: spiral or flexile; and, finally, marginal tentaculae (see glossary).

\section{Sense organs (Figs. 12-13)}

Ocelli. The eyes, or ocelli, are most developed in the Anthomedusae. They are also found in some Leptomedusae (e.g. Laodiceidae, Mitrocomidae, Tiaropsidae). From the outside, the ocelli appear as brown, red, or black spots on the tentacular bulbs or, in certain Leptomedusae, under the statocysts. Ocelli, according to the species, have a more or less complex structure. The eyes of Eleutheria, here considered as typical, are composed of a cupule constituted by intermixed ectodermal pigmented cells and by nerve cells, with a central crystalline formation. The whole is situated above the nettle ring, in the ectodermal layer from which it originates. In Tiaropsis, the pigment cells are endodermal.

Statocysts (lithocysts or otocysts). These organs of orientation and equilibrium are lacking in the Anthomedusae, but are present in the hydroids of Euphysa. They may be classified in two categories, those exclusively ectodermal, proper to Leptomedusae and those of ecto-endodermal origin, found in Limnomedusae, Actinulidae, Trachymedusae, and
Narcomedusae. The ectodermal statocysts of Leptomedusae develop in the velum, where they form open or closed pockets or vesicles, characterized by specialised cells, the lithocytes, containing a variable number of round concretions, called statoliths. The wall of the statocyst also bears sensory cells with long sensory bristles. According to the position of the medusa, the lithocytes press on the bristles, exciting the nerve cells.

The ecto-endodermal statocysts have a different structure. They are constituted by didermic clappers issued by the marginal circular canal in the fashion of a tentacle, and not by the velar ectoderm. The distal part of the clapper contains one or two endodermal cells provided with concretions (lithocytes). At the base of this club, ciliated sensory cells can be recognized. According to the inclination of the clapper, they strike the wall of the pocket or vesicle. Ecto-endodermal statocysts may be closed or open.

Cordyli. Ecto-endodermal sense organs in the form of clubs, devoid of statoliths, with or without cnidocysts. They are found implanted on the exumbrellar rim of the medusae of the families Hebellidae, Laodiceidae and Tiarannidae. Their function remains mysterious.

\section{The manubrium (Figs. 10A-B)}

From the centre of the subumbrella hangs, like the clapper of a bell, a tubular or quadrangular projection of various length and form, the manubrium. The base of the manubrium may be attached either directly to the subumbrellar roof or to a cone-shaped thickening of the mesoglea projecting downwards in subumbrellar cavity, the gastric peduncle. The manubrium may present an apical chamber, or caecum, extending in the mesoglea, and/or perradial or interradial manubrial pouches increasing the gastric surface and often bearing the gonads. The manubrium contains the gastric cavity that extends proximally into the radial gastrovascular canals and opens distally, inside or outside the subumbrellar cavity, by the mouth. The manubrium wall may be attached to radial canals and subumbrella by mesenteries of various lengths.

\section{The mouth (Figs. 11B, 12J)}

The mouth margin may be simple and circular or may have lips or lobes. The latter can be short or long, simple, folded or crenulated to varying degrees, with or without a cnidocyst armature. The 
mouth margin may have simple or branched oral tentacles.

\section{The gastrovascular system (Fig. 10)}

The gastric cavity, the radial canals, the circular canal and the tentacular canals, when they exist, form the gastrovascular system which serves for the digestion and distribution of food and for the circulation of oxygen, waste, cnidoblasts or even of gametes. The radial canals connect, through the mesoglea, the gastric cavity to the circular canal which runs all along the marginal rim of the umbrella; they are generally four, but can be more numerous, sometimes more than one hundred (e.g. 250 in Aequorea pensilis), usually even in number. The radial canals may be simple or branched, sinuous, jagged, denticulate, with diverticula etc. They usually develop centrifugally from the base of manubrium; a few medusae have nevertheless radial canals arising from circular canal (i.e. Melicertum, Orchistoma). Most of the canals issued from the circular canal, however, never reach the manubrium, and form the so-called centripetal canals. The radii corresponding to the radial canals are named the perradii, intermediate between them lie the interradii and midway between the perradii and the interradii are the adradii. The circular canal is usually simple and narrow; occasionally it is not hollow and consists of a solid core of endodermal cells (Laingiomedusae, Proboscydactyla). In the Narcomedusae, the circular canal, when present, follows the exumbrellar lobes and the peronia, forming what is called the peripheral canal system and the peronial canals (see glossary).

Crossing the mesoglea, a monostratified membrane, the "cathamnal" or endodermal lamella, interconnects the radial canals and, like these, connects the gastric cavity with the circular canal. It delimits two mesoglean layers, one thin, subumbrellar (inner mesoglea), the other well-developed, exumbrellar (outer mesoglea).

The gonads (Figs. 10, 11C)

The sex cells may develop and ripen either on the manubrium, or on the radial canals, or on both. "Gonads" position and form are of great importance in medusan classification. When on the radial canals, gonads may or may not completely surround the canals, be oval, globular, linear, folded, sinuous, saclike, etc. When on the manubrium, they may be either cylindrical, covering all its surface, or interradial, adradial, or perradial. Fertilisation is usually external, with free spawning of both males and females. In a few species internal fertilisation may occur: males spawn freely in the water, the sperms reach the eggs while still in the female gonad and fertilise them there. The resulting planulae are then liberated through the velar opening (e.g. Turritopsis, Eleutheria).

\section{Siphonophores (Figs. 14-15)}

Colonial, pelagic, swimming or floating Hydrozoa (except the deep-water, epibenthic, Rhodaliidae), forming highly polymorphic modular colonies of polypoid and medusoid zooids attached to a stem or stolon supported by a floating and swimming system.

Polypoid zooids of several sorts: pneumatophore, gastrozooids, dactylozooids, and bracts. All of them usually associated with the gonophores in repetitive groups, or cormidia, along the stolon. All polypoid structures without oral tentacles. The part of the stem below the floating system, bearing the cormidia, is the siphosome, usually representing most of animal's length. Floating system as pneumatophores and nectophores or swimming bells, together forming the nectosome. The complete and fully developed animal is referred to as the polygastric stage.

Histologically, the polypoid and medusoid zooids resemble the corresponding types of Hydroidomedusae.

\section{Polypoid structures}

The pneumatophore. The pneumatophore, or apical float, is present only in the Cystonectae and Physonectae. It is of larval ectodermal origin and consists of an external wall or pneumatocodon, and an inner ectodermal wall, or pneumatosaccus, lining the float cavity, typically lined by a chitinous layer. The pneumatosaccus differentiates the gas gland or pneumadenia, containing branched giant cells of unknown function. The pneumatophore may be of complex structure, its cavity may be divided in chambers by vertical septa. In most species the cavity of the float communicates with the exterior by an apical pore.

The gastrozooids. The gastrozooids, or feeding and digestive polyps, lack oral tentacles but have a long contractile basal trailing tentacle bearing lateral contractile branches or tentilla; they have usually a large basal thickening rich in cnidoblasts. The 
endoderm of the hypostomial region presents numerous folds rich in various gland cells. The gastrozooids are the only members of the colony capable of ingesting food, the extracellular digestion occurs in their cavity and their endodermal layer is the place of primary intracellular digestion. The feeding behaviour of the siphonophores has not been studied much (see Biggs, 1977; Carré and Carré, 1995).

The dactylozooids. The dactylozooids or palpons (= cystozooids or cystons) may bear small basal unbranched tentacles or palpacles. They have an accessory role in the intracellular digestion and possess an apical pore involved in the elimination of small waste particles, the big ones being eliminated by the mouth of the gastrozooid; they seem to have also a sensory function. The dactylozooids are absent in the calycophorans except Stephanophyes, and in the cystonects, in the physonects they are several per cormidium.

The bracts. The bracts are usually lamellar, they are limited by an ectodermal layer, enveloping a thick mesoglea containing an endodermal blind canal (bracteal canal), and they have a protective, floating and sensory function and may contain metabolic reserves. They are absent in cystonects, leaflike with a simple bracteal canal in physonects, in the Athorybiidae the bracts have a swimming function and replace the nectophores, in the Calycophora they are more complexly organized and have a branched bracteal canal, except in the Hippopodiidae, where bracts are absent. Their medusoid or polypoid origin is still discussed.

The siphosomal stem. The siphosomal stem or stolon is issued from the nectosome out of a more or less developed gutter-like furrow, the hydroecium, which gives a bilateral symmetry to the nectosome, protecting the siphosomal budding area and in which the stolon itself may sometimes withdraw. The stolon has the usual hydrozoan coenosarcal two-layered structure, separated by a thick mesoglea presenting radiating septa penetrating the ectoderm. In some Physonects the stolon forms a large plate bearing the cormidia. The cormidia are borne on the surface of the stolon arbitrarily considered ventral, although they may sometimes appear to encircle the stolon, an optical illusion due to stolon twisting.

\section{Medusoid structures}

They are of three sorts: nectophores or swimming bells and asexual or sexual medusoids.
The nectophores. The nectophores or swimming bells correspond to reduced medusae, they possess an umbrella, a subumbrellar cavity or nectosac, a velum (ostium), an endodermal lamella, 4 unequal radial canals, a circular canal, 2 nerve rings, striated subumbrellar and velar muscle. The nectophores are deprived of manubrium, mouth, tentacles and elaborated visible sense organs. They are very muscular and hence have exceptionally good swimming power. A simple or branched extension of the original larval gastrovascular system, or somatocyst, sometimes containing oil droplets (= oleocyst), runs along the dorsal surface of the hydroecium. The point of convergence of the radial canals has often an eccentric position on the nectosac and is usually connected to the somatocyst by the pedicular (palleal) canal. In most nectophores, the somatocyst develops at the origin of the pedicular canal. The nectophores of Physonectae present around the stem apico-lateral processes or apical wings which are sometimes bordered by cross ridges or lateral wings, their aboral region present a specialized area, or thrust block, separating the apical wings and abutting against the nectosomal stem.

Calycophorae usually have only one or two nectophores, an anterior and a posterior one; their nectophores have thin extensions, or basal lamellae, below the ostium of the nectosac, one or more of these lamellae comprise the mouth plate.

Gonozooid - sexual medusoids. The gonozooids of siphonophores may be represented by a single gonophore or by clusters of gonophores attached on a branched stem or gonodendron (= blastostyle). There may be several groups of gonophores per gonozooid. The gonodendron is usually associated with a specialised palpon or gonopalpon. The gonophores are sexual medusoids, their budding occurs like in other Hydoidomedusae with the formation of a medusary nodule, and they have typical medusan characteristics; female ones, however, may be deeply modified. Siphonophores may be monoecious or dioecious. The germ cells develop on the manubrium of the sporosacs or of the eumedusoids, the latter being rarely liberated. The Physonectae female gonophores develop only one egg, but their cormidia may form a succession of several male or female new gonophores. Calycophorae gonophores contain several eggs ( 2 to 30 ), usually their cormidia become free as eudoxia, able to form successively several generations of new gonophores during their free life, with the alternation of male and females structures. 
Asexual medusoids. Sterile or asexual medusoids may be associated to the sexual gonophores namely in the Cystonectae and in a few Calycophorae. They may have a propulsive and floating function.

The survival of isolated zooids seems impossible, but the cormidia of most Calycophorae represent real colonial units, breaking loose before the maturation of the gonophores and leading an independent existence, being then termed eudoxia.

A fully grown siphonophore colony may be considered as enlarged, larval nurse carriers (his paedophore) that itself does not become sexually mature but bud off adults, medusoid gonophores (Totton, 1965).

Siphonophores are carnivores, feeding mostly on small crustaceans and larval fish, but the largest colonies may feed as well on bigger preys like: polychaetes, pelagic molluscs or tunicates, aduldt fishes or even other siphonophores. Some fishes feed on siphonophores, in Mediterranean Forskalia for instance is the prey of fishes of the family Scombridae especially Teytragonorus cuvieri himself toxic for man.

\section{DEVELOPMENT}

\section{Life cycles (Figs. 16-19, 156)}

Not all the Hydrozoa present the classical life cycle usually described in the text books, i.e.: fertilised eggs, planula, larval hydroid, adult medusae, eggs and sperm, fertilised eggs and so on. This cycle is anyhow characteristic, as far it is known, of most Hydroidomedusae with the exception of the Siphonophora, where the planula gives rise to specialized larvae (i.e. calyconula and siphonula) developing directly into the siphonophoral adult polygastric stage. The above described Hydroidomedusae cycle may present several modifications. The most important one is the suppression of the medusa stage, a feature of almost half of the species. Even when medusae are not liberated, however, most gonophores still retain a medusan architecture. Other life-cycle modifications include, for instance: the presence of an embryonic encysted stage (e.g. Hydra, Margelopsis, Paracoryne) which is presumably a more common event than currently believed; the transformation of the planula into a single planktonic polyp that buds a single medusa that, during its formation, completely resorbs by the hydroid (i.e. Eirene hexanemalis); the existence of two cycle patterns, depending on the season, one typical and the other where the planula settles and directly produces medusae without forming hydranths (i.e. Laodicea indica), or forming a single hydranth, attached to the gonotheca (i.e. Clytia viridicans) etc. The study of Hydroidomedusae life cycles is one of the most promising fields in Hydrozoa biology and may give important indications for the understanding of their evolution.

In the Actinulidae and the Automedusae, development is direct, the embryo giving rise directly to a medusa without the presence of a true larval hydroid stage; in the Narcomedusae the embryonic stages may be external parasites of other animals.

The Polypodiozoa are represented by a single species, Polypodium hydriforme, which is the only known metazoan adapted to intra-cellular parasitism. Polypodium has a unique life cycle, having a succession of a free-living stage and of an intra-cellular parasitic stage of some Acipenseridae and Polyodontidae eggs.

\section{Sexual reproduction (Figs. 16-19).}

\section{Sex determination}

Hydrozoan are mostly dioecious except most of the Siphonophores and a few other monoecious Hydroidomedusae species. Simultaneous or successive hermaphrodites occur rarely (e.g. Amphogona, Eleutheria, certain Hydra and Tubularia, Eudendrium motzkossowskae, some Aglaopheniidae, some Clytia). In Plumularia setacea the colonies are recorded both monoecious and dioecious. The mechanism of sex detemination is not well known in the Hydrozoa. In general it is admitted that sex determination is genetic (see Tardent, 1985; Littlefield, 1994) but in several cases (e.g. Hydra, Clytia), sex determination appear ruled by environmental conditions, mainly by temperature and appears unstable (see Carré and Carré, 2000). In Hydra multiple genes are thought to influence sex with the degree of manifestation of either sex being dosedependent.

\section{Gametes and fertilisation}

The gametes of the Hydrozoa are generally of ectodermal origin, but in certain species they may be formed in the endoderm (e.g. Actinulida, Nannocoryne, Pegantha clara, Polypodium and Solmaris flavescens).

In most medusal forms, ripe eggs are shed immediately in the external medium. Nevertheless, 
there are forms in which the eggs remain either fixed on the gonads, or in the subumbrellar space (e.g. Corymorpha, Hybocodon), where they are fertilised and develop into planulae. In the species with reduced medusae, the eggs remain most often inside the gonothecae, where fertilisation occurs and development proceeds to a very advanced stage, from planulas to even young hydranths (e.g. Cordylophora, Halecium, Clava, etc ). Brood chambers can be present both in the medusa stage (Eleutheria) or in the hydroid stage (Fig. 8) the marsupium of some sertulariids, other species produce a mucous mass, the acrocyst, where development is completed (e.g. Calycella syringa, Dynamena pumila, Opercularella lacerata, Thuiaria arctica etc.). Gonothyraea species have "meconidia", reduced sexual stages disengaged from the gonothecae as cryptomedusoids but remaining attached to the blastostyle by a slender peduncle. The embryos develop inside these reduced medusae till planula liberation.

Male spawning normally occurs in the water and no copulation is known in the Hydrozoa. The existence of sperm attractants, produced by the eggs, has been first demonstrated in the Hydrozoa (Miller, 1972). Fertilisation can be internal (when the sperms reach the eggs while these are still on the female) or external (when sperms and eggs are shed in the water and meet there).

Gastrulation lead to the formation of a diblastic embryo: the planula. This embryo presents already a complex structure, very differentiated but also very different from one group to another.

Fully-developed planulae lead a free life of variable duration, from a few hours to several days, then attach by the anterior pole, generally enlarged, and glandular, to an appropriate support, collapse, and give rise to a primary polyp. The anterior region of the embryo is transformed into the fixation sole. The median zone, by evagination, becomes the primary stolon, whereas the posterior region constitutes the primordia of the first hydranth. Sometimes, several polyps bud off from a single planula (e.g. Oceania armata, Mitrocoma annae).

In certain hydroids, the planula does not immediately leave the gonophore, but continues its development in it, either partially, producing an intermediate stage, the actinula (i.e. Tubularia, Myriothela), or completely, a normal polyp living the gonophore (certain gonophores of Cordylophora). Some hydroids have zooxanthellate planulae (e.g. Haleci$u m$ ) that can survive for months before metamor- phosing into a polyp. Planula encystment is probably a very common event in the development of hydroids with fixed gonophores, since many species reproduce sexually at the end of the favourable season and then disappear. Sexual reproduction, in these cases, is not followed by an increase in population size but, instead, by the disappearance of all active stages. It is then reasonable to assume that planula encystment occurs.

In the Siphonophora, the planulae remain pelagic and are without the cellular differentiation typical of the other Hydroidomedusae planulae. They have a very short lifetime, usually much less than 24 hours, metamorphosing rapidly into more specialised pelagic larvae, the siphonula (usually with a primary or larval aboral bract and a primary oral gastrozooid) in the Physonectae, and the calyconula (with a unique latero-aboral, usually deciduous, larval nectophore and an oral primary gastrozooid) in the Calycophorae, both larval types developing into the adult sexual form or polygastric stage.

The Automedusae do not present a hydroid stage (hypogenetic) and possess either direct or parasitic development (certain Narcomedusae). They develop into young medusae either directly or through intermediate tentaculate, post-embryonic stages inappropriately called "Actinulae" that, in fact, are not polyps but larval medusae. Their planulae have a simple embryonic didermic cellular organisation lacking the specialised neural and glandular cells characterising most Hydroidomedusae.

Asexual reproduction (Figs. 16-17, 20-22).

The Hydrozoa have several types of asexual reproductive stages, asexual reproduction being one of the main characteristics of the group. The Trachymedusae and the Actinulidae, however, do not present asexual reproduction. The main patterns of asexual reproduction are:

Fission. Certain hydranths and a few hydromedusae may also reproduce by longitudinal or transversal fission (i.e. Protohydra, Hydra, the medusae of Cladonema and Clytia).

Podocysts or propagules (Figs. 17-22). Under adverse ecological conditions, some hydroid colonies isolate fragments of hydrocauli, hydrocladia or stolon, enveloped by perisarc, ensuring the propagation and direct dissemination of the species but that may also act as resting stages or cysts.

Budding of planula-like bodies, or frustules, of different types (Figs. 17, 22). This is more common 
in hydroids, but can occur exceptionnaly also in some medusae (i.e. Eucheiliota paradoxica).

Resting stages or cysts (Figs. 22D, 45H). Encysted embryos (from zygote to later stages) and planulae, can withstand adverse conditions by encystment. Cysts are presumably much more common than supposed, presently they are mainly known from solitary forms like Climacodon, Corymorpha, Fukaurahydra, Gonionemus, Hataia, Margelopsis, Moerisia etc. and in freshwater species as Craspedacusta, Limnocnida, Hydra etc. They are less common in colonial forms (present in Paracoryne) where the fragments of perisarc-covered hydrocaulus or stolons play the same role. Cysts may survive sometimes several years (e.g. Craspedacusta, 40 years).

Polyp budding, leading either to colony formation, or to a population increase in solitary forms. Exceptionally, some medusae produce polypoid structures (i.e., Bougainvillia platygaster, Proboscidactyla ornata, Teissiera medusifera, Zanclea medusopolypata).

Medusa budding, giving rise to the free sexual phase, the medusa, or to sessile, reduced gonophores. Some medusae multiply by budding, which may take place at various levels: on the manubrium (i.e., Dipurena gemmifera, Limnocnida tanganyicae, Cunina fowleri and C. frugifera), on the radial canals (i.e., Eucheilota paradoxica, Proboscidactyla ornata, Kantiella enigmatica), on the tentacular bulbs (i.e., Coryne prolifera, Hybocodon prolifer, Niobia dendrotentaculata), on the exumbrellar rim (i.e., Eleutheria dichotoma) or on the subumbrellar rim (i.e., Eleutheria claparedei). In the medusae of Clytia mccradyi and Eirene elliceana, the gonads produce blastostyles giving rice to medusary buds.

In the Hydroidomedusae, whether the medusary buds derive from polyps or from medusae, they develop in remarkably similar ways characterized by the presence of a didermic medusary nodule.

In certain Hydroidomedusae belonging to the families Bougainvilliidae (i.e. Lizzia blondina, Bougainvillia niobe), Hydractiniidae (Hydractinia minima), and Rathkeidae (Rathkea octopunctata), the medusary budding takes place by peculiar and remarkable processes, being exclusively ectodermic.

In the Automedusae, medusa budding occurs without medusary nodule, the subumbrellar cavity and velum are formed by folds and deepening of the oral embryonic ectoderm and are analogous, but not homologous, to the subumbrellar cavity and velum of the Hydroidomedusa; during embryonic development and medusa budding, the primary marginal tentacles are always formed before the subumbrellar cavity and the gastrovascular system.

In many Hydroidomedusae, the medusae develop only incompletely and remain attached to the polyp colony as fixed gonophores (Figs. 20-21). Several stages of medusa reduction have been recognised and several types of fixed gonophores may be distinguished:

Eumedusoids. Medusa almost complete, with radial canals, a subumbrellar space, sometimes with a manubrium, but generally without tentacles, sense organs, and velum; some have a free pelagic life. In the eumedusoids, "gonads" are on the manubrium when Anthomedusae (i.e. Pennaria, HydractiniaStylactis, Tubularia), on radial canals when Leptomedusae (i.e. Eugymnanthea, Orthopyxis).

Cryptomedusoids. More regressed stages, not presenting radial canals any more, but exclusively an endodermal lamina homologous to the gastrodermal lamella: the umbrella endoderm; still provided with a reduced subumbrellar space, or without any space which is then represented only by an ectodermal layer, the internal ectoderm (e.g. Cladocoryne floccosa, Clava squamata, Coryne muscoides).

Heteromedusoids. Highly atrophied fixed gonophores, devoid of umbrellar endoderm, but still possessing an internal ectoderm (e.g. Sertularia argentea, Laomedea flexuosa, Kirchenpaueria echinulata).

Styloids type I. The most regressed gonophores without internal ectoderm, or umbrellar endoderm, a simple evagination of the two constituting layers, the genital elements accumulating between both layers around a central or lateral axis, the spadix (e.g. Dicoryne, Eudendrium, Bimeria, Cordylophora).

Styloids type II. The regression is sometimes even more complete, with no trace left of gonophores, the gonads developing either in the ectoderm (e.g. Hydra, Gymnogonos, Hydrodendron) or in the endoderm (Actinulidae). A given species is not characterised by a single type of gonophores, the gonophores of one sex being often different from those of the other. In many cases, a gonophoral sexual dimorphism is thus observed.

Swimming gonophores (Fig. 21D). Sometimes strongly reduced medusa stages (cryptomedusoids and perhaps heteromedusoids) may become secondarily free gamete carriers again. They have gonads on the manubrium (spadix) both in the 
Lepto- and the Anthomedusae. Swimming gonophores, termed swimming sporosacs, have been reported for Dicoryne conybeari in form of flagellated gamete-carriers, deprived of any medusan structure. Several Leptomedusan species (of the genera Amphisbetia, Anthohebella, Dentitheca, Macrorhynchia, Monotheca, Nemalecium, Sertularia) have pelagic stages with medusan architecture, often without radial canals and circular canal, without tentacles and sense organs. The sexual elements are always on the "manubrium" in these Leptomedusae, the "manubrium" being in eccentric position. They can not been confused with eumedusoids, the first step of medusa reduction, still with most of the original non reproductive structures of the medusa: radial canals, circular canal, velum, sense organs, with maturation of the sexual cells according the classes (gonads on manubrium in Anthomedusae and on radial canals in Leptomedusae) and with a non eccentric position of the manubrium. The swimming gonophores are found mostly in Leptomedusae families with paedomorphic hydroids characterized by the possession of fixed and highly reduced gonophores (Aglaopheniidae, Sertulariidae, and Haleciidae).

\section{THE STINGING CELLS (Figs. 23-24, Table 1, 2)}

This section applies to all hydrozoan morphs. Stinging cells or cnidocytes are diagnostic of the Cnidaria; they are usually in the ectoderm, at different stages of development, from very young cnidoblasts to cnidocytes containing functional cnidocysts. Most of the cytoplasm of a mature cnidocyte is occupied by the capsule or cnidocyst with its apical differentiation, the operculum. The wall of the capsule is continuous with the inwardinvaginated cnidocyst tube. The cnidocyst tube can be either of uniform diameter or differentiated into a more or less dilated butt and a filament, each of these elements being either unarmed or armed with spines of variable size and shape. The capsule of the cnidocyst contains also a paralyzing and often-poisonous fluid, the capsular content, which is ejected through the filament tip when the cnidocyst discharges. Cnidocysts discharge occurs by eversion.

A complex network of fibrils, forming a kind of basketwork, generally surrounds the capsule. The cnidocyst displaces the nucleus of the cnidocyte either toward the base of the cell, or laterally. In the Capitata, for example, the most basal region of the cnidocyts, or cnidopod, contains a bundle of fibrils, connecting the capsule to the mesoglea. The apical region of the cnidocyte bears an eccentric, birefringent, bristle-like expansion, the cnidocil, set in a tubular chimney; the structure of the cnidocil recalls that of a modified flagellum. The structure, function, and formation of the cnidocil complex remain to be determined.

Cnidocysts have different functions (Purcell and Mills, 1988):

- adhesion to and entanglement of prey: acrophores, anacrophores, and desmonemes.

- penetration into prey: stenoteles, microbasic euryteles, microbasic mastigophores and isorhizae.

- adhesion of adults, larvae, and eggs to their substrate: demonemes, isorhizae, euryteles, and mastigophores.

- defense: stenoteles, euryteles, mastigophores, and isorhizae.

Cnidocysts develop in specialised regions, and not where they are utilised: the stolons in colonial forms, the median hydranth regions of certain colonial species without or with few stolons (Craspedacusta, Limnocnida, Clava, etc.) or of solitary ones (e.g. Hydra). In medusae, they differentiate either at the level of the nettle ring (Trachymedusae and some Limnomedusae) or, if this formation is missing, in the tentacular bulbs. Wrapped in the cnidocytes, they migrate from the cnidogenous regions toward the tentacles or other armed regions, through the ectoderm, the endoderm, the mesoglea or even the gastric cavity.

Some nudibranchs, turbellarian flatworms, ctenophores, and priapulids may accommodate numerous ingested cnidocysts (cleptocnidae) in their own tissues or in specialized structures (cnidosacs) and apparently use them for defence.

The cnidome is the cnidocyst complement of each species. Cnidomes usually comprise from 1 to 4 cnidocyst types, all specimens of the same species have the same cnidome. It is often the case, however, that polyps and medusae of the same species have different cnidomes (see Table 2).

Table 1, modified after Mariscal, 1974, describes the discharged stages of the most important cnidocysts, (see also Bouillon et al., 1986; 1988; Östman, 2000). The undischarged capsules may in some cases give also useful information and serve as a taxonomic character (see below, heteronemes, Bouillon et al.,1988) (Figs. 23-24). 
TABLE 1. - Morphology of the discharged stages of the most important types of cnidocysts.

ASTOMOCNIDAE: thread closed at the tip

RHOPALONEMES: thread club-shaped and much greater in volume than the capsule Anacrophores: thread without an apical projection*

Acrophores: thread with an apical projection*

SPIRONEMES: thread not club-shaped, generally forming a spiral coil distally

Haplonemes: thread without a well-defined shaft

Desmonemes: thread forming a corkscrew-like coil*

Heteronemes: thread with a well-defined shaft

Rhopaloides: shaft of unequal diameter

Euryteleloids: shaft dilated distally

Microbasic: shaft short, less than three times capsule length

Spiroteles: thread forms a spiral coil distally, 3 strong spines*

Aspiroteles: no thread beyond the shaft, 3 strong spines*

STOMOCNIDAE: most thread open at the tip

HAPLONEMES: thread without a well-defined shaft

Isorhizas: thread with uniform diameter

Atrichous: thread without well-developed spines

Basitrichous: thread with well-developed spines only at base

Merotrichous: thread with well-developed spines on the intermediate portion only*

Apotrichous: thread with well-developed spines on the distal portion only *

Holotrichous: thread with well-developed spines along whole length

Anisorhizas: thread slightly dilated toward base*

Atrichous: thread without well-developed spines*

Homotrichous: thread spiny throughout, spines all of equal size*

Heterotrichous: thread spiny throughout, spines larger at base of thread*

HETERONEMES: thread with a well-defined shaft, visible in undischarged capsule

Rhabdoides: shaft cylindrical, of the same diameter throughout

Mastigophores: thread continues beyond the shaft

Microbasic: shaft short, in undischarged cnidocysts almost of same length than capsule, usually straight

Microbasic b-mastigophore: shaft tapers gradually into thread

Microbasic p-mastigophore: shaft tapers abruptly into thread, V-shaped notch prominent at base of unfired shaft

Macrobasic: shaft long, more than two and a half time capsule length, in undischarged cnidocysts shaft much longer than capsule length, horseshoe-shaped or wind up in several loops *

Amastigophores: no thread beyond the shaft **

Microbasic: shaft short, less than two and a half times capsule length**

Macrobasic: shaft long, more two and an half times capsule length, undischarged shaft much longer than capsule length** Rhopaloides: shaft of unequal diameter

Mesoteles: shaft spindle-shaped, devoid of spines, no thread beyond the shaft

Euryteles: shaft dilated distally, thread continues beyond the shaft

Microbasic: shaft short, less than two and an half times capsule length, in undischarged cnidocysts almost of same length than capsule, usually straight

Homotrichous: spines of shaft all of same size*

Heterotrichous: spines of shaft of unequal size

Semiophoric: thread bent whiplike, with large flat spine medially*

Macrobasic: shaft long, more than two and a half times capsule length, in undischarged cnidocysts shaft much longer than capsule length, horseshoe-shaped or wind up in several loops*

Telotrichous: spines on distal portion of shaft only*

Merotrichous: spines not distal, found only on shaft area of uniform diameter proximal to terminal swelling*

Holotrichous: shaft spiny along whole length*

Stenoteles: shaft dilated at base, proximal part longer than distal one, 3 strong spines between the two parts, distal portion

armed by rows of lamella or spines, thread continues beyond the shaft

Pseudostenoteles: shaft dilated at base, proximal part shorter than distal one, 2 to 4 strong spines at constriction between the

two parts, smaller spines on distal part, sometimes also with a few large ones, thread continues beyond the shaft

Birhopaloides: discharged shaft with a distal and proximal dilatation either separated from each other or close together*

*Present only in Hydrozoa; **not present in Hydrozoa.

30 J. BOUILLON et al. 
TABle 2. - Cnidome of Hydrozoa families. Anis.het.: heterotrichous anisorhizas; Anis. Hom.: homotrichous anisorhizas; Apo.isor.: apotrichous isorhizas; Atr.isor.: atrichous isorhizas; Bas.isor.: basitrichous isorhizas; Bir.: birhopaloides; Des.: desmonemes; Eur.micr.: microbasic euryteles; Eur.macr.: macrobasic euryteles; Eur.sem.: semiophoric euryteles; Het.: heteronemes; Hol.isor.: holotrichous isorhizas; Mast micr. microbasic mastigophores; Mast macr.: Macrobasic mastigophores; Mero isor : merotrichous isorhizae; Meso.: mesoteles; Pst.: pseudostenoteles; Sten.: stenoteles ; H: hydroid stage; M: medusa stage; PS: polygastric stage; Com.: comments; ? : either the one or the other; ! : Perhaps.

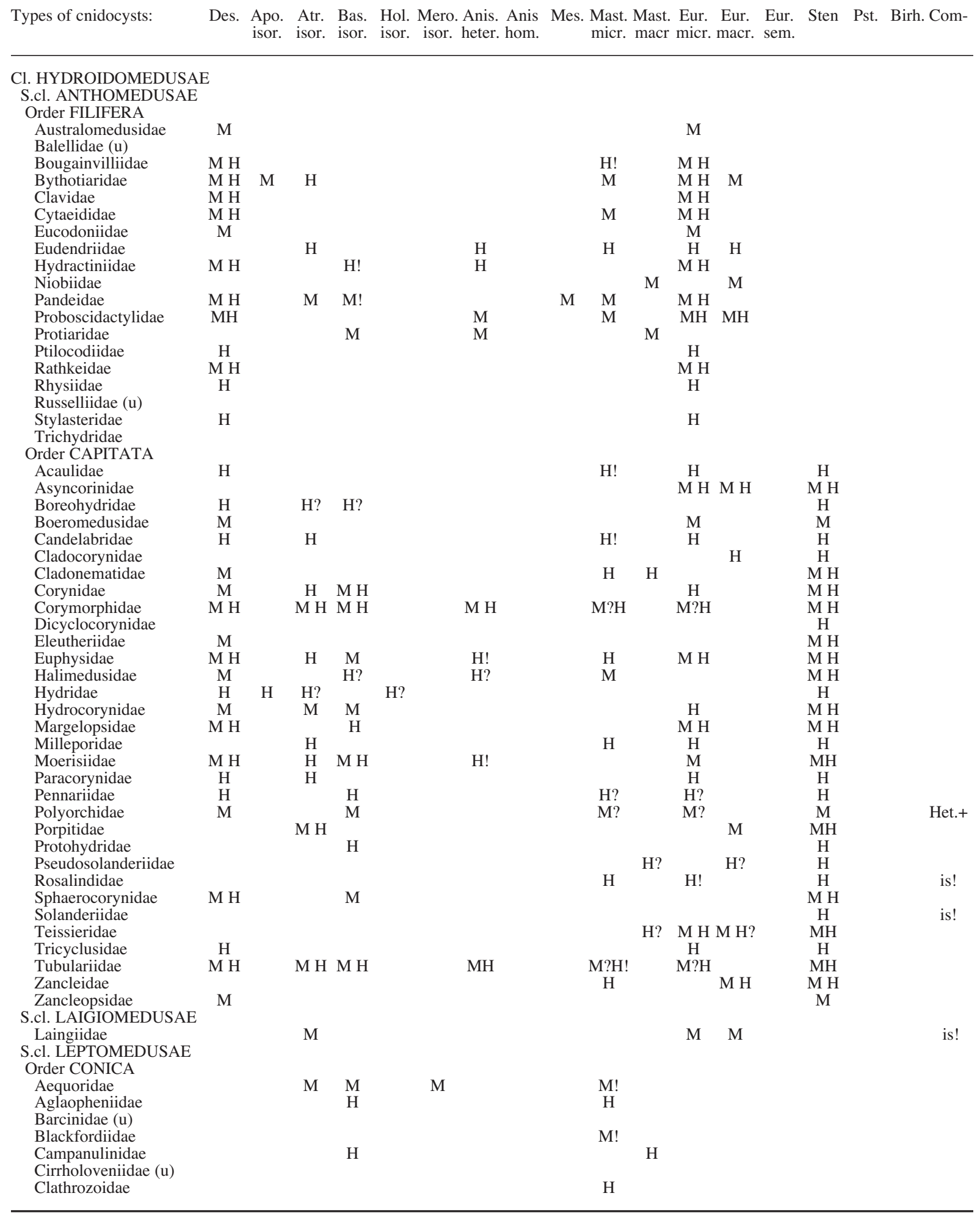


TABle 2 (Cont). - Cnidome of Hydrozoa families. Anis.het.: heterotrichous anisorhizas; Anis. Hom.: homotrichous anisorhizas; Apo.isor.: apotrichous isorhizas; Atr.isor.: atrichous isorhizas; Bas.isor.: basitrichous isorhizas; Bir.: birhopaloides; Des.: desmonemes; Eur.micr.: microbasic euryteles; Eur.macr.: macrobasic euryteles; Eur.sem.: semiophoric euryteles; Het.: heteronemes; Hol.isor.: holotrichous isorhizas; Mast.micr.: microbasic mastigophores; Mast.macr.: Macrobasic mastigophores; Mero isor.: merotrichous isorhizae; Meso.: mesoteles; Pst.: pseudostenoteles; Sten.: stenoteles ; H: hydroid stage; M: medusa stage; PS: polygastric stage; Com.: comments; ? : either the one or the other; ! : Perhaps.

Types of cnidocysts: Des. Apo. Atr. Bas. Hol. Mero. Anis. Anis Mes. Mast. Mast. Eur. Eur. Eur. Sten Pst. Birh. Comisor. isor. isor. isor. isor. heter. hom. micr. macr micr. macr. sem.

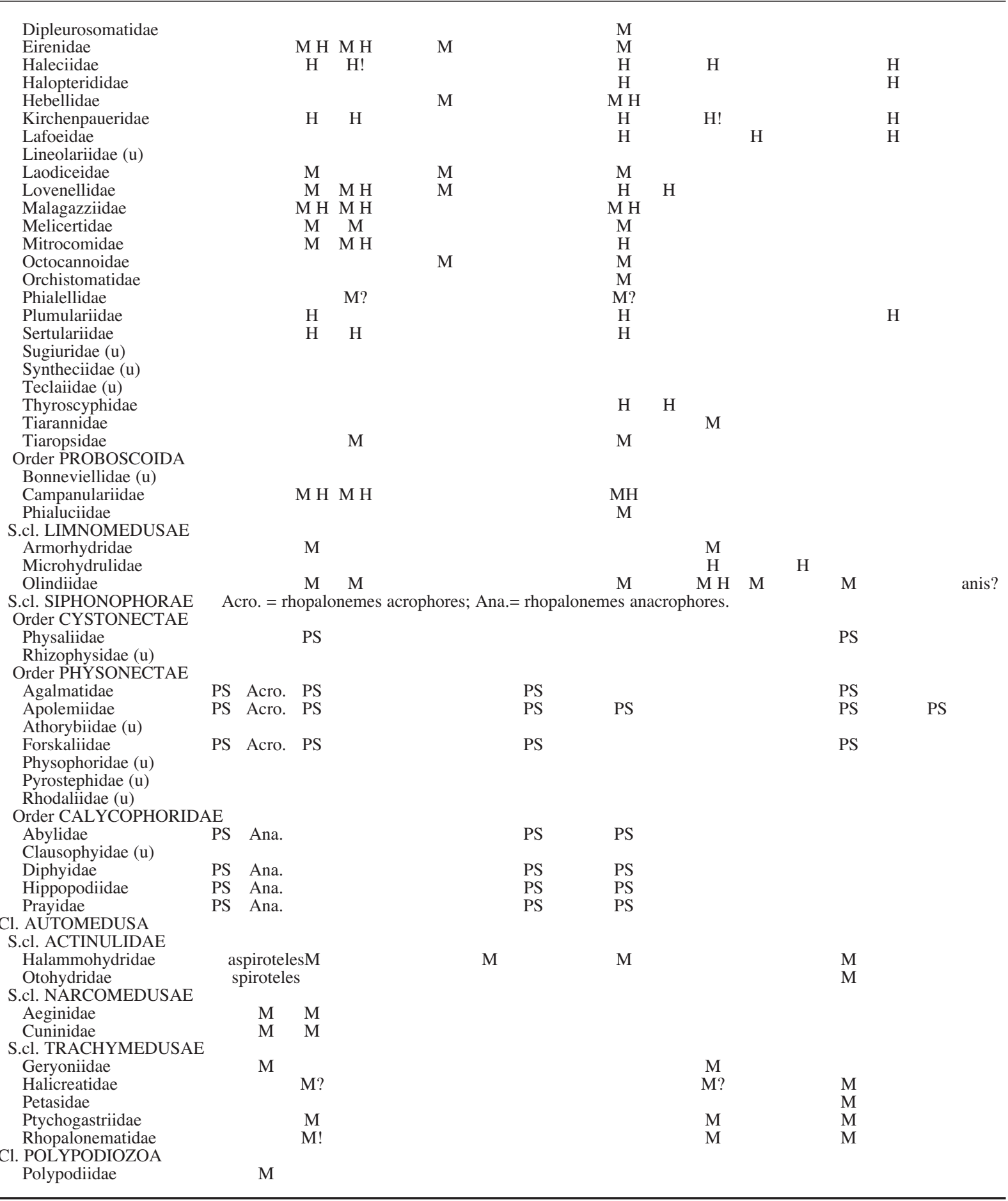

32 J. BOUILLON et al. 


\section{DIAGNOSTIC CHARACTERS}

Species descriptions must provide information about the state of diagnostic characters (Table 3). Insufficient description is the main cause of nomenclatural confusion and it is often the case that new species are based on slight variations of probably irrelevant characters. The following is a list of the diagnostic characters of both hydroids and medusae and of their possible states. A description should report on the state of all the diagnostic characters present in the material under description. The character state "absent" is not mentioned, since it is useless to state that a given character is not present. This, however, is to be mentioned when an important character (e.g. the presence of ocelli), present in phylogenetically near species, can be either present or absent. Stating the absence of ocelli, in this case, means that they have been searched for (since they are usually present in a given genus), but that they were not present in the described specimen. Character states are often split into further sub-states.

TABLE 3. - Diagnostic characters and characters states to describe the three main morphological types of Hydrozoa.

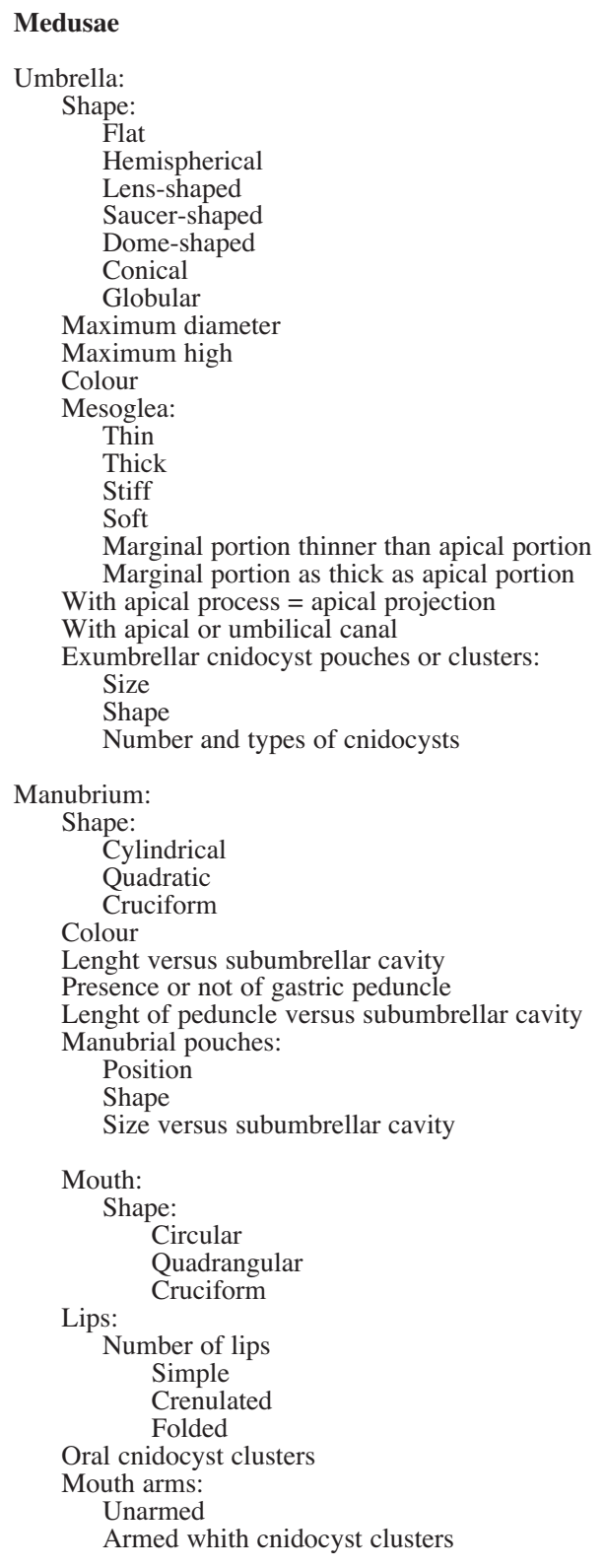

Oral tentacles:

Simple

Branched

Position of oral tentacles:

Arising from mouth rim

Arising above mouth rim

Mesenteries:

Length versus subumbrellar cavity

Radial canals:

Number

Simple

With diverticula

Bifurcated

Branched

Jagged

Swollen at some zones

With gonads (see gonads)

Incomplete:

Centripetal

Centrifugal

Ring canal:

Tubular

Filled by endodermal core

"Gonads":

Number

Colour

Position:

On radial canals

Near manubrium

Near umbrellar margin

In the middle of radial canal

Along the whole radial canal

On manubrium:

Proximal

Distal

Median

Completely surrounding manubrium

In one mass

In several masses

In longitudinal bands: Interradial

Perradial

Adradial

Shape:

Oval

Linear

Sinuous

Folded

Pendulous

Pouch-like

Split by a median groove

Egg size and number 
TABLE 3 (Cont.). - Diagnostic characters and characters states to describe the three main morphological types of Hydrozoa.

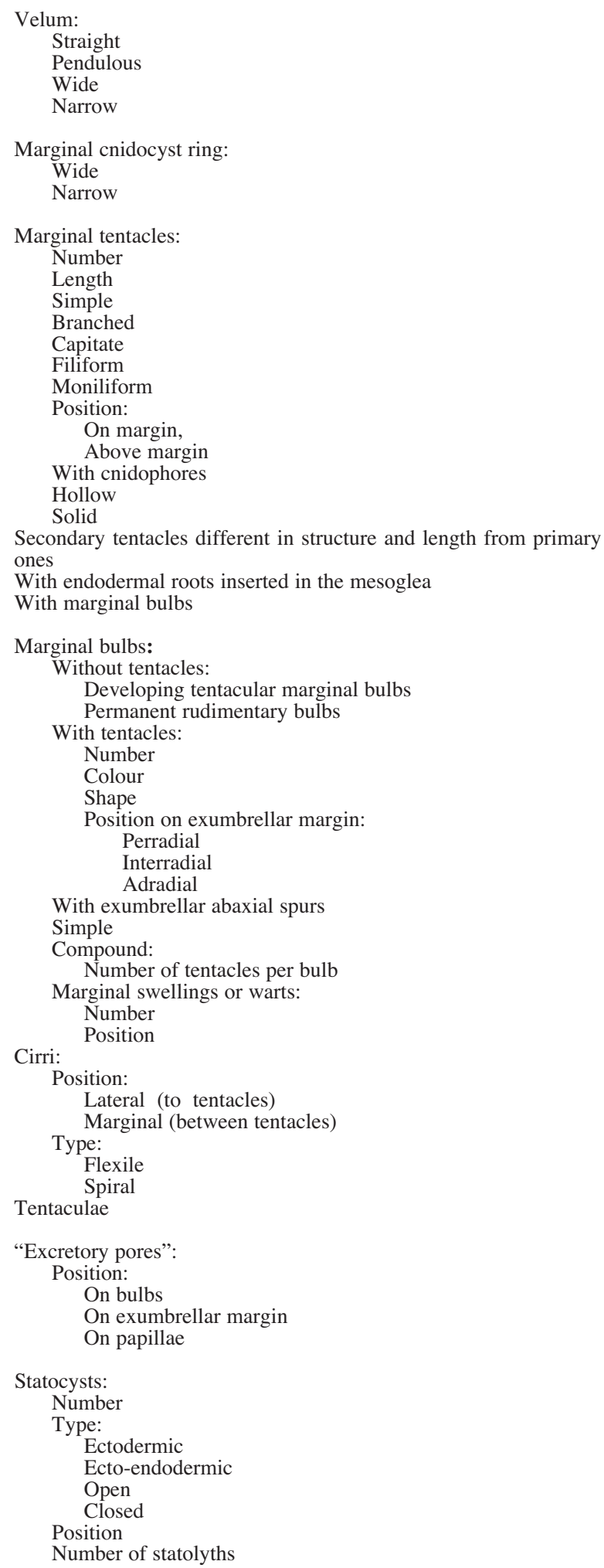

Cordyli:

$$
\text { Position }
$$$$
\text { With nematocysts }
$$

Ocelli:

Position:

$$
\begin{aligned}
& \text { Abaxial } \\
& \text { Adaxial }
\end{aligned}
$$

Location: On bulbs

On margin

On exumbrellar pouches

Colour

Ectodermal

Ecto-endodermal (associated with statocyst)

With lens

Shape:

Round

Oblong

Elongate

Cnidome:

State all nematocyst types and their position on the medusan body

Medusa buds:

Position:

On marginal bulbs

On manubrium

On margin

On radial canals

On exumbrella

On gonads

In gonothecae borne on radial canals

Specific characters exclusive for the Narcomedusae: Position of manubrial pouches:

$$
\text { Interradial }
$$$$
\text { Perradial }
$$

Number of primary tentacles (above peronia) Secondary marginal tentacles (on marginal lappets $=$ exumbrellar lobes)

Peripheral and peronial canals (peripheral canal system)

Number of marginal lappets

Number of peronia

Number of otoporpae

Specific characters exclusive for the Actinulidae:

Body shape:

$$
\text { Oval }
$$

Worm-like

Oral cone

Adhesive aboral organ

Nerve ring

Tentacular bulbs

Statocysts:

$$
\text { Aboral }
$$$$
\text { Marginal }
$$$$
\text { Number }
$$

Brood pouches

Gonads:

Gonochoric

Hermaphrodite

\section{Diagnostic characters and character states to describe polyps}

Solitary:

$$
\begin{aligned}
& \text { Type of fixation: } \\
& \text { By anchoring filaments } \\
& \text { By mucus secretion }
\end{aligned}
$$

Colonial:

Pelagic

Floating 
TABle 3 (Cont.). - Diagnostic characters and characters states to describe the three main morphological types of Hydrozoa.

Fixed:

Stolonal

Erect

With coenosteum (calcareous)

Hydrorhiza:

Simple

Reticular

Rhizcaulomic

Encrusting

Covered by perisarc

Covered by coenosarc

With spines (acanthozooids): Smooth

Serrate

Hydrocaulus:

Monosiphonic

Polysiphonic

Simple

Divided in internodes

Internodes with apophysis

Annulated

Unbranched

Branched:

Arborescent

Bushy

Cymose

Flabellate

Flexuose

Pinnate (alternate or opposite)

Plumose

Racemose

Spiral

Straight (biseriate or uniseriate)

Whorled

Verticillate

Hydrocladia:

Annulated

Unbranched

Branched:

Alternate

Opposite

Pinnate

Plumose

Spiralled

Verticillate

Hydranth (gastrozooid in polymorphic species)

Size range (can change much due to contraction and feeding)

Naked

Protected:

Hydrotheca (see character states below)

Pseudohydrotheca (see character states below)

With abcauline caecum

With mantle = ectodermal lamella:

Mantle with cnidocyst armature or ligula

With annular ectodermal fold

Hypostome:

Conical

Simple

With a glandular preoral chamber or button

Peduncled with a buccal cavity (sometimes termed: trumpet-shaped)

Oral tentacles:

Number

Length

Amphicoronate

Unicoronate

Asymmetrically arranged (one, two, etc.)

With intertentacular web (umbrellula)

Aboral tentacles:
Number

Length

Scattered

In whorls:

Number of whorls

Number of tentacles per whorl

Tentacle type:

Hollow

Solid

Capitate

Capitate ramified

Cateniform

Filiform

Moniliform

Pseudofiliform

Semifiliform

Semimoniliform

Transformed into nematodactyls

Transformed into sense organs (acnide)

Cnidocyst pouches on column

Gonophores (either fixed or medusa buds):

Above aboral tentacles

Among aboral tentacles

Below aboral tentacles

Single

In clusters

Pseudohydrotheca:

Covering hydranth base

Covering hydranth and tentacle bases

Hydrotheca:

On hydrorhiza:

Reptant (i.e. creeping)

Sessile

Pedicellate

On stem, and/or branches,

Pedicellate

Adnate

Sunk

Sessile

On apophysis (or hydrophore)

Alternate

Opposite

In longitudinal rows (state number

Irregularly arranged

Form:

Tubular

Campanulate

Cup-like

Dish-like

Armed with nematothecae (see nematothecae character states)

Operculate (see operculum character states)

Asymmetrical

With horizontal stripes

With longitudinal stripes

Perisarc of irregular thickness

Operculum:

Pleated (folded)

Segmented (discrete opercular flaps):

With creaseline at base

Number of flaps:

One:

Abcauline

Two

Three

Four

Many

Pyramidal 
TABle 3 (Cont.). - Diagnostic characters and characters states to describe the three main morphological types of Hydrozoa.

In form of a gable roof

Everted rim

Hydrothecal cusps (often called teeth):

Number

Straight

Obliquous

Flat

Folding inwards (this leads to the formation of longitudinal lines on the theca)

Shape:

Triangular

Castellate

Bicuspidate

Rounded

Internal teeth below margin:

Number

Intrathecal septum

Perisarcal diaphragm

Annular perisarcal thickening

Democytes

Spherule

Dactylozooids:

Spiral (spiral zooids)

Roughly straigth

Position:

On hydrorhiza

On stem (mainly nematophores)

On hydranth (the so-called cnidophore of Eudendrium)

Solid (Tentaculozooids)

Hollow

With tentacles

Cnidocyst arrangement:

Capitate

Filiform

Semimoniliform

Nematophores:

Sessile

Pedicellate

Naked

Protected by a nematothecae:

Immovable or fixed or one-chambered (monothalamic) Movable or two-chambered (bithalamic)

Position of nematothecae:

Hydrothecal

Lateral

Mesial $=$ inferior median

Superior

Caulin

Gonothecal

With sarcostyle and cnidostyle

Gonozooid:

Size

Position of gonophores:

Scattered

In whorls

In clusters

Isolated

Tentacles:

Number

Arrangement

Type (see above for character states)

Mouth present

Gonophores:

Simple

In clusters

On blastostyles

Aggregated
Position:

On hydranth

On hydrocaulus and/hydrocladia

On hydrorhiza

Sessile

Pedicellate

Giving rise to:

Free medusae

Eumedusoids

Fixed sporosac

Swimming sporosacs

Swimming gonophores:

With gastrovascular system

Without gastrovascular system

With central "manubrium" (spadix)

With eccentric "manubrium" (spadix)

With refringent corpuscles on umbrellar margin

Without gonothecae

With gonothecae:

Simple, unprotected

As corbula

As coppinia

As phylactocarps

As scapus

With nematothecae

Without nematothecae

Diagnostic characters and character states to describe siphonophores

Nectosome:

Nectophores:

Number

Position: (anterior and posterior in calycophorans)

Apical wings

Ascending branches

Basal facet

Basal lamella

Commisural canals

Commissures

Descending branches

Hydroecium

Lateral wings

Lateral canals

Mouth-plate

Ostial teeth

Pallial canal

Pedicular canal

Ridges

Somatocyst

Thrust-block

Siphonosome:

Gastrozooid:

Basigaster

Tentacle

Tentilla

Terminal filament

Palpons:

Palpacles

Gonodendron:

Gonopalpon

Gonophores

Eumedusoid

Sporosac

Eudoxid (bract + gonophore)

Bracts:

Bracteal canals

Neck-shield

Phyllocyst

Gonophore 
SIMPLIFIED KEYS FOR HYDROZOA SUBCLASSES IDENTIFICATION

\section{Hydroids}

1. Polyp generation planktonic, in the form of polymorphic colonies with a float and central gastrozooid .............. Anthomedusae Porpitidae

- Polyp generation usually sedentary; exceptionally planktonnic but different from above

2. Hydranth generally with a definite hydrotheca and gonothecae of definite shape ...... Leptomedusae

- Hydranth with no definite hydrothecae, or gonothecae.

3. Hydranth solitary or colonial, usually rather conspicuous; sometimes with a coenosteum; mostly with desmonemes ..... Anthomedusae

- Hydranth small, sessile; generally solitary or forming small reptant or bipolar colonies; never with desmonemes Limnomedusae

\section{Pelagic Hydrozoa}

1. Usually with sense organs, ocelli or statocysts, individuals as free swimming medusae, never colonial Hydromedusae.

- Without any kind of visible sense organs, forming pelagic and floating modular highly polymorphic colonies formed by the association of medusoid and polypoid zooids, medusoids never develop . ing into complete medusae...........Siphonophorae

\section{Hydromedusae}

The term hydromedusae is used here in the sense of "the medusae of the Hydrozoa" and comprises both Hydroidomedusa and Automedusa, without having a formal taxonomic rank. The key is just an identification tool, and is not intended to reflect phylogeny.

1. Without statocysts and gonads on manubrium .2

- With gonads on radial canals and, usually ectodermal statocysts. 3

- Statocysts ecto-endodermal, with endodermal axis .

2. "Gonads" on manubrium, occasionally extending for a short distance along basal region of radial canals; marginal tentacles solid or hol low; usually with tentacular bulbs; umbrella generally entire; with radial and circular canals; sense organs, where present, ocelli; umbrella typically bell-shaped; with hydroid stage
Anthomedusae

3. "Gonads" exclusively on manubrium; tentacles solid, above exumbrellar margin; with or without tentacular bulbs; umbrella lobed, divided by peronial grooves or similar structures; with radi al canals, circular canal as a solid core of endodermal cells; umbrella roughly hemispherical; hydroid stage unknown .................aingiidae.

- "Gonads" on radial canals, exceptionally contiguous with base of manubrium; marginal tentacles usually hollow; with tentacular bulbs; umbrella entire; with radial and circular canals; sense organs, when present, statocysts formed exclusively by the velar ectoderm, open or closed, sometimes cordyli, rarely ocelli; umbrella usually flattened; with hydroid stage... Leptomedusae.

4. "Gonads" on radial canals; marginal tentacles solid (a mixture of solid and hollow tentacles in Geronyidae); without tentacular bulbs; exumbrella entire; with an exumbrellar marginal cnidocyst ring; with radial and circular canals; statocysts as free marginal clubs, usually free, rarely enclosed by exumbrellar ectoderm; umbrella tall to hemispherical ; without hydroid stage...............Trachymedusae.

- "Gonads" on manubrium (often on manubrial pouches); primary tentacles solid, above exumbrellar margin, sometimes secondary, marginal tentacles; without tentacular bulbs; umbrella lobed, divided by peronial grooves; usually without radial canals; circular canal, when present, jagged, in form of peripheral system; statocysts usually as free marginal clubs; umbrella typically flatter than an hemisphere, with a central lens-shaped mass of mesoglea; without true hydroid stage... Narcomedusae.

- "gonads" on radial canals, exceptionally on manubrium; marginal tentacles hollow; without tentacular bulbs; umbrella entire; with radial and circular canals; with statocysts enclosed into the mesoglea near ring canal or in the velum; with hydroid stage................................. Limnomedusae.

- "Gonads" on manubrium, between ectoderm and endoderm; tentacles solid, with or without tentacular bulbs; umbrella entire or very reduced; without radial and circular canals; statocysts aboral or marginal; manubrium elongated, terminating in a simple mouth-opening; without hydroid stage.. ..Actinulidae. 


\section{OUTLINE CLASSIFICATION}

Class Hydroidomedusae Claus, 1877

Subclass Anthomedusae Haeckel, 1879

Order Filifera Kühn, 1913

Family Bougainvillidae Lütken, 1850

Family Bythotiaridae Maas, 1905. (= Calycopsidae)

Family Clavidae McCrady, 1859

Family Cytaeididae L. Agassiz, 1862

Family Eucodoniidae Schuchert, 1996

Family Eudendriidae Agassiz, 1862

Family Hydractiniidae L. Agassiz, 1862

Family Niobiidae Petersen, 1979

Family Pandeidae Haeckel, 1879

Family Proboscidactylidae

Hand and Hendrickson, 1950

Family Protiaridae, Haeckel 1879

Family Ptilocodiidae Coward, 1909

Family Rathkeidae Russell, 1953

Family Rhysiidae Brinckmann, 1965

Family Russelliidae Kramp, 1957

Family Stylasteridae Gray,1847

Family Trichydridae Hincks, 1868

Order Capitata Khün, 1913

Suborder Moerisiida Poche, 1914

Family Hydridae Linneaus, 1758

Family Moerisiidae Poche, 1914

Family Protohydridae Allman, 1888

Suborder Sphaerocorynida Petersen, 1990

Family Sphaerocorynidae Prévot, 1959

Suborder Tubulariida, Fleming, 1828

Family Acaulidae Fraser,1924

Family Boreohydridae Westblad, 1937

Family Candelabridae de Blainville, 1830

Family Cladonematidae Gegenbaur, 1857

Family Corymorphidae Allman, 1872

Family Corynidae Johnston, 1836

Family Euphysidae Haeckel, 1879

Family Paracorynidae Picard,1957

Family Pennariidae McCrady, 1859

Family Tricyclusidae Kramp, 1949

Family Tubulariidae Fleming, 1828

Suborder Zancleida Russell, 1953

Family Cladocorynidae Allman, 1872

Family Porpitidae Goldfuss, 1818

Family Rosalindidae Bouillon, 1985

Family Zancleidae Russell, 1953

Subclass Laingiomedusae Bouillon, 1978

Family Laingiidae Bouillon, 1978

Subclass Leptomedusae Haeckel, 1866 (1879)

Order Conica Broch, 1910
Family Aequoreidae Eschscholtz, 1829

Family Aglaopheniidae

Marktanner-Turneretscher, 1890

Family Barcinidae Gili, Bouillon, Pagès,

Palanques and Puig, 1999

Family Blackfordiidae Bouillon, 1984

Family Campanulinidae Hincks, 1868

Family Cirrholoveniidae Bouillon, 1984

Family Eirenidae Haeckel, 1879

Family Haleciidae Hincks, 1868

Family Halopterididae Millard, 1962

Family Hebellidae Fraser, 1912

Family Kirchenpaueriidae Stechow, 1921

Family Lafoeidae A. Agassiz, 1865

Family Laodiceidae Agassiz, 1862

Family Lovenellidae Russell, 1953

Family Malagazziidae Bouillon, 1984

Family Melicertidae Agassiz, 1862

Family Mitrocomidae Haeckel, 1879 (part); Torrey, 1909

Family Orchistomatidae Bouillon, 1984

Family Phialellidae Russell, 1953

Family Plumulariidae Agassiz, 1862

(Hincks, 1868)

Family Sertulariidae Lamouroux, 1812

Family Syntheciidae Marktanner-

Turneretscher, 1890

Family Teclaiidae Bouillon, Pagès, Gili, Palanques, Puig and Heusner, 1999

Family Thyroscyphidae Stechow, 1920

Family Tiarannidae Russell, 1940

Family Tiaropsidae Boero, Bouillon and Danovaro, 1987

Order Proboscoida Broch, 1910

Family Campanulariidae Jonhston, 1836

Family Phialucidae Bouillon, 1984

Subclass Limnomedusae Kramp, 1938

Family Armorhydridae Swedmark and Teissier, 1958

Family Microhydrulidae Bouillon and Deroux, 1967

Family Olindiidae Haeckel, 1879

Subclass Siphonophorae Eschscholtz, 1829

Order Cystonectae Haeckel, 1887

Family Physaliidae Linnaeus, 1758

Family Rhizophysidae Brandt, 1835

Order Physonectae Haeckel, 1888

Family Agalmatidae Brandt,1835

Family Apolemiidae Huxley, 1859

Family Athorybiidae Huxley, 1859

Family Forskaliidae Haeckel,1888

Family Physophoridae Eschscholtz, 1829 
Order Calycophoridae Leuckart,1854

Family Abylidae Agassiz,1862

Family Clausophyidae, Totton 1965

Family Diphyidae Quoy and Gaimard, 1827

Family Hippopodiidae Kölliker, 1853

Family Prayidae Kölliker, 1853

Family Sphaeronectidae Huxley,1859

Subclass Actinulidae Swedmark and Teissier, 1959

Family Halammohydridae Remane 1927

Family Otohydridae Swedmark and Teissier, 1958

Subclass Narcomedusae Haeckel, 1879

Family Aeginidae Gegenbaur, 1857, emend. Maas, 1904

Family Cuninidae Bigelow, 1913

Family Solmarisidae Haeckel, 1879

Subclass Trachymedusae Haeckel, 1866 (1879)

Family Geryoniidae Eschscholtz, 1829

Family Halicreatidae Fewkes, 1886

Family Petasidae Haeckel, 1879

Family Ptychogastriidae Mayer, 1910

Family Rhopalonematidae Russell, 1953

Class Polypodiozoae Raikova, 1988

Family Polypodiidae Poche, 1914

\section{SYSTEMATICS}

Class HYDROIDOMEDUSA Claus, 1877 Subclass ANTHOMEDUSAE Haeckel, 1879

Hydroid: typically athecate, without a rigid perisarcal theca covering the hydranth body, a gelatinous or membranous pseudohydrotheca may sometimes cover the hydranth base, adhering closely to the ectoderm.

Medusa: typically bell-shaped, with "gonads" confined on manubrium, sometimes extending on the most proximal parts of the radial canals; marginal sense organs, if present, ocelli, never statocysts or cordyli; marginal tentacles peripheral, hollow or solid, with tentacular bulbs (except for most of the Bythotiaridae, Eugotoea petalina, and Rhabdoon singulare); sexual reproduction through a complex planula stage with interstitial cells, neural cells, cnidoblasts and one or two types of glandular cells. Cnidome normally including desmonemes.

The Anthomedusae are divided into two orders: the Filifera (with cnidome including desmonemes and euryteles) and the Capitata (with cnidome including stenoteles). The name Filifera refers to the filiform tentacles of the hydroid stage, whereas the name Capitata refers to the mostly capitate tentacles of hydroids.
Order FILIFERA Kühn, 1913

Hydroid: hydranths with filiform tentacles (except in the dactylozooids of the Ptilocodiidae).

Medusa: with "gonads" forming separated interradial, adradial or perradial longitudinal masses on the walls of the manubrium (exceptionally encircling entire manubrium). Mouth either with four simple or complex lips, or circular, surmounted by oral manubrial tentacles. Marginal tentacles solid or hollow. Cnidome including usually desmonemes and microbasic euryteles, never stenoteles. Planulae having only one type of ectodermal glandular cells: spumous cells.

\section{Key to hydroid stages of the filiferan families}

1. Hydranth with trumpet shaped hypostome ........ Eudendriidae

- Hydranth with conical or rounded hypostome .2

2. Colonies with hydrorhiza forming a massive calcareous coenosteum .................Stylasteridae

- Colonies without massive calcareous coenosteum ................................................... 3

3. Dactylozooids usually present ...................... 4

- Dactylozooids absent ...................................... 7

4. Hydranth with tentacles .............................. 5

- Hydranth without tentacles .......... Ptilocodiidae

5. Hydranth with two tentacles Proboscidactylidae

- Hydranth with more than two tentacles ......... 6

6. Gonophores as non styloid fixed sporosacs, as eumedusoids or free medusae, produced on gonozooids only; dactylozoids when present naked Hydractiniidae

- Gonophores styloid, gonads inside hydranth walls; dactylozooids covered entirely or partially by perisarc Rhysiidae

7. Tentacles in distal (oral) whorls only .............. 9

- Tentacles in several whorls over the body or scattered over the entire body 8

8. Hydranth with tentacles scattered all over the body (exceptionally with nematothecae = Merona), colonies erect or stolonal; gonophores never developed on hydranth body...... Clavidae

- Hydranth with up to five irregular whorls of filiform tentacles; sessile; hydrorhiza forming a plate giving rise to unbranched colonies living in the prebranchial cavity of ascidians

Bythotiaridae

9. Colonies generally erected; polyps usually with a pseudohydrotheca covering partially or totally the body and tentacles; hypostome surrounded 
by one or more whorls of distal tentacles

Bougainvilliidae

- Colonies stolonal .. 10

10. Hydranth usually with base surrounded by a collar-like tube of perisarc or with a thin basal mucous-like perisarc structure. 11

- Hydranth with completely free base or with the body entirely covered with a mucous pseudohydrotheca Pandeidae

11. Hydrocaulus with a conspicuous cylindrical perisarc tube 12

- Hydranth with a reduced basal perisarcal cup ....

2. Hydranth almost completely retractable in his perisarcal tube, when contracted only the tips of the tentacles show beyond the edge of the tube; hydranth very slender and extensible; with one amphicoronate whorl of 6 filiform tentacles....... .Trichydridae

- Hydranth only partially retractable in his perisarc tube, very slender, elongated, cylindrical, with one whorl of about 10 long filiform tentacles with irregular clusters of large cnidocysts alternating with the tentacles; cnidome containing, among other cnidocysts merotrichous isorhizas Protiaridae

13.Hydranth with one more or less regular whorl of oral tentacles or with two closely alternating oral whorls; surrounding a conical hypostome; perisarcal collar where present chitinous, small, cup-shaped or vase-like, reproduction by medusa buds or fixed sporosacs......... Cytaeidae

- Hydranth with a single distal whorl of threadlike tentacles surrounding a rounded hypostome; with hydranth base surrounded by a gelatinous, mucous perisarcal structure; reproduction by medusa buds arising from hydrorhiza or more rarely from the base of hydranth...... Rathkeidae

\section{Key to the filiferan families, medusa stage}

1. Medusae with hollow tentacles; ocelli, when present, abaxial; mouth simple, lips usually without specialised cnidocyst armed structures, without oral tentacles (except Russsellidae).... 2

- Medusae with solid tentacles; ocelli, when present, adaxial; mouth either with simple lips, or with oral solid tentacles armed with cnidocyst clusters or presenting oral arms armed with cnidocyst clusters 7

2. Marginal tentacles without basal bulbs or swellings, terminated in a terminal cnidocyst cluster. Bythotiaridae

- Marginal tentacles usually with basal bulbs, without terminal cnidocyst clusters or capitations

3. With branched or divided radial canals............... 4

- With undivided radial canals ............................ 5

4. With two simple and two bifurcated radial canals; tentacular bulbs develop into medusae... Niobiidae

- With 4-6 branched radial canals, exumbrella with exumbrellar cnidocyst tracts; manubrium with radial gastric pouches; usually with no circular canal; without rudimentary bulbs....

Proboscidactylidae

5. With 4 unbranched oral tentacles, without terminal clusters of cnidocyst, situated above mouth opening.... Russellidae

- Without oral tentacles. 6

6. With 4 radial canals; with only 4 marginal tentacles in adults and without rudimentary bulbs; cnidome with merotrichous isorhizas....... Protiaridae

- With two or more tentacles in adults; with 4 unbranched radial canals (rarely 8 , Octotiara); manubrium usually without radial gastric pouches (except Annatiara) with or without rudimentary bulbs; cnidome without merotrichous isorhizas Pandeidae

7. With oral tentacles......................................... 8

- Without oral tentacles.................................... 9

8. With oral tentacles simple, situated on/or very near mouth rim Cytaeididae

- With oral tentacles simple or branched, distinctly inserted above mouth rim ........ Bougainvilliidae

9. Mouth with 4 distinct lips ........................... 10

- Mouth with 4 inconspicuous lips, each containing a group of about 100 cnidocysts ....... Eucodoniidae

10.Lips simple, without cnidocyst clusters ........ 11

- Mouth armed with cnidocyst clusters ........... 12

11. Tentacles in groups, 4-8 simple radial canals ..... .Australomedusidae*

- Tentacles solitary; 4 radial canals with usually fine, branched, anastomosing centripetal canals . Trichydridae

12. Mouth rim and lips covered with a continuous row of cnidocyst clusters along their margin...... Clavidae

- Mouth lips elongated to form perradial mouth arms with one or many distinct cnidocyst clusters 13

13.With exumbrellar didermic centripetal canals or 
rows of refringent spots issuing from a marginal cnidocyst ring . Ptilocodiidae

- Without didermic exumbrellar centripetal canals or refringents spot rows, without marginal cnidocyst ring 14 14. Marginal tentacles solitary ......... Hydractiniidae - Marginal tentacles in 8 groups ......... Rathkeidae * not represented in Mediterranean Sea.

\section{Family BougAINVILLIIDAE Lütken, 1850}

Hydroid: colony stolonal or erect, branched or unbranched, monosiphonic or polysiphonic; perisarc firm, terminating either at base of hydranths or forming a pseudohydrotheca; hydranths with one or more definite whorls of filiform distal tentacles, more or less close-set beneath conical hypostome; gonophores as free medusae or fixed sporosacs developing mostly on hydrocauli, hydrocladia, occasionally on hydrorhiza and rarely from modified hydranths.

Medusa: usually bell-shaped; manubrium short; mouth simple, circular, with simple or dichotomously branched oral tentacles, inserted distinctly above mouth rim and armed with cnidocyst clusters; 4 radial canals and circular canal; marginal tentacles solid, either solitary or in clusters, borne on 4,8 , or 16 tentacular bulbs; "gonads" on manubrium, either forming a continuous ring or on adradial, interradial or perradial axes; adaxial ocelli absent or present.

Remarks: the Bougainvilliidae comprise genera with well known free medusae and an assemblage of hydroid-based genera with fixed gonophores bearing one or more whorls of filiform tentacles beneath hypostome. As the reduction of free medusae to fixed gonophores may have occurred several times independently during the evolution of the Bougainvilliidae, it is impossible to refer paedomorphic species to any presently known medusa genus. Many of the hydroids of those genera have an almost similar morphology and few reliable diagnostic characters; they have been lumped and separated several times according to the different criteria. Furthermore, most bougainvilliid hydroids are not distinguishable from the presently known Pandeidae hydroids and, paradoxically, no hydroid species with fixed sporosacs has been described in this family (see Pandeidae). It is thus not to exclude that some of the Bougainvilliidae genera with fixed sporosacs could in fact belong to Pandeidae, or even to the Clavidae. Rees (1938) re-erected the genus Rhizorhagium Sars, 1874 for all the unbranched colonial bougainvilliid polyps with pseudohydrotheca not enveloping the tentacles, with one whorl of tentacles and with fixed sporosacs. Millard (1975) followed by Bouillon (1985) mistakenly included Parawrightia as synonym of Rhizorhagium. Calder (1988) proposed a division of the Bougainvilliidae into four sub-families, the Pachycordylinae, Rhizorhagiinae, Bimeriinae, Bougainvilliinae according to one or more of the following hydroid characters: presence of pseudohydrotheca, form of the hypostome (nippleshaped, dome-shaped), number of tentacle whorls, position of gonophores. Since the systematic value of some of these characters is questionable even at the generic level, this separation in sub-families is not adopted here. The pseudohydrotecae can cover hydranth body and a variable proportion of the tentacles as in the genera Bimeria, Koellikerina and Thamnostoma or extend only around hydranth as in the other Bougainvillidae genera. Calder's distinction between subfamilies based on the shape of the hypostome, dome-shaped in a subfamily Pachycordylinae nipple-shaped in the Rhizorhagiinae is nor very convincing. The hypostome shape being very variable, depending upon the degree of expansion, of contraction of the concerned specimen; it is also linked to stade of feeding, fixation etc. and, several members of the Rhizorhagiinae does not have a nipple-shaped hypostome and have so to be redistributed into other doubtful resurrected genera like Gravelya and Aselomaris not conform to the Calder's definition of the subfamily. It seems preferable to refrain the splitting the Bougainvillidae with fixed sporosacs into to many genera and we follow here with some slight modifications Rees suggestion (see key below) hoping for the proposal of a more natural classification. This seems not very realistic, if not impossible, without the help of molecular biology. The bougainvilliids with fixed sporosacs and one single whorl of tentacles could even been grouped into two genera only Bimeria with pseudohydrotheca covering part or all of the tentacles and Garveia with pseudohydrotheca extending only on hydranth body; the main differences between Rhizorhagium and Garveia are tenuous: unbranched colonies in Rhizorhagium or branched in Garveia.

References: Wedler and Larson (1986); Calder (1988); Pagès, Gili and Bouillon (1992); Bouillon (1995, 1999); Migotto (1996); Schuchert (1996); Bavestrello et al. (2000); Bouillon and Barnett (1999); Bouillon and Boero (2000). 


\section{Key to hydroids} 1. Pseudohydrotheca absent ..................................... 7

- Pseudohydrotheca present

2. Pseudohydrotheca covering tentacle bases ...... 3

- Pseudohydrotheca not covering tentacle bases...

3. Colonies producing fixed sporosacs...... Bimeria

- Colonies producing free medusae.. Koellikerina

4. Gonophores developing into free medusae. Bougainvillia

- Gonophores not developing into free medusae...

5. Gonophores borne on blastostyles and producing swimming sporosacs. Dicoryne

- Gonophores borne on pedicels and producing fixed sporosacs ................................................. 6

6. Hydrocauli branched, hypostome dome-shaped Garveia

- Hydrocauli rarely branched, hypostome nipple-shaped Rhizorhagium

7. Hydranth with one whorl of tentacles; fresh water animals. Velkovrhia

- Hydranth with 2-4 alternating close whorls of tentacles; marine animals Pachycordyle

\section{Key to medusae}

1. Oral tentacles simple unbranched .. 2

- Oral tentacles dichotomously branched ............ 3

2. With 4 radial canals Nubiella

- With 8 radial canals Lizzia

3. With solitary marginal tentacles.. Thamnostoma

- With marginal tentacles in 4 or 8 groups ......... 4

4. With marginal tentacles in 4 perradial groups .... Bougainvillia

- With marginal tentacles in 8 groups, 4 perradial, 4 interradial Koellikerina

Genus Bimeria Wright, 1859

Hydroid: colonies stolonal or with erect branching hydrocauli; stem with firm perisarc enveloping hydranth, extending as a pseudohydrothecal sheath over proximal portion of tentacles; hydranths ovoid to vasiform, hypostome dome-shaped, sometimes with a preoral cavity (i.e., Bimeria rigida), with one or two close oral whorls of tentacles; gonophores as fixed sporosacs, completely invested in perisarc on hydrorhiza and branches.

Reference: Calder (1988).
Bimeria vestita Wright, 1859

(Fig. 25A-C)

Colonies yellowish composed of hydrocauli erect, up to $30 \mathrm{~mm}$ high, monosiphonic and usually scarcely branched, with monopodial growth. Perisarc of the stem with several groups of 4-5 annuli along its length; hydrocladia roughly alternate, not in the same plane, annulated basally. Hydranth at the extreme of branches, partially covered by perisarc, these forming sheaths over basal parts of tentacles; 10-20 tentacles. Gonophores borne on stem and branches, on annulated pedicels, covered of gelatinous perisarc; male ovoid, with branching spadix; female ovoid to spherical, containing one ovum, which lack the perisarc when mature; colonies dioecious.

Records from Mediterranean: Adriatic, eastern and western Mediterranean.

Known seasonality: 7, 10-5.

Distribution: cosmopolitan species.

References: Picard (1958b); Millard (1975); Ramil and Vervoort (1992a); Boero and Bouillon (1993); Altuna (1994); Medel (1996); Avian et al. (1995); Medel and López-González (1996).

\section{Genus Bougainvillia Lesson, 1830}

Hydroid: colony usually erect, branched or unbranched, more rarely stolonal; perisarc terminating at base of hydranth or extending upwards as a pseudohydrotheca; hydranth fusiform to clavate, hypostome dome-shaped, with one distal whorl of tentacles, never enveloped by the pseudohydrotheca. Gonophores as free medusae, arising singly or in clusters from hydrocaulus, hydrocladia or hydrorhiza.

Medusa: 4 perradial clusters of identical solid marginal tentacles; 4 perradial oral tentacles dichotomously branching in normally developed medusae; "gonads" on manubrium, adradial, interradial or, rarely, perradial; with or without ocelli.

References: Calder (1988, 1993); Bouillon (1995); Schuchert (1996).

One doubtful medusa species with simple unbranched oral tentacles has been described from Mediterranean: Bougainvillia multicilia (Haeckel, 1879). (See Diagnosis below).

\section{Key to hydroids}

1. Hydrocauli monosiphonic; perisarc slightly wrinkled throughout. B. britannica. 
- Hydrocauli monosiphonic or polysiphonic often infested by detritus; wrinkled at base of hydrocladia..... B. muscus

\section{Key to medusae}

1. Marginal tentacles with adaxial ocelli 2

- Marginal tentacles without ocelli; two to four tentacles per marginal bulb, basal trunk of oral tentacles very long B. aurantiaca

2. Basal trunk of the oral tentacles very short, almost divided 5 or 6 times immediately from base; manubrium remarkably flat, quadrangular B. platygaster

- Basal trunk of oral tentacles long. 3

3. Manubrium short and broad ............................. 4

- Manubrium elongated narrow .......................... 5

4. Oral rentacles divided 1-2 times (rarely 3); marginal bulbs with 3-4 (rarely more) tentacles; ocelli round; male «gonads» extending cross-wise on subumbrella. B. muscus

- Oral tentacles divided 4-6 times; marginal bulbs with about 30 tentacles; ocelli as narrow transversal lines B. britannica

5. Manubrium with a long, narrow throat which project beyond velar opening; marginal bulbs with 4 very short tentacles; walls of umbrella thin B. maniculata

- Manubrium flask-shaped, about half as long as bell cavity; walls of umbrella thick; marginal bulbs with 8 long tentacles; frequently with medusa buds on manubrium B. niobe

Bougainvillia aurantiaca Bouillon, 1980 (Fig. 25D)

Medusa: umbrella up to $1.9 \mathrm{~mm}$, bell-shaped, mesoglea slightly thicker at the apex; manubrium conical, half to two thirds of subumbrellar cavity; with a very slight peduncle; oral tentacles with very long basal trunk and branching 2 to 3 times; «gonads» as interradial pads; tentacular bulbs broad, hemispherical with 2 to 3 marginal tentacles; no ocelli; marginal bulbs and «gonads» coloured in orange in living animals.

Hydroid: unknown.

Records from Mediterranean: eastern Mediterranean.

Known seasonality: 4-5.

Distribution: Indo-Pacific, Mediterranean.

References: Bouillon (1980); Goy et al. (1988, 1990, 1991); Boero and Bouillon (1993); Schuchert (1996).
Bougainvillia britannica (Forbes, 1841)

(Figs. 25E-H)

Hydroid: colonies with erected stems, not much branched and not densely distributed arising from a large meshed network of tubular stolons; hydrocauli and hydrocladia branches monosiphonic, their slightly transversally wrinkled perisarc, investing adult hydranths till tentacular level, forming cup-like pseudohydrothecae, expended hydranths extending well beyond pseudhydrothecae; hydranth terminal on hydrocauli and hydrocladia, club-shaped, with short conical hypostome, with up to 14 amphicoronate filiform tentacles. Medusa buds borne singly or in clusters on branched stalks arising from hydrocauli and hydrocladia; globular at maturity.

Medusa: umbrella $12 \mathrm{~mm}$ high, $10 \mathrm{~mm}$ wide, mesoglea thick, umbrellar cavity spacious, umbrella margin square; without gastric peduncle; manubrium short and broad, cross-shaped in transversal section; 4 oral tentacles with long basal trunk, in distal part divided 4-6 times with small terminal knobs; «gonads» adradial; marginal bulbs triangular, about half as broad than intervals, each provided with about 30 thin tentacles; with linear ocelli, adaxial on base of each tentacle.

Records from Mediterranean: Black Sea, hydroid form only?

Seasonality: ?

Distribution: Atlantic; Indo-Pacific; Mediterranean, Black Sea.

References: Thiel (1935); Russell (1953, 1970); Kramp (1961); Vannucci and Rees (1961); Edwards (1964, 1966b); Cornelius and Ryland (1990); Boero and Bouillon (1993).

\section{Bougainvillia maniculata Haeckel 1864}

(Fig. 25I)

Medusa: umbrella $1.5 \mathrm{~mm}$ high and wide, almost spherical, with thin walls; manubrium flask-shaped with narrow base and long narrow throat tube projecting beyond velar opening; oral tentacles with long trunks, divided twice; «gonads» interradial; marginal bulbs small, globular, each with short finger-shaped tentacles; ocelli large. Only seen by Haeckel, considered by Mayer (1910) as a degenerated form and doubtful species.

Hydroid: unknown.

Records from Mediterranean: western Mediterranean.

Known seasonality: 3-4. Endemic of the Mediterranean Sea. 
References: Haeckel (1864); Kramp (1959a, 1961); Mayer (1910); Boero and Bouillon (1993).

\section{Bougainvillia multicilia (Haeckel, 1879)}

Medusa: umbrella $6 \mathrm{~mm}$ high, $5 \mathrm{~mm}$ wide, with thin walls; manubrium globular to flask-shaped, with constricted base; without gastric peduncle; oral tentacles simple, unbranched! adradial «gonads»; marginal bulbs kidney shaped, with 10-12 tentacles, each with a red ocelli. Only seen by Haeckel, considered by Kramp $(1955,1959$ a, 1961) as a doubtful species.

Hydroid: unknown.

Records from Mediterranean: Strait of Gibraltar. Seasonality: 3.

Distribution: endemic of the Mediterranean Sea.

References: Kramp (1955, 1959a, 1961); Boero and Bouillon (1993).

\section{Bougainvillia muscus (Allman, 1863)} (Figs. 25J-K, 26A-B)

Hydroid: colonies arising from a irregular network of tubular stolons; hydroids variable in growth and form, from dwarf non-fascicled little-branched colonies to tall, tree-like colonies with profusely, irregularly, branched fascicled hydocauli; perisarc corrugated at base of hydrocladia thinning out over hydranths forming a thin pseudohydrothecae much variable in development; perisarc of hydrocauli and hydrocladia often infested by various detritus; hydranths cylindrical to fusiform, terminal on hydrocauli and hydrocladia; hypostome short, conical; with up to 20 amphicoronate filiform tentacles; medusa buds on moderately long stalks, arising singly or in groups on hydrocladia just below the hydranths.

Medusa: umbrella 2-3.5 mm wide and high, semiglobular, mesoglea fairly thick; manubrium bulbous, half of subumbrellar height; oral tentacles fairly long, divided 1-2 (rarely 3-4) times; 4 interradial «gonads» reaching perradii, globular in females and prolonged along perradial side of peduncle in males; marginal bulbs small, with 3-5 (rarely 6-9) long marginal tentacles; ocelli round; mature eggs covered with a layer of cnidocysts (microbasic euryteles).

Records from Mediterranean: eastern and western Mediterranean; Adriatic.

Known seasonality: present all the year.

Distribution: Atlantic, Indo-Pacific, Mediterranean, Arctic.
References: Russell (1953, 1970a); Picard (1958b); Kramp (1961), Vannucci and Rees (1961); Edwards (1964; 1966b); Berhaut (1970); Goy (1973b); Schmidt and Benovic (1977, 1979); Dowidar (1983); Gili (1986); Benovic and Bender (1987); Brinckmann-Voss (1987); Calder (1988); Goy et al. (1988, 1990, 1991); Boero and Bouillon (1993); Watson (1994); Avian et al. (1995); Ballard and Myers (1996); Benovic and Lucic (1996); Medel and López-González (1996); Schuchert (2001a); Peña Cantero and García Carrascosa (2002).

\section{Bougainvillia niobe Mayer, 1894} (Fig. 26C)

Medusa: umbrella $7 \mathrm{~mm}$ high, $5 \mathrm{~mm}$ wide, with vertical sides and flat rounded apex, umbrella walls thick; without gastric peduncle; manubrium flaskshaped; cross-shaped in transversal section, about half as long as umbrellar cavity; oral tentacles with long basal trunks, divided 4 times distally; medusa buds from eight radial side of manubrium; 8 adradial «gonads»; marginal bulbs oval, each with 8 tentacles, ocelli dark.

Hydroid: unknown.

Records from Mediterranean: eastern Mediterranean (as B. platygaster).

Known seasonality:?

Distribution: Atlantic; Mediterranean.

References: Kramp (1959a, 1961); Goy et al. (1988, 1990, 1991); Boero and Bouillon (1993).

\section{Bougainvillia platygaster (Haeckel, 1879)} (Fig. 26D)

Medusa: umbrella up to $12 \mathrm{~mm}$ wide and high, globe-shaped to cubical, with thick walls and flat top; exumbrella with perradial notches; manubrium quadrangular, very flat and broad, 4 times as wide than high; oral tentacles divided 5-6 times almost from base; «gonads» flat, as interradial pads; marginal bulbs small but broad, triangular, with 10-13 short tentacles; ocelli crescent-shaped; medusa buds produced directly from manubrium or from polypoid structures developed on manubrium.

Hydroid: unknown.

Records from Mediterranean: western Mediterranean (Bouillon, pers. obs.)

Known seasonality: 5.

Distribution: Atlantic, Indo-Pacific, Mediterranean. 
References: Kramp (1961); Winkler (1982); Pagès et al. (1992), Boero and Bouillon (1993); Bouillon (1995b).

\section{Genus Dicoryne Allman, 1859}

Hydrocaulus erect, branched or unbranched; perisarc conspicuous, terminating on or below hydranth body, never continued over tentacles base; hydranths with one distal whorl of filiform tentacles; gonophores on gonozooids (blastostyles) and released as free-swimming styloid sporosacs, flagellated and provided with one or two tentacles arising from their proximal, originally attached end.

Reference: Schuchert (1996, 2001a).

1. Hydranth with about 12 tentacles; released sporosacs with single ciliated process.

D. conybeari

- Hydranth with up to 16 tentacles; released sporosacs with two ciliated processes D. conferta.

\section{Dicoryne conferta (Alder, 1856)}

(Fig. 26E-G)

Colonies up to $25 \mathrm{~mm}$ growing on gastropod shells; hydrorhiza reticulate, without spines, clothed with perisarc, giving rise hydrocauli monosiphonic, unbranched or irregularly branched; axis increasing in diameter from base to distal end, clothed with thick perisarc which terminates below hydranth. Branches living stem at acute angle. Perisarc wrinkled, especially basally. Hydranth with one whorl of 10-13 filiform tentacles. Blastostyles borne on stem or on hydrorhiza, they are modified polyps without mouth or tentacles, but with a long and extensile hypostome with cnidocysts; gonophores in a dense cluster below hypostome; colonies dioecious. Gonophores as free-swimming, ciliated sporosacs with two tentacles basally; the female containing two eggs.

Records from Mediterranean: Adriatic, eastern and western Mediterranean.

Distribution: north Atlantic from Arctic to the Mediterranean; but also recorded in South-Africa.

References: Broch (1916) as Bouigainvillia conferta; Millard (1975); Boero and Bouillon (1993); Altuna (1994); Avian et al. (1995); Medel and López-González (1996); Schuchert (2001a).
Dicoryne conybeari (Allman, 1864)

(Fig. 27A)

Colonies encrusting, living on gastropod shells, hydrorhiza anastomosing, giving rise single stalked hydranths or monosiphonic and branched stems up to $10 \mathrm{~mm}$; branching irregularly acute; perisarc pale brown, transversely wrinkled, distending slightly distally. Hydranths pale brown, slightly dilated above, tentacles straight, up to 12 in one amphicoronate circlet, upper ones the longer, contracting partly within perisarc tube. Gonophores ovoid, on blastostyles borne on stolon and bearing cnidocysts distally, releasing sporosacs with one ciliated process.

Records from Mediterranean: Adriatic, eastern and western Mediterranean.

Distribution: northeastern Atlantic; Mediterranean.

References: Motz-Kossowska (1905); Cornelius and Ryland (1990); Boero and Bouillon (1993); Avian et al. (1995); Avian et al. (1995); Medel and López-González (1996).

\section{Genus Garveia Wright, 1859}

Hydrocaulus erect and branched, monosiphonic or polysiphonic; hydranth fusiform, hypostome dome-shaped, conical, surrounded by one distal whorl of tentacles; pseudohydrothecae covering polyp base but not extending over tentacles; gonophores as fixed sporosacs, borne on pedicels on hydrocauli or on hydrorhiza.

Reference: Calder (1988).

1. Branches adnate to the main axis basally G. grisea

- Branches separated of the main axis for all their length

2. Hydrocauli monosiphonic, up to $12 \mathrm{~cm}$. high, regularly branched, hydrocladia on short intervals and densely branched .. G. franciscana

- Hydrocauli polysiphonic basally, up to $4 \mathrm{~cm}$. high, not with a regular branching appearance, hydrocladia at irregular intervals and not densely branched. G. nutans

Garveia franciscana (Torrey, 1902)

(Figs. 27B-D)

Colonies erect and branched, up to $12 \mathrm{~cm}$ high; hydrocauli monosiphonic, thick, wrinkled and with 
several annuli at the beginning of branches; perisarc pale brown. Hydrocladia lateral and alternate, at acute angle with the axis, alternately branched; polyps borne on pedicels at secondary branches. Hydranth fusiform surrounded basally by a pseudohydrotheca, hypostome conical, 14-16 filiform tentacles in one whorl. Colonies dioecious, gonophores fixed sporosacs borne on short pedicels below the polyps, males ovoid and elongated, females spherical and smaller than males and containing 1-2 eggs.

Records from Mediterranean: eastern and western Mediterranean, Adriatic Sea.

Known seasonality: 9.

Distribution: cosmopolitan in temperate and tropical waters.

References: Morri (1982, 1986); Gili (1986); Boero and Bouillon (1993); Medel and LópezGonzález (1996).

\section{Garveia grisea (Motz-Kossowska, 1905)}

(Figs. 27E)

Colonies erect and branched, up to $3 \mathrm{~cm}$ high; hydrocauli monosiphonic or polysiphonic basally, thick, without annulations, perisarc grey. Hydrocladia alternate, adnate to the hydrocauli at their basal portion, giving rise secondary hydrocladia with the same disposition. Hydranth on secondary branches, covered basally by a pseudohydrotheca, with 7-10 filiform tentacles in one whorl, hypostome conical. Gonophores fixed sporosacs, borne on hydranth pedicels, ovoid, isolated or paired; the female with only one egg.

Records from Mediterranean: western Mediterranean.

Known seasonality: 10-6.

Reproduction: 10-1.

Distribution: endemic of the Mediterranean Sea.

References: Rossi (1961); Morri (1982); Boero and Bouillon (1993); Medel and López-González (1996); Medel (1996).

\section{Garveia nutans (Wright, 1859)}

(Figs. 27F-G)

Colonies about $25 \mathrm{~mm}$ high, composed of erect and branched hydrocauli, polysiphonic basally, branching mainly from alternate sides of stem. Perisarc pale brown, irregularly wrinkled, thin and becoming transparent under the hydranth, and forming a pseudohydrotheca around its base. Polyp pearshaped, with 10-12 filiform tentacles. Gonophores ovoid with apical truncated point, grouped on midregion of stem and main major branches, borne on short pedicels.

Records from Mediterranean: Adriatic, western Mediterranean.

Distribution: boreal and temperate waters around the world.

References: Leloup (1952) as Bimeria; Cornelius and Ryland (1990); Ramil and Vervoort (1992a); Boero and Bouillon (1993); Avian et al. (1995); Medel and López-González (1996).

\section{Genus Koellikerina Kramp, 1939}

Hydroid: known only for $K$. fasciculata: colonies arising from a creeping hydrorhiza formed by tubular stolons; hydrocauli and hydrocladia erected, branched and recovered by perisarc incrusted with mud and various detritus; perisarc forming a wrinkled pseudohydrothecae recovering hydranth and base of the tentacles, living only hypostome free; hydranth fusiform to pear-shaped, with conical hypostome, with an irregular whorl of up to 14 filiform tentacles, slightly knobbed at end; medusae bud stalked, borne singly on hydrocauli and hydrocladia.

Medusa: Bougainvilliidae with 8 groups of marginal tentacles, 4 perradial and 4 interradial, all alike in structure; with 4 oral perradial dichotomously branched tentacles; «gonads» on manubrium in adradial; interradial or perradial position; with or without ocelli. The endoderm of the gastric cavity of the Koellikerina presents numerous conspicuous endodermal expansions sustained by a mesoglean axis and containing excretory vacuoles (see Bouillon, Boero and Seghers, 1988a).

Remark: the hydroids described as Thamnostoma probably belong to the genus Koellikerina, see Petersen and Vannucci (1960).

Koellikerina fasciculata (Péron and Lesueur, 1810) (Figs. 27H-L)

Hydroid: see genus characters.

Medusa: umbrella $12 \mathrm{~mm}$ wide, $12 \mathrm{~mm}$ high, barrel-shaped to bell-shaped, with flatly rounded apex and thick walls; manubrium on short, broad gastric peduncle with quadrangular base; oral tentacles divided 7 times to form a dense network; 4 perradial horseshoe-shaped «gonads» with transverse furrows; 4 radial canals; 8 marginal bulbs, each with 10-23 tentacles; with dark red adaxial ocelli at base of each tentacle. 
Records from Mediterranean: eastern and western Mediterranean; Adriatic Sea; Black Sea.

Known seasonality: 3-7.

Distribution: Atlantic; Indo-Pacific (Red Sea, Indian Ocean); Mediterranean; Antarctic.

References: Thiel (1935); Ranson (1936); Babnik (1948); Petersen and Vannuci (1960); Goy (1973b); Vannucci and Navas (1973a); Gili (1986); Brinckmann-Voss (1987); Gili et al. (1987, 1988); Pagès et al. (1992); Boero and Bouillon (1993); Benovic and Lucic (1996); Avian et al. (1995); Medel and LópezGonzález (1996).

\section{Genus Lizzia Forbes, 1846}

Medusa: Bougainvillidae with simple, unbranched oral tentacles; with usually 8 marginal bulbs (exceptionally 16, Lizzia fulgurans) each with one solitary marginal tentacles or with unequal groups of marginal tentacles.

Hydroid: unknown

1. With more than one marginal tentacle on each marginal bulb and more tentacles on marginal perradial bulbs than on interradial ones

L. blondina

- With solitary marginal tentacles. 2

2. With 4 oral tentacles; 8 , sometimes 16 solitary marginal tentacles . L. fulgurans

- With 8 oral tentacles, in four perradial pairs; 8 marginal solitary tentacles L. octostyla

\section{Lizzia blondina Forbes, 1848}

(Figs. 28A-D)

Medusa: umbrella 1-2 mm high and wide, semiglobular, with fairly thick apex; manubrium, short, cone-shaped, with quadrangular base; with a short pyramidal gastric peduncle; 4 simple small oral tentacles, each with one terminal knob of cnidocysts; gonad interradial completely surrounding manubrium, ring-shaped; medusa buds on manubrium, before the «gonads» are ripe; 8 marginal bulbs, 4 perradial bulbs with up to 3 tentacles, 4 interradial bulbs never with more than one, frequently not all tentacles developed; no ocelli.

Records from Mediterranean: western Mediterranean; Adriatic Sea.

Known seasonality: 1-12.

Distribution: Atlantic, Mediterranean.

References: Kramp (1961); Berhaut (1970); Goy (1973b); Schmidt and Benovic (1979); Castelló i
Tortella (1986); Gili (1986); Gili et al. (1987, 1988); Boero and Bouillon (1993); Avian et al. (1995); Benovic and Lucic (1996); Medel and LópezGonzález (1996); Mills et al. (1996).

Lizzia fulgurans (A. Agassiz, 1865)

(Fig. 28E)

Medusa: umbrella $1 \mathrm{~mm}$ high, somewhat pyriform, mesoglea very soft and flexible; manubrium small; with a well developed, fairly long, pyramidal gastric peduncle, 1/3 umbrellar cavity; 4 simple oral tentacles; medusa buds on interradial walls of manubrium; 8, sometimes 16 marginal tentacles, stiff, carried curled upward, one on each marginal bulbs, no ocelli.

Records from Mediterranean: western Mediterranean.

Known seasonality: 6-7.

Distribution: Atlantic, Mediterranean.

References: Kramp (1961); Brinckmann-Voss (1987); Boero and Bouillon (1993).

\section{Lizzia octostyla (Haeckel, 1879)}

(Fig. 28F)

Medusa: umbrella $0.4 \mathrm{~mm}$ high, $5 \mathrm{~mm}$ wide, with bulging sides and low conical apex; manubrium on a well developed peduncle; 8 simple knobbed oral tentacles situated in pairs in the four perradial corners of the mouth tube; 4 swollen interradial «gonads», medusa buds on manubrium; 8 short equally developed marginal tentacles with small basal bulbs, old specimens sometimes with additional tentacles on each perradial bulb; no ocelli.

Records from Mediterranean: western Mediterranean; Adriatic Sea.

Known seasonality: 8-10.

Distribution: endemic of Mediterranean Sea.

References: Kramp (1961); Boero and Bouillon (1993); Benovic and Lucic (1996).

\section{Genus Nubiella Bouillon, 1980}

Bougainvillidae with simple unbranched oral tentacles; with 4 solitary marginal tentacles.

Nubiella mitra Bouillon, 1980

(Fig. 28G)

Medusa: umbrella $2.1 \mathrm{~mm}$ high, $1.6 \mathrm{~mm}$ wide, mitre-shaped, with a thick conical apical mesoglean 
projection, lateral walls of umbrella of uniform thickness, manubrium cylindrical, 2/3 umbrellar cavity height; with a small gastric peduncle; mouth circular, 4 oral tentacles with a rather large cnidocyst knob; radial and circular canal narrow; «gonads» encircling completely the manubrium except the most distal and proximal areas; 4 thin solitary marginal tentacles, their distal half thicker and armed with cnidocysts; marginal tentacular bulbs small, spherical; no ocelli; medusary buds in the aboral part of manubrium, immediately under the gastric peduncle.

Hydroid: unknown.

Records from Mediterranean: eastern Mediterranean.

Seasonality:?

Distribution: Indo-Pacific; Mediterranean.

References: Bouillon (1980, 1985a, 1995a); Goy et al. (1988, 1990, 1991); Boero and Bouillon (1993).

Genus Pachycordyle Weismann, 1883 =Clavopsella Stechow, 1919a in part = Thieliana Stepanjants, Timoshkin, Anokhin and Napara, 2000

Bougainvilliidae with well developed creeping colonies, with branched or unbranched hydrocauli; perisarc terminating at base of hydranth; hydranths club-shaped to spindle-shaped, with 2-4 alternating close whorls of filiform tentacles beneath hypostome, hypostome dome-shaped. Gonophores borne on stem, as fixed sporosacs or free eumedusoids without marginal tentacles, mouth or oral tentacles, radial canals or ring canal, seldom with velum, manubrium simple surrounded by gonads, no sense organs; they correspond to highly reduced medusae, resembling medusoid forms of siphonophores.

Remark: Pachycordyle has been include in the subfamily Pachycordylinae by Calder (1988) that Schuchert (2004) erected to the family level the Pachycordylidae but is here maintained in the Bougainvilliidae with which they present most affinities.

References: Calder (1988); Stepanjants et al. (2000); Schuchert (2004).

1. Gonophores as eumedusoids, distal end of perisarc not distinctly double-layered and not expanded P. napolitanai

- Gonophores as sessile sporosacs, distal end of perisarc double layered and expanded $P$. pusilla
Pachycordyle napolitana Weismann, 1883

(Fig. 28H)

Colonies stolonal, with reticular hydrorhiza growing over a gastropod shell. Pedicels of varied length but usually less than $1 \mathrm{~mm}$ long, slender basally, widening distally, bearing a distal hydranth. Perisarc moderately thin, wrinkled throughout, terminating at base of hydranth, pseudohydrotheca absent. Hydranths clubshaped to spindle shaped, with about 16 to 20 filiform tentacles in three or four close whorls, tentacles of one whorl alternating with those of adjacent whorls. Proximal tentacles often smaller than distal ones. Hypostome dome-shaped. Gonophores arising simply from hydranth pedicel on short wrinkled stalk, completely invested with perisarc.

Records from Mediterranean: western and eastern Mediterranean.

Seasonality: ?

Distribution: western Atlantic, Bermuda, Mediterranean.

References: Morri (1981); Calder (1988); Boero and Bouillon (1993); Schuchert (2004).

Pachycordyle pusilla (Motz-Kossowska, 1905)

(Fig. 30H)

Colonies minute stolonal colonies (up to $2 \mathrm{~mm}$ ) composed of unbranched pedicels ended by hydrothecae; perisarc thick, annulated basally, widening gradually towards distal extreme, taking a funnel appearance; polyps elongated, 8-12 filiform tentacles scattered through distal half; gonophores fixed sporosacs, ovoid-elongated, borne distally on hydranth pedicels.

Records from Mediterranean: eastern and western Mediterranean, Ligurian Sea.

Known seasonality: 3,4,8,10,12.

Distribution: endemic of the Mediterranean Sea.

References: Motz-Kossowska (1905); Morri (1981); Gili (1986); Roca (1986); Boero and Bouillon (1993); Medel and López-González (1996) all as Cordylophora pusilla. Schuchert (2004) as Pachycordyle pusilla.

Genus Rhizorhagium M. Sars, 1874

= Aselomaris Berrill, 1948

= Clavopsella Stechow 1919a in part $=$ Gravelya Totton, 1930

Hydrocauli erect, unbranched, bearing a single terminal hydranth and, rarely, one or two lateral ones as 
well; perisarc firm, continued over polyp as a pseudohydrotheca, but never investing tentacle bases, exceptionally with pseudohydrotheca stopping just above base of hydranth body ( $R$. michaeli); hydranth with one distal whorl of filiform tentacles, hypostome nipple-shaped or dome-shaped; gonophores as fixed sporosacs, borne on hydrorhiza and stems.

References: Hirohito (1988); Calder (1991); Schuchert (1996, 2001a).

1. Hydranth with pseudohydrotheca reduced to base of hydranth body R. michaeli

- Hydranth with a pseudohydrotheca extending over hydranth body $R$. arenosum

\section{Rhizorhagium arenosum (Alder, 1862)}

(Fig. 29A)

Stolonal colonies, hydrocaulus short, generally covered with minute grains of sand or with mud; hydranth enveloped by a pseudohydrothecae that does not envelop tentacles, with 6 - 12 long, slender distal tentacles in one whorl, amphycoronate; gonophores reduced to sporosacs, usually two in number, pyriform shortly stalked borne on the lower half of the hydrocaulus.

Records from Mediterranean: western Mediterranean.

Seasonality: ?

Distribution: Atlantic; Mediterranean.

References: Hincks (1868); Berril (1948); Boero and Bouillon (1993) Avian et al. (1995).

Rhizorhagium michaeli (Berril, 1948) (Figs. 29B-C)

Stolonal colonies densely creeping, with small polyps on peduncles that elongate with age. Hydranth with pseudohydrotheca stopping just above base of hydranth, hypostome conical, 9-12 filiform tentacles in one whorl; new polyps originated directly from the hydrorhiza. Gonophores fixed sporosacs (cryptomedusoids), arising at distal end of the hydrocaulus; the female gonophore produces up to eight large ova each covered by single-layered "armor" composed of functional cnidocysts.

Records from Mediterranean: western Mediterranean.

Seasonality: ?

Distribution: Atlantic; Mediterranean.

References: Piraino (1991, 1992); Boero and Bouillon (1993).

\section{Genus Thamnostoma Haeckel, 1879}

Medusa: Bougainvilliidae with 4 dichotomously branched oral tentacles, with 4,8 or more solitary marginal tentacles; with interradial «gonads»; with or without ocelli.

Hydroid: unknown.

Thamnostoma dibalia (Busch, 1851)

(Fig. 29D)

Umbrella $7 \mathrm{~mm}$ high, $6 \mathrm{~mm}$ wide; manubrium cubical; without gastric peduncle; with 4 interradial «gonads»; oral tentacles divided two or three times; 4 marginal tentacles; basal bulbs with ocelli.

Records from Mediterranean: western Mediterranean; Adriatic Sea.

Known seasonality: 5; 7-11.

Distribution: endemic of Mediterranean Sea.

References: Kramp (1961); Benovic (1976); Schmidt and Benovic (1979); Gili (1986); Boero and Bouillon (1993); Avian et al. (1995); Benovic and Lucic (1996); Medel and López-González (1996).

Genus Velkovrhia Matjasic and Sket, 1971

Fresh-water bougainvilliids forming erect colonies covered by perisarc; hydranths with two whorl of filiform tentacles, no pseudohydrotecae. Gonophores as styloid fixed sporosacs, borne on hydrocauli.

Velkovrhia enigmatica Matjasic and Sket, 1971

(Fig. 29E)

Diagnosis as for the genus.

Records from Mediterranean: Caves near Ljublajana and near Karlovac.

Distribution: not known.

Reference: Clausen and Salvini-Plawen (1986).

Family BYTHOTIARIDAE

Maas, 1905 (= Calycopsidae)

Hydroid: hydrorhiza plate-like, giving rise to unbranched colonies living in ascidian prebranchial cavities; hydranths sessile, with up to five irregular whorls of filiform tentacles; medusae buds arising from polyps.

Medusa: 4 lips, simple or crenulated; with or without centripetal canals; "gonads" simple or folded, adradial or interradial, on manubrial wall; 4 or 8 radial canals, simple or branching; 4,8 or more hollow marginal tentacles (mesoglea of distal part of 
tentacles often enlarged and strongly reducing endodermal axis), each terminating in a large cnidocyst cluster, with basal portion often adnate to exumbrella; marginal bulbs highly reduced or absent; with or without rudimentary or dwarf solid tentacles (Eumedusa); rarely with abaxial ocelli.

References: Bouillon et al., 1988a); Pagès, Gili and Bouillon (1992); Bouillon (1995); Schuchert (1996); Brinckmann-Voss and Arai (1998); Bouillon (1999); Bouillon and Barnett (1999); Bouillon and Boero (2000).

Key to hydroids (see family character)

\section{Key to medusae}

1. With centripetal canals, blind or joining base of manubrium Calycopsis

- No centripetal canals; radial canals bifurcated (some few additional branches may occur as abnormalities). Bythotiara

Genus Bythotiara Günther, 1903

Hydroid: when known see family diagnosis.

Medusa: Bythotiaridae with 4 simple or branching radial canals; without centripetal canals; «gonads» interradial with transverse furrows; with or without rudimentary or dwarfed tentacles entirely covered with cnidocysts.

\section{Bythotiara murrayi Günther, 1903}

(Figs. 30A-B)

Medusa: umbrella up to about $20 \mathrm{~mm}$ wide and high, globe-shaped, with thick walls; manubrium small, barrel-shaped; mouth with 4 simple lips; generally 4 radial canals bifurcating near point of origin in 8 straight canals joining circular canal (occasionally branching again); in adults as many long primary tentacles as ends of radial canals, generally 8, ending in terminal swellings; some secondary tentacles and minute dwarf tentacles; 4 interradial «gonads», with transverse furrows.

Hydroid: unknown.

Records from Mediterranean: eastern and western Mediterranean; Adriatic Sea.

Known seasonality: $2 ; 4 ; 5 ; 7-9 ; 11 ; 12$.

Distribution: Atlantic; Indo-Pacific; Mediterranean.

References: Kramp (1961); Benovic and Bender (1986, 1987); Bouillon et al.(1988a); Pagès , Bouillon and Gili (1991); Pagès, Gili and Bouillon (1992); Avian et al. (1995); Benovic and Lucic (1996).

\section{Genus Calycopsis Fewkes, 1882}

Medusa: Bythotiaridae with unbranched radial canals; with centripetal canals; «gonads» transversely folded, often forming 8 adradial rows; marginal tentacles of similar structure with cnidocysts only on the terminal knob and with adnate base.

Hydroid: unknown.

Calycopsis simplex Kramp and Damas, 1925 (Fig. 30C)

Medusa: umbrella $8 \mathrm{~mm}$ high, $8.5 \mathrm{~mm}$ wide, almost globular; mesoglea thick at the umbrella apex; manubrium cruciform, with large base, about half as long as umbrellar cavity; mouth with four simple lips; radial canals and circular canal narrow; «gonads» interradial, each with a longitudinal median groove and often a few transverse folds; four blind, interradial centripetal canals; eight tentacles, all alike, with a terminal cnidocyst knob, no marginal bulbs but tentacular base adnate to the exumbrella.

Hydroid: unknown.

Records from Mediterranean: western Mediterranean.

Known seasonality: 12.

Distribution: Atlantic, Mediterranean.

References: Kramp (1961); Goy (1973b); Boero and Bouillon (1993); Gili et al. (1998).

\section{Family ClavidaE McCrady, 1859}

Hydroid: colonies stolonal or erect, branched, monosiphonic or polysiphonic, arising from tubular, ramified hydrorhiza; hydranths sessile or pedicellate, naked, occasionally covered or retractable into a thin perisarc cone or tube (Clava, Merona, Rhizogeton, Tubiclava); with filiform tentacles scattered over hydranth body (oral and distal part of hydranth); nematophores present or absent. Gonophores as free medusae or fixed sporosacs developing from hydrorhiza, hydrocaulus, or from hydrorhizal blastotyles.

Medusa: Anthomedusae with a bell-shaped umbrella; with short manubrium; with a gastric gelatinous peduncle or with vacuolated endodermal cells forming a pseudo-peduncle; mouth armed with a continuous row of sessile cnidocyst clusters along whole margin; with 4 radial canals and circular canal; with solitary solid tentacles, numerous in adults; "gonads" on interradial walls of manubrium; with adaxial ocelli.

References: Wedler and Larson (1986); Calder (1988); Migotto (1996); Schuchert (1996, 2001a, 
2004); Bouillon (1995, 1999); Bouillon and Barnett (1999); Bouillon and Boero (2000).

Remark: The genus Clava presents undeniable relations with the hydractiniids (see Bouillon et al. 1997) and has been include in this family by Schuchert (2001a) who reintroduced the name Cordylophoridae von Ledenfeld, 1885 for the remaining genera of the former family Clavidae. Schuchert (2004) becoming aware of the existence of family Oceanidae Eschscholtz 1829 proposed to replace the junior family Cordylophoridae by the latter family name. The author underlying himself that the macrotaxonomy of the Oceanidae must be regarded as provisional and that the taxonomical validity of the genus Oceania has to be confirmed. The nomenclature incidences of those changes are complicated by the fact that the name Clavidae Mc Crady 1859 predates the Hydractiniidae Agassiz, 1862 threatening the latter name if the two are considered synonyms. Presently we consider better to maintain the current usage till more definitive information, like molecular phylogenetic investigations, have been well sorted out.

\section{Keys to polyps}

1. Colony erect and freely branched 2

- Colony stolonial, hydroids at most slightly branched; hydranth, or at least its pedicel, surrounded by perisarc ....

2. Branches not adnate to stem; gonophores as fixed sporosacs. Cordylophora

- Branches adnate to stem for some distance; gonophores as fixed sporosacs or free medusae

3. Gonophores producing free medusae. Turritopsis

- Gonophores as fixed sporosacs... Corydendrium

4. Hydranth retractable into perisarcal tube; gonophores on separate blastostyles; nematothecae present. Merona

- Hydranth not retractable into perisarcal tube; gonophores on hydranth body no nematothecae. Clava

\section{Key to genera with free medusae}

1. With manubrium mounted upon a short, solid, pyramidal, gelatinous, peduncle without endodermal vacuolated cells.... Oceania

- With manubrium mounted upon a pseudopeduncle formed by highly vacuolated endodermal cells Turritopsis

\section{Genus Clava Gmelin, 1791}

Hydroid: with stolonal colonies; hydrorhiza giving rise directly to sessile hydranths; hydranth naked except a low perisarcal collar round base, with conical hypostome, undifferentiated endoderm and filiform tentacles scattered throughout the body. Gonophores as fixed sporosacs (cryptomedusoids) borne by the hydranth below the tentacles.

References: Rossi et al. (2000); Schuchert (2001a).

Clava multicornis (Forskål, 1775)

(Fig. 30D)

Stolonal colonies, polyps nude, up to $5.5 \mathrm{~mm}$ high, reddish, usually grouped; 20-40 filiform tentacles scattered over the distal half of the hydranth. Gonophores spherical shortly pedicellate, borne below lower tentacles, grouped in "bunch", in one whorl of up to 80 gonophores; cryptomedusoids. Colonies dioecious. Cnidocysts: desmonemes $(2 \times 5$ $\mathrm{mm})$ and microbasic euryteles (5x8 $\mathrm{mm})$.

Records from Mediterranean: Adriatic, eastern and western Mediterranean.

Known seasonality: 5, 6, 7, 11.

Reproduction: 6, 7.

Distribution: eastern and western north-Atlantic, Mediterranean, Arctic Seas.

References: Leloup (1952); Naumov (1960); Gili (1986); Roca (1986); Cornelius and Ryland (1990); Boero and Bouillon (1993); Altuna (1994); Avian et al. (1995); Medel and López-González (1996); Schuchert (2001a); Peña Cantero and García Carrascosa (2002).

Genus Cordylophora Allman, 1844

Hydroid: Clavidae with erect colonies, hydrocaulus unbranched or monopodially branched with terminal hydranths; hydranths naked, fusiform, hypostome conical and with scattered filiform tentacles over much of the body. Gonophores as fixed sporosacs on hydranth pedicels, larvae and young polyps may develop within gonangia.

Reference: Schuchert (1996, 2004).

\section{Cordylophora caspia (Pallas 1771)} (Figs. 30E-G)

Colonies stolonal or with erect hydrocauli branched or unbranched, up to $4-8 \mathrm{~cm}$ high; perisarc smooth, corrugated or ringed at the base of branching. Hydranth with 12-24 filiform tentacles scattered 
throughout the polyp. Gonophores fixed sporosacs, ovoid to spherical, sessile or pedicellate, borne on stem or on hydranth pedicels.

Records from Mediterranean: Adriatic, western Mediterranean, Caspian Sea.

Distribution: cosmopolitan, mainly in temperate waters. References: Morri (1981); Boero and Bouillon (1993) Avian et al. (1995); Schuchert (2004).

\section{Genus Corydendrium Van Beneden, 1844}

Colonies with erect, polysiphonic and irregularly branched hydrocauli; branches adnate to hydrocaulus, or to other branches over part or all of their lengths; perisarc firm, covering up to hydranth base; hydranth elongate, tubular, tentacles filiform and scattered over the body. Gonophores as fixed sporosacs enclosed in perisarc, arising as blind, elongate sacs of coenosarc below hydranths and within perisarcal tubes of hydrocauli and hydrocladia branchlets.

Reference: Calder (1988); Schuchert (2004).

\section{Corydendrium parasiticum (Linnaeus, 1767)} (Figs. 31A-C)

Hydrocauli erect and polysiphonic, up to $4.5 \mathrm{~cm}$ high, perisarc firm, moderately thick, smooth or with some wrinkles; often encrusted with detritus and silt. Branching irregular in one or more planes, branches adnate to main axis basally, gradually curving outwards and becoming free distally; secondary branches may occurs in the same way. Perisarc becoming thin at hydranth base, ending below tentacles. Polyps elongate, constricted basally (below perisarcal tube), tentacles filiform (40 or more) scattered, hypostome conical. Gonophores wholly contained within perisarcal tube, arising from coenosarc and lying parallel to it, as long, slender cylinders without spadix; the female with about 13 eggs. Cnidocysts: desmonemes and heterotrichous microbasic euryteles.

Records from Mediterranean: western Mediterranean.

Distribution: temperate and tropical waters around the world.

References: Motz-Kossowska (1905); Millard (1975); Calder (1991); Boero and Bouillon (1993); Medel and López-González (1996); Schuchert (2004).

\section{Genus Merona Norman, 1865}

Clavidae with stolonal polymorphic colonies; gastrozooids unbranched, surrounded by a perisarc tube into which they can withdraw completely, and with scattered, filiform tentacles over much of the body; gonozooids without mouth and tentacles, with short perisarc tube around its base and borne on the stolon, producing fixed sporosacs, dactylozooids borne on stolon, usualy enclosed in a perisarc tube (nematotheca).

Reference: Medel et al. (1993); Schuchert (2004).

1.- Female gonozooids without cnidocysts; gonophores with a small number of big eggs ..... M. cornucopiae.

- Female gonozooids with cnidocysts at the apex; gonophores with great number of small eggs ..... M. ibera

\section{Merona cornucopiae (Norman, 1864)}

(Figs. 31D-E)

Hydrorhiza reticulate, growing on the bivalve mollusc Gouldia minima. Polyps arising directly from the stolon; gastrozooids surrounded by perisarc tube into which it can withdraw completely; tube gradually widening towards distal end and scarcely transparent, often with adhering sediment particles; up to 20 tentacles scattered over distal half of the hydranth. Dactylozooids numerous, scattered over stolon, each surrounded by a strong perisarc tube, widening towards distal end and there becoming wineglass-shaped. Gonozooids of both sexes different and in separated colonies; male gonozooids short and thick, with 16-20 gonophores in a dense cluster on the upper part, like a mulberry. The female gonozooids have a longer pedicel than the males and the distal half of the body bears 15-20 shortly stalked gonophores arranged randomly, each gonophore being ovoid and mucronate at the apex. Cnidocysts are present on gastrozooids, dactylozooids and stolon but not on female gonophore. Cnidocysts: microbasic euryteles, and desmonemes.

Records from Mediterranean: western Mediterranean, Naples.

Known seasonality: 5.

Distribution: temperate waters around the world.

References: Rees (1956a); Cabioch (1965); Gili (1986); Millard (1975); Ramil (1988); Medel et al. (1993); Boero and Bouillon (1993); Medel and López-González (1996); Schuchert (2004).

\section{Merona ibera}

Medel, García-Gómez and Bouillon, 1993

(Figs. 31F-H) 
Hydrorhiza reticulate giving rise directly unbranched gastrozooids, gonozooids and dactylozooids. Gastrozooids surrounded by perisarc tube into which it can withdraw completely; tube gradually widening towards end and scarcely transparent, often with adhering sediment particles. Body of gastrozooid with up to 20 filiform tentacles scattered over distal half. Dactylozooids numerous, scattered over entire stolon, each surrounded by a strong perisarc tube, widening towards end there becoming wineglass-shaped. Large microbasic euryteles occurring at the apex of each dactylozooid. Female gonozooids pinkish, each with a short wide collar of perisarc covering the base. Gonophores at distal third of blastostyle, cylindrical, elongate, containing small eggs regularly distributed in two or three rows along axial spadix. Extreme of apex of gonophore button-shaped, armed with ellipsoid microbasic euryteles.

Records from Mediterranean: only record from the Strait of Gibraltar (Mediterranean side, Algeciras Bay).

Known seasonality: 8.

Distribution: unknown.

References: Medel et al. (1993); Medel and López-González (1996); Schuchert (2004).

\section{Genus Oceania Péron and Lesueur, 1810}

Hydroid: not known from field, Metschnikoff (1886a) obtained ramified colonies with claviform hydranths having up to 13 filiform tentacles alternating in three whorls; gonophores not known.

Medusa: Clavidae with a short, solid, pyramidal, gelatinous, peduncle without endodermal vacuolated cells.

Reference: Schuchert (1996); Schuchert (2004).

\section{Oceania armata Kölliker, 1853}

(Figs. 31I-L)

Hydroid: see genus characters.

Medusa: umbrella 8-10 mm wide and high, bellshaped to pyriform, with flat top, walls uniformly thin; manubrium flask-shaped, cruciform in transverse section, on a shallow mesoglean peduncle; mouth rim crenulated, with a continuous row of spherical sessile cnidocyst clusters; 100-200 marginal solid tentacles, densely crowded, marginal bulbs elongated alternately slightly displaced adaxially and abaxially; «gonads» on interradial walls of manubrium; with adaxial ocelli.

Records from Mediterranean: eastern and western Mediterranean; Adriatic Sea; Black Sea?

Known seasonality: 1-9; 12.

Distribution: Atlantic, Indo-Pacific, Mediterranean.
References: Metschnikoff (1886a); Babnik (1948); Kramp (1961); Dowidar (1983); Benovic and Bender (1987); Brinckmann-Voss (1987); Goy et al. (1988, 1990, 1991); Boero and Bouillon (1993); Avian et al. (1995); Benovic and Lucic (1996); Schuchert (2004).

Genus Turritopsis McCrady, 1857

Clavidae with stolonal or erect colonies; hydrocaulus monosiphonic in small colonies, polysiphonic in larger irregularly branched and increasing in diameter from base to distal end; hydrocladia adnate and parallel to hydrocaulus or to other hydrocladia for some distance, before curving away at an acute angle and becoming free; hydrocaulus and hydrocladia covered by a firm double-layered perisarc, mostly infested with detritus and algae, hydranths terminal, naked, elongated, fusiform, with filiform tentacles irregularly scattered over distal three quarters of hydranth. Gonophores giving rise to free medusae; buds arising mostly one by one from short stems or pedicels below hydranths, enclosed in perisarc.

Medusa: with family characters but with a pseudopeduncle formed by highly vacuolated endodermal cells.

Hydroid: the polyp stages are indistinguishable.

References: Calder (1988); Schuchert (1996, 2004).

Remarks: Schuchert (2004) consider that the Mediterranean species of Turritopsis is different from the eastern Atlantic species Turritopsis nutricula McCrady, 1857 and the North Sea species $T$. polycirrha (Keferstein, 1862) and correspond to Turritopsis dohrnii (Weismann, 1883). It is however not excluded that $T$. dohrnii and $T$. nutricula coexist in the Mediterranean or that Turritopsis dohrnii correspond to a dwarf form of $T$. nutricula, dwarfism being a well known phenomenon in Mediterranean species: (Fage, 1952, Goy, 1995).

The records of Turritopsis from this area (Kramp, 1959; Schmidt, 1973; Dowidar, 1984; Goy et al, 1991) have all to be reconsidered.

\section{Key to medusae}

1. 14 to 32 marginal tentacles; 1.8 to $2.7 \mathrm{~mm}$ of bell size T. dohrnii

- 40 to 100 marginal tentacles; 3 to 4 , up to $6 \mathrm{~mm}$ T. nutricula

Turritopsis dohrnii (Weismann, 1883) (Fig. 32D)

Colonies of variable height, irregularly branched hydrocaulus monosiphonic in small colonies, polysi- 
phonic in larger; branches adnate and parallel to hydrocaulus or to other branches for some distance, before curving away at an acute angle and becoming free; hydrocaulus and hydrocladia recovered by a firm perisarc, consisting of two layers, mostly infested with detritus and algae, without annulations and terminating below hydranth base; hydranths terminal, naked, elongated, fusiform, with 12-20 filiform tentacles scattered over distal three quarters of hydranth; hypostome elongated conical; medusae buds arising mostly one by one from short stems below hydranths, pear shaped, enclosed in perisarc.

Medusa: umbrella up to $2.7 \mathrm{~mm}$ in height, $3.2 \mathrm{~mm}$ in diameter, bell-shaped to perform, higher than wide, mesoglea thicker at apex; manubrium large, crossshaped in transverse section, red in colour; 4 radial canals which appears to overtop 4 compact vacuolated endodermal masses situated above digestive part of manubrium; four lipped mouth with a continuous row of sessile cnidocyst clusters along margin; 14-32 closely spaced marginal tentacles sometimes with swollen tips; gonochoristic «gonads» interradial, infour distinct blocks; with adaxial ocelli rust coloured.

Records from Mediterranean: western Mediterranean; Adriatic.

Known seasonality: 7, 8.

Distribution: Mediterranean.

References: Neppi and Stiasny (1913); Piraino et al. (1996); Schuchert (2004).

Turritopsis nutricula McCrady, 1859 (Figs. 32A-C, E)

Colonies stolonal or erected and then irregularly branched and increasing in diameter from base to distal end, hydrocaulus monosiphonic in small colonies, polysiphonic in larger; branches adnate and parallel to hydrocaulus or to other branches for some distance, before curving away at an acute angle and becoming free; hydrocaulus and hydrocladia recovered by a firm perisarc, consisting of two layers, mostly infested with detritus and algae, without annulations and terminating below hydranth base; hydranths terminal, naked, elongated, fusiform, with 12-38 filiform tentacles scattered over distal three quarters of hydranth, proximal ones shorter than distal; hypostome elongated conical; medusae buds arising mostly one by one from short stems below hydranths, pear shaped, enclosed in perisarc.

Medusa: umbrella 4-11 mm high, bell-shaped to perform, higher than wide, mesoglea thicker at apex; manubrium large, cross-shaped in transverse section, red in colour; 4 radial canals which continue through the 4 compact vacuolated endodermal masses situated above digestive part of manubrium; four lipped mouth with a continuous row of sessile cnidocyst clusters along margin; 80-120 closely spaced marginal tentacles; «gonads» interradial, mature females often with developing embryos and planulae; with adaxial ocelli.

Records from Mediterranean: eastern and western Mediterranean; Adriatic.

Known seasonality: 3, 6-11.

Reproduction: $7,8$.

Distribution: Atlantic, Indo-Pacific, Mediterranean.

References: Vervoort (1968); Schmidt (1973); Dowidar (1983); Boero and Fresi (1986); Brinckmann-Voss (1987); Goy et al. (1988, 1990, 1991); Bavestrello et al. (1992); Ramil and Vervoort (1992a); Boero and Bouillon (1993); Avian et al. (1995); Medel and López-González (1996); Piraino et al. (1996); Schuchert (1996); Peña Cantero and García Carrascosa (2002); Schuchert (2004).

\section{Family Cytaeididae L. Agassiz, 1862}

Hydroid: colony usually non-polymorphic, hydrorhiza reticulate, covered by perisarc, without spines; gastrozooid sessile, with one whorl of filiform tentacles below conical hypostome, naked but base of hydranths often with a perisarc cup-shaped collar at base, sometimes of two sizes, smallest ones acting as dactylozooids; gonophores on hydrorhiza, as free medusae, medusoids with four radial canals, or as fixed sporosacs.

Medusa: umbrella bell-shaped; manubrium bulbous; mouth simple, circular, with 4 or more unbranched oral arms, either on or very near mouth rim; 4 radial canals and circular canal; 4 or 8 marginal solid tentacles; "gonads" interradial or encircling manubrium; no ocelli.

References: Calder (1988); Schuchert (1996); Bouillon (1995a; 1999); Bouillon and Barnett (1999); Bavestrello et al. (2000); Bouillon and Boero (2000).

Key to hydroids (Known only in the genus Cytaeis, with family characters).

\section{Key for medusae}

1. 4 marginal tentacles............................... Cytaeis

- 8 marginal tentacles......................... Paracytaeis

Genus Cytaeis Eschscholtz, 1829

= Perarella Stechow, 1922; Stylactella

Haeckel, 1889 in part: 
Hydroid: see family characters.

Medusa: with family characters, 4 radial canals.

Remark: Rees (1956b, 1962) re-established the Genus Perarella for species with fixed sporosacs or degenerated medusae. Since generic classification based exclusively on medusa reduction is presently rejected, Perarella is considered as congeneric with Cytaeis.

References: Calder (1988); Bouillon et al. (1991); Bavestrello (1987); Bavestrello et al. (2000).

1. Colonies giving rise to free medusae Cytaeis spp

- Colonies giving rise to gonophores

2. Gonophores with radial canals, circular canals and tentacular bulbs; wide collar of perisarc surrounding the base of the hydranth C. schneideri

- Gonophores without radial canals, circular canals and marginal bulbs. hydranth naked

C. propagulata

\section{Cytaeis propagulata (Bavestrello, 1987)}

(Figs. 32F-H)

Stolonal colonies living on Hinia incrassata shells; hydrorhiza following the grooves of the shell, sometimes originating tubes of naked coenosarc (propagules) with base surrounded by a collar of perisarc. Hydranth nude, without perisarcal collar, hypostome conical, 7-15 filiform tentacles in one whorl; spines and dactylozooids absent. Male and female gonophores similar, ovoid, young ones having spadix occupying about two-thirds of their lenghts, mature ones with spadix which narrows and disappears when gametes have been liberated; female gonophores with 15-25 eggs, without radial canals, circular canal, neither marginal bulbs. Cnidocysts: microbasic euryteles $(6 \times 3 \mathrm{~mm})$ and desmonemes $(4.5 \times 3 \mathrm{~mm})$.

Records from Mediterranean: western Mediterranean.

Distribution: endemic of Mediterranean Sea.

References: Bavestrello (1987); Boero and Bouillon (1993) (all as Perarella propagulata).

Cytaeis schneideri (Motz-Kossowska, 1905) (Fig. 32I)

Stolonal colonies strictly associated with colonies of the bryozoan Schizoporella longirostris, hydrorhiza reticulated with tubes of transparent perisarc. Polyps nude, of two types, one long and tubular with 8-14 fil- iform tentacles in one whorl, and an other very extensile filiform with only 4 short tentacles both with a wide collar of perisarc surrounding the base. Gonophore arising directly from the stolon, giving rise to medusoids almost spherical, with 4 radial canals, circular canal, 4 tentacular bulbs and a non functional manubrium. Female eumedusoids free swimming for about 5 days before spawning and afterwards degenerating, male present no swimming activity. Cnidocysts: desmonemes $(6.3 \times 3.6 \mathrm{~mm})$ and microbasic euryteles $(8.1 \times 3.1 \mathrm{~mm})$. The two kinds of gastrozooids of Cytaeis schneideri are related to two different trophic strategies the large gastrozooids feed on meiobenthic organisms consisting in nematodes and polychaetes or bryozoan larvae, the filiform gastrozooids engulfs and feeds on the distal portion of a single lophophoral tentacles of its bryozoan host. When the lophophore retract the gastrozooid is dragged into the bryozoan for a short time, the hydrozoan never catch portion of the lophoporal tentacle like Halocoryne epoizoica but merely suck the tentacle feeding on the food caught by the bryozoan lophophore. (Bavestrello et al. 2000).

Distribution: Mediterranean endemic.

References: Motz-Kossowska (1905) as Perigonimus schneideri; Gili (1986); Boero and Bouillon (1993); Medel and López-González (1996) (all as Perarella schneideri).

\section{Cytaeis spp. (Fig. 33A)}

Hydroid: see family characters

Medusa: umbrella up to $5 \mathrm{~mm}$ wide, $6 \mathrm{~mm}$ high, pear-shaped to globular, apical mesoglea about twice as thick than lateral walls; with or without a slight peduncle; manubrium large, pear-shaped; mouth with up to 32 simple, more or less capitate and adnate oral tentacles; with 4 broad radial canals; «gonads» interradial generally encircling the manubrium; marginal tentacles bulbs large, pyriform to triangular attached to exumbrella; medusae buds on base of manubrium.

Three nominal Cytaeis medusae species have been described from Mediterranean waters, Cytaeis pusilla Gegenbaur, 1857 (considered by Kramp (1961) as a doubtful species), Cytaeis tetraststyla Eschscholtz, 1829 and Cytaeis vulgaris Agassiz and Mayer, 1899 (considered once as a synonym of Cytaeis tetrastyla, once as a valid species, see Kramp (1959a), 1961, 1968). In fact, the variations existing between specimens of Cytaeis medusae from a single collection are overlapping the characters described for the different species, no certain characters are presently known by 
which Cytaeis species medusae can be distinguished morphologically and the connotation Cytaeis spp. will be used here.

Records from Mediterranean: eastern and western Mediterranean; Adriatic Sea.

Known seasonality: 1-7; 10.

Distribution: Atlantic, Indo-Pacific, Mediterranean.

References: Babnik (1948); Kramp (1961); Rees (1962); Goy (1973b); Brinckmann-Voss (1987); Calder (1988); Bouillon, Boero and Seghers (1991); Goy et al. (1988, 1990, 1991); Boero and Bouillon (1993); Avian et al. (1995); Benovic and Lucic (1996).

\section{Genus Paracytaeis Bouillon, 1978}

Medusa: with general characters of the family, with eight marginal tentacles; with 4 interradial exumbrellar opaque oval spots of special vacuolated cells located midway of umbrella.

Hydroid: not known.

Paracytaeis octona Bouillon, 1978 (Fig. 33B)

Umbrella up to $2.5 \mathrm{~mm}$ wide, $3 \mathrm{~mm}$ high, bellshaped; with 4 interradial exumbrellar opaque oval spots of special vacuolated cells located midway of umbrella; velum narrow; manubrium conical, half as long as umbrellar height; mouth circular, with up to 20 oral adnate capitate tentacles; «gonads» interradial, covering almost all manubrium surface; 8 marginal tentacles; with large marginal tentacular bulbs with adaxial and abaxial knob of cnidocysts; with medusa buds on interradial parts of manubrium.

Records from Mediterranean: eastern Mediterranean.

Known seasonality: 4; 5; 8-12.

Distribution: Indo-Pacific; Mediterranean.

References: Kramp (1961); Bouillon (1978a, 1980); Bouillon et al. (1988a); Lakkis and Zeidane (1985); Goy et al. (1988, 1990, 1991); Boero and Bouillon (1993).

\section{Family EuCODONIIDAE Schuchert, 1996}

Medusa: Anthomedusae with a bell-shaped umbrella, without pointed apical projection; exumbrella without cnidocysts tracks; manubrium quadrangular; with a developed, conical, gastric peduncle; mouth quadrangular; with 4 inconspicuous lips armed with cnidocysts; with 4 radial canal and circular canal; «gonads» encircling manubrium; with 4 solid marginal tentacles with a terminal swelling; marginal bulbs small; without ocelli.

Hydroid: unknown.

Genus Eucodonium Hartlaub, 1907

With the characteristics of the family.

Eucodonium brownei Hartlaub, 1907 (Fig. 33C)

Medusa: umbrella up to $1 \mathrm{~mm}$ high and wide; mouth lips containing each a group of about 100 cnidocysts; marginal bulbs with blackish pigment granules; cnidocysts along the entire tentacle surface and in terminal swellings; medusae buds arising from middle region of manubrium.

Records from Mediterranean: western Mediterranean; Adriatic.

Known seasonality: 1; 5-11.

Distribution: Atlantic, Indo-Pacific, Mediterranean.

References: Picard (1955b); Kramp (1961); Berhaut (1970); Brinckmann-Voss (1970, 1987); Goy (1970, 1972); Schmidt and Benovic (1979); Castelló i Tortella (1986); Avian et al. (1995); Benovic and Lucic (1996); Schuchert (1996).

\section{Family EudendriIdAe L. Agassiz, 1862}

Paedomorphic hydrozoa reduced to hydroid stage, colonies with erect, usually branched stem arising from a creeping hydrorhiza; hydrocaulus enclosed by firm perisarc either up to the base of the hydranth body, where the ectoderm makes a groove, or sometimes enveloping lower half of hydranth in a cupuliform process (E. vaginatum); hydranths large, urnshaped with pedunculate hypostome and one or more whorls of solid filiform tentacles immediately below it, sometimes presence of special cnidocyst-bearing processes erroneously called cnidophores; some species with a nettle ring immediately above the groove; endoderm of the oral part of the hypostome thin and not differentiated. Reproduction by fixed sporosacs borne on the hydranth body below the tentacles, male and female normally on separate colonies; reproductive hydranth often reduced to blastostyle, male gonophores usually with several chambers in linear series, female gonophores initially with curved spadix, each spadix with a single egg.

Remark: The systematic position of the family Eudendriidae is unclear, although it is a very uniform taxon, its phylogenetic affinities are not easy to 
establish and new criteria seem necessary to elucidate this problem.

References: Calder (1988); Bouillon (1995a); Schuchert (1996); Marques (1996); Marques et al. (2000), Schuchert (2001a).

1. Tentacles usually fewer than 35 , in one whorl Eudendrium

- Tentacles 40 or more, in two or more whorls ..... Myrionema

\section{Genus Eudendrium Ehrenberg, 1834}

Eudendriidae with short urn-shaped hydranths and a single whorl of tentacles of varied number but usually fewer than 35 .

Remark: cnidome features are essential for species identification:

References: Calder (1988); Marinopoulos (1992), Marques (1996); Marques, Peña Cantero and Vervoort (2000), Marques, Mergner, Höinghaus, Santos and Vervoort (2000); Watson (1985; 2000).

Key to the species: after Marques et al. 2000

1. Zooxanthellae present E. moulouyensis

- Zooxanthellae absent. 2

2. Only microbasic euryteles present .................. 3

- Two different types of cnidocyst present ......... 8

3. Microbasic euryteles of one size-class............ 4

- Microbasic euryteles of two size-class.............. 5

4. Unfascicled colonies without cnidophores. E. capillare

- Fascicled colonies with cnidophores

E. armatum

5. Female spadix ax-shaped ........... E. calceolatum

- Female spadix rounded, non ax-shaped ........... 6

6. Female and male gonophores unreduced ...........7

- Female and male gonophores reduced, narrow connection between chambers of male sporosac E. merulum

7. Unfascicled colonies, or at most stem with a complementary tube E. ramosum

- Fascicled colonies E. rameum

8. Complementary cnidocysts macrobasic euryteles

- Complementary cnidocysts atrichous isorhizas or heterotrichous anisorhizas .... 11

9. Male blastostyle unreduced, macrobasic euryteles never arranged in warts. 10

- Male and female blastostyles reduced, macrobasic euryteles arranged in aggregations or warts around hydranth body....... E. glomeratum 10.Female blastostyle hermaphroditic.... E. simplex

- Female blastostyle not hermaphoditic.... E. fragile

11. Complementary cnidocysts atrichous isorhizas .. 12

- Complementary cnidocysts heterotrichous anisorhizas, female immature spadix bifurcated. E. carneum

12. Female immature spadix bifurcated, some hydranths with cnidophores ........ E. racemosum

- Female immature spadix unbranched, no cnidophores E. elseaoswaldae

Eudendrium arbusculum Wright, 1859 (Figs. 33D-G)

Colonies up to 4 to $5 \mathrm{~cm}$ high, branching irregularly, hydrocaulus and main branches polysiphonic thining out to monosiphonic, branches either annulated throughout or with some smooth portions; perisarc thick; most hydranths of a colony usually with a large band of cindocysts just above the basal annular groove, tentacles about 20-22 in number; male gonophores on reduced blastostyles, usually two chambered, distal end with a conspicuous pad of large microbasic euryteles cnidocysts; female gonophores oval, borne on partially reduced blastostyle becoming completely at atrophied at maturity, blatotstyle becoming linked to the eggs by small peduncle, spadix unbranched, curving over the ovum. Cnidocysts: small and large microbasic euryteles?

Records from Mediterranean: Doubtful records from eastern and western Mediterranean (see Marques et al., 2000)

Seasonality: ?

Distribution: North Atlantic, Mediterranean?

References: Calder (1972); Marinopoulos (1992); Marques et al. (2000); Schuchert (2001a).

\section{Eudendrium armatum Tichomiroff, 1887} (Fig. 33H)

Colonies up to $65 \mathrm{~mm}$ high, composed of polysiphonic and branched hydrocauli; perisarc of the stem brown to yellowish (in younger parts), with several groups of annuli elsewhere; branches more or less alternate, but not in the same plane. Hydrocladia ringed basally, also with several annulations at the base of renovated portions. Polyp on pedicels, with 29-32 filiform tentacles and flared hypostome. Nematophore naked, large and thin, borne on pedi- 
cel, irregularly distributed throughout the colony. Female gonophore with a normal spadix, male gonophore with 2-3 chambers. Cnidocysts: heterotrichous microbasic euryteles ( $5 \times 3$ to $6 \times 4 \mu \mathrm{m})$ on tentacles and ectoderm, also the same type $(8 \times 4$ to $9 \times 4.5 \mu \mathrm{m})$ on the hypostome, the hydranth and on the hydrocaulus; butt thin.

Records from Mediterranean: eastern and western Mediterranean.

Known seasonality: 1,7.

Reproduction: 7.

Distribution: endemic of Mediterranean Sea.

References: Gili (1986); Boero and Fresi (1986); Marinopoulus (1992); Boero and Bouillon (1993); Medel and López-González (1996); Marques et al. (2000).

\section{Eudendrium calceolatum Motz-Kossowska, 1905} (Fig. 34A)

Colonies composed of monosiphonic and branched hydrocauli; axis and branches ringed basally. Hydranth urn-shaped. Mature female gonophore with the spadix axe-shaped; male gonophore with 1-2 chambers. Cnidocysts: heterotrichous microbasic euryteles $(20 \times 8$ to $30 \times 13 \mu \mathrm{m})$ on hypostome, hydranth and stem; butt thick, with two bulks, occupying $2 / 3$ the length of capsule; small heterotrichous microbasic euryteles $(6 \times 2.5$ to $9 \times 4 \mu \mathrm{m})$ on tentacles, ectoderm and elsewhere.

Records from Mediterranean: western Mediterranean.

\section{Known seasonality: 6}

Distribution: endemic of Mediterranean Sea.

References: Motz-Kossowska (1905); Marinopoulus (1992); Boero and Bouillon (1993); Marques et al. (2000).

\section{Eudendrium capillare Alder, 1856} (Fig. 34B-D)

Colonies small and slender, up to $17 \mathrm{~mm}$ high, composed of erect and monosiphonic hydrocauli irregularly to more or less alternately branched; hydrocladia in turn alternately to irregularly branched; pedicels long and bent; perisarc thicker basally and becoming thinner towards distally, yellowish to transparent, terminating at groove around base of hydranths; stem branches and pedicels with several annulations basally, but also with irregularly placed annulations elsewhere. Hydranth with a large and flared hypostome, 15-20 filiform tentacles in one whorl. Gonophores fixed sporosacs, borne on hydranths, the female in a whorl on hydranths with partially atrophied tentacles; spadix unbranched, curving over egg; the male with up to three chambers each, terminal one with an apical tubercle, borne on atrophied polyps. Cnidocysts: only heterotrichous microbasic euryteles (6.7-7.6 x 2.5-3.2 $\mu \mathrm{m})$.

Remark: See Marques et al. (2000) concerning the validity of the records of this species in the Mediterranean Sea.

Records from Mediterranean: eastern and western Mediterranean, Adriatic.

Known seasonality: present throughout all the year. Reproduction: 1-12.

Distribution: eastern and western Atlantic, Indian Ocean, eastern and western Pacific; Mediterranean.

References: Mammen (1963); Millard (1975); Millard and Bouillon (1974); Calder (1988); Cornelius and Ryland (1990); Marinopoulus (1992); Boero and Bouillon (1993); Avian et al. (1995); Medel and López-González (1996) Marques et al. (2000); Schuchert (2001a); Peña Cantero and García Carrascosa (2002).

\section{Eudendrium carneum Clarke, 1882 (= E. cunninghami) (Figs. 34E-I)}

Colonies densely branched, bushy, up to $105 \mathrm{~mm}$ high, composed of erect and polysiphonic hydrocauli, more or less alternately branched, major branches polysiphonic, secondary ones polysiphonic basally; perisarc thick, brownish in older parts, thinner and paler towards distally; branches and pedicels annulated basally, also occasional annulations elsewhere. Hydranth with a large flared hypostome and a shallow perisarc groove basally; filiform tentacles (27-32) in one whorl. Gonophores fixed sporosacs, borne on hydranth; females on reduced hydranths with partially atrophied tentacles, spadix bifid and acuminate, curving over egg; during development, spadices shed, embryos borne in perisarc-covered capsules arranged irregularly along annulated pedicel, terminal polyp eventually lost; male gonophores on atrophied polyps each with up to five chamber. Cnidocysts: heterotrichous anisorhizas (22.2-23.4x10.1-10.8 $\mu \mathrm{m})$, on hydranth, hypostome and on the stem; butt visible in undischarged cnidocysts; heterotrichous microbasic euryteles $(9 \mathrm{x} 4 \mu \mathrm{m})$ on tentacles and ectoderm.

Records from Mediterranean: Adriatic western Mediterranean.

Known seasonality and reproduction: 7-12.

Distribution: western and eastern Atlantic, Indian Ocean, Mediterranean, Red Sea; western Pacific. References: Vervoort (1968); Millard (1975); Gili 
(1986); Calder (1988); Marinopoulus (1992); Medel and López-González (1996); Marques et al. (2000).

\section{Eudendrium elsaeoswaldae Stechow, 1921} (Figs. 34J-K)

Colonies large and unfascicled, with long stems branches and pedicels; hydranth elongated; cnidocysts small microbsaic euryteles and atrichous isorhiza (13.9- 17.1 x 6.3-7-3 $\mu \mathrm{m})$. Only immature blastostyles of both sexes observed, male reducing tentacles in course of development, females with normal number of tentacles and unbranched spadix.

Remark: This species is usually not in the Mediterranean checklist because it's short description. (Marques et al. 2000).

Records from Mediterranean: western Mediterranean (Naples).

Seasonality: ?.

Distribution: endemic of Mediterranean Sea.

References: Stechow (1923d); Riedl (1959); Marques et al. (2000).

Eudendrium fragile Motz-Kossowska, 1905 (Fig. 34L)

Colonies small and delicate, hydrocauli monosiphonic unbranched or little branched; with some annuli at base of branches and hydranths. Polyp small, almost uncolored, hypostome flared, without perisarc groove basally. Female gonophores with unbranched spadix when mature; male gonophores with 1-2 chambers. Cnidocysts: heterotrichous microbasic euryteles and macrobasic euryteles (27.5-29.0 x 10.0-11.0 um).

Records from Mediterranean: eastern and western Mediterranean.

Known seasonality: 9-5.

Reproduction: 10-3.

Distribution: endemic of Mediterranean Sea.

References: Motz-Kossowska (1905); Boero and Fresi (1986); Marinopoulus (1992); Boero and Bouillon (1993); Marques et al. (2000).

\section{Eudendrium glomeratum (Picard, 1951)} (Figs. 34M-O)

Colonies up to $30 \mathrm{~cm}$ high, composed of hydrocauli polysiphonic and branched; perisarc brown and thick in older parts, becoming thin and yellowish to transparent in younger regions. Polyp urn-shaped, hypostome flared, tentacles filiform, 24-28 in one whorl. Female mature gonophore with unbranched spadix; male gonophore provided with one or two chambers; mature balstostyle with either a normal number of tentacles or a reduced number partly-atrophied tentacles. Cnidocysts: holotrichous macrobasic euryteles $(24 \times 10$ to $28 \times 11 \mu \mathrm{m})$, but long (4 times length of capsule) and spirally coiled around the big axis of the cnidocyst; these cnidocysts are concentrated in several groups characteristically conspicuous at the basal half of the polyp; also heterotrichous microbasic euryteles $(6 \times 2.5$ to $9 \times 4 \mu \mathrm{m})$ on tentacles and ectoderm.

Records from Mediterranean: Adriatic western and eastern Mediterranean.

Known seasonality: 10-4; reproduction: 9-3.

Distribution: north-eastern Atlantic, Indo-Pacific, Mediterranean (distribution probably wider; it resembles the species $E$. ramosum, and many records of the last species could possibly refer to E. glomeratum.

References: Motz-Kossowska (1905) as E. ramosum; Picard (1951c); Watson (1985); Boero and Fresi (1986); Roca (1986); Boero and Cornelius (1987); Bavestrello and Cerrano (1992); Boero and Bouillon (1993); Altuna (1994); Medel and LópezGonzález (1996); Marques et al. (2000); Peña Cantero and García Carrascosa (2002).

\section{Eudendrium merulum Watson, 1985}

(Figs. 35A-G)

Hydrorhiza tubular, giving rise to simple or branched erect stems up to $20 \mathrm{~mm}$ in heigth, unfascicled, lower stems roughly annulated up to the lowest branch. Hydranth small, with approximately 24 tentacles, a club-shaped hypostome and a distinct groove round the base below a ring of a few large cnidocysts. Colonies dioecious; male gonophores borne on lower stems in dense cluster up to 20 per blastostyle, blastostyles completely reduced with distinct neck connecting gonophore chambers; female gonophores borne thickly on lower parts of colonies, globular, fully reduced, up to 6 scattered on blastostyles, spadix unbranched during early ontogeny, shed when mature; eggs with thin pellicle, placed along axis of blastostyle. Cnidome: microbasic euryteles of two sizes: small ones 7-9 x $3.0 \mu$ m abundant on tentacles; large ones 16.5-25.0 x 8.0-13.3 $\mu \mathrm{m}$, having a much ornamented shaft and present in the cnidocyst ring and on spadix of female gonophores.

Records from Mediterranean: Adriatic, eastern and western Mediterranean.

Known seasonality: present throughout the all year. Reproduction. 1, 6-8. 
Distribution: Circumtropical.

References: Watson, (1985); Bavestrello and Piraino (1991); Boero and Bouillon (1993); Avian et al. (1995); Marques et al. (2000); Peña Cantero and García Carrascosa (2002).

\section{Eudendrium moulouyensis}

Marques, Peña Cantero and Vervoort, 2000

(Figs. 35H-M)

Colonies minute, stem fragile up to $15 \mathrm{~mm}$ high, main stem unfascicled. Hydrocaulus arising from stolonal hydrorhiza, irregularly branched in radiate plane up to second order over its whole extension in a few specimens, pedicels arising directly from main stem. Perisarc of main stem weakly developed brown up to half its length, single tubes not annulated. Hydranth slender, without distinctive groove in the aboral region; tentacles 25-28 in one whorl. Zooxanthellae present in hydranth and coenosarc. Only female gonophores described, styloid, mature blatostyles without tentacles and hypostome, spadix shed. Eggs circular encapsulate by a perisarc layer. Cnidocysts: small $(6.3-7.5 \times 3.2-3.5 \mu \mathrm{m})$ and large (10.0-15.0 x 5.0-8.7 $\mu \mathrm{m})$ heterotrichous microbasic euryteles.

Records from Mediterranean: western Mediterranean. Known seasonality: 7, 8.

Distribution: endemic of Mediterranean Sea.

References: Marques et al. (2000); Peña Cantero and García Carrascosa (2002).

\section{Eudendrium racemosum (Cavolini, 1785)} (Figs. 36A-D)

Colonies up to $160 \mathrm{~mm}$ high, composed of basally polysiphonic and branched hydrocauli; perisarc brown in older parts to yellowish in younger ones. Hydrocladia roughly alternate, not in the same plane. Hydranth on pedicel ringed basally; stem ringed on origins of hydrocladia and at other irregular intervals. Hydranth reddish, hypostome flared, tentacles filiform, 25-30 in one whorl. It is characteristic the presence of a digitiform and naked nematophore on the body of some hydranths. Gonophores on polyps with atrophied tentacles to a varying degree (those bearing mature gonophores totally atrophied), female gonophore with a bifid spadix not acuminate; male gonophore with 3 chambers. Cnidocysts: atrichous isorhiza (10.5x4 to $11 \mathrm{x} 4 \mu \mathrm{m})$ on hypostome, hydranth and on the hydrocauli; but invisible in undischarged cnidocysts; small heterotrichous microbasic euryteles $(6 \times 4$ to $7 \times 5 \mu \mathrm{m})$ on tentacles and ectoderm.
Records from Mediterranean: Adriatic, western and eastern Mediterranean.

Known seasonality: 5-12.

Reproduction: 6-10.

Distribution: widely distribution in the IndoPacific (Boero and Bouillon (1993), also present in the temperate and subtropical eastern Atlantic; cosmopolitan species (Marinopoulus, 1992).

References: Watson (1985); Boero and Fresi (1986); Marinopoulus (1992); Boero and Bouillon (1993); Avian et al. (1995); Medel and LópezGonzález (1996); Marques et al. (2000); Peña Cantero and García Carrascosa (2002).

\section{Eudendrium rameum (Pallas, 1766)} (Figs. 36E-G)

Colonies large (up to $25 \mathrm{~cm}$ ), bushy, with a fibrous basal mass, composed of erect, polysiphonic and branched hydrocauli; perisarc dark brown, minor branched ringed basally, sinuous to straight. Hydranths on ringed pedicels, hypostome bulbous, 20-24 filiform tentacles in one whorl. Gonophores unreduced ovoid, yellow, short-stalked, borne on and below hydranths, male with one chamber, female with a spadix. Cnidocysts: heterotrichous microbasic euryteles ( $23 \times 8$ to $25 \times 8 \mu \mathrm{m}$ ) on hypostome, hydranth and on the hydrocaulus; butt thin, straight, occupying totally the capsule; small heterotrichous microbasic euryteles $(8 \mathrm{x} 4 \mu \mathrm{m})$ on tentacles and ectoderm.

Records from Mediterranean: Adriatic, eastern and western Mediterranean.

Known seasonality: almost always present..

Reproduction: 6-9.

Distribution: cosmopolitan.

References: Naumov (1960); Gili (1986); Cornelius and Ryland (1990); Boero and Bouillon (1993); Avian et al. (1995); Medel and López-González (1996); Marques et al. (2000); Schuchert (2001a); Peña Cantero and García Carrascosa (2002).

\section{Eudendrium ramosum (Linneaus, 1758)} (Figs. 36H-L)

Colonies up to $175 \mathrm{~mm}$; hydrocauli polysiphonic basally, sometimes slender and flexuous with roughly alternate hydrocladia, sometimes stiff and bushy with irregular branching; branches monosiphonic. Perisarc smooth, with groups of several annuli above origins of branches, and also elsewhere. Hydranth on pedicel ringed basally, hypostome 
flared, tentacles filiform, and 14-29 in one whorl. Gonophores borne on hydranths with atrophied tentacles to a varying degree, female with an unbranched spadix, male with 1-2 chambers. Cnidocysts: large heterotrichous microbasic euryteles (22.2-28.0x8.7-13.3 $\mu \mathrm{m})$ on hypostome, the lower part of hydranth, and on the stem; butt thin, about $2 / 3$ to $3 / 4$ length of capsule, increasing in diameter distally but not coiled when undischarged; small heterotrichous microbasic euryteles on tentacles and ectoderm $(5.8 \times 2.7$ to $8.4 \times 4.2 \mu \mathrm{m})$.

Records from Mediterranean: Adriatic, eastern and western Mediterranean.

Known seasonality: 1-12.

Reproduction: 7-2.

Distribution: cosmopolitan.

References: Millard and Bouillon (1973, 1974); Millard (1975); Boero and Fresi (1986); Gili et al. (1989); Marinopoulus (1992); Boero and Bouillon (1993); Avian et al. (1995); Medel and LópezGonzález (1996); Marques et al. (2000); Schuchert (2001a); Peña Cantero and García Carrascosa (2002).

Eudendrium simplex Pieper, 1884 =E. motzkossowskae Picard, 1951 (Figs. 36M-P)

Colonies small, up to $12 \mathrm{~mm}$ high, composed of monosiphonic and unbranched or sparsely branched hydrocauli. Stem annulated on origins of branches and at other irregular intervals. Hydranth on pedicel annulated or corrugated throughout, tentacles filiform, 16-27 in one whorl. Gonophores on hydranths which conserve the tentacles, male and female on separate colonies; female gonophore with curved and unbranched spadix, hermaphroditic, containing one egg and one or more masses of spermatogenic cells at summit between spadix and superficial ectoderm; male gonophore unreduced, 1-2 chambered. Cnidocysts: holotrichous macrobasic euryteles ( $17 \times 7.5$ to $23.5 \times 10.5$ $\mu \mathrm{m})$ arranged in two whorls, one at the hypostome and the other one at the basal half of the hydranth; butt long (8-10 times length of capsule) spirally coiled around the big axis, swollen distally to about double the width when discharged, armed with spirally arranged barbs; small heterotrichous microbasic euryteles $(6.6 \times 2.5$ to $7.2 \times 3 \mu \mathrm{m})$ on tentacles and ectoderm.

Records from Mediterranean: eastern and western Mediterranean.

Known seasonality: 4-11.

Reproduction: 7-9, 11

Distribution: South Africa? Probably endemic to Mediterranean (see Marques et al., 2000).
References: Motz-Kossowska (1905); Millard and Bouillon (1974); Millard (1975); Boero and Bouillon (1993); Medel and López-González (1996) all as E. motzkossowskae; Marques et al. (2000); Peña Cantero and García Carrascosa (2002).

Eudendrium tenellum Allman , 1877

Recorded from Adriatic by Broch (1912), doubtful species.

Genus Myrionema Pictet, 1893

Eudendriidae with calyx of hydranth elongate, often columnar below tentacles; tentacles in two or more close whorls, number varied but usually 40 or more.

References: Calder (1988); Marques et al., 2000.

Myrionema amboinense Pictet, 1893

(Figs. 36Q-R)

Colonies up to $56 \mathrm{~mm}$ high, growing in groups, hydrocauli monosiphonic, sparingly and irregularly branched; perisarc thin and flexible, straw-colored to transparent, with annulations at bases of branches. Hydranth urn-shaped, with a long and cylindrical calyx, with a shallow perisarc groove basally; hypostome large, flared to knobbed; tentacles filiform, about 35-60 in two or more close whorls; hydranth and tentacles bearing large numbers of zooxanthellae. Gonophores fixed sporosarcs, borne on hydranth body; female with unbranched spadix; male with 1-4 chambers. Cnidocysts: microbasic euryteles heterotrichous (8.5-9.4 $\mu \mathrm{m} \times 3.5-3.8 \mu \mathrm{m})$ on tentacles, hydranth and elsewhere, butt thin, about 2/3-3/4 length of capsule; macrobasic euryteles on hydranth base and hypostome (21.8-23.4 $\mu \mathrm{m} \times$ 9.7-11.3 $\mu \mathrm{m})$.

Remarks: Marinopoulus (1992) includes this species in the genus Eudendrium.

Records from Mediterranenan: eastern Mediterranean.

Distribution: eastern and western Atlantic, Indian Ocean and Pacific Ocean; Mediterranean.

References: Millard and Bouillon (1973); Calder (1988); Marinopoulus (1992) as Eudendrium amboinense; Boero and Bouillon (1993); Marques et al. (2000).

Family HydractiniIdae L. Agassiz, 1862

Hydroid: colony stolonal, polymorphic, usually epizootic; hydrorhiza either as a reticulum formed by 
perisarc-covered stolonal tubes (sometimes with protective tubes: Clavactinia protecta), or as an encrusting mat issued from the coalescence of the stolonal system and either covered by a common layer of perisarc or with naked coenosarc; in some genera the hydrorhizal mat is invested by a calcareous skeleton; frequently with chitinous or calcareous spines forming sometimes pillars and branches; polyps sessile, naked; gastrozooids either with one whorl or with several closely alternating whorls of oral filiform tentacles or with scattered tentacles on the distal half of the body, exceptionally with one or two tentacles; dactylozooids, when present, with no tentacles; ectodermal vesicles of unknown function present or not in hydrorhiza (Hydrocorella, Janaria); gonophores typically borne on gonozooids with one or more whorls of oral tentacles or without tentacles and mouth ( = blastostyles), exceptionally on or in hydrorhiza ( $H$. cryptogonia), gonophores giving rise to fixed sporosarcs, eumedusoids or free medusae.

Medusa: Anthomedusae more or less bellshaped; with or without slight apical process; manubrium tubular to sac-shaped not extending beyond umbrella margin; with or without gastric peduncle; mouth with 4 simple or branched oral lips elongated to form arms armed with terminal clusters of cnidocysts (exceptionally mouth rim simple and armed with a cnidocysts ring: Kinetocodium, not present in Mediterranean); 4, 8 or more solitary, solid, marginal tentacles; with 4 radial canal and circular canal; «gonads» on manubrium, interradial, sometimes extending along the proximal portions of the radial canals; with or without ocelli.

References: Bouillon (1995a); Bouillon et al. (1997) and Boero et al. (1998); Schuchert (2001a).

Genus Hydractinia van Beneden, 1841 (junior synonym $=$ Podocoryna $)$

Hydroid: colonies with a stolonal reticular hydrorhiza formed by tubes covered with perisarc, or with an encrusting hydrorhiza covered with perisarc or with naked coenosarc; frequently with simple, canaliculated or branched spines. Hydranths sessile, naked, polymorphic: gastrozooids, gonozooids, and occasionally dactylozooids; gastrozooids with one or more close whorls of tentacles encircling the hypostome; dactylozooids without tentacles; gonophores as fixed sporosacs, released or retained eumedusoids, or free medusae arising from varyingly developed gonozooids, with one or more close whorls of tentacles or without tentacles and/or hypostome, being reduced to blastostyles;
Medusa: Hydractiniidae with 4 or more solid, simple marginal tentacles, not in groups; usually 4 or 8 simple or slightly branched mouth arms (which are dilatations of the perradial corners of the mouth rim see Fig. L Fig. 10.) armed with clusters of cnidocysts; with or without gastric peduncle; «gonads» on manubrium, interradial, but sometimes extending along proximal parts of radial canals; with or without ocelli; sometimes asexual reproduction by medusa budding on manubrium.

\section{Key to hydroids}

Due to their great morphological uniformity, the hydroid stages of Hydractinia are not easy to distinguish when they are in reproduction.

1. Colonies giving rise to medusae or eumedusoids

- Colonies giving rise to fixed sporosacs …….... 8

2. Colonies giving rise to free medusae ................. 3

- Colonies giving rise to eumedusoids ................. 5

3. Gastrozooids without basal perisarcal collar; gonophores 1 or usually 2 per gonozooid on a short pedicel; sometimes spiral dactylozooids.... H. areolata

- Gastrozooids with a basal perisarcal collar, gonozooid with 1 to 15 or occasionally more gonophores in clusters. 4

4. Hydranths 10- $15 \mathrm{~mm}$........................ H. borealis

- Hydranths up to $5.5 \mathrm{~mm}$....................... H. carnea

5. With encrusting hydrorhiza .............. H. aculeata

- Without encrusting hydrorhiza........................... 6

6. Gastrozooid tentacles in one whorl ... H. pruvoti

- Gastrozooid tentacles in several whorls........... 7

7. Gastrozooid with tentacles in more than 3 whorls; gonozooids with tentacles in two whorls, no spines. H. inermis

7 Gastrozooid with tentacles in 3 whorls, gonozooids with tentacles in one whorl; spines present. H. calderi

8. With a characteristic ring of large microbasic euryteles surrounding hypostome above a single whorl of $4-12$ tentacles both in gastrozooids and gonozooids H. fucicola

- Without this characters, usually about 8 tentacles surrounding hypostome H. echinata

\section{Key to the species with medusae}

1. Oral arms bifurcated once or twice; 24-32 marginal tentacles H. borealis

- Oral arms well developed, simple, undivided.. 2 
2. With medusa buds 3

- Without medusa buds 4

3. With 4 marginal tentacles.................. H. minima

- With 8 marginal tentacles................... H. minuta

4. «Gonads» on manubrium only; rarely more than 8 tentacles H. carnea

- «Gonads» on manubrium and on manubrial pouches; with 8 large and numerous 1 small marginal tentacles . H. areolata

\section{Hydractinia aculeata (Wagner, 1833)}

(Fig. 37A)

Colonies with encrusting hydrorhiza living on different gastropod shells; spines present. Gastrozooids with 8-12 tentacles, hypostome conical. Gonozooids shorter than gastrozooids, with 3-4 tentacles. Gonophores ovoid, borne in groups of 4-6, giving rise eumedusoids with 4 radial canals and circular canal.

Records from Mediterranean: Adriatic, eastern and western Mediterranean.

Distribution: endemic of Mediterranean Sea.

References: Motz-Kossowska (1905); Herberts (1964); Bavestrello (1985) Avian et al. (1995).

Hydractinia areolata (Alder, 1862).

(= Podocoryna hartlaubi Neppi and Stiasny, 1911) (Figs. 37B-I)

Colonies living on gastropod shells occupied by hermit crabs. Hydroid forming a closely meshed network of perisarc-covered stolon tubes from which arises gastrozooids, gonozooids, spines, and sometimes spiral dactylozooids and tentaculozooids; the gastrozooids are sessile, tubular to claviform, slightly tapering towards base, with a rounded-conical hypostome, with a single whorl of 4-14 amphicoronate filiform tentacles and without basal perisarcal collar; the gonozooids have the same shape than the gastrozooids but are smaller and slender and have only 7-8 filiform tentacles, the spines are smooth, tall, slender, gently tapering and somewhat curved, they are closely grouped and separated by areas free of perisarcal armature; the spiral zooids have a swollen hollow base above which they gradually tapers, becoming solid and terminating in a blunt tip armed with cnidocysts, they generally occurs near the rim of the colonies; the tentaculozooids are rare, not coiled and more slender than the spiral zooids; 1-2 (up to 5) medusa buds in the middle region of the gonozooid, at different stages attached by a short peduncle and often in opposite position, during medusa production gonozooids undergoes progressive reduc- tion, sometimes as such a degree that the gonophores appears issued from the hydrorhiza.

Medusa: umbrella 2-3.8 mm wide, bell shaped, about as high than wide, no apical process; mesoglea thin, thicker in apical region; velum broad; manubrium cylindrical, about half as high than subumbrellar cavity, with a very slight gastric peduncle, with four perradial manubrial pouches about one-third the length of the radial canals; 4 radial canals and circular canal narrow; mouth elongated with four perradial lips each with one terminal cnidocyst cluster; «gonads» interradial on manubrium wall and extending along manubrial pouches; up to 57 solid marginal tentacles with swollen basal bulbs, the four perradial and four interradial tentacles larger and approximately from the same size, remaining tentacles small and from different size; no ocelli; no medusa buds.

Records from Mediterranean: western Mediterranean; Adriatic.

Known seasonality: 10-5.

Distribution: Atlantic; Mediterranean.

References: Russell (1953); Kramp (1957b; 1961); Yamada (1961); Berhaut (1970); Edwards (1972); Goy (1973b); Schmidt and Benovic (1979); Castello i Tortella (1986); Brinckmann-Voss (1987); Boero and Bouillon (1993) Avian et al. (1995).

Hydractinia borealis (Mayer, 1900) (Fig. 37J-N)

Hydroid: colonies found on a variety of hosts and showing some variability with site. Hydroid presenting a stolonal reticular hydrorhiza formed by separated anastomosing perisarc-covered tubes, sometimes forming an encrusting sheet recovered by a common perisarc; generally with a few smooth, short, blunt spines, depending on host; hydranths sessile, naked, claviform or cylindrical when extended, with a delicate cup-like ring of perisarc around the base, hypostome conical to rounded, large, with one whorl of 12-16 amphicoronate filiform tentacles; a few scattered, slender tentaculozooids are often but not always presents, they have a short perisarcal collar at base, their tip is rounded, not swollen; no spiral-zooids observed; gonozooids more slender than gastrozooids, usually with less tentacles (up to 12), much variable in shape and size; medusa buds with short peduncle, borne in clusters, up to 15 or more, around a narrow zone of the upper part of the column, medusa buds at various stages of development, gonozooids often reduced, at the extreme, without tentacles and hypostome, reduced to a short column bearing one or two medusa buds at the apex (blatsostyle). 
Medusa: Umbrella up to $5 \mathrm{~mm}$ high and wide, bell-shaped, mesoglea thin; manubrium long and tubular, not extending beyond umbrellar margin, with no or on very short gastric peduncle; four long mouth-arms in latter stages bifurcated once or twice, each branch with a terminal cnidocyst cluster; «gonads» interradial, occupying greater part of the manubrium, no medusa buds; 16-32 marginal tentacles; without ocelli.

Records from Mediterranean: the presence of this species in Mediterranean is uncertain. It is include in the Mediterranean fauna by (Tregouboff, 1957) and (Picard, 1958b) but with no records, Riedl (1959) consider that reports of this species from Naples are uncertain; it has been also reported near Malta (Evans, 1968) but Edwards (1972) found out it was Turritopsis nutricula. As stated by Edwards (1972) further studies of Hydractinia medusa in the Mediterranean and Adriatic Sea are needed.

Distribution: Atlantic; Mediterranean?

References: Rees (1941b); Edwards (1972); Boero and Bouillon (1993) as Podocoryne borealis; Avian et al. (1995); Schuchert (2001a).

\section{Hydractinia calderi}

Bouillon, Medel and Peña-Cantero 1997

(Figs. 38A-B)

Hydrorhiza stolonal, reticular tubes covered with perisarc and adhering to gastropod shells. Gastrozooids cylindrical, elongated, up to $5 \mathrm{~mm}$ high, with basal perisarcal cup. Hypostome with 20-40 filiform tentacles in 3 whorls. Gonozooids much shorter, with basal perisarcal cup and 2-14 filiform tentacles in one whorl. Each gonozooid generally bearing one or two eumedusoids, rarely three, one always well developed, the others juvenile. Eumedusoids with four radial canals and an often reduced subumbrellar cavity with striated muscle, four large bulbs, and four smaller ones. Female eumedusoids with numerous eggs. Dactylozooids and spines present. Cnidome: microbasic euryteles (8.7-11 x $3.2 \mu \mathrm{m})$ and desmonemes (6.3-7.5 x 3.2-3.6 $\mu \mathrm{m})$.

Records from Mediterranean: western Mediterranean.

Seasonality: ?

Distribution: endemic of Mediterranean Sea.

References: Bouillon et al. (1997); Peña Cantero and García Carrascosa (2002).

Hydractinia carnea (M. Sars, 1846) (Figs. 38C-F)
Hydroid: colonies found mainly on shells of Nassarius or on other gastropods occupied by various hermit-crabs, more seldom on lamellibranches and crustaceans and still more rarely on rocks. Hydroid presenting a solonal, reticular hydrorhiza formed by perisarc-covered tubes, in old colonies or in region of densely aggregated polyps, the hydrorhiza becomes encrusting and is recovered by a common perisarc or by a coalescent layer of naked coenosarc; smooth, blunt, short spines often present arising from hydrorhiza, depending from the nature of the host; hydranths springing directly from stolons, single, naked, claviform to cylindrical, hypostome rounded, fairly large capable of much change of form, with a single whorl of up to 19 amphicoronate filiform tentacles, sometimes, with a short, delicate basal collar of perisarc; the fertile polyps or gonozooids become smaller during medusa development and the number of their tentacles decreases eventually to on or two, gonozooids often reduced to blastostyles; spiral zooids or tentaculozooids rarely present , usually only in colonies living on shells associated with hermit-crabs and then concentrated at the rim of the shell aperture; medusa buds borne in a whorled cluster around the upper part of the hydranth at some distance below tentacles,1-10 or more in number, at different stages of development.

Medusa: umbrella up to 1- $2.11 \mathrm{~mm}$ high and 2.42 mm wide, bell-shaped; no apical process; mesoglea thin; scattered cnidocysts on exumbrella; velum broad; manubrium cylindrical, no more than half the length of subumbrellar cavity; no gastric peduncle; mouth with four single round perradial clusters of cnidocysts; 4 radial canals and ring canal narrow; «gonads» interradial; 4 perradial marginal tentacles, and one to two interradial tentacles, making eight in all, often four perradial tentacles only (Hydractinia carnea exigua); no ocelli; no medusa buds on manubrium; often sexual mature at or shortly after liberation.

Records from Mediterranean: eastern and western Mediterranean; Adriatic; Black Sea.

Known seasonality: 1-9.

Reproduction :6-9.

Distribution: Atlantic; Indo-Pacific; Mediterranean.

References: Kramp (1961); Berhaut (1970); Edwards (1972); Goy (1973b); Gili (1986); Castelló i Tortella (1986); Brinckmann-Voss (1987); Goy et al. (1988, 1990; 1991); Boero and Bouillon (1993); Benovic and Lucic (1996); Avian et al. (1995); Medel and López-González (1996); Cerrano et al. (1998); Schuchert (2001a); Peña Cantero and García Carrascosa (2002). 
Hydractinia echinata (Fleming, 1828)

(Fig. 38G)

Encrusting hydrorhiza white to pale pink giving rise different kinds of polyps, living on gastropod shells but also on other solid substrata. Gastrozooids slender, widening upwards, about 8 tentacles in on whorl, hypostome conical. Gonozooids shorter than gastrozooids, with few tentacles and a ring of gonophores. Dactylozooids long, slender. Hydrorhiza about $3 \mathrm{~mm}$ thick, with numerous blunt conical chitinous spines with jagged edges. Gonophores of both sexes generally on different gonozooids; male gonophore yellow to white, ovoid; the female, pink and spherical.

Records from Mediterranean: western Mediterranean.

Records outside the Mediterranean: north-eastern Atlantic, Arctic Sea.

References: Vervoort (1946); Leloup (1952); Naumov (1960); Gili (1986); Cornelius and Ryland (1990); Boero and Bouillon (1993); Medel and López-González (1996); Schuchert (2001a).

Hydractinia exigua (Haeckel, 1880)

= Hydractinia carnea M. Sars, 1846

The exigua form with only four tentacles is commonly found in Mediterranean (Adriatic) but has also a been found in Roscoff and Plymouth mixed with specimens with interradial tentacles. It is nevertheless often regard as a well defined species (Picard, 1958b, Cerrano et al.,1998)

\section{Hydractinia fucicola (M. Sars, 1857)} (Fig. 39A)

Encrusting hydrorhiza covered by naked coenosarc, armed by numerous spines, living on different substrates (crustaceans, algae, hydrozoans); dactylozooids may be present. Gastrozooids pale pink, length up to $3 \mathrm{~mm}$, hypostome cylindrical, 8-12 tentacles. Gonozooids pink, hypostome trumpetshaped, 4-8 tentacles; male and female gonophores in separated colonies; male gonophore spherical; the female slightly flattened on both extremes, with 7-8 eggs. Both gastrozooids and gonozooids with a characteristic ring of large microbasic euryteles cnidocysts surrounding the hypostome above the single tentacle whorl (of 4-12 tentacles).

Records from Mediterranean: western Mediterranean.
Distribution: north eastern Atlantic, Mediterranean.

References: Motz-Kossowska (1905); CastricFey (1970); Medel and López-González (1996); Bouillon, et al. (1997).

\section{Hydractinia hooperii (M.Sars,1846)}

(Fig. 39B)

Colonies living mainly on gastropod shells or cirripedes; stolonal polymorphic. With smooth, cone shaped spines.Gastrozooids long and thin, with 11-16 tentacles set in one whorl around hypostome. Gonozooids with only six to eight tentacles and four gonophores, two well developed and two much smaller. Cnidome microbasic euryteles (7.1-7.9 x2.4-3.2 $\mu \mathrm{m})$ and desmonemes (5.5-6.3 x2.8-3-2 $\mu \mathrm{m})$.

Records from Mediterranean: western Mediterranean.

Known seasonality and reproduction: 7-8

Distribution: Atlantic, Mediterranen

References: Bouillon, et al. (1997); Peña Cantero and García Carrascosa (2002).

\section{Hydractinia inermis (Allman, 1872)}

(Fig. 39C)

Colonies living on different substrates (algae, sea-grasses, crustaceans, hydrozoans); spines on hydrorhiza absent; dactylozooids sometimes present. Gastrozooids (up to $4.2 \mathrm{~mm}$ high) with a basal perisarc cup and about 20 tentacles in two or several whorls, hypostome conical; gonozooids (up to 2 $\mathrm{mm}$ ) with two whorls of about 12 tentacles and bearing fixed eumedusoids, having eight tentacular bulbs, the females containing many eggs. Dactylozooids sometimes present. Cnidocysts: desmonemes, haplonemes and microbasic euryteles.

Records from Mediterranean: Adriatic, eastern and western Mediterranean.

Known seasonality: 2,4,5

Reproduction: 2,4,5.

Distribution: endemic of the Mediterranean.

References: Boero (1981);Gili (1986) as Stylactis; Medel and López-González (1996) as Stylactaria; Bouillon, et al. (1997); Peña Cantero and García Carrascosa (2002).

\section{Hydractinia minima (Trinci, 1903)} (Figs. 39D-E)

Medusa: umbrella globular or dome-shaped, about as high as wide $0.3-1 \mathrm{~mm}$; mesoglea thin, soft, 
a slight apical thickening; manubrium barrelshaped, length half of umbrella cavity, circular in cross section; four perradial lips elongated to form oral tentacles each terminating in a single spherical cluster of cnidocysts; gastric peduncle short; velum well developed; four interradial «gonads» surrounding manubrium when mature; asexual reproduction by budding from the manubrium wall, buds and «gonads» may be produced at the same time; four distinct narrow radial canals, circular canal indistinct; four solid perradial tentacles each with a oval marginal bulb; no ocelli.

Hydroid: unknown.

Records from Mediterranean: eastern and western Mediterranean; Adriatic Sea.

Known seasonality: 1-12.

Distribution: Atlantic; Indo-Pacific; Mediterranean.

References: Vannucci (1957); Kramp (1961); Berhaut (1970); Goy (1973b); Benovic (1973); Schmidt and Benovic (1979); Uchida and Sugiura (1977); Castello i Tortella (1986); Gili (1986); Benovic and Bender (1987); Brinckmann-Voss (1987); Goy et al. (1988, 1990, 1991); Boero and Bouillon (1993); Avian et al. (1995); Benovic and Lucic (1996); Medel and López-González (1996); Goy (1997).

\section{Hydractinia minuta (Mayer, 1900)} (Figs. 39F-G)

Medusa: umbrella 0.5-up to $2 \mathrm{~mm}$ high, slightly higher than broad, oval to pear-shaped, with apical projection; mesoglea moderately thick; velum well developed; manubrium short, circular in cross-section, on a well developed gastric peduncle; mouth with four perradial lips elongated to form oral arms terminating with a knob of cnidocysts; medusa buds on interradial walls of manubrium; narrow radial canals and circular canal; 4 perradial and 4 interradial marginal tentacles each with a small oval bulb; no ocelli; newly released medusa buds with 8 tentacles.

Hydroid: unknown.

Remarks: this species is very similar to Hydractinia minima and several authors have discussed the possible identity of the two species. Russell (1953); Vannucci (1957) and Kramp (1961) nevertheless maintain them distinct.

Records from Mediterranean: eastern and western Mediterranean; Adriatic Sea.

Known seasonality: 2-11.

Distribution: Atlantic; Indo-Pacific; Mediterranean.
References: Babnik (1948); Kramp (1961); Goy (1973b); Benovic (1976); Schmidt and Benovic (1979); Gili (1986); Benovic and Bender (1987); Goy et al. (1988, 1990, 1991); Boero and Bouillon (1993); Avian et al. (1995); Benovic and Lucic (1996); Medel and López-González (1996).

Hydractinia pruvoti (Motz-Kossowska, 1905) (Figs. 39H-I)

Encrusting hydrorhiza with numerous spines and sometimes dactylozooids living on gastropod shells. Gastrozooids (up to $15 \mathrm{~mm}$.) with 10-14 tentacles in one whorl, hypostome conical; gonozooids (up to 5 $\mathrm{mm}$.) with only one tentacle at the top; with 8-9 gonophores of which one, much more developed; eumedusoids with 4 marginal bulbs and several eggs.

Records from Mediterranean: western Mediterranean.

Distribution: endemic of Mediterranean Sea.

References: Motz-kossowska (1905); Medel and López-González (1996); Bouillon, et al. (1997); Bavestrello et al. ( 2000).

\section{Family NiOBIIDAE Petersen, 1979}

Hydroid: unknown.

Medusa: 2 simple and 2 bifurcated radial canals, so that six canals reach the circular canal; "gonads" on manubrium, interradial; marginal tentacular bulbs developing into medusae; no ocelli, gastric peduncle, and mesenteries.

References: Brinckmann, (1959); Bouillon (1995a; 1999); Bouillon and Boero (2000).

\section{Genus Niobia Mayer, 1900}

With the characters of the family.

Niobia dendrotentaculata Mayer, 1900 (Fig. 40A)

With the characters of the family.

Records from Mediterranean: western Mediterranean.

Distribution: present in the three great oceans.

References: Brinckmann (1959); Avian et al. (1995).

\section{Family PANDEIDAE Haeckel, 1879}

Hydroid: colonies usually stolonal, not branching; hydranth tentacles filiform, normally in one 
whorl, exceptionally in two or more whorls, or scattered, or absent; perisarc developed to a variable degree, occasionally forming a pseudohydrotheca or missing completely; reproduction mainly by free medusae, except in some modified genera of questionable affinity like Nudiclava $=$ Hydrichthys.

Medusa: umbrella bell-shaped, with or without apical projection; manubrium quadratic, usually large; with or without gastric peduncle; 4 oral lips, simple, or crenulated, or complexly folded; 4 radial canals (exceptionally 8, as in Octotiara) often broadened, or ribbon-like, or with jagged margin; rarely centripetal canals; with or without mesenteries; "gonads" either with smooth surface or complexly folded, on manubrium walls in adradial or interradial position, sometimes extending along radial canals, or completely perradial; 2 or more hollow marginal tentacles; bulbs mostly tapering, elongated, conical (almost carrot-shaped) and often laterally compressed; with or without rudimentary tentacles (tentaculae), or marginal warts; with or without abaxial ocelli; cnidome usually containing microbasic euryteles.

References: Wedler and Larson (1986); Calder (1988); Pagès, Gili and Bouillon (1992); Bouillon (1995a, 1999); Migotto (1996); Schuchert (1996); Brinckmann-Voss and Arai (1998); Bouillon and Barnett (1999); Bouillon and Boero (2000).

\section{Key to hydroids}

The hydroids of many Pandeidae are unknown, or known only as juveniles. Where known, some hydroids are so similar that it is almost impossible to try to make a key, conversaly as, like in the genus Merga, the colonies are so variable that they can be referred to any Pandeid genus.

1. Hydroids parasite of fishes, or of copepods parasite of fishes, hydrorhiza forming a naked encrusting Fig.; without tentacles Hydrichthys; Larsonia

- Hydrorhiza as creeping stolons ....................... 2

2. Hydranth sessile or almost sessile and naked .. 3

- Hydranth on more or less developed hydrocaulus covered with perisarc 5

3. Hydranth with one whorl of 4-6 tentacles............ Codonorchis

- Hydranth with more than one whorl of tentacles 4. Hydranth with 2 closely set whorls of tentacles . ................................................... Pandea - Hydranth with 3 whorls of tentacles
5. Hydranth without pseudohydrothecae. Stomotoca

- Hydranth with pseudohydrotheca ................

6. Pseudohydrotheca more or less gelatinous .......

. Pseudohydrotheca more or less gelatinous .........

- Pseudohydrotheca not gelatinous........ Neoturris

7. Hydrocaulus short, hydranth with a single row of 3-4 filiform tentacles Octotiara

- Hydrocaulus well developed; hydranth with an amphicoronate whorl of more than 8 filiform tentacles

Amphinema

\section{Key to medusae}

Where only juvenile medusae known: see Pandeidae incertae sedis, or juveniles, or conspecific, see below

1. With only two well developed marginal tentacles in adults

- With more than two well developed marginal tentacles in adults 3

2. With horse shoe-shaped interradial gonad with transversal bridge Codonorchis

- With adradial or interradial «gonads» in rows or sac-like «gonads» extending from adradial side of manubrium outwards along radial canals .......

Amphinema

3. With eight simple radial canals .......... Octotiara

- With 4 primary radial canals ............................. 4

4. «Gonads» smooth or corrugated; 4 fairly simple lips; manubrium cruciform; «gonads», usually adradial, smooth or exceptionally weakly corrugated Merga

- «Gonads» reticulate or folded, or both; oral lips more or less folded or crenulated. 5

5. «Gonads» reticulate, with isolated interradial pits, with or without additional folds

- «Gonads» reticulate, without isolated interradial pits, horse-shoe-shaped, with diverging horizontal folds directed towards outside Leuckartiara

6. «Gonads» reticulate, in 8 vertical, adradial series of transverse folds; interradial portion of manubrium walls with isolated pits .... Neoturris

- «Gonads» reticulate, without surrounding folds and with isolated interradial pits Pandea

\section{Genus Amphinema Haeckel, 1879}

Hydroid: when known, colony stolonal, with creeping hydrorhiza; hydrocaulus well-devel- 
oped, unbranched with a terminal hydranth, covered by perisarc often infested by detritus and extending to the base or the middle of the hydranths body but not developing in a real pseudohydrotheca; hydranth elongate, with one whorl of amphicoronate, filiform, oral tentacles; polyps bending over when stressed; medusa buds on short peduncles arising from hydrorhiza, hrydrocaulus, or both.

Medusa: generally with a large apical projection; sometimes with an apical chamber; typically with 2 opposite hollow marginal tentacles; with marginal warts or tentaculae; without gastric peduncle; manubrium with broad base; with or without mesenteries; 4 simple oral lips; "gonads" either adradial, interradial or perradial, occasionally extending along radial canals; with or without ocelli.

References: Brinckmann-Voss and Arai (1998); Rees (2000).

\section{Key to hydroids}

1. Distal perisarc margin on hydranths body difficult to observe A. dinema

- Distal perisarc margin on hydranths body well marked A. rugosum

\section{Key to medusae}

1. «Gonads» extending from adradial sides of manubrium outwards along radial canals; with ocelli . A. turrida

- «Gonads» on manubrium only; no ocelli......... 2

2. Margin between tentacles with rudimentary warts, without marginal tentaculae «gonads» simple, without folds A. dinema

- Margin between tentacles with short solid marginal tentaculae

3. «Gonads» adradial, folded A. rugosa

- «Gonads» interradial, smooth A. rubra

Amphinema dinema (Péron and Lesueur, 1810) (Figs. 40B-C)

Hydroid: colonies stolonal, with creeping hydrorhiza, giving rise to well developed unbranched hydrocauli with a terminal hydranth, hydrocauli longer than hydranths and covered by thin perisarc, with or without basal annulations, often infested by detritus and extending to the base of the hydranths but not developing in a pseudohy- drothecae, the distal perisarc margin on hydranths body difficult to observe; hydranths spindle-shaped with a rounded-conical hypostome, with one whorl of 8-14 amphicoronate filiform tentacles; medusa buds borne singly on short peduncles arising from hydrorhiza.

Medusa: Umbrella up to $4 \mathrm{~mm}$ wide and $6 \mathrm{~mm}$ high bell-shaped, with a large, conical, solid, apical projection, mesoglea of uniform thickness besides top; manubrium cross-like in section, flask-shaped, almost as long as bell cavity; mouth cruciform with 4 prominent, recurved lips; with 2 very long tapering opposed marginal tentacles with large elongated conical basal bulbs and 12-24 small marginal warts, without tentaculae; with 8 simple adradial smooth «gonads»; without ocelli.

Records from Mediterranean: eastern and western Mediterranean; Adriatic Sea.

Known seasonality: 2-11.

Distribution: Atlantic; Indo-Pacific; Mediterranean.

References: Rees and Russell (1937); Babnik (1948); Russell (1953); Kramp (1961); Goy (1973b); Schmidt and Benovic (1979); Gili (1986); Benovic and Bender (1987); Brinckmann-Voss (1987); Goy et al. (1988, 1990, 1991); Ramil (1988); Boero and Bouillon (1993); Avian et al. (1995); Benovic and Lucic (1996); Medel and López-González (1996); Schuchert (1996).

\section{Amphinema rubra (Kramp, 1957a)}

(Fig. 40D)

Medusa: umbrella $4.5 \mathrm{~mm}$ wide, $7 \mathrm{~mm}$ high, with fairly thick walls and fairly pointed apical projection; manubrium large, barrel-shaped; mesenteries long, half length of manubrium; mouth square, with 4 simple recurved lips; with broad apical chamber above manubrium; «gonads» covering interradial walls of manubrium, smooth; 2 opposed marginal tentacles with elongate conical bulbs; with 5-6 interradial tenon-like marginal tentaculae; without marginal warts; manubrium, «gonads» and lips deep reddish; without ocelli.

Hydroid: unknown.

Records from Mediterranean: western Mediterranean.

Known seasonality: $1 ; 8 ; 10$.

Distribution: Antarctic (Atlantic section); Mediterranean.

References: Kramp (1957a, 1961); Goy (1973b); Boero and Bouillon (1993); Gili et al. (1998) 
Amphinema rugosum (Mayer, 1900) (Figs. 40E-F)

Colonies stolonal, with creeping hydrorhiza, giving rise to single or slightly branched hydrocauli with terminal hydranths; perisarc with two to five annulations at hydrocauli base and extending to the middle of the hydranth body where it adheres to polyp with a well marked end, perisarc often infested with detritus; hydranths spindle shaped, with a dome-shaped hypostome, with one whorl of 8-12 amphicoronate filiform oral tentacles; 1-3 medusa buds borne on short stems from hydrorhiza and from hydrocauli.

Medusa: umbrella up to $6 \mathrm{~mm}$ high, slightly higher than wide, bell-shaped, with a large conical to hemispherical apical projection, mesoglea uniformly thin besides top; with slight perradial furrows in top umbrella; manubrium flask-shaped, cruciform in section, reaching almost umbrella margin; mouth cruciform, with 4 prominent, slightly recurved lips; eight «gonads» in adradial pairs, with 3-4 characteristic folds directed interradially; four broad radial canals with jagged and smooth margins; two diametrically opposed marginal tentacles with large, hollow, conical, tapering and very long bulbs; with 14 - 24 small marginal tentaculae; no ocelli.

Records from Mediterranean: eastern and western Mediterranean.

Known seasonality: 7.

Distribution: Atlantic; Indo-Pacific; Mediterranean.

References: Rees and Russell (1937); Russell (1953); Kramp (1961); Goy et al. (1988, 1990, 1991); Brinckmann-Voss (1987); Boero and Bouillon (1993); Schuchert (1996).

\section{Amphinema turrida (Mayer, 1900)} (Fig. 40G)

Medusa: umbrella 4-7 $\mathrm{mm}$ high, somewhat higher than wide, with a conical, hollow apical projection; manubrium pyriform, almost as long as subumbrellar cavity; mouth with four recurved, crinkled lips; «gonads» sac-like, folded, extending from adradial sides of the manubrium outwards along the 3/4 of the length of the four radial canals; typically 2 long, opposite, marginal tentacles with elongated, conical basal bulbs (sometimes 4 perradial tentacles, see Bigelow, 1909; Goy, 1973) and 12 to 26 small solid tentaculae often reduced to small rudimentary bulbs; tentac- ular bulbs, tentaculae or rudimentary bulbs all with a red ocelli.

Hydroid: unknown.

Records from Mediterranean: western Mediterranean.

Known seasonality: $4 ; 5$.

Distribution: Atlantic; Indo-Pacific; Mediterranean.

References: Bigelow (1909); Kramp (1961); Goy (1973b); Bouillon (1980); Boero and Bouillon (1993).

\section{Genus Codonorchis Haeckel, 1879}

Hydroid: colonies stolonal with simple creeping hydrorhiza; hydranths, small $(0.25 \mathrm{~mm})$ sessile, naked, fusiforme; hypostome short, conical; with a single whorl of 4-6 filiform tentacles; medusa buds on hydrorhiza with a pedicel of variable length, generally longer than hydranth.

Medusa: pandeidae with an apical projection; never with more than 2 opposite hollow marginal tentacles; with marginal tentaculae; without gastric peduncle; manubrium with broad base; with mesenteries; mouth cruciform with 4 simple lips; «gonads» horse-shoe-shaped; with ocelli.

Reference: Boero et al. (1997).

\section{Codonorchis octaedrus Haeckel, 1879}

(Fig. 40H, 41A)

Hydroid: colonies stolonal with simple creeping hydrorhiza; hydranths, small $(0.25 \mathrm{~mm})$ sessile, naked, fusiforme; hypostome short, conical; with a single whorl of 4-6 filiform tentacles; medusa buds on hydrorhiza with a pedicel of variable length, generally longer than hydranth.

Medusa: umbrella $2.5 \mathrm{~mm}$ wide, $4 \mathrm{~mm}$ high, with a high conical or globular apical projection; manubrium urn-shaped, with wide base, with a apical chamber; mouth cruciform, with 4 simple recurved lips; 4 broad ribbon-like radial canals, with jagged edges; with mesenteries; «gonads» interradial, horse-shoeshaped, linked by a transverse interradial bridge; 2 long opposite hollow marginal tentacles; marginal tentacular bulbs conical; up to 16 rudimentary bulbs with small tentacles; all bulbs with ocelli.

Records from Mediterranean: between Adriatic and Ionian Sea.

Known seasonality: $7 ; 8$.

Distribution: Atlantic, Mediterranean.

References: Kramp (1961); Boero et al. (1997). 


\section{Genus Leuckartiara Hartlaub, 1914}

Hydroid: when known, forming stolonal colonies; hydrocauli not or sparingly branched, covered by perisarc extending onto hydranth body forming a more or less gelatinous pseudohydrothecae which does not envelop the tentacles; hydranths with one whorl of oral filiform tentacles; medusae develop on hydrocauli or hydrorhiza and are covered by a thin perisarc.

Medusa: pandeidae usually with an apical projection of varying shape; with large manubrium connected to radial canals by mesenteries; mouth with extensively folded or crenulated margin; «gonads» interradial, bipartite but connected interradially, typically horse-shoe-shaped, with horizontal folds directed perradially; radial canals broad and ribbon-like, often with jagged edges; with numerous hollow tentacles with elongated, laterally compressed basal bulbs; often with rudimentary tentacles; usually with ocelli.

Only the hydroid of Leuckartiara octona is known (see below)

Recent reference: Schuchert (2004)

\section{Key to medusae}

1. With rudimentary marginal club-shaped tentacles 2

- No club-shaped rudimentary marginal tentacles; abaxial spurs not well developed ........ L. nobilis

2. With ocelli; with pronounced abaxial spurs L. octona

- Without ocelli, without spurs. L. brownei

Leuckartiara species are often difficult to distinguish, especially when immature (see diagnostic table in Xu et al., 1991 and in Pagès et al., 1992).

Leuckartiara brownei Larson and Harbison, 1990 (Fig. 41B)

Medusa: umbrella $10 \mathrm{~mm}$ high and $9 \mathrm{~mm}$ wide, conical, with a pointed apical projection of variable height; mesoglea fairly thick; velum narrow; manubrium greater than half of subumbrellar cavity; mouth with large crenulated lips; radial canals four, fairly broad, mostly smooth; mesenteries well developed; four perradial marginal tentacles, large, tapering, not laterally compressed; up to 28 rudimentary tentacle, clasping the exumbrella, the oldest more developed and interradial; all tentacles without spurs; «gonads» on interradial walls of the manubri- um, orange brown, each with a pair of main longitudinal folds adjacent to the interradii, making a continous interradial groove and with a few isolated folds in the adradii mostly oriented perradially; no ocelli;

Records from Mediterranean: western Mediterranean.

Known seasonality: 12, 1.

Distribution: Antarctic (Ross Sea, Weddell Sea); Mediterranean.

References: Larson and Harbison (1990); Bouillon et al. (2000).

Hydroid: unknown.

Leuckartiara nobilis Hartlaub, 1913

(Fig. 41C)

Medusa: umbrella up to $27 \mathrm{~mm}$ high and $20 \mathrm{~mm}$ wide, bell-shaped, with a well developed pointed or rounded solid apical projection; manubrium large, flask-shaped, with broad base and constricted near mouth, more than half as long as subumbrellar cavity; mouth with complexly folded, crenulated lips; «gonads» interradial, typically horse-shoe-shaped, covering whole walls of manubrium, with numerous divided horizontal folds; mesenteries along half the length of manubrium; radial canals very broad, with irregular and jagged outlines and sometimes short lateral diverticula; about forty or more marginal tentacles of different size, well spaced, tentacular bulbs elongated, laterally compressed which clasp the exumbrella margin, forming faintly developed abaxial spurs; no club shaped marginal rudiments; ocelli dark red.

Records from Mediterranean: western Mediterranean.

Known seasonality: $3 ; 4$.

Distribution: Atlantic, Arctic; Indo-Pacific, Mediterranean.

References: Kramp (1961); Goy (1973b); Gili (1986); Boero and Bouillon (1993); Medel and López-González (1996).

Hydroid: unknown.

Leuckartiara octona (Fleming, 1823) (Figs. 41D-F)

Hydroid: colonies generally epizootic, up to 5 $\mathrm{mm}$ high, growing on various animals (gastropod shells, crabs, fishes, other hydroids) or on rocks, stolonal, formed by single or slightly branched hydrocauli arising from a creeping hydrorhiza and 
bearing a terminal hydranth and occasionally 1-3 lateral ones as well or, sometimes, with sessile hydranths; hydrocauli increasing in diameter from base distally; perisarc surrounding hydrocauli, firm, often annulated or wrinkled, especially at base and expending over the hydranth body in form of a gelatinous pseudohydrothecae reaching the base of the tentacles but not investing them; pseudohydrothecae often covered by detritus; hydranths with a single whorl of 6-12 filiform tentacles and a conical hypostome; medusa buds borne on short peduncles completely invested by perisarc, arising from hydrorhiza and hydrocaulus.

Medusa: umbrella up to $20 \mathrm{~mm}$ high, higher than wide, bell-shaped, with a generally well developed conical or spherical solid apical projection, lateral walls thin; manubrium of varying length, with broad base, flask-shaped; «gonads» interradial, typically horse-shoe-shaped on whole surface of manubrium, with folds directed towards the perradii; radial canals with smooth or slightly jagged edges; mesenteries along about half the length of manubrium; with 12-32, usually 16 , long marginal tentacles with long conical laterally compressed marginal bulbs clasping umbrella and forming a pronounced abaxial spur and with 16 or more club shaped marginal rudimentary bulbs, all bulbs with abaxial ocelli.

Records from Mediterranean: eastern and western Mediterranean; Adriatic Sea.

Known seasonality: 2-8; 11.

Distribution: Atlantic; Indo-Pacific; Mediterranean.

References: Kramp (1961); Goy (1973b); Millard (1975); Schmidt and Benovic (1979); Bouillon (1980, 1985a); Gili (1986); Benovic and Bender (1987); Brinckmann-Voss (1987); Boero and Bouillon (1993); Altuna (1994); Avian et al. (1995); Benovic and Lucic (1996); Medel and López-González (1996); Schuchert (2001a).

\section{Genus Merga Hartlaub, 1914}

Hydroid: when known colonial, arising from a ramified hydrorhiza; hydrocauli slightly branched or not; hydranths on hydrocauli or almost sessile; with or without pseudohydrothecae which when present does not envelop the tentacles; hydranths with one whorl of filiform tentacles; free medusae arising from hydrocauli and hydrorhiza.

Medusa: Pandeidae with cruciform manubrium, with perradial edges of manubrium connected with radial canals by long mesenteries; manubrium never twisted; with smooth or exceptionally slightly folded or weakly corrugated «gonads», generally adradial; with simple or faintly crenulated oral lips; with 4-8 or more marginal tentacles; with or without rudimentary bulbs or tentaculae; with or without ocelli.

\section{Key to hydroids}

1. Hydranth borne on erected stem and covered with a wrinkled pseudohydrotheca .... M. galleri

- Hydranth on very short pedicel and without pseudohydrotheca M. tergestina

\section{Key to medusae}

1. Umbrella dome-like, without an apical projection

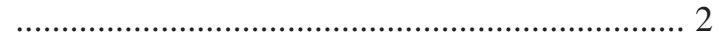

- Umbrella with a conspicuous apical projection 3

2. With only four perradial marginal tentacles........ M. tregoubovii

- With 8-12 marginal tentacles and 24-36 rudimentary bulbs M. violacea

3. With a narrow, pointed apical projection; 4-8 marginal tentacles and a few rudimentary bulbs; four simple faintly crenulated lips

M. tergestina

- With a wide apical projection; 8-16 marginal tentacles; without rudimentary bulbs; mouth with strongly folded lips M. galleri

\section{Merga galleri Brinckmann, 1962 (Figs. 41G-H)}

Hydroid: colonies branched, arising from a creeping hydrorhiza; hydranths borne on erected stems, each with a conical hypostome and one whorl of up to six filiform tentacles; hydrorhiza and hydrocauli, surrounded by a flexible perisarc covered by mud particles; perisarc forming a wrinkled pseudohydrotheca reaching the base of the tentacles; medusa buds developing on the stems and surrounded by perisarc.

Medusa: umbrella up to $1.15 \mathrm{~mm}$ high and 0.45 $\mathrm{mm}$ wide, with a very large apical projection; manubrium with a large base; large with strongly folded lips; radial canals broad, with slightly jagged outlines, entering manubrium by long mesenteries; 8 smooth, slightly folded «gonads», adradial, attached to mesenteries and to the sides of the manubrium; marginal tentacles 8-11 in females, 11-16 in males; marginal tentacular bulbs triangular, the four perra- 
dial with band-shaped ocelli the others with dot-like ocelli.

Records from Mediterranean: western Mediterranean.

Known seasonality: reared in laboratory from hydroids collected from May-September.

Distribution: endemic of Mediterranean Sea.

References: Brinckmann-Voss (1962); Boero and Bouillon (1993).

Merga tergestina (Neppi and Stiasni, 1912) (Figs. 41I-J)

Hydroid: colonies issued from a branched creeping hydrorhiza, forming a loose stolonal mat in old well developed colonies, pedicels very short terminating in a single hydranth, recovered with a thin perisarc till the base of the hydranths, often hydranths almost sessile, some longer and singly branched pedicels may occur in crowded colonies, upright pedicels not clearly demarcated from hydrorhiza; hydranth naked, elongated, almost cylindrical, slightly tapering under tentacular whorl and basally, with a conical hypostome, with a small number of amphicoronate filiform tentacles (6-8) held rather stiffly out; medusa buds borne on short pedicels on hydrorhiza, rarely on hydranth pedicel, enveloped by perisarc sheath.

Medusa: umbrella $4 \mathrm{~mm}$ wide, $7 \mathrm{~mm}$ high, with a narrow, pointed apical projection, with thin walls; manubrium 1/2-2/3 as long as bell cavity; mouth lips faintly crenulated; mature «gonads» interradial, smooth, slightly folded; 4-9 marginal tentacles with ocelli and few rudimentary bulbs without ocelli; medusa presenting more than one period of sexual maturity.

Records from Mediterranean: eastern and western Mediterranean; Adriatic Sea.

Known seasonality: 1-3; 5-11.

Distribution: Atlantic; Indo-Pacific; Mediterranean.

References: Vannucci and Yamada (1959); Kramp (1961); Benovic (1973); Schmidt and Benovic (1979); Brinckmann-Voss (1987); Bouillon (1980); Goy et al. (1988, 1990, 1991); Boero and Bouillon (1993); Avian et al. (1995); Benovic and Lucic (1996).

\section{Merga tregoubovii Picard, 1960} (Fig. 42A)

Medusa: umbrella $2.5 \mathrm{~mm}$ wide and high, globular, without apical projection; mesoglea thin, uni- form; manubrium quadrangular, large; no gastric peduncle; mouth with four simple recurved lips, slightly folded in old specimens; 4 large radial canals, ribbon-like, circular canal and velum normal; mesenteries along about half the length of the manubrium; «gonads» appear first as 8 voluminous, large, adradial contiguous masses, with an apical interradial bridge, usually fusing together and becoming completely interradial with age; with 4 long, perradial, marginal tentacles; marginal tentacular bulbs elongated conical.

Hydroid: unknown.

Records from Mediterranean: western Mediterranean.

Known seasonality: 9, 10.

Distribution: Indo-Pacific; Mediterranean.

References: Picard (1960b); Kramp (1961); Goy (1973b); Bouillon (1980); Boero and Bouillon (1993).

\section{Merga violacea (Agassiz and Mayer, 1899)}

(Fig. 42B)

Medusa: umbrella up to $7 \mathrm{~mm}$ wide, $11 \mathrm{~mm}$ high, dome-like, without apical projection, with thick walls; manubrium half as long as bell cavity, crossshaped in transverse section; mesenteries very long; «gonads» adradial; 4 slightly crenulated lips; 8-12 long marginal tentacles and 24-36 rudimentary tentacles, all with ocelli.

Hydroid: unknown.

Records from Mediterranean: eastern and western Mediterranean; Adriatic Sea.

Known seasonality: $7 ; 8$.

Distribution: Atlantic; Indo-Pacific; Mediterranean.

References: Kramp (1924; 1961); Goy (1973b); Goy et al. (1988, 1990, 1991); Boero and Bouillon (1993).

\section{Genus Neoturris Hartlaub, 1913}

Hydroid: when known forming colonial hydroids arising from stolonal hydrorhiza with terminal hydranth; perisarc of hydrocauli continuing up to the hydranth body but does not surround the tentacles; hydranths with one whorl of filiform oral tentacles; free medusae developing from hydrocauli sometimes from hydrorhiza, gonophores completely covered with perisarc.

Medusa: Pandeidae with apical projection varying much in shape and size, often reduced; manubri- 
um very large and broad, with well developed mesenteries; «gonads» in 8 adradial series with transverse folds directed towards interradii; depressed interradial parts of manubrium with isolated pits of «gonads»; with 8 or more hollow marginal tentacles with laterally compressed basal bulbs; without rudimentary tentacles or marginal warts; mostly without ocelli.

\section{Neoturris pileata (Forskål, 1775)}

(Figs. 42C-E)

Hydroid: colonies attached to shells of the bivalve mollusc Nucula living in deep water; hydrorhiza forming a close network of anastomosing stolons; hydranths borne on erect unbranched hydrocauli which are covered by an irregularly or spirally coiled perisarc; hydranths spindle-shaped with a prominent conical hypostome and with 4-9 filiform oral tentacles in a single whorl; perisarc forming a pseudohydrotheca extending till the base of tentacles; medusa buds on stems, or less commonly on stolons, completely covered by perisarc.

Medusa: Umbrella up to $25 \mathrm{~mm}$ wide and $40 \mathrm{~mm}$ high, bell-shaped, with variable apical projection; manubrium flask-shaped, of very variable length, never extending beyond exumbrellar margin, with broad base; mouth with very complexly folded and crenulated lips; mesenteries about half as long as manubrium; radial canals broad with short, sometimes branched lateral diverticula; «gonads» in 8 adradial series with transverse folds directed towards interradii; depressed interradial parts of manubrium with isolated pits of «gonads»; up to 90 (usually 60-80) marginal tentacles, densely crowded, marginal bulbs clasping exumbrella but not forming conspicuous abaxial spurs; without ocelli.

Records from Mediterranean: western Mediterranean; Adriatic Sea.

Known seasonality: $1-8 ; 11 ; 12$.

Distribution: Atlantic; Mediterranean.

References: Babnik (1948); Kramp (1961); Edwards (1965); Berhaut (1970); Goy (1973b); Schmidt and Benovic (1979); Gili (1986); Benovic and Bender (1987); Boero and Bouillon (1993); Avian et al. (1995); Benovic and Lucic (1996); Medel and López-González (1996).

\section{Genus Octotiara Kramp, 1953}

Hydroid: colonies with stolonal hydrorhiza; hydrocaulus short, covered by thin perisarc; hydranth, with a single row of 3-4 filiform tentacles; free medusa borne isolated on hydrorhiza.

Medusa: Pandeidae with eight simple radial canals, with or without gastric peduncle; with transversely folded «gonads»; without mesenteries.

Octotiara russelli Kramp, 1953

(Fig. 42F-H)

Hydroid: colonies with stolonal hydrorhiza, symbiotic with the bryozoan Steginoporella mandibulata; hydranth rising among zoeciae about 0,5 mm high, with a single row of 3-4 filiform tentacles; white rounded hypostome, reddish column; hydrocaulus short, covered by thin perisarc; medusa buds isolated on hydrorhiza.

Medusa: umbrella 7-11 mm wide, flatter than a hemisphere, sometimes with a large and broad gastric peduncle; manubrium in its entire length with eight deep longitudinal furrows; mouth tube long with 8 sharp edges terminating in 8 pointed lips; «gonads» along each of the eight perradial edges of the manubrium, deeply transversally folded, each with 7-10 furrows; with eight radial canals; usually 8 large marginal tentacles, but occasionally up to 32 , with about 64 small rudimentary tentacles; all without ocelli.

Records from Mediterranean: western Mediterranean.

Known seasonality: 4.

Distribution: Indo-Pacific; Mediterranean.

References: Kramp (1961); Kramp (1965, 1968); Goy (1973b); Boero and Bouillon (1989; 1993).

Genus Pandea Lesson, 1843

Hydroid: hydroids when known forming stolonal colonies arising from a creeping, ramified hydrorhiza fixed on the planktonic gastropod Clio cuspidata; hydranths naked, almost sessile; hydranths with filiform oral tentacles in 2 closely set whorls; free medusae borne on short pedicels covered by perisarc and arising directly from hydrorhiza.

Medusa: Pandeidae with or without apical projection; with or without longitudinal exumbrellar cnidocysts ribs; «gonads» at first in the adradii and eventually encircling manubrium, forming a complex network; lips wide and folded; radial canals ribbon-like; with long mesenteries; with more than 8 hollow marginal tentacles; without rudimentary marginal tentacles or marginal warts; with or without ocelli. 
Pandea conica (Quoy and Gaimard, 1827)

(Figs. 43A-B)

Hydroid: colonies arising from a creeping, ramified, stolonal hydrorhiza living on the planktonic gastropod Clio cuspidata; stolons thin covered by a fine perisarc, hydranths naked, on a short stem, almost sessile; hypostome conical; 8 filiform oral tentacles of variable length in 2 closely set whorls; medusae buds borne on short pedicels covered by perisarc and arising directly from hydrorhiza.

Medusa: umbrella up to $10 \mathrm{~mm}$ wide and 21 (sometimes $30 \mathrm{~mm}$ ) high, bell-shaped, with a rounded, bluntly or conical projection variable in length and ending in a peculiar opaque ectodermal thickening, mesoglea fairly thick mainly at top; with 16-24 (up to 44) longitudinal exumbrellar cnidocyst tracks that correspond to the number of marginal tentacles and originate from each tentacular bulb; manubrium large, pyramidal, almost filling upper half of subumbrellar cavity; mouth with short oral tube, with 4 perradial much folded and highly crenulated lips; radial canals fairly narrow, smooth, slightly jagged, circular canal narrow; mesenteries about $4 / 5$ of manubrium length; gonad large, on entire interradial walls of manubrium, forming a coarse meshednetwork of ridges with pits between; with 16-24 (sometimes up to 44) marginal tentacles, with conical, laterally compressed bulbs clasping the umbrella margin but devoid of well-developed abaxial spurs, no secondary tentacles; with ocelli.

Records from Mediterranean: eastern and western Mediterranean.

Known seasonality: 1-9; 12.

Distribution: Atlantic; Indo-Pacific; Mediterranean.

References: Picard (1956a); Kramp (1961); Berhaut (1970); Goy (1973b); Schmidt (1973); Dowidar (1983); Gili (1986); Brinckmann-Voss (1987); Dallot, Goy and Carré (1988); Boero and Bouillon (1993); Medel and López-González (1996); Mills et al. (1996).

\section{Family PROBOSCIDACTYLIDAE Hand and Hendrickson, 1950}

Hydroid: colonies of single hydroids arising from creeping naked stolons located around the lips of sabellid polychaete tubes; hydranths almost sessile, polymorph with gastrozooids and gonozooids, sometimes dactylozooids, gastrozooids with rounded hypostome, separated from the body by a con- striction, with a large cluster of cnidocysts or "cap" somewhat displaced onto one side of the hypostome, with 2 filiform tentacles arising close together, under the hypostomial constriction, opposite to the cnidocysts cluster; gonozooids and dactylozooids, without tentacles, mouthless and smaller the gastrozooids; free medusae lying very close to the tip of the gonozooid.

Medusa: Anthomedusae without statocysts and ocelli; without centripetal canals; manubrium with 4-6 or more radial gastric lobes extending along proximal portions of radial canals; with «gonads» surrounding manubrium and extending onto the gastric lobes; radial canals branched, obliterated canals may be present; usually without circular canal but with a solid endodermal marginal core; with numerous exumbrellar cnidocysts clusters or bands alternating with tentacles; marginal tentacles hollow, with swollen hollow base connected to the lumen of the radial canals.

Remarks: the systematical position of the Proboscidactylidae is not clear; they have traditionally been included in the Limnomedusae, mostly convenience and ignorance of their real affinities. Several authors consider that by some characters, mainly the structure of their tentacular base and the presence of desmonemes, they should be referred to the Anthomedusae Filifera (see Werner, 1984; Petersen, 1990; Schuchert, 1996). We tentatively follow here this suggestion and include them in the Pandeida because their hollow tentacles, but even in this suborder their relationships with the other families are not obvious. If the presence of desmonemes appears a valid argument to include this family in the Anthomedusae Filifera the presence of macrobasic euryteles in most of the Proboscidactyla species is confusing, this type of cnidocysts having only been found inside the Filifera in some species of the very particular family Eudendriidae.

\section{Genus Proboscidactyla Brandt, 1835}

Hydroid: with the characters of the family.

Medusa: Proboscidactylidae with manubrium presenting radial gastric lobes; «gonads» on manubrium and gastric lobes; with 4-6 or more branched radial canals, with clusters or bands of cnidocysts on the exumbrella; usually without circular canal; marginal tentacles hollow.

Proboscidactyla ornata (McCrady, 1859) (Figs. 43C-D) 
Hydroid: colonies of single naked hydroids arising from a creeping naked stolon located around the lips of sabellid polychaete tubes; hydranths polymorphic, basal part of gastrozooids with a small stalk which is almost unseen when contracted; gastrozooids increasing in width from base to top; with rounded hypostome, separated from the body by a constriction, with a large cluster of cnidocysts or "cap" somewhat displaced onto one side of the hypostome, with 2 filiform tentacles arising close together, under the hypostomial constriction, opposite to the cnidocysts cluster; gonozooids, without tentacles, mouthless and smaller the gastrozooids, 12 medusa buds lying very close to the tip of the gonozooid.

Medusa: umbrella $5 \mathrm{~mm}$ wide, slightly higher than hemispherical, mesoglea thick and rigid; manubrium normally with four radial lobes; mouth with four simple recurved lips; typically with four primary radial canals branching into 16-20 (rarely more) terminal branches and as many tentacles; no ring canal; medusa buds arising from corners of manubrium or forking from radial canals; polypoid structures on manubrium?

Records from Mediterranean: eastern and western Mediterranean; Adriatic.

Known seasonality: 1-12.

Distribution: Circumglobal in warm coastal waters.

References: Kramp (1961); Brinckman and Vannucci (1965); Vannucci (1966), Goy (1973b); Brinckmann-Voss (1987); Goy et al. (1988, 1990, 1991); Boero and Bouillon (1993); Avian et al. (1995); Benovic and Lucic (1996).

\section{Family Protiaridae Haeckel, 1879}

Hydroid: known only in Halitiara inflexa (Bouillon 1985a, b; Bouillon, Seghers and Boero, 1988) and Halitiara formosa (Brinckmann-Voss, pers. comm.) and are also very different of Pandeidae polyps, showing some resemblance to certain Campanulinidae hydroid species and mainly with Trichydra polyps (Bouillon, Seghers and Boero, 1988). Colonies arising from creeping stolons, hydranths issued from very short hydrocauli; hydrorhiza and hydrocauli recovered by perisarc, which forms a cup at the base of the hydranths; hydranths with one whorl of filiform tentacles, large cnidocysts alternating with the tentacles; gonophores unknown.

Medusa: Anthomedusae with only four fully developed marginal tentacles arising from conspicu- ous hollow tentacular bulbs, four simple radial canals and a circular canal, mouth with four simple lips; «gonads» interradial, with smooth surface; with or without mesenteries; without rudimentary bulbs; margin with or without cirri-like tentacles; exceptionally with ocelli.

Remarks: the differences between the diagnoses of the Protiaridae and Pandeidae appears at first sight rather small but the cnidome of the Protiaridae is very particular, containing among others, merotrichous isorhizas a type of cnidocysts which characterises normally only Leptomedusae families (Eirenidae, Eucheilotidae, Lovenellidae and Tiaropsidae).

1. Without marginal cirri Protiara

- With marginal cirri Halitiara

\section{Genus Halitiara Fewkes, 1882}

Medusa: Pandeidae with 4 straight radial canals; with 4 perradial marginal tentacles and several intermediate, solid cirrus-like marginal tentacles; without rudimentary marginal bulbs; mouth a simple cruciform opening; with or without mesenteries; interradial «gonads»; without ocelli, cnidome with merotrichous isorhiza.

Hydroid: see below Halitiara inflexa.

1. With apical projection, without mesenteries ....... . H. formosa

- Without apical projection, with mesenteries H. inflexa

\section{Halitiara formosa Fewkes, 1882}

(Fig. 43E)

Medusa: umbrella about $3 \mathrm{~mm}$ high, pearshaped, with solid apical projection, about half as long as bell cavity; no mesenteries; manubrium pyriform, about half as long as subumbrellar cavity; 4 long, hollow marginal tentacles and 24-35 short, solid, tightly coiled marginal cirrus-like tentacles; «gonads» interradial smooth; no ocelli.

Hydroid: see family.

Records from Mediterranean: eastern and western Mediterranean.

Known seasonality: 8-11.

Distribution: Atlantic; Indo- Pacific; Mediterranean.

References: Kramp (1961); Goy (1973b); Bouillon (1980; 1995b); Brinckmann-Voss (1987); Goy et al. (1988, 1990, 1991); Boero and Bouillon (1993). 
Halitiara inflexa Bouillon, 1980

(Figs. 43F-G)

Hydroid: colonies arising from creeping stolons, hydranths issued from very short hydrocauli; hydrorhiza and hydrocauli recovered by perisarc, which forms a cup at the base of the hydranths in which they can almost completely retract; hydranths, very slender, elongated, cylindrical, with short and conical hypostome, with one whorl of about 10 long filiform tentacles with irregular clusters of cnidocysts, large cnidocysts alternating with the tentacles; gonophores unknown.

Medusa: umbrella bell-shaped, $1.6 \mathrm{~mm}$ high and $1.2 \mathrm{~mm}$ in diameter; mesoglea moderately thick, gradually thickening towards top to about twice the thickness of the lateral walls; manubrium voluminous, quadrangular, length about two-thirds of bell cavity, joined to radial canals by mesenteries for half of their length; mouth with 4 simple lips; «gonads» large, bulging, filling interradial position completely, living free only a small perradial band of manubrium and the mouth region; four radial canals and circular canal, all narrow and with smooth margins; 4 long perradial marginal tentacles with broad conical tapering base, not laterally compressed; between each pair of marginal tentacles 3-6 short solid coiled cirri- like tentacles without bulbs.

Records from Mediterranean: eastern Mediterranean.

Seasonality: ?

Distribution: Indo-Pacific; Mediterranean.

References: Kramp (1961); Bouillon (1980, 1985b, 1995b); Bouillon, Seghers and Boero (1988); Goy et al. (1988, 1990, 1991); Boero and Bouillon (1993).

\section{Genus Protiara Haeckel, 1879}

Protiaridae with 4 marginal tentacles, without marginal cirri or tentaculae; with 4 smooth «gonads» on manubrium; mouth with 4 simple lips; without mesenteries.

Protiara tetranema (Péron and Lesueur, 1810) (Fig. 44A)

Medusa: umbrella $4 \mathrm{~mm}$ high, $4 \mathrm{~mm}$ wide, almost cubical; without apical projection; manubrium likewise cubical, half as long as umbrella cavity; mouth with 4 simple, not folded nor crenulated lips; 4 cylindrical «gonads», perradial (!); 4 long margin- al tentacles; marginal tentacular bulbs thickened each with an ocelli.

Records from Mediterranean: western Mediterranean, Adriatic Sea.

Distribution: Atlantic; Mediterranean.

Known seasonality: 10.

References: Hartlaub (1913); Pell (1918); Kramp (1959a, 1961); Boero and Bouillon (1993); Benovic and Lucic (1996).

Hydroid: unknown.

Family PTILOCODIIDAe Coward, 1909

Hydroid: hydrorhiza stolonal, reticular, or encrusting, covered by naked coenosarc; hydranths sessile, naked and polymorphic; gastrozooid without tentacles; dactylozooid with 4 or more capitate tentacles, sometimes filiform; gonophores on gonozooids or gastro-gonozooids; reproduction by fixed sporosacs, eumedusoids or free medusae.

Medusa: umbrella more or less bell-shaped; with or without radial exumbrellar furrows; didermic centripetal tracks or exumbrellar rows of refringent spots; with marginal cnidocyst ring; when present, marginal tentacles solid, with tips armed with cnidocysts; 4 radial canals and circular canal; manubrium tubular or bottle-shaped, with mouth arms with terminal cnidocyst clusters, "gonads" adradial or interradial.

References: Jarms (1987); Bouillon (1995a); Bouillon et al. (1997); Bouillon and Boero (2000).

Remark: two genera are only present in the Mediterranean Thecocodium as hydroid with fixed sporosacs and Tregoubovia only known by its medusa stage.

Genus Thecocodium Bouillon, 1967

Colonies dimorphic, stolonal, hydrorhiza covered with perisarc, reproduction by fixed sporosacs.

Thecocodium brieni Bouillon, 1967

(Fig. 44B)

Polyps arising from an irregular network of anastomosing stolon enclosed in thin perisarc. Gastrozooids without tentacles; dactylozooids tubular, elongated, retractile, more numerous than gastrozooids, without internal cavity neither apical orifice and with 4-5 capitate tentacles apically. Gonozooids similar to gastrozooids from which they develop by the growth, near the base of polyp, of a single 
gonophore, males fixed sporosacs, females eumedusoids. Cnidome: microbasic euryteles around gastrozooid hypostome and on dactylozooids tentacles; desmonemes on tentacles of dactylozooids.

Records from Mediterranean: western Mediterranean.

Distribution: north eastern Atlantic, Meditteranean.

References: Bouillon (1967); Edwards and Harvey (1983); Boero and Bouillon (1993).

\section{Genus Tregoubovia Picard, 1958}

Ptilocodiidae medusae without exumbrellar furrows; with didermic centripetal tracks; without marginal tentacles or marginal tentacular bulbs; with interradial «gonads».

Hydroid: unknown.

Tregoubovia atentaculata Picard, 1958a (Fig. 44C)

Medusa. umbrella $3.2 \mathrm{~mm}$ high, ovoid, mesoglea fairly thick; with up to 16 exumbrellar didermic centripetal processes issuing from marginal cnidocyst ring; velum normal; manubrium large, quadratic; mouth quadratic with 4 rather long perradial oral expansions, with one terminal cluster of cnidocysts, with four radial canal and circular canal narrow, with short mesenteries; «gonads» interradial; without marginal tentacles or marginal bulbs; no ocelli.

Records from Mediterranean: western Mediterranean.

Known seasonality: 6.

Distribution: endemic of Mediterranean Sea.

References: Picard (1958a), Goy (1973b); Boero and Bouillon (1993); Bouillon et al. (1997).

\section{Family RATHKEIDAE Russell, 1953}

Hydroid: colonial hydroids arising from ramified, creeping stolons; hydranths monomorphic, sessile, with one whorl of filiform tentacles surrounding a rounded hypostome; hydranth base surrounded by a thin gelatinous envelope; free medusa developing on hydrorhiza or more rarely at the base of hydranths.

Medusa: Anthomedusae with somewhat globular umbrella, with slight apical process; manubrium, short, cylindrical, not extending beyond umbrella margin; with gastric peduncle; with mouth with 4 lips elongated to form either simple or branched oral arms armed with terminal and usually also lateral clusters of cnidocysts; with 4 to 8 radial canals and circular canal; with «gonads» generally completely surrounding manubrium; with 8 groups of solid marginal tentacles; without ocelli.

\section{Genus Rathkea Brant, 1838}

Hydroid: with the characters of the family.

Medusa: Rhathkeidae with 4 radial canals and 4 oral arms armed with clusters of cnidocysts.

Rathkea octopunctata (M. Sars, 1835) (Figs. 44D-H)

Hydroid: colonies stolonal arising from ramified creeping stolons; hydranths small, sessile, cylindrical, naked except at their base surrounded by a thin gelatinous envelope; hypostome rounded-conical, one whorl of 4-6 thread-like filiform tentacles; medusa buds arising from stolons, exceptionally from hydranth.

Medusa: umbrella somewhat globular, up to 3-4 $\mathrm{mm}$ high and $4 \mathrm{~mm}$ wide, with rounded or domeshaped apical process, mesoglea moderately thick, especially in the apical region; velum broad; manubrium short, cylindrical or four-sided, with conical peduncle, $1 / 3$ to $1 / 4$ of length of umbrella cavity, not reaching beyond umbrella margin in full extension; mouth with four lips, each divided in two short stalked cnidocysts knobbed arms; in fully developed specimens one or two pairs of lateral cnidocysts clusters upon the sides of each lips; bases of oral arms continued on manubrium for some length as perradial ridges; four radial canals and circular canal narrow; «gonads» completely surrounding manubrium; eight marginal tentacular bulbs; four perradial each with up to five tentacles, four interradial bulbs each with up to three tentacles, at full development; no ocelli; medusa buds on manubrium, exclusively from ectodermal origin. Records form Mediterranean: eastern and western Mediterranean; Adriatic; Black Sea.

Known seasonality: 1-5.

Distribution: Atlantic; Indo-Pacific; Arctic; Mediterranean.

References: Werner (1956, 1958); Bouillon (1961-1962); Bouillon and Werner (1965); Berhaut (1970); Goy (1973b); Gili (1986); Boero and Bouillon (1993); Avian et al. (1995); Benovic and Lucic (1996); Medel and López-González (1996). 
Family RHYSIIDAE Brinckmann, 1965

Colonies stolonal, hydrorhiza covered with perisarc. Gastrozooids naked, with one whorl of filiform tentacles around a conical hypostome; dactylozooids filiform and without capitate tentacles, covered with perisarc up to the apical extreme which it armed with cnidocysts. Gonads on hydranths similar with the gastrozooids, no gonophores; male hydranths with 3 or 4 filiform tentacles, female hydranths transform itself resembling a sporosac structure.

\section{Genus Rhysia Brinckmann, 1965}

Rhysiidae with polymorphic colonies. Gastrozooids and gonozooids naked, arising directly from a creeping stolon. Tentaculozooids covered with perisarc up to the terminal cnidocyst cluster. Gonozooids similar to gastrozooids; male polyps with testicle which may occupy $8 / 10$ of the body wall; female polyps becoming completely converted into a sporosac with the endoderm forming a spadix feeding one egg, developing into a planula. One species in the Mediterranean.

\section{Rhysia autumnalis Brinckmann-Voss, 1965} (Fig. 44I)

Colonies with an anastomosing stolon which forms a wide and irregular net; perisarc covering the stolon up to the base of the polyps. Tentaculozooids with a stem covered by a perisarc and a terminal cluster of cnidocysts. Gastrozooids with 10 to 12 tentacles. Female gonozooids with 6 to 10 tentacles, which become reduced during the development of the embryo; male gonozooids with 3 or 4 tentacles which remain intact during the ripening of the gonad. Cnidocysts: stenoteles, microbasic euryteles and desmonemes.

Records from Mediterranean: western Mediterranean

Known seasonality: 9-1.

Distribution: endemic of Mediterranean Sea.

References: Brinckmann-Voss (1965b); Boero and Fresi (1986); Brinckmann-Voss et al. (1993)

Family RusselliIDAE Kramp, 1957

Anthomedusae with a apical projection; manubrium mounted upon a gastric peduncle; with four unbranched oral tentacles attached above mouth margin, without terminal cnidocyst clusters; mouth with four perradial lips; marginal tentacles hollow, without basal swellings, in 8 groups, 4 perradial and 4 adradial, each group with one large and two small tentacles; basal part of large tentacles sunken into deep furrows of umbrella margin; with 8 adradial «gonads»; with adaxial red ocellus at base of free portion of tentacles.

Hydroid unknown.

Genus Russellia Kramp, 1957a

With the characters of family.

\section{Russellia mirabilis Kramp, 1957a} (Fig. 45A)

Medusa: umbrella up to $9 \mathrm{~mm}$ wide, $15 \mathrm{~mm}$ high; apical projection large; gastric peduncle short, broad; mouth quadrangular, with short perradial lips; oral tentacles finger-shaped, with scattered cnidocysts along entire length; free end of large tentacles filiform?; «gonads» smooth occupying entire length of manubrium.

Records from Mediterranean: western Mediterranean.

Known seasonality: 4.

Distribution: Antarctic; Atlantic (West Indies); Mediterranean.

References: Navas-Pereira and Vannucci (1990); Pagès et al. (1999).

Family STYLASTERIDAE Gray, 1847

Colonies erect and branched with a thick calcareous exoskeleton (coenosteum); polyps polymorphic and retractile; gastrozooids with one whorl of filiform tentacles, exceptionally without any tentacle, gastric cavity containing usually a central style (gastrostyle); dactylozooids filiform, without tentacles. The two types of polyps are irregularly distributed or, more frequently, arranged in circles (cyclosystem) where one gastrozooid is surrounded by several dactylozooids. Gonophores reduced and developed inside the "ampullae", globose structures in the exoskeleton, in the colony surface, the female bigger than the male.

Reference: Cairns (1991).

Remarks: The Stylasteridae are very closely related to the Hydractiniidae but are represented by only one species in Mediterranean: Errina aspersa see below. 
Genus Errina Gray, 1835

(Figs. 45B-C)

Colonies usually flabellate but may be slightly bushy; branches robust to delicate, usually round in cross section, major may not anastomose; coenosteal texture usually reticulate with irregularly shaped granules, but may be linear and have low, rounded granules; the sides of dactylopore spines are sometimes imbricate; coenosteum white, orange, or pink; gastro- and dactylopores usually randomly arranged on branch; however, gastropores often more abundant on anterior side, sometimes aligned along the anterior or lateral branch edges; mayor gastropores may not bear an abcauline lip; gastrostyles usually of medium $\mathrm{H} / \mathrm{W}$; however, they range from 1.6-2.6 $\mathrm{mm}$, the longer styles held in place by transverse tabulae; styles lanceolate, usually vertically ridged, the ridges bearing simple and fused spines; a ring palisade present in some species; dactylopore spines shaped as grooved tubercles, the grooves predominantly directed away from the branch tip (adcauline); walls of the dactylopore spines usually thick, such that the groove constitutes only one-third the width of the spine; spines vary greatly in size from rudimentary to over $1 \mathrm{~mm}$ tall; small dactylopores also occur as slits, flush with the branch surface; spines often clustered and sometimes composite; no dactylostyles; ampullae vary from internal to slightly submerged to fully superficial hemispheres.

Reference: Cairns (1991).

Errina aspera (Linnaeus, 1767)

(see photos Figs. 9 and 10 in Zibrowius and Cairns, 1992)

Colonies primarily uniplanar but sometimes bushy, up to $20 \mathrm{~cm}$ high and wide; branches cylindrical, gradually tapering to pointed tips; coenosteum white and porous, predominantly of reticulategranular texture, but sides of dactylopore spines and inner gastropore tube surface imbricate; coenosteal strips wide, granules irregular in shape; gastropores circular, tubular, lacking ring palisade, without proximal lips; gastrostyle occupies lower half of gastropore tube, lanceolate, bearing short vertical spiny ridges; dactylopore spines mainly on distal branches, female ampullae hemispherical and often spinose as a result of short dactylopore spines, male ampullae internal, elliptical in shape, communicating to surface by a narrow efferent pore.
Records from Mediterranean: eastern and western Mediterranean.

Known seasonality: 6; 7 .

Distribution: Atlantic, Mediterranean.

Reference: Zibrowius and Cairns (1992).

Family TRICHYDRIDAE Hincks, 1868

Hydroid: colonies stolonal, with creeping stolon recovered by thin perisarc; hydranths sessile, with base surrounded by a collar-like tube of perisarc, with one amphicoronate whorl of filiform tentacles; gonophores and cnidocysts unknown.

Medusa: Anthomedusae without peduncle; mesoglea especially thick in upper part of umbrella; with four large, simple, pleated lips; with 4 radial canals; with numerous fine, lateral branched, anastomosing centripetal canals connecting non perradial marginal bulbs to the radial canals; «gonads» interradial; with solid marginal tentacles; with triangular marginal bulbs; without ocelli or any other apparent sense organ.

Remarks: the medusae of Trichydra were previously included in the Proboscydactilidae (as Pochella) but the «gonads» are not radial outgrowth of the stomach and there are no exumbrellar cnidocysts chambers characteristic of this latter family. The discovery of their alleged cycle does not resolve the problem of their taxonomical position; Trichydra polyps have been considered as Corynidae, as Campanulariidae, or to being next to the Lafoeidae and also tentatively as being the hydroid of Lizzia blondina (See Edwards, 1973a for a review). They present great morphological affinities with the polyps of Halitiara inflexa Bouillon, 1980 (see Bouillon Seghers and Boero, 1988; Bouillon, 1985b). The medusae have typical Anthomedusae characters in the structure and the form of the manubrium and of the «gonads» and in the structure of the tentacles but they differ from Halitiara medusae by several important characters.

Perhaps the study of the cnidome will give enough information's to solve this systematical puzzle; the Halitiara having very particular cnidocysts for Anthomedusae: merotrichous isorhiza. (See this paper Halitiara inflexa).

\section{Genus Trichydra Wright, 1858}

Medusa and hydroids with the characters of the family. 
Trichydra pudica Wright, 1858

(= Pochella polynema) (Fig. 45D-E)

Hydroid: colonies stolonal, with creeping stolon recovered by thin perisarc; base of hydranth surrounded by a collar-like tube of perisarc into which the hydranth can partially retract, when contracted only the tips of the tentacles show beyond the edge of the perisarc; hydranth cylindrical, very slender and extensible, with short conical hypostome; 6 solid, amphicoronate filiform tentacles carrying numerous irregularly disposed cnidocysts; young medusae were obtained from rearing by Edwards (1973a) from clinkers, he could however not observed the gonophores.

Medusa: umbrella about $4 \mathrm{~mm}$ wide and $3.5 \mathrm{~mm}$ high, somewhat bell-shaped to hemispherical; no exumbrellar cnidocysts tracks but exumbrella with scattered cnidocysts, apical mesoglea thick forming a rounded-conical apical projection; velum fairly broad; manubrium large, four-sided, about two-thirds of subumbrellar cavity; mouth with four large, wavy, pleated lips; 4 straight, smooth radial canals, fairly broad, with funnel-shaped dilatations at their origins of the manubrium; with numerous fine, branched, often anastomosing, centripetal canals, connecting non perradial marginal bulbs to the radial canals; circular canal visible in young specimens, embedded in the base of the crowded marginal bulbs in adults; «gonads» four, large, interradial pads; up to 48 ( or more) long, marginal, filiform solid tentacles with somewhat triangular marginal bulbs; no ocelli.

Records from Mediterranean: eastern Mediterranean; Adriatic Sea.

Known seasonality: 2; 4; 5; 8; 11.

Distribution: Atlantic, Indo-Pacific; Mediterranean.

References: Rees (1941a); Edwards (1973a); Schmidt and Benovic (1979); Arai and BrinckmannVoss (1980); Bouillon (1985a); Goy et al. (1988, 1990, 1991); Boero and Bouillon (1993).

\section{Order CAPITATA Kühn, 1913}

Hydranths: usually with capitate tentacles either in the adult polyps or during their larval life; gonophores generally borne on hydranth body.

Medusa: with "gonads" usually completely surrounding the manubrium; mouth simple and circular; marginal tentacles usually hollow (solid in Margelopsidae and Porpitidae); cnidome characterised by the presence of stenoteles; sexual repro- duction leading to planulae or actinulae; planulae with usually two types of ectodermal embryonic glandular cells: spumous and spheroulous ones.

References: Petersen (1990); Schuchert (1996; 2001a).

\section{Key to hydroids}

1. Hydranths with aboral tentacles only .................2

- Hydranths with oral and aboral tentacles.......... 3

2. Hydranth with numerous capitate tentacles arranged in 3-6 irregular aboral whorls around middle part of the hydranth body and with creeping stolonal hydrorhiza or with tentacles in 1 or 5-6 close alternate aboral whorls surrounding base of hypostome and with matlike hydrorhiza, forming a basal plate... Sphaerocorynida

- Hydranth claviform; with long hypostome; tentacles scattered in one or more aboral whorls under hypostome, hydrocaulus not clearly demarcated, short, ending in pedal disc or creeping stolon... Moerisiida

3. Hydranth with solid or parenchymatical oral tentacles in one whorl around hypostome or spreading down over hydranth body; with solid or parenchymatical aboral tentacles in one or three whorls or absent...................... Tubulariida

- Hydranths mono- or polymorphic, oral tentacles capitate or moniliform, aboral tentacles in whorls or scattered, either capitate, moniliform, ramified capitate, reduced, or without tentacles; hydroids as floating or fixed colonies; fixed colonies arising either from simple creeping stolonal tubes, from an encrusting basal mat, from upright branched hydrorihza consisting of a central axis of perisarc covered by coenosarc, or from a calcified exoskeleton ... Zancleida

\section{Key to medusae}

1. Marginal tentacles developed only at junction between radial canals and circular canal.......... 2

- Marginal tentacles developed at junctions between radial canals and circular canal and along entire circular canal (except Tiaricodon); manubium quadrate; mouth cruciform; interradial "gonads" on manubrium and radial lobes or on radial lobes only............. Moerisiida

2. Manubrium with flask-shaped quadrate or cruciform manubrium, mouth tube ending in round or cruciform mouth; with interradial 
"gonads"

- Generally with cylindrical manubrium with circular base; mouth usually simple and circular; "gonads" normally completely surrounding manubrium Tubulariida

3. Usually with exumbrellar cnidocyst pouches or tracks; tentacles with cnidophores (except the Porpitidae) Zancleida

- Medusae without this characters Sphaerocorynida

Suborder MOERISIIDA Poche, 1914

Hydroid: hydranth claviform, with long hypostome; tentacles aboral, scattered, or in one or more whorls under hypostome base; hydrocaulus not clearly demarcated, short, ending in pedal disc or in a creeping stolon; free medusae or reduced gonophores.

Medusa: manubrium quadrate, forming radial lobes; mouth cruciform; "gonads" interradial, on manubrium and radial lobes or on radial lobes only; marginal tentacles developed at junctions between radial canals and circular canal and along entire circular canal (except Tiaricodon); tentacular bulbs usually with abaxial ocelli; planulae with usually two types of ectodermal embryonic glandular cells: spumous and spheroulous ones.

References: Petersen (1990); Bouillon (1999); Bouillon and Barnett (1999); Bouillon and Boero (2000).

\section{Key to hydroids}

1. Hydranth with tentacles. 2

- Hydranth without tentacles $=$ Protohydridae

2. Hydranth with filiform or modified moniliform tentacles, in one whorl under hypostome; living in freshwater Hydridae

- Hydranth with moniliform or modified moniliform tentacles scattered or in one whorl around middle part of body; living in brackish or sea water Moerisiidae

\section{Key to medusae}

Only one family present in the Mediterranean = Moerisiidae

\section{Family HYDRIDAE Dana, 1846}

Hydroid: solitary fresh-water hydroids, with hollow filiform tentacles, but often moniliform distally, in one whorl under hypostome; eggs and sperm developed directly in ectoderm of polyps in wartlike protuberances, in hermaphrodite species "testis" develop on upper part of hydranth, "ovaries" on lower part; asexual reproduction by lateral buds, leading only to temporary colonies; lower part of hydranth with simple pedal disc and with central pore, no perisarc except on encysted embryos.

Remark: The Hydridae are here included in the Moerisiida (see Bouillon, 1985 and Petersen (1990) for comments) but it is not excluded that they may form an order by themselves.

$$
\begin{aligned}
& \text { Genus Hydra Linné, } 1758 \\
= & \text { Chlorohydra } \text { Schulze, } 1917 \\
= & \text { Pelmatohydra } \text { Schulze, } 1917
\end{aligned}
$$

(Figs. 45F-H)

With the characters of the family

A list of the European species is given by Grayson (1971).

References: Campbell (1987) Avian et al. (1995).

\section{Family MoERISIIDAE Poche, 1914}

Hydroid: hydranths with aboral tentacles moniliform or modified moniliform, scattered or in one whorl around middle part of the hydranth body; medusa buds on short pedicels between or just under the tentacles; polyp buds produced from lower part of hydranth; hydrocaulus short, ending in pedal disc forming podocysts, or with short stolon-like tubes ending in podocysts or hydranths.

Medusa: manubrium prismatic, with radial lobes on proximal parts of the 4 radial canals; no gastric peduncle; with or without centripetal canals; mouth simple, cruciform; usually without lips except in oldest specimens; "gonads" on manubrium and surrounding manubrial lobes or only on manubrial lobes overlying the radial canals; with either 4 , or 16-32, or several hundreds moniliform or modified moniliform hollow marginal tentacles with adnate bulbs; abaxial ocelli; no statocysts.

References: Petersen (1990); Bouillon (1995a; 1999); Bouillon and Barnett (1999); Bouillon and Boero (2000).

\section{Key to hydroids}

1. tentacles solid, scattered under long hypostome; tentacles with cnidocysts in a terminal knob and several adaxial knobs Odessia 
- Tentacles hollow, in one whorl or scattered; tentacles moniliform Moerisia

Key to medusae

1. Radial lobes of manubrium twisted; "gonads" lobed .... Halmomises

- Radial lobes of manubrium not twisted; "gonads" smooth 2

2. Marginal tentacles moniliform; "gonads" on manubrium continuous with those on manubrium lobes Moerisia

- Marginal tentacles with irregularly transverse cnidocyst claps or bands; "gonads" on manubrium, usually separated from those on manubrial lobes in adults Odessia

Genus Halmomises von Kennel, 1891 (unrecognisable)

\section{Genus Moerisia Boulenger, 1908 = Ostroumovia Hadzi, 1928}

Hydroid: with the general characters of the family, tentacles moniliform.

Medusa: either 4 or 16-32 moniliform marginal tentacles; no centripetal canals; "gonads" on manubrium, interradial, continuous with those on manubrial lobes.

Reference: Petersen (1990).

\section{Key to hydroids}

1. Hydranth attached to substratum by one or more pedal disc (podocysts). M. inkermanica

- Hydranth without podocysts; colony giving up hydrocauli M. lyonsi

\section{Key to medusae}

1. With marginal tentacles of different lengths .... 2

- With usually only 4 marginal tentacles of about equal length (exceptionally up to 16 or 22); mouth with no lips M. lyonsi

2. Manubrium with very short manubrial pouches, up to 16 marginal tentacles, marginal tentacular bulbs globular, mouth with distinct lips

\section{M. carine}

- Manubrium with long manubrial pouches, up to 36 marginal tentacles, proximal parts of tentacles narrow, mouth with no distinct lips

M. inkermanica
Moerisia carine Bouillon, 1978

(Fig. 46A)

Medusa: umbrella 2,6 mm wide and 3,3 mm high, bell-shaped with rounded apex; mesoglea very thick and consistent, mainly at apex, thinning towards umbrella margin; manubrium small, quadrangular, with 4 short perradial manubrial lobes, not overrunning the subumbrellar roof; mouth cruciform, with four small lips, covered with cnidocysts; «gonads» covering manubrium and extending on manubrial lobes; up to 16 marginal moniliform tentacles of different size; marginal bulbs large, globular, clasping exumbrella each with a large ocelli.

Records from Mediterranean: eastern Mediterranean.

Known seasonality: $7-12$.

Distribution: Indo-pacific; Mediterranean.

References: Bouillon (1978b); Lakkis and Zeidane (1985); Goy et al. (1988, 1990, 1991) Boero and Bouillon (1993).

Hydroid: unknown.

\section{Moerisia inkermanica}

Paltschikowa-Ostroumova, 1925

(Figs. 46B-D)

Hydroid: hydranth attached to substratum by one or more perisarcal pedal disks (podocysts) issued from stolon-like tubes, tubes often reduced to merely filaments, the hydranths may be solitary with a single pedal disk at base or even bipolar; perisarc delicate, gelatinous with adhering silt, covering stolon-tube and basal part of hydranth body; hydranth spindleshaped, slender at base and widening to tentacular region, with 4-12 hollow moniliform tentacles in one or two roughly alternating whorls; asexual reproduction: by medusa buds arising just under or amongst tentacles, by lateral hydranth buds arising just below tentacles (the budding hydranths may remain attached to the stolonal system of the parent), by stolonization from base, by podocysts.

Medusa: Umbrella up to $6.5 \mathrm{~mm}$ wide, $5.5 \mathrm{~mm}$ high, dome shaped, mesoglea very thick; manubrium small, cruciform, with long perradial manubrial lobes extending nearly to bell margin; mouth with cnidocyst perradial thickening, no real lips; with «gonads» on manubrium continuous with those on radial lobes, with distal portions often sac-like, pendent; up to 32 moniliform marginal tentacles of different lengths, proximal part of tentacle narrow, 
largely adnate to exumbrella; with carmine ocelli at the point of issue of the free parts of tentacles.

Records from Mediterranean: fresh water bodies of eastern and western Mediterranean; Azov Sea; Black Sea.

Known seasonality: 6-9.

Distribution: Atlantic; Indo-Pacific; Mediterranean.

References: Valkanov (1935, 1938, 1953); Kramp (1938a, b, 1961); Paspaleff (1938); Kramp (1942); Picard (1951a, 1955a); Bouillon et al, (1969); Brinckmann-Voss (1987); Boero and Bouillon (1993).

Moerisia lyonsi Boulenger, 1908

(Figs. 46E-G)

Hydroid: small colonies with short branched hydrorhiza of stolon-like tubes, the free ends of which narrowing to form the hydrocauli, stolon tubes recovered with annulated, delicate perisarc incrusted with detritus; extremity of hydrocauli and hydranths naked; hydrocaulus gradually merging into the hydranths which are claviform, with a rounded elongated hypostome, with about 4- 8 hollow long moniliform tentacles in one whorl; asexual reproduction: by medusa buds developing both above and below the circlet of tentacles, by lateral budding below the tentacles area of frustules and polyps (which become free), by multiple constriction and transverse fission of the basal part of the hydranths, by hydranth budding from hydrocauli, by podocyst borne on short solon-like tubes.

Medusa: umbrella $4.5 \mathrm{~mm}$ wide and $4 \mathrm{~mm}$ high, globular, mesoglea very thick, mainly at apex; manubrium cylindrical; mouth round, without lips; perradial lobes of manubrium about $2 / 3$ of the length of the radial canals; «gonads» interradial on manubrium walls in continuity with those on manubrial lobes; marginal tentacles moniliform, usually four, but sometimes 16 , rarely 22 , long, with prominent rings of cnidocyst.

Records from Mediterranean: Lake Qurum, Egypt.

Known seasonality: 3-5.

Distribution: Atlantic, Mediterranean.

References: Boulenger (1908); Picard (1951a); Kramp (1961).

\section{Genus Odessia Paspaleff, 1937}

Hydroid: with the general characters of the family; tentacles scattered under hypostome, each with one large terminal knob of cnidocysts and several adaxial knobs; with free medusae.

Medusa: Moerisiidae with «gonads» on perradial side of manubrium usually separated from those on manubrium walls in adults; without centripetal canals; 16-32 marginal tentacles with cnidocysts in irregular transverse claps or bands.

Odessia maeotica (Ostroumoff, 1896) (Fig. 46H-I)

Hydroid: hydranths usually solitary, conical, tapering basally, with a long conical hypostome; with numerous solid tentacles scattered under hypostome, each with one large terminal knob of cnidocysts and several adaxial knobs; pedal disc enclosed in perisarc, with polyp buds arising under tentacles and which may remain attached to parent polyp during a certain time forming temporarily colonies; medusa buds arising between and under the tentacles.

Medusa: umbrella up to $18 \mathrm{~mm}$ wide, usually much smaller, about as wide than high or somewhat lower, bell-shaped, mesoglea thick; perradial lobes of manubrium extending along proximal half or more of radial canals; in adult medusae the «gonads» on the interradial walls of manubrium are separated from those on the radial canals; 16-32 marginal tentacles with cnidocysts in irregularly transverse claps or bands, not in moliniform rings, marginal bulbs globular to elongated adnate to exumbrella.

Records from Mediterranean: Black Sea, Azov Sea; eastern and western Mediterranean; Adriatic.

Known seasonality: 4; 7-10.

Distribution: Atlantic; Mediterranean.

References: Picard (1951a, 1952, 1955a); Rees (1958); Kramp (1961); Sacchi (1961); Goy (1973b); Petersen (1990); Boero and Bouillon (1993) Avian et al. (1995).

\section{Family PROTOHYDRIDAE Allman, 1888}

Hydroid: paedomorphic, usually living in brackish-waters; hydranth solitary, spindle-shaped, without tentacles but with scattered cnidocyst warts, moving as caterpillars; ectodermal pedal disc; sexual products differentiated in endoderm, reproductive cycle unknown, asexual reproduction by transverse fission.

Remark: often classified near the Hydridae, based on assumptions and convenience more than 
facts. Phylogenetic position uncertain; here tentatively incorporated into the Moerisiida.

\section{Genus Protohydra Greef, 1869}

With the characters of the family References: Thiel (1988); Petersen (1990).

Protohydra leuckarti Greeff, 1869 (Fig. 47A-E)

With the characters of the family.

Records from Mediterranean: western Mediterranean (Canet Plage)

Seasonality: ?

Distribution: Cosmopolitan.

References: Delamare-Deboutteville (1960), Clausen (1971).

\section{Suborder SPHAEROCORYNIDA Petersen (1990)}

Hydroid: where known, hydrorhiza either stolonal, or mat-like, forming a basal plate hydrorhiza; numerous long capitate tentacles arranged in 3-6 irregular aboral whorls around middle part of hydranth column, or in 1 or 5-6 close alternate oral whorls surrounding hypostome; gonophores borne on middle part of body, or on basal part of hydrocaulus, or on hydrorhiza.

Medusa: manubrium flask-shaped, quadrate or cruciform in cross-section; "gonads" interrardial, adradial or circular; 2-4 perradial marginal capitate tentacles. (2000)

References: Petersen (1990); Bouillon and Boero

Only one family in Mediterranean:

\section{Family SPHAEROCORYNIDAE Prévot, 1959}

Hydroid: colony stolonal or erect; hydrorhiza creeping; hydrocaulus long, unbranched or slightly branched, with a terminal hydranth; perisarc thin, reaching hydranth base; hydranth vasiform with bulbous base, and proboscis; no oral tentacles but numerous solid, single or trifid capitate tentacles in 3-5 whorls around broadest part of column; gonophores as free medusae or as eumedusoids.

Medusa: umbrella bell-shaped, ovoid; apical mesoglea thick, apical projection conical or domeshaped, apical chamber broad; manubrium with quadrate base, either flask-shaped, or cruciform; mouth simple, round or cruciform; in non mature specimens "gonads" interradial, apparently divided in adradial masses by longitudinal median grooves, "gonads" confluent in perradii in adult specimens; 4 hollow, marginal tentacles with either adaxial or spirally-arranged cnidocyst clusters and terminating in an ellipsoid capitation; marginal bulbs large, clasping exumbrella, with an adaxial expansion; abaxial ocelli.

References: Wedler and Larson (1986); Calder (1988); Petersen (1990); Bouillon and Boero (2000).

$$
\begin{gathered}
\text { Genus Sphaerocoryne Pictet, } 1893 \\
=\text { Linvillea } \text { Mayer, } 1910
\end{gathered}
$$

Hydroid: colony stolonal; hydrocaulus long, simple or slightly branched; hydranth vasiform, with numerous simple solid capitate tentacles in 3-5 whorls around broadest part; gonophores on short branching blastostyles above or among tentacles.

Medusa: with the characters of the family.

\section{Sphaerocoryne bedoti Pictet, 1893}

(Fig. 47F-G)

Hydroid: colonies with creeping hydrorhiza usually embedded in sponges; hydrocaulus monosiphonic, unbranched, covered by a delicate perisarc and giving rise to solitary hydranth; perisarc smooth or with a few wrinkles or annulations; hydranth pyriform to bottle-shaped with 15-70 solid capitate tentacles of varying length arranged in 2-6 closely alternating whorls in the broadest basal part of the hydranth; hypostome elongated, conical; no oral tentacles; medusa buds borne on clusters (up to 12) just above tentacles, each cluster may bear more than 10 medusa buds. Cnidocysts: desmonemes, small stenoteles, large stenoteles.

Medusa: umbrella bell-shaped to ovoid, up to 4,5 $\mathrm{mm}$ high and $3.0 \mathrm{~mm}$ wide; with a conical or domeshaped apical projection and a broad apical chamber; manubrium simple, flask-shaped, with quadrate base, two third of umbrella cavity in length; mouth tube rather long, with simple rounded or more or less cruciform opening; with four simple radial canal; with 4 marginal tentacles bearing spirally arranged clusters of cnidocysts and a hollow, ellipsoid, terminal cnidocyst knob; four marginal bulbs large, clasping exumbrella, with an adaxial expansion, each bulb with a abaxial ocelli, «gonads» interradial with a longitudinal median groove which may divide them in adradial masses, adult medusae with «gonads» confluent in perradii. 
Records from Mediterranean: eastern Mediterranean.

Seasonality:?

Distribution: Atlantic; Indo-pacific; Mediterranean.

References: Prévot (1959); Kramp (1961); Mammen (1963); Yamada and Kommo (1973); Millard (1975); Bouillon (1984c); Hirohito (1988); Petersen (1990); Goy et al. (1991); Boero and Bouillon (1993)

\section{Suborder TUBULARIIDA Fleming, 1828}

Hydroid: hydranth with solid or parenchymatical oral tentacles in one whorl around hypostome or spreading down over hydranth body; with solid or parenchymatical aboral tentacles in one or three whorls or absent; free medusae or sporosacs.

Medusa: manubrium generally cylindrical, with circular base; mouth usually simple and circular; "gonads" normally completely surrounding manubrium; marginal tentacles developed only at junction between radial canals and circular canal; usually with 1 to 4 marginal tentacles, rarely 8 or more in the Cladonematidae.

References: Hirohito (1988); Petersen (1990).

\section{Key to hydroids}

1. Solitary 2

- Colonial

2. Pelagic. Margelopsidae

- Not pelagic

3. Hydrocaulus with parenchymatic endoderm often with peripheral canals 3

- Hydrocaulus without these characters ... 4

4. Hydranth with one whorl of moniliform or capitate oral tentacles or several whorls of fili form oral tentacles; with one to three whorls of moniliform or filiform aboral tentacles; perisarc usually feebly developed, restricted to base of hydrocaulus .............................. Corymorphidae

- Hydranth with capitate, moniliform, filiform or pseudofiliform oral tentacles, in one to several close-set whorls; one whorl of long pseudofiliform or filiform aboral tentacles; perisac well developed reaching hydranth base, forming a neck region... Tubulariidae

5. Tentacles capitate or not, disposed in distinct whorls 6

- Numerous scattered capitate tentacles Candelabriidae
6. One whorl of reduced tentacles, capitate or not, located in the oral or median part of the hydranth Boreohydridae

- Hydranth with several tentacle whorls............. 7

7. Hydrocaulus thin, with conspicuous inflated gelatinous periderm; oral whorl of capitate tentacles and 2 aboral whorls of moniliform tentacles . Tricyclusidae

- Hydrocaulus not surrounded by an inflated gelatinous periderm.

8. One or two whorls of oral capitate tentacles, and a distal aboral whorl of large fleshy filiform tentacles Acaulidae

- Oral whorl of short moniliform, capitate or filiform tentacles; moniliform or filiform aboral tentacles in 1 or 3 close-set whorls, or dispersed; often with aboral endodermal statocyst-like structure and adhesive mucus organ

Euphysidae

9. Colony polymorphic..................... Paracorynidae

- Colony monomorphic....................................... 10

10.Colony pinnate (feather-like) .......... Pennariidae

- Colony not pinnate ............................................ 11

11. One whorl of oral capitate tentacles and usually below it more capitate tentacles in whorls or scattered; there may be filiform tentacles below capitate ones; hypostome with or without distinct button of mucous gland cells around mouth....... Corynidae

- Only one oral whorl of capitate tentacles, sometimes one aboral whorl of filiform sensory tentacles; with glandular mucous cells forming a preoral cavity around the mouth .

Cladonematidae

\section{Key to medusae}

1. Reduced medusae, with 4 rudimentary bulbs ..... Pennariidae

- Medusae not reduced, exceptionally without tentacles 2

2. Marginal tentacles simple; with 1-4 marginal tentacles 3

- Marginal tentacles branched; usually with more than 4 radial canals................. Cladonematidae*

3. Marginal tentacular bulbs with ocelli.. Corynidae

- Marginal tentacular bulbs without ocelli ........ 4

4. Exumbrella without cnidocyst tracks .............. 5

- Exumbrella with cnidocyst tracks.. Tubulariidae

5. With 1-4 marginal tentacles, unequally developed or of the same length but all of same 
structure; without apical projection

Euphysidae

- With up to four marginal tentacles of different size and structure; umbrella dome-shaped or with pointed apex Corymorphidae

Remark: *The Cladonematidae are often separated in two families: the Cladonematidae and the Eleutheriidae

\section{Family ACAULIDAE Fraser, 1924}

Hydroid: hydranth solitary, pear-shaped, with 1 or 2 whorls of oral capitate tentacles, and with a distal aboral whorl of large fleshy filiform tentacles, which may be absent or replaced by capitate tentacles; attached to substrate by a reduced hydrocaulus (= "root" or "peduncle"), by means of a gelatinous fixation tube, or by anchoring filaments, or by a mucous secretion; gonophores as fixed sporosacs in the lower or middle part of the hydranth, asexual reproduction by transverse fission in some species.

References: Petersen (1990); Thomas et al. (1995); Schuchert (2001a).

\section{Genus Acauloides Bouillon, 1965}

Hydrocaulus attached to substrate by a modified basal part, secreting a gelatinous sheath or forming anchoring filaments or by an adhesive basal disc; hydranth pear-shaped, one oral whorl of capitate tentacles and scattered aboral capitate tentacles of irregular length, all with choral endoderm; gonophores in axils of scattered tentacles, asexual reproduction through transverse fission.

References: Thiel (1988); Petersen (1990); Thomas et al. (1995); Schuchert (2001a).

1. Hydrocaulus short, without gelatinous tube; hydranth with up to 25 tentacles.....

A. ammisatum

- Hydrocaulus elongated, covered with a gelatinous tube; hydranth with up to 69 tentacles or more. A. ilonae.

Acauloides ammisatum (Bouillon, 1965) (Fig. 47H)

Solitary polyps $(0.6-2 \mathrm{~mm})$ with a short peduncle, without gelatinous tube neither anchoring filaments, but attached to substrate by means of a mucous secretion. Tentacles capitate 10-25, without filiform tentacles. Oral tentacles 4-6 around hypostome, the remainders scattered over the body. Cnidocysts: stenoteles, desmonemes and holotrichous microbasic mastigophores.

Record from Mediterraneum: western Mediterannean.

Distribution: northeastern Atlantic, Mediterranean.

References: Bouillon (1965, 1971); Thiel (1988).

Acauloides ilonae (Brinckmann-Voss, 1966)

(Fig. 47I)

Hydroid: solitary polyps with gelatinous tube, which may elongate and serve as anchoring filament. Tentacles numerous, up to 69 or more. One whorl of short oral tentacles and one whorl of long aboral tentacles. Between these two whorls are a large number of scattered tentacles, which increase in length towards the aboral region. All tentacles capitate. Fixed gonophores in the axils of the tentacles. Cnidocysts: desmonemes; stenoteles and microbasic euryteles.

Records from Mediterranean: western Mediterranean.

Known seasonality: 1-6, 11-12.

Distribution: northeastern Atlantic, Mediterranean.

References: Brickmann-Voss (1966, 1970); Boero and Bouillon (1993).

Family BOREOHYDRIDAE Westblad, 1947

Hydroid solitary of small size, hydranths with one whorl of reduced tentacles, capitate or not, located in the oral or median part of the hydranth; perisarc reduced or absent. Gonophores where known as fixed sporosacs.

1. Hydranth with oral capitate tentacles and cnidocysts warts; hypostome normal

Boreohydra

- Hydranth with capitate tentacles in the middle of the body; hypostome extensible; one of the smallest hydrozoa known. Psammohydra

Genus Boreohydra Westblad, 1937

Hydroid: hydrocaulus covered by a detritus agglutinated sheath which may bear rhizoids; hydranth club-shaped, with one oral whorl of 3 to 4 
short capitate tentacles and numerous cnidocyst warts; gonophores as fixed sporosacs, resembling cryptomedusoids, which may be developing asexual polyp buds seated singly on lower part of hydranth; eggs occurring singly in ectoderm at border between hydranth and hydrocaulus, asexual reproduction through transverse fission.

Boreohydra simplex Westblad, 1937

(Fig. 47J)

See definition of the genus.

Records from Mediterranean: Adriatic?

Seasonality: ?

Distribution: Bipolar Atlantic, Mediterranean?

References: Thiel (1988); Petersen (1990) ; Schuchert (2001a)

\section{Genus Psammohydra Schulz, 1950}

Solitary mesopsammic hydroids with 3 to 5 non capitate tentacles in one circlet in the middle of the body; with adherent elements around its extensile mouth used during caterpillar-like movements. Sexual reproduction unknown, asexual reproduction by fission.

Remarks: Psammohydra has been seldom observed, it is one of the smallest known hydroid, measuring 250 to $400 \mu \mathrm{m}$; sometimes considered as incertae sedis it is here included in the Boreomedusae because its cnidome (desmonemes, atrichous isorhizas and stenoteles) and its unique row of tentacles (Bouillon, 1985).

\section{Psammohydra nanna Schulz, 1950}

(Fig. 47K)

See definition of the genus.

Records from Mediterranean: western Mediterranean and Adriatic.

Seasonality: ?

Distribution: western Baltic, northeastern Atlantic, Mediterranean.

References: Schulz (1950); Clausen and SalviniPlawen (1986); Thiel (1988); Petersen (1990); Avian et al. (1995).

\section{Family CANDELABRIDAE de Blainville, 1830}

Hydroid: solitary or forming pseudo-colonies; hydrocaulus short, stout, with tubular or root-like adhesive processes, with or without perisarc; hydranth elongated, cylindrical, with thickened mesoglea and endodermal villi; numerous scattered, hollow capitate tentacles, simple or compound; gonophores fixed, developing directly on hydranth or on coryniform blatostyles from aboral part of hydranth, under body tentacles.

References: Petersen (1990); Stepanjants et al., (1990); Segonzac and Vervoort (1995); Schuchert (1996, 2001a).

Genus Candelabrum de Blainville, 1830 = Myriothela Sars, 1851

Hydranth solitary, long, cylindrical with numerous densely packed, simple capitate tentacles; hydrocaulus plate- or tuber-like, with adhesive processes that end in discs covered by firm, lamellar perisarc; gonophores as fixed sporosacs borne on coryniform blastostyles developed from aboral part of hydranth; fertilized eggs borne on special tentacle-like claspers situated among blastostyles arising below the area of body tentacles; reproduction by actinula larvae.

References: Petersen (1990); Segonzac and Vervoort (1995); Schuchert (1996), Watson (1997).

\section{Candelabrum cocksii (Vigurs, 1850)} (Fig. 48A)

Hydranth 1-2 cm long, composed of foot, blastostyle region and trunk (distal part of the body). Foot large, only slightly shorter than blastostyle region, with a number of slender prolongations that attach body to substrate, basis of each prolongation with chitinous perisarcal disk; chitinous perisarc gradually extending upwards and covering whole foot, externally more or less spinous. Monoecious, blastostyles slender, with male and female gonophores and with some developing eggs attached by claspers (feeding tentacles); dispersed capitate tentacles also occur on blastostyles. There is no terminal circle of tentacles. Cnidocysts: large and small desmonemes and stenoteles.

Records from Mediterranean: no records but in the area of the Bay of Cádiz (south Spain).

Seasonality: ?

Distribution: north-eastern Atlantic, Mediterranean?.

References: Bedot (1911); Rees (1957); Manton (1940); Segonzac and Vervoort (1995); Medel (1996); Medel and López-González (1996). 
Family Cladonematidae Gegenbaur, 1857

Hydroid: colonial, stolonal or erect, with creeping stolons; stem unbranched or sparingly branched; hydranth spindle-shaped, one whorl of 4-5 solid oral capitate tentacles, with or without aboral whorl of sensory filiform tentacles; mouth with oral ectodermal mucous gland cells forming a preoral chamber; medusa buds not enclosed in perisarcal film, carried singly or in clusters at base of hydranth, distal to aboral tentacles, when these are present.

Medusa: able to walk and/or swim; with or without a thickened continuous or broken ring of cnidocysts around umbrellar margin, with or without apical chamber above manubrium; manubrium cylindrical, with or without perradial pouches; mouth either with short lips, armed or not with cnidocyst clusters, or with ramified oral tentacles; with variable number of radial canals, some branched, some simple, final number of canals entering circular canal usually corresponding to, or exceptionally exceeding, the number of marginal tentacles; marginal tentacles hollow, with some capitate branches and some adhesive branches; "gonads" either completely surrounding manubrium, on subumbrella, or in special brooding pouches; with abaxial ocelli.

References: Wedler and Larson (1986); Calder (1988); Migotto (1996); Schuchert (1996); Bouillon (1999); Bouillon and Barnett (1999); Bouillon and Boero (2000); Schierwater and Ender (2000).

\section{Key to hydroids}

1. Medusa buds in clusters or on short blastostyles at hydranth base; no aboral tentacles Eleutheria

- Medusa buds borne singly on hydranth body, immediately above aboral tentacles, or in same position when those are absent.

\section{Cladonema and Staurocladia}

\section{Key to medusae}

1. Bell high; marginal tentacles branching more than once Cladonema

- Bell flat; marginal tentacles branching only once

2. One cnidocyst knob on upper tentacular branches Eleutheria

- More than one cnidocyst knob on upper tentacular branches Staurocladia
Genus Cladonema Dujardin, 1843

Hydroid: with the characters of the family; with mostly stolonal colony; hydrocaulus occasionally branching, medusa buds borne singly on hydranth body.

Medusa: creeping and swimming; manubrium cylindrical, with perradial pouches; mouth with short lips armed with 4 to 6 cnidocyst clusters; no apical chamber above manubrium; variable number of radial canals, some branched, some simple, final number of canals entering circular canal usually of same number as marginal tentacles; "gonads" completely surrounding manubrium; variable number of hollow branching marginal tentacles, each with 1 to 6 branches ending in an organ of adhesion and 1 to 10 branches with clusters of cnidocysts; with ocelli.

References: Petersen (1990); Wedler and Larson (1986); Calder (1988); Schuchert (1996); Bouillon (1995a; 1999); Bouillon and Barnett (1999); Bouillon and Boero (2000); Schierwater and Ender (2000).

Cladonema radiatum Dujardin, 1843

(Fig. 48B-D)

Hydroid: slender, simple or slightly branching colonies arising from creeping ramified stolons; perisarc smooth terminating shortly below hydranth; hydrocaulus with terminal hydranths; hydranths clavate, with a rounded hypostome, with an oral whorl of 4-5 capitate tentacles and a basal whorl of 4-5 aboral filiform tentacles alternating with capitate tentacles and with a slight terminal swelling; apical ectoderm of hypostome presenting a well developed glandular peri-oral cavity; medusa buds borne naked, singly on hydranth just above filiform tentacles.

Medusa: umbrella when full grown about $4 \mathrm{~mm}$ high, $3 \mathrm{~mm}$ wide, bell-shaped, slightly higher than broad, mesoglea moderately thin, sometimes with a slight apical projection; velum rather broad; manubrium spindle-shaped, not extending beyond umbrella margin, with usually five, sometimes four, perradial pouch-like outgrowths in its middle region; mouth with usually five, sometimes four, short protuberances or lobes, each armed with cnidocyst clusters; usually five, sometimes four, thin primary radial canals some of which bifurcate to form ten, sometimes eight, radial canals in all; circular canal narrow; «gonads» on the upper twothirds of manubrium and on the perradial pouches; 
usually ten, sometimes eight, marginal tentacles, corresponding to the number of radial canals; marginal tentacles branched, with elongated thickened bases from the under side of which grow one to four (up to10) short tentacles with adhesive organs; the branched upper portions of the marginal tentacles are beset with numerous cnidocyst clusters; with a black or deep crimson abaxial ocellus at the base of each marginal tentacle; colour of manubrium and marginal tentacles red, bright-red or brown.

Records from Mediterranean: eastern and western Mediterranean; Adriatic Sea; Black Sea.

Known seasonality: 5-8.

Distribution: Atlantic; Indo-Pacific; Mediterranean.

References: Allman (1872); Kramp (1961); Bouillon (1966, 1968b); Berhaut (1970); Bodo (1970); Bouillon and Houvenhaghel (1970); Brinckmann-Voss (1970; 1987); Goy (1973b); Bouillon and Nielsen (1974); Calder (1988); Boero and Bouillon (1993); Avian et al. (1995); Benovic and Lucic (1996); Medel and López-González (1996).

\section{Genus Eleutheria Quatrefages, 1842}

Hydroid: with the characters of the family, but with oral tentacles only and medusa buds borne in clusters or on short blastostyles at base of hydranth.

Medusa: umbrellar margin with a thickened cnidocyst ring; with brood pouch above manubrium; manubrium simple; mouth, simple circular; "gonads" reduced, hermaphroditic; tentacles bifurcated, lower branch with adhesive disk, upper branch with only one terminal cnidocyst cluster; asexual reproduction by budding from circular canal either from subumbrellar side (E. claparedei) or from exumbrellar side (E. dichotoma); with ocelli.

1. 6 radial canals, 5-14 marginal tentacles; medusabuds exumbrellar; brood pouch present

E. dichotoma

- 4-6 radial canals, 8-10 marginal tentacles; medusa-buds subumbrellar; brood pouch absent E. claparedei

Eleutheria claparedei Hartlaub, 1889 (Figs. 48E-F)

Hydroid: similar to E. dichotoma polyp, see below, seldom founded in field and mainly known from polyps raised from planulae.

Medusa: umbrella $0.4 \mathrm{~mm}$ high, $0.5 \mathrm{~mm}$ wide; flatter than hemispherical; with a thick marginal cnidocyst ring; manubrium cylindrical to conical extending slightly beyond umbrella margin, with 46 radial canals; «gonads» in specialized umbrellar brood pouches situated above manubrium; medusa buds from subumbrellar side of ring canal into umbrella cavity; 8-10 solid marginal tentacles not corresponding to the radial canals; marginal tentacles bifurcate, one branch with adhesive disk, the other with a cnidocyst knob; one abaxial ocelli on each tentacular base.

Records from Mediterranean: western Mediterranean.

Known seasonality: 6.

Distribution: Atlantic; Mediterranean.

References: Kramp (1961); Brinckmann-Voss (1970); Boero and Bouillon (1993).

\section{Eleutheria dichotoma Quatrefages, 1842 (Figs. 48G-H)}

Hydroid: colonies small, with a creeping hydrorhiza, unbranched or slightly branched; perisarc smooth delicate, extending to base of hydranth; hydranth sessile or with rudimental hydrocaulus, solitary; cylindrical, very extensile, with large rounded-conical hypostome; with a oral whorl of up to 10 capitate tentacles; apical endoderm of hypostome presenting a glandular peri-oral cavity; medusa buds naked borne in clusters or on short stalks near base of the hydranth.

Medusa: umbrella $0.3 \mathrm{~mm}$ high, $0.5 \mathrm{~mm}$ wide, flatter than hemispherical; with a thick marginal cnidocyst ring; manubrium cylindrical to conical extending slightly beyond umbrella margin; with usually six radial canals; «gonads» in specialised umbrellar brood pouches situated above manubrium; medusa buds on exumbrellar side of circular canal; up to 14 solid marginal tentacles, usually 5-6, not corresponding to the radial canals; tentacles bifurcated, lower, unarmed, branch with an adhesive disk, the upper with a single cnidocyst knob; one abaxial ocelli on each tentacular base.

Records from Mediterranean: eastern and western Mediterranean; Adriatic Sea; Black Sea.

Known seasonality: 3-10.

Distribution: Atlantic; Mediterranean.

References: Kramp (1961); Brinckmann-Voss (1970, 1987); Goy (1973b); Bouillon (1966, 1968 a, b); Boero and Bouillon (1993); Avian et al. (1995); Benovic and Lucic (1996); Medel and LópezGonzález (1996). 
Genus Staurocladia Hartlaub, 1917

Hydroid: hydranths with an oral whorl of capitate tentacles and with or without aboral filiform tentacles.

Medusa: Cladonematidae adapted for crawling and walking; without brood pouch above manubrium; «gonads» around manubrium or developed in ectodermal manubrial pockets; with 6-11 radial canals some bifurcating shortly distal to manubrium; mouth circular with or without cnidocysts knobs; with up to 60 marginal tentacles, dichotomous, upper branch with several cnidocyst clusters, lower with adhesive organ; with ocelli; often asexual reproduction by medusa budding or by fission.

Staurocladia portmanni Brinckmann, 1964a (Figs. 48I-J)

Hydroid: small stolonal colonies covered with perisarc extending till base of the hydranths; hydranths borne on short non branching hydrocauli arising directly from hydrorhiza; hydranths spindle shaped to cylindrical, with rounded-conical hypostome, with 3-4 oral capitate tentacles and an aboral whorl of always six filiform tentacles; apical ectoderm of hypostome presenting a well developed glandular peri-oral cavity; medusa buds naked, one or more seldom two just above aboral tentacles.

Medusa: umbrella up to 4-6 mm wide, and 2.5$5 \mathrm{~mm}$ high; flat bell-shaped; with a thick cnidocyst ring on the margin of exumbrella; manubrium pear-shaped almost filling subumbrellar cavity, with 5 interradial manubrial pouches, manubrium not extending beyond subumbrellar margin; mouth with five lip-like protuberances armed with cnidocysts; five radial canals originating near the upper centre of manubrium and remaining attached to its roof for some distance, generally bifurcating when becoming free so that up to 10 radial canals are joining the circular canal; proximal part of radial canals giving off endodermal finger-like expansions to exumbrella; with up to 25 marginal tentacles bifurcating at some distance of origin in an upper (aboral) and a lower (oral) branch; the main stem of the tentacles bear two opposite lateral cnidocyst knobs immediately proximally to the ramification of the tentacles, upper branch ending in a terminal cluster of cnidocysts and bearing two to five cnidocyst knobs on its aboral side and alternating with them, two to four knobs on its oral side; the lower tentacular branch terminates in a adhesive suckerlike organ; the «gonads» surrounding completely the manubrium and manubrial pouches; each tentacles with an abaxial ocelli.

Records from Mediterranean: western Mediterranean.

Known seasonality: 5-7.

Distribution: endemic of Mediterranean Sea.

References: Brinckmann (1964a); BrinckmannVoss (1970); Bouillon (1966, 1978a); Boero and Bouillon (1993).

\section{Family CORIMORPHIDAE Allman, 1872}

Hydroid: solitary, hydrocaulus long, distally pointed or rounded, hollow or more or less filled by parenchymatic endoderm; lower part with short papillae or/and longer anchoring didermic filaments; either with one whorl of moniliform or capitate oral tentacles or several whorls of filiform oral tentacles; one to 3 whorls of moniliform or filiform aboral tentacles; gonophores as free medusae or fixed sporosacs.

Medusa: dome shaped or with pointed apex; manubrium not extending beyond umbrella margin (except in Yakovia but this is presumably an artifact due to fixation), sausage-shaped or exceptionally with sac-like processes; mouth, simple circular; 1- 4 capitate or moniliform marginal tentacles, of different size and structure, exceptionally branched, and rudimentary tentacles; "gonads" undivided surrounding all length of manubrium and exceptionally also in sac-like processes of manubrium (Gotoea).

References: Kramp (1949); Calder (1988); Petersen (1990); Pagès, Gili and Bouillon (1992); Schuchert (1996); Bouillon (1999); Bouillon and Barnett (1999); Bouillon and Boero (2000).

\section{Key to hydroids}

1. Hydranth bilaterally symmetrical, with two sets of filiform tentacles, gonophores as fixed sporosacs. Branchiocerianthus

- Hydranth radially symmetrical.. 2

2. Hydranth with filiform tentacles only Corymorpha

- Hydranth with all tentacles not filiform........... 3

3. Hydranth with numerous oral capitate tentacles in irregular whorls. Euphysora

- Hydranth with moniliform oral tentacles .... Vannucia 


\section{Key to medusa}

1. With only 1 marginal tentacle 2

- With 3 short or rudimentary marginal tentacles and 1 long principal marginal tentacles different in structure Euphysora

2. Exumbrella divided 4 prominent leaf-shaped facets separated by 4 longitudinal large and deep grooves..... Eugotea

- Exumbrella with uniform surface .... 3

3. Umbrella margin slightly oblique to vertical axis, umbrella with no apical process; principal marginal tentacle, short and thick, ending in long and large, oval, ectodermal swelling containing numerous cnidocysts. Vannuccia.

- Umbrella margin at right angles to vertical axis, principal marginal tentacles different. ... 4

4. Principal marginal tentacle, slender, long, moniliform; umbrella with pointed apical process. Corymorpha

- Principal marginal tentacle with one large terminal cnidocysts knob; umbrella without pointed apical process Paragotoea

Genus Branchiocerianthus Mark, 1898

Hydroid: paedomorphic hydrozoa reduced to hydroid stage, hydranth in some species very large over $2 \mathrm{~m}$, bilaterally symmetrical and eccentrically seated on hydrocaulus; with several whorls of filifom oral tentacles and one whorl of filiform aboral tentacles, with a thin diaphragm dividing gastric cavity into oral and aboral chambers; oral chamber with unbranched radial canals between blastostyles and aboral tentacles; hydrocaulus long, with parenchymatic endoderm with longitudinal canals, rooted by anchoring filaments; perisarc rudimentary. Gonophores as fixed sporosacs borne on blastostyles arising immediately above the aboral tentacles.

References: Brinckmann-Voss (1970); Petersen (1990).

\section{Branchiocerianthus italicus Stechow, 1921}

Only one specimen found by Lo Bianco in 1909, who did not describe it or gave a name, citing only it was $10 \mathrm{~cm}$ high and had numerous tentacles. The name italicus was latter on suggested by Stechow (1921a, 1923d) for this unique specimen but without any further description or diagnoses.

Records from Mediterranean: western Mediterranean, gulf of Naples.
Known seasonality: 3.

Distribution: endemic of Mediterranean Sea.

References: Lo Bianco (1909); Brattström (1957); Brinckmann-Voss (1970).

\section{Genus Corymorpha M. Sars, $1835=$ Amalthaea Schmidt, 1852}

Hydroid: hydrocaulus with thin perisarc, parenchymatic endoderm with longitudinal peripheral canals; lower part with short papillae or/and long anchoring didermic filaments; hydranth vasiform with one or several closely set whorls of oral filiform tentacles, and one whorl of aboral filiform tentacles; parenchymatic diaphragm; free medusae or fixed gonophores.

Medusa: dome-shaped or with pointed apical process, usually with apical canal; one long moniliform tentacle and 3 non tentacular rudimentary bulbs.

Corymorpha nutans M. Sars, 1835

(Fig. 49A-C)

Hydroid: large solitary hydroid, hydrocaulus subcylindrical, somewhat narrowed upwards and downwards, basal end with short sensorial papillary projections and lower down numerous elongated rooting, anchoring, filaments; hydrocaulus filled with parenchymatic endoderm with numerous longitudinal anastomising peripheral canals; perisarc a transparent membranous tube; hydranth flaskshaped to vasiform with about 20 to 80 oral filiform contractile tentacles arranged in several irregular whorls, and 20 to 32 aboral much longer, uncontractil filiform tentacles; hydranth and distal part of hydrocaulus bend downwards; medusa buds borne in dense clusters on about 15-20 branching peduncles just above aboral tentacles; asexual reproduction by constriction of the hydrocaulus aboral end.

Medusa: umbrella up to $6 \mathrm{~mm}$ high (including apical process), about twice as high than wide, with a high, pointed apical process and a long, narrow umbilical canal, mesoglea thick; velum fairly wide; manubrium large, cylindrical, on short gastric peduncle, about $2 / 3$ of the length of subumbrella, in full extension reaching slightly beyond exumbrellar margin; mouth simple, tube-like armed with cnidocysts; 4 radial canals and circular canal fairly broad; «gonads» completely surrounding manubrium but living peduncle and mouth free; one single long marginal tentacle, moniliform; 3 perradial non ten- 
tacular bulbs smaller than the tentacular one; with resting eggs.

Records from Mediterranean: western Mediterranean, Adriatic Sea; Black Sea.

Known seasonality: 1-8.

Distribution: Atlantic; Mediterranean; Black Sea.

References: Babnik (1948); Russell (1953); Kramp (1961); Berhaut (1970); Brinckmann-Voss (1970, 1987); Goy (1973b); Schmidt and Benovic (1979); Gili (1986); Benovic and Bender (1987); Boero and Bouillon (1993); Avian et al. (1995); Benovic and Lucic (1996); Medel and LópezGonzález (1996); Schuchert (2001a).

Genus Eugotoea Margulis, 1989

Corymophidae with exumbrella divided in 4 prominent leaf-shaped facets separated by 4 longitudinal large and deep grooves; with one marginal tentacle with a terminal cnidocyst knob; without marginal bulbs.

Eugotoea petalina Margulis, 1989 (Fig. 49D-F)

Medusa:umbrella $0.7 \mathrm{~mm}$ high, $0.8 \mathrm{~mm}$, wide, almost globular, mesoglea thick; exumbrella divided in 4 prominent leaf-shaped, oval, perradial facets separated by 4 longitudinal large and deep grooves, a brown pigmented spot on the aboral third of each facet; manubrium, large occupying almost whole subumbrellar cavity, extending till umbrella opening; mouth surrounded with cnidocysts; radial canals simple; gonads surrounding central part of manubrium; one perradial marginal tentacle with a terminal cnidocyst knob; no tentacular or rudimentary marginal bulbs.

Hydroid: unknown.

Records from Mediterranean: eastern Mediterranean.

Known seasonality: 2.

Distribution: endemic of Mediterranean Sea.

References: Kramp (1961); Margulis (1989); Gili et al. (1998).

Genus Euphysora Maas, 1905

Hydroid: known for E. bigelowi; hydrocaulus with thin perisarc, with cavity filled by parenchymatic endoderm with a limited number of simple peripheral endodermal canals, with anchoring rootlets; hydranth vasiform, with 35 oral tentacles set in irregular rows on hypostome, more or less distinctly capitate, with scattered cnidocyst batteries; 15-20 aboral elongated non contractile filiform tentacles; a parenchymatic diaphragm separates the hypostome from the polyp body; medusa buds in clusters on slightly branched inflated pedicels arising above aboral tentacles.

Medusa: usually with 3 short or rudimentary tentacles and one long principal tentacle that differs from others not only in size, but also in structure.

References: Huang Jiaqui (1999), Xu and Huang (2003).

\section{Key for the medusae}

1. Principal tentacle moniliform, the three others cone-shaped E. annulata

- Principal tentacle with a single row of adaxial cnidocysts knobs E. bigelowi

Euphysora annulata Kramp, 1928 (Fig. 49G)

Medusa: umbrella $2 \mathrm{~mm}$ high, $1.4 \mathrm{~mm}$ wide, barrel-shaped, with thin mesoglea, with a pointed apex, with a conspicuous umbilical canal; manubrium wide, as long as umbrellar cavity; principal marginal tentacle long, moniliform; the three other perradial tentacles short, cone-shaped, the one opposite the main tentacle the longest.

Records from Mediterranean: eastern Mediterranean; Adriatic Sea.

Known seasonality: 11.

Distribution: Indo-Pacific; Mediterranean.

References: Schmidt (1973); Schmidt and Benovic (1977; 1979); Xu and Huang (2003).

Hydroid: unknown.

Euphysora bigelowi Maas, 1905

(Figs. 49H-I)

Hydroid: only known from rearing. Hydranths solitary; borne on a long, stout, hydrocaulus enclosed in a thin membranous perisarc which is attached to an annular ring of thickened basal ectoderm slightly below hydranth base; hydrocaulus cavity filled by parenchymatic endoderm with a limited number of simple peripheral endodermal canals, presenting papillae in its aboral third and more aborally numerous anchoring rootlets; hydranths vasiform, with 35 oral more or less distinctly capitate 
tentacles set in irregular rows on hypostome; with 15-20 aboral elongated non contractile filiform tentacles; a parenchymatic diaphragm separates the hypostome from the polyp body; medusa buds borne in clusters on slightly branched inflated pedicels arising above aboral tentacles; asexual reproduction by basal constriction of hydrocaulus.

Medusa: umbrella up to $13 \mathrm{~mm}$ high, with a large conical apex at the end of which is a collection of small papillae; with or without an apical canal which is mainly developed in non completely mature specimens; manubrium cylindrical, $2 / 3$ to as long as umbrellar cavity; mouth circular; principal marginal tentacle long, with several large cnidocysts knobs in unilateral, adaxial position and a distinct terminal knob, the three other perradial bulbs each with a short, pointed tentacle variable in length and without cnidocysts clusters.

Records from Mediterranean: eastern Mediterranean.

Known seasonality: 2.

Distribution: Indo-Pacific; Mediterranean.

References: Kramp (1961); Schmidt (1973), 1976; Sassaman and Rees (1978); Xu and Huang (2003).

\section{Genus Paragotoea Kramp, 1942 (after Kramp} (1961), not Ralph, 1959)

Corymorphidae without exumbrellar cnidocyst tracks; with 4 radial canals, without gastric pouches; with circular mouth; with 1 well-developed solid tentacle terminating in large knob of cnidocysts and 3 very large marginal bulbs without tentacles.

Paragotoea bathybia Kramp, 1942 (Fig. 49J)

Medusa: umbrella up to $1.6 \mathrm{~mm}$ wide, $2 \mathrm{~mm}$ high, square or rectangular, with thin exumbrellar walls, with conical apex containing refractive droplets; scattered cnidocysts on exumbrella; manubrium broadly flask-shaped to globular, extending from half subumbrellar cavity to umbrella margin, proximal part vacuolated, distal part sexual; mouth circular, rim with cnidocysts; 4 conspicuous radial canals enlarged distally, with large endodermal cells and narrow light; 4 very large prominent marginal bulbs, 1 tentacular, 3 non tentacular similar, each with an ectodermal abaxial spur; 1 stiff tapering marginal tentacle, proximal part hollow, distal part solid with very thick mesoglea, with large terminal knob of cnidocysts; gonads first interradial, in the distal half of the manubrium, encircling slowly manubrium with age.

Hydroid: unknown.

Records from Mediterranean: western Mediterranean.

Known seasonality: 5; 7; 9; 10.

Distribution: Atlantic; Antarctic; Arctic; Mediterranean.

References: Kramp (1942, 1961); Ralph (1959); Brinckmann-Voss (1970, 1987); Goy (1973b, 1983, 1997); Dallot, Goy and Carré (1988); Margulis (1989); Pagès and Bouillon (1997); Stepanjants et al. (1997); Brinckmann-Voss and Arai (1998).

Remarks: After Brinckman-Voss and Arai (1998) the specimens described from the Mediterranean by Brinckmann-Voss (1970, 1987); Goy (1971, 1973b); Dallot, Goy and Carré (1988) should not belong to Paragotoea bathybia.

$$
\begin{gathered}
\text { Genus Vannuccia } \text { Brinckmann-Voss, } 1967 \\
=\text { Altairina } \text { Vargas-Hernández } \\
\text { and Ochoa-Figueroa, } 1991
\end{gathered}
$$

Hydroid: hydrocaulus long, cylindrical, slightly enlarged at its two extremities, aboral third with papillae and, more aborally, numerous rooting anchoring filaments; filled with parenchymatic endodermal cells presenting numerous peripheral longitudinal canals; surrounded by a flexible perisarc extending slightly below hydranth; hydranth vasiform, 12-14 oral moniliform tentacles with 4-6 cnidocyst clusters, 16 to 20 long aboral filiform tentacles with a more or less developed terminal swelling; parenchymatic diaphragm; medusa buds naked, in clusters on short blastostyles above aboral whorl of tentacles; asexual reproduction by transverse constriction of the basal part of the hydrocaulus.

Medusa: bell margin usually slightly asymmetrical, with or without apical process; no exumbrellar cnidocyst tracks; marginal bulbs small, simple; 1 swollen marginal tentacle, hollow for half its length and ending in long, large, oval to cylindrical swelling armed with cnidocysts.

References: Vargas-Hernandez and OchoaFigueroa, 1991.

Vannuccia forbesii (Mayer, 1894) (Figs. 49K-L)

Hydroid: solitary, hydrocaulus long cylindrical, slightly enlarged at its two extremities, aboral third 
of hydrocaulus with papillae and, more aborally numerous rooting anchoring filaments; hydrocaulus filled with parenchymatic endodermal cells presenting numerous peripheral longitudinal canals; hydrocaulus surrounded by a flexible perisarc extending slightly below hydranth; hydranth vasiform, with 12-14 oral moniliform tentacles carrying 4-6 cnidocysts clusters, with 16 to 20 very long aboral filiform tentacles with a more or less developed terminal swelling; with a parenchymatic diaphragm; medusa buds borne naked in clusters on short blastostyles just above aboral whorl of tentacles; asexual reproduction by transverse constriction of the basal part of the hydrocaulus.

Medusa: umbrella $3 \mathrm{~mm}$ high, bell-shaped, ellipsoidal, with slightly asymmetrical margin; mesoglea evenly thin, without apical process or apical canal; without exumbrellar tracks of cnidocysts; manubrium cylindrical, length half to two-thirds of umbrella height; «gonads» encircling manubrium for almost all its length; 4 narrow radial canals and circular canal; one voluminous marginal tentacle at the base of the longest radial canal, hollow for half its length, ending in long, large, oval cnidocyst swelling; three marginal bulbs the one opposite the tentacle larger than the other ones.

Records from Mediterranean: western Mediterranean, medusae raised from hydroids.

Known seasonality: 9-2.

Distribution: Atlantic; Indo-Pacific; Mediterranean.

References: Kramp (1961); Brinckmann-Voss (1967, 1970).

\section{Family CORYNIDAE Johnston, 1836}

Hydroid: branched or unbranched, monophormic colonies rising from a creeping stolon or encrusted base; hydranths with an oral whorl of capitate tentacles and often more capitate tentacles below, in whorls or scattered; sometimes filiform tentacles (specialised sense organs) below capitate ones; gonophores usually on polyps, either as sessile sporosacs, eumedusoids or free medusae. Cnidome where known : stenoteles with or without isorhizas or mastigophores.

Medusa: umbrella bell-shaped; with or without apical chamber; no cnidocyst tracks; manubrium tubular; mouth simple, circular; 4 radial canals and circular canal; with four tentacular bulbs with gastrodermal chamber and 2-4 hollow equally developed marginal tentacles; "gonads" encircling manubrium completely, in one or more rings; mostly with abaxial ocelli. Cnidome where known: as in hydroids but additionally with desmonemes.

References: Wedler and Larson (1986); Calder (1988); Brinckmann-Voss (1989); Petersen (1990); Kubota and Takashima (1992); Pagès et al. (1992); Migotto (1996); Schuchert (1996, 2001b); Bouillon (1999); Bouillon and Barnett (1999); Bouillon and Boero (2000).

\section{Key to hydroids}

1. Distinct button of ectodermal mucous gland cells around mouth; gonophores as free medusae; polyps often associated with sponges Dipurena

- No distinct button of ectodermal mucous gland cells around mouth 2

2. Gonophores develop either in the upper axil of the lower capitate tentacles or amongst the lower whorl. Coryne

- Gonophores develop below capitate tentacles and over filiform tentacles Sarsia

\section{Key to medusae}

1. "Gonads" divided in two or more rings (except Dipurena gemmifera) Dipurena

- "Gonads" not interrupted, undivided ............... 2

2. Adult medusae with manubrium extending beyond umbrella margin, with a thin proximal part. Sarsia

- Adult medusae with manubrium not extending beyond umbrella margin, without thin proximal part Coryne

Genus Coryne Gaetner, 1774

= Syncoryna Ehrenberg, 1834; Staurocoryne

Rotch, 1872; Actigia Stechow, 1921

Hydroid: colony stolonal or erect, branching; hydranth with an oral whorl of capitate tentacles and with or without capitate tentacles either scattered or in at least three whorls below oral one, with or without filiform tentacles; hypostome without distinct button of ectodermal mucous gland cells; gonophores as free medusae or fixed sporosacs developing singly or in couples, on short pedicels either in the upper axil of the lower capitate tentacles or amongst the lower whorl.

Medusa: adult medusae with manubrium not extending beyond umbrella margin and without thin 
proximal part; marginal bulbs without adaxial cnidocyst pads; "gonads" undivided.

References: Brinckmann-Voss (1989, 2000); Petersen, (1990); Kubota and Takashima (1992); Pagès et al. (1992); Schuchert, (1996, 2001b); Brinckmann-Voss and Arai (1998).

\section{Key to hydroids}

In the Mediterranean the hydroids of the genus Coryne are difficult to differentiate from each other, the characters often being variable and overlapping.

1. Gonophores non-axillary C. producta

- Gonophores axillary 2

2. With filiform tentacles, colonies 1 to $2 \mathrm{~cm}$ in height. C. pintneri.*

- Without filiform tentacles 3

3. Colonies large $5-15 \mathrm{~cm}$ 4

- Colony small up to $3 \mathrm{~cm}$, bushy, number of tentacles 18-28, annulations of branches irregular and broad C. pusilla**

4. Colonies broad elongate; number of tentacles 16 to 22 ; annulations of branches in narrow rings... C. muscoides.**

- Colonies often forming tufts; number of tentacles up to 35 ; perisarc of branches smooth with some annulations stretches C. eximia

*Filiform tentacles are not always present and then the species is hardly distinguishable from smaller colonies of C. pusilla (see Schuchert, 2001b).

**In the Mediterranean populations resembling $C$. muscoides or $C$. pusilla pose considerable difficulties by showing all possible forms between the forms found in the Atlantic. (Schuchert, 2001b).

\section{Key to medusae}

1. Medusa usually with an apical chamber; umbrella up to $10 \mathrm{~mm}$ C. producta

- Medusa without apical chamber ....................... 2

2. Medusa without medusa budding ....... C. eximia

- Medusa presenting medusa budding on tentacle bulbs C. prolifera

Coryne eximia Allman, 1859 (Fig. 50A-D)

Hydroid: colonies 1-5 cm arising from creeping ramified hydrorhiza, stolonal or erected; erected colonies profusely and irregularly branched often forming tufts, final hydrocauli with a tendency to unilateral arrangement; perisarc of hydrocaulus terminating as a very delicate layer or sometimes in a basal cup at the base of the hydranth, perisarc mainly smooth but ringed at base of hydrocauli and hydrocladia; hydranth cylindrical to spindle shaped, with conical-rounded hypostome, with a oral whorl of 4-5 capitate tentacles and 20-35 capitate tentacles scattered or in indistinct whorl over the body of hydranth; medusa buds borne on single pedicels in upper axils of tentacles of lower tentacles

Medusa: umbrella 3-4 mm in height, a little higher than wide, bell-shaped to cylindrical, mesoglea thicker at the apex; manubrium cylindrical, in full extension about as long as subumbrellar cavity, without apical chamber; mouth simple circular; manubrium almost entirely surrounded by «gonads», eggs few and large; 4 simple moderately broad radial canals, circular canal narrower, radial canals entering marginal bulbs adaxially; 4 marginal tentacles fairly extendible, proximal part smooth otherwise beset with numerous clasping cnidocysts clusters in indistinct spiral and a terminal cluster.

Records from Mediterranean: eastern and western Mediterranean. The Mediterranean occurrence of this species seems to need re-confirmation (Schuchert, 2001b).

Known seasonality: 3-6.

Distribution: Atlantic, Indo-Pacific, Arctic, Mediterranean.

References: Russell (1953); Kramp (1957b, 1961); Brinckmann-Voss (1970, 1989); Goy (1973b); Petersen (1990); Goy et al. (1988, 1990, 1991); Kubota and Takashima (1992); Pagès et al. (1992); Boero and Bouillon (1993); Avian et al. (1995); Medel and López-González (1996); Schuchert (1996, 2001b).

Coryne muscoides (Linnaeus, 1761) (Fig. 50E-F)

Colonies with elongated shoots, up to $15 \mathrm{~cm}$ in height, dichotomously or irregularly branched; perisarc brown in old colonies to almost transparent in young ones, always annulated throughout with narrow rings, usually extending up to the aboral tentacles of the hydranth in a funnel-shaped; polyp pink, hydranth with 16 to 22 capitate tentacles, arranged in an oral whorl of 4-6 tentacles and lower tentacles scattered or in three to four indistinct whorls, the single tentacles of successive whorls alternate in their position. Gonophores fixed 
sporosacs, borne in the upper axil of lower tentacles. Cnidocysts: Stenoteles and desmonemes.

Records from the Mediterranean: western Mediterranean (Italy, France, Spain).

Known seasonality: 1-12.

Distribution: north-eastern Atlantic, Mediterranean.

References: Mammen (1963); Brinckmann-Voss (1970); Patriti (1970); Boero and Bouillon (1993); Altuna (1994); Medel (1996); Medel and LópezGonzález (1996); Schuchert (2001b); Peña Cantero and García Carrascosa (2002).

\section{Coryne pintneri Schneider, 1898} (Figs. 51A-B)

Colonies mostly stolonal occasionally sparingly branched with two hydranths, rarely with up to five side branches; up to $2 \mathrm{~cm}$ in height; perisarc not thick, yellowish, feebly annulated to smooth, frequently 2 or 3 annulations separated by smooth intervals. Hydranths with 15-21 capitate tentacles either scattered or in 4-5 whorls, below them a whorl of 2-6 short filiform tentacles which are often absent, but always present in regenerating hydranths. Gonophores fixed sporosacs, borne in two whorls in upper axil of tentacles in middle of hydranth body.

Known seasonality: 11.

Records from Mediterranean: western Mediterranean (Italy), Adriatic.

Distribution: endemic of Mediterranean Sea.

References: Brinckmann-Voss (1970); Boero and Fresi (1986); Boero and Bouillon (1993); Avian et al. (1995); Schuchert (2001b).

\section{Coryne producta (Wright, 1858)}

(Figs. 51C-D)

Hydroid: colonies stolonal, with creeping hydrorhiza formed by a network or ramified stolons; hydrocaulus short, simple or rarely slightly and irregularly branched; perisarc smooth; hydranth elongated, larger distally, up to $1.5 \mathrm{~mm}$ in height; hypostome dome-shaped, short; hydranth with one whorl of 4-6 oral tentacles, 1-4 alternating whorls of capitate tentacles with 3-6 tentacles per whorl, the uppermost row larger than the rest; with a single aboral whorl of 3-6 filiform tentacles; medusa buds borne among or below the lowest whorl of capitate tentacles.

Medusa: umbrella up to $7 \mathrm{~mm}$ wide, $10 \mathrm{~mm}$ high, bell-shaped, with thick walls, manubrium cylindrical almost as long as bell cavity, with a distinct conical apical chamber with vestiges of umbilical canal; mouth simple, tubular; «gonads» completely surrounding manubrium; radial canals entering endodermal chamber of bulbs in middle; 4 long perradial marginal tentacles with many crescent-shaped cnidocyst clusters a small cylindrical terminal cnidocyst knob; with large marginal bulbs each with an ocellus.

Records from Mediterranean: eastern and western Mediterranean; Adriatic.

Known seasonality: 3-11.

Distribution: Atlantic; Mediterranean.

References: Kramp (1961); Brinckmann-Voss (1970); Benovic (1973); Altuna (1993a); Boero et al. (1993); Avian et al. (1995); Benovic and Lucic (1996); Medel and López-González (1996); Schuchert (2001b).

Coryne prolifera (Forbes, 1848) (Figs. 51E-G)

Medusa: umbrella about $3 \mathrm{~mm}$ high and wide, bell-shaped, walls fairly thin, umbrella margin quadratic; manubrium small, almost cylindrical, about 2/3 as long as umbrella cavity; «gonads» surrounding almost whole length of manubrium living only both ends free; marginal tentacular bulbs large and tapering, with clusters of cnidocysts; medusa budding from the marginal tentacle bulbs.

Records from Mediterranean: western Mediterranean; Black Sea.

Known seasonality: 5.

Distribution: Atlantic; Mediterranean.

References: Kramp (1961); Goy (1973b); Boero and Bouillon (1993); Schuchert (2001b).

Hydroid: unknown.

Coryne pusilla Gaertner, 1774 (Figs. 51H-I)

Colonies erect, branching several times, up to 3 $\mathrm{cm}$ in height; colonies shape rather broad an bushy, perisarc brown, annulated throughout, annulations of branches irregular and broad; hydranth red brown with white dots, spindle shaped, with a conical proboscis, sometimes with a perisarcal funnel like dilatation; about 18-28 tentacles, all capitate, in an oral whorl of 4-5 tentacles and scattered lower tentacles. Gonophores fixed sporosacs, borne in upper axil of the tentacles along lower $1 / 2$ to $2 / 3$ of hydranth. 
Known seasonality: 1-12.

Records from Mediterranean: western and eastern Mediterranean (Spain, France, Italy, Croatia, Greece).

Distribution: north-eastern Atlantic; doubtful records from Indian Ocean and Pacific, Mediterranean.

References: Brinckmann-Voss (1970); Millard (1975); Boero (1981); Boero and Fresi (1986); Gili (1986); Boero and Bouillon (1993); Altuna (1994); Avian et al. (1995); Medel and López-González (1996); Schuchert (2001b).

Coryne epizoica Stechow, 1921

(Fig. 51J)

Colonies with creeping hydrorhiza giving rise stems up to $3 \mathrm{~mm}$ high; perisarc brown, annulated throughout. Hydranth with capitate tentacles which are usually scattered but show a tendency towards arrangement in whorls. Gonophores fixed sporosacs, borne in groups, 1-5 on the upper part of the stem. Cnidocysts: Stenoteles and desmonemes.

Records from Mediterranean: western Mediterranean (Italy, France), record doubtful in Trieste.

Distribution: endemic of Mediterranean Sea.

References: Brinckmann-Voss (1970); Boero and Bouillon (1993); Avian et al. (1995); Schuchert (2001b).

Incertae sedis (mature gonophore unknown)

Coryne caespes Allman, 1871

Hydrorhiza composed by a creeping entangled mass of tortuous tubes, giving rise hydrocauli closely set, unbranched or scarcely branched; perisarc irregularly annulated. Hydranth elongated, with about 25 tentacles. Gonophores fixed sporosacs, borne on short peduncles from the axils of the tentacles.

Records from Mediterranean: Gulf of La Spezia (Italy).

Distribution: endemic of Mediterranean Sea.

Reproduction: ?

References: Brinckmann-Voss (1970); Boero and Bouillon (1993); Schuchert (2001b).

\section{Coryne fucicola (de Filippi, 1866)}

(Fig. 51K)

Species not described from its natural environment but from an aquarium. Picard (1958) consid- ered Coryne fucicola synonymous with Coryne pintneri Schneider, 1897; the only difference with $C$. pintneri is the size and numbers of tentacles and the absence of filiform tentacles. Brinckmann-Voss does not agree and considers that it is a valid species difficult to identify due to the absence of knowledge from its natural environment.

Diagnosis: Colonies up to $40 \mathrm{~mm}$ high; stem erect, simply branched; stem and hydrorhiza enclosed in a thin perisarc; hydranth with numerous capitate tentacles, scattered and distant from each other; hydranth body pink, tentacles white. Gonophores fixed sporosacs developing between the tentacles.

Records from Mediterranean: western Mediterranean (Italy, France).

Distribution: endemic of Mediterranean Sea.

References: Brinckmann-Voss (1970); Schuchert (2001b).

\section{Genus Dipurena McCrady, 1859}

Hydroid: colony stolonal, creeping, rarely with branching stems; often associated with sponges; hydranth with one whorl or several whorls of capitate tentacles all over body, either scattered or in more or less distinct whorls, sometimes with a whorl of filiform tentacles beneath capitate ones; hypostome with a conspicuous button of high ectodermal gland cells; gonophores giving rise to free medusae usually in clusters, on short pedicels or blastostyle.

Medusa: with 4 similar perradial tentacles; marginal bulbs without adaxial cnidocyst pads; with or without linear swellings on radial canals; "gonads" divided in two or more rings around manubrium (except D. gemmifera) ; endoderm of sexual parts digestive, endoderm of non sexual parts chordal; manubrium usually extending well beyond umbrellar margin; with ocelli.

References: Petersen (1990); Pagès et al. (1992); Schuchert (1996, 2001b).

\section{Key to hydroids}

1. One whorl of oral capitate tentacles and one whorl of aboral filiform tentacles .......... D.reesi

- Several whorls or scattered capitate tentacles below oral tentacles; filiform tentacles present or absent

2. Perisarc enclosing hydrocaulus halfway of its length D. halterata

- Perisarc wide into which basal part of hydranth can retract. 


\section{Key to medusae}

1. Medusa presenting medusa budding along manubrium, gonads only on the distal swollen part of manubrium D. gemmifera

- Medusa not presenting medusa buds along manubrium, gonads in two or more cylinders around manubrium 2

2. Marginal tentacles with well developed terminal knob of cnidocysts and several cnidocyst rings.. D. halterata

- Marginal tentacles with irregularly distributed cnidocyst clusters and a small terminal knob .. 3

3. Dome shaped umbrella; maximum high $5 \mathrm{~mm}$; manubrium in full extension 3 times length of umbrella; with oval to elongate apical chamber; «gonads» in 2-9 segments ....... D. ophiogaster*

- Triangular-shaped umbrella; maximum size 4 $\mathrm{mm}$; manubrium in full extension 2 times length of umbrella; with globular apical chamber;

«gonads» in 2 segments D. reesi*

The medusa of Dipurena ophiogaster and D. reesi are rather similar making many of their records questionable, but their hydroids are quite different.

A forth species of Dipurena was described from the Mediterranean by Haeckel, 1864, Dipurena doligogaster, but it is most similar to Dipurena ophiogaster and the two species are considered conspecific by most of the authors (see Russell, 1953; Kramp, 1961; Brinckmann-Voss, 1970, Schuchert, 2001b).

Dipurena gemmifera (Forbes, 1848) (Fig. 52A)

Medusa: umbrella up to $5 \mathrm{~mm}$ high, bell-shaped, more or less pyriform; mesoglea moderately thick; with short apical chamber; manubrium very long and thin, two times as long as umbrella height, composed of a thin proximal, long serpentine non digestive part and a swollen distal digestive part; mouth simple circular; «gonads» around distal swollen end of manubrium; medusa buds at intervals along the serpentine part of manubrium above oral dilatation; marginal tentacles short with small marginal bulbs, with irregularly, transverse, clasps of cnidocysts and a distinct terminal cnidocyst knob.

Records from Mediterranean: eastern and western Mediterranean; Adriatic.

Known seasonality: 1; 9-12.

Distribution: Atlantic; Mediterranean.
References: Picard (1960a); Kramp (1961); Berhaut (1970); Brinckmann-Voss (1970, 1987); Goy (1973b); Benovic (1973); Schmidt and Benovic (1979); Castelló i Tortella (1986); Gili (1986); Benovic and Bender (1987); Goy et al. (1988, 1990, 1991); Petersen (1990); Boero and Bouillon (1993); Avian et al. (1995); Benovic and Lucic (1996); Medel and López-González (1996); Schuchert (2001b).

Remarks: After Hartlaub (1907) there may possibly be two or more ring-like «gonads». Picard (1960a) described the polyp stage, but obtained only the newly released medusae and his identification is somewhat doubtful and needs reconfirmation (see Schuchert 2001b).

Dipurena halterata (Forbes, 1846)

(Figs. 52B-E)

Hydroid: colonies stolonal, simple unbranched, with hydrorhiza embedded in sponges, only the most distal part of the hydrocaulus and the hydranth emerging; perisarc smooth enclosing hydrocaulus halfway of its length; hydranth clavate to cylindrical with rounded hypostome, ectoderm of hypostome differentiating a well developed button of mucous gland cells, up to 24 identical capitate tentacles distributed in an oral whorl of 4- 5 tentacles and irregularly scattered tentacles along the body, without filiform tentacles; medusa buds borne in middle of hydranth independent of tentacles or on blatostyles (reproductive exhaustion).

Medusa: umbrella up to $6 \mathrm{~mm}$ wide, $8 \mathrm{~mm}$ high, bell shaped, with globular apical chamber; manubrium 2-3 times longer than umbrella height, with a long serpentine proximal part and a swollen distal part; mouth simple circular; ... middle part of radial canals with linear swellings; marginal tentacles of uniform diameter, smooth for most of their length, each with large terminal cnidocyst knob and 3 to 6 distinct rings of cnidocysts just above; tentacular bulbs prominent each with an abaxial ocellus; «gonads» in 2 or more rings, living upper third free.

Records from Mediterranean: eastern and western Mediterranean; Adriatic.

Known seasonality: 3; 5-10; 12.

Distribution: Atlantic; Indo- Pacific; Mediterranean.

References: Rees (1939); Babnik (1948); Kramp (1961); Berhaut (1970); Brinckmann-Voss (1970,1987); Bouillon (1971); Goy (1973b); Schmidt and Benovic (1979); Lakkis and Zeidane 
(1985); Gili (1986); Goy et al. (1988, 1990, 1991); Pagès et al. (1992); Boero and Bouillon (1993); Avian et al. (1995); Benovic and Lucic (1996); Medel and López-González (1996); Schuchert (2001b).

Dipurena ophiogaster Haeckel, 1879

(Figs. 52F-H)

Hydroid: colonies stolonal, generally unbranched or branched once, up to $4 \mathrm{~mm}$ high, arising from a creeping, ramified hydrorhiza; perisarc thin, smooth covering stolons and hydrocaulus, the perisarc of hydrocaulus widens distally and the basal part of hydranth is able to retract into this enlargement; hydranth clavate to cylindrical, with large rounded hypostome, ectoderm of hypostome differentiating a well developed cap of gland cells, with 10-18 capitate tentacles in one oral whorl of 4 tentacles and below them lower capitate tentacles scattered or in indistinct whorls, with one aboral whorl of 2-6 filiform tentacles (often reduced or absent); medusa buds singly or in clusters of 3-4, borne below capitate tentacles and above filiform ones.

Medusa: umbrella bell-shaped, 4-5.5 mm high, 1.5 times higher than wide; mesoglea uneven thick, becoming gradually thicker from margin towards top, at apex 3 times as thick as lateral wall; relaxed velum spanning half to two-fifths of radius; manubrium very long, up to 3 times the umbrella height, with long a thin serpentine proximal part and a broader distal (oral) extremity; with distinct rounded apical chamber; mouth simple, tube like; «gonads» distributed in 2-9 broad rings, encircling completely manubrium living upper third free, most distal one covering the distal swollen part; with 4 narrow radial canals and circular canal; four marginal bulbs, rather flat, with cnidocysts pads and bearing each an abaxial dark brown ocellus, bulb cavity egg-shaped; circular canal entering bulbs adaxially; with 4 very long a thin tentacles, length up to 5 times umbrella height, with numerous irregularly distributed cnidocyst clusters and a small terminal cluster.

Records from Mediterranean: eastern and western Mediterranean.

Known seasonality: 3-6.

Distribution: Atlantic; Indo-Pacific; Mediterranean.

References: Kramp (1961); Brinckmann-Voss (1970, 1987); Bouillon (1966, 1971; 1978b, 1985b, 1995a); Goy (1973, 1997); Moreno et al. (1984);
Lakkis and Zeidane (1985); Goy et al. (1988, 1990, 1991); Pagès et al. (1992); Boero and Bouillon (1993); Medel and López-González (1996); Schuchert (2001b).

Dipurena reesi Vannucci, 1956

(Figs. 52I-K)

Hydroid: colonies stolonal arising from a creeping hydrorhiza formed by a very wide network of stolons; perisarc covering stolons and hydrocaulus; hydranths club-shaped to fusiform, with rounded hypostome, ectoderm of hypostome differentiating a large button of mucous gland cells; with one whorl of 4-5 oral capitate tentacles and at lower third one aboral whorl of 4-5 aboral filiform tentacles; 1-3 medusa buds developing above aboral tentacles.

Medusa:.. umbrella $3.9 \mathrm{~mm}$ wide, $2.5 \mathrm{~mm}$ high, bell-shaped but with rounded top; manubrium with globular apical chamber, at least two times longer than umbrella height, divided in a long serpentine proximal part and a thicker cylindrical distal one; marginal tentacles long with numerous irregular clusters of cnidocysts, terminal cnidocyst knob inconspicuous or absent; «gonads» in 2-3 rings encircling manubrium, one distal, others half way down on serpentine part of manubrium, end of gonads rings taper gently.

Records from Mediterranean: western Mediterranean, medusae raised from hydroids.

Known seasonality: $1 ; 3 ; 12$.

Distribution: Atlantic; Mediterranean.

References: Vannucci (1956); Brinckmann-Voss and Petersen (1960); Kramp (1961); Berhaut (1970); Brinckmann-Voss (1970, 1987); Pages et al. (1992); Altuna (1993a); Boero and Bouillon (1993); Medel and López-González (1996); Schuchert (2001b).

\section{Genus Sarsia Lesson, 1843 = Stauridosarsia Mayer, 1910}

Hydroid with one oral whorl of capitate tentacles and with or without lower capitate tentacles, with or without filiform tentacles; tentacles usually longer and thinner than in other Corynidae; gonophores as free medusae or fixed sporosacs developing below capitate tentacles on over filiform once; cnidome with or without isorhiza cnidocysts.

Medusa with manubrium extending beyond umbrella margin, divided in a thin, long, serpentine proximal part and a swollen distal one; "gonad" 
forming cylinder around thin serpentine part of manubrium living distal part free.

References: Brinckmann-Voss (1989, 2000); Petersen, (1990); Kubota and Takashima (1992); Pagès et al. (1992); Schuchert, (1996, 2001a, b); Brinckmann-Voss and Arai (1998).

Sarsia tubulosa (M. Sars, 1835)

(Figs. 53A-J)

Hydroid: colonies stolonal, issued from an irregular, large meshed, anastomised network of tubular stolons, up to $1,3 \mathrm{~cm}$; hydrocauli erected simple or slightly branched; perisarc smooth or slightly wrinkled, corrugated, never truly annulated; hydranths very elongated, clavate, with conical-rounded hypostome, with 10-25 capitate tentacles distally arranged along digestive part of the hydranth, in whorls which are often rather irregular, proximal part of hydranth without tentacles and with chordal endoderm (sphincter); basal part of hydranth covered with a thin filmy periderm; 1-8 medusa buds borne on short peduncles chiefly but not exclusive at base of lowest tentacles; sometimes hydranth reduced to blastostyles.

Medusa: umbrella up to $18 \mathrm{~mm}$ high, bellshaped, somewhat higher than wide, with interradial exumbrellar furrows, mesoglea moderately thick; with a distinct apical chamber of varying length, usually globular; manubrium, cylindrical, very long, extending 2-3 times the height of the umbrella, consisting in a long thin, slender tubular proximal part and a spindle shaped capacious distal portion; mouth circular armed with cnidocysts; marginal tentacles bulbs broad, radial canals entering marginal bulbs abaxially and enclosed in the mesoglea for a short distance, glandular thickenings along radial canals throughout most of the growth of the medusa, becoming diminished in the adult; marginal tentacles very long with numerous clusters and patches of cnidocysts, terminal knob spherical inconspicuous; «gonads» forming a uniform thickening along the tubular part of the manubrium living both end free.

Records from Mediterranean: eastern and western Mediterranean; Black Sea.

Known seasonality: 4-5.

Distribution: Atlantic; Indo-Pacific; Mediterranean.

References: Kramp (1961); Brinckmann-Voss (1970); Edwards (1978, 1983); Gili (1986); Goy et al. (1988, 1990, 1991); Boero and Bouillon (1993); Medel and López-González (1996); Schuchert (2001 a, b).
Family EUPHYSIDAE Haeckel, 1879

Hydroid: solitary, hydrocaulus without parenchymatic endoderm and peripheral canals, surrounded by a reduced perisarc often of more or less gelatinous consistency or naked; hydranth without parenchymatic diaphragm, with an oral whorl of short moniliform, capitate or filiform tentacles; aboral tentacles moniliform or filiform, in one or three close-set whorls, or dispersed; hydranth often with an aboral irregular whorl of 4-16 short papillae, each with an endodermal statocyst-like structure or with an adhesive mucus organ; gonophores as free medusae or fixed sporosacs developing above aboral whorl of tantacles.

Medusa: umbrella generally evenly rounded; no exumbrellar cnidocyst tracks; manubrium stoutly cylindrical, not extending beyond umbrella margin; mouth simple, circular; 1-4 marginal tentacles, either unequally developed or of similar length, all of same structure; "gonads" encircling almost all length of manubrium.

Remarks: Petersen (1990) recognised only two genera with medusae within the family Corymorphidae: Corymorpha and Euphysa. Euphysa medusae were defined by him as follow: "Medusa with evenly rounded umbrella, without apical canal; with one to four tentacles unequally developed, but all of same structure, moniliform or modified moniliform; manubrium stout, cylindrical, with small round mouth, shorter than bell cavity". Petersen's definition, however, appears not well founded: Euphysa flammea, E. japonica, Euphysomma brevia, for instance, have four tentacles that are not unequally developed. Petersen considered the following genera as identical with Euphysa: Hypolytus; Heteractis; Meiorhopalon and Euphysomma. Euphysomma is here considered as valid.

References: Petersen (1990); Pagès et al. (1992); Bouillon (1999); Bouillon and Barnett (1999); Bouillon and Boero (2000).

\section{Key to hydroids}

1. Mesopsammic hydranth with one type of tentacles more or less filiform; hydrocaulus with four short papillae with endodermal statocyst, covered by leaf-like ectodermal lappet Siphonohydra

- Hydranth with two types of tentacles, oral capitate tentacles and aboral monilifiliform tentacles; hydrocaulus with an irregular whorl of 
glandular papillae, each with an endodermal statocyst-like structure below aboral whorl of tentacles ..... Euphysa

Genus Euphysa Forbes, 1848

= Hypolytus Murbach, 1899 = Meiorhopalon Salvini-Plawen, 1987

Hydroid: hydrocaulus about twice as long as hydranth, embedded in a soft, sticky perisarc, covered by mud and detritus; with an irregular whorl of glandular papillae, each with an endodermal statocyst-like structure below aboral whorl of tentacles; hydranth almost cylindrical, with rounded hypostome, with 3-10 oral capitate tentacles and up to 20 aboral moniliform tentacles; asexual reproduction by constriction of distal end of hydrocaulus and budding of new hydranths with reversed polarity on lower part of mother hydranth; medusa buds singly or in clusters just above aboral tentacles.

Medusa: umbrella evenly rounded; 1-4 marginal tentacles often unequally developed but all of the same structure, tentacles usually moniliform. Reference: Brinckmann-Voss and Arai (1998).

Key to hydroids (see below E. aurata)

\section{Key to medusae}

1. With one marginal tentacle in adult.... E. aurata - With 4 similar tentacles in adult ...... E. flammea

Euphysa aurata Forbes, 1848 (Figs. 54A-D)

Hydroid: solitary, with hydrocaulus about twice as long as hydranth, embedded in a soft, sticky perisarc covered by mud and detritus; hydranth almost cylindrical, with rounded hypostome, with 310 oral capitate tentacles and up to 20 aboral moniliform tentacles; with an irregular whorl of papillae each with an endodermal statocyst below aboral whorl of tentacles; asexual reproduction by constriction of the distal end of hydrocaulus and of budding of new hydranths with reversed polarity on lower part of mother hydranth; medusa buds borne singly or in clusters just above the aboral tentacles.

Medusa: umbrella about $6 \mathrm{~mm}$ high, higher than wide, bell-shaped, with rounded apex, mesoglea thick, especially in apical region; without pointed apex; with horizontal umbrella margin; velum fairly wide; manubrium large, cylindrical, shorter than bell cavity, in extension never reaching beyond exumbrellar margin; mouth simple, circular, surrounded by cnidocysts; 4 radial canal and circular canal narrow; gonad encircling almost all manubrium, living upper end of manubrium and mouth area free; one single, perradial marginal tentacle, moniliform, 3 non-tentacular perradial marginal bulbs smaller than tentacular bulb and with slight spurs; with winter resting eggs.

Records from Mediterranean: eastern and western Mediterranean; Adriatic.

Known seasonality: 1-12.

Distribution: Atlantic; Indo-Pacific; Mediterranean.

References: Werner (1959); Kramp (1961); Berhaut (1970); Brinckmann-Voss (1970, 1987); Benovic (1973,1976); Benovic and Bender (1987); Goy (1973, 1997); Gili (1986); Goy et al. (1988, 1990, 1991); Boero and Bouillon (1993); Avian et al. (1995); Benovic and Lucic (1996); Medel and López-González (1996); Gili et al. (1998); Schuchert (2001a).

Euphysa flammea (Linko, 1905)

(Fig. 54E)

Medusa: umbrella $12 \mathrm{~mm}$ high, $7 \mathrm{~mm}$ wide, bellshaped, umbrella walls fairly thin; manubrium cylindrical, about two-thirds as long as umbrellar cavity; radial canals and circular canal narrow; «gonads» encircling almost whole manubrium except mouth area; four perradial marginal tentacles covered with scattered groups of cnidocysts, all alike in adult, youngest stages with only one tentacle, the other added successively.

Records from Mediterranean: eastern Mediterranean.

Seasonally: 5-7.

Distribution: Arctic circumpolar; Atlantic; IndoPacific; Mediterranean.

References: Kramp (1961); Goy et al. (1988, 1990, 1991); Boero and Bouillon (1993).

Hydroid: unknown.

Genus Siphonohydra Salvini-Plawen, 1966

Paedomorphic Hydrozoa reduced to hydroid stage; solitary, mesopsammic; hydranth club-shaped with an oral whorl of four very short tentacles alternating with an aboral whorl of four longer tentacles with parenchymatic endoderm, tentacles of both whorls more or less filiform; with buds above the aboral tentacles; upper end of hydrocaulus with four 
short papillae with endodermal statocyst, covered by leaf-like ectodermal lappet. Gonophores unknown.

References: Clausen and Salvini-Plawen (1986); Salvini-Plawen (1987); Thiel, H. (1988); Petersen (1990).

Siphonohydra adriatica Salvini-Plawen, 1966 (Fig. 54F)

With the characters of the genus.

Records from Mediterranean: Adriatic. Seasonally: 2.

Distribution: endemic of Mediterranean Sea.

References: Clausen and Salvini-Plawen (1986); Salvini-Plawen (1987); Thiel, H. (1988) Avian et al. (1995).

\section{Family PARACORYNIDAE Picard, 1957}

Hydroid: colony flat, circular, polymorphic; basal Fig. divided in upper layer of broad endodermal cavities and basal layer of large, parenchymatic endoderm cells continuous with those in dactylozooids, transversed by mesogloeal lamellae, all enveloped in layer of ectoderm, lacking perisarc; gastrozooid short, stout, with 1 to 4 whorls of solid capitate tentacles; gonozooids short, lacking tentacles and mouth; dactylozooids around edge of colony, long, finger-shaped, filled with parenchymatic endoderm; gonophores cryptomedusoid; eggs developed into actinulae inside gonophore, or into encysted resting stage.

Reference: Bouillon (1974b, 1975); Petersen (1990).

Genus Paracoryne Picard, 1957

With the characters of the family.

Paracoryne huvei Picard, 1957

(Fig. 54G)

Stolonal colonies with encrusting hydrorhizae composed of naked coenosarc, giving rise three different kinds of polyps (gastrozooids, dactylozooids and gonozooids); gastrozooids with 12-26 tentacles irregularly distributed in four verticils at distal half; dactylozooids large without tentacles neither mouth; gonozooids without tentacles neither mouth; gonophores fixed sporosacs (cryptomedusoids), male and female in different colonies; male gonophores in number of 210 per gonozooid, ovoid, with a characteristic apical prolongation; female gonophores 2-4 per gonozooid, bigger and more spherical than the males, young gonophores with an apical prolongation (as in the males) which is absent and replaced by an orifice in the mature gonophores; cnidome: desmonemes, microbasic euryteles, stenoteles.

Records from Mediterranean: western Mediterranean.

Known seasonality: 1 to 6 . (as cyst 7 to 12 ).

Distribution: endemic of Mediterranean Sea.

References: Bouillon (1974b, 1975); Gili (1986); Boero and Bouillon (1993); Medel and LópezGonzález (1996).

Family PenNariddae McCrady, 1859

Hydroid: colony large, pinnate, arising from a network of creeping stolons; hydrocaulus monosiphonic, giving rise alternately from opposite sides to two series of numerous unbranched hydrocladia lying in one plane; longest hydrocladia in the middle of colony, gradually decreasing in length upwards and downwards; perisarc thick, firm; hydrocaulus and hydrocladia with terminal hydranths (monopodial); numerous hydranths on short pedicels originating on upper side of the hydrocladia; hydranths spindle- or pear-shaped, with dome-shaped hypostome; a whorl of 4-6 oral capitate tentacles, up to 18 capitate tentacles scattered or in more or less regular whorls on hydranth body, aboral whorl of up to 16 semifiliform to slightly capitate aboral tentacles; 35 eumedusoids arising on short stalks just above aboral tentacles; sexes separated per colony; eumedusoids free or not.

Medusa: reduced to short-living eumedusoids; manubrium not extending beyond umbrella margin; mouth simple, circular or absent; 4 radial canals; "gonads" completely surrounding manubrium; 4 permanently rudimentary tentacles, usually reduced to mere bulbs, with or without ocelli.

Remarks: many of the reduced medusa species described in this family could be eumedusoids belonging to several Tubulariida or Zancleida families; only the few species with known cycle can be referred to the Pennariidae.

References: Wedler and Larson (1986); Calder (1988); Migotto (1996); Schuchert (1996); Bouillon and Barnett (1999); Bouillon and Boero (2000).

\section{Genus Pennaria Goldfuss, 1820}

Eumedusoid and hydroid with characters of the family. 
Pennaria disticha Goldfuss, 1820

(Figs. 55A-C)

Hydroid arising from a network of creeping stolons and forming large, pinnate, feather- like colonies; hydrocaulus monosiphonic giving rise alternately from opposite sides to two series of numerous unbranched hydrocladia lying in one plane; longest hydrocladia in the middle of the colonies, gradually decreasing in length upward and downwards; perisarc thick, firm; hydocaulus and hydrocladia with terminal hydranths (monopodial); numerous hydranths on short pedicels originating on upper side of the hydrocladia; hydranths spindle or pear-shaped, with domeshaped hypostome; with a whorl of 4-6 oral capitate tentacles, up to 18 capitate tentacles scattered or in more or less regular whorls on hydranth body and an aboral whorl of up to 16 semifiliform to slightly capitate aboral tentacles, 3-5 eumedusoids arising on short stalks just above aboral tentacles; sexes are separated per colony; eumedusoids free or not.

Records from Mediterranean: eastern and western Mediterranean, Adriatic.

Known seasonality: 11-4.

Distribution: warm waters around the world.

References: Vervoort (1959); Brinckmann-Voss (1970); Rossi (1971); García Corrales et al. (1985); Gili (1986); Calder (1988); Avian et al. (1995); Medel (1996); Medel and López-González (1996); Schuchert (1996).

\section{Family TricYCLUSIDAE Kramp, 1949}

Paedomorphic Hydrozoa reduced to hydroid stage, solitary, with pear-shaped hydranth, one whorl of six capitate oral tentacles and two widely spaced whorls each of 8-14 stout, solid aboral, imperfect moniliform, tentacles; hydrocaulus thin, same length as hydranth, ending in small pedal disc; perisarc covering hydrocaulus inflated, of gelatinous aspect; hydroid buds produced from lower part of hydranth; actinuloid larvae arising from under aboral tentacles. Gonophores as fixed sporosacs, only male have been observed.

Reference: Petersen (1990).

Genus Tricyclusa Stechow, 1919

With the characters of the family.

Tricyclusa singularis (Schulze, 1876)

(Fig. 55D)
Hydroid pear-shaped, with three whorls of capitate tentacles (oral, middle and proximal whorls). Between the middle and oral whorl the body narrows to form a slender neck. Four oral tentacles, each with a terminal knob of cnidocysts; six tentacles in the middle whorl; proximal whorl near the posterior end of the body, with 12 tentacles in two closely approximated whorls of six tentacles pointing upwards and six tentacles pointing downwards. Middle and proximal whorls of tentacles with two groups of cnidocysts on their distal half in addition to the terminal knob. Gonophores cryptomedusoids.

Records from the Mediterranean: western Mediterranean?, Adriatic.

Distribution: northeastern Atlantic, Mediterranean.

References: Rees (1941a, 1957); Petersen (1990); Boero and Bouillon (1993) Avian et al. (1995).

\section{Family TUBULARIIDAE Fleming, 1828}

Hydroid: solitary or colonial; hydrocaulus divided into distal neck region covered by thin perisarc, and proximal stem which may be either short and thick with tuber-like aboral processes, or long, cylindrical or cone-shaped with basal disc or with stolons covered by thicker perisarc; neck perisarc secreted from a groove on the hydranth proper; hydranth vasiform, tentacles in two sets, oral ones filiform or pseudofiliform in one to several close-set whorls, exceptionally capitate, or moniliform, (oral tentacles often slightly capitate or capitate in juveniles); aboral ones in one whorl, long pseudofiliform or filiform, sitting on a more or less developed parenchymatic cushion; gonophores as free medusae or fixed sporosacs; often actinula larvae.

Medusa: usually with exumbrellar cnidocyst tracks; 4 radial canals; mouth usually circular; "gonads" encircling manubrium completely; 1-4 marginal tentacles; no ocelli.

References: Wedler and Larson (1986); Calder (1988); Petersen (1990); Migotto (1996); Schuchert (1996); Bouillon (1999); Bouillon and Barnett (1999); Bouillon and Boero (2000).

\section{Key to hydroids}

1. Hydrocaulus lumen open, without parenchyme and peripheral endodermal canals but with longitudinal endodermal ridges. 2

- Hydrocaulus filled with parenchyme and with 
longitudinal peripheral endodermal canals; hydrocaulus widening from base to distal end

\section{Tubularia}

2. Oral tentacles in one whorl; two, rarely up to five longitudinal endodermic ridges; medusa radially symmetrical with 2 or 4 groups of tentacles

Ectopleura

- Oral tentacles in two whorls; up to 8 or more longitudinal endodermic ridges; medusae asymmetrical with one group of marginal tentacles. Hybocodon

\section{Key to medusae}

1. With tentacular marginal bulbs 2

- Without tentacular marginal bulbs..... Rhabdoon

2. With normal, symmetrical umbrella.................. 3

- With asymmetrical umbrella, bell margin obliquely set to the vertical axis ...... Hybocodon

3. With longitudinal exumbrellar cnidocyst tracks or rows Ectopleura

- Cnidocysts in scattered or in clumps Plotocnide

\section{Genus Ectopleura L. Agassiz, 1862}

Hydroid: solitary or colonial; hydrocaulus high, simple, with open lumen, without parenchymatic endoderm and longitudinal endodermal canals, but weakly divided by two, rarely up to five, internal longitudinal endodermic ridges; perisarc thin, covering pyriform neck region, originating from collar on neck region and does not cover whole neck; hydranth vasiform with filiform (except in $E$. wrighti where they are moniliform to capitate) oral tentacles in one whorl and a whorl of long, filiform, aboral tentacles; gonophores right above aboral tentacles, producing free medusae, eumedusoid or fixed sporosacs.

Medusa: umbrella symmetrical, rounded, or pyriform; 8 longitudinal exumbrellar cnidocyst rows, issuing in pairs from tentacular bulbs; manubrium short, at most reaching bell margin; 2 opposite or 4 equally developed, simple perradial marginal tentacles, moniliform or with abaxial cnidocyst clusters; 4 radial canals.

Remarks: many hydroid-based nominal species of Ectopleura have recently been described, the medusae being known either as just liberated juveniles or as medusa buds; some medusae with unknown cycle, and described long ago, could correspond to some of those hydroids. In groups with species based on either polyps or medusae only, rearing experiments are necessary to elucidate life cycles before assigning new specific names.

Recent references: Schuchert (2001a, 2003).

\section{Key to hydroids}

1. Colonies producing free medusae 2

- Colonies producing not released medusae........ 3

2. Hydroid solitary, with 14-25 filiform oral tentacles E. dumortierii

- Hydroid colonial, with 5-10 slightly capitate tentacles E. wrighti

3. Gonophores cryptomedusoids; female gonophores with 8 laterally flattened crests surrounding the opening .... E. crocea.

- Gonophores eumedusoids; female gonophores with 3-4 short round apical processes which may be flattened E. larynx

\section{Key to medusae}

1. With four perradial marginal tentacles

- With two opposite marginal tentacles E. dumortieri

2. «Gonads» surrounding manubrium and forming 4 sac-like interradial pouches ...... E. sacculifera

- «Gonads» only surrounding manubrium........... 3

3. With short conical apical chamber and apical canal; marginal tentacles with six to nine abaxial cnidocysts clusters and a larger terminal one ..... E. minerva

- Without apical chamber and apical canal; tentacles with a terminal knob of cnidocysts, one or two distal spherical rings of cnidocysts and proximally one abaxial cnidocysts cluster . E. wrighti

Ectopleura crocea (L.Agassiz, 1862) (Figs. 55E-F)

Hydroid colonial; hydrorhiza forming a dense mat giving rise to cluster of numerous polyps; stem unbranched, up to $70 \mathrm{~mm}$ high, perisarc firm and smooth, with scattered groups of several annulations; coenosarc with 2-5 longitudinal endodermal ridges. Polyp reddish, with one oral whorl of 18-24 filiform tentacles with their bases adnate to hypostome, and one aboral whorl of 22-30 slender tentacles longer than the oral ones; cnidocysts of aboral tentacles, concentrated in a longitudinal band of the aboral side. Oral tentacles circular in cross-section, aboral ones for-sided. Neck region more than $1 / 2$ length of 
hydranth, finely and longitudinally striated, with a collar at lower edge which forms a shallow groove from which perisarc covering the neck region is secreted. Gonophores in small groups on pedicels borne on blastostyles (about 8) in circles close to bases of aboral tentacles. Gonophores cryptomedusoid, without radial canals and ring canal, immature male gonophores elongate ovoid, spherical when mature, with four tentacle rudiments; female gonophores ovoid to spherical with eight, laterally flattened, thin transparent crests surrounding opening of bell through which spadix often protrudes; newly released actinula without oral tentacles. Cnidocysts: Stenoteles and desmonemes (in Brickmann-Voss, 1970).

Records from Mediterranean: western Mediterranean, Adriatic.

Known seasonality: 1 to 12 .

Distribution: circuntropical in shallow waters.

References: Brinckmann-Voss (1970) as Tubularia; Petersen (1990); Boero and Bouillon (1993) as Tubularia; Avian et al. (1995); Medel and LópezGonzález (1996) all as Tubularia.

\section{Ectopleura dumortierii (Van Beneden, 1844)} (Figs. 55G-J)

Colonies stolonal; hydrocaulus, erect, up to 100 $\mathrm{mm}$ high, solitary, simple or slightly branched, ending in a terminal hydranth and increasing in width from base to distal end; perisarc horn-coloured covering hydrocaulus till proximal end of hydranth, irregularly annulated; hydrocaulus endoderm with up to 4 longitudinal ridges; neck region with gland cells forming an indistinct collar; hydranth flaskshaped, with a rounded hypostome; with one whorl of 14-25 rather short rounded oral filiform tentacles, with oval bases not adnate to hypostome and one whorl of up to 30 long, aboral, semifiliform tentacles; up to 10 , once dichotomously branched, blastostyles above aboral tentacles, bearing clusters of medusa buds at their terminal end.

Medusa: umbrella 2-3 $\mathrm{mm}$ high, nearly spherical, mesoglea very thick, especially in apical region; apical canal sometimes present; velum fairly broad; exumbrella with four pairs of cnidocyst tracks; manubrium very large, spherical at base, tapering towards mouth, extensile; mouth simple, tube-like, mouth rim with cnidocysts; 4 perradial marginal tentacles with large basal bulbs and prominent round cnidocyst clusters on abaxial surface; «gonads» completely surrounding manubrium, living mouth area free; development through a pro-actinula and actinula stage.
Records from Mediterranean: eastern and western Mediterranean; Adriatic Sea.

Known seasonality: 1-12.

Distribution: Atlantic; Indo-Pacific, Mediterranean.

References: Kramp (1959a, 1961); Berhaut (1970); Brinckmann-Voss (1970, 1987); Benovic (1973); Schmidt and Benovic (1979); Dowidar (1983); Castello i Tortella (1986); Benovic and Bender (1987); Goy (1973b); Gili (1986); Goy et al. (1988, 1990, 1991); Hirohito (1988); Petersen (1990); Boero and Bouillon (1993); Avian et al. (1995); Benovic and Lucic (1996); Medel and López-González (1996).

Ectopleura larynx (Ellis and Solander, 1786) (Figs. 56A-B)

Hydroid colonial, hydrorhiza forming dense mat giving rise to numerous stems in dense groups up to $70 \mathrm{~mm}$ high; perisarc of hydrocauli firm and smooth but with irregular annulations; coenosarc with 2 longitudinal ridges. Polyp with long hypostome, one oral whorl of up to 20 long, slender, filiform tentacles adnate to hypostome and forming longitudinal ridges over distal half of hypostome, and one aboral whorl of 20-25 longer filiform tentacles, slender, laterally flattened at their bases, distance between to adjacent tentacles equal to the tentacle base diameter. Neck region with longitudinal striations, nearly as long as hydranth, and with a collar grooved basally which produces the thin perisarc covering the neck. Gonophores on blastostyles in circles around oral and aboral tentacles. Male gonophores on, up to 12 , long pedicels borne on up to 12 long, pendant, and unbranched blastostyles; female gonophores on, up to 12 , shorter blastostyles (with up to 8 gonophores) dichotomously branched. Gonophores eumedusoids, without radial canals but with ring canal; female ovoid, with 3-4 short round apical processes which may be flattened giving the "ears" appearance; male gonophores longer and slender, with very short, closely-set apical processes; actinula, at liberation, with an aboral whorl of 6-13 tentacles with swollen tips; oral tentacles not yet developed or as 3-5 rudiments.

Records from Mediterranean: western Mediterranean.

Known seasonality: 3, ?

Distribution: mainly northern (west and east) Atlantic; northern Pacific; Mediterranean (records from southern hemisphere probably due to transport by ships (Petersen, 1990). 
References: Gili (1986) as Tubularia; Petersen (1990); Medel and López-González (1996) as Tubularia; Schuchert (2001a).

\section{Ectopleura minerva Mayer, 1900b}

(Fig. 56C)

Medusa: umbrella 2,5 $\mathrm{mm}$ high, pear-shaped to conical bell-shaped, narrowing at base; mesoglea thicker apically but without clear apical projection; exumbrella with 4 pairs of longitudinal cnidocysts tracks originating from the marginal bulbs and extending near apex of umbrella; manubrium tubular, about two third length of umbrella cavity, with short conical apical chamber and apical canal, the size of both depending on age and preservation; mouth simple, tubular; radial canals and circular canal narrow; with two moderately broad opposite marginal tentacular bulbs and two slightly smaller non tentacular bulbs; the two opposite perradial marginal tentacles each with six to nine abaxial cnidocysts clusters and a larger terminal one; «gonads» completely surrounding manubrium living most distal part free, tentacles and manubrium typically cream in color.

Remarks: the medusa Ectopleura minerva has been described from Florida, it is known from the Bermudas, the Mediterranean, the Seychelles, India, China, Japan and the Bismarck Sea. Ectopleura minerva hydroid stage is still unknown, several Ectopleura types of hydroid have been described producing unreleased or just released two tentaculated medusae, particularly E. pacifica Thornely, 1900 from Papua New Guinea, but none of them have their adult stage known and rearing experiments will thus be necessarily before elucidating and clarifying their complex and confuse synonymy.

Records from Mediterranean: eastern and western Mediterranean.

Known seasonality: 1-12.

Distribution: Atlantic; Indo-Pacific; Mediterranean.

References: Kramp (1961); Goy (1973b); Sugiura (1977); Bouillon (1978 a,b); Calder (1988); Hirohito (1988); Petersen (1990); Goy et al. (1988, 1990, 1991); Schuchert (1996).

Hydroid: unknown.

Ectopleura sacculifera Kramp, 1957a (Fig. 56D)

Medusa: umbrella $3 \mathrm{~mm}$ high, $2.8 \mathrm{~mm}$ wide slightly conical, mesoglea thick, exumbrella with 8 cnidocysts tracks issuing in pairs from the four marginal bulbs, continuing almost to apex, and forming 8 slight crests along exumbrella; manubrium half as long as umbrellar cavity; «gonads» surrounding the manubrium and forming four large, interradial, saclike pouches hanging down from middle part of manubrium almost to mouth level; two long opposite marginal tentacles, their distal part with 20- 25 abaxial clusters of cnidocysts and two rudimentary bulbs.

Hydroid: unknown.

Records from Mediterranean: western Mediterranean.

Known seasonality: 2.

Distribution: Indo-Pacific; Mediterranean.

References: Kramp (1961); Brinckmann-Voss (1970, 1987); Bouillon (1978b); Boero and Bouillon (1993).

Ectopleura wrighti Petersen, 1979 (Fig. 56E)

Hydroid: colonial issued from a creeping hydrorhiza, stolons not clearly demarcated from hydrocauli; hydranth very slender, vasiform with one oral whorl of 5-10 slightly capitate or moniliform tentacles which are not adnate to hypostome and an aboral whorl of 11-20 filiform tentacles; neck region long and slender, with low ring-shaped collar forming groove from which thin outer periderm is secreted; hydrocaulus slender, unbranched, of equal width throughout; inner lumen divided into two longitudinal canals by two endodermal ridges formed by highly vacuolated cells, periderm flexible, thin and smooth, covering hydrocauli and stolons; medusa buds born above the aboral tentacle whorl; carried on 5-8 short, dichotomously branched blastostyles.

Medusa: umbrella nearly hemispherical, with four longitudinal meridian pairs of cnidocyst tracks; with four perradial marginal bulbs; with two opposite marginal perradial tentacles with a terminal knob of cnidocysts and distally one or two spherical cnidocyst knobs encircling tentacle, proximally one abaxial cnidocyst cluster; manubrium nearly as long as subumbrellar cavity; completely encircled by «gonads».

Records from Mediterranean: hydroid eastern and western Mediterranean, Adriatic. Only young medusae liberated in the laboratory known (Brinckmann-Voss, 1970).

Known seasonality: 1-12. 
Distribution: Atlantic?; western Mediterranean.

References: Brinckmann-Voss (1970, 1987); Petersen (1979, 1990); Boero and Bouillon (1993); Avian et al. (1995), Peña Cantero and García Carrascosa (2002).

\section{Genus Hybocodon L. Agassiz, 1862}

Hydroid: solitary, with high stems, hydrorhiza irregularly branched; hydrocaulus tubular, with open lumen, without parenchyme and longitudinal peripheral canals but weakly divided by eight or more longitudinal endodermic ridge; perisarc originating just below hydranth and much inflated around whole neck region; secreted from groove between hydranth and neck; oral tentacles filiform to pseudofiliform in two closely set whorls, aboral tentacles in one whorl, filiform to pseudofiliform; blatostyles dichotomously branched.

Medusa: bilaterally symmetrical, with umbrella margin at oblique angle to vertical axis; no pointed apical process; with or without exumbrellar cnidocyst tracks; manubrium cylindrical on short peduncle not extending beyond umbrellar margin; 4 radial canals, 1 short, 2 medium sized and one longer; with 1 simple or compound marginal bulb with 1-3 moniliform tentacles corresponding to the longest radial canal; 3 remaining perradial bulbs rudimentary.

\section{Hybocodon prolifer L. Agassiz, 1862}

(Figs. 56F-H)

Hydroid: colonies with hydrorhiza formed by branching stolons embedded in sponges; hydrocaulus solitary or sparingly aggregated, long, gradually enlarging to just below hydranth, with firm perisarc; endoderm of hydrocaulus with a central lumen and several longitudinal ridges; neck region between hydrocaulus and hydranth surrounded by a loose filmy, wrinkled perisarc; hydranth pearshaped, with a rounded hypostome, with up to 50 short oral filiform tentacles in 2 closely set whorls, the most distal being the shorter and up to 31 longer aboral filiform tentacles in one whorl, the base of aboral tentacles adnate to basal part of hydranth; medusa buds on branching blastostyles, bearing numerous buds, just above aboral tentacles; the older medusa buds themselves carrying buds while still fixed on hydranths.

Medusa: umbrella $3 \mathrm{~mm}$ wide, up to $5 \mathrm{~mm}$ high, bell-shaped, evenly rounded, umbrella margin oblique to vertical axis, mesoglea moderately thick; usually with 5 longitudinal exumbrellar cnidocyst tracks, 2 issued from tentacular bulb, 1 track from each non tentacular bulb; velum moderately broad; manubrium large cylindrical mounted on a short peduncle never reaching beyond margin even in full extension; mouth with a narrow ring of cnidocysts; 1 tentacular bulb with 1 or more moniliform tentacles (with adaxial clasps according to Schuchert, 1996) and with medusae buds, 3 non tentacular bulbs reduced; «gonads» completely surrounding manubrium, living peduncle and most distal portion free; medusa buds on marginal bulbs; eggs developing in actinulae on manubrium which may later be found free in plankton.

Records from Mediterranean: western Mediterranean.

Known seasonality: 3-6.

Distribution: Atlantic; Indo-Pacific; Antarctic, Arctic; Mediterranean.

References: Kramp (1961); Arai and Brinckmann-Voss (1980); Gili (1986); Boero and Bouillon (1993); Medel and López-González (1996); Schuchert (1996, 2001a).

Genus Plotocnide Wagner, 1885

Tubulariidae with exumbrellar cnidocysts scattered singly or in clumps; with a dome-shaped apical chamber lined with vacuolated endodermal cells.

Plotocnide borealis Wagner, 1885

(Fig. 56I)

Medusa: umbrella up to $3.5 \mathrm{~mm}$ wide and high; spherical to bell-shaped, with rounded apex, mesoglea very thick mainly at apex, thinning slightly towards umbrella opening; with exumbrellar cnidocysts scattered singly or in clumps; with a dome-shaped apical chamber lined with vacuolated endodermal cells above manubrium; manubrium flask-shaped, half as long as umbrellar cavity; mouth simple with a ring of cnidocysts; «gonads» a thick ring around manubrium, living mouth and uppermost portion of manubrium free; radial canals and circular canal simple; with 4 threadlike, solid marginal tentacles ending in a large, oval, swelling studded with cnidocysts; marginal tentacular bulbs small globular.

Remarks: the presence of this arctic species in the eastern Mediterranean is based on a single small specimen (less than $1 \mathrm{~mm}$ high) described by Goy et al. (1988), lacking apparently most of the character- 
istic features of the species: no vacuolated apical chamber, no apical mesoglea thickening, no exumbrellar cnidocysts, no ring-shaped «gonads». This identification is doubtful

Hydroid: unknown.

Known seasonality: 1.

Distribution: Arctic and Subarctic, circumpolar; Atlantic; Indo- Pacific; Mediterranean?

References: Beyer (1955) Hand and Kan (1961); Kramp (1961); Hartlaub (1907); Kramp (1942, 1959a, 1961, 1968); Naumov (1960-1969); Arai and Brinckmann-Voss (1980); Goy et al. (1988, 1991); Boero and Bouillon (1993).

\section{Genus Rhabdoon Keferstein and Ehlers, 1861}

Tubulariidae with single hollow marginal tentacle ending in large, complex knob of cnidocyst clusters; without marginal tentacular bulbs; manubrium occupying almost entire bell cavity; with vacuolated cells containing refractive droplets along 4 radial canals, at manubrium apex and bell margin; «gonads» surrounding distal $2 / 3$ of manubrium.

Rhabdoon singulare Keferstein and Ehlers, 1861 (Fig. 56J)

Medusa:umbrella $1.6 \mathrm{~mm}$ wide, $2.1 \mathrm{~mm}$ high, barrel-shaped, apex dome-shaped, mesoglea thin at the apex larger at the umbrellar sides; exumbrella margin thick, irregular, containing numerous cnidocysts; subumbrellar opening and velum narrow; exumbrella with 4 perradial longitudinal exumbrellar cnidocyst tracks, 4 additional interradial and sometimes adradial ones; manubrium large flaskshaped occupying almost the entire subumbrellar cavity, upper third vacuolated; mouth simple, circular, covered with cnidocysts; 4 protruding radial canals; «gonads» on the two distal thirds of the manubrium; with a single hollow tentacles ending in a large knob consisting of numerous stalked capitations containing cnidocysts.

Hydroid: unknown.

Records from Mediterranean: eastern and western Mediterranean; Adriatic Sea.

Known seasonality: 1-11.

Distribution: Atlantic; Indo-Pacific; Mediterranean.

References: Kramp (1961); Brinckmann-Voss (1970, 1987); Benovic (1976); Benovic and Bender (1987), Goy (1973, 1983); Dallot, Goy and Carré (1988); Pagès et al. (1992); Boero and Bouillon
(1993); Avian et al. (1995); Benovic and Lucic (1996).

\section{Genus Tubularia Linnaeus, 1758}

Hydroid: solitary; hydrocaulus long, tubular, widening from base to distal end, inner lumen filled with parenchymatic endoderm, penetrated by 8 or more longitudinal endodermal peripheral canals, one wider than the others; circular or lobed basal disc, and supporting tubes developed from lower part of stem; thin perisarc around neck secreted from groove between hydranth base and neck; hydranth vasiform, with two or more whorls of oral filiform and one whorl of filiform aboral tentacles; bases of aboral tentacles continued as ridges over hydranth base; blastostyle with unbranched main stem, with or without thin side branches; gonophores reduced to eumedusoid or to sessile cryptomedusoid, with or without distal processes, in which the origin from a biradially symmetrical medusa, can be usually traced.

Refrences: Petersen (1990); Schuchert (2001).

\section{Key}

1. Female gonophore eumedusoid, without any tentacle, with four radial canals and a ring canal T. Indivisa

- Female gonophore cryptomedusoid, with one tentacle-like process, without radial canal and ring canal T. ceratogyne

Tubularia ceratogyne Pérès, 1920 (Figs. 57A-B)

Hydroid solitary but growing in clusters. Hydrocaulus up to $c a 60 \mathrm{~mm}$, with one larger and about seven smaller peripheral canals surrounding parenchymatic centre, perisarc firm, annulations absent; stem attached to substrate by irregularly shaped basal disc forming one or two short rhizomes covered by thick perisarc and 2-4 supporting tubes irregularly wrinkled originating from lower part of stem. Hydranth with long oral tentacles adnate basally to hypostome and connected to hypostome by thin membrane for some distance; aboral tentacles about 30, with oval bases; neck region nearly as long as hydranth, covered by thin perisarc originating in groove between hydranth base and neck. Gonophores on short pedicels on 712 (usually 8) long and unbranched blastostyles; female ovoid, cryptomedusoid, without radial 
canals and ring canal, with one hollow, tentaclelike process bent over opening of gonophore; male spherical, cryptomedusoid, without distal processes. Female gonophores inserted irregularly over surface of blastostyle, male gonophores arranged in four to five longitudinal rows; cnidome: desmonemes, anisorhiza, microbasic euryteles, stenoteles.

Records from Mediterranean: recorded only from the Strait of Gibraltar and nearby areas of Gulf of Cádiz.

Known seasonality and reproduction: 6;10;12.

Records outside the Mediterranean: northeastern Atlantic.

References: Teissier (1965); Patriti (1970); Hughes (1983); Petersen (1990); Medel and LópezGonzález (1996).

Tubularia indivisa Linnaeus, 1758 (Figs. 57C-F)

Polyps solitary but in clusters; stem up to 200 $\mathrm{mm}$ high (but usually shorter), perisarc firm and smooth; coenosarc with one larger and 9-12 smaller peripheral canals around central lumen; stem attached to substrate by relatively broad and thick lobate basal disc, and several supporting tubes originating from lower half of stem, which grow over substrate as short rhizomes. Hydranth with up to 6 whorls of 40-60 long oral tentacles continued over hypostome as longitudinal ridges and 25-35 aboral tentacles with laterally-flattened oval bases; neck region as long as hydranth, covered by thin perisarc originated in groove between the hydranth base and distal part of the neck. Gonophores on short pedicels borne on up to 12 unbranched blastostyles (each with up to 30 older gonophores); female gonophore eumedusoid, ovoid to spherical, with four radial canals of unequal length and a ring canal, without tentacles; male gonophore cryptomedusoid, ovoid to spherical, with rounded distal end; actinula with whorl of short oral tentacles at liberation; cnidome: desmonemes, anisorhiza, microbasic euryteles, stenoteles.

Records from Mediterranean: eastern and western Mediterranean, Adriatic.

Distribution: temperate to colder waters of northern Atlantic and Pacific, Arctic Sea, Mediterranean.

References: Naumov (1960); Petersen (1990); Cornelius and Ryland (1990); Boero and Bouillon (1993); Avian et al. (1995); Medel and LópezGonzález (1996); Schuchert (2001a).
Suborder ZANCLEIDA Russell 1953

Hydroid: colony floating or fixed; fixed colonies arising either from simple creeping stolonal tubes, from an encrusting basal mat, from upright branched hydrorihza consisting of a central axis of perisarc covered by coenosarc, or from a calcified exoskeleton; hydranths monomorphic or polymorphic, oral tentacles capitate or moniliform, aboral tentacles in whorls or scattered, either capitate, moniliform, ramified capitate, reduced or without tentacles; free medusae, eumedusoids or sporosacs.

Medusa: manubrium flask-shaped, with quadrate or octagonal base and cylindrical mouth tube; "gonads" usually interradial; exumbrellar cnidocyst pouches or tracks; 0-2 or 4 marginal tentacles with or without abaxial cnidophores; marginal tentacles developed only at junction between radial and circular canals; with or without ocelli.

References: Petersen (1990); Boero, Bouillon and Gravier-Bonnet (1995); Bouillon (1999); Bouillon and Barnett (1999); Boero, Bouillon and Gravili (2000).

\section{Key to hydroids}

1. Hydroids. Porpitidae.

- Holonies fixed by hydrorhizae ......................... 2

2. Hydrorhiza incrusting forming an a crust-like stolonal plate... Rosalindidae

- Hydrorhiza formed by creeping stolon tubes recovered by perisarc

3. Cnidocysts on hydranth body wall arranged in conspicuous rounded patches; hydranth with moniliform or modified moniliform aboral tentacles. Cladocorynidae.

- Cnidocysts not in patches on hydranth body wall; hydranth without moniliform tentacles

Zancleidae.

\section{Key to medusae}

1. Marginal tentacles terminating in a single large spherical cnidocyst knob. Porpitidae

- Marginal tentacles with numerous stalked capsules containing cnidocysts, stalk of the capsules threadlike, very extensile (cnidophores) Zancleidae

\section{Family CladocoRYNIDAE Allman, 1872}

Hydroid: stem simple or slightly branched, rising from a creeping stolon; hydranth club-shaped, oral 
tentacles moniliform or capitate, in one whorl, aboral tentacles moniliform or branched capitate, scattered or in several whorls; cnidocysts on body wall arranged in conspicuous rounded patches or scattered around the base of oral and aboral tentacles; gonophores carried singly or on short, branched pedicels, on lower or middle part of hydranth; with free medusae or fixed cryptomedusoids sporosacs.

Medusa: only two exumbrellar pouches, containing macrobasic euryteles, on non tentaculate perradial marginal bulbs; tentaculate perradial marginal bulbs very large, without cnidocyst pouches; tentacles with cnidophores; "gonads" interradial on manubrium.

References: Wedler and Larson (1986); Bouillon, Boero and Seghers (1987); Petersen (1990); Boero, Bouillon and Gravier-Bonnet (1995); Migotto (1996); Schuchert (1996).

\section{Genus Cladocoryne Rotch, 1871}

Hydrocaulus long, unbranched or sparingly branched, covered by perisarc, arising from a creeping hydrorhiza; hydranth club-shaped, with oral whorl of 4-6 short capitate tentacles, one to four whorls of branched-capitate aboral tentacles; one or two patches of macrobasic eurytele cnidocysts on hydranth body; gonophores as cryptomedusoid fixed sporosacs or as medusa buds, on short pedicels between or over aboral tentacles.

\section{Cladocoryne floccosa Rotch, 1871}

(Fig. 57G)

Colonies composed of creeping hydrorhizae giving rise erect and sparingly branched hydrocauli; perisarc yellowish to transparent, smooth or with several groups of annulations; hydranth nude with an oral whorl of 4-6 short capitate tentacles and 1-4 whorls of branched capitate aboral tentacles; oval areas of microbasic euryteles cnidocysts on the hydranth. Gonophores spherical (cryptomedusoids) on short pedicels between or over aboral tentacles. Cnidocysts: macrobasic euryteles and stenoteles.

Records from Mediterranean: eastern and western Mediterranean, Adriatic.

Known seasonality: 4-7.

Reproduction: 4-7

Distribution: temperate and tropical waters around the world.

References: Rossi (1961); Brinckmann-Voss (1970); Gili (1986); Boero and Bouillon (1993);
Avian et al. (1995); Medel and López-González (1996); Peña Cantero and García Carrascosa (2002).

\section{Family PORPITIDAE Goldfuss, 1818}

Hydroid: colony floating, with a chitinous internal skeleton, covered by mantle, and forming a floating chamber; with a central large gastrozooid and marginal gastro-gonozooids and dactylozooids.

Medusa: 4 or 8 of exumbrellar stenotele cnidocyst tracks issued from marginal bulbs; 4 or 8 radial canals and a circular canal; manubrium short, conical; with quadrate or octagonal base; mouth circular; "gonads" perradial or irregularly arranged perradially and interadially; 2 opposite, perradial, capitate marginal tentacles; with or without 2 additional smaller capitate tentacles adaxial to the first; tentacles with macrobasic euryteles; zooxanthellae generally present.

References: Bouillon (1984d); Calder (1988); Petersen (1990); Pagès et al. (1992); Schuchert (1996); Bouillon (1999); Bouillon and Barnett (1999); Bouillon and Boero (2000).

\section{Key to hydroids}

1. Disc-shaped floating colony without sail Porpita

- Oval to elliptical-shaped floating colony; with a median sail Velella

\section{Key to medusae}

1. 4 radial canals; manubium with quadrate base; 4 capitate tentacles. Velella

- 8 radial canals; manubrium octagonal; 2 capitate tentacles Porpita

Genus Porpita Lamarck, 1801 = Porpema Haeckel, 1888

Hydroid: colony floating, dark blue, diameter up to $30 \mathrm{~mm}$, mostly smaller, with disk-shaped mantle and internal float, margin soft, flexible; central region firm, slightly convex, with a central pore and numerous stigmata; mantle with radiating endoderm canals; internal chitinous float consisting of a series of concentric chambers; a disk-shaped reservoir of cnidocysts between float and central gastrozooid; under surface with one large central gastrozooid, a median circle of gastro-gonozooids, and a peripheral circle of dactylozooids; central gastrozooid short and broad

110 J. BOUILLON et al. 
with a terminal mouth, without tentacles or prominent cnidocyst clusters; gastro-gonozooids clavate, lacking tentacles but with prominent cnidocyst clusters scattered over body, medusae develop near base in clusters; dactylozooids with a distal whorl of 4 capitate tentacles, body with varying number of short, small capitate tentacles in 3 vertical rows.

Medusa: with 8 radial canals; manubrium conical, with octagonal base; 2 opposite marginal capitate tentacles, 6 non tentaculate bulbs; "gonads" 8, perradial; short exumbrellar cnidocyst tracks above each bulb.

Porpita porpita (Linnaeus, 1758)

(Figs. 57H-I)

With the characters of the genus.

Records from Mediterranean: eastern and western Mediterranean, Adriatic.

Known seasonality: 5-7; 10.

Distribution: Atlantic; Indo-Pacific; Mediterranean.

References: Brinckmann-Voss (1970, 1987); Daniel (1976); Bouillon (1984d); Castelló i Tortella (1986); Calder (1988); Pagès et al. (1992); Avian et al. (1995); Medel and López-González (1996); Bouillon and Boero (2000).

\section{Genus Velella Lamarck, 1801}

Hydroid: colony floating; float flattened, oval, elliptical, with a triangular sail; up to $40 \mathrm{~mm}$ long and $20 \mathrm{~mm}$ wide, higher in the centre than at the edges; two mirror images of the animal [left and right sailing; the prevalence of one form in one region may be due to sorting by prevailing winds (Edwards, 1966a)]; float and sail kept rigid by a chitin support covered by mantle tissue; margin of float soft and flexible; chitin float oval to slightly Sshaped with concentric air chambers; mantle tissue with network of endoderm canals; in centre of underside a single large gastrozooid or "siphon" encircled by a ring of medusa producing gastrogonozooids and a peripheral band of dactylozooids; central feeding zooid broadly oval with an elongated hypostome, without tentacles or medusa buds; gastro-gonozooids spindle-shaped with a swollen mouth region, lacking tentacles but with warts of cnidocyst clusters concentrated in distal half; on proximal half of hydranth numerous medusa buds growing in groups from short blastostyles; dactylozooids long and tapering, oval in cross section, with cnidocysts concentrated in two lateral bands on the narrow sides, mouth lacking; colour: float deeply blue when alive, medusa buds yellow-olive from symbiotic algae.

Medusa: with 4 exumbrellar cnidocyst rows, 4 radial canals; 2 pairs of opposite, perradial tentacles, a short adaxial one and a long abaxial one, each with a large terminal cnidocyst cluster; 2 perradial marginal bulbs without tentacles; manubrium conical with quadrate base; mouth tubular; "gonads" irregularly arranged perradially and interradially.

Velella velella (Linnaeus, 1758) (Figs. 57J-K)

With the characters of the genus.

Records from Mediterranean: eastern and western Mediterranean, Adriatic.

Known seasonality: 2-5.

Distribution: Atlantic; Indo-Pacific; Mediterranean.

References: Leloup (1929); Mackie (1959, 1960); Edwards (1963b, 1966a); Brinckmann-Voss (1964, 1970, 1987); Daniel (1976); Larson (1980); Bouillon (1984d); Castelló i Tortella (1986); Calder (1988); Pagès et al. (1992); Avian et al. (1995); Medel and López-González (1996); Bouillon and Boero (2000).

\section{Family RosalindidAE Bouillon, 1985}

Hydroid: colonial; stolonal, with a Fig.-like or trabecular chitinized skeleton, consisting of a thin perisarcal sheet covered by coenosarc and an external peridemal film; coenosarc supported by perisarcal spines and trabeculae forming a more or less thick framework of meshes isolated or sometimes organised in rose-like alveolar stuctures surrounding the polyps; hydranth plump sausage-shaped, with 30-60 scattered capitate tentacles, almost sessile, sometimes with a basal perisarcal calice; cnidome comprising subspherical stenoteles and macrobasic mastigophres; fixed gonophores or free medusae?, with two tentacles apparently provided with cnidophores, known in one species (Rosalinda naumovi), carried singly or on short pedicels among proximal tentacles; cnidome stenoteles macrobasic mastigophores and isorhiza.

Genus Rosalinda Totton, 1949

With the characters of the family. 


\section{Rosalinda incrustans Kramp, 1947}

(Figs. 58A-C)

Colonies $3 \mathrm{~mm}$ in height, with simple trabecular skeleton, with all hydranths naked.

Records from Mediterranean: western Mediterranean (Rosas Gulf).

Known seasonality: 12 ?

Distribution: Atlantic, (west of Gibraltar), Mediterranean.

References: Vervoort (1966b); Watson (1978); Antsulevich and Stepanjants (1985), Boero et al. (1995); Bouillon and Boero (2000).

\section{Family ZanCLEIDAE Russell, 1953}

Hydroid: colonial; hydrorhiza creeping, stolonal; perisarc enveloping hydrocaulus and hydrorhiza not lamellar, as a simple tube; hydrocaulus unbranched; polyps monomorphic or polymorphic; gastrozooid either with oral and aboral capitate tentacles, or with reduced capitate tentacles, or without tentacles; gonozooid and dactylozooid, when present, varied in expression.

Medusa: umbrella bell-shaped; 4 perradial exumbrellar cnidocyst pouches, either oval, clavate, elongate or linear, usually containing stenoteles; mouth simple, circular, without oral tentacles (except in Oonautes, of uncertain family affinity; see Capitata incertae sedis); 4 radial canals (exceptionally bifurcated in Ctenaria, of uncertain family affinity; see Capitata incertae sedis); marginal tentacles 0,2 or 4 , hollow, each with numerous abaxial cnidophores, with macrobasic euryteles; "gonads" usually interradial, rarely in a single mass around manubrium; without ocelli.

References: Wedler and Larson (1986); Calder (1988); Petersen (1990); Gravili et al. (1996); Schuchert (1996); Bouillon (1999); Bouillon and Barnett (1999); Boero et al. (2000); Bouillon and Boero (2000).

\section{Key to hydroids}

1. Gastrozooid reduced, without tentacles Halocoryne

- Gastrozooid with numerous tentacles ... Zanclea

Genus Halocoryne Hadzi, 1917

Either eumedusoids with no tentacles and no mouth; with 4 radial canals; with four perradial bulbs and four cnidocyst exumbrellar pouches; «gonads» surrounding manubrium; or medusae either Zanclea-like or with very elongated tentacular bulbs bearing short tentacles armed with short and stiff cnidophores.

Hydroid: stolonal, living in association with bryozoans; polymorphic; gastrozooids reduced, without tentacles; hypostome armed or not with cnidocysts; dactylozooids columnar, slender, usually with one or two terminal cnidocyst knobs, sometimes with lateral rows of cnidocysts as well, without mouth; reproduction by eumedusoids or free medusae.

Reference: Piraino et al. (1992).

\section{Halocoryne epizoica Hadzi, 1917}

(Figs. 58D-E)

Hydroid: colonies stolonal, polymorphic, symbiotic with bryozoans; hydrorhiza reticular, hydranths naked, sessile; gastrozooids very thin, cylindrical, lacking tentacles but with two prominent ectodermal swellings containing stenoteles on opposite sides of the mouth; dactylo-gonozooids stouter than gastrozooids, without mouth and tentacles, with a terminal spherical cnidocyst cluster and up to five additional cnidocysts clusters along one side of the body or arranged in a interrupted spiral towards hydrorhiza; released eumedusoids borne single or in clusters on short pedicels on lower part of dactylo-gonozooids; cnidome: stenoteles of two sizes.

Medusa: eumedusoids; without mouth and tentacles; with 4 radial canals; with four perradial marginal bulbs; with four cnidocyst exumbrellar pouches connected with marginal bulbs; gonads surrounding manubrium. Cnidome: stenoteles in exumbrellar, macrobasic euryteles (?) sometimes in exumbrellar pouches, macrobasic mastigophores on exumbrella.

Records from Mediterranean: eastern and western Mediterranean, Adriatic.

Known seasonality: 4-6?

Distribution: endemic of Mediterranean Sea.

References: Piraino et al. (1992); Avian et al. (1995); Boero et al. (2000).

\section{Genus Zanclea Gegenbaur, 1857}

Hydroid: colonial, stolonal hydroids, often associated with bryozoans or molluscs; hydranths monomorphic or polymorphic. Polymorphic colonies may present gastrozooids, dactylozooids, tentaculozooids and sometimes gastro-gonozooids; 
gastrozooids on unbranched short pedicels, often almost sessile, elongated, cylindrical or claviform with an oral whorl of capitate tentacles and numerous aboral capitate tentacles scattered or in several whorls over the entire body; tentacles rarely reduced to mere cnidocyst patches; perisarc covering hydrohiza and entire hydrocaulus or confined to lower part of hydrocaulus only; dactylozooids and tentaculozooids when present varied in expression; medusa buds carried singly or in clusters on short pedicels, either scattered among or under the aboral tentacles or on hydrorhiza or on hydranths reduced to blastostyles .

Medusa: Zancleidae with bell-shaped or almost spherical umbrella, lateral walls evenly thin, mesoglea slightly thicker at the apex; with exumbrellar perradial cnidocyst patches or tracts; mouth simple, circular; with 4 simple radial canals; marginal tentacles when present, 0,2 or 4 , with numerous abaxial cnidophores; «gonads» interradial; cnidome generally with stenoteles and macrobasic euryteles, without desmonemes, no ocelli.

The genus Zanclea comprises at least 3 species in the Mediterranean, Zanclea costata, Zanclea sessilis and Zanclea giancarloi (Gravili et al., 1996; Cerrano et al., 1997; Boero et al., 2000).

Most of the various existing Zanclea species are actually not identifiable without a detailed study of the structure of the macrobasic euryteles cnidocysts of the polyp stage and the knowledge of their complete life cycle, the medusae are usually indiscernible and must be referred as Zanclea spp. (Figs. $58 \mathrm{~F}-\mathrm{H})$.

General references: Russell and Rees (1936); Brinckmann-Voss (1970,1987); Benovic and Bender (1987); Goy (1973b); Millard and Bouillon (1973); Bouillon (1974a); Gili (1986); Goy et al. (1988, 1990, 1991); Calder (1992); Boero and Bouillon (1993); Avian et al. (1995); Benovic and Lucic (1996); Gravili et al. (1996); Medel and LópezGonzález (1996); Cerrano et al. (1997); Boero et al . (2000).

\section{Key to hydroids}

1. Apotrichous macrobasic euryteles with shaft coiled in a horse-shoe shape in undischarged capsules ............................................... Z. sessilis

- Macrobasic euryteles with a spirally coiled shaft along long axis of the capsules in undischarged capsules 2

2. Holotrichous macrobasic euryteles .... Z. costata
- Apotrichous macrobasic euryteles Z. giancarloi

\section{Zanclea costata Gegenbaur, 1857}

(Figs. 59A-D)

Hydroid: hydrorhiza on margin of bivalve shell; pedicel covered by corrugated to annulated perisarc; hydranths cylindrical, with an oral whorl of 4-6 tentacles and about 40-60 capitate aboral tentacles scattered over entire hydranth body; medusa buds between tentacles in the mid-upper part of hydranth. Cnidome: Stenoteles of two sizes in tentacle capitations; holotricous macrobasic euryteles with a shaft coiled spirally along the main axis of undischarged capsules, abundant in hydrorhiza and rare in hydranth body; microbasic mastigophores rare in hydranth and hydrorhiza.

Medusa: see diagnosis as for the genus.

Records from Mediterranean: Ionian coast of Apulia.

Known seasonality: 1-7.

Distribution: Mediterranean, all other records have to be confirmed on basis of hydroid cnidome studies.

References: Medel and López-González (1996); Cerrano et al. (1997); Boero et al. (2000).

\section{Zanclea giancarloi}

Boero, Bouillon and Gravili, 2000

(Figs. 59E-I)

Hydroid: hydrorhiza reticular, growing under the skeleton of the bryozoan host; hydranths elongated, cylindrical, with a whorl of four-eight oral capitate tentacles and 50-60 aboral capitate tentacles scattered over the whole hydranth body; hypostome whitish, hydranth transparent; gastric wall pinksalmon; pedicel covered by slightly corrugated brownish perisarc; medusa buds in clusters among tentacles in the lower third of the hydranth. Cnidome: stenoteles of two sizes in tentacle capitations; apotrichous macrobasic euryteles of two sizes, both with shaft coiled along the long axis of capsule, the larger ones with spines for one fifth of their length when extruded, the smaller ones with spines for one tenth of their length, both present in hydrorhiza and hydranth body.

Medusa: see diagnosis as for the genus.

Records from Mediterranean: Ionian Sea.

Known seasonality: 6-9.

Distribution: endemic to Mediterranean Sea. 
References: Gravili et al. (1996); Boero et al. (2000).

Zanclea sessilis (Gosse, 1853)

(Figs. 59J-M)

Hydroid: hydrorhiza reticular, covered by the bryozoan skeleton in the central part of the colony and unrecovered at its margin; pedicel short; perisarc thin, encrusted by sediment particles, not annulated, whitish, hydranth column cylindrical; four-six oral capitate tentacles, 20-40 aboral capitate tentacles, scattered on the distal half or three quarters of hydranth column; hypostome milk white, column transparent, with reddish gastric wall; medusa buds in clusters, growing below the tentacled part of the hydranth, fertile hydranths gradually decreasing in size and tentacle number. Cnidome: apototrichous macrobasic euryteles with shaft coiled in a horseshoe shape, disposed in circle in between oral tentacles and in hydrorhiza, rare in hydranth column; stenoteles of two sizes in tentacle capitations.

Medusa: see diagnosis as for the genus.

Records from Mediterranean: coast of Apulia.

Known seasonality: 2-3.

Distribution: Mediterranean, all other records have to be confirmed on basis of hydroid cnidome studies.

References: Medel and López-González (1996); Boero et al. (2000).

\section{Subclass LAINGIOMEDUSAE Bouillon, 1978}

\section{Hydroid: unknown.}

Medusa: umbrella almost hemispherical, margin lobed, divided by peronial grooves or similar structures; 4 radial canals; no typical circular canal but a solid core of endodermal cells around umbrella margin; tentacles solid, inserted on exumbrellar surface above margin; tentacular bulbs in contact or not with the endodermal circular core; alternating with the tentacles there may be narrow exumbrellar cnidocyst bands or triangular ciliated fields; manubrium simple, quadrangular, tubular or conical; mouth opening simple, quadrangular to circular; "gonads" in 4 masses on the manubrium or as epidermal lining of interradial pockets of the manubrium; marginal sense organs apparently missing; cnidome: macrobasic mastigophores or macrobasic euryteles. Sexual reproduction unknown.

Remark: The Laingiomedusae represent the smallest group of Hydroidomedusa, two of the four species presently include in this subclass, Kantiella enigmatica and Laingia jaumotti present medusa budding with formation of a medusary nodule. This character and the presence of marginal tentacular bulbs allow their inclusion in the Hydroidomedusa. They present a mosaic of characters of Narcomedusae and Hydroidomedusa, more information about their life cycle are needed to ascertain their affinities with the other subclasses.

References: Pagès et al. (1992); Bouillon (1999); Bouillon and Barnett (1999); Bouillon and Boero (2000).

\section{Family LAINGIIDAE Bouillon, 1978c}

Laingiomedusae with umbrella divided by peronial grooves or similar structures so that umbrellar margin is lobed; four radial canals; no typical circular canal but a solid core of endodermal cells around umbrella margin; tentacles solid, inserted on the exumbrellar surface above bell margin; alternating with the tentacles there may be narrow exumbrellar cnidocyst bands or triangular ciliated fields; manubrium simple quadrangular, tubular or conical; mouth opening quadrangular to circular; «gonads» in four masses on the manubrium or as epidermal lining of interradial pockets of the manubrium; marginal sense organs apparently missing. Cnidome include macrobasic mastigophores or macrobasic euryteles. Sexual reproduction unknown.

1. With exumbrellar cnidocyst bands; marginal tentacular bulbs largely separated from marginal circular strand. Kantiella

- Without exumbrellar cnidocysts bands but with interradial ciliated fields; marginal bulbs only somewhat displaced towards exumbrella.

Fabienna

Genus Fabienna Schuchert, 1996

Laingiidae with slightly lobed umbrella margin; with four perradial tentacles that have their origin somewhat displaced towards the exumbrella; interradial triangular ciliated fields; larger cnidocysts confined to tentacle tips in one terminal cluster immediately followed proximally by an adaxial cluster; the two clusters may fuse in older individuals; cnidome includes macrobasic euryteles; «gonads» develop on manubrium only, in an interradial position.

Hydroid: unknown. 
Fabienna oligonema (Kramp, 1955)

(= Pochella oligonema) (Fig. 60A)

Medusa: umbrella $2 \mathrm{~mm}$ wide and high, mesoglea thick; with interradial triangular ciliated fields; with very broad gastric peduncle; manubrium cruciform; mouth with four simple inconspicuous lips; «gonads» interradial, oval, cushion-like; 4 simple radial canals; 4 perradial marginal tentacles with cnidocysts in a terminal cluster and a adjacent cluster, fused in adults.

Records from Mediterranean: eastern Mediterranean.

Known seasonality: 8; 9; 12.

Distribution: Atlantic; Mediterranean.

References: Kramp (1961); Goy et al. (1988, 1990, 1991); Dowidar (1983); Boero and Bouillon (1993); Schuchert (1996).

Genus Kantiella Bouillon, 1978

Laingiidae with exumbrellar cnidocyst bands; «gonads» on walls of four manubrial interradial pouches; 4 short marginal tentacles with terminal cluster of cnidocysts, above peronia-like structures.

Hydroid: unknown.

Kantiella enigmatica Bouillon, 1978 (Figs. 60B-C)

Medusa: umbrella 3-4 mm wide, 2-3 mm high, hemispherical, mesoglea thick at apex; exumbrella with 4-8 exumbrellar cnidocyst bands; with short and broad gastric peduncle; manubrium quadrangular; mouth margin quadrate or circular, without marked lips, mouth rim covered by cnidocysts; with 4 simple radial canals with virtual cavity, no real circular canal but a solid marginal endodermic core; 4 short marginal tentacles with terminal cluster of cnidocysts, inserted above peronia-like structures; «gonads» on interradial expansions of manubrium; with medusa buds on manubrium.

Records from Mediterranean: eastern Mediterranean. Seasonality: ?

Distribution: Indo-pacific; Mediterranean.

References: Bouillon (1978a, c ; 1985); Goy et al. $(1988,1990,1991)$.

Subclass LEPTOMEDUSAE Haeckel, 1866 (1879)

Hydroid: as "Thecata" hydroids; all parts of colony typically surrounded and protected by a rigid chitinous perisarcal structure of definite shape: hydranth with hydrotheca, nematophore with nematotheca and gonophores with gonotheca. Rarely with naked hydranths.

Medusa: flatter than bell-shaped, typically with hemispherical or flattened umbrella; "gonads" confined to radial canals, exceptionally extending onto the proximal part of manubrium; marginal sense organs, when present, in form of ectodermal velar statocysts, rarely cordyli, occasionally adaxial ocelli; marginal tentacles peripheral and hollow (except in Obelia), with tentacular bulbs; cnidome: often microbasic mastigophores and merotrichous isorhizae. Reproduction through a complex planula stage with cnidoblasts, interstitial cells, neural cells and usually two types of embryonic glandular cells.

\section{Order CONICA Broch, 1910}

Hydranth with a simple, generally conical or rounded-conical hypostome, without a "buccal cavity" beneath mouth opening; medusa varied in expression.

\section{Key to hydroids}

1. Hydranth naked, without intertentacular membrane Melicertidae

- Hydranth typically with hydrotheca (when exceptionally naked, i.e. Eirenidae, with intertentacular membrane)... 2

2. Hydrothecae with operculum ............................... 3

- Hydrothecae without operculum ......................... 8

3. Hydrothecae generally bilaterally symmetrical; usually with marginal teeth

- Hydrothecae radially symmetrical; without true marginal teeth 5

4. Hydrothecae generally pedicellate; usually with annular perisarcal diaphragm; hydranths with a basally annular ectodermal fold .....

Thyroscyphidae

- Hydrothecae generally sessile adnate; with diaphragm in few pedicellate forms, others having an eccentric hydropore; in some species with an abcauline gastric caecum and mantle (ectodermal lamella); without a basally annular ectodermal fold Sertulariidae

5. Operculum of two pleated membranes meeting one another like a gabled roof. Tiarannidae

- Operculum of 4 or more valves sharply or not sharply demarcated from hydrothecal wall...... 6 
6. Hydrothecae sessile; all medusa families with pleated or segmented operculum and with "Cus pidella-like" colonies.

.... Campanulinidae in part; Cirrholovenellidae, ...........Laodiceidae, Mitrocomidae, Tiaropsidae.

- Hydrothecae pedicellate $=$ all the medusa families with pleated or segmented operculum with "Campanulina-type" of hydroids .............. 7

7. Hydranth without intertentacular web Campanulinidae in part; ..Lovenellidae, Phialellidae

- Hydranth with intertentacular web. ..Aequoreidae; Blackfordiidae; Campanulinidae in part Eirenidae; .Lovenellidae, Malagazziidae

8. Hydrothecae saucer shaped or basin-shaped, usually to small to contain contracted hydranth . Haleciidae

- Hydrothecae usually deep enough to contain contracted hydranth.... . .9

9. Hydrothecae always restricted to one side of stem or branches; nematophores present in regular arrangement, usually 3-5 per hydrothecae

- Hydrothecae on two or more sides of stem or branches; nematophores if present seldom regularly arranged 13

10.'Paired lateral nematothecae present and fused to hydrothecae. Aglaopheniidae

- Paired lateral nematothecae present or absent, when present not fused to hydrothecae ........... 11

11.Paired lateral nematothecae absent; median nematothecae usually reduced and seldom twochambered. Kirchenpaueriidae

- Paired lateral nematothecae present; nematothecae usually two-chambered 12

12. Hydrocladia arising from erect stem; no cauline .......hydrothecae; hydrocauli when polysiphonic giving rise to hydrocladia from a single axial tube. Plumulariidae

- Hydrocladia arising from erect main stem or directly independently from hydrorhiza; stem or branches either with cauline hydrothecae or fas cicled and giving rise to hydrocladia or pinnae from any of its component tubes.

Halopterididae

13. Hydrotheca with a definite floor always sessile and bilaterally symmetrical, no nematothecae.... Syntheciidae

- Hydrothecae with no definite floor; with or without diaphragm hydrothecae sessile or pedunculate bilaterally or radially symmetrical, nematothecae present or absent. 14

14. Colonies usually stolonal; hydrothecae pedicellate; either with an annular perisarcal thickening and membranous diaphragm or thick diaphragm an no annular thickening; gonophores as swimming sporosacs, eumedusoids or free medusae, gonothecae single. Hebellidae

- Colonies usually erect; hydrothecae with or without pedicel, with or without diaphragm; without annular perisarcal thickening; gonophores as fixed sporosacs, gonothecae aggregated, exceptionally single or in pairs Lafoeidae

\section{Key to medusae}

1. Without statocysts or cordyli............................. 2

- With statocysts or cordyli.................................... 3

2. With large, broad, gastric peduncle, with numerous filiform, solid tentaculiform structures without marginal bulbs and not in connection with circular canal, with numerous ocelli Orchistomatidae

- Gastric peduncle absent or very weakly developed, without marginal tentaculiform structures, rarely with ocelli; with base of manubrium attached over its whole surface........ Melicertidae

3. With cordyli or cordyli like structures ............. 4

- With statocysts..................................................... 7

4. Manubrium with 4 perradial lobes connected with subumbrella; with cordyli like structures; «gonads» on manubrium and extending on perradial lobes ................................. Tiarannidae

- Manubrium without perradial lobes .................. 5

5. With cordyli like structures; gonads elongated forming linear sacs on radial canals, separated from manubrium; with or without open statocysts Teclaiidae

- With cordyli........................................................ 6

6. With 4 or 8 simple radial canals..... Laodiceidae

- With 4 or more branched radial canals Hebellidae

7. With open statocysts......................................... 9

- With closed statocysts ......................................... 8

8. With closed statocysts and adaxial ocelli.

Barcinidae

- With closed statocyst and without ocelli........ 10

9. Open statocyts associated with ocelli Tiaropsidae

- Open statocysts without ocelli..... Mitrocomidae 10. With distinct gastric peduncle; with 8 or many 
statocysts Eirenidae

- Without distinct gastric peduncle .. 11

11. Manubrium very broad; with many (more than eight) radial canals; tentacle bulbs with excretory pores on or not on excretory papillae . Aequoreidae

- Manubrium narrow; with normally 4-8 radial canals .. 12

12. Tentacle bulbs with excretory pores, 4-8 radial canals (sometimes 12). Malagazziidae

- Tentacle bulbs without excretory pores 13

13. Tentacle bulbs with lateral cirri.... Lovenellidae

- Tentacle bulbs without lateral cirri..... . .14

14.Exumbrella with marginal cirri

Cirrholoveniidae

- Exumbrella without marginal cirri .. 15

15. «Gonads» divided in two lateral parts separated by a median groove; 8 marginal statocysts Phialellidae

- «Gonads» completely surrounding radial canals; 8 or more statocysts. 16

16. Endodermal core of tentacles extending inwards from bell margin into bell mesoglea ... Blackfordiidae

- No endodermal tentacular expansions ..Campanulariidae (see under Proboscoida)

Family AEQUOREIDAE Eschscholtz, 1829

Hydroid: of "campanulinid" type; colony stolonal or erect, when erect only sparingly and sympodially branched; hydrotheca delicate, tubular, elongated, radially symmetrical, operculum as a continuation of hydrothecal wall, formed by several triangular convergent folds continuing downwards nearly to base of hydrotheca and not delimited by creaseline; in older colonies operculum generally lost, hydrotheca reduced to a perisarcal collar, acquiring a haleciid shape; hydranth contractile, with intertentacular web, tentacles amphicoronate, moniliformlike when completely extended; gonothecae pedicellate, very large, cylindrical, giving rise to one rarely to two medusae.

Medusa: manubrium very wide, circular; usually no gastric peduncle; many simple or branched radial canals; "gonads" on radial canals, separated from manubrium; marginal tentacles hollow; usually with excretory pores or papillae; no marginal or lateral cirri; statocysts closed; no ocelli.

Remark: without knowledge of life cycle, the hydroids of Aequorea are inadequate for species diagnosis (see Cornelius, 1995); some hydroid- based nominal species of Aequorea have nevertheless been described; their medusae, however, might have been known since a long time and they could be junior synonyms for instance: Aequorea africana Millard, 1966; Aequorea philippina Watson, 1998.

References: Russell (1970b); Pagès, Gili and Bouillon (1992); Watson (1998); Bouillon (1999); Bouillon and Barnett (1999); Bouillon and Boero (2000).

\section{Key for the medusae}

1. Radial canals branched or bifurcated

- Radial canals simple, undivided ........... Aequorea

Genus Aequorea Péron and Lesueur, 1810

Hydroid: when known, with the characters of the family. The hydroids are inadequate for diagnosis (see above) (Figs. 61A-D).

Medusa: Aequoreidae with numerous simple radial canals; subumbrella without rows of gelatinous papillae.

\section{Key to medusae}

1. «Gonads» no more than half as long as radial canals .............................................. A. conica

- «Gonads» along almost whole length of radial canals

2. About 4-10 or more times as many radial canals as tentacles.... A. pensilis

- With at least half as many tentacles as radial canals. A. forskalea

\section{Aequorea conica Browne, 1905}

(Fig. 60D)

Medusa: umbrella $9 \mathrm{~mm}$ wide, 10-12 $\mathrm{mm}$ high, conical, with very thick mesoglea; manubrium half as wide as umbrella diameter, often broad and flat; mouth with long and slender lips with inward furrow which continues along inside of manubrium to radial canals; about 16 radial canals, twice as many tentacles (20-30), and as many small bulbs, both without excretory papillae or pores; about twice as many statocysts as tentacles; «gonads» laterally compressed, in proximal half of radial canals.

Records from Mediterranean: eastern Mediterranean.

Known seasonality: 6. 
Distribution: Indo-Pacific; Mediterranean.

References: Kramp (1961); Goy et al. (1988, 1990, 1991); Boero and Bouillon (1993).

Hydroid: unknown.

Aequorea forskalea Péron and Lesueur, 1810 (Figs. 60E-F, 61A-D)

Hydroid: colonies minute, stolonal with single or slightly branching erect hydrocauli which are imperfectly annulated or spirally grooved throughout their length; hydrothecae cylindrical, with a long conical folded operculum tapering to a fine sharp point, the folds continuing as striations of perisarc downwards nearly to base of hydrotheca, hydrothecal base at right angles to lateral walls; hydranths very extensile, with about 20 amphicoronate filiform oral tentacles united at their base by a prominent intertentacular membranous web; gonothecae very large and cylindrical, blunt-ended, arising from hydrocaulus on short imperfectly annulated stems just below hydranths and containing one rarely two medusa buds.

Medusa: umbrella large, up to $175 \mathrm{~mm}$ wide, saucer-shaped, thick in centre, gradually thinning towards margin; manubrium half as wide as umbrella; radial canals usually $60-80$, sometimes fewer or up to 160; «gonads» along almost whole length of radial canals; tentacles generally fewer than radial canals but varying from half to twice as many; tentacle bulbs elongate, conical; small bulbs few, scattered; excretory pores on short papillae; 5 -10 statocysts between successive radial canals.

Records from Mediterranean: eastern and western Mediterranean; Adriatic.

Known seasonality: 1-12.

Distribution: Atlantic; Indo-Pacific, Mediterranean.

References: Rees, 1938; Babnik (1948); Russell (1953); Kramp (1961); Berhaut (1970); Goy (1973b); Brinckmann-Voss (1987); Gili (1986); Goy et al. (1988, 1990, 1991); Boero and Bouillon (1993); Cornelius (1995); Avian et al. (1995); Benovic and Lucic (1996); Medel and López-González (1996).

\section{Aequorea pensilis (Eschscholtz, 1829)} (Figs. 61E-F)

Medusa: umbrella up to $100 \mathrm{~mm}$ wide, more or less biconvex, with thin margin; manubrium 1/2-2/3 as wide as umbrella; «gonads» extending along almost entire length of manubrium; 150-250 radial canals; $10-16$ tentacles and as many small rudimen- tary bulbs; tentacle bulbs with long lateral extensions, no abaxial keel; without excretory papillae but excretory pores present as slits; statocysts very numerous.

Hydroid: unknown.

Records from Mediterranean: ?

Seasonality: ?

Distribution: Atlantic; Indo-Pacific, Mediterranean?

References: Russell (1953); Kramp (1961); Boero and Bouillon (1993).

Genus Zygocanna Haeckel, 1879

Medusa: Aequoreidae with numerous radial canals, branched or bifurcated; exumbrella sometimes with radial rows of gelatinous papillae.

Hydroid: unknown.

Zygocanna vagans Bigelow, 1912 (Figs. 61G-H)

Medusa: umbrella up to $76 \mathrm{~mm}$ wide, flat, thin, but of hard consistency; exumbrella with radial bands of gelatinous papillae alternating with radial canals; velum broad; manubrium occupying 1/3-1/2 of umbrellar diameter, roof of the manubrium presenting a cruciform structure bifurcating two or four times before reaching the manubrium periphery where the bifurcations give rise to about 30-45 non branched radial canals; mouth with crenulated lips; «gonads» extending along greatest part of radial canals without reaching the umbrella margin; 28-70 tentacles and several small rudimentary bulbs, with long excretory papillae; statocysts very numerous.

Records from Mediterranean: Adriatic Sea.

Known seasonality: 10.

Distribution: Atlantic; Indo-Pacific; Mediterranean.

References: Babnik (1948) as Zygocanna. sp.; Boero and Bouillon (1993); Avian et al. (1995).

Family AglaopheniIdae L. Agassiz, 1862

Hydroid: colony upright, mono- or polysiphonic, branched or unbranched, arising from creeping hydrorhiza or from anchoring filaments; hydrocladia alternate or opposite in one plane, or arranged spirally; hydrothecae uniseriate, usually completely adnate, margin usually cusped, with or without intrathecal septum, absent from hydrocaulus except in basal most segment; nematophores with nema-

118 J. BOUILLON et al. 
tothecae, not as naked sarcostyles; nemathothecae at least partially fused to hydrothecae, one-chambered (monothalamic) and immovable; hydrotheca typically flanked by three nematohtecae (five in some species of Aglaophenia and sometimes in Cladocarpus), usually with one pair of lateral nematothecae, and with an unpaired median inferior nemathotheca that may be doubled or have two terminal apertures; sometimes also a pair of superior nematothecae; gonothecae lacking nematothecae, unprotected, or surrounded by recurved branches in phylactocarp, or nearly completely enclosed within corbula both richly provided with nematothecae; fixed sporosacs or swimming gonophores.

References: Svoboda (1979); Svoboda and Cornelius (1991); Cornelius (1995); Migotto (1996); Calder (1997); Calder and Vervoort (1998); Watson (2000); Ansín Agís et al. (2001); Schuchert (2001a, 2003).

\section{Key to hydroids}

1. Gonotheca unprotected Gymnangium

- Gonotheca protected in corbula or in phylactocarp 2

2. Gonotheca protected in corbula replacing hydrocladia with secondary ribs 3

- No true corbula, gonotheca solitary and protected by branched or unbranched phylactocarps.

3. Corbula ribs comprising nematothecae and hydrothecae. Lytocarpia

- Corbula comprising only nematothecae.

4. Phylactocarps formed by a modified hydrocladium, single or aggregated into pseudo-corbulae Macrorhynchia

- Phylactocarps arising as appendages of an unmodified hydrocladium ....

5. Hydrocladia arranged in a spiral around stem .... Streptocaulus

- Hydrocladia arranged in two longitudinal rows.. Cladocarpus

\section{Genus Aglaophenia Lamouroux, 1812 = Pentandra von Ledenfeld, 1884}

Hydroid: colony erect, hydrocaulus branched or unbranched, monosiphonic or polysiphonic, arising from creeping hydrorhiza or anchoring filaments; hydrocladia unbranched, pinnately arranged, arising from alternate apophyses; hydrothecae only on hydrocladia, typically more or less cone to sacshaped, margin usually deeply toothed; intrathecal septum variably developed; each hydrotheca flanked typically by a pair of lateral nematothecae and a partly to wholly adnate, median inferior nematotheca sometimes a pair of median superior nematothecae; gonothecae aggregated, enclosed within a corbula formed by modified hydrocladia bearing alternately inserted secondary ribs with nematothecae and lacking basal hydrothecae, corbula ribs fused or not; as fixed sporosacs, or released swimming gonophores.

Remark: Von Lendenfeld (1884) created Pentan$d r a$ to accommodate $P$. balei and $P$. parvula, with 5 nematothecae surrounding the hydrothecae: one median inferior, two lateral and a pair of superior (see diagnoses and Fig. 16 by Von Lendenfeld, 1884), the last pair having been treated by many authors as a supplementary pair of lateral nematothecae! Bedot (1921) listed a series of genera and species showing deviations in numbers to the typically three hydrothecal nematothecae and stated that there was no need to create new genera for such variations. We agree with his conclusions and consider Pentandra as congeneric with Aglaophenia.

References: Svoboda and Cornelius (1991); Ramil and Vervoort (1992a); Cornelius (1995); Calder (1997).

1. Stems without any basal prosegment A. picardi

- Stems with one or more basal prosegment ...... 2

2. Hydrotheca with a greatly developed transverse abcauline septum recurved at the tip.....

A. kirchenpaueri

- Hydrotheca without this character ................... 3

3. Free part of mesial nematotheca long, usually much longer than the free part of abcauline wall, and directed away from hydrotheca

A. tubulifera

- Mesial nematotheca without this character...... 4

4. Coenosarc with zooxanthellae; perisarc of stem, hydrocladia and corbulae yellowish to brown .5

- Coenosarc without zooxanthellae; perisarc of the stem, hydrocladia and corbulae not with a same colour....

5. Colonies growing only on Sea grasses, stem sometimes with intersegments; hooked apical stolons in summer... A. harpago

- Colonies growing in different substrates, without intersegments neither hooked apical stolons A. tubiformis 
6. Hydrotheca with the adcauline intrathecal septum long; hydrotheca usually narrowed basally, shape triangular more than tubular .... 7

- Hydrotheca with the adcauline intrathecal septum usually short or absent; hydrotheca tubular. 8

7. Rim with non-uniform cusps, in side view mesial cusp inclined toward lumen; second pair of cusps bifid A. parvula

- Rim with uniform cusps; second pair of cusps single A. octodonta

8. Mature cormoid comprising one or many plumes branched or unbranched 9

- Mature cormoid comprising a single and unbranched plume A. lophocarpa

9. Branching dichotomous ...................... A. pluma

- Branching trichotomous or irregularly bifid .. 10

10.Ramus arising from apical end of a segment with prosegments, comprising several roughly normally arranged cormidia. A. acacia

- Ramus always arising from a normal caulus segment which has one normally developed cladium A. elongata

Aglaophenia acacia Allman 1883 (Figs. 62A-D)

Colonies pinnate (up to $\mathrm{ca} 200 \mathrm{~mm}$ ), stems grouped closely, monosiphonic and branched; axis brown, athecate basally, followed by a prosegment; remainder parts thecate, nodes oblique; internodes of the axis with three nematothecae and an abortive hydrotheca (pseudonematotheca). Major branches (rami) widely spaced on stem, typically paired, or one of a pair replaced by a corbula; at point of branching, caulus bending back versally resulting in a trichotomous arrangement. Secondary hydrocauli with some of the basal internodes without hydrocladia, but with cormidia almost similar to those of the hydrocladia; however, the mesial nematotheca is placed on the lower part of the internode, without contact with the abcauline hydrothecal wall. Hydrocladia white, alternate, closely set, one cormidium per internode, nodes transverse; hydrotheca narrow and deep (length/breadth ratio: 1-2), rim with 9 shallow cusp, outermost longest; intrathecal ridge short; mesial nematotheca short, reaching half length of hydrothecal abcauline wall, 1/3 of the nematothecae free; aperture gutter shaped; lateral nematothecae surpassing hydrothecal rim, slightly swollen. Male and female corbula white, with the costae completely fused, male without free costa; female sometimes first/last rib on each side free.
Records from Mediterranean: eastern and western Mediterranean.

Known seasonality: 1-12.

Reproduction: 1, 2, 4-8, 12.

Distribution: northern Atlantic (east and west), Mediterranean.

References: Fraser (1944); Svoboda (1979); Svoboda and Cornelius (1991); Boero and Bouillon (1993); Avian et al. (1995); Cornelius (1995); Medel and Vervoort (1995); Medel and LópezGonzález (1996); Ansín Agís et al. (2001); Peña Cantero and García Carrascosa (2002).

\section{Aglaophenia elongata Meneghini, 1845 (Figs. 62E-G)}

Hydrocauli monosiphonic, up to $300 \mathrm{~mm}$ high, pinnate and branched, closely grouped. Axis brownish, basally with 1-4 prosegment, nodes oblique. Remainder internodes each bearing three nematothecae and one abortive hydrothecae (pseudonematothecae); nodes indistinct. Branches arising between mesial, proximal nematothecae and cladium or corbula, with 1-3 prosegment basally. Ramus and cladium of same internode aligned parallel with each other; up to $4^{\text {th }}$ order of branching. Hydrocladia yellow, alternate, spaced on stem, cormidia with one hydrothecae and three gutter-shaped nematothecae. Hydrotheca narrow and deep (length/breadth ratio: 1.7-2.5), rim with 9 uniform cusps; adnate mesial nematotheca reaching 1/3-1/2 of the hydrotheca, free end short. Lateral nematothecae slightly above hydrothecal rim. Male and female corbulae in different colonies. Corbulae short, yellowish to white, 4-6 pairs of ribs fused in female, with slits in male; free costa absent. Hydranth very large with usually long tentacles.

Records from Mediterranean: western and eastern Mediterranean, Adriatic.

Known seasonality: 1,;4,;7-11.

Reproduction: 4;6-11.

Distribution: widely reported around the world but records outside Mediterranean seem erroneous (Svoboda and Cornelius, 1991).

References: Svoboda (1979); Svoboda and Cornelius (1991); Boero and Bouillon (1993) Avian et al. (1995); Peña Cantero and García Carrascosa (2002).

Aglaophenia harpago von Schenck, 1965 (Figs. 62H-K)

Hydrorhizae growing only along sea grass blade. Well developed monosiphonic hydrocauli brown, up 
to $18 \mathrm{~mm}$, bending backwards; one prosegment basally separated by very deep oblique furrows, which allow bending in response to current surge; remainder parts of the axis composed of segments bearing one pseudonematothecae and three nematothecae gutter shaped; nodes slightly oblique; in some stems, intermediate segments with frontal nematothecae occurs distally, between hydrocladiabearing segments. Caulus ended by thick, narrow hook may occurs specially in spring and summer. Coenosarc of the colony with zooxanthellae. Hydrocladia brown, more spaced than in other Aglaophenia species; cormidia with one hydrothecae and three nematothecae. Hydrothecae may vary from long and narrow in some colonies to wider and shorter in other ones (length/breadth ratio: 1.8, -1.4). Colonies dioecious, corbulae brown, short, 4-6 pairs of ribs fused in female, partly open in male.

Records from Mediterranean: eastern and western Mediterranean, Adriatic.

Known seasonality: 2, 3, and 5, 6, 8, 9.

Reproduction: 3-7.

Distribution: endemic of Mediterranean Sea.

References: Svoboda (1979); Gili (1986); Roca (1986); Svoboda and Cornelius (1991); Boero and Bouillon (1993); Avian et al. (1995); Medel and López-González (1996).

\section{Aglaophenia kirchenpaueri (Heller, 1868) (Figs. 63A-D)}

Hydrocauli pinnate, up to $200 \mathrm{~mm}$ high yellowish to brown, monosiphonic and unbranched; basal part of the axis athecate, followed by up to three prosegments, each with a frontal nematotheca. Remainder internodes with three nematothecae and a pseudonematotheca; nodes oblique. Hydrocladia yellow or brown, alternate, closely set; cormidia each with one hydrothecae and three nematothecae (one median inferior and two laterals); nodes transverse. Hydrotheca not deep (length/breadth at rim: 1-1.3), with a greatly developed transverse abcauline septum recurved at the tip; rim with 9 marginal cusps, first pair on both sides longest, remainder marginal cusps grading towards axis of cormidium. Median nematothecae not surpassing hydrothecal rim, 2/3 adnate, aperture gutter-shaped. Lateral nematothecae projecting slightly above hydrothecal rim; distal portion curved outwards, aperture gutter-shaped. Corbulae yellow or brown, male partially open, usually without free costae; female usually closed and with free costa.
Records from Mediterranean: western Mediterranean as far east as Adriatic Sea.

Known seasonality: 1-12.

Reproduction: 2; 4-11.

Distribution: northeastern Atlantic from British coasts to Cape Verde Islands; Mediterranean.

References: Patriti (1970); Svoboda (1979); Svoboda and Cornelius (1991); Ramil and Vervoort (1992a); Boero and Bouillon (1993); Cornelius (1995); Medel and Vervoort (1995); Medel and López-González (1996); Ansín Agís et al. (2001); Peña Cantero and García Carrascosa (2002).

\section{Aglaophenia lophocarpa Allman, 1877} (Figs. 63E-H)

Hydrocauli pinnate, up to $c a 50 \mathrm{~mm}$, monosiphonic and unbranched; colour brown. Axis basally with 1-3 prosegment with frontal nematothecae separated by transverse nodes; remainder parts with internodes bearing hydrocladia; each with one pseudonematothecae and three nematothecae; nodes indistinct. Hydrocladia widely spaced on stem; hydrothecae narrow and deep (length/breadth at rim: 1.7-2.1), rim with 9 uniform cusps; short intrathecal septum in lower third of hydrothecae; adnate part of mesial nematotheca reaching the middle of hydrotheca, free part short, foramen into hydrothecae usually open; lateral nematothecae reaching the hydrothecal rim or slightly overtopping. Colonies dioecious; female corbulae brown, ribs fused; male white, ribs usually with slits between nematothecae, but fused ribs may occurs.

Records from Mediterranean: western and eastern Mediterranean, Adriatic.

Known seasonality and reproduction: 4-9.

Distribution: tropical eastern Atlantic (Azores, Guinea Bissau); Caribbean; Mediterranean.

References: Svoboda (1979); Gili, Vervoort and Pagès (1989); Svoboda and Cornelius (1991); Ramil and Vervoort (1992a); Boero and Bouillon (1993); Ansín Agís et al. (2001).

\section{Aglaophenia octodonta (Heller, 1868)}

(Figs. 63I-L)

Hydrocauli monosiphonic, yellowish to brown and unbranched. Axis basally, with several transverse nodes and with 1-3 prosegments separated by oblique nodes; remainder parts composed of hydrocladia bearing internodes, with three gutter-shaped nematothecae and a pseudonematothecae; nodes oblique. 
Hydrocladia transparent to yellowish, closely alternate; cormidia separated by transverse nodes. Hydrothecae not deep (length/breadth at rim: 1.11.4), narrowing basally and thus of triangular shape; rim with 9 uniform cusps; adcauline septum in lower third of hydrothecal cavity well developed; median nematothecae $2 / 3$ adnate, free end short almost reaching the hydrothecal rim; end of nematothecae usually curved outwards and reaching almost at level of hydrothecal rim. Lateral nematothecae small, apical part swollen, reaching hydrothecal rim. Male corbula white, without free costa and usually partly open; female corbula yellow, usually closed, with one well developed free costa.

Records from Mediterranean: eastern and western Mediterranean, Adriatic.

Known seasonality and reproduction: throughout the year.

Distribution: northeastern Atlantic and Mediterranean.

References: Rossi (1961); Svoboda (1979); Gili (1986); Roca (1986); Svoboda and Cornelius (1991); Ramil and Vervoort (1992a); Boero and Bouillon (1993); Avian et al. (1995); Medel and Vervoort (1995); Medel and López-González (1996); Ansín Agís et al. (2001); Peña Cantero and García Carrascosa (2002).

Aglaophenia parvula Bale, 1882 (Figs. 64A-D)

Hydrocauli monosiphonic, up to $70 \mathrm{~mm}$, yellowish to brown, unbranched or dichotomously branched. Axis basally provided or not with several transverse nodes and 1-3 prosegments separated by oblique nodes; remainder internodes each with three nematothecae and a pseudonematothecae. Hydrocladia alternate, closely set, divided into cormidia separated by transverse nodes. Hydrotheca fairly deep, narrowing basally, with a triangular aspect; rim with nine unequal marginal cusps, outermost cusp single, unpaired, flexed interiorly; third pair bifid apex in varied degree; intrathecal septum well developed, almost reaching opposite hydrothecal wall; mesial nematothecae almost reaching hydrothecal rim; lateral nematohtecae short, not reaching hydrothecal rim. Colonies dioecious, male corbula with small slits between nematophores of ribs; female corbula ribs fused with exception of rachial basis.

Records from Mediterranean: found in the nearby areas of the Strait of Gibraltar.

Seasonality: ?
Distribution: eastern Atlantic; S Australia, Mediterranean?.

References: Millard (1975) as A. pluma parvula; Ramil (1988); Gili et al. (1989); Svoboda and Cornelius (1991); Medel and Vervoort (1995); Medel and López-González (1996); Ansín Agís et al. (2001).

Aglaophenia picardi Svoboda, 1979 (Figs. 64E-H)

Hydrocauli monosiphonic and unbranched, up to $80 \mathrm{~mm}$, axis brown, without any basal prosegment, but several transverse nodes may occurs. Remainder parts composed of thecate internodes bearing hydrocladia, each with three nematothecae and a pseudonematothecae; nodes oblique. Hydrocladia alternate, widely spaced, perisarc transparent, divided into cormidia by transverse nodes. Hydrothecae deep (length/breadth at rim: 1.5), rim with nine uniform cusps, adcauline septum in lower third of hydrotheca inconspicuous or absent; median nematothecae gutter shaped, almost complete adnate to the hydrothecae, this with almost a half of its length free. Lateral nematothecae reaching hydrothecal rim. Corbulae transparent to white, male with large openings between the pairs of opposite costae; female closed, with the proximal pairs of ribs almost free.

Records from Mediterranean: eastern and western Mediterranean, Adriatic.

Known seasonality: 1-12.

Reproduction: 1-12

Distribution: northeastern Atlantic (N Spain, Cape Verde Is.), Black Sea; Mediterranean.

References: Svoboda (1979); Isasi (1985); Svoboda and Cornelius (1991); Ramil and Vervoort (1992a); Avian et al. (1995); Medel and Vervoort (1995); Medel and López-González (1996); Ansín Agís et al. (2001); Peña Cantero and García Carrascosa (2002).

Aglaophenia pluma (Linnaeus, 1758) (Figs. 64I-L)

Hydrocauli monosiphonic up to $150 \mathrm{~mm}$, brown, unbranched or dichotomously branched; basal part of the axis athecate, followed by one or two prosegments; remainder internodes, each with three nematothecae and a pseudonematotheca; nodes oblique. Hydrocladia alternate, with whitish cormidia separated by transverse nodes. Hydrotheca deep (length/breadth at rim: 1.3-1.5), rim with nine cusps 
of varied length; intrathecal adcauline septum usually well developed, median nematothecae 2/3 adnate, not reaching the margin of the hydrothecae; lateral nematothecae reaching the rim of the hydrothecae; aperture of nematothecae gutter-shaped. Colonies dioecious, male and female corbulae white, with free costa; male close, with slit like openings between the costae, female with fused costae and smaller slits. Hydranth small, transparent, cylindrical, hypostome held at level of hydrothecal rim, rounded and low; ten tentacles emerging of hydrothecal rim.

Records from Mediterranean: western Mediterranean.

Known seasonality and reproduction: almost all the year.

Distribution: cited as cosmopolitan species, but this need of evaluation due to identification problems. Reliably reported from Shetlands, British Islands, France, Belgium, Spain and Portugal, in the north eastern Atlantic.

References: Vervoort (1946); Patriti (1970); Svoboda (1979); Svoboda and Cornelius (1991); Boero and Bouillon (1993); Medel and Vervoort (1995); Medel and López-González (1996); Ansín Agís et al . (2001); Peña Cantero and García Carrascosa (2002).

\section{Aglaophenia tubiformis \\ Marktanner-Turneretscher, 1890 (Figs. 65A-E)}

Hydrocauli monosiphonic up to $150 \mathrm{~mm}$, yellowish to brown, unbranched or dichotomously branched. Axis basally athecate, with several transverse nodes, followed by one (rarely two) prosegment separated by oblique nodes. Remainder internodes each with three nematothecae and a pseudonematothecae. Hydrocladia alternate, yellowish to brown, divided into cormidia by transverse nodes; cormidia composed of one hydrothecae and three nematothecae. Hydrotheca deep (length/breadth at rim: 1.5-2), rim with 9 more or less equal cusps, intrathecal adcauline septum moderately developed; mesial nematotheca arising between the middle and upper third of hydrotheca, free portion of variable length; lateral nematothecae reaching or overtopping the hydrothecal rim; nematothecae with a gutter shaped aperture. Coenosarc filled with zooxanthellae. Colonies dioecious; corbulae brown, with the first pair of ribs free; male with slits between ribs; female with almost completely fused ribs.

Records from Mediterranean: eastern and western Mediterranean, Adriatic (but not Black Sea).

Known seasonality: 1-12.
Reproduction: 2-10.

Distribution: northeastern Atlantic, Mediterraean.

References: Svoboda (1979); Ramil (1988); Svoboda and Cornelius (1991); Ramil and Vervoort (1992a); Boero and Bouillon (1993); Alvarez (1993); Avian et al. (1995); Medel and Vervoort (1995); Medel and López-González (1996); Peña Cantero and García Carrascosa (2002).

\section{Aglaophenia tubulifera (Hincks, 1861)} (Figs. 65F-I)

Colonies pinnate up to $60 \mathrm{~mm}$, composed of monosiphonic and unbranched hydrocauli with alternate hydrocladia. Axis basally with a prosegment separated by oblique nodes; occasionally also with several transverse nodes; remainder parts composed of bearing-hydrocladia internodes, each with one pseudonematothecae and three nematothecae; nodes transverse. Hydrocladia alternate, closely packed, each composed of a large number of cormidia; nodes transverse. Hydrotheca not deep; adcauline septum weakly developed, rim with 9 marginal cusp, the median one longest. Nematothecae around hydrotheca without embayment; mesial nematothecae long, free part directed away from hydrotheca. Coenosarc with zooxantellae. Colonies dioecious; male corbula with slits between ribs, female with almost completely fused ribs and a basal free costa. Hydranth short, cylindrical, when extending not projecting beyond hydrothecal rim; hypostome hemispherical, ten short tentacles.

Records from Mediterranean: western Mediterranean (Spain, Morocco).

Known seasonality: 5, 6, 7, 9.

Reproduction: 5, 6, 7.

Distribution: northeastern Atlantic, Mediterranean.

References: Patriti (1970); Svoboda (1979); Gili et al. (1989); Svoboda and Cornelius (1991); Boero and Bouillon (1993); Medel and Vervoort (1995); Medel and López-González (1996); Ansín Agís et al. (2001).

Genus Cladocarpus Allman, 1874

= Aglaophenopsis Fewkes, 1881

= Nematocarpus Broch, 1918

= Wanglaophenia Vervoot and Watson, 2003

Hydroid: colony erect, monosphonic or polysiphonic, hydrocaulus branched or unbranched, bearing alternate usually unbranched hydrocladia; hydrocladia internodes with numerous septa; hydrotheca deep, 
often S-shaped, with or without intrathecal septa, usually with a median abcauline tooth, with or without lateral teeth; nemathotheca usually with more than one aperture, median inferior nematotheca short, usually below hydrotheca, never reaching thecal margin, sometimes a superior nematotheca; gonothecae not contiguous, usually protected by loose phylactocarps with either unbranched or dichotomously branched axis made of a regular succession of segments each with 2-3 nematothecae and bearing an alternate apophysis supporting a nematophorous branch, usually without hydrothecae, phylactocarp structures resembling stag antlers.

Remarks: Ramil and Vervoort (1992 b) pointed out that the genus Cladocarpus contains two groups of species with a different morphology of phylactocarps. In the first one, the phylactocarp is homologous with the hydrocaulus of Aglaopheniidae, unbranched or branched and with segments bearing nematophorous branches; in the second one, being similar to the structure of hydrocladia, with segment bearing each pairs (or a pair) of nematothecae in opposite pairs. The first group of species, in their opinion, should remain in Cladocarpus Allman, 1874 and the second group should be placed in Streptocaulus Allman, 1883. But as remarked by Schuchert (2001 a) some species of Cladocarpus have the proximal part of the phylactocaps of one type and the distal one of the other (Cladocarpus bonneviae) and in some species of Cladocarpus the phylactocarps are not referable to one of the described types (C. integer). Schuchert (2001a) consider therefore that the genus needs comprehensive phylogenetical analyses to recognize monophyletic taxa with sufficient reliability and that the types of phylactocarps have to been defined more precisely.

1. Abcauline hydrothecal wall curvate 2

- Abcauline hydrothecal wall straight 3

2. Abcauline hydrothecal wall with double curvature; with intrathecal septum .. C. sinuosus

- Abcauline wall strongly concave; without intrathecal septum C. tenuis

3. Aperture of hydrotheca even ...... C. pectiniferus

- Aperture of hydrotheca with a prominent abcauline cusp C. multiseptatus

Cladocarpus multiseptatus (Bale, 1915) (Fig. 65K)

Colonies pinnate up to $c a 15 \mathrm{~mm}$; hydrocauli polysiphonic composed of several tubes of which, a "main" frontal axis bearing nematothecae. Hydrocladia borne on apophyses, alternate; internodes with one hydrotheca and three nematothecae, one median inferior and two lateral; nodes slightly oblique; each internode with 9-13 transverse perisarcal septa behind hydrothecae, 2-4 below and 1-2 above. Hydrotheca tubular, deep, tapered basally, widing distally; adcauline wall entire adnate; abcauline wall slightly curved outwards at distal third; margin sinuous, with a prominent median abcauline cusp. Nematothecae tubular, gradually narrowing towards distal end; median inferior not reaching hydrothecal base, with two apertures, one distally, slit-shaped, the other one, circular, at the end of a short tube basally on the nematotheca, and directed towards hydrocladial wall; lateral nematothecae reaching beyond hydrothecal rim, also with two apertures, one apical, with a sinuous rim, and another one basal, on adcauline side, at end of short tube with a incomplete internal septum at its base; cauline nematothecae with unique apical aperture. Gonothecae protected by unbranched phylactocarps with nematothecae.

Records from Mediterranean: only Alboràn Sea. Known seasonality: 6.

Distribution: N Spain, Australia and Mediterranean (Alboràn Sea).

References: Ramil and Vervoort (1992a); Alvarez (1993); Medel and López-González (1996).

\section{Cladocarpus pectiniferus Allman, 1883}

(Figs. 65L-N, 66A-C)

Hydrocauli polysiphonic basally, up to $100 \mathrm{~mm}$ high, growing from matting of perisarcal tubules. Frontal tube of the axis with a row of frontal nematothecae and apophyses bearing hydrocladia; usually 2-5 nematothecae between two apophyses but very variable, one nematothecae borne in the axil of each apophysis. Nematothecae tubular, with a single apical aperture. Hydrocladia alternate, composed of internodes separated by slightly oblique nodes; each internode with one hydrotheca and three nematothecae, one median inferior and two laterals; internodes with 17-27 septa. Hydrothecae tubular, elongated; walls almost straight; adcauline wall entire adnate, abcauline wall slightly curved outwards distally; rim smooth, somewhat convex frontally. Nematothecae tubular, with two openings, one terminal with slightly serrated border, and one basal adcauline; lateral nematothecae with the two apertures connected, may occurs also; median inferior nematothecae 
reaching or not hydrothecal base; lateral nematothecae overtopping hydrothecal rim. Phylactocarps in pairs at first hydrocladial internode, composed of rachis bearing gonothecae and paired nematothecae; rachis with four internodes, each with basal and distal septum; first two segments with two pairs of nematothecae, the rest with only one pair; nematothecae tubular, elongated, with two apertures, one distally, finely serrated, and one basal, large and oval; one or two additional, smaller may occurs in between.

Records from Mediterranean: only Alboràn Sea. Known seasonality: 5, 6

Distribution: northeastern Atlantic, from Iceland to Morocco, and Alboràn Sea.

References: Vervoort (1966); Ramil and Vervoort (1992 a and b); Medel and López-González (1996); Schuchert (2001a).

\section{Cladocarpus sinuosus Vervoort, 1966} (Figs. 66D-I)

Colonies pinnate with monosiphonic or polysiphonic and unbranched hydrocauli up to $53 \mathrm{~mm}$; main frontal axis bearing a row of nematothecae and alternate hydrocladial apophyses; one nematothecae is borne in the axil of each apophysis; hydrocladium composed of hydrothecate internodes separated by oblique septa; internodes sinuous, with one hydrothecae and three nematothecae, one median inferior and two laterals overtopping hydrothecal rim. each internode internally with 8-12 thick septa: 3 basal, 6-8 behind hydrothecae and one apical; hydrotheca deep, with transverse adcauline septum recurved at the tip at lower third; adcauline wall entire adnate, concave above insertion of septum; abcauline wall with double curvature, strongly convex in basal half, and strongly concave at about distal third; rim even, with a unique median abcauline cusp. Median inferior nematotheca almost reaching hydrothecal base, with two apertures, one distal and one basal towards hydrothecal wall; lateral nematothecae tubular, with two apertures, one terminal and one mesial, with intrathecal septum; cauline nematothecae also with two apertures, one terminal and one basal, towards axial wall; phylactocarp borne on first internode of hydrocladium, curved and unbranched, with short internodes with two very long, curved nematothecae with up to four apertures, one terminal and the rest along the upper surface; gonothecae below first pair of nematothecae, ovoid with truncated distal end.
Records from Mediterranean: only Alboràn Sea. Known seasonality: 6.

Distribution: eastern Atlantic (coasts of Africa) and Alboràn Sea.

References: Vervoort (1966); Millard (1975); Gili et al. (1989); Ramil and Vervoort (1992a); Medel and López-González (1996).

\section{Cladocarpus tenuis Clarke 1879}

(Figs. 66J-K)

Hydrocaulus unfascicled attaining a height of about $40 \mathrm{~mm}$, very delicate, bearing alternate hydrocladia, containing some oblique nodes in basal region only, bearing a row of nematothecae on anterior surface, of which one is seated in the axil of each apophysis; hydrocladium consisting of weakly sigmoid thecate internodes separated by slightly oblique nodes; internodes containing numerous septa and bearing three nematothecae, one median inferior and two laterals; hydrotheca very deep and slender, not sigmoidally curved, narrowest in the center then widening to margin, abcauline wall concave in the centre; adcauline wall straight; without intrathecal septum; margin with one mediane abcauline tooth and crenulated lateral edges; median inferior nematotheca free from hydrotheca, short not reaching thecal base; with large fan-shaped terminal aperture, lateral nematotheca tubular, overtopping thecal margin, with terminal aperture; cauline nematothecae similar to median inferior; phylactocarp borne on first internode of hydrocladium, unbranched, segmented, with two long nematothecae on each internode, nematotheca with three apertures, one terminal and two laterals; gonothecae unknown.

Records from Mediterranean: western Mediterranean.

Seasonality: ?

Distribution: Gulf of Mexico; West Indies; Mediterranean.

References: Nutting (1900); Vervoort (1966); Millard (1975); Marinopoulos (1981).

$$
\begin{gathered}
\text { Genus Gymnangium Hincks, } 1874 \\
=\text { Haliaria } \text { Stechow, } 1921 \\
=\text { Halicetta } \text { Stechow, } 1921
\end{gathered}
$$

Hydroid: colony erect, often stout, monosiphonic or polysiphonic, arising from a creeping hydrorhiza or from anchoring filaments; hydrocladia unbranched, alternate or opposite, giving off from opposite sides of 
hydrocaulus; hydrothecae only on hydrocladia, typically more or less cone-shaped, intrathecal septum present or absent, margin with or without cusps; each hydrotheca with a pair of lateral nemathotecae and a single adnate median inferior nematotheca, conspicuously longer than hydrotheca (2-3 times), and having more than one opening; gonotheca solitary, usually borne on hydrocladia, not protected by phylactocarps or corbulae; fixed sporosacs, one species with swimming gonophores (G. ferlusi).

References: Cornelius (1995); Calder (1997); Schuchert (2003).

Gymnangium montagui (Billard, 1912)

(Figs. 66L-O)

Colonies erect and monosiphonic up to $120 \mathrm{~mm}$, with a yellowish to brown hydrocauli and a thick hydrorhiza. Axis segmented into short internodes; nodes slightly oblique; each internode with two lateral apophyses bearing hydrocladia, alternate, one basal and the another one distal; two cups-shaped nematothecae are located basally to each apophysis, an upper and a lower. Hydrocladia alternate, closely set, internodes short, nodes almost transverse; each internode with one hydrotheca and three nematothecae; hydrotheca cup-shaped, 2/3 of adcauline wall adnate, a distinct, slightly curved abcauline internal septum at half length of abcauline wall, dividing it into two convex portions; hydrothecal aperture inclined downward, rim sinuous, occasionally with indication of lateral cusp on each side; lateral nematothecae also cupshaped, median nematotheca much elongated, curved, surpassing hydrothecal border considerably, free part at least half length of adnate part or more, opening gutter-shaped, along whole free length; gonothecae in two rows on frontal aspect of colony, each attached to hydrocladial apophysis, colour white, conical, truncate distally and there with concavity.

Records from Mediterranean: Atlantic species found in Algeciras Bay (Strait of Gibraltar).

Known seasonality: 5, 7, 12.

Reproduction: 5.

Records outside the Mediterranean: eastern Atlantic.

References: Millard (1975); Cornelius (1995); Medel and Vervoort (1995); Medel and LópezGonzález (1996).

Genus Lytocarpia Kirchenpauer, 1872 = Acanthocladium Allman, 1883 = Thecocarpus Nutting, 1900
Hydroid: colony erect, branched or unbranched, bearing alternate unbranched pinnate hydrocladia; hydrotheca sac-shaped to deep, usually with intrathecal septum; generally with teeth or lobed margin; mesial outer tooth of hydrothecal rim usually prominent; median inferior nematotheca fairly short, not reaching hydrothecal margin, sometimes a superior dissymmetrical nematotheca (i.e. L. peramata); corbulae formed by modified hydrocladia bearing secondary unfused ribs bearing a row of approximately 12 nemathothecae, some, in at least one sex, bearing one hydrotheca; fixed sporosacs.

References: Calder (1997); Schuchert (2001a, 2003).

1. Hydrothecate internodes with 2-3 poorly developed internal septa .................... L. distans

- Hydrothecate internodes with 6-13 well developed internal septa ......... L. myriophyllum

Lytocarpia distans (Allman, 1877) (Figs. 67A-B)

Hydrocauli polysiphonic up to $200 \mathrm{~mm}$ high, growing on a hydrorhiza composed of numerous tubes. Frontal tube of the axis with a longitudinal row of nematothecae and lateral hydrocladial apophyses, 2-5 nematothecae between two apophyses. Hydrocladia alternate, in the same plane, with internodes separated by transverse nodes, each with one hydrotheca and three nematothecae, one median inferior and two laterals; internal septa poorly developed, two under the median nematothecae and one behind hydrotheca at same level as intrathecal septum. Hydrothecae elongated, narrowed basally; adcauline wall completely adnate, intrathecal septum poorly developed; rim with shallow cusps, but a prominent one frontally. Median inferior nematotheca short, reaching the hydrothecal base; lateral nematothecae small, rim at same level of hydrothecal rim; all nematothecae with a gutter-shaped aperture. Corbulae with 10-14 costae, each with one basal hydrotheca, 2-3 abcauline nematothecae and 6-10 adcauline ones.

Records from Mediterranean: western Mediterranean.

Known seasonality: 8. Corbulae: 8 .

Distribution: northeastern Atlantic and Pacific; Mediterranean.

References: Bedot (1921); Vervoort (1972); Gili (1986); Ramil and Vervoort (1992a); Boero and Bouillon (1993); Medel and López-González (1996). 
Remark: species very similar to L. Myriophyllum but clearly differs in the shape of hydrothecae, the median inferior nematothecae, the adcauline wall and in the development and number of internodal septa (see Ramil and Vervoort, 1992a).

\section{Lytocarpia myriophyllum (Linnaeus, 1758)} (Figs. 66P-U)

Hydrorhiza composed of numerous fibers living the hydrocaulus over different levels. Stem polysiphonic, up to about $350 \mathrm{~mm}$, yellowish to brown, pinnate and unbranched; up to four well marked oblique nodes arranged basally; axis with a "main" frontal tube and many parallel secondary ones, all with a longitudinal row of small cup-shaped nematothecae. Hydrocladia borne on main tube; alternate, in the same plane. Hydrocladial internodes each with one hydrothecae and three nematothecae, one median inferior and two laterals; a varied number (6-13) of perisarcal septa developed transversally in the internodes; nodes transverse. Hydrotheca more or less cylindrical, rounded and with transverse adcauline septum basally; rim with shallow cusps, but frontal one on abcauline wall very prominent. Mesial nematothecae reaching the lower forth of hydrothecae, free part short, aperture with a deep adcauline embayment; lateral nematothecae slightly overtopping hydrothecal rim, aperture with a deep adcauline embayment. Corbulae large, open, 5-20 costae, each with usually one, but up to three basal hydrothecae and several nematothecae, usually 2 abcauline and 5-9 adcauline; gonothecae ovoid, alternate, up to 24 in a same corbula.

Records from Mediterranean: western Mediterranean, Adriatic.

Known seasonality: 6-8. Corbulae: 8 .

Distribution: Arctic, eastern Atlantic (till Guinea Bissau); Mediterranean; Indo-Pacific records need to be evaluated.

References: Gili, Vervoort and Pagès (1989); Ramil and Vervoort (1992a); Boero and Bouillon (1993); Cornelius (1995); Avian et al. (1995); Medel and Vervoort (1995); Medel and LópezGonzález (1996).

$$
\begin{gathered}
\text { Genus Macrorhynchia Kirchenpauer, } 1872 \\
=\text { Lytocarpus Allman, } 1883 \\
=\text { Nematophorus Clarke, } 1879
\end{gathered}
$$

Hydroid: colony erect, hydrocauli branched or unbranched, polysiphonic, often stout, arising from creeping hydrorhiza or anchoring filaments; hydrocladia unbranched, pinnately arranged, arising alternately from apophyses on axial tube of hydrocaulus and branches; hydrothecae only on hydrocladia, more or less cone to sac-shaped; hydrothecal margin dentate; abcauline or adcauline intrathecal septum present; cauline internodes with triangular nemathotheca; each hydrotheca with a pair of lateral nemathotecae and a single partly adnate median inferior nematotheca; gonophores usually fixed sporosacs, exceptionally one species with swimming sporosacs (Macrorhynchia philippina Kirchenpauer, 1872), gonothecae on unbranched phylactocarps formed by modified hydrocladia, occurring single or aggregated in pseudocorbula.

References: Calder (1997); Schuchert (2003).

Macrorhynchia philippina (Kirchenpauer, 1872) (Figs. 67C-H)

Colonies about 15-20 cm high; hydrocauli polysiphonic, strongly and irregularly branched. Branches arising from peripheral tubes of stem, monosiphonic or slightly polysiphonic, with a basal part bearing median nematothecae and a distal part bearing alternate hydrocladia. Axial tube of stem and distal part of branches with internodes each with one hydrocladial apophysis and two nematothecae; mamelon present on anterior surface of apophysis. Hydrocladia not very long, with 10-15 internodes each with one hydrotheca, two lateral nematothecae and one median hydrotheca; nodes straight or slightly oblique. Hydrotheca with a thick abcauline intrathecal septum and an adcauline intrathecal one at lower level; margin with two pairs of low, rounded cusps and a thickened abcauline median cusp continuous basally with the abcauline intrathecal septum and projecting distally as a short spine. Lateral nematothecae tubular, projecting above hydrothecal margin, with two openings, one distal and one mesial; free part of the median nematotheca long, overtopping hydrothecal margin, with three openings, one rounded distal, one on upper surface at base of free part, and one into the hydrohteca; 02 internodal septa. Phylactocarp borne on apophyses, with a hydrothecate internode basally, this followed by several gonothecae-bearing internodes, on which the hydrotheca has been replaced by and apophysis bearing a gonothecae; gonothecae large, disc-shaped, dioecious, giving free medusoids, these without radial canals, circular canal, tentacles and tentacular bulbs. 
Records from Mediterranean: eastern Mediterranean.

Seasonality: ?

Records outside the Mediterranean: tropical waters of the Atlantic, Pacific and Indian Oceans.

References: Vervoort (1968); Gravier (1970); Millard (1975); Boero et al. (1997), Watson (2000).

\section{Genus Streptocaulus Allman, 1883 \\ = Aglaophenopsis Fewkes, 1881 =Nematocarpus Broch, 1918}

Hydroid: colony erect; hydrocauli branched or unbranched; hydrocladia pinnate in young colonies, gradually becoming spirally arranged by axis torsion with age; hydrothecae adnate, hydrothecal rim with weakly developed cusps; three hydrothecal nematothecae present; fixed sporosacs protected by phylactocarps with axis homologous to a hydrocladium; rachis axis unbranched or irregularly branched, divided in segments, each bearing one or several pairs of more or less opposite lateral nematothecae; rachis axis bearing one or more gonothecae; when axis and phylactocarps are long, the structure appears centipede-like.

Remark: The genus Streptocaulus seems polyphyletic based on phylactocarp morphology (Calder, 1997).

References: Ramil and Vervoort (1992a); Medel and Vervoort (1995); Calder (1997); Ramil et al. (1998).

\section{Streptocaulus dollfusi (Billard, 1924)} (Figs. 67I-K)

Hydrocauli long (up to about $400 \mathrm{~mm}$ ), polysiphonic, yellowish, occasionally irregularly branched. Only a frontal tube of the stem thecate and bearing hydrocladia, divided into internodes by means of transverse nodes; segments with a distal bearing hydrocladia apophysis, and a row of frontal nematothecae (usually 3-5); one of them shorter, in the axil of the apophysis, occasionally also another one besides of the apophysis; all nematothecae with two apertures, one terminal and one basal at the adcauline wall. Hydrocladia alternate, more or less in the same plane; internodes with one hydrothecae and three nematothecae; nodes slightly oblique; six perisarcal ring at the base of median nematothecae (one, but occasionally doubled) and behind the hydrothecae (five). Hydrothecae long, fully adnate, abcauline wall convex in lower half, straight and inclined in upper half; a transverse adcauline septum in lower third, this typically recurved upwards. Hydrothecal rim with rounded and weakly developed cusps on each side or only sinuous side, and with a distinct abcauline, frontal cusp. Mesial nematothecae not reaching the hydrotheca base, tubular, rim circular, deep adcauline embayment; lateral nematothecae overpassing hydrothecae, with two apertures, one apical and another one adcaulinar, opening into hydrothecal cavity. Phylactocarp composed of eight segments, each with a pair of opposite nematothecae, these with wide apertures; gonothecae on the basal segment; female cylindrical, ends rounded, aperture sub-distal and oval, male shorter, ovoid, with a terminal aperture.

Records from Mediterranean: western Mediterranean (S. Spain).

Known seasonality: 7.

Distribution: eastern Atlantic (from Morocco to Senegal), Mediterranean?.

References: Billard (1924, 1934); Vervoort (1959); Patriti (1970); Boero and Bouillon (1993); Medel and Vervoort (1995); Medel and LópezGonzález (1996).

Family BARCINIDAE

Gili, Bouillon, Pagès, Palanques and Puig, 1999

Hydroid: unknown.

Medusa: marginal vesicles closed; ocelli adaxial; manubrium narrow, no peduncle; 4 simple radial canals; 4 marginal tentacles; tentacular bulbs large, globular; "gonads" linear, ribbon-like, surrounding radial canals.

\section{Genus Barcino}

Gili, Bouillon, Pagès, Palanques and Puig, 1999

With the characters of the family.

\section{Barcino foixensis}

Gili, Bouillon, Pagès, Palanques and Puig, 1999 (Figs. 67L-M)

With the characters of the family.

Records from Mediterranean: western Mediterranean.

Known seasonality: 5.

Distribution: endemic of Mediterranean Sea

References: Gili et al. (1999).

Family BLACKFORDIIDAE Bouillon, 1984

Hydroid: colonies reptant, rarely slightly ramified, bearing 2-3 hydrothecae on each stem; hydrothecae, 
tubular exhibiting longitudinal striations, its lower part sharply broadened directly above hydrocaulus and separated from it by a diaphragm; operculum consisting of numerous triangular flaps meeting centrally and showing no clear demarcation from the hydrothecal margin; hydranth with conical hypostome and a whorl of 12-16 filiform tentacles, an intertentacular membranous web present; gonothecae developing on stem or on stalk of the hydranths, sacciform, one medusa at a time in each gonophore

Medusa: manubrium narrow, short; mouth with 4 long, fluted lips; numerous hollow tentacles; tentacle endodermal core extending inwards from bell margin into bell mesoglea; 4 radial canals; "gonads" completely surrounding radial canals; marginal tentacles numerous 80-250, no permanent rudimentary tentacles; numerous closed statocysts.

References: Valkanov (1935); Logvinenko (1959); Naumov (1960, 1969); Denayer (1973); Zhang Jinbiao (1977, 1979); Moore (1987); Bouillon et al. (1988b); Mills and Somner (1995); Bouillon (1999); Bouillon and Boero (2000); Mills and Rees (2000).

Genus Blackfordia Mayer, 1910

See family characters.

Blackfordia virginica Mayer, 1910

(Figs. 67N; 68A-B)

Hydroid: with the characters of the family.

Medusa: umbrella $14 \mathrm{~mm}$ wide, higher than a hemisphere, with rounded apex; manubrium narrow, half as long as subumbrellar cavity, four long fluted lips; gonads linear, from corner of manubrium extending along somewhat more than half the length of radial canals; about 80 long marginal tentacles with finger-shaped or broadly oval diverticula into bell margin; one (rarely 2) statocysts between successive tentacles, each with 2-3 concretions; often with black pigment granules at base of the statocysts.

Records from Mediterranean: eastern Mediterranean.

Known seasonality: 7.

Distribution: Antlantic; Indo-Pacific; Mediterranean; Caspian Sea.

References: see above family.

Family CAMPANILINIDAE Hincks, 1868 auct.

Hydroid: colony stolonal or erect; hydrocaulus branched or unbranched; hydrotheca usually cam- panulate or cylindrical, with or without pedicel, always covered by operculum of several triangular flaps, sharply demarcated from hydrotheca or not; with or without diaphragm; with or without nematophore; gonophores as fixed sporosacs or as free medusae.

Medusa: see remarks below.

Remarks: The Campanulinidae represent a polyphyletic taxon, traditionally comprising species having hydroids of a generalised "campanulinid type». The distinction between two types of operculum (pleated or segmented, formed by numerous flaps which may or not be delimited by a prominent crease-line at the base of the cusps) has not the taxonomic value that it was formerly given (see Lovenellidae).

Many "campanulinid" hydroids release medusae that are referable to unrelated medusabased families This is not the only case of inconsistency between hydroid and medusan morphology: Rees (1956), for instance, already showed that the hydroids (nearly 40 species) referred to the hydroid-based genus Perigonimus M. Sars 1846, which are as similar morphologically to each other as are the "Campanulinid" hydroids, are referable to five medusa-based families: four of Anthomedusae and even one of Leptomedusae. Most of the described "Campanulinid" hydroids, unfortunately, have unknown or poorly known life cycles and, as a consequence, cannot be confidently identified at a generic or family level. Due to the difficulty of assigning such operculate hydroids to familygroup taxa, taxonomists have usually lumped them, for convenience, in the family Campanulinidae. Only the knowledge of the complete life cycles of those species will contribute to resolve this situation. Calder (1991), to avoid the practice of employing the Campanulinidae as a catch-all family, provisionally included the genera Opercularella and Plicatotheca (see remarks under Opercularella) in the Phialellidae and included into "Family incertae sedis" those genera which cannot be assigned with any degree of certainty to a family (for instance Lafoeina and Egmundella). Calder (1991) proposed also a new definition of the family Campanulinidae covering more or less the Eirenidae Haeckel, 1879. He also argued that Campanulina tenuis Van Beneden, 1847, the misidentified type genus of Hincks Campanulinidae family (see Campanulina), could correspond to a hydroid with regressed hydrotheca, similar those found in some aged eirenid hydroids and 
that, due to this similarity, the two families should be considered identical, with the name Campanulinidae having priority. We do not follow this proposal: Campanulina tenuis is a poorly described, non-operculate, species considered here as an incertae sedis (see Campanulina). This species can in any case be attributed to an existing genus of Eirenidae, a medusa-based family with a vast array of hydroid types. Finally, campanulinid regressed hydroids similar to those described for some Eirenidae exist in many other Leptomedusae families. It appear thus that, at present, it is not possible to obtain a complete and satisfactory classification of campanulinid hydroids and that, as stated by Cornelius (1995), the Campanulinidae paradox has still to be resolved, and little is to be gained from attempting a new family diagnosis or from retaining the old one.

In the diagnosis given above we keep in the Campanulinidae only the genera from which the gonosome is known as fixed sporosacs, the species with identifiable medusae being transferred to their medusae families in agreement with the law of priority. The campanulinid hydroids with fixed sporosacs can represent the results of multiple and independent medusa reduction within different Leptomedusae family groups and it is presently impossible to refer them safely to any family with free medusae and to establish their real phylogenetic relationships It seems more reasonable to retain them under a common denomination until further research will allow more natural groupings, than to include them, without phylogenetic support, in any medusa-based family; molecular biology techniques will surely help to resolve these ambiguities. The campanulinid genera with unknown gonosome will be provisionally included here in the Campanulinidae incertae sedis. This appears more convenient than to put them in "Family incertae sedis" as proposed by Calder (1991), since our proposal at least gives an idea of the general morphology of the hydroid stage.

Reference: Schuchert (2001a).0

\section{Key to campanuliniid hydroids with fixed sporosacs, unidentifiable medusa buds or unknown gonophores}

1. Opercular valves seated in distinct embayments of thecal margin and sharply demarcated from it Calycella
- Operculum of numerous segments, opercular valves not sharply demarcated ....................... 2

2. Nematophores present .................................. 3

- Nematophores absent ..................................... 4

3. Hydrotheca sessile and tubular; nematothecae oval to tubular; gonophores producing fixed sporosacs or medusa buds Lafoeina

- Hydrotheca pedicellate widest at distal end, tubular to top-shaped; nematotheca not tubular; gonophores where known with medusa buds ..... Egmundella

4. Hydrotheca pedicellate 5

- Hydrotheca sessile, rising directly from stolon, long and tubular, gonophores unknown or con taining unidentifiable medusa buds (when free adult medusae known, see medusae genera)....... Cuspidellla

5. Gonophores unknown or containing unidentifiable medusa buds (when free adult medusae known, see medusae genera)........ Campanulina

- Gonophores as fixed sporosacs.... Opercularella

\section{Genus Calycella Allman 1864}

Hydroid: colony stolonal; pedicel usually sharply twisted and short; hydrotheca tubular, deep, margin crenulated; operculum with a scalloped crease-line at base of opercular segments not quite meeting in the centre; hydranth without intertentacular web; nematophores absent; gonophore borne on hydrorhiza as fixed sporosacs, acrocyst with no medusa stage has been recorded.

Remark: Calycella gracilis Hartlaub, 1897 has unknown gonophores and is here considered as incertae sedis, its diagnosis is not taken in consideration in the above keys.

References: Cornelius (1995); Hirohito (1995); Blanco et al. (2000).

\section{Calycella syringa (Linnaeus, 1767)} (Figs. 68C-E)

Colonies composed of a tortuous stolon giving rise to numerous hydrothecae with spiral pedicels. Hydrotheca cylindrical, elongated, slightly narrower basally; rim with low cusps and with low typically 8-10 flapped operculum; this often missing. Hydrothecal pedicels annulated; gonophores as fixed sporosacs, gonothecae on short and ringed pedicels; ovoid, aperture in male broad, in female with a short introverted tube extending inside gonothecae; embryos held in acrocyst. 
Records from Mediterranean: western Mediterranean, Adriatic.

Seasonality: ?

Distribution: nearly cosmopolitan in coastal waters.

References: Hamond (1957); Ramil (1988); Cornelius and Ryland (1990); Boero and Bouillon (1993); Cornelius (1995); Medel and LópezGonzález (1996); Schuchert (2001a).

\section{Genus Lafoeina G.O. Sars, 1874 = Keratosum Hargitt, 1909}

Colonies stolonal, or irregularly branched, with polysiphonic stem; hydrotheca cylindrical, pedicel absent, operculum composed of numerous triangular segments without basal crease-line; hydranth without intertentacular web; nematotheca tubular, without operculum, aperture minute and sub-distal on one side; gonotheca similar to hydrotheca, same size or larger; gonophores, when known, as fixed sporosacs or giving rise to medusae buds with four tentacles and eight lateral cirri; adult medusa unknown.

References: Calder (1991); Cornelius (1995); Hirohito (1995); Blanco et al. (2000).

\section{Lafoeina tenuis G.O. Sars, 1874} (Figs. 69E-G)

Colonies minute, stolonal; stolon branched, usually anastomosed, giving rise to hydrothecae and nematothecae. Hydrothecae tubular, narrower basally, lacking pedicels, operculum with about 10 triangular segments. Nematothecae tubular, length variable, rounded distally, aperture lateral, subdistal; gonophores as free medusa described only within gonothecae; gonothecae similar to the hydrothecae.

Records from Mediterranean: western Mediterranean, Adriatic Sea.

Seasonality: ?

Distribution: north Atlantic (eastern and western) and Indian Ocean, Mediterranean.

References: Hadzi (1917, 1959); Bouillon (1971) as Lafoeina vilaevelebitti; Millard and Bouillon (1973) as Egmundella amirantensis; Ramil (1988); Ramil and Vervoort (1992a); Peña Cantero and García Carrascosa (2002) as Egmundella amirantensis; Cornelius (1995); Calder (1991) as Lafoeina amirantensis; Boero and Bouillon (1993) as E. amirantensis and L. tenuis; Altuna (1994) as Lafoeina tenuis; Hirohito (1995) as L. vilaevelebitti; Medel and López-González (1996); Medel (1996); Watson (2000); Schuchert (2001a).

\section{Genus Opercularella Hincks, 1868}

Colonies stolonal or erect, sympodially branched; hydrotheca pedicellate, cigar-shaped or ovoid; opercular flaps gradually merging with walls of the hydrothecae without distinct boundaries, opercular segment not quite meeting in the centre; pedicel with 5 or more twist not well differentiate from hydrothecae; degenerate diaphragm present; hydranth intertentacular web where present not well developed.

Gonophores as fixed sporosacs, usually the female usually with acrocyst within the planulae develop. Gonothecae on pedicel arising from main stem or on hydrorhiza.

Remark: Rees (1939) revised the Campanulinidae and proposed to put together for the sake of convenience into the genus Opercularella all campanuliniid species with fixed sporosacs or with unknown gonophores. Calder (1991) provisionally included the genera Opercularella and Plicatotheca in the Phialellidae without any convincing taxonomical reason if not to remove those two genera from the dubious scope of the Campanulinidae. But doing so he transferred the problem from one family to another, making confusion in the Phialellidae. Almost all specialists agree that medusa reduction is not a reliable phylogenetic taxonomic character to separate two genera but, in a large taxon like the Campanulinidae, it is impossible, at the state of our present knowledge, to attribute the species with fixed sporosacs (for instance Opercularella) to the corresponding genera with free medusae. The genus Opercularella is accepted here in a more restricted sense than Rees (1939), including only the forms with fixed gonophores, the "Opercularella-like hydroid" species with unknown gonophores or indeterminable medusa buds being referred to the genus Campanulina incertae sedis, pending further information about their cycles.

Recent references: Calder (1991); Cornelius (1995); Genzano (1995); Blanco et al. (2000); Schuchert (2001a).

Opercularella lacerata (Johnston, 1847) (Figs. 69H-K)

Colonies erect and branched, composed of delicate stems annulated and spirally grooved through- 
out, giving rise hydrothecae pedicellate arranged irregularly. Hydrothecae somewhat tubular, narrower basally and distally, operculum with 9-12 deep and pointed valves without basal crease-line; basal diaphragm present; gonophores as fixed sporosacs; gonothecae usually pedicellate borne on stem or on stolon; male sub-cylindrical, female larger, narrower gradually towards basally, wider and truncate distally.

Records from Mediterranean: western Mediterranean.

Seasonality:?.

Distribution: north Atlantic Ocean. Indo-Pacific records doubtful (Cornelius (1995)).

References: García-Carrascosa (1981); Altuna (1994); Cornelius (1995); Medel and LópezGonzález (1996); Schuchert (2001a).

"Campanulinidae" incertae sedis with gonophores unknown or gonophores with indeterminable medusa buds:

\section{Genus Campanulina auct.}

Hydroid: colony stolonal or erect; hydrotheca tubular, with a pointed pleated or segmented operculum which may or not be delimited basally by a crease line; no nematophores; usually with diaphragm; gonophores unknown or arising as indeterminable medusa buds.

Remarks: the original diagnosis of Campanulina tenuis, type species of Campanulina, was a brief preliminary account made by Van Beneden in 1847 of a non operculate, non fertile hydroid, not corresponding to the concept of an operculate Campanulinidae as understood by all further authors, Van Beneden (1867) included (see Rees, 1939, Calder, 1991). Campanulina tenuis has never been observed since its diagnosis and should be considered as an indeterminate species. The Genus Campanulina has slowly been the dumping ground for species belonging to several other Campanulinidae genera; even at the present day the same hydroid species can be found described in literature under different genera names (Opercularella, Campanulina and Phialella) depending the authors, showing the great confusion existing within the campanulinid hydroids and the definition of their genera! Such confusion is partly linked to the difficulty to distinguish morphologically from each other the different hydroid species but, above all, to the absence of knowledge about their life cycle. The Genus Campanulina is here conserved as collective group for the "Campanulinid type" species with unknown or incompletely known cycle awaiting the discovery of their type of gonophoral contents or of the determinable medusae allowing their final attribution to a completely diagnosed genus.

\section{Campanulina panicula G.O. Sars, 1874} (Figs. 68F-I)

Stem erect, straight, monosiphonic, typically smooth and unbranched. Hydrothecae borne on single or on branched pedicels, alternate and laterally to the main axis. Pedicels annulated basally; hydrotheca conical, narrower basally, diaphragm distinct, operculum conical, with about 20 segments, without demarcation line basally; gonotheca borne on axis or on hydrothecal pedicels; shortly pedicellated, cylindrical, elongated, slightly asymmetric and truncate distally, gonothecal aperture broad; reproduction unknown perhaps a developing medusa (Rees and Rowe, 1969).

Records from Mediterranean: western Mediterranean.

Seasonality: ?

Distribution: Moderately deep to deep waters of the Atlantic, Pacific and Indian Oceans (Ramil and Vervoort, 1992a), Mediterranean.

References: Ramil and Iglesias (1988b); Ramil and Vervoort (1992a); Cornelius (1995); Medel and López-González (1996); Schuchert (2001a).

\section{Genus Cuspidella Hincks, 1866}

(Figs. 69A-B)

Colonies stolonal, with tubular and usually sessile hydrothecae, lacking pedicel, in some species separated from stolon by basal constriction; operculum conical, several cups meeting centrally, with or without basal crease-line; hydranth extensile, tentacles amphicoronate, with or without basal web and hypostome conical. Gonophores, where known, growing to free medusae; gonothecae, where present, resembling hydrotheca but usually larger.

Remarks: What is named by Cornelius (1995) "Cuspidella facies", describes stolonal colonies with tubular and usually sessile hydrothecae, lacking pedicels, in some species separated from stolon by basal constriction; operculum conical, several cups meeting centrally, with or without basal crease-line; hydranth extensile, tentacles amphicoronate, with or without basal web and hypostome conical. Gonothecae, when are present, resembling hydrotheca but usually larger. This polypoid stage is found in sever- 
al hydroidomedusae families, and when described in ignorance of the corresponding medusa stage, they have been, for convenience, referred to the nominal genus Cuspidella. They must be considered as a "collective group" awaiting further investigations. In this way, Mediterranean species referred to this genus may be considered as doubtful species which need to be linked to their corresponding medusae.

\section{Cuspidella costata Hincks, 1868}

Records from Mediterranean: western Mediterranean

Known seasonality: $7,8$.

Distribution: see remark.

References: Aguirrezabalaga et al. (1988); Altuna and García-Carrascosa (1990); Medel and López-González (1996).

Remark: This species is in part, conspecific with Lafoeina tenuis and with Laodicea undulata.

Cuspidella humilis (Alder, 1862)

Hydroid: hydrothecae arising directly from a creeping hydrorhiza; without pedicel, but basal part of the hydrotheca distinctly constricted and sometimes slightly undulated; hydrotheca more or less cylindrical, narrowed basally; operculum with several 12-16 triangular valves, with crease line in the diagnosis by Gili (1986), but not in Vervoort (1968). Hydranth long, hypostome with 12 filiform tentacles.

Known seasonality: 7, 8.

Records from Mediterranean: western Mediterranean.

Distribution: ?

References: García-Corrales, et al. (1979); Gili (1986); Medel and López-González (1996).

Remarks: doubtful records and species. This species is considered partly as conspecific of Lafoeina tenuis (see Cornelius (1995).For Naumov (1951, 1969) Cuspidella humilis should be the hydroid of Staurophora mertensii.

The records of this species in the Mediterranean coasts by García-Corrales et al, (1979), are considered by Altuna (1994) as Calycella syringa (Linnaeus, 1767). The Diagnosis of the species by Gili (1986) resembles to Lafoeina tenuis.

\section{Genus Egmundella Stechow, 1921b}

Hydroid: colony usually stolonal, infrequently erect and branched; hydrocaulus polysiphionic; hydrotheca pedicellate, deeply campanulate, turbinate, widest at distal end, thin perisarcal shelf present; operculum cone-shaped not distinctly demarcated from hydrotheca; diaphragm present or reduced; nematophores solitary or aggregated, bulbous through clavate or tubular, on hydrorhiza or on both hydrorhiza and hydrocaulus; gonophores giving rise to medusa buds, gonotheca borne on hydrorhiza, non pedicellate or shortly pedicellate, similar to hydrotheca.

Remark: this genus is considered incertae sedis pending futher knowledge about the nature of the adult medusae.

References: Calder (1991); Hirohito (1995).

Egmundella grimaldii Leloup, 1940 (Figs. 69C-D)

Hydroid: hydrorhiza stolonal, polysiphonic; hydrotheca elongated, diaphragm thin; pedicel short with one proximal spiral annulus; nematotheca fusiform, pedicellate; gonophore unknown.

Records from Mediterranean: western Mediterranean.

Distribution:?

References: Leloup (1940b); Alvarez (1993).

Egmundella valdiviae Stechow, 1923

Hydroid: similar to E. grimaldii but with a longer pedicel.

Reference: Marinopoulos (1981)

Family CIRRHOLOVEnIIDAE Bouillon, 1984

Hydroid: when known, colony stolonal of "Cuspidella" type; hydrotheca sessile, tubular, closed by a pyramidal operculum formed by numerous flaps meeting centrally and not clearly demarcated; no intertentacular web; gonotheca unknown.

Medusa: manubrium small; 4 simple radial canals; "gonads" on radial canals separated from manubrium; marginal tentacles hollow; with marginal cirri; 4 or more closed statocysts.

\section{Genus Cirrholovenia Kramp, 1959b}

Hydroid: only known in C. tetranema, see family characters.

Medusa: 4-40 marginal tentacles; 7-8 marginal cirri between successive marginal tentacles.

FAUNA OF THE MEDITERRANEAN HYDROZOA $\mathbf{1 3 3}$ 
Cirrholovenia tetranema Kramp, 1959b (Figs. 70A-C)

Hydroid: see family characters.

Medusa: umbrella up to $1.5 \mathrm{~mm}$ wide and high, mesoglea thin; manubrium small, cruciform; mouth with very short simple lips; «gonads» thick, cylindrical along almost entire length of radial canals; 4 long perradial marginal tentacles, with broad bulbs; no rudimentary bulbs; 7-8 marginal cirri in each quadrant; 4 interradial or 8 adradial statocysts sometimes up to nine.

Records from Mediterranean: eastern and western Mediterranean.

Known seasonality: 2-11.

Distribution: Atlantic; Indo-Pacific; Mediterranean.

References: Kramp (1959b; 1961); Goy (1973b); Brinckmann (1965, 1987); Moreira (1975); Lakkis and Zeidane (1985); Goy et al. (1988, 1990, 1991); Boero and Bouillon (1993); Kubota (1995).

\section{Family EIRENIDAE Haeckel, 1879}

Hydroid: colony of benthic species stolonal or erect ramified; bivalve-inhabiting species without perisarc, with pedal disc, usually solitary; planktonic species (Eirene hexanemalis) solitary, polyp budding totally into a single medusa; hydrotheca cylindrical in young colonies of erect forms, with diaphragm and folded pleated operculum formed by convergent flaps not demarcated from the hydrothecal rim (Campanulina type); in older colonies of this type, operculum generally lost and hydrotheca reduced to perisarcal collar, of haleciid type; hydrotheca usually reduced or absent in stolonal colonies, hydranth naked, borne directly on hydrorhiza or on short pedicels ( $\mathrm{Cam}$ panopsis type); hydranth of commensal species elongated, extensile, with filiform tentacles in a single amphicoronate whorl; intertentacular web present; gonophores on hydranths, hydrocaulus, or hydrorhiza, naked or more usually at least initially in a gonotheca, in form of medusae or medusoids with gonads on radial canals.

Medusa: manubrium small, usually on rather well differentiated gastric peduncle; 4-6 simple radial canals running from circular canal across underside of bell and along peduncle to manubrium; with or without excretory papillae or pores; with hollow tentacles; with or without cirri or marginal warts; "gonads" on radial canals separated from manubrium, in each species on well defined part(s) of radial canal; 8 to many statocysts; without ocelli.
References: Russell (1963c); Calder (1991), Pagès et al. (1992); Bouillon (1999); Bouillon and Barnett (1999); Bouillon and Boero (2000); Kubota (2000).

\section{Key to hydroids}

The hydroids of the Eirenidae are indistinguishable from each other they can be of "campanulina", "campanopsid" or "eugymnanthea" type.

\section{Key to medusae}

1. With more than 8 , typically with indefinite number of statocysts........................................ 2

- With usually 8 statocysts (rarely 12); without excretory papillae .............................................. 3

2. Without cirri; with or without excretory papillae Eirene

- With lateral cirri at base of some or all marginal tentacles; with excretory papillae.... Helgicirrha

3. Degenerated medusae without marginal tentacles Eugymnanthea

- Normal medusae, with marginal tentacles ....... 4

4. Without cirri ...................................................... 5

- With lateral cirri on marginal warts and usually also on marginal tentacles; «gonads» on subumbrella, or on gastric peduncle or on both..

Eutima

5. Without cirri and marginal warts, «gonads» restricted to subumbrella Eutonina

- Without cirri, with marginal warts, with «gonads» along entire length of radial canals..... Neotima

\section{Genus Eirene Eschscholtz, 1829}

Hydroid: Campanopsis or Campanulina type or approaching it, see family characters.

Medusa: distinct gastric peduncle; no marginal or lateral cirri or marginal swellings; with or without excretory pores; 4- 6 simple radial canals; "gonads" on subumbrellar part of radial canals, not extending to gastric peduncle; numerous statocysts.

Reference: Kubota (2000).

Remarks: some Eirene species have been described only from the hydroid stage with medusa buds, the adult medusa stage being not known! They must, of course, be considered as indeterminate species; the eireniid hydroids alone being inadequate for generic or specific diagnosis (i.e.: Eirene troglodyta Watson, 1998). 
Eirene viridula (Péron and Lesueur, 1810) (Figs. 70D-H)

Hydroid: not reported from field, description only based on laboratory cultures. Colonies formed by branching or anastomosing stolons with short erected hydrocauli each bearing up to ca 5 hydranths; perisarc smooth to sinuous throughout; hydrothecae reduced or lacking, depending on age; hydranths of Campanopsis type, with cylindrical body tapering slightly basally and with a conical-rounded hypostome, with about 10-24 amphicoronate oral filiform tentacles; intertentacular membranous basal web reported; gonothecae long oblong, round-truncated above and below, with thin walls and possibly dropping during medusa development; gonophore probably containing a single medusa bud.

Medusa: umbrella up to $30 \mathrm{~mm}$ wide or even larger, hemispherical, mesoglea of middle portion of umbrella fairly thick, thinner at sides; velum narrow; gastric peduncle elongated, slender, reaching beyond exumbrellar margin; manubrium fairly short, small; mouth with four very long pointed lips with crenulated margins; 4 radial canals an circular canal narrow; «gonads» linear limited to disk of subumbrella, extending from somewhat beyond base of peduncle almost to exumbrellar margin, straight, slightly sinuous; about 70 or more marginal tentacles of different sizes, small and large alternating, marginal bulbs conical, with distinct excretory papillae; 50 or more or statocysts.

Records from Mediterranean: eastern and western Mediterranean; Adriatic Sea.

Known seasonality: 2-12.

Distribution: Atlantic; Indo-Pacific; Mediterranean.

References: Kramp (1936, 1961); Gunzl (1959, 1964); Berhaut (1970); Goy (1973b); Bierbach and Hofmann (1973); Schmidt (1973); Benovic (1976); Hüdgen (1978); Schmidt and Benovic (1979); Dowidar (1983); Lakkis and Zeidane (1985); Castello i Tortella (1986); Gili (1986); Benovic and Bender (1987); Goy et al. 1988, 1990, 1991); Kubota and Horita (1992); Boero and Bouillon (1993); Cornelius (1995); Avian et al. (1995); Benovic and Lucic (1996); Medel and López-González (1996).

\section{Genus Eugymnanthea Palombi, 1935}

Hydroid: hydroids epizootic on molluses bivalves.

Eirenidae reduced to eumedusoid; with marginal statocysts, without marginal tentacles; with or without manubrium.

Reference: Kubota (2000).

Eugymnanthea inquilina Palombi, 1935

(Figs. 71A-B)

Hydroid: epizootic of molluscs bivalves, solitary or forming small colonies; hydranth tubular, without hydrothecae, with a conical hypostome; with a single whorl of 20-24 filiform tentacles; with an intertentacular membranous web, fixed to the host by a basal disc; often young hydranths budding from the middle part of the primary hydranth body; 1-2 medusa buds at the basal part of the hydranths.

Medusa: umbrella up to $0.55 \mathrm{~mm}$ high and wide, without manubrium and tentacles; four simple radial canals; four sac-like «gonads» on radial canals, not lobular, 8 adradial statocysts with 3 or 4 statoliths.

Records from Mediterranean: eastern and western Mediterranean, Adriatic.

Known seasonality: 7-9.

Distribution: endemic of Mediterranean Sea

References: Kramp (1961); Kubota (1979, 1983, 1985, 1987); Gili (1986); Gili et al. (1988); Boero and Bouillon (1993); Piraino et al. (1994) Avian et al. (1995).

Genus Eutima McCrady, 1859

Hydroid: colonies formed either by single hydranths or by erected colonies arising from creeping stolons or by epizoite naked polyps; in non epizoite forms the hydrocaulus is with smooth perisarc, the young colonies have a cylindrical hydrothecae with diaphragm and a folded pleated operculum formed by convergent flaps not demarcated from the hydrothecal rim (Campanulina type); in older colonies of this type, the operculum is generally lost and the hydrothecae is reduced to a perisarcal collar looking like an haleciid hydrothecae, usually the hydranths tentacles are connected basally by a membranous web.

Medusa: with distinct gastric peduncle; with lateral cirri (often difficult to observe and destroyed after fixation); with marginal swellings or warts; without excretory pores; 4 simple radial canals; «gonads» on radial canals, beneath subumbrella or on gastric peduncle or on both; with 8 (exceptionally 12) statocysts.

References: Brooks (1884, 1886); Bouillon (1985a, 1995a); Cornelius (1995); Kubota (2000). 


\section{Key to hydroids}

Hydroids inadequately known for diagnostic features. Eutima gracilis has gonophores including about eight medusa buds, Eutima. gegenbauri usually one (see diagnosis).

\section{Key to medusae}

1. With 4 «gonads», restricted to gastric peduncle E. gracilis

- With 8 «gonads», 4 on subumbrella, 4 on gastric peduncle.

2. Peduncular «gonads» along greater part of gastric peduncle, 4 marginal tentacles ... E. mira

- Peduncular «gonads», short, in middle part of gastric peduncle; 8-18 marginal tentacles E. gegenbauri

\section{Eutima gegenbauri (Haeckel, 1864)}

(Figs. 71C-G)

Hydroid: mostly known from reared material, only Graeffe (1884) recorded the hydroid in the field from the Adriatic Sea. Colonies arising from a creeping hydrorhiza; hydrocauli short with smooth perisarc reaching the base of the hydranth, hydrothecae reduced or lacking in old specimens; hydranths of Campanopsis type, club-shaped with a single whorl a of about 18-20 filiform tentacles connected basally by a intertentacular membranous web; gonothecae cylindrical on a short stalk, containing one exceptionally two medusa buds.

Medusa: umbrella $20 \mathrm{~mm}$ wide, almost hemispherical, apical mesoglea thick; velum narrow; manubrium short, cross-shaped in transversal section; gastric peduncle very long, narrow, prismatic, broad based but tapering, extending far beyond exumbrella margin; mouth with four short lips with crenulated margin; 4 straight radial canals and circular canal narrow; eight «gonads», four short on middle portion of peduncle or nearer manubrium, four on subumbrella extending from base of peduncle almost to umbrella margin; 8-16 marginal tentacles (sometimes up to 32) without marked marginal bulbs and 60-80 marginal warts all with adaxial excretory papillae armed with cnidocysts; marginal tentacles and marginal warts each with one or two lateral cirri; 8 statocysts.

Records from Mediterranean: eastern and western Mediterranean, Adriatic.

Known seasonality: 1-12.
Distribution: Atlantic; Indo- Pacific; Mediterranean.

References: Claus (1881); Graeffe (1884); Russell (1953, 1970a); Kramp (1961); Berhaut (1970); Goy (1973b); Benovic (1973); Schmidt and Benovic (1979); Castello i Tortella (1986); Gili (1986); Boero and Bouillon (1993); Cornelius (1995); Avian et al. (1995); Benovic and Lucic (1996); Medel and López-González (1996).

Eutima gracilis (Forbes and Goodsir, 1851) (Figs. 71H-L)

Hydroid: not known from field, reared by Werner and illustrated by Russell (1970a). Hydranths of Campanulina type, long cylindrical with a single whorl of about 28 tentacles united by a large membranous basal web; hydrothecae lacking or strongly reduced; gonothecae cylindrical, long, with truncate end and containing up to 8 developing medusae.

Medusa: umbrella up to $13 \mathrm{~mm}$ wide (exceptionally to $30 \mathrm{~mm}$ ), almost hemispherical when fully grown, mesoglea thick; with extremely long, narrow gastric peduncle extending far beyond bell margin and with small conical base; velum fairly narrow; manubrium short; cross-shaped in transversal section; mouth with 4 small, simple lips; 4 straight radial canals and circular canal narrow; 4 «gonads» restricted to narrow portion of gastric peduncle, extending almost from base of peduncle to manubrium; with 24 (sometimes more) long perradial marginal tentacles without distinct marginal bulb; with $40-80$ or more marginal warts; tentacles and warts usually all with one lateral cirri, on each side; 8 statocysts.

Records from Mediterranean: eastern and western Mediterranean; Adriatic Sea.

Known seasonality: 2, 4-12.

Distribution: Atlantic; Indo-Pacific?; Mediterranean.

References: Babnik (1948) Russell (1949, 1970a); Kramp (1961); Benovic (1973); Schmidt and Benovic (1979); Benovic and Bender (1987); Goy et al. (1988, 1990, 1991); Gili et al. (1991); Boero and Bouillon (1993); Cornelius (1995); Avian et al. (1995); Benovic and Lucic (1996); Medel and López-González (1996).

\section{Eutima mira Mc Crady, 1859 (= E. orientalis)} (Figs. 72A-B)

Hydroid: the development of this species has been followed by Brooks 1884, 1886, who described 
a "campanulinid" hydroid which can not been attributed to any specific hydroid species.

Medusa: umbrella up to $30 \mathrm{~mm}$ wide, usually smaller, as broad as high, nearly hemispherical, mesoglea thick, especially in apical region; with a long slender, tapering gastric peduncle, 2-3 as long as umbrella diameter; manubrium small, flask-shaped, cruciform in section; mouth with 4 simple recurved lips; 4 straight radial canals and narrow circular canal; 8 elongate sinuous «gonads», 4 on middle third of the peduncle, 4 on subumbrella; 4 long hollow marginal tentacles with elongated basal marginal bulbs; about 100 marginal warts; marginal bulbs and warts usually with lateral cirri; 8 statocysts.

Records from Mediterranean: eastern Mediterranean.

Known seasonality: 4, 5, 11.

Distribution: Atlantic; Indo-Pacific; Mediterranean.

References: Kramp (1961); Schmidt (1973, 1976); Dowidar (1983); Goy et al. (1988, 1990, 1991); Bouillon (1978a, 1984b, 1995b); Bouillon et al. (1988b); Boero and Bouillon (1993).

Genus Eutonina Hartlaub, 1897

Hydroid: of campanulinid erect type, hydrotheca very delicate, in young specimens cylindrical, with diaphragm and conical operculum formed by convergent sharp flaps not demarcated from hydrothecal rim; in old specimens the hydrotheca disintegrates, living just a crumpled membranous collar sheath; hydranth very long, with up to 20 amphicoronate tentacles linked by a basal web; gonotheca cylindrical, tapered below, squarely-truncate above, arising from stem just under a hydranth.

Medusa: with 8 statocysts; without cirri; without marginal warts; "gonads" restricted to subumbrella, not extending onto peduncle.

Reference: Rees J.T. (1978)

\section{Eutonina scintillans (Bigelow, 1909)}

(Fig. 72C)

Medusa: umbrella $10 \mathrm{~mm}$ wide, $5 \mathrm{~mm}$ high, mesoglea thick; with short peduncle; manubrium globular; mouth with 4 simple or crenulated lips; «gonads» along 1/4-1/3 of subumbrellar parts of radial canals; about 30 marginal tentacles; 8 statocysts.

Hydroid: unknown.

Records from Mediterranean: western Mediterranean; Adriatic Sea.
Known seasonality: 7, 10.

Distribution: Indo-Pacific; Mediterranean.

References: Kramp (1961); Goy (1973b); Boero and Bouillon (1993); Avian et al. (1995); Benovic and Lucic (1996).

Genus Helgicirrha Hartlaub, 1909

Hydroid: campanopsid; colony with a net-like hydrorhiza giving rise to unbranched upright hydranths; hydrorhiza and base of hydranths enclosed in a thin and sticky perisarc; hydranth naked, club-shaped, with 26 to 30 amphicoronate filiform tentacles with a small intertentacular web; medusa buds borne in the middle of hydranth or sometimes even higher, single or up to three per hydranth.

Medusa: with lateral cirri at the base of some or all marginal tentacle bulbs; with excretory papillae.

1. Mouth with long, pointed, crenulated lips .......... H. cari

- Mouth with rudimentary lips ............ H. shulzei

Helgicirrha cari (Haeckel, 1864)

(Figs. 72D-E)

Medusa: umbrella 25-50 mm wide, 6-15 mm high, rather flat, with thin mesoglea; gastric peduncle narrow, short, half as long as umbrella radius; manubrium small; mouth with long lanceolated lips, with crumpled margins; «gonads» linear, narrow, extending from near base of peduncle to near umbrella margin; 50-60-short marginal tentacles, with large conical marginal bulbs and without lateral cirri; moreover about 100 still smaller tentacles, with small conical bulbs, each with one pair of lateral cirri; all bulbs with excretory papillae; with about 100 statocysts.

Hydroid: unknown.

Records from Mediterranean: western Mediterranean.

Known seasonality: 2, 6, 7, 10.

Distribution: Atlantic; Mediterranean.

References: Kramp (1936, 1961); Boero and Bouillon (1993).

Helgicirrha schulzei Hartlaub, 1909

(Figs. 72F-J)

Hydroid: colonies with a net like hydrorhiza giving rise to unbranched upright hydranths; 
hydrorhiza and base of hydranths enclosed in a thin and sticky perisarc; hydranths club-shaped, with a conical hypostome surrounded by 26 to 30 amphicoronate filiform tentacles linked by a small basal intertentacular membranous web; medusa buds born in the middle of the hydranths or sometimes even higher, single or up to three per hydranth.

Medusa: umbrella 30-40 mm wide, somewhat flatter than a hemisphere, mesoglea fairly thick; gastric peduncle narrow, elongated conical, extending beyond umbrella margin; manubrium small, short, somewhat square in transverse section; mouth with four very short, upwardly curved and slightly folded lips; «gonads» on radial canals, straight, or sometimes sinuous, extending from near base of peduncle almost to umbrella margin; 30-40 large marginal tentacles with elongated conical marginal bulbs and with or without lateral cirri; up to 100 or more small tentacles or rudimentary bulbs each with one pair of lateral cirri, tentacular and rudimentary bulbs with adaxial excretory papillae; 50 or more statocysts.

Records from Mediterranean: eastern and western Mediterranean, Adriatic.

Known seasonality: 1, 3-12.

Distribution: Atlantic; Indo-Pacific (Red Sea); Mediterranean.

References: Babnik (1948); Kramp (1936, 1961); Bouillon (1971); Goy (1973b); Benovic (1973); Brinckmann-Voss (1973); Schmidt (1976); Castello i Tortella (1986); Gili (1986); Benovic and Bender (1987); Brinckmann-Voss (1987); Goy et al. (1988, 1990, 1991); Boero and Bouillon (1993); Cornelius (1995); Avian et al. (1995); Benovic and Lucic (1996); Medel and López-González, (1996).

\section{Genus Neotima Petersen 1962}

Eutimidae with 8 statocysts, without cirri; with marginal warts; with «gonads» on entire length of radial canals. Hydroid unknown.

\section{Neotima lucullana (Delle Chiaje, 1822)}

(Figs. 73A-B)

Medusa: umbrella up to $74 \mathrm{~mm}$ wide, flatter than a hemisphere, mesoglea thin; gastric peduncle with broad base, somewhat longer than umbrella cavity, manubrium small; mouth with large crenulated lips; 60-70 short marginal tentacles, 7 marginal warts between successive tentacles; 8 statocysts.

Hydroid: unknown.
Records from Mediterranean: western Mediterranean; Adriatic.

Known seasonality: 3-10.

Distribution: endemic of Mediterranean Sea.

References: Kramp (1961); Petersen (1962); Gili (1986); Brinckmann-Voss (1987); Boero and Bouillon (1993); Avian et al. (1995); Benovic and Lucic (1996); Medel and López-González (1996).

\section{Family HaLECIIDAE Hincks, 1868}

Paedomorphic hydrozoa reduced to hydroid stage; colonies stolonal or erect arising from a creeping hydrorhiza; hydrothecae sessile or pedicellate, shallow; hydranth much larger than hydrotheca, often robust, with or without intertentacular web, hydrothecal rim usually even, strongly to scarcely flaring, hydrothecae lacking operculum; renovation common, regenerated hydrothecae arranged in tiers; diaphragm and a ring of large, often birefringent desmocytes usually present basally; endoderm of hydranths differentiated into proximal digestive part and distal on digestive pert, nematophores nematothecae and nematodactyls present or absent; gonophores usually as fixed sporosacs, some species with acrocysts, medusa stage totally suppressed from life cycle except exceptionally as swimming sporosacs present in one genus (Nemalecium), gonothecae solitary or grouped into a glomulus, infrequently with naked gonophores.

Remarks: for the genera Campalecium and Hydranthea see Lovenellidae.

References: García Corrales et al. (1978); Calder (1991); Cornelius (1975b, 1995, 1998); Migotto (1996); Calder and Vervoort (1998); Medel and Vervoort (2000); Watson (2000).

1. Colonies without nematothecae.......... Halecium

- Colonies with nematothecae ....... Hydrodendron

Genus Halecium Oken, 1815 = Baleum Billard, 1929 = Plumalecium Antsulevich, 1982 = Sagamihydra Hirohito, 1995

Hydroid: colony usually erect, monosiphonic or polysiphonic, branched or unbranched, arising from a creeping hydrorhiza, stem and branches divided in internodes bearing apophyses near distal end; hydrothecae alternate, sessile or pedicellate, borne on apophyses when not pedicellate, shallow; rim commonly everted and regenerated; a ring of large desmocytes and a basal diaphragm; hydranth not

138 J. BOUILLON et al. 
retractable into hydrotheca, often with an annular bugle half way up the gastric column; intertentacular web present or not; nematophores and nematodactyls absent; gonophores as fixed sporosacs sometimes with acrocyst, gonothecae either solitary or aggregated to form a glomulus, usually sexually dimorphic, sometimes with gonophoral polyps or arising from within hydrothecae; typically sexually dimorphic.

References: Calder (1991); Cornelius (1975, 1995, 1998); Hirohito (1995); Migotto (1996); Pagliara et al. (2000).

1. Hydrotheca recurved at the rim 2

- Hydrotheca not recurved at the rim

2. Comma-shaped perisarc fold present at the base of hydrophores .....

- Hydrophores without this character H. sibogae

3. Internodes smooth 3

- Internodes with annulations ................................ 6

4. Nodes oblique........................................................ 5

- Nodes transverse............................... H. tenellum

5. Primary hydrotheca separated from the apophysis by a node, gonothecae with rows of spines H. muricatum

- Without these characters; hydrothecae with abcauline thickening.... H. delicatulum

6. Monosiphonic colonies with regularly annulated internodes; gonothecae corrugated and without terminal aperture. H. pusillum

- Polysiphonic colonies with irregularly undulated internodes; female gonothecae not corrugated and with terminal aperture

\section{H. labrosum}

7. Internodes of varied length and with undulations

- Internodes of equal length.

8. Nodes distinct; female gonothecae not corrugated and without distal hydrotheca

H. lankesteri

- No distinct nodes, several undulations present; female gonothecae corrugated and with two hydrothecae opening distally H. nanum

9. Hydrothecae sessile 10

- Hydrothecae with a short hydrophore H. petrosum

10. Hydrothecae shallow 11

- Hydrothecae deep, internodes with a thick perisarc..... H. liouvillei

11. Hydrothecal renovations sessile, without hydrophores. H. sessile

- Hydrothecal renovations provided with distinct hydrophores 12

12.Colonies pinnate, hydrocladia straight, parallel; female gonothecae with pair of hydrothecae opening distally..... H. halecinum

- Colonies bushy, not regularly pinnate, branches flexuous; female gonothecae kidney-shaped; hydrothecae opening in centre of concavity H. beanii.

\section{Halecium banyulense Motz-Kossowska (1911)} (Figs. 73C-E)

Colonies with polysiphonic and densely branched hydrocauli; only the extreme of branching monosiphonic. Perisarc thick, but thinner towards distal end of branches. Hydrotheca deep, margin everted. Female gonophores borne on stem and hydrocladia, numerous, with longitudinal undulations; male gonophores shorter than females, borne on upper parts of the colony, more or less smooth.

Records from Mediterranean: western Mediterranean.

Seasonality: ?

Distribution: endemic of Mediterranean Sea.

References: Motz-Kossowska (1911); Picard (1958b); Boero and Bouillon (1993).

Halecium beanii (Johnston, 1838)

(Figs. 73F-J)

Adult colonies up to $c a 250 \mathrm{~mm}$, composed of erect, polysiphonic and pinnately branched hydrocauli; hydrocladia alternate, in the same plane, flexuose, varied in length, some of them branched. Hydrocladia (but not their branching) borne laterally, originate from base of hydrothecae, these becoming axillary. Monosiphonic parts of the axis and hydrocladia separated into internodes by means of slightly oblique nodes; hydrothecae borne laterally, alternate, at upper part of internodes. Hydrotheca shallow, walls almost parallel, rim not everted. Primary hydrotheca sessile; renovation frequent, all with hydrophores of similar length, smooth and short. Female gonotheca kidney-shaped, with two hydrothecae in the middle of concave side; male ovoid, elongated, with a terminal aperture.

Records from Mediterranean: western Mediterranean, Adriatic.

Known seasonality: 2, 4-12.

Reproduction: 9

Distribution: eastern and western Atlantic, IndoPacific, Arctic, sub-Antarctic, Mediterranean. 
References: Millard (1975); Calder (1991); Boero and Bouillon (1993); Avian et al. (1995); Cornelius (1995); Medel and López-González (1996); Medel, García and Vervoort (1998); Medel and Vervoort (2000); Schuchert (2001a).

Halecium conicum Stechow, 1919 (Figs. 73K-M)

Colonies small, slightly branched, with maximum 5 to 6 hydrothecae; hydrotheca conical, large, relatively deep, rim slightly everted, gonophores generally on hydrorhiza, irregular, almost ovalate in female, more slender in male.

Records from Mediterranean: western Mediterranean.

Known seasonality: 10-6.

Distribution: endemic of Mediterranean Sea.

Reference: as Halecium minutum by Motz-Kossowska (1911).

Halecium delicatulum Coughtrey, 1876 (Figs. 74A-D)

Colonies up to $25 \mathrm{~mm}$ composed of monosiphonic or polysiphonic and irregularly branched hydrocauli, often growing in dense groups. Stem and branches internodes separated by oblique nodes alternately directed left and right; hydrantophores well developed, alternate, borne laterally at the upper part of internodes and ended by hydrothecae. Hydrotheca shallow, widening towards the aperture, rim even, circular and everted; with diaphragm basally; also a perisarcal thickening (pseudodiaphragm) at adcauline side of the hydrotheca is present; wall with desmocytes for attachment of the hydranth; several hydrothecae may originate from previous one, with more or less development of their hydranthophores. Male gonotheca ovoid and elongated, compressed laterally; female gonotheca almost spherical and slightly compressed laterally; aperture circular.

Records from Mediterranean: western Mediterranean.

Known seasonality: almost always present.

Reproduction: 4-11.

Distribution: eastern and western Atlantic, Mediterranean, Pacific, Arctic, Antarctic.

References: Patriti (1970); Vervoort (1972); Millard (1975); Ramil and Vervoort (1992a); Boero and Bouillon (1993); Medel and López-González (1996); Medel, García and Vervoort (1998); Medel and Vervoort (2000); Peña Cantero and Carrascosa (2002).

Halecium halecinum (Linnaeus, 1758)

(Figs. 74E-J)

Well developed colonies with stiffly erect, polysiphonic and pinnately branched hydrocauli up to $190 \mathrm{~mm}$ high; hydrocladia straight, alternate, in the same plane, at constant angle of $40^{\circ}-60^{\circ}$ to the main axis, arising frontally or backwards of the hydrothecae. Monosiphonic parts of the axis and hydrocladia divided into internodes by means of slightly oblique nodes. Hydrothecae borne laterally, alternate, at upper part of internodes. Hydrotheca shallow, with almost parallel walls, rim not everted; primary hydrotheca sessile, adcauline side close to internode; several renovations may occurs, these hydrothecae with hydrophores of varied lengths, but usually secondary hydrotheca with the longest one. Male gonothecae ovoid and elongated; female gradually widening towards truncated distal end, aperture on side with two hydrothecae, on the other side a shoulder more or less developed.

Records from Mediterranean: eastern and western Mediterranean, Adriatic.

Known seasonality: present all the year.

Reproduction: 1,5,10.

Distribution: eastern and western Atlantic, Mediterranean, Indo-Pacific, Arctic.

References: Naumov (1960); Patriti (1970); Millard (1975); Boero and Bouillon (1993); Avian et al. (1995); Cornelius (1995, 1998); Medel and LópezGonzález (1996); Medel, García and Vervoort (1998); Medel and Vervoort (2000); Schuchert (2001a).

Halecium labrosum Alder, 1859 (Figs. 74K-P)

Hydrocauli erect and polysiphonic, up to 100 $\mathrm{mm}$ high. Internodes provided with irregular undulations, each inserted laterally at distal part of previous internode with characteristic upward curve near base; nodes no distinct. Hydrotheca at the end of internode; short, rim everted and recurved downwards; renovations frequent. Gonothecae borne on short 1-2 ringed pedicels, without gonophoral hydranths; male oval and elongated, aperture distal, small; female ovoid, large, aperture on short collar.

Records from Mediterranean: eastern and western Mediterranean, Adriatic. 
Known seasonality: 7-2.

Reproduction: 9, 10, 12, 2.

Distribution: eastern and western Atlantic, Mediterranean, Pacific, Arctic.

References: Gili (1986); Ramil (1988); Ramil and Iglesias (1988a); Boero and Bouillon (1993); Altuna (1994); Avian et al. (1995); Cornelius (1995, 1998); Medel and López-González (1996); Schuchert (2001a).

Halecium lankesteri (Bourne, 1890)

(Figs. 75A-C)

Colonies monosiphonic, up to $80 \mathrm{~mm}$, erect inside the water, unbranched or imperfectly pinnate. Internodes of irregular length, separated by slightly oblique nodes, 0-10 (usually 1) internodes between hydrothecae. Hydrotheca borne laterally, alternate, at distal end of internode; sessile, short, walls almost parallel, rim not everted, aperture directed outwards, almost at right angle with the main axis; renovations frequent. Gonothecae borne on short pedicels below hydrothecae; male ovoid and elongated, aperture distal; female kidney-shaped, aperture laterally, at the end of a tube at distal third, with 1-2 hydranths.

Records from Mediterranean: eastern western Mediterranean, Adriatic.

Known seasonality: 4-11.

Reproduction: 7-11.

Distribution: eastern Atlantic, Indian Ocean, Mediterranean.

References: Millard (1975); Gili (1986); Ramil and Iglesias (1988a); Boero and Bouillon (1993); Altuna (1994); Cornelius (1995, 1998); Medel and López-González (1996); Peña Cantero and García Carrascosa (2002).

Halecium liouvillei Billard, 1934 (Figs. 75D-F)

Hydrocauli erect, up to ca $34 \mathrm{~mm}$, monosiphonic or polysiphonic basally, branched or unbranched. Axis with a zigzag appearance; often with some annulations basally. Internodes with thick perisarc; nodes oblique. Primary hydrotheca alternate, borne laterally at upper part of internodes; sessile, deep, walls gradually diverging from base onward, adcauline side usually longer than abcauline one; adcauline wall separated from internode; hydrothecal rim occasionally everted but not recurved; renovations frequent, but secondary hydrophores usually longer and annulated. Female gonotheca arising from inside of hydrotheca, on annulated pedicel narrower basally, gradually widening towards distal end, this being truncated with two adnate hydrothecae on side and a shoulder on the other side. Male gonotheca unknown.

Records from Mediterranean: western Mediterranean.

Known seasonality: 2, 5 .

Reproduction: 2.

Distribution: eastern Atlantic, Mediterranean.

References: Billard (1934); Patriti (1970); Ramil and Iglesias (1988a); Altuna (1994); Medel, García and Vervoort (1998); Medel and Vervoort (2000).

Halecium mediterraneum Weissman, 1883

Colonies erect, hydrocauli monosiphonic and branched, hydrophores borne laterally at the upper part of internodes, nodes oblique, annulations at nodes may be present. Primary hydrotheca on well developed hydrophore; rim everted; hydrothecal renovations frequent. Gonothecae pear-shaped, somewhat elongate and with smooth perisarc.

Remarks: the description of $H$. mediterraneum by Gili (1986) is not according with his drawings, which resembles to $H$. delicatulum; the description and drawings of $H$. mediterraneum by Llobet (1987) are according too with the species $H$. delicatulum. Medel and López-González (1996) consider $H$. mediterraneum as conspecific with $H$. delicatulum; in the present work it is considered as a doubtful species.

Halecium muricatum (Ellis and Solander, 1786) (Figs. 75G-J)

Big colonies composed of erect, polysiphonic and branched hydrocauli up to $200 \mathrm{~mm}$. Internodes separated by transverse to oblique nodes. Hydrothecae laterally, alternate at distal end of internodes, borne on short apophyses ended by a node and provided with hydrophores; several renovations may occurs. Hydrotheca short, walls gradually diverging, rim even and curved downwards. Male and female gonothecae similar, borne on short and thin pedicels, ovoid and flattened, provided with rows of spines, without gonophoral hydranths; growing on main stem or, occasionally, in stolons.

Records from Mediterranean: western Mediterranean.

Known seasonality: 11.

Reproduction: 11. 
Distribution: eastern and western? Atlantic, Mediterranean, Pacific, Arctic.

References: Vervoort (1946); Naumov (1960); Gili (1982); Boero and Bouillon (1993); Medel and López-González (1996); Cornelius (1995, 1998); Schuchert (2001a).

Halecium nanum Alder, 1859 (Figs. 75K-M)

Hydrocauli monosiphonic, up to $3 \mathrm{~mm}$, unbranched or irregularly branched in several planes, sometimes dichotomously. Internodes borne laterally at upper part of previous internode, narrowed, curved and with several annulations basally; smooth distally; no distinct nodes. Primary hydrotheca at distal end of each internode, sessile, shallow, walls frequently thick and diverging, but not everted at the rim; secondary hydrothecae provided with hydrophores also annulated basally. Gonophores fixed sporosacs. Female gonothecae sac-shaped, borne on short pedicels arising on lateral apophysis to the hydrothecae; one side of gonotheca with two closely adpressed tubes largely immersed in gonothecal wall and annulated, each topped by a hydrotheca provided with hydranth; opposite side of gonotheca convex; male gonothecae?

Records from Mediterranean: western and eastern Mediterranean, Adriatic.

Known seasonality: 4-12.

Distribution: eastern and western Atlantic, Mediterranean, Pacific?.

References: Calder (1991); Boero and Bouillon (1993); Avian et al. (1995); Cornelius (1995); Medel and López-González (1996); Medel, García and Vervoort (1998); Medel and Vervoort (2000).

Halecium petrosum Stechow, 1919 (Figs. 76A-C)

Hydrocauli monosiphonic, up to $35 \mathrm{~mm}$ robust, stiff, with a thick perisarc; hydrotheca alternate, laterally at the end of each internode; nodes oblique. Hydrotheca sessile, but adcauline wall not adnate to the axis; walls gradually widening towards distally, rim not flared; hydrothecal renovations frequent, secondary hydrantophore large and with undulate perisarc. Female gonothecae big, borne on hydrorhiza or on hydrocauli, ovoid to spherical aperture apical with two hydranths; male gonothecae arising from inside of the hydrotheca or below it, sac-shaped, elongated.
Records from Mediterranean: western Mediterranean, Adriatic.

Known seasonality: always present.

Reproduction: 8-11.

Distribution: endemic of the Mediterranean Sea.

References: Motz-Kossowska (1911) as $H$. robustum?; Stechow (1923d); García-Carrascosa (1981); Llobet (1987); Peña Cantero and García Carrascosa (2002).

Halecium pusillum (M. Sars, 1857)

(Figs. 76D-G)

Colonies delicate, composed of stolon giving rise to erect and monosiphonic hydrocauli. Perisarc of internodes thin and annulated throughout; apical stolons frequent. Hydrothecae at end of each internode, branches originating laterally, below hydrothecae, curved at base. Hydrothecae shallow, walls straight at basal half and curved outward at distal half. Female gonothecae ringed throughout, with a lateral aperture provided with two hydranth; male gonothecae oval, elongated and with transverse undulations.

Records from Mediterranean: western Mediterranean.

Known seasonality: 1-12.

Reproduction: 2-4, 10

Distribution: eastern and western Atlantic, Mediterranean, Indic, Pacific?.

References: Gili (1986); Ramil and Iglesias (1988a); Boero and Bouillon (1993); Avian et al. (1995); Medel, García and Vervoort (1998); Peña Cantero and García Carrascosa (2002).

\section{Halecium reflexum Stechow, 1919}

Following Cornelius (1975; 1995), Roca (1986) and Altuna (1994) this species is here provisionally considered as conspecific with $H$. labrosum.

\section{Halecium sessile Norman, 1867}

(Fig. 76H-L)

Colonies up to $50 \mathrm{~mm}$, monosiphonic or polysiphonic and branched; larger colonies more or less pinnate, with several order of branching and in several planes. Internodes geniculate or not, nodes transverse to slightly oblique. Hydrocladia borne on distal apophysis below primary hydrothecae. Hydrothecae laterally at distal part of internodes; very shallow, walls gradually diverging, rim even, 
not everted; aperture at right angle with the axis of internode; hydrothecal renovation frequent, secondary hydrothecae usually forming directly on diaphragm of previous hydrothecae, appearing several hydrothecal rim very closed. Female gonothecae kidney shaped, with a tubular aperture on concave side with two hydranths. Male gonothecae oval, elongated, slightly curved; aperture terminal.

Records from Mediterranean: western Mediterranean.

Known seasonality: 6.

Distribution: eastern and western Atlantic, Mediterranean, Indo-Pacific.

References: Vervoort (1966); Ramil and Vervoort (1992a); Boero and Bouillon 1993; Altuna (1994); Cornelius (1995, 1998); Medel and López-González (1996); Schuchert (2001a).

\section{Halecium sibogae Billard, 1934} (Figs. 76M-O)

Hydrocauli erect, up to $90 \mathrm{~mm}$, polysiphonic and pinnately branched; perisarc thick in older parts. Distal parts of the colony monosiphonic, internodes geniculate, nodes oblique. Each internode distally with well developed primary hydrophore; next internode borne laterally to the hydrophore without distinct apophysis. Adcauline wall of primary hydrophore at place of fusion with wall of internode with characteristic comma-shaped internal perisarcal fold. Hydrotheca with distinct basal diaphragm and widening distally, rim flared. Hydrothecal renovations frequent, secondary hydrophores sometimes with one-two basal annulations; length varied. Male and female gonothecae similar, almost spherical, frequently showing a quadrangular cross section, and with one or two more or less developed basal projections, more pronounced in the female gononothecae, and apically with two more or less developed elevations between which is situated the aperture at the end of a cone.

Records from Mediterranean: Alborán Sea (species penetrating into the Mediterranean but probably not yet dispersed in it).

Known seasonality: 6-8.

Reproduction: 7.

Distribution: eastern Atlantic warm waters, Mediterranean.

References: Billard (1934); Patriti (1970); Ramil and Vervoort (1992a); Medel and López-González (1996); Medel et al. (1998); Medel and Vervoort (2000); Peña Cantero and García Carrascosa (2002).
Halecium tenellum Hincks, 1861

(Figs. 77A-E)

Colonies composed of hydrocauli monosiphonic up to $20 \mathrm{~mm}$ high, very thin and delicate, irregularly branched. Internodes long, in zigzag, separated by transverse nodes. Hydrothecae borne laterally at upper part of internodes, alternate and provided with a well developed hydrophore; hydrotheca shallow, walls widening from base to top giving a wide aperture; rim everted and curved outwards. Secondary hydrotheca, provided with hydrophore, may occurs from primary hydrothecae; branching may originate from hydrothecal base. Male gonothecae ovate and flattened; female similar but slightly larger and broader.

Records from Mediterranean: western Mediterranean, Adriatic, Algeria, Black Sea.

Known seasonality: 10-5, 7, 9.

Reproduction: 4-5.

Distribution: eastern and western Atlantic, Mediterranean, Indo-Pacific, Arctic, Antarctic.

References: Vervoort (1959); Naumov (1960); Patriti (1970); Millard (1975); Boero and Bouillon (1993); Cornelius (1995, 1998); Migotto (1996); Medel, García and Vervoort (1998); Medel and Vervoort (2000); Schuchert (2001a).

Genus Hydrodendron Hincks, 1874

= Ophiodissa, 1919a = Scoresbia Watson, 1969

Colonies stolonal or erect, monosiphonic or polysiphonic; hydrothecae short cylindrical, haleciid type, pedicellate or on internodal apophyses, in two alternate rows in erect colonies, basal part with or without desmocytes; hydranth with or without an intertentacular web; nematophore extensile, elongate, simple-ended or capitate; nematotheca, when present, simple, sometimes minute; gonophores as solitary fixed sporosacs, gonothecae simple or aggregated in a glomulus.

Remark: the Genus Hydrodendron is here defined as by Rees and Vervoort (1987) and Vervoort (1987) so to include, among others, the genera Ophiodissa and Scoresbia.

References: Calder (1991); Cornelius (1995); Hirohito (1995).

\section{Hydrodendron mirabile (Hincks, 1866)}

(Figs. 77F-K)

Colonies up to $50 \mathrm{~mm}$, composed of erect and monosiphonic hydrocauli branched distally. Intern- 
odes separated by transverse nodes. Hydrophores borne laterally, alternate, at upper part of internodes, variable in length and usually with several annulations; perisarc of hydrophores thicker basally and progressively thinner towards the distal end. Hydrotheca deep, widening from halfway onward, rim everted, occasionally curved downwards. Nematothecae present on hydrorhiza and on hydrophores, tubular in basal 2/3, cup-shaped distally; nematophores elongate, capitate distally, strongly retractile. Stems with distal stolons developing from hydrothecae. Hydranth provided with 20 tentacles. Gonothecae borne hydrorhiza, on short pedicels, barrel-shaped spacely ringed throughout, aperture wide on a short collar.

Records from Mediterranean: eastern and western Mediterranean, Adriatic.

Known seasonality: 2, 4, 6, 7, 10-12.

Reproduction: 7

Distribution: eastern and western Atlantic, IndoPacific, Mediterranean.

References: Rees and Vervoort (1987); Gili, Vervoort and Pagès (1989); Boero and Bouillon (1993); Medel and López-González (1996) both as Ophiodissa; Cornelius (1995); Medel, García and Vervoort (1998); Medel and Vervoort (2000); Peña Cantero and García Carrascosa (2002).

\section{Family HalOPTERIDIDAE Millard, 1962}

Colonies with either erect hydrocauli, or with hydrocladia arising directly from hydrorhiza; hydrocaulus, when present, branched or unbranched, monosiphonic or polysiphonic, arising from a creeping or root-like hydrorhiza, giving rise to alternate or opposite, or irregularly arranged, branched or unbranched, hydrocladia; when arising from polysiphonic hydrocauli and branches, hydrocladia given off from either a single axial tube or from superficial tubes; hydrothecae on hydrocladia typically large, with cusped or uncusped rim; cauline hydrothecae typically present, well developed, less frequently atrophied, lacking on polysiphonic hydrocladia and branches, when component tubes give rise to hydrocladia; nematophores with nematothecae, not as naked sarcostyles; nemathothecae typically well developed, varied in structure, one- or two-chambered, movable or immovable, not fused to hydrothecae (except in the lateral nematothecae of Antennellopsis which are partly fused); a minimum of three, one median inferior and a pair of lateral, adjacent to each hydrotheca; cnidome: usually microbasic mastigophores of several size classes, sometimes isorhizas, microbasic euryteles and pseudostenoteles; gonophores as fixed sporosacs contained in a simple gonotheca, usually solitary, arising from caulus or hydrocladia, neither aggregated or protected by phylactocarps, frequently sexually dimorphic, with at least the female normally bearing nematothecae.

References: Cornelius (1995), Migotto (1996); Calder (1997); Schuchert (1997); Peña Cantero et al., (1999); Watson (2000); Ansín Agís et al. (2001); Schuchert (2001).

1. Unbranched erect stems arising directly from creeping hydrorhiza; without hydrocladia Antennella

- Erect structures branched, either as cormoids, branched hydrocladia or polysiphonic stems ... 2

2. Hydrocladia with large "mamelons" (atrophied hydrothecae) 3

- Hydrocladia without "mamelons" ........................4

3. With unbranched hydrocladia.. Pseudoplumaria

- With hydrocladia branched in a regular fashion. Polyplumaria

4. Stem normally monosiphonic, cormoids pinnate Halopteris

- Stem polysiphonic and with one main axial tube bearing hydrocladia. Schizotricha

Genus Antennella Allman, 1877

Hydrocladia arising directly, independently, from a creeping hydrorhiza, normally unbranched, not polysiphonic; hydrotheca cup- to vase-shaped, rim even untoothed; nematotheca two-chambered, movable; lateral nematothecae flanking each hydrotheca and borne on prominent peduncles adhering to hydrothecal wall; colony often monoecious, gonophores as fixed sporosacs, gonotheca solitary, sexually dimorphic, borne on hydrocladia with basal nematothecae.

References: Hirohito (1995); Calder (1997); Schuchert (1997).

1. Ahydrothecate internodes with one single distal nematotheca, colonies dioecious A. ansini

- Ahydrothecate internodes with two median nematothecae, colonies monoecious ................. 2

2. Hydrotheca surrounded by four nematothecae; distal chamber of lateral nematothecae widening distally..... A. secundaria

- Hydrotheca surrounded by three nematothecae; distal chamber of lateral nematothecae globose, with two deep emargination. A. siliquosa 


\section{Antennella ansini \\ Peña Cantero and García Carrascosa (2002) \\ (Figs. 77L-O)}

Colonies with solonal hydrorhiza giving small unbranched stems, proximal part of stem composed of one or several ahydrothecate internodes bearing up to 3 nematothecae. Remaining stem composed of alternately arranged hydrothecate and ahydrothecate internodes. Stem with up to 12 hydrothecae. Hydrothecal internode with one hydrotheca and three nematotheca, one mesial inferior and two laterals. Mesial nematothecae short without apohysis, lateral nematothecae short, on short apophyses, distal part rounded with deeply scooped inner and outer walls. Ahydrothecate internodes longer than hydrothecate ones with a single distal nematothecae. All nematothecae two-chambered.. Hydrothecae abcaudally directed, cup-shaped, slightly widening at their aperture, adcauline wall free for approximatively half its length, abcauline wall slightly convex. Hydrothecal aperture circular, rim slightly laterally depressed. Colonies dioecious. Gonothecae usually on basal internodes, on short antero-lateral apophysis, up to two gonophores per stem. Male gonophore fusiform basally curved with one or two nematothecae, aperture circular, situated at distal truncated part of gonothecae. female gonotheca on short apohysis with short basal segment strongly flattened carrying one or two nematothecae, aperture larger than in male gonothecae.

Records from Mediterranean: western Mediterranean.

Known seasonality: 5, 7, 8 .

Reproduction: 5, 7, 8 .

Distribution: eastern Atlantic; Mediterranean.

References: Peña Cantero and García Carrascosa (2002).

\section{Antennella secundaria (Gmelin, 1791)} (Figs. 77P, 78A-D)

Colonies forming ramified, tubular stolons with erect stems, usually unbranched up to about $25 \mathrm{~mm}$; coenosarc reddish. Basal part of the axis divided into several internodes by transverse nodes, with a variable number of nematothecae. Rest of the stem heteromerously segmented. Hydrothecate segments with one hydrothecae surrounded by four nematothecae, one median inferior inmovable, one pair of laterals, and one axillar. Non-hydrothecate internodes with two median nematothecae. Hydrotheca cup-shaped, walls parallel to slightly divergent, $1 / 3$ to $1 / 2$ adnate, rim even, aperture at $45^{\circ}-55^{\circ}$ with the main axis. Nematothecae all two-chambered and with a very wide embayment; median inferior inmovable, not reaching the level of the hydrotheca, median nematotheca on the internodes similar; axillar nematotheca similar but much shorter than the first; lateral nematothecae movable, borne on well developed pedicels; basal chamber elongated, distal chamber widening distally. Gonothecae of both sexes often on the same axis, borne under hydrothecae, on pedicels of two segments ; female elongated, cylindrical, narrowed basally, with a circular lid and two opposite basal nematothecae; male shorter, curved, also provided with two basal lateral nematothecae.

Records from Mediterranean: eastern and western Mediterranean, Adriatic.

Known seasonality: present all the year.

Reproduction: 3 -11.

Distribution: cosmopolitan species with a preference for warmer waters.

References: Patriti (1970); Millard (1975); Gili and García-Rubíes (1985); Ramil (1988); Cornelius and Ryland (1990); Ramil and Vervoort (1992a); Boero and Bouillon (1993); Avian et al. (1995); Medel and Vervoort (1995); Medel, and LópezGonzález (1996); Schuchert (1997); Ansín Agís et al. (2001); Peña Cantero and García Carrascosa (2002).

Antennella siliquosa (Hincks, 1877) (Figs. 78E-I)

Ramified stolons with upright and unbranched stems up to $45 \mathrm{~mm}$ high, with a whitish coenosarc. Basal part of the axis divided on a variable number of segments bearing frontal nematothecae by means of transverse nodes; remainder parts heteromerously segmented, with nodes alternatively oblique and transverse. Hydrothecate segments with one hydrothecae and three nematothecae, one median inferior, and two laterals ones. Non-hydrothecate segments bearing two median nematothecae. Hydrotheca cylindrical, walls almost parallel, slightly divergent distally, 1/2 adnate, rim even, aperture at $35^{\circ}-45^{\circ}$ with the main axis. Nematothecae all twochambered, aperture with embayment. Median nematothecae all similar, but median inferior to the hydrotheca wider, this one not reaching the level of the hydrotheca; lateral nematothecae borne on pedicels, not reaching the hydrothecal margin, basal 
chamber longer and elongated if compared with the rest; distal chamber typically globose, with a deep emargination on inner and outer side. Gonothecae on both sexes on the same axis, borne on pedicels with two segments. Female elongate, somewhat flattened, truncated distally and curved basally, with up to four nematotheca; male shorter, pyriform, extreme rounded; two basal nematothecae, both with apical flat lid.

Records from Mediterranean: western Mediterranean, Adriatic.

Known seasonality: 5-10.

Reproduction: 5, 7, 9, 10.

Distribution: eastern Atlantic (England, France, Strait of Gibraltar, Morocco, Ivory Coast), Mediterranean.

References: Vervoort (1959) as Antennella diaphana f. siliquosa; Patriti (1970); García Corrales et al. (1978); Ramil and Vervoort (1992a) both as Halopteris diaphana f. siliquosa; Boero and Bouillon (1993); Avian et al. (1995); Medel and Vervoort (1995); Medel and López-González (1996); Schuchert (1997); Ansín Agís et al. (2001).

\section{Genus Halopteris Allman, 1877}

Colonies typically erect, unbranched or branched, forming pinnate cormoids arising from a creeping hydrorhiza, often with a hinge-joint near base; hydrocaulus usually monosiphonic, rarely polysiphonic, bearing hydrothecae and pinnately arranged hydrocladia; in polysiphonic stems, all tubes can give rise to cormidia; hydrocladia almost always unbranched, alternate or in opposite pairs, or opposite basally and alternate distally, in one plane, sometimes (as secondary growth-form) arising independently from hydrorhiza; hydrothecae cup-shaped, on hydrocaulus and hydrocladia, margin entire or with one median abcauline cusp; nematothecae polymorphic, movable or immovable ones on a given colony, one- or twochambered, lateral nemathotecae typically borne on prominent peduncles adhering to hydrothecal wall; gonophores as fixed sporosacs, gonothecae arising from hydrocaulus or hydrocladia, solitary, with or without nematothecae.

References: Hirohito (1995); Calder (1997); Schuchert (1997).

1. Main axis homomerously segmented H. liechtensternii

- Main axis heteromerously segmented 2

2. Hydrotheca with two pairs of lateral nematothecae H. catharina

- Hydrotheca with one pair of lateral nematothecae H. diaphana

\section{Halopteris catharina (Johnston, 1833)}

(Figs. 78J-N)

Colonies pinnate up to $40 \mathrm{~mm}$ high arising from branched stolons; stems monosiphonic and unbranched. Basal part composed of several segments bearing two longitudinal rows of nematothecae, nodes transverse. Remainder axis heteromerously segmented by alternate oblique and transverse nodes. Hydrocladia opposite, borne laterally bellow hydrothecae, on long stem apophyses. Hydrothecate segments with one hydrothecae and five nematothecae, one median inferior and two pairs of lateral ones. Non-hydrothecate segments with one to four nematothecae. Hydrocladia with a first athecate segment; remainder segments as in the main axis, but non-hydrothecates with 1-2 nematothecae. Hydrothecae cup-shaped, in the middle of the internode, walls straight almost parallel, 1/2 adnate, rim smooth, aperture at $45^{\circ}$ with the axis. Nematothecae all two-chambered and movable, upper chamber with a deep embayment. Outer pair of lateral nematothecae reaching the rim or slightly beyond it, on long apophyses; inner pair at base of those apophyses. Gonothecae of both sexes on the same colony, on the stem and hydrocladia. Female cylindrical somewhat flattened, narrowed at base, with two nematothecae; truncated distally, with annular thickening and lid; basal pedicel with two segments. Male gonothecae smaller and elongated.

Records from Mediterranean: western and eastern Mediterranean.

Known seasonality: 1-4, 6-8, 12.

Reproduction: 3, 6.

Distribution: temperate and southern-boreal regions of the eastern and western sides of the Atlantic.

References: Picard (1958b); Vervoort (1972); Ramil and Vervoort (1992a); Boero and Bouillon (1993); Cornelius (1995); Medel and López González (1996); Schuchert (1997, 2001a); Ansín Agís et al. (2001).

Halopteris diaphana (Heller, 1868) (Figs. 780-T)

Colonies pinnate with erect, monosiphonic and unbranched stems up to $12 \mathrm{~mm}$. Basal parts with a

146 J. BOUILLON et al. 
varied number of segments separated by transverse nodes bearing a row of median nematothecae. Remainder parts of the axis heteromerously segmented, with alternate oblique and transverse nodes. Hydrocladia alternate, on apophyses laterally to the hydrothecae. Hydrothecate internodes of the main axis and hydrocladia composed of one hydrothecae and three nematothecae, one median inferior and two laterals. Non-hydrothecate segments with 1-2 median nematothecae (usually one on the hydrocladia). Hydrotheca in the middle of the segment, cupshaped, walls slightly widening, $1 / 2$ adnate, rim even, aperture at $50^{\circ}-60^{\circ}$ with the axis. All nematothecae two chambered and movable, with adcauline embayment. Median inferior nematotheca not reaching the hydrotheca, lateral ones on very short apophyses, just reaching the hydrothecal border. Gonothecae of both sexes only seen on separate colonies, on stem and hydrocladia, with two segmented pedicels. Female evenly curved for its entire length, narrowed basally, with 2-4 basal nematothecae; distal end truncate, with a convex lid. Male gonothecae oblong, slightly curved, with 2 basal nematothecae.

Records from Mediterranean: western and eastern Mediterranean, Adriatic.

Known seasonality: 1, 2, 4-10.

Reproduction: 4, 6-9.

Distribution: circumtropical species.

References: Boero and Bouillon (1993); Avian et al. (1995); Medel and Vervoort (1995); Medel and López-González (1996); Schuchert (1997); Ansín Agís et al. (2001); Peña Cantero and García Carrascosa (2002).

\section{Halopteris liechtensternii \\ Marktanner-Turneretscher, 1890}

(Figs. 79A-G)

Colonies pinnate with erect, monosiphonic and unbranched stems up to $30 \mathrm{~mm}$. Basal part composed of several segments with nematothecae, separated by means of transverse nodes. Remainder main axis homomerously segmented by means of oblique nodes, but at distal extreme, heteromerously segmentation may occurs by additional transverse nodes. Hydrocladia alternate, on lateral apophyses besides hydrothecae; most basal hydrocladia sometimes branched; hydrocladia heteromerously segmented. Segments on main axis with one hydrothecae and 7-8 nematothecae; one median inferior almost reaching hydrothecal base, two lat- eral ones, seated on short pedicels and reaching the hydrothecal rim, two axillar and two or three median superior. Hydrothecate segments on hydrocladia with one hydrothecae surrounded by five nematothecae (one median inferior, two laterals, and two smaller ones on the upper axil of the hydrothecae); non-hydrothecate segments with 1-2 median nematothecae. Hydrotheca cup-shaped, walls slightly diverging towards margin, adcauline wall $1 / 2$ adnate, rim even and circular, aperture at $40^{\circ}-50^{\circ}$ with the main axis. Nematothecae all two chambered. Median inferior nematotheca with a distal chamber scoop-shaped, without adcauline wall; lateral nematotheca with a longer basal chamber; margin of the distal chamber even or with shallow emarginations on adcauline wall; pair of nematothecae behind hydrothecae reduced, indistinctly two-chambered, scoop-shaped; remainder nematothecae similar to median inferior ones, but longer. Gonothecae of both sexes on same colony. Female borne on stem and hydrocladia, on two-segmented pedicels; oval, truncated distally, with thickened ring of prosaic and lid; two basal nematothecae. Male borne on hydrocladia, smaller, sac-shaped and without nematothecae.

Records from Mediterranean: eastern and western Mediterranean and Adriatic (central Mediterranean?).

Known seasonality: 3, 5-10.

Reproduction: 5-8, 10.

Distribution: endemic of Mediterranean Sea.

References: Motz-Kossowska (1908) as Plumularia; Rossi (1961); Boero and Bouillon (1993); Medel and Vervoort (1995); Medel and LópezGonzález (1996); Schuchert (1997); Avian et al. (1995); Peña Cantero and García Carrascosa (2002)

\section{Genus Polyplumaria G. O. Sars, 1874}

Colony with erect, strongly ramified, pinnate stems, rigid in appearance, typically polysiphonic; branches of hydrocaulus opposite or nearly so; hydrocladia branched, regularly arranged, placed on an apophysis with a much developed, large "mamelon" (considered as an atrophied hydrotheca) on its superior surface; hydrothecal rim smooth; gonophores as fixed sporosacs, gonothecae with or without nematothecae.

Remarks: sometimes included in the Plumulariidae.

References: Calder (1997); Schuchert (1997; 2001a)

FAUNA OF THE MEDITERRANEAN HYDROZOA 147 
Polyplumaria flabellata G.O. Sars, 1874 (Figs. 79H-L)

Hydrocauli erect, up to $350 \mathrm{~mm}$, polysiphonic and branched, with some thick stolonal fibers basally; branches arranged opposite o nearly so, usually polysiphonic over part of their lengths. Tubes of stem and branches with nematothecae. Main axis of branches segmented into internodes, bearing alternate apophyses with a large mamelon and a pair of nematothecae; hydrocladia borne on the apophyses, segmented, first internode shorter and athecate, occasionally fused with the apophysis, remainder ones each with big hydrotheca and 4 nematothecae: one median inferior, two laterals, and one median superior which may occasionally be placed on a separate internode, nodes oblique. Hydrotheca cupshaped, walls gradually widening, margin slightly everted and even; adcauline wall 1/3 adnate. Lateral nematothecae reaching hydrothecal rim or slightly shorter, all nematothecae two-chambered, basal chamber longer and narrower, apical chamber cupshaped and with deep adcauline embayment. The hydrocladia may be branched, the branch originating from the first internode. Male and female gonothecae similar, borne on short pedicels near base of hydrocladium, inverted pear-shaped, obliquely truncate above, aperture large; 4 small nematothecae near base.

Records from Mediterranean: only just inside the Mediterranean, at the Strait of Gibraltar.

Known seasonality: 6, 7.

Distribution: sub-tropical to cool-temperate waters on the eastern Atlantic, Mediterranean.

References: Gili, Vervoort and Pagès (1989); Ramil and Vervoort (1992 a, c); Cornelius (1995); Medel and Vervoort (1995); Medel and LopezGonzález (1996); Ansín Agís et al. (2001); Schuchert (2001a).

Genus Pseudoplumaria Ramil and Vervoort (1992)

Colonies composed of rigid, strongly ramified, polysiphonic, occasionally forked hydrocaulus, with alternate or opposite branches; hydrocladia always unbranched, alternately arranged along axis, placed on an apophysis with a much developed, large "mamelon" (considered as an atrophied hydrotheca) on its superior surface; hydrotheca exclusively found on the hydrocladia, hydrothecal border smooth; mobile, immobile and reduced nematothecae two-chambered (bithalamic) present.
Gonophores as fixed sporosacs, gonothecae single with a few nematothecae on basal region.

Remarks: sometimes included in the Plumulariidae. References: Calder (1997); Schuchert (1997).

Pseudoplumaria marocana (Billard, 1930)

(Figs. 79M-P)

Colonies with a thick, polysiphonic, much branched stem about to $220 \mathrm{~mm}$ high, rising from thick matting of hydrorhizal fibers; branches opposite, in one plane. Axial tubes with two longitudinal rows of small nematothecae; "main" frontal axis with alternate apophyses bearing hydrocladia (2-6 per internode), each with one "mamelon" surrounded by three nematothecae. Hydrocladia with 1-2 basal internodes with a single nematotheca, the remainder ones with one hydrotheca and four nematothecae; nodes oblique (but the first transverse). Hydrotheca big, cylindrical, margin not everted and even. Median inferior nematotheca two-chambered, basal chamber very short and immobile, apical chamber with a deep adcauline embayment; lateral nematothecae larger, reaching hydrothecal rim, movable, two-chambered, apical chamber with a minor embayment; fourth nematotheca found in axil between free part adcauline wall and internode, reduced to a peridermal sac; coenosarc of the colony with zooxanthellae; gonothecae pyriform with two short basal segments.

Records from Mediterranean: found only at the entrance (Algeciras Bay, Strait of Gibraltar).

Known seasonality: 6, 7.

Distribution: tropical temperate eastern Atlantic, Mediterranean.

References: Patriti (1970); Gili, Vervoort and Pagès (1989) part of the material of Polyplumaria flabellata; Ramil and Vervoort (1992c), Medel and Vervoort (1995); Medel and López-González (1996); Ansín Agís et al. (2001)

\section{Genus Schizotricha Allman, 1883}

Colonies with polysiphonic, erect stem, which may be branched or unbranched, with one main axial tube bearing pinnately arranged hydrocladia and hydrothecae, and several undivided accessory tubes provided only with nematothecae; hydrocladia alternate, the majority branched sympodially from anterior or lateral surface immediately below hydrothecae; hydrotheca cup-shaped, with smooth rim; nematotheca 2-chambered and movable, lateral

148 J. BOUILLON et al. 
nemathotecae not fused to their pedicel or to hydrothecae; gonophores as fixed sporosacs, gonothecae inserted on hydrocladia between hydrothecae and provided with nematothecae.

References: Schuchert (1997); Peña Cantero et al. (1999).

Schizotricha frutescens (Ellis and Solander, 1786) (Figs. 80A-E)

Colonies composed of erect, polysiphonic and pinnate stems up to about $75 \mathrm{~mm}$ high, arising from flattened mass of hydrorhiza tubes. Hydrocladia alternate, laterally under the hydrothecae. Secondary and tertiary hydrocladia sometimes present, arising from the first hydrothecae of the hydrocladia. Primary tube of the stem with a longitudinal row of hydrothecae. Hydrocladia segmented on long segments by transverse nodes, with 1-5 hydrothecae, each one surrounded by 3 nematothecae, one median inferior and two laterals. Hydrotheca cupshaped, deep, adcauline wall completely adnate, rim smooth. Median inferior nematotheca some distance below hydrothecae; lateral nematotheca over reaching hydrothecal margin. Male and female gonothecae on different colonies, borne on axis and hydrocladia below hydrothecae; pear-shaped, narrowed basally, with two nematothecae.

Records from Mediterranean: western Mediterranean, Adriatic.

Known seasonality: 2, 6, 7.

Reproduction: 6.

Distribution: eastern temperate and subtropical Atlantic, Mediterranean.

References: Millard (1975); Ramil and Vervoort (1992a); Boero and Bouillon (1993); Cornelius and Ryland (1990); Avian et al. (1995); Cornelius (1995) as Polyplumaria; Medel and LópezGonzález (1996); Schuchert (1997, 2001a).

\section{Family HebelLidae Fraser, 1912}

Hydroid: colony stolonal, hydrotheca campanulate with smooth margin, short or long distinct pedicel; hydrothecal base with annular perisarcal thickening and membranous diaphragm or thick diaphragm an no annular thickening; gonotheca solitary, with or without operculum, arising from hydrorhiza; exceptionally with nematothecae (Bedotella); gonophores as fixed sporosacs, or swimming gonophores, or eumedusoids, or free medusae.
Medusa: umbrella flat; manubrium short and flat, mouth with irregular lips; with marginal cordyli; with 4 or more branched radial canals; marginal tentacles hollow; "gonads" linear to sinuous on the radial canals; with or without marginal cirri; with or without adaxial ocelli; without statocysts.

Remarks: this family is usually included in the Lafoeidae A. Agassiz, 1865, but has often been separated as a subfamily by several authors (see Calder, 1991; Boero et al., 1997 for a review). The family Hebellidae was established by Fraser (1912) to accommodate the following genera (see Calder, 1991): Bedotella; Halisiphonia, Hebella, Hebellopsis and Scandia, whose hydroids typically have stolonal colonies, campanulate hydrothecae with a diaphragm or an annular thickening or both, and single gonothecae. As stated by Calder (1991), in the Lafoeidae, Filellum is stolonal, a diaphragm is present in Abietinella, Cryptolaria and Zygophylax, and single gonothecae are found in some species of Cryptolarella. We recognise what Calder (1991) considered as a subfamily of the Lafoeidae, the Hebellinae, as a separate family: the Hebellidae. In fact, although certain of the Hebellidae characters are shared with some Lafoeidae genera, none of them have all those characters together; Filellum is stolonal but has no diaphragm and has aggregated gonothecae; some Cryptollarella have a single gonotheca, but they have no diaphragm and are erect; Abietinella, Cryptolaria and Zygophylax have a diaphragm but have erect colonies and coppinia.

Hebellid medusae, till recent years, were only known by juvenile indeterminable stages. De Andrade and Migotto (1997) reared immature medusae from a Hebella species, showing relationship with Laodiceidae, perhaps with the medusabased genus Staurodiscus, and Migotto and De Andrade (2000) elucidated the life cycle of Hebella furax which should be referred to genus Toxorchis, possibly to T. kellneri (Toxorchis is here considered as congeneric with Staurodiscus, see below). The Laodiceidae contain two distinct groups of medusa genera, those with unbranched radial canals from which several life cycles are known, the hydroids being all "Cuspidella-like", and two genera with branched radial canals, whose life cycle were unknown till the observations of the above cited authors, and having Hebella hydroids. Those two particular genera are here included in the family Hebellidae. The Leptomedusae contain so four families with cordyli or cordyli-like structure the Hebellidae, the Laodiceidae, the Teclaiidae and the Tiarannidae. 
References: Calder (1991); Migotto (1996); De Andrade and Migotto (1997); Boero et al. (1997); Migotto and De Andrade (2000); Watson (2000).

\section{Key to hydroids and medusae}

1. Gonophores producing fixed sporosacs ............ 2

- Gonophores not producing fixed sporosacs; hydrothecae sharply separated from pedicel.... 3

2. Colony with nematophores and nematothecae.... Bedotella

- Colony without nematophores ............... Scandia

3. Gonophores as swimming sporosacs Anthohebella

- Gonophores not as above .. 4

4. With eumedusoids or immature medusae ............ Hebella

- With free mature medusae; some or all of the radial canals branched, branches joining or not ring canal Staurodiscus

Genus Anthohebella Boero, Bouillon and Kubota, 1997

Hydroid: colonies stolonal; hydrotheca on short pedicel, campanulate, usually with thin annular thickening and thin membranous diaphragm; swimming gonophores, with velum, 4 radial canals, 4 atentaculate marginal bulbs; "gonads" on spadix (manubrium); gonotheca solitary originating from hydrorhiza.

Remarks: Watson (2000) described a new species of Anthohebella, A. darwinensis, but the gonophores of this species are devoid of manubrium and no reference is made in the description to the position of the gonads, although the gonophore is considered as nearly mature. This species is here mantained in the Anthohebella awaiting more information.

Anthohebella parasitica (Ciamician, 1880) (Figs. 80F-H)

Colonies stolonal; hydrothecae on short and annulated pedicels, campanulate, margin curved, usually with annular thickening and a thin membranous diaphragm; hydranth with conical hypostome; reproduction by swimming gonophores, with velum, 4 radial canals, 4 atentaculate marginal bulbs; "gonads" on spadix (manubrium), gonothecae nearly twice the length of the hydrotheca, originating from hydrorhiza, on short and annulated pedicels tapered basally, wide and truncated distally, with 4-5 operculars flaps.
Records from Mediterranean: eastern and western Mediterranean, Adriatic.

Known seasonality: present all the year.

Reproduction: 1-12

Distribution: warm waters around the world.

References: Boero (1980); Gili (1986), Medel and López-González (1996), all as Hebella parasitica; Peña Cantero and García Carrascosa (2002).

\section{Genus Bedotella Stechow, 1913}

Colonies stolonal or erect, branched, polysiphonic; hydrothecae campanulate, borne irregularly on all surface of branches and sometimes on hydrorhiza, free, non adherent, distinctly pedicellate, with thin diaphragm; margin even and slightly everted; nematophore in shortly globular pedunculate nematotheca on hydrocaulus and hydrocladia; gonophores as fixed sporosacs, gonothecae solitary, strongly compressed, disc-shaped, not aggregated.

References: Ramil and Vervoort (1992a); Alvarez (1993b).

Bedotella armata (Pictet and Bedot, 1900) (Figs. 80I-K)

Colonies stolonal or with erect stems (occasionally as a combination of both), up to $15 \mathrm{~mm}$ high. Stolonal colonies with creeping tubes or an anastomosing, irregular network of stolonal tubes. Erect colonies composed of a number of adnate stolons basally attached by means of creeping stolons that may bear hydrothecae and nematothecae. Perisarc thin and transparent over whole colony. Hydrotheca campanulate, walls narrowing towards basally, occasionally slightly asymmetric in lower third, rim circular and everted. Hydrothecal renovations common. Hydrothecal pedicels with a few rings or undulations of perisarc, near insertion on stolon. Nematothecae globular, with a short pedicel, arranged irregularly, frequently in groups of 4-5 nematothecae. Gonothecae of a big size ( 6 × $6 \mathrm{~mm}$ ), fan-shaped, compressed laterally borne on short pedicels.

Records from Mediterranean: western Mediterranean (France, only one record); also recorded at the Strait of Gibraltar.

Distribution: Northeastern Atlantic, Mediterranean.

References: Rees and White (1966); Marinopoulus (1981) as Campanularia; Ramil and Vervoort (1992a); Altuna (1994); Medel and LópezGonzález (1996). 


\author{
Genus Hebella Allman, 1888 \\ = Hebellopsis Hadzi, 1913
}

Hydroid: colonies stolonal; hydrotheca on short pedicel, campanulate to cylindrical, usually with annular thickening and membranous or perisarc-like diaphragm; gonophores either as released eumedusoids with mature "gonads" on radial canals, or as medusa already mature at liberation with 4 radial canals, each with a proximal gonad; 4 perradial atentaculate bulbs and 4 small interradial atentaculate bulbs; manubrium short; mouth and gastric cavity present; during life span some tentacles and more marginal bulbs may grow, or as juvenile immature free medusa.

Medusa: adult medusa unknown.

Remarks: the genus Hebella will probably have to be split in the future when more life cycles will be completely described, several hebelliform hydroids giving apparently rise to different medusa morphotypes. See also remarks under Scandia.

References: Blanco et al. (1994); Altuna Prados (1996); Boero, Bouillon and Kubota (1997).

Hebella furax Millard, 1957: see below Staurodiscus

Hebella scandens (Bale, 1888) (Figs. 81A-E)

Hydroid: colonies epizootic on other hydroids; hydrothecae with flared margin, mostly oblique, but bent $90^{\circ}$ when growing over host hydrothecae, with smooth to slightly corrugated walls, asymmetrical, with perisarcal diaphragm; pedicels short, smooth or annulated; hydranths with 12-16 tentacles; gonothecae containing up to 4 medusa buds, bigger than hydrothecae, asymmetrical, with undulated walls, truncated distally, tapering toward base, on short pedicels, operculum with 4 opercular flaps.

Records from Mediterranean: eastern and western Mediterranean, Adriatic.

Known seasonality: 1, 2, 4-7, 11, 12.

Distribution: Atlantic; Indo-Pacific; Mediterranean.

References: Rossi (1961); Millard (1975); Gili (1986); Roca (1986); Calder (1991) as Hebellopsis; Genzano and Zamponi (1992); Avian et al. (1995); Medel and López-González (1996) as Hebellopsis; Boero et al. (1997); Peña Cantero and García Carrascosa (2002).

\author{
Genus Scandia Fraser, 1912 \\ = Croatella Hadzi, 1916
}

Colonies stolonal, sometimes sympodial, arising from a creeping hydrorhiza; hydrotheca large, campanulate, usually borne on long pedicels, with a basal rounded annular perisarcal thickening; gonophores fixed sporosacs, gonotheca solitary.

Remarks: Scandia differs from Anthohebella and Hebella in not being associated to supporting hydroids and in gonothecal content. It could be merged with Hebella.

1. Female gonophore spherical.................. S. gigas

- Female gonophore oval, more or less corrugated S. michael-sarsi

\section{Scandia gigas (Pieper, 1828)}

(Figs. 81F-H)

Colonies composed of erect pedicels scarcely, dichotomously or irregularly branched and ended by hydrothecae. Perisarc of pedicels undulated or twisted throughout. Hydrothecae tubular, elongated, walls sometimes asymmetrical, narrowing gradually towards the base, with a hydrothecal diaphragm; margin everted, rim even. Female gonothecae spherical, male sac-shaped and elongated.

Records from Mediterranean: eastern and western Mediterranean, Adriatic.

Known seasonality: 1, 4-6, 8, 9, 11.

Reproduction: 4-8.

Distribution: temperate waters from western and eastern Atlantic and North Pacific, Mediterranean.

References: Boero (1981); Gili (1982; 1986); Roca (1989); Boero and Bouillon (1993); Altuna (1994); Avian et al. (1995); Medel (1996); Medel and López González (1996); Peña Cantero and Garcia Carrascosa (2002).

Scandia michaelsarsi (Leloup, 1935)

(Figs. 81I-L)

Colonies with long, erect pedicels unbranched or branched, ended by hydrothecae. Pedicels irregularly wrinkled or twisted perisarc. Hydrothecae tubular, deep, walls slightly asymmetrical, rounded basally, margin everted, aperture circular; base of the hydrotheca with a thick hydrothecal diaphragm; gonophores unknown, gonothecae borne on stolon, with short pedicels, ovalate; the female longer and more slender than the male, more or less corrugated, 
truncate, with the aperture occupying only a part of the upper part.

Records from Mediterranean: western Mediterranean

Seasonality: ?

Distribution: Atlantic, Mediterranean.

References: Fraser (1944) as Scandia mutabilis; Vervoort (1959) as Hebella michael-sarsi; GarcíaCorrales et al. (1979); Boero and Bouillon (1993); Medel and López-González (1996); Boero et al. (1997).

$$
\begin{gathered}
\text { Genus Staurodiscus Haeckel } 1879 \\
\text { = Toxorchis Haeckel, } 1879
\end{gathered}
$$

Hydroid: colonies generally epizootic on other hydroids, mainly plumulariids and aglaopheniids, Hebella-like; with the hydrorhiza sometimes penetrating into the perisarc of the host as a parasitic form; hydrothecae almost conical when growing on upper part of the host, cylindrical when growing on lower part of same host; asymmetrical to symmetrical; with everted margin, sharply or slightly oblique, with short to long, wrinkled or annulated pedicels; with membranous diaphragm (sometimes absent) and annular thickening; hydranth with 20-26 tentacles; gonophores as free medusae; gonotheca as big or slightly bigger than hydrotheca, with four opercular flaps, on short pedicel, slightly undulated walls, truncated distally, tapering at base, containing up to three medusae.

Medusa: with 4 or more main primary radial canals, some or all branching one or more times, primary canal and some or all of the branches reaching circular canal; "gonads" on primary radial canals and branches; numerous tentacles and cordyli; with or without cirri; with or without ocelli.

Remarks: the life cycle Hebella furax Millard, 1957 has been elucidated by Migotto and De Andrade (2000); the hydroid giving rise to a Staurodiscus (Toxorchis) type of medusa, presumably Staurodiscus kellneri Mayer, 1910. The differences between Staurodiscus and Toxorchis are ambiguous and tenuous, the main character being the supposed mode of ramification of the radial canals. In Staurodiscus, ramifications are described as branches formed after the development of the primary canal which first reach the circular canal, whereas in Toxorchis ramifications were believed to be bifurcation of the primary canal which himself never reached the circular canal (see Kramp, 1962; Bouillon, 1984b). Migotto and De Andrade (2000), studying the cycle of a Toxorschis medusa (obtained from Hebella furax), described a development of the radial canals and of their branches similar to that observed in Staurodiscus. There are so presently no reasonable reasons to separate the two genera.

\section{Staurodiscus kellneri Mayer, 1910}

(Figs. 82A-D)

Diagnosis: see above.

Records from Mediterranean: western Mediterranean.

Seasonality: ?

Distribution: Indo-pacific, Mediterranean.

References: García Corrales et al. (1979); Gili (1982); Boero et al. (1997); De Andrade and Migotto (1997); Migotto and De Andrade (2000).

\section{Family KIRCHENPAUERIIDAE Stechow, 1921a}

Colonies either with erect, branched or unbranched hydrocaulus, monosiphonic or polysiphonic or stolonal (Ophinella); issued from a creeping hydrorhiza; hydrocladia alternate, arising in polysiphonic hydrocauli from a single dominant axial tube; hydrothecae small, occurring only on hydrocladia, with or without marginal cusps, with or without an abcauline intrathecal septum, adnate or not; nematophores with nematothecae often rudimentary or occurring as naked sarcostyles; when present, nematothecae simple, typically one-chambered although two-chambered in some taxa (i.e.: Naumovia, Ventromma), not fused to hydrothecae; paired lateral nematophores and nematothecae absent; gonophores as fixed sporosacs; gonotheca solitary, lacking nematothecae, on stem or hydrocladia, exceptionally on hydrorhiza (Pycnotheca).

Remark: cnidome usually composed of microbasic mastigophores and sometimes pseudostenoteles, microbasic euryteles, and haplonemes. Stepanjants et al. (1998) described, in some specimens of Wimveria, desmoneme-like capsules from undischarged cnidocysts. The presence of desmonemes seems very doubtful in Leptomedusae and result presumably of contamination by cnidocysts issued from other species. The family Kirchenpaueriidae needs critical revision, the genera being not clearly defined and their diagnoses often overlapping. The genera Naumovia, Ventromma and Wimveria present only slight differences with Kirchenpaueria and could eventually be included in it.

References: Cornelius (1995); Migotto (1996); Calder (1997); Stepanjants et al. (1998); Peña Can- 
tero and Marques (1999); Ansín Agís et al. (2000).

1. Nematophores with well developed nematothecae.... Ventromma

- Nematophores nude or with reduced nematothecae. Kirchenpaueria

\section{Genus Kirchenpaueria Jickeli, 1883}

Stem unbranched, monosiphonic, with alternate, pinnate, unbranched hydrocladia, in simple forms arising directly from hydrorhiza; hydrotheca cupshaped, without intrathecal septum, with unthooted rim, partially or completely adnate; no cauline hydrothecae; nematotheca typically 1-chambered and movable, mesial nematothecae present or absent, sometimes poorly developed, reduced or even absent, nematophores with or without nematothecae present also on stem pending species; gonophores as fixed sporosacs, gonotheca solitary, not annulated, often with longitudinal ridges and spines.

Recent references: Cornelius (1995); Schuchert (2001a).

1. Nematophores with club-shaped nematothecae.. K. bonnevieae

- Nematophores nude (stem and above hydrotheca) or with a minute frontal peridermal shield (below hydrotheca). K. pinnata

Kirchenpaueria bonnevieae (Billard, 1906) (Figs. 82E-H)

Colonies pinnate with erect, monosiphonic and unbranched hydrocauli up to about $45 \mathrm{~mm}$. Basal parts of the main axis unsegmented, with several nematothecae. Remainder parts composed of segments separated by transverse nodes; each internode bearing a latero-distal apophysis, one "mamelon" on upper surface of apophysis and two nematothecae, one basally and another on upper surface of apophysis; two additional nematothecae may occurs. Hydrocladia borne on the apophyses at the upper part of segments; alternate, with hydrothecate internodes separated by slightly oblique nodes; each segment with one hydrotheca in lower half and two median nematothecae, below and above hydrothecae. Hydrotheca cup-shaped; completely adnate, rim smooth, aperture tilted upwards. All nematothecae one-chambered and movable, club-shaped, narrowed basally, with a circular aperture distally; gonothecae borne on apophyses, on short pedicels two segmented; elongated, tapered basally, widely and truncate distally.

Records from Mediterranean: Alborán Sea only.

Known seasonality: 6.

Distribution: North Atlantic, Indo-Pacific, Indian Ocean; Alborán Sea.

References: Vervoort (1966a); Millard (1975) both as Kirchenpaueria triangulata; Ramil and Vervoort (1992a); Medel and López-González (1996); Ansín Agís et al.(2001); Schuchert (2001a).

\section{Kirchenpaueria pinnata (Linnaeus, 1758)}

(Figs. 82I-L, 83A-B)

Colonies pinnate with erect, monosiphonic, and occasionally branched hydrocauli up to about $42 \mathrm{~mm}$. Basal part of the axis with several internodes separated by transverse nodes; the remainder segmented on internodes bearing hydrocladia, these alternate, on lateral apophyses at the upper part of the segment. Apophysis with a naked nematophore on the upper side; another one is disposed laterally on the axis, just above the apophysis. Hydrocladia with a first shorter athecate internode, with transverse node basally and oblique one distally (occasionally several of this internode may occurs); remainder internodes thecate, or in an irregular sequence of thecate and athecate internodes separate by transverse nodes. Thecate internodes with one hydrotheca and two nematophores, one median inferior and another median superior. Hydrotheca cup-shaped, walls gradually diverging, adcauline wall almost entire adnate. Median inferior nematophore with a minute frontal peridermal shield; median superior behind hydrotheca completely nude. Gonothecae of both sexes similar, borne on hydrorhiza or in a row on the axis; sacshaped, with short pedicels, hexagonal in cross section, with six longitudinal carinae bearing digitiform prolongations of widely varied development, even absent in some gonothecae.

Records from Mediterranean: eastern and western Mediterranean, Adriatic.

Known seasonality: present all the year.

Reproduction: 1-12.

Distribution: eastern Atlantic, Indo-Pacific, Mediterranean.

References: García-Corrales et al. (1978); Boero and Bouillon (1993); Cornelius (1995); Avian et al. (1995); Medel and Vervoort (1995); Medel and López-González (1996); Ansín Agís et al.(2001); Schuchert (2001a); Peña Cantero and García Carrascosa (2002). 
Genus Ventromma Stechow 1923

Colonies erect, monosiphonic or polysiphonic, with branched or unbranched hydrocauli arising from creeping hydrorhiza; hydocladia alternate, typically unbranched; hydrothecae only on hydrocladia, cup-shaped, margin entire, without intrathecal septum; nematophores usually with small, 2-chambered nematothecae, hydrothecate internodes with a median inferior and a median superior nematotheca, no lateral nematophores and nematothecae; nematophores or nematothecae also on stems; gonophores as fixed sporosacs, gonotheca solitary, with transverse annulations.

Remark: Cornelius (1995) pointed out that this genus is not satisfactorily defined; this author includes Ventromma Stechow, 1923d in the Subfamily Plumulariinae L. Agassiz, 1862, instead of in the subfamily Kirchenpaueriinae where most authors include it and where it is even often regarded as congeneric with Kirchenpaueria Jickeli, 1883.

Ventromma halecioides (Alder, 1859) (Figs. 83C-G)

Colonies pinnate with erect, basally polysiphonic and often branched hydrocauli up to about $40 \mathrm{~mm}$ high. Monosiphonic parts of the axis separated into internodes by transverse nodes; each segment with a lateral apophysis distally bearing a nude nematophore; a cup-shaped nematotheca is borne laterally on the segment, above the apophysis. Hydrocladia borne on the apophysis, alternate, heteromerously segmented, nodes transverse; basal part beginning with a short athecate internode. Thecate segments with one hydrotheca and two nematothecae, one median superior and one median inferior at some distance of the hydrothecae. Hydrotheca on distal half of internode, cup-shaped, almost completely adnate, abcauline wall slightly convex, rim smooth and circular, aperture $80^{\circ}$ with the axis. Nematothecae two-chambered, small, basal chambers very short, distal one cup-shaped, with adcauline embayment. Gonothecae borne on the axis, barrel-shaped, narrowed basally, truncate distally, with a circular lid; walls with transverse and distinct ribs.

Records from Mediterranean: eastern and western Mediterranean, including Black Sea, Adriatic.

Known seasonality: 6-3.

Reproduction: 3, 6, 7, 9.

Distribution: cosmopolitan species.
References: Gili and García-Rubíes (1985); Gili (1986); García-Corrales et al. (1978); Boero and Bouillon (1993); Avian et al. (1995); Cornelius (1995); Medel and Vervoort (1995); Medel and López-González (1996); Peña Cantero and García Carrascosa (2002).

\section{Family LAFOEIDAE A. Agassiz, 1865}

Paedomorphic hydrozoa usually reduced to hydroid stage, hydroids colonial, either erect or stolonal, arising from a creeping hydrohiza, hydrothecae varying from tubular to campanulate in shape; radially or bilaterally symmetrical, usually adherent more seldom pedicellate; margin entire; operculum usually absent; with or without diaphragm; without annular perisarcal thickening; hydranth with a conical hypostome surrounded by a whorl of filifom tentacles; abcauline diverticulum present or absent; nematophores present or absent. Cnidome: where known microbasic mastigophores. When known, gonophores as fixed sporosacs; gonothecae aggregated into coppinia or scapus, exceptionally solitary.

References: Calder (1991); Ramil and Vervoort (1992a); Blanco et al. (1994); Cornelius (1975b, 1995); Hirohito (1995); Calder and Vervoort (1998).

1. Hydrotheca stalked ........................................... 2

- Hydrotheca not stalked, usually adherent ........ 3

2. Hydrothecae in two longitudinal rows: with diaphragm or reduced annulus; nematophores and nematothecae usually present ... Zygophylax

- Hydrothecae irregularly on all sides; with no diaphragm or annular thickening; without nematophores Lafoea

3. Mature colonies stolonal: hydrothecae adherent to hydrorhiza Filellum

- Mature colonies with erect, branching stem .... 4

4. Diaphragm present between hydrotheca and stem apophysis; nematophores and nematothecae normally present ........................... Cryptolaria

- Normally no diaphragm and no nematophores... Acryptolaria

\section{Genus Acryptolaria Norman, 1875}

Colonies normally erect, stolonal when young, more or less alternately branched; hydrocaulus and hydrocladia polysiphonic, with an axial tube overgrown by accessory tubes; all branches with two longitudinal rows of alternate hydrothecae, sessile, 
tubular, adnate to axial tube or immersed basally in accessory tubes, curving outwards and becoming free distally; diaphragm absent; nematophores absent; gonophores as fixed sporosacs, gonothecae aggregated in coppinia with or without modified hydrothecal tubes.

Remark: Stepanjants (1979) described an operculum in Acryptolaria operculata?

\section{Acryptolaria conferta (Allman, 1877)} (Figs. 83H-L)

Colonies composed of erect, polysiphonic and branched stems bearing hydrocladia. Axis and most part of branches and hydrocladia, composed of numerous tubes longitudinally arranged and anastomosed with each other; monosiphonic parts with a sympodial structure, axis straight to geniculate, hydrothecae lateral, in the same plane and alternate; tubular, basal part merging into the stolon, distal part free and curved outwards, rim even and circular, hydrothecal renovations frequent. Gonothecae in coppiniae with several amphora-shaped gonothecae; acrocyst present in female gonothecae.

Remark: Ramil and Vervoort (1992) created the subspecies minor based in its minor size and the lack of intermediate specimens between the two forms.

Records from Mediterranean: western Mediterranean.

Known seasonality: 4, 6, 9.

Distribution: cosmopolitan

References: Vervoort (1968); Patriti (1970); Millard (1975); Roca (1986, 1989); Templado et al. (1986); Calder (1991); Ramil and Vervoort (1992a); Boero and Bouillon (1993); Medel and LópezGonzález (1996); Schuchert (2001a).

\section{Genus Cryptolaria Busk, 1857}

Colonies normally erect, pinnate, stolonal in young stages; main stem polysiphonic, occasionally forked; hydrocladia sub-alternate, all in one plan; main axis with 2 or 4 longitudinal rows of sub-opposite hydrothecae; hydrotheca sessile, tubular, without pedicel, directly on apophysis, adcauline wall adherent to hydrocladia for some distance at least in some part of colony, usually curved outwards, separated from apophysis by a distinct diaphragm; nematophores and nematothecae present; gonophores as fixed sporosacs, gonothecae aggregated to form a coppinia.

Reference: Rees and Vervoort (1987).
Cryptolaria pectinata (Allman, 1888)

(Figs. 84A-D)

Colonies up to $40 \mathrm{~mm}$ high; hydrocauli erect, strongly polysiphonic and occasionally forked, basally with small disk of stolonal fibers as attachment to the substratum. Hydrocladia subalternate, also polysiphonic. Perisarc strong and thick, becoming thinner at the hydrothecae. Nodes absent. Hydrothecae biserially arranged in one plane on stem and hydrocladia, borne on small apophyses, tubular, narrowed basally and curved distally; about $1 / 2$ of the adcauline wall adnate to the internode, but axillary hydrothecae often completely free from axial tube; diaphragm thick and oblique; rim smooth, circular and slightly everted, hydrothecal renovations frequent. Nematothecae present on frontal part of hydrothecal apophyses, deep tumblershaped, rounded basally, with or practically without a short pedicel, rim circular and not everted. Secondary tubules parallel to axis and hydrocladia and covering basal portion of hydrothecae, usually bearing many, irregularly distributed nematothecae. Gonophores, fixed sporosacs, gonothecae arranged in coppinia flask-shaped, firmly adpressed for about two-thirds of length and with slender, free neck provided with one or two lateral openings and one or two curved distal horns; coppinia provided with branched nematothecae which project above the surface. The coppiniae are dioecious.

Records from Mediterranean: only recorded at the Strait of Gibraltar

Distribution: deep waters of the Atlantic and Pacific Oceans, Strait of Gibraltar.

References: Ralph (1958); Millard (1975); Gili et al. (1989); Ramil and Vervoort (1992a); Medel and López-González (1996).

\section{Genus Filellum Hincks, 1868}

Colonies stolonal, stolon filiform, creeping on substrate, usually over other hydroids, irregularly branched; hydrotheca sessile, tubular, arising singly from hydrorhiza, adnate basally, curving centrally and becoming free and bending upwards in varying degrees distally; no diaphragm and operculum; no nematophores and nematothecae; gonophores as fixed sporosacs, gonothecae either closely adpressed together, with lateral walls contiguous, touching each other, or weakly aggregated, being isolated, not in close contact; coppinia usually hermaphrodite, with or without modified hydrothecal protective tubes. 
Reference: Peña Cantero et al. (1998).

1. Coppinia with protective tubes 2

- Coppinia without protective tubes F. disaggregatum

2. With minute corrugations over the upper surface of the adnate part hydrotheca, coppinia with straight accesory tubes... F. serratum

- Without such corrugation, adnate part of hydrotheca smooth, coppinia with simple curved accessory tubes $F$. serpens

Filellum disaggregatum

Peña Cantero, García Carrascosa and Vervoort, 1998 (Figs. 84E-F)

Colonies stolonal, consisting of filiform hydrorhizal stolons, giving rise to hydrotheca parallel to the stolons which, depending of substratum forms a more or less tight mesh. Hydrotheca tubular adnate to substratum for more than half their length, hydrothecal aperture circular; rim even and smooth, slightly widening and everted at aperture. Perisarc of hydrotheca smooth, hydrothecal renovations frequent. Coppinia with gonothecae irregularly arranged, not in close contact, pear-shaped, with long neck. Widest part of gonothecae adnate to substratum, some gonothecae with renovations of aperture. Protective tubes absent, defensive functions being carried out by normal hydroids from which hydrothecae are situated near gonothecae. Planula continuing their development outside the gonotheca connected to it by means of a filament.

Records from Mediterranean: western Mediterranean, Chafarinas Islands.

Known seasonality: 8.

Distribution: endemic of Mediterranean Sea.

References: Peña Cantero et al. (1998); Peña Cantero and García Carrascosa (2002).

\section{Filellum serpens (Hassall, 1848)}

(Figs. 84G-H)

Colonies stolonal, tortuous, irregularly branched, generally epizootic on other hydroids; hydrothecae tubular, at irregular intervals, sessile, basal part (1/4$2 / 3$ ) merging into the stolon, distal part curving upwards from the stolon, adnate portion smooth; rim even, usually everted, several hydrothecal renovations frequent; hydranth with 8-12 amphicoronate tentacles, hypostome conical; gonothecae in her- maphrodite coppiniae; coppinia with simple curved accessory tubes.

Records from Mediterranean: eastern and western Mediterranean, Adriatic.

Known seasonality: 1, 3, 5-7, 9-12.

Distribution: cosmopolitan.

References: Millard (1975); Gili (1982, 1986); García-Carrascosa et al. (1987); Cornelius and Ryland (1990); Boero and Bouillon (1993); Avian et al. (1995); Cornelius (1995); Medel and LópezGonzález (1996); Peña Cantero et al. (1998); Schuchert (2001a); Peña Cantero and García Carrascosa (2002).

Filellum serratum (Clarke, 1879)

(Figs. 84I-J)

Colonies stolonal and irregularly branched, generally epizootic on other hydroids; hydrotheca sessile, basal part merging into the stolon, adnate portion provided with numerous external transverse ridges, free part curving upwards from the stolon, tubular, rim even, usually everted, several hydrothecal renovations frequent; gonophores as fixed sporosacs, gonothecae aggregated to form a coppinia firmly adpressed cylindrical, with terminal aperture and with straight accessory tubes.

Records from Mediterranean: western Mediterranean.

Known seasonality: 4 - 7, 9, 10, 12.

Distribution: cosmopolitan species.

References: Millard (1975); García-Corrales et al. (1979); Gili (1982, 1986); Roca (1986); Calder (1991); Boero and Bouillon (1993); Medel and López-González (1996); Peña Cantero et al. (1998); Schuchert (2001a); Peña Cantero and García Carrascosa (2002).

Genus Lafoea Lamouroux, 1821

Colonies occasionally stolonal but usually erect, branched, with polysiphonic hydrocaulus, terminal branches of hydrocaulus monosiphonic; hydrothecae irregularly arranged, tubular to deeply campanulate; radially symmetrical but sometimes bent and thus bilaterally symmetrical, usually free from stem or stolon, pedicel generally spirally twisted, sometimes absent, not always well defined, diaphragm absent, hydrothecal base indistinctly separated from pedicel by ring of small desmocytes; gonophores as fixed sporosacs, gonothecae aggregated in hermaphrodite coppinia with modified tubes. 
Lafoea dumosa (Fleming, 1820)

(Figs. 84K, 85A-D)

Colonies stolonal, erect, or both in the same stolon. Stolonal colonies monosiphonic; erect colonies polysiphonic and irregularly branched, composed of parallel tubes each bearing hydrothecae at irregular intervals. Hydrotheca tubular, elongate, narrower basally, rim even; hydrothecal pedicels, when present, usually twisted. Hydranth with approximatelly 20 tentacles, amphicoronate, hypostome conical. Gonothecae in hermaphrodite coppiniae.

Records from Mediterranean: western Mediterranean, Adriatic.

Known seasonality: 1, 5- 7, 9-11.

Distribution: nearly cosmopolitan.

References: García-Corrales et al. (1979); Gili (1982, 1986); Roca (1986); Ramil and Vervoort (1992a); Boero and Bouillon (1993); Avian et al. (1995); Cornelius (1995); Medel and LópezGonzález (1996); Schuchert (2001a).

\section{Genus Zygophylax Quelch, 1885}

Colonies usually erect, pinnate or flabellate, rarely stolonal; stem occasionally forked, polysiphonic with the exception of distal parts; hydrocladia in most species in one plane but sometimes in various planes; hydrothecae arising from stem, branches and hydrocladia, alternately in two longitudinal rows and from the axial tube when polysiphonic, tubular to deep campanulate, never adherent, usually merging into a pedicel of various length, with distinct diaphragm often reduced to mere annulus; abcauline caecum present (?); nematophores and nematothecae generally present on hydrothecal apophyses and on hydrocladial tubes; gonophores as fixed sporosacs, gonothecae arranged in coppinia or scapus.

Reference: Rees and Vervoort (1987).

1. Gonothecae with numerous nematophorous ramules pointing in all directions.... Z. biarmata

- Gonotheca with no special accumulation of nematothecae. Z. brownei

Zygophylax biarmata Billard, 1905 (Figs. 85E-J)

Hydrocauli erect and polysiphonic, imperfectly pinnate. Monosiphonic parts of the axis slightly geniculate, without nodes, hydrothecal apophyses alternate and in the same plane. Hydrotheca tubular, narrower basally, with a short peduncle, diaphragm oblique, walls slightly asymmetric, rim even, slightly everted; nematothecae inserting on hydrothecal apophysis, one on each side of hydrotheca, tubular, with a short and spherical pedicel, rim even and slightly everted; renovations frequent on hydrothecae and nematothecae; hydrocladia alternate, arising below hydrothecae, on apophyses; hydrothecae arranged as in the main axis; secondary hydrocladia may occurs; gonophores as fixed sporosacs, coppinia open, loose, composed of sessile globular gonothecae, each with an outwards and downwards curving neck with terminal orifices, rim strongly everted; with numerous nematophorous ramules pointing in all directions, occasionally ended by a small hydrotheca.

Records from Mediterranean: western Mediterranean.

Seasonality: ?

Distribution: eastern Atlantic, Indian Ocean, Mediterranean.

References: Patriti (1970); Templado et al. (1986); Rees and Vervoort (1987); Ramil and Vervoort (1992a); Boero and Bouillon (1993); Altuna and Alvarez (1995); Medel and López-González (1996); Medel (1996).

Zygophylax brownei Billard, 1924 (Figs. 85K-M)

Hydrocauli slightly polysiphonic basally, weakly geniculate in monosiphonic regions, perisarc firm, pinnate, with alternate apophyses supporting hydrocladia, nodes absent; each apophysis with axial hydrotheca and a nematotheca; hydrocladium separated from apophysis by distinct perisarcal constriction. Hydrocladia with internodes bearing one to five alternate apophyses with hydrothecae, occasional nodes; hydrothecae large, almost cylindrical but asymmetric, with adcauline wall usually more convex than abcauline, narrowing basally, diaphragm concave but perpendicular, attached by means of thickened perisarcal ring; rim circular, slightly everted, renovations frequent; pedicel irregularly wrinkled, occasionally kinked; nematothecae cup-shaped, cylindrical, rounded basally, with short pedicels, rim circular, renovations frequent; gonophores as fixed sporosac, gonothecae quite separated from another, not conjoined in a coppinia, but clustered thickly round parts of stem, deep oval, 
with two aperture, not compressed, with no special accumulation of nematothecae.

Records from Mediterranean: western Mediterranean.

Distribution: north-eastern Atlantic, Mediterranean.

References: Rees and Vervoort (1987); Ramil and Vervoort (1992a); Medel and López-González (1996); Boero et al., 1997; Schuchert (2001a).

\section{Family LAODICEIDAE Agassiz, 1862}

Hydroid: of "Cuspidella" type; colony stolonal; hydrotheca tubular, sessile, often with transversal growth-rings, sometimes with basal constriction at origin, or exceptionally a poorly delimited pedicel (Ptychogena); operculum conical comprising several pleated flaps meeting centrally, with visible crease-line basally; hydranth lacking intertentacular web, with amphicoronate tentacles; gonotheca resembling hydrotheca, but larger.

Medusa: with marginal cordyli with or without cnidocysts; with 4 or 8 , simple radial canals; marginal tentacles hollow; "gonads" on radial canals, on radial canals and lobes of manubrium or into manubrial pouches; with or without marginal cirri; with or without adaxial ocelli; without statocysts.

References: Russell (1963a) ; Bouillon et al. (1991); Pagès et al. (1992); Bouillon (1999); Bouillon and Barnett (1999); Bouillon and Boero (2000).

\section{Key to hydroids}

When known, the hydroids have a "Cuspidella facies" (see family characters); indistinguishable from each other and inadequate for diagnosis.

\section{Key to medusae}

1 Radial canals open grooves forming large cruciform mouth. Staurophora

- Radial canals closed 2

2. With four radial canals simple or with short lateral diverticula 3

- With 8 simple radial canals Melicertissa

3 With well developed manubrial perradial pouches; «gonads» on proximal part of manubrium and in manubrium pouches, germ cells developing on numerous lateral lamellar folds of the proximal part of the radial canals included in the pouches Guillea

- Without marginal perradial pouches; «gonads» simple, wavy along radial canals, sometimes

adjacent to manubrium. Laodicea

Genus Guillea Bouillon, Pagès,

Gili, Palanques, Puig and Heussner, 2000

Laodiceidae medusae with well developed manubrial perradial pouches; with complex «gonads» on proximal part of manubrium and in manubrial pouches, germ cells developing in manubrial pouches on numerous lateral lamellar folds of the proximal part of the radial canals; with marginal cirri and ocelli.

Guillea canyonincolae Bouillon, Pagès, Gili, Palanques, Puig and Heussner 2000 (Figs. 85N-P)

Medusa: umbrella higher than a hemisphere, dome-shaped, $4.5 \mathrm{~mm}$ wide, $4.0 \mathrm{~mm}$ high; with vertical walls and flatten, rounded apex, mesoglea uniformly thick; velum narrow; manubrium quadrangular, short, with four perradial gastric, gonadial pouches; mouth large, almost circular, without distinct lips but with margin swollen, faintly folded; four simple narrow radial canals penetrating manubrium above gonadial pouches and not meeting exactly in the centre of manubrial roof; circular canal narrow; «gonads» developing perradially on dorsal proximal part of manubrium and extending into the gastric pouches, germ cells differentiating along numerous lateral lamellar folds issued from and perpendicular to the proximal parts of the radial canals included in the pouches, folds gradually tapering in centripetal direction towards dorsal parts of the manubrium; up to 24 marginal tentacles with coiled extremity; marginal bulbs broad, rounded; one club-shaped cordyli without cnidocysts and one to two spiral cirri between successive tentacles; one ocelli on adaxial side of each marginal bulb.

Hydroid: unknown.

Records from Mediterranean: western Mediterranean.

Known seasonality: 12.

Distribution: endemic of Mediterranean Sea.

References: Bouillon et al. (2000).

Genus Laodicea Lesson, 1843

Hydroid: "Cuspidella" type, see family characters; hydrotheca sessile.

Medusa: with small manubrium, sometimes with small perradial lobes; with four radial canals, simple

$158 \mathrm{~J}$. BOUILLON et al. 
or with short lateral diverticula; with simple wavy "gonads"; with or without marginal cirri; with or without adaxial ocelli.

Reference: Bouillon et al. (1991).

Numerous non-valid species of Laodicea have been described from Mediterranean. See Kramp (1959a, 1961); Boero and Bouillon (1993).

- Laodicea bigelowi Neppi and Stiasny, 1912 = Laodicea undulata (Forbes and Goodsir, 1851).

- Laodicea neptuna Mayer 1900 = doubtful species.

- Laodicea ocellata Babnik (1948) = doubtful species.

1. «Gonads» in short, complexly folded lateral diverticula of the proximal half of radial canals, tentacles without abaxial basal spurs; no marginal cirri L. fijiana

- «Gonads» sinuous on radial canals contiguous with manubrium; tentacles with abaxial basal spurs; with marginal cirri. L. undulata

Laodicea fijiana Agassiz and Mayer, 1899 (non Maas, 1905, 1906) (Fig. 86A)

Medusa: umbrella $6 \mathrm{~mm}$ high and wide; manubrium quadrate, 1/4 height of umbrella cavity; «gonads» upon short complex lateral diverticula in proximal half of radial canals; about 70 marginal tentacles without basal spurs, very few cordyli, no cirri.

Kramp $(1953,1961)$ retains this species only for the specimens of Fiji Islands? The L. fijiana described from other localities are synonym of $L$. indica which a possibly synonym of $L$. undulata, see below.

Records from Mediterranean: eastern Mediterranean.

Known seasonality: 11.

Distribution: Indo-Pacific (Fiji Islands?); Mediterranean.

References: Kramp (1961); Schmidt (1973).

Hydroid: unknown.

Laodicea undulata (Forbes and Goodsir, 1851) (Figs. 86B-G)

Hydroid: colonies of "Cuspidella type", forming a creeping hydrorhiza from which arise single, sessile, cylindrical hydrothecae; terminal operculum pyramidal bearing 8-10 teeth meeting centrally, sharply demarcated from the hydrothecae margin; old hydrothecae with transverse growth rings; hydranth long, very extensile, based on a delicate diaphragm; hypostome tall, conical; with a single whorl of 10-12 filiform, amphicoronate tentacle, no intertentacular membranous web; gonothecae as hydrothecae but twice as long, including several developing medusae at different stages.

Medusa: umbrella up to $37 \mathrm{~mm}$ wide, slightly flatter than a hemisphere, saucer-shaped; mannerism short, with square base and short per radial lobes; mouth with short, slightly folded, crenulated, recurred lips; 4 simple radial canals, circular canal narrow; «gonads» elongated, with sinuated pendent folds, issuing from corners of manubrium along perradial lobes and half part of radial canals or almost to umbrella margin, «gonads» may be developed even in small specimens and, the same individual may present more than one sexual cycle; up to 400600 hollow marginal tentacles with faintly developed basal bulbs, small abaxial spurs on young marginal tentacles, often absent in adults ones; 1-2 spiral cirri present (often lost by preservation) usually 1 cordyli between tentacles or rudimentary bulbs; ocelli present each third or fifth tentacle, on each tentacle when juvenile.

Remarks: L. undulata is very similar to L. indica, differing only by quantitative characters such as the number of ocelli and tentacles, several authors regard them as conspecific.

Records from Mediterranean: eastern and western Mediterranean, Black Sea; Adriatic Sea.

Known seasonality: 1-12.

Distribution: Atlantic, Indo-Pacific?, Mediterranean.

References: Russell (1936, 1953); Goy (1973b); Schmidt and Benovic (1979); Bouillon (1984b, 1985a); Benovic and Bender (1987); Gili (1986); Brinckmann-Voss (1987); Goy et al. (1988, 1990, 1991); Bouillon, Boero and Fraschetti (1991); Ramil and Vervoort (1992a); Boero and Bouillon (1993); Cornelius (1995); Avian et al. (1995); Benovic and Lucic (1996); Medel and López-González (1996); Mills et al. (1996).

\section{Genus Melicertissa Haeckel, 1879}

Laodiceidae medusa with 8 simple radial canals; with adaxial ocelli; with or without cirri.

Hydroid: unknown.

\section{Melicertissa adriatica Neppi, 1915} (no figure known)

Medusa: umbrella $46 \mathrm{~mm}$ wide, flatter than a hemisphere, with fairly thick mesoglea; manubrium 
short, bell-shaped; mouth with 8 short crenulated lips; «gonads» linear, along whole length of radial canals; 8 perradial marginal tentacles and between them 16 other marginal tentacles all alike; 3-5 cordyli between successive tentacles each with a black ocelli and even more marginal cirri.

Remarks: Picard, in Kramp (1961) page 444, refers doubtfully this species to Octogonade mediterranea Zoja, 1896, a Tiaropsidae with compound sense organs, with different marginal tentacular structures and, without cordyli (See Tiaropsidae).

Records from Mediterranean: Adriatic Sea.

Known seasonality: 3-4.

Distribution: endemic of Mediterranean Sea.

References: Neppi (1915); Kramp (1959a, 1961); Boero and Bouillon (1993); Avian et al. (1995); Benovic and Lucic (1996).

\section{Genus Staurophora Brandt, 1834}

Hydroid: a typical cuspedellid, hydrotheca sessile; gonothecae unknown.

Medusa: Laodiceidae with unusual cross-shaped manubrium; mouth openings extending along the 4 radial canals transformed for a long distance into open grooves, only most distal parts remaining free and closed; mouth arms slit-like, with strongly folded lips; «gonads» on diverticula in lateral walls of cruciform, enlarged, mouth-radial canal complex; without cirri; with adaxial ocelli.

\section{Staurophora mertensii Brandt, 1834} (Figs. 86H-L)

Hydroid: colonies typically «cuspidellid», forming a reptant hydrorhiza from which arise at irregular intervals, wide, unstalked, cylindrical hydrothecae; operculum pyramidal formed of 10-12 triangular flaps meeting centrally, sharply demarcated from hydrothecal margin; hydranths extensile, with a conical-rounded hypostome, with up to 12 tentacles; no intertentacular membranous web; gonothecae not known.

Medusa: umbrella 100-300 mm wide, flatter than hemispherical; mesoglea thick and smooth; exumbrella with numerous short centripetal furrows; manubrium, mouth and radial canals combined to form a large perradial cross reaching nearly umbrella, mouth openings extending along the 4 radial canals transformed for a long distance into open grooves, only most distal parts remaining free and closed; mouth arms slit-like, with strongly folded lips; «gonads» on diverticulae of the four radial canals, more developed in middle region of each canal; numerous hollow, short, marginal tentacles (up to several thousand), with elongate conical marginal bulbs and well developed pointed endodermal roots; tentacles approximately alternating with cordyli and each with adaxial ocelli.

Records from Mediterranean: medusa never found in Mediterranean but doubtful records of the polypoid stage from south and eastern Spanish coast.

Seasonality: ?

Distribution: Arctic (circumpolar); Indo-Pacific (N. Japan, Alaska, bipolar); Atlantic; Mediterranean?.

References: Naumov (1951,1960-1969); Kramp (1961); García-Carrascosa (1981)?; García-Carrascosa et al. (1987)? ; Boero and Bouillon (1993); Cornelius (1995); Medel and López-González (1996).

\section{Family LOVENELLIDAE Russell, 1953}

Hydroid: colony stolonal or erect, sympodial; hydrotheca pedicellate, elongate, everted-conical to bell-shaped, with diaphragm; operculum conical, formed either by many triangular plates on embayments in shallowly cusped hydrothecal margin and well demarcated from hydrothecal wall by noticeable crease line, or by a folded continuation of the hydrothecal wall, lacking hinge-like base; hydrothecae may renovate, but often collapsing, disintegrating in old specimens, just a crumpled collar-shaped sheath remaining around hydranth base; hydranth with endodermal epithelium differentiated into distinct parts, upper one digestive, basal one formed by chordal cells; with or without intertentacular web; gonophores as free medusae, gonothecae pedunculate.

Medusa: manubrium short; no gastric peduncle; no excretory pores; 4 simple radial canals; marginal tentacles hollow, with lateral cirri; no marginal cirri; "gonads" on radial canals, not reaching manubrium; without or with 8 (exceptionally 4 or 12) or indefinite number of statocysts, 16 or more when adult; no ocelli.

Remarks: the family Lovenellidae was created by Russell (1953) for Leptomedusae with lateral cirri, 4 radial canals, no marginal cirri, peduncle and excretory pores, Lovenella-like hydroids with a well demarcated operculum and hydrothecal margin embayments. Russell (1953) distinguished Lovenella, with an indefinite number of statocysts, from Eucheilota with usually 8 statocysts. Kramp (1959a) adopted these views and later (Kramp, 1959b; 1961; 1968) 
added the genus Cirrholovenia with marginal cirri, so modifying Russell's original definition. Calder (1971, 1975) observed that the hydroid of Lovenella gracilis lacks the opercular embayments that should be typical of the genus Lovenella, having an operculum in continuation with the hydrotheca. He consequently resurrected the genus Dipleuron for this species (Calder, 1991). Bouillon (1985a), considering the impossibility to integrate the diagnostic characters of the polyps and medusae, separated Kramp's Lovenellidae in three families: the Cirrholoveniidae with medusae with marginal cirri and "cuspidellid" hydroids; the Eucheilotidae with medusae with lateral cirri, 8 statocysts and "campanulinid" hydroids with a well demarcated operculum but without hydrothecal embayments; and the Lovenellidae with lateral cirri, an indefinite number of statocysts and a "Lovenella" type of hydroid, with a well demarcated opeculum with embayments of hydrothecal margin. The study of " Lovenellidae" life cycles, however, shows that if the medusae of these family present clear diagnostic characters, their hydroids are puzzling, all belong to a "campanulinid" type but their opercular structures present differences even within the same genus. It is thus hopeless to refer with confidence one or another type of opercular structure to a family-group taxon, particularly to a medusa-based family. After Kramp $(1919,1932 b)$, too a great importance has been given to the opercular structures of the Campanulinida. Opercula can be different within the same family (see, for instance, the Tiaropsidae and the Lineolariidae) or even within the same genus: in Phialella, for instance, some species have opercular flaps demarcated from hydrothecae and other do not (Boero, 1987), and even different hydrothecae on the same hydrocaulus may present the two opercular types. Opercular structure, thus, is evidently inconstant and cannot be used to distinguish families or even genera. The more, in many campanulinids the operculum can completely disappear, with the apical part of the hydrotheca, during normal colony growth, as shown by Werner (1968 a and b) in Eucheilota maculata and Eutonina indicans or can even be absent in some species of a normally operculate genus (many Eirenidae), only a little more than a collar remaining at the base of the hydrothecae of fully developed hydranths, looking like a haleciid theca (see for instance Werner, 1968, fig.14 and Fig. 87: Figs. 8 to 13). The family Eucheilotidae is consequently considered as synonym of the Lovenellidae and the genera Eucheilota and Lovenella are again included in the Lovenellidae, being defined as above for the medusa stage, the hydroid being characterised by "campanulinid polyps" with an operculum well or not well demarcated from the hydrotheca, with hydrothecae having or not marginal embayments, or reduced to a basal collar; usually with an intertentacular web; cnidome generally with merotrichous haplonemes. The family Cirrholoveniidae, with marginal cirri and "cuspedelliid" type of hydroids, is kept as valid. Two genera, Hydranthea with free eumedusoids and Campalecium with newly released medusae of Eucheilota type are here tentatively included in the Lovenellidae. They were formerly considered as Haleciidae due to the collar shape of their hydrothecae; in our opinion they are campanulinid hydroids with reduced thecae similar to reduced stages of Lovenellidae, but might well represent the basal state from which paedomorphic species with fixed gonophores and reduced hydrotheca originated the Haleciidae.

References: Russell (1963b); Pagès et al. (1992); Bouillon (1999); Bouillon and Barnett (1999); Bouillon and Boero (2000); Schuchert (2001a, 2003).

\section{Key to hydroids}

1. Hydroid of "Campanulina" facies .................... 2

- Hydroid with reduced hydrotheca, of "haleciid" facies.............................................................. 3

2. Hydranth with intertentacular web ... Eucheilota

- Hydranth without intertentacular web.

3. Gonophores producing eumedusoids; gonothecae on hydrorhiza, reduced or absent..... Hydranthea

- Gonophores producing free medusae; gonothecae growing from pedicel just under hydrothecae. Campalecium

\section{Key to medusae}

1. With usually no more than 8 statocysts ..Eucheilota

- With an indefinite number of statocysts (16-32) Lovenella

\section{Genus Campalecium Torrey, 1902}

Hydroid: colony typically stolonal, pedicel of varied length bearing terminal hydranth, often secondary pedicels forming sympodial branches; hydrotheca collar-shaped, shallow, often regenerated, with a distinct diaphragm, large desmocytes; hydranth relative- 
ly large, elongated, cylindrical, not retractable into hydrotheca; up to 30 amphicoronate tentacles; with or without intertentacular web endodermal epithelium differentiated into distinct part the upper digestive, the basal part formed by chordal cells; gonophores giving rise to free medusae; gonothecae clavate or rounded arising beneath hydrothecal pedicel, each with several medusa buds.

Medusa: only medusa buds or juvenile medusae of Eucheilota type presently known, pending the species.

References: Watson (1993); Bouillon and Boero (2000); Boero, unpublished observations.

1. Cnidome with merotrichous haplonemes

- Cnidome microbasic mastigophores C. medusiferum C. cirratum

? Campalecium cirratum "Millard and Bouillon (1975)"; not Haeckel, 1879 (Figs. 87A-B)

Hydroid: as for genus, cnidome microbasic mastigophores.

Medusa: only medusa buds known from gonothecae, with four perradial marginal bulbs of which two bear tentacles, with lateral cirri, without marginal warts, with eight statocysts.

Records from Mediterranean:?

Distribution: Indo-Pacific; Mediterranean?

Seasonality: ?

References: Millard and Bouillon (1975); Calder (1991); Altuna Prado, 1993b.

Campalecium medusiferum Torrey, 1902 (Figs. 87C-E)

Hydroid: As for genus, cnidome with merotrichous haplonemes

Medusa: Only young medusae known with four perradial marginal tentacles, four perradial marginal bulbs and eight statocysts, without lateral cirri and marginal warts.

Records from Mediterranean: eastern and western Mediterranean, Adriatic.

Known seasonality: 5-9, 11, 12.

Distribution: Atlantic, eastern Pacific, Mediterranean.

References: Motz-Kossowska (1911); Huvé (1954); Boero (1981); Gili (1986); Boero and Sara (1987); Calder (1991); Altuna Prado (1993b) Avian et al. (1995).
Remarks: The systematic position of these two species is discussed under Lovenella cirrata.

\section{Genus Eucheilota McCrady, 1859}

Hydroid: colony of "campanulinid" type; hydrotheca with diaphragm, often reduced to a collar shaped sheath around base of adult hydranths, operculum well developed, not demarcated; hydranth with intertentacular web; gonotheca long, pedicellate on erect stems, with one to five medusa buds.

Medusa: with usually 8 statocysts.

References: Ramil (1988); Cornelius (1995); Bouillon and Boero (2000).

Remarks: the polyp of the species Campomma hincksii (Hartlaub, 1897) has been considered by Cornelius (1995) as synonymous of Eucheilota maculata. If it is so, Eucheilota maculata would be present in the Mediterranean, recorded under the name of Campomma hincksii. However, the hydroids of most Campanuliniidae are very similar, the medusa being necessary to identify the species; as the medusa has not been found in the Mediterranean, we consider the following records Mediterranean of "Eucheilota maculata" hydroids as doubtful: Gili (1982, 1984); Gili and Castelló (1985) all as Campanulina; Medel and López-González (1996) as Campomma.

\section{Key to medusa}

1. With medusa buds on radial canals; with 4 marginal tentacles and 4 or more rudimentary bulbs, all with 1-3 pairs of lateral cirri; 8 statocysts E. paradoxica

- Without medusa buds on radial canals.............. 2

2. With 16 marginal tentacles an 16 rudimentary bulbs all with one pair of lateral cirri; about 24 small knobs without cirri; 8 statocysts E. ventricularis

- With 4 marginal tentacles with one pair of lateral cirri and a number of rudimentary bulbs, some of which have cirri; 8 statocysts; immature medusae E. maasi

Eucheilota maasi Neppi and Stiasny, 1911 (Fig. 87F)

Medusa: only young medusa known. Umbrella 3-5 $\mathrm{mm}$ wide, $3 \mathrm{~mm}$ high, mesoglea thick; manubrium cylindrical, half as long as umbrella cavity; 
small, immature, «gonads» on middle part of radial canals; 4 marginal tentacles with rounded bulbs with one pair of lateral cirri, a number of rudimentary bulbs, some of which flanked by cirri; 8 statocysts.

Hydroid: unknown.

Records from Mediterranean: Adriatic Sea.

Known seasonality: 4, 7, 9, 10, 12.

Distribution: endemic of Mediterranean Sea.

References: Neppi and Stiasny (1913); Kramp (1961); Boero and Bouillon (1993); Avian et al. (1995); Benovic and Lucic (1996).

Eucheilota maculata Hartlaub, 1894 (Figs. 87G-L)

Hydroid: see genus definition. Hydroid doubtfully reported from Mediterranean and Adriatic Seas. Medusa never collected in Mediterranean Sea

Eucheilota paradoxica Mayer, 1900 (Fig. 87M)

Hydroid: not known from field. Carré and Carré (1990) obtained in culture hydranths differentiating from medusae maintained during two months at $15^{\circ} \mathrm{C}$. The hydroids developed on the radial canal at the position usually occupied by the gonads. Those hydranths were able to capture preys and to feed but medusae reduction occurred gradually and finally the medusae were reduced to a mass constituting the base of the polyps. Following Carré and Carré those polyps are very similar to those described for Eucheilota maculata by Werner (1968a), unfortunately the authors never could induce their settlement.

Medusa: umbrella $5 \mathrm{~mm}$ wide, higher than a hemisphere, sometimes with a slight apical projection, mesoglea moderately thick; manubrium small, flask-shaped; mouth with 4 simple lips; 4 narrow radial canals and narrow circular canal; «gonads» along middle portion of radial canals; with 4 hollow marginal tentacles with large bulbs, and 4 or more rudimentary bulbs; all bulbs with 1-3 pairs of lateral cirri of unequal size; with 8 marginal statocysts; active medusa budding on radial canals in non sexual mature specimens, the daughter medusae begin to develop medusa buds before they become free; frustules and hydranths developing on radial canals at the position usually occupied by the «gonads» under certain environmental conditions.

Records from Mediterranean: eastern and western Mediterranean
Known seasonality: 2-12.

Distribution: Atlantic; Indo-Pacific; Mediterranean.

References: Kramp (1959b, 1961); Uchida and Sugiura (1975); Schmidt and Benovic (1977); Bouillon (1984 a, b; 1995b); Castelló i Tortella (1986); Bouillon et al. (1988b); Dallot et al. (1988); Carré and Carré (1990); Goy et al. (1988, 1990, 1991); Boero and Bouillon (1993).

\section{Eucheilota ventricularis McCrady, 1959}

(Fig. 88A)

Medusa: umbrella $10 \mathrm{~mm}$ wide, hemispherical; manubrium short; mouth with four prominent lips; «gonads» linear, along middle $1 / 3$ or $2 / 3$ of radial canals; 16 marginal tentacles and 16 rudimentary bulbs all with one pair of lateral cirri and about 24 minute knobs without cirri; 8 statocysts.

Hydroid: unknown.

Records from Mediterranean: eastern Mediterranean.

Known seasonality: 1-5, 12.

Distribution: Atlantic; Indo-Pacific, Mediterranean.

References: Kramp (1959b, 1961); Bouillon, 1984b; Lakkis and Zeidane (1985)); Goy et al., 1988, 1990, 1991; Boero and Bouillon (1993).

\section{Genus Hydranthea Hincks, 1868}

Hydroid: colonies stolonal, hydrotheca short, collar-shaped, shortly pedicellate; hydranth elongated, large, with intertentacular web with merotrichous haploneme cnidocysts; gonophores as eumedusoid, only short-lived male free eumedusoids known; without tentacles; with four radial canals; "gonads" on radial canals, 8 statocysts; gonothecae reduced or absent; when present, attached to hydrorhiza.

References: Cornelius (1995); Bouillon and Boero (2000).

\section{Hydranthea margarica (Hincks, 1862)}

(Figs. 88B-D)

Hydroid: colonies stolonal bearing single hydranths at irregular intervals, stolon with haustorial projections beneath providing additional attachment; hydrothecae very short, collar-shaped with slightly divergent walls and basal diaphragm, on smooth short pedicels inserted directly to stolon; 
hydranth very elongated, slender, not retractable in hydrothecae, widest just below tentacles base and tapering gradually to base, with a cone-shaped hypostome, with 20-30 amphicoronate webbed tentacles; endodermal epithelium differentiated into distinct part the upper digestive, the basal part formed by chordal cells; gonothecae short or absent, when present a shallow dish on a short pedicel; gonophore a single eumedusoid; merotrichous haplonemes scattered or in clumps through tissues of hydranth, stolon and particularly conspicuous on tentacular web, developing eggs reported in hydrorhiza of colonies lacking gonophores.

Medusa: released eumedusoids almost spherical, about $0.5 \mathrm{~mm}$ in diameter, surrounded by a thin perisarc, with four branched radial canals filled with purplish or orange granules as well as ring canal; with eight statocysts; «gonads» on manubrium filling the whole subumbrella, numerous cnidocyst on exumbrella.

Records from Mediterranean: eastern and western Mediterranean, Adriatic.

Known seasonality: 5-8, 10, 11.

Reproduction: 8, 10.

Distribution: Atlantic, Indo-Pacific (Seychelles), Mediterranean.

References: Hincks (1868); Huvé (1954); Millard and Bouillon (1973); Cornelius (1975b, 1995); Gili (1986); Boero and Sara (1987); Boero and Bouillon (1993); Avian et al. (1995); Peña Cantero and García Carrascosa (2002).

Remarks: the presence of only eight statocysts in the eumedusoid could indicate some relationship of this genus with the genus Eucheilota.

\section{Hydranthea incertae sedis}

\section{Hydranthea aloysii (Zoja, 1893)}

Colony reptant, stolon bearing single hydranths at irregular intervals. Hydranth up to $4 \mathrm{~mm}$ in height, on a slightly ringed pedicel, with 12-18 amphicoronate tentacles linked by an intertentacular web. Hydrotheca very short, delicate, with a thin diaphragm. Large cnidocysts kidney-shaped up to $15 \times 5.0 \mu \mathrm{m}$ occuring throughout stolon, hydranth tissues and in tentacular web, small cnidocysts 9-10 x $2.5 \mu \mathrm{m}$ scattered throughout entire colony. Gonophores unknown.

Remark: this species is insufficiently described, its reproduction is unknown it could be any haliciid or lovenelliid, perhahs a juvenile of $H$. margarica.
Records from Mediterranean: western Mediterranean, Adriatic.

Known seasonality: not found in nature, only known from laboratory rearing.

Distribution: endemic of Mediterranean Sea.

References: Hadzi (1914) as Georginella diaphana; Huvé (1954); Boero and Sara (1987); Boero and Bouillon (1993); Avian et al. (1995).

Genus Lovenella Hincks, 1868

= Mitrocomium Haeckel, 1879

Hydroid: colony "Campanulina" type; stolonal or upright and sympodial; hydrotheca pedicellate, elongate, everted-conical to bell-shaped; operculum conical, formed either by many triangular Figs. with embayments of the hydrothecal margin and well demarcated from hydrothecal wall by noticeable crease line, or formed by a folded continuation of the hydrothecal wall, lacking hinge-like base; diaphragm present; no intertentacular web; no nematophores.

Medusa: with an indefinite number of statocysts.

Remark: all Lovenella-like hydroids with unknown cycle must be included in the Campanulinidae incertae sedis.

\section{Key of the medusae}

1. 8-16 marginal tentacles, each with 3-4 pairs of lateral cirri; several marginal warts without cirri L. cirrata

- With more than 16 marginal tentacles, with no marginal warts

2. With 16-24 marginal tentacles, each with 1-3 pairs of lateral cirri; «gonads» oval, longitudinally divided, very close to circular canal

L. clausa

- With 21 marginal tentacles, each with one pair of lateral cirri; «gonads» oval, midway of radial canals length L. gracilis

Remarks: included here there is information on Lovenella chiquita Millard, 1957 whose juvenile medusae are known from South Africa and the polyps described doubtfully from the Spanish coasts (see below).

Lovenella chiquita Millard, 1957 (Figs. 88E-H)

Hydroid: hydrorhiza creeping, often epizootic on other hydroids giving rise to short erected stems bear- 
ing a terminal hydranth or branched sympodially up to 9 times each limb terminating in a hydrothecae, stems annulated throughout; hydrothecae deep- campanulate, smooth, margin with 8-10 shallow bays; operculum of 8-10 converging segments with a gap between their central points; diaphragm delicate; hydranth with over 12 tentacles; gonothecae arising from hydrorhiza on short annulated pedicels, smooth elongated, tapering below truncated above, containing two medusa.

Medusa: only newly liberated medusae of this species are known. Umbrella $0.4 \mathrm{~mm}$ wide, $0.3 \mathrm{~mm}$ high, mesoglea thin; manubrium short; mouth quadrangular simple; «gonads» not yet developed; without lateral cirri or marginal warts; 8 marginal tentacles; 8 statocysts.

Records from Mediterranean: western Mediterranean, only the polyp stage has been described once from the Spanish coast (García-Corrales et al., 1979), presumably a doubtful determination, this species being considered as endemic from South Africa, see Millard (1975).

References: Kramp (1961); García-Corrales et al. (1979); Boero and Bouillon (1993).

Remark: the juvenile medusae of the above described species do not present enough diagnostic features to be assigned to one or another medusa family, the polyp stage closely resembles that of Lovenella clausa hence its inclusion in the genus Lovenella by Millard $(1957,1975)$ and Bouillon (1985a) and in the present paper, awaiting further informations about the mature medusa stage.

Lovenella cirrata (Haeckel, 1879) (Fig. 88I)

Hydroid: colonies typically stolonal issued from a creeping hydrorhiza from which arise numerous (up to almost 100) solitary, almost sessile, unbranched; hydranths; hydrothecae very shallow, collar shaped, marginal rim somewhat everted, with a distinct basal diaphragm; hydranth very elongated, slender, tapering gradually to base and just below tentacles base which is the widest part of the body, with a cone-shaped hypostome, with 24 tentacles in one whorl, amphicoronate, hydranths not retractable into hydrothecae, intertentacular web present with large elongated cnidocysts (presumably merotrichous haplonemes); gonothecae borne at the base of the hydrothecae, half as long as the living hydranth, tubular, conical tapering from end to base, aperture apical extending along whole width; gonophore with 4 medusa buds (after Brinckmann, 1959a).
Medusa: umbrella $16 \mathrm{~mm}$ wide, almost hemispherical; manubrium short, urn-shaped; 4 simple lips; 4 sausage-shaped «gonads» on distal half of radial canals; 8-16 marginal tentacles with conspicuous basal bulbs, each flanked by 3-7 pairs of lateral spiral cirri; usually with 3-5 rudimentary marginal warts between successive tentacles; about 16 statocysts.

Records from Mediterranean: eastern and western Mediterranean, Adriatic.

Known seasonality: 4, 6, 10.

Distribution: Atlantic (Brazil, W. Africa); IndoPacific (Malayan Archipelago, Bismarck Sea); Mediterranean.

References: Kramp (1959a, 1961); Brinckmann (1959a); Millard and Bouillon (1975); Boero (1981); Dowidar (1983); Boero and Sara (1987); Brinckmann-Voss (1987); Calder (1991); Altuna Prados (1993b); Pagès et al. (1992); Boero and Bouillon (1993) Avian et al. (1995).

Remarks: Brickmann (1959a) reared young medusae, which at birth presented already lateral cirri and marginal warts from a hydroid that she tentatively identified with the Haleciidae Haleciella microtheca Hadzi, 1914. The comparison of the 14 days old medusae from laboratory with young and adult medusae found in the plankton let her to identify those young medusae as Lovenella cirrata. Haliciella microtheca considered as a Haleciid has been synonymized with Campalecium medusiferum Torrey, 1902 by Huvé (1954), as Campalecium cirrata by Millard and Bouillon (1975) and Yamada (1995) and as Mitrocomium cirratum by Calder (1991).

In our opinion, the hydroid described by Brinckmann (1959a) (see above for the description) is not a haleciid but is a campanulinid hydroid with reduced hydrotheca similar to those described by Werner in Eucheilota maculata and in Eutonina indicans and found in several Eirenidae hydroids (see Werner, 1968 Fig. 14, and Figs. in Russell, 1970a). Brinckmann in 1959 was not aware of the existence of such hydrothecal structures and normally interpreted the short priest collar-shaped hydrotheca of Lovenella cirrata as a haleciid one. Millard (1975) already pointed out the resemblance existing between the hydrothecae of haleciids to those of some campanulinids which have loosed their operculae and distal parts; Boero and Sara (1987) underlined the possibility that Campanulinidae hydranths with reduced hydrothecae could have been assigned to the Haleciidae and speculated that such a type of campanulinids could be at the origin 
of the haleciids which by paedomorphis loosed the medusa phase while the hydroids became more developed. Very close affinities seems thus undeniably exist between this two families and the suborder Haleciida proposed by Bouillon (1984b) to match with the other orders he introduced at the same time should be suppressed, the Halecioidea being included in the Campanulinida.

Hydranthea margarica hydroids liberate free eumedusoids and have great affinities with the campanulinid polyps mainly by their particularly elongated body with a long non-digestive basal part, their unbranched polyps and merotrichous haplonemes cnidocysts. Hydranthea may represent what could have been a first step to the loose of a free medusae stage in the Lovenellidae leading so by paedomorphis and specialisation of the hydroid to the Haleciids with fixed gonophores (see Boero and Sara, 1987). Nemalecium lighti with campanulinid hydranths and eumedusoids is already a true haleciid having pseudostenotele cnidocysts; this species could represent a further step in the evolution to the colonial and polymorphic haleciids. If this is the case one of the two families (Lovenellidae and Haleciidae) both created by Hincks (1868) should have priority under the condition that the Haleciids are monophyletic.

There is a great confusion between the "Campalecium" like species. It is far from excluded that Haleciella microtheca, Campalecium medusiferum, Campalecium cirratum and Lovenella cirrata are all conspecific as suggested by Clader (1991) who united them all under the reintroduced generic name of Mitrocomium Haeckel, 1879. The differences observed at the hydroid level being nothing else than variations that could be expected within a single species. If such is the case the genus Lovenella Hincks, 1868 has nevertheless precedence over: Campalecium Torrey, 1902; Haliciella, Hadzi, 1914 and Mitrocomium Haeckel, 1879.

However, we concur with Boero (1981a) that Lovenella cirrata, Campalecium medusiferum and Campalecium cirratum cannot be at the present stage of our knowledge considered as synonyms. The hydranths of Lovenella cirrata are different from those of Campalecium cirratum being almost sessile; solitary, their juvenile medusae present not only lateral cirri but also the rudimentary warts characteristic of the adult medusa species. Only the new borne medusa of Campalecium medusiferum are known and they are deprived from lateral cirri and warts and cannot presently been assigned with certi- tude to any Leptomedusae family, their polyps are rather similar to those of L. cirrata. Campalecium cirratum medusae are only known from gonophores as medusa buds which seems to present lateral cirri; their polyps have pedicels of variable length, they occasionally may present one or two sympodial branches, they have microbasic mastigophores cnidocysts (Millard and Bouillon, 1975) instead of the merotrichous haplonemes present in the two other species. More studies on Campalecium medusiferum and $C$. cirratum life cycles are undoubtly needed, only the knowledge of their adult medusae will clear up their real affinities. It is also still necessarily to clarify the problem of the synonymy between the Mediterranean, American California and Bermuda forms of Campalecium. It is interesting to underline that presently the adult medusae of L. cirrata are known from Mediterranean, from the Malayan Archipelago, from the Bismarck Sea, from Brazil and W.African waters but have never been found in eastern Pacific and the North American basin from where the polyps of Campalecium medusiferum have been described respectively by Torrey (1902) and Calder (1991).

\section{Lovenella clausa (Lovén, 1836)}

(Figs. 88J-K, 89A-D)

Hydroid: colonies comprising either single pedicels or short erect shoots arising from a creeping hydrorhiza; pedicels with 2-5 rings below hydrothecae and above origin from hydrorhiza; hydrothecae long and narrow, thin walled, roughly cylindrical, tapering towards base, widest at aperture; operculum of 8-10 triangular converging flaps seated in embayment of the hydrothecae margin and sharply demarcated from the wall; often 2-3 renovated hydrothecae inside oldest one; hydranth long extending length of hydrotheca beyond aperture, with ca 14-16 tentacles, probably no intertentacular web; gonothecae elongated, axillary, tapering from truncated end towards base, sides often slightly sinuous, aperture terminal, containing up to 25 medusa buds maturing simultaneously

Medusa: umbrella 5-9 mm wide, hemispherical, mesoglea moderately thick; manubrium short, small; without gastric peduncle; mouth with 4 simple lips; «gonads» oval, longitudinally divided, very close to circular canal; 16-24 marginal tentacles; marginal tentacular bulbs large, conical; 1-3 pairs of lateral, spiral cirri on either side of each tentacular base; 16-23 statocysts. 
Records from Mediterranean: western Mediterranean. Medusa not known from Mediterranean, only dubious records of hydroids.

Known seasonality: 1, 4, 6, 7-9.

Distribution: Atlantic; Mediterranean?

References: Kramp (1961); Picard (1958b); Gili (1986); Boero and Bouillon (1993); Cornelius (1995); Medel and López-González (1996); Peña Cantero and García Carrascosa (2002).

\section{Lovenella gracilis (Clarke, 1882)}

(Figs. 89E-G)

Hydroid: colonies with monosiphonic hydrocaulus slightly branched or unbranched; divided into internodes by septa at more or less regular intervals; typical annulations absent except on the hydranth pedicels and at base of the stems; hydrothecae alternate on short pedicels, operculum a folded continuation of the hydrothecal wall, lacking hinge-like base, with about 8 facets when folded; 14 or more tentacles, no intertentacular web; diaphragm thin; gonothecae clavate, truncate terminally, borne near the base of hydrothecal pedicels, several medusa buds in each.

Medusa: umbrella about $2.1 \mathrm{~mm}$ wide, $1.1 \mathrm{~mm}$ high, hemispherical; velum wide; manubrium urnshaped; mouth with 4 simple lips; 4 radial canals and circular canal narrow; «gonads» oval midway of radial canals length; oldest specimens with 21 marginal tentacles each with 1 pair of cirri; 33 statocysts.

Remark: diagnosis taken from Calder (1971) and based on raised material from polyp colonies.

Records from Mediterranean: western Mediterranean only juvenile medusae and hydroids known.

Known seasonality: 5.

Distribution: Atlantic; Mediterranean.

References: Huvé (1952 a, b); Picard (1958b); Calder (1971, 1991); Boero and Bouillon (1993).

\section{Family MaLAGAZZIIDAE Bouillon, 1984}

Hydroid: Where known of the "campanulinid type"; colonies stolonal; hydrothecae shortly pedicellate, with a conical operculum formed by numerous convergent segment not clearly demarcated from the hydrothecal wall; hydranths with an intertentacular web; gonothecae claviform arising from the stolons.

Medusa: with small manubrium; without gastric peduncle; with $4-8$, sometimes up to 12 radial canals; «gonads» completely surrounding radial canals and separated from manubrium; with adaxial excretory papillae; no permanent rudimentary marginal bulbs (all bulbs potentially transforming into tentacles); with closed statocysts; without ocelli; without cirri.

\section{Genus Octophialucium Kramp, 1955}

Malagazziidae medusa with normally 8 radial canals; mouth with 8 lips.

Hydroid: where known of the "campanulinid" type, see family characters (Bouillon, 1984a, b).

\section{Octophialucium funerarium}

(Quoy and Gaimard, 1827) (Figs. 89H-J)

Medusa: umbrella 30-40 mm wide, lens-shaped to saucer-shaped, mesoglea thick except near exumbrellar margin, virtually no subumbrellar cavity; velum fairly broad; manubrium very small, with base in form of eight-rayed star; mouth with 8 simple, short pointed lips; typically 8 straight, narrow, radial canals in adults ( 4 when young); «gonads» short, along distal $1 / 4$ of radial canals, near margin, but not reaching circular canal; 64-128 marginal tentacles; marginal bulbs well developed, with excretory papillae; usually one to three, usually two, statocysts between successive tentacles.

Hydroid: unknown.

Records from Mediterranean: eastern and western Mediterranean; Adriatic.

Known seasonality: 3-8, 12.

Distribution: Atlantic; Mediterranean.

References: Kramp (1961); Goy (1973b); Bouillon (1985a, 1995a); Gili (1986); Benovic and Bender (1987); Boero and Bouillon (1993); Avian et al. (1995); Cornelius (1995); Benovic and Lucic (1996); Medel and López-González (1996); Mills et al. (1996).

\section{Family Melicertidae Agassiz, 1862}

Hydroid: where known colonies stolonal with branching stolons and erect shoots bearing one, sometimes two, hydranths; perisarc thinning away completely below base of the hydranths, no hydrotheca; hydranth large, broad in the middle, attenuate below, tapering gently above, with narrow, amphicoronate tentacles; without intertentacular web; gonophores borne on the column of hydranth, no gonothecae (hydroid only known in Melicertum). 
Medusa: with base of manubrium attached over its whole surface; with eight simple or bifurcated radial canals; with hollow marginal tentacles; without marginal or lateral cirri and statocysts; with or without ocelli.

Reference: Russell (1963a).

Genus Orchistomella Kramp, 1959

Melicertidae with eight or more radial canals, all of which arise from manubrium; with or without ocelli, «gonads» unknown.

Hydroid: unknown.

Orchistomella graeffei (Neppi and Stiasny, 1911) (No figure known)

Medusa: umbrella $4 \mathrm{~mm}$ wide, highly vaulted, mesoglea very thick; gastric peduncle?; manubrium quite flat; mouth with 8 simple lips; 8 fully developed radial canals and in each octant about 12 young blindly ending canals; 8 marginal tentacles with large pear-shaped marginal bulbs; 2-3 rudimentary bulbs between successive tentacles. Probably young specimens of Aequorea (Picard in Kramp, 1961 page 444).

Hydroid: unknown.

Records from Mediterranean: western Mediterranean; Adriatic Sea.

Known seasonality: 7-10.

Distribution: endemic of Mediterranean Sea.

References: Neppi and Stiasny (1911); Kramp (1959b, 1961, 1968); Goy (1973b); Boero and Bouillon (1993); Avian et al. (1995); Benovic and Lucic (1996).

Family MitrocomidAE Haeckel, 1879 (part); Torrey, 1909

Hydroid: usually poorly known, most of the "Cuspidella" type; hydrothecae tubular sessile; with pyramidal operculum made either of several triangular flaps, or of pleats in the continuing of hydrothecal tube, all not well demarcated from the hydrothecal wall, lacking a crease-line at base of the flaps or pleats; hydranth extensile, with a single usually amphicoronate whorl of filiform tentacles; no intertentacular web; no nematophores; gonophores where known scarcely pedicellate, on hydrorhiza.

Medusa: with bases of manubrium attached to subumbrella along continuation of radial canals; with 4 or more simple radial canals; marginal tenta- cles hollow; marginal cirri present in some genera; with «gonads» oval or linear, only on radial canals; with open statocysts.

References: Kramp (1932a); Pagès et al. (1992); Bouillon (1999); Bouillon and Barnett (1999); Bouillon and Boero (2000).

\section{Key to medusae}

1. With marginal cirri 2

- Without marginal cirri; with numerous open statocysts. Foersteria

2. With numerous open statocysts ........ Mitrocoma

- With 8-16 open statocysts. Mitrocomella

\section{Genus Foersteria \\ Arai and Brinckmann-Voss (1980)}

Mitrocomidae medusae with 4 radial canals; with numerous open statocysts; without marginal cirri.

Hydroid: unknown.

1. Manubrium short and very broad, $1 / 3$ umbrella width, entirely coloured in dark purple-brown; 40 open statocysts; mouth with simple lips; with large rounded marginal bulbs F. antoniae

- Manubrium short, small, 1/7 umbrella width, with 4 interradial brown lines; 7080 open statocysts; mouth lips groove-shaped; marginal bulbs small, conical F. araiae

Foersteria antoniae Gili, Bouillon, Pagès, Palanques, Puig, and Heussner, 1998

(Figs. 90A-C)

Medusa: umbrella up to $6 \mathrm{~mm}$ wide, $3 \mathrm{~mm}$ high, flatter than a hemisphere, almost quadratic from above, mesoglea rather thick; without gastric peduncle; manubrium very short and large with quadratic base, $1 / 3$ of the width of the umbrella, intensely and uniformly coloured in dark purple-brown; mouth with four simple, very short lips; radial canals and circular canal narrow; «gonads» form and size depending on sex, male «gonads» elongated, on about the $4 / 5$ of the distal half of radial canals, female, «gonads» small, spherical, with few eggs (515) near circular canal; up to 40 marginal tentacles; marginal bulbs large, rounded, with two masses of brown pigment; up to 40 open statocyst, $0-2$ between successive marginal tentacle.

Records from Mediterranean: western Mediterranean. 
Known seasonality: 4 and 5.

Distribution: endemic of Mediterranean Sea.

References: Gili et al. (1998).

Hydroid: unknown.

Foersteria araiae Gili, Bouillon, Pagès, Palanques and Puig, 1999

(Figs. 90D-E)

Medusa: umbrella up to $7 \mathrm{~mm}$ wide and high, hemispherical, mesoglea thick; without gastric peduncle; manubrium very short, with square base, with 4 interradial dark brown lines, 1/7 as high as umbrellar cavity and $1 / 7$ as wide as umbrella; mouth with four short, groove-shaped lips, surrounded by cnidocysts, four radial canals and circular canal narrow; «gonads» small, oval or rounded, split longitudinally, on distal half of radial canals near but not in contact with circular canal; up to 40 long, coiled, marginal tentacles; marginal tentacular bulbs conical, small with brown pigment inside; 70-80 open marginal statocysts, 1-3 between each two tentacles.

Records from Mediterranean: western Mediterranean.

Known seasonality: 5.

Distribution: endemic of Mediterranean Sea.

References: Gili, Bouillon, Pagès, Palanques and Puig (1999).

\section{Genus Mitrocoma Haeckel, 1864}

Hydroid: colonies where known of "Cuspidella" type, operculum with numerous sharp pointed, triangular flaps meeting centrally and presenting no clear limits with the hydrothecal margin.

Medusa: with 4 radial canals; with numerous open statocysts; with marginal cirri.

\section{Mitrocoma annae Haeckel, 1864} (Figs. 90F-J)

Hydroid: (Metschnikoff, 1886a) reared the hydroid of this medusa which is typically a «cuspidellid», the hydrothecae are sessile, cylindrical, wide and elongated and arise at irregular intervals from a linear, creeping, stolon; hydrothecae closed by a pyramidal operculum with numerous sharp pointed, triangular flaps meeting centrally and presenting no clear limits with the hydrothecal margin; hydranths extensile, with conical hypostome; 12-16 filiform tentacles in a single whorl, no basal inter- tentacular membranous web; gonothecae unknown.

Medusa: umbrella 30-40 mm wide, flatter than a hemisphere, mesoglea thick; manubrium very small, 1/8-1/10 of umbrella diameter; mouth lips fairly short; radial canals and circular canal narrow; «gonads» linear, sinuous, along distal 1/2-3/4 of radial canals, not reaching circular canal, with a median division; 60-100 wrinkled marginal tentacles, with conical bulbs; with 3-8 marginal cirri between successive marginal tentacles; $60-100$ open statocysts.

Records from Mediterranean: western Mediterranean; Adriatic.

Known seasonality: 1-3; 5 .

Distribution: endemic of Mediterranean Sea.

References: Kramp (1932a, 1957b, 1961); Brinckmann-Voss (1987); Boero and Bouillon (1993); Avian et al. (1995); Benovic and Lucic (1996).

Genus Mitrocomella Haeckel, 1879

Hydroid: where known, colonies of "Cuspidella" type; with pleated operculum, presenting no clear limits with the hydrothecal margin; see family characters.

Medusa: with 4 radial canals; with marginal cirri which may or not be spirally coiled; with 8,12 or 16 (exceptionally up to 19) statocysts. Hydroid: Where known, colonies of "Cuspidella" type; with pleated operculum, presenting no clear limits with the hydrothecal margin; see family characters.

\section{Mitrocomella brownei (Kramp, 1930)} (Figs. 91A-D)

Hydroid: only an incomplete diagnosis of a primary polyp is known (Rees and Russell, 1937). Hydrothecae tubular, arising from a creeping stolon, with pleated conical operculum of about 5-7 teeth meeting centrally and not clearly demarcated from the hydrotheca; hydranth extensile, with 8-12 filiform, amphicoronate tentacles, no basal web between tentacles; hypostome conical; gonothecae unknown.

Medusa: umbrella 4-9 mm wide; flatter than a hemisphere, mesoglea uniformly thin; manubrium small, short, quadratic; mouth with 4 simple, slightly recurved lips; 4 straight, narrow radial canals widen proximally as enter manubrium, circular canal narrow; 4 «gonads» near distal ends of radial canals divided longitudinally, female somewhat elongated, male oval; typically 16 , up to 24 margin- 
al tentacles; 6-8 spiral marginal cirri between successive tentacles; typically 8 (-11) open statocysts.

Records from Mediterranean: western Mediterranean.

Known seasonality: $4 ; 5$.

Distribution: Atlantic; Indo-Pacific; Mediterranean.

References: Kramp (1930, 1932a, 1957b, 1961); Gili (1986); Pagès et al. (1992); Boero and Bouillon (1993); Cornelius (1995); Medel and LópezGonzález (1996).

\section{Family ORChISTOMATIDAE Bouillon, 1984a}

Leptomedusae with very short manubrium; with large gastric peduncle; mouth with 8-30 sinuous or crenulated lips; with 8 or more radial canals, simple, ramified, or in clusters of 4; up to 64 marginal tentacles, laterally compressed; no marginal cirri, but numerous filiform tentaculiform structures devoid of marginal bulbs, not in contact with circular canal, in each intertentacular space; "gonads» usually on proximal parts of radial canals; numerous (up to 800 ) adaxial ocelli; no statocysts or cordyli; without excretory pores or papillae.

Hydroid: unknown.

Genus Orchistoma Haeckel, 1879

With the characters of the family.

Orchistoma agariciforme Keller, 1884 (Fig. 91E)

Medusa: umbrella up to $15 \mathrm{~mm}$ wide, $5 \mathrm{~mm}$ high; flat-topped with vertical sides, apical mesoglea very thick; manubrium cruciform, wide and very shallow; large funnel-shaped, gastric peduncle, longer than umbrella cavity; mouth with 4 groups of 4 long complexly folded lips; $16-20$ or more radial canals, more or less in group of 4-5; one swollen gonad on each radial canal, close near manubrium; 16-27 or more short marginal tentacles; with elongated conical marginal tentacular bulbs; about 8-10 tentaculiform structures without bulbs and connections with the circular canal, adnate to exumbrella, between tentacles; about 16-20 adaxial ocelli between successive tentacles, no ocelli on the tentacular bulbs.

Records from Mediterranean: western Mediterranean.

Known seasonality: 9-11.

Distribution: Indo-Pacific; Mediterranean.
References: Kramp (1959a, 1961); Bouillon (1984 a, b); Boero and Bouillon (1993).

\section{Family PHIALELLIDAe Russell (1953)}

Hydroid: colony stolonal or erect sympodial, arising from a creeping hydrorhiza; hydrotheca pedicellate, tubular to deeply campanulate, persistent, with a cone-shaped operculum formed by separate triangular flaps demarcated or not from hydrothecal margin by a basal crease line; diaphragm present; gonophores as free medusae, gonotheca usually stolonal, sometimes on erect shoot.

Medusa: manubrium small; no gastric peduncle; 4 radial canals; "gonads" on radial canals, separated from manubrium and divided into two lateral parts by a median groove; tentacles hollow, smooth or moniliform; no excretory pores, lateral or marginal cirri; 8 closed statocysts, usually each on a bulbouslike swellings; without ocelli.

References: Russell (1963b); Boero (1987); Calder (1991).

Genus Phialella Browne, 1902

Medusa and hydroids with the characters of the family.

Phialella quadrata (Forbes, 1848): (Figs. 91F-J, 92A-C)

Hydroid: colonies formed of simple or alternately branched hydranths rising from a creeping smooth hydrorhiza; hydrocaulus erect, distinctly annulated throughout; hydrothecae conical, campanulinid, on ringed pedicel closed by a ca 10 pleated membranous operculum formed of deep and acute convergent segments, meeting centrally and not clearly demarcated from the hydrothecal margin, with a delicate diaphragm; hydranths very extensile with about sixteen oral filiform tentacles in one whorl; gonothecae large, flat-topped, tapering sharply below, usually rising from hydrorhiza more occasionally from hydrocaulus on short annulated stems.

Medusa: umbrella $13 \mathrm{~mm}$ wide, nearly hemispherical, mesoglea fairly thick; manubrium quadratic, short, with small base; with 4 short, slightly folded recurved lips; radial canals and circular canal narrow; «gonads» on distal third of radial canals, but not reaching bell margin, elongated-oval, with a 
characteristic median groove; 16-32 hollow marginal tentacles with small globular marginal bulbs; no ocelli; with 8 statocysts on cushion-like bulbous swellings; often with 4 black interradial spots on base of manubrium.

Records from Mediterranean: eastern and western Mediterranean, Adriatic.

Known seasonality: 6, 8, 10, 11.

Distribution: Atlantic; Indo-Pacific; Mediterranean.

References: Huvé (1953) ?; Kramp (1961); Schmidt (1973); Schmidt and Benovic (1977); García-Corrales et al. (1979)?; Fulton et al. (1985); Gili (1986); Goy et al. (1988, 1990, 1991); Boero and Bouillon (1993); Avian et al. (1995); Cornelius (1995); Medel and López-González (1996).

\section{Family PlumulariIDAe McCrady, 1859;}

Colonies upright, monosiphonic or polysiphonic, arising from creeping, rootlike, or disc-shaped hydrorhiza; hydrocauli branched or unbranched, hydrocladia alternate, opposite or in verticils, arising in polysiphonic hydrocauli from a single axial tube; hydrothecae typically small (hydranths usually too large to fit inside hydrotheca), with or without marginal cusps, uniseriate, usually at least partially adnate, occurring only on hydrocladia, cauline hydrothecae absent; nematophores with well developed nematothecae, not as naked sarcostyles; all nematothecae (axillar, cauline or hydrothecal) usually two-chambered (bithalamic) and movable, a minimum of three nematothecae adjacent to hydrothecae, one mesial inferior and a pair of lateral ones; gonophores as fixed sporosacs, exceptionally as swimming gonophores; gonothecae solitary, without nematothecae; with or without phylactocarps (Fig. D: Figs. 2 and 3; Fig. G: Fig. B2; Fig. H: Fig. 2A).

References: García Corrales et al. (1978); Cornelius (1995); Hirohito (1995); Migotto (1996); Medel and Vervoort (1995); Calder (1997); Calder and Vervoort (1998); Peña Cantero and Vervoort (1999); Watson (2000); Ansín Agís et al. (2001).

1. Hydrocladia bearing a single hydrothecae, pseudoterminally Monotheca

- Hydrocladia bearing several hydrothecae ........ 2

2. Hydrocladia arranged in alternate verticils ......... Nemertesia

- Hydrocladia not arranged in verticils Plumularia

\section{Genus Monotheca Nutting, 1900}

Colonies minute, erect, monosiphonic, with unbranched or sparingly branched stems; hydrocladia alternate, typically unbranched, short, each with two internodes: a basal ahydrothecate one and second, bearing the terminal hydrotheca; hydrotheca large, only on hydrocladia, margin more or less entire, sinuous; adcauline side completely adnate to internode, hydrothecate internode with a single median inferior nematotheca and a terminal pair of lateral nematothecae above hydrothecae, cauline nematothecae present or not ; nematothecae ordinarily bithalamic, movable; gonophores as solitary fixed sporosacs or swimming gonophores (M. obliqua, M. margaretta), gonothecae at base of hydrocladium, usually large, ovate, truncated distally and tapering at base, with wide terminal opening, usually lacking nematothecae, not protected.

Remarks: some Monotheca may occasionally have 2-3 hydrotheca per hydrocladium so, they are often treated as a synonym of Plumularia (see Millard, 1975; Bouillon, 1985; Hirohito, 1995).

References: Medel and Vervoort (1995); Migotto (1996); Calder (1997); Gravier and Migotto (2000).

1. Abcauline wall of hydrotheca convexe; one or two nematotheca in axil of hydrocladium.

M. obliqua.

- Abcauline wall of hydrotheca straight or concave; two nematothecae in axil of hydrocladium M. pulchella.

Monotheca obliqua (Johnston, 1847) (Fig. 92D-F)

Colonies with erect and unbranched stem up to $40 \mathrm{~mm}$, growing on flattened stolons with distinct internal partitions. Stem zigzag, internodes slightly curved, each bearing a latero-distal apophysis, one to two nematothecae at the level of the apophysis insertion, and another nematothecae on the segment. Hydrocladia borne on the apophyses, each comprising a basal athecate internode and another with one hydrotheca surrounded of three nematothecae, one median inferior which reach the base of the hydrotheca, and two immediately above and behind hydrotheca. All nematothecae two chambered, basal chamber narrow, tubular; distal cup-shaped. Hydrothecae cup-shaped, entire adnate, rim even but sinuous, aperture at right angle with the internode. Gonothecae imperfectly known: male oval narrowing both ends, apical 
aperture small; female cylindrical, truncate distally, tapering basally, borne on stem below hydrothecae.

Records from Mediterranean: western and eastern Mediterranean, Adriatic.

Known seasonality: 1-6-10, 12.

Reproduction: 2, 5-10.

Distribution: cosmopolitan.

References: García-Corrales et al. (1978); Boero and Fresi (1986); Gili (1986); Roca (1987); Avian et al. (1995); Cornelius (1995); Medel and LópezGonzález (1996); Peña Cantero and García Carrascosa (2002)

Monotheca pulchella (Bale, 1882) (Figs. 92G-K)

Colonies comprising strong and reticulated hydrorhizae with erect, monosiphonic and usually unbranched hydrocauli up to about $7 \mathrm{~mm}$ high. Main stem segmented into internodes by means of transverse nodes. Each segment with three nematothecae and a latero-distal apophysis; nematothecae seated one lower on the axis, and the others flanking the apophysis. Hydrocladia borne on the apophyses, alternate, each composed of two segments, the basal one athecate, limited by transverse nodes and with an internal perisarcal rim distally; the distal one thecate, with one hydrotheca and three nematothecae, one median inferior reaching the base of the hydrotheca, and two laterals above the hydrotheca. Hydrotheca deep campanulate, completely adnate, margin even somewhat everted, aperture almost $90^{\circ}$ with the axis. Nematothecae all similar and two-chambered; basal chamber narrower and longer; distal chamber cupshaped, inner side lowered. Gonothecae inserting usually on basal segments of stem; female big, cylindrical, truncate distally, ringed throughout, aperture apical, with a circular lid.

Records from Mediterranean: western Mediterranean (Spain).

Known seasonality: 2, 5, 7, 8, 12.

Reproduction: 2, 7, 8.

Distribution: Atlantic coasts of the Strait of Gibraltar; Indo-pacific (Australia, New Zealand), South Africa and Argentine, western Mediterranean (Spain)?

References: Ralph (1961); Watson (1973); Millard (1975); García-Corrales et al. (1978) as Plumularia femina; Boero and Bouillon (1993) as Plumularia; Medel and Vervoort (1995); Medel and López-González (1996).

\section{Genus Nemertesia Lamouroux, 1812 = Sciurella Allman, 1883}

Colonies monosiphonic or polysiphonic, branched or unbranched; coenosarc of the stem canaliculated or not; hydrocladia arranged in verticils in mature colonies, number of hydrocladia per verticil typically increasing with age, young colonies sometimes just biseriate, pinnate; hydrocladia of one verticil typically alternating with those above and below, forming twice (or more) the number of longitudinal rows, increasing progressively up the colony; hydrothecae cup-shaped, margin even; hydrothecal nematothecae two-chambered, movable; gonophores as fixed sporosacs; gonotheca unprotected, usually borne on hydrocladial apophysis, without nematothecae.

Remarks: Allman (1871) reported reduced medusoids in Nemertesia antennina but his observation has not been confirmed by further studies (see Millard, 1975; Hughes, 1977).

Recent references: Schuchert (2001a, 2003).

1. Hydrocladia having a hydrotheca not on every internode or on alternate internodes (heteromerously segmented) 2

- Hydrocladia having a hydrotheca on every internode (homomerously segmented)............ 4

2. First hydrocladial internode athecate, with one nematotheca; rest of hydrocladium composed of thecate intenodes separated by oblique nodes..... N. fascicule

- Thecate and athecate hydrocladial internodes alternating. 3

3. Non hydrothecate internodes usually with one nematothecae N. antennina

- Non hydrothecate internodes constantly with two nematothecae. N. perrieri

4. Internodes with several transverse perisarcal septa N. ventriculiformis

- Internodes without septa ................................. 5

5. Coenosarc of main stem not caniculate, gonotheca crescent-shaped ............ N. norvegica

- Coenosarc of main stem caniculate, gonotheca curved-ovoid or elongated.

6. Hydrocladial internodes with 4 nematothecae.... N. ramosa

- Hydrocladial internodes with 3 nematothecae.... N. tetrasticha

Nemertesia antennina (Linnaeus, 1758) (Figs. 92L-S) 
Hydrorhiza formed by a mass of intertwining and branched fibers springing from basal part of the stems. Hydrocauli monosiphonic, up to $350 \mathrm{~mm}$ high, unbranched and divided into internodes by means of indistinct transverse nodes; each segment bearing one or two verticils with four to six apophyses; each verticil alternate in position with the following; a "mamelon" and up to seven nematothecae on upper surface of each apophysis. Coenosarc of the stem canaliculated. Perisarc of the hydrocladia thin, contrary to the thick one of the apophyses. Hydrocladia heteromerously segmented by means of oblique to transverse nodes; basalmost part with two shorter internodes each bearing one nematotheca; non-hydrothecate segments with one nematotheca (occasionally two), hydrothecate internodes with one hydrotheca and three nematothecae, one median inferior and two laterals. Hydrotheca small, cup-shaped, entire adnate to the axis, rim even, somewhat sinuous, aperture slightly directed downwards. All nematothecae two chambered and conical; basal chamber longer than apical, this provided with adcauline embayment; in some colonies, basal chamber of lateral nematothecae rather elongated. Gonothecae borne on the apophyses, male and female similar, ovoid, with oval latero-distal aperture.

Records from Mediterranean: western Mediterranean, Adriatic.

Known seasonality: 5-8, 10-12.

Reproduction: 7, 10.

Distribution: cosmopolitan.

References: Vervoort (1966); Gili (1982); Ramil and Vervoort (1992a); Cornelius (1995); Avian et al. (1995); Medel and Vervoort (1995); Medel and López-González (1996); Schuchert (2001a).

Nemertesia falcicula (Ramil and Vervoort (1992) (Figs. 93A-E)

Colonies rising from an intertwining hydrorhiza of perisarcal fibers, supporting one tubular polysiphonic stem giving rise to several monosiphonic and unbranched hydrocauli, up to $25 \mathrm{~mm}$ high; hydrorhiza covering basal part of the axis with numerous two chambered nematothecae (basal chamber narrow and longer, distal one cup shaped); hydrocauli divided into internodes by straight, at times obscure nodes; each internode with one to three distal apophyses and one to four nematothecae under apophysis; in basal part of hydrocauli apophysis and hydrocladia in decussate verticils of three, in distal part apophysis and hydrocladia alternately directed left an right, forming a plumularoid form of colony in those part; each apophysis with "mamelon" on superior surface, with two axillary and occasionally additional nematothecae above "mamelon"; first hydrocladial internodes with one nematotheca, rest of hydrocladium composed of thecate intenodes separated by oblique nodes, each with one hydrothecae and four nematothecae: one mesial inferior, two laterals, and one suparcalycine; hydrothecae small, cup-shaped, adcauline wall completely adnate; abcauline wall thickened in older hydrothecae; rim even, perpendicular to the length of the axis; lateral nematothecae inserted on small apophyses near hydrothecal rim; all nematothecae two-chambered and movable; gonothecae inserted on apophyses, with a short pedicel, strongly curved, falcate; aperture laterally displaced, circular, apparently with a circular operculum; male and female gonothecae on same colonies, female gonothecae in medio-distal part, male gonothecae above female ones on distal part of colony.

Records from Mediterranean: western Mediterranean.

Known seasonality and reproduction: 6-7.

Distribution: Atlantic, Mediterranean.

References: Ramil and Vervoort (1992a); Medel and López-González (1996) all as Plumularia falcicula; Ansín Agís et al., 2001.

Nemertesia irregularis (Quelch, 1885) $=$ Nemertesia antennina.

Nemertesia norvegica (G.O. Sars, 1874) (Figs. 93F-K)

Colonies up to $100 \mathrm{~mm}$, small, delicate, main stem straight, usually monosiphonic; coenosarc of main stem not caniculated; internodes elongated; 28 hydrocladia per internode; hydrocladia biseriate, straight; alternate-pinnate basally, bushy distally; hydrotheca wholly adnate, uniseriate, with straightsides with a tendency to jug-like lip towards outer margin; nematothecae typically one mesial and two laterals, but arrangement varied between colonies; gonothecae borne single or by pairs, on minute apophysis, crescent-shaped to sausage-shaped, aperture circular.

Records from Mediterranean: western Mediterranean.

Known seasonality: 1, 7 .

Reproduction: ? 
Distribution: Atlantic and Mediterranean.

References: Cornelius (1995); Schuchert (2000; 2001a); Ansín Agís et al. (2001).

\section{Nemertesia perrieri (Billard, 1901)}

(Figs. 93L-Q)

Colonies with a intertwined hydrorhizal matting springing from basal parts of the axis; hydrocauli monosiphonic, up to about $250 \mathrm{~mm}$, each with several internal coenosarcal tubes, with a thick perisarc, segmented into internodes by badly visible straight transverse nodes; each internode with a verticil of three to four apophyses distally, verticils decussate; no nematothecae visible on hydrocaulus, each apophysis with small "mamelon" on superior surface and four or five nematothecae, two in the axil, one pair above "mamelon" and one unpaired at distal end of apophysis near node; hydrocladia with a thin perisarc, heteromerously segmented into hydrothecate and non-hydrothecate internodes by means of transverse to oblique nodes; basal-most internode shorter, hydrothecate segments with one hydrotheca and three nematothecae, one median inferior and two laterals; non-hydrothecate internodes with two nematothecae, one in lower third one in upper third; all internodes with two internal perisarc rings of varied development; hydrotheca small, cup-shaped, with diverging walls, adcauline wall entirely adnate, rim smooth, even, without lateral undulations; all nematothecae two-chambered, conical, basal chamber longer than apical, this with adcauline embayment, movable; gonothecae on apophysis, on short pedicel, ovoid, with elongated latero-distal and oval aperture.

Records from Mediterranean: western and central Mediterranean.

Known seasonality: 1 to 8 .

Reproduction: 2 to 8 .

Distribution: mainly eastern Atlantic; Pacific, Mediterranean.

References: Vervoort (1959); Gili, Vervoort and Pagés (1989); Ramil and Vervoort (1992a) as $N$. irregularis; Medel and Vervoort (1995) as N. irregularis; Medel and López-González (1996) as $N$. irregularis; Ansín Agís et al., (2001); Peña Cantero and García Carrascosa (2002).

Nemertesia ramosa (Lamarck, 1816) (Figs. 94A-F)

Well developed colonies composed of strongly intertwined hydrorhizal matting, formed by many ramified tubes giving rise large polysiphonic and branched stems up to about $200 \mathrm{~mm}$ high. Hydrocauli with a thick perisarc, one of the tubes of greater diameter, giving rise hydrocladia in the monosiphonic and weakly polysiphonic parts and divided into internodes by means of transverse nodes. Coenosarc of main stem canaliculate. Apophyses of hydrocladia at nodes, in opposite pairs in younger parts of the axis, in verticils of three to ten in the older ones; verticils of succeeding pairs alternate. Apophyses with a "mamelon" on the upper surface and several nematothecae (up to seven); perisarc very thick, contrary to the thin perisarc of the hydrocladia. Hydrocladium separated into thecate internodes by means of transverse nodes, each with one hydrothecae and four nematothecae, one median inferior, two laterals and one median superior at the distal part of the segment. Hydrothecae small, cup-shaped, entire adnate, rim even, aperture at right angle with the axis. Nematothecae all two-chambered, conical; basal chamber longer, apical chamber shorter, with a wide adcauline embayment. Male and female gonothecae similar, ovoid, obliquely truncated distally with a subterminal and oval aperture, narrower basally, with a short pedicel.

Records from Mediterranean: eastern and western and central Mediterranean, Adriatic.

Known seasonality: 6, 7, 10-3.

Reproduction: 1, 2, 7, 12.

Distribution: eastern Atlantic; western Atlantic only in Greenland, Mediterranean.

References: García-Carrascosa et al. (1987) as $N$. disticha; Ramil and Vervoort (1992a); Boero and Bouillon (1993); Avian et al. (1995); Cornelius (1995); Medel and Vervoort (1995); Medel and López-González (1996); Ansín Agís et al. (2001); Schuchert (2001a); Peña Cantero and García Carrascosa (2002).

Nemertesia tetrasticha (Meneghini, 1845) (Figs. 94G-K)

Polysiphonic colonies irregularly branched. Segments of the stem with two lateral apophysis with one "mamelon" and four nematothecae at upper surface. Coenosarc of main stem canaliculate; hydrocladia borne on the apophyses, two cladia per segment, alternate in position. Internodes of the hydrocladium with one cup-shaped hydrotheca and three nematothecae, one median inferior and two laterals; nodes slightly oblique. Gonothecae on short pedicels, borne 
on the axils of the stem with the apophyses; elongated, aperture sub-apical and circular.

Records from Mediterranean: western Mediterranean, Adriatic.

Distribution: endemic of the Mediterranean Sea.

References: García-Carrascosa et al. (1987) as $N$. disticha; Boero and Bouillon (1993); Avian et al. (1995); Medel and López-González (1996).

\section{Nemertesia ventriculiformis (Marktanner- Turneretscher, 1890)}

(Figs. 94L-P)

Hydrocauli up to about $50 \mathrm{~mm}$ high, monosiphonic, occasionally polysiphonic basally, and unbranched; hydrorhiza composed of many ramified tubes. Stem in adult colonies undivided, arrangement of apophyses along axis without characteristic pattern, but all in various vertical planes with tendency to form verticils; however many different arrangement may occur, including an irregular disposition. A "mamelon" and generally four nematothecae are disposed on upper surface of apophyses. Hydrocladia homomerously segmented; nodes oblique. Segments, also the apophyses, may develop internal transverse septa (up to 12 per internode). Internodes with one hydrotheca in basal third and four nematothecae, one median inferior, two laterals and one median superior (occasionally placed on separated intermediated segment). Hydrotheca small, cup-shaped, entire adnate, rim even, aperture at right angle with the axis. All nematothecae twochambered. Gonothecae on short pedicels, elongated and curved, aperture sub distal.

Records from Mediterranean: western Mediterranean.

Known seasonality and reproduction: 6.

Distribution: temperate eastern Atlantic and Mediterranean.

References: Castric-Fey (1970); Vervoort (1959, 1972) both as $N$. incerta; Ramil and Vervoort (1992a); Medel and López-González (1996).

\section{Genus Plumularia Lamarck, 1816}

Colonies normally erect (stolonal when epizooic), arising from a creeping hydrorhiza or from anchoring filaments; hydrocauli mostly monosiphonic, branched or unbranched, giving off alternate apophyses; hydrocladia typically unbranched, pinnately arranged or sometimes occurring in gradual spiral, but not in verticils, divided into internodes; hydrothecae occurring only on hydrocladia, typically two or more per hydrocladium, small, typically cup-shaped, partly or almost totally adnate, margin entire, unthoothed; with or without intrathecal septum; axil and cauline nematothecae variable in number, three hydrothecal nematothecae, one median and two lateral ones flanking each hydrotheca, ordinarily bithalamic and movable; gonophores as solitary, unprotected, fixed sporosacs, neither armed with nematothecae, sometimes with acrocyst.

1. With one nematothecae on non-hydrothecal segments .......................................... P. setacea

- With two nematothecae on non-hydrothecal segments ............................................. P. syriaca

Plumularia setacea (Linnaeus, 1758) (Figs. 95A-E)

Colonies pinnate composed of monosiphonic and unbranched hydrocauli up to $c a 60 \mathrm{~mm}$, with alternate hydrocladia. Stem divided into internodes by means of transverse nodes, each segment bearing two nematothecae, one basal and one distal, the last almost in the axil of a lateral apophysis. Hydrocladia borne on the apophyses of the stem, alternate, in the same plane, heteromerously segmented into hydrothecate and non-hydrothecate internodes by means of transverse nodes. Hydrothecate internodes with one hydrotheca and three nematothecae, one median inferior and two latero-superiors. Nonhydrothecate segments with one frontal nematotheca, usually with one perisarcal septum above and below it; septum also may occurs basally on hydrothecate internodes. First hydrocladial internode athecate and shorter. Hydrotheca cup-shaped, entire adnate, rim even, aperture slightly tilted downwards. Nematothecae all two-chambered, conical, basal chamber longer, apical one shorter and wider, provided with adcauline embayment. Gonothecae on the same stem or not, typically forming neat continuous line down central axis; female elongated fusiform, smooth, narrower distally with a tubular neck more or less developed; apical aperture narrow and circular; male narrower and smaller than female, less attenuate above, tapering to a minute orifice.

Records from Mediterranean: western and eastern Mediterranean (up to Greece), Adriatic.

Known seasonality: 2-8, 11, 12.

Reproduction: 2, 3, 5-9.

Distribution: cosmopolitan. 
References: Rossi (1961); Millard (1975); García-Corrales et al. (1978); Gili (1982); Ramil and Vervoort (1992a); Boero and Bouillon (1993); Avian et al. (1995); Cornelius (1995); Medel and Vervoort (1995); Medel and López-González (1996); Watson (2000); Ansín Agís et al.(2001); Schuchert (2001a) Peña Cantero and García Carrascosa (2002).

\section{Plumularia syriaca Billard,1931} (Fig. 95F)

Colony erect, not branched, monosiphonic, $5 \mathrm{~cm}$ in height. Hydrocaulus with caulines nematothecae. Hydrocladia alternate, borne on apophyses of the stem having two or three nematothecae and a mamelon at their base. Hydrocladia heteromerously segmented into hydrothecate and non-hydrothecate internodes by means of transverse nodes. Hydrothecate internodes with one hydrotheca and three nematothecae, one median inferior and two latero-superiors. Nonhydrothecate segments with two nematothecae. Hydrotheca small, cup-shaped, entire, adnate, rim even. Nematothecae all two-chambered, conical, basal chamber longer, apical one shorter and wider. Gonothecae not known.

Records from Mediterranean: eastern Mediterranean (Alexandrette).

Seasonality:?

Distribution: endemic of Mediterranean Sea.

References: Billard (1930-1931); Boero and Bouillon (1993).

\section{Family SERTULARIIDAE Lamouroux, 1812}

Colonies normally erect, exceptionally stolonal; hydrothecae bi- or multiseriate, exceptionally, secondarily apparently uniseriate trough secondary modification, sessile through adnate to wholly sunk within perisarc, or exceptionally pedicellate, radially to bilaterally symmetrical, rim usually cusped, operculum of 1-4 flaps; diaphragm in the few pedicellate forms, others having a clearly defined basal floor pierced by narrow and eccentric hydropore (excepting Sertularella diaphana); hydranth completely retractable in hydrotheca, in some species with abcauline gastric caecum when hydranth contracts and mantle (ectodermal lamella); cnidome: generally small and often large microbasic mastigophores and sometimes haplonemes; gonophore as fixed sporosacs, exceptionally as swimming gonophores (Amphisbetia opercula$t a$ ), gonothecae solitary, usually sexually dimorphic, on stem or branches, acrocyst often present, in
Fraseroscyphus gonothecae arising from within hydrothecal cavity.

Remarks: the Sertulariidae is the most speciose Hydrozoan family and are generally easily recognised at family level. Their delimitation into genera is, however, a hazardous and controversial question due to the great variability among genera, generic diagnoses being poorly differentiated from each other and often overlapping. Generic diagnoses are mostly based on colony form (stolonal or erect) and on thecae characters such as hydrothecal shape, position, structure, and number hydrothecal teeth, number of opercular flaps, etc., but some of these characters are variable, even in a single colony. Hydranth characters such as the presence or absence of an abcauline caecum, of an annular ectodermal fold (see glossary) have been given great importance for separating genera, but those structures have also not been seriously and systematically investigated in all the described genera or species or even families. The Sertulariidae comprise an unreasonable number of species, more than 500 ! (only 800 valid species of medusae have been recorded for all the superclass Hydrozoa), population variations of a single species have often been given a specific rank, and it should be refrained to describe new genera and species without having actually studied specific population variations, both external and internal hydranth morphology and life cycles.

References: Nutting (1904); Splettstösser (1929); Vervoort (1993b) list; Cornelius (1995); Hirohito (1995); Migotto (1996); Calder and Vervoort (1998); Watson (2000); Schuchert (2001, 2003); Vervoort and Watson (2003).

1. Hydrothecae apparently uniseriate

- Hydrothecae biseriate Hydrallmania

2. Hydrotheca with operculum of one flap (valve).

- Hydrotheca with operculum of two or four flaps

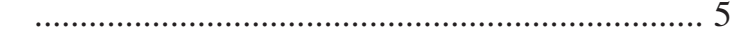

3. Flap adcauline ...................................... Diphasia

- Flap abcauline ...................................................... 4

4. Retracted hydranth with abcauline caecum..........

Thuiaria

- Retracted hydanth without abcauline ceacum.... Salacia

5. Operculum of four flaps; rim with four cusps .... Sertularella

- Operculum of two flaps. 6

6. Hydrothecal cusps markedly unequal 
Amphisbetia

- Hydrothecal cusps approximately equal ......... 7

7. Retracted hydranth without abcauline caecum; hydrothecal pairs often grouped ....... Dynamena

- Retracted hydranth with abcauline caecum; hydrothecal pairs never grouped........ Sertularia

\section{Genus Amphisbetia L. Agassiz, 1862}

Colonies erect, usually branched, monosiphonic; hydrothecae opposite and biseriate, roughly tubular and partly adnate, with 2 long sharp abcauline marginal cusps and sometimes a small adcauline one; operculum of 2 unequal valves, larger one adcauline, smaller one abcauline; retracted hydranth with abcauline caecum; gonophores as fixed sporosacs, or swimming gonophores (Amphibestia operculata), gonothecae solitary, large, usually ovate.

\section{Amphisbetia operculata (Linnaeus, 1758)} (Figs. 95G-I)

Colonies with erect stems (up to ca $145 \mathrm{~mm}$ ) and reticulated hydrorhizae; hydrocauli dichotomously branched, no difference between hydrocaulus and hydrocladia structure, nodes transverse; hydrothecae tubular, one pair per internode, adcauline walls convex, 1/2 to complete adnate; abcauline walls straight, with a thick perisarc, aperture sloping inwards, rim with a long abcauline cusp and one or two short lateral ones; reproduction by swimming gonophores; gonothecae of both sexes probably indentical, large, ovate, aperture terminal and circular, on a very short collar and one-flapped operculum.

Records from Mediterranean: western Mediterranean, Adriatic.

Known seasonality: 6, 7.

Reproduction: 6.

Distribution: almost cosmopolitan, though avoiding pure Arctic and Antarctic.

References: Millard (1975); García-Corrales et al. (1980); Gili (1982); Ramil (1988); Boero and Bouillon (1993); Cornelius (1979, 1995); Medel and López-González (1996); Medel and Vervoort (1998).

\section{Genus Diphasia L. Agassiz, 1862}

Colonies erect, pinnately branched or unbranched; hydrocaulus mono- or polysiphonic; hydrocaulus, and hydrocladia when present, with hydrothecae in 2 , rarely 3 longitudinal rows; hydrotheca tubular, sessile, adnate to partly sunk, usually expanding distally, in opposite to alternate pairs, hydrothecal margin sproutshaped, unthoothed or with 2 to 4 teeth, operculum of one adcauline flap; gonophores as fixed sporosacs; gonothecae sometimes with spines forming brood chambers (marsupium) in females.

References: Calder (1991); Cornelius (1995); Hirohito (1995).

1. Hydrotheca typically totally transversally ringed ................................................. D. delagei

- Hydrotheca not transversally ringed ................. 2

2. Main stem broader than hydrocladia in well developed colonies ........................................ 3

- Main stem same width as hydrocladia in well developed colonies*

3. Hydrotheca sharply out-turned, hydrocladia rigidly straight, male and female gonothecae similar. D. pinastrum

- Hydrotheca gradually out-turned, hydrocladia not rigidly straight, male and female gonothecae different D. margareta

4. Hydrotheca with longitudinal grooves on the wall; female gonotheca with brood chamber and without spines D. rosacea

- Hydrotheca without longitudinal grooves on the wall; female gonotheca without brood chamber and with spines. D. attenuata

*excepting in D. attenuata var. robusta.

\section{Diphasia attenuata (Hincks, 1866)}

(Figs. 95J-N)

Colonies (up to $c a 50 \mathrm{~mm}$ ) with erect and monosiphonic hydrocauli bearing hydrocladia arranged pinnately, in the same plane; stem and hydrocladia same width (excepting in the var. robusta). Hydrothecae in opposite pairs on axis and on hydrocladia, tubular, curved gradually (not sharply) outwards; adcauline wall 1/2-1/3 adnate; aperture circular, rim even, with deep adcauline embayment; operculum circular attached to adcauline side; hydrothecal renovations frequent. Male gonotheca cylindrical, with 6 longitudinal ridges ending above in points; female 6sided, with 1-3 whorls of elongated spines distally and aperture on small terminal cone.

Records from Mediterranean: Strait of Gibraltar.

Known seasonality: 1, 5, 6.

Reproduction: 5.

Distribution: mainly records from temperate and tropical eastern Atlantic, but also several records from the Pacific, Strait of Gibraltar. 
References: Vervoort (1959); Cornelius (1979, 1995); Medel et al. (1991); Ramil and Vervoort (1992a); Medel and López-González (1996); Medel and Vervoort (1998) spp. robusta.

Diphasia delagei Billard, 1912

(Figs. 96A-C)

Colonies up to $23 \mathrm{~mm}$ high, growing on others hydroids; hydrorhiza lineal, giving rise hydrocauli alternately to oppositely arranged, erect and unbranched. Basal most internode of the axis athecate, topped by oblique node; remainder internodes thecates, nodes indistinct. Hydrothecae in opposite pairs; tubular, elongated, adnate almost completely to the internode, distal portion curved outwards; adcauline wall of a pair not touching; rim with a shallow adcauline sinus into which the circular operculum is attached. Hydrotheca totally and finely ringed transversally; rings well marked and running distally till close under hydrothecal rim; rings also visible on dorsal and frontal aspect of the internode. Gonothecae (male $=$ female ?) borne under a pair of hydrothecae, large, sack-shaped, disposed parallel to the axis, a major part of its dorsal wall in direct contact with the internode; narrowed and curved frontally distally, with a small circular aperture; the gonotheca is also densely transversally ribbed.

Records from Mediterranean: only found at the Strait of Gibraltar (Tarifa, Spain).

Known seasonality: 7.

Distribution: temperate and tropical eastern Atlantic, Strait of Gibraltar.

References: Cornelius (1979; 1995); Ramil and Vervoort (1992a); Medel (1996); Medel and LópezGonzález (1996); Medel and Vervoort (1998).

Diphasia margareta (Hassall, 1841)

(Figs. 96D-G)

Stem erect, robust (up to $c a 210 \mathrm{~mm}$ ), monosiphonic and pinnately branched; nodes transverse; main axis thicker than hydrocladia in older colonies. Hydrothecae biseriated, opposite to subopposite on both stem and branches; at half their length sharply curving outwards, abcauline wall internally with perisarcal thickening in area of curvature; adcauline wall 1/2-3/4 adnate; rim directed upwards, with a large adcauline embayment where the circular operculum is attached. Female gonotheca large, pyriform, with four longitudinal ribs bearing 1-3 spines; male smaller, quadrangular in cross section, with a spine in each upper corner, aperture at the end of a cone.

Records from Mediterranean: western Mediterranean, Adriatic.

Known seasonality: 1, 2 5, 6, 7, 10.

Reproduction: 1, 2, 7, 10.

Distribution: temperate and sub-tropical northeastern Atlantic, Mediterranean.

References: Vervoort (1959) as D. pinaster; Teissier (1965) as D. pinaster; Cornelius (1979, 1995) as D. pinaster; García et al. (1980); Ramil (1988); Gili, Vervoort and Pagés (1989); Ramil and Vervoort (1992a); Boero and Bouillon (1993); Medel and López-González (1996); Medel and Vervoort (1998); Schuchert (2001a).

\section{Diphasia pinastrum (Cuvier, 1830)} (Figs. 96H-L)

Colonies robust, with erect and monosiphonic hydrocauli and hydrocladia arranged pinnately, secondary branches may occurs; main stem thicker than hydrocladia. Hydrothecae on opposite pairs, both on axis and hydrocladia, tubular sharply curved outwards to form an angle of c. $90^{\circ}$ with the axis, adcauline wall $2 / 3$ adnate, abcauline wall with strong perisarcal peg or ledge at the lever of inflexion; hydrothecal rim even, with a large adcauline embayment, aperture wide, operculum single, attached to the adcauline sinus. Gonothecae male $=$ female, borne on basis of hydrothecae, quadrangular in cross section, shaped as an inverted pyramid, narrowing towards basally; apically with four blunt cusps, circular aperture in the middle, at the end of a cone; interior of each cusp with fine canal communicating with small opening at top of cusp.

Records from Mediterranean: Strait of Gibraltar and Alboràn Sea.

Known seasonality and reproduction: 6.

Distribution: temperate eastern Atlantic and Mediterranean.

References: Patriti (1970); Cornelius (1979); Ramil and Vervoort (1992a); Altuna (1994); Cornelius (1995) as D. alata; Medel and Vervoort (1998).

Diphasia rosacea (Linnaeus, 1758) (Figs. 97A-D)

Colonies small (up to $50 \mathrm{~mm}$ ) composed of erect and monosiphonic hydrocauli with hydrocladia alternately arranged (with some secondary branch- 
ing); hydrocladia same width as stem. Axis and hydrocladia with internodes separated by oblique nodes, each with a pair of opposite to sub-opposite hydrothecae. Hydrotheca tubular, gradually to rather abruptly curved outwards, adcauline wall 1/2-1/3 adnate; aperture circular, rim even, with slight adcauline embayment, operculum circular, attached to the inner side. Male gonotheca straight-sided, narrowed basally, with 6-8 longitudinal ridges ending in blunt spines surrounding terminal cone and aperture. Female gonotheca tubular, narrowing towards basally, with 8 longitudinal ridges ending above and forming brood chamber; one opposite pair of spines usually longer than remaining six and often notched on outer edge.

Records from Mediterranean: only found at the Strait of Gibraltar.

Known seasonality: 6, 7.

Reproduction: 7.

Distribution: eastern and western Atlantic, Strait of Gibraltar.

References: Naumov (1960); Cornelius (1979, 1995); Ramil and Vervoort (1992a); Medel and López-González (1996); Schuchert (2001a).

\section{Genus Dynamena Lamouroux, 1812}

Colonies erect, branched or unbranched, monosiphonic; hydrocaulus, and hydrocladia when present, with hydrothecae in two longitudinal rows; hydrothecae tubular, sessile, partly to completely adnate, usually expending distally, in opposite to sub-opposite pairs, occasionally in groups of 2 or more pairs per internode; hydrothecal margin tridentate; median adcauline tooth smaller and less conspicuous than lateral teeth; operculum of 2 flaps, adcauline one usually smaller than the abcauline and divided into two parts by a median line; some species with mantle (ectodermal lamella), with or without distal batteries of large cnidocysts; gonophores as fixed sporosacs, planula often brooded in an external acrosyst, gonothecae solitary.

References: Calder (1991); Cornelius (1995); Hirohito (1995); Schuchert (2001a, 2003).

\section{Dynamena disticha (Bosc, 1802)} (Figs. 97E-H)

Hydrocauli erect, (up to $\mathrm{ca} 30 \mathrm{~mm}$ ) monosiphonic, and unbranched. Axis athecate basally and ended by oblique node; remainder internodes thecates with transverse nodes distinct or indistinct; each with an opposite pair of frontally placed hydrothecae. Hydrotheca tubular, basal half parallel with the axis, distal half curving outwards forming $45^{\circ}$ with the axis; adcauline walls of each pairs of hydrothecae $1 / 2-2 / 3$ touching frontally. Gonothecae almost spherical, with rounded transverse ridges and truncate distally, aperture circular on a short collar; operculum with one valve circular.

Records from Mediterranean: eastern and western Mediterranean, Adriatic

Known seasonality: 1-12.

Reproduction: 2, 6-11.

Distribution: circumglobal, in subtropical and tropical seas.

References: Rossi (1961); Millard (1975) as D. cornicina; Boero and Fresi (1986); Calder (1991); Boero and Bouillon (1993); Cornelius (1979); Medel, García and García-Gómez (1991); Avian et al. (1995); Medel and López-González (1996); Medel and Vervoort (1998); Peña Cantero and García Carrascosa (2002).

\section{Genus Hydrallmania Hincks, 1868}

Colonies erect, monosiphonic; hydrocaulus giving off spirally-arranged pinnate branches bearing alternate hydrocladia; hydrothecae sessile, partially adnate, secondarily arranged along one side of hydrocladia and appearing uniseriate though slightly inclined alternately to the left and right, contiguous, in groups of 3-10; young colonies and occasional branches of mature ones with alternate and biseriate arrangement; hydrotheca with two marginal cusps often ill-defined or absent; operculum of two delicate flaps; retracted hydranth with abcauline caecum; gonophores as solitary fixed sporosacs.

Hydrallmania falcata (Linnaeus, 1758)

(Figs. 97I-L)

Colonies long (up to $640 \mathrm{~mm}$ ) but drooping when out of water, hydrocaulus monosiphonic, separated into athecate internodes by oblique nodes; hydrocladia pinnately branched, borne on apophysis with axillary hydrothecae, alternately arranged in basal part of the axis and becoming helicoidal in upper parts; basal most internode short and athecate, the remainders with three hydrothecae, one of which is axillary, and apophysis supporting a secondary hydrocladium, these being alternate, in a same plane. Hydrothecae on primary and secondary hydrocladia in a single row, but alternately curved towards left and right 
sides of the axis (but alternate and in two rows in young colonies). Hydrotheca more or less tubular but widest basally, rim with two blunt lateral cusps bordering a large adcauline and a smaller abcauline sinus; operculum of two flaps. Gonothecae male = female, ovate, aperture terminal, broad, circular.

Records from Mediterranean: only found at the Strait of Gibraltar (in the west side).

Known seasonality: 6, 7.

Reproduction: 7.

Distribution: mainly north Atlantic (western and eastern), but also records from South Africa (probably doubtful) and from N Pacific Ocean, Strait of Gibraltar.

References: Naumov (1960); Cornelius (1979, 1995); Ramil and Vervoort (1992a); Vervoort (1993a); Medel and López-González (1996); Medel and Vervoort (1998); Schuchert (2001a).

\section{Genus Salacia Lamouroux, 1816}

Colonies erect, monosiphonic; hydrocladia, when present, either opposite or alternate and of different structure than hydrocaulus, internodes being of irregular length; hydrothecae on hydrocaulus and hydrocladia, in 2 longitudinal rows, in opposite or subopposite pairs, sessile, partly or completely adnate, without marginal cusps, hydrothecal aperture triangular, operculum with single abcauline circular flap; retracted hydranth without abcauline caecum; gonophores as solitary fixed sporosacs.

References: Calder (1991); Hirohito (1995); Schuchert (2003).

Salacia desmoides (Torrey, 1902) (Figs. 98A-E)

Hydrocauli erect (up to $c a 75 \mathrm{~mm}$ ), monosiphonic, usually irregularly branched, hydrocladia similar in structure with hydrocauli. Athecate basal part of the axis of variable length, remainder thecates internodes with one or two pairs of opposite hydrothecae; nodes oblique. Hydrothecae tubular, straight at their bases and curved outwards distally, forming $90^{\circ}$ with axis; adcauline walls of each pairs partially touching frontally; plane of aperture tilted to the basal part of the axis; rim almost circular, operculum attached at the middle of abcauline part. Gonothecae barrel-shaped, with shallow transverse grooves, gradually disappearing on distal part, with a short collar and a wide circular aperture.

Records from Mediterranean: eastern and western Mediterranean.
Known seasonality: 4, 5, 7, 8, 10.

Reproduction: 7, 8 .

Distribution: tropical and subtropical Pacific and Atlantic; also Indian Ocean, Mediterranean.

References: Gili (1986) as S. dubia; Roca (1987); Boero and Bouillon (1993) also as $S$. dubia; Peña Cantero (1995); Medel et al. (1991); Medel and López-González (1996); Medel and Vervoort (1998); Peña Cantero and García Carrascosa (2002).

\section{Genus Sertularella Gray, 1848}

Hydroid: colony erect, branched or unbranched, monosiphonic or polysiphonic; hydrocaulus and hydrocladia, when present, with two longitudinal rows of alternate, sessile hydrothecae; hydrothecal margin with 4 teeth; submarginal teeth present or absent, operculum pyramidal, composed of 4 triangular valves; retracted hydranth with abcauline caecum; gonophores as solitary fixed sporosacs, acrocyst in some species.

Remarks: the number of inner teeth may sometimes vary in the same colony; namely in S. miurensis, where they can vary from 0 to 5 (Hirohito, 1995). Due to the great variability existing among the species belonging to this genus, there are not "good" characters to separate the different species. In this key, we have included only the species considered valid; a revision of the specific characters is needed in this genus.

References: Ramil, Parapar and Vervoort (1992); Vervoort (1993b) list; Hirohito (1995).

1. Hydrotheca with intrathecal projections .......... 2

- Hydrotheca without intrathecal projections ..... 3

2. Hydrothecal walls symmetrical, aperture more or less perpendicular to the hydrothecal axis S. ellisii

- Hydrothecal walls asymmetrical, aperture tilted upwards; usually abcauline marginal cusp enlarged S. mediterranea

3. Stem and hydrocladia dichotomously branched S. crassicaulis.

- Stem pinnate or irregularly branched 4

4. Colonies pinnate, stiff and polysiphonic when adult; gonothecae often with 2 wide rounded apical cusps S. gayi

- Colonies irregularly branched, flexuous, monosiphonic or polysiphonic basally; gonothecae with 2-4 pointed narrow apical cusps S. polyzonias 
Sertularella crassicaulis (Heller, 1868)

(Figs. 98F-I)

Hydrocauli erect, polysiphonic basally, up to $c a$ $60 \mathrm{~mm}$, dichotomously branched in different planes; hydrocauli and hydrocladia similar in structure; internodes separated by oblique nodes alternately sloping towards left or right side. Hydrothecae laterally to the axis, alternate, one per internode, cylindrical, almost as wide as long, adcauline wall $1 / 2$ adnate to the internode; aperture directed to the upper part of the axis. Gonothecae elongated, ovoid, with transverse undulations, apical distinct neck with three cusps.

Records from Mediterranean: western Mediterranean, Adriatic.

Seasonality: present all the year.

Reproduction: 10-2, 4-5.

Distribution: endemic of the Mediterranean Sea.

References: Stechow (1919); Picard (1956b); Gili (1982, 1986); Boero and Bouillon (1993); Medel et al. (1991); Avian et al. (1995); Medel and López-González (1996).

Sertularella cylindritheca (Allman, 1888) $=$ Sertularelloides cylindritheca $($ Allman, 1888)

\section{Sertularella ellisii}

(Deshayes and Milne-Edwards, 1863)

(Figs. 99A-E)

Hydrocauli erect, up so $50 \mathrm{~mm}$ high, monosiphonic, irregularly branched; stem and hydrocladia with the same structure, divided into thecate internodes by oblique nodes alternatively directed to the left and the right. Hydrothecae lateral to the axis, alternate, one per internode and in the same plane; tubular, walls symmetrical, swollen in basal half and narrowed in distal half; abcauline wall $1 / 3$ adnate; aperture more or less perpendicular to the hydrothecal length axis; 3-5 intrathecal projections more or less developed; when are 5, three are adcaulinar (one medium, in the same axis of the marginal cusp, and two laterals) and 2 are abcaulinar (lateral to the cusps). Gonothecae ovoid, transversally undulated, often smooth basally, neck with 3-4 apical cups. Great variability through the species and with intermediate forms; thus, the internodes may have several weak annulations, aperture of hydrothecae in some colonies are tilted in adcauline or abcauline direction and the walls of the hydrotheca may have transverse undulations.
Note: we consider that S. fusiformis Hincks, 1861 and S. lagenoides Stechow, 1919 are conspecific of S. ellisii.

Records from Mediterranean: eastern and western Mediterranean, Adriatic.

Seasonality: present all the year.

Reproduction: 2-12.

Distribution: mainly eastern Atlantic, but also records in western Atlantic and Pacific; Mediterranean.

References: Rossi (1961, 1971); Cornelius (1979, 1995) as S. gaudichaudi ; Morri (1981); Gili (1986); Gili et al. (1989); Ramil et al. (1992a); Boero and Bouillon (1993) as S. gaudichaudi; Medel et al. (1991); Medel and López-González (1996); Medel and Vervoort (1998); Peña Cantero and García Carrascosa (2002).

Sertularella gayi (Lamouroux, 1821) (Figs. 99F-I, 100A)

Well developed colonies with stems erect, polysiphonic and pinnate (up to $c a 160 \mathrm{~mm}$ ); secondary branches may be present; hydrorhiza strong, radially ramified. Internodes thecates, separated by oblique nodes alternatively directed to the left and the right. Hydrothecae present in the monosiphonic parts of the hydrocaulus and hydrocladia; lateral, alternate; tubular, swollen basally and slightly narrowed distally, usually with the margin tilted outwards, in abcauline direction; approximately $1 / 2$ of the adcauline wall adnate to the internode; old hydrothecae many times with the abcauline wall thickened; adcauline wall many times with transverse undulations, more or less pronounced. Gonothecae elongated ovoid, distal half annulated; aperture circular usually flanked by two cusps, typically one larger than the other, but 3-4 cusps may occurs; colonies dioecious, with acrocyst external to female gonothecae.

Records from Mediterranean: western Mediterranean.

Known seasonality: 1-10.

Reproduction: 1, 5, 9.

Distribution: eastern Atlantic; Mediterranean.

References: Vervoort (1959, 1966, 1972); Picard (1956b); Teissier (1965); Cornelius (1979, 1995); García-Corrales et al. (1980); Gili (1986); Gili et al. (1989); Medel et al. (1991); Ramil et al. (1992); Ramil and Vervoort (1992a); Boero and Bouillon (1993); Medel and López-González (1996); Medel and Vervoort (1998); Schuchert (2001a). 
Sertularella mediterranea Hartlaub, 1901 (Figs. 100B-D)

Hydrocauli erect (up to $23 \mathrm{~mm}$ high), monosiphonic and irregularly branched; stem and hydrocladia divided into thecate internodes by oblique nodes alternatively directed to the left and the right. Hydrothecae tubular, displace laterally, alternate one per internode, 1/3-1/2 of the adcauline wall adnate; abcauline and adcauline walls not symmetrical, the first one usually more or less straight, enlarged distally in a pronounced marginal cusp; the second one, swollen basally and narrowing distally; margin of the hydrothecae tilted upwards in adcauline direction; internal projections present, in the same arrangement that in Sertularella ellisii. Great variability throughout the species, the marginal abcauline cusp may be not enlarged, and the aperture of the hydrotheca may vary its orientation even inside of the same colony; the abcauline wall sometimes undulated. Gonothecae elongated, ovoid, transversally ringed, and narrowed distally, with 3-4 apical cusps; with acrocyst external to female gonothecae.

Records from Mediterranean: eastern and western Mediterranean, Adriatic

Known seasonality and reproduction: always. Distribution: eastern Atlantic, Mediterranean.

References: Picard (1956b) as S. ellisi f. mediterranea; Millard (1975); Cornelius $(1979,1995)$ as $S$. gaudichaudi; García-Corrales et al. (1980) as $S$. picta; Medel et al. (1991); Ramil and Vervoort (1992a); Medel and López-González (1996); Medel and Vervoort (1998); Peña Cantero and García Carrascosa (2002).

\section{Sertularella polyzonias (Linnaeus, 1758)} (Figs. 100E-I)

Colonies erect but flexuous, up to $c a 70 \mathrm{~mm}$, main stem monosiphonic or polysiphonic basally, hydrocladia arranged irregularly, with some second and third order branching. Thecate intenodes of hydrocauli and hydrocladia separated by oblique nodes alternatively directed to the left and the right. Hydrothecae lateral, alternate, in the same plane, tubular, swollen basally and narrowed distally, walls usually thin, approximately. 1/2 adcauline wall adnate; margin slightly tilted outwards or perpendicular to the axis of the hydrotheca, internal projections can be present, but this is incidental. Gonothecae elongated, horizontally ridged, narrowed distal- ly, with 2-4 (usually 4) apical cusps; female gonothecae with acrocyst.

Records from Mediterranean: western Mediterranean, Adriatic, Black Sea, Red Sea.

Known seasonality: almost always present.

Reproduction: 1-12.

Distribution: cosmopolitan.

References: Picard (1956b); Naumov (1960); Rossi (1971); Millard (1975); Cornelius (1979, 1995); Gili et al. (1989); Medel et al. (1991); Ramil and Vervoort (1992); Ramil and Vervoort (1992a); Boero and Bouillon (1993); Avian et al. (1995); Medel and López-González (1996); Medel and Vervoort (1998); Schuchert (2001a); Peña Cantero and García Carrascosa (2002).

Sertularella tenella (Alder, 1856) (Figs. 100J-K, 101A)

Hydrorhiza tortuous giving rise erect and monosiphonic stems, usually unbranched (up to $c a 20$ $\mathrm{mm}$ ), variously zigzag. Hydrothecae alternate, walls more or less symmetrical, usually with 3-6 annulations, sometimes slight or even absent; adcauline wall 1/4 adnate, rim 4 cusped, aperture perpendicular to the longitudinal axis of the hydrotheca. Gonothecae oval, with 3-4 apical cusps and transversally ribbed.

Records from Mediterranean: ?

Distribution: Northern Atlantic, Caribbean Sea; N Pacific Ocean.

References: Vervoort (1993a); Boero and Bouillon (1993); Cornelius (1995); Medel and LópezGonzález (1996); Schuchert (2001a).

Note: doubtful species, probably conspecific with Sertularella rugosa (Cornelius (1995).

\section{Doubtful species}

Sertularella cubica García-Corrales, AguirreInchaurbe and González-Mora, 1980

(Fig. 101B)

Colonies erect, monosiphonic, simple or branched (with one or two hydrocladia). Hydrocaulus divided into internodes by oblique nodes. Hydrothecae alternate, narrow at base, widening abruptly towards rim, with a circular section basally being slightly rectangular distally; adcauline wall 1/3 adnate; rim large with 4 cusps separated by shallow incisions; three intrathecal cusps reduced to absent in some hydrothecae. Gonothecae not known. 
Records from Mediterranean: western Mediterranean.

Distribution: not known.

References: García-Corrales et al. (1980).

\section{Genus Sertularia Linnaeus, 1758}

Colonies erect, arborescent, pinnate or simple, monosiphonic; hydrothecae borne on stem and branches, sessile, partly adnate, oppositely or alternately in two longitudinal rows, hydrothecal margin with two lateral cusps about midway of abcauline and adcauline edges and, in some species, a third median adcauline one; operculum non pyramidal, two-valved, adcauline valve smaller than abcauline; retracted hydranth with abcauline caecum, in some species mantle or ectodermal lamella present, with or without distal batteries of large cnidocysts; gonophore as fixed sporosacs, sometimes planula brooded in external acrocyst, exceptionally as swimming gonophores (Sertularia marginata).

1. Hydrotheca with transverse perisarcal septum at the curvature of abcauline wall 2

- Hydrotheca without transverse septum ............ 3

2. Adult colonies pinnate; internodes of the stem with three hydrothecae, one most basal and two superior subopposite S. marginata

- Adult colonies unbranched; internodes of the stem with two opposite hydrothecae

S. turbinato

3. Colonies usually dichotomously branched, nodes transverse and oblique; perisarc of the gonotheca smooth and without apical cusps ........ S. distans

- Colonies usually unbranched, nodes oblique; perisarc of the gonotheca with transverse ribs and four apical cusps S. perpusilla

Sertularia distans Lamouroux, 1816 (Figs. 101C-G)

Colonies erect, up to $40 \mathrm{~mm}$ high, monosiphonic and dichotomously branched, branches borne frontally and dorsally to the axis; stem and branches divided into alternated athecates and thecates internodes; the athecates with basal transversal node and distal oblique one, which constitute the basal node of several thecates internodes separated by more or less distinct transverse nodes. Hydrothecae arranged in opposite pairs, usually separated frontally; tubular and curved outwards, forming $60^{\circ}-90^{\circ}$ with the axis; narrowed distally; adcauline wall $1 / 3-1 / 2$ adnate to the axis; margin with two lateral cusps and a third smaller adcauline one, operculum with two valves, the adcauline smaller and folded in the middle. Gonothecae arising from short pedicels, elongateovoid, to nearly spherical in cross section, smooth, aperture nearly circular at the end of a short collar; operculum circular.

Records from Mediterranean: eastern and western Mediterranean, Adriatic

Known seasonality: present all the year.

Reproduction: 3, 4, 5, 7, 8 .

Distribution: temperate and tropical Atlantic, Pacific and Indian Ocean; Mediterranean.

References: Rossi (1971); Millard (1975); Calder (1991) as Tridentata; Medel et al. (1991); Ramil and Vervoort (1992a); Boero and Bouillon (1993); Cornelius (1995) as Tridentata; Medel and LópezGonzález (1996); Medel and Vervoort (1998); Peña Cantero and García Carrascosa (2002).

\section{Sertularia marginata (Kirchenpauer, 1864)} (Figs. 101H-K)

Hydrocauli monosiphonic, up to ca $25 \mathrm{~mm}$, pinnate when adult, unbranched when younger; straight to geniculate in younger parts; all internodes thecates, except in the basal part of the colony and hydrocladia; nodes slightly oblique; axial internodes with three hydrothecae (occasionally two), one basal, axilary with the apophysis of the hydrocladium, and two subopposite. Hydrocladial internodes with two hydrothecae opposite touching frontally; tubular and curved outwards slightly frontally and obliquely upwards, forming $30^{\circ}-90^{\circ}$ with the axis of the internode; adcauline wall $2 / 3$ adnate, abcauline basally with a transverse line of perisarc to the level of the elbow; margin with two lateral cusps, occasionally enlarged, and a third small adcaulinar; operculum with two valves, a larger semicircular abcauline flap, and a smaller adcauline flap folded in the middle. Gonothecae large, drum-shaped, with transverse ribs and two rounded lateral spines sometimes very developed, aperture circular wide provided of a circular operculum, releasing swimming gonophores.

Records from Mediterranean: western Mediterranean.

Known seasonality: 49.

Distribution: tropical and subtropical Atlantic, Pacific and Indian Ocean; Mediterranean.

References: Patriti (1970); Millard (1975); García-Corrales et al. (1980); Calder (1991) as Triden- 
tata; Medel et al. (1991); Boero and Bouillon (1993); Watson (1994); Medel and López-González (1996); Medel and Vervoort (1998).

\section{Sertularia perpusilla Stechow, 1919}

(Figs. 102A-B)

Colonies erect, up to $c a 7 \mathrm{~mm}$, usually unbranched; internodes thecate excepting in basal parts, separated by distinct or indistinct oblique nodes; hydrothecae opposite, touching frontally, tubular and curved outwards, forming $80^{\circ}-90^{\circ}$ with the axis; adcauline wall $1 / 2$ adnate to the axis; margin with three cusps, two laterals and one abcauline; operculum with two valves. Gonothecae elongated-ovoid, with transverse ribs and four small apical cusps.

Records from Mediterranean: eastern and western Mediterranean, Adriatic.

Known seasonality: present all the year.

Reproduction: 3-9.

Distribution: Mediterranean.

References: Gili (1982, 1986); Boero and Fresi (1986); Roca (1987); Boero and Bouillon (1993); Avian et al. (1995); Medel and López-González (1996); Peña Cantero and García Carrascosa (2002).

Sertularia turbinata (Lamouroux, 1816) (Figs. 102C-E)

Hydrocauli monosiphonic, up 10-16 mm high, unbranched, basal portion with one to several athecate internodes separated of the remainder thecate ones by an oblique hinge-joint; nodes oblique, distinct or indistinct. Hydrothecae opposite, one pair per internode, usually contiguous frontally and separated at the back; tubular and curved outwards, adcauline wall $1 / 2-3 / 4$ adnate to the axis, abcauline wall convex basally; perisarc of the hydrothecae thickened near the margin, internal surface of abcauline wall with a ridge of perisarc at elbow; hydrothecal aperture facing outwards to obliquely upwards, margin with two large pointed lateral cusps and smaller median adcauline cusp; operculum of two valves, a larger abcauline one and a smaller adcauline flap folded in the middle. Hydranth with an abcauline diverticulum. Gonothecae barrel-shaped, with transverse ribs and with a wide distal aperture.

Records from Mediterranean: western Mediterranean.

Seasonality: ?

Distribution: Warmer parts of Atlantic, Pacific and Indian Ocean, Mediterranean.
References: Vervoort, (1959); Millard, (1975) Boero and Bouillon, (1993); Watson, (1994); Peña Cantero, Svoboda and Vervoort (1997); Medel and Vervoort, (1998).

\section{Genus Thuiaria Fleming, 1828}

Colonies pinnate, palmate or bottle-brushshaped; hydrocladia subopposite, alternate, or all around stem; hydrothecae on hydrocaulus and hydrocladia, cylindrical, broadened in lower part, narrowed toward aperture; partly or completely adnate or totally sunk in cladia, hydrothecal rim usually circular (except in $T$. gonorhiza, where it is sinuous), hydrothecal operculum of a single abcauline attached flap; hydrothecae multiseriate, on hydrocaulus in two opposite, subopposite or alternate longitudinal rows, (except in a few species like: $T$. arctica, with 4 longitudinal rows, and $T$. zachsi, with 6 to 8 longitudinal rows) falling in the same plane, on hydrocladia, with a similar distribution to hydrocauli or as verticils formed by three or more hydrothecae, verticils alternately crossing in right angles, the number of longitudinal rows of hydrothecae being so twice the number of hydrothecae (up to 13 rows recorded); retracted hydranth with abcauline caecum; gonophores as fixed solitary sporosacs, in many species female ones forming a marsupium (acrocyst), in other species female ones with distal spines forming an external brood chamber (pseudomarsupium), gonothecae on hydrocauli and hydrocladia, inserted directly under a hydrotheca.

Thuiara thuja (Linnaeus, 1758)

(Figs. 102F-J)

Main stem unbranched, slightly zigzag, dark brown to black, often lacking hydrocladia in basal 1/3-3/4, in nature colonies up to $50-250 \mathrm{~mm}$ high, with hydrocladia all around stem, in form of bottle bush; hydrocladia usually dichotomous, pale horn coloured, inserted close together, forked 2-4 times, ending bluntly; young colonies pinnate; hydrothecae only on hydrocladia, alternate in two rows (rarely three) entirely sunk within hydrocladia, cylindrical below, tapering above; operculum circular attached on lower side; gonothecae male = female, eggshaped, inverted-conical smooth to slightly rugose, tapering below and more sharply above, aperture circular, often a short collar, no pedicel, acrocyst in female. 
Records from Mediterranean: the record of this species in the Mediterranean by Naumov (1969) needs confirmation.

Seasonality: ?

Distribution: Atlantic, Pacific, Mediterranean?

References: Naumov (1969); Cornelius (1995); Peña Cantero, Svoboda and Vervoort (1997).

\section{Family SYNTHECIIDAE \\ Marktanner-Turneretscher, 1890}

Colonies erect, unbranched or with pinnately arranged hydrocladia, arising from a creeping hydrorhiza, commonly monopodial with terminal growing points, hydrothecae sessile, bilaterally symmetrical, in two or more longitudinal rows on hydocaulus and hydrocladia, alternate or opposite, partly adnate, no real diaphragm but with a definite basal floor perforated by a distinct hydropore, hydrothecal rim unthooted, operculum and nematophores absent; gonophore as fixed sporosacs, gonothecae arising from within hydrothecal cavity or from fenestrae below hydrothecae or from hydrorhiza.

Remarks: following Broch (1918) the hydrotheca of the Syntheciidae is lined by an ectodermal lamella and the hydranths should possess an abcauline caecum (Synthecium hians) but those characters have not been verified for all the species.

References: Calder (1991); Watson (2000); Schuchert (2003).

\section{Genus Synthecium Allman, 1872}

Colonies erect, branched or unbranched, monoor polysiphonic; hydrocaulus bearing hydrocladia usually in opposite pairs to subopposite pairs forming two longitudinal rows; two longitudinal rows of opposite to subopposite sessile hydrothecae on hydrocaulus and hydrocladia, usually tubular, partly adnate, margin entire; without operculum; hydranths with abcauline caecum in some species; gonophores as solitary fixed sporosacs, gonothecae generally dioeciuos arising from within hydrothecal cavity.

Synthecium evansi (Ellis and Solander, 1786) (Figs. 102K-L)

Colonies erect, pinnate and monosiphonic, up to $100 \mathrm{~mm}$ high; thick perisarc in old colonies; hydrocladia opposite, in the same plane. Stem and hydrocladia divided into thecate internodes by distinct or indistinct transverse nodes, except in the most basal part. Hydrothecae lateral and opposite, one to two pairs per internode, cylindrical, distal part curving outwards; adcauline wall $2 / 3$ adnate to the axis; rim even, circular, renovation of the margin very frequent. Gonothecae borne on the aperture of the hydrotheca, fusiform, pointed apically, with deep transversal ridges.

Records from Mediterranean: western Mediterranean, Adriatic.

Known seasonality: present throughout all the year.

Reproduction: 6, 7, 10, 11.

Distribution: eastern Atlantic (Strait of Gibraltar and Canary Islands), Mediterranean.

References: Gili (1982, 1986); Roca (1986,1989); Izquierdo et al. (1986); Boero and Fresi (1986); Ramil and Vervoort (1992a); Boero and Bouillon (1993); Avian et al. (1995); Medel and López-González (1996); Peña Cantero and García Carrascosa (2002).

Family TeclaiIdae Bouillon, Pages, Gili, Palanques, Puig and Heussner 2000

Leptomedusae with 4 simple radial canals; with hollow tentacles; with 4 simple lips; with «gonads» elongated forming linear sacs on radial canals, separated from manubrium; with one to three cordyliform structure between successive tentacles; without ocelli; without cirri; with or without open stotocyst.

1. Medusae with open statocysts ......... Parateclaia

- Medusae without statocysts ................... Teclaia

Genus Parateclaia Bouillon, Pages, Gili, Palanques, Puig and S. Heussner 2000

Medusa: Teclaiidae with open statocyst. Hydroid: unknown.

Parateclaia euromarge Bouillon, Pages, Gili, Palanques, Puig and S. Heussner 2000

(Figs. 103A-B)

Medusa: umbrella $6.0 \mathrm{~mm}$ wide, $4.5 \mathrm{~mm}$ high; somewhat flatter than hemispherical; mesoglea fairly thick at the apex, thinning towards umbrella margin; exumbrella sprinkled with cnidocysts; velum narrow; manubrium short, square, with large base, about $1 / 4$ of subumbrella cavity height and $1 / 3$ of umbrella cavity width without gastric peduncle, colour light brown; mouth with 4 simple groove- 
shaped lips, white in colour; as long as manubrium height; with 4 simple radial canals not meeting in the centre of the manubrial roof, circular canal narrow; up to 24 hollow marginal tentacles; with elongated conical marginal bulbs each with two large brown bands; «gonads» elongated, cylindrical extending along the middle $2 / 3$ of the radial canals and living both ends free; up to three cordyliform conical structures, each with central brown pigment spots and terminal cnidocysts; one to two open statocysts between successive marginal tentacles.

Records from Mediterranean: western Mediterranean.

Known seasonality: 12.

Distribution: endemic of Mediterranean Sea.

References: Gili et al. (2000),

Hydroid: unknown.

Genus Teclaia Gili, Bouillon, Pagès, Palanques and Puig, 1998

Medusa: Teclaiidae without statocyst. Hydroid: unknown.

Teclaia recincolae Gili, Bouillon, Pagès, Palanques, and Puig, 1998

(Figs. 103C-F)

Medusa: umbrella $6 \mathrm{~mm}$ wide, $4 \mathrm{~mm}$ high, a little flatter than hemispherical, mesoglea rather thick in the apical region; manubrium square, flat, 1/4 subumbrellar cavity height, 1/3 umbrella width; mouth with 4 groove-shaped simple lips; 4 radial canal and circular canal narrow; «gonads» elongated, linear, half to three-quarters length of radial canals, close to manubrium, up to 26 marginal tentacles; marginal tentacular bulbs elongated, cylindrical; 1-2 cordyliform structures between successive tentacles, no cirri, no ocelli.

Records from Mediterranean: western Mediterranean.

Known seasonality: 5.

Distribution: endemic of Mediterranean Sea.

References: Gili et al. (1998).

Hydroid: unknown.

\section{Family THYROSCYPHIDAE Stechow, 1920}

Colonies stolonal or erect, arising from a creeping hydrorhiza, commonly monopodial, with terminal growing points; hydrothecae radially to bilaterally symmetrical, pedicellate, or both sessile and pedicellate in the same colony, or sessile but adnate only at diaphragm level (?); hydrothecal margin either entire or with 2 to 4 teeth; operculum of one, 3 or 4 valves and either persistant or shed early; annular perisarcal diaphragm usually present; hydranths with mantle (ectodermal lamella) and a basal annular ectodermal fold; cnidome: microbasic and macrobasic mastigophores; gonophores as fixed sporosacs.

Remarks: Calder (1991) considered that the presence of an ectodermic lamina or mantle lining the interior of the hydrotheca could be diagnostic of the Thyroscophidae but this structure is polyphyletic being also present in some Aglaopheniidae and amongst the Sertulariidae, for instance in some Dynamena, Sertularella and Sertularia, and so is not a convenient family or generic character (see also Cnidoscyphus below). We concur, however, with Calder that the presence of an ectodermal annular ectodermal fold is, at the state of our knowledge about hydranth structure, a good diagnostic character for the delimitation of the Thyroscyphidae. The genera with an abcauline caecum previously included in this family are considered here as belonging to the Sertulariidae.

1. Hydrotheca pedicellate Thyroscyphus

- Hydrotheca sessile Sertularelloides

\section{Genus Sertularelloides Leloup, 1937}

Hydroid: colony erect, simple, monosiphonic, arising from a strong ramified, reticulate hydrorhiza; hydrocauli monosiphonic, split in slender internodes with a hydrotheca near distal end; hydrocladia alternate in the same plane and with same structure than the hydrocauli, arising immediately under a cauline hydrotheca; hydrothecae large, cylindrical, alternate, sessile or on renovate apophyses in old colonies, adcauline adnate portion much reduced; hydrothecal rim quadrangular, with 4 teeth separated by shallow embayments; operculum with 4 low flaps, which do not close the aperture of the hydrotheca, diaphragm present; hydranth with a basal annular ectodermal fold; gonophores as fixed solitary sporosacs, gonothecae larger than hydrothecae, arising just below a hydrotheca, pedicellate, elongate and quadrangular apex with 4 marginal cusps.

Remarks: Sertularella mercatoris Leloup, 1937 the type and only species of this genus, is conspecific with the nominal species Sertularella cylindritheca Allman, 1888. Microscopical examination 
of the type material of Sertularelloides and of specimens of Sertularella cylindritheca from the "Institut Royal des Sciences naturelles de Belgique" shows the presence of an annular membrane, already described in the latter species by Vervoort (1959). For this reason we follow here Vervoort (1959) and Calder, (1991), in considering this species a member of the Thyroscyphidae.

References: Calder (1991); Medel et al. (1991); Ramil and Vervoort (1992a); Migotto (1996); Medel and Vervoort (1998); Watson (2000).

Sertullaroides cylindritheca (Allman, 1888) (Fig. 103G-I, 104A-C)

With the characters of the genus.

Records from Mediterranean: western Mediterranean.

Known seasonality: 5-8.

Reproduction: 7.

Distribution: western and eastern Atlantic (subtropical and tropical waters); Mediterranean.

References: as Sertularella cylindritheca: Vervoort (1959, 1968); Patriti (1970); García-Corrales et al. (1980); Gili et al. (1989); Ramil and Vervoort (1992a); Boero and Bouillon (1993); Medel et al. (1991); Medel and López-González (1996); Medel and Vervoort (1998).

Genus Thyroscyphus Allman, 1877 = Cnidoscyphus Splettstösser, 1929

Colonies erect, branched, monosiphonic or polysiphonic; hydrothecae large, pedicellate, coneshaped, campanulate, to nearly cylindrical, alternately arranged on opposite side of hydrocaulus and hydrocladia; hydrothecal adcauline wall usually more protuberant than abcauline wall; margin entire or with 4 teeth; diaphragm present; operculum of one or 4 valves either shed early or persistent; hydranth with mantle (ectodermal lamella) and basal annular ectodermal fold, with or without distal batteries of large cnidocysts, abcauline caecum absent; gonophores as fixed sporosacs.

Remarks: Cnidoscyphus was included by Millard (1975), Bouillon (1985) and Calder (1991) in the genus Thyroscyphus. Vervoort (1993b), Medel and Vervoort, (1998) nevertheless, retained the genus Cnidoscyphus for the species having large cnidocysts in the distal part of the mantle or ectodermal lamella; this character being also found in some Dynamena, Sertularia, Symmetroscyphus and Thy- roscyphus has no generic diagnostic value and Cnidoscyphus is thus kept here as congeneric with Thyroscyphus.

Thyroscyphus fruticosus (Esper, 1793) (Figs. 104D-H)

Stem stiff and woody, monosiphonic, giving of irregularly alternate hydrocladia predominantly in one plane, reaching $150 \mathrm{~mm}$, no division into nodes, segmentation visible on smaller branches only, branches not in zigzag; two rows of hydrothecae strictly alternate on opposite side of stem and branches, pedicel short, thick, smooth or with one or two constrictions, borne on a wide apophysis, normally demarcated from hydrotheca by a shallow groove on abcauline side; hydrotheca tubular, not expanding to margin, curved outwards, with adcauline wall convex and abcauline wall straight or slightly concave; hydrothecal margin with four low, rounded teeth and thickened ridge just below edge; operculum of four equal triangular valves, shed early; diaphragm in form of thickened perisarcal ring; more powerfully developed on adcauline side; hydranth with a basal annular ectodermal fold; gonothecae arising from stem apophysis, below hydrotheca, female wider and shorter than male, obliquely truncated distally contening one egg which develop in planula in situ.

Records from Mediterranean: western Mediterranean.

Seasonality: ?

Distribution: Indo-Pacific; Mediterranean. Reference: Vervoort (1967); Millard (1975); Watson (2000).

\section{Family TIARANNIDAE Russell, 1940}

Colonies erect or stolonal, of "Stegopoma" type; hydrotheca pedicellate or sessile, deep, asymmetrictubular; operculum formed by two pleated membranes which meet one another like a gabled roof, with straight ridges above and on the sides of hydrotheca, continuing up at each end, thus all imparting a bilateral symmetry to the distal part of hydrotheca; gonophores as free medusae or fixed sporosacs, gonothecae usually resembling hydrothecae, but larger.

Medusa: no apical projection; no gastric peduncle; manubrium wide, cross-shaped, with 4 perradial pouches joined to subumbrella; mouth with 4 simple or crenulated lips; 4 simple radial canals; 
"gonads" folded on interradial walls of manubrium and/or on perradial manubrial pouches; marginal tentacles numerous, hollow; hollow cordyli-like structures bearing cnidocysts; no ocelli.

References: Pagès et al. (1991; 1992); Bouillon (1999); Bouillon and Barnett (1999); Bouillon and Boero (2000).

\section{Key to polyps}

1. Colonies stolonal Modeeria

- Colonies erect Stegopoma

\section{Key to medusae}

1. «Gonads» on perradial manubrial pouches only, widely split longitudinally Krampella

- «Gonads» on manubrium and perradial gastric pouches, in regular transverse folds ... Modeeria

Genus Krampella Russell, 1957

Tiarannidae medusa with 4 perradial manubrial pouches extending almost to circular canal; «gonads» not sac-like nor folded on radial pouches, widely separated longitudinally; 8 marginal tentacles; up to five cirrus like tentaculae between successive marginal tentacles.

Hydroid: unknown.

1. With fine strands of tissue connecting walls of radial canals and manubrial pouches with exumbrellar surface; «gonads» elongated K. dubia

- Without fine strands of tissue connecting walls of radial canals and manubrial pouches with exumbrellar surface; «gonads» oval to bean-shaped K. tardenti

Krampella dubia Russell, 1957

(Figs. 104I-J)

Medusa: umbrella $4 \mathrm{~mm}$ high, $4.5 \mathrm{~mm}$ wide, hemispherical, mesoglea moderately thick; manubrium with large base, quadrate, with four perradial pouches extending along all length of radial canals; 4 radial canals, very short, linking the most distal parts of manubrial pouches to ring canal; about sixteen fine strands of tissue connecting walls of radial canals and manubrial pouches with exumbrellar surface; «gonads» elongated, along distal 2/3 of perradial manubrial pouches, widely separated longitudinally; 4 perradial and 4 interradial marginal tentacles; marginal tentacular bulbs conical; 3-6 small marginal cirrus-like tentacles between each pair of marginal tentacles; no statocysts nor ocelli seen.

Hydroid: unknown.

Records from Mediterranean: western Mediterranean; Adriatic Sea.

Known seasonality: 5, 8, 10.

Distribution: Atlantic; Mediterranean.

References: Kramp (1961); Russell (1957, 1970a); Goy (1973b); Schmidt and Benovic (1977); Benovic and Bender (1987); Boero and Bouillon (1993); Benovic and Lucic (1996); Gili et al. (1998).

Krampella tardenti Gili, Bouillon and Pagès, 1998 (Figs. 105A-C)

Medusa: umbrella $4.5 \mathrm{~mm}$ wide, $4 \mathrm{~mm}$ high, almost hemispherical, with a slightly conical or rounded apex, mesoglea of uniform thickness; manubrium large, 2/3 of bell height, with quadrate base, with 4 broad and long perradial pouches extending almost till umbrella margin, manubrium walls with 4 interradial bands of brown pigments; mouth quadrate, with 4 simple lips; radial canals very short, linking the most distal parts of manubrial pouches to ring canal; no tissue strands linking radial canals or manubrial pouches to exumbrella ; 8 «gonads» oval to bean-shaped along the most distal third of the manubrial perradial pouches, widely separated longitudinally; 4 perradial and 4 interradial marginal tentacles; marginal tentacular bulbs conical; 3 (2-4) long, solid cirrus like spirally coiled tentaculae between successive tentacles; no statocysts nor ocelli seen.

Hydroid: unknown.

Records from Mediterranean: Antikhytira Strait, eastern Mediterranean.

Known seasonality: 6.

Distribution: endemic of Mediterranean Sea.

References: Gili et al. (1998).

\section{Genus Modeeria Forbes, 1848}

Hydroid: colonies stolonal. Hydrotheca pedicel late, deep and tubular, with margin produced on two sides. Operculum of two longitudinally pleated membranes seated in the embayment of the margin and meeting one another like a gable. No diaphragm, no nematothecae, no intertentacular web; gonothecae similar to hydrothecae. 
Medusa: with «gonads» transversally folded on interradial walls of manubrium and extending outwards along the perradial pouches.

\section{Modeeria rotunda (Quoy and Gaimard, 1827)}

(Figs. 105D-K)

Colonies stolonal; hydrothecae arising singly from hydrorhiza at irregular intervals, large, tubular, tapering below into a smooth, straight or slightly curved, non annulated pedicel; hydrothecal aperture closed by an operculum formed by two pleated membranes which meet one another like a gabled roof, with straight ridges above and sides of hydrotheca continuing up at each end, the all imparting a bilateral symmetry to the distal part of the hydrotheca; with a very thin diaphragm often destroyed by preservation; hydranth not extending far beyond hydrothecal aperture; up to 13 filiform tentacles in a single unicoronate whorl, no basal intertentacular membranous web, hypostome rounded-conical; gonothecae resembling hydrothecae with gabled operculum, but larger, pedicel reportedly short to non existent; gonophore with up to 4 developing medusae.

Medusa: umbrella $20 \mathrm{~mm}$ wide, somewhat less high, hemispherical, mesoglea very thick, with rounded apex; manubrium short, broad, cruciform, perradial edges of manubrium connected over entire length with subumbrella, forming 4 perradial pouches; mouth with 4 large, slightly crenulated lips; 4 radial canals, straight, smooth, entering middle of manubrium to form the perradial pouches, narrow circular canal; «gonads» in regular transverse folds on interradial walls of manubrium, extending outwards on perradial pouches; $16-28$ hollow marginal tentacles with large conical marginal bulbs; 1-3 (4) minute cordyli-like appendages with distal bundle of cnidocysts between successive tentacles; cnidome microbasic euryteles.

Records from Mediterranean: western Mediterranean, Adriatic.

Known seasonality: 4, 6.

Distribution: Atlantic; Indo-Pacific; Antarctic; Arctic; Mediterranean.

References: Kramp (1961); Edwards (1963a, 1973b); Ramil and Vervoort (1992a); Alvarez (1993a); Altuna (1994); Avian et al. (1995); Cornelius (1995); Mills et al. (1996); Stepanjants et al. (1997); Brinckmann-Voss and Arai (1998); Gili et al. (1998); Peña Cantero and García Carrascosa (2002).

\section{Genus Stegopoma Levinsen, 1893}

Tiarannidae with pleated hydrothecal operculum in form of gabled roof, hydranth lacking intertentacular web, gonotheca resembling hydrotheca but larger.

Remark: All species with a Stegopoma hydroid and with medusa buds are referable to the genus Modeeria; the genus Stegopoma is here kept for the species with fixed sporosacs; all the species with unknown gonophores should be considered as Tiarannidae incertae sedis.

\section{Stegopoma bathyale Vervoort, 1966} (Figs. 106A-C)

Colonies big, about $100 \mathrm{~mm}$ high, of sympodial structure; hydrocauli strongly polysiphonic, thick, axis usually forked; branching irregular but in the same plane. Monosiphonic parts divided into weakly geniculate or slightly undulate internodes, each topped by a pedicelate hydrotheca, following internode arising basally to the hydrotheca. Perisarc thick on axis and in nodes but fairly abruptly thinning out on pedicel. Hydrotheca similar to those of Modeeria rotunda, but a trifle more bulky, slightly curved outwards; hydrothecal pedicels wrinkled or indistinctly ringed, hydrothecal walls very thin. Branches becoming rapidly covered by secondary tubules, axillary hydrotheca remaining free; branch rebranching repeatedly. Gonophores as fixed sporosacs? Gonothecae borne on stem and branches, elongated, tubular, apparently produced by one of secondary tubules, completely adnate with branch or axis and covered by net of anastomosing tubules; aperture apical and circular; it is unknown if they produce free medusae or not.

Records from Mediterranean: only records from the area of the Strait of Gibraltar (off Cádiz).

Distribution: temperate and subtropical eastern Atlantic (from deep waters), Strait of Gibraltar.

References: Vervoort (1966); Ramil and Vervoort (1992a); Medel and López-González (1996).

Family TIAROPSIDAE

Boero, Bouillon and Danovaro, 1987

Hydroid: colony "Cuspidella" like; hydrotheca tubular, sessile or with reduced pedicel; operculum of numerous flaps demarcated or not from the rest of hydrotheca by a crease line; gonophores as free medusae, gonotheca tubular or rounded, laterally 
compressed, operculate or not, with short peduncle, growing singly from hydrorhiza.

Medusa: 4 or 8 radial canals (exceptionally up to 16); one or two types of marginal tentacles (long and rudimentary, both with marginal bulbs); sense organs compound, comprising an ecto-endodermal ocellus and an open velar statocyst.

References: Boero, Bouillon and Danovaro (1987); Pagès et al. (1992); Bouillon (1999); Bouillon and Barnett (1999); Bouillon and Boero (2000).

1. With numerous (50-60) compound sense organs; mouth with eight lips .... Octogonade

- With 8 or 16 (exceptionally 48) compound sense organs; mouth with four lips ......... Tiaropsidium

Genus Octogonade Zoja, 1896

Tiaropsidae medusae with 8 radial canals; mouth with 8 lips; with numerous compound statocysts; with two kinds of tentacles; without marginal cirri.

Hydroid: unknown.

Octogonade mediterranea Zoja, 1896 (Figs. 106D-F)

Medusa: umbrella 60-70 mm, globular, with bulging sides, mesoglea thick; velum fairly broad; manubrium small, tubular, octagonal; with 8 small but distinct lips; «gonads» linear, along almost entire length of the 8 radial canals, living a short part free at both ends; 16 long marginal tentacles and 150-160 small rudimentary tentacles, containing diverticula from the circular canal; 50- 60 compound sense organs.

Records from Mediterranean: western Mediterranean; Adriatic Sea.

Known seasonality: 2, 4, 6-12.

Distribution: endemic of Mediterranean Sea.

References: Zoja (1896); Kramp (1961); Picard (1958b); Boero and Bouillon (1993); Avian et al. (1995); Benovic and Lucic (1996)

\section{Genus Tiaropsidium Torrey, 1909}

Hydroid: colonies of "Cuspidella" type; operculum formed by several flaps sharply demarcated from the hydothecal margin; gonothecae rounded, compressed laterally, without operculum.

Medusa: with 4 or more (up to 16) simple radial canals; mouth with four lips; with 8 or 16 (rarely 48) compound sense organs; with two kind of tentacles; without marginal cirri.

Tiaropsidium mediterraneum (Metschnikoff, 1886a)

(Figs. 106G-I)

Hydroid: colonies stolonal; hydrothecae tubular, with short, wavy or straight annulated hydroclade, operculum with 7-10 flaps with broad base and pointed apex, meeting centrally and sharply demarcated from the hydrothecal margin; hydranth completely retractable in the hydrothecae; with one whorl of amphicoronate tentacles; no intertentacular membranous basal web; gonothecae borne on hydrorhiza, large, pyriform, almost not pedunculate and developed in one plane.

Medusa: umbrella $7 \mathrm{~mm}$ wide, $5 \mathrm{~mm}$ high, mesoglea thick; manubrium short, fairly broad; mouth with four short, simple lips; 4 radial canals and circular canal narrow; 2 opposite, long, perradial tentacles, and 2 small perradial bulbs; with five rudimentary tentacles in each quadrant, smaller than the marginal bulbs; «gonads» elongated, on distal $2 / 3$ of the radial canals; eight compound sense organs.

Records from Mediterranean: western and central Mediterranean.

Known seasonality: 1, 2, 12.

Distribution: endemic of Mediterranean Mediterranean.

References: Hadzi (1915); Huvé (1956); Kramp (1961); Picard (1958b); Boero, Bouillon and Donavaro (1987); Boero and Bouillon (1993).

\section{Order PROBOSCOIDA Broch, 1910}

Hydroid: hydranths with a complex, flared to globose, more or less pedunculate hypostome, forming a "buccal cavity" beneath the mouth.

Medusa: varied in expression, with closed statocysts; never with cordyli, open statocysts, excretory pores, cirri or ocelli.

Key to hydroids (see family characteristics)

\section{Key to medusae}

1. Without permanent tenon-like rudimentary marginal bulbs Campanulariidae

- With triangular, tenon-like permanent rudimentary marginal bulbs... Phialuciidae 
Family CAmpanulariIdae Johnston, 1836

Hydroid: colony erect or stolonal; hydrothecae bell-shaped or campanulate, radially or, secondarily, bilaterally symmetrical; generally pedicellate, rim cusped or not, with basal diaphragm or inward annular projection of perisarc; hydranth generally tubular, with flared or globose hypostome delimiting a "buccal cavity", gastric endoderm of uniform structure; hydrothecal spherules present or not; gonophores as free medusae, eumedusoids or sporosacs, in gonothecae.

Medusa: manubrium short; no gastric peduncle; 4 radial canals (except in Gastroblasta and Pseudoclytia); with or without velum (without in Obelia); "gonads" completely surrounding radial canals, separated from manubrium; tentacles hollow (except in Obelia where they are solid and with a short prolongation of endoderm into bell mesoglea); with or without tenon-like rudimentary bulbs; no cirri, excretory papillae or pores; numerous (16-200) closed, velar, marginal statocysts (8 in Obelia, each situated on underside of the basal bulb of some marginal tentacle); no ocelli. (Fig. 7: 3)

References: Nutting (1915); Russell (1963b); García Corrales et al. (1978); Östman (1983); Calder (1991); Pagès et al. (1992); Cornelius (1995); Hirohito (1995); Boero et al. (1996); Migotto (1996); Bouillon (1999); Bouillon and Barnett (1999); Bouillon and Boero (2000); Medel and Vervoort (2000).

Remarks: the classification of the Campanulariidae is unsatisfactory; generic divisions, as in many other families of Leptomedusae hydroids, are not well defined, and vary even in modern works (see: Calder 1991, Cornelius 1982; 1995; Hirohito 1995). Hirohito (1995), for instance, taking in account some morphological characters such as presence and absence of diaphragm, presence or absence of sub-hydrothecal spherules, treated Orthopyxis and Rhizocaulus as Campanularia, and Laomedea and Gonothyraea as Obelia so simplifying greatly the generic contents of the family. But Obelia is a very different from the other Campanulariidae genera at the medusa level and the reduction of free medusae to fixed gonophores may have occurred several times independently during the evolution of the Campanulariidae and so it is impossible to refer presently the taxa with fixed sporosacs to any presently known medusa genus. Nevertheless many genera are very close to each other for instance: Hartlaubella and Lameodea, Rhyzocaulus and Cam- panularia, Tulpa and Campanularia could be merged without great difficulty.

\section{Key to hydroids}

1. Colony usually stolonal or with short unbranched uprights 2

- Colony with erect stems, bearing alternate hydrothecae ....................................................... 4

2. Hydrotheca with true diaphragm, with free medusae Clytia

- Hydrotheca without true diaphragm; with annular perisarcal thickening near base ............ 3

3. Hydrothecal walls with unthickened perisarc; gonophores as fixed sporosac ..... Campanularia

- Pydrothecal walls with perisarc variably thickened; gonophores as eumedusoids Orthopyxis

4. Gonophores released as free medusae .............. 5

- Gonophores not released as free medusae ....... 7

5. Medusa with solid marginal tentacles; no velum (see key below).......................................... Obelia

- Medusa with hollow tentacles and velum........ 5

6. Medusa with one manubrium ................... Clytia

- Medusa with more than one manubrium ............. Gastroblasta

7. Gonophores forming degenerate medusae, meconidia ...... Gonothyraea

- Gonophores as fixed sporosacs or degenerate medusae Laomedea

8. Stem typically monosiphonic

- Stem polysiphonic already early in life.. Hartlaubella

\section{Key to medusa}

1. With more than four radial canals ...................... 2

- With normally four radial canals........................ 3

2. With up to 20 radial and centripetal canals; with numerous manubria each with 4 lips

Gastroblasta

- With up to seven radial canals; with one manubrium and as many lips than radial canals . .Pseudoclytia

3. With reduced medusae; without manubrium; without tentacles. Orthopyxis

- With normally developed medusae; with one manubrium with 4 lips; with tentacles . 4

4. With hollow marginal tentacles and normal velum $=$ Clytia

- With solid marginal tentacles; without velum..... Obelia 


\section{Genus Campanularia Lamarck, 1816}

Colonies stolonal, seldom erect and branched; hydrorhiza not anastomosing; hydrothecal pedicel unbranched; hydrothecae campanulate or bell-shaped, with entire or cusped margin, demarcated from pedicel basally by a variably developed annular perisarcal thickening; hydrothecal walls with unthickened perisarc, not abruptly everted distally; true diaphragm absent, sub-hydrothecal spherule present; gonophores as fixed sporosacs, gonothecae on hydrorhiza.

References: Calder (1991); Cornelius (1995); Schuchert (2001).

1. Length of the hydrotheca $>500 \mathrm{~mm}$, with lines running down from rim; cusps castellate; gonotheca truncate distally, aperture wide. C. hincksii

- Length of the hydrotheca $<500 \mathrm{~mm}$, without lines; cusps pointed; gonotheca with a narrow aperture at the end of a neck of variable length.. C. volubilis

Campanularia hincksii Alder, 1856 (Figs. 107A-F)

Colonies up to $15 \mathrm{~mm}$ high, composed of stolon with erect and unbranched pedicels bearing a single hydrotheca at the top. Perisarc of the pedicels smooth to sinuous, usually with several annuli basally and with a characteristic spherule below hydrothecae. Hydrothecae cylindrical, sides parallel, clearly longer than wider, rim castellate, 8-15 cusps either truncate, notched or distinctly bicuspidate, distal half of hydrothecae usually slightly polygonal on cross section, surface with longitudinal striae; basal diaphragm thick, conspicuous. Gonothecae borne on stolon, male and female similar, cylindrical, perisarc smooth or irregularly undulated, truncated apically, with operculum circular; planula brooded within the female gonotheca

Records from Mediterranean: eastern and western Mediterranean; Adriatic, Black Sea.

Known seasonality: 1-12.

Reproduction: 1-12.

Distribution: almost cosmopolitan, avoiding pure Arctic and Antarctic.

References: Millard (1975); Cornelius (1982, 1995); Gili (1986); Calder (1991); Boero and Bouillon (1993); Avian et al. (1995); Medel and López-González (1996); Medel and Vervoort (2000); Schuchert (2001a); Peña Cantero and García Carrascosa (2002).

\section{Campanularia raridentata Alder, 1862}

(Fig. 107G)

Colonies stolonal, composed of erect pedicels each supporting a hydrotheca, perisarc of pedicels smooth, ringed basally and below hydrothecae. Hydrotheca cylindrical, sub-hydrothecal spherule present, rim with 6-8 wide rounded triangular cusps. Gonothecae usually borne on stolons from short and ringed pedicels, barrel-shaped, smooth and with circular distal apertures.

Records from Mediterranean: western Mediterranean.

Known seasonality: 4, 5, 6.

Distribution: northeastern Atlantic.

References: Gili and Castelló (1985) as Clytia hemispherica raridentata; Gili and García-Rubíes (1985); Gili (1986); Llobet (1987); Llobet et al. (1991); Medel and López-González (1996).

Remarks: Campanularia raridentata described by Hincks, 1868 was referred to Clytia hemisphaerica by several authors such as Vervoort (1968) or Cornelius (1982). Llobet (1987) showed, in her drawings, hydrothecae without diaphragm, but with annular thickening and gonothecae smooth and barrel-shaped. We agree with the author o.c., that Hincks, 1868 described something similar in $C$. hemispherica; the same occurs with Gili (1986). The record of Campanularia raridentata, Alder, 1862 by Llobet (1987) is here considered as doubtful.

\section{Campanularia volubilis (Linnaeus, 1758)} (Figs. 107H-M)

Stolonal colonies up to 3-4 $\mathrm{mm}$ high, with erect pedicels each with a single hydrotheca, arising at irregular intervals from the hydrorhiza. Pedicels smooth to spirally annulated throughout. Hydrothecae with sub-hydrothecal spherule, rim with 10-12 shallow bluntly pointed cusps, fine longitudinal striae running to the cusps may be present. Male and female gonothecae similar, usually borne on stolon, flask shaped, smooth, aperture narrow at the end of neck of indefinite length, absent when young. Planula as dispersal stage.

Records from Mediterranean: western Mediterranean.

Distribution: NE Atlantic, eastern Pacific, Mediterranean.

References: Aguirrezabalaga et al. (1986); Cornelius and Ryland (1990); Boero and Bouillon (1993); Cornelius (1995); Medel and López- 
González (1996); Schuchert (2001a); Peña Cantero and García Carrascosa (2002).

\section{Genus Clytia Lamouroux, 1812}

Hydroid: colony reptant, unbranched stolonal or erect branched, usually minute, monosiphonic or polysiphonic; hydrorhiza branched but not anastomosing; hydrothecae deep, campanulate, hydrothecal rim sinuous or deeply indented, with clefts between round to sharply-pointed cusps; true hydrothecal diaphragm; subhydrothecal spherule absent (present in C. hummelincki); gonophores as free medusae, gonotheca conical.

Medusa: manubrium short; velum normal; marginal tentacles hollow; no tenon-like permanent rudimentary bulbs; numerous statocysts.

Remarks: very few species of Clytia medusae are clearly identified, most morphological characters used to distinguish them possibly falling in the range of variation that can be expected in a single species and having little or no taxonomic value. Most of the Clytia species described hereunder are only known by their hydroids stage and should be considered as incertae sedis. The genus needs a careful revision, with careful elucidation of life cycles and molecular work.

Reference: Pagliara et al. (2000).

\section{Key for Hydroid}

1. Hydrothecal cusps projecting inwards and with outwards perisarc projections in bays between nearby cusps C. viridicans

- Hydrothecal cusps different ... 2

2. Hydrothecal cusps oblique C. gracilis.

- Hydrothecal cusps upright. 3

3. Hydrothecal cusps with characteristic longitudinal perisarcal ridge. C. linearis

- Hydrothecal cusps without any perisarcal ridge

4. Hydrothecal cusps usually bicuspidate, hydrotheca cylindrical, deep .......... C. paulensis

- Hydrothecal cusps not bicuspidate, hydrotheca campanulate, not deep ... 5

5. Hydrothecal diaphragm thin .... C. hemispherica

5. Hydrothecal diaphragm thick C. noliformis

\section{Key to medusa}

1. «Gonads» small in the middle of the radial canals and giving rise to numerous blastostyles carrying medusa buds C. mccradyi
- «Gonads» thick; without blastostyles ..... 2

2. Manubrium, «gonads» and marginal bulbs bright green ..... C. viridicans

- Manubrium, «gonads» and marginal bulbs transparent or of different colour 3

3. «Gonads» voluminous along almost whole length of radial canals 4

- «Gonads» linear or oval, along maximum $1 / 3$ of the length of radial canals nearer to margin than to manubrium

4. With 16 marginal tentacles; usually 3 statocysts between successive marginal tentacles C. discoida

- With 24-36 marginal tentacles; one statocysts between successive tentacles...... C. macrogonia

5. With oval «gonads»; 16 marginal tentacles; umbrella up to 6-8 mm wide............. C. gracilis

- With linear «gonads».......................................... 6

6. Up to 32 marginal tentacles and more than 16 statocysts in adults, umbrella up to $20 \mathrm{~mm}$ wide C. hemisphaerica

- No more than 16 marginal tentacles and 16 statocysts in adults, umbrella $6 \mathrm{~mm}$ wide C. noliformis

Clytia discoida (Mayer, 1900) (Fig. 108A)

Medusa: umbrella $4 \mathrm{~mm}$ wide, almost hemispherical; manubrium urn-shaped, with bulging sides, mouth with four recurved lips; 16 short marginal tentacles with large basal bulbs; usually three statocysts between tentacles; gonads on greater part of radial canals, thick, cylindrical, eggs very large.

Hydroid: unknown.

Records from Mediterranean: western Mediterranean.

Seasonality: ?

Distribution: Atlantic, Mediterranean

References: Kramp (1959a, 1961); Bouillon and Boero (2000).

Clytia gracilis (M. Sars, 1850)

(Figs. 108B-G)

Hydroid: colonies delicate, up to $20 \mathrm{~mm}$ high, comprising a creeping hydrorhiza from which arise several erect hydrocauli, some forking 2-3 times, with long internodes and pedicels; hydrothecae deep-campanulate, with 8-12 large pointed cusps inclined to one side, diaphragm thin, pedicel base incurving; 1-ca 25 annuli at internodes and pedicel 
base; hydranth about 7 times as long than broad when fully extended, with typically 18-20 tentacles; gonothecae arising from hydrorhiza on short slender pedicels, long, urn-shaped, constricted abruptly below rim and below this more gradually, smooth walled, wide mouthed; planktonic colonies have been described in Atlantic waters.

Medusa: umbrella up to $8 \mathrm{~mm}$ wide, nearly hemispherical, mesoglea thin; manubrium small quadrate to cruciform; mouth with 4 simple lips; 4 straight radial canals; «gonads» oval to round, with few eggs, along the third distal quarter of the radial canals; up to 16 marginal tentacles; marginal bulbs with spherical base; 1-2 statocysts between successive tentacles. This medusa is often confound with other Clytia medusae mainly with $C$. hemisphaeri$c a$, the discrimination between those different species may perhaps be possible by the use cnidocysts microstructure (Östman, 1979, 1983).

Records from Mediterranean: hydroid found in eastern and western Mediterranean and Adriatic.

Known seasonality: 4-8, 10, 11.

Reproduction: 6-9.

Distribution: Atlantic; Indo-Pacific; Mediterranean for the hydroid stage. Atlantic for the planktonic colonies.

References: Kramp (1961); Cornelius and Östman (1986); Calder (1991); Boero and Bouillon (1993); Vervoort (1993a); Avian et al. (1995); Cornelius (1995); Medel and López-González (1996); Medel and Vervoort (2000); Schuchert (2001a); Peña Cantero and García Carrascosa (2002).

Clytia hemisphaerica (Linnaeus, 1767) (Figs. 108H-K)

Hydroid: colonies usually stolonal but occasionally erect, arising from a creeping hydrorhiza; hydrothecal pedicels borne at close intervals, sometimes forking; hydrothecae campanulate, rim with ca 8-14 broad rounded-triangular cusps; diaphragm thin; pedicels straight, with one to several rings top and bottom and in some specimens also centrally; some pedicels with secondary pedicels, these having characteristic upward curved basal region; hydranths 3-4 times as long than broad when fully extended, with usual 24-30 tentacles; gonothecae arising from hydrorhiza on short, slender pedicels, tubular, typically with deeply concertinared walls resembling a Chinese lantern, but gonothecal walls may be smooth in some specimens, wide mouthed (Calder, 1988; Cornelius, 1995).
Medusa: umbrella up to $20 \mathrm{~mm}$ wide, nearly hemispherical or flatter, mesoglea fairly thin; manubrium small, quadrate, with small base; mouth always with 4 simple lips; "gonads» oval or linear 1/2-3/4 of length of radial canals without median furrow, nearer to margin than to manubrium; usually 4 straight radial canals (sometimes more, up to 12); typically 32 (16-58) marginal tentacles; marginal tentacular bulbs globular, prominent; few partially developed marginal bulbs; velum narrow; 1-3 usually 2 statocysts between successive tentacles.

Records from Mediterranean: eastern and western Mediterranean; Adriatic.

Known seasonality: 1-12.

Reproduction: 1-12.

Distribution: Atlantic; Indo-Pacific; Mediterranean.

References: Trégouboff (1957); Roosen-Runge (1970); Goy (1973b); Gili (1986); Benovic and Bender (1987); Calder (1991); Goy et al. (1988, 1990, 1991); Cornelius (1982, 1995); Boero and Bouillon (1993); Avian et al. (1995); Benovic and Lucic (1996); Mills et al. (1996); Medel and LópezGonzález (1996); Medel and Vervoort (2000); Schuchert (2001a); Peña Cantero and García Carrascosa (2002).

Clytia hummelincki (Leloup, 1935) (Figs. 109A-E)

Hydroid: colonies stolonal, up to $4.5 \mathrm{~mm}$ high, with a creeping hydrorhiza. Pedicels long, relatively thick, annulated basally and with occasional groups of annuli elsewhere; distal end of pedicel with slight swelling just beneath a subhydrothecal spherule. Hydrotheca shallow, cup-shaped, hydrothecal walls with relatively thin perisarc; margin smooth, occasionally oblique; diaphragm thin, slightly oblique, basal chamber shallow.

Medusa: only immature medusa known.

Records from Mediterranean: Ionian coast of southern Italy.

Records outside the Mediterranean: eastern and western Atlantic.

References: Millard (1975); Cornelius (1982) as Laomedea; Calder (1991); Boero et al. (1997b).

Clytia linearis (Thorneley, 1899)

(Figs. 109F-I)

Hydroid: colonies reptant, up to $40 \mathrm{~mm}$ high, bearing erect pedicels unbranched or subsympodial- 
ly branched; pedicels and branches ringed basally and distally, topped by hydrothecae; branches arising laterally, at the upper part of the axis; hydrothecae very deep, cylindrical, sides almost parallel, narrowing basally, with a thin diaphragm, straight or slightly oblique; margin wide, 10-12 acute cusps with characteristic longitudinal central perisarcal band or ridge extended further of the cusps. Gonothecae usually axillar, borne on short and ringed pedicels, elongate-oval, truncate distally, narrow sub-distally and basally; enclosing up to eight developing medusa buds.

Medusa: only juvenile medusa just released known.

Records from Mediterranean: eastern and western Mediterranean, Adriatic.

Known seasonality and reproduction: throughout the year.

Distribution: tropical and subtropical waters of Atlantic, Pacific and Indian Ocean, Mediterranean.

References: Rossi (1961); Marinopoulos (1979); Millard (1975); García-Corrales et al. (1978); Gili and García-Rubíes (1985); Boero and Fresi (1986); Cornelius (1987); Calder (1991); Ramil and Vervoort (1992a); Boero and Bouillon (1993); Altuna Prados (1995); Avian et al. (1995); Migotto, 1996; Medel and López-González (1996); Medel and Vervoort (2000); Peña Cantero and García Carrascosa (2002)

\section{Clytia maccradyi (Brooks, 1888)}

(Fig. 109J)

Hydroid: Brooks (1888) saw young medusae released from a hydroid colony and identified them as $C$. mccradyi medusae. Brook's description of the hydroid did not differ from that of $C$. hemisphaerica (see Cornelius 1982, Carré et al., 1995). Mayer (1910) doubted Brook's observation; the hydroid phase of this medusae is thus still not known with certitude.

Medusa: umbrella $15 \mathrm{~mm}$ wide, about twice as broad than high; mesoglea of soft consistence; manubrium short and stout; mouth with four recurved lips; sexual development by four small, swollen, «gonads», situated in the middle part of the radial canals, asexual reproduction through hydroid blastostyles giving rise to medusae buds and originating at the same place than «gonads» and instead them in sexually immature specimens; 16- 24 marginal tentacles; marginal tentacular bulbs conical; 12 statocysts between tentacles.
Records from Mediterranean: eastern and western Mediterranean.

Known seasonality: 7-10.

Distribution: Atlantic; Indo-Pacific; Mediterranean.

References: Brooks (1888); Kramp (1961); Goy (1970, 1972); Cornelius (1982); Bouillon et al. (1986); Benovic and Bender (1987); Brinckmann-Voss (1987); Goy et al. (1991); Boero and Bouillon (1993); Carré et al. (1995); Benovic and Lucic (1996).

Clytia macrogonia Bouillon, 1984 (Fig. 109K)

Medusa: umbrella $4 \mathrm{~mm}$ wide, discoidal; manubrium small, cruciform, with rounded perradial lobes; mouth with 4 simple lips; 4 radial canals and circular canal narrow; «gonads» cylindrical, along almost whole length of radial canals, females with few (about $20)$ very large eggs; with 24- 36 short marginal tentacles; marginal tentacular bulbs large, globular; with one statocyst between successive tentacles.

Records from Mediterranean: eastern Mediterranean.

Seasonality: ?

Distribution: Indo-Pacific, Mediterranean.

References: Kramp (1961); Bouillon (1984); Goy et al. (1991); Boero and Bouillon (1993).

Hydroid: unknown.

Clytia noliformis auct. (McCrady, 1859) (Figs. 110A-E)

Hydroid: colonies stolonal with creeping hydrorhiza; pedicel strongly annulated basally and distally; hydrothecae campanulate, margin with about 13-15 blunt, broadly triangular teeth; with a thick diaphragm; basal chamber shallow, subspherical; hydranth with about 25-30 filiform tentacles; gonothecae laterally flattened, arising from hydrorhiza, on short annulated stalks.

Medusa: umbrella $6 \mathrm{~mm}$ wide, $3 \mathrm{~mm}$ high, flatter than a hemisphere; manubrium tubular; mouth quadrate, with four simple lips; 4 radial canals; 16 marginal tentacles; 16 intervening statocysts; «gonads» elongated, on the distal third or fourth of the radial canals, female «gonads» bearing 20-35 large ova. The newly hatched medusa of Clytia noliformis differs from corresponding stages of $C$. hemiphaerica by complete absence of «gonads».

Records from Mediterranean: western Mediterranean, Adriatic. 
Known seasonality: 1-5, 7-12.

Distribution: Atlantic; Indo-Pacific; Mediterranean.

References: Picard (1949); Brian and Pérès (1953); Vannucci and Ribeiro (1955); Vannucci (1957); Kramp (1961); Berhaut (1970); Gili (1986); Calder (1991); Llobet et al. (1991); Boero and Bouillon (1993); Avian et al. (1995).

\section{Clytia paulensis (Vanhöffen, 1910)} (Figs. 110F-J)

Hydroid: colonies with erect and delicate smooth pedicels, ringed basally and below hydrothecae (sometimes also centrally), usually unbranched, each supporting a hydrotheca. Hydrotheca cylindrical, deep, with a thin diaphragm at base; rim with 711 cusps usually bicuspidate and rounded. Hydranth provided with 16-22 tentacles. Gonotheca cylindrical, probably male similar than female, tapering gradually below and slightly above, smooth, borne on stolon on short and ringed pedicels.

Medusa: undescribed, pre-release medusa with 4 tentacle buds.

Records from Mediterranean: eastern and western Mediterranean.

Known seasonality: 4-9.

Reproduction: 4, 5, 7, 8.

Distribution: cosmopolitan.

References: Millard (1975); Marinopoulos (1979); Cornelius (1982); Boero and Fresi (1986); Calder (1991); Cornelius and Ryland (1990); Ramil and Vervoort (1992a); Boero and Bouillon (1993); Cornelius (1995); Medel and López-González (1996); Medel and Vervoort (2000); Peña Cantero and García Carrascosa (2002).

\section{Clytia viridicans (Leuckart, 1856)} (Figs. 110K-L)

Hydroid: colonies stolonal, growing on algae; pedicel short, annulated at base and below hydrotheca; hydrotheca conical, with 7-9 cusps, projecting inwards and with outwards perisarc projections in bays between nearby cusps; hydranths with pedunculate hypostome and 14-18 amphicoronate tentacles, the ones oriented downwards laying on the perisarc projections between adjacent cusps, the ones oriented upwards being sustained by cusps; gonophores as free medusa; gonothecae on hydrorhiza either corrugated or smooth, containing up to four developing green medusae.
Medusa: not known from nature. Umbrella flattened, about $11 \mathrm{~mm}$ wide, exumbrella transparent, mesoglea thin; manubrium bottle-shaped on a short peduncle; mouth with four corrugated lips, 16-32 marginal tentacles,; 24-40 statocysts; «gonads» oval elongated along the distal part of radial canals not reaching umbrellar margin; manubrium, «gonads» and tentacular bulbs bright green in living material.

Records from Mediterranean: western Mediterranean.

\section{Seasonality:?}

Distribution: endemic of Mediterranean Sea.

References: Haeckel (1864); Metschnikoff (1886a,b); Russell (1953); Cornelius (1982); Pagliara et al. (2000).

\section{Genus Gastroblasta Keller 1883}

Medusa: Campanulariidae with several manubria; with up to 20 radial and centripetal canals; with normal velum; with hollow marginal tentacles; without tenon-like permanent rudimentary bulbs; with numerous statocysts.

Hydroid: Clytia-like, living embedded in sponges, gonophores on hydrorhiza.

\section{Gastroblasta raffaelei Lang, 1886} (Figs. 110M, N)

\section{Hydroid: see above.}

Medusa: umbrella up to $6 \mathrm{~mm}$ wide, more or less elliptical; with up to 20 radial and centripetal canals; up to 9 complete and 7 rudimentary urn-shaped manubria, each with four simple lips; «gonads» sometimes developed in the middle parts of on one or more radial canals; with 26 well developed marginal tentacles and 17 rudimentary ones; 34 marginal statocysts. Reproduction by fission; perhaps a variety of Clytia hemisphaerica (see Russell, 1953; Cornelius, 1982).

Records from Mediterranean: western Mediterranean; Black Sea.

Known seasonality: 7-10.

Distribution: endemic of Mediterranean Sea.

References: Lang (1886); Kramp (1959a, 1965); Vannucci (1966); Cornelius (1982).

\section{Genus Gonothyraea Allman, 1864}

Colonies erect, branched or unbranched, monosiphonic or polysiphonic; stem divided into regular internodes bearing alternate hydrothecae; hydrothecae 
campanulate to bell-shaped, radially symmetrical; hydrothecal rim cusped; with true diaphragm; gonophores forming degenerate medusae (mecodonia), extruded from gonotheca but remaining attached while planula develops in a sac-like mecodonium with marginal tentacles, but no mouth or sense organs; gonotheca urn-shaped, pedicellate axillary on stem.

Reference: Cornelius (1995).

\section{Gonothyraea loveni (Allman, 1859)}

(Fig. 111A-E)

Hydrocauli erect, up to $100 \mathrm{~mm}$, flexuous, monosiphonic, internodes straight to strongly curved, somewhat irregularly branched and ringed basally. Hydrothecae borne distally on the internodes, alternate, hydrothecal pedicels usually annulated throughout; hydrothecae bell-shaped, deep, rim delicate with 6-12 castellate cusps provided with a minute notch; diaphragm straight. Hydranth with 19-33 tentacles. Gonothecae long, cylindrical, narrowing basally, borne on ringed pedicels; medusoids develop internally and, when ripe, dangle in groups of 2-3 at entrance to gonotheca; medusoids roughly spherical, with 4-8 long, irregularly held tentacles, a circular canal, without mouth neither sense organs; males with about 5 marginal tentacles; females with 8 marginal tentacles and 3-5 eggs which are fertilized and develop into planulae in situ.

Records from Mediterranean: western Mediterranean, Adriatic.

Known seasonality: 4, 7-9.

Reproduction: 4, 9.

Distribution: eastern and western Atlantic, IndoPacific and Arctic Ocean, Mediterranean.

References: Millard (1975); Östman (1979); Gili (1982, 1986); Isasi and Sáiz (1986); Boero and Bouillon (1993); Altuna (1994); Avian et al. (1995); Cornelius (1995); Medel and López-González (1996); Schuchert (2001a).

\section{Genus Hartlaubella Poche, 1914}

Colonies erect, polysiphonic, branched or unbranched, growing on branched but not anastomosing hydrorhiza; hydrocauli divided in regular internodes bearing alternate hydrothecae; hydrothecae campanulate with castellated, often abraded rim, radially symmetrical, on pedicels, with true diaphragm; gonophores as fixed sporosacs with large embryos, gonothecae axillary, inverted conical.

Reference: Cornelius (1995).
Hartlaubella gelatinosa (Pallas, 1766)

(Figs. 111F-J)

Well developed colonies bushy, main stem erect, up to $200 \mathrm{~mm}$, branched, thick and polysiphonic. Final branches monosiphonic, alternate on both sides of the axis, tending to be disposed in right angle pairs, more or less dichotomously branched and flexuose. Internodes basally ringed, nearly straight to curved. Hydrothecae borne on ringed pedicels, small, cylindrical, rim often abraded smooth but firstly castellate, 12-14 blunt cusps each with a central notch of varied depth, gaps between rounded; diaphragm transverse. Gonothecae (male and female similar) cylindrical, borne on ringed pedicels, narrower basally, wider distally, circular aperture on a short collar.

Records from Mediterranean: western Mediterranean, Black Sea.

Distribution: northeastern Atlantic, western Atlantic and Indo-Pacific (New Zealand); Mediterranean.

References: Cornelius (1982, 1995); Cornelius and Ryland (1990); Boero and Bouillon (1993).

Genus Laomedea Lamouroux, 1812

Colonies erect, monosiphonic, branched or unbranched, growing on branched but not anastomosing hydrorhiza; hydrocauli divided in regular internodes bearing alternate hydrothecae; hydrotheca campanulate, rim even or cusped, radially symmetrical, on pedicels, with true diaphragm; gonophores as fixed sporosacs, gonothecae sessile or shortly pedicellate stolonal or axillary.

References: Östman (1982); Cornelius (1995).

1. Colonies monosiphonic or bisiphonic .............. 2

- Colonies polysiphonic ....... L. pseudodichotoma

2. Female gonotheca with a characteristic subterminal introverted curving tubular aperture ..... L. calceolifera

- Female gonotheca without this character......... 3

3. Internodes long, usually rigidly straight, in zigzag ............................................ L. angulata

- Internodes slightly curved or flexuose ............. 4

4. Rim of the hydrotheca smooth ......... L. flexuosa

- Rim of the hydrotheca bimucronate. L. neglecta

Laomedea angulata Hincks, 1861 (Figs. 111K-P) 
Colonies up to $15 \mathrm{~mm}$ high, composed of erect, flexuose, monosiphonic and unbranched stems, markedly zigzag, growing on an almost straight, little branched or unbranched stolon. Internodes distinctly straight, forming angle $90^{\circ}-120^{\circ}$ between them, ringed basally; when present, tendril stolons recurved at the tip. Hydro thecae borne on ringed pedicels, bell-shaped, delicate, rim even more often flared distally, diaphragm usually transverse, delicate to thickened specially at the extremes. Gonothecae growing on stolons, borne on ringed pedicels; female ovate, aperture apical and wide, planulae developed inside; male also ovate, but apical aperture narrower, with several gonophores. Hydranth with 16-28 tentacles.

Records from Mediterranean: eastern and western Mediterranean, Adriatic.

Known seasonality: 1, 2, 9 .

Reproduction: 9.

Distribution: northeastern Atlantic (Europe), Mediterranean.

References: Gili (1982, 1986); Cornelius (1982, 1995); Ramil (1988); Boero and Bouillon (1993); Avian et al. (1995); Medel and López-González (1996).

\section{Laomedea calceolifera (Hincks, 1871)} (Figs. 112A-F)

Colonies up to $30 \mathrm{~mm}$ high, comprising erect and monosiphonic stems usually unbranched, growing on smooth but tortuous stolons. Axis flexuose, internodes slightly curved, separated by several annuli at their base. Hydrothecae at the upper part of the internodes, lateral and alternate to the left and the right, borne on pedicels with several annuli, sometimes with smooth central portions; hydrothecae deep, bell-shaped, margin even and flared distally; diaphragm transverse to oblique. Male and female gonothecae dissimilar when mature, female club-shaped, with sub-terminal introverted curving tubular aperture on one side; male cylindrical, elongate, narrower basally and truncate distally, aperture terminal, central, at the end of introverted tube.

Records from Mediterranean: western and eastern Mediterranean, Adriatic, Black Sea.

Known seasonality: 1, 4-7, 10.

Reproduction: 1, 5, 7, 10.

Distribution: eastern and western Atlantic (mainly northern parts), Mediterranean.

References: Vervoort (1968); Marinopoulos (1979); Cornelius (1982, 1995); Gili (1986); Boero and Fresi (1986); Ramil (1988); Boero and Bouillon (1993);
Altuna (1994); Avian et al. (1995); Medel and LópezGonzález (1996); Medel and Vervoort (2000).

\section{Laomedea flexuosa Alder, 1857}

(Figs. 112G-M)

Colonies up to $30 \mathrm{~mm}$ high, comprising erect, branched or unbranched and flexuose stems growing on a branching stolon. Internodes usually curved and ringed basally. Hydrothecal pedicels slightly narrower distally, ringed throughout, although smooth central portion may occurs, pedicels laterally to the axis, alternate to the left and right. Hydrothecae bell-shaped, walls strong, sometimes thickened, rim even, diaphragms transverse. Female gonotheca borne on ringed pedicel, cylindrical, elongated, narrower basally, distally truncate, aperture distal and wide; male gonotheca shorter, roughly ovated, also with a circular and apical aperture but narrower than female.

Records from Mediterranean: western Mediterranean, Adriatic.

Known seasonality: 4, 5, 8. Reproduction: 4.

Distribution: western and eastern Atlantic, Mediterranean.

References: Cornelius (1982, 1995); Gili (1982, 1986); García-Carrascosa et al. (1987); Ramil (1988); Boero and Bouillon (1993); Alvarez (1993); Altuna (1994); Medel and López-González (1996); Schuchert (2001a).

\section{Laomedea neglecta Alder, 1856} (Figs. 113A-D)

Colonies delicate with monosiphonic or bisiphonic stems; internodes long and narrow, often wider in the middle than at ends, 3-10 rings basally, curved to almost straight; each sharply inturned basally. Hydrothecae on long tapering distally pedicels with up to 20 annuli; delicate, walls unthickened and cylindrical; diaphragm oblique to transverse; rim usually bimucronate. Gonotheca male similar to female, cylindrical to inverted-conical, truncate above. Acrocyst in female, eggs or embryos possibly extruded singly.

Records from Mediterranean: Adriatic.

Known seasonality: 4-10.

Reproduction: 4-10.

Distribution: northeastern Atlantic, Mediterranean.

References: Vervoort (1946); Cornelius (1995); Schuchert (2001a). 
Laomedea pseudodichotoma Vervoort, 1959 (Figs. 113E-H)

Hydrorhiza composed of a tangle mass of perisarcal tubules, giving rise erect, polysiphonic and branched stems up to $50 \mathrm{~mm}$ high; branches with secondary ramifications. In monosiphonic parts, stem slightly geniculate, internodes separated by 23 annuli. Hydrothecae borne laterally at the extreme of each segment, hydrothecal pedicel oblique, on distinct apophysis, with 4-8 annulations; hydrotheca elongated conical, rim even and slightly everted; diaphragm at basal part oblique. Male gonotheca sac-shaped and truncated distally; the female thin, elongated and narrowing distally.

Remark: Cornelius, 1982 pointed out that the gonophores could be free heteromedusoids.

Records from Mediterranean: western Mediterranean (Alborán Sea and Chafarinas Islands).

Known seasonality: 1-8.

Reproduction: 1-7.

Distribution: temperate and tropical eastern Atlantic; Mediterranean.

References: Vervoort (1959, 1966); Cornelius (1982, 1995); Ramil and Vervoort (1992a); Peña Cantero (1995); Medel and López-González (1996); Medel and Vervoort (2000); Peña Cantero and García Carrascosa (2002).

\section{Genus Obelia Péron and Lesueur, 1810}

Hydroid: colonies erect, branched or unbranched, monosiphonic or polysiphonic, variably flexuose; stolons not anastomosing; internodes annulated proximally, supporting distally a pedicellate hydrothecae on apophysis; hydrotheca bell-shaped to campanulate, radially symmetrical, margin cusped or uncusped, true hydrothecal diaphragm, no sub-hydrothecal spherule; hydranth with globose hypostome forming a "buccal cavity"; gonophores as free medusae, gonothecae inverted conical, usually with raised terminal aperture but sometimes simply truncated.

Medusa: umbrella 2.5- $6 \mathrm{~mm}$ wide, circular, flat, mesoglea very thin; without gastric peduncle; mouth with 4 simple lips; 4 radial canals; «gonads» spherical to ovoid, sac-like, hanging from middle to end of the radial canals; numerous short, stiff solid, not extensile marginal tentacles; tentacles with short endodermal roots extending into bell mesoglea; 8 statocysts situated on underside of basal bulbs of some marginal tentacles.
Remarks: various nominal species of Obelia hydroids are common throughout the world but the medusae specimens of this genus cannot be reliably determined down to species level. The following nominal species have been cited from Mediterranean: Obelia bidentata Clarke, 1875; Obelia dichotoma (L., 1758); Obelia fimbriata (Dalyell, 1848); Obelia geniculata (L.1758); Obelia longissima (Pallas, 1766) their medusa are undiscernable and are designed under Obelia spp. (Figs. 114A-B).

According to Zamponi and Genzano (1990 a), the medusae of Obelia dichotoma Hincks, 1868 and Obelia longissima (Pallas, 1766), could be distinguishable by their cnidome composed by atrichous isorhizas, atrichous anisorhizas and basitrichous isorhizas in $O$. dichotoma and by microbasic mastigophores and macrobasic mastigophores in $O$. longissima. The presence of macrobasic mastigophores appears nevertheless improbable in the genus Obelia although they have been found in other Leptomedusae. Östman (1982) has found by electron microscopy minute differences in the cnidocyst fine morphology of newly liberated medusae $O$. dichotoma, O. longissima and O. geniculata.

Records from Mediterranean: eastern and western Mediterranean, Adriatic Sea.

Known seasonality: 1-12.

Distribution: cosmopolitan genus.

References: Kramp (1961); Goy (1973b); Bouillon (1984b); Fulton et al. (1985); Gili (1986); Cornelius (1975a, 1987, 1990, 1995); Benovic and Bender (1987); Brinckmann-Voss (1987); Zamponi and Genzano (1990 b); Pagès et al. (1992); Boero and Bouillon (1993); Benovic and Lucic (1996); Medel and López-González (1996).

\section{Key to the hydroid}

1. Hydrothecal rim with bimucronate cusps (embayments sometimes uniform).

$O$. bidentata

- Hydrothecal rim smooth or with shallow cusps..

2. Perisarc of internodes thickened, usually one side thicker than the other one; hydrothecal pedicel short, perisarc of hydrotheca thickened, rim smooth ..... O. geniculata

- Without these characters .................................. 3

3. Colony very long, flexible, stem brown to black; in older colonies side branches ceasing growth at roughly uniform length but gradually shorter towards growing tip O. longissima 
- Colony loosely fan-shaped, stem pale to midbrown, never black; sides branches typically irregular in length.... O. dichotoma

Obelia bidentata Clarke, 1875 (Figs. 113I-M)

Hydroid: well developed colonies up to $350 \mathrm{~mm}$ high, comprising polysiphonic although slender main stems, from which, lateral branches, roughly in right-angles pairs are given on both sides. Branches flexuose, giving alternately secondary branches with alternate branchlets provided with hydrothecal pedicels at nodes; third, even fourth, order ramification may occur. Internodes long, ringed basally; hydrothecal pedicels originated distally, alternate, ringed throughout or with smooth central portion. Hydrotheca almost cylindrical, elongated, often slightly asymmetric, rim with bimucronate cusps, but embayments sometimes uniform. Female and male gonothecae equal, usually inverted-conical, aperture apically, on a short collar.

Records from Mediterranean: western Mediterranean, Adriatic, Black Sea.

Known seasonality: 5,6,8-1.

Reproduction: 5-11.

Distribution: warmer waters of eastern and western Atlantic and Indo-Pacific, Mediterranean.

References: Cornelius (1982, 1995); Gili (1986); Boero and Fresi (1986); Gili et al. (1989); Calder (1991); Boero and Bouillon (1993); Altuna (1994); Avian et al. (1995); Migotto (1996); Medel and López-González (1996); Medel and Vervoort (2000); Peña Cantero and García Carrascosa (2002).

Obelia dichotoma (Linnaeus, 1758) (Figs. 114C-G)

Hydroid: colonies very varied in size and shape. Stems erect, up to $35 \mathrm{~cm}$ high, monosiphonic and branched, flexuose to straight, thickened in old colonies. Internodes with several annuli at their base. Hydrothecae alternate, lateral, borne on completely annulate pedicels at the upper part of the internodes. Hydrotheca bell-shaped, usually not very deep, thin walled, many times thrown into fine longitudinal folds; rim even to crenate, slightly flared; diaphragm transverse to oblique. Gonothecae usually inverted-conical on annulate pedicels, truncated at the distal end, with a short distal neck when mature, where the aperture is.
Records from Mediterranean: eastern and western Mediterranean, Adriatic.

Known seasonality: present all the year.

Reproduction: all the year.

Distribution: cosmopolitan.

References: Millard (1975); Cornelius (1975, 1982, 1995); Gili (1982, 1986); Calder (1991); Ramil and Vervoort (1992a); Boero and Bouillon (1993); Avian et al. (1995); Medel and López-González (1996); Medel and Vervoort (2000); Schuchert (2001a); Peña Cantero and García Carrascosa (2002).

Obelia geniculata (Linnaeus, 1758)

(Figs. 114H-I, 115A-E)

Hydroid: colonies erect, usually unbranched, monosiphonic up to about $20 \mathrm{~mm}$; stems markedly flexuose, internodes curved, thickened (more evident in older parts), usually one side thicker than the other one and alternate towards the internodes, which are ringed basally. Hydrothecal pedicels short (composed of 2-3 wide annuli), alternate, borne laterally at distal end of each internode. Hydrotheca bell-shaped, not very deep, walls and diaphragm thickened, rim smooth. Gonothecae borne on the stem or on the stolon; on short annulated pedicels, male and female equal, inverted-conical to cylindrical, narrower at their base, wider distally domed with a central tubular aperture.

Records from Mediterranean: eastern and western Mediterranean, Adriatic.

Known seasonality and reproduction: throughout the year.

Distribution: cosmopolitan.

References: Patriti (1970); Cornelius (1975, 1982, 1995); Millard (1975); Gili (1982, 1986); Boero and Bouillon (1993); Vervoort (1993a); Altuna (1994); Avian et al. (1995); Medel and López-González (1996); Migotto (1996); Medel and Vervoort (2000); Schuchert (2001a); Peña Cantero and García Carrascosa (2002).

\section{Obelia longissima (Pallas, 1766)} (Figs. 115F-K)

Hydroid: colonies long and flexuose, up to $40 \mathrm{~cm}$ high; main stem monosiphonic, dark, with lateral and alternated branches; in older colonies may be polysiphonic, and forked. Internodes usually nearly straight, thickened in older portions of the stem, annulated basally; nodes (but not the internodes) dark in young branches. Side branches of the stem 
also flexuose, usually branched in two at their origin; internodes pale when young, becoming darker after; internodes long, in zigzag, ringed basally. Hydrothecal pedicels alternate, at the end of each internode; hydrotheca elongate, bell-shaped, without longitudinal striae, perisarc very thin, diaphragm transverse to oblique, rim shallow castellate or with shallow rounded cusps, slightly flared. Gonothecae inverted-conical, narrower basally, aperture distally on a short collar.

Records from Mediterranean: western Mediterranean, Adriatic.

Distribution: nearly cosmopolitan, Red Sea.

References: Ramil (1988); Boero and Bouillon (1993); Altuna (1994); Avian et al. (1995); Cornelius (1995); Medel and López-González (1996); Schuchert (2001a).

\section{Genus Orthopyxis L. Agassiz, 1862}

Hydroid: colonies stolonal or with short unbranched uprights stems; hydrorhiza branched and anastomosing; hydrotheca campanulate, fundamentally radially symmetrical but sometimes biradially symmetrical with walls laterally compressed and oval in cross section; perisarcal wall variably thickened; rim even or toothed; without true diaphragm but variably developed perisarcal thickening, sub-hydrothecal spherule; gonophores as eumedusoids either free, facultatively retained, or never released; no manubrium and tentacles but with 8 statocysts, gonothecae on hydrorhiza.

Remark: Sometimes considered as congeneric with Campanularia.

References: Calder (1991); Cornelius (1995).

\section{Orthopyxis asymmetrica Stechow, 1919}

Remarks: Cornelius (1982) considers Campanularia assymetrica Stechow, 1919 conspecific with Orthopyxis integra. Östman et al. (1987) did not find distinct differences in the cnidome of both species. Nevertheless many authors studying Mediterranean material keep the two species separated (see Peña Cantero and García Carrascosa, 2002).

Orthopyxis crenata (Hartlaub, 1901) (= Eucopella bilabiata and Eucopella crenata)

(Figs. 116A-H)

Hydroid: colonies composed of unbranched erected pedicels bearing hydrothecae; stolon anasto- mosing. Perisarc of pedicel thickened and usually undulated throughout; sub-hydrothecal spherule present. Hydrotheca bell-shaped, walls thickened in more or less degree, ring of perisarc basally separating a small spherical chamber; rim with 8-13 short rounded cusps varied from deep and distinct to very shallow; hydranth with about 14 tentacles. Gonothecae borne on stolons, on short pedicels; sac-shaped, truncate distally, strongly compressed laterally, perisarc irregularly undulated; containing 2 eumedusoids buds.

Eumedusoid: umbrella pyriform, up to $1.5 \mathrm{~mm}$ high, thin walls; exumbrella with 30-40 longitudinal meridional ridges; circular canal narrow; 4 radial canals closed and obliterated near apex, giving rise to numerous blindly ending side branches; no manubrium; no marginal tentacles; «gonads» developed between branches of radial canals, bell cavity almost filled with sexual products; 8 adradial statocysts.

Records from Mediterranean: eastern and western Mediterranean. Only hydroids known.

Known seasonality: 3-12.

Reproduction: $3,9$.

Distribution: Atlantic; Indo-Pacific; Mediterranean.

References: Millard (1975); Marinopoulos (1979); Boero (1981); Cornelius (1982, 1992, 1995); Gili (1986); Ramil (1988); Boero and Bouillon (1993); Medel and López-González (1996); Genzano and Zamponi (1997); Medel and Vervoort (2000); Peña Cantero and Carrascosa (2002).

Orthopyxis everta (Clarke, 1877)

Cornelius (1982) suggests that this species could be synonymous with $O$. crenata.

Orthopyxis integra (MacGillivray, 1842) (Figs. 116I-S)

Hydroid: stolonal colonies with pedicels bearing hydrothecae; hydrorhiza tortuous, anastomosing and thick. Pedicels thick-walled and usually undulated throughout; sub-hydrothecal spherule present. Hydrothecae bell-shaped, thick walled in variable degree, rim smooth, usually unthickened and often flared; basally a ring of perisarc limiting a small spherical chamber; hydranth with 25-30 tentacles. Gonothecae of both sexes similar, borne on stolons, on a short pedicels; sac-shaped, contour often irregular, truncate distally, usually flattened, but some- 
times circular in transverse section; females with 13 eumedusoids buds.

Eumedusoid: umbrella bell-shaped, higher than wide, mesoglea fairly thick; 4 radial canals either meeting at apex or each closing before they meet, each one with one irregularly-lobed sac-like outgrowth midway along each side; «gonads» on lobes of radial canals outgrowths; no marginal tentacles; 8 statocysts; sexually mature on release.

Records from Mediterranean: eastern and western Mediterranean, Adriatic.

Known seasonality: present throughout the year Reproduction: 4-8.

Distribution: Atlantic; Indo-Pacific; Mediterranean.

References: Kramp (1961); Teissier (1965); Cornelius (1982, 1995); Boero and Fresi (1986); Boero and Bouillon (1993); Vervoort (1993a); Avian et al. (1995); Medel and López-González (1996); Medel and Vervoort, (2000); Schuchert (2001a); Peña Cantero and García Carrascosa (2002).

\section{Orthopyxis rubra (Behner, 1914) = Agastra rubra Behner, 1914}

Remarks: Kramp (1961) considering the medusa stage alone keeps A. rubra as a distinctive species. Nevertheless, the majority of authors consider it an invalid species (see Cornelius, 1982) or conspecific with Orthopyxis integra (see Stefani, 1959; Millard, 1975).

\section{Genus Pseudoclytia Mayer, 1900}

Hydroid: unknown.

Medusa: more than 4 radial canals and a corresponding number of manubrial lips.

Pseudoclytia pentata (Mayer, 1900) (Fig. 117A)

Medusa: umbrella up to $8 \mathrm{~mm}$ or more; with more than four radial canals; manubrium flaskshaped; mouth with the same number of lips than radial canals; «gonads» sac-like round or oval in the middle or distal part of radial canals without median furrow; up to 20 marginal tentacles; tentacular bulbs globular, prominent; few partially developed marginal bulbs; velum narrow; normally 1, sometimes up to 3 statocysts between successive tentacles.

Records from Mediterranean: eastern and western Mediterranean; Adriatic Sea.

Known seasonality: 8; 9.
Distribution: Atlantic; Indo-Pacific; Mediterranean.

References: Kramp (1959a, 1961); Goy (1970); Schmidt and Benovic (1977); Cornelius (1982); Bouillon (1984); Boero and Bouillon (1993).

Hydroid: unknown.

\section{Subclass LIMNOMEDUSAE Kramp, 1938}

Hydroid: when known, very simple, solitary or colonial; small, sessile; with or without tentacles; often close to planula structure and budding planula-like structures or frustules; body plans range from forms without mouth and permanent gastric cavity = feeding planula: Microhydrulidae, to forms with mouth and hypostome, but without tentacles, forming transitory colonies or definitive colonies with a limited number of individuals: Craspedacusta, Limnocnida, Olindias; to forms with hypostome and tentacles: Calpasoma, Gonionemus, Scolionema, Vallentinia; no perisarcal thecae, but cysts and stolons covered by chitin.

Medusa: usually without marginal cnidocyst ring (except Craspedacusta and Limnocnida); with "gonads" along radial canals or exceptionally on manubrium (Armorhydra and Limnocnida). Marginal tentacles peripheral, hollow, without true basal bulb, tentacles base usually with a parenchymatic endodermal core embedded in the umbrellar mesoglea. Marginal sense organs as internal enclosed ecto-endodermal statocysts embedded in the mesoglea near ring canal or in the velum (only in Craspedacusta); without ocelli. Exceptionally reduced medusoids (Monobrachium). Planulae, when known, with cnidoblasts but without embryonic glandular cells.

The Limnomedusae is a small group of Hydroidomedusa (medusa budding with entocodon) with a dimorphic benthic-pelagic cycle; the hydroid stages are small, poorly developed, rarely modular; medusa production is comparatively much reduced; many of the present-day Limnomedusae inhabit fresh-or brackish-waters and their medusae are often seasonal, whereas the hydroids and the resting stages are perennial, resisting adverse conditions: Craspedacusta cysts can survive 40 years while completely desiccated.

\section{Key to hydroids}

1. Hydroids reduced to a spherical or irregular body having from 20 to $480 \mu \mathrm{m}$, without 
tentacles, mouth and gastric cavity

Microhydrulidae

- Hydroids with permanent mouth and gastric cavity Olindiidae

\section{Key to medusae}

1. Reduced medusae, creeping burrowed in coarse sand sediments; without radial canals, statocysts and nerve system Armorhydridae

- Free swimming medusae, with radial canals, statocysts and nerve system Olindiidae

\section{Family ARMORHYDRIDAE} Swedmark and Teissier, 1958

Hydroid: polyp small, solitary, mesopsammic, attached to sand grains by mucoid periderm; about 10 short but extensible capitate-like tentacles, small hypostome, mouth inconspicuous; tentacular frustules and podocysts; gonophores as free medusae, borne on body (Lacassagne, 1968a; 1973).

Medusa: reduced, creeping within the interstices in coarse sand sediments; umbrella margin with a whorl of two kind of solid tentacles, filiform and adhesive; manubrium voluminous, linked to subumbrella by longitudinal septa containing endodermal tubes; "gonads" on manubrium; velar opening narrow; no radial canals, nerve system, statocysts or any other visible sense organ; sexes separate.

References: Swedmark and Teissier (1958d), Thiel (1988).

Genus Armorhydra Swedmark and Teissier, 1958

With the characters of the family.

\section{Armorhydra janowiczi}

Swedmark and Teissier, 1958 (Figs. 117B-C)

Medusa: umbrella 1-4 mm; with 8-30 marginal tentacles, filiform ones alternating with capitate ones having a terminal adhesive papillae; about 12 longitudinal septa; gonads on manubrium.

Hydroid: see family.

Records from Mediterranean: western Mediterranean, Adriatic.

Known seasonality: 3, 4.

Distribution: Atlantic; Mediterranean.

References: Swedmark and Teissier (1958d); Salvini-Plawen (1966); Lacasagne (1968a; 1973); Clausen (1971); Avian et al. (1995).
Family MicroHYDRULIDAE

Bouillon and Deroux, 1967

Reduced to a spherical or irregular body ranging from 20 to $480 \mu \mathrm{m}$, included in the superficial biological layer covering immersed objects in the sea or epibiotic on bivalve shells; didermic but very simple, without tentacles and mouth, gastric cavity becomes temporarly visible only when food is engulfed; body covered by mucus, with a basal lamella of periderm; sexual reproduction unknown, asexual reproduction by mobile frustules.

References: Thiel (1988); Jarms and Tiemann (1996).

\section{Key to hydroids}

1. Cnidocysts: microbasic euryteles Microhydrula

- Cnidocysts: microbasic semiophoric euryteles ... Rhaptapagis

\section{Genus Microhydrula Valkanov, 1965}

Hydroid: body rounded or elongated, terminal end either hemispherical or cauliflower-like in shape and armed with cnidocysts pending the species, ectoderm in a well definite unistratified layer, basal layer of periderm thin; frustules formed by a great number of small cells; living in biotic substrata and in sediments or on burrowing bivalves; cnidome: microbasic euryteles.

\section{Microhydrula pontica Valkanov, 1965} (Figs. 117D-E)

Hydroid: $0.24 \mathrm{~mm}$ in height, living in biotic substrata and in sediments.

Records from Mediterranean: eastern Mediterranean.

Known seasonality: 6-9.

Distribution: Atlantic; Mediterranean.

References: Bouillon and Deroux (1967); Thiel (1988); Jarms and Tiemann (1996).

Genus Rhaptapagis Bouillon and Deroux, 1967

Hydroid: body irregular; ectoderm not very regularly organised; peridermal basal lamella thick; frustules formed by a reduced number of large cells; cnidome: microbasic semiophoric euryteles. 


\section{Rhaptapagis cantacuzenei \\ Bouillon and Deroux, 1967 (Fig. 117F)}

With the characters of the genus.

Records from Mediterranean: eastern Mediterranean. Known seasonality: 6-9.

Distribution: Atlantic; Mediterranean.

References: Bouillon and Deroux (1967); Thiel (1988); Jarms and Tiemann (1996).

\section{Family OLINDIIDAE Haeckel, 1879}

Hydroid: usually solitary, seldom colonial; generally reduced, minute, either without tentacles or with one tentacle, or with a few tentacles in a single ring, sometimes with dactylozooids; no theca; active asexual reproduction by buds or frustules; usually with free medusae, exceptionally with free or fixed eumedusoids.

Medusa: with or without centripetal canals; internal ecto- endodermal statocysts; simple, unbranched radial canals; "gonads" on radial canals or exceptionally on manubrium (Limnocnida); no ocelli.

References: Uchida (1929); Pagès et al. (1992); Bouillon (1999); Bouillon and Barnett (1999); Bouillon and Boero (2000).

\section{Key to hydroids}

1. With tentacles 4

- Without tentacles 2

2. Enclosed in a long perisarcal tube, solitary, marine Olindias

- Hydranth not enclosed in perisarc.

3. Fresh-water form; solitary but often forming small transitory colonies Craspedacusta

- Sea water form; only primary polyps known, inconspicuous (almost $0,1 \mathrm{~mm}$ ) atentaculate, gross morphology similar to those of Craspedacusta Maeotias

4. Colonial, hydranth with one tentacle Monobrachium

- Solitary, hydranth with more than one tentacle ..

5. Small, flat, discoid; with not well defined hypostomial region Scolionema

- Small, with a conspicuous conical hypostome ... Gonionemus

\section{Key to medusa}

1. Statocysts in elongated vesicles enclosed in velum Craspedacusta
- Statocysts spherical enclosed in mesoglea of umbrella margin 2

2. With centripetal canals ...................................... 3

- Without centripetal canals ................................... 4

3. With primary tentacles projecting above umbrella margin and with terminal adhesive pads, secondary tentacles on umbrella margin without adhesive pads Olindias

- All tentacles on umbrella margin and without adhesive pads...................................... Maeotias

4. Tentacles in groups on bell margin ........ Gossea

- Tentacles not in groups........................................ 5

5. With numerous statocysts ............... Gonionemus

- With no more than 16 statocysts ..... Scolionema

Genus Craspedacusta Lankester, 1880

Hydroid: fresh-water, solitary or forming small reptant colonies of 2 to 4 , rarely 7 polyps; hydranths without tentacles, cylindrical, with apical mouth (hypostome) surrounded by cnidocysts forming a spherical capitulum under which the polyp is slightly tapering, forming a distinct neck; basal portion of hydranths with periderm covering, attaching colony to substrate; medusa buds lateral, on the middle or lower part of body column, often becoming terminal by hydranth reduction; asexual reproduction by frustules, transversal division and resting stages (cysts).

Medusa: well developed marginal cnidocyst ring, no gastric peduncle; 4 simple radial canals; no centripetal canals; "gonads" only on radial canals, hanging, pouch-like; evenly distributed marginal tentacles all of one kind, no adhesion organs; closed ecto-endodermal statocysts in the velum and forming centripetal tubes.

Remarks: numerous species of Craspedacusta have been described, mainly from China, and it is not unlikely that they represent nothing more than variations of a single species.

\section{Craspedacusta sowerbyi Lankester, 1880} (Figs. 118A-F)

Hydroid: with the character of the genus.

Medusa: umbrella 10-20 mm wide, slightly flatter than a hemisphere; mesoglea fairly thick; with well developed marginal cnidocyst ring; velum broad and well developed; manubrium large, upper portion conical with broad square base, tapering downwards to cross-shaped distal region; mouth with four simple or slightly folded lips, extending 
beyond umbrella margin; four straight radial canals and circular canal broad and massive; four large smooth triangular pouch-like gonads, with rounded comers, hanging down into subumbrellar cavity from points of junction of radial canals with manubrium; with 200 to 400 or more, hollow marginal tentacles, in several series situated at different levels on umbrella margin, oldest four perradial marginal tentacles being largest and highest; bases of marginal tentacles adherent to exumbrella; surface of marginal tentacles covered with evenly distributed papillae each with three to ten cnidocysts; 100 to 200 , or more statocysts, usually about half number of marginal tentacles; statocysts situated in velum, forming centripetal tubes with basal enlargements near umbrella margin.

Records from Mediterranean: in freshwaters of Mediterranean coasts.

Known seasonality: 1-3.

Distribution: cosmopolitan in freshwaters and sometimes in brackish waters of temperate and tropical areas.

References: Payne (1924); Dejdar (1934); Kramp (1961); Reisinger (1957); Bennett (1966); Naumov and Stepanjants (1971); Acker (1976); Acker and Muscat (1976); Culberson (1976); Ludwig (1977); Dendy (1978); Dumont (1994); Avian et al. (1995); Stepanjants et al. (1997); Jankowski (2001).

\section{Genus Gonionemus A. Agassiz, 1862}

Hydroid: hydroid small, solitary, devoid of hydrorhiza, with a conspicuous conical hypostome and a circlet of 4-6 very long tentacles; medusa buds, frustules, cysts formed by intensive asexual budding.

Medusa: Olindiidae without or with slight peduncle; with 4 simple radial canal; without centripetal canals; with folded gonads on radial canals only; with evenly distributed marginal tentacles all of one kind, with organs of adhesion; with numerous statocysts enclosed in mesoglea.

Gonionemus vertens A. Agassiz, 1862 (Figs. 118G-J, 119A-D)

Hydroid: polyp generation in form of a small, short, solitary, sessile conical or flask-shaped hydranths devoid of hydrorhiza, base large circular, with a thin basal periderm, with a conspicuous conical hypostome and a circlet of 4-6 very long tentacles; the polyps often embedded in detritus and clinging to the substrate with some of their tentacles; medusa buds arising from the lower part of the hydranth; elongated, mobile frustules formed in the same area, polyps may reduce themselves and transform in cysts.

Medusa: umbrella 15-20 mm wide, hemispherical or somewhat flatter; mesoglea moderately thick; manubrium fusiform, slightly shorter than umbrella cavity; with a slight gastric peduncle; mouth with 4 short slightly crenulated lips; gonads along greater portion of radial canals, each in form of pendant sac folded sinuously on alternate sides of radial canals; 60-80 long rather stiff marginal tentacles, with spiral or annular cnidocysts clusters, each with an adhesive pad near distal end which is sharply bent; closed ecto-endodermal statocyst about as numerous as tentacles.

Records from Mediterranean: western Mediterranean, Adriatic.

Known seasonality: 6-9.

Distribution: Arctic; Atlantic; Indo-Pacific; Mediterranean.

References: Joseph (1925); Werner (1950 a and b); Kramp (1961); Picard (1951b, 1955a); Goy (1973b); Edwards (1976); Arai and BrinckmannVoss (1980); Boero and Bouillon (1993) Avian et al. (1995)

Genus Gossea L. Agassiz, 1862

Medusa: Olindiidae with four simple radial canals; with or without gastric peduncle; without centripetal canals; with folded ribbon-like gonads only on radial canals; with one kind of tentacles, some of which are arranged in groups; without adhesive pads; with statocysts enclosed in exumbrellar mesoglea.

Hydroid: unknown.

Gossea corynetes (Gosse, 1853) (Figs. 119E-F)

Medusa: umbrella 12-16 mm wide, 8-10 mm high, bell-shaped or hemispherical, mesoglea fairly thick and rigid especially in apical region; manubrium short, quadratic, one third to one half height of subumbrellar cavity; mouth with four simple crenulated lips; 4 gonads linear, wavy, forming deep hanging pouches along two thirds of radial canals; 24 marginal tentacles in eight groups, 4 perradial and 4 interrradial, all of about equal size, and 8-16 smaller isolated marginal tentacles, one between 
adjacent groups, all tentacles with rings of cnidocysts, endodermal core of tentacles extending into marginal mesoglea; 24 statocysts, 3 between adjacent groups of tentacles.

Records from Mediterranean: eastern Mediterranean.

Known seasonality: 9, 11.

Distribution: Atlantic; Mediterranean.

References: Kramp (1961); Bouillon (1978a);

Dowidar (1983), Boero and Bouillon (1993).

Hydroid: unknown.

Genus Maeotias Ostroumoff, 1896

Hydroid: only primary polyps known, inconspicuous (almost 0,1 mm) atentaculate, gross morphology similar to that of Craspedacusta.

Medusa: with centripetal canals; numerous tentacles with tightly packed cnidocyst rings, all on umbrellar margin and without adhesive pads; "gonads" on radial canals, statocysts about in same number as tentacles.

References: Mills and Sommer (1995); Mills (2000); Rees and Gershwin, (2000); Mills and Rees (2000).

\section{Maeotias marginata (Modeer, 1791) \\ = Maeotias inexspectata Ostroumoff, 1896}

(Figs. 119G-H)

Hydroid: see family characters.

Medusa: umbrella up to $39 \mathrm{~mm}$ wide and $24 \mathrm{~mm}$ high; with numerous centripetal canals of different size, up to 15 per quadrant; manubrium prismatic, with four perradial lobes extending onto radial canals; mouth with four very long crenulated, frilly, lips with clusters of cnidocysts; gonads folded, extending only along the manubrial lobes, up to 600 marginal tentacles with simple tightly packed rings of cnidocysts and numerous short, club-shaped marginal appendages corresponding to the base of the oldest tentacles; statocysts about in same number as tentacles.

Records from Mediterranean: Black Sea; Azov Sea; Danube estuary.

Known seasonality: 7-9.

Distribution: Atlantic; Indo-Pacific; Mediterranean.

References: Kramp (1961); Borcea (1929); Calder and Burrell (1969); Denayer (1973); Boero and Bouillon (1993); Mills and Sommer (1995); Rees and Gershwin, (2000); Mills and Rees (2000)
Genus Monobrachium Mereshkowsky, 1877

Hydroid: colonies stolonal creeping, living on bivalve shells; hydrorhiza reticulated or incrusting or both reticulated and incrusting, covered or not by a thin perisarc; hydranth sessile, claviform, only one oral filiform tentacle; hypostome large, club-shaped; sometimes dactylozooids in form of peduncled cnidocyst knobs; gonophores peduncled on hydrorhiza giving fixed or free eumedusoids, sexual cells borne in hydrorhizal coenosarc and migrating in eumedusoid radial canals after eumedusoid formation; with or without statocysts.

Reference: Marche-Marchad (1963).

\section{Monobrachium parasiticum Mereschkowsky, 1877}

(Fig. 120A)

Hydroid: colonies stolonal, with densely reticulated hydrothiza, often forming a fused mat on bivalves molluscs, growing usually on the apex zones and along the grooves of the shell; thin perisarc present in reticulated part of colonies; hydranths grouped, tubular, narrower at base, hypostome separated from body by a rather deep constriction, with only one long apical tentacle, with a considerable accumulation of cnidocysts around hypostome; dactylozooids in form of short peduncled cnidocyst knobs; gonophores on hydrorhiza, on a short peduncle, ovoid, giving rise to free or attached eumedusoids, with rudimentary manubrium, without mouth, with 4 radial canals and up to 16 short marginal tentacles; gonads on radial canals in eight longitudinal rows, living distal and proximal parts of the canals free.

Records from Mediterranean: western Mediterranean

Distribution: Atlantic; Pacific; Mediterranean.

References: Ramil (1988); Besteiro et al. (1990); Kubota (1991); Medel and López-González (1996); Jarms and Mühlenhardt-Siegel (1998).

\section{Genus Olindias F. Müller, 1861}

Medusa: Olindiidae with 4 radial canals and numerous centripetal canals; numerous tentacles of two kinds: primary tentacles issuing above bell margin, with distal adhesive pads and cnidocysts in transverse clasps, and secondary tentacles on bell margin, without adhesive pads, with cnidocysts in rings; gonads with papillliform processes; numerous marginal clubs which may transform into tentacles, stato- 
cysts usually in pairs at base of primary tentacles.

Hydroid: Only known in Olindias phosphorica see below.

Olindias phosphorica (Delle Chiaje, 1841) (Figs. 120B-E)

Medusa: umbrella 40-60 mm wide, almost hemispherical, mesoglea fairly thick; 11-19 centripetal canals per quadrant; 30-60 primary tentacles; usually two statocysts at base of each primary tentacle; 100120 secondary tentacles; 100-170 marginal clubs.

Hydroid: the polyps have not been yet found in field. Weill (1936) described from laboratory observations a small solitary hydranth without tentacles enclosed in a cylindrical or irregularly curved hydrothecae covering more than half its length, and much longer than the polyp itself; mouth distal surrounded by large cnidocysts.

Records from Mediterranean: western Mediterranean, Adriatic.

Known seasonality: 6-11.

Distribution: Atlantic; Mediterranean.

References: Kramp (1961); Goy (1973b); Castelló i Tortella (1986); Gili (1986); Brinckmann-Voss (1987); Boero and Bouillon (1993); Avian et al. (1995); Medel and López-González, 1996; Goy (1997).

\section{Genus Scolionema Kishinouye, 1910}

Hydroid: solitary, small, and discoid; with not well defined hypostomial region, with up to 5 tentacles; presenting varied and intensive lateral asexual budding: medusa buds, frustules, cysts.

Medusa: Olindiidae without or with slight peduncle; with 4 simple radial canals; without centripetal canals; with folded gonads on $1 / 2$ to $1 / 3$ of distal part of radial canals only; with evenly distributed marginal tentacles all of one kind, with rudimentary organs of adhesion; with never more than 16 statocysts enclosed in mesoglea.

Scolionema suvaensis (Agassiz and Mayer, 1899) (Figs. 120F-H)

Hydroid: solitary, small, short, flat, discoid, with not well defined hypostomial region, with up to 3-5 tentacles; hydranths embedded in diatoms and detritus, presenting intensive lateral asexual budding of frustules or of resting stages (cysts) depending on environmental condition and more seldom medusa buds, after medusa bud formation the hydranth is reduced to a kind of frustule without mouth and tentacles.

Medusa: umbrella $9 \mathrm{~mm}$ wide, about $6 \mathrm{~mm}$ high, mesoglea thick; gastric peduncle indicated; manubrium cruciform, about half as long as umbrellar cavity; mouth with four small lips; gonads extending along distal 1/2 - 1/3 of radial canals, ribbon-shaped, much folded; 40 to 70 marginal tentacles of different lengths, with globular marginal bulbs, cnidocysts rings along whole length of tentacles, distal end sharply bent; adhesive pats rudimentary except in old tentacles; 16 statocysts; medusa budding on radial canals.

Reference: Goy (1973a).

\section{Limnomedusae incertae sedis}

Genus Calpasoma Furmann, 1939

Hydroid: living in freshwater, of small size (100$600 \mu \mathrm{m})$; solitary but sometimes bi- or tripolar; 2 irregular whorls of tentacles at oral end, each tentacle consisting of a process of a single ectodermal cell (tentaculocyte) scattered with a few cnidocysts; hydranth reproducing only asexually, forming new polyps of their own type or frustules, never producing medusae; sometimes considered as a tentaculate form of Craspedacusta but no inter-conversion has been observed between the two forms. Following the authors they are considered or as two distinct species or as two stable forms of the same species.

Calpasoma dactyloptera Fuhrmann, 1939

(Fig. 121A)

With the characters of the family.

Records from Mediterranean: fresh water aquariums in Israel.

Known seasonality: all the year?

Distribution: Brazil; Hawaii; Hungary; Israel; Switzerland; USA (Indiana).

References: Furmann (1939); Rahat and Campbell (1974); Jankowski (2001).

Subclass SIPHONOPHORAE Eschscholtz, 1829 (Figs. 14, 15, 19)

Pelagic, pleustonic or epibenthic Hydrozoa, forming highly polymorphic modular colonies of polypoid and medusoid zooids attached to a stem or stolon supported by a floating and/or swimming system. 
Polypoid zooids of several sorts: pneumatophore, gastrozooids, dactylozooids, and bracts. All of them usually associated with the gonophores in repetitive groups, or cormidia, along the stolon. All polypoid structures without oral tentacles. The part of the stem below the floating system, bearing the cormidia, is the siphosome, usually representing most of animal's length. Floating system composed by pneumatophores and/or nectophores (swimming bells) together forming the nectosome. The complete and fully developed animal is referred as the polygastric stage. Histologically, the polypoid and medusoid zooids resemble the corresponding types of Hydroidomedusae.

Three orders of Siphonophorae may be distinguished on the basis of the presence or absence of either an apical pneumatophore or of nectophores grouped in a nectosome: the Cystonectae possessing only a pneumatophore; the Physonectae possessing both a pneumatophore and a nectosome; the Calycophorae with only a nectosome.

Cnidome. The Siphonophorae have a cnidome of 9 cnidocyst types depending on the suborders: acrophores, anacrophores, desmonemes, stenoteles, homotrichous anisorhizae, atrichous isorhizae, microbasic mastigophores and birhopaloids, 4 of them being exclusive to the group but not common to all species: acrophores, anacrophores (doubtfully recorded for Tiaricodon coeruleus by Wenqiao and $\mathrm{Xu}, \mathrm{1990})$, homotrichous isorhizae and birhopaloids. The cystonects seem to posses only isorhizae and stenoteles; the physonects have a general cnidome formed by acrophores, desmonemes, homotrichous anisorhizae, atrichous isorhizae, microbasic mastigophores, stenoteles and birhophaloides, the latest being exclusively found in the apolemiids Apolemia uvaria and Tottonia contorta; the calycophorans have anacrophores, desmonemes, stenoteles, homotrichous anisorhizae, microbasic mastigophores. The singlet microtubules of the cnidocyst cilium are very numerous, varying from 300 to 400, whereas in the other Hydrozoa the number varies between 8 and 22 .

Remarks: the Siphonophorae can be considered as colonies of cormidia, formed by polypoid structures that are so specialised to be assimilated to the organs of an individual (the colony). They are sometimes considered as an enlarged larval nurse carrier or paedophore not becoming sexually mature but budding off sexual medusoids which may be released along with other stem constituents (Totton 1965). The cnidome suggests affinity with the Anthomedusae since desmonemes, typical of this subclass, are present in some groups; also stenoteles are typical of Anthomedusae but are shared also with some Automedusae. Recent molecular analysis of siphonophore species also support their relationship with Anthomedusae (Collins, 2000, 2002). There is no alternation of benthic and pelagic life; the colonies remain pelagic along all their life-cycle (except the bentho-pelagic Rhodaliidae). Each gonophore has a limited number of eggs ( 1 in the Physonects, 2 to 30 in the Calycophores, see above), but a cormidium can form successive gonophores increasing the number of eggs, and the modular colonies, furthermore, are formed by numerous cormidia. Compared to most Antho-and Leptomedusae, whose benthic colonies are long-lived, can undergo a resting phase and to produce higher numbers of eggs or medusae, the Siphonophorae apparently have a much lower reproductive rate but little is known on this part of its biology.

References: Mackie and Boag (1963); Purcell (1984); Pagès and Gili (1992); Mackie et al, (1987); Kirkpatrick and Pugh (1984); Purcell and Mills (1988); Pugh (1999).

\section{Order CYSTONECTAE Haeckel, 1887}

Siphonophores with a relatively large pneumatophore and without nectosome; pneumatophore with apical pore; cormidia with gastrozooid, tentacle and gonodendron, without bracts; gonodendron with gonopalpons, gonophores and asexual swimming bells.

\section{Key to the families}

1. Pleustonic, pneumatophore horizontal Physaliidae

- Epi- and mesopelagic, pneumatophore oval to rounded Rhizophysidae

Family PhysaliIdae Brandt, 1835

This family is monotypic for Physalia physalis, the Portuguese Man O'War.

Reference: Totton, (1960), Carré and Carré (1995).

\section{Genus Physalia Lamarck, 1801}

Physalids with huge, asymmetric pneumatophore, purplish blue in colour, up to $30 \mathrm{~cm}$ in 
length; top of the pneumatophore formed by an erectile "sail" running diagonally; cormidia attached to one side of the float, tentacles can stretch down many meters.

References: Totton (1960); Pagès and Gili (1992).

Physalia physalis (Linné, 1758)

(Figs. 121B-D)

The only pleustonic siphonophore. Colonies consisting of a large, purplish blue pneumatophore that floats on the sea surface, reaching about $30 \mathrm{~cm}$ in length in the largest specimens. The pneumatophore carries the polyps, which form cormidia at the oral end; its top an erectile sail, the all drifting at the mercy of the winds. Pneumatophore enantiomorphic, two forms, each the mirror image of the other. Each cormidium consisting of a gastrozooid associated with a tentacle and a gonodendron; however, unlike other siphonophores, tentacle separating from the basigaster during the later stages of development. The tentacles may attain several metres in length. Continuous formation of new cormidia. As the cormidia mature, new gastrozooids gradually lose their tentacles and becoming palpons. Small medusoid gonophores developing at the bases of the terminal palpons. Functional gonophores of a given colony are of a single sex only.

Records from Mediterranean: eastern and western Mediterranean, Adriatic.

Known seasonality: 3-6.

Distribution: widely distributed in tropical and subtropical regions in the three great oceans and sporadically found in the Mediterranean.

References: Totton (1965); Daniel (1974); Kirkpatrick and Pugh (1984); Gili (1986), Pagès and Gili (1992); Avian et al, (1995); Pugh (1999).

\section{Family RHIZOPHYSIDAE Brandt, 1835}

Oval-rounded pneumatophore with hypocystic villi at its base.

References: Carré and Carré (1995); Pugh (1999).

Genus Rhizophysa Péron and Lesueur, 1807 = Epibulia Haeckel, 1888

Rhizophysids with no wing-like processes (ptera) in young gastrozooids.

Reference: Purcell (1981a).
Rhizophysa filiformis (Forskål, 1775) (Figs. 121E-F)

Pneumatophore oval, $4.9 \mathrm{~mm}$ high by $4.0 \mathrm{~mm}$ wide. Apical pore surrounded by a dark red circular spot. Pneumacodon, or outerwall, separated from pneumtosaccus, or inner wall, by a large cavity. Pneumatosaccus occupying the upper half of the pneumatophore. Hypocystic villi well developed occupying the lower half. Polyps developing at the base of the pneumatophore. Gastrozooids with three types of tentilla: tricoronuate, the most common; palmate, or dendritic; and in the shape of a bird's beak. Gonotheca shaped like clusters of grapes located halfway between each pair of gastrozoids.

Records from Mediterranean: western Mediterranean.

Known seasonality: 2-9.

Distribution: Uncommon but widely distributed in the three great oceans and the Mediterranean.

References: Biegelow and Sear (1937); Pagès and Gili (1992); Mills et al. (1996); Pugh (1999).

\section{Order PHYSONECTAE Haeckel, 1888}

Siphonophorae with an apical pneumatophore and, beneath it, a series of nectophores, except the Athorybiidae which lack nectophores or with a reduced nectophore. Nectophores arranged in two opposite rows or circular chains forming the nectosomal region around the stem. Most of Physonectae present two budding zones, one under the pneumatophore giving nectophores and the other at the basal end of the nectosome, giving the cormidia that form the siphosome. Cormidia with bracts, with dactylozooids. Without asexual medusoids on the siphosome. When known with siphonula larvae.

Key to families (mostly after Pugh, 1999)

1. Nectophores present 2

- Nectophores absent ........................................... 7

2. Nectophores deeply hollowed axially and with tentacles between them; small delicate bracts..... Apolemiidae

- Nectophores not hollowed axially, nectosomal tentacles absent............................................. 3

3. Nectosome and siphosome elongate, with a narrow stem 4

- Nectosome and/or siphosome contracted or reduced 7

4. Nectophores bilaterally symmetrical, arranged 
biserially 5

- Nectophores dorso-ventrally flattened, usually asymmetric in shape, arranged in spiral....

Forskaliidae

5. Nectophores with straight dorsal radial canal.. 6

- Nectophores with sinuous dorsal radial canal..... Pyrostephidae*

6. Tentilla uncoiled; cnidoband hypertrophied; no cnidocyst on terminal process .......... Erennidae*

- Tentilla coiled; cnidoband normal . Agalmatidae

7. Nectosome reduced or absent; siphosome reduced to solid body or corm ...... Athorybiidae

- Nectosome normal........................................... 8

8. Nectosome elongated; siphosome shortened into laterally expanded spiral sac bearing enlarged palpons; bracts absent................ Physophoridae

- Nectosome and siphosome contracted to form a solid corm; with a pneumatophore and an aurophore Rhodaliidae*

*not present in Mediterranean Sea.

\section{Family Agalmatidae Brandt, 1835}

Physonect siphonophores with a biserial arrangement of nectophores in the nectosome and a long usually contractile siphosome. This is rather a catch all family. For many agalmatids four types of cnidocysts are present in the tentillum: homotrichous anisorhizas; either microbasic mastigophores or stenoteles; desmonemes and acrophores.

Remark: this is rather a catch all family.

References: Carré and Carré (1995); Pugh (1999).

Genus Agalma Eschscholtz, 1825

Agalmatids with tricornuate tentilla consisting of a central swelling and two contractile lateral filaments.

References: Pagès and Gili (1992); Mills et al. (1996).

Agalma clausi Bedot, 1888

(Figs. 122A-C)

Siphosomal stem rigid. Leaf-like bracts with deep red pigment spots on the surface, particularly the younger ones. Tricornuate tentilla that can be completely enclosed inside the involucrum.

Records from Mediterranean: Strait of Messina, Alborán Sea.

Known seasonality: 4.

Distribution: Mediterranean and tropical Atlantic (Mills et al. 1996).
References: Bedot (1888); Mills et al. (1996).

Agalma elegans (Sars, 1846) Fewkes, 1880

(Figs. 122D-F)

Pneumatophore elongate, small, $1.1 \mathrm{~mm}$ high, apex red. Two rows of alternating nectophores attached to the stem. Nectophores V-shaped, with two prominent lateral wings. An apico-lateral ridge running from the apex of the lateral wing to the midpoint of the nectophore, an infero-lateral ridge running along the outer margin, and a latero-ventral ridge located on the central portion of the nectophore. Nectosac T-shaped. Pedicular canal short. Siphosomal stem contractile. Bracts triangular, elongate, foliaceous in appearance, dorsal surface convex, $9 \mathrm{~mm}$ long, with a central bracteal canal, extending to about four-fifths the length of the bract, occasionally continuing as a very fine canal to the distal end. Tentilla tricornuate.

Records from Mediterranean: eastern and western Mediterranean.

Known seasonality: 12, 2 to 6.

Distribution: widely distributed in tropical and subtropical regions in the three great oceans and the Mediterranean (Alvariño, 1971).

References: Totton (1956, 1965); Palma (1973); Kirkpatrick and Pugh (1984); Pagès and Gili (1992); Lakkis and Zeidane (1995); Pugh (1999).

Agalma okeni Eschscholtz, 1825

(Figs. 122G-I)

Pneumatophore elongate, $7.0 \mathrm{~mm}$ high, apex pigmented. Nectophores similar to those of A. elegans, but nectosac Y-shaped. Bracts firm, up to $5.0 \mathrm{~mm}$ long, prismatic, triangular, gradually thickening towards the distal portion, which has three vertical ridges delimiting four distal facets. Bracteal canal filiform, central, not reaching the distal facets.

Records from Mediterranean: eastern and westen Mediterranean.

Known seasonality: 5 and 6.

Distribution: widely distributed in tropical and subtropical regions in all seas and in the Mediterranean (Alvariño, 1971).

References: Totton (1965); Gili (1986); Pagès and Gili (1992); Lakkis and Zeidane (1995); Pugh (1999).

Genus Cordagalma Totton, 1932

Agalmatids with unicornuate tentilla; with heart- 
shaped nectophores devoid of lateral or vertical lateral ridges.

References: Pagès and Gili (1992); Margulis (1993); Carré and Carré (1995); Mills et al. (1996); Pugh (1999).

Cordagalma ordinata (Haeckel, 1888)

= Cordalgama cordiforme Totton, 1932

(Figs. 123A-B)

Colonies extremely fragile, reaching up to $30 \mathrm{~cm}$ in length. Nectosome occupying a third of colony length. Pneumatophore fusiform, apex lightly pigmented. Two opposing rows of alternating nectophores. Adult colonies having up to 40 heartshaped nectophores with two rounded latero-anterior lobes and an acute centro-inferior lobe, $2.0 \mathrm{~mm}$ high by $1.4 \mathrm{~mm}$ wide. Lateral radial canals, ascending from the ostial canal, join the dorsal canal at the apex without describing a sigmoidal curve. Bracts shaped like a truncated pyramid, with four lateral facets. Very distinctive tentilla with a larval structure and simplified cnidome.

Records from Mediterranean: western Mediterranean.

Known seasonality: 4, 5.

Distribution: uncommon but widely distributed in warm waters throughout the world (Carré C., 1968b; Carré D., 1973; Gili, 1986), Great Barrier Reef (Totton, 1932), Chile (Palma, 1977). Epipelagic species also present at depths down to $726 \mathrm{~m}$ depth in the Alborán Sea (Mills et al., 1996).

References: Totton (1932, 1965); Carré C. (1968b); Carré D. (1973); Palma (1973, 1977); Pagès and Gili (1992); Mills et al. (1996); Pugh (1999).

Genus Halistemma Huxley, 1859

Agalmatids whose tentilla have a single terminal filament (unicornuate) and only a vestigial involucrum. Characteristic sigmoidal courses for radial canals on the nectosac of the nectophore that begins with a downward sweep.

References: Pugh and Youngbluth (1988); Pagès and Gili (1992); Pugh (1999).

Halistemma rubrum (Vogt, 1852)

(Figs. 123C-G)

Pneumatophore oval, $5.0 \mathrm{~mm}$ high by $5.3 \mathrm{~mm}$ wide. Up to 46 nectophores per colony in two rows. Nectophore shape variable but squarish in appearance, up to $5.2 \mathrm{~mm}$ in height, $6.6 \mathrm{~mm}$ in width, and $4.0 \mathrm{~mm}$ in dorso-ventral length. Two prominent lateral wings and extensive central thrust block containing the pedicular canal, more conspicuous in older nectophores. Nectosac large, T-shaped. Characteristic pattern of lateral radial canals describing three curves along the lateral surface of the nectosac; middle curve widest. Apicolateral ridges not always reaching the level of the ostium. Bracts thin and leaf-shaped, variable in shape but usually with two lateral processes and a larger central one.

Records from Mediterranean: eastern and western Mediterranean.

Known seasonality: 2-6, 10,12.

Distribution: widely distributed in the three great oceans and in the Mediterranean (Alvariño, 1971).

References: Totton (1965); Alvariño (1971) as Stephanomia rubra; Carré D. (1971); Kirkpatrick and Pugh (1984); Avian et al. (1995); Lakkis and Zeidane (1995); Pugh (1999).

\section{Genus Lychnagalma Haeckel 1888}

Agalmatids with nectophores arranged biserially; apico-lateral ridges prominent and divided close to the base; lateral ridges extending out towards the top of the nectophore before reaching the apico-lateral ridges. Characteristic large tentilla consisted of a stalk, a tightly coiled cnidoband heavily armed with cnidocysts, and a terminal vesicle from which arise eight regularly spaced filaments (Pugh and Harbison, 1986).

\section{Lychnagalma utricularia (Claus, 1879)}

(Figs. 123, 124A-D)

Diagnosis: like the genus

Records from Mediterranean: Strait of Messina, Alborán Sea.

Known seasonality: 4.

Distribution: Mediterranean and Atlantic (Bahamas)

References: Pugh and Harbison (1986); Mills et al. (1996).

\section{Genus Marrus Totton, 1954}

Agalmatids with nectophores truncated apically, nectosacs with straight, unlooped radial canals; with unicornuate tentilla.

Reference: Andersen (1981). 
Marrus orthocanna Totton, 1954

(Figs. 124E-G)

Nectophores longer than broad, up to $15 \mathrm{~mm}$ in length, with no distinct lateral ridges. The apical ridges divide close to the ostium and delimit two narrow, triangular distal facets. Thrust block welldeveloped and longer than the rounded lateral processes. Nectosac triangular. Bract roughly triangular with a flimsy, tacky appearance.

Records from Mediterranean: western Mediterranean.

Known seasonality: 6,12.

Distribution: North Atlantic and Mediterranean.

References: Totton (1965); Andersen (1981); Kirkpatrick and Pugh (1984); Gili (1986).

Genus Nanomia A. Agassiz, 1865

Agalmatids whose unicornuate tentillum has a basal involucrum. Characteristic arrangement of the gonodendra in that male and female ones, attached at the base of palpons, alternate on either side.

Reference: Pagès and Gili (1992).

Nanomia bijuga (delle Chiaje, 1841)

(Figs. 125A-D)

Pneumatophore elongate, very small, $1.8 \mathrm{~mm}$ high, apex pigmented. Nectophores quadrangular, flattened in the abaxial-adaxial plane, L-shaped in lateral view, up to $2.3 \mathrm{~mm}$ high. Lateral wings twisting towards the adaxial or ventral surface of the colony. Nectophore with a well-developed ostial mouth, ostial velum broad. Looped lateral radial canals on extensive nectosac. Pedicular canal long. Bracts leaf-like, variable in morphology, often with 3 processes at the distal end, occasionally with a cross ridge.

Records from Mediterranean: eastern and western Mediterranean.

Known seasonality: 4-11.

Distribution: widely distributed in warm and temperate regions of the three great oceans, and the Mediterranean (Alvariño, 1971).

References: Totton (1965); Carré D. (1969b); Alvariño (1971) as Stephanomia bijuga; Rottini (1971); Palma (1986); Gili (1986); Pagès and Gili (1992); Avian et al. (1995); Lakkis and Zeidane (1995); Pugh (1999).

Family ApOLEMiIDAE Huxley, 1859

Uniquely, amongst the physonects, there is a ten- tacle or clump of tentacles between each pair of nectophores. Nectophore deeply hollowed axially, forming a pair of large axial wings. Nectosac extensive, lateral radial canals follow an S-shape course of varying complexity. Bracts small and flimsy. This family requires a through review.

References: Carré and Carré (1995); Pugh (1999).

Genus Apolemia Eschscholtz, 1829

Apolemiids with 1-6 tentacles between each pair of nectophores.

Reference: Carré and Carré (1995).

Apolemia uvaria (Lesueur,? 1811)

(Figs. 126A-D)

Colonies reaching several metres in length. Pneumatophore bulb-shaped, widening near the apex. Nectosome with up to twelve nectophores arranged in two parallel rows along the stem. Largest nectophore $3.7 \mathrm{~mm}$ high, $3.4 \mathrm{~mm}$ wide and $4.2 \mathrm{~mm}$ deep. Nectophore consisting of two wings looking like those of a butterfly, with a deep ventral thrust block. Nectosac large. Lateral radial canals S-shaped with short branches on the upper loop. Groups of five to six nectosomal tentacles issuing from the base of the nectophores near the pedicular canal, at the base of muscular lamellae. Siphosome up to several metres in length, composed of several cormidia. Each cormidium consists of a gastrozooid and about fifty palpons, both with thin filiform tentacles of a single type issuing from their bases. Palpons long and delicate. Bracts, like the nectophores, covered by opaque spots bearing cnidocysts on the outer surface.

Records from Mediterranean: western Mediterranean.

Known seasonality: 8-4.

Distribution: Seldom caught epiplanktonic species. Cited in the Mediterranean, in the vicinity of Naples, Messina, Monaco, and Villefranche-surMer (Alvariño, 1971). In the Atlantic Ocean cited off the British Isles (Kirkpatrick and Pugh, 1984) and Norwegian fjords (Båmstedt et al., 1998).

References: Totton (1965); Carré and Carré (1973, 1995), Alvariño (1971); Kirkpatrick and Pugh (1984); Pagès and Gili (1992); Båmstedt et al. (1998).

\section{Family ATHORYBIIDAe Huxley, 1859}

Physonects with relatively large pneumatophore. Nectosome greatly reduced or absent. Siphosome 
reduced to a dense corm on which the cormidia are arranged in a spiral.

References: Biggs and Harbison (1978); Carré and Carré (1995).

\section{Genus Athorybia Eschscholtz, 1829}

Athorybiids without nectosome; pneumatophore large; bracts flimsy with inconspicuous rows of cnidocysts.

References: Totton (1954); Pagès (2002).

Athorybia rosacea (Forskål, 1775) (Figs. 126E-F)

Pneumatophore large, red pigmented, with cormidia arranged in spiral around it. No nectosome. Elongate, flimsy bracts with 7 inconspicuous rows of cnidocysts running down the convex dorsal side.

Records from Mediterranean: western Mediterranean. Known seasonality: 9-4.

Distribution: Atlantic and Mediterranean.

References: Pugh (1999); Pagès (2002).

Family FORSKALIIDAE Haeckel, 1888

Physonects with cylindrical or cone-shape nectosome, whose numerous nectophores have a multiserial, spiral arrangement. Nectophores flattened dorso-ventrally, often asymmetrical in shape. Nectosac restricted to basal half, with straight radial canals. Siphosome also coiled, with gastrozooids borne on long stalks. Gastrozooids borne on long peduncles that are covered in bracts. Bracts usually gelatinous and of variable shape of four types: stem, bolster and two kinds of knee-shape. Several gonopalpons, with palpacles, present on gonodendra, which bear both male and female gonophores.

References: Carré and Carré (1995); Pugh (1999), Pugh (2003).

Genus Forskalia Kölliker, 1853

With the characters of the family.

Reference: Pagès and Gili (1992); Pugh (1999); Pugh (2003)

Forskalia asymmetrica Pugh 2003 (Figs. 126G-H)

Large nectophores, with small rounded left axial wing, and a small central apical incision. No lateral incisions or pockets. No rete mirabile. Adult bracts of four types. Gonodendra bearing long gonopalpons, with palpacles; with female gonophores attached close to their bases. Male gonophores attached at end of a stalk.

Records from Mediterranean: off Villefranchesur-Mer, off Messina (Sicily) and in the Alborán Sea.

Known seasonality: 4.

Distribution: Mediterranean and Atlantic (the Bahamas; off Woods Hole, USA).

Reference: Pugh (2003).

Forskalia contorta (Milne Edwards 1841) $=$ F. leuckarti Bedot 1893

(Fig. 127A-F)

Large nectophores with large left axial wing, without central apical incision. Longitudinal flap on upper side in apical half. Lateral basal pockets extend in flaps onto the lower surface. Nectosac with pronounced lateral wings, with dorsal and ventral canals usually not arising from pedicular canal. No pigment spots on ostium. Rete mirabile present or absent in pedicular canal. Three types of adult bract; with only one knee-shaped type, whose bracteal canal bends through a right-angle and has a short side branch. Female gonophores, in two bunches, borne on long stalk, extending beyond male ones.

Records from Mediterranean: western Mediterranean, Adriatic.

Known seasonality: 9-6.

Distribution: rare, to date only caught in the Mediterranean (Totton, 1965) and observed from submersibles at depths between 150 and $600 \mathrm{~m}$ in the Bahamas (Youngbluth, 1984).

References: Totton (1965); Youngbluth (1984); Pagès and Gili (1992); Avian et al. (1995); Pugh (1999), Pugh (2003).

Forskalia edwardsi Kölliker, 1853 (Figs. 127G-H)

Nectophores with small left axial wing, and no central apical incision; with apical thickened mesoglea. Small yellow pigment spot on ostium where dorsal radial canal joins ring canal. No rete mirabile. Four types of adult bract: knee-shape ones without side branch to bracteal canal. Gonodendra with female gonophores not having elongated base. Palpacle of gonopalpon has appearance of a string of beads. 
Records from Mediterranean: off Villefranchesur-Mer.

Known seasonality: in winter.

Distribution: western Mediterranean, Red Sea, Atlantic and Pacific.

References: Totton (1965); Youngbluth (1984); Pagès and Gili (1992); Pugh (1999), Pugh (2003).

\section{Forskalia formosa Keferstein and Ehlers 1861} (Figs. 127I-K)

Nectophores with large, pointed left axial wing, and shallow but broad and rounded right wing. Small apical incision between them. Small lateral, but no baso-lateral pockets. No rete mirabile. Four types of adult bract; knee-shaped ones without side branch to canal. Gonodendra with female gonophores, in two bunches, attached close to bases of gonopalpons; male gonophores borne on long stalk.

Records from Mediterranean: off Villefranchesur-Mer, off Messina (Sicily) and Alborán Sea.

Known seasonality: in winter.

Distribution: Mediterranean and Atlantic (The Bahamas).

References: Avian et al. (1995); Mills et al. (1996), Pugh (2003).

\section{Family PHYSOPHORIDAE Eschscholtz, 1829}

Physonects with a flimsy, apparently ridgeless nectophores each with an extensive nectosac, which has characteristic, looped lateral radial canals. Both dorsal and ventral canals are sinuous. Siphosome compact sac on which the simple, bractless cormidia are borne in spiral. Each cormidium has a single, greatly enlarged palpon. Monotypic family for the species Physophora hydrostatica.

Reference: Carré and Carré (1995).

\section{Genus Physophora Forskål, 1775}

With the characters of the family.

Reference: Pagès and Gili (1992).

\section{Physophora hydrostatica Forskål, 1775} (Figs. 128A-C)

Pneumatophore elongate, $4.5 \mathrm{~mm}$ high, $1.1 \mathrm{~mm}$ wide, with a pore in the apical reddish region. Nectosome consisting of up to 12 nectophores in two alternate rows. Nectophore flimsy, devoid of conspicuous ridges and up to $20 \mathrm{~mm}$ high. Nectosac Y- shaped. Upper half of radial canals describes a highly characteristic sigmoidal curve. Pedicular canal prominent. Palpons characteristic by their large size and banana-shape, with long and fine palpacles. Palpons covering and protecting the rest of the elements making up the bag-like siphosome and bearing clusters of cnidocysts on their distal ends.

Records from Mediterranean: western Mediterranean

Known seasonality: 9-4.

Distribution: widely distributed in tropical and subtropical regions in the three great oceans and in the Mediterranean (Alvariño, 1971).

References: Totton (1965); Alvariño (1971); Kirkpatrick and Pugh (1984); Gili (1986); Pagès and Gili (1992); Pugh (1999).

\section{Order CALYCOPHORAE Leuckart, 1854}

Highly polymorphic Siphonophorae without pneumatophore, with a reduced nectosome typically formed by one or two but sometimes more nectophores. Usually with a single bract per cormidia (except the Hippopodiidae without bracts), without dactylozooids (except in Stephanophyes), in some cases with asexual medusoid structures on siphosome. Generally the cormidial units are detached successively from the stem and become eudoxid or sexual stage. Usually a calyconula larvae.

Key to the families (after Pugh, 1999)

1. Nectophores dorso-ventrally flattened 2

- Nectophores not dorso-ventrally flattened, bracts present .......................................................... 3

2. .........Up to $15+$ similar, closely applied, dorsoventrally fattened nectophores bearing protuberances or spines; large but shallow nectosac; bracts absent ............... Hippopodiidae

- Small, flattened nectophores, with vestigial nectosac and reduced somatocyst.

Prayidae, subfamily Amphicaryoninae

3. Nectophores and bracts rounded, smooth-walled, with thick mesoglea. 4

- Nectophores and bracts pointed, toothed or of irregular shape ............................................... 6

4. Usually 2 nectophores ................................... 5

- Single, fragile, larval nectophore, with a simple somatocyst and narrow hydroecium; small, fragile bract with a single canal Sphaeronectidae

5. Two nectophores of approximately equal size, forming an apposed pair; somatocyst simple or 
branched; bracts with 5 or 6 branches to the canal system Prayidae, subfamily Prayinae

- Two nectophores of unequal size, with reduced somatocysts; nectosac of smaller nectophore usually reduced or obsolent; bracts with two branches to canal system Prayidae, subfamily Amphicaryoninae*

6. Two morphologically different nectophores; one (anterior) superimposed over the other (posterior) 8

- With usually a single nectophore 7

7. Single, usually large nectophore bearing simple or toothed ridges; somatocyst usually branched; large bract without neck shield and extensively branched canal system. ......... Prayidae, subfamily Nectopyramidinae*

- Single, usually small, apically pointed nectophore, with simple caecal somatocyst; bract conical or angular.... 9

8. Posterior nectophore with a somatocyst; anterior nectophore with extensive opening of hydroecium onto ventral surface; small bract with phyllocyst and 2 canals extending into neck shield. Clausophyidae

- Posterior nectophore without somatocyst; hydroecium of anterior nectophore usually opens basally; bracts conical or angular, with phyllocyst and, at most, one canal .... 9

9. Conical stream-lined anterior nectophore, usually with shallow hydroecium; posterior nectophore, when present, usually apically truncated and of similar size or smaller than anterior one; conical bracts Diphyidae

- Anterior nectophore angular, with inflated somatocyst and deep hydroecium; posterior nectophore, when present, larger than anterior one; rigid angular bracts Abylidae

*not present in the Mediterranean Sea.

\section{Family ABYLIDAE Agassiz, 1862}

Calycophorans with rigid, angular nectophores, the posterior one, without a somatocyst, usually being much larger, and bearing serrated ridges and teeth. In all but one species the somatocyst of the anterior nectophore has curved over to occupy a ventral position. The hydroecium of the anterior nectophore is an enclosed tube opening basally. During development a temporary larval bract is formed before the larval nectophore. The latter is retained in the polygastric stage as the anterior nectophore.
References: Sears (1953); Carré and Carré (1995); Pugh (1999).

Genus Abyla Quoy and Gaimard, 1827

Abylid with 10 or 11 facets in anterior nectophores. The apical facet is divided by a transverse ridge, and many ridges are serrated, particularly basally. Dorsal nectosac and median hydroecium are long tubes extending almost to apex of nectophore. The large oval somatocyst lies ventrally. Posterior nectophore with long, tapering apical apophysis, has only 4 ridges. The ventral ridges define the hydroecial wings and are heavily serrated basally. The left hydroecial wing bears a toothed comb or flap. Five, usually serrated, ostial teeth. Prismatic bracts with 6 facets, the dorsal one being rectangular. Very large phyllocyts, with 2 canals running down toward the ventro-lateral corners of the apical facet. The bracts cannot, at present, be identified specifically.

Reference: Pugh (1999).

\section{Abyla haeckeli Lens and van Riemsdijk, 1908} (Figs. 128D-F)

Anterior nectophore as wide as long, without wing-like processes. Transverse ridge separates ventral facet from apico-ventral one. Posterior nectophore with up to 5 teeth on comb. Lateral ostial teeth closer to dorsal tooth than ventral ones.

Reference: Pugh (1999).

$$
\text { Genus Abylopsis Chun, } 1888
$$

Abylid whose anterior nectophore has a pentagonal dorsal facet without a median ridge. Seven-facet anterior nectophore, but without an apical facet, and pentagonal dorsal and ventral facets. The somatocyst has an apical diverticulum. Posterior nectophore has prominent basal teeth and with 5 ridges and a short curved apical apophysis. The left lateral ridge bifurcates close to the apex. Flaps on both wings of hydroecium. Bracts with 7 facets. Phyllocyst with swollen apico-lateral branches and apical diverticulum, while distally is a narrow tube.

References: Pagès and Gili (1992); Pugh (1999).

Abylopsis eschscholtzi (Huxley, 1859) (Figs. 128G-K)

Dorsal and ventral facets of anterior nectophore almost pentagonal, of nearly equal size, with strong- 
ly serrated ridges. Lateral radial canals forming a right angle from the pedicular canal and directed towards the ostial canal, without ascending loop. Posterior nectophore less than twice as long as wide, with relatively large apical apophysis. Each hydroecial wing bearing a secondary wing whose inner margins is fused. Between four and eight teeth on the curve on the left wing, three or four on the right wing. Bracts cuboidal, their dorsal facet forms a regular pentagon, their apico-lateral facets rectangular.

Records from Mediterranean: eastern and western Mediterranean.

Known seasonality: 4 to 7 .

Distribution: common and abundant in the warm and temperate regions in the three great oceans, less common in the Mediterranean (Alvariño, 1971). Epipelagic distribution (Pugh, 1974).

References: Totton (1965); Alvariño (1971); Rottini (1971); Daniel (1974); Pugh (1974, 1999); Gili (1986); Pagès and Gili (1992); Avian et al. (1995); Lakkis and Zeidane (1995).

Abylopsis tetragona (Otto, 1823) (Figs. 129A-E)

Polygastric stage: anterior nectophore polyhedral with seven faces. Ventral and dorsal surfaces pentagonal, the latter higher, up to $10 \mathrm{~mm}$ in height. Ridges weekly serrated. Hydroecium deep, reaching nearly the midpoint of the nectophore. Radial canals of nectosac originating at the junction with the pedicular canal and rising towards the upper end, forming an ascending loop, and then descending to the circular canal. Somatocyst globular, with an apical diverticulum at the level of the nectosac. Posterior nectophore up to $40 \mathrm{~mm}$ in length, rectangular, three times as long as wide, with a prominent apophysis. Four radial canals in the upper half, five in the lower one because the left ventral canal has a blind termination halfway up and a little above the origin of a new canal forming a right angle and directed towards the ostial canal. A "rete" at the base of the right ventral canal, from which a short, blind ventral canal issues towards the left. Upper half of the right wing of hydroecium bearing a comb-like structure with about nine teeth. Lower portion bearing five basal teeth varying in size, right ventral tooth largest. Bract up to $7.0 \mathrm{~mm}$ high, elongated, pentagon with apico-lateral facets trapezoidal. Upper half of phyllocyst bearing two thick, lateral processes above the hydroecium and extending towards the apical surface in the form of a narrow diverticulum.
Gonophore in the shape of a rectangular prism 4.6 $\mathrm{mm}$ high with four distinct ridges ending in four acute basal cusps, the ventral cusps somewhat larger than the dorsal ones.

Records from Mediterranean: eastern and western Mediterranean.

Known seasonality: present all the year.

Distribution: quite common in the temperate regions of the three main oceans, and in the Mediterranean (Alvariño, 1971). Epipelagic (Pugh, 1974), but also present in the mesopelagic zone (Gili et al., 1987a).

References: Totton (1965); Carré C. (1967b); Alvariño (1971); Palma (1973); Pugh (1974, 1999); Bone and Trueman (1982); Gili (1986); Gili et. al. (1987a); Pagès and Gili (1992), Avian et al. (1995); Lakkis and Zeidane (1995); Buecher (1999); Gamulin and Krisnic (2000).

\section{Genus Bassia Agassiz, 1862}

Abylines whose anterior nectophore has not an apical diverticulum to the somatocyst, and with the hydroecium not extending below the basal facet. Somatocyst large and globular. Posterior nectophore with 4 ridges ending in short basal teeth. Bract with median apical ridge has a quadrilateral dorsal facet. Phyllocyst is a long tube, swollen apically, without apico-lateral branches. Gonophore with four longitudinal ridges which end basally in minute teeth.

Bassia bassensis (Quoy and Gaimard, (1833) 1834) (Figs. 129F-I)

Polygastric stage: ridges on specimens fixed in formalin taking on a bluish-white hue (same applies to eudoxids). Anterior nectophore a seven-sided polyhedral with pentagonal dorsal and ventral surfaces. Two quadrangular apico-lateral surfaces joined by a central apical ridge. Two large baso-lateral surfaces separated from the apico-lateral surfaces by a horizontal ridge. Hydroecium deep, reaching the midpoint of the nectophore, with a large quadrangular opening. Nectosac relatively small, with lateral radial canals running from the ostial canal to the junction with the pedicular canal, with only a slight curve instead of an arc. Apices of hydroecium and nectosac more or less at the same level. Somatocyst large, globular, devoid of diverticulum or apical projection. Posterior nectophore higher than the anterior nectophore, up to 15.0 $\mathrm{mm}$ high, consisting of four ridges, not as thin as in the anterior nectophore. Bases of ventral ridges compris- 
ing two prominent teeth, right tooth larger than left tooth. Eudoxid: bract in the form of a seven-sided polyhedral with well-developed ridges. Dorsal surface rhomboidal, ventral surface in the shape of a fivepointed star. Apico-lateral surfaces quadrangular. Baso-ventral margins of lateral surfaces describing a curve ending in a medial tooth. Hydroecium large, deep, hook-shaped, reaching to the midpoint of the bract. Phyllocyst is a long tube long, without lateral processes. Gonophore with four lateral ridges that end basally in minute teeth.

Records from Mediterranean: eastern and western Mediterranean.

Known seasonality: 3, 12.

Distribution: Present in the temperate regions of the three great oceans and in the Mediterranean (Alvariño, 1971).

References: Totton (1965); Palma (1973); Daniel (1974); Kirkpatrick and Pugh (1984); Gili (1986); Pagès and Gili (1992); Carré and Carré (1995); Lakkis and Zeidane (1995); Pagès et al. (2001).

\section{Genus Ceratocymba Chun, 1888}

Abylid with characteristically shaped bract, called a cymba. Anterior nectophore with 7 facets. Apical facet not divided by a transverse ridge. Posterior nectophore long and narrow, without wing-like expansions. Short dorsal ridge ends on the dorsal tooth. Bracts with a median dorsal ridge. Left lateral facet divided by another ridge. Bracts roughly triangular with a concave apical facet and prominent lateral horns. Phyllocyst with 2 thin ventro-lateral branches. Its distal end bends dorsally to form a blind sac.

References: Pagès and Gili (1992); Pugh (1999).

Ceratocymba sagittata (Quoy and Gaimard, 1827) (Figs. 130A-C)

Polygastric stage: anterior nectophore pyramidal, elongate, up to $40.0 \mathrm{~mm}$ high. Large, tapered apical process called a pyramidal process. Four ridges converging at the apex. Characteristic apical surface of the family Abylinae no longer present. Hydroecium bell-shaped, with a large opening, in the centre of the base of the nectophore. Nectosac narrow, high, reaching almost to the apex of the nectophore. Lateral radial canals ascending over a short segment of the nectosac from the pedicular canal, describing a very tight arc and then descending towards the ostial canal. Somatocyst oval, positioned between the dorsal surface of the nectophore and the dorsal surface of the hydroecium; not extending past the apex of the hydroecium. Posterior nectophore elongated, oblong, up to $50.0 \mathrm{~mm}$ high, pointed apically. Left ventral wing ending in a characteristic prominent, elongate, serrated basal tooth. Comb on right ventral wing bearing six teeth; inferior margins of both wings dentate. Eudoxid: bract roughly triangular, with two supra-lateral horns and a dorsal ridge ending in a point basally. Up to $20.0 \mathrm{~mm}$ high. Apical surface triangular, concave. Characterized by a right lateral ridge, originating at the lower margin, stopping before it reaches the apico-dorsal ridge. Phyllocyst cylindrical, with two filiform lateral projections and a basal tip recurved upwards. Gonophore with basal teeth varying in size. A relatively short, inconspicuous hook issuing from one of the ventral ridges, curving towards the base of the hydroecium. Teeth located above the hook on the ventral margin of the opposite wing. A small dorsal tooth. Lateral ridge near the bracteal wall deeper than the opposing ridge at the apex.

Records from Mediterranean: Strait of Gibraltar. Seasonality: ?

Distribution: widely distributed in the Atlantic Ocean, where its range is very broad. Also present in temperate regions in other seas and in the Mediterranean (Alvariño, 1971).

References: Bigelow and Sears (1937); Totton (1965); Casanova (1980); Alvariño (1981); Kirkpatrick and Pugh (1984); Pagès and Gili (1992); Pugh (1999).

Genus Enneagonum Quoy and Gaimard, 1827

Abylids where the large, pyramidal anterior nectophore is the only developed. The conical somatocyst is situated above the hydroecium, and extends to a greater height than the nectosac. The bract is cuboidal, with slightly concave facets. Swollen somatocyst with 2 lateral and apical processes.

Reference: Pagès and Gili (1992).

Enneagonum hyalinum Quoy and Gaimard, 1827 (Figs. 130D-F)

Polygastric stage developing only a single nectophore. Nectophore pyramidal, up to $15.0 \mathrm{~mm}$ wide. All surfaces homologous to those in other Abylopsinae, except that in E. hyalinum, there is a median ridge subdividing what is equivalent to the dorsal surface in other Abylopsinae. The two dorsal surfaces and the two apico-lateral surfaces visible when viewed from 
the apex. A triangular basal surface beneath the dorsal surfaces, the two baso-lateral surfaces, and the ventral surface all visible when viewed basally. Ridges and basal margins slightly dentate. Somatocyst carrotshaped, consisting of two thickened lateral processes and an apical diverticulum, lacking a descending dorsal segment, differentiating it from the somatocysts of the rest of the members of the family Abylidae. Arc followed by the lateral radial canal including a blind diverticulum. Eudoxid: bract cuboidal, $4.0 \mathrm{~mm}$ high. Five surfaces: apical, dorsal, ventral, and two laterals. No baso-lateral surfaces, the entire space being occupied by the large hydroecial opening. Swollen phyllocyst with 2 lateral and apical processes. Gonophore with a well-developed apophysis occupying nearly a third of the gonophore.

Records from Mediterranean: eastern and western Mediterranean.

Known seasonality: 3.

Distribution: common in warm and temperate regions in the three great oceans, and in the Mediterranean (Alvariño, 1971). Epipelagic but also abundant in the mesopelagic zone down to a depth of 1000 m (Pugh (1974).

References: Bigelow and Sears (1937); Totton (1965); Daniel (1974); Pugh (1974, 1999); Kirkpatrick and Pugh (1984); Gili (1986); Pagès and Gili (1992); Lakkis and Zeidane (1995).

\section{Family Clausophyidae Totton, 1965}

Both anterior and posterior nectophores possess a somatocyst: The phyllocyst of the eudoxid bract when known has two fine branch canals that run down into the neck shield.

\section{Genus Clausophyes Lens and Riemsdijk, 1908}

Nectophores rounded, smooth, unridged, laterally flattened. Anterior nectophore usually smaller than posterior one, with deep hydroecium in basal half and with a long, thin somatocyst which has an elongated swelling towards its apex. Lateral canal of both nectophores are looped.

References: Pugh (1995, 1999).

\section{Clausophyes ovata (Keferstein and Ehlers 1860)} (Figs. 130G-I)

Polygastric stage: anterior nectophore up to 20 $\mathrm{mm}$ in height, roughly triangular but rounded at its base. The deep hydroecium reaches to about the height of the nectophore and is open at the ostial level. Posterior nectophore up to $30 \mathrm{~mm}$ in height, with a large notched mouth. The hydroecium extends the length of the nectophore and is bounded by large lateral wings. The somatocyst is long and narrow.

Eudoxid: bract conical, up to $8 \mathrm{~mm}$ in height, with a rounded apex and an extensive neck-shield. The phyllocyst, slightly swollen basally reaches the apex. The gonophore is undescribed.

Records from Mediterranean: off Messina (Sicily), Adriatic, western Mediterranean.

Known seasonality: present all the year.

Distribution: Atlantic, Pacific, Mediterranean

References: Keferstein and Ehlers (1861, as Diphyes ovata), Kirkpatrick and Pugh (1984); Patriti (1969) as Clausophyes massiliana, Gamulin and Krisnic (2000).

Family DIPHYIDAE Quoy and Gaimard, 1827

Calycophorae with polygastric stage with one or two dissimilar streamlined definitive nectophores arranged serially. Anterior nectophore with somatocyst, posterior not; hydroecium generally reduced in anterior nectophore; the nectosac occupies most of the nectophore. (1999)

References: Carré and Carré (1995), Pugh

Genus Chelophyes Totton, 1932

Diphyids with rigid nectophores; anterior one with 5 ridges, dorsal one extends only a short distance up from the ostium. Claw-shaped hydroecium. Posterior nectophore apically pointed, mouth-Fig. divided with two strong asymmetric teeth. Bracts with conical eudoxids, small rounded neck-shield, hydroecium cylindrical and long that almost stretches the apex.

References: Pagès and Gili (1992); Pugh (1999).

Chelophyes appendiculata (Eschscholtz, 1829) (Figs. 130J-K, 131A-C)

Polygastric stage: Anterior nectophore of firm consistency. Up to $12.0 \mathrm{~mm}$ in height by $3.6 \mathrm{~mm}$ in dorso-ventral width. Only three ridges, the two ventral ridges and the right lateral ridge (sensu Bigelow) converging at the apex. Left lateral ridge not reaching the apex and only a short section of the dorsal 
ridge visible above the ostium. Hydroecium hornshaped, directed towards the ventral surface and extending to approximately one sixth of the nectophoral height. Basal lamella divided into two square wings with sharp outer ends; basal lamella margin convex. Fusiform, long somatocyst that arises at the apex of the hydroecium, reaching twothirds to three-quarters of nectosac height. Posterior nectophore $8.2 \mathrm{~mm}$ in height by $2.0 \mathrm{~mm}$ in dorsoventral width, apex pointed, same consistency as that of the anterior nectophore slightly asymmetrical. Four ridges each ending basally in a conspicuous tooth, left tooth longer than right one. Ventral ridges bearing a tooth at the level of the ostium. Basal lamella entire, concave. Hydroecial canal long.

Eudoxid: bract roughly conical, hood-shaped, with a short, rounded neck-shield. Hydroecium deep. Phyllocyst cylindrical elongated reaching nearly to the apex. Gonophore composed of four longitudinal ridges. Peduncle long, penetrating into the bracteal cavity, rigidly attached to the bracteal margin.

Records from Mediterranean: eastern and western Mediterranean.

Known seasonality: 1-12.

Distribution: widely distributed in warm and temperate regions in the three great oceans and the Mediterranean (Alvariño, 1971); one of the most common and abundant siphonophores in all seas. Epipelagic species also dwelling in the mesopelagic zone (Pugh, 1974; Gili et al., 1987).

References: Totton (1965); Pugh (1974, 1999); Bone and Trueman (1982); Mackie and Carré (1983); Kirkpatrick and Pugh (1984); Gili (1986), Gili et al. (1987); Pagès and Gili (1992), Carré and Carré (1995); Lakkis and Zeidane (1995); Buecher (1999); Gamulin and Krisnic (2000).

\section{Chelophyes contorta}

(Lens and Van Riemsdijk, 1908)

( Figs. 131D-F)

Polygastric stage: anterior nectophore consistency firm, up to $4.6 \mathrm{~mm}$ in height by $1.7 \mathrm{~mm}$ in dorso-ventral width. Similar to that of $C$. appendiculata, the main difference is that the ventral facet is strongly twisted to the right. Five serrate ridges, (three to the apex) only a short section of the dorsal ridge visible above the ostium, right lateral ridge not reaching the apex. Ventral surface and somatocyst twisted to the right. Hydroecium cornuate, directed towards the ventral surface, not as deep as in $C$. appendiculata, edge blunt. Basal lamella divided into two quadrangular wings, with a small tooth on the baso-central end of each. Posterior nectophore with five serrate ridges, ventral ridges longer on upper half of nectophore, shorter on the lower half, ending in sharp point longer on the left ventral ridge. Upper ventral Fig. fingernailshaped issuing from the right ridge and directed towards the left ridge.

Eudoxid: very similar to that of C. appendiculata (Totton, 1965).

Records from Mediterranean: ?Alborán Sea.

Seasonality: ?

Distribution: widely distributed in warm and temperate regions in the Pacific and Indian oceans. Occasionally present in the Atlantic, where it has been recorded off Honduras, Venezuela, Bermuda, and Cape Verde. Cited in the Alborán Sea in the Mediterranean, near the Strait of Gibraltar (Alvariño, 1971). Nevertheless, the Atlantic records are doubtful because it seems that this species shows mainly an Indo- Pacific distribution.

References: Alvariño (1971); Pagès and Gili (1992); Pugh (1999).

\section{Genus Dimophyes (Chun, 1897)}

Diphyids with anterior nectophore without ridges, mouth Fig. undivided, hydroecium largely opened on its ventral side, carrot-shape somatocyst reaching to about two thirds the height of the nectophore. Posterior nectophore reduced, with the opening of the nectosac lying dorso-basally. Conical bract with extensive neck-shield that is run by a median canal from the phyllocyst; the latter with apical and lateral horns. Monotypic genus.

References: Pagès and Gili (1989, 1992d); Pugh (1999).

Dimophyes arctica (Chun, 1897) (Figs. 131G-I)

Polygastric stage: anterior nectophore devoid of ridges, apex arched, $15.0 \mathrm{~mm}$ in height. Hydroecium deep, bell-shaped, with ventral opening, and summit above the ostium. Basal lamella high, entire, without wings. Somatocyst carrot-shaped, reaching to threequarters of nectophore height. Posterior nectophore seldom found and much reduced. The deep hydroecium is bounded by two broad wings. The nectosac opens on to the baso-dorsal surface. 
Eudoxid: up to $10 \mathrm{~mm}$ in height. The bract is conical with an extensive, thin neck shield. The phyllocyst has apical and lateral horns and a fine basal process, which passes down the neck shield. The gonophore has a very small mouth and any traces of a hydroecium.

Records from Mediterranean: western Mediterranean.

Known seasonality: present all the year.

Distribution: cosmopolitan species, inhabiting the three great oceans as well as the Antarctic, Arctic, and Mediterranean (Alvariño, 1971). Mesopelagic distribution in tropical latitudes, more epipelagic distribution in boreal and austral latitudes (Pugh, 1984; Pagès and Schnack-Schiel, 1996), though it may be found throughout the upper 1.000 metres of the water column (Pugh, 1974).

References: Totton (1965); Pugh (1974, 1984, 1999); Kirkpatrick and Pugh (1984); Pagès and Gili (1992).

\section{Genus Diphyes Cuvier, 1817}

Diphyids with 5 complete longitudinal ridges in the anterior nectophores and 3 prominent dorsal teeth in general. Deep hydroecium. Posterior nectophores, when developed, also with 3 ostial teeth in general and a long apical process (apophysis). Bracts generally helmet-shaped.

References: Pagès and Gili (1992); Pugh (1999).

Diphyes bojani (Eschscholtz, 1829) (Figs. 131J-K)

Polygastric stage: anterior nectophore elongated bearing five long, variably serrated ridges converging at the apex to form a pyramid, pentagonal in cross-section, $10.0 \mathrm{~mm}$ in height by $3.0 \mathrm{~mm}$ in dorso-ventral width. Three basal teeth all of the same size. Nectosac cylindrical, reaching nearly to the apex of the nectophore, upper third tapering. Hydroecium deep, extending to about one-third the height of nectophore, narrower than in D. dispar. Somatocyst fusiform, tip reaching nearly to the apex of the nectosac. Basal lamella entire, bearing a thin median crest. Posterior nectophore with five serrated ridges, upper third tapering, forming a prominent apophysis. Up to $6.6 \mathrm{~mm}$ in height by $2.2 \mathrm{~mm}$ in dorso-ventral width.

Eudoxid: bract shield-shape that covers the upper ventral half of the gonophore, different from that from all other diphyids.
Records from Mediterranean: western Mediterranean.

Known seasonality: present all the year.

Distribution: widely distributed in tropical and subtropical regions in the three great oceans and in the Mediterranean (Alvariño, 1971).

References: Totton (1965); Alvariño (1981); Pagès and Gili (1992); Pugh (1999).

Diphyes dispar Chamisso and Eysenhardt, 1821

(Figs. 132A-C)

Polygastric stage: anterior nectophore large, up to $36.0 \mathrm{~mm}$ in height by $18.0 \mathrm{~mm}$ in dorso-ventral width. Five ridges; dorsal ridge slightly dentate, dorso-basal tooth larger than the two baso-lateral teeth. Nectosac cylindrical, the upper portion tapering to a narrow caecal extension ending close to the apex of the nectophore. Hydroecial opening large, square, very deep, reaching to half of nectophore height or more. Somatocyst cylindrical, of variable length, but not exceeding the filiform apex of the nectosac, curving dorsally towards the nectosac until it touches. Basal lamella entire, margin concave. The dorsal ostial tooth is considerably larger than the lateral one. Mouth Fig. not divided. Posterior nectophore bearing five ridges, height $27.0 \mathrm{~mm}$, dorso-ventral width $13.0 \mathrm{~mm}$. Prominent apical apophysis fitting into the hydroecium of the anterior nectophore. Hydroecial groove large, bounded ventrally by a flat hook-shaped plate directed towards one of the lateral walls. Tooth at basal end of dorsal ridge dentiform, slightly larger than the lateral teeth.

Eudoxid: Bract conical, hood-shaped, with a large, rounded base. Hydroecium shallow, phyllocyst cylindrical, narrow, tapering near the tip, not reaching the apex of the bract. Gonophore with four denticulate ridges. Bases of the two dorsal ridges sharp, each of the two ventral ridges terminating in a small tooth and joined by an entire basal lamella.

Records from Mediterranean: eastern and western Mediterranean.

Known seasonality: 9-12.

Distribution: widely distributed in temperate and warm regions of the three great oceans, and the Mediterranean (Alvariño, 1971). Species epipelagic, occasionally present at greater depths (Pugh, 1974).

References: Cervigón (1958); Totton (1965); van Soest (1973); Pugh (1974, 1999); Pagès and Gili (1992); Lakkis and Zeidane (1995); Gamulin and Krisnic (2000). 


\section{Genus Eudoxoides Huxley, 1859}

Diphyids with small, rigid anterior nectophores, spirally twisted or not, with 5 serrated ridges, the dorsal one being complete. Mouth Fig. divided; no conspicuous ostial teeth. Posterior nectophore, when developed, with curved furrow between apex and pedicel.

Reference: Pagès and Gili (1989, 1992); Pugh (1999).

Eudoxoides spiralis (Bigelow, 1911)

(Figs. 132D-H)

Polygastric stage: only one nectophore developed, spiralled, up to $12 \mathrm{~mm}$ in height, consistency firm. Five twisted serrated ridges, but only four at apex as left ventral ridge joins the right ventral ridge just below the apex. Bases of ventral ridges dissimilar, in that the right ridge starts from the ventral notch in the hydroecium, while the left ridge starts at the level of the ostium. Hydroecium deep, carrotshaped, with a rounded apex. Bases of the lateral walls of the hydroecium asymmetrical, with sharp ends. Basal lamella divided into two lanceolate wings, right wing larger than left one somatocyst, carrot-shaped, arising from a tiny peduncle and reaching around the midpoint of the nectosac.

Eudoxid: bract hood-shaped about $4.0 \mathrm{~mm}$ height, with two serrated ridges and a large, deep neck-shield. Phyllocyst thick and straight, reaching nearly the apex. Gonophore twisted, with four slightly dentate ridges, truncated at the summit.

Records from Mediterranean: eastern and western Mediterranean.

Known seasonality: 3-6, 9,10.

Distribution: widely distributed in the temperate regions of the three great oceans and the Mediterranean (Alvariño, 1971; Pugh, 1974).

References: Cervigón (1958), Totton (1965); Pugh (1974, 1999); Kirkpatrick and Pugh (1984); Gili (1986); Pagès and Gili (1992); Avian et al. (1995); Lakkis and Zeidane (1995).

\section{Genus Lensia Totton, 1932}

Diphyids with pyramidal anterior nectophores, generally ridged, number and disposition of the ridges being variable, from 5 to many. Small, divided mouth, with shallow hydroecium, rarely extending above ostial level. No ostial teeth. Posterior nectophore, when developed, truncated apically with a rounded mouth. Bracts helmet-shaped. Shape of phyllocyst generally resembling that of somatocyst of anterior nectophore; (need of review).

References: Pagès and Gili (1992); Pugh (1999).

Lensia campanella (Moser, 1925)

(Fig. 133A-B)

Polygastric stage: anterior nectophore up to 6.3 $\mathrm{mm}$ in height by $3.0 \mathrm{~mm}$ in dorso-ventral width laterally compressed. Often twisted due to preservation. Walls smooth, rounded, bearing five very fine, barely discernible ridges, one dorsal, two laterals, and two ventral. Basal lamella slanted upwards towards the ventral surface. Hydroecium very flat. Basal lamella short, divided into two halves with rounded margins. Nectosac large, occupying nearly the entire nectophore. Somatocyst ovoid, slanted towards the basal lamella, with a short, thin peduncle. Pedicular canal moving to the base of the somatocyst. Posterior nectophore not been described.

Eudoxid: bract conical with rounded apex, with minute hydroecium. Club-shaped phyllocyst.

Records from Mediterranean: eastern and Western Mediterranean.

Known seasonality: present all the year.

Distribution: epipelagic (Pugh, 1974) common in tropical regions of the three great oceans and in the Mediterranean (Alvariño, 1971).

References: Totton (1965); Carrè D. (1967); Carré C. (1968a); Pugh (1974, 1999); Pagès and Gili (1992); Avian et al. (1995); Lakkis and Zeidane (1995); Gamulin and Kršinić (2000).

\section{Lensia conoidea (Keferstein and Ehlers, 1860)} (Figs. 133C-E)

Polygastric stage: anterior nectophore up to 20 $\mathrm{mm}$ high, consistency firm, with five complete ridges converging at an acute apex; basal end of dorsal ridge forming a tooth extending to below the level of the ostium. Basal lamella short, wide, cleft, extending underneath the nectosac. Hydroecium basal and minute. Somatocyst fusiform and vacuolated, reaching the midpoint of the nectosac. Base of basal lamella slanted upwards towards the ventral surface. Posterior nectophore rectangular but bearing five ridges, up to $20 \mathrm{~mm}$ high. Mesogloea thick, occupying nearly the entire ventral half of the nectophore. Basal lamella asymmetrical, with a central notch; left lappet somewhat higher than right lappet. 
Eudoxid: bract conical, approximately $4 \mathrm{~mm}$ in height, with a long, swollen phyllocyst.

Records from Mediterranean: eastern and western Mediterranean.

Known seasonality: present all the year.

Distribution: common and abundant in all seas, and in the Mediterranean (Bigelow and Sears, 1937; Alvariño, 1971), spanning a broad depth distribution from the surface down to the bathypelagic zone.

References: Bigelow and Sears (1937); Totton (1965); Carré D. (1967); Rottini (1971); Palma (1973); Pugh (1984,1999); Kirkpatrick and Pugh (1984); Gili (1986); Pagès and Gili (1992); Lakkis and Zeidane (1995); Gamulin and Krisnic (2000).

Lensia fowleri (Bigelow, 1911) (Figs. 133F-H)

Polygastric stage: anterior nectophore high, up to $20.0 \mathrm{~mm}$ in height. Five complete ridges converging at the apex. Lateral ridges curving slightly towards the ventral surface at the base. Basal lamella large. Hydroecium extremely flat. Somatocyst ovoid or spherical, resting on the extensive basal lamella, entirely below the level of the ostium. Basal lamella divided into two wings. Posterior nectophore smaller and delicate. Hydroecium delimited, by two triangular-shaped wings, the small mouthFig. is undivided. Eudoxid: the bract is elongated, up to $4.5 \mathrm{~mm}$ in height, and rounded apically, with a wide neck shield which bears a marginal notch. The phyllocyst is small and globular.

Records from Mediterranean: eastern and western Mediterranean.

Known seasonality: present all the year.

Distribution: more frequent and abundant in the Atlantic Ocean but extending into temperate regions of the Pacific and Indian oceans and the Mediterranean (Bigelow and Sears, 1937; Alvariño, 1971). Reported at depths down to $800 \mathrm{~m}$ (Leloup and Hentschel, 1935) but mainly dwelling in the upper $250 \mathrm{~m}$ (Pugh, 1974).

References: Totton (1965); Gamulin (1966); Rottini (1971); Pugh (1974, 1999); Casanova (1980); Kirkpatrick and Pugh (1984); Pagès and Gili (1992); Avian et al. (1995); Lakkis and Zeidane (1995).

Lensia hotspur Totton, 1941

(Fig. 133I)

Polygastric stage: anterior nectophore with five complete ridges, lateral ridges closer to dorsal ridge than to ventral ridges. Small, less than $10.0 \mathrm{~mm}$ in height. Hydroecium minute, very flat, located below the level of the ostium. Somatocyst, short, angled obliquely, exhibiting great morphological variability, ovate or sausage-shaped, ventrally slanted, with a short peduncle. Basal lamella divided into two rounded, dorsally slanted wings. Posterior nectophore difficult to distinguish from that of the other Lensia species but has a rounded notch on the mouth-Fig.. Eudoxid: not yet discovered.

Records from Mediterranean: western Mediterranean, Alborán Sea.

Known seasonality: in winter.

Distribution: widely distributed in tropical regions of the Atlantic Ocean, but distribution range extending from latitude $59^{\circ} \mathrm{N}$ (Fraser, 1967) to $40^{\circ}$ $\mathrm{S}$. Isolated presence in the Indian and Pacific oceans (Alvariño, 1971). Recently cited in the Alborán Sea, near the Strait of Gibraltar (Dallot et al., 1988).

References: Pagès and Gili (1992); Pugh (1999).

Lensia meteori (Leloup, 1934)

(Fig. 134A)

Polygastric stage: anterior nectophore very small and delicate, apex rounded, apparently without ridges, up to $7.0 \mathrm{~mm}$ high. Hydroecium narrow, high, slanting ventrally upwards, basal lamella indistinguishable from ventral surface of hydroecium, divided into two quadrangular wings. Upper edge of hydroecium above the level of the ostium. Somatocyst small, pyriform or globe-shaped, with a short pedicel. Posterior nectophore and eudoxid have not been described.

Records from Mediterranean: eastern and western Mediterranean.

Known seasonality: present all the year.

Distribution: inhabiting temperate regions in the three great oceans (Alvariño, 1971), and in the Mediterranean (Leloup, 1934; Gili, 1986). Broad vertical distribution extending down to $800 \mathrm{~m}$ in depth (Pugh, 1974).

References: Totton (1965); Rottini (1971); Daniel (1974); Pugh (1974, 1999); Kirkpatrick and Pugh (1984); Gili (1986); Pagès and Gili (1992); Avian et al. (1995); Carré and Carré (1995); Lakkis and Zeidane (1995); Gamulin and Kršinić (2000).

Lensia multicristata (Moser, 1925) (Figs. 134B-D)

Polygastric stage: anterior nectophore elongate, up to $15 \mathrm{~mm}$ in height, with seven longitudinal 
ridges, latero-ventral ridges reaching neither the apex nor the ostial margin of the nectophore, lateral ridges ending slightly above the level of the ostium. Hydroecium small, as a shallow groove located below the level of the ostium. Basal lamella wide, divided into two wings whose inner margins are formed by a rounded tooth directed towards the hydroecium. Somatocyst filiform, with an extremely thin peduncle, reaching nearly the midpoint of the nectosac. Posterior nectophore with five ridges, lateral ridges not reaching the ostium. Basal lamella low and broad. Eudoxid not yet discovered, although Kirkpatrick and Pugh (1984) suggested that it might be Eudoxia tenuis (Patriti, 1965).

Records from Mediterranean: Adriatic, eastern (Crete and Ionian Seas) and western Mediterranean.

Known seasonality: present all the year.

Distribution: mesopelagic species (Pugh, 1984) distributed in the temperate regions of the three great oceans, and the Mediterranean (Bigelow and Sears, 1937; Alvariño, 1971).

References: Bigelow and Sears (1937); Totton (1965); Rottini (1971); Pugh (1974, 1999); Kirkpatrick and Pugh (1984); Pugh (1984); Gili (1986); Pagès and Gili (1992); Lakkis and Zeidane (1995); Gamulin and Kršinić (2000).

\section{Lensia subtilis (Chun, 1886)}

(Figs. 134E-G)

Polygastric stage: anterior nectophore conical, fragile, laterally compressed, apex rounded, apparently devoid of ridges but with folds. Up to $10 \mathrm{~mm}$ in height. Hydroecium wide, short, slanting upwards towards the ventral surface, upper edge above the level of the ostium. Somatocyst composed of a long, straight peduncle reaching to the midpoint of the nectophore, ending in a globe. Basal lamella small, divided into two wings. Posterior nectophore approximately the same size as the anterior nectophore, with five ridges, truncate apex, and rounded small basal lamella.

Eudoxid: bract small and rounded with a short phyllocyst. The gonophore has hydroecial folds only on the proximal part.

Records from Mediterranean: eastern and western Mediterranean.

Known seasonality: 1-12.

Distribution: temperate regions of the three great oceans and the Mediterranean (Alvariño, 1971). Epiplanktonic, though it may extend down to depths of 500-1000 m (Pugh, 1974; Gili et al., 1987a).
References: Cervigón (1958); Totton (1965); Pugh (1974, 1999); Ianora and Scotto di Carlo (1981); Kirkpatrick and Pugh (1984); Gili (1986); Pagès and Gili (1992); Avian et al. (1995); Carré and Carré (1995); Lakkis and Zeidane (1995); Gamulin and Kršinić (2000).

Lensia subtiloides (Lens and Van Riemsdijk, 1908) (Figs. 135A-B)

Polygastric stage: anterior nectophore $3.7 \mathrm{~mm}$ high by $1.4 \mathrm{~mm}$ wide, consistency firm with five ridges converging at the apex. Hydroecium very shallow, summit at the same level as the ostium. Basal lamella slanting upwards towards the ventral surface. Mouth wide, with two short wings with rounded borders slightly overlapping. Somatocyst club-shaped, one-third/one-fifth of nectophore height. Posterior nectophore $3 \mathrm{~mm}$ in height with a slight apical promontory and a small tooth on the right side of the apex.

Eudoxid: bract rounded with club-shaped phyllocyst.

Records from Mediterranean: western Mediterranean.

Known seasonality: 12.

Distribution: present, though uncommon, in temperate coastal waters of the three great oceans and the Mediterranean (Alvariño, 1971). Frequently collected together with Diphyes chamissonis, to which appear to be associated in the Indo-Pacific region (Totton, 1954; Pagès et al., 1989).

References: Bigelow and Sears (1937); Totton (1965); Daniel (1974); Gili (1986); Pagès and Gili (1992); Lakkis and Zeidane (1995); Pugh (1999).

\section{Genus Muggiaea Bush, 1851}

Diphyids with posterior nectophore not developed. Pyramidal anterior nectophore with 5 ridges. Deep hydroecium, not open ventrally, oblique, divided mouth. Somatocyst lies very close to nectosac wall.

References: Pagès and Gili (1989, 1992); Pugh (1999).

\section{Muggiaea atlantica Cunningham, 1892 (Figs. 135C-D)}

Polygastric stage: Nectophore small, up to $7 \mathrm{~mm}$ in height, with five complete relatively straight ridges converging at the apex. No basal teeth. 
Hydroecium bell-shaped, relatively deep, up to onethird of nectophore height, the lower half situated below the level of the ostium. Somatocyst long, filiform, running closely along the ventral surface of the nectosac, ending in a small thickening at the level of the apex of the nectosac. Basal lamella wide, divided into two wings whose medial margins overlap.

Eudoxid: bract small, conical, dorsal surface longer than ventral surface. Sutural surface broad, flattened, suture prominent. Phyllocyst club-shaped. Hydroecial cavity shallow. Gonophore slightly twisted, with four ridges running from the base to the apex. Basal lamella short, curved.

Records from Mediterranean: eastern and western Mediterranean.

Known seasonality: 1-12.

Distribution: neritic species inhabiting warm and temperate regions of the three great oceans and the Mediterranean (Bigelow and Sears, 1937; Alvariño 1971).

References: Russell (1938); Totton (1965); Daniel (1974); Purcell (1982); Kirkpatrick and Pugh (1984); Gili (1986); Gili et al. (1987a), Gili et al. (1987b); Gili et al. (1988); Pagès and Gili (1992); Lakkis and Zeidane (1995); Pugh (1999); Gamulin and Kršinić (2000).

\section{Muggiaea kochi (Will, 1844)}

(Figs. 135E-F)

Polygastric stage: nectophore similar to that of $M$. atlantica, with five ridges converging at the apex. Up to $7 \mathrm{~mm}$ in height. Lateral ridges describing a characteristic sigmoidal curve. Hydroecium conical, less deep than in M. atlantica, reaching onequarter of nectosac height. Basal lamella divided into two equal rectangular wings. Somatocyst filiform, cylindrical, reaching the midpoint of the nectosac.

Eudoxid: the bract is roughly conical, with a flattened facet, an asymmetrical basal process, and a very shallow hydroecial depression. The phyllocyst is club-shaped. The gonophores have four longitudinal ridges. There is a short, curved mouth.

Records from Mediterranean: eastern and western Mediterranean.

Known seasonality: 1-12.

Distribution: Atlantic species abundant in neritic waters of temperate regions (Alvariño, 1971). In the southern hemisphere collected to latitude $23^{\circ} \mathrm{S}$ off
Brazil (Leloup and Hentschel, 1935). In the Pacific reported in the vicinity of the Galapagos Islands (Alvariño and Leira, 1986) and near the Panama Canal after entering from the Atlantic (Alvariño, 1974), Mediterranean.

References: Totton (1965); Alvariño (1971, 1974); Rottini (1971); Kirkpatrick and Pugh (1984); Gili (1986); Pagès and Gili (1992); Lakkis and Zeidane (1995); Pugh (1999); Gamulin and Kršinić (2000).

Genus Sulculeolaria Blainville, 1834

Diphyids whith anterior nectophore with rounded apex, and without ridges; posterior nectophore of similar size with extensively looped lateral radial canals. Replacement nectophores of both types frequently with different characters. Small leaf-like bracts with direct release of gonophores, without eudoxid stage. Bracts of various species are not distinguishable.

References: Carré C. (1979); Pagès and Gili (1992); Pugh (1999).

Sulculeolaria biloba (M. Sars, 1846) (Figs. 135G-I)

Polygastric stage: anterior nectophore conical, without ridges, apex rounded. Firm consistency. Up to $20 \mathrm{~mm}$ high. Ostial margin devoid of teeth. Radial canals with transverse commissures connected to the ventral canal nearly at the level of the ostium. Somatocyst ovoid or filiform, sloping ventrally, onesixth of nectophore height. Basal lamella divided into two large, rounded lappets, without protuberances. Posterior nectophore rectangular, up to 24.6 $\mathrm{mm}$ in height. No ostial teeth. Basal lamella consisting of two lateral lappets and a central mouth, with furrows reaching to half of lamella height; protuberances absent.

Records from Mediterranean: eastern and western Mediterranean, Adriatic.

Known seasonality: 4.

Distribution: warm, and temperate waters of the three great oceans (Alvariño, 1971), and in the Mediterranean (Gili, 1986). The numerous synonyms used for this species in the past make it difficult to confirm some of the early records, as discussed previously by Totton (1954).

References: Carré C. (1979); Kirkpatrick and Pugh (1984); Pagès and Gili (1992); Avian et al. (1995); Lakkis and Zeidane (1995; Pugh (1999). 


\author{
Sulculeolaria chuni \\ (Lens and van Riemsdijk, 1908) \\ (Figs. 136A-B)
}

Polygastric stage: anterior nectophore conical, without ridges, apex rounded, consistency more delicate than other species of the genus. Up to $8 \mathrm{~mm}$ high. Ostial margin without teeth. Radial canals without transverse commissures in the first anterior nectophore, but commissures present in the replacement nectophore. Somatocyst quite straight, filiform or fusiform, up to two-fifths to three-fifths of nectophore height. Basal lamella short, divided into two lappets, without protuberances. Posterior nectophore cylindrical, up to $8.6 \mathrm{~mm}$ in height. No teeth on the ostial margin. Basal lamella divided into two rounded lappets separated by a shallow medial notch. Secondary posterior nectophore similar.

Records from Mediterranean: eastern and western Mediterranean.

Known seasonality: present all the year, mainly 4-12.

Distribution: common species in equatorial and tropical regions in the three great oceans (Alvariño, 1971) and the Mediterranean (Bigelow and Sears, 1937; Carré C., 1979).

References: Cervigón (1958); Totton (1965); Rottini (1971); Palma (1973); Carré C. (1979); Ianora and Scotto di Carlo (1981); Gili (1986); Pagès and Gili (1992); Avian et al. (1995); Lakkis and Zeidane (1995); Pugh (1999); Gamulin and Kršinić (2000).

\section{Sulculeolaria quadrivalvis Blainville, 1834} (Figs. 136C-D)

Polygastric stage: anterior nectophore conical, apex rounded, without ridges firm consistency. Large, up to $20 \mathrm{~mm}$ in height. Ostial margin bearing two lateral and two dorsal teeth, well-developed, decreasing in size in the replacement anterior nectophores. Radial canals with transverse commissures linking the canals to the ventral canal at the level of the lower third of the nectosac. Transverse commissure tending to be smaller in replacement nectophores and sometimes not reaching the dorsal canal in the second following nectophore. Somatocyst elongate, sinuous, ventrally slanted, one-fifth to two-fifths of nectophore height in size, tending to be straighter in following nectophores. Two prominent, rounded basal lappets, each with a small protuberance on the dorsal margin, decreasing in size and disappearing in replacement nectophores. Posterior nectophore up to $26.6 \mathrm{~mm}$ high. Nectosac with an oblique annular constriction affecting the upper dorsal and lower ventral halves. Ostial margin with two dorsal and two lateral teeth. Basal lamella divided into two large, rounded lobes with a central furrow occupying three-fourths of basal lamella length. Each lappet bearing an acute protuberance on the upper dorsal portion.

Records from Mediterranean: eastern and western Mediterranean.

Known seasonality: present all the year.

Distribution: widely distributed in tropical and subtropical regions in the three great oceans and in the Mediterranean (Bigelow and Sears, 1937; Alvariño, 1971).

References: Totton (1965); Alvariño (1981); Palma (1973); Carré (1979); Kirkpatrick and Pugh (1984); Gili (1986); Pagès and Gili (1992); Avian et al. (1995); Lakkis and Zeidane (1995); Pugh (1999); Gamulin and Kršinić (2000).

\section{Sulculeolaria turgida (Gegenbaur, 1853)} (Figs. 136E-F)

Polygastric stage: anterior nectophore conical, apex rounded, firm consistency, reaching $15 \mathrm{~mm}$ in height. Ostial margin devoid of teeth. Somatocyst small, ovoid or filiform, one-twentieth of nectophore height. Radial canals without transverse commissures in the first nectophore (NA1), but transverse commissures are present in the replacement nectophore (NA2), attached to the ventral canal above the level of the pedicular canal. Basal lamella divided into two lappets by a deep furrow reaching to the ostial margin, shorter in NA2. Toothlike protuberances absent. Posterior nectophore cylindrical, tapering towards the ostial margin. Up to $10.0 \mathrm{~mm}$ high. No teeth on the ostial margin. Basal lamella entire, large, rounded, devoid of protuberances.

Records from Mediterranean: mainly Adriatic, eastern and western Mediterranean.

Known seasonality: 12-9.

Distribution: uncommon but distributed in temperate regions in the three great oceans, and in the Mediterranean (Bigelow and Sears, 1937; Alvariño, 1971). Epiplanktonic distribution.

References: Totton (1965); Carré (1979); Kirkpatrick and Pugh (1984); Gili (1986); Pagès and Gili (1992); Avian et al. (1995); Pugh (1999); Gamulin and Kršinić (2000). 
Family HiPPOPODIIDAE Kölliker, 1853

Calycophorae with biserial arrangement of up to 16 or more flattened definitive nectophores in varying stages of development, the youngest being apical, nectophores fitting tightly together around a thin stem which can be retracted between them; without bracts, somatocyst curving smoothly over mid-dorsal surface of hydroecium and is without central organ.

Reference: Carré and Carré (1995).

Genus Hippopodius Quoy and Gaimard, 1827

Hippopodiid whose larval nectophore nectosac has only two radial canals.

References: Pagès and Gili (1992); Pugh (1999).

Hippopodius hippopus (Forskål, 1776)

(Figs. 137A-D)

Colonies formed by up to 16 nectophores arranged in two series opposite each other joined by a thin central stem. Upper nectophores younger, lower nectophores dropped from the colony as new nectophores form at the apex. Definitive nectophore hard and tough, horseshoe-shaped, up to $20.6 \mathrm{~mm}$ high and $16.0 \mathrm{~mm}$ wide. It may become opaque during fixation. Four rounded dorsal protuberances variable in size forming an arc above the ostium; the two central protuberances smaller. The nectosac is relatively large and a rete mirabile is located on the ventral radial canal, larger in juveniles.

Records from Mediterranean: eastern and western Mediterranean.

Known seasonality: present all the year.

Distribution: widely distributed in tropical and subtropical regions in the three great oceans, and in the Mediterranean (Bigelow and Sears, 1937; Alvariño, 1971; Pugh 1974).

References: (Bigelow and Sears, 1937); Totton (1965); Carré D. (1968a); Rottini (1971); Pugh (1974, 1999), Kirkpatrick and Pugh (1984, 1999); Gili (1986); Pagès and Gili (1992); Avian et al. (1995); Lakkis and Zeidane (1995); Gamulin and Kršinić (2000).

\section{Genus Vogtia Kölliker, 1853}

Hippopodiid of which the nectosac of larval nectophore has 4 radial canals.

References: Pagès and Gili (1992); Pugh (1999).
Vogtia glabra Bigelow, 1918

(Figs. 137E-F)

Colonies composed of two parallel rows of nectophores attached obliquely to a central stem. Oldest nectophores placed at the base of the colony. Youngest nectophores elongate, up to $7.3 \mathrm{~mm}$ high by $4.6 \mathrm{~mm}$ wide, with a triangular apical process consisting of three rounded protuberances, a larger central protuberance and two smaller lateral protuberances, halfway along the height of the nectophore. Rete mirabile present. Deep hydroecial groove from the base of the apex on the ventral surface of the nectophore, protected by lateral wings. Adult nectophore more rounded, up to $30.0 \mathrm{~mm}$ in diameter, horseshoe-shaped. Characterized by two rounded dorso-lateral processes and an additional apical process. Hydroecial groove shallower; hydroecium large and flattened.

Records from Mediterranean: eastern and western Mediterranean.

Known seasonality: 5.

Distribution: widely distributed in the Atlantic Ocean from Ireland to Tristan da Cunha (Leloup, 1955). Sporadically present in the Pacific and Indian oceans and the Mediterranean (Alvariño, 1971).

References: Pugh (1974, 1984, 1999); Kirkpatrick and Pugh (1984); Gili (1986); Pagès and Gili (1992); Lakkis and Zeidane (1995).

\section{Vogtia pentacantha Kölliker, 1853} (Fig. 137G)

Colonies organized like the rest of the hippopodiids. Nectophore five pointed, up to $15 \mathrm{~mm}$ with small gelatinous teeth on the ridges, but with smooth facets except for occasional protuberances near the central ridge. Nectosac relatively small. Polygastric stage fragile and seldom found intact in net collections

Records from Mediterranean: southern Adriatic, eastern and western Mediterranean

Seasonality: ?

Distribution: Atlantic, Mediterranean.

References: Bigelow and Sears (1937); Trégouboff (1957); Rottini (1971); Gamulin and Kršinić (2000).

Vogtia serrata (Moser, 1925)

(Fig. 137H)

Nectophore roughly triangular, up to $40 \mathrm{~mm}$ in diameter, with two small flaps at the centre of base. 
Neither the distinctive ridges nor the facets bear spines or protuberances, and a small, deep hollow exist beneath each lateral process.

Records from Mediterranean: western Mediterranean.

Seasonality: ?.

Distribution: infrequent but inhabiting tropical and subtropical regions in the three great oceans, and the Mediterranean (Alvariño, 1971).

References: Bigelow and Sears (1937); Kirkpatrick and Pugh (1984); Pugh (1999).

Vogtia spinosa Keferstein and Ehlers, 1861 (Fig. 138A)

Colonies composed of two parallel rows of nectophores attached obliquely to a central stem. Up to 19 nectophores, pentagonal in shape, up to $20 \mathrm{~mm}$ in length. Spine-like gelatinous tubercles closely spaced on the upper surface of the nectophore. Ventral surface a deep concavity devoid of spines. Nectosac large, flattened, with four radial canals and a rete mirabile on the ventral surface.

Records from Mediterranean: western Mediterranean.

Seasonality: ?

Distribution: infrequent but inhabiting tropical and subtropical regions in the three great oceans, and in the Mediterranean (Alvariño, 1971).

References: Bigelow and Sears (1937); Totton (1965); Pugh (1974, 1999); Kirkpatrick and Pugh (1984); Pugh, 1984; Pagès and Gili (1992).

\section{Family PRAYIDAE Kölliker, 1853}

Nectophores relatively large and usually rounded, mesoglea abundant; larval nectophore sometimes retained during polygastric stage or replaced by one to four definitive nectophores, whose somatocysts are often complexly branched; the eudoxid bracts are rounded and unridged.

References: Carré and Carré (1995); Pugh (1999).

\section{Subfamily AMPHICARYONINAE Chun, 1888}

Two nectophores differing in size. The larger, rounded one is believed to be the retained larval nectophore. The first definitive one smaller or vestigial. The bracteal canals are reduced to 2 long hydroecials. Bracts undistinguishable at present.

References: Carré and Carré (1995); Pugh (1999).

\section{Genus Amphicaryon Chun, 1888}

Prayid with two dissimilar nectophores; the larger, witch is possibly the retained larval nectophore, partly encloses the reduced or vestigial definitive nectophore. The nectosac of the latter does not have an external opening. The eudoxid bract has a pair of lateral hydroecial canals.

References: Pagès and Gili (1992); Pugh (1999).

\section{Amphicaryon acaule Chun, 1888}

(Figs. 138B-C)

Polygastric stage: colonies globe-shaped, composed of two nectophores. Larval nectophore large, ovoid, up to $10.7 \mathrm{~mm}$ in height, higher than wide, partially surrounding the vestigial nectophore. Larger nectophore has a nectosac somewhat higher than half nectophore height with four radial canals, the dorsal canal longer than the ventral canal. Upper portion of lateral canal forming a right angle. Vestigial nectophore is a disc within the ventral cavity of the larger nectophore. Nectosac with four simple radial canals, not open to the outside.

Eudoxid: small and thin, with two straight canals. It is folded to form a shield to the bell-shaped gonophores.

Records from Mediterranean: western Mediterranean.

Known seasonality: 9-4.

Distribution: present in tropical and subtropical regions of the three great oceans, and of the Mediterranean (Alvariño, 1971; Pugh, 1974). Epipelagic species that has been caught in the mesopelagic zone (Pugh, 1974).

References: Bigelow and Sears (1937); Totton (1965); Palma (1973); Daniel (1974); Pugh (1974, 1999); Kirkpatrick and Pugh (1984); Pagès and Gili (1992).

Subfamily Prayinae Chun, 1897

Prayid with two, occasionally up to 4 , rounded, smooth-walled nectophores of similar size. Bracts with 6 canals, occasionally reduced to 5 .

References: Carré and Carré (1995); Pugh (1999).

Genus Desmophyes Haeckel, 1888

Prayid with usually two avoid flimsy, cylindrical nectophores but there can be up to 6 biserially arranged nectophores. Nectosac occupying less than 
half the height of the nectophores; with an ascending but no descending branch to the somatocyst; with four straight radial canals. Somatocyst unbranched and with a distinctive whitish swelling at the apex. Bracts small, compact and kidney-shaped, characterized by the presence of a large white spherical or ovoid central organ, giving rise to the thin bracteal canal. Gonophores fragile and reduced.

References: Pugh and Harrison (1987); Pugh (1992).

\section{Desmophyes annectens Haeckel, 1888} (Figs. 138D-F)

Polygastric stage: large swelling at the distal end of the ascending branch of the somatocyst. Nectosac occupying one-quarter the nectosac height.

Eudoxid: bracteal dorsal canal arises centrally from an inflated vesicle. Gonophore with two symmetrically arranged mantle canals and without lateral flaps toward their apices.

Records from Mediterranean: Villefranche-surmer.

Known seasonality: ?

Distribution: Atlantic; Mediterranean.

References: Pugh and Harbison (1987); Pugh (1992).

Desmophyes villafrancae (Carré, 1969)

(Figs. 139A-C)

Polygastric stage: nectosac occupying twothird/two-fifth the nectophore height

Eudoxid: bracteal dorsal canal arises from the right hydroecial canal. Gonophore with a single mantle canal.

Records from Mediterranean: Villefranche-surmer (western Mediterranean).

Known seasonality: 5.

Distribution: endemic of Mediterranean Sea.

References: Carré C. (1969a); Pugh and Harbison (1987); Pugh (1992).

\section{Genus Lilyopsis Chun, 1885}

Prayid whose polygastric stage has two, possibly more very delicate and opposite conoid nectophores up to $10 \mathrm{~mm}$ in height; large nectosacs. Definitive nectophore has a bifurcated somatocyst and sinuous lateral canals on the nectosac. Larval nectophore has a simple somatocyst, slightly swollen at its tip, and straight radial canals on the nectosac.

Eudoxid: bract like a cushion, with central origin of dorsal canal. Gonophore with a single mantle canal.
References: Carré and Carré (1995); Pugh (1999).

Lilyopsis rosea Chun, 1885

(Figs. 139D-F)

Diagnosis: like for the genus

Records from Mediterranean: western Mediterranean.

Known seasonality: ?

Distribution: Atlantic; Mediterranean.

References: Carré C. (1969b); Carré and Carré (1995), Pugh and Harbison (1987), Pugh (1999).

Genus Prayola Carré, 1969

Prayid with an apposed pair of conoid nectophores, whose extensive nectosacs (>half the height of the nectophore) open dorso-basally. The radial canals on the nectosac are slightly curved, suggesting an open S. The very short somatocyst possesses neither an ascending nor a descending branch. The bracts have only five bracteal canals, there being no dorsal canal. The gonophores possess a hydroecial gutter and two mantle canals of equal length. No special, asexual nectophores are present.

Reference: Pugh and Harbison (1987).

Prayola tottoni Carré 1969

(Figs. 140A-D)

Polygastric stage: both nectophores conoidal, of same size, up to $5 \mathrm{~mm}$ in height and $4.5 \mathrm{~mm}$ in diameter. Pedicular canal almost horizontal. Nectosac more than half of nectophore height. Radial canals unequal, the ventral short straight the other slightly curved. Simple and very short superficial somatocyst, in both nectophores.

Eudoxid: bracts elliptical, cushion-like, with five short branched bracteal canals, no dorsal canal. Gonophore subspherical; pedicular canal vertical giving rise to two symmetrical mantle canals.

Records from Mediterranean: off Villefranchesur-Mer (western Mediterranean).

Known seasonality: 4.

Distribution: endemic of the Mediterranean Sea.

References: Carré C. (1969c); Pugh and Harbison (1987).

\section{Genus Rosacea sensu Bigelow, 1911}

Prayid with two medium, rounded nectophores with simple somatocyst without side branches. Sinuous lateral radial canals on nectosac. Bracts kidney- 
shaped, but with characteristic arrangement of canals.

References: Pugh and Harbison (1987); Pagès and Gili (1992); Pugh (1999.

\section{Rosacea cymbiformis (Delle Chiaje 1822)} (Figs. 140E-F, 141A)

Polygastric stage: definitive nectophore less rounded, more flattened and elongate than in $R$. plicata, up to $17.5 \mathrm{~mm}$ high. The two definitive nectophores are attached ventrally, one partially surrounding the other. Hydroecium shallow, comprising a ventral canal with two faint lateral projections extending, dorso-basally, from near the apex to the ostium of the nectosac. Nectosac displaced dorsally, small, less than two-fifths of nectophore height, lateral radial canals curving three times, forming a $\mathrm{W}$ from the pedicular canal to the ostial ring canal. Somatocyst with descending branch as in $R$. plicata. Eudoxid: bract less compact than that of $R$. plicata, with the dorsal bracteal canal arising proximal to the spur on the left hydroecial canal.

Records from Mediterranean: Adriatic and western Mediterranean.

Known seasonality: 9-5.

Distribution: relatively common species, more abundant in the Atlantic, taken off the British Isles (Kirkpatrick and Pugh (1984), in the Bay of Biscay and off the Azores (Leloup, 1955), also taken in the Mediterranean (Bigelow and Sears, 1937). The depth distribution appears to be more epiplanktonic than that of $R$. plicata.

References: Totton (1965); Daniel (1974); Purcell (1981); Kirkpatrick and Pugh (1984); Pagès and Gili (1992); Avian et al. (1995); Pugh (1999); Gamulin and Kršinić (2000).

\section{Rosacea plicata sensu Bigelow 1911}

(Figs. 141B-C)

Polygastric stage: two types of nectophore, a temporary larval and a definitive one. Larval nectophore small, globe-shaped, $4.7 \mathrm{~mm}$ in size. Similar to that of the Hippopodidae, except that the pallial canal makes a sharp turn around the central organ. This nectophore is replaced by two larger definitive nectophores up to $18.0 \mathrm{~mm}$ in height. Mesoglea thick but not rigid, and consequently specimens when preserved and easily deformed, hindering identification and creating confusion with $R$. cymbiformis.Nectophores without ridges, globeshaped or cylindrical. Nectosac dome-shaped, locat- ed at the base of the nectophore, reaching to one the quarter nectophore height. Radial canals curving twice to form a horizontal S. Hydroecium ventral, deep, occupying a large part of the central portion of the nectophore without reaching either the apex or the base. Somatocyst simple with descending branch.

Eudoxid: bract kidney-shaped and compact. The longitudinal bracteal canals are reduced to spurs, and the dorsal canals raise distal to the spur on the left hydroecial canal. The gonophores are simple and bell-shaped.

Remark: the nectophores of the two Rosacea species can be difficult to tell apart. Generally $R$. cymbiformis lives in shallower depth than $R$. plicata.

Records from Mediterranean: western Mediterranean.

Known seasonality: 9.

Distribution: mesopelagic species (Pugh, 1984) widely distributed in the three great oceans and in the Mediterranean (Alvariño, 1971).

References: Totton (1965); Kirkpatrick and Pugh (1984); Pugh (1984, 1999); Gili (1986); Pugh and Harbison (1987); Pagès and Gili (1992).

\section{Family SpHAERONECTIDAe Huxley, 1859}

Calycophorae that retain the larval nectophore as the only one in the polygastric stage.

References: Carré and Carré (1995); Pugh (1999).

Genus Sphaeronectes Huxley, 1859

With the characters of the family.

References: Pagès and Gili (1992); Pugh (1999).

Sphaeronectes bougisi Carré D, 1968

(Figs. 141D-E)

Polygastric stage: nectophore small, $1.0 \mathrm{~mm}$ in height; spheroidal, slightly conical apically. Nectosac sub spherical, occupying the quasi totality of nectophore volume. Velum large, ventral. Pedicular canal virtual, very short, giving rise sagittally to two radial canals, the ventral short in almost immediate contact with the marginal canal, the dorsal longer and running up to the apex of the nectosac, the two lateral canals are straight, issued from to different points of the nectosac apex, the right one being located more ventrally than the left one, both connected to the marginal canal. Hydroecium conical, 
symmetrical to the sagittal plan, triangular, small, located at the base of the ventral face. Somatocyst without peduncle, vertical, fusiform, at the ventral side of the nectosac. Siphosome with 3 to 4 cormidial buds.

Eudoxid: only just detached cormidia known, bract hemispherical with a globulous phyllocyst, gastrozooid with a short peduncle.

Records from Mediterranean: western Mediterranean.

Known seasonality: 7.

Distribution: endemic of the Mediterranean Sea. References: Carré D. (1968 b), Carré C. (1968 d); Gili (1986).

\section{Sphaeronectes fragilis Carré C. 1968} (Figs. 141F-G)

Polygastric stage: nectophore spheroidal, slightly cylindrical, with thin walls, fragile, up to $5 \mathrm{~mm}$ in height. Pedicular canal virtual. Nectosac large up to $4.5 \mathrm{~mm}$, subspherical. Radial canals looped with a secondary loop on the descending branch, their intersection with dorsal canal in ventral position on the nectosac. Hydroecium conical, symmetrical, in the sagittal plan, not very deep, $2 / 5$ of nectosac height. Somatocyst vertical on ventral side of nectosac with a subspherical thickening and a long peduncle.

Eudoxid: not known.

Records from Mediterranean: eastern and western Mediterranean.

Known seasonality: present all the year.

Distribution: endemic of Mediterranean Sea.

References: Carré C. (1968e); Avian et al. (1995); Gamulin and Kršinić (2000).

\section{Sphaeronectes gamulini Carré C. 1966} (Figs. 142A-D)

Polygastric stage: nectophore spheroidal, slightly conical up to $1.5 \mathrm{~mm}$ in height and diameter. Nectosac subspherical, $3 / 4$ of the nectophore height. Pedicular canal short but visible. Right lateral canal inserted slightly above left radial canal. Radial canals looped, their intersection with dorsal canal in the ventral position on the nectosac. Hydroecium conical relatively deep, laterally flattened, $1 / 2$ nectosac height, on the left of the sagittal plan. Somatocyst horizontal, on the right lateral ventral side of the nectosac, with a terminal ovoid thickening and a distinct stalk of the same size
Eudoxid: bract hemispherical, flat, hydroecium indistinct. Phyllocyst fungi form, globular with a peduncle of about the same size than body.

Records from Mediterranean: eastern and western Mediterranean.

Known seasonality: present all the year.

Distribution: endemic of the Mediterranean Sea. References: Carré (1968e); Ianora and Scotto Di Carlo (1981); Avian et al. (1995); Gamulin and Kršinić (2000).

\section{Sphaeronectes gracilis (Claus, 1873, 1874)}

(Figs. 142E-F)

Polygastric stage: nectophore spheroidal, quite fragile, up to $8.0 \mathrm{~mm}$ in height. Nectosac small, reaching to half of nectophore height. Four straight radial canals arising from the same point at the apex of the nectosac over which bends the long, narrow, tubular, hydroecium which runs from the external opening to the pedicular canal at the apex of the nectosac. Velum broad. Pedicular canal long, readily distinguishable. Somatocyst horizontal, short, fusiform, and curved with a distal swelling, directed towards the dorsum above the apex of the nectosac. Eudoxid: (called diplophysa) bract small and spherical, with clear basal wings. The phyllocyst is long, obliquely angled and club-shaped. The gonophore is a simple bell, thickened towards its apex.

Records from Mediterranean: Adriatic, eastern and western Mediterranean.

Known seasonality: present all the year.

Distribution: common in Mediterranean (Trègouboff, 1957; Patriti, 1964; Rottini, 1971; Ianora and Scotto Di Carlo, 1981); in the Atlantic collected off the Canary Islands (Chun, 1892) and the British Isles (Kirkpatrick and Pugh, 1984). In the Pacific collected off California (Purcell and Kremer, 1983); Chile (Palma, 1977) and Japan.

References: Totton (1965); Carré C. (1968e); Carré D. (1969a); Rottini (1971); Palma (1973); Ianora and Scotto Di Carlo (1981); Purcell and Kremer (1983); Kirkpatrick and Pugh (1984); Pagès and Gili (1992); Avian et al. (1995); Lakkis and Zeidane (1995); Pugh (1999); Gamulin and Kršinić (2000).

\section{Sphaeronectes irregularis (Claus, 1873)} (Fig. 142G)

Polygastric stage: nectophore spheroidal slightly conical, up to $7.1 \mathrm{~mm}$ in height and $5.7 \mathrm{~mm}$ in diameter. The radial canals are looped, their intersection 
in the ventral part of the nectosac. Nectosac the $2 / 3$ of nectophore height. Pedicular canal virtual. Hydroecium conical laterally flattened, not very deep, 1/3 of nectophore height. Somatocyst pyriform not pedunculate, vertical on the ventral side of the nectosac.

Eudoxid: hemispherical, slightly conical. Phyllocyst ovoid to piriform with a very short peduncle, length less than $1 / 2$ of the bract height. Hydroecium not well developed, basal wing not very distinct.

Records from Mediterranean: eastern and western Mediterranean.

Known seasonality: present all the year.

Distribution: Mediterranean, Pacific.

References: Trégouboff (1957); Avian et al. (1995); Lakkis and Zeidane (1995); Gamulin and Kršinić (2000).

Class AUTOMEDUSA Lameere, 1920 emend. (see Bouillon and Boero 2000).

(Actinulidae, Narcomedusae, Trachymedusae)

Subclass ACTINULIDAE

Swedmark and Teissier, 1959

Free living, solitary, minute (up to 1.5-2 mm) members of the interstitial fauna of marine sand, resembling "actinuloid" larvae (e.g. Solmundella larvae); umbrella present or reduced; manubrium, or gastric tube, elongated, terminating into a simple mouth-opening; without canal system; with or without a cone-shaped aboral adhesive organ formed by incurved ectoderm; with one or two amphicoronate rings of solid tentacles, either aboral or marginal; with or without brood chamber (= remains of subumbrellar cavity); sexual cells in the endoderm of the manubrium wall; free ecto-endodermal statocysts similar to those of the Trachy- and Narcomedusae, inserted between adjacent tentacles; body covered by flagella; direct development and no classical planula-like stage, embryonic development giving rise to halhydrula larvae; no asexual reproduction; cnidome containing either stenoteles or microbasic mastigophores and, among others, atrichous anisorhizas and two particular cnidocysts: spirotele and aspirotele spironemes.

Distinctive Automedusa features: statocyst structure, embryonic development, formation of the brood chamber (subumbrellar cavity) by means of a circular invagination around the manubrium.

References: Swedmark and Teissier (1966); Laccassagne (1968a).
1. With conical aboral adhesive organ; a nerve ring; two aboral amphicoronate rings of tentacles; gonochoric; without brood pouch (i.e. subumbrellar cavity)...... Halammohydridae

- No aboral adhesive organ; no nerve ring; one marginal ring of tentacles of two kinds, adhesive and armed ones; with or without a brood pouch (i.e. subumbrellar cavity); hermaphroditic, viviparous Otohydridae

\section{Family HALAMMOHYDRIDAE Remane 1927}

Body as a long gastric tube (manubrium) with a terminal mouth, with a small aboral cone, separated from manubrium by a neck, bearing an adhesive organ; aboral nerve ring; one aboral whorl of amphicoronate solid tentacles, alternating with ecto-endodermic statocysts; gonochoric; without brood pouch.

References: Thiel (1988); Bouillon and Boero (2000)

Genus Halammohydra Remane, 1927

With the characters of the family.

References: Swedmark (1956, 1957); Clausen (1967, 1971); Swedmark and Teissier (1958 a and b); Laccasagne (1968b).

1. 14 tentacles and 7 statocysts ...... H. octopodides

- up to 28 tentacles and 12 statocysts H. schulzei

Halammmohydra octopodides Remane, 1927 (Fig. 143A)

Hallammohydra usually with up to 14 amphicoronate tentacles and 7 statocysts, tentacles without large basal thickening; one unique gonad; body 0.3 to $0.4 \mathrm{~mm}$ high.

Records from Mediterranean: Adriatic.

Seasonality: ?

Distribution: Cosmopolitan.

References: Salvini-Plauwen (1966); Thiel (1988); Avian et al. (1995).

Halammohydra schulzei Remane, 1927 (Figs. 143B-D)

Halammohydra with usually 28 amphicoronate tentacles (sometimes up to 32) and 12 statocysts; tentacles with a large basal thickening; generally two opposite gonads; body 0.7 to $0.8 \mathrm{~mm}$ high. 
Records from Mediterranean: Adriatic, western Mediterranean.

Seasonality:?

Distribution: Cosmopolitan.

References: Salvini-Plauwen (1966); Thiel (1988); Avian et al. (1995).

\section{Family OTOHYDRIDAE}

Swedmark and Teissier, 1958

Umbrella ovoid, containing the manubrium; one ring of marginal tentacles of two kinds: adhesive and armed ones; with one whorl of statocysts; with or without a brood pouch (= subumbrellar cavity); hermaphroditic, viviparous.

References: Swedmark and Teissier (1958 a and c); Clausen (1971); Laccasagne (1973); Bouillon and Boero (2000).

Genus Otohydra Swedmark and Teissier, 1958

With the characters of the family.

Otohydra vagans Swedmark and Teissier, 1958c (Figs. 143E-F)

Otohydridae with brood pouch, with up to 24 , usually $12-16$ tentacles; 8 to 12 statocysts; body $0.35 \mathrm{~mm}$ long.

Records from Mediterranean: Adriatic.

Seasonality: ?

Distribution: Atlantic, Mediterranean.

References: Swedmark and Teissier (1958c); Thiel (1988); Avian et al. (1995).

\section{Subclass NARCOMEDUSAE Haeckel, 1879}

Umbrella usually flattened, with a central lensshaped mass of mesoglea and much thinner rim. Umbrellar margin lobed, divided by peronial grooves. Tentacles solid, inserted on exumbrella at some distance from margin, just above peronial grooves, without tentacular bulbs, their endodermal core in contact with the manubrial endoderm passing through the mesoglea of the umbrella as a "root"; sometimes small secondary tentacles on margin. Manubrium very broad and short, with entire circular periphery or with perradial or interradial peripheral pouches. Generally without radial canals; circular canal absent or looped into the marginal flaps to form a "peripheral canal system". "Gonads" on manubrium and/or on manubrial pouches. Medusa with direct development or with tentacled larvae parasitizing other medusae, polychaetes, or fishes; those primary larvae by successive budding give rise to numerous juvenile medusae or to secondary larvae which transform later on into juvenile medusae. They may also develop more complicate structures (stolo-prolifers) which give rise to numerous medusae, representing perhaps the first step to colony formation and modular life. All medusa buds never develop through a medusary nodule. Longitudinal axis of the larvae and adults correspond to the transversal planula axis (in the other medusae those axes coincide). Marginal sense organs as free ecto-endodermal statocysts (only one species with closed ecto-endodermal statocysts). With or without otoporpae. Cnidome: atrichous and apotrichous isorhizae.

References: Uchida (1928); Bouillon (1987, 1999); Bouillon and Barnett (1999); Bouillon and Boero (2000).

1. Without manubrium pouches ........ Solmarisidae

- With manubrium pouches .................................. 2

2. Pouches perradial ................................ Cuninidae

- Pouches interradial............................... Aeginidae

Family AEGINIDAE Gegenbaur, 1857 (sens em. Maas, 1904)

Narcomedusae with interradial divided manubrial pouches containing the gonads; with or without peripheral canal system. With perradial primary tentacles living umbrella between marginal pouches, in number at least half than manubrial pouches; with or without secondary tentacles on umbrella margin. Pouches extending beyond the point of origin of primary tentacles. With or without otoporpae.

References: Bouillon (1999); Bouillon and Barnett (1999); Bouillon and Boero (2000).

1. With only 2 tentacles Solmundella

- With 4 or more tentacles .................................... 2

2. With 8 (or more) tentacles and twice as many manubrial pouches; with secondary tentacles..... Aeginura*

- With 4-6 tentacles; 4-6 peronia and 8-12 manubrial pouches Aegina

*not present in the Mediterranean.

\section{Genus Aegina Eschscholtz, 1829}

Aeginidae with typically 8 primary manubrial pouches, occasionally 10 to 12 ; with peripheral 
canal system; with typically 4 , occasionally 5 or 6 , marginal primary tentacles; without secondary tentacles; without otoporpae.

\section{Aegina citrea Eschscholtz, 1829}

(Fig. 144A)

Umbrella up to $50 \mathrm{~mm}$, hemispherical, mesoglea rigid, thick at the apex, thinner toward periphery; velum well developed; manubrium large, circular and flattened, lower portion conical, usually with 8 rectangular gastric pouches, occasionally with 1012 , some or all may have slight medium clefts or notches; mouth simple circular; peripheral canal system present; gonads on manubrial pouches sometimes extending to manubrium; 4 solid tentacles emerging at upper end of the 4 peronia in deep furrows; no secondary tentacles; 4 lappets with numerous statocysts, 2-20 per lappet; no otoporpae; 5 or 6rayed specimens occur frequently.

Records from Mediterranean: western Mediterranean.

Known seasonality: 4-5.

Distribution: Atlantic, Indo-Pacific, Mediterranean, Antarctic, Arctic.

References: Kramp (1961); Arai and Brinckmann-Voss (1980); van der Spoel and Bleeker (1988); Carré D. et al. (1989); Larson et al. (1991); Bouillon (1995b, 1999); Gili et al. (1998); Bouillon and Barnett (1999).

\section{Genus Solmundella Haeckel, 1879}

Aeginidae with 8 manubrial pouches; without peripheral canal system; with 4 peronia but only 2 long tentacles; without secondary tentacles; without otoporpae.

\section{Solmundella bitentaculata}

(Quoy and Gaimard, 1833) (Figs. 144B, 148F)

Umbrella up to $12 \mathrm{~mm}$ wide, usually much smaller, rounded apex, keel-shaped along the axis leading to tentacles, apical mesoglea very thick, lateral walls thin; velum well developed; manubrium short, lenticular, with 8 rectangular manubrial pouches with rounded edges; mouth circular simple; 2 long, tapering, opposite tentacles issuing from umbrella above manubrium, near apex; gonads in subumbrellar wall, under manubrial pouches; 4 peronia in deep grooves; no peripheral system or otoporpae; 8-32 statocysts.
Records from Mediterranean: eastern and western Mediterranean; Adriatic.

Known seasonality: 1-12.

Distribution: Atlantic, Indo-Pacific, Mediterranean, Antarctic.

References: Babnik (1948); Trégouboff (1957); Kramp (1961); Goy (1973b); Castello i Tortella (1986); Gili (1986); Benovic and Bender (1986, 1987); Brinckmann-Voss (1987); Goy et al. (1991); Boero and Bouillon (1993); Avian et al. (1995); Benovic and Lucic (1996); Medel and LópezGonzález (1996); Gili et al. (1998); Bouillon (1999); Bouillon and Barnett (1999).

\section{Family CUNINIDAE Bigelow, 1913}

Narcomedusae with perradial and undivided manubrial pouches; with or without peripheral canal system; with tentacles living umbrella opposite centre of each manubrial pouch and thus equal in number to that of the pouches; pouches not extending beyond point of origin of tentacles; with or without otoporpae.

References: Bouillon (1999); Bouillon and Barnett (1999); Bouillon and Boero (2000).

1. Without otoporpae Solmissus

- With otoporpae Cunina

\section{Genus Cunina Eschscholtz, 1829}

Cuninidae with otoporpae, with or without peripheral canal system.

1. With peripheral system; manubrial pouches wide and quadratic, more than twice as wide as the septa between them C. globosa

- Without peripheral canal system. 2

2. Manubrium on a broad conical gastric peduncle; 9-14 manubrial pouches; up to $57 \mathrm{~mm}$ wide C. proboscidea

- Without peduncle. 3

3. With 4 manubrial pouches and primary tentacles C. simplex

- With (7-9) usually 8 manubrial pouches and primary tentacles C. octonaria

Several doubtful and unrecognisable species of the genus Cunina have been described from the Mediterranean waters namely $C$. lativentris Gegenbaur, 1857 = probably $C$. globosa; C. polygonia (Haeckel, 1879); C. vitrea, Gegenbaur, 1857 juvenile $=C$. proboscidea . 
Cunina globosa Eschscholtz, 1829

(Figs. 144C-D)

Umbrella up to $18 \mathrm{~mm}$ wide; conical or almost globular; mesoglea thick; manubrium circular on a broad gastric peduncle; up to 10-14 manubrial pouches, wide and quadratic, more than twice as wide as the septa between them; 10-14 relatively short tentacles, issuing from the centre of the bases of the manubrial pouches at a short distance only above the umbrella margin, no ectodermal pads below tentacles bases; peripheral canals well developed; marginal lappets short and broad with 3 statocysts; otoporpae short and oval.

Records from Mediterranean: western Mediterranean.

Known seasonality: 4, 6; 7.

Distribution: Atlantic, Indo-Pacific, Mediterranean.

References: Kramp (1961); Gili (1986); Bouillon (1987,1999); Pagès et al. (1992); Boero and Bouillon (1993); Medel and López-González (1996); Gili et al. (1998); Bouillon and Barnett (1999).

Cunina octonaria McCrady, 1859

(Figs. 144E, 145A, 149A-H)

Umbrella 5-7 mm wide, somewhat flatter than a hemisphere, usually 8 (7-9) square manubrial pouches, very close together; no peripheral canals; tentacles project about midway between margin and apex, a thick and broad ectodermal pad below base of each tentacle; with 2-5 generally 3 statocysts on each marginal lappet; otoporpae small; larvae developed in manubrium or attached to the medusae.

Reproduction: development through a secondary larval structure or a "stolon prolifer".

Records from Mediterranean: eastern and western Mediterranean.

Known seasonality: 2, 3, 6, 8-12.

Distribution: Atlantic; Indo-Pacific; Mediterranean.

References: Kramp (1961); Schmidt (1973, 1976); Lakkis and Zeidane (1985); Goy et al. (1988, 1990, 1991); Bouillon (1987); Boero and Bouillon (1993).

Cunina proboscidea E. and L. Metschnikoff, 1871 (Figs. 145B-C)

Umbrella up to $57 \mathrm{~mm}$ wide, somewhat conical; manubrium long, conical, mouth often projecting beyond velar opening; with a large gastric peduncle; 9-14 manubrial pouches, long, rectangular, separated by narrow spaces; peripheral canal system degenerated; tentacles very short; marginal lappets bluntly rounded, each with 3-4 statocysts, otoporpae, short, club-shaped.

Hydroid: Complex development in the manubrium of the mother medusae and afterwards in the manubrial cavity of Geryonia (Trachymedusae) (see Bouillon, 1987).

Records from Mediterranean: western Mediterranean.

Known seasonality: 3, 9.

Distribution: Mediterranean.

References: Ranson (1936); Kramp (1961); Bouillon (1987); Boero and Bouillon (1993).

Cunina simplex Gili, Bouillon, Pagès, Palanques, Puig and Heussner, 1998

(Fig. 145D-E)

Umbrella higher than a hemisphere, almost globular, $3.7 \mathrm{~mm}$ wide and $2.8 \mathrm{~mm}$ high; mesoglea thick, manubrium large, circular with 4 small, perradial, tongue-shaped, undivided manubrial pouches narrowing in width from base outwards; septa between pouches very wide; with 4 primary tentacles living umbrella opposite centre of each stomach pouch; with 4 peronia; without secondary tentacles on umbrella margin; gonads on manubrium and manubrial pouches walls; with a narrow peripheral canal system; marginal lappets rectangular, large each with 3 small, circular, otoporpae and 1-2 statocysts per quadrant.

Records from Mediterranean: western Mediterranean.

Known seasonality: 4.

Distribution: endemic of the Mediterranean Sea. References: Gili et al. (1998).

Genus Solmissus Haeckel, 1879

Cuninidae without otoporpae, without peripheral canal system.

References: Bouillon (1999); Bouillon and Barnett (1999).

1. Exumbrella with numerous gelatinous warts or discoid cnidocysts patches; manubrial pouches pentagonal; umbrella up to $50 \mathrm{~mm}$ wide; maximum number of tentacles $16 ; 5-8$ statocysts per marginal lappet S. albescens 
- Exumbrella smooth; manubriual pouches oval; umbrella up to $100 \mathrm{~mm}$ wide; number of tentacles 20-40; 2-5 statocysts per marginal lappet. S. incisa

Solmissus albescens Gegenbaur, 1857 (Figs. 146A-B)

Umbrella up to $50 \mathrm{~mm}$ in diameter; central part of umbrella doubly convex, lenticular; bell collar thin, flexible, contractile; exumbrella scattered either with small but distinct gelatinous warts and/or with flat discoid or elongated cnidocyst patches which may be found only on the lappets; velum broad; manubrium large, circular with 14-16 marginal perradial pouches, pentagonal in shape and somewhat wider than long, their outer angles lying under the tentacle roots; with wide mouth opening; with 14-16 tentacles nearly as long as the umbrella diameter, tapering and not very flexible; about 14-16 marginal lappets, rectangular but with rounded angles on their outer margin, each with 5-8 statocysts; gonads developed in the subumbrellar ectoderm of manubrium and manubrial pouches.

Records from Mediterranean: eastern and western Mediterranean.

Known seasonality: 1-12.

Distribution: endemic of the Mediterranean Sea.

References: Trégouboff (1957); Kramp (1961); Berhaut (1970); Goy (1973b); Gili (1986); Benovic and Bender (1987); Goy et al. (1988, 1990, 1991); Mills and Goy (1988); Boero and Bouillon (1993); Avian et al. (1995); Benovic and Lucic (1996); Medel and López-González (1996); Mills et al. (1996); Gili et al. (1998), Osborn (2000).

\section{Solmissus incisa (Fewkes, 1886)}

(Figs. 146C-D)

Umbrella up to $100 \mathrm{~mm}$ wide, flat, disk-like, with thin and flexible margin, mesoglea fairly thick but soft and fragile, exumbrella smooth; velum well developed; manubrium large, circular, covering subumbrella surface; 20 to 40 perradial manubrial pouches, oval in outline, usually somewhat longer than wide, septa between them alternating with tentacle roots; 20-40 marginal tentacles, stiff, tapering, up to slightly longer than diameter of umbrella; no peripheral canal system; gonads?; marginal lappets rectangular, about as long as broad, each with 2-5 statocysts, no otoporpae.

Records from Mediterranean: western Mediterranean
Seasonality: ?

Distribution: Atlantic, Indo-Pacific, Mediterranean?.

References: Ranson (1936); Russell (1953); Kramp (1961); Arai and Brinckmann-Voss (1980); Larson et al. (1991); Boero and Bouillon (1993).

Remarks: $S$. incisa is closely related to $S$. albescens, Ranson (1936) suggested that $S$. incisa is merely a giant form of $S$. albescens.

\section{Family SOLMARISIDAE Haeckel, 1879}

Narcomedusae without manubrial pouches, the periphery of the manubrium being circular and unbroken; with or without peripheral canal system; gonads on manubrial wall or on manubrial wall diverticula; with numerous tentacles living umbrella at level of periphery of the manubrium. With or without otoporpae.

References: Bouillon (1999); Bouillon and Barnett (1999); Bouillon and Boero (2000).

1. With peripheral canal system; with otoporpae....

- Without peripheral canal system; without otoporpae. Solmaris

Genus Pegantha Haeckel, 1879

Solmarisidae with gonads forming diverticula of margin of oral manubrium wall; with peripheral canal system; with otoporpae.

1. Exumbrella with deep radiating furrows from tentacles to apex, surrounded by ribs and supplementary ridges........................ P. triloba.

- Exumbrella smooth; peripheral canals narrow throughout their length; with 12-16 marginal lappets P. rubignosa

Two other Pegantha species, P. mollicina (Forskäl, 1775) and P. zonaria (Haeckel, 1879) have been described from the Mediterranean waters but are considered as unrecognisable species (see Kramp, 1961).

Pegantha rubiginosa (Kölliker, 1853) (Figs. 147A-B)

Umbrella up to about $16 \mathrm{~mm}$ wide, domeshaped, mesoglea very thick, smooth, with 12-16 marginal lappets, rectangular with rounded corners, 
each with 4-6 statocysts; the two middle otoporpae long and narrow, frequently longer than the lappet, the lateral ones shorter; peripheral canals very narrow throughout their length; gonads without radial diverticulae.

Development through two sexual generations and a "stolon prolifer".

Records from Mediterranean: eastern and western Mediterranean.

Known seasonality: 1-12.

Distribution: Atlantic; Indo-Pacific; Mediterranean.

References: Kramp (1957b, 1959, 1961); Goy (1973b); Schmidt (1976); Bouillon (1987); Boero and Bouillon (1993); Avian et al. (1995); Goy (1997).

Pegantha triloba Haeckel, 1879

(Figs. 147C, 148G)

Umbrella up to $30 \mathrm{~mm}$ wide, hemispherical; mesoglea very rigid, apex somewhat flattened; exumbrella with deep radiating furrows from tentacles to near apex, surrounded by ribs and supplementary ridges; velum broad; manubrium circular, broad; mouth simple, circular; 12-16 tentacles somewhat longer than umbrella diameter; 1216 marginal lappets ovate, with sharp pointed end, each with up to 20 statocysts; gonads adhering to base of manubrium consisting in central sacs with variously subdivided lobes projecting into each lappet cavities; otoporpae long tapering outwards.

Development through primary larvae with eight capitate tentacles budding of successive medusa buds and finally metamorphosing himself in medusae.

Records from Mediterranean: western Mediterranean.

Known seasonality: 5.

Distribution: Atlantic, Indo-Pacific, Mediterranean.

References: Vanhöffen (1913); Kramp (1961); Schmidt (1973); Winkler (1982); Bouillon (1987); Pagès et al. (1992).

\section{Genus Solmaris Haeckel, 1879}

Solmarisidae without peripheral canal system; without otoporpae, with simple annular gonads.

References: Bouillon (1999); Bouillon and Barnett (1999).
1. With 6-8 statocysts on each marginal lappet; up to $35 \mathrm{~mm}$ wide; with $18-20$ tentacles

S. solmaris

- With 1-4 statocysts on each marginal lappet ... 2

2. Umbrella less than $7 \mathrm{~mm}$ wide when adult S. leucostyla

- Umbrella more than $7 \mathrm{~mm}$ wide when adult ... 3

3. Umbrella $12-15 \mathrm{~mm}$ wide; with $30-36$ or more tentacles and lappets S. corona

- Umbrella 15-23 mm wide; with 12-17 tentacles and lappets S. flavescens

Solmaris vanhoeffeni Neppi and Stiasny, 1911 has been described from the Adriatic Sea, this species is considered by Thiel (1936) as conspecific with S. flavescens and Kramp (1961) regards it as a juvenile stage of some other species.

Solmaris corona (Keferstein and Ehlers, 1861) (Figs. 147D-E)

Umbrella 12-15 $\mathrm{mm}$ wide, lens-shaped, with thick mesoglea; manubrium circular covering all lower surface of upper half of umbrella; gonads forming a broad ring on outer part of subumbrellar manubrium wall; with 30-36 or more marginal tentacles and marginal lappets, lappets rectangular up to twice as long as broad, usually with $2(1-4)$ statocysts mounted on large cushion, with long bristles.

Records from Mediterranean: western Mediterranean.

Known seasonality: 7.

Distribution: Atlantic; Indo-Pacific; Mediterranean.

References: Russell (1953); Trégouboff (1957); Kramp (1961); Boero and Bouillon (1993).

Solmaris flavescens (Kölliker, 1853)

(Figs. 148A-C)

Umbrella 15-23 mm wide, thick, lens-shaped, mesoglea of central umbrellar disk lenticular and quite thick, lateral sides thin; velum large; manubrium flat and lenticular; gonads in the subumbrellar floor of the manubrial margin; with 12-17 (usually 13-15) long, stiff, marginal tentacles at right angles to the umbrellar sides and as many marginal lappets and peronia; marginal lappets thin, quadrate, each with 2- 4 statocysts.

Records from Mediterranean: western Mediterranean; Adriatic.

Known seasonality: 1-5, 9-12. 
Distribution: Atlantic; Indo-Pacific; Mediterranean.

References: Trégouboff (1957); Kramp (1961); Gili (1986); Brinckmann-Voss (1987); Bouillon et al. (1988a); Boero and Bouillon (1993); Avian et al. (1995); Medel and López-González (1996); Goy (1997).

\section{Solmaris leucostyla (Will, 1844)}

(Fig. 148D)

Umbrella 3-7 mm wide, flat to hemispherical; velum small; 12-26 slender tentacles and as many marginal lappets; the lappets quadratic, each with usually one statocysts (1-3); perhaps a variety of $S$. flavescens.

Records from Mediterranean: western Mediterranean; Adriatic.

Known seasonality: 1-12.

Distribution: endemic of Mediterranean Sea.

References: Trégouboff (1957); Kramp (1961); Berhaut (1970); Goy (1973b); Castelló i Tortella (1986); Gili (1986); Benovic and Bender (1987); Bouillon (1987); Boero and Bouillon (1993); Avian et al. (1995); Medel and López-González (1996); Mills, et al. (1996).

Solmaris solmaris (Gegenbaur, 1857) (Fig. 148E)

Umbrella 25-35 mm wide, flat, lenticular; concavo-convex; 18-20 long tentacles; marginal lappets quadratic, each with 6-8 statocysts

Records from Mediterranean: western and central Mediterranean.

Known seasonality: 3, 5 .

Distribution: endemic of Mediterranean Sea.

References: Trégouboff (1957); Kramp (1961); Gili (1986); Boero and Bouillon (1993); Medel and López-González (1996).

\section{Subclass TRACHYMEDUSAE Haeckel, 1866}

Medusa with hemispherical or deep bellshaped umbrella. Margin entire with a thickened peripheral cnidocyst ring. Radial canals and circular canal present. Velum often with heavy musculature. With solid marginal tentacles or with a mixture of solid and hollow ones, without true tentacular bulbs, with endodermal cores continuing in the mesoglea of the umbrella as short "roots". With or without centripetal canals. Manubrium with or without gastric peduncle. "Gonads" usually on radial canals. Without polyp stage; a differentiated planula stage is lacking in a number of Trachymedusae, the gastrula developing immediately into young medusae, in others, the planula stage is retained and gives rise to a post-embryonic tentacled larval stage before transforming into medusae. No adult or larval asexual budding observed. Marginal sense organs as free sensory clubs exceptionally enclosed in the mesoglea or in the velum. Cnidome: generally stenoteles associated with microbasic euryteles or/and atrichous isorhizae.

References: Uchida (1928); Bouillon (1999); Bouillon and Barnett (1999); Bouillon and Boero (2000).

1. With centripetal canals Geryoniidae

- Without centripetal canals

2. With broad, circular manubrium and broad radial canals Halicreatidae

- Manubrium and radial canals narrow Rhopalonematidae

Family GERYONIIDAE Eschscholtz, 1829

Trachymedusae with gastric peduncle; 4-6 radial canals (sometimes more); with centripetal canals; gonads on radial canals, flattened and leaf-shaped; 2 kinds of marginal tentacles, solid and hollow; ectoendodermal statocysts enclosed in mesoglea.

References: Bouillon (1999); Bouillon and Barnett (1999); Bouillon and Boero (2000).

1. With 6 radial canals, six gonads, mouth with six lips Geryonia

- Usually with 4 radial canals and gonads (sometimes more), mouth with four lips

Liriope

Genus Geryonia Péron and Lesueur, 1810

Geryoniidae with six lips; six radial canals and six gonads.

Geryonia proboscidalis (Forskäl, 1775) (Figs. 150A-C)

Umbrella 35-80 mm wide, almost hemispherical; manubrium small, on long, conical, gastric peduncle; mouth with 6 simple lips; with six radial canals; up to 7 centripetal canals between each radial 
canals; gonads heart-shaped, very broad above; 6 long, perradial hollow tentacles with cnidocyst rings and 6 small, solid interradial tentacles with adaxial cnidocyst clusters; 12 statocysts.

Records from Mediterranean: eastern and western Mediterranean; Adriatic.

Known seasonality: 1-3, 6-8, 11, 12.

Distribution: Atlantic, Indo-Pacific, Mediterranean.

References: Kramp (1961); Berhaut (1970); Goy (1973b); Brinckmann-Voss (1987); Goy et al. (1988, 1990, 1991); Boero and Bouillon (1993); Avian et al. (1995); Benovic and Lucic (1996); Medel and López-González (1996).

\section{Genus Liriope Lesson, 1843}

Geryoniidae with four lips; usually four radial canals and four gonads, sometimes more.

\section{Liriope tetraphylla}

(Chamisso and Eysenhardt, 1821)

(Figs. 150D-I)

Umbrella 10-30 $\mathrm{mm}$ wide, hemispherical, apex somewhat flattened; mesoglea thick, rigid; velum broad; manubrium small, on long, cylindrical gastric peduncle, longer than umbrellar diameter; mouth with 4 simple lips boarded with cnidocysts; with normally 4 radial canals (sometimes more); 1-7 centripetal canals in each quadrant; with marginal cnidocyst ring; typically 4 long hollow perradial tentacles with cnidocyst rings and 4 small solid interradial tentacles with adaxial cnidocyst clusters; with gonads variable in shape and size, generally heart-shaped, on either side of the middle of radial canals; 8 statocysts.

Records from Mediterranean: eastern and western Mediterranean; Adriatic; Black Sea.

Known seasonality: 1-12.

Distribution: Atlantic, Indo-Pacific, Mediterranean.

References: Kramp (1961); Berhaut (1969, 1970); Goy (1973b); Castelló i Tortella (1986); Gili (1986); Benovic and Bender (1987); Brinckmann-Voss (1987); Zamponi and Genzano (1988); Scemes and McNamara (1991); Boero and Bouillon (1993); Avian et al. (1995); Benovic and Lucic (1996); Desouza et al. (1996); Medel and López-González (1996); Mills et al. (1996); Goy (1997).
Family HaLiCREATIDAE Fewkes, 1886

Trachymedusae with wide, circular manubrium; mouth circular, without distinct lips; without peduncle; without centripetal canals; with 8 or more broad radial canals; with numerous marginal tentacles of different size, but all structurally alike and arranged in single series; each marginal tentacle with flexible proximal portion and stiff spine-like distal portion; with free ecto-endodermal statocysts.

References: Bouillon (1999); Bouillon and Barnett (1999); Bouillon and Boero (2000).

1. With about 16 or more radial canals .. Halitrephes

- With 8 radial canals Haliscera

Genus Haliscera Vanhöffen, 1902

Halicreatidae with 8 radial canals; with a continuous row of marginal tentacles; without papillae on the exumbrella.

1. Umbrella hemispherical, with evenly rounded apex and fairly thin walls; gonads close to manubrium; six tentacles in each octant H. racovitzae

- Umbrella with very thick dome-shaped apex; gonads well separated from manubrium, eight to twelve tentacles in each octant

2. Umbrella with distinct conical apical projection; 64-72 marginal tentacles in adult ....... H. conica

- Umbrella with very thick, hemispherical apex, about 96 marginal tentacles in adult H. bigelowi

Haliscera bigelowi Kramp, 1947

(Figs. 151A-B)

Umbrella 15-19 $\mathrm{mm}$ wide, 9-10 $\mathrm{mm}$ high, almost hemispherical, umbrella with a very thick dome-shaped mesogleal apex comprising about $2 / 3$ of the umbrella height, mesoglea thin at sides and margin; velum very broad; manubrium broad, flat, slightly conical; mouth simple, circular; 8 straight, broad radial canals and broad circular canal; in adults, about 12 solid marginal tentacles in each octant, flexile proximally, stiff distally; the base of each tentacles surrounded by a small thickening of marginal cnidocyst tissue; with 8 gonads broadly oval, flat, about $2 / 5$ as long as the radial canals, situated slightly nearer 
the manubrium than to bell margin; 3 statocysts in each octant.

Records from Mediterranean: western Mediterranean; Adriatic.

Known seasonality: 1, 5, 7, 12.

Distribution: Atlantic; Indo-Pacific, Mediterranean; Arctic.

References: Kramp (1961); Naumov (19601969); Schmidt and Benovic (1977); Gili (1986); Boero and Bouillon (1993); Avian et al. (1995); Medel and López-González (1996); Gili et al. (1998).

\section{Haliscera conica Vanhöffen, 1902} (Fig. 151C)

Umbrella up to $18 \mathrm{~mm}$ wide, with thick, bluntly conical apical projection; gonads oval on the middle portion of the eight broad radial canals; 8-9 marginal tentacles, flexile proximally and stiff distally and 2 statocysts in each octant, the base of each tentacle surrounded by a broad thickening of the marginal cnidocyst tissue.

Records from Mediterranean: western Mediterranean.

Known seasonality: 2, 4-10.

Distribution: Antarctic; Atlantic; Indo-Pacific; Mediterranean.

References: Kramp (1961); Goy (1973b); Dallot, Goy and Carré (1988); Boero and Bouillon (1993), Mills et al, (1996); Goy (1997); Gili et al. (1998).

Haliscera racovitzae (Maas, 1906) (Figs. 151D-E)

Umbrella $8 \mathrm{~mm}$ wide, $4 \mathrm{~mm}$ high, almost hemispherical; with fairly thin walls, mesoglea thin, flaccid, apex evenly rounded; velum very wide; manubrium a truncated cone, broad, flat; mouth simple, circular; 8 radial canals, narrow distally, circular canal fairly narrow; gonads flat, shield-shaped, along 1/2-2/5 of proximal part of the radial canals, very close to manubrium; with 6 solid tentacles, flexile proximally and stiff distally in each octant; with 2 statocysts in each octant.

Records from Mediterranean: western Mediterranean.

Known seasonality: 9.

Distribution: Atlantic, Indo-Pacific, Antarctic, Mediterranean.

References: Kramp (1961); Gili et al. (1998).
Genus Halitrephes Bigelow, 1909

Halicreatidae with 16 or more radial canals; with a continuous row of tentacles; without papillae on exumbrella.

Halitrephes maasi Bigelow, 1909

(Fig. 151F)

Umbrella up to $100 \mathrm{~mm}$ wide, low, rounded, smooth, without exumbrella papillae; mesoglea thin, soft and flaccid; velum well developed; manubrium small with simple circular mouth; 16-30 broad, ribbonlike radial canals, some may be bifurcated, circular canal broad; 100-300 marginal tentacles, flexile proximally and stiff distally in continuous row; shape of adult gonads unknown; number of statocysts unknown.

Records from Mediterranean: eastern Mediterranean.

Known seasonality: 3.

Distribution: Atlantic, Indo-Pacific, Antarctic, Mediterranean.

References: Kramp (1961); Goy et al, (1991); Gili et al. (1998).

Family PETASIDAE Haeckel, 1879

Trachymedusae with four radial canals; without peduncle and centripetal canals; with well developed manubrium; with 4 sac-like gonads on radial canals; with marginal tentacles not in clusters, solid, with a terminal club-shaped knob of cnidocysts; with free statocysts.

References: Bouillon (1999); Bouillon and Barnett (1999); Bouillon and Boero (2000).

Genus Petasus Haeckel, 1879

Petasidae with marginal tentacles regularly arranged, at equal intervals.

Petasus atavus Haeckel, 1879

(Fig. 151G)

Umbrella $1 \mathrm{~mm}$ wide and high, globular; manubrium prismatic; mouth with 4 short lips; with 4 protrusive, spindle-shaped or band-shaped gonads, along greater part of the radial canals; four marginal tentacles with ciliated club-shaped end; four free statocysts.

Records from Mediterranean: eastern Mediterranean 
Known seasonality: 4.

Distribution: Atlantic, Mediterranean. (1910).

References: Kramp (1959a, 1961); Mayer

Family PTYCHOGASTRIIDAE Mayer, 1910

Trachymedusae with either simple manubrium without mesenteries, or with eight-lobed manubrium, with eight mesenterial partitions; with marginal tentacles grouped into more or less well defined clusters, some with adhesive disks or with very numerous tentacles, not in clusters but inserted at various levels of exumbrella; no centripetal canals or peduncle; with 8 radial canals; gonads either attached onto manubrium, on sides of 8 manubrial lobes, or on radial canals adjacent to manubrial lobe; free ecto-endodermal statocysts.

References: Bouillon and Boero (2000).

\section{Genus Ptychogastria Allman, 1878}

Ptychogastriidae with marginal tentacle in clusters, some with adhesive disks; manubrium with lateral lobes; with eight mesenterial partitions; gonads on the sides of the manubrial lobes or on radial canals adjacent to manubrial lobes.

\section{Ptychogastria asteroides (Haeckel, 1879) (Figs. 152A-C)}

Umbrella 4-5 mm wide, hemispherical to bellshaped, with fairly thin mesoglea and a small rounded apical projection; exumbrella with 16 raised radiating ridges extending from centre of exumbrella to margin where they end in 16 conical marginal lobes beset with a few cnidocysts and numerous varied inclusions; manubrium eight-lobed; with eight mesenteries; mouth with four simple lips, rich in cnidocysts and granular gland cells; with 8 radial canal; with 8 egg-shaped gonads on proximal $1 / 3$ of radial canals adjacent to manubrium and linked to him by the mesenterial septa; with 16 isolated solid tentacles armed with rings of cnidocysts and 200 to 260 solid tentacles, most of them with adhesive organs, and few scattered cnidocysts, in 16 clusters arising from the marginal lobes, velum thick, powerful; 16 free statocysts.

Records from Mediterranean: western Mediterranean, Adriatic.

Known seasonality: 1-12.

Distribution: endemic of the Mediterranean Sea.
References: Kramp (1961); Picard (1955a); Brinckmann-Voss (1987); Boero and Bouillon (1993); Avian et al. (1995); Gili et al. (1998, 1999).

\section{Family RHOPALONEMATIDAE Russell, 1953}

Trachymedusae with a narrow manubrium; with or without peduncle; without centripetal canals; usually 8 , rarely more, narrow radial canals; mouth with distinct lips; with marginal tentacles evenly distributed, sometimes of two kinds, each marginal tentacle of uniform structure throughout or with proximal portion differing from distal one; with gonads either on radial canals globular, linear, or hanging in pouches into subumbrellar cavity, or forming a continuous ring around base of manubrium and extending outwards along radial canals; with free, rarely enclosed ecto-endodermal statocysts.

References: Bouillon (1999); Bouillon and Barnett (1999); Bouillon and Boero (2000).

1. Gonads in a continuous band around manubrium extending outwards on radial canals

Homoeonema

- Gonads isolated, on radial canal, sometimes adjacent to manubrium .................................... 2

2. Without gastric peduncle................................. 3

- With gastric peduncle...................................... 7

3. With 4 gonads only, pendent; 4 large and 24 small marginal tentacles ................... Tetrorchis

- With 8 (rarely more) gonads .............................. 4

4. With two kinds of marginal tentacles; with enclosed statocysts Rhopalonema

- With tentacles all of one kind; with free club-shaped statocysts ... 5

5. onads adjacent to manubrium (sometimes also 8 gonads free from manubrium); very numerous tentacles Arctapodema

- Gonads separated from manubrium .

6. Gonads globular, distal, contiguous to circular canal; with 8 tentacles.... Sminthea

- Gonads linear, with 48 or more marginal tentacles Pantachogon

7. Gastric peduncle short conical (in young specimens almost invisible); gonads attached on subumbrellar portions of radial canals ............ 8

- Gastric peduncle long, slender; gonads attached to peduncular portions of radial canals ........... 9

8. With only two pendent gonads ................ Persa

- With 8 gonads ................................ Amphogona

9. Gonads linear on peduncle only.......... Ransonia

- Gonads sausage-shaped, pendent ................... 10 
10. Gonads attached to peduncle Aglaura

- Gonads attached to subumbrellar portions of radial canals Aglantha

\section{Genus Aglantha Haeckel, 1879}

Rhopalonematidae with a long and slender gastric peduncle; with eight pendent sausage-shaped gonads on subumbrellar portions of the eight radial canals; with numerous tentacles all alike; with free club shaped marginal statocysts.

1. Gonads on radial canals close to base of peduncle, 8 statocysts A. digitale

- Gonads on radial canals about midway between peduncle and umbrela margin, 16 statocysts ...... A. elata

Aglantha digitale (O.F.Müller, 1766)

(Figs. 152D-E)

Umbrella cylindrical, 10-40 $\mathrm{mm}$ high, about twice high than wide, with a small conical projection, lateral mesogleal walls thin, subumbrellar muscles strong; peduncle slender, long, conical, almost as long as subumbrellar cavity; manubrium small; mouth with four simple lips, eight, long, sausageshaped gonads, arising from the radial canals near the apex of the subumbrella and hanging freely in subumbrellar cavity; 80 or more solid marginal tentacles with a core of single endodermal chordal cells; 8 free statocysts.

Records from Mediterranean: western Mediterranean.

Known seasonality: 4

Distribution: Atlantic; Indo-Pacific; Mediterranean.

References: Kramp (1924, 1959a); Russell (1953); Gili (1986).

Remarks: Kramp (1924) described this species from the middle of the Strait of Gibraltar and estimated that this species was attempting to enter in the Mediterranean where this species had however never been found (see Kramp, 1959a, 1961; Goy 1972); Gili in 1986 collected 2 specimens in front of Barcelona.

Aglantha elata (Haeckel, 1879) (Fig. 152F)

Umbrella 10-12 mm high, 3-4 mm wide, narrow, elongated, with pointed apical projection; gastric peduncle cylindrical about half as long as bell cavity; manubrium small, $1 / 8$ as long as gastric peduncle; four triangular lips; eight gonads about as long as gastric peduncle, attached to about middle points of subumbrellar parts of radial canals; 40-48 marginal tentacles; 16 free statocysts.

Records from Mediterranean: Adriatic Sea.

Known seasonality: 8.

Distribution: Atlantic; Pacific; Mediterranean.

References: Kramp (1959a); Schmidt and Benovic (1977).

Genus Aglaura Péron and Lesueur, 1810

Rhopalonematidae with slender gastric peduncle; with 8 sausage-shaped gonads attached on peduncle, not on subumbrella; with numerous tentacles all alike, with free club-shaped statocysts.

Aglaura hemistoma Péron and Lesueur, 1810 (Fig. 152G)

Umbrella 4-6 mm high, 3-4 mm wide; with vertical, parallel walls, with very narrow longitudinal ridges, with flattened apex, mesoglea exceedingly thin; margin almost octagonal in cross section; velum extremely broad, usually hanging downwards; gastric peduncle, conical, somewhat shorter than subumbrellar radius; manubrium small, flaskshaped; mouth with four small, simple, projecting lips; 8 narrow radial canals and narrow circular canal; gonads sausage-shaped attached on the peduncle at the place of juncture of the radial canals with the manubrium; 48-85 marginal tentacles all alike; 8 statocysts.

Records from Mediterranean: eastern and western Mediterranean; Adriatic Sea.

Known seasonality: 1-12.

Distribution: Atlantic, Indo-Pacific; Mediterranean.

References: Kramp (1961); Berhaut (1970); Albertini-Berhaut (1971b); Goy (1973b); Castelló i Tortella (1986); Gili (1986); Benovic and Bender (1987); Brinckmann-Voss (1987); Goy et al. (1988, 1990, 1991); Boero and Bouillon (1993); Avian et al. (1995); Benovic and Lucic (1996); Medel and López-González (1996).

Genus Amphogona Browne, 1905

Rhopalonematidae with short, conical gastric peduncle, exumbrella smooth; with ellipsoidal or 
sac-shaped, pendant gonads on the 8 radial canals, gonads usually of unequal size; with tentacles all alike, not densely crowded; with free club-shaped statocysts.

Amphogona pusilla Hartlaub, 1909 (Fig. 152H)

Umbrella 1.5- $6 \mathrm{~mm}$ wide, nearly hemispherical, with thin mesoglea; manubrium small, short; with short conical gastric peduncle; mouth with four simple lips; 8 simple radial canals; 8 gonads, spherical to elongated, on distal part of the radial canals, living 1/4 of the length of radial canal near circular canal free; 16 marginal tentacles with basal enlargements, statocysts unknown.

Records from Mediterranean: western Mediterranean.

Known seasonality: 4.

Distribution: Indo-Pacific; Mediterranean.

References: Kramp (1961, 1965); Goy (1973b); Boero and Bouillon (1993).

\section{Genus Arctapodema Dall, 1907}

Rhopalonematidae without gastric peduncle; with gonads on radial canals adjacent to manubrium; with 8 narrow radial canals; numerous tentacles, all alike, in a single row; free statocysts.

1. Manubrium with 16 radial folds; gonads pendent on radial canals, near base of manubrium A. australis

- Manubrium with 8 radial lobes; gonads extending from radial lobes of the manubrium outwards on proximal parts of radial canals, sometimes also pairs of small gonads on radial canals separated from manubrium. A. ampla

Mills et al, (1996) found in the Alborán Sea an Arctapodema sp. that they could not assign to either of the above-cited species.

Arctapodema ampla (Vanhöffen, 1902)

(Figs. 152I-J)

Umbrella up to $15 \mathrm{~mm}$ wide, somewhat flatter than a hemisphere, mesoglea thin; manubrium short, urn-shaped, with 8 radial lobes; mouth with four simple lips; 8 simple radial canals; with 8 swollen gonads of unequal size, some divided in two halves, extending from radial lobes of manubrium outwards onto proximal parts of radial canals; sometimes also 8 pairs of small gonads on radial canals, separated from manubrium; about 100 tentacles; 4-8 statocysts.

Records from Mediterranean: western Mediterranean, Adriatic.

Known seasonality: 3, 5, 7, 9-11.

Distribution: Antarctic; Southern and tropical Atlantic; Mediterranean.

References: Kramp (1961); Goy (1973b); Boero and Bouillon (1993); Avian et al. (1995).

Arctapodema australis (Vanhöffen, 1912)

(Figs. 153A-C)

Umbrella up to $23 \mathrm{~mm}$ wide and $14 \mathrm{~mm}$ high, mesoglea thin; manubrium short and broad, with 16 radial folds; mouth with four simple lips; 8 gonads globular or club-shaped, pendent, on the radial canals near base of the manubrium; about 112 marginal tentacles; statocysts unknown; manubrium red in adults.

Records from Mediterranean: western Mediterranean; Adriatic Sea.

Known seasonality: 4, 7-10.

Distribution: Antarctic; Indo-Pacific; Mediterranean.

References: Kramp (1961); Schmidt and Benovic (1977); Benovic and Bender (1987); Benovic and Lucic (1996); Gili et al. (1998).

Genus Homoeonema (Maas, 1893). Browne, 1903

Rhopalonematidae without gastric peduncle; gonads forming a continuous band around base of manubrium and extending outwards along proximal half of 8 radial canals; numerous tentacles, all alike; vesicular statocysts.

Homoeonema platygonon Browne, 1903 (Figs. 153D-G)

Umbrella up to $2 \mathrm{~mm}$ high, bell shaped, higher than wide, with round or more rarely conical apex mesoglea thin, apical part containing numerous fat droplets and irregular inclusions (crystals); no peduncle; manubrium short, flat, quadratic; mouth with 4 simple, short, recurved lips, the tips armed with stenoteles; no apical process; up to 80 closely crowded marginal tentacles, issued from an exumbrellar marginal ring rich in cnidocysts and irregular inclusions; base of tentacles enlarged, 
containing cnidocysts and inclusions, giving rather abruptly rise to the proximal parts of the tentacles which are straight, devoid of cnidocysts and have their endodermal core built by large cubical chordal cells (perhaps flexible), distal parts of the tentacles spirally coiled, crowded with cnidocysts, endodermal core formed by flattened, disk-shaped, chordal cells; no cirri or non tentacular bulbs; eight fairly wide radial canals, full of irregular inclusions, circular canal not visible included in the marginal cnidocyst ring; velum very large; gonads, in adults 8 elongated masses along the $1 / 2$ or $2 / 3$ of the proximal part of the radial canals, their most proximal ends being fused and forming a small ring surrounding the base of the manubrium, in young specimens the gonads appear first as oval masses on the proximal third of the radial canals and then slowly extend downwards and upwards, they finally become confluent in the upper interradial parts and encircle the manubrial base; vesicular statocysts.

Records from Mediterranean: western Mediterranean; Adriatic.

Known seasonality: 2, 4, 5, 7, 8, 10-12.

Distribution: Atlantic; Mediterranean; Arctic.

References: Kramp (1947, 1959, 1961); Boero and Bouillon (1993); Avian et al. (1995); Benovic and Lucic (1996); Gili et al. (1998).

\section{Genus Pantachogon Maas, 1893}

Rhopalonematidae without gastric peduncle; with the apical outlines of the subumbrellar muscular fields forming an entire circle; with gonads on the 8 radial canals separated from manubrium; with 48 or more tentacles all alike; free club-shaped marginal statocysts.

1. Umbrella mitre-shaped, with gelatinous apical projection; 48 marginal tentacles...... P. militare

- Umbrella without apical projection; 64 marginal tentacles. P. haeckeli

Pantachogon haeckeli Maas, 1893 (Figs. 153H-J, 154A)

Umbrella about $20 \mathrm{~mm}$ wide and high, bellshaped, sometimes wider than high, without apical projection, mesoglea fairly thin; umbrella with very strong and conspicuous musculature, forming an entire circle; large specimens with 32 fine exumbrellar longitudinal meridional furrows; velum very broad; manubrium small, varying in length, octagonal at base; mouth with 4 simple, small, pointed lips; no gastric peduncle; 8 narrow, straight radial canals, circular canal narrow; gonads initially forming discontinuous linear swellings along distal $2 / 3$ or almost whole length of the radial canals, which eventually coalesce and become folded transversally; 64 marginal tentacles all alike in one row; 64 free club-shaped statocysts.

Records from Mediterranean: eastern Mediterranean.

Known seasonality: 1, 3, 9, 11, 12.

Distribution: Atlantic, Indo-Pacific, Antarctic, Arctic, Mediterranean.

References: Kramp (1961); Dowidar and ElMaghraby (1970); Arai and Brinckmann-Voss (1980); Winkler (1982); Dowidar (1983); Goy et al. (1988, 1990, 1991); Boero and Bouillon (1993); Gili et al. (1998).

Pantachogon militare (Maas, 1893)

(Fig. 154B)

Umbrella 7-10 $\mathrm{mm}$ wide, $6 \mathrm{~mm}$ high; mitreshaped, with a well developed apical projection; gonads lancet-shaped, on distal half of 8 radial canals; 48 tentacles all alike; 4 (or more) statocysts.

Records from Mediterranean: western Mediterranean.

Seasonality: ?

Distribution: Atlantic; Mediterranean; Antarctic?.

References: Kramp (1959a, 1961); Boero and Bouillon (1993).

\section{Genus Persa McCrady, 1859}

Rhopalonematidae with a short gastric peduncle; with only two oval or sausage-shaped gonads, pendant, near middle point of the subumbrellar portions of two opposite radial canals; 8 radial canals; with numerous long tentacles, all alike, each with a terminal knob; with free club-shaped statocysts.

Persa incolorata McCrady, 1859 (Figs. 154C-D)

Umbrella $3 \mathrm{~mm}$ wide, $4 \mathrm{~mm}$ high, with or without a small apical projection, mesoglea very thin; velum broad; with a very retractile gastric peduncle; manubrium tubular, elongated; mouth with four small, broadly rounded, prominent lips; 8 narrow 
radial canals; with only two oval or sausage-shaped gonads, pendant, near middle point of the subumbrellar portions of two opposite radial canals; up to 48 marginal tentacles all alike, each with a terminal knob; 8 club-shaped statocysts.

Records from Mediterranean: eastern and western Mediterranean; Adriatic.

Known seasonality: 1-12.

Distribution: Atlantic; Indo-Pacific; Mediterranean.

References: Kramp (1961); Berhaut (1970); Albertini-Berhaut (1971b); Goy (1973b); Castelló i Tortella (1986); Gili (1986); Benovic and Bender (1987); Goy (1987); Goy et al. (1988, 1990, 1991); Pagès et al. (1992); Boero et al, (1993); Avian et al. (1995); Benovic and Lucic (1996); Medel and López-González (1996); Gili et al. (1998).

\section{Genus Ransonia Kramp, 1947}

Rhopalonematidae with high conical umbrella (similar to Aglantha); with long and narrow gastric peduncle; 8 radial canals; linear, discontinuous, gonads along peduncular portions of radial canals, not on subumbrella; numerous tentacles, all alike; statocysts unknown.

Ransonia krampi (Ranson, 1932) (Fig. 154E-G)

Umbrella $8 \mathrm{~mm}$ wide, $15 \mathrm{~mm}$ high, conical, with thin walls, with small apical projection; gonads more or less discontinuous along the eight radial canals on the long, narrow peduncle; about 88 marginal tentacles.

Records from Mediterranean: western Mediterranean.

Known seasonality: 4.

Distribution: Atlantic; Mediterranean.

References: Kramp (1959a, 1961); Gili (1986); Boero and Bouillon (1993); Medel and LópezGonzález, 1996; Mills et al. (1996).

\section{Genus Rhopalonema Gegenbaur, 1857}

Rhopalonematidae without gastric peduncle; with gonads along the radial canals separated from manubium; with marginal tentacles of two kinds: large, club-shaped, perradial tentacles with swollen ends and inter-and adradial short, stiff, cirri-like tentacles also with swollen ends; with enclosed statocysts.
1. Umbrella with a distinct apical knob; gonads oval, in the middle third of radial canals; statocysts close beside tentacles....... R. velatum

- Umbrella without apical knob; gonads along distal 2/3 of radial canals; statocysts in the middle of spaces between tentacles R. funerarium

\section{Rhopalonema funerarium Vanhöffen, 1902} (Figs. 155A-D)

Umbrella up to $17 \mathrm{~mm}$ wide and $14 \mathrm{~mm}$ high, hemispherical to somewhat conical but without apical projection, mesoglea stiff, but fairly thin; no gastric peduncle; velum very broad; manubrium narrow, elongated, quadrilateral with octagonal base, contractile, hardly reaching velar opening; mouth with 4 simple lips; 8 narrow straight radial canals, narrow circular canal; gonads as elongated, linear pouches, extending along distal $2 / 3$ of the radial canals; 8 large radial marginal tentacles with swollen ends, 3 very short, club-shaped cirrus-like tentacles in each octant, 32 enclosed statocysts in the middle of the spaces between tentacles.

Remarks: Rhopalonema funerarium is considered by several authors as a deep-water race of $R$. velatum. However, it is a distinct species for Kramp (1961; 1965; 1968). In fact, most of the characters used to distinguish between the two presumed species (form of the umbrella, development of the gonads) appears to be nothing more than intraspecific variations, perhaps the position of the statocysts is the only valid character allowing the separation of the two forms.

Records from Mediterranean: eastern and western Mediterranean,Adriatic.

Known seasonality: 1-3, 6, 9, 10.

Distribution: Atlantic, Indo-Pacific, Mediterranean.

References: Kramp (1961); Dowidar (1983); Gili (1986); Benovic and Lucic (1996); Medel and López-González (1996); Gili et al. (1998).

\section{Rhopalonema velatum Gegenbaur, 1857}

Umbrella 8-10 mm wide, $6.6 \mathrm{~mm}$ high, somewhat flatter than a hemisphere, with a solid conical or dome-like apical thickening, mesoglea stiff, but fairly thin, except at apex; velum very broad almost closing umbrella cavity; manubrium narrow, elongated, cylindrical, with octagonal base, contractile, reaching extended almost velar opening; no gastric peduncle; 
mouth with 4 simple or somewhat elongated lips, often strongly recurved; 8 straight radial canals and circular canal narrow; gonads linear or oval on middle third of the 8 radial canals; 8 large radial marginal tentacles, 1-3 short cirrus-like tentacles in each octant, all tentacles with swollen ends; an enclosed statocyst close besides each right side of the perradial tentacles and interradial cirrus-like tentacles.

Records from Mediterranean: eastern and western Mediterranean; Adriatic Sea; Black Sea.

Known seasonality: 1-12 (see Albertini-Berhaut, 1971a).

Distribution: Atlantic; Indo-Pacific; Antarctic; Mediterranean.

References: Kramp (1961); Albertini-Berhaut (1970a); Goy (1973b); Castello i Tortella (1986); Gili (1986); Benovic and Bender (1987); Brinckmann-Voss (1987); Goy et al. (1988, 1990, 1991); Boero and Bouillon (1993); Avian et al. (1995); Benovic and Lucic (1996); Medel and LópezGonzález (1996); Gili et al. (1998).

\section{Genus Sminthea Gegenbaur, 1857}

Rhopalonematidae without gastric peduncle; with globular gonads on very distal parts of the 8 radial canals; with only 8 perradial tentacles; with enclosed statocysts.

\section{Sminthea eurygaster Gegenbaur, 1857} (Figs. 155G-I)

Umbrella up to $6 \mathrm{~mm}$ wide and about half as high, umbrella-shaped, with a small apical projection, mesoglea stiff, fairly thin; velum well developed; manubrium short, cylindrical; mouth with 4 short simple lips; no gastric peduncle; 8 straight radial canals, circular canal narrow; 8 perradial marginal tentacles; gonads globular to egg-shaped on radial canals very close to circular canal; 8 interradial enclosed statocysts.

Records from Mediterranean: eastern and western Mediterranean; Adriatic.

Known seasonality: 1, 5-9.

Distribution: Atlantic; Indo-Pacific; Antarctic; Mediterranean.

References: Kramp (1961); Vannucci (1966); Berhaut (1970); Goy (1973b); Gili (1986); Benovic and Bender (1986, 1987); Goy et al. (1988, 1990, 1991); Boero and Bouillon (1993); Avian et al. (1995); Benovic and Lucic (1996); Medel and López-González (1996); Gili et al. (1998).
Genus Tetrorchis Bigelow, 1909

Rhopalonematidae without gastric peduncle; with only 4 pendant sausage-shaped gonads attached to 4 of the 8 radial canals near the middle points; with 4 large perradial and several small marginal tentacles.

Tetrorchis erythrogaster Bigelow, 1909

(Figs. 155J-L)

Umbrella 10-12 $\mathrm{mm}$ wide and $8 \mathrm{~mm}$ high, pyriform, apex mesoglea very thick, lateral mesoglea thin; velum well developed; no gastric peduncle; manubrium tubular, brilliant carmine, reaching slightly beyond velar opening; mouth with 4 small, simple lips; 8 straight radial canals, circular canal narrow; 4 sausage-shaped gonads attached to every second radial canals, middle to distal in position; 4 large perradial tentacles opposite fertile radial canals and 16-24 small tentacles not placed in reference to the radial canals; statocysts unknown.

Records from Mediterranean: eastern Mediterranean.

Known seasonality: 10-12.

Distribution: Atlantic; Indo-Pacific; Mediterranean.

References: Bigelow (1909); Kramp (1961); Lakkis and Zeidane (1985); Goy et al. (1988, 1990, 1991); Boero and Bouillon (1993); Gili et al. (1998).

\section{Class POLYPODIOZAE}

Family PolyPODIIDAE Poche, 1914.

See characters of subclass

Genus Polypodium Ussow, 1887

See characters of subclass.

Polypodium hydriforme Ussow, 1885

(Fig. 156)

See characters of subclass, free stage $2-5 \mathrm{~mm}$ in size.

Records from Mediterranean: Fresh water basins of the Azov and Black Sea.

Known seasonality: Free living stage: 5-7.

Distribution: Fresh-water Basins of Russia; Roumania; Iran, North America.

References: Raikova (1958, 1973, 1980, 1988, 
1994); Suppes and Meyer (1975); Dick et al. (1991). Monteiro, Okamura and Holland (2002); Okamura et al. (2002); Zrzavy (2001); Zrzavy and Hypsa (2003).

\section{COLLECTION OF THE MATERIAL}

\section{Hydroids}

Benthic hydroids have been traditionally collected with dredges and grabs, from ordinary boats or research vessels. This practice has led to the collection of a host of large colonies of Sertulariidae, Aglaopheniidae, Syntheciidae, Sertulariidae, these being evident during sorting. The identification of inconspicuous hydroids, either alive or preserved, necessitates careful sorting of material, inspecting each substrate fragment while in liquid. Many hydroids are commonly associated with algae, sea grasses, sponges, other hydroids, anthozoans, bryozoans, molluscs (bivalve, gastropods, pteropods), annelids, crustaceans, ascidians, fishes, and must be searched for under a stereomicroscope. Hydroids are common inhabitants of shaded hard substrates. Intertidal specimens can be collected easily at low tides, whereas subtidal specimens are best collected by SCUBA diving, since the crevices and small cavities they prefer are difficult to sample from the surface. While collecting, it is important to be aware of the substrates that are possibly conducive to hydroid settlement. These must be collected even if no specimens are evident. Kept in the laboratory, in calm water, these substrates might reveal fruitful catches.

Deep and soft-bottom species must be collected from boats, with either dredges or grabs. In shallow water, however, soft bottom hydroids can be seen while SCUBA diving, since some species are rather conspicuous. Interstitial species are collected by the standard techniques of meiobenthic research.

Many hydroids are not recognisable if not fertile, and information on complete life cycle is necessary for an accurate identification. If at a specific site an hydroid without gonophores is located, it is advisable to collect specimens periodically (at least once per month) until ripe colonies are found These must be kept in the laboratory for gonophore rearing. Even groups that are usually thought to be completely paedomorphic, and so deprived of medusae, have recently been found to produce swimming gonophores. Far too many species and genera have unknown hydroids or medusa stages, so that life cycle elucidation is still a priority for the study of this group.

\section{Medusae}

Gelatinous plankton is very fragile and easily torn and damaged when collected.

Hydromedusae can be caught by plankton nets that are very slowly towed behind a large or a small powered vessel or a even a row boat for about ten to twenty minutes depending on the abundance of the plankton. For hydromedusae the mesh size of the net should be about 200-250 $\mu \mathrm{m}$, larger meshes let escape many small specimens, smaller meshes are to easily clogged and damage the specimens. In coastal waters the opening of the net should be from $30 \mathrm{~cm}$ to $1 \mathrm{~m}$ depending the power of the vessel, much wider openings are used in open sea and deep waters where the fauna is sparser. In areas very rich in plankton, a hand net or even a bucket may be used. The richest catches are generally obtained in the early morning or at dusk and on rising tides. For qualitative horizontal subsurface sampling the plankton net is towed by a rope of $50 \mathrm{~m}$ or more behind the vessel to eliminate turbulence. For sampling in few meters below the surface a buoy can be attached with a rope of known length to one side of the ring opening and a weight on the other side. Sampling between fixed depths requires closing nets. Quantitative sampling is possible with plankton nets fitted with a flow-meter a little behind their front, after calibration these water-meters give a measure of the quantity of water filtered.

If it is impossible to sort the medusae immediately, the catch should as quickly as possible be fixed at once with formaldehyde, so to obtain a final solution of $5 \%$ fixative (see fixation). If the material can be brought rapidly to the laboratory, the plankton samples, shielded from direct sunlight and kept as cool as possible should be examined under stereo-microscope and the medusae individually removed with wide-mouthed pipettes and placed in finger bowls of clear sea water. After observation they can either be kept for rearing or anaesthetised and fixed as described below. This last method is of course the most rewarding, allowing observation of the living animals characters and perfect fixation. 


\section{TECHNIQUES}

\section{Fixation and preservation of the material}

\section{Hydroids}

Colonies are usually preserved directly either in formaldehyde or alcohol. This practice usually leads to specimens with poorly preserved coenosarc, skeletal parts being the only well preserved items. This is the reason why the material coming from "expeditions" is very rich in large thecate colonies, whereas athecate and delicate forms are apparently absent. In order to have properly preserved hydroid material, the same techniques employed for the medusae should be used. Modern molecular techniques require fixation in alcohol, since DNA probes are impossible in formalin-preserved material. When possible, thus, a batch of specimens should be preserved in alcohol. Whole mounts, obtained by dehydration of specimens and mount in microscope slides, is very advisable. Mounted specimens can be studied also after centuries, whereas those preserved in liquid tend to disintegrate. This is very important for the preservation of type material.

\section{Medusae}

Hydromedusae should be anaesthetised before being fixed; most of the fixatives cause shrinking and deformations. The animals should be allowed to extend in a vessel of water where the anaesthetic substance should be added slowly, crystal by crystal or drop by drop. The most common anaesthetic substances for marine medusae are menthol crystals, propylene phenoxetol and magnesium chloride (about $7.5 \% \mathrm{Mg} \mathrm{Cl} 2,6 \mathrm{H} 20$ in fresh water), the last being the most recommended (Smaldon and Lee, 1979). For general taxonomic purposes hydromedusae can be fixed in $10 \%$ buffered formaldehyde in seawater (the commercial formaldehyde being considered as 100\%) and preserved for short periods in $5 \%$ formaldehyde. The effects of formaldehyde preservation on size and weight of hydromedusae have been studied by de Lafontaine and Leggett (1989). Buffering with borax or calcium carbonate should be avoid since the medusae may adhere to any precipitate formed by those chemicals on the bottom of the containers, so should be hexamine which destroy the mesoglea, the best buffer seems to be sodium glycerophosphate. Alcohol should not be used as fixative because it leads to shrinkage, distortion and contraction of the specimens. Nevertheless, for long term preservation, for instance in museum collections, the formaldehyde is not adequate causing auto-maceration of the tissues and should be replaced by $70 \%$ alcohol. The passage from formaldehyde to alcohol must imperatively be gradual, going from formaldehyde to a very dilute alcoholic solution (less than 10\%) and then, step by step ( $10 \%$ by $10 \%$ ), in several days, to the final 70 $\%$ solution (Petersen, 1976). Polythene containers should be avoided, chemical precipitates being able to damage the specimens. For histological studies the best fixative is, after anaesthetisation, cold (5-8 C.) acidic Bouin's fixative ( $=75 \%$ of a solution of saturated aqueous solution of picric acid $+25 \%$ from a commercial formaldehyde: just before use $5 \%$ glacial acetic acid should be added to this solution). The material can afterwards be preserved for a long time in $5 \%$ commercial formaldehyde the specimens being less affected after this treatment by formaldehyde auto-maceration.

A method of long-term storage has been developed by Van Impe (1992) where the medusae are suspended in a solid agar-agar gel colored with serva-blue and from which extraction is easy when required. This method is particularly useful for transportation and for long term conservation; all holotypes should be stored in such a gel which up to a certain point also avoids drying out and stain nicely the medusae tissues in blue.

In most of the Museum collections the majority of the hydromedusae specimens, including holotypes, have been destroyed because of the disastrous habit of the museum keepers to put label cards into the storing jars containing the specimens. Such a custom should be totally avoided because after a few manipulations or a single material expedition to a specialist, only the label remains. Should also be avoided the cotton or paper material caps whose fibers adhere and damage the specimens.

\section{Preparation of permanent microslides}

\section{Hydromedusae and siphonophores}

Anaesthetisation: 1) with magnesium chloride $7.5 \%$ in fresh water, add drop by drop to the jar containing the medusa or siphonophore in sea water till complete anaesthetisation. 2) with menthol crystals, add crystal by crystal till complete anaesthetisation.

Fixation: buffered formaldehyde $10 \%$

Coloration: hemalun*; boracic carmin** 
1) mount in hydro-or aquamount:

- from formaldehyde to water

- from water to aquamount $50 \%$-water $50 \%$, half an hour

- to pure aquamount, half an hour

- place a drop of aquamount on the stand-slide

- place the material in the drop

- put a little drop of aquamount on the cover slide

- put the cover-slide on the stand-slide

2) mount in Canada balsam:

- from fixator to alcohol $10 \%$ and then step by step, $10 \%$ by $10 \%$ to final alcohol $100 \%$; all steps half an hour

- $75 \%$ alcohol $100 \%$ and xylol $25 \%$, half an hour

- 50\% alcohol 100\% xylol 50\%, half an hour

- pure xylol, half an hour

- balsam 50\% xylol 50\%, half an hour

- place a large drop of balsam $50 \%$ xylol $50 \%$ on the stand-slide

- place the material in the drop

- place a little drop of pure balsam on the cover slide

- put the cover-slide on the stand-slide

\section{Hydroids}

Anaesthetisation: a) with magnesium chloride $7.5 \%$ in fresh water, add drop by drop to the jar containing the hydroid in sea water. b) with menthol crystals, add crystal by crystal till complete anaesthetisation.

Fixation: formaldehyde $10 \%$ or alcohol $75 \%$ or Bouin's fixative****

Coloration: hemalun*; boracic carmin**; hemalun, eosin, light green $* * *$

- from fixator to alcohol $75 \%$ (can stay for ever)

- alcohol $75 \%$ to alcohol $90 \%$, half an hour

- alcohol $90 \%$ to alcohol $100 \%$, half an hour

- alcohol $100 \%$ to $50 \%$ alcohol $100 \%$ and $50 \%$ pure xylol, half an hour

- to pure xylol, half an hour

- balsam $50 \%$ xylol $50 \%$, half an hour

- place a large drop of balsam $50 \%$ xylol $50 \%$ on the stand-slide

- place the material in the drop

- put a little drop of pure balsam on the cover slide

- put the cover-slide on the stand-slide *hemalun:

- solution of $1 \mathrm{gr}$ of hematoxylin, $0.2 \mathrm{gr}$ of sodium iodate, $50 \mathrm{gr}$ of potassium alum in $1000 \mathrm{cc}$ of distillate water; colour from 5 to 20 minutes depending size

- differentiate (removing the excess of colour so to have a pure nuclear stain) in a solutions of $1 \%$ of alum

- wash in tap (calcareous) water till the colour becomes dark bleu

- put in alcohol $75 \%$ and mount in balsam or in keep in water and mount in hydro-or aquamount (see above)

** boracic carmin:

- solution of (Na2B407, 10H2O) (borax) 4\% in $100 \mathrm{cc}$ of water +2 to $3 \mathrm{gr}$ of carmin.

- let the objects from a few minutes to several ones in this solution depending their size

- differentiate in a solution of $100 \mathrm{cc}$ of alcohol $75 \%+6$ droplets of $\mathrm{HCl}$

- when the colour is satisfactory put in alcohol $90 \%$ and mount in balsam or return to water and mount in hydro-or aquamount (see above)

$* * *$ hemalun, eosin, light green

hemalun see*

- colour in eosin $1 \%$ in distillate water for one minute

- wash in distillate water and dedifferentiate in alcohol $70 \%$

- put in alcohol $90 \%$

- colour in a solution of light green $0.5 \%$ alcohol 50 or $70 \%$ for a few minutes

- differentiate in $90 \%$ alcohol

- transfer in alcohol $100 \%$ and mount in balsam (see above)

$* * * *$ Bouin's fixative

saturated picric acid in distillate water $75 \%+$ pure formaldehyde $25 \%$

- this two solutions can be mixed and prepared in advance $=100 \%$

- at the moment of fixation add $5 \%$ glacial acetic acid

- wash the hydroids in $75 \%$ alcohol till disappearing of picric acid; transfer them for staining or conservation in alcohol $75 \%$ 


\section{GLOSSARY}

abaxial: away from the main axis, or on a site remote from it; in a medusa marginal tentacle, the outer tentacular surface, in siphonophores the dorsal side.

abcauline caecum, or blind sac, or abcauline diverticulum: a finger-shaped, blind expansion of the abcauline wall of the hydranth in many Sertulariidae and some Syntheciidae, mainly evident in contracted hydranths. Due in part to the attachment of the ectoderm of this region to the mantle and/or hydrothecal wall, preventing its complete withdrawal. It imparts a bilateral symmetry to the hydranth. In the Sertulariidae used in generic diagnoses, although the caecum is less evident when the hydranth expands. For instance in the Sertulariidae present in Abietinaria, Calamphora, Cratitheca, Hydrallmania, Parascyphus, Sertularella, Sertularia, Symplectoscyphus, Thuiaria. In other genera of Sertulariidae the hydranth is withdrawn symmetrically into the hydrotheca and there is no caecum, although a mantle may be present (for instance Dictyocladium, Diphasia, Dynamena, Idiellana, Salacia).

abcauline: on the side away from the caulus, the opposite is adcauline.

acnide tentacle: tentacle deprived from cnidocysts, sensory tentacle in capitate hydroids.

acraspedote: medusae lacking velum.

acrocyst: a gelatinous, apparently structureless body extending from the gonophore and held outside the gonothecal opening, where embryos develop (brood chamber).

acrosphere: conspicuous ectodermal knob at the end of a tentacle, laden with numerous cnidocysts $=$ capitation.

actinula: creeping, postembryonic, tentaculated larval stage, characteristic of some Anthomedusae, resembles a small hydranth, usually with two or more circles of tentacles, developing directly into a hydroid stage. Not homologous to the tentaculated post-embryonic larvae of the Trachymedusae and Narcomedusae, inappropriately called "Actinulae", with only one aboral circle of tentacles, a different histological structure and giving rise directly to medusae.

adaxial: position opposite to abaxial, facing towards the main axis; in a medusa marginal tentacle, the inner tentacular surface, in siphonophores the ventral side.

adcauline: directed towards the caulus, see abcauline. adhesive pad: adhesive structure lacking cnidocysts, usually located near tentacle tip, sometimes along tentacle surface.

adnate: having part or all of one side in contact with, or fixed to, another structure, (e.g. adaxial side of a marginal tentacle fixed to the exumbrella in Leuckartiara adnata; hydrothecae having part or all of one side in contact with the supporting stem).

adradial: the axes or sectors lying between the perradial and interradial ones; in a medusa with 4 radial canals there are 4 perradial axes; 4 interradial axes and 8 adradial axes and 16 sectors.

alternate: in hydroids, hydrocladia or hydrothecae arising alternately on the left and the right side of the stem.

amphicoronate: alternate up and down arrangement of a single row of oral tentacles.

ampulla: superficial or internal rounded chamber from the outer surface (coenosteum) of calcareous hydrozoan colonies, containing the gonophores, usually forming blister-like convexities on the surface in the Stylasteridae, often with an efferent duct.

anastomosing: branched structure in which some branches rejoin and fuse with others to form a network.

aneural conduction: type of conduction where the impulses are linked with electrical activities of cellular membranes other than neural (e.g. epithelial cells, muscular cells, of both ectodermal and endodermal origin).

annular ectodermal fold = ring fold: folding of the mantle, linking the proximal part of the hydranth to the hydrotheca, evident in contracted hydranths (Thyroscyphidae).

annular perisarcal ring or thickening: see diaphragm.

annulus - annulation: an encircling groove or any ring-shaped structure in a hydroid stem, usually with thinning of perisarc, allowing passive bending. One in a series of rings in perisarc, typically in groups directly below hydranths, demarcating the internodes, at nodes, or where stems branch.

apical knob or chamber: small aboral chamber at the apex of the manubrium, protruding into the apical umbrellar mesoglea (e.g. some Coryne; Amphinema rubra; Euphysora furcata, Plotocnide borealis, etc.).

apical or umbilical canal: during the development of a medusa bud, an opening provides continuity and exchanges between the "maternal" gastric 
cavity and that of the bud. Generally this opening disappears after liberation, but in some medusae it remains as a small canal or duct projecting from the manubrium into the apical mesoglea and often leading upwards to the outside (e.g. Coryne producta, Corymorpha nutans).

apical projection or process: a rounded or pointed, usually roughly conical mesoglear extension of the top of the umbrella (e.g. Amphinema, Leuckartiara).

apical wings: apico-lateral processes of physonect nectophores, which extend around stem.

apical: situated at the apex.

apophysis: short process of the hydrocaulus that bears the hydrocladia, or of the hydrocladia bearing the hydrothecae (see hydrophore).

arborescent: polyp colony with a stout hydrocaulus bearing many scattered branches at its distal end.

Athecate-athecata: In polyps, lacking a proper hydrotheca (ahydrothecate): the hydroids of the Anthomedusae. In stems internodes lacking any thecate formation: hydrothecae, nematothcae, gonothecae etc.

athorybia stage: larval stage in physonect development bearing a pneumatophore, primary gastrozooid, tentacles and a ring of larval bracts.

aurophore: gas secreting portions of the pneumatophore, partially constricted off as bell-like bodies in the physonect family Rhodaliidae.

basal facet of mouthFig.: ventral surface of mouth in calycophoran anterior nectophore, which may articulate with posterior nectophore.

basal lamella: a thin extension of the nectophore below the ostium of the nectosac on its ventral side; one or more lamellae comprise the mouthplate.

basal web $=$ intertentacular web $=$ umbrellula

basigaster: basal part of the siphonophore gastrozooid.

battery: aggregation of various types of cnidocysts within a single ectoderm cell, often in groups.

bell: see umbrella.

bicoronate: arrangement of oral tentacles in two whorls.

bicuspidate: having two cusps (said of hydrothecal cusps).

bifid: forked into two roughly equal parts.

bimucronate: with two sharp points (e.g. the hydrothecal cusps of Obelia bidentata).

binomen: ( binominal) comprising the two names that together form the scientific name of a species, comprising the genus name followed by the specific name.

biseriate: in two rows.

blastostyle: carrier of gonophores generally reduced to a didermic axis or stalk bearing the developing gonophores: medusae or their reduced derivatives medusoids or sporosacs.

blind canal: centrifugal or radial canal that do not join circular canal (e.g. Toxorchis); centripetal canals that do not join radial canals or manubrium (e.g. some Calycopsis).

bract: protective or buoyant siphosomal element, usually containing much mesoglea and gastrovascular expansions. Absent in Cystonects, present both in Physonects (except the family Physophoridae) and Calycophores (except in the Family Hippopodiidae)

brood chamber: protective chamber within which planulae develop (gonothecal acrocyst, marsupium, brood chamber of Eleutheria medusae etc.).

budding: asexual reproduction in which a new organism develops as an outgrowth or bud from the parent, either remaining attached (to form a colony) or becoming detached from the parent. Common in Cnidaria. Budded polyps and Automedusa derive from simple buds; the medusae of Hydroidomedusa derive from special buds, containing the entocodon.

bugle: in haleciids an annular thickening of unknown function often present half way up the gastric column of the hydranths, perhaps the limit between two histological distinct regions of the endoderm.

bulb: see tentacular or non tentacular marginal bulb. bushy: polyp colony whose hydrocaulus bears many lateral branches throughout its length.

butt $=$ shaft: enlarged portion of cnidocyst tubule, it may bear stylets and/or spines, either of uniform or not uniform diameter.

campanopsid: hydroids having hydrothecae reduced or absent of the form characteristic of the nominal genus Campanopsis, i.e. hydranths with an intertacular web, each arising singly from a stolon; perisarc is thinning completely away below the hydranths, medusae buds formed on hydranth (see Helgicirrha shulzei; Eirene viridula).

campanulate or campanuliform: bell-shaped.

campanulinid: hydroids having hydrothecae of the form characteristic of the nominal Genus Campanulina, i.e., with campanulate, pedicellate hydrotheca with conical operculum formed by several triangular, convergent pleats or segments meeting centrally and which may be or may not 
be sharply demarcated from the hydrothecal margin, usually with diaphragm; such forms are not necessarily closely related.

canaliculate: of a stem comprising several coenosarcal tubes in a common perisarc.

capitate: tentacle or nematophore with a distinct differentiated, large ectodermal knobbed end (acrosphere) richly armed with cnidocysts and often with sensory cells. Not to be confused with a simple accumulation of cnidocysts.

capsule (cnidocyst capsule): double-walled envelope of cnidocysts, containing the soft, coiled tubule, intracapsular liquid and bearing a distal operculum.

cateniform: tentacle with cnidocysts in a distinct large terminal capitation and with numerous spirally arranged small cnidocyst clumps.

cathamnal lamella: endodermal sheet connecting the radial canals through the umbrellar jelly and separating the outer from the inner mesoglea.

caulus: main stem (hydrocaulus).

central organ: swelling at junction of the canal system and stem in some Prayidae siphonophores.

centrifugal canal: canal issued from the manubrium and directed towards umbrellar margin.

centripetal canal: canal issued from the circular canal and directed towards the manubrium (e.g. Calycopsis).

cheval-de-frise: see ring palissade.

chordal or chordoid: formed by a core of single disklike or cylindrical cells placed end to end in a single row (e.g. solid tentacles of Obelia medusae).

circlet: whorl or ring of tentacles whose bases are almost at the same level.

circular or ring canal: simple canal running around the umbrellar margin, linking the ends of the radial canals; occasionally the circular canal is not hollow but consist of a solid core of endodermal cells (e.g. Proboscidactyla, Laingiomedusae). In the Narcomedusae, with umbrellar margin deeply cleft into broad flaps, the circular canal when present, follows the edge of the margin of the exumbrellar flaps and is called "peripheral canal system", whose vertical parts are the peronial canals.

cirrus (cirri): small tentacular-like organ situated on the umbrellar margin between the marginal tentacles, solid and devoid of swollen marginal tentacular bulbs. Two types are generally found:

spiral cirri: coiling spirally, with scattered cnidocysts and a terminal cluster of cnidocysts (e.g. Mitrocomella). flexile cirri: straight, do not coil and have cnidocysts in rings (e.g. Cosmetira).

Cirri may be immediately adjacent to the marginal bulbs and are then said lateral cirri (e.g. Eucheilota), they may also occur along the umbrellar margin in the inter-spaces between marginal tentacles, they are then called marginal cirri (e.g. Cosmetira, Phialopsis).

cladium: a branchlet off the main stem or caulus (hydrocladium).

clasp: part of a marginal bulb embracing the exumbrella (e.g. Leuckartiara) (see exumbrellar spur).

cleptocnidae (cnidosacs): cnidocysts deriving from cnidarian prey, kept in specialised structures of nudibranchs, Nemertea, Turbellaria etc.

cnidae: a general term for the stinging or adhesive cells characteristic and source of the name of the phylum Cnidaria: cnidocysts, spirocysts and ptychocysts.

cnidoband: structure on the tentillum bearing dense aggregations of various kinds of cnidocysts, and gives rise to endfilament.

cnidoblast: developing cnidocyte, often used as synonym with cnidocyte.

cnidocil: bristle-shaped projection adjacent to operculum at the distal end of a cnidocyte; serves as trigger to discharge the cnidocyst.

cnidocyst (or stinging cell): stinging organelle characteristic of the Cnidaria, it consists of a doublewalled capsule, secreted by a particular cell called cnidocyte, containing a refringent fluid, a distal operculum, and a coiled and folded tubule (shaft, thread or internal tube) which everts and straightens on discharge. Following the structure of the internal tube, different types of cnidocysts are recognised, they are of great use in taxonomy. Cnidocyst are used for prey capture, defense, and attachment. They are known to be under nervous control (= nematocyst).

cnidocyst marginal ring = nettle ring: a dense band of cnidocytes and cnidocysts encircling the exumbrellar margin, characteristic of the Trachymedusae but present also in some species of other sub-classes.

cnidocyte: specialised cell type, usually located in the ectoderm. It consists of a basal nucleus, a distal cnidocil and contains the cnidocyst; cell walls with supporting roots. Typically concentrated in the tentacles.

cnidome: entire complement of cnidocyst types in a given taxon.

cnidophore: cnidocyst-filled cellular capsules cov- 
ered by numerous long cilia and attached to tentacles by elongated, filiform and very contractile stalks of special structure; characteristic of most of the Zancleida (see remarks in Weill 1934 p. 404; Bouillon, 1974), not to be confused with branched capitate tentacles or with the special cnidocysts-bearing processes of Eudendrium racemosum and $E$. armatum.

cnidothylacium: cluster of cnidocysts enclosed in an endodermal canals running along the umbrella.

coenosarc: the living tissue of a hydroid colony, the living tubes connecting the various polyps of a colony, formed by ectoderm, mesoglea and endoderm, typically covered by perisarc.

coenosteum: calcareous exoskeleton in hydrozoan colonies (i.e. Milleporidae, Stylasteridae), bearing pores for the gastrozooids (gastropores), dactylozooids (dactylopores) and "nematophores" (nematopores). In Stylasteridae the texture of the coenosteum is either a reticulate maze or a series of straight parallel, longitudinal bands of calcium carbonate (= linear coenosteal strips); these often covered by granules or bear imbricated scales. The coenosteum has mainly to types of texture: reticulate-granular and linear-imbricate. The two other combinations, i.e. reticulate-imbricate and linear- granular, are very rare.

colony: asexually-produced assemblage of zooids that have a common coenosarc, deriving from a single event of sexual or asexual reproduction.

column: the tubular part of a polyp, excluding the hypostome, the tentacles and, if any, the most basal region.

commissural canals: transverse connections of the nectosac between lateral radial and dorsal canals (in Sulculeolaria spp. only).

compound sense organ: marginal sense organ formed by an ecto-endodermal ocellus and an open ectodermal statocyst (in the Tiaropsidae).

congeneric: species referable to the same genus.

conspecific: referable to the same species.

coppinia: a close aggregation of numerous gonothecae together in a muff-like structure including also modified, elongate polyps (presumed defensive) (e.g. in the Lafoeidae).

corallum: the calcareous skeleton of a colony as a whole.

corbula (corbulae): protective basket-like group of modified hydrocladia (called corbulacostae or ribs) typically provided with nematothecae, loosely fused or lying closely parallel, bent around and protecting several gonangia in the space within Aglaopheniidae. (see phylactocarps). The primary modified hydrocladium, rachis or axis of the corbula, is called gonocladium, it bears the first secondary hydrocladium, or gonohydrocladium, which support the accessory hydrocladia differentiated in corbulacosta.

corbulacosta (corbulacostae): one of the modified hydrocladia of a corbula; also called ribs, they are alternately inserted to the gonocladium.

cordylus (cordyli): minute, marginal, club-shaped structures situated on the umbrellar margin between the tentacles. With a narrow peduncle and a thick distal portion, either hollow or completely filled by endoderm, with cnidocysts or not, function unknown, probably sensory (e.g. Laodiceidae, Tiarannidae).

corm: contracted nectosome and siphosome of the Rhodaliidae forming a globular mass below the pneumatophore.

cormidium: in thecate hydroids, a repeated unit of the cladium comprising an internode, one hydrotheca and usually three nematothecae, delimited by annuli; in siphonophores, an organised group of siphosomal elements, usually including a gastrozooid, tentacle, palpons (in physonects), blastostyle and bracts.

cormoid: erect polyp-bearing elements of a colony that arise from a common hydrorhiza or hydrorhiza-like stem, e.g. one single feather-like structure of a Halopteris colony or a simple stem of Antennella species. A cormoid is a hydrocaulus, or its homologue, and all accessory structures.

craspedote: medusae with a velum.

crenulated: having low rounded cusps or lobes separated by sharp but shallow notches (e.g. of mouth lips).

cruciform: cross-shaped.

crumpling: see introversion.

cryptomedusoid: strongly reduced medusa; seldom with free pelagic life (swimming sporosacs, and gonophores); without radial canals but with an endodermal lamina lining the exumbrellar ectoderm: the umbrella endoderm (homologous to the cathamnal lamella); subumbrellar cavity reduced or represented only by an ectodermal layer: the internal ectoderm, germ cells on spadix (= manubrium), in eccentric position.

cusp: distal projection (often called tooth) from the rim of a hydrotheca or a gonotheca.

cuspidellid: hydroid morphologically referable to the nominal Genus Cuspidella. Colonies stolon- 
al; hydrotheca tubular, usually sessile, without pedicel; operculum conical, made of several pleats or cusps meeting centrally, with or without crease-line at base; differing from "campanulid" in lacking pedicel and diaphragm.

cyclosystem: an arrangement of pores in which several dactylopores surround central gastropore in calcareous Hydrozoa.

cymba: angular and flattened eudoxid bract, characteristic of Abyla spp.

cymose: colony not growing distally but from successive lateral branches.

cyst: generally chitinous, protective structure containing eggs, embryos or even portion of an organism in an inactive stage. Cysts are resting stages, usually resistant to adverse environmental conditions. They can be either part of the normal life cycle or appear depending on circumstantial conditions.

dactylopore: a small pore in the coenosteum of calcareous Hydrozoa housing dactylozooids, may be borne on projections.

dactylostyle: see style.

dactylotome: the lateral slits which borders the gastropores tube in Stylasteridae.

dactylozooid (= machozooid): defensive polyp, usually highly extensible and mobile, richly armed with cnidocysts, often a reduced and modified gastrozooid; usually deprived of mouth and either without or with a reduced number of tentacles. Some with characteristic structure (see tentaculozooid, nematophore, sarcostyle and spiral zooid), some with chemioreceptors.

desmocyte: minute chitinous rivet anchoring the skeleton (theca) to the mesoglea of the hydranth (= punctae or birefringent nodules).

diaphragm: protrusion of the endoderm partitioning the gastric cavity in some hydroids (Corymorphidae); in many thecate hydroids, a thin inwardly projecting, circular, chitinous shelf at the base of the hydrotheca, sometimes an annular thickening of a less defined nature occupies the same position. The centre of the diaphragm is perforated by a hole by which the ceoenosarc passes.

diastemas: a gap, a space between. In the Stylasteridae, when cyclosystems are aging, the dactylopores become obsolete and are filled with coenosteum. The section of cyclosystem missing dactylopores is called a diastema.

diploblastic: being composed of two epithelia, i.e. formed by an outer ectoderm and an inner endoderm, separated by a kind of relatively undiffer- entiated connective layer, the mesoglea, usually not regarded as a real tissue layer.

direct development: development where the medusa stage will give rise to another medusa without passing through a hydroid phase (e.g. Trachymedusae) or where a hydroid will produce directly another hydroid (e.g. Hydra).

distal: at the far end, near the end (opposite = proximal).

ectoderm: outermost cellular layer (epidermis).

ectodermal lamella or lining = ectodermal lamina: see mantle.

ectodermal statocyst: marginal sense organ of equilibrium developed in the velum and entirely ectodermal, formed in depressions or pockets of the velum and either remaining open (open ectodermal statocysts of, e.g. Mitrocomidae, Tiaropsidae) or being sealed by velar tissues (closed ectodermal statocysts, e.g. the other Leptomedusae). Characterised by special cells or lithocytes containing one or more tiny polygonal or spherical concretion (statolith $=$ otolith). Closed statocysts with a basal cushion of cells with sensory cilia. ecto-endodermal ocelli: photoreceptors found in the Tiaropsidae where the cup-shaped mass of pigment is formed by the endoderm of the circular canal, the nerve elements being ectodermal. The ocelli of the other Hydroidomedusa are completely ectodermal in origin. In the Tiaropsidae the ocelli are associated with open ectodermal statocysts forming a compound sense organ.

ecto-endodermal statocyst $=$ tentaculocyst $=$ sensory club: club-like, sense organ of equilibrium growing out of the umbrellar margin in the fashion of a tentacle; formed by an endodermal axis originating from the circular canal and covered by the umbrellar ectoderm. With one or more distal, large endoderm cell (lithocytes) each containing a solid concretion (statolith). In this form they are called "free ecto-endodermal statocysts or free sensory clubs" (e.g. Narcomedusae and Trachymedusae). In some species sensory clubs are enveloped by mesoglea or by an ectodermal vesicle embedded in the mesoglea, being called "closed ecto-endodermal statocysts" (e.g. Limnomedusae, few Trachymedusae and of a genus of Narcomedusae: Sigiweddelia).

ecto-theca: ectodermal layer surrounding in some species medusa buds and more generally reduced gonophores.

egestion: the elimination of undigested food through the mouth opening. 
embayment: a rounded or pointed gap between two adjacent cusps along the rim of a hydrotheca.

embryo: an early developmental stage resulting from repeated cleavage and subsequent growth of a zygote. Embryological development passes through several stages, such as morula, blastula, and gastrula, the latter corresponding to the embryonic stage where the germ layers become established first. In the Hydrozoa, the gastrula is the two-layered developmental stage in which the rudimentary endoderm layer differentiate = planula. In contrast to larvae, embryonic stages are neither planktotrophyc nor lecythotrophic and cannot lead a long independent existence, except when encysted.

endoderm: innermost cellular layer, lines the gastrovascular cavities.

entocodon $=$ glockenkern $=$ medusary nodule: a solid multistratified nodule produced between ecto- and endoderm by an invagination of the apical budding zone during the morphogenesis of medusa buds or of fixed gonophores, later on developing a cavity: the future subumbrellar cavity. Endodermal components of buds (manubrium, gastro-vascular canals) formed by evagination of the "mother" endoderm (spadix). In few medusae, budding is exclusively ectodermic (Bougainvillia niobe, Lizzia blondina, Hydractinia minima, Rathkea octopunctata), the entocodon developing both ectodermal and endodermal components of the buds.

epibolic: a type gastrulation with the smaller cells of the animal pole growing down over the vegetal pole cells and enclose them, the large cells becoming the endoderm and forming an archenteron.

epilithic: living on stones or inorganic hard substrates in general.

epiphytic: living on plants, without parasitising them.

epizoic: living on animals, without parasitising them.

eudoxid: reproductive stage of calycophorans that usually becomes detached from polygastric stage. Each eudoxid comprises typically a bract, a gastrozooid, a tentacles with tentilla, and a succession of sexual gonophores and, possibly asexual gonophores.

eumedusoid: reduced medusa with radial canals and subumbrellar cavity, with or without manubrium; when present, manubrium not eccentric; generally without tentacles, usually with sense organs, with velum; "gonads" on manubrium when Anthomedusae, on radial canals when Leptomedusae. Often with short free pelagic life; the first step in medusa reduction.

excretory papillae: papillae situated either between marginal tentacles, or at base of some marginal structures (tentacular bulbs, non-tentacular or rudimentary bulbs, or marginal warts), or on the radial canals. With an opening, or excretory pore, in contact with the cavity of the bulbs or of the gastro-vascular system. Used for the elimination of undigested material.

excretory pore: opening of the excretory papillae. Sometimes papillae are absent and pores open at the surface of the supporting structures (see excretory papillae).

exumbrella: upper, aboral convex surface of the umbrella (see umbrella).

exumbrellar cnidocyst cluster or band: exumbrellar specialised tissue in form of oval, club-shaped, spoon-shaped, or elongated patches containing cnidocysts, localised immediately above the marginal bulbs (Zancleoidea) or on exumbrellar margin between tentacles (e.g. Proboscidactyla).

exumbrellar spur: upwards growth of marginal tentacular bulbs, clasping umbrellar margin (e.g. Leuckartiara).

fascicled: stem comprising two or more coenosarc tubes united in a composite single stem structure (= polysiphonic). Sometimes fascicled stems are due to coalescence of colonies deriving from several planulae that settled together on the same spot.

filiform: a straight tentacle, lacking prominent cnidocyst clusters, the cnidocyst appearing more or less evenly distributed.

flabellate: fan-shaped hydroid colony.

flexuose: hydroid with hydrocauli or hydrocladia with successive internodes directed alternately left and right, in a zigzag fashion. Flexuose colonies are usually biseriate, bearing hydranths in two opposite, often alternate rows.

frustule: little didermic tissue portion formed asexually either by budding or by constriction, acting as dormant and/or dispersion stage. Generally formed by polyps, exceptionally by medusae; all develop into polyps.

funnel: an expanded chamber at the bottom of the pneumatophore where the lining ectoderm is modified to form the gas gland.

gas-gland: specialised area of modified ectoderm which secretes gas to inflate pneumatophore (see 
funnel), the gas gland may be simple (Agalma) or branched (Rhizophysa).

gastric cavity: in medusae see manubrial cavity; in the hydranth, simple undivided enlargement of the digestive part of the hydranth body.

gastric peduncle $=$ peduncle: a cone-shaped median extension from the subumbrellar mesoglea projecting downwards into the subumbrellar cavity, bearing the manubrium terminally; the radial canals run down along the peduncle to reach the manubrium; varied in shape and size (e.g. long and narrow in Eutima mira; large and pyramidal in Bougainvillia macloviana; very short in Phialopsis diegensis).

gastric pouches: see manubrial pouches.

gastropore: the large pores housing the gastrozooids, in calcareous Hydrozoa.

gastrostome: the mouth of the gastropore.

gastrovascular system: in medusae the coelenteron or enteron, comprising the manubrium cavity (stomach) and the gastrovascular canals (i.e., the radial and circular canals and their derivatives). In hydroids the hydranth cavity and the coenosarcal canals. It serves for the digestion and distribution of food, the circulation of oxygen, waste, cnidoblasts and even gametes.

gastrozooid: feeding polyp with mouth and normally with tentacles, without reproductive organs.

gemmule: asexual reproductive body, see cyst and frustule.

glomulus: in certain Haleciidae, a grouping of several to numerous laterally contiguous gonothecae each with a tubular neck, jointly borne on an irregularly branched network of tubes.

gonad: an organ such as an ovary or a testis which produces sex cells or gametes. There are no real organs in Hydrozoa, so this term is inappropriate although largely used by specialists. We use this term in brackets, being aware that, in medusae, "gonads" indicates the place, usually on manubrium walls or/and on the radial canals, where the sex cells become mature. The position of the germ cells has a considerable value in classification. When "gonads" are on the manubrium they may completely surround it, being cylindrical, or be in interradial, adradial or perradial position. When situated on the radial canals, they usually develop on their lateral walls but, in some medusae, they are continuous also over the ventral wall (e.g. Clytia hemisphaerica). Their position along the course of the radial canals is often a diagnostic character as are their shape and size. gonangium (gonangia): in colonial hydroids, a reproductive unit consisting of the outer gonotheca and enclosed blastostyle bearing one or many gonophores.

gonodendron: in siphonophores, an organised group of gonopalpons, gonophores and occasionally asexual nectophores, developed from the siphosome.

gonopalpon: a specialised palpon, budded from the gonodendron.

gonophoral polyp: polyp protruding from the gonothecal opening of some Halecium species, perhaps with defense and/or feeding function.

gonophore: asexual reproductive structure normally developing into medusa buds; in many Hydrozoa, however, the medusae are reduced to a varying degree and are not liberated anymore, remaining attached to the hydroid, or to the siphosome, in the gonophoral structures. They are then called fixed gonophores, or sporosacs, or fixed sporosacs since they are not released anymore. The gonophores give origin to the generative elements, ova or spermatozoa (see medusa reduction).

gonosome: the gonophores and their protective structures.

gonotheca: chitinous structure with a distal opening, surrounding and protecting a gonophore.

gonozooid: reproductive polyp, male or female, bearing gonophores; usually a modified gastrozooid at various stages of morphological reduction and often with few or no tentacles.

hermaphroditic: a colony of hydroids is hermaphroditic when all its zooids are hermaphroditic; but a colony may functionally be hermaphroditic when composed of both male and female zooids. heteromedusoid $=$ sporosac: highly atrophied medusa devoid of radial canals, umbrellar endoderm, tentacles and sense organs; internal ectoderm remnant of subumbrellar cavity still present.

heteromerous segmentation: segmentation of hydrocaulus or hydrocladia by alternate hydrothecate and non-hydrothecate segments, oblique and transverse nodes thus alternating.

hinge joint: a joint consisting of diamond-shaped thickenings of the stem perisarc, set obliquely in the sagittal plane and connected by relatively thin perisarc; it allows some bending in certain directions but not in others. The function is to orientate the colony in a favorable position in respect to food-bearing currents. 
hollow tentacle: tentacle either with a central cavity in continuation with the cavity of the tentacular bulbs or, when these are missing, of the circular canal, or without any lumen but with an endodermal core formed by several peripheral rows of cells (parenchymatic). In the Bythotiaridae the tentacles are hollow, but the mesoglea of the distal part of the tentacles is often enlarged and reduces strongly the endodermal axis.

homomerous segmentation: segmentation of hydrocaulus or hydrocladia through uniform segments, usually separated by oblique nodes.

homonym: identical names denoting different taxa (see International Code of Zoological Nomenclature for further explanation).

hydranth: the feeding polyp of a hydroid colony.

hydrocaulus: main stem of a fixed, erect hydroid colony, typically bearing branches, the final of which, or hydrocladia, bearing the hydranths.

hydrocladia: final lateral, hydranth-bearing branch of the main stem (or hydrocaulus) or of its branches, in an erect hydroid colony.

hydroecium: ventral cavity of calycophoran nectophore into which the siphosome may be wholly or partly retracted.

hydroid: the polypoid stage, or prolonged post-planula larva, of the Hydroidomedusa.

hydrophore: perisarcal structure at the base of the hydranths in some members of the family Solanderiidae. Often as two parallel triangular processes. In some Leptomedusae species each hydranth arise from a short process situated near the the distal end of an internode termed hydrophore (apophysis). In Haleciidea protusion or pedicel carrying the hydrotheca.

hydropore: a hole in the definite floor of hydrotheca, in Syntheciidae, Sertulariidae and Plumulariidae, trough which the coenosarc passes, connects the hydranth with the rest of the gastrovascular system.

hydrorhiza (hydrorhizae): all structures by which fixed hydroids are attached to the substratum, normally in form of a network of branching, anastomosed, creeping tubes or stolons; hydrorhizal tubes may fuse in a mat, becoming encrusting or forming other different structures.

hydrotheca (hydrothecae): chitinous structure surrounding entirely or partially the hydranth in most Leptomedusae.

hydrotheca reduction: In some Campanulinida families, for instance the Eirenidae and the Eucheilotidae, only the newly developed polyps have a completely developed hydrotheca, with age these become reduced, losing their operculum and apical part, and are no longer high enough to accommodate the hydranths (haleciidlike).

hypocystic villus (villi): ectodermal processes of the gas-gland or pneumadenia in some Cystonect siphonophores.

hypostome: distal end of the hydranth, carrying the mouth at its end.

intathecal ridge: small internal perisarc extension into cavity of hydrotheca, for structural reinforcement.

internode: a segment often dividing hydrocauli and hydrocladia by partitions or nodes, part between two nodes, often delimited above and below by perisarcal annuli.

interradial: the radial axis lying in between two adjacent perradii; between the radial canals. In Narcomedusae the axis between gastric pouches.

intertentacular web = basal web = umbrellula: thin, transparent sheet, often containing cnidocysts, connecting the base of the hydranth tentacles of some leptomedusan hydroids.

intrathecal septum: internal and transversal shelf or ridge of perisarc inside the hydrotheca.

introversion = crumpling: the turning inwards of the exumbrellar margin and the tentacles into the subumbrellar cavity afterwards closed by the velum, often with distal part of manubrium hanging out. An answer to various excitations like, stress, the presence of other medusae, chemicals, food, etc.; it depends on excitation of the epithelial aneural conduction.

involucrum: in siphonophores a fold rounds the base, or the whole, of a tentillum.

juvenile: a developmental stage which has attained the adult body plan (i.e., symmetry, general body shape and major functional systems such as locomotion and feeding), but not sexual reproduction.

lappet: a lobe-like extension around umbrellar margin (some Laingiomedusae, the Narcomedusae).

larva: in the post-embryonic development of an animal, an immature intermediate stage distinctly different in morphology and physiology from the sexual adult. A complex life cycle can have more than one larval stage. In the Hydrozoa, the planula is often referred to as larva, whereas it is more properly defined as a gastrula (either hollow, coelogastrula, or solid, stereogastrula). In a strict sense, the larva of the Hydrozoa with a complex cycle is the hydroid, even though, through paedomorphosis, many species perform 
sexual reproduction in the hydroid stage, due to medusa reduction or suppression.

lateral cirri: see cirri.

lateral nematothecae: nematothecae arranged one each side of hydrothecal aperture, to which they are lateral in position.

lateral ridges: cross ridges, bordering the apical wings, present on some physonect nectophores; there may be apico-lateral, infra-lateral, and vertical-lateral ridges.

ligula: an extensile outgrowth armed with cnidocysts from the base of the adcauline side of hydranths in some Salacia and Sertularia (a nematophore? see mantle).

lip: lobe-like extension of manubrial margin surrounding the mouth (see mouth). Lips may be of simple or complicated structure (i.e. crenulated, folded, short, elongated, pointed, rounded) armed or not with cnidocysts distributed uniformly or in clusters. In the Rathkeidae, lips are elongated, simple or branched and armed with terminal and usually also lateral cnidocyst knobs.

lithocyte: a cell containing a movable concretion or statolith, closely associated with sensory cells, located in a statocyst. (see ectodermal statocyst and ecto-endodermal statocyst).

lithostyle: see statocyst.

mamelon: a minute mound or nipple-shaped perisarc protuberance found on the upper surface of a hydrocladia-bearing apophysis. A small aperture in the centre communicates with the coenosarc. Origin and function unclear: either associated with nematophores Plumulariidae and Aglaopheniidae, or considered as an atrophied hydrotheca in the Halopterididae.

mantle: In Porpitidae (Anthomedusae) an outfolding along the float edge of the hydroid stage, probably acting as stabilizer. In Leptomedusae hydroids (some Sertulariidae and the Thyroscyphidae), the mantle, or ectodermal supporting lamella or "Haftlamella", is a thin layer of ectoderm lining the interior of the hydrotheca. Usually issued from the base of the hydranth, wrapping the hydranth completely when withdrawn, forming a roofing plate ("deckenplatte"). Sometimes with specialised regions of attachment to the hydranth and to the hydrotheca. In some genera a medio-basal annular lamella, the annular ectodermal fold, may link, like a diaphragm, the mantle to the hydranth body, in other genera the abcauline caecum region is attached to mantle directly or by a perculiar extension. In some genera the distal part of the mantle may contain cnidocysts, often in large aggregations (= kind of nematophores?). The ligula is presumably a mantle differentiation. A mantle may also exist in some gonangia of paedomorphic Leptomedusae, enveloping temporarily the gonophores.

mantle canal: in siphonopores, upper and lower diverticula of the pedicular canal at the point of its entry into a nectophore or gonophore.

manubrial or gastric cavity (= stomach): central cavity of the manubrium in connection with the exterior by the mouth and ending in the radial canals openings, delimited by an endodermal layer histologically divided into several regions, named according to function: oral, digestive, stomachal, cnidoblastic, or sexuated when the "gonads" develop on the manubrium. Rather uniform in structure throughout the various subclasses, except in Koellikerina (Bougainvilliidae) where the endoderm of the gastric cavity presents numerous conspicuous endodermal expansions sustained by a mesoglean axis and containing excretory vacuoles.

manubrial or gastric pouch or pocket: lateral perradial or interradial extension of the manubrial cavity (e.g. in Narcomedusae, Tiarannidae, Gotoea).

manubrium: axial didermic projection of the subumbrella containing the gastric or stomachal cavity, distally bearing the mouth and proximally leading to the radial canals. Manubria are greatly varied in shape and size, ranging from tubular to cruciform, quadratic, fusifom, barrel-shaped, flask-shaped, short, long, narrow or very large, etc. Erroneously considered as synonym with stomach (see stomach).

marginal bulbs: see tentacular or non tentacular marginal bulbs.

marginal cirri: see cirri.

marginal cnidocyst ring: see cnidocyst marginal ring.

marginal lappet: one in a series of lobe-like extensions around umbrellar margin (e.g. Narcomedusae).

marginal tentacle: a tentacle inserted on the edge, or margin, of the umbrella.

marginal vesicle: see statocyst.

marginal wart or swelling: small, wart-like swelling of the umbrellar margin, never destined to carry tentacles and not in connection with the circular canal (e.g. Eutima mira). 
marsupium: brood chamber formed by longitudinal gonothecal ribs, spines or leaves in female gonophores of some species of sertulariids hydroids (see brood chamber).

medusa budding: asexual budding of medusae. In hydroids, it occurs on the lateral wall of the polyp, on the hydrorhiza, on the hydrocauli, on the hydrocladia or on specialised structures. Common also among hydromedusae; medusa buds are formed either on the manubrium, the radial canals, the marginal bulbs or the subumbrellar rim. Medusa buds, in the Hydroidomedusa, imply the presence of an entocodon (see entocodon).

medusa reduction: in many Hydoidomedusae, the medusa becomes reduced, abortive, not living the colony anymore, the hydroid becoming the paedomorphic carrier of the sexual cells. Medusa reduction to fixed gonophores or sporosacs evolved independently in many Hydrozoa families and has no phylogenetic value. Reduction may be more or less pronounced pending the species, ranging from stages similar to the adult medusa (free or fixed medusoids) to stages where all medusan structures fail to develop, the germ cells being located in the ectoderm of the polyp body. Different main morphological stages of medusa regression have been recognised and described (see: eumedusoids; cryptomedusoid; heteromedusoid; styloids), they represent the most typical stages of reduction, with intermediate grades in each type. In many species male and female fixed gonophores belong to different types of sporosac. Medusa reduction is exceptional in Limnomedusae; at the species level it is less common in the Anthomedusae than in Leptomedusae where this phenomenon is the rule in most of the families with conspicuous colonies, which never present a real free medusa stages, like the: Aglaopheniidae; Clathrozoidae; Haleciidae; Halopterididae; Plumulariidae; Sertulariidae; Syntheciidae. The small leptomedusan colonies are usually characterised by free medusae, the smallest hydroids often producing the biggest medusae!

medusa: free living, sexual, pelagic adult stage in the cnidarian life cycle.

medusary nodule: see entocodon.

mesentery: in some species, a perradial tissue layer attaching the lateral walls of the manubrium to the subumbrella (see: Leuckartiara octona, Neoturris papua, Pandeopsis ikarii) mesial $(=$ median $)$ nemathotecae: nematothecae located in the vertical mid-line of the hydrotheca, one below, or median inferior, and one above hydrotheca, or median superior, more rarely on ahydrothecate stems, cauline nematothecae, or on internodes.

mesoglea: a non-cellular substance lying between the ectoderm and the endoderm; it forms the gelatinous bulk of the umbrella (the jelly of jellyfish) and a lamella-like layer (mesolamella) in polypoid forms. Synonym with extracellular matrix (ECM).

modular: consisting of a series of morphologically similar structural units.

monilifiliform: with dispersed small isolated clusters of cnidocysts on the adoral side of the tentacle and with a continuous band of cnidocysts along the aboral side.

moniliform: a tentacle with a terminal capitation and rather regularly spaced conspicuous clumps or bands of tall epidermal cells bearing cnidocysts. monopodial: branching pattern of stems in which the oldest hydranth remains at the distal end.

mouth arm: expansion or dilatation of a perradial corner of the manubrial mouth rim armed with cnidocyts clusters, usually open, groove-shaped (e.g. Hydractiniidae).

mouth: opening of the gastric cavity to exterior; in hydranth, at the end of the hypostome; in medusae, at the end of the manubrium, simple and circular or with either simple or complicated lips (see lips). Serves for both ingestion and elimination (egestion).

mouth: see basal lamella.

neck shield: thin extension of eudoxid bract, partly surrounding gonophores.

nectophore: Asexual medusoid swimming bells, grouped together in the apical part of the siphonophores 1 to form a region called nectosome. Differ from hydromedusae bell by their bilateral symmetry. Velum, radial canals, ring canal, endodermal lamella, a double nerve ring, striated muscles present. Manubrium, tentacles, "gonads", sense organs absent. Polymorphic, serving for propulsion. Absent in Cystonectae and in the physonect, Athorybia.

nectosac: the central cavity of nectophore, opening to exterior via an ostium and having muscular walls with propulsive function (= subumbrella cavity).

nectosome: section of stem bearing the nectophores. nematocladium (nematocladia): the upper fused part 
of a corbula rib.

nematodactyl: specialised tentacle with glandular base and bearing a strong cnidocyst armature (typical of Nemalecium).

nematocyst: $=$ cnidocyst

nematophore: type of highly extensible dactylozooid, mainly known in Leptomedusan hydroids, representing a strongly reduced hydranth richly armed with cnidocysts, without mouth or tentacles, with virtual or totally absent gastric cavity, either protected (see nemathotheca) or naked. In some Aglaopheniids the nematophores have two recognised portions, the body of the structure also called "sarcostyle" (see sarcostyle) and the region bearing the cnidocysts or cnidostyle. In Stylasteridae see nematopore. (see tentaculozooid).

nematopore: small shallow pores in the coenosteum of Stylasteridae housing the "nematophores", dense concentrations of long slender cnidocysts perpendicular to the branch surface, common around cyclosystems especially on pseudosepta and lids.

nematotheca: chitinous theca of varied structure surrounding a nematophore. In the Plumularioidea either sessile, immovable and one-chambered (monothalamic), or pedicillate, mobile and twochambered (bithalamic). Present also in some anthomedusan hydroids (Merona).

neoteny: a type of paedomorphosis due to retardation of somatic development, so that sexual maturity is attained by organisms retaining juvenile characters.

nerve ring: hydromedusae have two nerve rings around umbrella margin, usually on opposite sides of the velum, separated by a mesoglean lamella: a subumbrellar one, above velum attachment (inner or upper nerve ring) and an exumbrellar one, below velum attachment (outer or lower nerve ring). The two are connected by neurites.

nettle ring: see cnidocyst ring.

node: externally visible constricted section of hydrocaulus or hydrocladium marking junction of two internodes (see internode).

non-tentacular marginal bulb or rudimentary bulb: marginal bulb developed on the umbrella margin without bearing tentacles; such bulbs never develop tentacles; others can be the result of tentacle reduction. It is necessary to distinguish between bulbs that are permanently without tentacles, permanent non-tentacular marginal bulbs or rudimentary marginal bulbs, as in Cirrhitiara superba, Aequorea macrodactyla, and bulbs on which marginal tentacles will develop later on during medusan growth (developing tentacular marginal bulbs, as in Clytia and Malagazziidae).

oblate: flattened at the two poles; in medusae, species which contract primarily near bell margin when swimming, producing a low-velocity jet (e.g. Aequorea, Clytia).

ocellus (pl. ocelli): multicellular photoreceptor, common in Anthomedusae, usually abaxial or adaxial on marginal bulbs. Round, oblong or elongated spots, black, brown, yellow or red, consisting of a small mass or cupule of pigmented cells associated with nerve cells. A lens may be present. Of ectodermal origin, except in the Tiaropsidae (see ecto-endodermal ocelli).

octant: an eighth of the umbrella; the space between the interradii in a medusa with 4 radial canals.

operculum: lid-like structure closing hydrothecae or gonothecae. Some comprise a single flap, others have two, three, four or many flaps meeting in the centre; opercular valves may be simple inwards folds of the distal part of the hydrothecae (pleated), or segments of the primary covering of the hydrotheca seated and hinged in embayments (prominent crease-line) of the hydrothecal margin; they may be cast away during hydranth growth or after medusa liberation. The term also refers to the lid covering the opening of cnidocysts.

opposite: in hydroids, two hydrocladia or hydrothecae that arise on the same level, one pointing to the right, the other to the left.

oral tentacle: tentacle arising above the mouth rim of some medusae with circular mouth. Simple and located just above the mouth rim in the Cytaeididae, simple or branched and situated well above the mouth rim in the Bougainvilliidae. Tentacles located immediately below the hypostome of hydroids.

oral: near the mouth, the opposite end being aboral. ostium: nectosac opening, through which water is expelled for propulsion (= velar opening).

otoporpae: in some Narcomedusae, vertical, elongated, oval or even rounded ectodermal tracts with bristles and cnidocysts running upwards from each statocyst over the exumbrella margin. paedomophosis: acceleration (progenesis) or retardation (neoteny) of somatic development, leading to adults retaining juvenile features.

paedophore: an asexual, larval nurse carrier (i.e. colonies of siphonophores, the hydroids) budding of the sexual adults medusoids or medusae. 
pallial canal: section of gastrovascular system which joins the radial canals on nectosac to the pedicular canal or the somatocyst = pedicular canal

palmate: a form like that of an open palm or hand; in hydroids, a hydrocaulus with largely ascending, long branches converging strictly or loosely in one plane $=$ thuja-like.

palpacle: a small tentacle borne on a palpon in siphonophores.

palpon: in siphonophores, a cormidial element, probably a reduced gastrozooid, which may have sensory or excretory functions?

pedicel: stalk of a hydrotheca, a gonotheca or a hydranth (= stem, hydroclade); in general, in animals any stalk like structures $(=$ pedicle $=$ peduncle).

pedicle: in zoology a small stalk (= pedicel = peduncle).

pedicular canal: section of gastrovascular system which joins the apical point of convergence of the radial canals to somatocyst in calycophoran siphonophores, may present descending, ascending expansions or even branches. (see mantle canal)

peduncle: see gastric peduncle. In general in animals any stalk or stalk-like process $(=$ pedicel $=$ pedicle).

periderm: mucoproteinic coating (= glycocalyx) of the exposed surface of hydroids and medusae. Not to be confused with perisarc.

peripheral canal system: see circular canal.

peripheral canal: in some hydroids, longitudinal peripheral canals of the hydrocaulus, in medusae, see circular canal.

perisarc: the chitinous exoskeleton surrounding the coenosarc of most hydroids. In the Anthomedusae the polyps are usually never surrounded by perisarc, in the Leptomedusae they usually are (see hydrothecae, gonothecae and nematothecae).

peronia: in Narcomedusae and some Laingiomedusae, an ectodermal strands at the base of the tentacles rich in cnidocysts, muscles and nerves. The peronia are formed by the fusion of subumbrellar and exumbrellar ectoderm without interposition of mesoglea. At the base of the peronia the margin of the umbrella remains curved, giving the umbrella its lobed, scalloped appearance (marginal lappets). The peronia and the exumbrellar position of the tentacles result from developmental circumstances; during Narcomedusae development, the endodermal core of the tentacles issues from the manubrium; when umbrella growth, the tentacles remain attached close to the manubrium and the tentacular ectoderm, maintaining its connection with the umbrella margin, extends on the exumbrella forming the peronia (see also tentacular roots).

peronial canal: in Narcomedusae the part of the peripheral canal system running vertically along the peronia (see circular canal).

perradial: the main radial axes of a medusa, corresponding in most species to the radial canals. In Narcomedusae the axis opposite each gastric pouch.

phagocytosis: the process by which cells surround, and engulf, a food particle which is then digested. The feeding method employed in particular by some unicellular protozoans and Cnidaria.

phorocyt: nurse cell.

phylactocarps: in some Aglaopheniidae, modified hydrocladia or appendages to a hydrocladium, forming a protective structure typically armed with nematohecae around gonothecae, similar to corbula hydrocladia, but more widely spaced, not fused and less modified.

phylactogonium: in some mature Aglaopheniids, accesory branch of bifurcated hydrocladia bearing the gonangium and its defensive differentiations.

phyllocyst: reduced canal system in an eudoxyd bract, equivalent to the somatocyst in a nectophore.

phyllozooid: $=$ bract

pinnate: hydroid colony with branches (alternate or opposite) on each side of hydrocaulus, usually nearly in one plane, resembling a feather.

planula: an embryonic free-swimming post blastula stage into which most of the Hydrozoa eggs become directly developed $(=$ gastrula $=$ coelogastrula or stereogastrula). Improperly called larva since, from a developmental point of view, it is an embryo (see embryo and larva). Planula of Hydrozoa do not feed but live entirely off yolk, the planulae of some species have zooxanthellae. Attached to substratum by their usually broader anterior end.

Fig.lets: see coenosteum.

plumose: hydroid colony with closely arranged lateral branches, usually in one plane (see pinnate). pneumadenia: gas-gland at the base of the pneumatophore cavity.

pneumatocodon: outer ectodermal wall of the pneumatophore separated from the inner wall or pneumatosaccus by gastrovascular space lined 
by endoderm, containing muscle fibers.

pneumatophore: apical gas-filled float, present in Cystonectae and Physonectae; in the latter its function can be for orientation rather than buoyancy. Derived directly from the larval stage, probably represents a highly modified polyp. In some species the gastrovascular cavity may be divided by vertical septa clothed with endoderm (Anthophysa).

pneumatosaccus: inner ectodermal wall of the pneumatophore, separated from pneumatocodon by gastrovascular space and typically lined by a chitinous layer (see pneumatocodon).

podocyst: multicellular capsule from nipped-off portions of coenosarc, functioning as a cyst.

polygastric stage: in siphonophores, the complete animal bearing both asexual and reproductive elements (nectosome and siphosome).

polymorphic: bearing different morphs (in hydroids: gastrozooids, gonozooids, dactylozooids, etc.).

polyp: basic individual of the hydroids; may either be isolated or form colonies; represented by different types, such as hydranths, gonozooids and dactylozooids.

polysiphonic $=$ fascicled: a hydroid stem made of more than one coenosarc and perisarc tube.

primary polyp: the hydranth formed by the development of a newly settled planula.

proboscis: hypostome in a hydranth.

progenesis: a type of paedomorphosis due to acceleration of the gonad development, so that sexual maturity is attained by organisms retaining juvenile characters.

prolate: lenghtened in the direction of the polar diameter; in medusae, species which contract over their entire length when swimming, producing a high velocity jet: i.e., Aglantha, Sarsia.

propagule: any asexual or sexual morph leading to propagation.

proximal: at the near end, towards or at the base of attachment.

pseudofiliform: tentacles with scattered cnidocysts in a relatively low epidermis along the adoral side and a concentration of cnidocysts in tall epidermis on the aboral side.

pseudohydrotheca: a film-like, often gelatinous, flexible coat covering partly or entirely the hydranth body of some Anthomedusae hydroids, it has little form and adheres closely to the hydranth ectoderm, not homologous to the perisarcal hydrothecae but apparently similar in function (e.g. some bougainvilliids and pandeids). pseudosepta: radially arranged ridges between the dactylozooids of a cyclosystem.

ptera: lateral aliform expansions in the gastrozooids of the rhizophysid physonect genus Bathyphysa

quadrant: a quarter of the umbrella; the space between perradii in a medusa with 4 radial canals.

radial canal: canal leading from the perradial corners of the manubrium to the circular canal. Usually straight and narrow, with smooth sides. In some species large, ribbon-like (e.g. Amphinema) and with jagged outgrowths (e.g. Leuckartiara). Typically four, but more numerous in many medusae, exceeding sometimes more than 100 (e.g. Aequorea). Normally simple, but in certain species branched and sometimes whose branches never reach the circular canal (e.g. Staurodiscus). Generally growing centrifugally, from the manubrium to the circular canal, except in a few species where they arise centripetally (e.g. Melicertoides; the centripetal canals). Siphonophore nectosacs have four radial canals linked by the ring canal. They are unequally developed and their point of convergence is only exceptionally at the apex of the nectosac.

ramified capitate: branched tentacles with a capitation on each branch.

renovation: a new hydrotheca developing within an old one, sometimes repeatedly, resulting in a tier of hydrothecae one within the other; sometimes only the hydrothecal margin renovates.

rete: (rete mirabile) in siphonophores a flattened, disc-shaped expansion on a canal; function unknown.

rhizocaulomic: stolonal colonies with erect hydrorhiza formed by a bundle of parallel stolons.

rhizoid: in hydroids, lateral rootlike structure attaching the stolon to the subtratum

ring canal: see circular canal.

ring fold: see annular ectodermal fold.

ring palisade $=$ cheval-de-frise: In Stylasteridae ring of tiny, blunt spines projecting from the wall of the gastropore tube at the level of the gastrostyle tip. It constricts the gastropore tube in a lower gastrostyle chamber and an upper funnel-shaped part leading to the branch surface. When the gastrostyle is absent, the ring palisade forms a solid ring constricting the gastropore tube in a small flat lower chamber, which contains the bulk of the gastrozooid and a larger spacious upper chamber into which the dactylozooids enter. 
rudimentary bulb: see non-tentacular marginal bulb. sail: thin erect, sail-like structure extending across surface in Velella.

sarcopore: see sarcostyle.

sarcostyle: specialised type of nematophore found mainly in the Plumularioidea and exceptionally in a few other families, naked, emerging through a hole of the perisarc (sarcopore) or protected by a minute nematotheca, or sarcotheca. Mobile, armed with cnidocysts, some distally rich in adhesive gland cells and playing a role in phagocytosis or in cleaning the surrounding perisarc. Body of the nematophores in some Aglaopheniids.

sarcotheca: see sarcostyle.

scapus: a structure similar to coppinia but lacking the protective elongate polyps.

scutum: Fig. or shield-like process.

semifiliform: tentacle with a capitation stretched towards the aboral side.

semimoniliform: tentacle with a large capitation and numerous small cnidocyst clusters on the adoral side. sensory club: see ecto-endodermal statocyst.

septum: an internal partition, for instance an inward projection of hydroid perisarc which may occur in the stolon, hydrocaulus, hydrocladium or hydrothecae.

shaft: see butt.

siphon: unusual specialisation for attachment and strengthening, seen in Hartlaubella gelatinosa and some other hydroids, consisting of an unsegmented tubular outgrowth of hydrocaulus, resembling a stolon, running back from the distal end of each segment of the main hydrocaulus toward the base of the colony and closely pressed to the main stems; the siphon branch out basally into the substratum and ends blindly.

siphosome: in siphonophores, section of the stem below nectosome, usually long, bearing cormidia.

solid tentacle: tentacle without central cavity, with an endodermal core formed by a single row of disk-like or superimposed cylindrical vacuolated cells (see chordal).

somatocyst: in calycophoran siphonophores, prominent extension of the stem into the nectophore may contain oil droplets.

spadix: the central finger-shaped core formed by an evagination of the "mother" endoderm, covered by entocodonial ectoderm, forming the manubrium in a medusa or supporting ripe sex cells in most of the reduced gonophores (see sporosacs). Its central cavity is continuous with that of the colony.

spermatophore: a compact mass or packet of spermatozoa either liberated as such or transferred to a female.

spherule $=$ locule $=$ basal space: a globular region of pedicel directly beneath hydrotheca, formed by two adjacent annular constrictions.

sphincter (isthmus): cellular structure at the aboral end of hydranths that can be closed so to allow localised digestion of prey and to prevent the transfer of too large prey pieces from the gastric cavity to the lumen of the stolonal system; in Campanulariids and Eudendriids also to the constriction of the base of the hypostome.

spine: one of numerous chitinous spines projecting from perisarc-covered hydrorhizal network. Also one in the series of minute spines on tubule of cnidocysts.

spiral zooid: modified polyp without mouth, with a gastric cavity, bearing either terminal cnidocyst aggregations or stout cnidocyst knobs or very short tentacles richly armed with cnidocysts and tending to twist or coil into spiral, characteristic of some Hydractiniidae (a type of dactylozooid). spiral: colony appearance due to spiral arrangement of hydrocladia around the main stem.

sporosac: reduced type of gonophore remaining fixed to the hydroid and in which the sex cells ripen directly, of different types (see eumedusoids, cryptomedusoids, heteromedusoids and styloids).

spur canal: reduced longitudinal canals in gastrovascular system of siphonophore prayid eudoxid bracts; in medusae, see exumbrellar spur.

statocyst $=$ lithostyle $=$ tentaculocyst $=$ sensory club: see ectodermal statocyst and ecto-endodermal statocyst.

statolith = otolith: minute concretion composed of organic material and minerals, mainly calcium carbonate, enclosed within the lithocytes of statocysts, their movement stimulates sensory receptors (see ectodermal statocyst and ectoendodermal statocyst).

stem: in hydroids, a general term for any main erect structure which can bear hydrocladia or hydranths; in siphonophores, the stem or stolon is divided in two distinct regions (see stolon).

stolon: in hydroids, creeping or erect hollow tube protected by perisarc and containing the same ecto-endodermal tissues of the polyps (coenosarc), generally adhering to the substrate forming a complex system, or hydrorhiza. Under 
adverse environmental conditions only the stolons of many colonies survive, acting as resting stages until proper conditions return. In siphonophores, the stolon or stem is an extensile or not, ecto-endodermic tube (coenosarc) along which the various types of zooids are borne, organised down such that two distinct regions can be recognised the nectosome and the siphosome (only one the siphosome in Cystonect), both forming the polygastric stage.

stolonal colonies: colonies where the growth is horizontal and the hydranths arise directly or from short unbranched pedicels from a common creeping hydrorhiza.

stomach: internal pouch or cavity of the manubrium or of the hydranth in which food digestion is initiated. Often erroneously used instead of manubrium (see manubrium, manubrial or gastric cavity).

straight: hydroid colony with a non-flexuose main stem, either biseriate (with hydranths in two opposite rows) or uniseriate (with hydranths in a single row).

striated muscle: a muscle with striated fibers, in Hydrozoa present in the subumbrella of medusae or reduced gonophores.

style: in some calcareous hydrozoans, upright spine at the base of gastropore, occasionally also in dactylopore.

styloid sporosac: the most regressed type of gonophore, without internal ectoderm and umbrellar endoderm; reduced to a single evagination of the two germ layers, between which the genital elements accumulate.

subumbrella: see umbrella.

subumbrellar cavity: see umbrella.

subumbrellar surface: see umbrella.

sucker: adhesive structure in medusae, located either along or at the tip of the tentacles or at the tip of specialised stalk-like structures, usually lacking cnidocysts.

swimming gonophore: pelagic stage derived from strongly reduced medusa stages (cryptomedusoids and perhaps heteromedusoids) developing as free gamete carriers; usually without radial canals and circular canal (present in Anthohebella); without tentacles; without sense organs; with sexual elements always on "manubrium" even in Leptomedusae, the manubrium or spadix in eccentric position. They can not been confused with eumedusoids, the first step of medusa reduction, still with most of the original non reproductive structure of the medusa: radial canals, circular canal, velum, sense organs, with maturation of the sexual cells according the classes (on manubrium in Anthomedusae on radial canals in Leptomedusae) and with a non eccentric position of the manubrium. Found mostly in Leptomedusae families with paedomorphic hydroids characterized by the possession of fixed and highly reduced gonophores; some are known in Anthomedusae (e.g. Pachycordyle).

swimming sporosac: liberated sporosac with a non medusoid swimming apparatus (ex. Dicoryne).

synonym: two or more names applied to the same taxon. Synonymised species or genera are said conspecific or congeneric.

synonymy: the list of synonyms applied to a taxon, other than the currently accepted name.

tabulae: in Milleporidae, horizontal calcareous Figs. crossing the cavities of the gastropores and dactylopores, the most recent secreted tabula corresponds to the level of the alive part of the coenosteum.

tentacle: usually highly contractile cnidocyst-bearing processes with sensory, defending, feeding and occasionally anchoring functions. In the medusae, the tentacles are usually on the umbrella margin = marginal tentacles, or on exumbrella. They may also occur around the mouth = oral tentacles; in hydroids, the tentacles may be located immediately below the hypostome = oral tentacles and/or in one or more distinct rings on the hydranth body $=$ aboral tentacles or even scattered over the whole body. Tentacles types vary according to the distribution of cnidocyst armature; the most common types are capitate, cateniform, filiform, moniliform, pseudofiliform, ramified capitate.

tentaculae: small solid marginal tentacles (usually without marginal bulbs, but in contact with the circular canal) located between normal hollow tentacles (e.g. Amphinema rugosum).

tentacular marginal bulb: in most Antho- and Leptomedusae, a dilated portion of the proximal part of a marginal tentacle, next umbrellar margin, contains a cavity in communication with the circular canal and with the tentacular cavity of hollow tentacles. Of various shapes, mostly simple but in some medusae compound, originating several tentacles (e.g. Hybocodon, Bougainvillia); they perform digestive activities; are centers of cnidoblast formation and, in some species, bear 
ocelli. In Anthomedusae and Leptomedusae a new marginal tentacle is normally preceded by the formation of a bulb on which it will develop (see marginal bulb). In some medusae there are no true tentacular bulbs: i.e. in the Limnomedusae, Narcomedusae, Trachymedusae, in the majority of the Bythotiaridae, in the Anthomedusae Eugtoea petalina and Rhabdoon singularis.

tentacular root: projection of the endodermal tentacular core into the umbrella mesoglea (Blackfordia, Obelia, some Limnomedusae, Trachymedusae and the Narcomedusae) (see peronia).

tentaculiform structure: solid marginal structure resembling tentaculae, without marginal bulb and with no contact with circular canal (exclusive to Orchistomatidae).

tentaculocyst: see ecto-endodermal statocyst.

tentaculozooid: reduced dactylozooid similar to tentacle in structure, with a solid core of chordal endoderm and no mouth or gastric cavity, richly armed with cnidocysts and often with chemosensory receptors; very extensible and contractile.

tentilla: in siphonophores, side branches of the gastrozooid tentacle, bearing expanded terminal aggregations of cindocysts (see cnidoband).

theca: chitinous extension typically protecting any kind of polyp.

thecate: name for the hydroid stage of the Leptomedusae, usually with thecae protecting hydranths and gonophores.

thread: hollow thin tube coiled inside cnidocyst capsule. Turned inside out when discharged. Discharged threads may be differentiated into a proximal dilated section, shaft or butt, and a thinner distal section, the thread or tubule.

thrust block: in physonect siphonophores, aboral section of a nectophore, separating apical wings and abutting against nectosomal stem.

transverse commisures: $=$ commissural canals .

trophosome: all structures of a colony except the reproductive ones.

tubule: see thread.

umbilical canal: see apical canal.

umbrella: main body of medusa, excluding manubrium and tentacles; generally resembling a bell or an umbrella. Shapes: bell-shaped, bowl-shaped, dome-shaped, flat, hemispherical, pointed, saucer-shaped, tall, turreted. The outer, generally convex, surface is the exumbrellar surface (exumbrella); the inner concave surface is the subumbrellar surface (subumbrella), the concavity being the subumbrellar cavity. The edge of the umbrella is the umbrellar margin.

umbrellula: see intertentacular web.

vasiform: vase-shaped, with broad base and slender top.

velar ridge: in calycophoran siphonophores, dorsal cross ridge parallel to the ostium, on nectophores of Gilia reticulata and some Lensia species (e.g. Lensia lelouveteau)

velar: of the velum.

velum: horizontal fold projecting inwards from umbrellar margin, living a central, circular hole, the velar opening. It consists of two layers of ectoderm separated by a thin mesoglean lamella; the inner ectoderm, of subumbrellar origin, possesses striated muscles. The velum serves in the propulsion and the orientation of the medusa, by acting like a photographic diaphragm, during swimming the medusa can adjust the diameter of its aperture, which can become as wide as the umbrella or almost closed. (in Siphonophores often called ostium).

veronica: in siphonophores, a spiral movement which spreads the tentacles into a characteristic pattern.

verticillate: arranged in a succession of whorls, whorled.

zooid: in colonial hydroids, any of several types of individual polyps: dactylozooids, gastrozooids, gonozooids etc.

zooxanthellae: unicellular algae, living in symbiotic association in the tissues of many Cnidaria.

\section{ACKNOWLEDGEMENTS}

The publication of this book has been partially supported by a grant of the Spanish Ministerio de Ciencia y Tecnología, REN2002-11397-E). This study was partially supported by a PEET project of the National Science Foundation of the USA, by COFIN and FIRB projects of MIUR, and by the Provincial Administration of Lecce. J.B. gratefully acknowledges the financial support of the "Foundation Universitaire David and Alice Van Buuren", he is greatly indebted to $\mathrm{Mr}$ Jean-Philippe Bouillon for some of the medusa drawings, and finally last but not least he thanks his wife "Janine" in whose time this work has been done, mainly for her patience and daily support. We are indebted to Jordi Corbera for permission to reproduce his drawings previously published in Pagès et al. (1992), Pagès and Gili (1992), Gili et al. (1998b, c, 1999) and Bouillon et al. (2000). 


\section{REFERENCES}

Acker, T.S. - 1976. Craspedacusta sowerbii: an analysis of an introduced species. In: G.O. Mackie (ed.), Coelenterate Biology and behaviour, pp. 219-226. Plenum Publishing Corporation, New York.

Acker, T.S. and A.M. Muscat. - 1976. The ecology of Craspedacusta sowerbii Lankester, a freshwater hydrozoan. Am. Midl. Nat., 95: 323-336.

Agassiz, A. - 1865. North American Acalephae. In: Illustrated Catalogue of the Museum of Comparative Zoologie, at Harvard College, No. II, 234 pp.

Agassiz, A. and A.G. Mayer. - 1899. Acalephs from the Fiji Islands. Bull. Mus. comp. Zool. Harv., 32: 157-189.

Agassiz, L. - 1862a. Contributions to the Natural History of the United States of America. 2nd monograph. Little, Brown and Co., Boston.

Agassiz, L. - 1862b. Tabular view of the whole order Hydroida. Contr. Nat. Hist. U.S.A., 4: 366-72.

Aguirrezabalaga, F., A. Altuna, M.D. Arraras, I. Miguel, A. Romero, M.J. Ruiz de Ocenda, D. San Vicente and M. Ibañez. - 1986. Contribución al conocimiento de la fauna marina de la costa Vasca. IV. Lurralde, 9: 133-158.

Albertini-Berhaut, J. - 1971a. Variations saisonnières de la trachyméduse Rhopalonema velatum Gegenbaur 1856 dans le golfe de Marseille. Comparaison avec celles déjà observées dans d'autres régions méditerranéennes. Bull. Soc. zool. Fr., 95: 241-247.

Albertini-Berhaut, J. - 1971b. Distribution des trachyméduses Persa incolorata McGrady 1857, Aglaura hemistoma Péron et Lesueur 1809 dans le golfe de Marseille. Bull. Soc. zool. Fr., 95: 677-687.

Alldredge, A.L. - 1983. The quantitative significance of gelatinous zooplankton consumers. In: M.J.R. Fasham (ed.), Flows of energy and materials in marine ecosystems: theory and practice, pp. 407-433. Pergamon Press, New York.

Allman, G.J. - 1871-1872. A Monograph of the Gymnoblastic or Tubularian Hydroid. Ray Society, London.

Allman, G.J. - 1888. Report on the Hydroida dredged by H.M.S Challenger during the years 1873-76. Part II. Tubularinae, Corymorphinae, Campanularinae, Sertularinae and Thalamorphora. Rep. Scient. Res. Voy. H.M.S. Challenger during the years 1873-1876. Zoology, 23: 1-90.

Altuna Prados, A. - 1994a. Estudio faunístico, ecológico y biogeográfico de los Cnidarios bentónicos de la costa vasca. Ph.D. Thesis, Univ. of Navarra.

Altuna Prados, A. - 1994b. El género Sarsia Lesson, 1843 (Cnidaria: Hydrozoa) en la costa Vasca. Kobie, 21: 27-41.

Altuna Prados, A. - 1994c. Notas sobre los cnidarios bentónicos de la costa Vasca I.- Mitrocomium cirratum Haeckel, 1879 y Halecium liouvillei Billard, 1934 (Cnidaria: Hydrozoa). Kobie, 21: 43-54.

Altuna Prados, A. - 1995. Description de Clytia linearis (Thornely, 1899) (Cnidaria, Hydrozoa) y su variabilidad en la Costa Vasca; consideraciones biocenológicas, biogeográficas y ecológicas sobre la especie. Kobie, 22: 59-66.

Altuna Prados, A. - 1996. Hebella scandens (Bale, 1888) (Cnidaria, Hydrozoa); una experiencia de cultivo con descripción de la fase medusa. Thalassas. 12: 53-61.

Altuna Prados, A. and C. Álvarez Claudio. - 1995. El género Zygophylax Quelch, 1885 (Cnidaria, Hydrozoa) en el golfo de Vizcaya. Misc. Zool., Barcelona, 17: 1-16.

Alvarez Claudio, M.C. - 1993a. Hidrozoos bentónicos y catálogo de Antozoos de la plataforma y talud continentales de la costa central de Asturias. Ph.D. Thesis, Univ. of Oviedo.

Alvarez Claudio, M.C. - 1993b. Bedotella armata (Cnidaria, Hydrozoa, Lafoeidae) in the Bay of Biscay, with description of its gonothecae. Misc. Zool., Barcelona, 17: 265-267.

Alvariño, A. - 1957. Estudio del zooplancton del Mediterranéo Occidental. Boln Inst. esp. Oceanogr., 81: 1-26.

Alvariño, A. - 1971. Siphonophores of the Pacific with a review of the world distribution. Bull. Scripps Inst. Oceanogr. tech. ser., 16: 14-32.

Alvariño, A. - 1974. Distribution of Siphonophores in the regions adjacent to the Suez and Panama canals. Fish. Bull., 72: 527-546.

Alvariño, A. - 1981. Siphonophorae. In: D. Boltowskoy (ed.), Atlas del zooplancton del Atlántico sudoriental, pp. 383-441. Institu- to Nacional de Investigación y Desarrollo Pesquero, Ministerio de Comercio e Intereses Marítimos, Argentina.

Alvariño, A. and X. Leira. - 1986. El zooplancton del Pacífico Ecuatoriano. Inv. Mar. CICIMAR, 3: 69-110.

Andersen, O.G.N. - 1981. Redescription of Marrus orthocanna (Kramp, 1942) (Cnidaria, Siphonophora). Steenstrupia, 7: 293-307.

Ansín Agís J., F. Ramil and W.Vervoort. - 2001. Atlantic Leptolida (Hydrozoa, Cnidaria) of the families Aglaopheniidae, Halopteriidae, Kirchenpaueriidae and Plumulariidae collected during the CANCAP and Mauritania-II expeditions of the National Museum of Natural History, Leiden, The Netherlands. Zool. Verh., Leiden, 333: 1-268.

Antsulevich A.E. and S.D. Stepanjants. - 1985. Novy predstavitel' redkogo roda Rosalinda (Hydroidea) v Dal'nevostochnykh vodakh. A new species of a rare genus Rosalinda (Hydroidea) in the Far East waters. Zool. Zh., 64: 1140-1147.

Arai, M.N. - 1988. Interactions of fish and pelagic coelenterates. Can. J. Zool., 66: 1913-1927.

Arai, M.N. and A. Brinckmann-Voss. - 1980. Hydromedusae of British Columbia and Puget Sound. Can. Bull. Fish. aquat. Sci., 204: 1-192.

Arvanitidis, C., G. Bellan, P. Drakopoulos, V. Valavanis, C. Dounas, A. Koukouras and A. Elefhteriou. - 2002. Seascape biodiversity patterns along the Mediterranean and the Black Sea: lessons from the biogeography of benthic polychaetes. Mar. Ecol. Progr. Ser., 244: 139-152

Avian, M., F. Boero, C. Mills, L. Rossi and L. Rottini-Sandrini. 1995. Cnidaria, Ctenophora. In: A. Minelli, S. Ruffo and S. La Posta (eds.), Checklist delle specie della Fauna Italiana. Bologna, 3: 1-38.

Avsar, D. - 1999. Physico-chemical characteristics of the eastern Mediterranean in relation to distribution of the new Scyphomedusae (Rhopilema nomadica). Tr. J. Zool., 23 (Suppl. 2): 605-616

Babnik, P. - 1948 . Hidromeduze iz srednjega in junega Jadrana v Letih 1939 in 1940. Hydromedusae from the middle and South Adriatic 1939 and 1940. Acta Adriat., 3: 275-340.

Ballard, L. and A. Myers. - 1996. Seasonal changes in vertical distribution of five species of the family Bougainvilliidae (Anthomedusae) at Lough Hyne, south-west Ireland. Sci. Mar., 60: 69-74.

Båmstedt, U., J.H. Fosså, M.B. Martinussen and A. Fosshagen. 1998. Mass occurrence of the physonect Apolemia uvaria (Lesueur) in Norwegian waters. Sarsia, 83: 79-85.

Bavestrello, G. - 1985. Idroidi simbionti di paguri e gasteropodi nella riviera ligure di levante. Oebalia, 11: 349-362.

Bavestrello, G. - 1987. Diagnosis of the hydroid Perarella propagulata sp. nov. (Cnidaria, Hydrozoa) and a discussion of relations within the superfamily Bougainvillioidea Petersen. In: J. Bouillon, F. Boero, F. Cicogna and P.F.S. Cornelius (eds.), Modern trends in the Systematics, Ecology and Evolution of Hydroid and Hydromedusae, pp. 19-27. Clarendon Press, Oxford.

Bavestrello, G. and C. Cerrano. - 1992. Aggregate colonies in Eudendrium glomeratum Picard 1952 (Cnidaria, Hydrozoa, Anthomedusae). Sci. Mar., 56: 333-335.

Bavestrello, G. and S. Piraino. - 1991. On two Eudendrium (Cnidaria, Hydrozoa) species from the Mediterranean Sea. Oebalia, 17: 197-207.

Bavestrello, G., S. Puce, C. Cerrano and A. Balduzi. - 2000. Life history of Perarella schneideri (Hydrozoa, Cytaeididae) in the Ligurian Sea. Sci. Mar., 64 (Suppl. 1): 147-150.

Bavestrello, G., S. Puce, C. Cerrano, L. Castellano and A. Arillo. 2000. Water movement activating fragmentation: a new dispersal strategy for hydractiniid hydroids. J. mar. biol. Ass. U.K., 80: $361-362$.

Bavestrello, G., C. Sommer and M. Sara. - 1992. Bi-directional conversion in Turritopsis nutricula (Hydrozoa). In: J. Bouillon, F. Boero, F. Cicogna, J.-M. Gili and R.G. Hughes (eds.), Aspects of Hydrozoan Biology. Sci. Mar., 56: 137-140.

Bedot, M. - 1888. Sur l'Aglama clausi n. sp.. Revue suisse Zool., 5: 73-91.

Bedot, M. - 1904. Siphonophores provenant des campagnes du yacht 'Princesse Alice', 1892-1902. Rés. Camp. scient. Prince Albert I Monaco., 27: 1-27.

Bedot, M. - 1911. Notes sur les Hydroïdes de Roscoff. Archs. Zool. exp. gén., 5 Sér. 6: 201-208. 
Bedot, M. - 1919. Les variations d'Aglaophenia pluma (L.). Revue suisse Zool., 27: 243-281.

Bedot, M. - 1921. Hydroïdes provenant des campagnes des yachts Hirondelle et Princesse-Alice (1887 à 1912). I. Plumularidae. Rés. Camp. scient. Prince Albert I de Monaco, 60: 1-73.

Bennett, I. - 1966. The fringe of the sea. Rigby, Adelaide.

Benović, A. - 1973. Idromedusae dell'Adriatico settentrionale nell'anno 1965. Boll. Pesca Piscicol. Idrobiol., 28: 59-70.

Benović, A. - 1976. Hydromedusae (Cnidaria) from two stations in the southern Adriatic and Tyrrhenian Seas in the year 19671968. Pubbl. Staz. zool. Napoli., 40: 1-10.

Benović, A. and A. Bender. - 1986. Medusa from the open waters of the Adriatic Sea (1974-1976). Studia Marina, 17-18: 55-74.

Benović, A. and A. Bender. - 1987. Seasonal distribution of medusae in the Adriatic Sea. In: J. Bouillon, F. Boero, F. Cicogna and P.F.S. Cornelius (eds.), Modern trends in the Systematics, Ecology and Evolution of Hydroid and Hydromedusae, pp: 117-131. Clarendon Press, Oxford.

Benović, A. and D. Lucić. - 1996. Comparison of hydromedusae findings in the northern and southern Adriatic Sea. Sci. Mar., 60: $129-135$.

Berhaut, J. - 1969. Variations mensuelles d'abondance de la trachyméduse Liriope tetraphylla (Chamisso et Eysenhard, 1821) dans le golfe de Marseille. Bull. Mus. Hist. nat. Paris, 40: 12221231

Berhaut, J. - 1970. Étude qualitative, quantitative et écologique des hydroméduses du golfe de Marseille. Téthys, 1: 667-708.

Berrill, N.J. - 1948. The life cycle of Aselomaris michaeli, a new gymnoblastic hydroid. Biol. Bull. mar. biol. Lab. Woods Hole, 95: 289-295.

Besteiro, C., J.S. Troncoso, J. Parapar, L.V. Salvini-Plawen and V. Urgorri. - 1991. Hallazgos de Monobrachium parasitum (Cnidaria, Hydrozoa) en asociacion con Digitaria digitaria (Mollusca, Bivalva). Iberus, 9: 91-96.

Beyer, F. - 1955. Plotocnide borealis Wagner in the Oslofjord. Nytt Mag. Zool., 3: 94-98.

Bianchi, C. N., and C. Morri. - 2000. Marine biodiversity of the Mediterranean Sea: Situation, problems and prospects for future research. Mar. Poll. Bull., 40: 367-376.

Bierbach, M. and D.K. Hoffmann. - 1973. Experimentelle Untersuchungen zum Stockwachstum und zur Medusenbildung bei den marinen Hydrozoon Eirene viridula. Helgoländer wiss. Meeresunters., 25: 63-84.

Bigelow, H.B - 1909. Reports on the scientific results of the expedition to the eastern tropical Pacific, in charge of Alexander Agassiz, by the U.S. Fish Commission Steamer 'Albatross', from October, 1904, to March, 1905, Lieut. Commander L. M. Garrett, U.S.N., commanding. XVI. The Medusa. Mem. Mus. comp. Zool. Harv., 37: 1-243.

Bigelow, H.B. - 1911a. Biscayan plankton collected during a cruise of H.M.S. 'Research' 1900. Part XIII. The Siphonophora. Trans. Linn. Soc. Lond. (Zool.), 10: 337-358.

Bigelow, H.B. - 1911b. The Siphonophorae. Reports of the scientific research expedition to the tropical Pacific. Albatros. XXIII. Mem. Mus. comp. Zool. Harv., 38: 173-402.

Bigelow, H.B. - 1913. Medusa and Siphonophorae collected by the U.S. Fisheries Steamer 'Albatross' in the Northwestern Pacific, 1906. Proc US, natn. Mus, 44: 1-119.

Bigelow, H.B. - 1918. Some Medusa and Siphonophorae from the western Atlantic. Bull. Mus. comp. Zool. Harv., 62: 365-442.

Bigelow, H.B. - 1919. Hydromedusae, siphonophores and ctenophores of the 'Albatross' Philippine Expedition. In: Contributions to the biology of the Philippine Archipelago and adjacent region. Bull. U.S. natn. Mus., 100: 279-362.

Bigelow, H.B. and M. Sears. - 1937. Siphonophorae. Rep. danish oceanogr. Exped Medit., 11. (Biol.) H. 2: 1-144.

Biggs, D.C. - 1977. Field studies on fishing, feeding, and digestion in Siphonophores. Mar. Behav Physiol. 4: 261-74.

Biggs, D.C. and G.R. Harbison. - 1976. The siphonophore Bathyphysa sibogae Lens and van Riemsdijk 1908 in the Sargasso Sea, with notes on its natural history. Bull. Mar. Sci., 26: 14-18.

Biggs, D.C. and G.R. Harbison. - 1978. Athorybia lucida, a new species of siphonophore (Physonectae, Athorybiidae) from the North Atlantic Ocean. Bull. Mar. Sci., 28: 537-542.

Biggs, D.C., P.R. Pugh and C. Carré. - 1978. Rosacea flaccida n. sp., a new species of siphonophore (Calycophorae Prayinae) from North Atlantic Ocean. Beaufortia, 27: 207-218.

Billard, A. - 1904a. Contribution à l'étude des Hydroides (multipli- cation, régénération, greffes variations). Annls. Sci. nat. zool., 20: $1-251$.

Billard, A. - 1904b. Hydroïdes récoltés par M.Ch. Gravier dans le golfe de Tadjourah. Bull. Mus. Hist. nat. Paris, 10: 480-485.

Billard, A. - 1924. Note sur une espèce nouvelle de Plumularide des côtes du Maroc (Cladocarpus dollfusi). Bull. Soc. zool. Fr., 49: 87-89.

Billard, A. - 1931. Hydroïdes des côtes de Syrie (Mission Gruvel). In: A. Gruvel (ed.), Les états de Syrie. Richesse marines et fluviales. Exploitation actuelle - Avenir. Bibltque. Faune Colon. Françaises, 3: 389-395.

Billard, A. - 1934. Note sur quelques hydroïdes du Maroc. Bull. Soc. zool. Fr., 59: 227-231, 468.

Billard, A. - 1938. Note sur une espèce de campanularidés (Clytia gravieri, Billard). Bull. Mus. natn. Hist. nat. Paris, 210: 429432.

Bitar, G. and S. Bitar-Kouli. - 1995. Aperçu de bionomie bentique et répartition des différents faciès de la roche littorale à Hannouch (Liban-Méditerranée Orientale). Rapp. P.-v. Réun. Comm. int. Explor. Mer Méditerr., 34: 19.

Blanco, O.M., M.O. Zamponi and G.N. Genzano. - 1994. Lafoeidae de la Argentina (Coelenterata, Hydrozoa, Hydroida). Nat. patagón., Cien. Biol., 2: 1-31.

Blanco, O.M., M.O. Zamponi and G.N. Genzano. - 2000. Campanulinidae de la Argentina (Coelenterata, Hydrozoa, Hydroida). Rev. Mus. La Plata, 14: 267-278.

Bodo, F. - 1970. Etude du développement embryonnaire de l'Anthoméduse Cladonema radiatum Dujardin (Athecate, Capité, Cladonematidae). Ann. Embryol. Morphogen., 3: 309-313.

Boero, F. - 1980a. Hebella parasitica (Cnidaria, Hydroida): a thecate polyp producing an anthomedusa. Mar. Biol., 59: 133-136.

Boero, F. - 1980b. Life cycles of hydroids and hydromedusae: some cases of difficult interpretation. Mem. Biol. mar. Oceanogr., suppl. 10: 181-197.

Boero, F. - 1981. Systematics and ecology of the hydroid population of two Posidonia oceanica meadows. P.S.Z.N.I, Mar. Ecol., 2: 181-197.

Boero, F. - 1984. The ecology of marine hydroids and effects of environmental factors: a review. P.S.Z.N.I, Mar. Ecol., 5: 93118.

Boero, F. - 1987. Life cycles of Phialella zappai n. sp., Phialella fragilis and Phialella sp. (Cnidaria, Leptomedusae, Phialellidae) from central California. J. nat. Hist., 21: 465-480.

Boero, F. - 1994. Fluctuations and variations in coastal marine environments. P.S.Z.N.I, Mar. Ecol., 15: 3-25.

Boero, F. - 1996. Episodic events: their relevance in ecology and evolution. P.S.Z.N.I, Mar. Ecol., 17: 237-250.

Boero, F. - 2001. Light after dark: the partnership for enhancing expertise in taxonomy. Trends in Ecol. Evol. 16: 266.

Boero, F. - 2002. Ship-driven biological invasions in the Mediterranean Sea. CIESM Workshop Monographs, 20: 87-91.

Boero F., A. Balduzzi, G. Bavestrello, B. Caffa and R. CattaneoVietti. - 1986. Population dynamics of Eudendrium glomeratum (Cnidaria: Anthomedusae) on the Portofino Promontory (Ligurian Sea). Mar. Biol., Berl., 92: 81-85.

Boero, F., G. Belmonte, G. Fanelli, S. Piraino and F. Rubino. 1996. The continuity of living matter and the discontinuities of its constituents: do plankton and benthos really exist?. Trends in Ecol. Evol. 11: 177-180.

Boero, F. and J. Bouillon. - 1989. The life cycles of Octotiara russelli and Stomotoca atra (Cnidaria, Anthomedusae, Pandeidae). Zoologica Scr., 18: 1-7.

Boero, F. and J. Bouillon. - 1993. Zoogeography and life cycle patterns of Mediterranean hydromedusae (Cnidaria). Biol. J. Linn. Soc., 48: 239-266.

Boero, F., J. Bouillon and R. Danovaro. - 1987. The life cycle of Tiaropsidium roseum (Tiaropsidae, fam nov., Leptomedusae, Cnidaria). Indo-Malayan Zool., 4: 293-302.

Boero, F., J. Bouillon and N. Gravier-Bonnet. - 1995. The life cycle of Pteroclava krempfi (Cnidaria, Hydrozoa, Cladocorynidae), with notes on Asyncoryne philippina (Asyncorynidae). Sci. Mar., 59: 65-76.

Boero, F., J. Bouillon and C. Gravili. - 2000. A survey of the Zancleidae, with diagnosis of new species. Ital. J. Zool., 67: 93-124.

Boero, F., J. Bouillon and S. Kubota. - 1997. The medusae of some species of Hebella Allman, 1888, and Anthohebella gen. nov. (Cnidaria, Hydrozoa, Lafoeidae) with a world synopsis of the species. Zool. Verh., Leiden, 310: 1-53. 
Boero, F., J. Bouillon and S. Piraino. - 1992. On the origins and evolution of hydromedusan life cycles (Cnidaria, Hydrozoa). Bolletino di Zoologia, In: R. Dallai (ed.), Sex origin and evolution, pp. 59-68. Selected symposia and monographs U.Z.I. 6. Mucchi, Modena.

Boero, F., J. Bouillon and S. Piraino. - 1996. Classification and phylogeny in the Hydroidomedusae (Hydrozoa, Cnidaria). In: S. Piraino, F. Boero, J. Bouillon, P.F.S. Cornelius and J.-M. Gili (eds.), Advances in Hydrozoan Biology. Sci. Mar., 60: 17-33.

Boero, F., J. Bouillon and S. Piraino. - 1997. Heterochrony, generic distinction and phylogeny in the Family Hydractiniidae (Hydrozoa, Cnidaria). Zool. Verh., Leiden, 323: 25-36.

Boero, F. and F. Briand. - 2001. Executive summary. In: Gelatinous Zooplankton outbreaks: theory and practice. CIESM Workshop Series, 14: 7-22.

Boero, F. and P.F.S. Cornelius. - 1987. First records of Eudendrium glomeratum (Cnidaria: Hydroida) in British and Irish waters, and taxonomic comments. Ir. Nat. J., 22: 244-246.

Boero, F and E. Fresi. - 1986. Zonation and evolution of a Rocky bottom hydroid community. P.S.Z.N.I, Mar. Ecol., 7: 123-150.

Boero, F., C. Gravili, F. Denitto, M.P. Miglietta and J. Bouillon. 1997. The rediscovery of Codonorchis octaëdrus (Hydroidomedusae, Anthomedusae, Pandeidae), with an update of the Mediterranean hydroidomedusan biodiversity. Ital. J. Zool., 64: 359-365.

Boero F., C. Gravili, P. Pagliara, S. Piraino, J. Bouillon and V. Schmid. - 1998. The Cnidarian premises of metazoan evolution: from triploblasty, to coelom formation, to metamery. Ital. J. Zool., 65: 5-9.

Boero, F. and M. Sarà. - 1987. Motile sexual stages and evolution of Leptomedusae (Cnidaria). Boll. Zool., 54: 131-139.

Bone, Q. and E.R. Trueman. - 1982. Jet propulsion of the Calycophoran siphonophores Chelophyes and Abylopsis. J. mar. biol. Ass. U. K., 62: 315-327.

Borcea, I. - 1929. Maeotias inexpectata, dans le liman de Razelm (Roumanie). Annls scient. Univ. Jassy., 15: 643-655.

Bouillon, J. - 1957. Etude monographique du genre Limnocnida. (Limnoméduse). Annls Soc. r. Zool. Belg., 87: 253-500.

Bouillon, J. - 1961-1962. Sur le bourgeonnement médusaire manubrial de Rathkea octopunctata. Annls Soc. r. Zool. Belg., 92: 7-25.

Bouillon, J. - 1965. Diagnose préliminaire de trois hydroïdes de Roscoff. In: G. Teissier (ed.), Inventaire de la faune marine de Roscoff (Cnidaires-Cténaires), p. 54. Station biologique, Roscoff.

Bouillon, J. - 1966. Les cellules glandulaires des hydroïdes et des hydroméduses. Leur structure et la nature de leurs sécrétions. Cah. Biol. mar., 7: 157-205.

Bouillon, J. - 1967. Révision de la famille des Ptilocodiidae avec la description d'un nouveau genre et d'une nouvelle espèce. Bull. Acad. r. Belg. Cl. Sci., 53: 1106-1131.

Bouillon, J.- 1968a. Introduction to Coelenterates. In: M. Florkin and B.T. Scheer (eds.), Chemical Zoology, Vol. II, pp. 81-145. Academic press, London.

Bouillon, J. - 1968b. Sur la structures des tentacules adhésifs des Cladonematidae et Eleutheriidae (Anthoméduses). Pubbl. Staz. zool. Napoli, 36: 471-504.

Bouillon, J. - 1971. Sur quelques hydroïdes de Roscoff. Cah. Biol. mar., 12: 323-364.

Bouillon, J. - 1974a. Diagnose de Teissiera milleporoides, nouveau genre et nouvelle espèce de Zancleidae des Seychelles (Hydrozoaires; Athécates; Anthoméduses), avec une révision des hydroïdes Pteronematoidea. Cah. Biol. mar., 15: 113-154

Bouillon, J. - 1974b. Sur la structure de Paracoryne huvei, Picard, 1957. (Coelenterata, Hydrozoa, Athecata). Mém. Acad. r. Belg., Cl. Sci., $4^{\circ}, 18: 5-45$

Bouillon, J. - 1975. Sur la reproduction et l'écologie de Paracoryne huvei Picard (Tubularioidea, Athecata, Hydrozoa, (Cnidaria). Archs Biol., 86: 45-96.

Bouillon, J. - 1978a. Hydroméduses de l'archipel des Séchelles et du Mozambique. Revue Zool. afr., 92: 118-172.

Bouillon, J. - 1978b. Hydroméduses de la mer de Bismarck (Papouasie, Nouvelle-Guinée). I. Anthomedusae Capitata (Hydrozoa). Cah. Biol. mar., 19: 249-297.

Bouillon, J. - 1978c. Hydroméduses de la mer de Bismarck (Papouasie, Nouvelle-Guinée). II. Limnomedusa, Narcomedusa, Trachymedusa et Laingiomedusa (sous-classe nov.). Cah. Biol. mar., 19: 473-483.
Bouillon, J. - 1980. Hydroméduses de la mer de Bismarck (Papouasie, Nouvelle-Guinée). III. Anthomedusae-Filifera (Hydrozoa-Cnidaria). Cah. Biol. mar., 21: 307-344.

Bouillon, J. - 1983. Sur le cycle biologique de Eirene hexanemalis (Goette 1886) (Eirenidae, Leptomedusae, Hydrozoa, Cnidaria). Cah. Biol. mar., 24: 421-427.

Bouillon, J. - 1984a. Révision de la famille des Phialuciidae (Kramp 1955) (Leptomedusae, Hydrozoa, Cnidaria), avec un essai de classification des Thecatae-Leptomedusae. IndoMalayan Zool., 1: 1-24.

Bouillon, J. - 1984b. Hydroméduses de la mer de Bismarck (Papouasie Nouvelle-Guinée). IV. Leptomedusae (Hydrozoa, Cnidaria). Indo-Malayan Zool., 1: 25-112.

Bouillon, J. - 1984c. Sphaerocoryne peterseni: Nouvelle espèce d'Anthoméduse de la Papouasie Nouvelle-Guinée. IndoMalayan Zool., 1: 245248.

Bouillon, J. - 1984d. Sur la méduse de Porpita porpita (Linné, 1758) (Velellidae, Hydrozoa, Cnidaria). Indo-Malayan Zool. 1: 249-254.

Bouillon, J. - 1985a. Essai de classification des HydropolypesHydroméduses (Hydrozoa-Cnidaria). Indo-Malayan Zool., 2: 29-243.

Bouillon, J. - 1985b. Notes additionelles sur les Hydroméduses de la mer de Bismarck (Hydrozoa-Cnidaria). Indo-Malayan Zool., 2: $245-266$.

Bouillon, J. - 1987. Considérations sur le développement des Narcoméduses et sur leur position phylogénétique. Indo-Malayan Zool., 4: 189-278.

Bouillon, J.- 1995a. Classe des Hydrozoaires. In: P.P. Grassé and D. Doumenc (eds.), Traité de Zoologie, 3(2), pp. 29-416. Masson, Paris.

Bouillon, J. - 1995b. Hydromedusae of the New Zealand Oceanographic Institute. (Hydrozoa, Cnidaria). N.Z. Jl Zool., 22: 223238 .

Bouillon, J. - 1999. Hydromedusae. In: D. Boltvoskoy (ed.), South Atlantic Zooplancton, Vol. 1, pp. 385-465. Backhuys Publishers, Leiden.

Bouillon, J. and T.J. Barnett. - 1999. The marine fauna of New Zealand: Hydromedusae (Cnidaria: Hydrozoa). Niwa Biodiversity Memoir, New Zealand, 113: 5-136.

Bouillon J., F. Bazin, and J.J. Cleret. - 1969. Une Limnoméduse: Ostroumovia inkermanica dans le canal de Caen (Calvados, France). Bull. Soc. linn. Normandie, 10: 75-79.

Bouillon, J. and F. Boero. - 2000a. Hydrozoa: A new classification in the light of old knowledge. Thalassia Salentina, 24: 3-46.

Bouillon, J. and F. Boero. - 2000b. Synopsis of the families and genera of the Hydromedusae of the world, with a list of the species. Thalassia Salentina, 24: 47-296.

Bouillon, J and F. Boero - 2000c. Phylogeny and classification of Hydroidomedusae. Thalassia Salentina, 24: 1-296.

Bouillon, J., F. Boero, F. Cicogna and P.F.S. Cornelius. - 1987. Modern trends in the Systematics, Ecology and Evolution of Hydroids and Hydromedusae. Claredon Press, Oxford., 328 pp.

Bouillon, J., F. Boero, F. Cicogna, J.-M. Gili and R.G. Hughes. 1992. Non-siphonophoran Hydrozoa: what are we talking about?. Sci. Mar., 56: 279-284.

Bouillon, J., F. Boero and S. Fraschetti. - 1991. The life cycle of Laodicea indica (Laodiceidae, Leptomedusae, Cnidaria). In: R.B. Williams, P.F.S. Cornelius, R.G. Hughes and E.A. Robson (eds.), Coelenterate Biology: Recent research on Cnidaria and Ctenophora. Hydrobiologia, 216/217: 151-157.

Bouillon, J. F. Boero and N. Gravier-Bonnet. - 1986. Pseudostenoteles, a new type of nematocyst, and its phylogenetic meaning within the Haleciidae (Cnidaria, Hydrozoa). IndoMalayan Zool., 3: 63-69.

Bouillon, J., F. Boero, C. Gravili, J.-M. Gili and F. Pagès. - (in press). An introduction to Hydrozoa for Taxonomists. Ann. Mus. natn. Hist. nat. Paris.

Bouillon, J., F. Boero and G. Seghers. - 1987. Redescription of Cladocoryne haddoni Kirkpatrick and a proposed phylogeny of the superfamily Zancleoidea (Anthomedusae, Hydrozoa, Cnidaria). Indo-Malayan Zool., 4: 279-292.

Bouillon, J., F. Boero and G. Seghers. - 1988a. Notes additionnelles sur les Hydroméduses de la Mer de Bismark (HydrozoaCnidaria). II. Indo-Malayan Zool., 5: 87-100.

Bouillon, J., F. Boero and G. Seghers. - 1988b. Notes additionnelles sur les méduses de Papouasie Nouvelle-Guinée. III. Indo-Malayan Zool. 5: 225-253. 
Bouillon, J., F. Boero and G. Seghers. - 1991. Notes additionnelles sur les méduses de Papouasie Nouvelle-Guinée (Hydrozoa, Cnidaria). IV. Cah. Biol. mar., 32: 387-411.

Bouillon, J., M. Claereboudt and G. Seghers. - 1986. Hydroméduses de la Baie de Hansa (Mer de Bismarck; Papouasie Nouvelle Guinée). Répartition, conditions climatiques et hydrologiques. Indo-Malayan Zool., 3: 105-152.

Bouillon, J. and G. Deroux. - 1967. Remarques sur les Cnidaires du type de Microhydrula pontica Valkanov, 1965, trouvés à Roscoff. Cah. Biol. mar., 8: 253-272.

Bouillon, J. and N. Gravier-Bonnet. - 1987. Pseudosolanderia picardi, nouveau genre et nouvelle espèce de Rosalindidae de la Réunion (Anthomedusae, Hydrozoa, Cnidaria). Bull. Mus. natn. Hist. nat. Paris, 9(A): 755-771.

Bouillon, J. and P.A. Grohmann. - 1990. Pinushydra chiquitita gen. et sp. nov. (Cnidaria, Hydrozoa, Athecata), a solitary marine mesopsammic polyp. Cah. Biol. mar., 31: 291-305.

Bouillon J., P.A. Grohmann. - 1994. A new interstitial stolonal hydroid: Nannocoryne gen. nov. mammylia sp. nov. (Hydromedusae, Anthomedusae, Corynidae). Cah. Biol. mar., 35: 431-439.

Bouillon, J. and G. Houvenaghel. - 1970. Histophysiologie de la digestion chez Cladonema radiatum, Dujardin 1843 (Anthomeduse). Pubbl. Staz. zool. Napoli., 38: 71-108.

Bouillon, J. and Cl. Levi. - 1971. Structure et ultrastructure des attaches hydranthes-hydrothèques chez les polypes Thecata. $Z$. Zellforsch. Mikrosk. Anat., 121: 218-231.

Bouillon, J., D. Medel and A.L. Peña Cantero. - 1997. The taxonomic status of the genus Stylactaria Stechow, 1921 (Hydroidomedusae, Anthomedusae, Hydractyniidae) with the description of a new species. Sci. Mar., 61: 471-486.

Bouillon, J. and M. Nielsen. - 1974. Etude de quelques organes sensoriels de cnidaires. Archs. Biol., Paris, 85: 307-328.

Bouillon, J., F. Pages, J.-M. Gili, A. Palanques, P. Puig and S. Heussner. - 2000. Deep-water Hydromedusae from LacazeDuthiers canyon (Banyuls-sur-Mer, Northwestern Mediterranean), including the description of two new genara (Guillea and Paracteclaia). Sci. Mar., 64(Suppl. 1): 87-95.

Bouillon, J., G. Seghers and F. Boero. - 1988. Note sur les cnidocystes des hydroméduses de la mer de Bismarck (PapouasieNouvelle Guinée). Indo-Malayan Zool., 5: 203-224.

Bouillon, J. and B. Werner. - 1965. Production of medusae buds by the polyps of Rathkea octopunctata (M. Sars) (Hydroida Athecata). Helgoländer wiss. Meeresunters., 12: 137-148.

Boulenger, Ch. - 1908. On Moerisia lyonsi, a new hydromedusan from Lake Qurun. O. Jl microsc. Sci., 52: 357-378.

Brian, A. and J.M. Pérès. - 1954. Recherches récentes sur les invertébrés bentiques dans la Méditerranée et l'Adriatique. Rapp. P.-v. Réun. Comm. int. Explor. scient. Mer Méditerr., 12: 143-161.

Brandt, J.F. - 1835. Polypus. Acalephas. Discophoras et Siphonophoras, nec non Echinodermata continens. Prodomus descriptionis observatum. 1: 1-76.

Brattström, H. - 1957. Branchiocerianthus norvegicus n. sp. from the Hardangerfjord, western Norway. Aarb. Univ. Bergen, mat.-naturv., 6: 1-10.

Brien, P. - 1961. Etude d'Hydra picardi (nov. spec.). Origine et répartition des nématocystes. Gametogénèse. Involution postgamétique. Evolution réversible des cellules interstitielles. Bull. biol. Fr. Belg., 95: 301-364.

Brien, P. - 1963. Elements de zoologie et notions d'anatomie comparée. Desoer (ed.), 1-535 pp.

Brien, P. and M. Reniers-Decoen - 1950. Etude d'Hydra viridis. La blastogénèse, la spermatogénèse, l'ovogénèse. Annls Soc. zool. Belg., 81: 33-110.

Briggs, J.C. - 1974. Marine Zoogeography. McGraw-Hill, New York.

Brinckmann, A. - 1959a. Ueber den Generationswechsel von Eucheilota cirrata (Haeckel 1879). Pubbl. Staz. zool. Napoli, 31: 82-89.

Brinckmann, A. - 1959b. Ueber das Vorkommen von Niobia dendrotentaculata Mayer im Mittelmeer. Pubbl. Staz. zool. Napoli, 31: 334-336.

Brinckmann, A. - 1962. The life cycle of Merga galleri sp. n. (Anthomedusae, Pandeidae). Pubbl. Staz. zool. Napoli, 33: 1-9.

Brinckmann, A. - 1964a. Observations on the biology and development of Staurocladia portmanni sp. n. (Anthomedusae, Eleutheridae). Can. J. Zool., 42: 693-706.

Brinckmann, A. - 1964b. Observations on the structure and devel- opment of the medusa of Velella velella (Linné 1758). Vidensk. Meddr dansk naturh. Foren., 126: 327-336.

Brinckmann, A. - 1965a. The life cycle of the medusa Cirrholovenia tetranema Kramp (1959a) (Leptomedusae, Lovenellidae) with a hydroid of the genus Cuspidella Hincks. Can. J. Zool., 43: $13-15$.

Brinckmann, A. - 1965b. The biology and development of Rhysia autumnalis gen. nov., sp. nov. (Anthomedusae-Athecatae, Rhysiidae fam. nov.). Can. J. Zool., 43: 941-952.

Brinckmann-Voss, A. - 1966. The morphology and development of Acaulis ilonae sp. nov. (order Anthomedusae-Athecatae, Fam. Acaulidae). Can. J. Zool., 44: 291-301.

Brinckmann-Voss, A. - 1967. The hydroid of Vannuccia forbesii (Anthomedusae, Tubulariidae). Breviora, 263: 1-10.

Brinckmann-Voss, A. - 1970. Anthomedusae/Athecatae (Hydrozoa, Cnidaria) of the Mediterranean. Part. I: Capitata. Fauna e Flora del Golfo di Napoli, 39: 1-96.

Brinckmann-Voss, A. - 1973. The life cycle of Eirene lactea (Mayer, 1900) and Helgicirrha schulzei Hartlaub, 1909 (phylum Cnidaria, class Hydrozoa, order Leptomedusae, family Eirenidae). Publ. Seto mar. biol. Lab., 20: 63-72.

Brinckmann-Voss, A - 1987. Seasonal distribution of hydromedusae (Cnidaria, Hydrozoa) from the Gulf of Naples and vicinity, with observations on sexual and asexual reproduction in some species. In: J. Bouillon, F. Boero, F. Cicogna and P.F.S. Cornelius (eds.), Modern trends in the Systematics, Ecology and Evolution of Hydroid and Hydromedusae, pp.133-141. Clarendon Press, Oxford

Brinckmann-Voss, A. - 1989. Sarsia cliffordi n. sp. (Cnidaria, Hydrozoa, Anthomedusae) from British Columbia, with distribution records and evaluation of related species. Can. J. Zool., 67: 685-691.

Brinckmann-Voss, A. - 2000. The hydroid and medusa of Sarsia bella sp. nov. (Hydrozoa, Anthoathecatae, Corynidae), with a correction of the 'life cycle' of Polyorchis penicillatus (Eschscholtz). In: C.E. Mills, F. Boero, A. Migotto and J.-M. Gili (eds.), Trends in Hydrozoan Biology - IV. Sci. Mar., 64 (Suppl. 1): 189-195.

Brinckmann-Voss, A. and M.N. Arai. - 1998. Futher notes on Leptolida (Hydrozoa: cnidaria) from Canadian Pacific Waters. Zool. Verh., Leiden, 323: 37-68.

Brinckmann-Voss A., D.M. Lickey and C.E. Mills. - 1993. Rhysia fletcheri (Cnidaria, Hydrozoa, Rhysiidae), a new species of colonial hydroid from Vancouver Island (British Columbia, Canada) and the San Juan Archipelago (Washington, U.S.A.). Can. J. Zool., 71: 401-406.

Brinckmann, A. and K.W. Petersen. - 1960. On some distinguishing characters of Dipurena reesi Vannucci 1956 and Cladonema radiatum Dujardin 1843. Pubbl. Staz. zool. Napoli, 31: 386-392.

Brinckmann, A. and M. Vannucci. - 1965. On the life-cycle of Proboscidactyla ornata (Hydromedusae, Proboscidactylidae). Pubbl. Staz. zool. Napoli, 34: 357-365.

Broch, H. - 1910. Die Hydroiden der Arktischen Meere. Fauna Arct., 5: 128-248.

Broch, H. - 1912. Hydroidenuntersuchungen. Vergleichende Studien an Adriatischen hydroiden. K. nor. Vidensk. Selsk. Skr., 1: 1-65.

Broch, H. - 1916. Hydroida. (Part I). Danish Ingolf Exped., 5: 1-66.

Broch, H. - 1918. Hydroida. (Part II). Danish Ingolf Exped., 5: 1206.

Broch, H. - 1929. Craspedote Medusen. Teil II. Trachylinen. Nord. Plankton, 6: 481-539.

Brooks, W.K. -1883 . On the origin of alternation of generations in Hydro-medusae. Johns Hopkins Univ. Circ., 2: 73.

Brooks, W.K. - 1884. On the life history of Eutima, and on radial symmetry in hydroids. Zool. Anz., 7: 709-711.

Brooks, W.K. - 1888. The life history of Epenthesis mccradyi (n. sp.). Stud. biol. Lab. Johns Hopkins Univ., 4: 147-162.

Brooks, W.K. - 1895. The sensory clubs or cordyli of Laodice. J. Morphol., 10: 287-304

Brooks, W.K. - 1896. The life history of the Hydromedusae. A Discussion of the origin of the medusae, and of the signification of metagenesis. Mem. Boston Soc. Nat. Hist., 3: 359-430.

Browne, E.T. - 1926. Siphonophorae from the Indian Ocean. Trans. Linn. Soc. Lond. (Zool.), 2: 55-86.

Buecher, E. - 1999. Apperance of Chelophyes appendiculata and Abylopsis tetragona (Cnidaria, Siphonophora) in the bay of Villefranche, northwestern mediterranean. J. Sea Res., 41: 295-307. 
Bush, W. - 1851. Beobachtungen ueber Anatomie und Entwicklung einiger wirbelosen Seetiere. Berlin.

Cabioch, L. - 1965. Sur la présence de dactylozoïdes chez Merona cornucopiae (Norman). Cah. Biol. mar., 6: 401-405.

Cairns, S.D. - 1986. A revision of the Northwest Atlantic Stylasteridae (Coelenterata: Hydrozoa). Smithson. Contr. Zool. 418: $1-131$.

Cairns, S.D. - 1991 - The Marine Fauna of New Zealand: Stylasteridae (Cnidaria: Hydroida) Mem N. oceanogr. Inst, $98 \mathrm{pp}$

Calder, D.R. - 1971. Hydroid and hydromedusae of southern Chesapeake Bay. Virginia Inst. mar. Sci., Spec. Pap. mar. Sci., 1: 1-125.

Calder, D.R. - 1972. Some athecate hydroids from the shelf waters of northern canada. J. Fish. Res. Bd Can., 29: 217-228.

Calder, D.R. - 1975. Biotic census of Cape Cod Bay: hydroids. Biol. Bull. mar. biol. Lab. Woods Hole, 149: 287-315.

Calder, D.R. - 1988. Shallow water hydroids of Bermuda. The Athecatae. Life Sci. Contr. R. Ontario Mus., 148: 1-107.

Calder, D.R. - 1991. Shallow-water hydroids of Bermuda. The Thecatae, exclusive of Plumularioidea. Life Sci. Contr. R. Ontario Mus., 154: 1-140.

Calder, D.R - 1992. Case 2806. Zanclea costata Gegenbaur, 1856 (Cnidaria, Hydrozoa): proposed conservation of both generic and specific names. Bull. zool. Nom., 49: 184-186.

Calder, D.R. - 1993. Bougainvillia aberrans (Cnidaria, Hydrozoa), a new species of hydroid and medusa from the upper bathyal zone of Bermuda. Can. J. Zool., 71: 997-1002.

Calder D.R. - 1997. Shallow-water hydroids of Bermuda (Superfamily Plumularoidea). Life Sci. Contr. R. Ontario Mus., 161: 1-85.

Calder, D.R. and V.G.Jr. Burrell. - 1969. Brackish water hydromedusa Maeotias inexpectata in North America. Nature, 222: 694695.

Calder, D.R. and W. Vervoort. - 1998. Some hydroids (Cnidaria: Hydrozoa) from the mid-Atlantic Ridge, in the North Atlantic Ocean. Zool. Verh., Leiden, 319: 1-65.

Campbell, R.D. - 1987. A new species of Hydra (Cnidaria: Hydrozoa) from North America with comments on species clusters within the genus. Zool. J. Linn. Soc., 91: 253-263.

Carré, C. - 1966. Sphaeronectes gamulini sp. n. Une nouvelle espèce de Siphonophore Calycophore méditerranéen. Vie Milieu, 17: 1069-1076.

Carré, C. - 1967. Le développement larvaire d'Abylopsis tetragona Otto, 1823 (Siphonophorae, Calycophore, Abylidae). Cah. Biol. mar., 8: 185-193.

Carré, C. - 1968a. L'eudoxie de Lensia campanella Moser, 1925 avec des précisions sur le stade polygastrique (Siphonophore Calycophore Diphyidae). Bull. Mus. natn. Hist. Nat. Paris, 40: 438-445.

Carré, C. - 1968b. Diagnosis d'un Siphonophore Agalmidae Cordagalma cordiformis Totton 1932. Beaufortia, 212: 79-86.

Carré, C. - 1968c. Sphaeronectes fragilis n. sp., une nouvelle espèce de Siphonophores Calycophore méditerranéen, Bull. Inst. océanogr. Monaco, 67: 1-9.

Carré, C. - 1968d. Sphaeronectes bougisi sp. n., nouveau Siphonophore Calycophore Sphaeronectidae, du plancton méditerranéen, Bull. Mus. natn. Hist. Nat. Paris, 40: 446-449.

Carré, C. - 1968e. Contribution à l'étude du genre Sphaeronectes Huxley, 1859. Vie Milieu, 19(A): 85-94.

Carré, C. - 1969a. Rosacea villafrancae sp. n., un nouveau siphonophore calycophore Prayinae de la mer Méditerranée. Beaufortia, 16(214): 109-117.

Carré, C. - 1969b. Sur le genre Lilyopsis Chun 1885, avec une redescription de l'espèce Lilyopsis rosea Chun 1885 (Siphonophore, Prayinae) et une Diagnosis de sa phase calyconula. Cah. Biol. mar., 10: 71-81.

Carré, C. - 1969c. Prayola tottoni gen. sp. n., nouveau genre et nouvelle espèce de Siphonophore calycophore Prayinae de la Mer Méditerranée. Vie Milieu, 20: 31-42.

Carré, C. - 1979. Sur le genre Sulculeolaria Blainville, 1834 (Siphonophora, Calycophorae, Diphyidae). Ann. Inst. océanogr., Paris, 55: 27-48.

Carré, C. and D. Carré. - 1969. Etude de cnidome et de la cnidogenèse chez Apolemia uvaria Lesueur, 1811 (Siphonophore Physonecte). Expl. Cell Res., 81: 237-249.

Carré, C. and D. Carré. - 1995. Ordre des Siphonophores. In: D. Doumenc (ed.), Traité de Zoologie. Anatomie. Systématique Biologie. Cnidaires. Ctènaires, Tome III Fascicule 2, pp. 523596. Masson, Paris.
Carré, D. - 1967. Etude du développement larvaire de deux Siphonophores Lensia conoidea (Calycophore) et Forskalia edwardsi (Physonecte). Cah. Biol. mar., 8: 233-251.

Carré, D. - 1968a. Sur le développement postlarvaire d'Hippopodius hippopus (Forskål). Cah. Biol. mar., 9: 417-420.

Carré, D. - 1968b. Sphaeronectes bougisi sp. n., nouveau siphonophore calycophore sphaeronectidae du plancton méditerranéen. Bull. Mus. natn. Hist. nat., 40: 446-449.

Carré, D. - 1969a. Etude de développement larvaire de Sphaeronectes gracilis (Claus 1873) et de S. irregularis (Claus 1873) (Siphonophore, Calycophore). Cah. Biol. mar., 9: 31-34.

Carré, D. - 1969b. Etude histologique du développement de Nanomia bijuga (Chiaje 1841), Siphonophore Physonecte Agalmidae. Cah. Biol. mar., 10: 325-341.

Carré, D. - 1971. Etude du développement d'Halistemma rubrum Vogt (1852) Siphonophore Physonecte Agalmidae. Cah. Biol. mar., 12: 77-94.

Carré, D. - 1973. Etude du développement de Cordagalma cordiformis Totton, 1932, Siphonophore Physonecte, Agalmidae. Bijdr. Dierk., 41: 113-118.

Carré, D. and C. Carré. - 1990. Complex reproductive cycle in Eucheilota paradoxica (Hydrozoa: Leptomedusae): medusae, polyps and frustules produced from medusa stage. Mar. Biol., Berl., 104: 303-310.

Carré, D. and C. Carré. - 2000. Origin of germ cells, sex determination, and sex inversion in medusae of the genus Clytia (Hydrozoa, Leptomedusae): the influence of temperature. $J$. Exp. Zool., 287: 233-242.

Carré, D., C. Carré and C. Mills. - 1989. Novel cnidocysts of Narcomedusae and a medusivorous Ctenophore, and confirmation of kleptocnidism. Tissue Cell, 21: 723-734.

Carré, D., C. Carré, F. Pagès and J.-M. Gili. - 1995. Asexual reproduction in the pelagic phase of Clytia mccradyi (Hydrozoa, Leptomedusae). Sci. Mar., 59: 193-202.

Casanova, J.P. - 1980. Campagnes du 'Meteor' dans l'Atlantique NE. Siphonophores, Méduses et Thécosomes. Distribution verticale et comparaisons faunistiques avec la Méditerranée. Meteor Forsch Erbgeb., Reidhe D, 32: 15-32.

Castello,.G. - 1986. Cnidarios planctónicos de superficie: Faunística y factores de distribución en la costa Catalana. Tesis Licenciatura, Univ. Barcelona.

Castric-Fey, A. - 1970. Sur quelques hydraires de l'archipel des Glénans (Sud-Finistère). Vie Milieu, (A)21: 1-23.

Cerrano, C., D. Amoretti and G. Bavestrello. - 1997. The polyp and the medusae of Zanclea costata Gegenbaur (Cnidaria, Hydrozoa). Ital. J. Zool., 64: 177-180.

Cerrano, C., G. Bavestrello, S. Puce and M. Sarà.. - 1998. Biological cycle of Podocoryna exigua (Cnidaria: Hydrozoa) from a sandy bottom of the Ligurian Sea. J. mar. biol. Ass. U.K., 78: $1101-1111$

Cerrano, C., G. Bavestrello, C.N. Bianchi, R. Cattaneo-Vietti, S. Bava, C. Morganti, C. Morri, P. Picco, G. Sara, S. Schiaparelli, A. Siccardi and F. Sponga. - 2000. A catastrophic mass-mortality episode of gorgonians and other organisms in the Ligurian Sea (North-western Mediterranean), summer 1999. Ecol. Let. 3: 284-293.

Cervigón, F. - 1958. Contribución al estudio de los sifonóforos de las costas de Castellón (Mediterráneo Occidental). Invest. Pesq., 12: 21-47.

Chamisso, A. de and C.G. Eysenhardt. - 1821. De animalibus quibusdam e classe vermium Linneana. Fasc. 2. Nova Acta Leopoldina, 10: 342-374.

Chiaje, S. delle. - 1828-1830. Memorie sulla storia e notomia degli animali senza vertebre del regno di Napoli, Vol. I-IV. Napoli.

Chiaje, S. delle. - 1841. Memorie sulla storia e notomia degli animali senza vertebre del regno di Napoli, Vol. V. Napoli.

Chun, C. - 1885. Ueber die cyclische Entwicklung der Siphonophoren. 2. S.B. preuss. Akad. Wiss., pp. 511-529.

Chun, C. - 1886. Ueber Bau und Entwicklung der Siphonophoren. Sitzber. Akad. wiss. Berlin, 38: 681-688.

Chun, C. - 1888. Bericht ueber eine nach den Canarischen Inseln im Winter 1887-1888 ausgefürte Reise. S.B. preuss. Akad. Wiss., 11: 41-73.

Chun, C. - 1892. Die Canarischen Siphonophoren in monographischen Darstellungen. II. Die Monophyiden. Abh. senckenb. naturf. Ges., 18: 57-114.

Chun, C. - 1895. Biologische Studien über pelagische Organismen (1). Die Knospungsgesetze der proliferirenden Medusen. Bib- 
liotheca Zoologica, Stutgart., 75 pp.

Chun, C. - 1897. Die Siphonophoren der Plankton-Expedition. Ergen. Plankton Exp., 2 K.b.: 1-126.

CIESM, 2001. Gelatinous zooplankton outbreaks: theory and practice. CIESM Workshop Series, Monaco, 14: 112. www.ciesm.org/publications/Naples01.pdf

CIESM, 2002. Alien marine organisms introduced by ships in the Mediterranean and Black Seas. CIESM Workshop Monographs, Monaco, 20: 136. www ciesm org/publications/Istan-bul02.pdf

Claus, C. - 1873. Ueber die abstammung der Diplophysen und ueber eine neue gruppe von Diphyiden. Nachr. Ges. Wiss. Gottingen, 9: 257-261.

Claus, C. - 1877. Studien über Polypen und Quallen der Adria. Denkschr. Akad. Wiss. Wien., 38: 1-64.

Claus, C. - 1881. Breiträge zur kenntniss der Geryonopsiden und Eucopiden-Entwicklung. Arb. Zool. Inst. Univ. Wien, Zool. Stat. Triest., 4: 89-120.

Clausen, C. - 1967. Morphological studies of Halammohydra Remane (Hydrozoa). Sarsia, 29: 349-370.

Clausen, C. - 1971. Interstitial Cnidaria: present status of their systematics and ecology. In: N.C. Hulings (ed.), Proceedings of the first international conference on Meiofauna. Smithson. Contr. Zool., 76: 1-8.

Clausen, C. and L. Salvini-Plawen. - 1986. Cnidaria. In: L. Botosaneanu (ed.), Stygofauna Mundi. A faunistic, distributional and ecological synthesis of the worldfauna inhabiting subterranean waters, pp. 33-42. E.J. Brill/Dr. Backhuys, Leiden.

Collins, A.G. - 2000. Towards understanding the phylogenetic history of Hydrozoa: Hypothesis testing with $18 \mathrm{~S}$ gene sequence data. Sci. Mar., 64 (Suppl. 1): 5-22

Collins, A.G. - 2002. Phylogeny of Medusozoa and the evolution of cnidarian life cycles. J. evol. Biol., 15: 418-432.

Coma, R., J.-M. Gili and M. Zabala. - 1994. Trophic ecology of a benthic marine hydroid Campanularia everta. Mar. Ecol. Progr. Ser., 119: 211-220.

Coma, R., M. Ribes, J-M. Gili, M. Zabala - 2000. Seasonality in coastal benthic ecosystems. Trends in Ecol. Evol. 15: 448-453.

Cornelius, P.F.S. - 1975a. The hydroid species of Obelia (Coelenterata: Hydroida: Campanulariidae) with notes on the medusa stage. Bull. Br. Mus. nat. Hist., Zool., 28: 249-293.

Cornelius, P.F.S. -1975 b. A revision of the species of Lafoeidae and Haleciidae (Coelenterata: Hydroida) recorded from Britain and nearby seas. Bull. Br. Mus. nat. Hist., Zool., 28: 373-426.

Cornelius, P.F.S. - 1979. A revision of the species of Sertulariidae (Coelenterata: Hydroida) recorded from Britain and nearby seas. Bull. Br. Mus. nat. Hist., Zool., 34: 243-321.

Cornelius, P.F.S. - 1982. Hydroid and medusae of the family Campanulariidae recorded from the eastern North Atlantic, with a world synopsis of genera. Bull. Br. Mus. nat. Hist., Zool., 42: 37-148.

Cornelius, P.F.S. - 1987. The hydranths of Clytia linearis (Cnidaria, Hydrozoa) and related species. In: J. Bouillon, F. Boero, F. Cicogna and P.F.S. Cornelius (eds.), Modern trends in the Systematics, Ecology and Evolution of Hydroid and Hydromedusae, pp. 291-297. Clarendon Press, Oxford.

Cornelius, P.F.S. - 1990. European Obelia (Cnidaria, Hydroida): systematics and identification. J. nat. Hist., 24: 535-578.

Cornelius, P.F.S. - 1995. North-west European thecate hydroids and their medusae (Cnidaria, Leptolida, Leptothecatae). Synopses of the British Fauna, n.s., 50(1): 1-347; 50(2): 1-386.

Cornelius, P.F.S. - 1998. Taxonomic characters from the hydranths of live thecate hydroids: European Haleciidae (Cnidaria: Lepthothecatae). Zool. Verh., Leiden., 323: 79-97.

Cornelius, P.F.S. and C. Östman. - 1986. On the names of two species of the genus Clytia Lamouroux, 1812 (Cnidaria, Hydrozoa) common in western Europe. Z.N.(S.) 2493. Bull. zool. Nom., 43: 163-169.

Cornelius, P.F.S. and J.S. Ryland. - 1990. Hydrozoa. In: P.J. Hyward and J.S Ryland (eds.), The marine fauna of the British Isles and North-West Europe. Introduction and Protozoans to Arthropods, pp. 101-159. Oxford University Press.

Coward, W.E. - 1909. On Ptilocodium repens a new gymnoblastic hydroid epizoic on a Pennatulid. Proc. Akad. Wetensh. Amsterdam, Sect. Sci., 11: 635-641.

Culberson, D.E. - 1976. Encystment and excystment of the polyp of the fresh water jellyfish, Craspedacusta sowerbii (Cnidaria: Hydrozoa). J. Alabama Acad. Sci., 47: 125.

Cunningham, J.T. -1892 . On a species of siphonophore observed at Plymouth. J. mar. biol. Ass. U.K., 2: 212-215.

Cuvier, G.L. - 1817. Le règne animal distribué d'après son organisation.

Dallot, S., J. Goy and C. Carré. - 1988. Peuplerments de carnivores planctoniques gélatineux et structures productives en Méditerranée occidentale. Oceanol. Acta, n.sp.: 193-209.

Damas, H. - 1939. Sur la présence dans la Meuse belge de Branchiura sowerbyi (Beddart), Craspedacusta sowerbyi et Urnatella gracilis. Annls Soc. zool. Belg., 69: 293-310.

Daniel, R. - 1974. Siphonophora from the Indian Ocean. Mem. Zool. Survey India, 15: 12-42.

Daniel, R. - 1976. Chondrophora of the Indian Ocean. J. mar. biol. Ass. India, 18: 110-121.

Dawydoff, C. - 1928. Traité d'Embryologie Comparée des Invertébrés. Masson and Cie., Paris, pp. 1-930.

De Andrade, L.P. and A.E. Migotto. - 1997. Is there a link between Hebella hydroids (Hydrozoa, Lafoeidae) and Staurodiscus medusae (Hydrozoa, Laodiceidae). VII Colacmar Congresso Latino-americano sobre Ciências do Mar, 1: 35-36.

De Blainville, H.M.D. - 1830. Zoophytes. In: Dictionnaire ds Sciences Naturelles, 60, pp. 1-548. F.G. Levrault, Paris.

De Blainville, H.M.D. - 1834. Manuel d'actinologie ou de zoophytologie, 2 vols, pp. 1-695. F.G. Levrault, Paris.

Dejdar, E. - 1934. Die Süsswassermeduse Craspedacusta sowerbyi Lankester in monographischer Darstellung. Z. Morph. Ökol. Tiere, 28: 595-691.

De Lafontaine, Y. and W.C. Leggett. - 1989. Changes in size and weight of hydromedusae during formalin preservation. Bull. mar. Sci., 44: 1129-1137.

Delage, Y. and E. Herouard. - 1901. Les Coelentérés. In: Traité de Zoologie Concrète, II, pp. 1-848. Paris,

Delamare-Debouteville, C. - 1960. Biologie des eaux souterraines littorals et continentals. Hermann, Paris., $740 \mathrm{pp}$.

Della Tommasa, L., G. Belmonte, A. Palanques, P. Puig and F. Boero. - 2000. Resting stages in a submarine canyon: a component of shallow-deep-sea coupling? Hydrobiologia, 440: 249-260.

Denayer, J.C. - 1973. Trois méduses nouvelles ou peu connues des côtes françaises: Maeotias inexspectata Ostroumov, 1896 , Blackfordia virginica Mayer, 1910, Nemopsis bachei Agassiz, 1849. Cah. Biol. mar., 14: 285-294.

Dendy, J.S. - 1978. Polyps of Craspedacusta sowerbyi as predators on young striped bass. Prog. Fish-Cult., 40: 5-6.

Desouza, M.M. E. Scemes and E.G. Mendes. - 1996. Behavioral modifications of Liriope tetraphylla (Chamisso and Eysenhardt) (Cnidarians, Hydrozoa, Trachymedusae) induced by hyposmotic conditions. J. exp. mar. Biol. Ecol., 206: 223-236.

Dick, T.A., H.L. Holloway and A. Choudhury. - 1991. Polypodium sp. (Coelenterata) from lake sturgeon (Acipenser fulvescens, Rafinesque) in the pairie region of Canada. J. Parasit., 77: 483484.

Dowidar, N.M. - 1983. Medusa of the Egyptian Mediterranean waters. In: Workshop on jellyfish blooms in the Mediterranean., pp. 9-16. Athens

Dowidar, N.M. - 1985. Medusa of the Egyptian Mediterranean waters. Rapp. P.-v. Réun. Comm. int. Explor. scient. Mer Méditerr., 29: 239-243.

Dowidar, N.M and A.M. El-Maghraby. - 1970. The neritic zooplankton of the South eastern Mediterranean at Alexandria. Bull. Inst. Oceanogr. Fish., 1: 227-273.

Dumont, H. - 1994. The distribution and ecology of fresh-and brackish-water medusae of the world. Hydrobiologia, 272: 112.

Edwards, C. - 1963a. On the Anthomedusae Tiaranna rotunda and Modeeria formosa. J. mar. biol. Ass. U. K., 43: 457-467.

Edwards, C. - 1963b. Observations on the distribution of Velella in the Atlantic and the Mediterranean. Rep. Challenger Soc., 3: $24-25$

Edwards, C. - 1964. The hydroid of the Anthomedusa Bougainvillia brittannica. J. mar. biol. Ass. U.K., 44: 1-10.

Edwards, C. - 1965. The hydroid of the medusa Neoturris pileata. J. mar. biol. Ass. U.K., 45: 443-468.

Edwards, C. - 1966a. Velella velella (L.): the distribution of its dimorphic forms in the Atlantic Ocean and the Mediterranean, with comments on its nature and affinities. In: H. Barnes (ed.), Some contemporary studies in marine science, pp. 283-296, Allen and Unwin Ltd., London.

Edwards, C. - 1966b. The hydroid and the medusa Bougainvillia 
principis, and a review of the British species of Bougainvillia. J. mar. biol. Ass. U.K., 46: 129-152.

Edwards, C. - 1972. The hydroids and the medusae Podocoryne areolata, P. borealis and P. carnea. J. mar. biol. Ass. U.K., 52: 97-144.

Edwards, C. - 1973a. The hydroid Trichydra pudica and its medusa Pochella polynema. J. mar. biol. Ass. U.K., 53: 87-92.

Edwards, C. $-1973 \mathrm{~b}$. The medusa Modeeria rotunda and its hydroid Stegopoma fastigiatum, with a review of Stegopoma and Stegolaria. J. mar. biol. Ass. U.K., 53: 573-600.

Edwards, C. - 1973c. Contributory thoughts on form, function, habitat and classification of hydroids and hydromedusae. In: T. Tokioka and S. Nishimura (eds.), Recent trends in coelenterate biology. The Proceedings of the second International Symposium on Cnidaria. Publ. Seto mar. biol. Lab., 20: 11-22.

Edwards, C. - 1976. A study in erratic distribution: the occurrence of the medusa Gonionemus in relation to the distribution of oysters. Adv. mar. Biol., 14: 251-284.

Edwards, C. -1978 . The hydroids and medusae Sarsia occulta sp. nov., Sarsia tubulosa and Sarsia loveni. J. mar. biol. Ass. U.K., 58: $291-311$

Edwards, C. - 1983. The hydroids and medusae Sarsia piriforma sp. nov. and Sarsia striata sp. nov. from the west coast of Scotland, with observations on other species. J. mar. biol. Ass. U.K., 63: 49-60.

Edwards, C. and S.M. Harvey. - 1983. Observations on the hydroids Coryne pintneri and Thecocodium brieni new to the British list. J. mar. biol. Ass. U.K., 63: 37-47.

Eschscholtz, K.W. - 1825. Bericht über die zooloogische Ausbeute während der Reise von Kronstadt is St Peter und St Paul. Oken's Isis, 16: 733-47.

Eschcholtz, F. - 1829. System der Acalephen. Eine ausfûhrliche Beschreibung aller medusenartigen Strahltiere, pp. 1-90. Berlin.

Evans, F. - 1968. Le zooplancton de Malte. Pelagos, 9: 5-20.

Falkowski, P.G. - 2002. The ocean's invisible forest. Scient. Am. 287: $38-45$

Fewkes, J.W. - 1880. Contributions to the knowledge of the tubular jelly-fishes. Bull. Mus. comp. Zool. Harv., 6: 127-146.

Fewkes, J.W. - 1881. Studies of the jellyfishes of Narragansett Bay. Bull. Mus. comp. Zool. Harv., 8: 141-182.

Fewkes, J.W. - 1882. Notes on acalephs from the Tortugas, with a description of new genera and species. In: Explorations of the surface fauna of the Gulf Stream, under the auspices of the U.S. Coast Survey, by Alexander Agassiz. Bull. Mus. comp. Zool. Harv., 9: 251-289.

Fewkes, J.W. - 1886. Report on the medusae collected by the U.S.F.C. Steamer Albatross, in the region of the Gulf Stream, in 1883-84. Rep. U.S. Comm. Fish., 12: 927-980.

Fleming, J. - 1828. A history of British animals, exhibiting the descriptive characters and systematical arrangement of the genera and species of quadrupeds, birds, reptiles, fishes, Mollusca, and Radiata of the United Kingdom. Edinburgh, Ball and Bradfutek, pp. i-xxiii, 1-565

Forskal, P. - 1775. Descriptiones animalium quae in itinere orientali observavit, post mortem editit Carsten Niebuhr. Copenhagen, Hauniae, pp-ixxiv, 1-164.

Forskal, P. - 1776. Icones rerum naturalium post mortem auctoris editit Carsten Niebuhr. Hauniae, 15, 43 pls

Francour, P., C.F. Boudouresque, J.G. Harmelin, M.L. HarmelinVivien, and J.P. Quignard. - 1994. Are the Mediterranean Waters Becoming Warmer? Information from Biological Indicators. Mar. Pollut. Bull. N. S., 28: 523-526.

Fraser, C. McLean. - 1912c. Some hydroids of Beaufort, North Carolina. Bull. Bur. Fish. U.S., 30: 337-387.

Fraser, C. McLean. - 1924. Acaulis primarius Stimpson. Trans. $R$. Soc. Can., 318 (sect. V): 167-173.

Fraser, C. McLean-1944. Hydroid of the Atlantic coast of North America, pp. 1-451. The Univ. of Toronto Press, Toronto.

Fraser, J.M. - 1967. Siphonophorae in the plankton to the north and west of the British Isles. Proc. R. Soc. Edinb., (B)70: 1-30.

Fulton, R.S., and R.C. Wear. - 1985. Predatory feeding of the hydromedusae Obelia geniculata and Phialella quadrata. Mar. Biol., Berl., 87: 47-54.

Fuhrmann, O. - 1939. Sur Craspedacusta sowerbyi Lank. et un nouveau Coelentéré d'eau douce, Calpasoma dactyloptera, $\mathrm{n}$. g., n. sp. (note préliminaire). Revue suisse Zool., 46: 363-368.

Gamulin, T. - 1966. Contribution to the knowledge of Lensia fow- leri (Bigelow) (Siphonophora, Calycophora). Pubbl. Staz. zool. Napoli, 35: 16.

Gamulin, T. and F. Kršinić. - 2000. Calycophores (Siphonophora, Calycophorae) of the Adriatic and Mediterranean Seas. Natura Croatica, 9: 1-198.

García-Carrascosa, A.M. - 1981. Hidrozoos tecados (Hydrozoa Calyptoblastea) del litoral mediterráneo español: faunística, ecología, bionomía bentónica y biogeografía. Ph.D. Thesis, Univ. of Valencia.

García-Carrascosa, A.M., J.V. Escarti and R. Silvestre. - 1987. Cnidarios bentónicos de las Islas Columbretes. In: L.A. Alonso Matilla, J.L. Carretero and A.M. García-Carrascosa (eds.), Islas Columbretes. Contribución al estudio de su medio natural, pp. 363-389. Conselleria d'Obres Públiques, Urbanisme i Transports, Generalitat Valenciana, València.

García Corrales, P., A. Aguirre Inchaurbe and D. González Mora. 1978. Contribución al conocimiento de los hidrozoos de las costas españolas. Parte I: Halécidos, Campanuláridos y Plumuláridos. Bol. Inst. esp. Oceanogr., 4: 5-73.

García Corrales, P., A. Aguirre Inchaurbe and D. González Mora. 1980. Contribución al conocimiento de los hidrozoos de las costas españolas. Parte III: 'Sertulariidae'. Bol. Inst. esp. Oceanogr. 6: 1-67.

García Corrales, P. and A. Aguirre Inchaurbe. - 1985. La especie Halocordyle disticha (Goldfus, 1820) y sus sinonimias. Bol. Inst. esp. Oceanogr., 2: 85-96.

García-Corrales, P., V. Buencuerpo Arcas and M.V. Peinado De Diego. - 1979. Contribución al conocimiento de los hidrozoos de las costas españolas. Parte II: 'Lafoeidae', 'Campanulinidae' y 'Syntheciidae'. Bol. Inst. esp. Oceanogr., 5: 5-39.

Gegenbaur, C - 1853. Beiträge zur näheren Kenntniss de Schwimmpolypen. (Siphonophoren). Z. Wiss. Zool., 5: 442-54.

Gegenbaur, C. - 1857. Versuch eines Systemes der Medusen mit Beschreibung neuer oder wenig gekannter Formen; zugleich ein Beitrag zur Kenntniss der Fauna des Mittelmeeres. Z. Wiss. Zool., 8: 202-273.

Genzano, G.N. - 1995. New records of hydropolyps (Cnidaria, Hydrozoa) from South-western Atlantic Ocean. Misc. Zool., 18: $1-8$.

Genzano, G.N. and M.O. Zamponi. - 1992. Los hidrozoos bentónicos de la costa de mar del Plata. Univ. N. Mar del Plata., 1-90.

Genzano, G.N. and M.O. Zamponi. - 1997. Frecencia de estudio y diversidad de los hidrozoos bentónicos de la plataforma continental Argentina. Frequency of study and diversity of benthic Hydrozoa of the Argentine continental shelf. Cienc. Mar., 23: 285-302.

Gibbons, M.J. and J.S. Ryland. - 1989. Intertidal and shallow water hydroids from Fiji. I. Athecata to Sertulariidae. Mem. Qd. Mus., 27: $377-432$.

Gili, J.-M. - 1982. Fauna de cnidaris de les illes Medes. Treballs Inst. Cat. Hist. nat., 10: 1-175.

Gili, J.-M. - 1986. Estudio sistemático y faunístico de los Cnidarios de la costa catalana. Ph.D. Thesis, Univ. of Barcelona.

Gili, J.-M. - 2000. Frontline view of an invasion. Science, 287: 1762.

Gili, J.-M., V. Alvà, R. Coma, C. Orejas, F. Pagès, M. Ribes, M. Zabala, W. Arntz, J. Bouillon, F. Boero and R.G. Hughes. 1998. The impact of small benthic passive suspension feeders in shallow marine ecosystems: the hydroids as an example. Zool. Verh., Leiden, 323: 99-105.

Gili, J.-M., J. Bouillon and F. Pagès. - 1998. A new species of Krampella (Hydrozoa, Hydroidomedusae, Tiarannidae) from deep waters of Antikythira Strait (Cretan Sea, North East Mediterranean). Sci. Mar., 62: 135-139.

Gili, J.-M., J. Bouillon, F. Pagès, A. Palanques, P. Puig and S. Heussner. - 1998. Origin and biogeography of deep water Mediterranean Hydromedusae including the description of two new species collected in submarine canyons of Northwestern Mediterranean. Sci. Mar., 62: 113-134.

Gili, J.-M., J. Bouillon, F. Pagès, A. Palanques and P. Puig. - 1999. Submarine canyons as habitats of prolific populations: three deep-sea Hydroidomedusae in the western Mediterranean. $J$. Linn. Soc. Lond. Zool., 125: 313-329.

Gili, J.-M. and C. Castelló. - 1985. Hidropólipos de la costa norte del Cabo de Creus (N.E. Cataluña). Miscel. Zool., Barcelona, 9: 7-24.

Gili, J.-M. and A. García-Rubies. - 1985. Contribution à la connaissance de la faune d'hydropolipes de l'île de Majorque. 
Anales de Biol., secc. Biol. anim., 3, I: 37-53.

Gili, J.-M. and R.G. Hughes. - 1995. The Ecology of marine benthic hydroids. Oceanogr. mar. Biol. A. Rev., 33: 351- 426.

Gili, J.-M., F. Pagès and T. Riera. - 1987. Distribución de las especies más frecuentes de sifonóforos calicóforos en la zona norte del Mediterráneo occidental. Invest. Pesq., 51: 323-338.

Gili, J.-M., F. Pagès, A. Sabatés and J.D. Ros. - 1988. Small scale distribution of a cnidarian population in the western Mediterranean. J. Plank. Res., 10: 385-401.

Gili, J.-M., F. Pagès and F. Vives. - 1987. Distribution and ecology of a population of planktonic cnidarians in the western Mediterranean. In: J. Bouillon, Boero F., Cicogna F. and P.F.S. Cornelius (eds.), Modern trends in the Systematics, Ecology and Evolution of Hydroid and Hydomedusae, pp. 157-170. Clarendon Press, Oxford

Gili, J.-M., J.D. Ros and F. Pagès. - 1987. Types of bottoms and benthic Cnidaria from the trawling grounds (littoral and bathyal) off Catalonia (NE Spain). Vie Milieu, 37: 85-98.

Gili J.-M., W. Vervoort and F. Pagès. - 1989. Hydroid from the West African coast: Guinea Bissau, Namibia and South Africa. Sci. Mar. 53: 67-112.

Goldfuss, G.A. - 1818. Ueber die Classification der Zoophyten. Isis, pp. 1008-1013.

Goy, J. - 1970. Sur le bourgeonnement de trois hydroméduses: Eucodonium brownei Hartlaub, 1907, Phialidium mccradyi (Brooks 1888) et Scolionema suvaense (A. Agassiz et Mayer 1899) Cr hebd Séanc. Acad. Sci., Paris, (D)270: 1392-1395.

Goy, J. - 1973a. Les Hydroméduses de la mer Ligure. Bull. Mus. natn. Hist. nat. Paris, (3)83, Zool., 62: 965-1008.

Goy, J. - 1973b. Gonionemus suvaensis: structural characters, developmental stages and ecology. In: T. Tokioka and S. Nishimura (eds.), Recent trends in research in coelenterate biology. The Proceedings of the second international symposium on Cnidaria. Publs Seto mar. biol. Lab., 20: 525-536.

Goy, J. - 1983. Les hydroméduses dans les parages du Détroit de Gibraltar. Rapp. P.- v. Réun. Commn int. Explor. scient. Mer Méditerr., 28: 133-134.

Goy, J. - 1985. Coelentérés et planctonologie: In Van Präet (ed.), Apport des coelentérés à la biologie marine. Oceanis, 11: 325337.

Goy, J. - 1991. Hydromedusae of the Mediterranean sea. Hydrobiologia, 216/217: 351-354.

Goy, J. - 1997. The medusae (Cnidaria, Hydrozoa) and their trophic environment: an example in the North-western Mediterranean. Ann. Inst. océanogr., 73: 159-171.

Goy, J., S. Lakkis and R. Zeidane. - 1988. Les méduses de la Mediterranée orientale. Rapp. P.-v. Réun. Commn int. Explor. scient. Mer Méditerr., 31: 299.

Goy, J., S. Lakkis and R. Zeidane. - 1990. Les méduses de la Mediterranée orientale. In: J. Godeaux (ed.), A propos des migrations lessepsiennes, Bull. Inst. océanogr., no. spéc., 7: 7988.

Goy, J., S. Lakkis and R. Zeidane. - 1991. Les Méduses (Cnidaria) des eaux libanaises. Annls Inst. océanogr., Monaco, 67: 99-128.

Graeffe, Ed. - 1884. Übersicht der Seethierfauna des Golfes von Triest nebst Notizen über Vorkommen, Lebensweise, Ersheinungs und Fortpflanzungszeit der eizelnen Arten. Arb. Zool. Inst. Univ. Wien Zool. Stat. Triest., 5: 33-362.

Gravier, N. - 1970. Libération des médusoides par Macrorhynchia philippina Kirchenpauer, 1872 (Hydroida, Plumulariidae). Recl Trav. Stn mar. Endoume, 10: 253-257.

Gravier, N and A.E. Migotto - 2000. Gonangium development and medusoid of Nemalecium lighti (Hargitt, 1924) (Cnidaria: Hydrozoa, Haleciidae). In: C.E. Mills, F. Boero, A. Migotto and J.-M. Gili (eds.), Trends in Hydrozoan Biology - IV. Sci. Mar., 64 (Suppl. 1): 207-213.

Gravili, C., F. Boero and J. Bouillon - 1996. Zanclea species (Hydroidomedusae, Anthomedusae) from the Mediterranean. Sci. Mar. 60: 99-108.

Gray, J.E. - 1847. An outline of the arrangement of stony corals. Ann. Mag. nat. Hist., 19: 120-128.

Grayson, R.F. - 1971. The freshwater Hydras of Europe. 1. A review of the European species. Arch. Hydrobiol., 68: 436-449.

Günzl, H. - 1959. Zur Physiologie der Medusenbildung bei Eirene viridula. Naturwissenschaften, 46: 337.

Günzl, H. - 1964. Untersuchungen über die Auslösung der Medusenknospung bei Hydroid-polypen. Zool. Jb., Anat., 81: 491-528.
Hadži, J. - 1914. Poredbena hidroidska istraivanja. III. Haleciella microtheca g. n., sp.n.; Georginella diaphana g. n., sp. n.; Halanthus adriaticus g. n., sp. n.; Campanopsis clausa (Hadzi) i o porodici Campanopsida uopce. Rad. jugosl. Akad. Znan. Umjetn., Mat. Prir. Razr., 202: 191-241.

Hadži, J. - 1915. O regeneraciji (renovaciji) hidranta u tekatnih hidroida. Rad. jugosl. Akad. Znan. Umjetn., Mat. Prir. Razr., 208: $113-210$

Hadži, J. - 1917. Rezultati biolokih istraivanja Jadranskoga mora. Hidroidi II. Halocoryne epizoica g. n. sp. n.; Laföeina vilaevelebiti sp. n. Prirod. Istraz. hrv. slav., mat.-prirod. Razreda $(=$ Bull. Trav. Cl. Sci. Mat. Nat.) 11-12: 1-61.

Hadži, J. - 1959. Stiri knidariološke studije. (Vier knidarologische Studien). Razpr. Slov. Akad. Znan. Umjet., 5: 45-103.

Haeckel, E. - 1864. Beschreibung neuer craspedote Medusen aus dem Golfe von Nizza. Jena, Zeits. Naturw., 1: 325-342.

Haeckel, E. - 1866. Generellen Morphologie. 2: 57.

Haeckel, E. - 1879. Das System der Medusen. Gustav Fisher Verlag, Jena

Haeckel, E.- 1887-1888. System der Siphonophoren. Jena, Zeits. Naturw., 22: 1-46.

Haeckel, E. - 1888. Report on the Siphonophorae. Rep. sci. res. H.M.S. Challenger, Zool., 28: 1-380.

Hamond, R. - 1957. Notes in the Hydrozoa of the Norfolk coast. $J$. Linn. Soc. Lond. (Zool.), 43: 294-324.

Hand, C. $-1957 \mathrm{a}$. The systematic, affinities, and hosts of the one tentacled commensal hydroid Monobrachium with new distributional records. J. Wash. Acad. Sci., 47: 84-88.

Hand, C. and J.R. Hendrickson. - 1950. A two-tentacled, commensal hydroid from California (Limnomedusae, Proboscidactyla). Biol. Bull. mar. biol. Lab. Woods Hole, 99: 74-87.

Hand, C. and Lai Bing Kan. - 1961. The medusae of Chukcki and Beaufort seas of the arctic ocean including the description of a new species of Eucodonium (Hydrozoa: Anthomedusae). Techn. Pap. Arctic Inst. N. Am., 6: 1-23.

Harris, A. - 1990. Sessile animals of the sea shore. Chapman and Hall (eds.), London, 377 pp.

Hartlaub, C. - 1907-1917. Craspedote Medusen. Teil I. Lief. 1-4. Nord. Plankton, 12: 1- 479.

Herberts, C. -1964 . Note au sujet de la reproduction de 1'Hydraire Hydractinia aculeata (Wagner, 1833). Recl Trav. Stn. mar. Endoume, (Bull. 34)50: 161-165.

Hertwig, O. and R. Hertwig - 1878. Das Nervensystem und die Sinnesorganen der Medusen. Vogel (ed.), Leipzig.

Hincks, T. - 1861-1862. A catalogue of the zoophytes of south Devon and south Cornwall. Ann. Mag. nat. Hist., 8: 152-161, 251-262, 290-297, 360-366; 9: 22-30.

Hincks, T. - 1868. The History of the British hydroid zoophytes. John Van Voorst, London.

Hirohito. - 1988. Athecata. In: The hydroids of Sagami Bay, Part 1, pp. 1-179. Biological Laboratory Imperial Household, Tokyo.

Hirohito. - 1995. Thecata. In: The hydroids of Sagami Bay, Part 2 , pp. 1-243. Biological Laboratory Imperial Household, Tokyo.

Horridge, G.A. - 1969. Statocysts of medusae and evolution of stereocilia. Tissue Cell, 1: 341-353.

Hsü, K.J., L. Montader, D. Bernouilli, M.B. Cita, A. Erickson, R.E. Garrison, R.B. Kidd, F. Mélières, C. Müller, and R. Wright. 1978. History of the Mediterranean crisis. Rep. Deep-Sea Drilling Project, Washington US Govern, 42 (Suppl. 1): 10531078.

Huang, Jia-Qi. - 1999. Three new species of Genus Euphysora from China seas (Hydrozoa: Anthomedusae, Corymorphidae). Acta Oceanol. Sin., 18: 435-441.

Hündgen, M. - 1978. Biology of colonial hydroids. 1. Morphology of polyp of Eirene viridula (Thecata: Campanulinidae). Mar. Biol., 45: 79-92.

Hughes, R.G. - 1983. The life-history of Tubularia indivisa (Hydrozoa: Tubulariidae) with observations on the status of $T$. ceratogyne. J. mar. biol. Ass. U.K., 63: 467-479.

Hughes, R.G. - 1977. Aspects of the biology and life-history of Nemertesia antennina (L.) (Hydrozoa: Plumulariidae). J. mar. biol. Ass. U. K., 57: 641-657.

Huvé, P. - 1952a. Révision des polypes campanulinides méditerranéens. Pt.1. Recl. Trav. Stn. mar. Endoume, 4: 34-52.

Huvé, P. - 1952b. Révision des polypes campanulides méditerrannéens. Pt. 2. Dipleuron gracilis (Clarke) 1882, nouvel hydraire Campanulinide européen. Vie Milieu, 3: 389-396.

Huvé, P. - 1953. Biologie de l'hydraire Hypsorophus quadratus 
(Forbes) 1848 en Méditerranée occidentale. Bull. Inst. océanogr. Monaco, 1019: 1-11.

Huvé, P. - 1954. Hydranthea et Campalecium, genres méditerranéens aberrants d'Hydroïdes de la famille des Haléciidae. Recl Trav. Stn. mar. Endoume, 13: 173-192.

Huvé, P. - 1956. Hydroida. Campanulinidae Tiaropsidium mediterraneum (Metschnikoff) 1886. Iconographie de la faune et de la flore Méditerranéennes, n. sér. 1.

Huxley, Th.H. - 1859. The oceanic Hydrozoa; a description of the Calycophoridae and Physophoridae observed during the voyage of H.M.S. 'Rattlesnake', in the years 1846-50. Royal Society of London.

Hyman, L.H. - 1940. Protozoa through Ctenophora. In: The Invertebrates, Vol. I, pp.1-726. McGraw-Hill, London.

Ianora, A. and B. Scotto Di Carlo. - 1981. The distribution and annual cycles of Siphonophora Calycophora in the Gulf of Naples. Arch. Oceanogr. Limnol., 20: 51-65.

Isasi, I. - 1985. Fauna de Cnidarios bentónicos del Abra de Bilbao. M.Sc. Thesis, Univ. of País Vasco.

Isasi, I. and J.I. Saiz. - 1986. Sistemática de Cnidarios del Abra de Bilbao. Cuad. Invest. Biol., 9: 67-74.

Iwasa, M. - 1934b. Revision of Stylactis and its allied genera, with description of Stylactella (Stylactis) yerii n. sp.. J. Fac. Sci. Hokkaido imp. Univ., 2: 241-277.

Izquierdo, M.S., P. García-Corrales and J.J. Bacallado. - 1986. Contribución al conocimiento de los hidrozoos caliptoblástidos del Archipiélago Canario. Parte II: Plumulariidae. Contribution to the study of the calyptoblastid hydrozoans of the Canary Islands (Spain): II. Plumulariidae. Bol. Inst. esp. Oceanogr., 3: 49-66

Jankowski, T. - 2001. The freshwater medusae of the world - a taxonomic and systematic study with some remarks on other inland water jellyfish. Hydrobiologia. 462: 91-113.

Jarms, G. and U. Mühlenhardt-Siegel. - 1998. Monobrachium parasiticum (Cnidaria: Hydrozoa) epizoic on Antarctic bivalves and its polarity. Zool. Verh., Leiden, 323: 125-139.

Jarms, G. and H. Tiemann. - 1996. On a new hydropolyp without tentacles, Microhydrula limopsicola n. sp., epibiotic on bivalve shells from the Antarctic. In: S. Piraino, F. Boero, J. Bouillon, P.F.S. Cornelius and J.-M. Gili (eds.), Advances in Hydrozoan Biology. Sci. Mar., 60: 109-115.

Johnston, G.J. - 1836-1837. A catalogue of the zoophytes of Berwickshire. Hist. Berwicksh. Nat. Club, 1: 107-108

Johnston, G. - 1847. A history of the British zoophytes. 2nd edition, Vol. 1, pp. 1-488. Van Voorst, London.

Joseph, H. - 1925. Zur Morphologie und Entwicklungsgeschichte von Haleremita und Gonionemus. Ein Beitrag zur systematischen Beurteilung der Trachymedusen. Z. wiss. Zool., 125: 374 434.

Kawamura, T. - 1915. Calcyonid Siphonophorae. I to V. Zool. Mag. Tokyo., 27: 135-142; 191-198; 317-324; 428-440; 577586.

Keferstein, W. and E. Ehlers - 1860. Auszug aus den Beobachtungen über die Siphonophoren von Neapel und Messina angestellt in Winter 1859-60. Nachr. Ges. wiss. Göttingen, 23: 254-262.

Keferstein W. and E. Ehlers. - 1861. Zoologische Beiträge gesammelt in winter 1859-1860 in Neapel und Messina. W. Engelman, Leipzig.

Kideys, A.E. and A.C. Gücü. - 1995. Rhopilema nomadica: A lessepsian scyphomedusan new to the Mediterranean coast of Turkey. Israel J. Zool. 41: 615-617.

Kirkpatrick, P.A. and P.R. Pugh. - 1984. Siphonophores and Velellids. Synopsis of the British Fauna (New Series), No. 29, Linnean Society of London, London., $154 \mathrm{pp}$.

Kölliker, A. - 1853a. Die Schwimmpolypen oder Siphonophoren von Messina, pp. 1-112. Wilhem Engelmann, Leipzig.

Kölliker, A - 1853b. Bericht über einige im Herbste 1852 in Messina angestellte vergleichend-anatomische Untersuchungen. In: Gegenbaur, Kölliker and Müller (eds.), Z. wiss. Zool., 4: 298370 .

Kramp, P.L. - 1919. Medusae. Pt. 1. Leptomedusae. Dan. Ingolf Exped., 5: 1-111.

Kramp, P.L. - 1920. Athomedusae and Leptomedusae. Rep. Sci. Res. Michael Sars N. Atl. Deep-Sea Exped., 1910, 3: 1-14.

Kramp, P.L. - 1924. Medusae. Rep. Danish Oceanogr. Exped., 1908-1910, 2, Biol.(H1): 1-67.

Kramp, P.L. - 1930. Hydromedusae collected in the South Western part of the North Sea and in the eastern part of the Channel in
1903-14. Mém. Mus. r. Hist. nat. Belge, 45: 1-55.

Kramp, P.L. - 1932a. A revision of the medusae belonging to the family Mitrocomidae. Vidensk. Meddr dansk naturh. Foren., 92: 305-384.

Kramp, P.L. - 1932b. Hydroids. In: The Godthaab expedition 1928. Meddr Grönland, 79: 1-86.

Kramp, P.L. - 1933. Craspedote Medusen III. Leptomedusen. Nord. Plankton., 22: 541-602.

Kramp, P.L. - 1936. On the Leptomedusae of the genera Eirene Eschscholtz and Helgicirrha Hartlaub. Vidensk. Meddr dansk naturh. Foren., 99: 239-262.

Kramp, P.L. - 1938a. Die Meduse von Ostroumovia inkermanica (Pal. Ostr.) und die systematische Stellung der Olindiiden. Zool. Anz., 122: 103-108.

Kramp, P.L. - 1938b. Die Meduse von Ostroumovia inkermanica (Pal.-Ostr.) und die systematische Stellung der Moerisiiden und Olindiiden. Trud. chernomorsk. biol. Sta. Varna, 7: 45-68.

Kramp, P.L. - 1942. Medusae. In: The Godthaab Expedition, 1928. Meddr Grönland, 81: 1-168.

Kramp, P.L. - 1947. Medusae. Part III. Trachylina and Scyphozoa, with zoogeographical remarks on all the medusae of the northern Atlantic. Dan. Ingolf Exped., 5: 1-66.

Kramp, P.L. - 1949. Origin of the hydroid family Corymorphidae. Vidensk. Meddr dansk naturh. Foren., 111: 183-215.

Kramp, P.L. - 1955. A revision of Ernst Haeckel's determinations of a collection of Medusae belonging to the Zoological Museum of Copenhagen. In: Papers in marine Biology and Oceanography. H.B. Bigelow Commemoration Volume. Deep-Sea Res., 3 (Suppl.): 149-168.

Kramp, P.L. - 1957a. Hydromedusae from the Discovery collections. Discovery Rep., 29: 1-128.

Kramp, P.L. - 1957b. Some Mediterranean Hydromedusae collected by A.K. Totton in 1954 and 1956. Vidensk. Meddr dansk naturh Foren., 119: 115-128.

Kramp, P.L. - 1959a. The Hydromedusae of the Atlantic Ocean and adjacent waters. Dana-Rep., 46: 1-283.

Kramp, P.L.- 1959b. Some new and little known Indo-Pacific medusae. Videnk. Meddr dansk naturh. Foren., 121: 223-259.

Kramp, P.L. - 1961. Synopsis of the medusae of the world. J. mar. biol. Ass. U.K., 40: 1- 469

Kramp, P.L. - 1962. Medusa of Vietnam. Vidensk. Meddr dansk naturh. Foren., 124: 305-366.

Kramp, P.L. - 1965. The Hydromedusae of the Pacific and Indian Oceans. Dana-Rep., 63: 1-162.

Kramp, P.L. - 1968. The Hydromedusae of the Pacific and Indian Oceans. Sect. II and III. Dana-Rep., 72: 1- 200.

Kramp, P.L. and D. Damas. - 1925. Les Méduses de la Norvège. Introduction et partie spéciale. Vidensk. Meddr dansk naturh. Foren., 80: 217-323.

Kubota, S. - 1979. Occurrence of a commensal hydroid Eugymnanthea inquilina Palombi from Japan. J. Fac. Sci. Hokkaido Univ., 21: 396-406.

Kubota, S. - 1983. Studies on the life history and systematics of the Japanese commensal hydroids living in bivalves, with some reference to their evolution. J. Fac. Sci. Hokkaido Univ., 23: 296402.

Kubota, S. - 1985. Systematic study on a bivalve inhabiting hydroid Eugymnanthea inquilina japonica Kubota from central Japan. J. Fac. Sci. Hokkaido Univ., 24: 70-85.

Kubota, S. - 1987. The origin and systematics of four Japanese bivalve-inhabiting hydroids. In: J. Bouillon, F. Boero, F. Cicogna and P.F.S. Cornelius (eds.), Modern trends in the Systematics, Ecology and Evolution of Hydroid and Hydromedusae, pp. 275-287, Clarendon Press, Oxford.

Kubota, S. - 1991. An undescribed colony form of Monobrachium parasitum (Limnomedusae: Olindiasidae) commensal with a new host bivalve Cladella lubrica in northern Japan. Proc. Jap. Soc. syst. Zool., 45: 1-6.

Kubota, S. - 1995. Cnidome and growth of a Medusa of Cirrholovenia tetranema (Leptomedusae, Cirrholoveniidae) in Japan. Publ. Seto mar. biol. Lab., 36: 365-378.

Kubota, S. - 2000. Parallel, paedomorphic evolutionary processes of the bivalve-inhabiting hydrozoans (Leptomedusae, Eirenidae) deduced from the morphology, life cycle and biogeography, with special reference to taxonomic treatment of Eugymnanthea. In: C.E. Mills, F. Boero, A. Migotto and J.-M. Gili (eds.), Trends in Hydrozoan Biology - IV. Sci. Mar., 64 (Suppl. 1): 241-247. 
Kubota, S. and T. Horita. - 1992. A new Hydromedusa of the genus Eirene (Leptomedusae; Eirenidae) from Toba, Japan. Zool. Sci., 9: 413-421.

Kubota, S. and Y. Takashima. - 1992. Rediagnosis of Sarsia japonica (Nagao) (Hydrozoa: Corynidae) from Hokkaido, Japan. Publ. Seto mar. biol. Lab., 35: 371-381.

Kühn, A. - 1913. Entwicklungsgeschichte und Verwandschaftsbeziehungen der Hydrozoen. I. Teil: Die Hydroiden. Erg. Fortschr. Zool., 4: 1-284.

Lacassagne, M.M. - 1968a. Deux nouveaux type de nématocystes astomocnides chez les Actinulides (Hydrozoiaires): les eurytéloïdes spirotèles et aspirotèles. C.r. hebd. séanc. Acad. Sci., Paris, 266: 892-894.

Lacassagne, M.M. - 1968b. Les anisorhizes atriches, nouveau type de nématocystes stomocnides présent chez deux formes d'Halammohydra (Hydrozoaires, Actinulides). C.r. hebd. séanc. Acad. Sci., Paris, 266: 2090-2092.

Lacassagne, M.M. - 1973. Biologie des Hydrozoaires mésopsammique. Proc. II. Meiofauna Conference, York. (Abstract).

Lakkis, S. - 1971. Contribution à l'étude du zooplancton des eaux libanaises. Mar. Biol., Berl., 11: 138-148

Lakkis, S. and R. Zeidane. - 1985. Les Hydroméduses des eaux néritiques libanaises: composition et distribution. Rapp. P.-v. Réun. Commn int. Explor. scient. Mer Méditerr., 29: 179-180.

Lakkis, S. and R. Zeidane. - 1995. Distribution of Siphonophores in Lebanese waters (eastern Mediterranean). Proceedings of the 6th International Conference on Coelenterate Biology, pp. 301306.

Lamarck, J.B. - 1801. Système des animaux sans vertèbres. Paris, $432 \mathrm{pp}$

Lameere, A. - 1920 ó 1921. Notes de Zoogénie. III. Origine et Evolution des Acalèphes. Annls Soc. r. zool. malacol. Belg., 51: 58 62.

Lamouroux, J.V.F. - 1812. Extrait d'un mémoire sur la classification des polypes coralligènes non entièrement pierreux. Nouv. Bull. Sci. Soc. philom., Paris, 63: 181-188.

Lang, A. - 1886. Gastroblasta raffaelli. Eine durch eine Art unvollständiger Theilung entstehende Medusen-Kolonie. Jena. Zeits. Naturw., 19: 753-763.

Larson, R.J. - 1980. The medusa of Velella velella (Linnaeus, 1758) (Hydrozoa, Chondrophorae). J. Plank. Res., 2: 183-186.

Larson, R.J. and G.R. Harbison. - 1990. Medusae from McMurdo Sound, Ross Sea including the description of two new species, Leuckartiara brownei and Benthocodon hyalinus. Polar Biol., 11: $19-25$.

Larson, R.J., G.I. Matsumoto, L.P. Madin and L.M. Lewis. - 1992. Deep-sea benthic and benthopelagic medusae: recent observations from sumersibles and a remotely operated vehicle. Bull. mar. Sci., 51: 277-286.

Larson, R.J., C.E. Mills and G.R. Harbison. - 1991. Western Atlantic midwater hydrozoan and scyphozoan medusae: in situ studies using manned submersibles. Hydrobiologia, 216/217: 311-317.

Laval, Ph., J.-C. Braconnot, C. Carré, J. Goy, P. Morand and C.E. Mills. - 1989. Small-scale distribution of macroplankton and micronekton in the Ligurian Sea (Mediterranean Sea) as observed from the manned submersible Cyana. J. Plank. Res., 11: 665-685

Leloup, E. - 1929. Recherches sur l'anatomie et de développement de Velella spirans Forsk. Archs Biol., 39: 395-478.

Leloup, E. - 1934. Siphonophores Calycophorides de l'Océan Atlantique tropical et austral. Bull. Mus. r. Hist. nat. Belg., 10: 1-87.

Leloup, E. - 1935. Hydraires calyptoblastiques des Indes Occidentales. Mém. Mus. r. Hist. nat. Belg., 2: 1-73.

Leloup, E. - 1940a. Quelques hydropolypes de la baie de Sagami, Japon. (2e note). Bull. Mus. r. Hist. nat. Belg., 16: 1-13.

Leloup, E. - 1940b. Hydropolypes provenant des croisières du Prince Albert Ier de Monaco. Rés. Camp. scient. Albert I de Monaco, 104: 1-38.

Leloup, E. - 1952. Coelentérés. In: Faune de Belgique, pp.1-283. Institut Royal des Sciences naturelles, Bruxelles, Belgique.

Leloup, E. - 1955. Siphonophores. Rep. Sci. Res. Michael Sars N. Atl. Deep-Sea Exped., 5: 124

Leloup, E. and E. Hentschel. - 1935. Die verbreitung der Calycophoren Siphonophoren in Südatlankischen ozean. Wiss. Ergeb. Deutschen Atlantischen, Expedition 'Meteor' 1925. 1927, 12: 1-31.
Lens, A.D. and T. Van Riemsdijk. - 1908. The siphonophora of the 'Siboga' Expedition. Siboga Exped., 9: 1-130.

Lesueur, C.A. - 1811. Voyage de découvertes aux terres australes. Hist. Nat. Partie Iconographique et gravures par M.C.A. Lesueur, 1-5, 1 pl., Paris.

Leuckart, R. - 1853. Zoologische Untersuchungen. I. Siphonophoren, pp. 1-95.

Leuckart, R. - 1854. Zur näheren Kenntniss der Siphonophoren von Nizza. Arch. Naturgesch. Jahrg., 22: 249-377.

Leuckart, R. - 1856. Beiträge zur Kenntniss der Medusenfauna von Nizza. Arch. Naturg. 22: 1-40.

Linko, A. - 1900. Observations sur les Méduses de la Mer Blanche. Trudy imp. S.-Peterb. Obshch. Estest. 29: 137-156.

Linnaeus, C. - 1758. Systema naturae, vol. 1, pp. 1-824. Tenth edition. L. Salvii, Holmiae (Stockholm). L. Salvii.

Littlefield, C. - 1994. Cell-cell interactions and the control of sex determination in Hydra. Seminars Devl Biol., 5: 13-20

Llobet, I. - 1987. Faunística y distribución espacio-temporal de una población de hidropólipos epibiontes del alga Halimeda tuna en el Mediterráneo Occidental. M.Sc. Thesis, Univ. de Barcelona.

Llobet, I., R. Coma, M. Zabala, J.-M. Gili and R.G. Hughes. - 1991. The population dynamics of Orthopyxis crenata (Hartlaub, 1901) (Hydrozoa, Cnidaria), an epiphyte of Halimeda tuna in the northwestern Mediterranean. J. exp. mar. Biol. Ecol., 150: 283-292.

Lo Bianco, S. - 1909. Notize biologiche riguardanti specialmente il periodo di maturità sessuale degli animali del Golfo di Napoli. Mitth. zool. Stat. Neapel, 19: 513-761.

Logvinenko, B.M. - 1959. On finding the medusa Blackfordia virginica in the Caspian Sea. J. Zool. U.S.S.R., 38: 1257-1258.

Lotan, A., R. Ben-Hillel and Y. Loya. - 1992. Life cycle of Rhopilema nomadica: A new immigrant scyphomedusan in the Mediterranean. Mar. Biol. 112: 237-242.

Ludwig, H.W. - 1977. 99.26 per cent water content in the freshwater medusa Craspedacusta sowerbii. Z. Naturf., (C)32: 10111012.

Lütken, C. - 1850. Nogle Bemaerkninger om Medusernes systematiske Inddeling, navnlig med Hensyn til Forbes's History of British Naked-eyed Medusa. Vidensk. Meddr dansk naturh. Foren., 1850: 15-35

Maas, O. - 1904. Méduses provenant des campagnes des yachts 'Hirondelle' et 'Princesse Alice' (1888-1903). Rés. Camp. scient. Albert I de Monaco, 28: 1-71.

Maas, O. - 1905. Die Craspedoten Medusen der Siboga-Expeditie. Siboga Exped., 10: 1-84.

McCrady, J. - 1859. Gymnophtalma of Charleston Harbor. Proc. Elliott Soc. Nat. Hist. Charleston, South Carolina, 1: 103-221.

Mackie, G.O. - 1959. The evolution of the Chondrophora (Siphonophora- Disconanthae): new evidence from behavioural studies. Trans. R. Soc. Can., 3, 53: 7-20.

Mackie, G.O. - 1960. The structure of the nervous system in Velella. O. Jl. microsc. Sci., 101: 119-131.

Mackie, G.O. and D.A. Boag. - 1963. Fishing, Feeding and Digestion in Siphonophores. Pubbl. Staz. zool. Napoli, 33: 178-196.

Mackie, G.O. and D. Carré. - 1983. Coordination in a Diphyid Siphonophore. Mar. Behav. Physiol., 9: 139-170.

Mackie, G.O., P.R. Pugh and J.E. Purcell. - 1987. Siphonophore biology. Adv. mar. Biol., 24: 97-262.

Maldonado, A. - 1985. Evolution of the Mediterranean basis and a detailed reconstruction of Cenozoic paleoceanography. In: R. Margalef (ed.), Western Mediterranean, pp. 17-59. Pergamon Press, Oxford.

Mammen, T.A. - 1963. On a collection of hydroids from South India. I. Suborder Athecata. J. mar. biol. Ass. India, 5: 27-61.

Manton, S. -1940 . On two new species of the hydroid Myriothela. Scient. Rep. Br. Graham Land Exped., 1: 255-293.

Mapsone, G.M. - 1998. Bargmannia lata, an undecribed species of physonect siphonophore (Cnidaria, Hydrozoa). Zool. Verh., Leiden, 323: 141-147.

Marche-Marchad, I. - 1963. Un nouvel hydraire non pélagique Monobrachium drachi n. sp. (Limnomedusae) trouvé dans la Baie de Gorée (Sénégal). C.r. hebd. Séanc. Acad. Sci., Paris, 257: 1347-1349.

Marcus, N. and F. Boero - 1998. Production and plankton community dynamics in coastal aquatic systems: the importance of benthic-pelagic coupling and the forgotten role of life cycles. Limnol. Oceanogr., 43: 763-768. 
Margalef, R. - 1985. Introduction to the Mediterranean. In: R. Margalef (ed.). Western Mediterranean, pp. 1-16. Pergamon Press, Oxford.

Margulis, R.Y. - 1971. The distribution of siphonophores of the genus Lensia in the Atlantic Ocean. Oceanology, 11: 80-84.

Margulis, R.Y. - 1980. Redescription of Tottonia contorta and composition of the family Apolimidae (Siphonophora, Physophorae) (in Russian). Zool. Zh., 59: 342-348.

Margulis, R.Y. - 1989. Novye gidroidnye meduzy semestva Tubulariidae (Coelenterata, Hydrozoa). New hydroid jelly-fishes of the family Tubulariidae (Coelenterata, Hydrozoa). Zool. Zh., 68: $126-130$.

Margulis R.Y. - 1993. Cordalgama tottoni Sp. n - A new siphonophore from the suborder physonectae (Cnidaria Hydrozoa, Siphonophora) (in Russian). Zool. Zh., 72: 14-19.

Marinopoulos, J. - 1979. Biological survey of the eastern Mediterranean Sea: Hydroid (preliminary study). Rapp. P.-v. Réun Commn int. Explor. scient. Mer Méditerr., 25: 119-1120.

Marinopoulos, J. - 1981. Contribution à la connaissance des Hydraires profonds de la Méditerranée. Rapp. P.-v. Réun Commn int. Explor. scient. Mer Méditerr., 27: 175-76.

Marinopoulus, J. - 1990. Le genre Eudendrium (Cnidaria): revision des espèces méditerranéennes. Rapp. P.-v. Réun. Comm. int. Explor. scient. Mer Méditerr., 32: 311.

Marinopoulus, J. - 1992. Contribution à l'étude du genre Eudendrium (Hydrozoa: Hydroida) de la Méditerranée: taxonomie et phylogénie. In: D. Bellan (ed.), Spéciation et biogéographie en mer Méditerranée. Bull. Inst. océanogr. Monaco, no. spéc. 9: 53-66.

Mariscal, R.N. - 1974. Nematocysts. In: L. Muscatine and H.M. Lenhoff (eds.), Coelenterate Biology. Reviews and new perspectives, pp. 129-178. Academic Press, London.

Marktanner-Turneretscher, G. - 1890. Die Hydroiden des k.k. naturhistorischen Hofmuseums. Ann. Naturh. Mus. Wien, 5: 95-286.

Marques, A.C - 1996. A critical analysis of a cladistic study of the genus Eudendrium (Cnidaria: Hydrozoa), with some comments on the family Eudendriidae. J. Comp. Biol. 1: 153-162.

Marques, A.C., A.L.P. Cantero and W. Vervoort. - 2000. Mediterranean species of Eudendrium Ehrenberg, 1834 (Hydrozoa, Anthomedusae, Eudendriidae) with the description of a new species. J. Zool., 252 (Part 2): 197-213.

Marques, A.C., H. Mergner, R. Höinghaus, C.M.D. Santos and W. Vervoort. - 2000. Morphological study and taxonomical notes on Eudendrium (Cnidaria: Hydrozoa: Athecate/Anthomedusae). Zool. Med. Leiden, 74: 76-118.

Matjasic, J. and B. Sket. - 1971. Jamski hidroid s slovenskaga krasa. A cave hydroid from Slovene karst. Biol. Vestnik., 19: 139-145.

Matthews, D.C. - 1966. A comparative study of Craspedacusta sowerbyi and Calpasoma dactyloptera life cycles. Pacif. Sci. 20: 246-259.

Maurer, B.A. - 1999. Untangling ecological complexity, The macroscopic perspective. University of Chicago Press, Chicago., $251 \mathrm{pp}$.

Mayer, A.G. - 1910. Medusa of the world. Hydromedusae. Vol. I, II. Carnegie Institution, Washington, pp. 1-735.

Medel, M.D. - 1996. Estudio taxonómico de los hidrozoos del Estrecho de Gibraltar. Ph.D. Thesis, Univ. of Sevilla.

Medel Soteras, M.D., F.J. García and J.C. García-Gómez. - 1991. La familia Sertulariidae (Cnidaria: Hydrozoa) en el estrecho de Gibraltar y la península ibérica: Aspectos taxonómicos y zoogeográficos. Cah. Biol. mar., 32: 503-543.

Medel M.D., J.C. García-Gómez and J. Bouillon. - 1993. An undescribed species of Merona (Cnidaria: Hydrozoa: Clavidae) from southern Spain with remarks on other species of the genus. J. nat. Hist. 27: 513-519.

Medel, M.D. F.J. García and W. Vervoort - 1998. The family Haleciidae (Cnidaria: Hydrozoa) from the Strait of Gibraltar and nearby areas. Zool. Meded., Leiden, 72: 29-50.

Medel, M.D. and P.J. López-González. - 1996. Updated catalogue of the Hydrozoans from the Iberian Peninsula and Balearic Islands with remarks on zoogeography and affinities. Sci. Mar., 60: 183-209.

Medel, M.D. and W. Vervoort. - 1995. Plumularian hydroids (Cnidaria: Hydrozoa) from the Strait of Gibraltar and nearly areas. Zool. Verh., Leiden. 300: 1-72.

Medel, M.D. and W. Vervoort. - 1998. Atlantic Thyroscyphidae and Sertulariidae (Hydrozoa, Cnidaria) collected during the
CANCAP and Mauritania-II expeditions of the National Museum of Natural History, Leiden, The Netherlands. Zool. Verh., Leiden, 320: 3-85.

Medel, M.D. and W. Vervoort.- 2000. Atlantic Haleciidae and Campanulariidae (Hydrozoa, Cnidaria) collected during the CANCAP and Mauritania-II expeditions of the National Museum of Natural History, Leiden, The Netherlands. Zool. Verh., Leiden, 330: 1-68.

Meinesz, A. - 1999. Killer algae, the true tale of biological invasion. Translated by Daniel Simberloff. The University of Chicago Press, 360 pp.

Meneghini G. - 1845. Osservazioni sull'ordine delle Sertulariee della classe dei Polipi. Memorie R. Ist. veneto Sci., 2: 183-199.

Metschnikoff, E. - 1886a. Embryologische Studien an Medusen. A. Hölder Publisher, Wien, 159 pp.

Metschnikoff, E. - 1886b. Medusologische Mittheilungen. Arb. Zool. Inst. Univ. Wien, Zool. Stat. Triest, 6: 237-266.

Miglietta, M.P., L. Della Tommasa, F. Denitto, C. Gravili, P. Pagliara, J. Bouillon and F. Boero. - 2000. Approaches to the ethology of hydroids and medusae (Cnidaria, Hydrozoa). Sci. Mar., 64 (Suppl. 1): 63-71.

Migotto, A.E - 1996. Benthic shallow-water hydroids (Cnidaria, Hydrozoa) of the coast of São Sebastião, Brazil, including a checklist of Brazilian hydroids. Zool. Verh., Leiden, 306: 1125 .

Migotto, A.E. and L.P. De Andrade. - 2000. The life cycle of Hebella furax (Cnidaria: Hydrozoa): a link between a lafoeid hydroid and a laodiceid medusa. J. nat. Hist., 34: 1871-1888.

Millard, N.A.H. - 1957. The Hydrozoa of False Bay, South Africa. Ann. S. Afr. Mus., 43: 173-243.

Millard, N.A.H. - 1959. Hydrozoa from ships' hulls and experimental plates in Cape Town docks. Ann. S. Afr. Mus., 45: 239-256

Millard, N.A.H. - 1962. The Hydrozoa of the south and west coasts of South Africa. Part I. The Plumulariidae. Ann. S. Afr. Mus., 46: 261-319.

Millard, N.A.H. - 1966. The Hydrozoa of the south and west coasts of South Africa. Part III. The Gymnoblastea and small families of the Calyptoblastea. Ann. S. Afr. Mus., 48: 427-487.

Millard, N.A.H. - 1975. Monograph on the Hydroida of southern Africa. Ann. S. Afr. Mus., 68: 1-513.

Millard, N.A.H. and J. Bouillon. - 1973. Hydroid from the Seychelles (Coelenterata). Annls Mus. r. Afr. Centrale, Sci. Zool., 206: $1-106$

Millard, N.A.H. and J. Bouillon. - 1974. A collection of hydroids from Moçambique, East Africa. Ann. S. Afr. Mus., 65: 1-40.

Millard, N.A.H. and J. Bouillon. - 1975. Additional hydroids from the Seychelles. Ann. S. Afr. Mus., 69: 1-15.

Miller, R.L. - 1972. Gel filtration of the sperm attractants of some marine Hydrozoa. J. exp. Zool., 182: 281-297.

Mills, C.E. - 2000. The life cycle of Halimedusa typus, with discussion of other species closely related to the family Halimedusidae (Hydrozoa, Capitata, Anthomedusae). Sci. Mar., 64: 97-106.

Mills, C.E. - 2001. Jellyfish blooms: are populations increasing globally in response to changing ocean conditions? Hydrobiologia, 451: 55-68.

Mills, C.E., F. Boero, A. Migotto and J.-M. Gili. - 2000. Trends in Hydrozoan Biology - IV. Sci. Mar., 64 (Suppl. 1): 1-284.

Mills, C.E. and J. Goy. - 1988. In situ observations of the behaviour of mesopelagic Solmissus Narcomedusae (Cnidaria, Hydrozoa). Bull. Mar. Sci., 43: 739-751.

Mills, C., P.R. Pugh, G.R. Harbison and S.H.D. Haddock. - 1996. Medusa, siphonophores and ctenophores of the Alborán Sea, south western Mediterranean. Sci. Mar., 60: 143-163.

Mills, C.E. and J.T. Rees. - 2000. New observations and corrections concerning the trio of invasive hydromedusae Maeotias marginata ( $M$. inexpectata), Blackfordia virginica, and Moerisia sp. in the San Francisco Estuary. Sci. Mar., 64: 151-155.

Mills, C. and F. Sommer. - 1995. Invertebrate Introductions in marine habitats: two species of hydromedusae (Cnidaria) native to Black Sea, Maeotias inexspectata and Blackfordia virginica invade San Francisco Bay. Mar. Biol., 122: 279-288.

Milne Edwards, H. 1841. - Observations sur la structure et les fonctions de quelques Zoophytes, Mollusques et Crustacés des côtes de France. Ann. sci. nat., 16: 193-232.

Moore, R.C. - 1956. A Treatise on Invertebrate Paleontology: Part F. Coelenterara. F1-F498. Geological Society of America and University of Kansas Press, Lawrence. Kansas. 
Moore, S.J. - 1987. Rediagnosis of the Leptomedusae Blackfordia virginica. J. Mar. Biol. Ass. U. K., 67: 287-291.

Moreira, G.S. - 1975. Sobre duas Leptomedusae do litoral do estado de Sao Paulo. Ciênc. Cult., S. Paulo, 27: 556-558.

Moreno, I. and J. Fernádez-Alcázar. - 1984. Estudio del zooplancton epiplanctónica de la costera de Gijón. VI. Sifonóforos. Cuad. Invest. Biol., 5: 21-28.

Morri, C.- 1980. Alcune osservazioni sulle Cordylophora italiane (Cnidaria, Hydroida). Atti V. conv. Gr. G. Gadio Varese, Maggio: $151-170$.

Morri, C. - 1981. Idrozoi lagunari. Guide per il riconoscimento delle specie animali delle acque lagunari e costiere italiane. Consiglio Nazionale delle Ricerche, Roma, AQ1/94, 6: 7-105.

Morri, C.-1982. Sur la présence en Méditerranée de Garveia franciscana (Torrey, 1902) (Cnidaria, Hydroida). Cah. Biol. mar., 23: $381-391$.

Morri, C. and F. Boero. - 1986. Marine fouling hydroids. In: Catalogue of the main marine fouling organisms, 7, Hydroids: 1-91. Comité international permanent pour la recherche sur la préservation de matériaux en milieu marin. Office d'études marines et atmosphériques, Belgium.

Moser, F.- 1925. Die Siphonophoren der Deutschen Südpolar Expedition, 1901-1903. Dtsch. Südpol. Exped., 17: 15-41.

Motz-Kossowska, S. - 1905. Contribution à la connaissance des hydraires de la Méditerranée occidentale. I.- Hydraires Gymnoblastiques. Arch. Zool. exp. gén., 3: 39-98.

Motz-Kossowska, S. - 1908. Quelques considérations à propos de Plumularia liechtensterni Mark. Turn. et des espèces affines. Arch. Zool. exp. gén., 3: 53-59.

Motz-Kossowska, S. - 1911. Contribution à la connaissance des hydraires de la Méditerranée occidentale. II.- Hydraires calyptoblastiques. Arch. Zool. exp. gén., 6: 325-352.

Naumov, D.V. - 1951. Nekotorye dannye o zhiznennykh tsiklakh metageneticheskikh meduz. Some data on life cycle of metagenetic jellyfishes. Dokl. Akad. Nauk SSSR, 76: 747-750.

Naumov, D.V. - 1960-1969: Hydroid and hydromedusae of the USSR. Keys to the fauna of the USSR. Zoological Institut of the Academy of Science of the URSS, 70: 660.

Naumov, D.V. and S.D. Stepan'yants. - 1971. Novii vid meduz Craspedacusta (Hydrozoa) is morskoi laguni. A new species of the genus Craspedacusta (Hydrozoa) from a sea lagoon. Zool. Zh., 50: 1094-1097.

Navas-Pereira, D. and M. Vannucci. - 1990. Antarctic Hydromedusae and water masses. Pesq. antárt. bras., 2: 101-141.

Neppi, V. - 1912. Adriatische Hydromedusen. Sber. Akad. wiss. Wien, math.- nat. Kl., Abt. I, 121: 707-734.

Neppi, V. - 1915. Vorläufige Mitteilung über die während der Terminfarthen auf S.M. Schiff 'Najade' gesammelten Adriatischen Medusen. Anz. Akad. Wiss. Wien, 52: 2-5.

Neppi, V. - 1922. Meduse adriatiche (Risoltato dell'esame del materiale raccolto durante le crociere adriatiche delle nave Najade negli anni 1911-14). Memorie R. Comitato Talassogr. ital., 101: 1-38.

Neppi, V. and G. Stiasny. - 1911. Die Hydromedusen des Golfes von Triest. Zool. Anz., 38: 395-399.

Neppi, V. and G. Stiasny. - 1912. Nachtrag zu unsrer Mitteilung: Die Hydromedusen des Golfes von Triest. Zool. Anz., 39: 556557.

Neppi, V. and G. Stiasny. - 1913. Die Hydromedusen des Golfes von Triest. Arb. zool. Inst. Univ. Wien zool. Stn Triest, 20: 23-92.

Neto, T. And L. Lourenço. - 1973. Sifonóforos calicóforos do Arquipélago de Cabo Verde. Notas Cent. Biol aquat. trop., 33: $1-55$

Nutting, C.C. - 1900. American hydroids. Part I. The Plumularidae. Smithson. Inst. U.S. Nat. Mus., 4: 1-285.

Nutting, C.C. -1904 . American hydroids. Part II. The Sertulariidae. Spec. Bull. U.S. natn. Mus., 4: 1-325.

Nutting, C.C. - 1915. American hydroids. Part III. The Campanularidae and Bonneviellidae. Smithson. Inst. U.S. Nat. Mus., 4: 1-126.

Osborn, D.A. - 2000. Cnidarian "Parasites" on Solmissus incisa, a Narcomedusa. In: C.E. Mills, F. Boero, A. Migotto and J.-M. Gili (eds.), Trends in Hydrozoan Biology - IV. Sci. Mar., 64 (Suppl. 1): 157-163.

Osman, R.W. - 1977. The establishment and development of a marine epifaunal community. Ecol. Monogr., 47: 37-63.

Östman, C. - 1979. Two types of nematocysts in Campanulariidae (Cnidaria, Hydrozoa) studied by light and scanning electron microscopy. Zool. Scr., 8: 5-12.
Östman, C.- 1982. Nematocysts and taxonomy in Laomedea, Gonothyraea and Obelia (Hydrozoa, Campanulariidae). Zoologica Scr., 11: 227-241.

Östman, C. - 1983. Taxonomy of Scandinavian hydroids (Cnidaria, Campanulariidae) a study based on nematocyst morphology and isoenzymes. Acta Univ. Upsal., 672: 1-22.

Östman, C. - 2000. A guideline to nematocyst nomenclature and classification, and some note on the systematic value of nematocysts. In: C.E Mills, F. Boero, A Migotto and J.-M. Gili (eds.), Trends in Hydrozoan Biology - IV. Sci. Mar., 64: 31-46.

Otto, A.W. - 1823. Beschreibung einiger neuen Mollusken und Zoophyten. Nova Acta Leopoldina, 11: 273-314.

Paes De Andrade, L. and A. Migotto. - 1997. Is there a link between Hebella hydroids (Hydrozoa, Lafoeidae) and Staurodiscus medusae (Hydrozoa, Laodiceidae)? VII Colacmar congresso Latino-Americana Sobre Ciéncias do Mar, 1: 35-36.

Pagès, F. - 2002.. The status of three rare siphonophores (Cnidaria, Hydrozoa) described by Tamiji Kawamura: Batyphysa japonica, Athorybia longifolia and Forskalia misakiensis. Sci. Mar. 66: 375-382.

Pagès, F. and J. Bouillon. - 1997. A rediagnosis of Paragotoea bathybia Kramp, 1942 (Hydroidomedusae: Corymorphidae) with a new diagnosis for the genus Paragotoea. Sci. Mar., 61: 487-493.

Pagès, F., J. Bouillon and J.-M. Gili.- 1991. Four new species of Hydromedusae (Cnidaria, Hydrozoa) from the coast of southwestern Africa. Zool. Scr. 20: 89-98.

Pagès, F. and J.-M. Gili. - 1989. Siphonophores (Cnidaria, Hydrozoa) collected during the "Magga Dan" Expedition (1967) from Africa to Antarctica. Sci. Mar., 53: 53-57.

Pagès, F. and J.-M. Gili. - 1992. Siphonophores (Cnidaria, Hydrozoa) of the Benguala Current (southeastern Atlantic). In: F. Pagès, J.-M. Gili and J. Bouillon (eds.), Planktonic Cnidarians of the Benguela Current. Sci. Mar., 56(Suppl. 1): 65-112.

Pagès, F., J.-M. Gili and J. Bouillon. - 1992. Medusae (Hydrozoa, Scyphozoa, Cubozoa) of the Benguela Current (southeasthern Atlantic). In: F. Pagès, J.-M. Gili and J. Bouillon (eds.), Planktonic Cnidarians of the Benguela Current. Sci. Mar., 56(Suppl. 1): 1-64.

Pagès, F., H.E. González, M. Ramón, M. Sobarzo and J.-M. Gili.2001. Assemblages of gelatinous zooplankton associated to water masses in the Humboldt Current System and potential predatory impact by Bassia bassensis (Siphonophora: Calycophorae). Mar Ecol. Prog. Ser., 210: 13-24

Pagès, F. and P. Pugh. - 2002. Fuseudoxid: the exclusive sexual stage of the calycophoran siphonophore Crystallophyes amygdalina (Clausophyidae, Crystallophyina). Acta Zool., 83: 329-336.

Pagès, F., P. Pugh and V. Siegel. - 1999. The discovery of an Antarctic epipelagic medusan in the Mediterranean. J. Plank. Res., 21: 2431-2435

Pagès, F. and S.B. Schnack-Schiel. - 1996. Distribution patterns of the mesozooplankton, principally siphonophores and medusae, in the vicinity of the Antarctic Slope Front (Eastern Weddell Sea). J. Mar. Syst., 9: 231-248.

Pagès, F., H.M. Verheye, J.M. Gili and J. Flos. - 1991. Shorttern effects of coastal upwelling and wind reversals on epiplanktonic cnidarians in the southern Benguela ecosystem. S. Afr. J. mar. Sci., 10: 203-211.

Pagliara, P., J. Bouillon and F. Boero. - 2000. Photosynthetic planulae and planktonic hydroids: contrasting strategies of propagule survival. Sci. Mar., 64: 173-178.

Palma, S. - 1973. Contribución al estudio de los sifonóforos encontrados frente a la costa de Valparaíso. 1) Taxonomía. Invest. Mar., 4: 17-88.

Palma, S. - 1977. Contribución al estudio de los sifonóforos encontrados frente a la costa de Valparaíso. Aspectos ecológicos. Mem. II. Sinp. Latinoam. Oceanogr. Biol. Cumaná, Venezuela, 24-28/10/75, 2: 119-133.

Palma, S. - 1986. Sifonóforos fisonectes colectados frente a Punta Curaumilla, Valparaíso. Invest. Mar., 14: 69-78.

Palombi, A. - 1936. Eugymnanthea inquilina nuova Leptomedusa derivante da un atecato idroide ospite interno di Tapes decussatus L. Pubbl. Staz. zool. Napoli, 15: 159-168.

Paspaleff, G.W.- 1938. I. Einleitung. II. Die Polypen Ostroumovia inkermanika (Pal.- Ostr.). In: P.L. Karmp and G.W. Paspaleff (eds.), Ueber die Polypen und Medusenformen von Ostroumovia inkermanika (Pal.- Ostr.). Trud. chernomorsk biol. Sta. Varna, 7: 27-44. 
Patriti, G. - 1964. Les Siphonophores Calycophores du Golfe du golfe de Marseille. Recl. Trav. Stn. mar. Endoume, 35: 185-258.

Patriti, G. - 1969. Clausophyes massiliana sp. n. nouvelle espèce de siphonophore calycophore bathypélagique des eaux méditerranéennes. Téthys, 1: 255-260.

Patriti, G. - 1970. Catalogue des cnidaires et cténaires des côtes Atlantiques marocaines. Trav. Inst. scient. Chérifien, Zool., 35: $1-149$.

Payne, F. - 1924. A study of the fresh-water medusa, Craspedacusta ryderi. J. Morph., 38: 387-430.

Pell, M. - 1918. Hydromedusae of Hungarian Adriatic ('Najade') Expeditions 1913, 1914. Allat. Köslem., 17: 22-32.

Pell, M.- 1938. The Hydromedusae of the Adriatic, collected by the 'Najade'. Math. természettud. Ert., 57: 919-930.

Peña Cantero, A.L. - 1995. Hidrozoos bentónicos de las Islas Chafarinas: faunística, ecología, biocenología y biogeografía. $\mathrm{Ph}$. D. Thesis, Univ of Valencia.

Peña Cantero, A.L. and A.M. García Carrascosa. - 2002. The benthic hydroid fauna of the Chafarinas Islands (Alborán Sea, western Mediterranean). Zool. Verh., Leiden. 337: 1-180.

Peña Cantero, A.L., A.M. García Carrascosa and W. Vervoort. 1998. On the species of Filellum Hincks, 1868 (Cnidaria, Hydrozoa) with the description of a new species. J. nat. His., 32: $159-172$

Peña Cantero, A.L., A.M. García Carrascosa and W. Vervoort. 1999. Review of the genus Schizotricha Allman, 1883 (Cnidaria, Hydrozoa, Halopteriidae). J. nat. Hist., 33: 351-386.

Peña Cantero, A.L. and A.C. Marques. - 1999. Phylogenetic analysis of the Antarctic genus Oswaldella Stechow, 1919 (Hydrozoa, Leptomedusae, Kirchenpaueriidae). Contrib. Zool., 68: 83-93.

Peña Cantero, A.L., A. Svoboda and W. Vervoort. - 1997. Species of Staurotheca Allman 1888 (Cnidaria: Hydrozoa) from recent antarctic expeditions with R.V. Polarstern, with the description of six new species. J. nat. Hist., 31: 329-381.

Pérès, C. - 1920. Notes sur la faune marine du Boulonnais II. Tubularia ceratogyne n. sp. Bull. Soc. zool. Fr., 45: 27-33.

Pèron, F. and C.A. Lesueur. - 1807-1816. Voyage de découvertes aux terres Australes exécuté pendant 1800-04, et redigé par M.F. Péron. Paris.

Petersen, K.W. - 1962. A discussion of the genus Tima (Leptomedusae, Hydrozoa). Vidensk. Meddr dansk naturh. Foren., 124: 101-113.

Petersen, K.W. - 1976. Fixation and preservation of planktonic coelenterates. In: H.F. Steedman (ed.), Zooplankton fixation and preservation, pp. 268-269. UNESCO, Paris.

Petersen, K.W. - 1979. Development of coloniality in Hydrozoa. In: G. Larwood and B. Rosen (eds.), Biology and systematics of colonial organisms. Symp. Syst. Assoc., 11: 105-139.

Petersen, K.W. - 1990. Evolution and Taxonomy in Capitate Hydroid and Medusa. Zool. Jl linn. Soc., 100: 101-231.

Petersen, K.W. and M. Vannucci. - 1960. The life cycle of Koellikerina (Anthomedusae, Bougainviliidae). Pubbl. Staz. zool. Napoli, 31: 473-492.

Picard, J. - 1949. Sur la présence en Méditerranée de Clytia noliformis (McGrady). Bull. Mus. Hist. nat. Marseille, 9: 184190.

Picard, J. - 1951a. Contribution à l'étude des méduses de la famille des Moerisiidae. Bull. Inst océanogr. Monaco, 994: 1-16.

Picard, J. - 1951b. Notes sur les hydroméduses méditerranéennes de la famille des Olindiadidae. Archs Zool. exp. gén., 88: 39-48.

Picard, J. - 1951c. Note sur les hydraires littoraux de Banyuls-surMer. Vie Milieu, 2: 338-349.

Picard, J. - 1952. Note sur deux hydroïdes récoltés dans les étangs méditerranéens du littoral français. Vie Milieu, 2: 528-529.

Picard, J. - 1955a. Nouvelles recherches sur les Hydroméduses des Herbiers méditerranéens de Posidonies. Recl Trav. Stn mar. Endoume, 15: 59-71.

Picard, J. - 1955b. Sur la position systématique d' Eucodonium brownei Hartlaub (1907). Recl Trav. Stn Mar. Endoume, 15: 95-98.

Picard, J. - 1956a. Le premier stade de l'hydroméduse Pandea conica, issu du l' hydropolype Campaniclava cleodorae. Bull. Inst. océanogr. Monaco, 1086: 1-11.

Picard, J. - 1956b. Les espèces et formes méditerranées du genre Sertularella. Vie Milieu, 7: 258-266.

Picard, J. - 1957. Étude sur les Hydroïdes de la superfamille Pteronematoidea, 1. Généralités. Bull. Inst. océanogr. Monaco, 1106: 1-12.
Picard, J. - 1958a. Tregoubovia n. gen. atentaculata n. sp. Nouvelle Anthoméduse, dépourvue de tentacules récolté dans le plancton profond de Villefranche-sur-mer. Rapp. P.-v. Réun. Commn int. Explor. scient. Mer Méditerr., 14: 185-186.

Picard, J. - 1958b. Origines et affinités de la faune d'hydropolypes (Gymnoblastes et Calyptoblastes) et d'hydroméduses (Anthoméduses et Leptoméduses) de la Méditerranée. Rapp. P.-v. Réun. Commn int. Explor. scient. Mer Méditerr., 14: 187199.

Picard, J. - 1960a. Le polype Coryne gemmifera (Forbes) 1848 et la systématique générique chez les Corynidae. Rapp. P.-v. Réun. Commn int. Explor. scient. Mer Méditerr., 15: 109-112.

Picard, J. - 1960b. Merga tregoubovii, nouvelle anthoméduse Pandeidae du plancton de Villefranche-sur-Mer. Rapp. P.-v. Réun. Commn int. Explor. scient. Mer Méditerr., 15: 333-336.

Piraino, S. - 1991. The adaptive pattern of growth and reproduction of the colonial hydroid Clavopsella michaeli. In: R.B. Williams, P. F. Cornelius, R.G. Hughes and E.A. Robson (eds.), Coelenterate Biology: Recent research on Cnidaria and Ctenophora. Hydrobiologia, 216/217: 229-234.

Piraino, S. - 1992. The 'stinging' egg of Clavopsella michaeli (Berrill, 1948) (Hydrozoa, Cnidaria). Boll. Zool., 59: 251-256.

Piraino, S., F. Boero, J. Bouillon, P.F.S. Cornelius and J.-M. Gili. 1996. Advances in Hydrozoan Biology. Sci. Mar., 60: 1-243.

Piraino, S., J. Bouillon, F. Boero. - 1992. Halocoryne epizoica Cnidaria, Hydrozoa), a hydroid that 'bites'. In: J. Bouillon, F. Boero, F. Cicogna, J.-M. Gili and R.G. Hughes (eds.), Aspects of hydrozoan biology. Sci. Mar., 56: 141-147.

Piraino, S., G. Fanelli, F. Boero. - 2002. Variability of species' roles in marine communities: change of paradigms for conservation priorities. Mar. Biol., 140: 1067-1074.

Piraino, S., C. Todaro, S. Geraci and F. Boero. - 1994. Ecology of the bivalve-inhabiting hydroid Eugumnanthea inquilina in the coastal sounds of Taranto (Ionian Sea, SE Italy). Mar. Biol., 118: 695-703.

Piraino, S., F. Boero, B. Aeschbach and V. Schmid. - 1996. Reversing the life cycle: Medusa transforming into polyps and cell transdifferentiation in Turritopsis nutricula (Cnidaria, Hydrozoa). Biol. Bull., 190: 302-312.

Poche, F. - 1914. Das System der Coelenterata. Arch. Naturgesch., 80: $47-128$

Por, F.D. - 1978. Lessepsian migration. The influx of Red Sea biota into the Mediterranean by way of the Suez Canal. Ecol. Stud., 23: $1-228$.

Por, F.D. - 1989. The legacy of Tethys. An aquatic biogeography of the Levant. Kluwer Academic Publishers, Dordrecht.

Prevot, E. - 1959. Morphologie et évolution des structures tentaculaires chez les hydraires Gymnoblastes Capitata. Recl Trav. Stn mar. Endoume, 29: 91-126.

Pugh, P.R. - 1974. The vertical distribution of the Siphonophores collected during the SOND cruise 1965. J. mar. biol. Ass. U. K., 54: $25-90$.

Pugh, P.R. - 1983. Benthic Siphonophores: a review of the family Rhodaliidae (Siphonophora, Physonectae). Phil. Trans. R. Soc., Lond., 301: 165-300.

Pugh, P.R. - 1984. The diel migrations and distribution within a mesopelagic community in the North East Atlantic. 7. Siphonophores. Prog. Oceanogr., 13: 461-489.

Pugh, P.R. - 1992a. A revision of the subfamily Nectopyramidinae (Siphonophora, Prayidae). Phil. Trans. R. Soc., Lond., 335: 281-322.

Pugh, P. - 1992. Desmophyes haematogaster new species of prayine siphonophore (Calycophorae, Prayidae). Bull. mar. Sci., 50: 89-96.

Pugh, P.R. - 1995. Clausophyes tropica (Siphonophorae, Calycophora), a new siphonophore species from the tropical Atlantic. Bull. mar. Sci., 57: 453-459.

Pugh, P.R. - 1999. Siphonophorae. In: D. Boltvoskoy (ed.), South Atlantic Zooplancton, Vol. 1, pp. 467-513. Backhuys Publishers, Leiden.

Pugh, P.R., in press. - A revision of the family Forskaliidae.

Pugh, P.R. and G.R. Harbison. - 1986. New observations on a rare physonect siphonophore, Lychnagalma utricularia (Claus, 1879). J. mar. biol. Ass. U. K., 66: 695-710.

Pugh, P.R. and G.R. Harbison. - 1987. Three new species of prayine siphonophore (Calycophorae, Prayidae) collected by a submersible, with notes on related species. Bull. mar. Sci., 41: $68-91$. 
Pugh, P.R. and M.J. Youngbluth. - 1988. A new species of Halistemma (Siphonophora: Physonectae: Agalmidae) collected by submersible. J. mar. biol. Ass. U.K., 68: 1-14.

Pulliam, R.H. - 1988. Sources, sinks, and population regulation. The American Naturalist, 132: 652-661.

Purcell, J.E. - 1981a. Feeding ecology of Rhizophysa eysenhardti a siphonophore predator of fish larvae. Limnol. Oceanogr., 26: 424-432.

Purcell, J.E. - 1981b. Selective predation and caloric consumption by the siphonophore Rosacea cymbiformis. Mar. Biol., 63: 283294.

Purcell, J.E. - 1982. Feeding and growth of the siphonophore Muggiaea atlantica Cunningham 1892. J. exp. mar. Biol. Ecol., 62: $39-54$

Purcell, J.E.- 1984. The functions of the nematocysts in prey capture by epipelagic siphonophores (Coelenterata, Hydrozoa). Biol. Bull., 166: 310-327.

Purcell, J.E. and P. Kremer. - 1983. Feeding and metabolism of the siphonophore Sphaeronectes gracilis. J. Plank. Res., 5: 95-106.

Purcell, J.E. and C.E. Mills. - 1988. The correlation between nematocyst types and diets in pelagic Hydrozoa. In: D.A. Hessinger and H. Lenhoff (eds.), The Biology of Nematocysts: 463-485, Academic Press Inc., New York.

Quoy, J.R.C. and J.P. Gaimard. - 1827. Observations zoologiques faites à bord de l'Astrolabe, en mai 1826, dans le détroit de Gibraltar. Annls Sci. nat., 10: 1-21, 172-193, 225-239.

Quoy, J.R.C. and J.P. Gaimard. - 1833. Voyage de découvertes de l'Astrolabe pendant les années 1826, 1827, 1828-1829 sous le commandement de M.J. Dumont-D'Urville. Zoologie, 4: 1-390.

Rahat, M. and R.D. Campbell. - 1974. Three forms of the tentacled and non-tentacled fresh-water coelenterate polyp genera Craspedacusta and Calpasoma. Trans. Am. microsc. Soc., 93: 235-241.

Raikova, E.V. - 1973. Life cycle and systematic position of Polypodium hydriforme Ussov (Coelenterata), a Cnidarian parasite of the eggs of Acipensiridae. In: T. Tokioka and s. Nishimura (eds.), Recent trends in research in coelenterate biology. The Proceedeings of the second international symposium on Cnidaria. Publ. Seto mar. biol. Lab., 20: 165-173.

Raikova, E.V. - 1980. Morphology, ultrastructure and development of the parasitic larva and its surrounding trophamnion of Polypodium hydriforme Ussov (Coelenterata). Cell Tissue Res., 206: 487-500.

Raikova, E.V - 1988. On the systematic position of Polypodium hydriforme Ussov, 1885 (Cnidaria). In: V.M. Koltum and S.D. Stepanjants (eds.), Porifera and Cnidaria. Modern and perspective investigations, pp. 116-122. Akad. Nauk, SSSR

Raikova, E.V. - 1994. Life cycle, cytology, and morphology of Polypodium hydriforme, a coelenterate parasite of the eggs of acipenseriform fishes. J. Parasit., 80: 1-22.

Ralph, P.M.- 1958. New Zealand thecate hydroids. Part II.- Families Lafoeidae, Lineolariidae, Haleciidae and Syntheciidae. Trans. R. Soc. N.Z., 85: 301-356.

Ralph, P.M. - 1959. The status and affinities of the Anthomedusan Paragotoea bathybia Kramp. Proc. Zool. Soc. Lond., 133: 171177.

Ralph, P.M. - 1961. New Zealand thecate hydroids. Part IV.- The family Plumulariidae. Trans. R. Soc. N.Z., Zool., 1: 19-74.

Ramil Blanco, F.J. - 1988. Hidrozoos de Galicia. Ph.D. Thesis, Univ. of Santiago de Compostela.

Ramil, F.J. and A. Iglesias. - 1988a. La familia Haleciidae (Cnidaria, Hydrozoa) en las costas de Galicia. Thalassas, 6: 71-78.

Ramil, F.J. and A. Iglesias. - 1988b. Sobre la presencia de Opercularella panicula (Sars, 1873) (Cnidaria, Hydrozoa) en las costas de la peninsula Ibérica. Thalassas, 6: 79-82.

Ramil, F.J., J. Parapar and W. Vervoort. - 1992. The genus Sertularella Gray, 1848 (Cnidaria: Hydrozoa) along the coasts of Galicia (Spain). Zool. Meded., Leiden, 66: 493-524.

Ramil, F.J. and W. Vervoort. - 1992a. Report on the Hydroida collected by the "BALGIM" expedition in and around the Strait of Gibraltar. Zool. Verh., Leiden, 277: 3-262.

Ramil, F.J. and W. Vervoort. - 1992b. Some considerations concerning the genus Cladocarpus (Cnidaria: Hydrozoa). In: J. Bouillon, F. Boero, F. Cicogna, J.-M. Gili and R.G. Hughes (eds.), Aspects of hydrozoan biology. Sci. Mar., 56: 171-176.

Ramil, F.J. and W. Vervoort. - 1992c. Pseudoplumaria gen. nov. a new Atlantic genus of the family Plumulariidae (Cnidaria: Hydrozoa). Zool. Meded., Leiden, 66: 485-492.
Ramil, F.J. and W. Vervoort and J.A. Ansín. - 1998. Report on the Haleciidae and Plumularioidea (Cnidaria, Hydrozoa) collected by the French SEAMOUNT 1 Expedition. Zool. Verh., Leiden, 322: 1-42.

Ranson, G. - 1936. Méduses provenant des campagnes du Prince Albert I de Monaco. Rés. Camp. scient. Albert I de Monaco, 92: $1-245$.

Rees, J.T. - 1978. Laboratory and field studies on Eutonina indicans (Coelenterata, Hydrozoa), a common Leptomedusa of Bodega Bay, California. Wasmann J. Biol., 36: 201-209.

Rees, J.T. - 2000. A pandeid hydrozoan, Amphinema sp., new and probably introduced to central California: life history, morphology, distribution, and systematics. Sci. Mar., 64: 165-172.

Rees, J.T. and L.A. Gershwin. - 2000. Non-indigenous hydromedusae in California's upper San Francisco Estuary: life cycles, distribution, and potential environmental impacts. Sci. Mar., 64: 73-86.

Rees, W.J - 1938. Observations on British and Norwegian hydroids and their medusae. J. mar. biol. Ass. U.K., 23: 1-42.

Rees, W.J. - 1939a. A revision of the genus Campanulina van Beneden, 1847. Ann. Mag. nat. Hist., 113: 433-447.

Rees, W.J. - 1939b. The hydroid of the medusa Dipurena halterata F. J. mar. biol. Ass. U.K., 23: 343-346.

Rees, W.J. - 1941a. Notes on British and Norwegian hydroids and medusae. J. mar. biol. Ass. U.K., 25: 1-7, 129-141.

Rees, W.J. - 1941b. On the life history and developmental stages of the medusa Podocoryne borealis. J. mar. biol. Ass. U.K., 25: 307-316.

Rees, W.J. - 1956a. On the hydroid Merona cornucopiae (Norman). J. mar. biol. Ass. U.K., 35: 499-506.

Rees, W.J. - 1956b. Revision of the hydroid genus Perigonimus. Bull. Br. Mus. nat. Hist., Zool., 3: 337-350.

Rees, W.J. - 1957. Evolutionary trends in the classification of capitate hydroids and medusae. Bull. Br. Mus. nat. Hist., Zool., 4: 455-534.

Rees, W.J. - 1958. The relationship of Moerisia lyonsi Boulenger and the family Moerisiidae, with capitate hydroids. Proc. Zool. Soc. Lond., 130: 537-545.

Rees, W.J. - 1962. Hydroid of the family Cytaeidae L. Agassiz 1862. Bull. Br. Mus. nat. Hist., Zool., 8: 381-400.

Rees, W.J. and M. Rowe. - 1969. Hydroids of the Swedish west coast. Acta Regiae Soc. scient. litt. Gothoburg., Zool., 3: 1-23.

Rees, W.J. and F.S. Russell. - 1937. On rearing the hydroids of certain medusae, with an account of the methods used. J. mar. biol. Ass. U.K., 22: 61-82.

Rees, W.J. and W. Vervoort.- 1987. Hydroids from the John Murray Expedition to the Indian Ocean, with revisory notes on Hydrodendron, Abietinella, Cryptolaria and Zygophylax (Cnidaria: Hydrozoa). Zool. Verh., Leiden, 237: 1-209.

Rees, W.J. and E. White. - 1966. New records and fauna list of hydroids from the Azores. Ann. Mag. nat. Hist., ser. 13, 9: 271-284.

Reisinger, E - 1957. Zur Entwicklungsgeschichte und Entwicklungsmechanik von Craspedacusta (Hydrozoa, Limnotrachylina). Z. Morph. Ökol. Tiere, 45: 656-698.

Remane, A. - 1927. Halammohydra, ein eigenartiges Hydrozoon der Nord- und Ostsee. Z. Morph. Okol. Tiere, 7: 643-677.

Rengarajan, K. - 1973. Siphonophores obtained during the cruises of R.V. Varuna from the west coast of India and the Laccadive Sea. J. mar. biol. Ass. India, 15: 12-51.

Ribera d'Alcalá, M., F. Conversano, F. Corato, P. Licandro, O. Mangoni, D. Marino, M.G. Mazzocchi, M. Modigh, M. Montresor, M. Nardella, V. Saggiorno, D. Sarno, and A. Zingone. 2004. Seasonal patterns in plankton communities in a pluriannual time series at a coastal Mediterranean site (Gulf of Naples): an attempt to discern recurrences and trends. Sci. Mar., 68(Suppl. 1): 65-83.

Riedl, R. - 1959. Die Hydroiden des Golfes von Neapel und ihr Anteil an der Fauna unterseeischen Höhlen. In: Ergebnisse der österreichischen Tyrrhenia-Expedition 1952, Teil xvi. Pubbl. Staz. zool. Napoli, 30 (suppl.): 591-755.

Riedl, R. - 1970. Fauna und Flora der Adria, ed. 2. Verlag Paul Parey, Hamburg and Berlin. 640 pp.

Roca, I. - 1986. Estudio de los cnidarios bentónicos de las aguas costeras de Mallorca. Ph.D. Thesis, Univ de les illes Balears.

Roca, I. - 1987. Hydroids on Posidonia in Majorcan waters. In: J. Bouillon, F. Boero, F. Cicogna and P.F.A. Cornelius (eds.), Modern Trends in the Systematics, Ecology and Evolution of 
Hydroids and Hydromedusae, pp. 299-310. Clarendon Press, Oxford.

Roca, I. - 1989. Hidroideos de fondos de pesca de arrastre de las costas de Mallorca. VI Simp. Bentos Marino, pp. 43-53.

Roosen-Runge, E.C. - 1970. Life cycle of the hydromedusa Phialidium gregarium (A. Agassiz, 1862) in the laboratory. Biol. Bull. mar. biol. Lab. Woods Hole, 139: 203-221.

Rossi, L. - 1961. Idroidi viventi sulle scogliere del promontorio di Portofino (Golfo di Genova). An. Mus. Civ. St. nat. Genova, 72: 68-85.

Rossi, L. - 1971. Guida a cnidari e ctenofori della fauna italiana. Qd. Civ. Staz. Idrob. Milano., 2: 1-101.

Rossi, S., J.-M. Gili and R.G. Hughes. - 2000. The effects of exposure to wave action on the distribution and morphology of the epiphytic hydrozoans Clava multicornis and Dynamena pumila. In: C.E. Mills, F. Boero, A. Migotto and J.-M. Gili (eds.), Trends in Hydrozoan Biology - IV. Sci. Mar., 64: 135-140.

Rottini, L. - 1971. Siphonophori del Mediterraneo Orientale: Mare di Creta e Jonio. Boll. Pesca Piscicol. Idrobiol., 26: 199-208.

Russell, F.S.- 1933 . The seasonal distribution of macroplancton as shown by catches in the 2-meter stramin ring-trawl in off-shore waters of Plymouth. J. mar. biol. Ass. U.K., 19: 73-82.

Russell, F.S. - 1936. On the hydroid of Laodicea undulata. J. mar. biol. Ass. U.K..., 20: 581-588.

Russell, F.S. - 1938. On the development of Muggiaea atlantica Cunningham. J. mar biol. Ass. U.K. 22: 441-446.

Russell, F.S. - 1940. On the nematocysts of hydromedusae III. $J$. mar. biol. Ass. U.K., 24: 515-523.

Russell, F.S. - 1949. On the hydroid of Eutima gracilis (Forbes and Goodsir). J. mar. biol. Ass. U.K., 28: 479-480.

Russell, F.S. - 1953. The medusae of the British Isles. Anthomedusae, Leptomedusae, Limnomedusae, Trachymedusae and Narcomedusae. Cambridge University Press, London. 530 pp.

Russell, F.S. - 1957. On a new medusa, Krampella dubia, n. g., n. sp. J. mar. biol. Ass. U.K., 36: 445-447.

Russell, F.S. - 1963a. Hydromedusae. Families: Dipleurosomatidae, Melicertidae, Laodiceidae. Fiches ident. Zooplancton, 99: 1-4.

Russell, F.S. - 1963b. Hydromedusae. Families: Campanulariidae, Lovenellidae, Phialellidae. Fiches ident. Zooplancton, 101: 1-4.

Russell, F.S. - 1963c. Hydromedusae. Families: Phialuciidae, Eirenidae, Eutimidae. Fiches ident. Zooplancton. 102: 1- 4.

Russell, F.S. - 1970a. The medusae of the British Isles. Pelagic Scyphozoa with a supplement to the first volume on hydromedusae. Cambridge Universiy Press, London. 284 pp.

Russell, F.S. - 1970b. Hydromedusae. Family: Aequoridae. Fiches ident. Zooplancton, 128: 1-4.

Russell, F.S. - 1977. Hydromedusae. Families: Zancleidae, Cladonemidae, Eleutheriidaei. Fiches ident. Zooplancton, 153 $1-4$.

Russell, F.S. and W.J. Rees.- 1936. On rearing the hydroid Zanclea implexa and its medusa Zanclea gemmosa with a review of the genus Zanclea. J. mar. biol. Ass. U.K., 21: 107-129.

Sacchi, C.F.- 1961. L'évolution récente du milieu dans l'étang saumatre dit 'Lago di Patria' (Naples) analysée par sa macrofaune invertébrée. Vie Milieu, 12: 37-65.

Sandifer, P.A. and T.I.J. Smith. - 1979. Experimental aquaculture of the Malaysian prawn, Macrobranchium rosenbergii in South Carolina. In: T.V.R. Pillay and W.A. Dill (eds.), Advances in aquaculture, pp. 306-311. United Nations Food and Agriculture Organization, Rome,

Sars, M. - 1846. Fauna littoralis Norvegicae 1. Christiania.

Sassaman, C. and JT. Rees. - 1978. The life cycle of Corymorpha (= Euphysora) bigelowi (Maas, 1905) and its significance in the systematics of Corymorphid Hydromedusae. Biol. Bull. mar. biol. Lab. Woods Hole, 154: 485-496.

Scemes, E. and J.C. McNamara. - 1991.The ultrastructure of the radial neuromuscular system of the jellyfish Lyriope tetraphylla (Hydrozoa, Trachymedusae): implications in crumpling behavior. Biol. Bull. mar. biol. Lab. Woods Hole, 181: 474-483.

Schierwater, B. and A. Ender. - 2000. Sarsia marii n. sp. (Hydrozoa, Anthomedusae) and the use of 16S rDNA sequences for unpuzzling systematic relationships in Hydrozoa. Sci. Mar., 64: $117-122$.

Schmidt, G.H.- 1983. The hydroid Tubularia larynx causing 'bloom' of the ascidians Ciona intestinalis and Ascidiella aspersa. Mar. Ecol. Progr. Ser. 12: 103-105.

Schmidt, H.-E - 1973. Hydromedusae from the eastern Mediterranean Sea. Israel J. Zool., 22: 151-167.
Schmidt, H.-E. - 1976. Comparison between the Hydroida fauna of the eastern Mediterranean and the Red Sea. In: Symposium on the eastern Mediterranean Sea IBP/PM-UNESCO. Acta Adriat., 18: 259-266.

Schmidt, H.-E. and A. Benovic. - 1977. Notes on the Hydromedusae (Cnidaria) from the Adriatic Sea. J. mar. biol. Ass. U.K., 57: 635-640

Schmidt, H.-E. and A. Benovic. - 1979. Cruises of R/V "Vila Velebita" in the Kvarner region of the Adriatic Sea, XII. Hydromedusae (Cnidaria). Thalassia jugosl., 15: 3-4.

Schoener, T.W. - 1987. The geographical distribution of rarity. Oecologia, 74: 161-173.

Schuchert, P. - 1996. Athecate hydroids and their medusae (Cnidaria: Hydrozoa). New Zeal. Oceanogr. Inst. Mem., 106: 1-159.

Schuchert, P. - 1997. Review of the family Halopterididae (Hydrozoa, Cnidaria). Zool. Verh., Leiden, 309: 1-162.

Schuchert, P. - 2001a. Hydroid of Greenland and Iceland (Cnidaria, Hydrozoa). Meddelelser om Gronland, Bioscience, 53: 1-184.

Schuchert, P. - 2001b. Survey of the family Corynidae (Cnidaria, Hydrozoa). Rev. Suisse Zool., 108: 739-878.

Schuchert, P. - 2003. Klasse Hydrozoa. In: R. Hofrichter, Das Mittelmeer, pp. 534-570. Spektrum Akademischer Verlag, Heidelberg.

Schuchert, P. - 2004. Revision of the European athecate hydroids and their medusae (Hydrozoa, Cnidaria): families Oceanidae and Pachycordylidae. Rev. Suisse Zool., 11: 315-369.

Schuchert, P., in preparation. Catalogue of living Hydrozoa.

Schulz, E. - 1950. Psammohydra nanna, ein neues solitäres Hydrozoon in der westlichen Beltsee. (Studien an Hydrozoa, II). Kieler Meeresforsch., 7: 122-137.

Sears, M. - 1953. Notes on siphonophores. 2. A revision of the Abylinae. Bull. Mus. comp. Zool. Harv., 109: 11-19.

Segonzac, M. and W. Vervoort. - 1995. First record of the genus Candelabrum (Cnidaria, Hydrozoa, Athecata) from the MidAtlantic Ridge: a description of a new species and a review of the genus. Bull. Mus. natn. Hist. Nat., Paris, sér 4, 17: 31-64.

Siddall, M.E., D.S. Martin, D. Bridge, S.S. Desser, and D.K. Cone. -1995 . The demise of a phylum of protists: Phylogeny of Myxozoa and other parasitic cnidaria. J. Parasit., 81: 961-967.

Singla, C.L. - 1975. Statocysts of Hydromedusae. Cell Tissue Res., 158: $391-407$

Smaldon, G and E.W. Lee. - 1979. A synopsis of Methods for the Narcotisation of Marine Invertebrates. Inf. Ser.R. Scot. Mus.(Nat. Hist.), 6: 1-96.

Spanier, E. and B.S. Galil. - 1991. Lessepsian migration: a continuous biogeographical process. Endeavour, 15: 102-106.

Splettstösser, W. - 1929. Beiträge zur Kenntnis der Sertulariiden. Thyroscyphus Allm., Cnidoscyphus nov. gen., Parascyphus Ritchie. Zool. Jb., Syst., 58: 1-134.

Standing, J. - 1976. Fouling community structure: effects of the hydroid Obelia dichotoma on larval recruitment. In: G.O. Mackie (ed.), Coelenterate ecology and behaviour, pp. 155164. Plenum Press, New York.

Steche, O. - 1911. Hydra und die Hydroiden, zugleich eine Einfürhung in die experimentelle Behandlung biologischer Probleme an niederen Tieren. Monographien einheimischer Tiere, 3: $1-162$.

Stechow, E. - 1919. Zur Kenntnis der Hydroidenfauna des Mittelmeeres, Amerikas und anderer Gebiete, nebst Angaben über einige Kirchenpauer'sche Typen von Plumulariden. Zool. Jb., Syst., 42: 1-172.

Stechow, E. - 1920. Neue Ergebnisse auf dem Gebiete der Hydroidenforschung Sb. Ges. Morph. Phys., München, 31: 9-45.

Stechow, E. - 1921a. Neue Genera und Species von Hydrozoen und anderen Evertebraten. Arch. Naturgesch., (A)87: 248-265.

Stechow, E. - 1921b. Ueber Hydroiden der Deutschen TiefseeExpedition, nebst Bemerkungen über einige anderer Formen. Zool. Anz., 53: 223-236.

Stechow, E. - 1923a. Neue Hydroiden der Deutschen Tiefsee-Expedition, nebst Bemerkungen über einige anderer Formen. Zool. Anz., 56: 1-20.

Stechow, E. - 1923b. Die Hydroidenfauna der japanischen Region. J. Coll. Sci. Imperial Univ. Tokyo, 44: 1-23.

Stechow, E. - 1923c. Über Hydroiden der Deutschen Tiefsee-Expedition, nebst Bemerkungen über einige anderer Formen. Zool. Anz., 56: 97-119.

Stechow, E. - 1923d. Zur Kenntis der Hydroidenfauna des Mittelmeeres, Amerikas und anderer Gebiete. II. Teil. Zool. Jb., 
Syst., 47: 29-270.

Stefani, R. - 1959. Sulla variabilità ecologica di un Idrozoo (Campanularia caliculata Hincks). Boll. Zool., 26: 115-120.

Stepan'yants, S.D. - 1979. Gidroidy vod antarktiki i subantarktiki. In: Rezul'taty biologicheskikh issledovanii sovetskikh antarkticheskikh ekspeditsii, 6. Issled. Fauny Morei, 22: 1-99.

Stepan'yants, S.D., O.V. Sheiko and T.O. Napara. - 1990. Fabulosus kurilensis gen. et sp. n. (Hydrozoa, Cnidaria) - Novi gidroidny polip na shel'fe Kuril'skikh ostrovov. Fabulosus kurilensis gen. et sp. n. (Hydrozoa, Cnidaria), a new hydroid polyp of the Kuril Islands shelf. In: S.V. Vasilenko (ed.), Sistematika i ekologiya bespozvonochnykh dal'nevostochnykh more i estuariev. Systematics and ecology of invertebrates of seas and estuaries if the Far East. Trudy zool. Inst. Leningrad, 218: 5-17.

Stepan'yants S.D., O.A. Timoshkin, B.A. Anokhin and T.O. Napara.- 2000. A new species of Pachycordyle (Hydrozoa, Clavidae) from Lake Biwa (Japan), with remarks on this and related Clavid genera. Sci. Mar. 64: 225-236.

Stepan'yants, S.D., A. Svoboda, A.L. Peña Cantero and O. Sheiko. - 1998. Wimveria gen. nov. for Schizotricha divergens Naumov, 1960, from the Commander Islands, with comments on the scope of the family Kirchenpaueriidae (Cnidaria: Hydrozoa). Zool. Verh., Leiden, 323: 221-234.

Stepan'yants, S.D., A. Svoboda and W. Vervoort. - 1997. The problem of bipolarity, with emphasis on the Medusozoa (Cnidaria: Anthozoa excepted). In: J.C. den Hartog (ed.), Proceedings of the 6th international Conference on Coelenterate Biology, pp.455-464. The Leeuwenhorst, The Netherlands.

Stokes, D.R. - 1974. Physiological studies of conduction systems in the colonial hydroid Hydractinia echinata. 1. Polyp specialitation. J. exp. Zool., 190: 1-18.

Sugiura, Y. - 1977. Occurrence of medusae of the genus Ectopleura from Japanese waters. Annotnes zool. Jap., 50: 36-39.

Suppes, V.C. and F.P. Meyer. - 1975. Polypodium sp. (Coelenterata) infection of paddlefish (Polyodon spathula) eggs. J. Parasit., 61: 772-774.

Sutherland, J. and R. Karlson. - 1977. Development and stability of the fouling community at Beaufort, North Carolina. Ecol. Monogr., 47: 425-446

Svoboda, A. - 1979. Beitrag zur Okologie, Biometrie und Systematik der Mediterranen Aglaophenia Arten (Hydroidea). Zool. Verh., Leiden, 167: 1-114.

Svoboda, A and P.F.S. Cornelius. - 1991. The European and Mediterranean species of Aglaophenia (Cnidaria: Hydrozoa). Zool. Verh., Leiden, 274: 1-72.

Swedmark, B. - 1956a. Etude de la microfaune des sables de Marseille. Archs Zool. exp. gén., 93, notes et revue 2: 70-95.

Swedmark, B. - 1956b. Variation morphologique des différentes populations régionales d'Halammohydra. In: Colloque international de biologie marine. Station Biologique de Roscoff. Année biol., 33: 183-189.

Swedmark, B. - 1964. The interstitial fauna of marine sand. Biol. Rev., 39: 1-42

Swedmark, B. and G. Teissier. - 1958a. Halammohydra et Otohydra, Hydrozoaires de la microfaune des sables et l'ordre des Actinulides. Int. Congr. Zool., Sect. IV, 15: 1-3.

Swedmark, B. and G. Teissier. - 1958b. Halammohydra vermiformis n. sp. et famille des Halammohydridae Remane. Bull. Soc. zool. Fr., 82: 38-49.

Swedmark, B. and G. Teissier. - 1958c. Otohydra vagans n. g., n. sp., Hydrozoaires des sables, apparenté aux Halammohydridées. C.r. hebd. séanc. Acad. Sci., Paris, 247: 238-240.

Swedmark, B. and G. Teissier. - 1958d. Armorhydra janoviczi n. g. n. sp. Hydroméduse benthique. C.r. hebd. séanc. Acad. Sci., Paris, 247: 133

Swedmark, B and G. Teissier - 1959. Halammohydra et Otohydra, Hydrozoaires de la microfaune des sables et l'ordre des Actinulides. Proc. XV. int. Congr. Zool.: 330-331.

Swedmark, B. and G. Teissier. - 1966. The Actinula and their evolution significance. In: W.J. Rees (ed.), The Cnidaria and their evolution. Symp. zool. Soc. Lond., 16: 119-133.

Tardent, P. - 1978. Coelenterata, Cnidaria. In: F. Siedel. (ed.), Morphogenese der Tiere, Lief. 1: A-I: 71-415. Gustav Fisher, Stuttgart, New york.

Tardent, P. - 1985. The differentiation of germ cells in Cnidaria. In: A. Monroy and H. Halvorson (eds.), The origin and evolution of sex, pp. 163-197. Alan R. Liss, Inc., New York.
Teissier, G. - 1922. Sur le développement et la valeur morphologique du gonophore de Dynamena pumila L. Bull. Soc. zool. Fr., 47: 259-263.

Teissier, G. - 1965. Inventaire de la faune marine de Roscoff. Cnidaires-Cténaires. Trav. Stn Biol. Roscoff., 16:1-53.

Templado, J., A.M. García Carrascosa, L. Baratech, R. Capaccion, A. Juan, A. López Ibor, R. Silvestre and C. Massó. - 1986. Estudio preliminar de la fauna asociada a los fondos coralígenos del mar de Alborán (SE de España). Boln Inst. esp. Oceanogr., 3: 93-104.

Thiel, H. - 1988. Cnidaria. In: R.P. Higgins and H. Thiel (eds.), Introduction to the study of meifauna, pp. 266-272. Smithson. Instn Press, Washington, D.C.

Thiel, M.E. - 1935. Zur Kenntis der Hydromedusenfauna des Schwarzen Meeres. Zool. Anz., 111: 161-174.

Thiel, M.E. - 1936. Systematische Studien an den Trachylinae der Meteorexpedition, zugleich ein Beitrag zu einer Revision der Trachylinae. Zool. Jb., Syst., 69: 1-92.

Thomas, M.B. and N.C. Edwards. - 1991. Cnidaria Hydrozoa. In: F.W. Harrison and J.A. Westfall (eds.), Microscopic anatomy of invertebrates, Vol. 2, pp. 91-184. J. Wiley \& Sons.

Thomas, M.B., N.C. Edwards and R.P. Higgins. - 1995. Cryptohydra thieli n. gen., n. sp.: a meiofaunal marine hydroid (Hydroida, Athecata, Capitata). Invertebr. Biol., 114: 107-118.

Torrey H.B. - 1909. The Hydroida of the Pacific coast of North America. Univ. Calif. Publs. Zool., 6: 11-31.

Torrey H.B. - 1909. The Leptomedusae of the San Diego region. Univ. Calif. Publs. Zool., 6: 11-31.

Totton, A.K. - 1930. Coelenterata. Part V.- Hydroida. Nat. Hist. Rep. Br. Antarct. ('Terra Nova') Exped., 1910, Zool., 5: 131-252.

Totton, A.K. - 1932. Siphonophora. Scientific Reports. Great Barrier Reef Expedition, 1928-29, 4: 317-374.

Totton, A.K. - 1941. New species of the siphonophores genus Lensia. Ann. Mag. Hist. Lond., 8: 145-168.

Totton, A.K. - 1954. Siphonophora of the Indian Ocean together with systematic and biological notes on related specimens from other oceans. Discovery Rep., 27: 11-62.

Totton, A.K. - 1956. Development and metamorphosis of the larva of Agalma elegans (Sars) (Siphonophora Physonectae). Papers Mar. Biol. and Oceanogr., Deep-Sea Res., 3 (Suppl.): 239-241.

Totton, A.K. - 1960. Studies on Physalia physalis (L.). 1. Natural history and morphology. Discovery Rep., 30: 301-368.

Totton, A.K. - 1965. A synopsis of the Siphonophora. British Museum (Natural History), London. 230 pp.

Trégouboff, G. - 1957. Hydroméduses. In G. Trégouboff and M. Rose, Manuel de Planctonologie méditerranéenne, Tome 1, pp. 265-307. C.N.R.S., Paris

Uchida, T. - 1927a. Studies on Japanese Hydromedusae. I. Anthomedusae. J. Fac. Sci. Tokyo Univ. (Zool.), 1: 145-241.

Uchida, T. - 1928. Studies on Japanese Hydromedusae. 2. Trachomedusae and Narcomedusae. Jap. J. Zool., 2: 73-97.

Uchida, T. - 1929. Studies on Japanese Hydromedusae. 3. Olindiadae. Annotnes zoo. jap., 12: 351-373.

Uchida, T. - 1933. Medusa from the vicinity of Kamchatka. J. Fac. Sci. Hokkaido Imp. Univ., 2: 125-133.

Uchida, T. and Z. Nagao. - 1959. The life history of Japanese brackish-warter hydroid, Ostroumovia horii. J. Fac. Sci. Hokkaido Univ., 14: 265-281.

Uchida, T. and Y. Sugiura. - 1975. On the seasonal change of the Leptomedusa, Eucheilota paradoxica. Proc. Jap. Acad. Sci., 51: 330-335.

Uchida, T. and Y. Sugiura. - 1977. On medusa-budding in the Anthomedusa, Podocoryne minima (Trinci). Publ. Seto mar. biol. Lab., 24: 52-57.

Van Beneden, P.J. - 1847. Un mot sur le mode de reproduction des animaux inférieurs. Bull. Acad. r. Belg., 14: 448-462.

Van Beneden, P.J. - 1867. Recherches sur la faune littorale de Belgique. (Polypes). Mém. Acad. r. Belg., 36: 1-207.

Valkanov, A. - 1935. Notizen über die Brackwässer Bulgariens.I. Annls Univ. Sofia, Fac. Phys. Mat., 31: 249-303.

Valkanov, A. - 1938. Übersicht der Hydrozoenfamilie Moerisiidae. Jb. Univ. Sofia, Phys. Mat. Fak., Naturwiss., 34: 251-320.

Valkanov, A. - 1953. Revision der Hydrozoenfamilie Moerisiidae. Trudy morsk. biol. Sta. Stalin, 18: 33-47.

Valkanov, A. - 1965. Microhydrula pontica n. g. n., sp. Ein neuer solitärer Vertreter der Hydrozoen. Zool. Anz., 174: 134-147.

Van Der Spoel, S. and J. Bleeker. - 1988. Medusa from the Banda 
Sea and Aru Sea plankton, collected during the Snellius II Expeditions, 1984-1985. Indo-Malayan Zool., 5: 161-262.

Van Impe, E. - 1992. A method for the transportation, long term preservation and storage of gelatinous planktonic organisms. Sci. Mar., 56: 237-238.

Van Soest, R.W.N. - 1973. Planktonic coelenterates collected in the North Atlantic Ocean. Bijdr. Dierk., 43: 119-125.

Vanhoeffen, E. - 1913. Die Craspedoten Medusen der "Vettor Pisani”. Zoologica, Stuttg., 26: 1-34.

Vannucci, M. - 1956. Biological notes and description of a new species of Dipurena (Hydrozoa, Corynidae). Proc. Zool. Soc. Lond., 127: 479-487.

Vannucci, M. - 1957. On Brazilian hydromedusae and their distribution in relation to different water masses. Bolm Inst. oceanogr. Univ. S. Paulo, 8: 23-109.

Vannucci, M.- 1966. Total net plankton volume and hydromedusae from fixed stations in the Gulf of Naples. In: H. Barnes (ed.), Some contemporary studies in marine Sciences, pp. 675-697. Allen and Unwin Ltd., London.

Vannucci, M. and D. Navas.- 1973a. Distribution of hydromedusae in the Indian ocean. In: B. Zeitzschel, (ed.), The Biology of the Indian Ocean. Ecol. Stud., 3: 273 -281.

Vannucci, M. and D. Navas. - 1973b. On the ecology of Indian Ocean Hydromedusae. I.O.B.C. Handbook, 5: 1-54

Vannucci, M. and L.C. Ribeiro. - 1955. O ciclo reprodutivo de Clytia cylindrica L. Agass., 1862 (Hydrozoa; Campanulariidae) Dusenia 6: 69-80.

Vannucci, M. and W.J. Rees. - 1961. A revision of the genus Bougainvillia (Anthomedusae). Bol. Inst. oceanogr. S. Paulo, 11: $57-100$.

Vannucci, M. and M.G.B. Soares Moreira. - 1966. Some hydromedusae from the Gulf of Naples with diagnosis of a new genus and species. Pubbl. Staz. zool. Napoli, 35: 7-12.

Vannucci, M. and M. Yamada. - 1959. The life cycle of Merga tergestina (Anthomedusae, Pandeidae). Pubbl. Staz. zool. Napoli, 31: 320-333.

Vargas-Hernández, J.M and E. Ochoa-Figueroa. - 1991. Un nuevo género y diagnosis de una nueva especie para la familia Tubulariidae (Hidrozoa: Anthomedusae) en el Pacifico Mexicano. Brenesia, 33: 75-80.

Vervoort, W. - 1946. Hydrozoa (C 1) A. Hydropolypen. Fauna Nederl., 14: 1-336.

Vervoort, W. - 1959. The Hydroida of the tropical west coast of Africa. Atlantide Report. Scient. Res. Danish Exped. coasts trop. W. Afr., 1945-1946, 5: 211-325.

Vervoort, W. - 1966a. Bathyal and abyssal hydroids. Galathea Report, Scient. Res. Danish Deep-Sea Exped., 1950-1952, 8: 97-174.

Vervoort, W. - 1966b. Skeletal structure in the Solanderiidae and its bearing on hydroid classification. In: The Cnidaria and their evolution. Symp. Zool. Soc. London. 16: 373-396.

Vervoort, W. - 1967. The Hydroida and Chondrophora of the Israel South Red Sea Expedition, 1962. In: Israel South Red Sea Expedition, 1962, Reports, No. 25. Bull. Sea Fish. Res. Stn Israel, 43: 18-54.

Vervoort, W. - 1968. Report on a collection of Hydroida from the Caribbean region, including an annotated checklist of Caribbean hydroids. Zool. Verh., Leiden, 92: 1-124.

Vervoort, W. - 1972. Hydroid from the Theta, Vema and Yelcho cruises of the Lamont-Doherty geological observatory. Zool. Verh., Leiden, 120: 1-247.

Vervoort, W - 1987. Evaluation of taxonomic characters in the Hydroida, particularly in the Thecata (=Leptomedusae). In: J. Bouillon, F. Boero, F. Cicogna, F and P.F.S.Cornelius (eds.), Modern trends in the Systematics, Ecology and Evolution of Hydroid and Hydromedusae, pp. 83-103. Clarendon Press, Oxford.

Vervoort, W. - 1993a. Report on hydroids (Hydrozoa Cnidaria) in the collection of the Zoological Museum, University of TelAviv, Israel. Zool. Meded., Leiden, 67: 537-565.

Vervoort, W. - 1993b. Cnidaria, Hydrozoa, Hydroida: Hydroid from the western Pacific (Philippines, Indonesia and New Caledonia) I: Sertulariidae (Part 1). In: Résultats des Campagnes MUSORSTOM, 11. Mém. Mus. natn. Hist. nat. Paris, (Zool.), 158: 89-298.

Vervoort, W. - 1995. Bibliography of Leptolida (non-Siphonophoran Hydrozoa, Cnidaria). Works published after 1910. Zool. Verh., Leiden, 301: 1-432.
Vervoort, W. and J.E. Watson. - 2003. The marine fauna of New Zealand: Leptothecata (Cnidaria: Hydrozoa) (Thecate hydroids). NIWA Biodiv. Mem., 119: 1-538.

Vetter, E.W. and P.K. Dayton. - 1998. Macrofaunal communities within and adjacent to a detritus-rich submarine canyon system. Deep-Sea Res.,II 45: 25-54.

Vogt, C. - 1852. Ueber die Siphonophoren. Z. Wiss. Zool., 3: 522525.

Von Lendenfeld, R. - 1884. Die australischen Plumulariden. Zool. Anz., 7: 548-550.

Von Lendenfeld, R. - 1885. The Australian Hydromedusae. Proc. Linn. Soc. N.S.W., 9: 206-241; 345-353; 401-420; 467-492; 581-634.

Von Salvini-Plawen, L.- 1966. Zur Kenntnis der Cnidaria des nordadriatischen Mesopsammon. In: VI. Meeresbiologisches Symposium. Veröff. Inst. Meeresf. Bremerh., 2: 165-186.

Von Salvini-Plawen, L. - 1987. Mesopsammic Cnidaria from Plymouth. J. mar. biol. Ass. U.K., 67: 623-637.

Von Schenck, D.A. - 1965. Aglaophenia harpago, a new species of the Plumulariidae (Hydroidea). Pubbl. Staz. zool. Napoli, 34: 211-215.

Wang Wenqiao, Xu Zhenzu. - 1990. Nematocysts of some medusae from Xiamen Harbour. J. Oceanogr. Taiwan Strait., 9: 161165.

Watson, J.E. - 1973. Hydroids. In: Pearson Island Expedition, 1969-9. Trans. Roy. Soc. S. Aust., 97: 153-200.

Watson, J.E. - 1978. New species and new records of Australian athecate hydroids. Proc. R. Soc. Vict., 90: 301-314.

Watson, J.E. - 1985. The genus Eudendrium (Hydrozoa: Hydroida) from Australia. Proc. R. Soc. Vict., 97: 179-221.

Watson, J.E. - 1993. Two new species of Haleciidae (Hydrozoa: Hydroida) from Southern Australia. Proc. R. Soc. Vict., 105: 81-84.

Watson, J.E. - 1994. Shallow water hydroids from eastern Bass Strait. Vict. Nat., 111: 65-70.

Watson, J.E. - 1997. The hydroid fauna of the Houtman Abrolhos Islands, western Australia. In: F.E. Wells, (ed.), The Marine Flora and Fauna of the Houtman Abrolhos Islands, western Australia, pp. 503-546. Western Australian Museum, Perth.

Watson, J.E - 1998. Troglodytes of a muddy bottom: the hydroid fauna of holes in the seabed. Zool. Verh., Leiden, 323: 247-256.

Watson, J.E. - 2000. Hydroid (Hydrozoa: Leptothecatae) from the Beagle Gulf and Darwin Harbour, northern Australia. The Beagle, Records of the Museums and Art Galleries of the Northern Territory, 16: 1-82.

Wedler, E. and R. Larson. - 1986. Athecate hydroids from Puerto Rico and the Virgin Islands. Stud. Neotrop. Fauna Environ., 21: 69-101

Weill, R. - 1936. Existence de larves polypoïdes dans le cycle de la Trachyméduse Olindias phosphorica Della Chiaje. C.r. hebd. séanc. Acad. Sci., Paris, 203: 1018-1020.

Werner, B. - 1950a. Die Meduse Gonionemus murbachi Mayer im Sylter Wattenmeer. Zool. Jb., Syst., 78: 471-505.

Werner, B.- 1950b. Weitere Beobachtungen über das Auftreten der Meduse Gonionemus murbachi Mayer im Sylter Wattenmeer und ihre Entwicklungsgeschichte. Verh. dt. Zool. Ges., 1949: 138-151

Werner, B.- 1956. Ueber die entwicklungsphysiologische Bedeutung des Fortpflanzungswechsels der Anthomeduse Rathkea octopunctata M. Sars. Zool. Anz., 156: 159-177.

Werner, B.- 1958. Die Verbreitung und das jahreszeitliche Auftreten der Anthomeduse Rathkea octopunctata M. Sars, sowie die Temperaturabhängigkeit ihrer Entwicklung und Fortpflanzung. Helgoländer wiss. Meeresunters., 6: 138-170.

Werner, B. - 1959. Dauerstadien bei marinen Hydrozoen. Naturwissenschaften, 46: 238

Werner, B. - 1968a. Polypengeneration und Entwicklungsgeschichte von Eucheilota maculata (Thecata-Leptomedusae). Mit einem Beitrag zur Metodik der Kultur mariner Hydroiden. Helgoländer wiss. Meeresunters., 18: 136-168.

Werner, B. - 1968b. Polypengeneration und Entwicklung von Eutonina indicans (Thecata-Leptomedusae). Helgoländer wiss. Meeresunters., 18: 384-403.

Werner, B. - 1984: Stamm Cnidaria, Nesseltiere. In: V.A. Kaestner (ed.), Lehrbuch der speziellen Zoologie, 1(2, Cnidaria, Ctenophora, Mesozoa, Plathelminthes, Nemertini, Entoprocta, Nemathelminthes, Priapulida), pp. 1-305. G. Fischer, Stuttgart. Westblad, E. - 1937. Boreohydra simplex n. gen., n. sp., ein Solitär- 
polyp von der norwegischen Küste. Ark. Zool., 29: 1-6.

Will, J.G. - 1844. Hora Tergestinae der im Herbste 1843 bei Trieste beobachteten Akalephen, 1-86. Leipzig.

Winkler, J.Th - 1982. The hydromedusae of the Amsterdam Mid North Atlantic Plankton Expeditions 1980 (Coelenterata, Hydrozoa). Beaufortia, 32: 27-56.

Xu Zhen-Zu and Huang Jia-Qi. - 2003. On new species and records of Euphysora in Taiwan strait and its ajacent waters. $J$. Oceanogr. Taiwan Strait, 22: 136-144.

Xu Zhen-Zu, Huang Jia-Qi and Xu Chen. - 1991. On new species and record of hydromedusae in the upwelling region off the Minnan-Taiwan Bank fishing ground, China. Minnan-Taiwan Bank Fishing Ground. Upwelling Ecosystem study, pp. 469486. Science Press, Beijing.

Yamada, M. - 1961. Polyp and medusa of Podocoryne hartlaubi Neppi and Stiasny (Hydrozoa) from the Gulf of Naples. Pubbls Staz. zool. Napoli, 32: 134-143.

Yamada, M. and K. Konno. - 1973. Polyp and medusa of the hydroid Sphaerocoryne multitentaculata (Warren) from Japan. In: T. Tokioka and S. Nishimura (eds.), Recent trends in research in coelenterate biology. Proceedings second international symposium on Cnidaria. Publs Seto mar. biol. Lab., 20: 103-109.

Young, C.M. and F.S. Chia. - 1987. Abundance and distribution of pelagic larvae as influenced by predation, behavior, and hydrographic factors. In: A.C. Giere et al. (eds.), pp. 385-463. Reproduction of marine invertebrates. Vol. IX, General aspects: seeking unity in diversity. Blackwell Scientific Publications, Oxford.
Youngbluth, M.J. - 1984. Water column ecology: In situ observations of marine zooplankton from a manned submersible. In: N.C. Fleming (ed.), Divers, Submersibles and Marine Science, pp. 45-57. Occasional Papers in Biology, No. 9, University of Newfoundland

Zaitsev, Y. and B. Öztürk. - 2001. Exotic species in the Aegean, Marmara, Black, Azov and Caspian Seas. 1-265.

Zamponi, M.O. and G.N. Genzano. - 1988. Nuevas ediciones a la medusofauna de la región subantartica. II. Trachymedusae (Coelenterata: Hydrozoa). Neotrópica, 34: 33-39.

Zamponi, M.O. and G.N. Genzano. - 1990a. The use of nematocyst for identification of the common medusa-stage of the Genus Obelia Peron and Lesueur, 1810 (Leptomedusae, Campanulariidae) from the subantarctic region. Plankton Newsletter, 13: 21-23.

Zamponi, M.O. and G.N. Genzano. - 1990b. Ciclos biologicos de celenterados litorales. IV. La validez de Obelia longissima (Pallas, 1766) (Leptomedusae: Campanulariidae). Spheniscus, 8: $1-7$.

Zhang Jinbiao. - 1977. Studies on the Hydromedusae and Ctenophores from the coastal waters of Jiangsu and Zhejuang provinces. Marine Science Technol. (= Oceanol. Technol. sin.). 7: 95-107.

Zhang Jinbiao. - 1979. A preliminary analysis on the Hydromedusae fauna of the China Sea area. Acta oceanol. sin., 1: 127137.

Zibrowius, H. and S.D. Cairns. - 1992. Revision of the northeast Atlantic and Mediterranean Stylasteridae (Cnidaria: Hydrozoa). Mém. Mus natn. Hist. nat. Zool., 153: 9-135. 

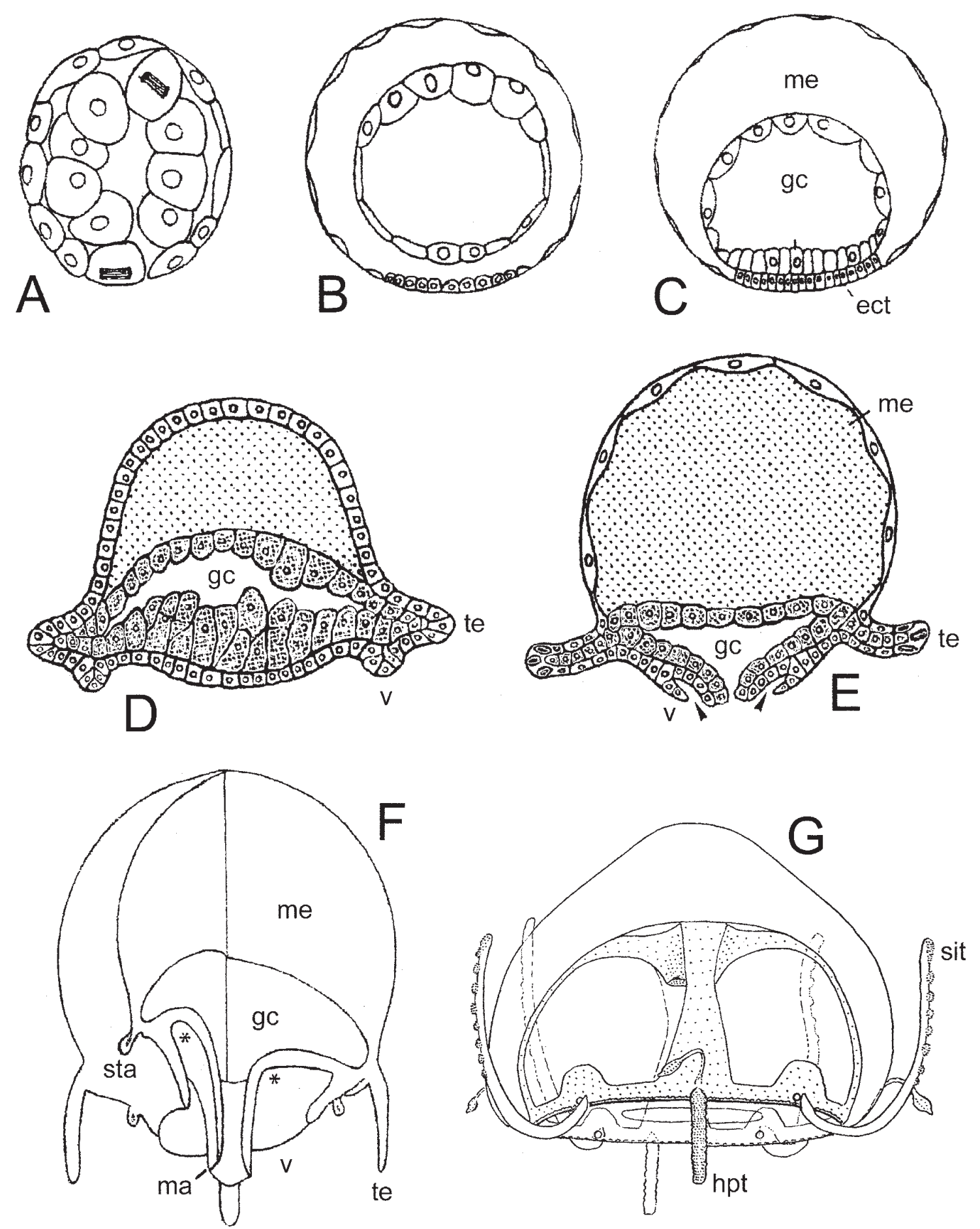

FIG. 1. - Organogenesis of the subumbrellar cavity in Automedusae. A to G: development of Liriope tetraphilla, Trachymedusae. A and B: planula; C: planula developing the gastric cavity and the oral ectodermal thickening; D: oral thickening forming the tentacles and the velum; E: differentiation of the manubrium and the subumbrellar cavity, increasing development of the mesoglea; F: fully developed juvenile medusae, left side: an interradial section; right side: a perradial section; G: young specimen of Liriope e. (A to C, E after Metschnikoff, 1886a; D after Maas, 1905; F redrawn from Delage and Herouard, 1901; G after Russell, 1953). Arrows and asterisk: subumbrellar cavity; ect: ectoblastic thickening; gc: gastric cavity; hpt: secondary hollow perradial marginal tentacle; ma: manubrium; me: mesoglea; sta: statocyst; sit: solid interradial marginal tentacle; te: marginal tentacle of young medusae; v: velum. 

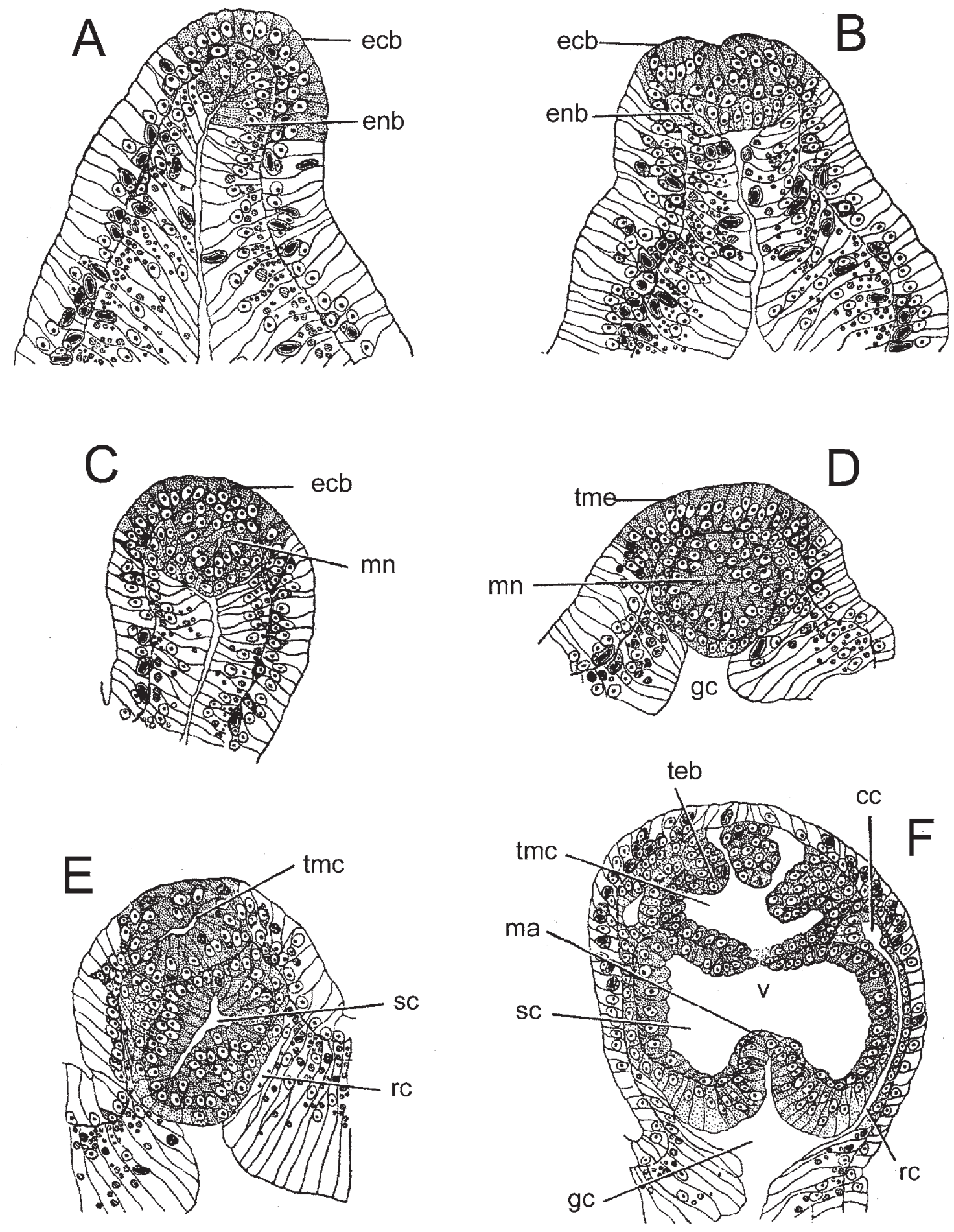

FIG. 2. - Organogenesis of the subumbrellar cavity in Hydroidomedusa (Limnocnida tanganyicae). A: diferentiation of the ectoderm and endoderm in ectoblast and endoblast at the beginning the budding processes; B: ectoblastic proliferation and formation of the endoblastic plate; C: origin of the medusary nodule and the endodermal cup; D: growth of the medusary nodule, formation of the ectodermal tentacular mass and origin of the radial canal from the endodermal cup; E. appearance of the subumbrellar cavity within the medusary nodule, formation of the tentacular cavity within the ectodermal tentacular mass and of the radial canals; F: almost fully grown medusae, showing the subumbrellar cavity, the manubrium, the radial canals, the circular canal, the gastric cavity, the velum, and the tentacles (from Bouillon, 1957). cc: marginal or circular canal; ecb: ectoblast; enb: endoblast; gc: gastric cavity of the budding hydroid or medusae; ma: manubrium; $\mathrm{mn}$ : medusary nodule; rc: radial canal; sc: subumbrellar cavity; teb: tentacular bud; tmc: cavity of the tentacular mass; tme: ectoderm of the future tentacular mass; v: velum. 

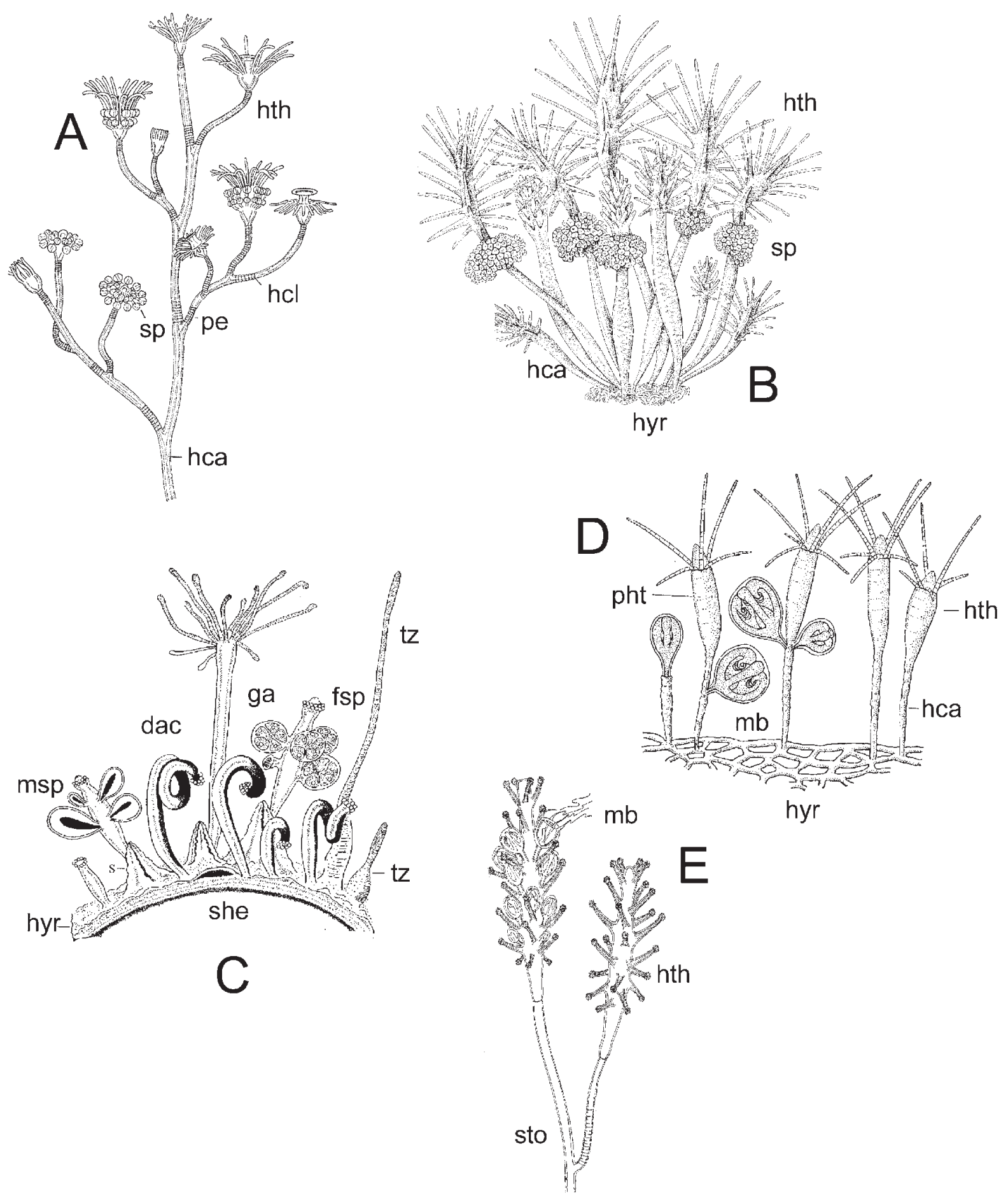

FIG. 3. - Morphology of hydroids. Anthomedusae. A to C: paedomorphic life cycle reduced to hydroid stage and fixed sporosac: A: Eudendrium ramosum; B: Clava multicornis; C: Hydractinia echinata; D and E: life cycle comprising a medusae stage: D: Neoturris pileata; E: Coryne eximia (A and C after Allman, 1871; B after Edwards, 1965; D after Stokes, 1974; E after Russell, 1953). dac: dactylozooid; fsp: female sporosac; ga: gastrozooid; hca: hydrocaulus; hcl: hydrocladium; ht: hydrothecae; hth: hydranth; hyr: hydrorhiza; mb: medusa bud; msp: male sporosac; pe: pedicel; pht: pseudohydrotheca; she: shell; sp: fixed sporosac; tz: tentaculozooid. 


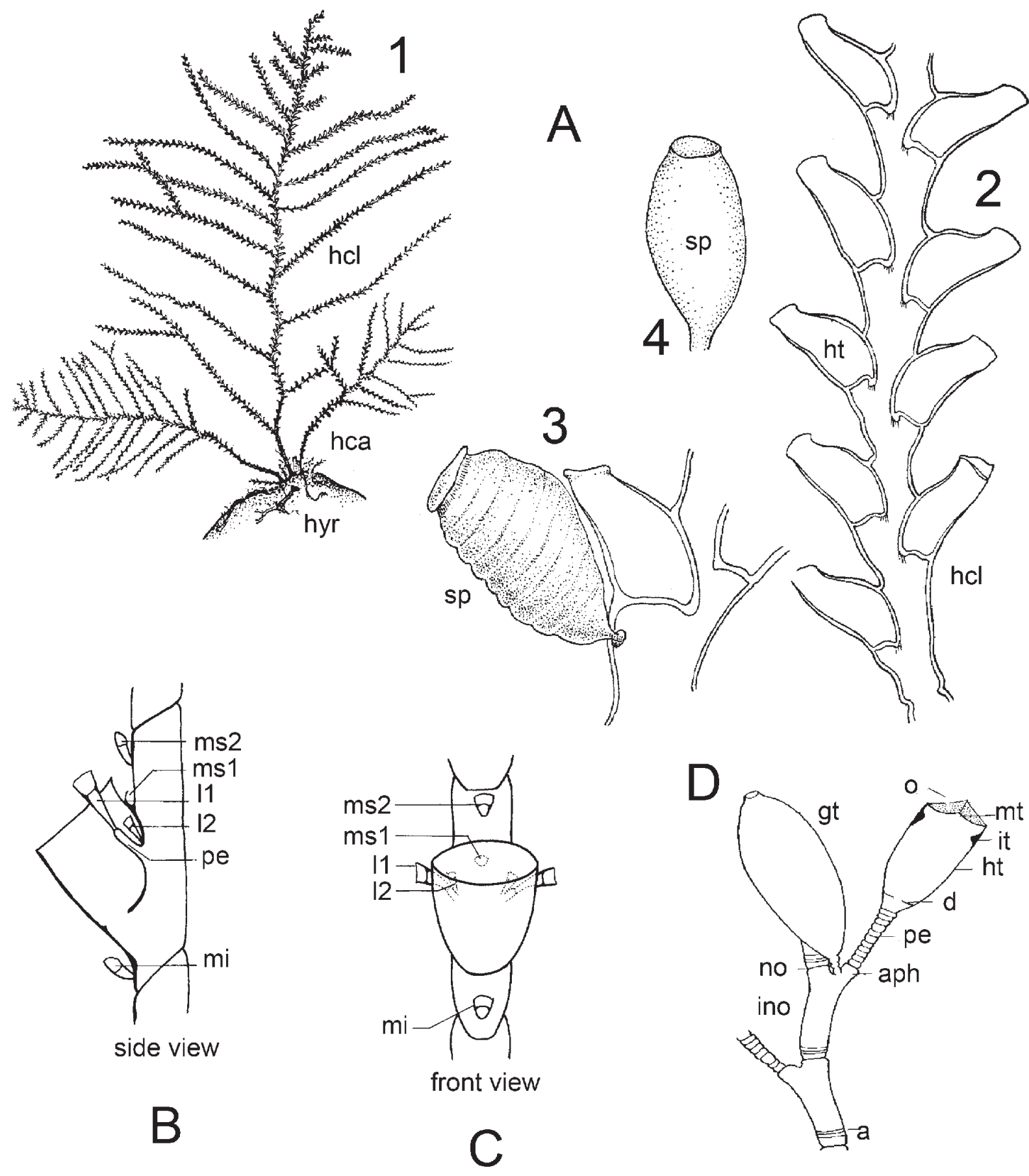

FIG. 4. - Morphology of the hydroids. Leptomedusae. Paedomorphic life cycle reduced to hydroid stage and fixed sporosac. A: Sertulariidae (Abietinaria abietina): 1: whole colony; 2: part of hydrocladium; 3: detail of hydrotheca and gonotheca; 4: gonotheca. B and C: Plumulariidae: position of nematothecae; B: side view; C: front view. D: part of skeleton of a pedicellate and symmetrical hydrothecae (A after Leloup, 1952; B, C and D after Millard, 1975). a: annulations; aph: apophysis; d: diaphragm; gt: gonothecae; hca: hydrocaulus; hcl: hydrocladium; ht: hydrotheca; hyr: hydrorhiza; ino: internode; it: internal tooth; 11: first lateral nematothecae; 12: second lateral nematothecae; mi: median inferior nematothecae; ms1: first median superior nematothecae; ms2: second median superior nematothecae; mt: marginal tooth; no: node; o: operculum; pe: pedicel; sp: fixed sporosac. 


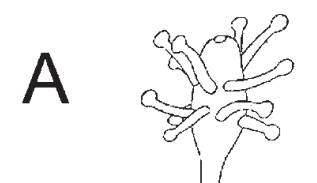

17

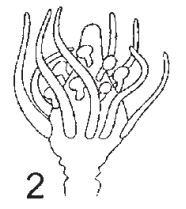

$2\}$

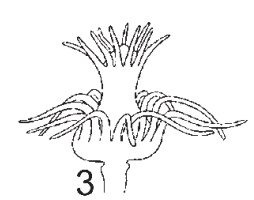

$3\}$

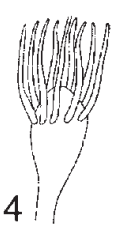

$4: 1$
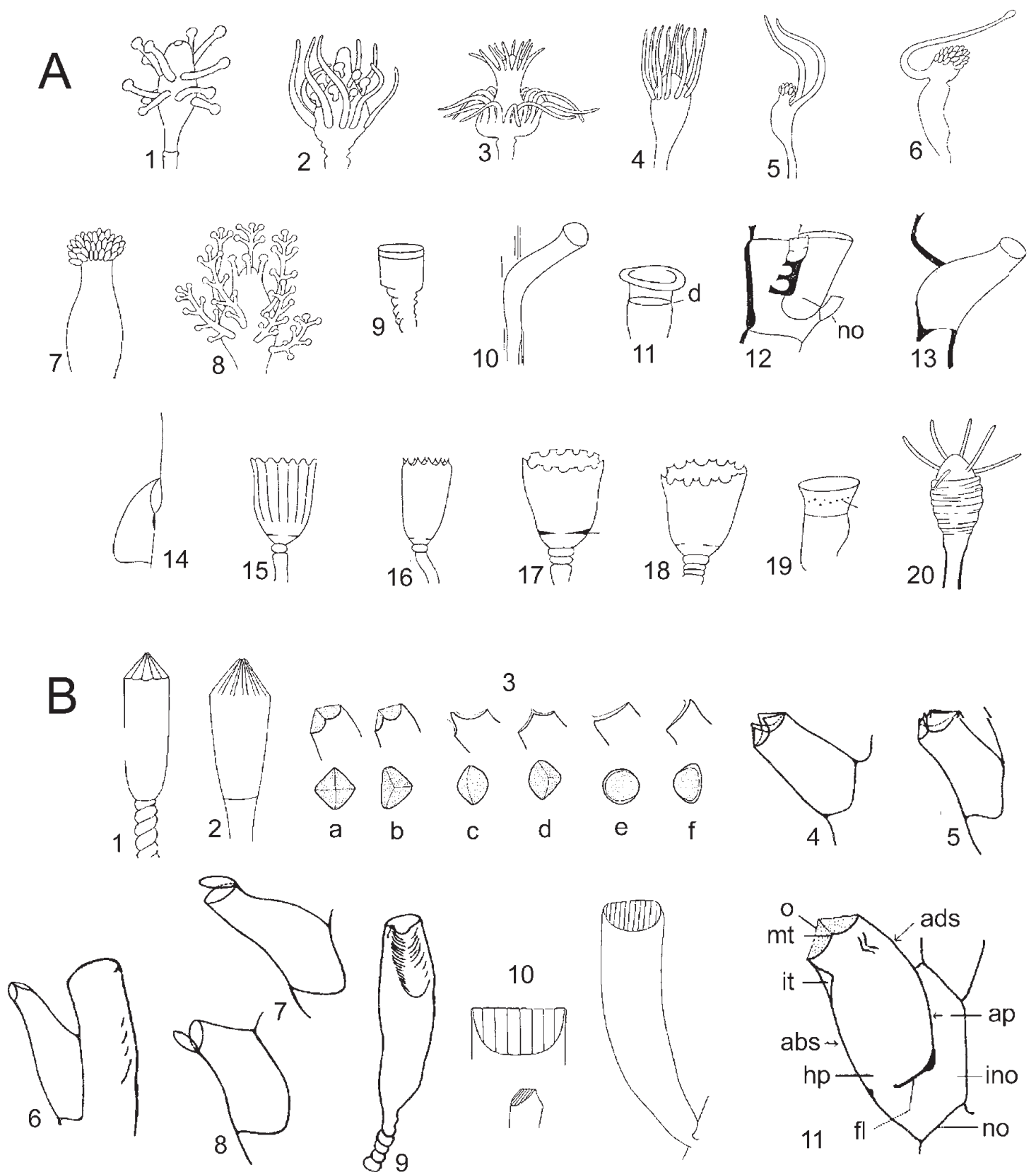

FIG. 5. - Morphology of hydroids. A, 1 to 8: some of the different forms, arrangement and number of tentacles occurring in hydrozoan hydranths: 1: Coryne with capitate tentacles; 2: Pennaria with semifiliform and capitate tentacles; 3 : Tubularia with filiform and monilifilifiorm tentacles; 4: Hydractinia with filiform tentacles; 5: Proboscidactyla with two filiform tentacles and a hypostomial capitulum of cnidocysts; 6: Monobrachium with one filiform tentacle and a hypostomial capitulum of cnidocyst; 7: Craspedacusta without tentacles, with only a hypostomial capitulum of cnidocysts; 8: Cladocoryne with ramified capitate tentacles. A, 9 to 20: various forms of hydrothecae found in hydrozoan hydranths: 9, 10, 11 and 19: tubular; 15 to 18: bell-shaped; 12, 13: adnate; 14: sunk; 20: pseudohydrotheca; 9: Halecium speciosum; 10. Grammaria stentor; 11: Halecium labrosum; 12. Cladocarpus formosus: 13: Abietinaria abietina: 14: Thuiaria laxa; 15: Campanularia groenlandica; 16: Clytia gracilis; 17: Gonothyraea loveni; 18: Hartlaubella gelatinosa; 19: Halecium halecinum; 20: Bougainviliidae or Pandeidae sp. (all after Naumov, 1969 modified). B, 1 to 11: form and structure of operculum: 1 and 2 Campanulinidae: 1: Calycella syringa, operculum formed by numerous flaps meeting in the centre, each flap seated in a hinged embayment and demarcated by basal prominent crease line; 2: Campanulina panicula, operculum made by many segments which are simple inward folds of the distal part of the hydrothecae meeting centrally. 3: Sertulariidae arrangement of marginal teeth and opercular valves (adcauline side on right): a: four valves and four teeth; b: three valves and three teeth; c: two valves and two teeth, adcauline larger; d: two valves and two teeth, abcauline larger; e: 1 valve, hinge adcauline; f: 1 valve, hinge abcauline. 4 to 8 and 11: Sertulariidae; 9 Lafoeidae; 10 Tiarannidae. $4:$ Sertularella, 4 valves; 5: Symplectoscyphus, 3 valves; 6: Sertularia, 2 valves; 7: Abietinaria, 1 adcauline valve; 8: Thuiaria, 1 abcauline valve; 9: pseudo-operculum of Lafoea fructicosa; 10: gable-shaped operculum from Stegopoma plicatile; 11: Sertularella: hydrothecal shape and structure (1, 2 and 10 after Cornelius, 1995; 3 and 11 after Millard, 1975; 4 to 9 after Naumov, 1969). abs: abcauline side; ads: adcauline side; ap: adnate part; fl: floor; hp: hydropore; ino: internode; it: internal tooth; mt: marginal tooth; no: node; o: operculum. 


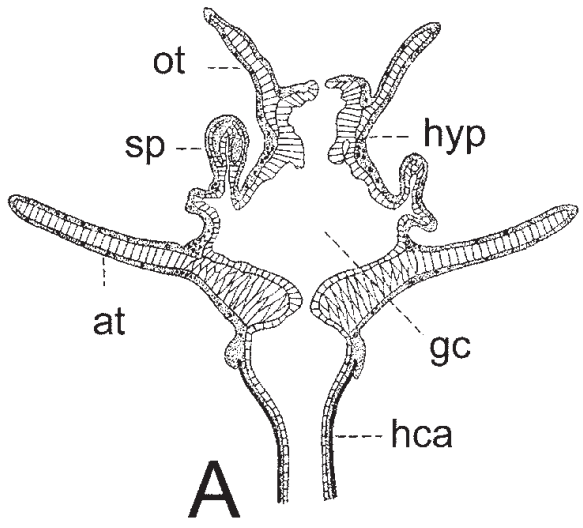

hyp …

o

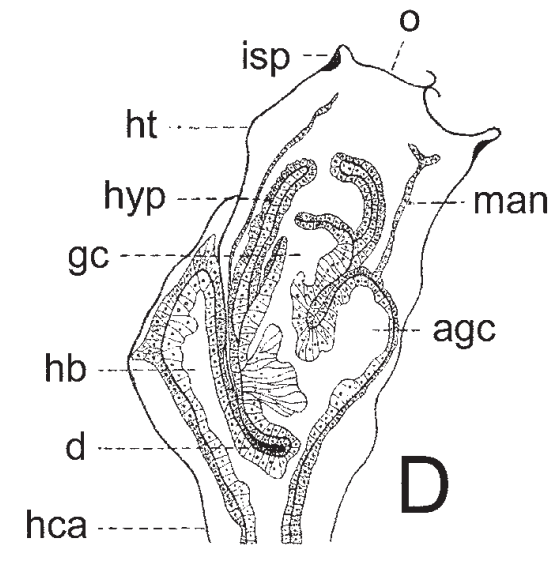

hca
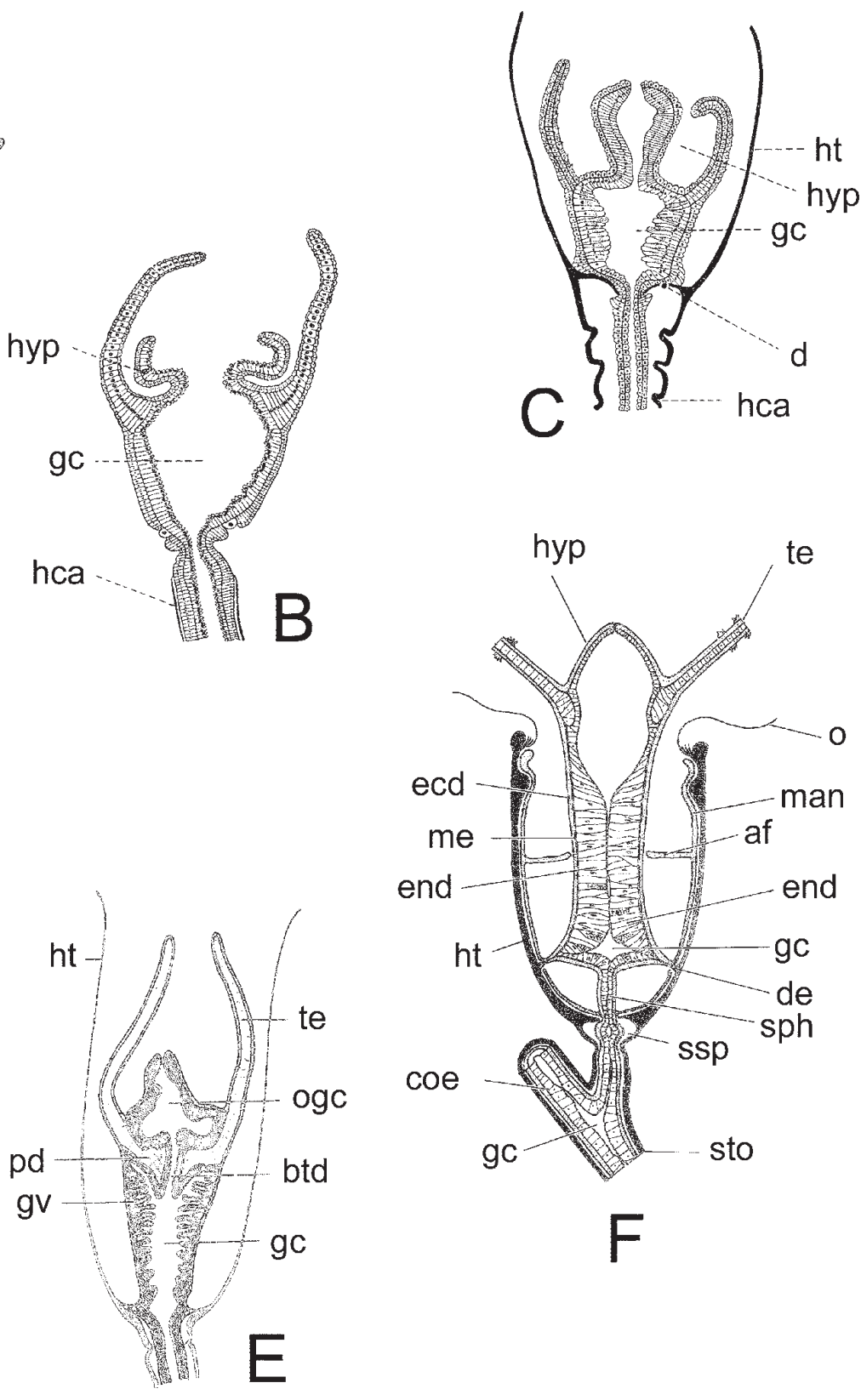

hyp

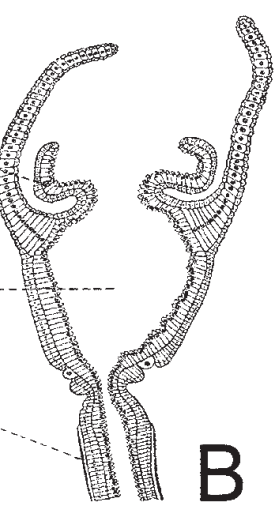

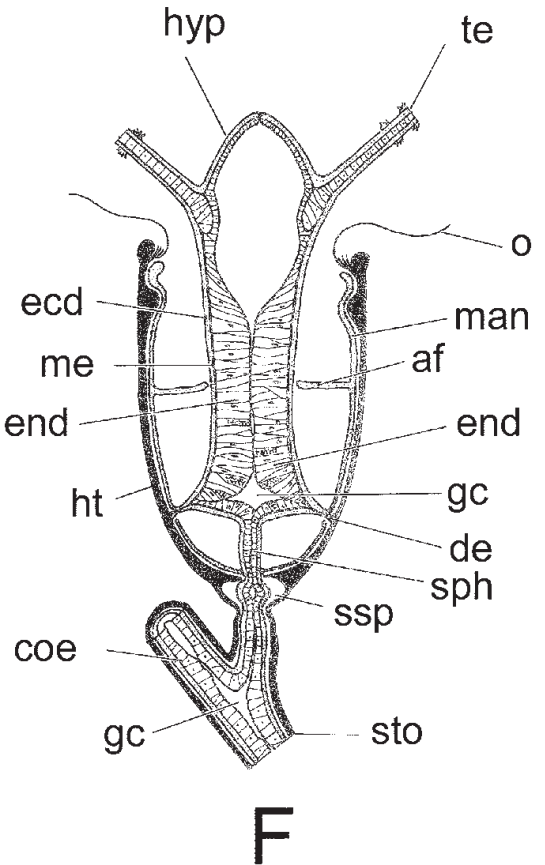

FIG. 6. - Morphology of the hydroids. Schematic longitudinal sections illustrating the structure of different gastrozooids. A: Ectopleura (Tubularia) larynx showing the parenchymatic diaphragm or cushion under the aboral tentacle whorl, proper to most Tubulariidae; B: Eudendrium ramosum pointing out the trumpet-shaped hypostome typical of the family; C: Laomedea flexuosa, outlining the globose hypostome and buccal cavity distinctive of the Campanulariidae; D: Sertularella crassicaulis, a retracted hydranth showing the mantel and abcauline gastric caecum; E: Bonneviella enterovillosa with an oral gastric cavity formed by an annular expansion of the tentacular bases; F: Thyroscyphus marginatus presenting the mantel and its annular fold characteristic of the Thyroscyphidae. (A and B after Leloup, 1952; C and D after Kohn, 1913; E after Naumov, 1969; F after Harris, 1990). af: annular fold; agc: abcauline gastric caecum; at: aboral tentacle; btd: basal tentacular diaphragm; coe: coenosarc; d: diaphragm; de: desmocyte; ecd: ectoderm; end: endoderm; gc: gastric cavity; gv: gastric villosities; hb: hydranth bud; hca: hydrocaulus; ht: hydrothecae; hyp: hypostome; isp: internal spine; man: mantel; me: mesoglea; o: operculum; ogc: oral gastric cavity; ot: oral tentacle; pd: parenchymatic diaphragm; sp: sporosac; sph: sphincter; ssp: suhydrothecal spherule; sto: stolon; te: tentacle. 


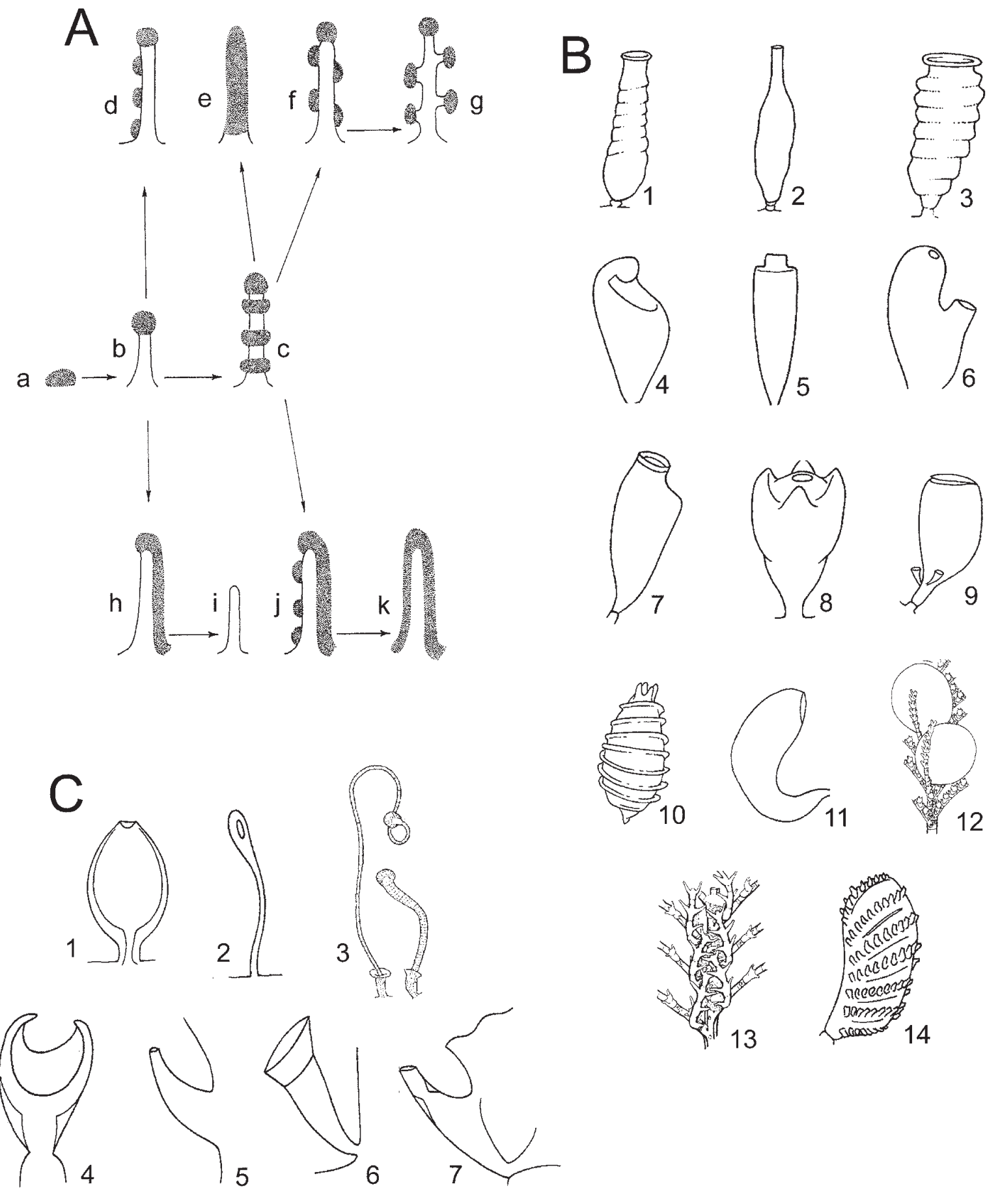

FIG. 7. - Morphology of the hydroids. A: Schema of the different types of tentacular structures and their evolution: a: primordial cnidocysts button; b: capitate; c: moniliform; d: semimoniliform; e: filiform; f: cateniform; g: ramified-capitate; h: semifiliform; i: acnide; j: monifiliform; k: pseudofiliform. B, 1 to 14: various forms of gonothecae: 1: Campanularia hincksi; 2: Plumularia setacea; 3: Clytia hemispherica; 4: Laomedea calceolifera; 5: Obelia sp.; 6 and 7: Halecium sp.; 8: Diphasia alata; 9: Halopteris catharina; 10: Symplectoscyphus tricuspidatus; 11: Nemertesia sp.; 12: Macrorhynchia filamentosus; 13: Cladocarpus valdiviae; 14: Aglaophenia sp.; C, 1 to 7: various forms of nematothecae: 1: Lovenella producta; 2: Lafoeina tenuis; 3: Hydrodendron mirabilis; 4: Halopteris catharina; 5: Kirchenpaueria sp.; 6: Plulmulariidae; 7: Aglaophenia sp. (A after Prévot, 1959; B1-11, B14, C1, C2, C4-7 after Cornelius, 1995; B12-13 and C 3 after Millard, 1975). 

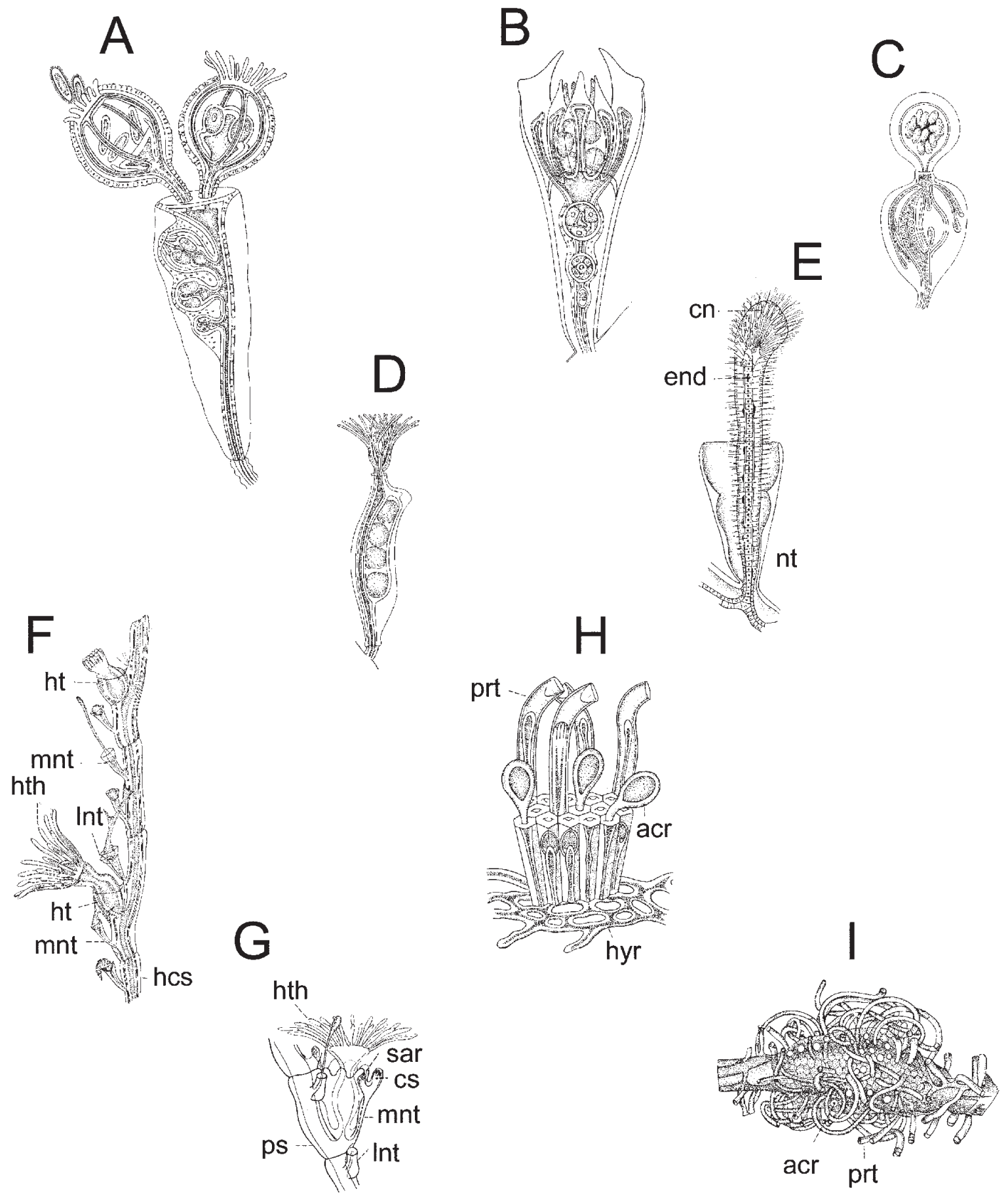

FIG. 8. - Morphology of the hydroids. Leptomedusae. A to D: different types of gonothecae: A: meconodia of Gonothyraea loveni; B: marsupium of Diphasia rosacea; C: acrocyst of Dynamena pumila; D: gonangium with hydranths from Halecium halecinum. E to I: different types protective organs: E: nematophore and nematothecae of a Plumularia; F: portion of a hydrocladium of Nemertesia antennina showing the lateral and median nematothecae. G: hydrocladium portion of an Aglaophenia sp. with detail of the nematophores and nematothecae; H: coppinia of Lafoeidae; I: detail of a coppinia (all from Leloup, 1952). acr: acrocyst; cn: cnidocyste; cs: cnidostyle; end: endoderm; hcs: hydrocladium segment; ht: hydrotheca; hth: hydranth; hyr: hydrorhiza; lnt: lateral nematotheca; mnt: median nematotheca; nt: nematotheca; prt: tubes of the protective polyps; ps: perisarc; sar: sarcostyle. 

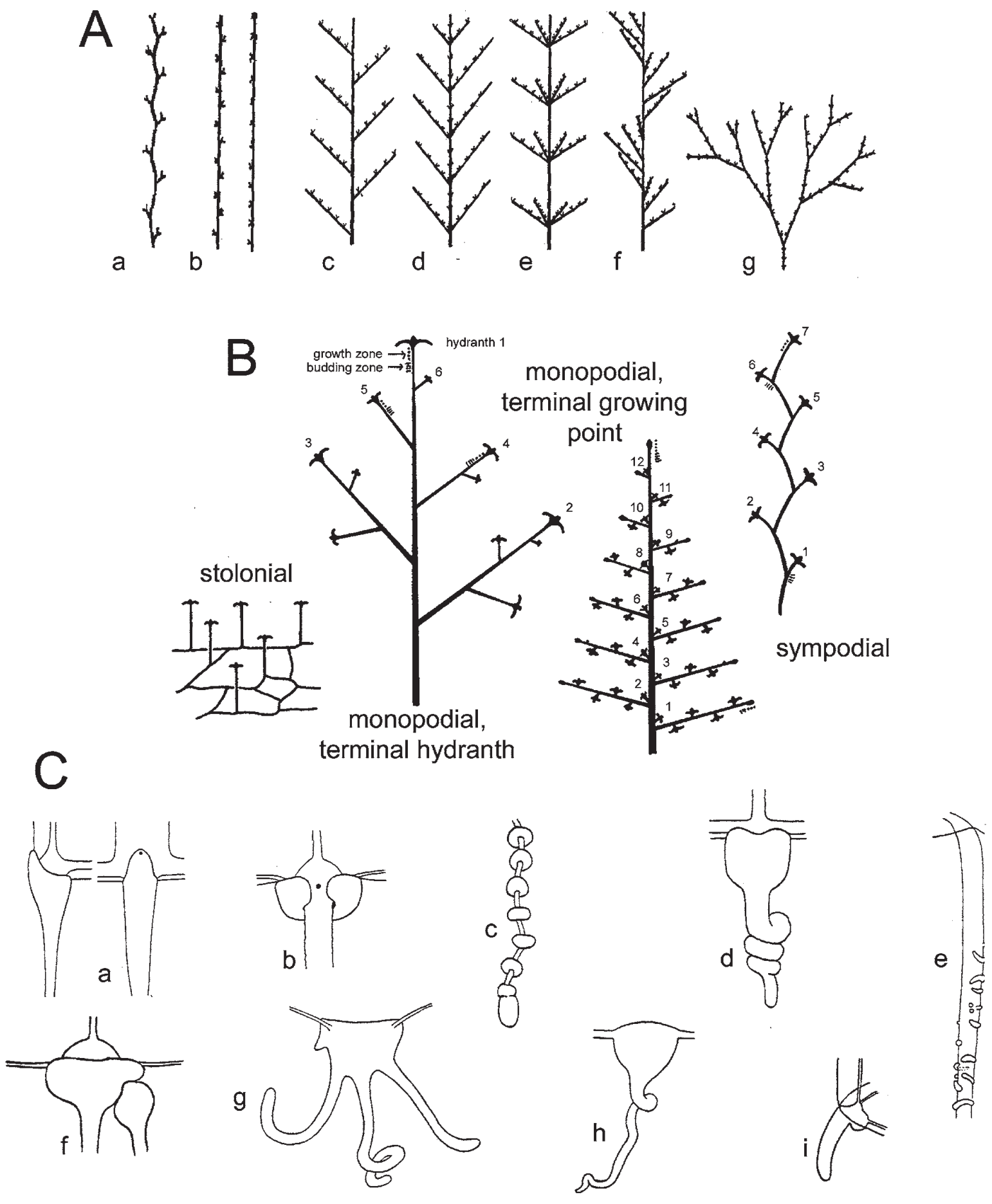

FIG. 9. - A and B: Morphology of the hydroids: A: type of stem and branching: a: geniculate; b: straight; c: alternate; d: opposite; e: whorled; f: spiral; g: dichotomous. B: form of growth and colony formation (A and B after Millard, 1975). C: Morphology of the medusae. Diagrams of marginal tentacles of different medusae: a: Leuckartiara octona (Anthomedusae); b: Sarsia tubulosa (Anthomedusae); c: Corymorpha nutans (Anthomedusae); d: Cosmetira pilosella (Leptomedusae); e: Gossea corynetes (Limnomedusae); f: Hybocodon prolifer (Anthomedusae); g: Bougainvillia britannica (Anthomedusae); h: Clytia hemispherica (Leptomedusae); i: Proboscidactyla stellata (Anthomedusae) (C after Russell, 1953). 

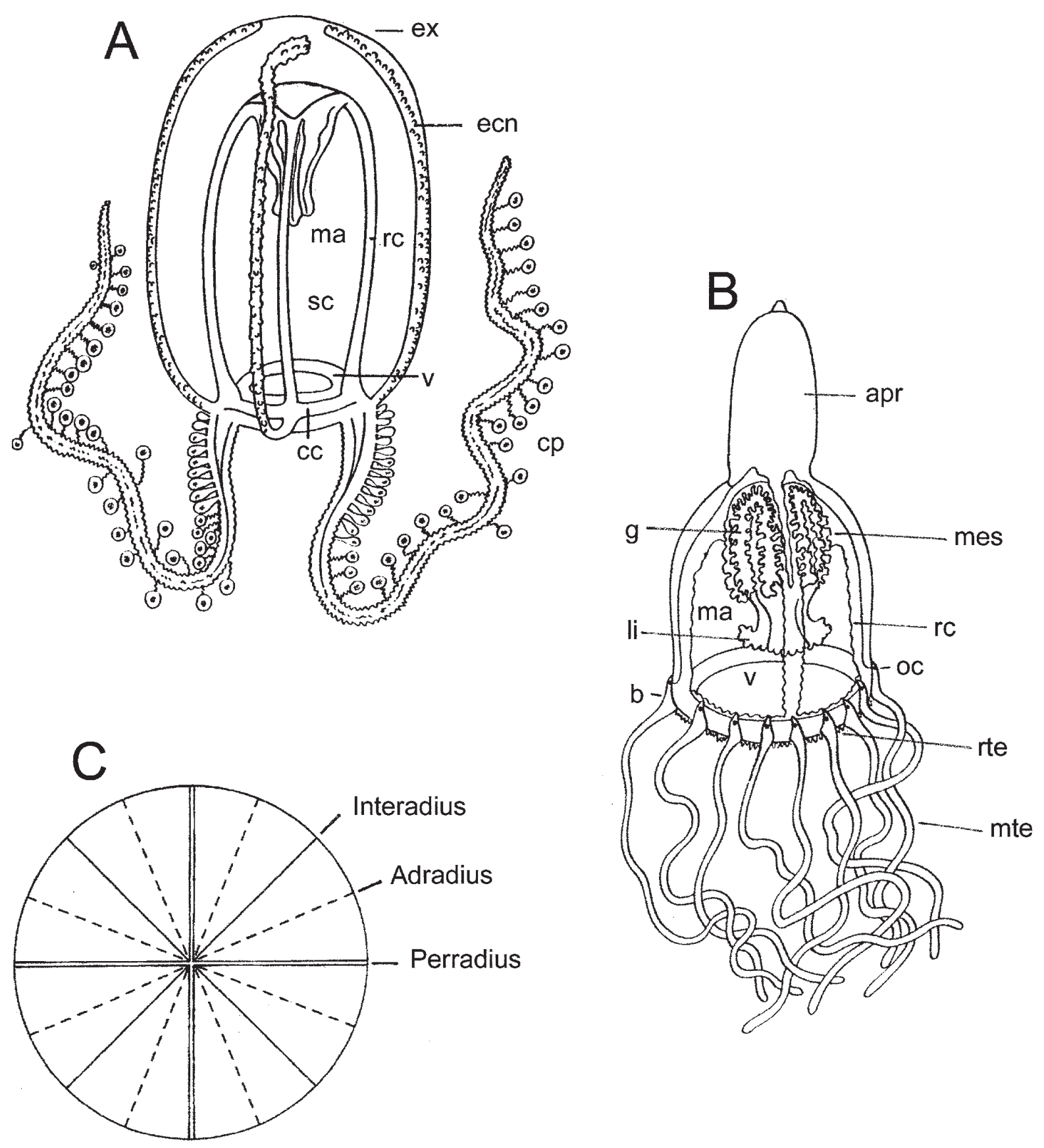

FIG. 10. - Morphology of the medusae. A: medusae of Zanclea sp. (Zancleidae, Anthomedusae) showing the cnidophores and the exumbrellar cnidocyst tracts; B: Leuckartiara octona (Pandeidae, Anthomedusae) showing the apical process, the mesenteries and the rudimentary marginal bulbs; C: diagram defining the radii of a hydromedusae with 4 radial canals. (A and B after Mayer, 1910; C after Russell, 1953). apr: apical process; b: tentacular bulbs; cc: circular canal; cp: cnidophore; ecn: exumbrellar cnidocyst tract; ex: exumbrella; g: gonad; li: lip; ma: manubrium; mes: mesentery; mte: marginal tentacle; oc: ocelli; rc: radial canal; rte: rudimentary tentacles; sc: subumbrellar cavity; v: velum. 


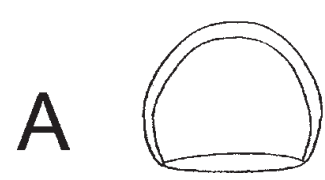

a

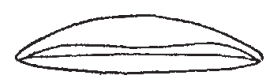

e

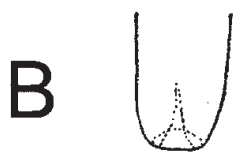

a

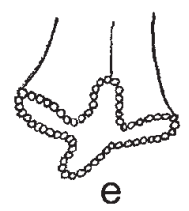

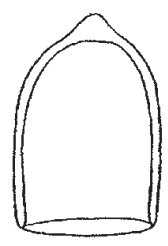

b
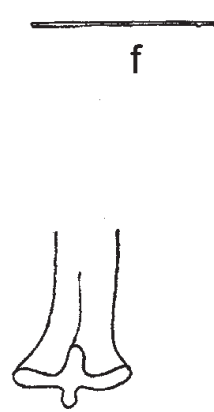

b
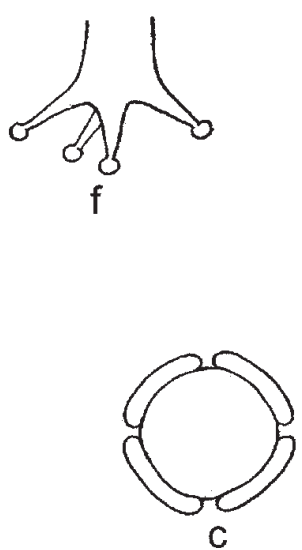

C
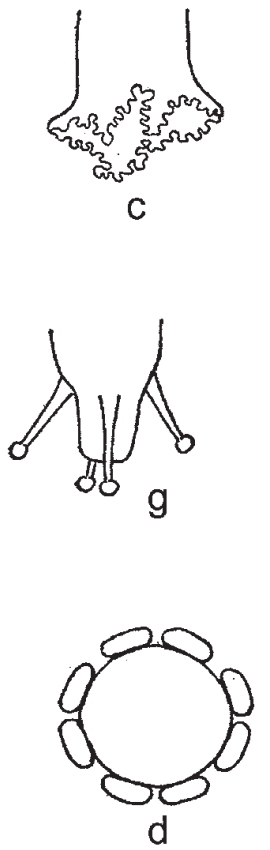

d

C

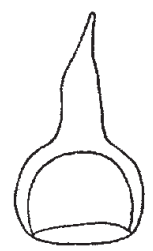

$\mathrm{g}$

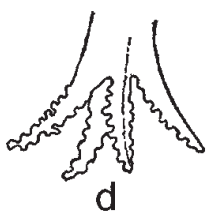

d

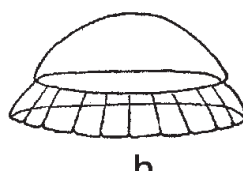

$\mathrm{h}$

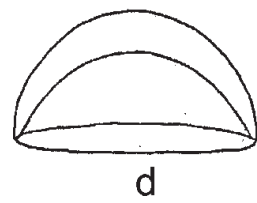




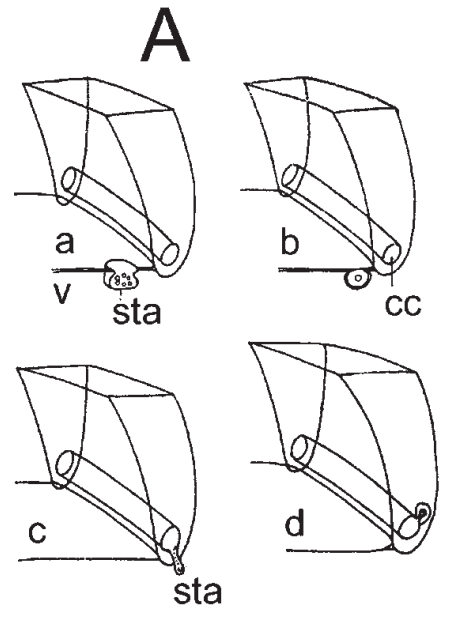

D

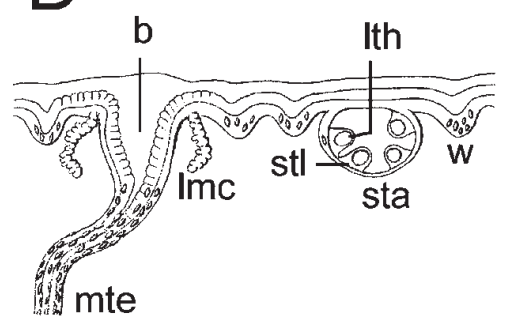

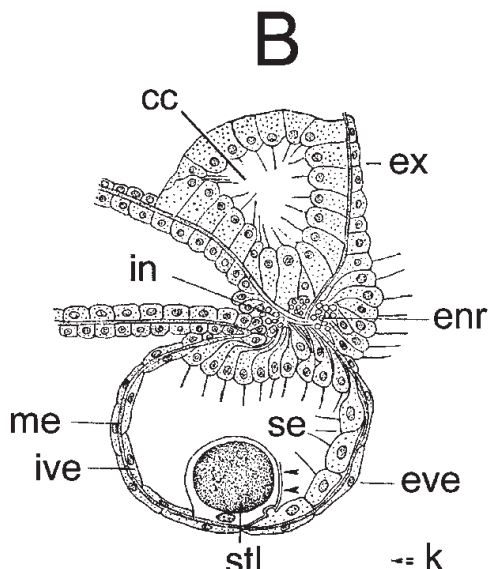

stl

$=\mathrm{K}$

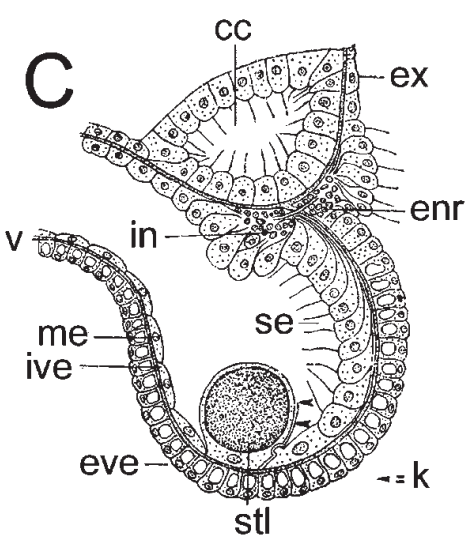

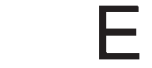

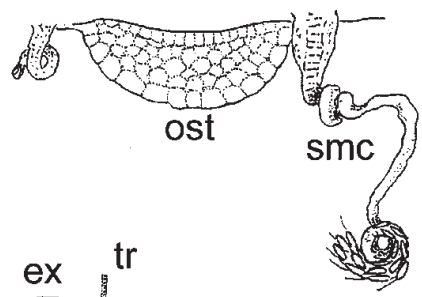

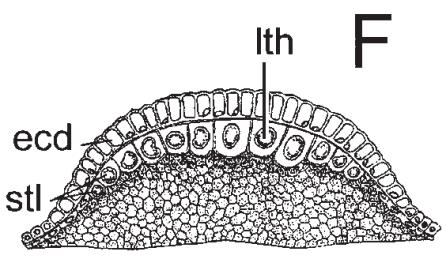
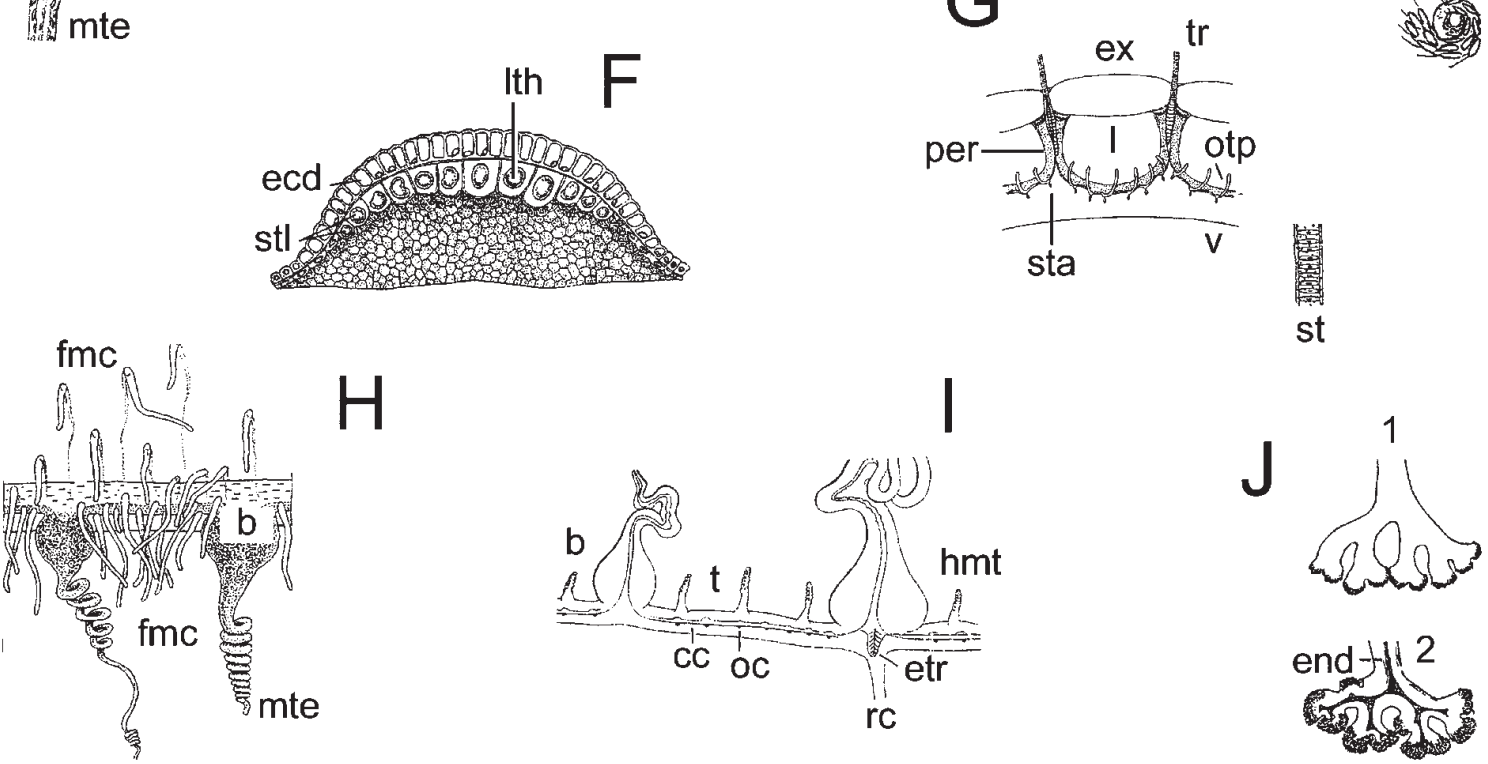

FIG. 12. - Morphology of the medusae. A to C: Structure of sense organs: statocysts. A: different types of statocysts: a: open ectodermal velar statocyst; b: closed ectodermal velar statocyst; c: free ecto-endodermal statocyst; d: enclosed ecto-endodermal statocyst. B: diagram of a radial section of a closed ectodermal velar statocyst; C: diagram of a radial section of an open ectodermal velar statocyst. D to I: detail of marginal structures: D: part of the bell margin of Eutima coerulea (Leptomedusae) showing a closed statocyst, marginal warts and lateral cirri; E: marginal open statocyst and marginal cirri of Mitrocomella brownei, Leptomedusae; F: open statocyst of Mitrocoma (Leptomedusae); G: bell margin of the Narcomedusae Pegantha rubiginosa showing the marginal lappets the peronia and the otoporpae; H: portion of the umbrella margin of Cosmetira pilosella (Leptomedusae) showing the marginal flexile cirri; I: part of the bell margin of Orchistoma pileus (Leptomedusae) showing the tentaculiform structures. J: detail of the lips of Hydractinia (Podocoryne) areolata (Anthomedusae): 1: outer side, 2: inner side showing the free gastric endoderm (A, E and H after Russell, 1953; B and C after Singla, 1975; D, G and I after Mayer, 1910; F after Hertwig and Hertwig, 1878; J after Kramp and Damas, 1925). b: marginal tentacular bulb; cc: circular canal; ecd: ectoderm; end: endoderm; enr: exumbrellar or external nerve ring; etr: endodermal tentacular root; eve: external epithelium of the statocyst vesicle; ex: exumbrella; fmc: flexile marginal cirri; hmt: hollow marginal tentacle; in: subumbrellar or internal nerve; sta: statocyst; ive: internal epithelium of the statocyst vesicle; k: kinocilium; 1: marginal lappet of Narcomedusa; lmc: lateral marginal cirri; lth: lithocyte; me: mesoglea; mte: marginal tentacle; oc: ocellus; ost: open statocyst; otp: otoporpae; pc: peripheral canal; per: peronia; rc: radial canal; smc: spiral marginal cirri; stl: statolith; t: tentaculiform structure of the Orchistomidae; tr: tentacular root; se: sensory epithelium; st: solid marginal tentacle; v: velum; w: marginal wart. 

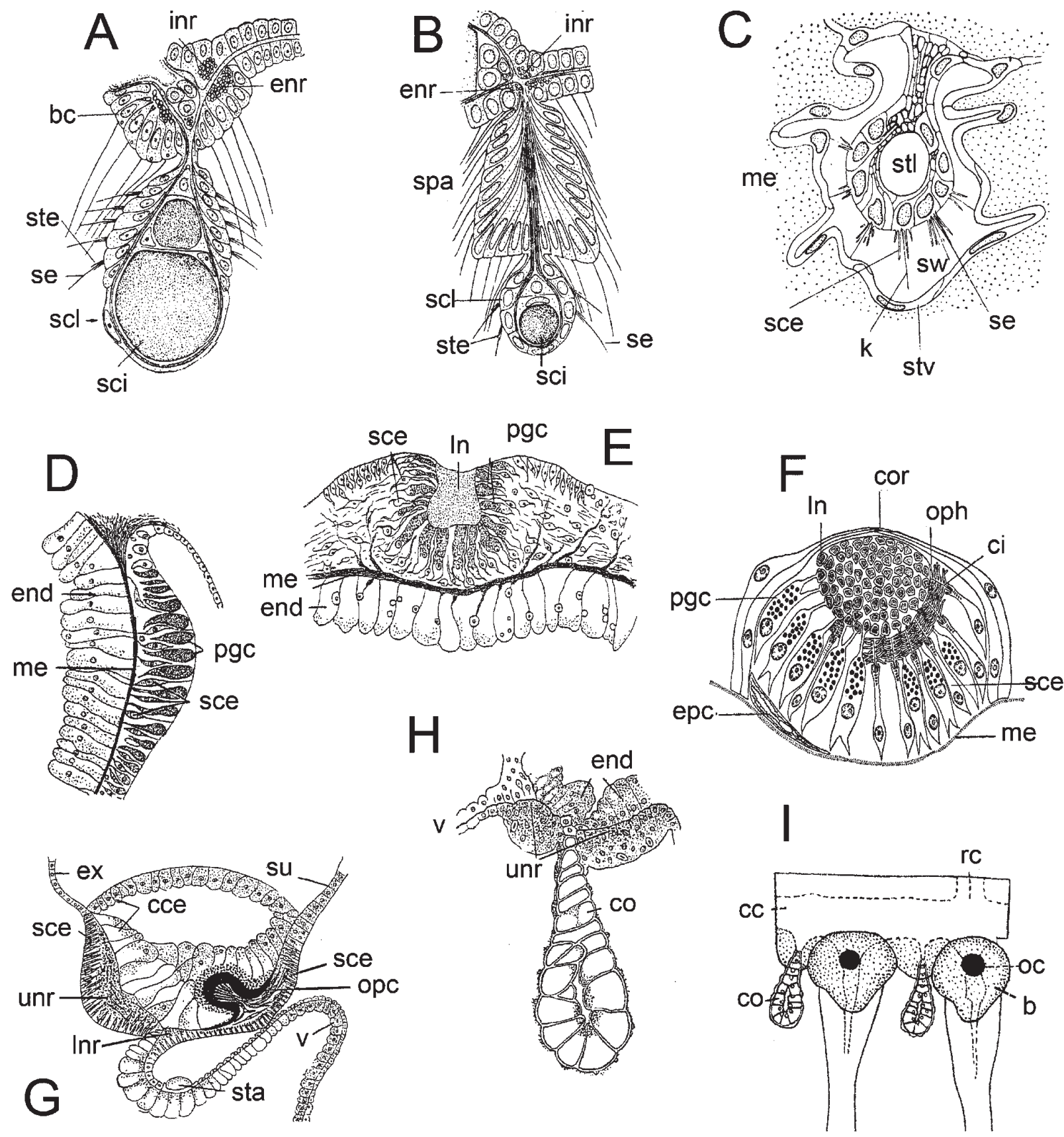

FIG. 13. - Morphology of the medusae. Structure of sense organs: A to C: statocysts: A: Diagram of a radial section of a free ecto-endodermal statocysts of Aegina citrea, Narcomedusae; B: Diagram of a radial section of a free ecto-endodermal statocyst of Solmissus marshalli, Narcomedusae; C: Diagram of a radial section of an enclosed ecto-endodermal statocyst of Rhopalonema velatum, Trachymedusae. D to G: ocelli: D: simple ocelli from Neoturris (Anthomedusae); E: complex ocelli from Sarsia (Anthomedusae); F: ultrathin section through a complex ocelli of Cladonema radiatum (Anthomedusae); G: open statocyst with ecto-endodermal ocelli from Tiaropsis (Leptomedusae). H and I: cordyli: H: cordylus from Laodicea (Leptomedusae); I: part of the bell margin of Laodicea showing the position of the cordyli (A and B after Singla, 1975; C after Horridge 1969, D, E and G after Linko, 1900; F after Bouillon and Nielsen, 1974; H after Brooks, 1895; I after Kramp, 1919). oph: photoreceptor portion of the ocelli; ax: axon; b: marginal bulb; bc: basal cushion; cc: circular canal; cce: endoderm of the circular canal; ci: cilia; co: cordyli; cor: cornea; end: endoderm; enr: exumbrellar or external nerve ring; epc: embryonic pigmented cells; ex: exumbrella; inr: subumbrellar or internal nerve ring; k: kinocilium; ln: lens; lnr: lower nerve ring; me: mesoglea; mv: microvilly; ne: nerves; oc: ocelli; opc: pigment cup of the ocelli; pg: pigment; pgc: pigmented cell; pho:photoreceptor cell; rc: radial canal; sce: sensory cells; sci: sensory cilia; scl: sensory club; se: sensory epithelium; spa: sensorial papilla; sta: statocyst; ste: stereocilia; stl: statolith; stv: enclosing vesicle of the statocyst; su: subumbrella; sw: sea water; te: tentacle; unr: upper nerve ring; v: velum; va: vacuole. 

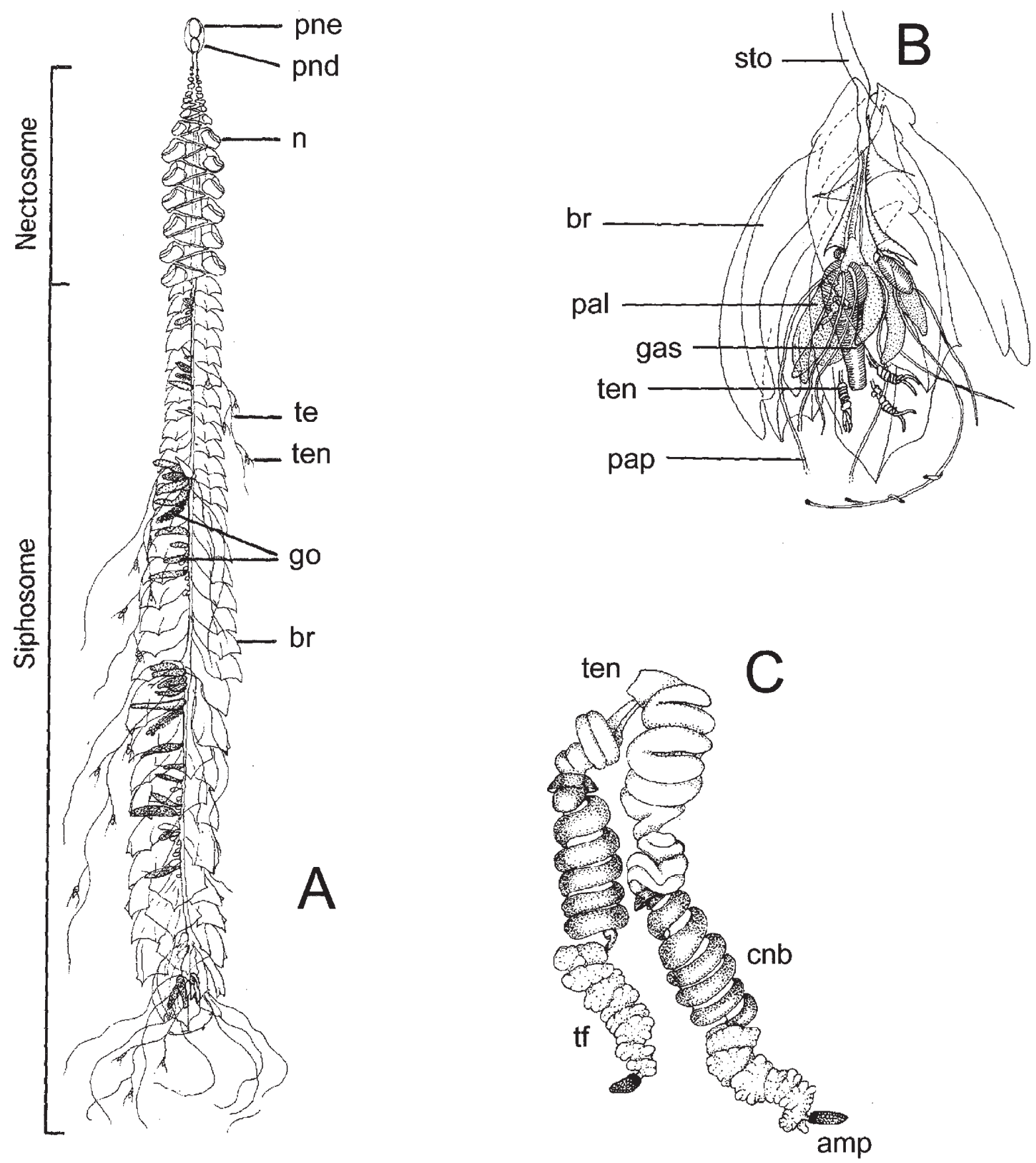

FIG. 14. - Morphology of the Siphonophores. A to C: Agalma elegans (Physonectae): A: general structure of the polygastric stage; B: distal part of a siphosome; $\mathrm{C}$ : detail of a side branch of the tentacle or tentilla (all after Totton, 1965). br: bract; cnb: cnidoband; ga: gastrozooid; go: gonophore; n: nectophore; pne: pneumatophore; pal: palpon; pap: palpacle; pnd: pneumadenia; sto: stolon; te: tentacle; ten: tentillium; tf: terminal filament. 

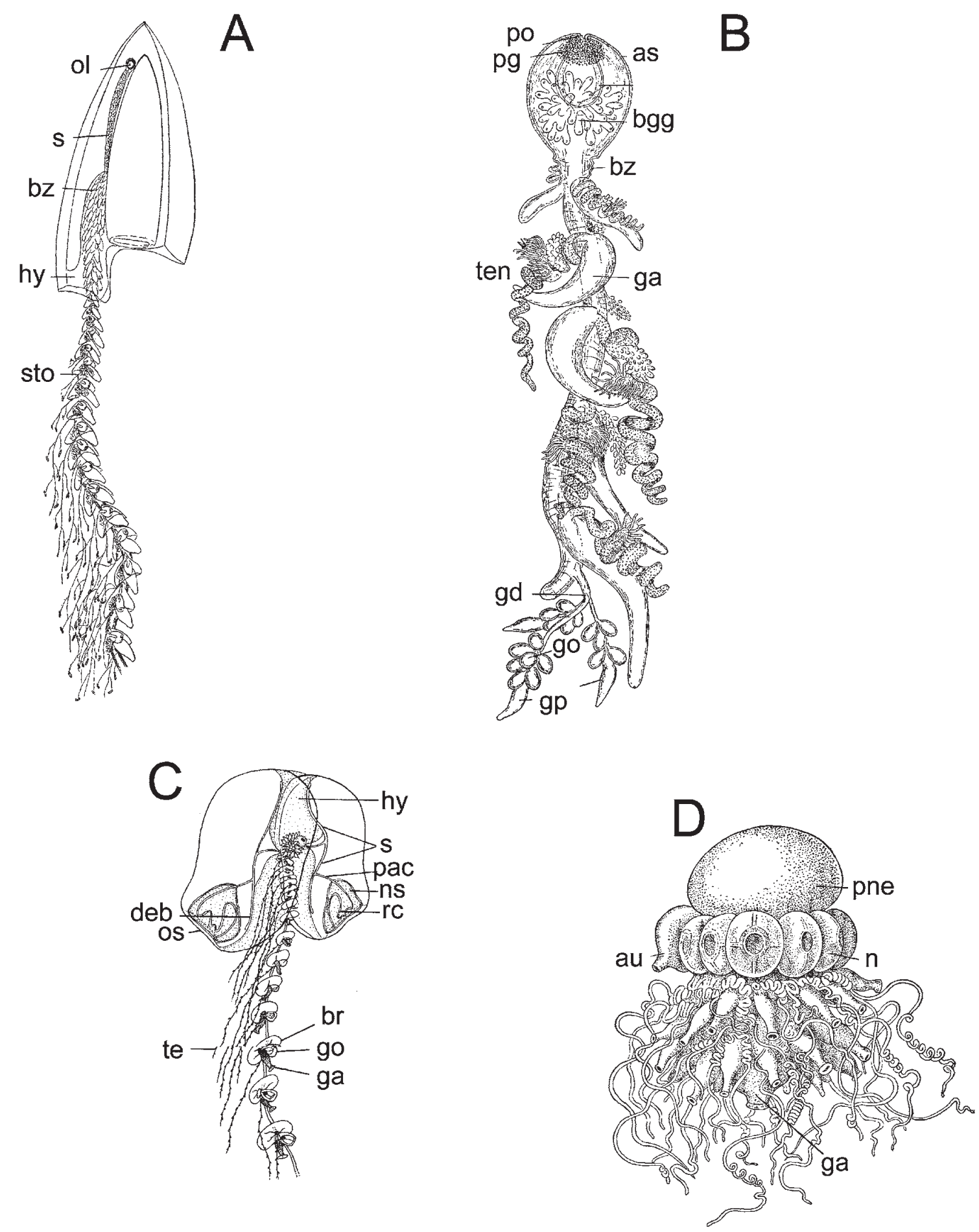

FIG. 15. - Morphology of the Siphonophores. Various morphological types. A: example of a monophyid calycophoran Muggiaea atlantica, Diphyidae; B: specimen of Rhizophysa, Rhizophysidae, Cystonectae; C: whole polygastric phase of Rosacea cymbiformis, Prayinae, Calycophorae, with two opposite nectophores; D: specimen of the genus Stephalia with an aurophore, Rhodaliidae, Physonectae (A and B after Hyman, 1940; C after Totton, 1965; D after Haeckel, 1888). as: air sac; au: aurophore; bgg: branched gas gland; br: bract; bz: budding zone; deb: descending branch; ga: gastrozooid; go: gonophore; gd: gonodendron; gp: gonopalpon; hy: hydroecium; n: nectophore; ns: nectosac; ol: oleocyte; os: ostium; pac: pallial canal; pg: pigment; pne: float or pneumatophore; pnc: pneumatocodon; po: pore; rc: radial canal; s: somatocyst; sto: stolon; te: tentacle; ten: tentillium. 

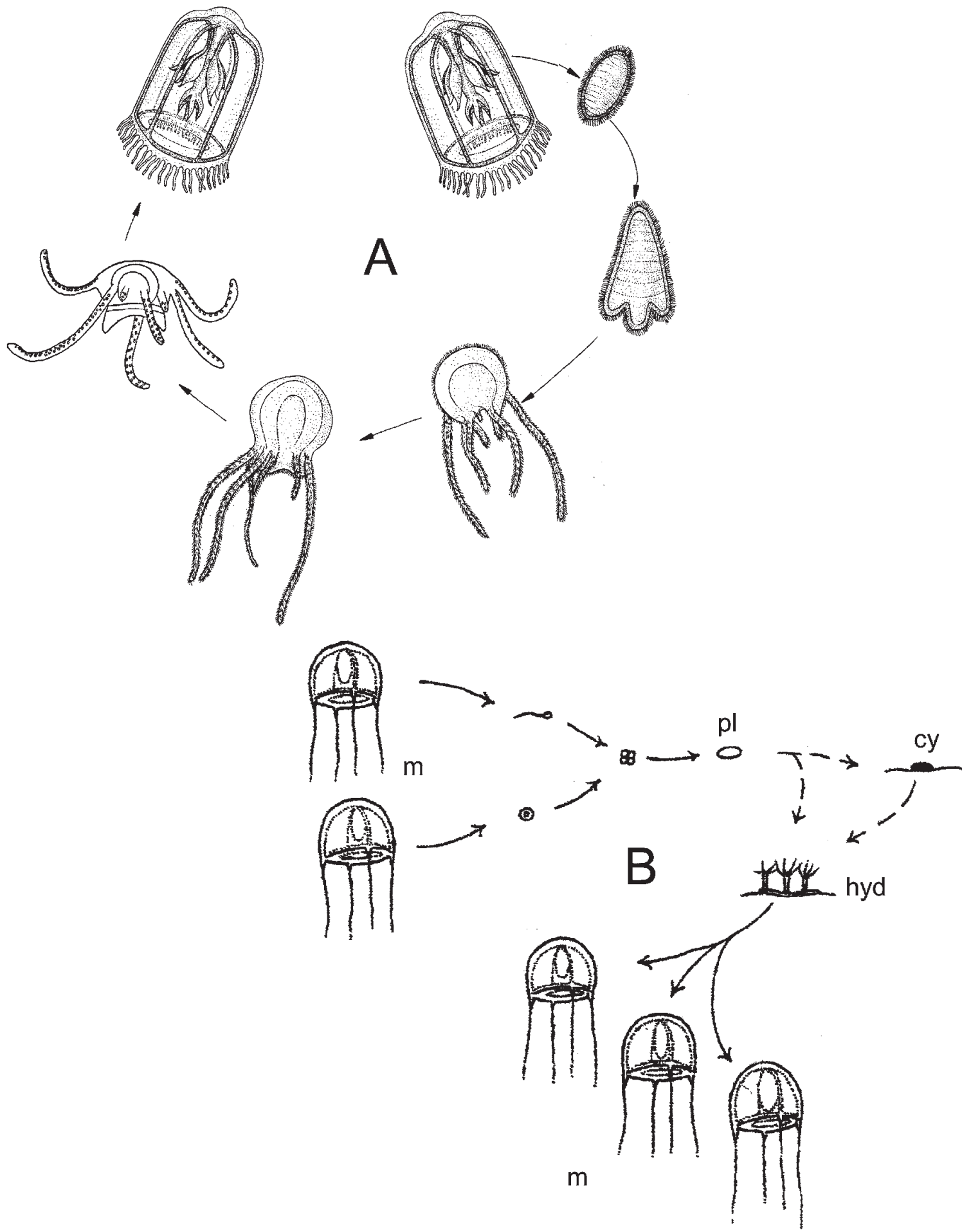

FIg. 16. - Life cycles. A: Typical Automedusae life cycle pattern. Life cycle of Aglaura hemistoma; B: Typical Hydroidomedusae life cycle pattern (A after various sources; B after Boero, Bouillon and Piraino, 1992). cy: cyst; fr: frustule; hyd: hydroid; m: medusae; pl: planula. 

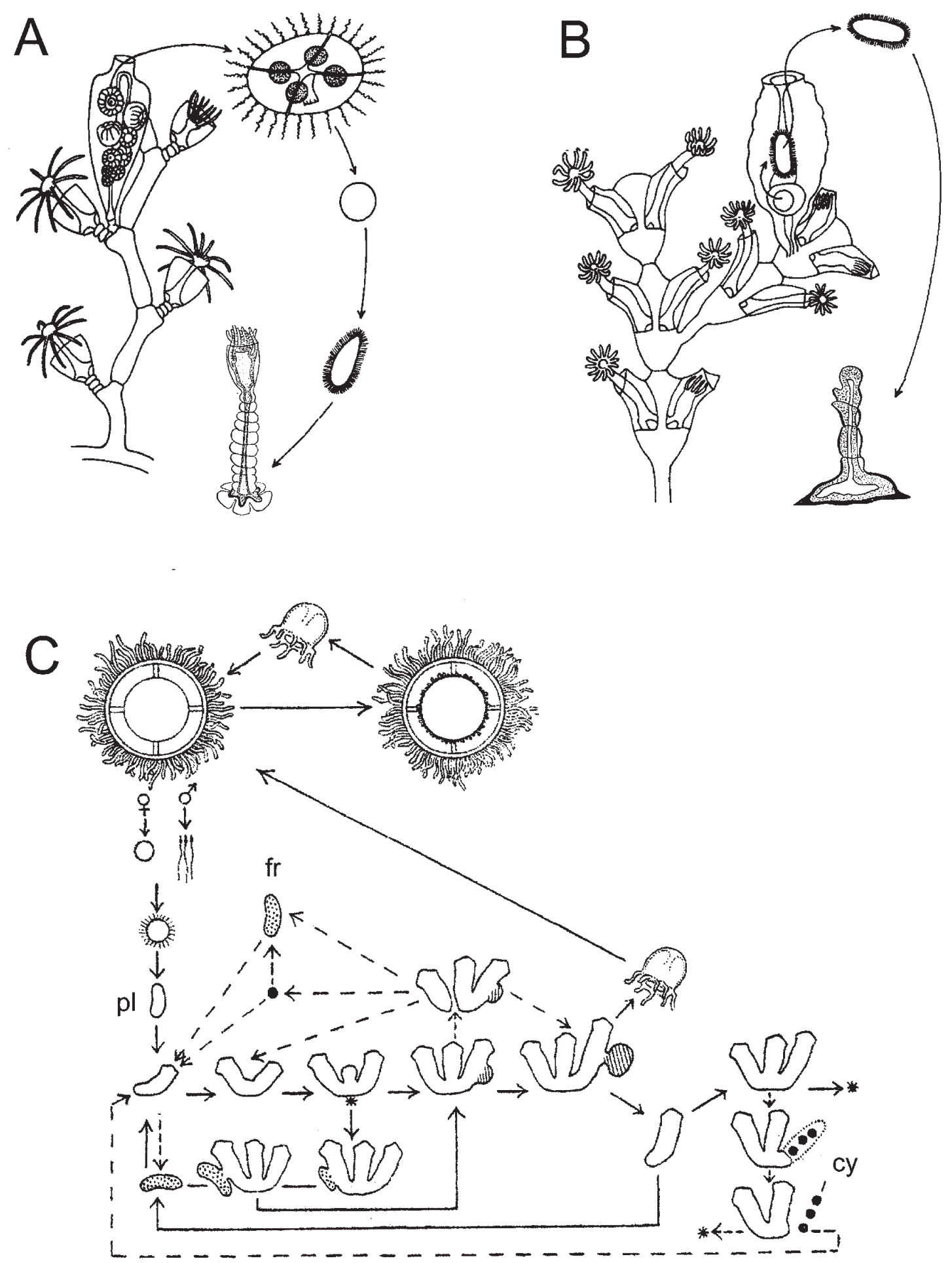

FIG. 17. - Life cycles. A: Hydromedusan life cycle with hydroid and medusae stages (Obelia); B: paedomorphic hydroidomesan life cycle with fixed gonophore (Dynamena); C: schema of the life cycle of a Limnomedusae (Limnocnida tanganyicae), the dashed lines show the parts of the cycle that happens in bad ecological conditions. Stippled areas indicate frustules (normal resistant and dispersive stages); large dots indicate resistant cysts; hatched areas show medusa budding (A and B after Cornelius, 1995; C after Bouillon, 1957). 

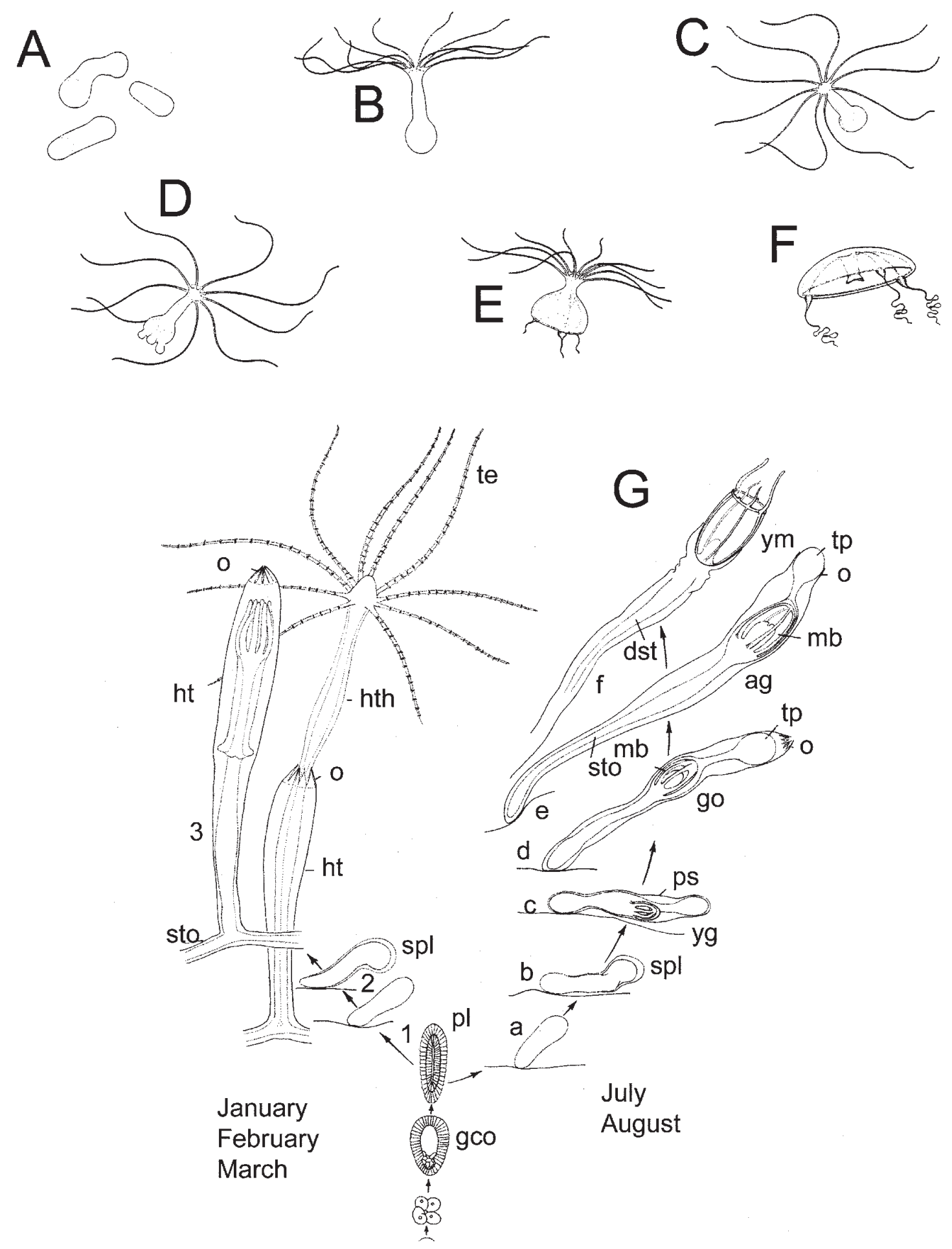

FIG. 18. - Various types hydroidomedusan life cycles. A to F: Life cycle of Eirene hexanemalis, Leptomedusae; the planula develop in a pelagic solitary hydranth which transforms itself in a single medusa; G: Life cycle patterns in Laodicea indica (Lepomedusae) from Bismarck Sea, Papua New Guinea. During the wet season (left: 1, 2, 3) the planula development produces a hydroid colony which eventually will produce medusae; during the dry season (right: a to f) the planula produces a gonotheca which will degenerate after producing a single medusa (A to F after Bouillon, 1983; G after Bouillon et al., 1991). ag: adult gonophore; dst: degenerating stolon; gco: gastrulating coeloblastula; go: gonophore; ht: hydrotheca; hth: hydranth; mb: medusa bud; o: operculum; pl: planula; ps: perisarc; spl: settling planula; sto: stolon; te: tentacle; tp: terminal plate; yg: young gonophore; ym: young medusa ready to be liberated. 
A
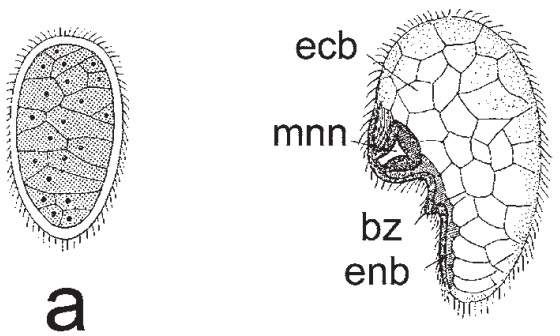

b

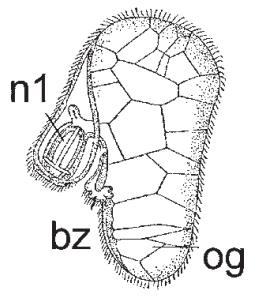

C

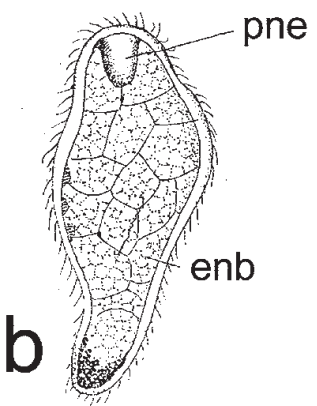

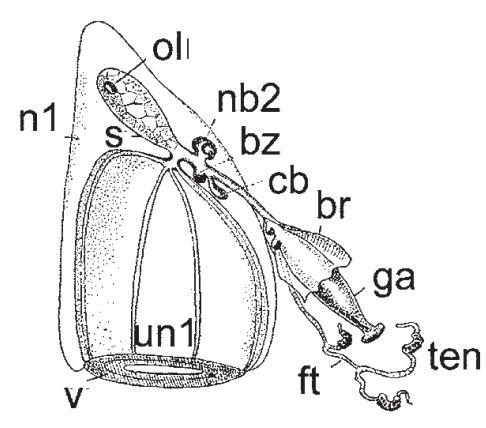

d

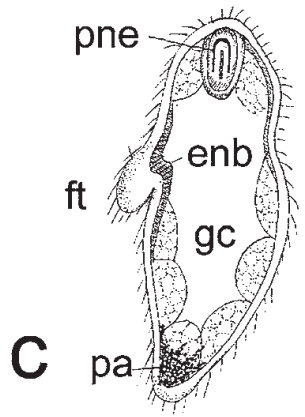

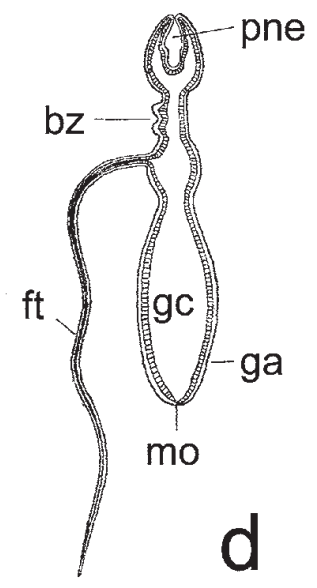

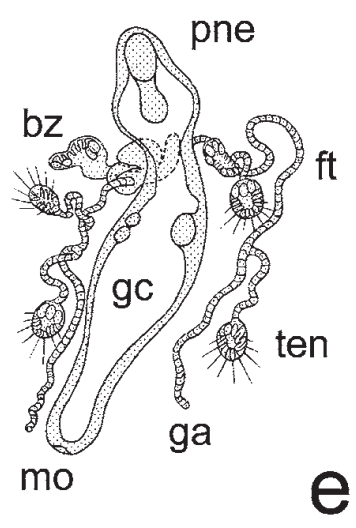

FIG. 19. - Siphonophores life cycle. A: developmental stages of a calycophorid; B: developmental stages of a physophorid (Aa after Metschnikoff, 1874; Ab, Ac and Ad redrawn from Dawydoff, 1928; Ba, Bb, Bc, Bf after Chun, 1886; Bd after Delage and Hèrouard, 1901). br: bract; bz: primary budding zone; cb: cormidial bud; ecb: ectoblast; enb: primary endoblast; ft: fishing tentacle; ga: primary gasterozooid; gc: gastric cavity; mnn: medusary nodule of the primary bell or nectophore; mo: mouth; n1: primary deciduous nectophore; nb2: bud of the secondary or permanent nectophore; ol: oleocyte; og: outline of the future gastrozooid; pa: pigmented area; pne: pneumatophore; s: somatocyst; ten: tentilla; un1: umbrella of the primary nectophore; v: velum. 

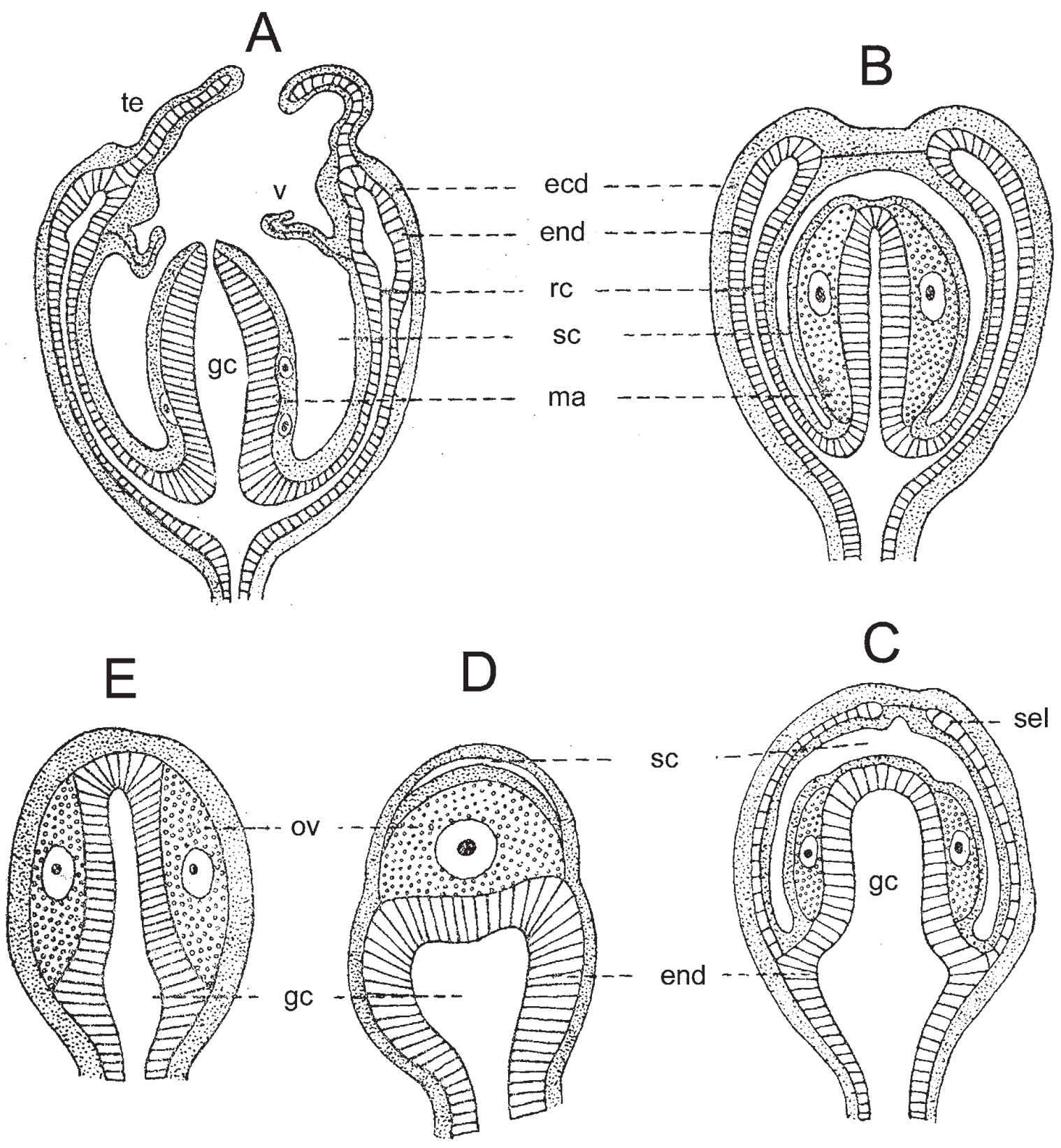

FIG. 20. - Development. Asexual reproduction. Regressive evolution of the medusa: A: fully developed medusa; B: eumedusoid; C: cryptomedusoid; D: heteromedusoid; E: styloid (all after Kühn, 1913). ecd: ectoderm; end: endoderm; gc: gastric cavity; ma: manubrium; ov: ovo cyte; rc: radial canal; sel: subumbrellar endodermic lamella; sc: subumbrellar cavity; te: tentacle; v: velum. 

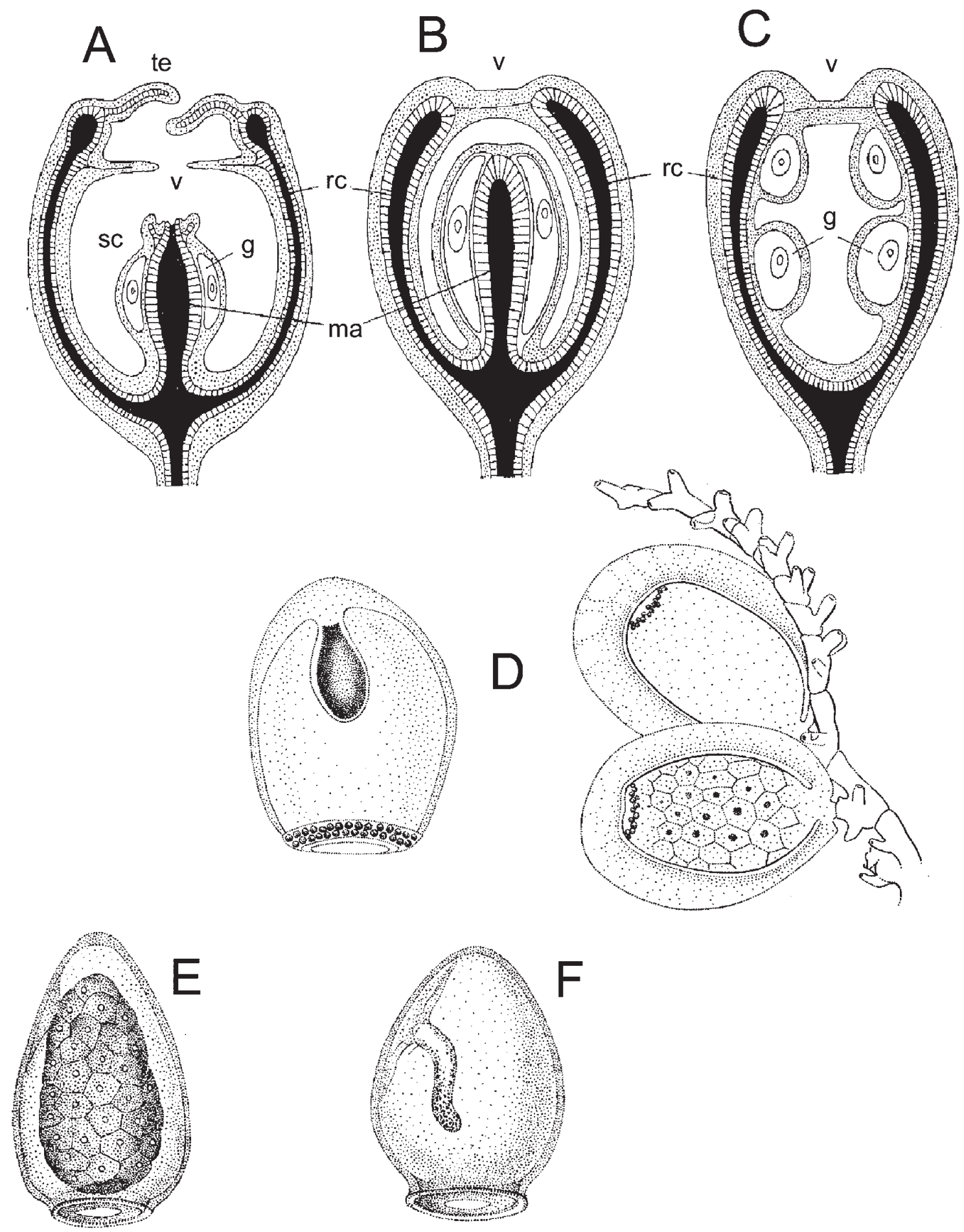

FIG. 21. - Development. Asexual reproduction. Eumedusoids and swimming sporosacs: A: eumedusoid of Hydractinia carnea, Anthomedusae having usually a short life-time; B: more regressed an ephemeral eumedusoid of Pennaria (Anthomedusae) with gonads on manubrium; C: ephemeral regressed eumedusoid of Orthopyxis integra (Leptomedusae) with gonads on radial canals and without manubrium; D: gonophores and free swimming sporosac of Macrorhynchia (Lytocarpus) philippina (Leptomedusae), the gonads are on an eccentric manubrium; E: free swimming female sporosac of Amphisbetia operculata (Leptomedusae) before spawning; F: idem E but after spawning, note also in the two figures the eccentric position of the manubrium (A, B and C after Kühn, 1913; D after Gravier, 1970; E and F after Teissier, 1922). g: gonad; ma: manubrium; rc: radial canal; sc: subumbrellar cavity; te: tentacle; v: velum. 


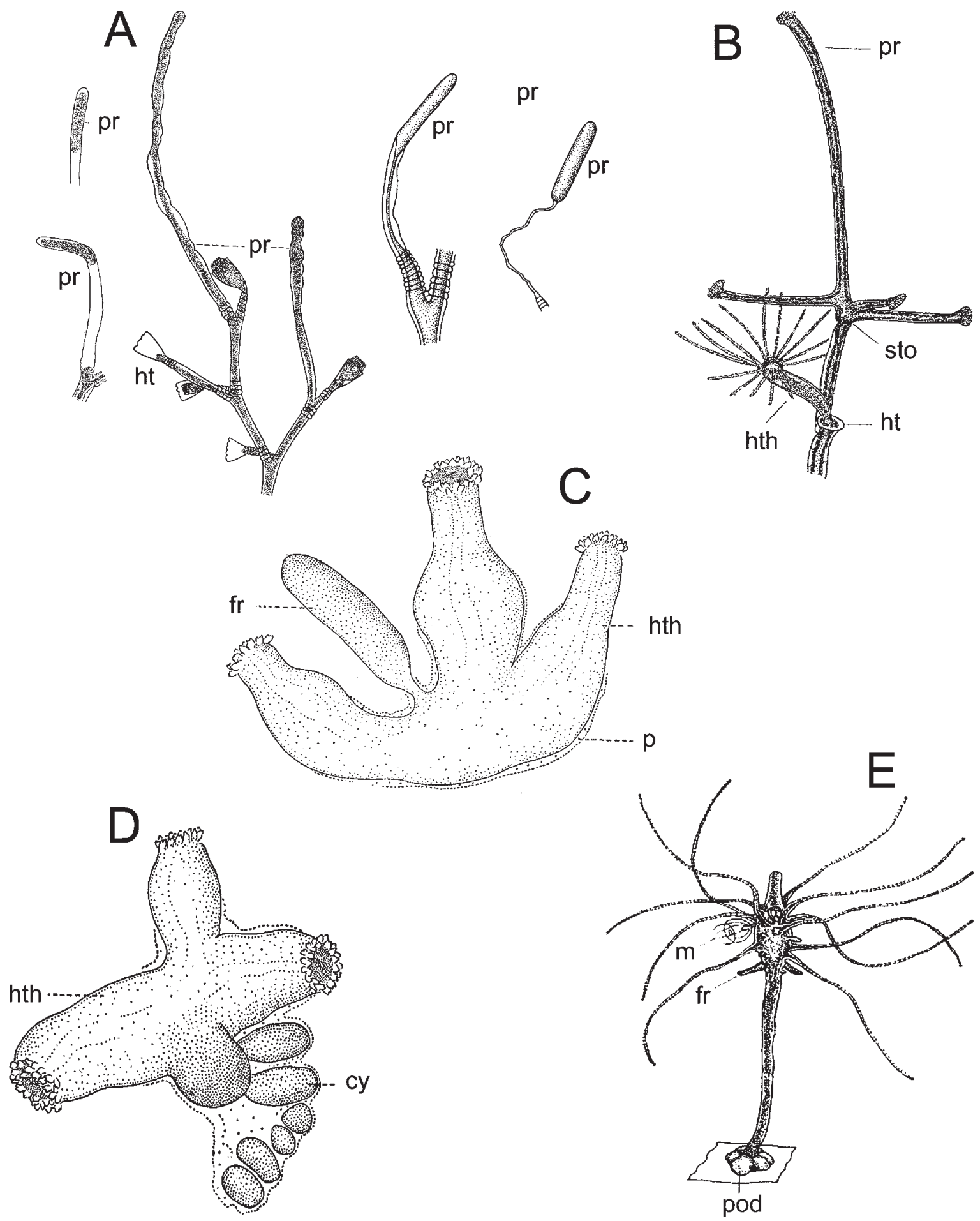

FIG. 22. - Development. Asexual reproduction. Cysts; frustules; propagules; podocysts: A: different types of propagules observed in the genus Obelia, Leptomedusae; B: propagule of Halecium pusillum, Leptomedusae; C: frustule formation in Limnocnida tanganyicae, Limnomedusae; D: cyst formation in Limnocnida tanganyicae, Limnomedusae; F: podocyst of Moerisia horii, Anthomedusae. (A after Billard, 1904; B after Werner, 1984; C and D after Bouillon, 1957; E after Uchida and Nagao, 1959). cy: cyst; fr: frustule; ht: hydrotheca; hth: hydranth; m: medusa; p: periderm; pod: podocyst; pr: propagule; sto: stolon. 


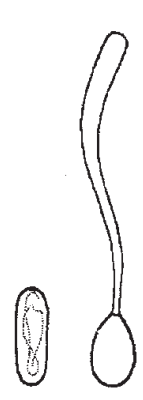

A

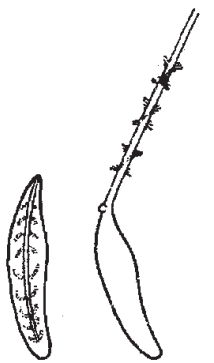

G

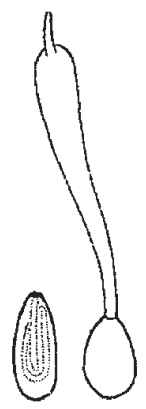

B

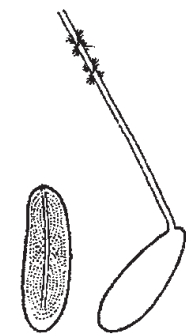

$\mathrm{H}$

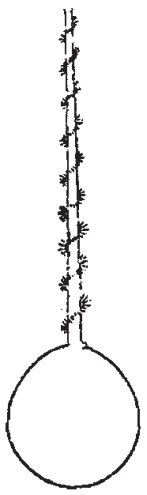

M

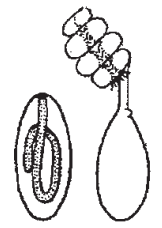

C

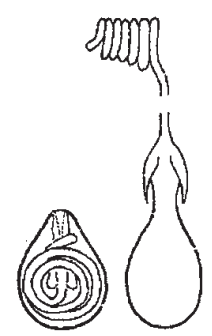

D

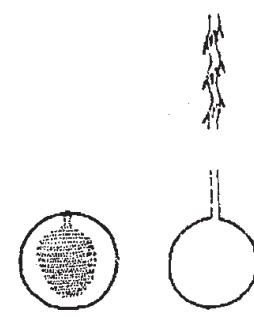

I

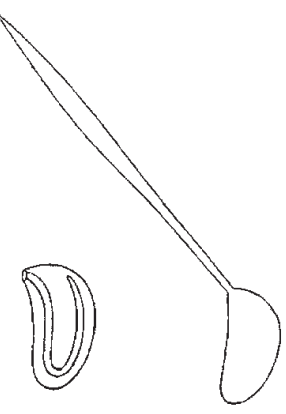

$\mathrm{N}$

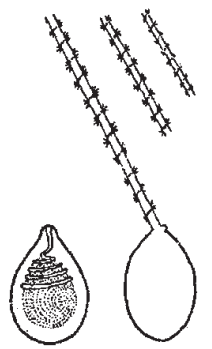

$\mathrm{J}$

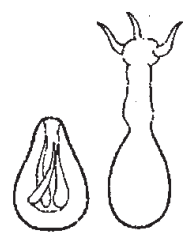

E

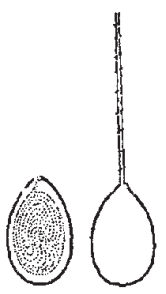

F

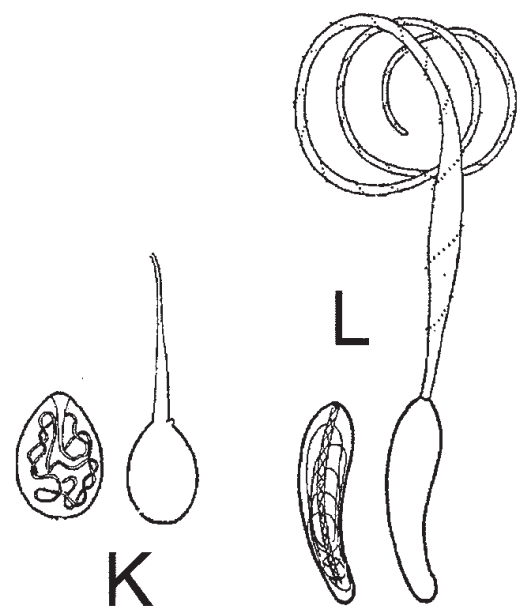

$\mathrm{K}$

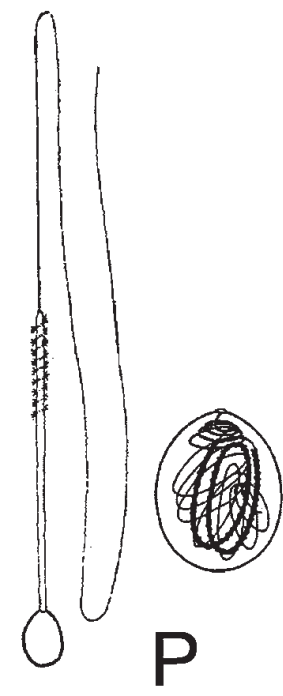

FIG. 23. - Morphology of cnidocysts. Different types of cnidocysts described in hydroids and medusa: A: anacrophore; B: acrophore; C: desmoneme; D: spirotele; E: aspirotele; F: atrichous isorhiza; G: basitrichous isorhiza; H: merotrichous isorhiza; I: apotrichous isorhiza; J: holotrichous isorhiza; $\mathrm{K}$ : atrichous anisorhiza; L.: homotrichous anisorhiza; $\mathrm{M}$ : heterotrichous anisorhiza; N: macrobasic atrichous mesotele; O: microbasic mastigophore; P: macrobasic mastigophores. (all after Mariscal, 1974; except N after Bouillon et al., 1988). 

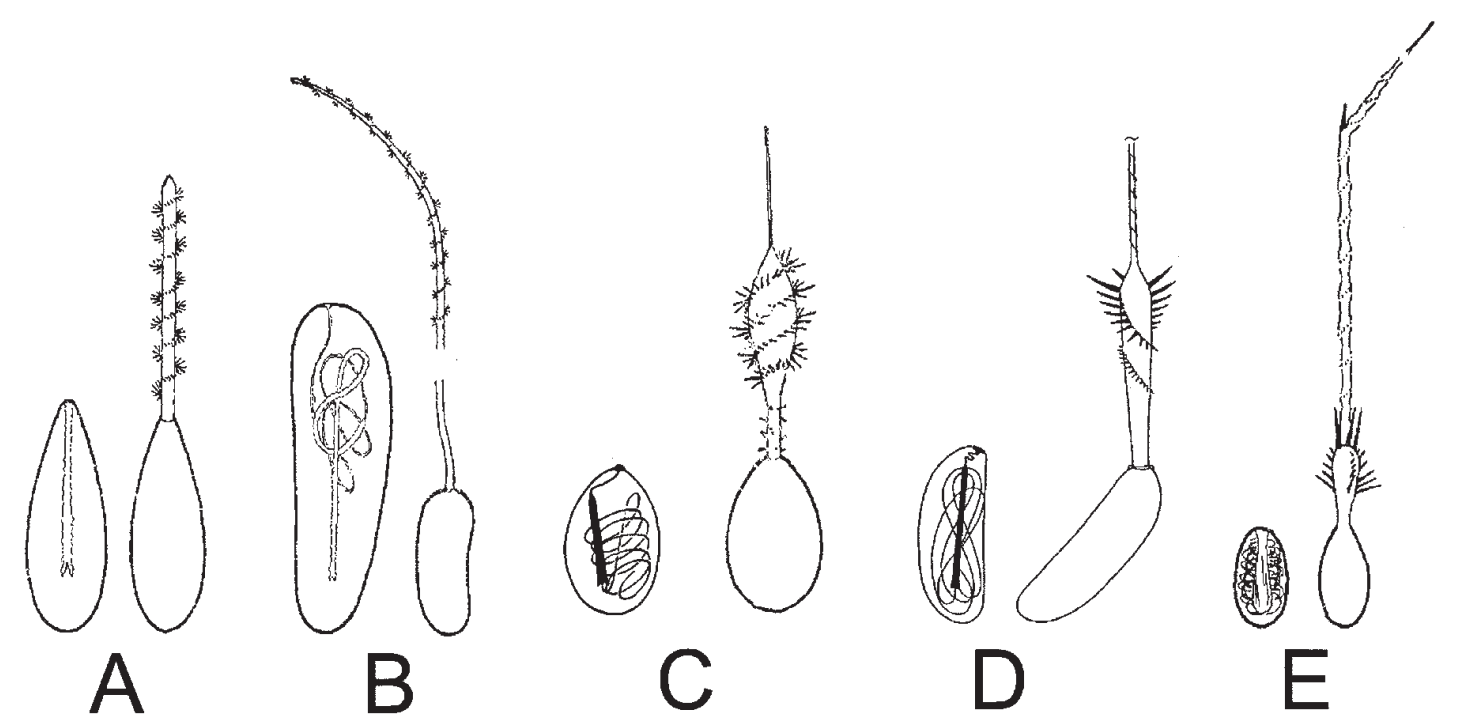

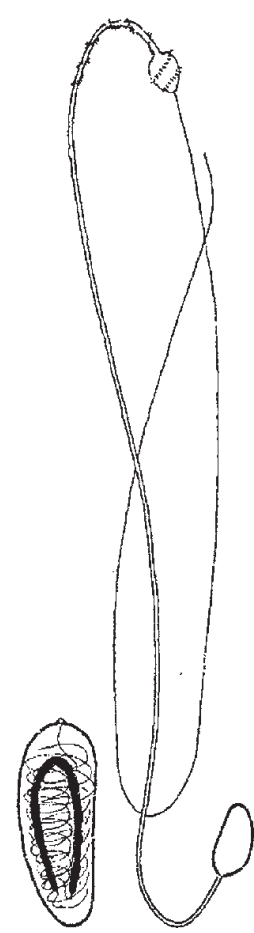

$\mathrm{F}$

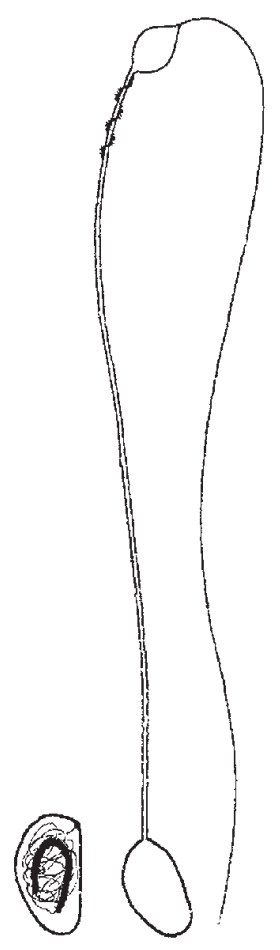

G
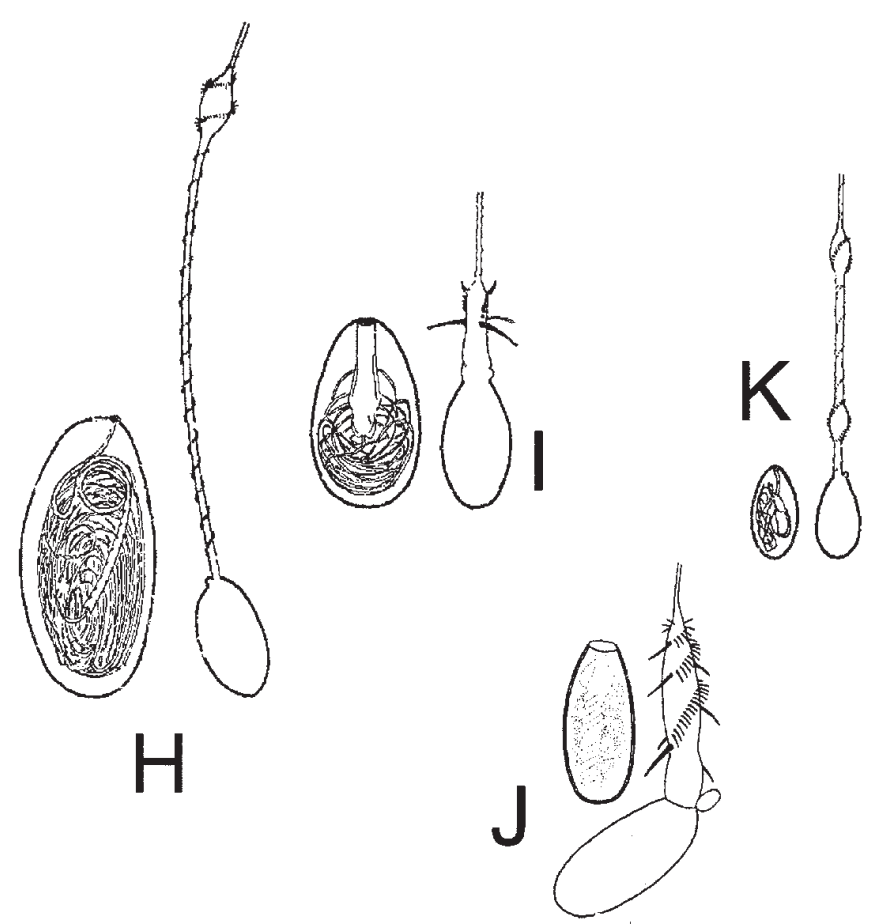

FIG. 24. - Morphology of cnidocysts. Different types of cnidocysts (end): A: microbasic amastigophores; B: macrobasic amastigophores; C: homotrichous microbasic eurytele; D heterotrichous microbasic eurytele; E: semiophoric microbasic eurytele; F: telotrichous macrobasic eurytele; G: merotrichous macrobasic eurytele; H: holotrichous macrobasic eurytele; I: stenotele; J: pseudostenotele; K: birhopaloid (A to I and K after Mariscal, 1974; J after Bouillon et al.,1986). 

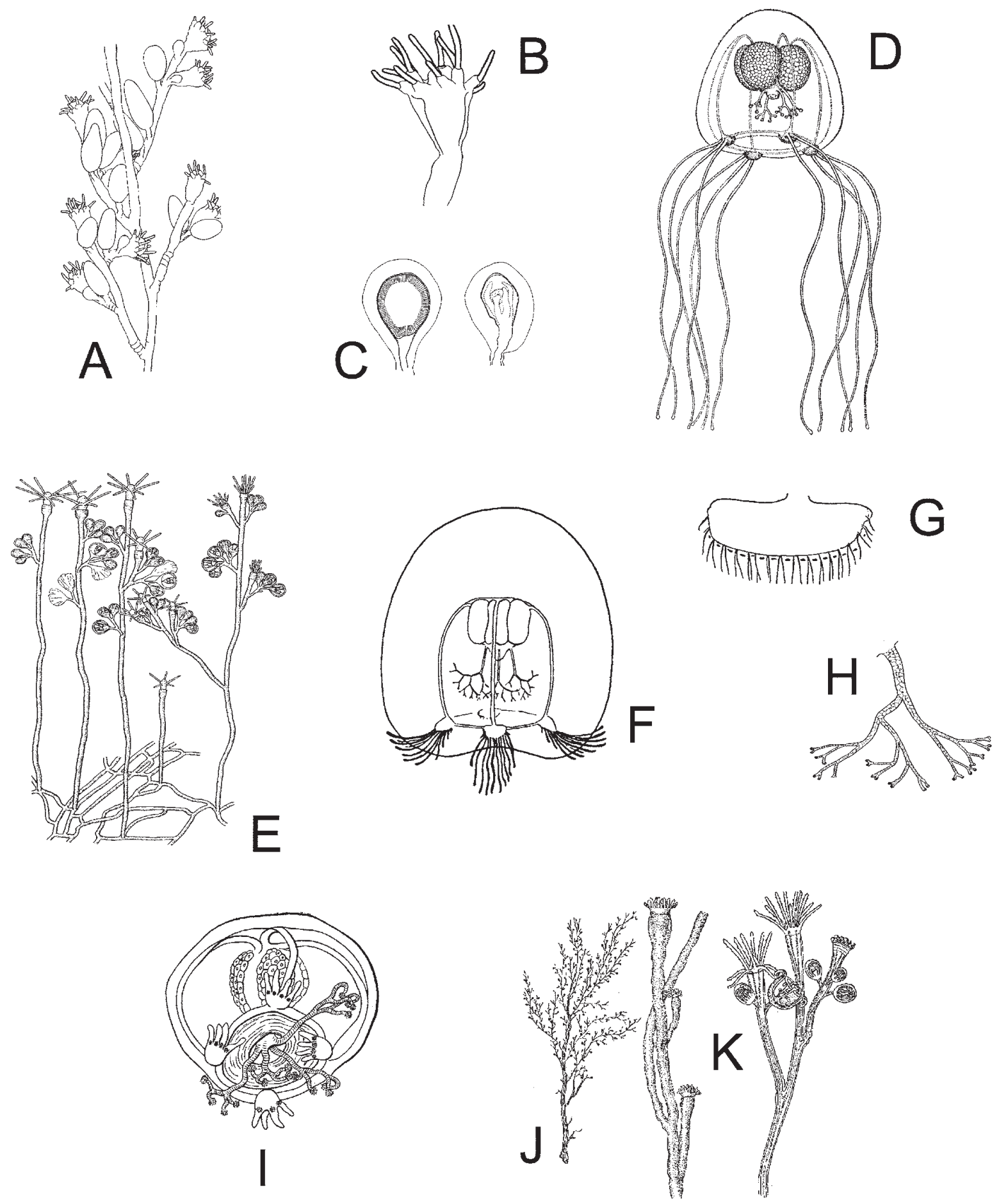

FIG. 25. - Anthomedusae. Filifera. Bougainvilliidae. A to C: Bimeria vestita: A: part of stem with hydranths and male gonophores, B: hydranth showing perisarcal sheats round tentacles, C: female gonophores enveloped in a perisarcal coat; D to K: Bougainvillia: D: Bougainvillia aurantiaca: mature medusa; E to $\mathrm{H}$ : Bougainvillia britannica: E: hydroid colony with hydranths and medusa buds, F: adult medusa, G: marginal bulb, H: oral tentacle; I: Bougainvillia maniculata mature medusa; J and K: Bougainvillia muscus: J: branch of a colony, K: details showing hydranths and medusa buds (A to C after Hirohito, 1988; D after Bouillon, 1978b; E after Edwards, 1964; F Kramp, 1959a; $\mathrm{G}$ and H after Russell, 1953; I after Mayer, 1910; J and K after Leloup, 1952). 

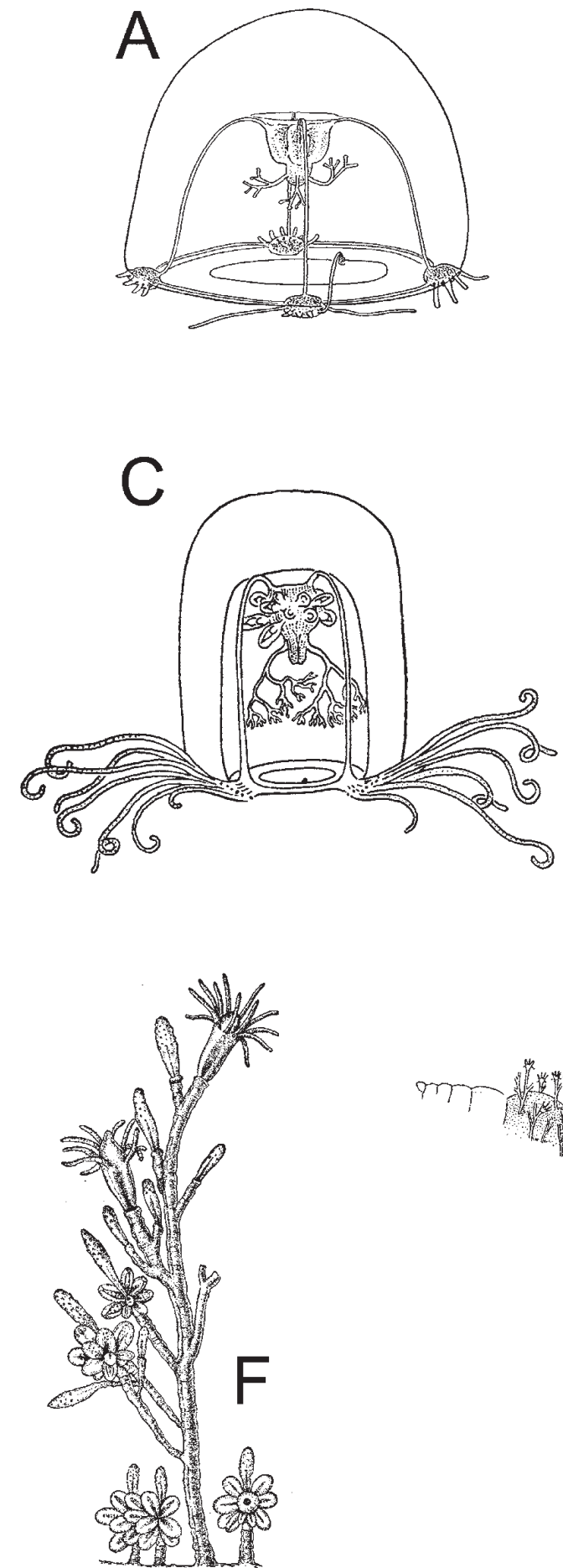
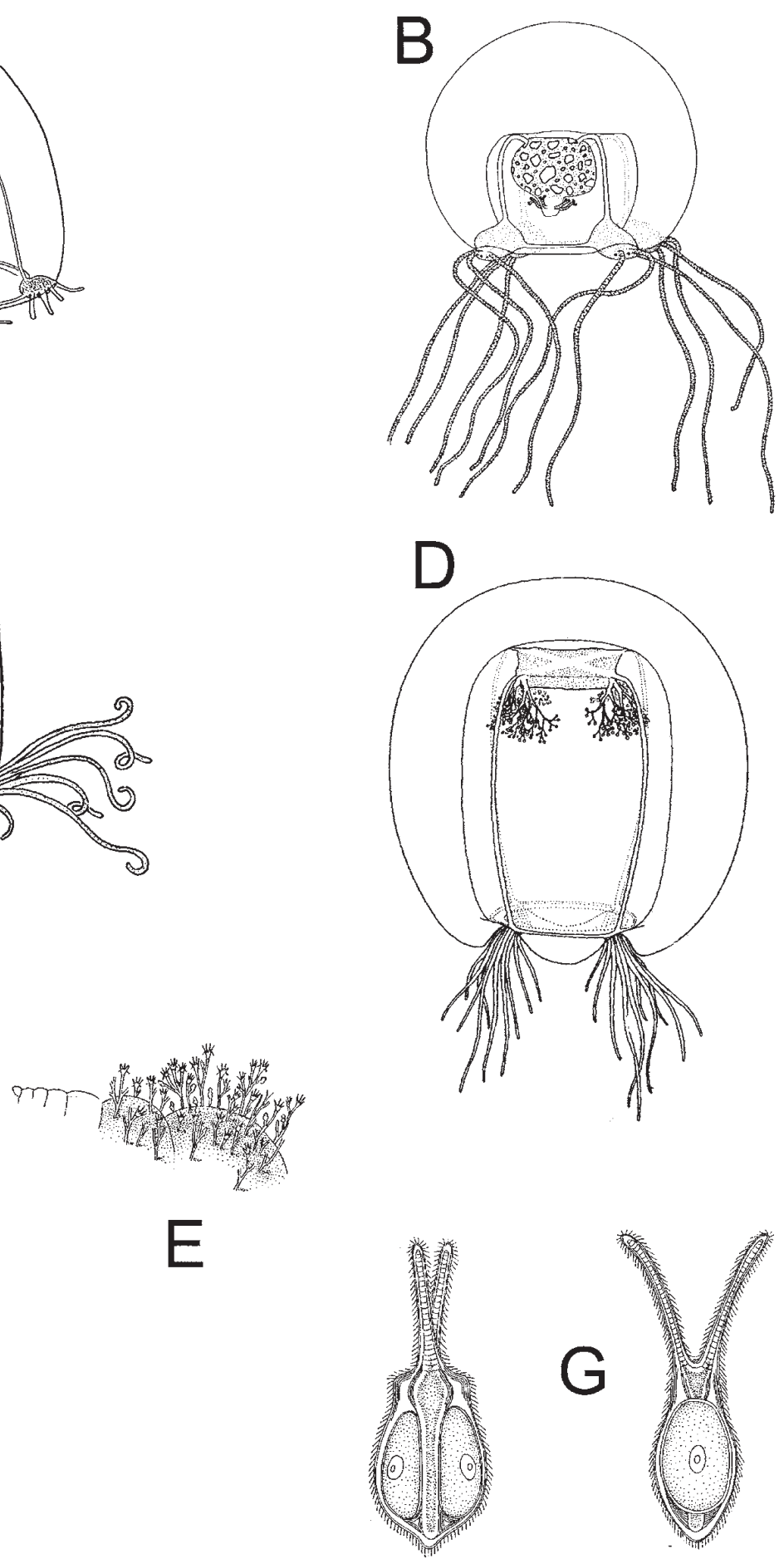

FIG. 26. - Anthomedusae. Filifera. Bougainvilliidae. A and B: Bougainvillia muscus: mature medusae; C: Bougainvillia niobe: medusa with manubrial medusa buds; D: Bougainvillia platygaster adult medusa; E to G: Dicoryne conferta: E: general view of a colony living on a gastropod shell, F: part of a colony with hydranths and gonozooids; G: swimming sporosacs (A after Russell, 1953; B after Calder, 1988; C after Kramp, 1959a; D after Schuchert, 1996; E to G after Leloup, 1952). 

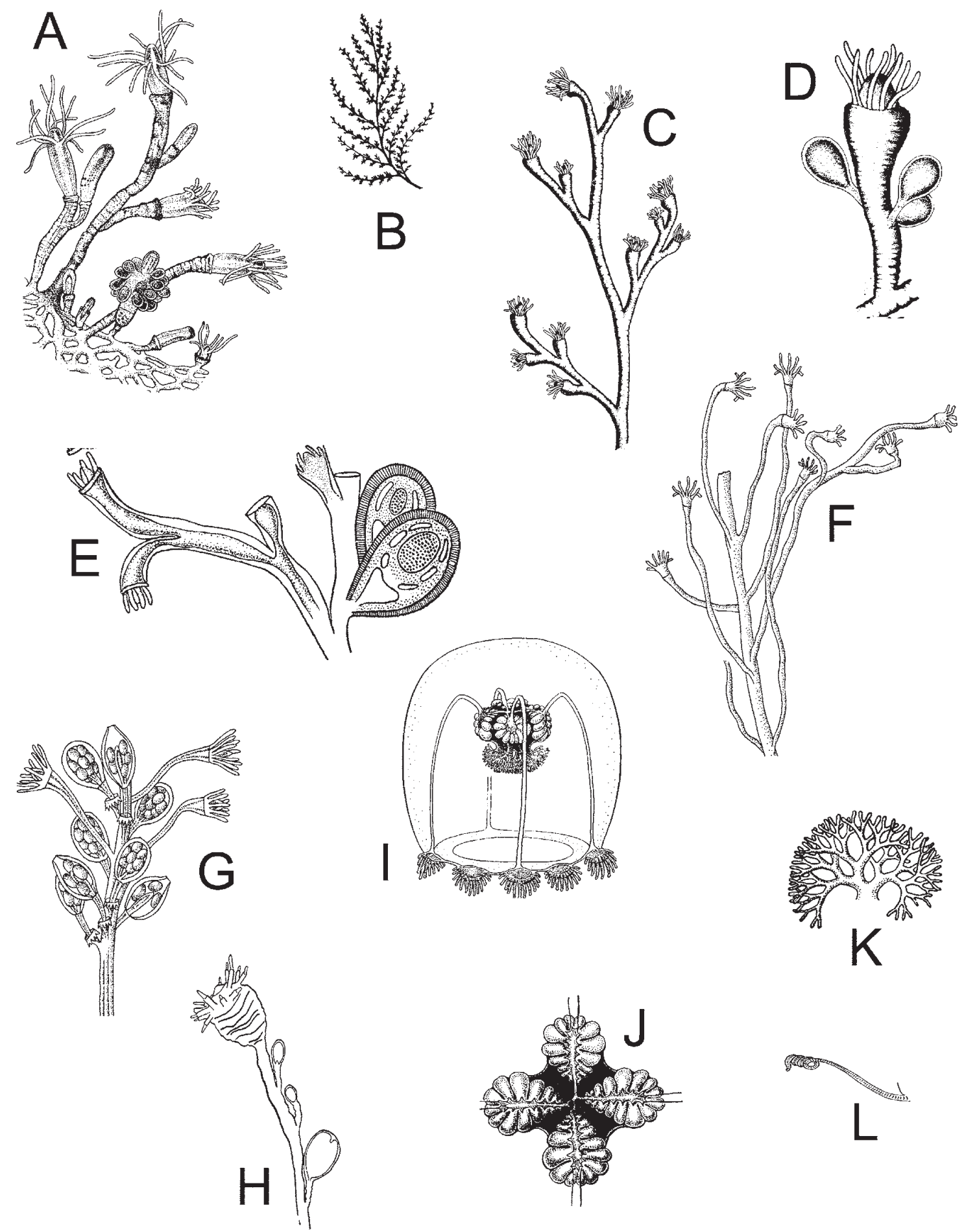

FIG. 27. - Anthomedusae. Filifera. Bougainvilliidae. A: Dicoryne conybeari colony with gonozooids; B to G: Garveia: B to D: Garveia franciscana: B: general view of a colony, C: branch of a colony, D: hydranth with gonophores; E: Garveia grisea: fragment of a colony with gonophores: F and G: Garveia nutans: F. fragment of a colony; G: part of colony with gonophores; $\mathrm{H}$ to L: Koellikerina fasciculata: $\mathrm{H}$ : hydranth with medusa buds, I: adult medusa, J: aboral view of manubrium, K: oral tentacle, L: isolated perradial marginal tentacle (A after Cornelius et al., 1990; B to D after Morri, 1981; E after Motz-Kossowska, 1905; F and G after Leloup, 1952; H after Petersen and Vannucci, 1960; I to L after Mayer, 1910). 

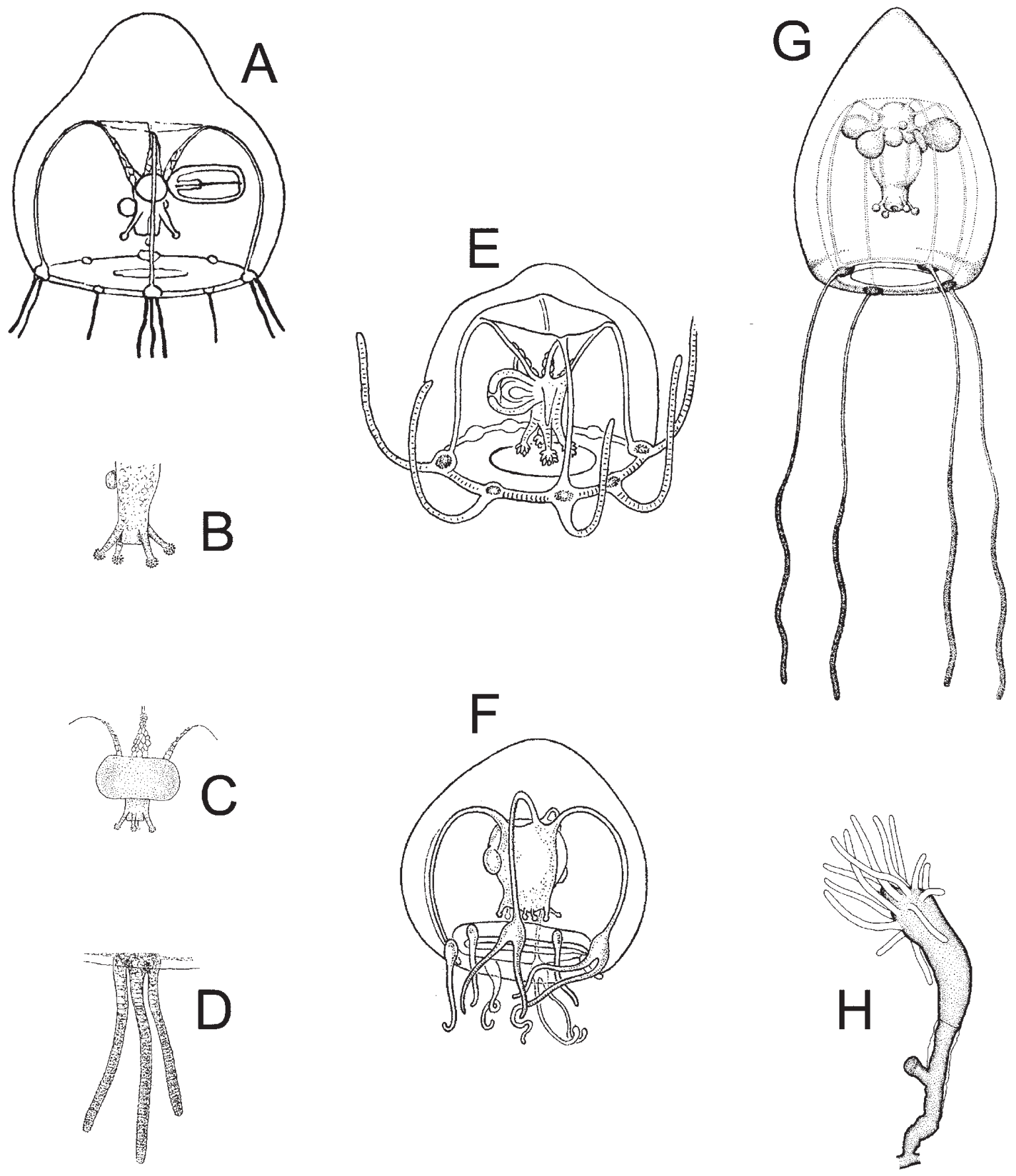

FIG. 28. - Anthomedusae. Filifera. Bougainvilliidae. A to F: Lizzia: A to D: Lizzia blondina: A: adult medusa with manubrial medusa buds, B: mouth with oral tentacles, C: manubrium with gonad; D: perradial marginal tentacle group; E: Lizzia fulgurans medusa with manubrial medusa buds; F: Lizzia octostyla medusa; G: Nubiella mitra adult medusa with manubrial medusa buds; $\mathrm{H}$ : Pachycordyle napolitana hydranth (A, E and F after Kramp, 1959a; B to D after Russell, 1953; G after Bouillon, 1980; H after Calder, 1988). 


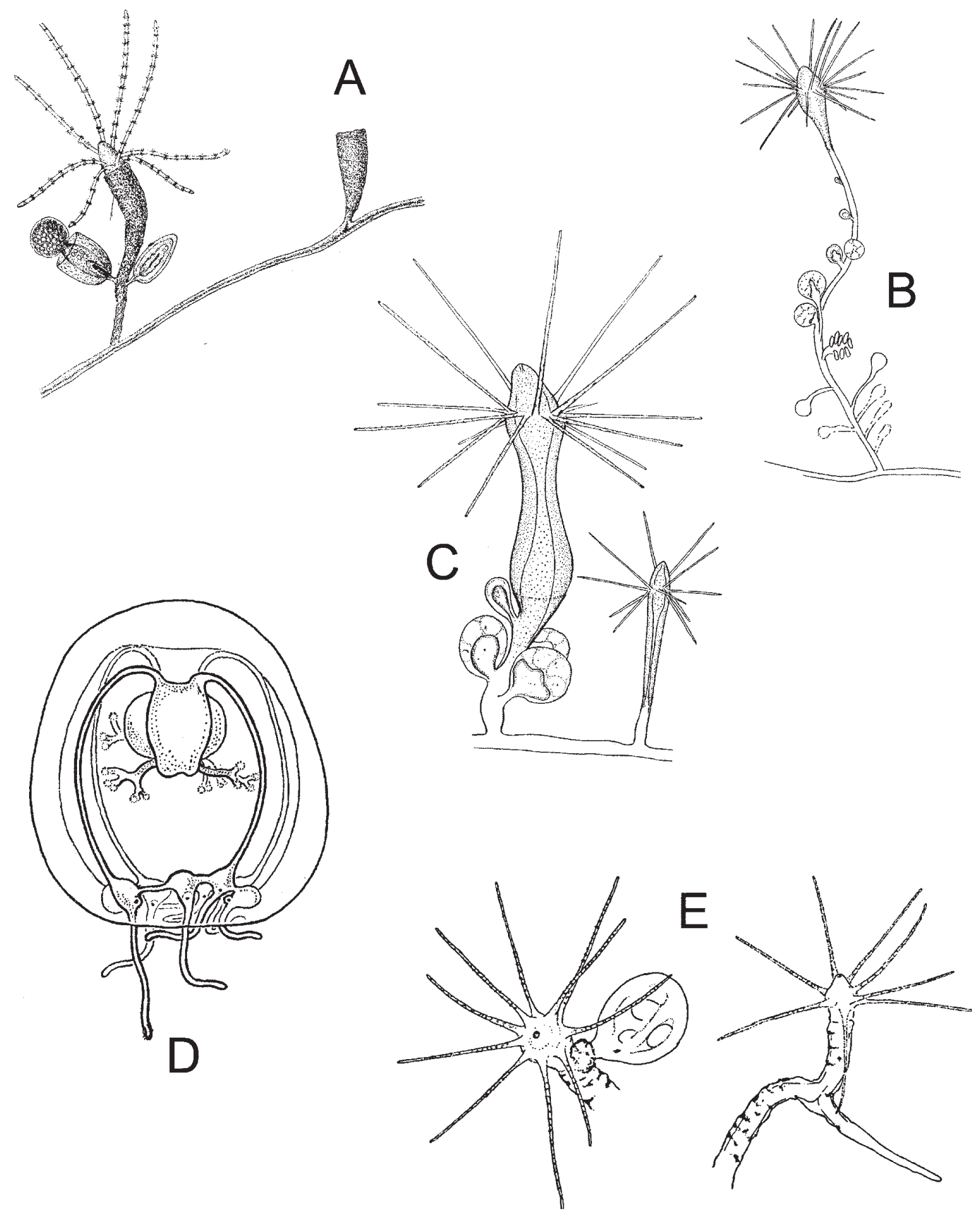

FIG. 29. - Anthomedusae. Filifera. Bougainvilliidae. A to C: Rhizorhagium. A: Rhizorhagium arenosa part of colony with hydranth and gonophores; B and C: Rhizorhagium michaeli: B: branch of colony showing hydranth and succession of gonophores from distal juveniles to proximal stalk remnants; C: detail of hydranth with gonophores; D: Thamnostoma dibalia mature medusa; E: Velkovrhia enigmatica hydranths, one with fixed sporosac (A after Hincks, 1868; B and C after Berrill, 1948; D after Kramp, 1959a; E after Clausen and SalviniPlawen, 1986). 

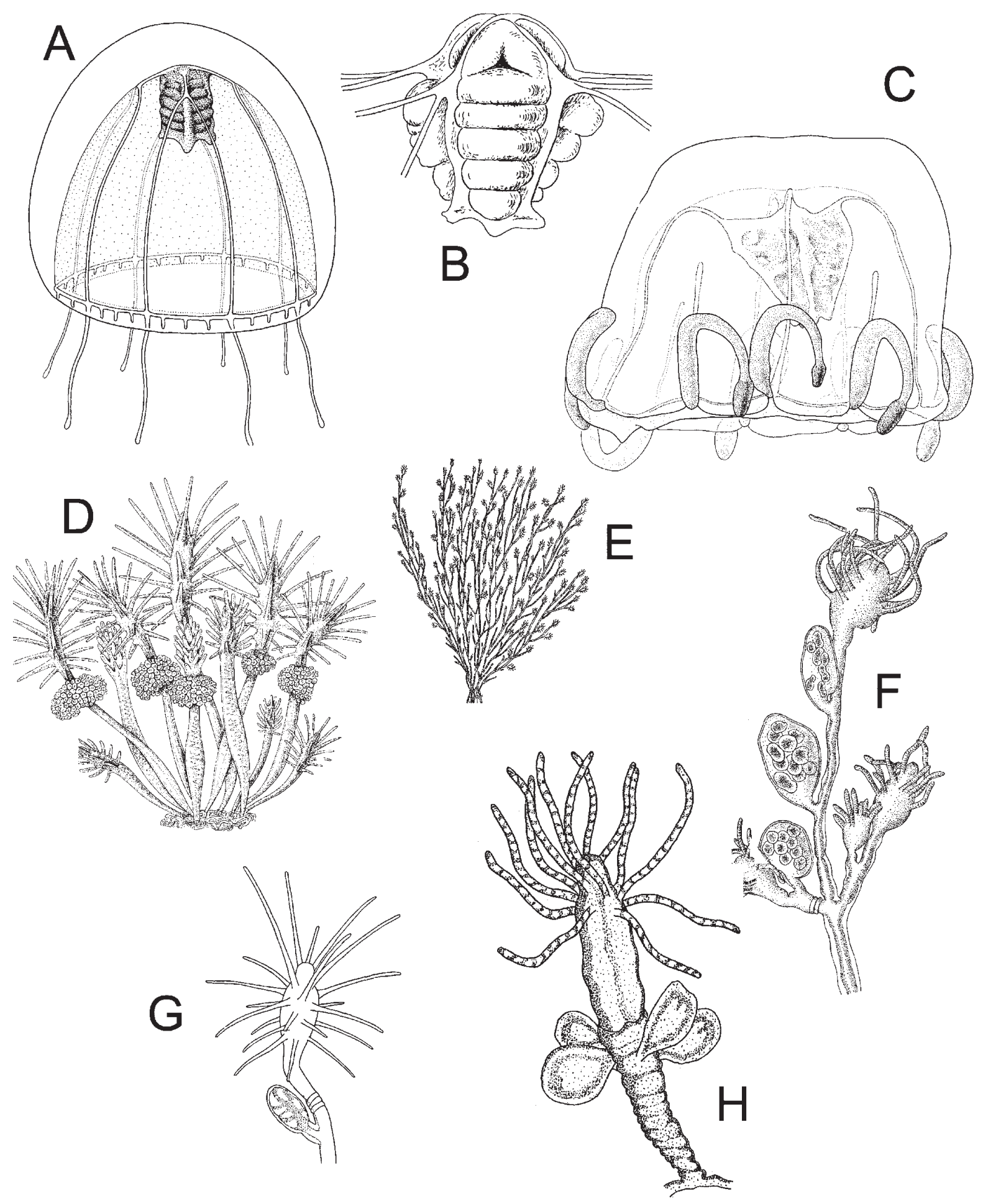

FIG. 30. - Anthomedusae. Filifera. Bythotiaridae. A and B: Bythotiara murayi: A: adult medusa; B: manubrium and gonads. C: Calycopsis simplex: adult medusa; D to H: Clavidae: D: Clava multicornis: colony with gonophores; E to H: Cordylophora: E to G: Cordylophora caspia: E: general view of a colony, F: branch of a colony with hydranths and gonophores, G: detail of a hydranth with young gonophore; H: Pachycordyle (Cordylophora pussilla): hydranth with gonophores (A and B after Russell, 1953; C and H after Gili et al., 1988; D after Allman, 1871; E and F after Leloup, 1952; G after Schuchert, 1996). 

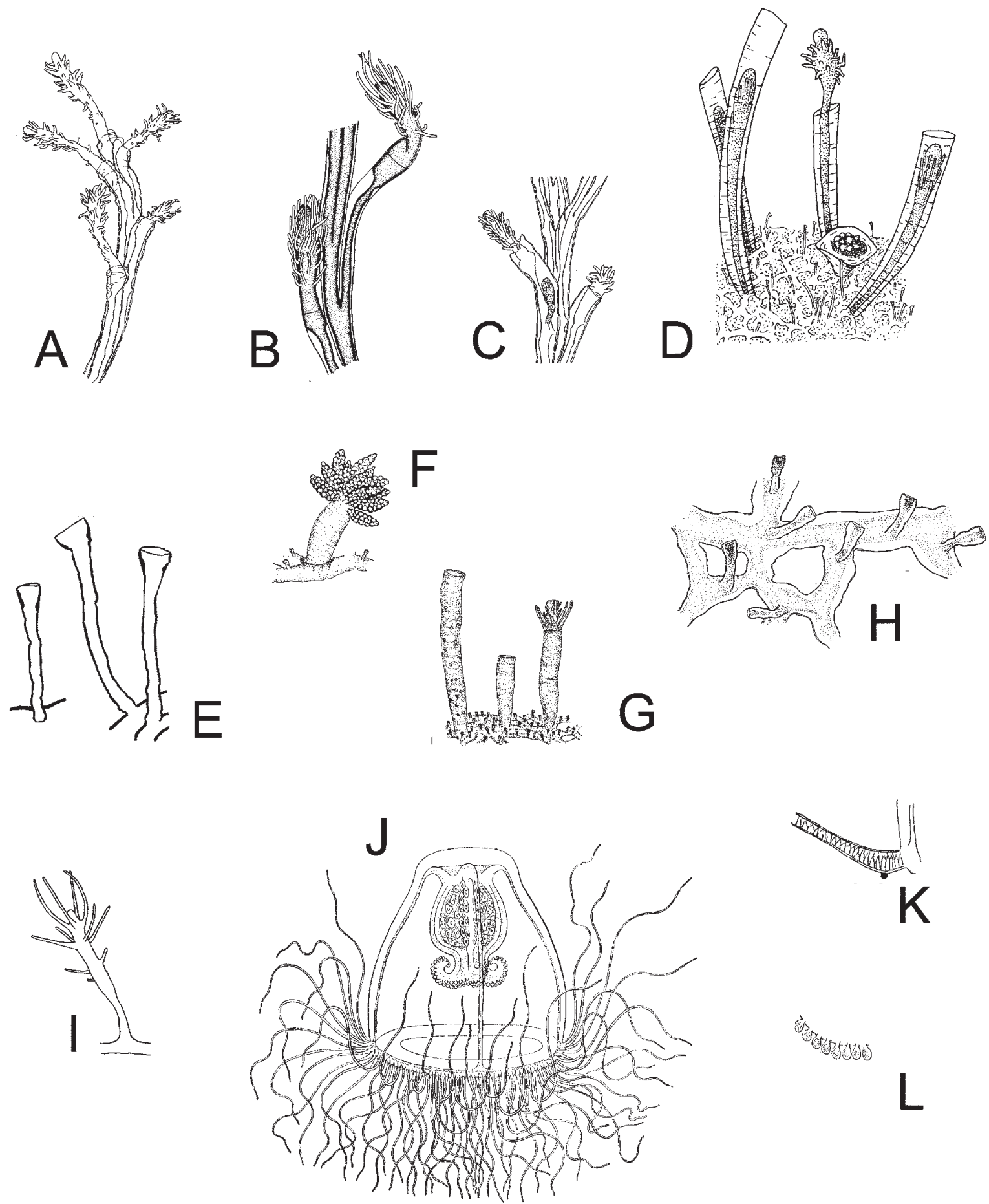

FIG. 31. - Anthomedusae. Filifera. Clavidae. A to C: Corydendrium parasiticum: A: part of colony with hydranths; B: detail of hydranths; $\mathrm{C}$ : part of stem with hydranths and male gonophores within perisarcal tubes; D to H: Merona: D and E: Merona cornucopiae: D: part of colony growing on bivalve showing gastrozooids, one gonozooid and nematophores, $\mathrm{E}$ : nematothecae; F to $\mathrm{H}$ : Merona ibera: $\mathrm{F}$ : gonozooid and dactylozooids; G: fragment of a colony with hydranths, hydrothecae and dactylozooids; H: hydrorhiza with dactylozooids; I to L: Oceania armata: I: polyp stage; J: adult medusa; K: part of marginal tentacle showing the position of the ocellus; L: part of mouth lip showing the cnidocyst clusters (A and C after Hirohito, 1988; B after Calder, 1988; D and E after Millard, 1975; F to H after Medel et al, 1993; I after Schuchert, 1996; J to L after Mayer, 1910). 

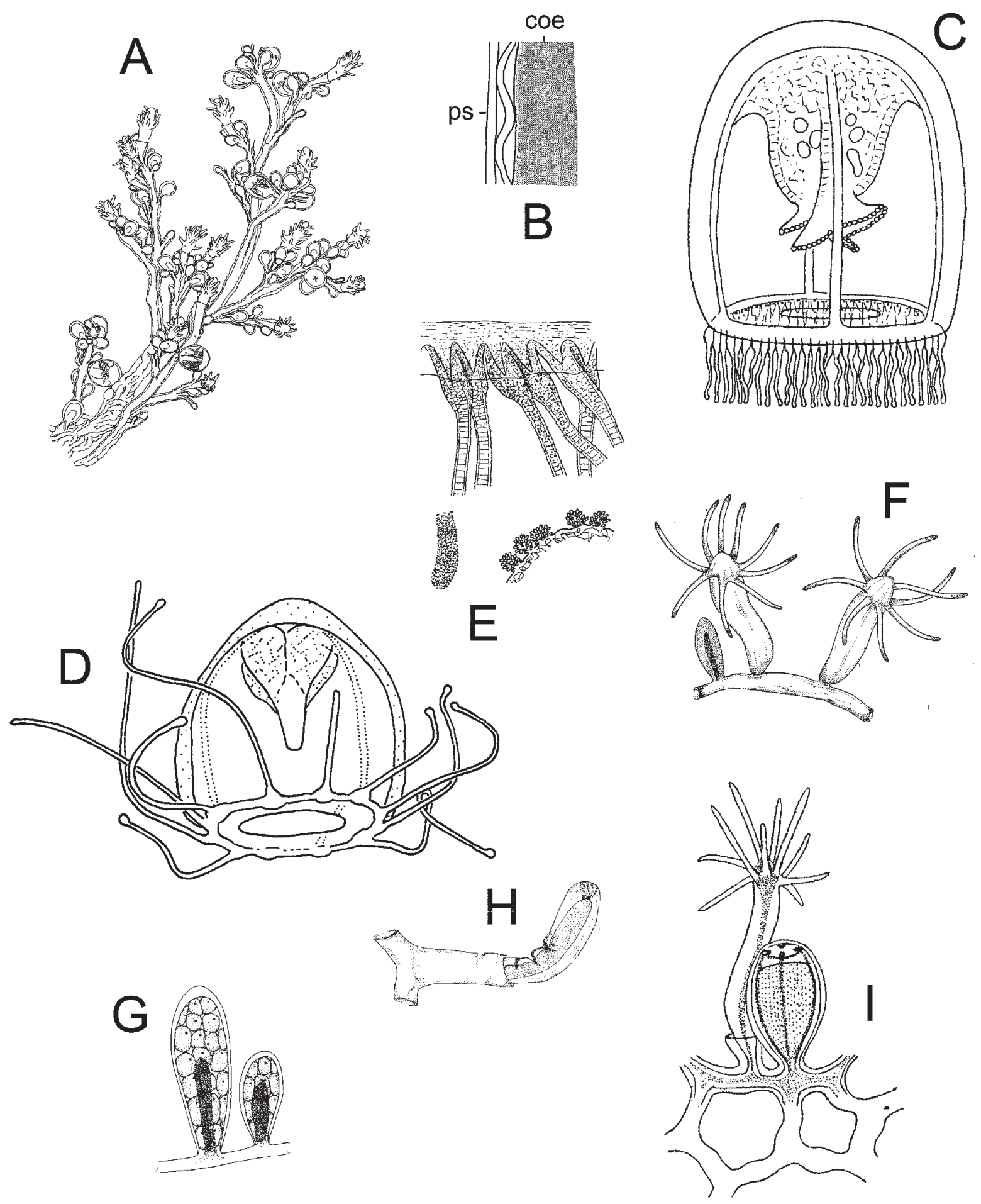

FIG. 32. - Anthomedusae. Filifera. Clavidae. A to C and E: Turritopsis nutricula: A: part of stem of an erect colony with adnate branches, hydranths and medusa buds; B: drawing of the stem region showing the double layered structure of perisarc (coe: coenosarc; ps: perisarc); C: adult medusa; E: above base of marginal tentacles, ocelli omitted, left: tip of a marginal tentacle, below: margin of mouth lip showing the cnidocyst clusters; D: Turritopsis dohrnii young medusa. Cytaedididae. F to I: Cytaeis: F to H: Cytaeis propagulata: F: hydranths with gonophores; G: female gonophores; H: propagula; I: Cytaeis schneideri: hydranth with gonophore (A after Hirohito, 1988; B and D after Schuchert, 1996; C after Kramp, 1968; D after Schuchert, 2004; E after Russell, 1953; F, G and H after Bavestrello, 1987; I after Motz-Kossowska, 1905). 

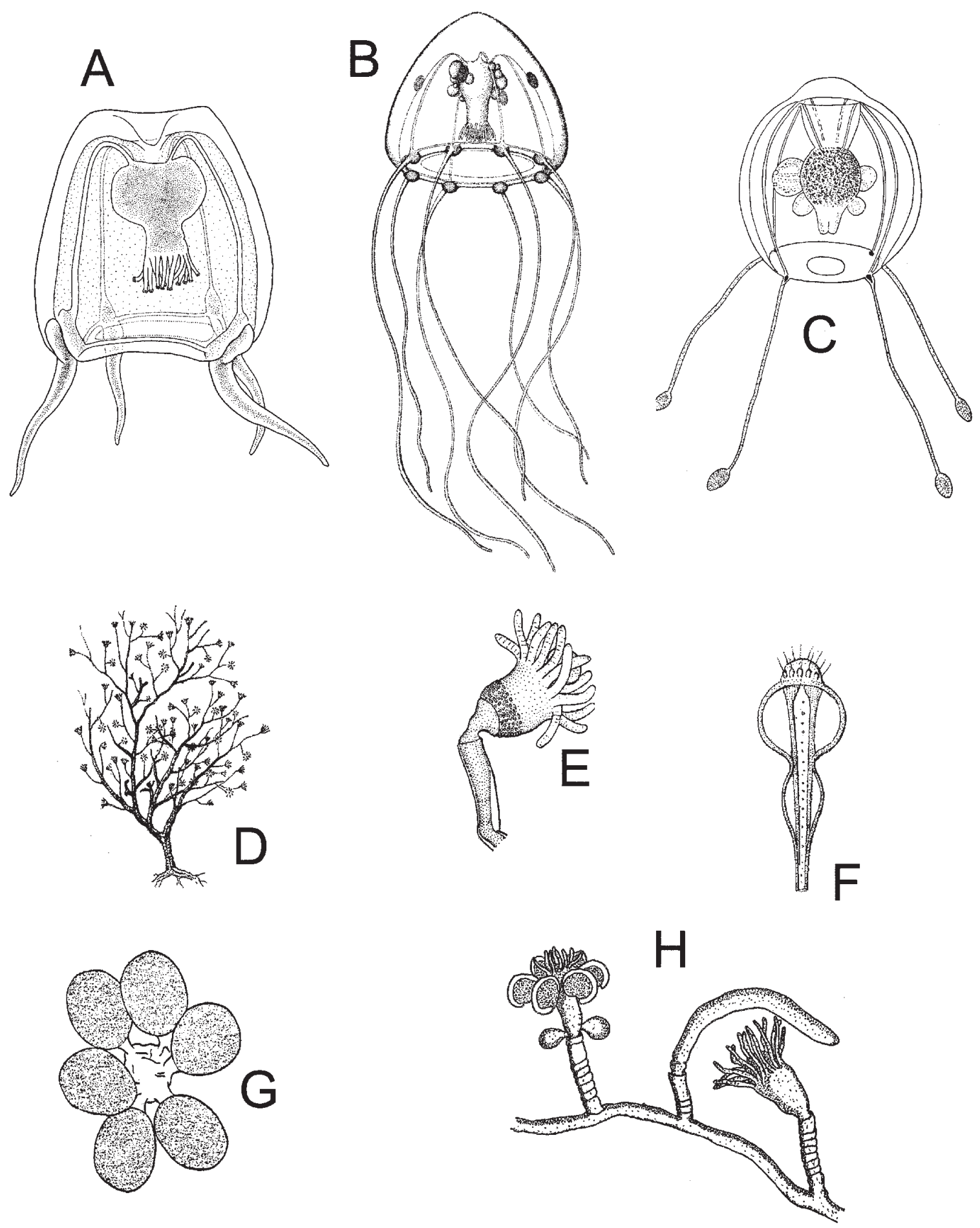

FIG. 33. - Anthomedusae. Filifera. Cytaedididae. A: Cytaeis sp.: adult medusa; B: Paracytaeis octona: adult medusa with medusa buds; C: Eucodoniidae. C: Eucodonium brownei: adult medusa. Eudendriidae. D to H: Eudendrium: D to G: Eudendrium arbusculum: D: general view of a colony, E: detail of a hydranth, F and G: male gonophores; H: Eudendrium armatum: portion of a colony (A after Pagès et al., 1992; B after Bouillon, 1978a; C after Russell, 1953; D and F after Hincks, 1868; E and G after Calder, 1972; H after Gili, 1986). 

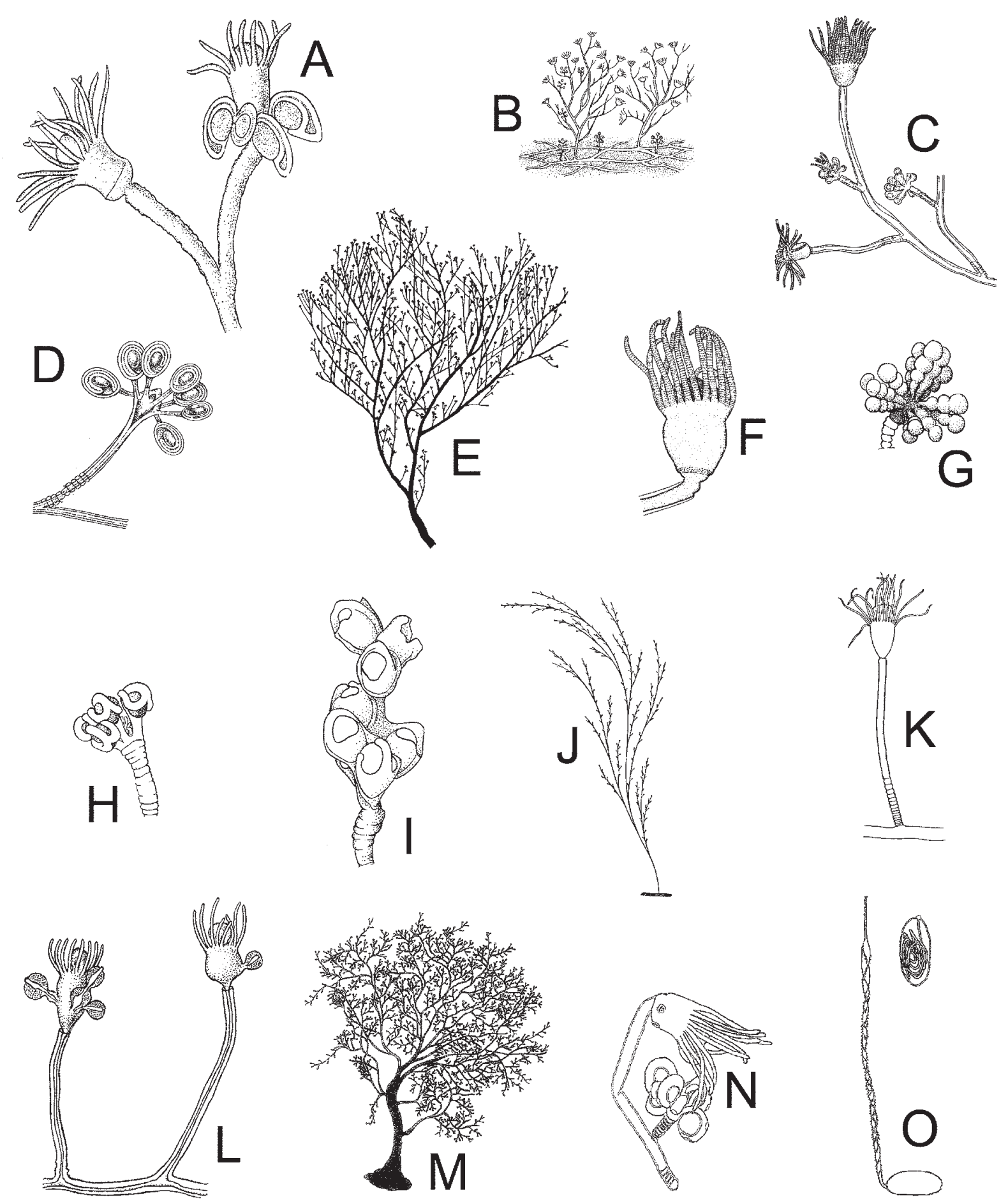

FIG. 34. - Anthomedusae. Filifera. Eudendriidae. A to K: Eudendrium: A: Eudendrium calceolatum fragment of a colony; B to D: Eudendrium capillare: B: general view of a colony; C: hydroclade with male gonophores; D: female gonophores; E to I: Eudendrium carneum: E: colony; F: detail of a hydranth; G: mature male blastostyle; H: young female blastosyle; I: old female blastostyle with spadices shed living basket-shaped capsules; J and K: Eudendrium elsaeoswaldae: J: colony; K: hydranth; L: Eudendrium fragile: part of colony; M to O: Eudendrium glomeratum: M: general aspect of a colony; N: hydranth with female gonophores; O: undischarged and discharged macrobasic euryteles (A and L after Motz-Kossowska, 1905; B to D after Leloup, 1952; E, G to I after Millard, 1975; F after Calder,1988; J and K after Stechow, 1923d; M to O after Boero et al., 1986). 

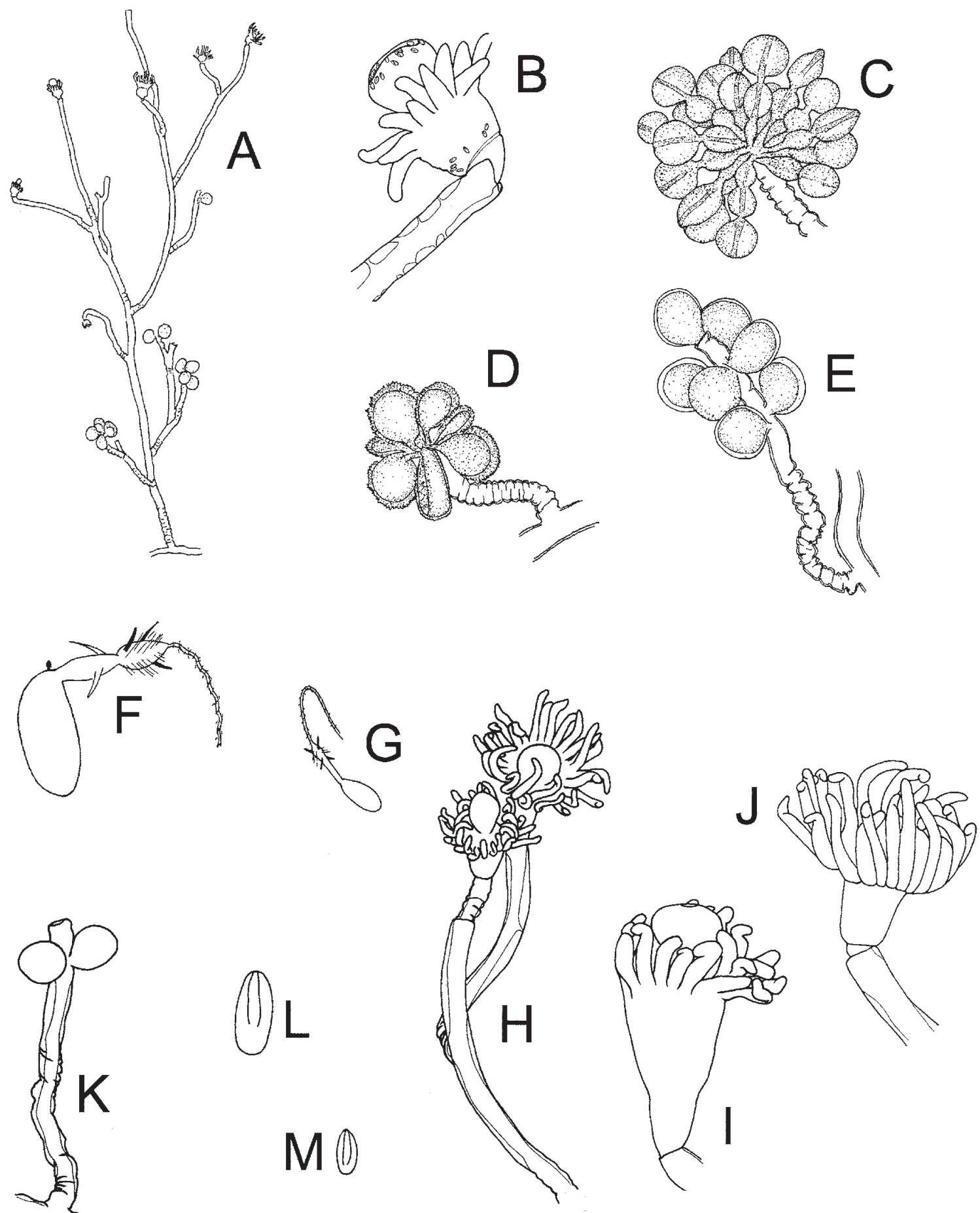

FIG. 35. Anthomedusae. Filifera. Eudendriidae. A to M: Eudendrium: A to G: Eudendrium merulum: A: whole stem; B: hydranth showing cnidocyst arrangement; C: mature male gonophore; D and E: female gonophores; F: large microbasic euryteles from hypostome and hydranth body; G: small microbasic euryteles from tentacles; H to M: Eudendrium moulouyensis: H: part of a branch and two hydranths; I and J: detail of hydranths; K: mature female blastostyle; L and M: microbasic euryteles. (A, C to G after Watson, 1985; B after Peña Cantero and García Carrascosa, 2002; H to M after Marques et al., 2000). 

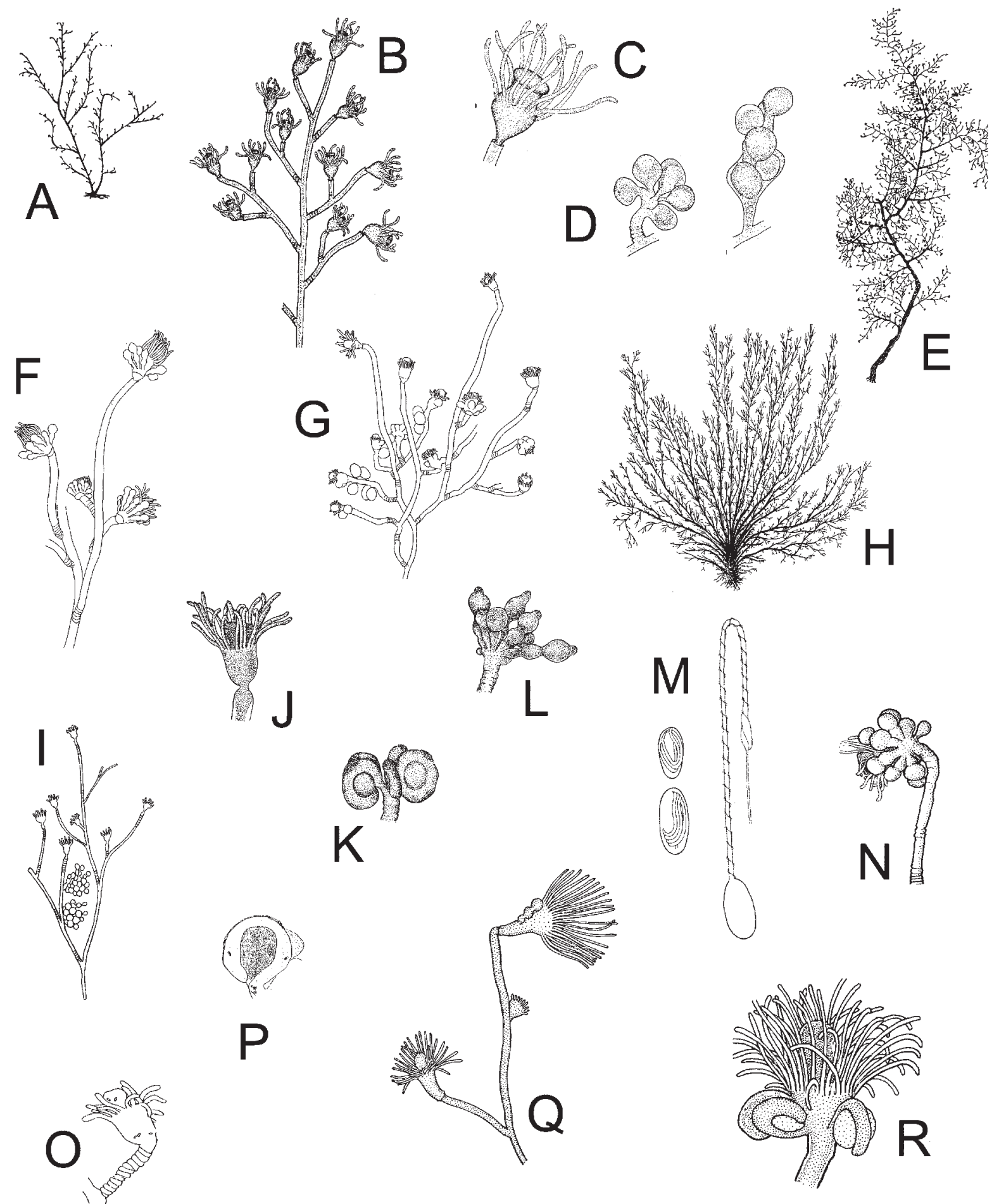

FIG. 36. - Anthomedusae. Filifera. Eudendriidae. A to P: Eudendrium: A to D: Eudendrium racemosum: A: general view of a colony, B: branch of a colony; C: detail of a hydranth; D: gonophores: at left female, at right male; E to G: Eudendrium rameum: E: part of a colony, F: part of stem with male blastostyles, G: fragment of stem with hydranths and female blastostyles; $\mathrm{H}$ to L: Eudendrium ramosum: $\mathrm{H}$ : general view of a colony, I: hydroclade with male gonophores; J: detail of a hydranth; K: detail of a female gonophore; L: detail of a male gonophore; M to P: Eudendrium simplex: M: large discharged and undischarged macrobasic euryteles; N: mature male gonophores; O: hydranth, P: female gonophore, with sperm capsule; Q and R: Myrionema amboinense: Q: hydrocaulus, hydranths and male gonophore, R: hydranth with female gonophores (A to D after Morri, 1981; E to G after Hirohito, 1988; H to L after Leloup, 1952; M and N after Millard, 1975; O and P after Boero, 1981; Q and R after Calder,1988). 

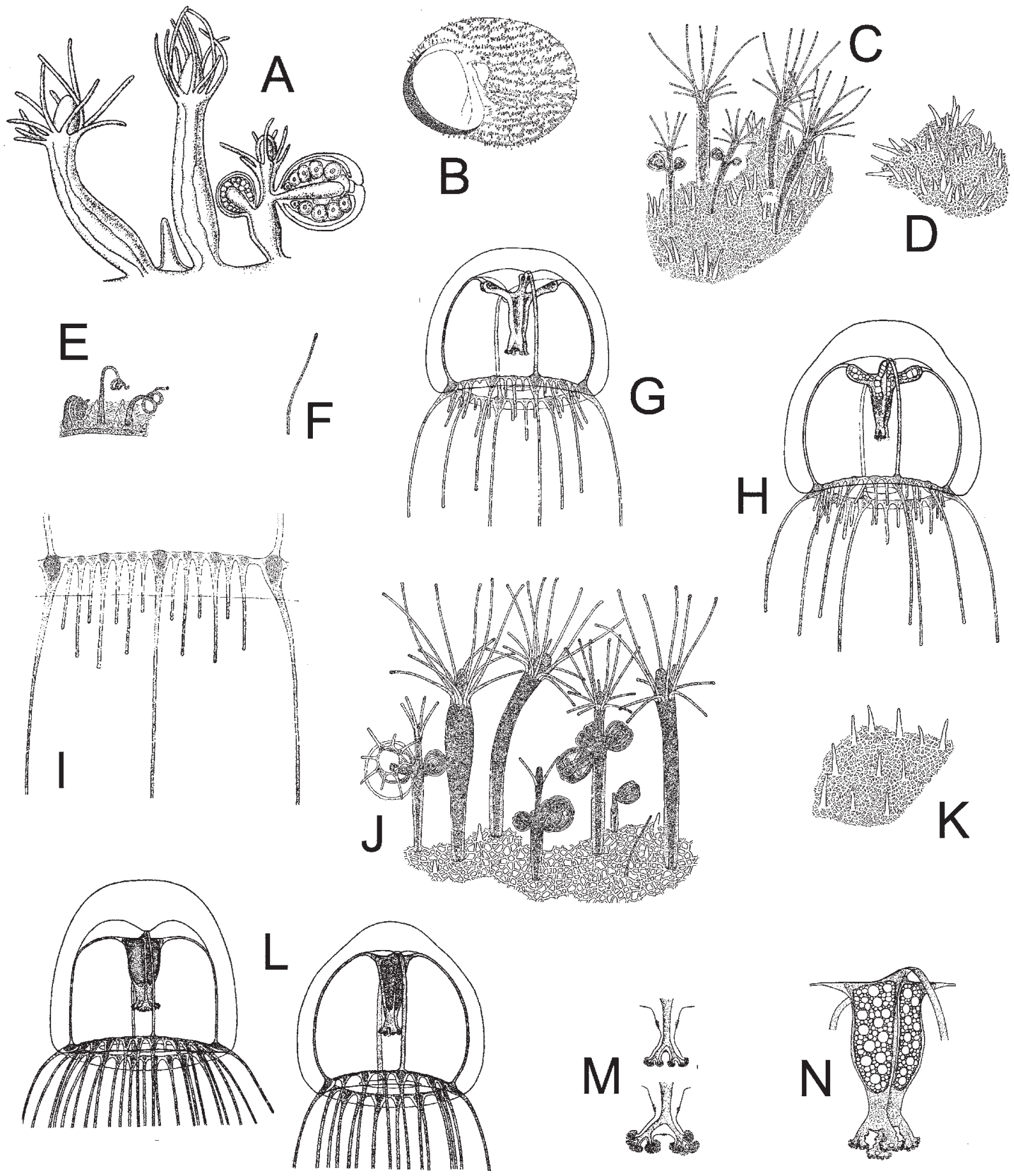

FIG. 37. - Anthomedusae. Filifera. Hydractiniidae. A to N: Hydractinia: A: Hydractinia aculeata: fragment of a colony; B to I: Hydractinia areolata: B: colony on a shell of Natica; C: portion of a colony; D: portion of colony hydranths omitted to show the arrangement of the spines; E: group of spiral zooids; F: tentaculozooid; G: male medusa; H: female medusa; I: quadrant of bell margin of ripe female. J to N: Hydractinia borealis: J: colony living on a shell of Aporrhais, showing hydranths, gonozooids, blastostyles, spines and tentaculozooids; K: portion of a colony hydranths omitted to show the arrangement of the spines; L: two male medusae; M: adoral view of the lips: above of a maturing female, below of a mature female; N: manubrium of a large mature female (A after Motz-Kossowska, 1905; B to N after Edwards, 1972). 

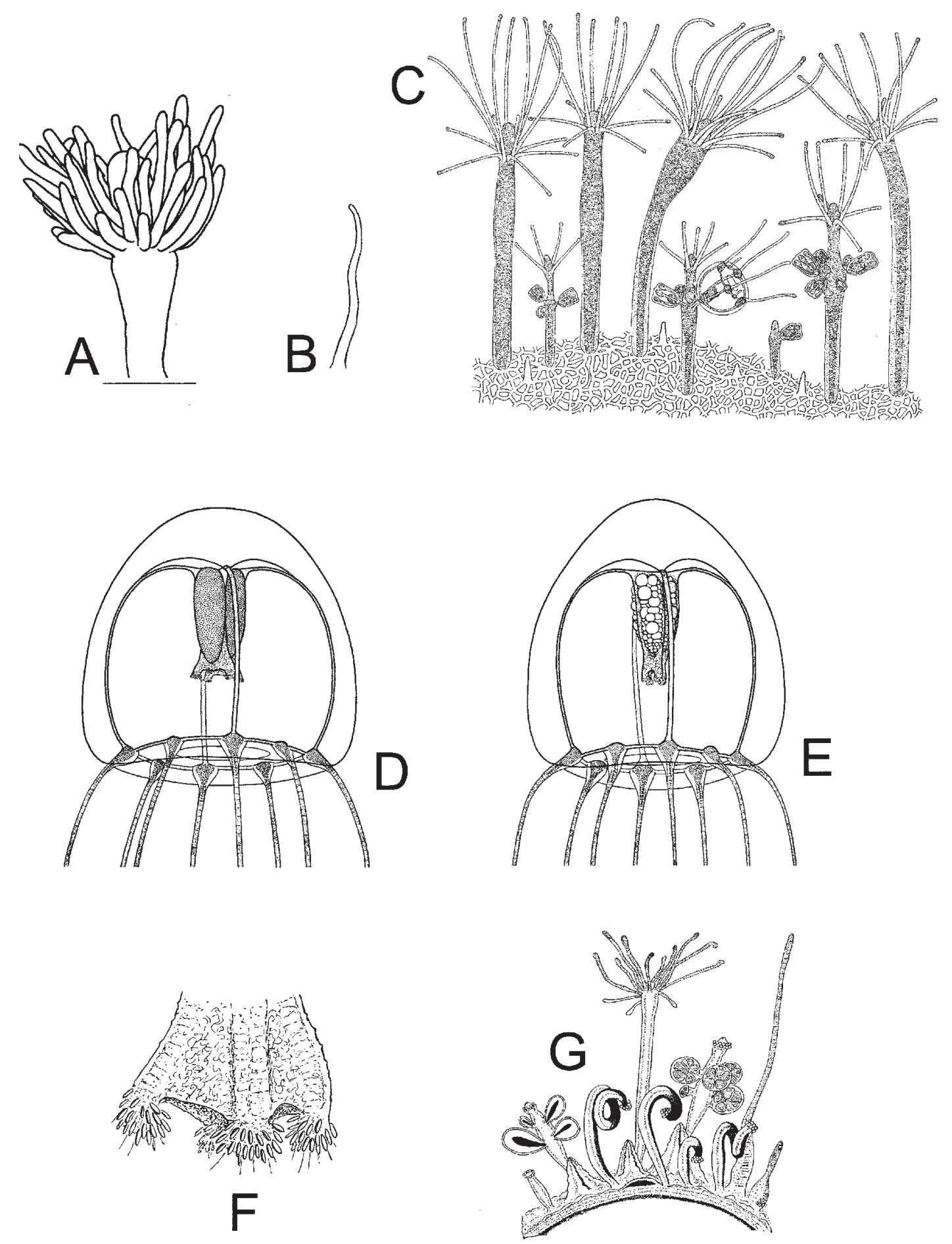

FIG. 38. - Anthomedusae. Filifera. Hydractiniidae. A to B: Hydractinia calderi: A: apical part of an adult gastrozooid; B dactylozooid. C to F: Hydractinia carnea: C: colony living on the shell of a Nassarius, showing gastrozooids, gonozooids, blastostyles and spines; D: male medusa; E: female medusa; F: mouth of a newly liberated medusae. G: Hydractinia echinata portion of a colony (A and B after Bouillon et al., 1997; C to F after Edwards, 1972; G after Stokes, 1974). 

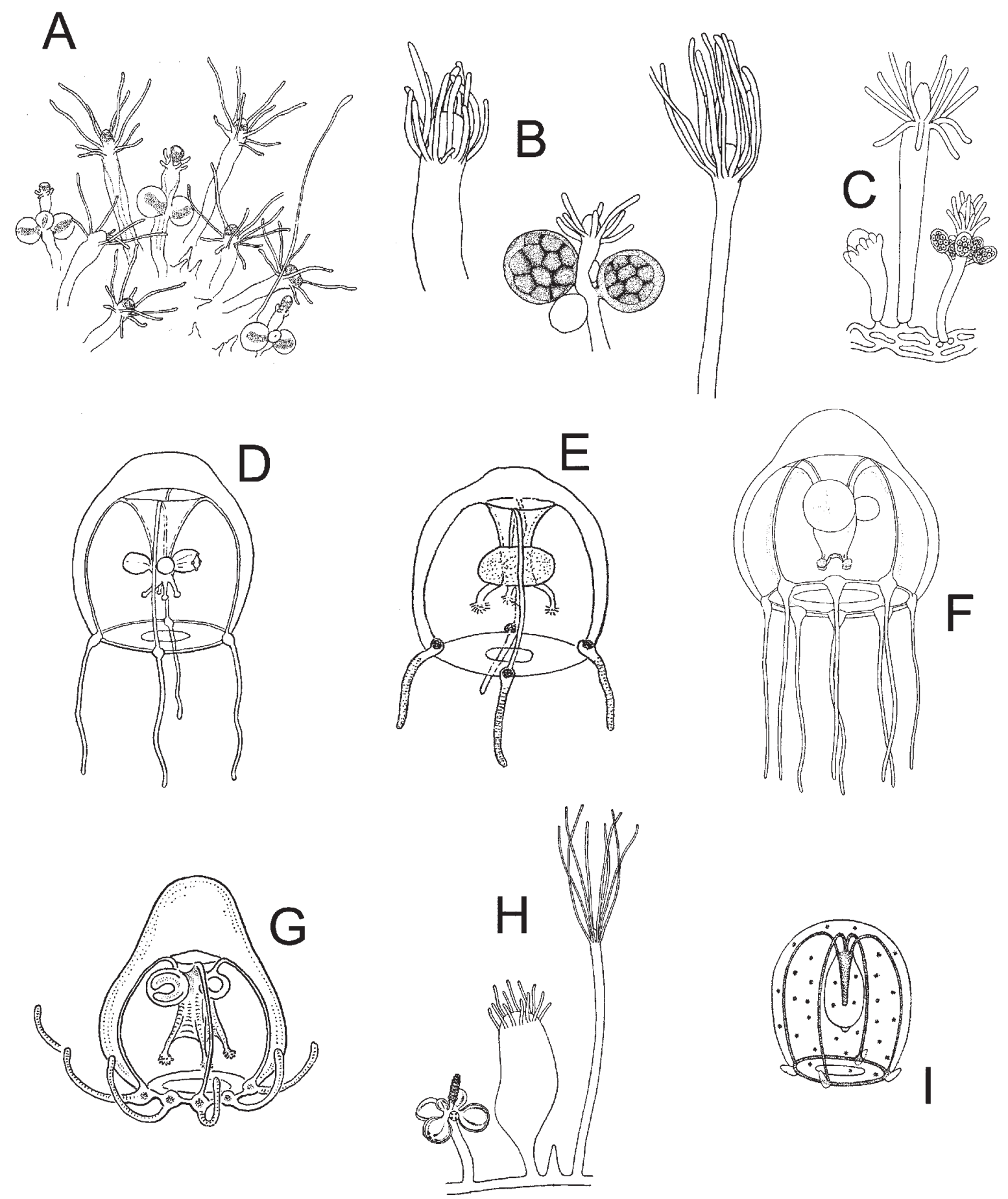

FIG. 39. - Anthomedusaee. Filifera. Hydractiniidae. A: Hydractinia fucicola: part of a colony; B: Hydractinia hooperii: left and right: gastrozooids, centre: a gonozooid with gonophores; C: Hydractinia inermis: portion of a colony with gonophores; D and E: Hydractinia mini$m a$ : medusae; $\mathrm{F}$ and $\mathrm{G}$ : Hydractinia minuta: medusae; $\mathrm{H}$ and I: Hydractinia pruvoti: $\mathrm{H}$ : fragment of a colony with blastostyle; I: eumedusoid (A after Castric-Fey, 1970; B after Peña Cantero and Carracosa, 2002; C, H and I after Iwasa, 1934; D after Kramp, 1968; E after Russell, 1953; F after Schuchert, 1996; G after Kramp, 1959a). 

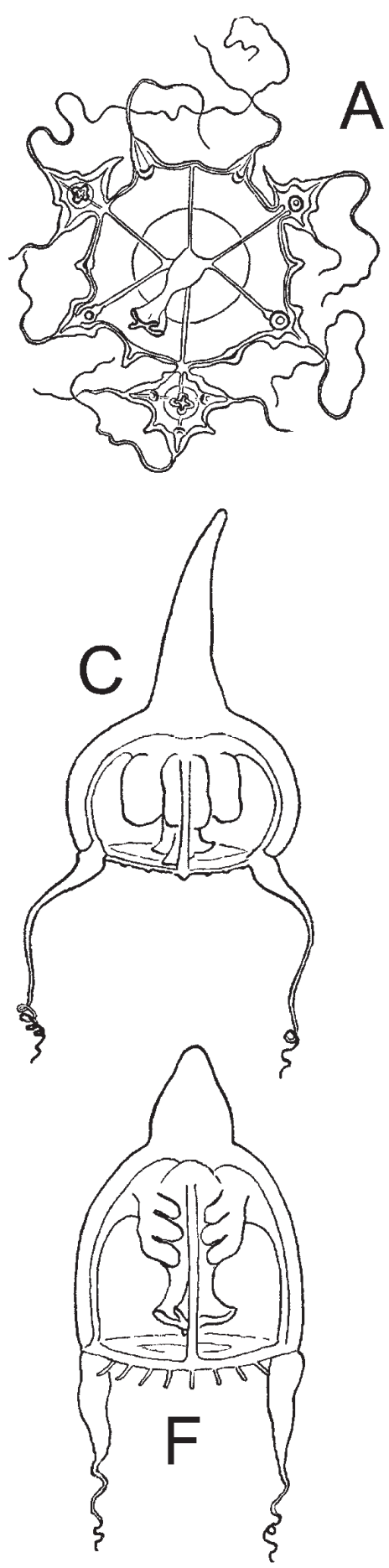
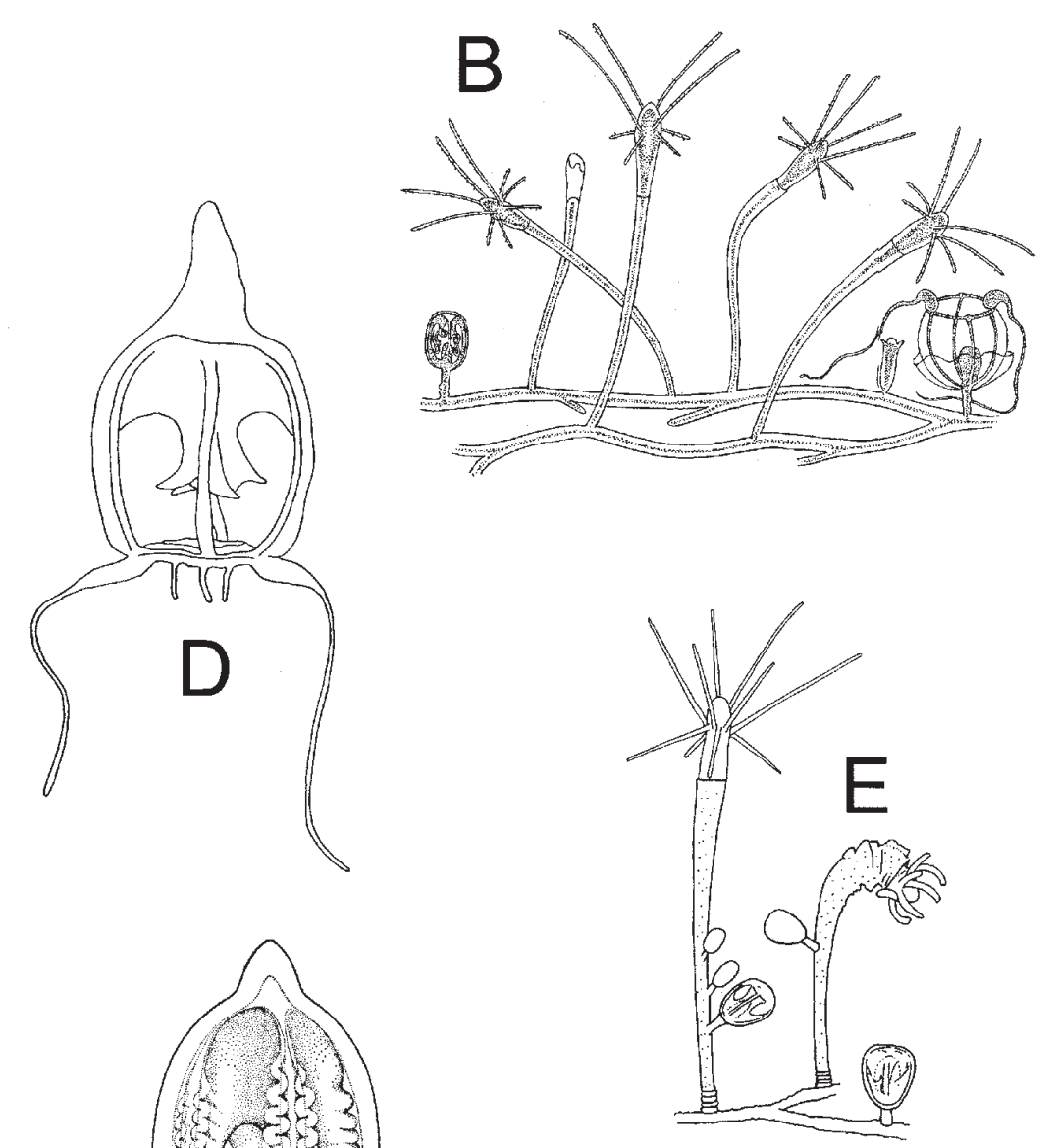

G
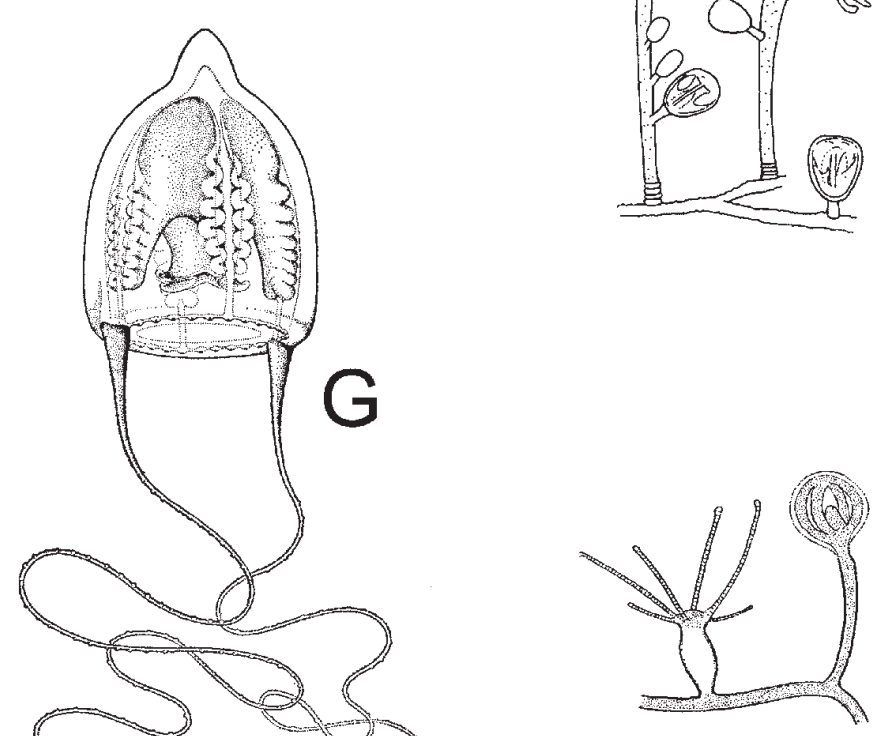

$\mathrm{H}$

FIG. 40. - Anthomedusae. Filifera. Niobiidae. A: Niobia dendrotentacula: medusa with tentacular bulbs transforming in medusa buds. Pandeidae: B to G: Amphinema: $\mathrm{B}$ and C: Amphinema dinema: $\mathrm{B}$ : portion of a hydroid colony, C: medusa. D: Amphinema rubra: medusa; E and F: Amphinema rugosum: E: fragment of a hydroid colony. F: medusa. G: Amphinema turrida: medusa; H: Codonorchis octaedrus: hydranth and medusa bud (A after Kramp, 1959a; B after Leloup, 1952; C and F after Kramp, 1968; D after Goy, 1972; G after Bouillon, 1980; H after Boero et al., 1997). 


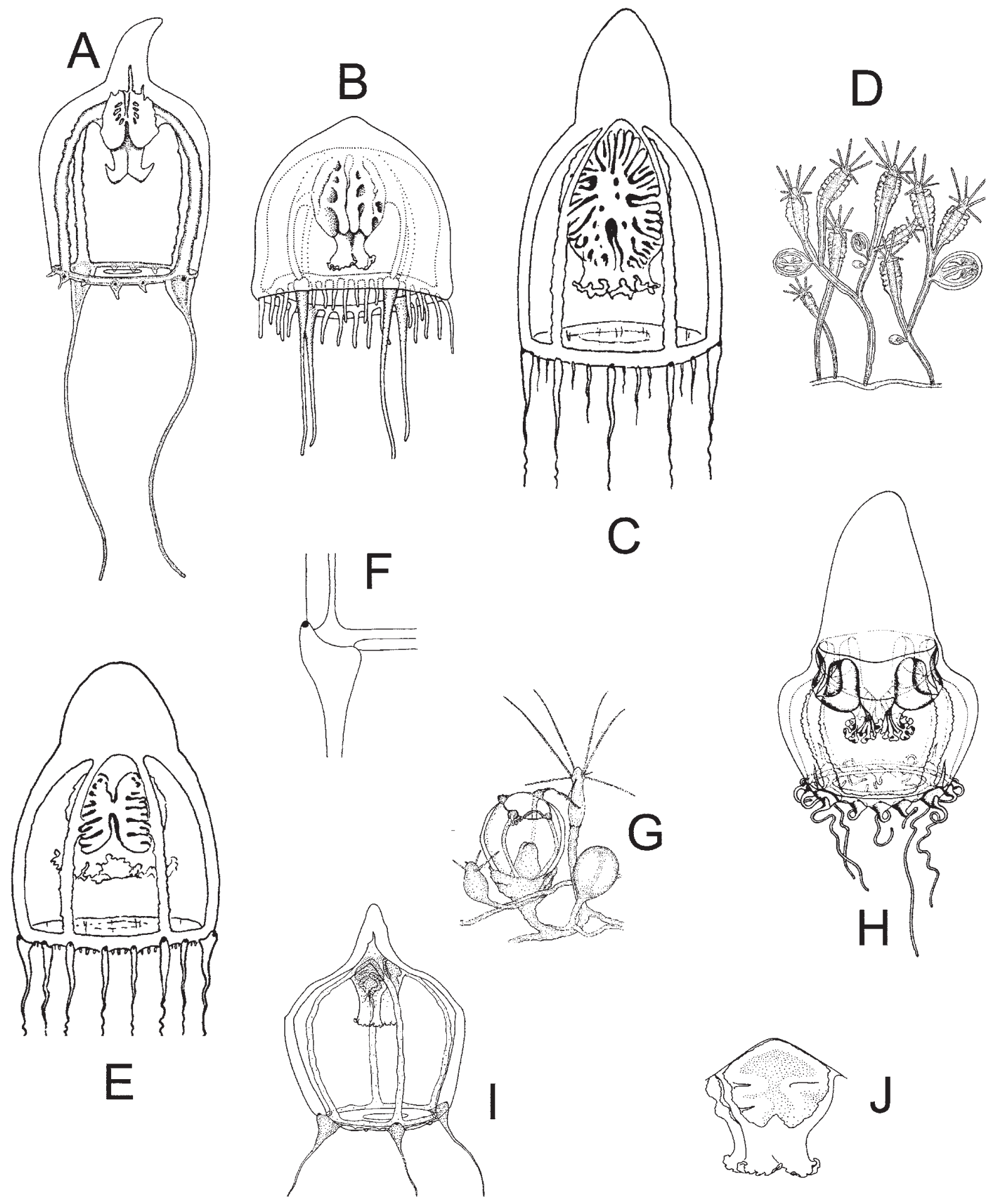

FIG. 41. - Anthomedusae. Filifera. Pandeidae. A: Codonorchis octaedrus: adult medusa; B to F: Leuckartiara: B: Leuckartiara brownei: medusa; C: Leuckartiara nobilis: medusa; D to F: Leuckartiara octona: D: portion of a hydroid colony; E: medusa; F: diagram of lateral view of a marginal tentacle showing abaxial spur. G to J: Merga: $\mathrm{G}$ and H: Merga galleri: G: portion of a hydroid colony with hydranth and medusa buds; H: medusa. I and J: Merga tergestina: I: mature medusa; J manubrium and mouth (A after after Boero et al., 1997; B after Larson and Harbison, 1990; C and E after Kramp, 1959a; D and F after Russell, 1953; G and H after Brinckmann, 1962; I and J after Vannucci and Yamada, 1959). 

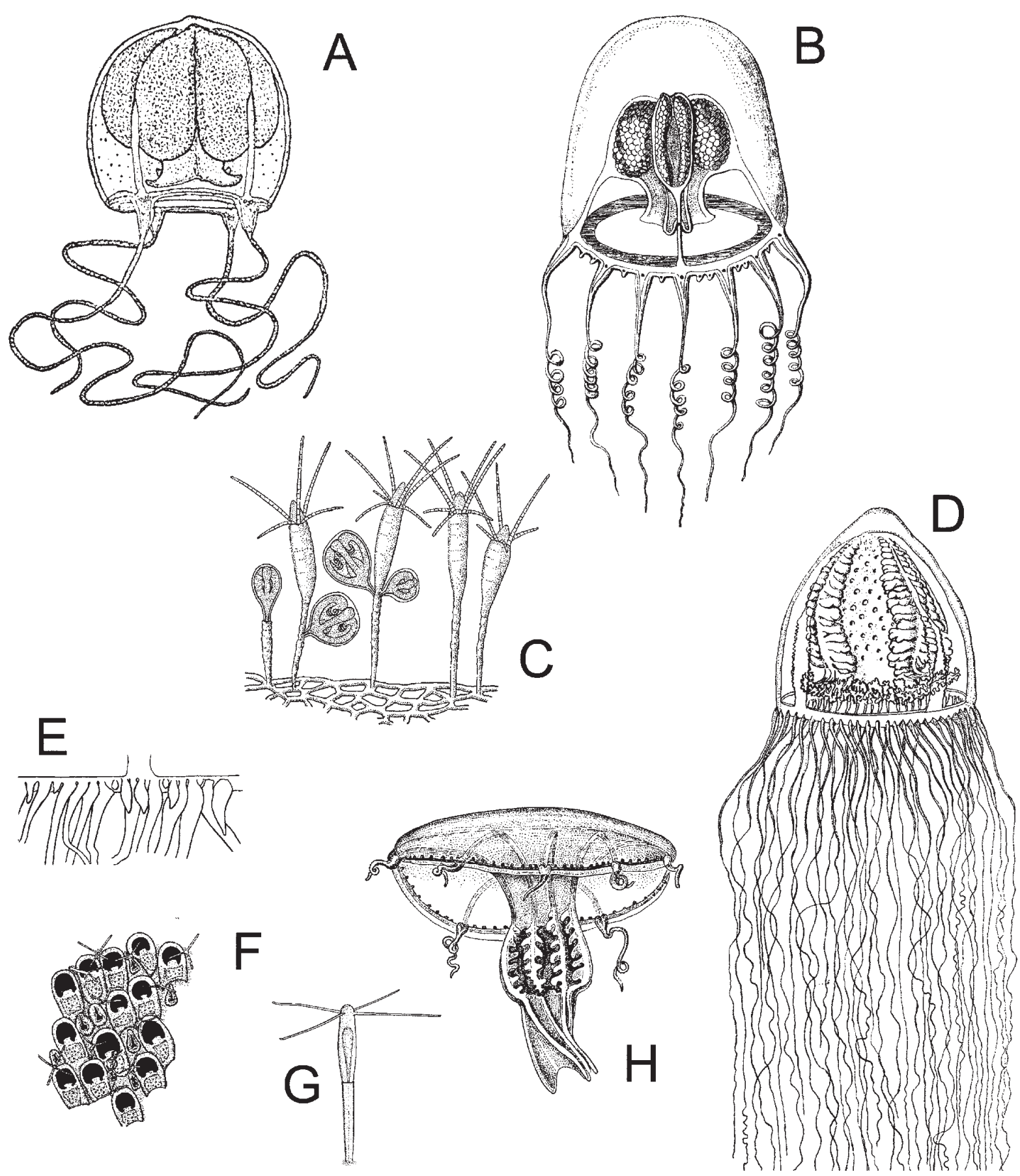

FIg. 42. - Anthomedusae. Filifera. Pandeidae. A: Merga tregoubovii: adult medusa; B: Merga violacea: mature medusa; C to E: Neoturris pileata: C: portion of a hydroid colony; D: adult medusa; E: portion of umbrella margin. F to H: Octotiara russelli: F: hydroid colony with hydranth and medusa buds growing on the bryozoan Steginoporella mandibulata; G: detail of hydranth; H: adult medusa (A after Picard, 1960; B after Kramp, 1959a; C after Edwards, 1965; D after Hartlaub, 1914; E after Russell, 1953; F and G after Boero and Bouillon, 1989; H after Kramp, 1968). 


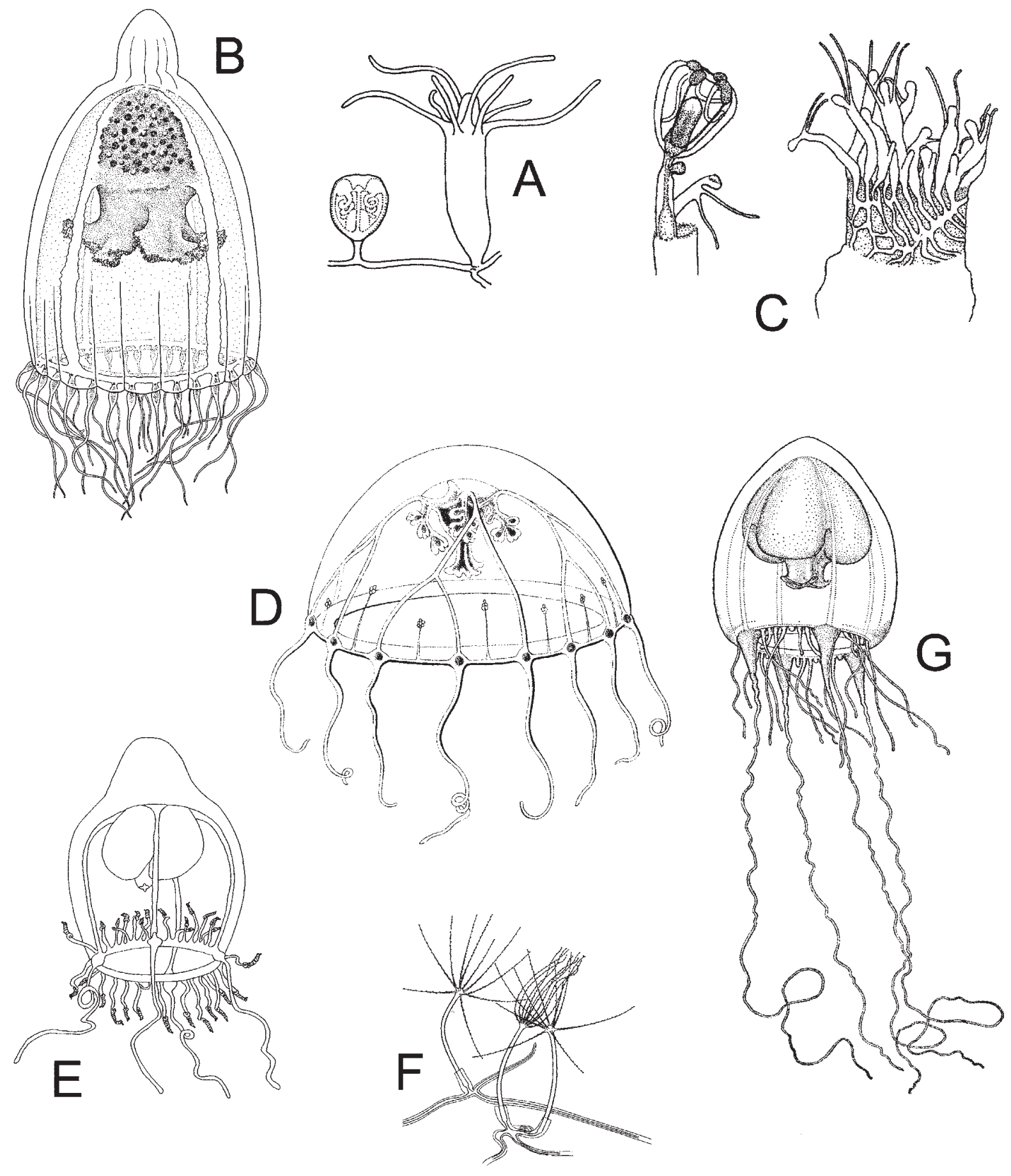

FIg. 43. - Anthomedusae. Filifera. Pandeidae. A and B: Pandea conica: A: hydranth and medusa bud; B: adult medusa. Proboscidactylidae. C and D: Proboscidactyla ornata: C: left hydroid and medusa bud, right hydroid colony on the edge of a tube of the polychaete Sabellaria; D. adult medusa with medusa buds on manubrium. Protiaridae. E to G: Halitiara: E. Halitiara formosa: adult medusa, F and G: Halitiara inflexa: F: hydroid colony; G: fully-grown medusa (A after Picard, 1956a; B after Pagès et al, 1992; C after Brinckmann-Voss and Vannucci, 1965; D after Mayer, 1910; E after Bouillon, 1995; F after Bouillon, 1985b; G after Bouillon, 1980). 


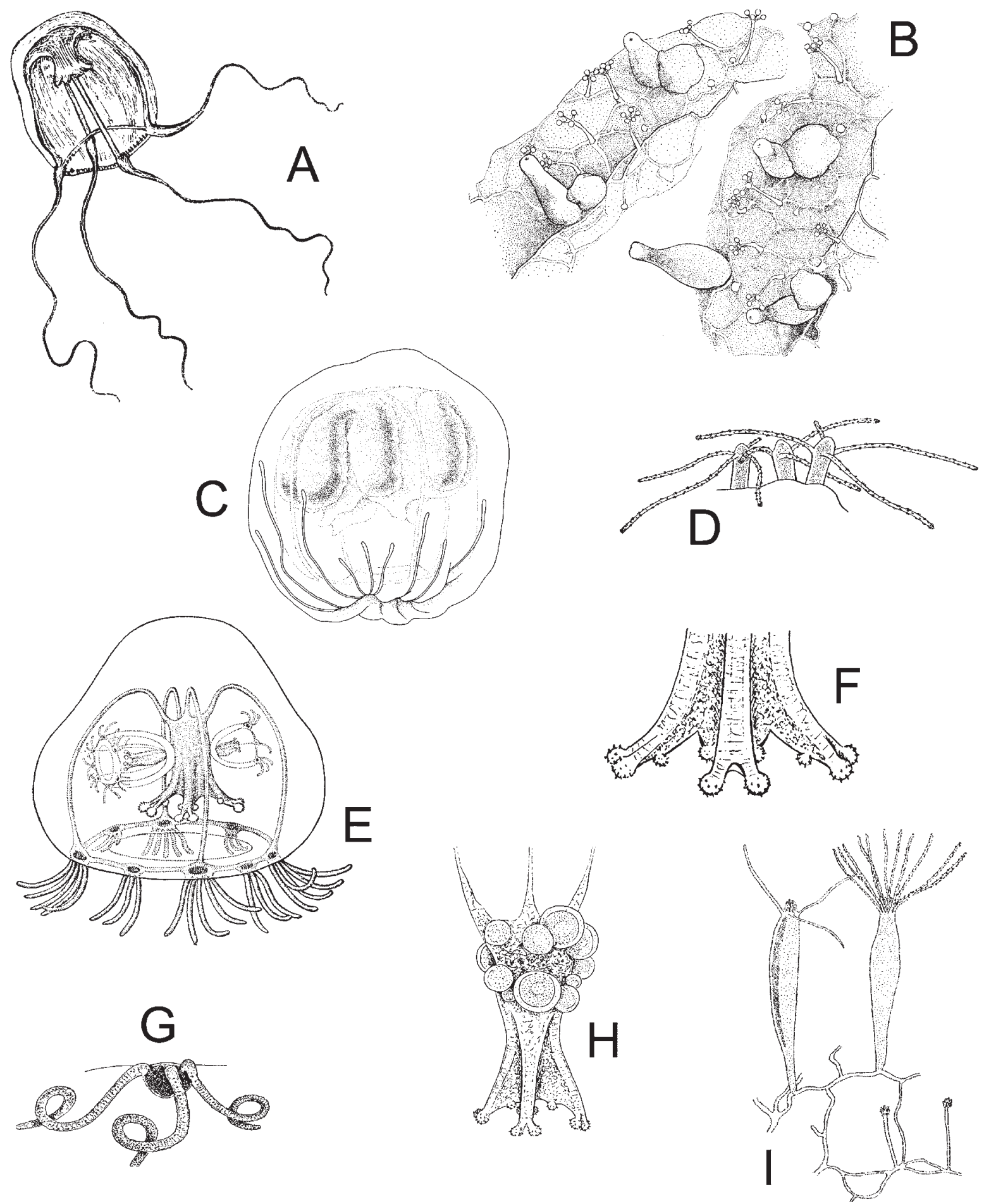

FIg. 44. - Anthomedusae. Filifera. Protiaridae. A: Protiara tetranema: medusa. Ptilocodiidae. B: Thecocodium brieni: two hydroid colonies; C: Tregoubovia atentaculata: adult medusa. Rhatkeidae. D to H: Rathkea octopunctata: D: hydroid; E: medusa with manubrial medusa buds; F: mouth; G: interradial marginal tentacle group; H: manubrium and gonads. Rhysiidae. I: Rhysia automnalis: male colony (A after Hartlaub, 1913; B after Bouillon, 1967; C after Bouillon et al, 2001; D, F to H after Russell, 1953; E after Naumov, 1969; I after Brinckmann, 1965b). 

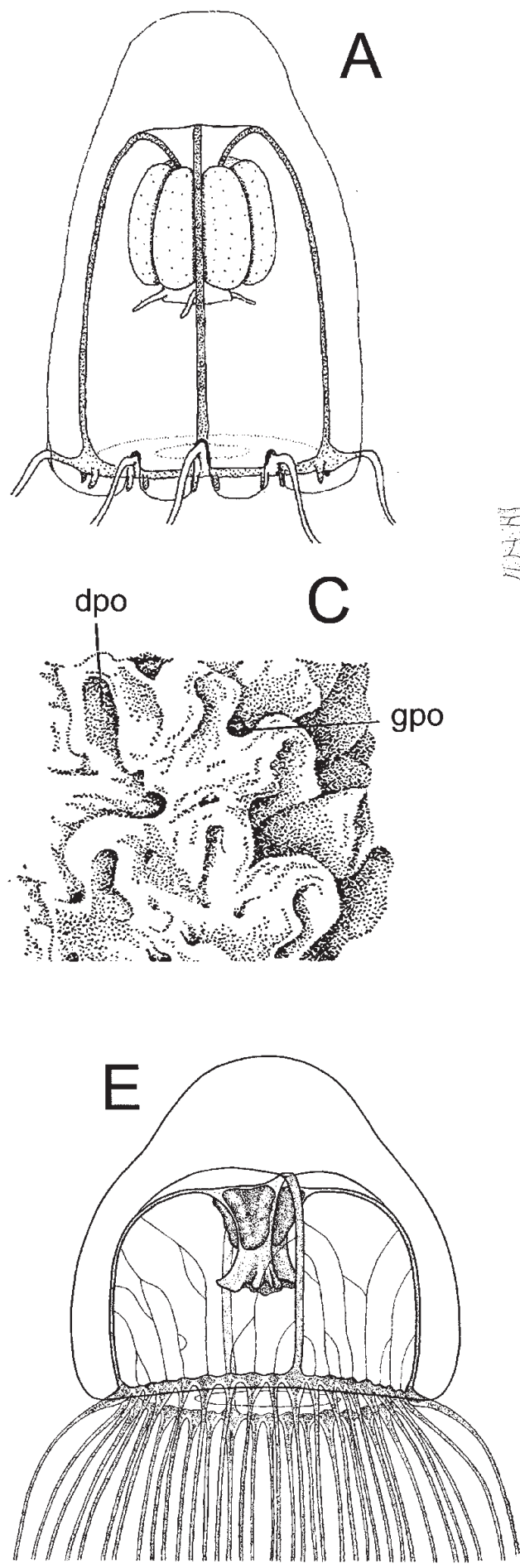
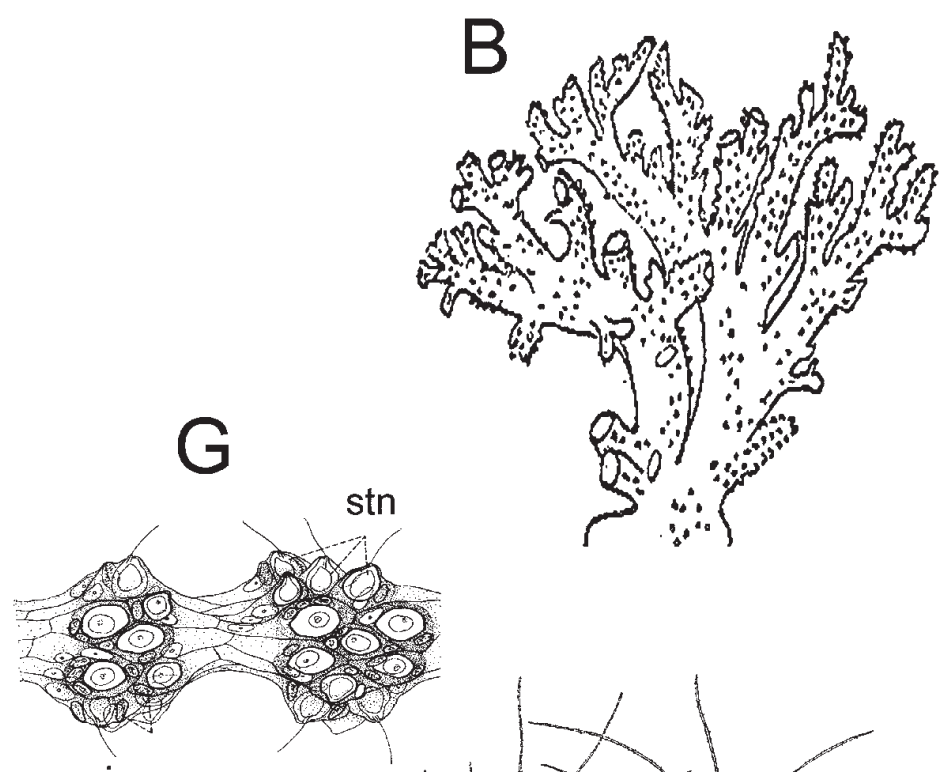

isr

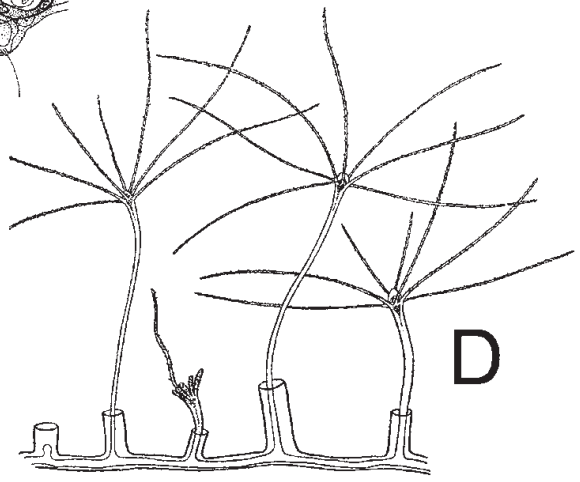

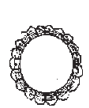

a<smiles>c1ccccc1</smiles>

b
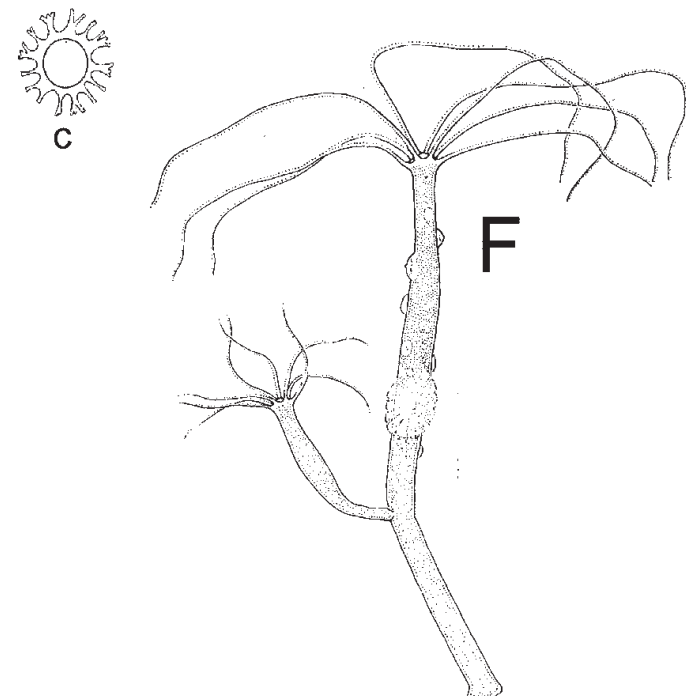

FIG. 45. - Anthomedusae. Filifera. Russelliidae. A: Russellia mirabilis: fully-grown medusa. Stylasteridae. B and C: Errina: B: general aspect of a colony; C: detail of a branch (gpo: gastropore, dpo: dactylopore). Trichydridae. D and E: Trichydra pudica: D: hydroid colony, E: mature medusa Capitata. Moerisiida. Hydridae. F to H: Hydra: F: Hydra viridis with bud and gonads; G: terminal moniliform portion of a tentacle of Hydra pirardi (isr: isorhiza, stn: stenoteles); H: encysted eggs: a: Hydra viridissima; b: Hydra attenuata; c: Hydra vulgaris (A after Pagès et al., 1999; B and C after Moore, 1956, D after Russell, 1953; E after Edwards, 1973a; F after Brien and Reniers-Decoen, 1950; G after Brien, 1961; H after Steche, 1911). 


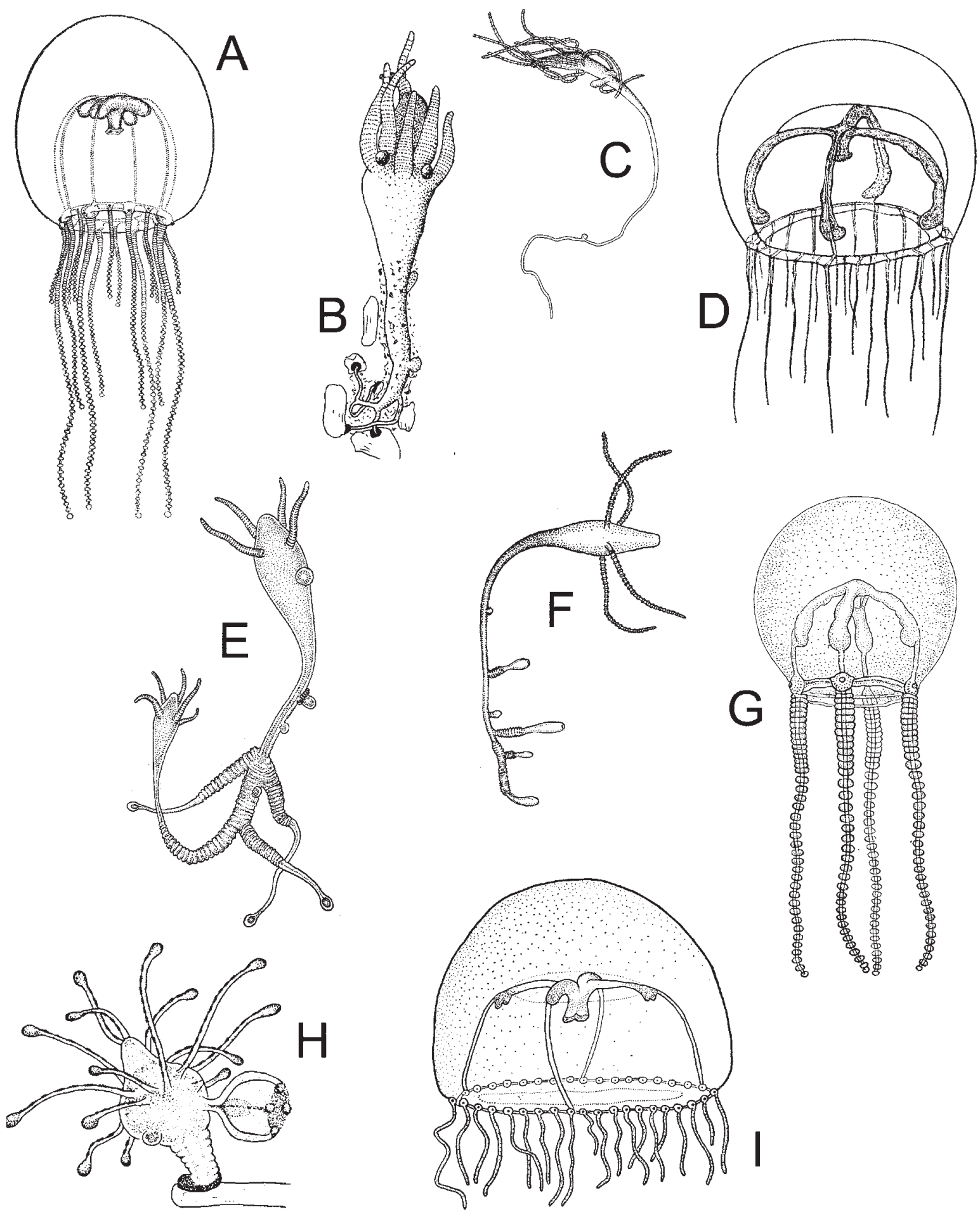

FIG. 46. - Anthomedusae. Capitata. Moerisiidae. A to G: Moerisia: A: Moerisia carine: fully-grown medusa; B to D: Moerisia inkermanica: B: hydroid showing pedal discs and medusa buds; C: hydroid showing lateral buds; D: adult medusa. E to G: Moerisia lyonsi: E and F: hydroids; G: mature medusa. H and I: Odessia maeotica: H: hydroid with medusa bud, I: mature medusa (A after Bouillon, 1978c; B and C after Millard, 1975; D after Kramp, 1959a; E to G after Rees, 1958; H and I after Morri, 1981). 


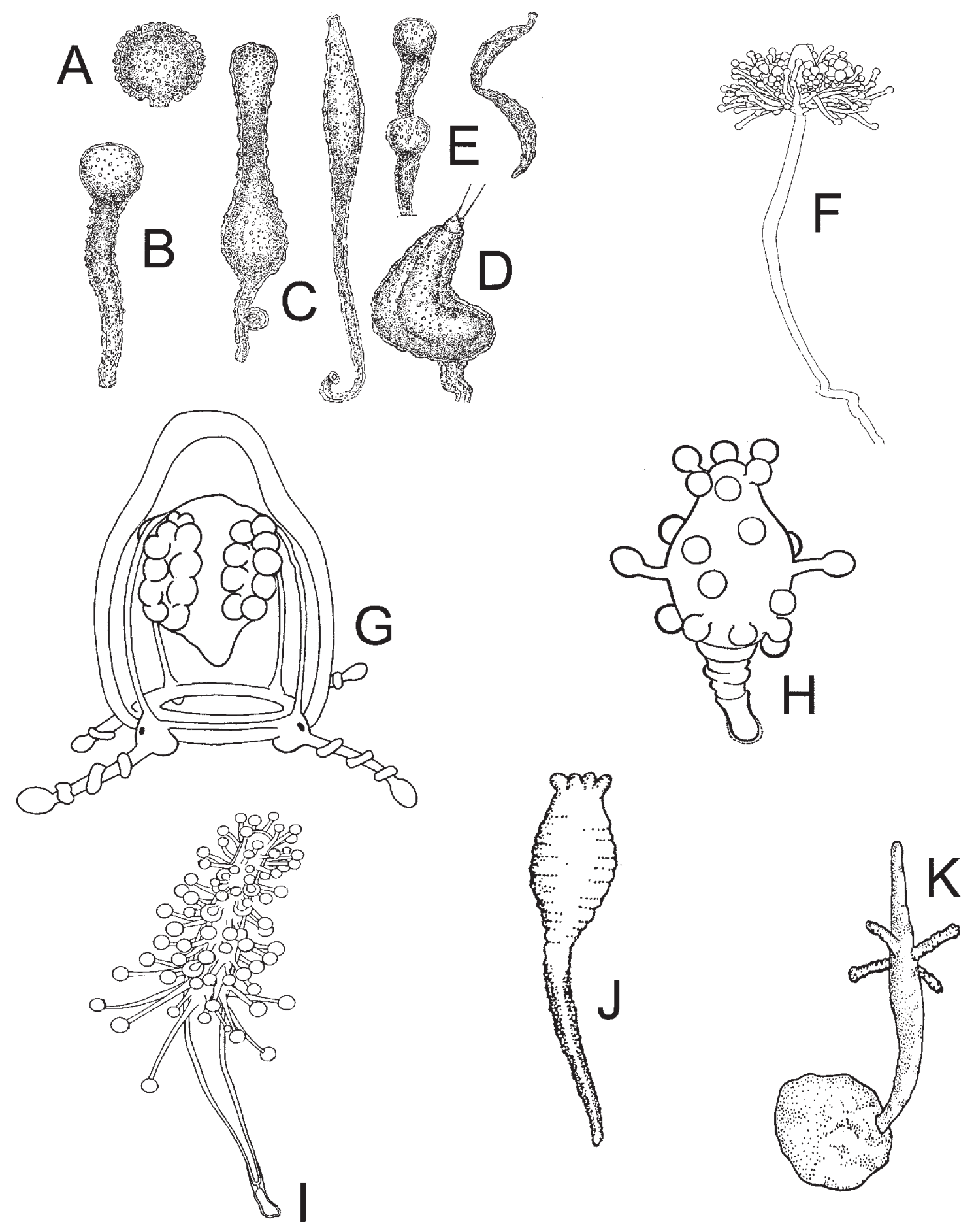

FIG. 47. - Anthomedusae. Capitata. Protohydridae. A to E: Protohydra leuckarti: A: contracted hydranth; B and C: various stages of relaxed hydranths; D: hydranth feeding on a copepode; E: two stages of transversal fission. Sphaerocorynidae. F and G: Sphaerocoryne bedoti: F: hydroid; G: fully-grown medusa. Tubulariida. Acaulidae. H and I: Acauloides. H: Acauloides ammisatum hydroid, I: Acauloides ilonae: hydroid; J: Boreohydra simplex: hydranth; K: Psammohydra nanna: hydranth (A to E after Leloup, 1952; F after Hirohito, 1988; G after Petersen, 1990; H after Bouillon, 1971; I after Brinckmann-Voss, 1966; J after Westblad, 1937; K after Clausen and Salvini-Plawen, 1986). 

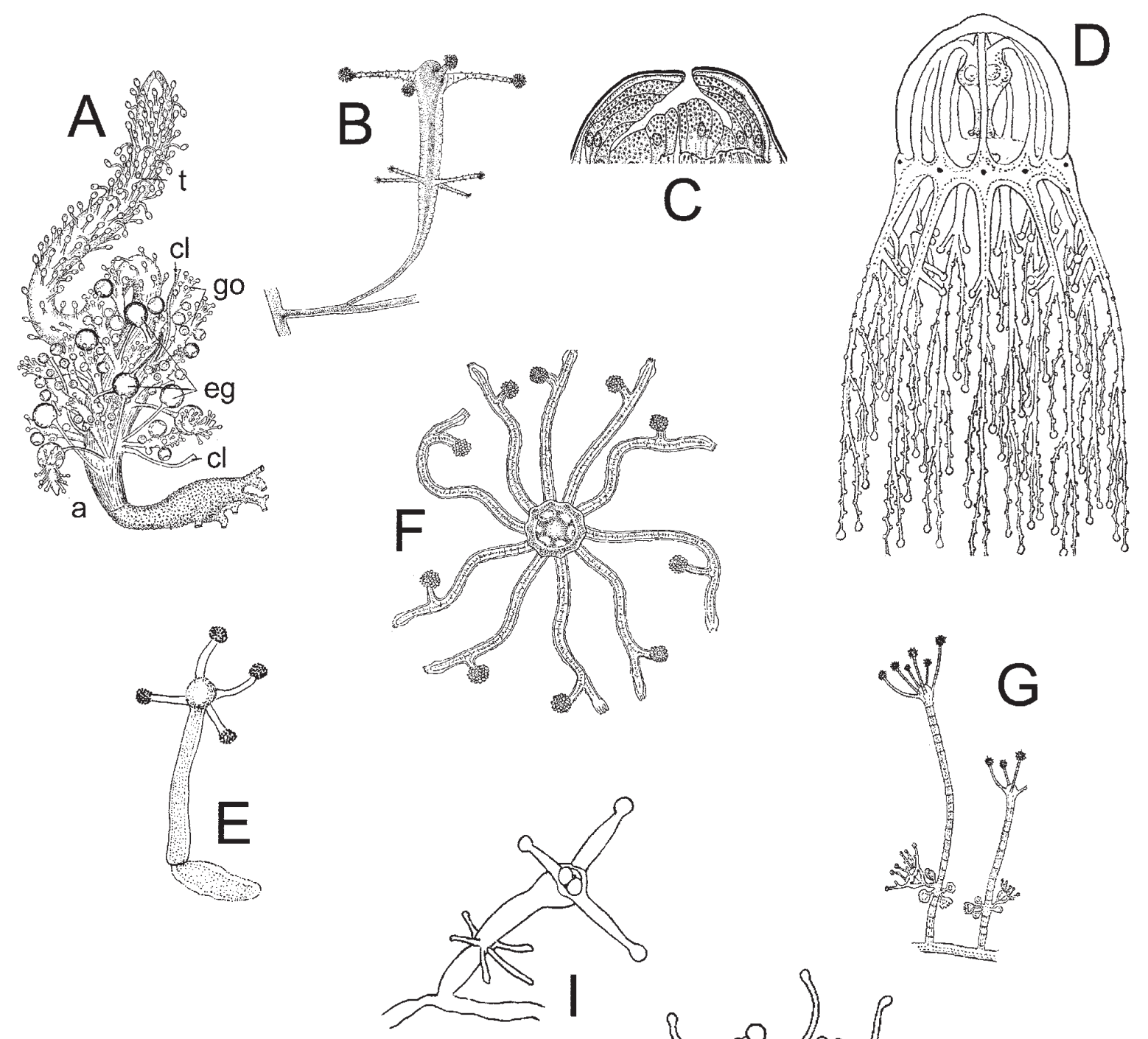

C
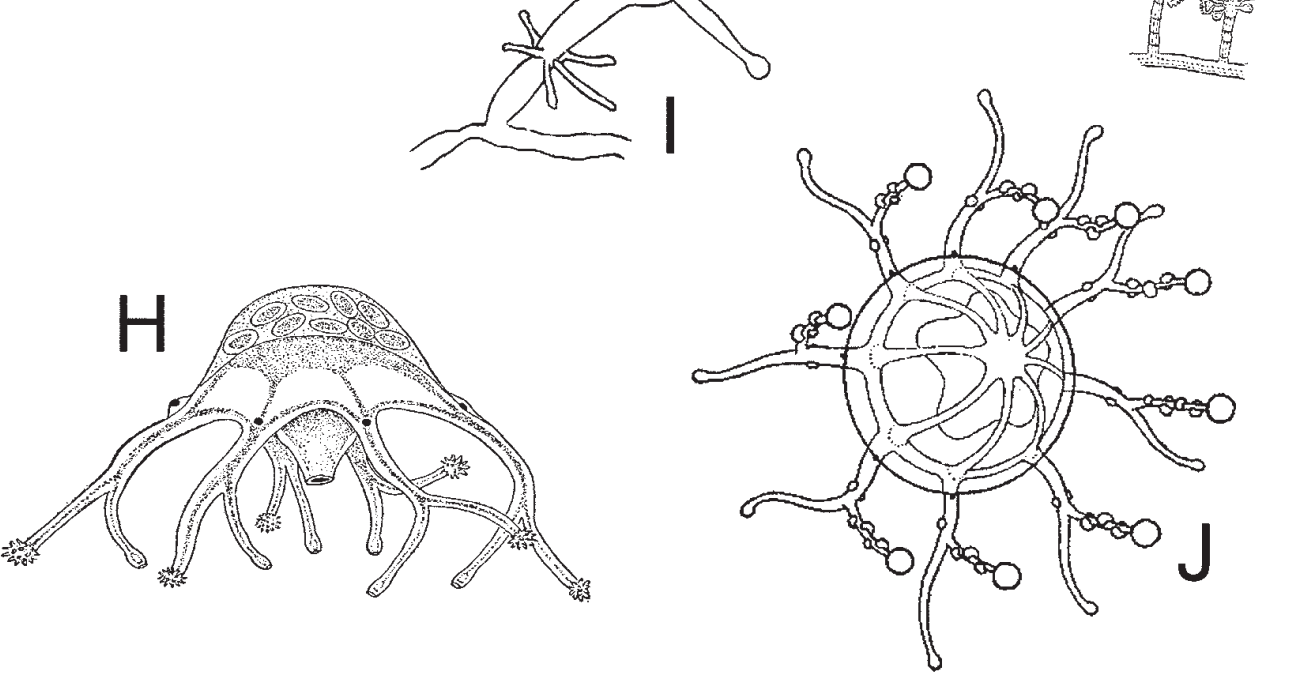

FIG. 48. - Anthomedusae. Capitata. Candelabridae. A: Candelabrum cocksi hydranth. Cladonematidae. B to D: Cladonema radiatum: B: hydroid; C: schema of hypostome showing the ectodermal glandular oral cavity. D: fully-grown medusa; E to H: Eleutheria: E and F: Eleutheria claparedei: E: hydranth, F: medusa. G and H: Eleutheria dichotoma: G: part of colony with hydranths developing medusa buds, H: mature medusa with planulae inside brooding pouch. I and J: Staurocladia portmanni: I: hydranth; J: adult medusa (A after Hyman, $1940 ;$ B after Leloup, 1952, C after Bouillon, 1971; D after Russell, 1953; E after Brinckmann-Voss, 1970; F after Mayer, 1910; G after Hincks, 1861; H after Hincks, 1868; I after Bouillon, 1978b; J after Brinckmann, 1964a). 


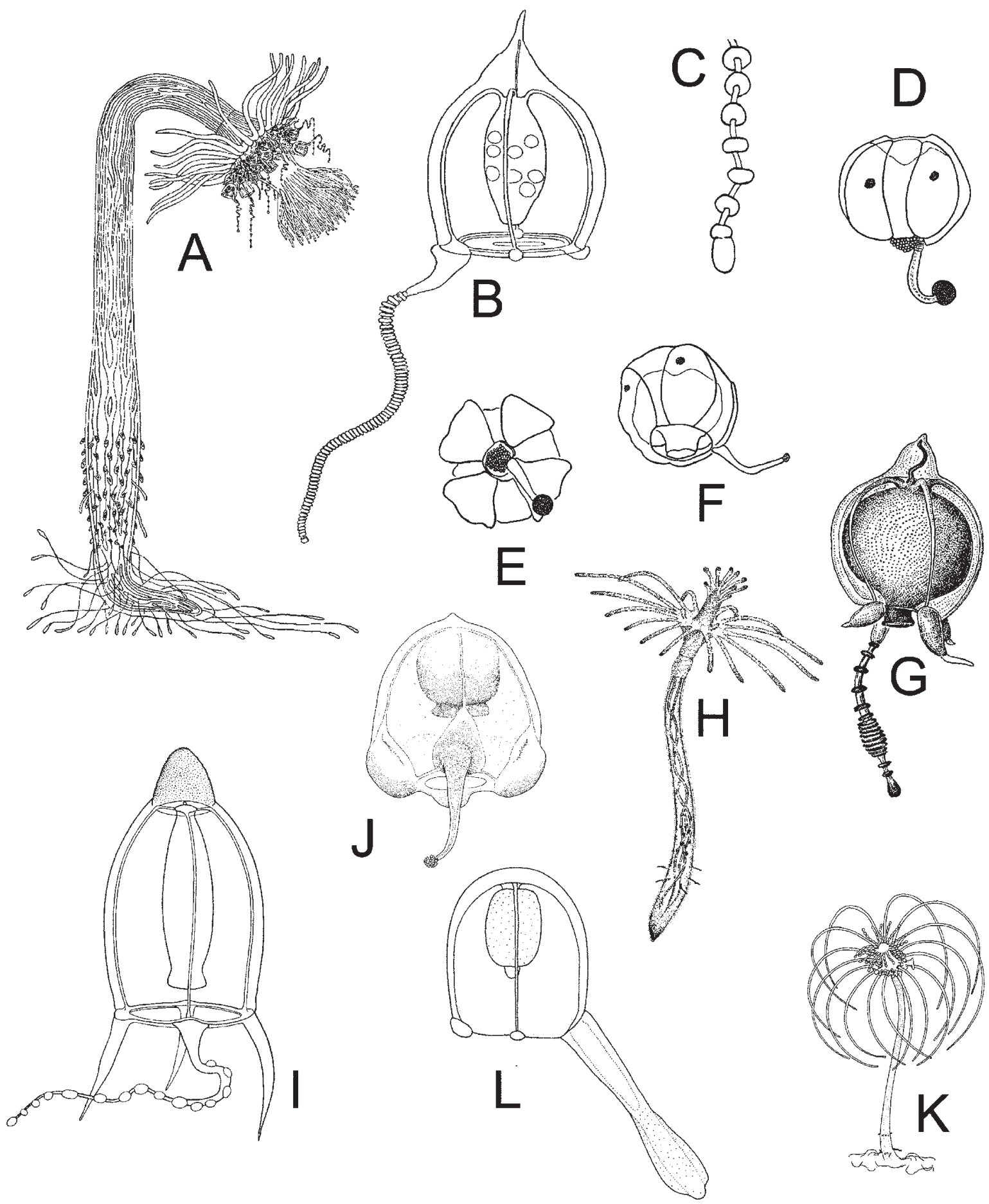

FIG. 49. - Anthomedusae. Capitata. Corymorphidae. A to C: Corymorpha nutans: A: hydranth; B: adult medusa; C: tip of medusa tentacle. D to F: Eugotoea petalina: mature medusa: D and F: lateral views; E: oral view; G to I: Euphysora: G: Euphysora annulata: adult medusa; H and I: Euphysora bigelowi: H: hydranth; I: adult medusa. J: Paragotoea bathybia: mature medusa; K and L: Vannuccia forbesii: K: hydranth; L: mature medusa (A after Allman, 1872; B and G after Kramp, 1959a; C after Russell, 1953; D to F after Margulis, 1989; H after Sassaman and Rees, 1978; I after Petersen, 1990; J after Pagès and Bouillon, 1997; K and L after Schuchert, 1996). 

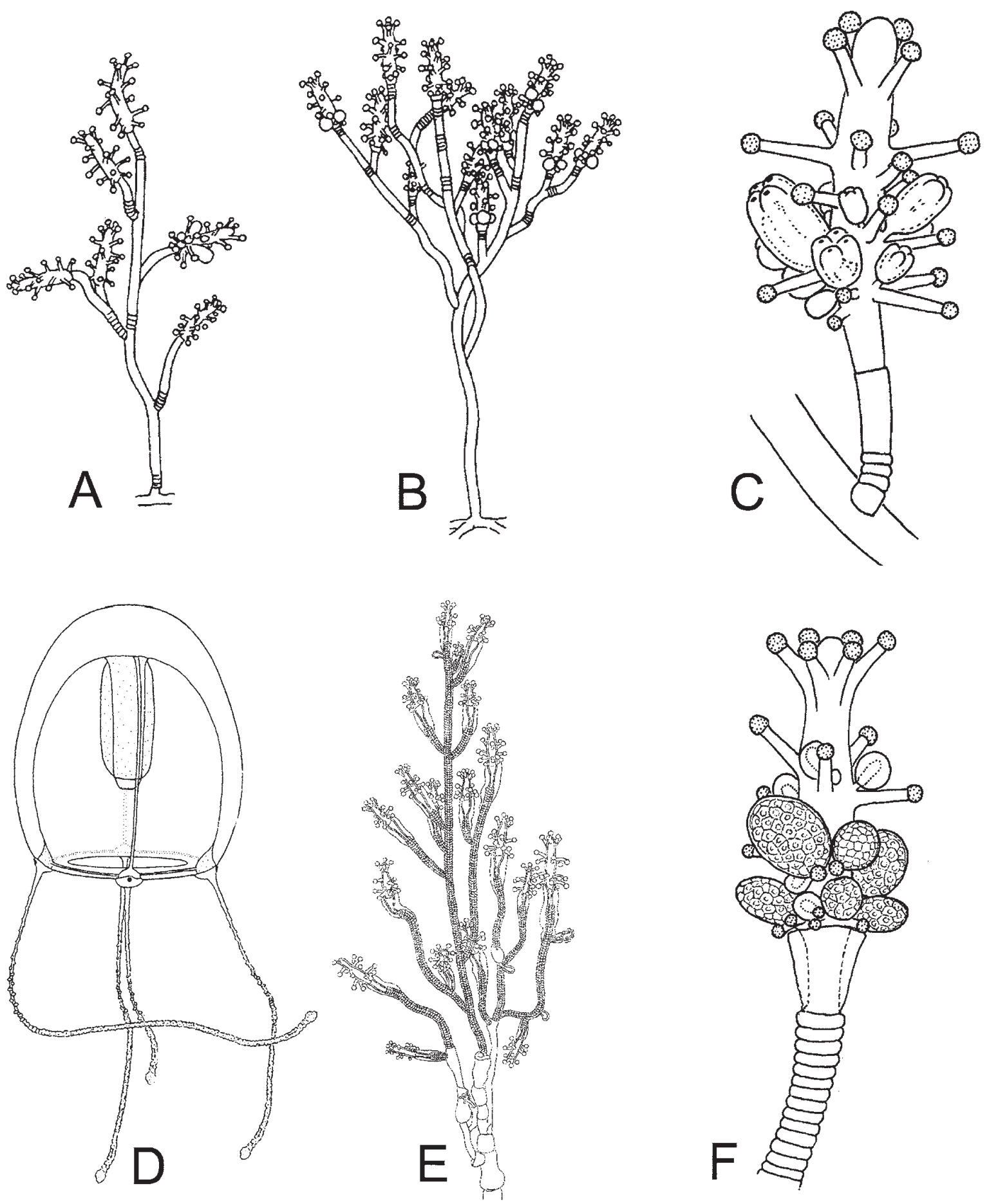

FIG. 50. - Anthomedusae. Capitata. Corynidae. A to F: Coryne: A to D: Coryne eximia: A and B: general view of two colonies; C: hydranth with medusa buds; D: mature medusa. E and F: Coryne muscoides: E view of a part of a colony; F: hydranth with gonophores (A, B and D after Schuchert, 1996; C and F after Schuchert, 2001b; E after Brinckmann -Voss, 1970). 

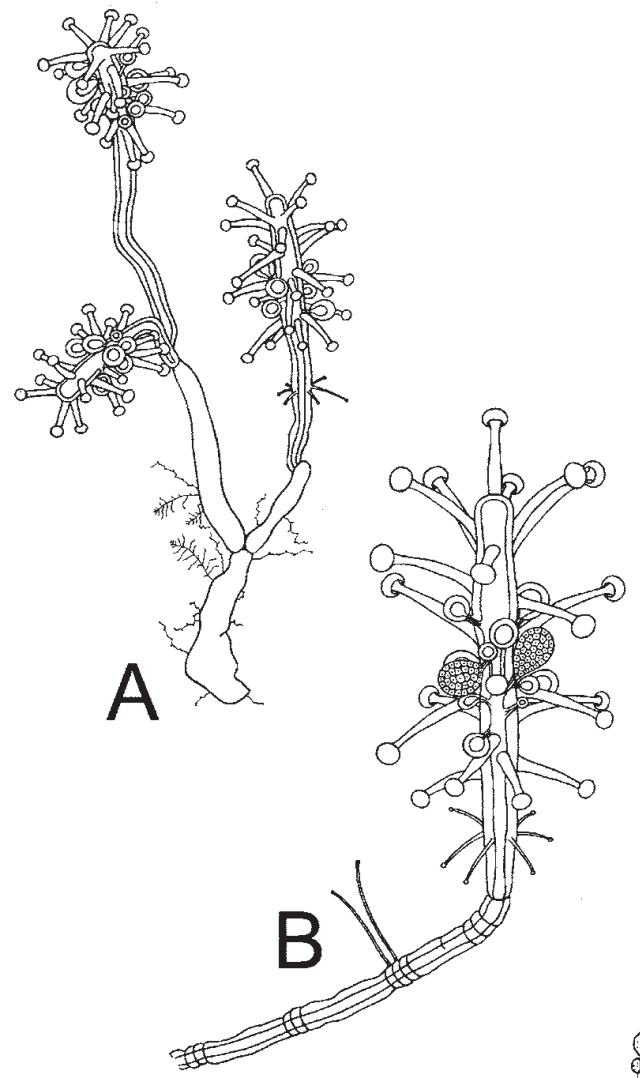

$\ddot{x}$

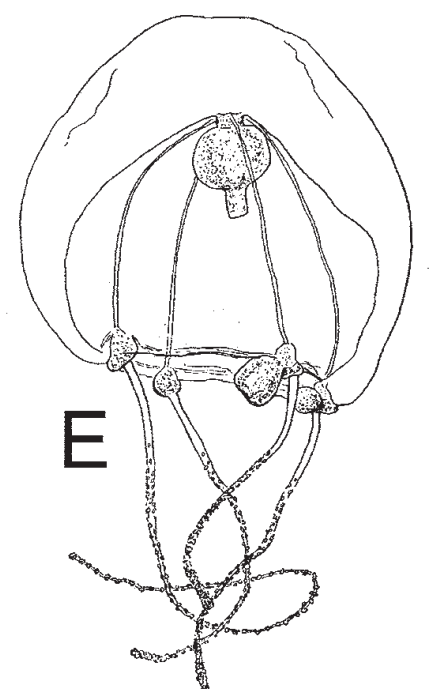

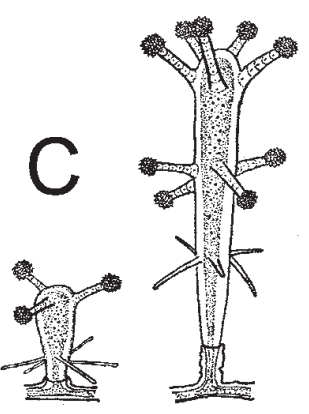
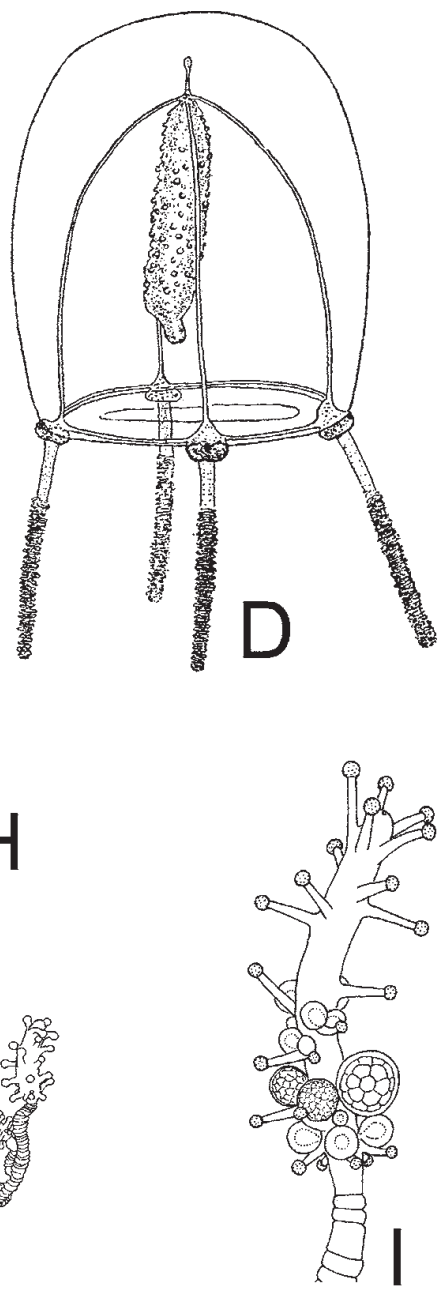

FIG. 51. - Anthomedusae. Capitata. Corynidae. A to K: Coryne. A and B: Coryne pintneri: A: detail of a colony; B: hydranth with gonophores. C and D: Coryne producta: C: two hydranths; D: adult medusa. E to G: Coryne prolifera: E: adult medusa; F: tentacle bulb with medusa buds; G: medusa marginal tentacle tip. H and I: Coryne pusilla: H: part of a colony; I: hydranth with gonophores. J: Coryne epizoica; K: Coryne fucicola (A, B and K after Brinckmann-Voss, 1970; C, D and E after Russell, 1953; F, G, I and J after Schuchert, 2001b; H after Hirohito, 1988). 

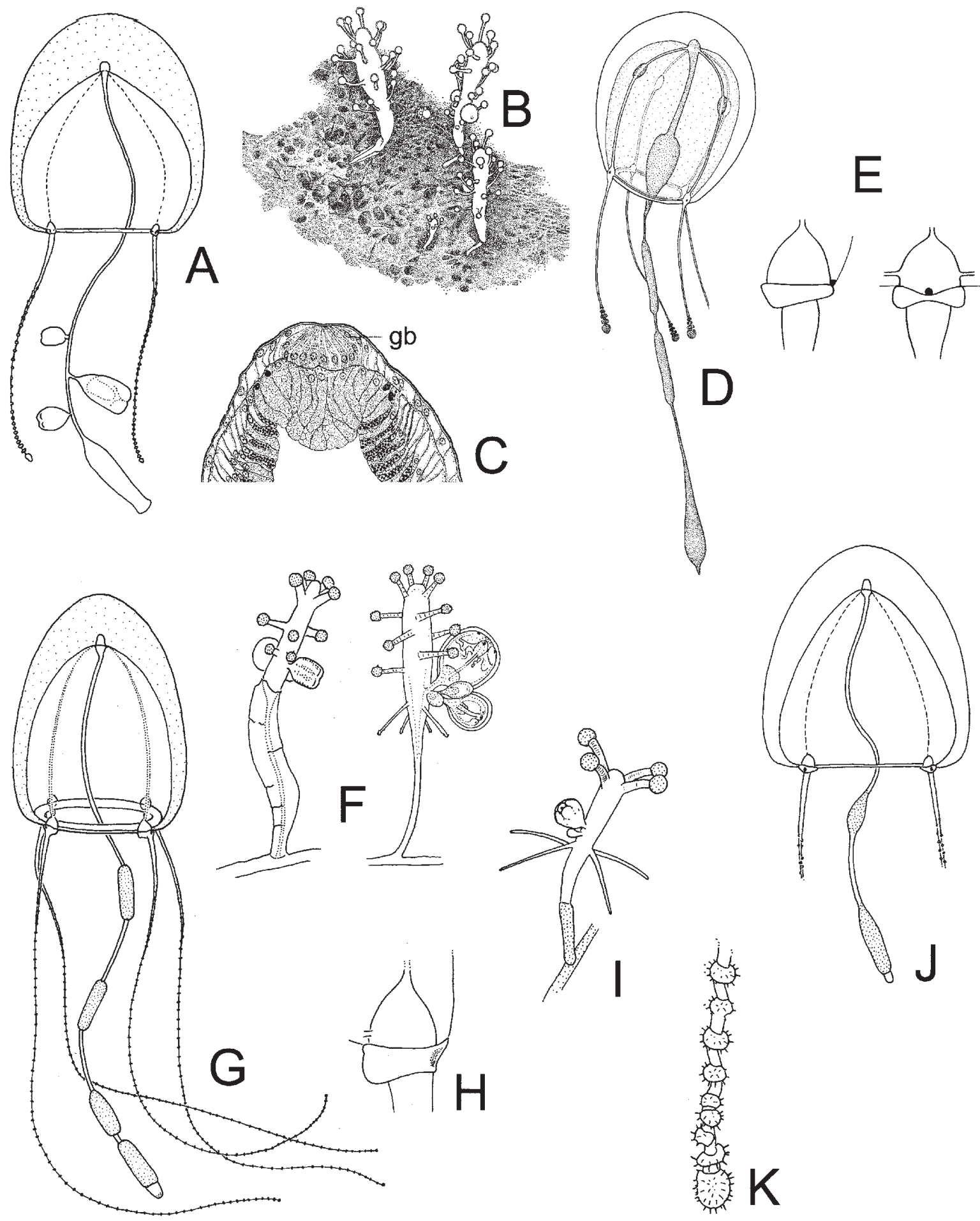

FIG. 52. - Anthomedusae. Capitata. Corynidae. A to K: Dipurena: A: Dipurena gemmifera: medusa with medusa buds; B to E: Dipurena halterata: B: hydroid colony in a sponge; C: longitudinal section of hypostome showing the glandular mucous button (gb) characteristic of the genus; D: adult medusa, E: marginal tentacular bulbs, lateral and frontal view. F to H: Dipurena ophiogaster: F: two hydranths; G: adult medusa; H: lateral view of a marginal bulb of a mature medusa. I to K: Dipurena reesi: I: hydranth; J: adult medusa; K: tip of medusa tentacle, note the long, spiny cnidocils (A, F to K after Schuchert, 2001b, B after Bouillon, 1971; C after Bouillon, 1968; D and E after Pagès et al., 1992). 

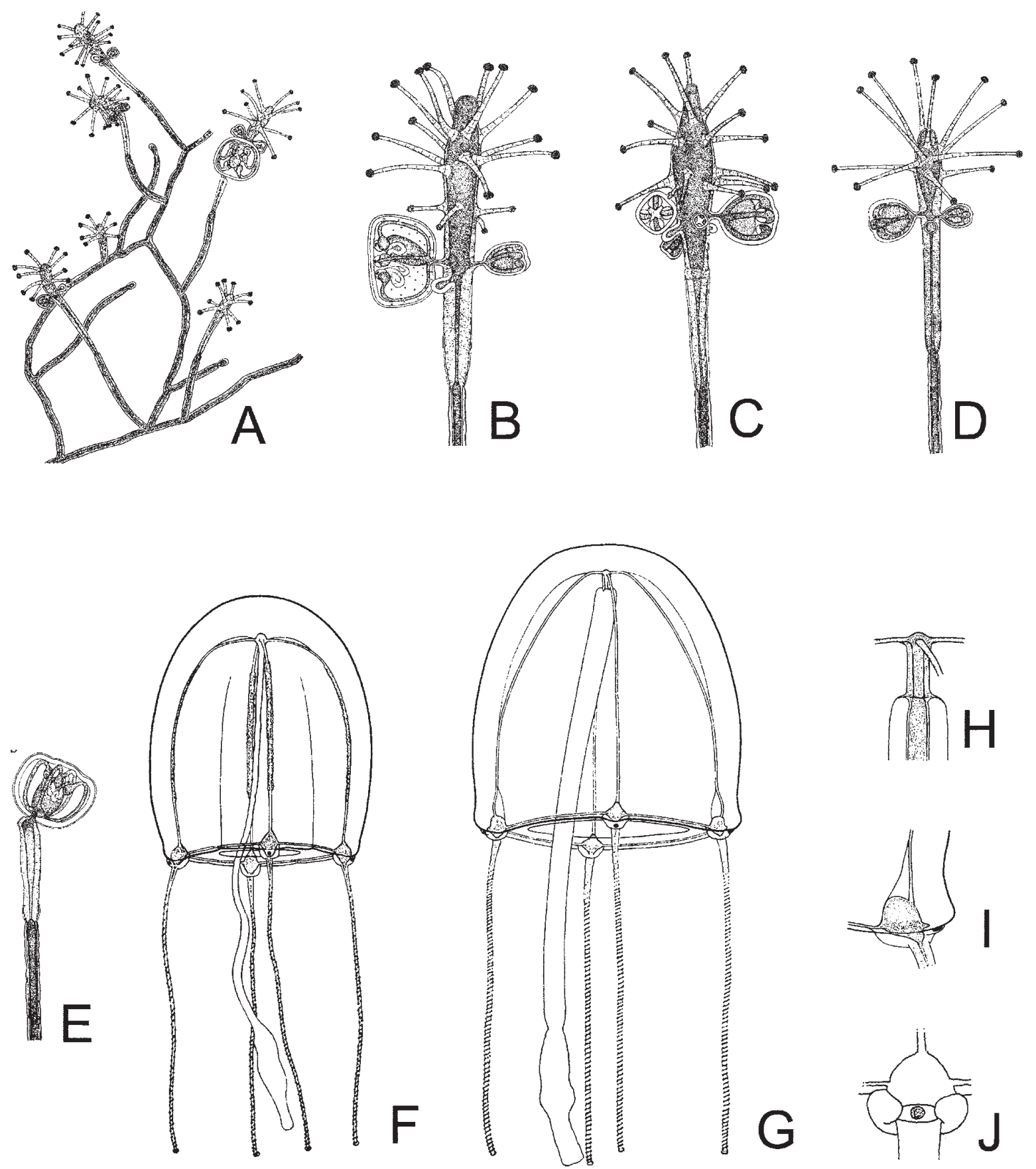

FIG. 53. - Anthomedusae. Capitata. Corynidae. A to J: Sarsia tubulosa: A: fragment of a colony; B to D: detail of hydranths with medusa buds; $\mathrm{E}$ : hydranth regressing during reproductive exhaustion with gonophore shorty before release; F: subadult medusa, note enlarged radial canals; G: mature medusa; H: basal part of manubrium; I and J: lateral and frontal view of a marginal bulb (A to I after Edwards, 1978; J after Schuchert, 2001b). 

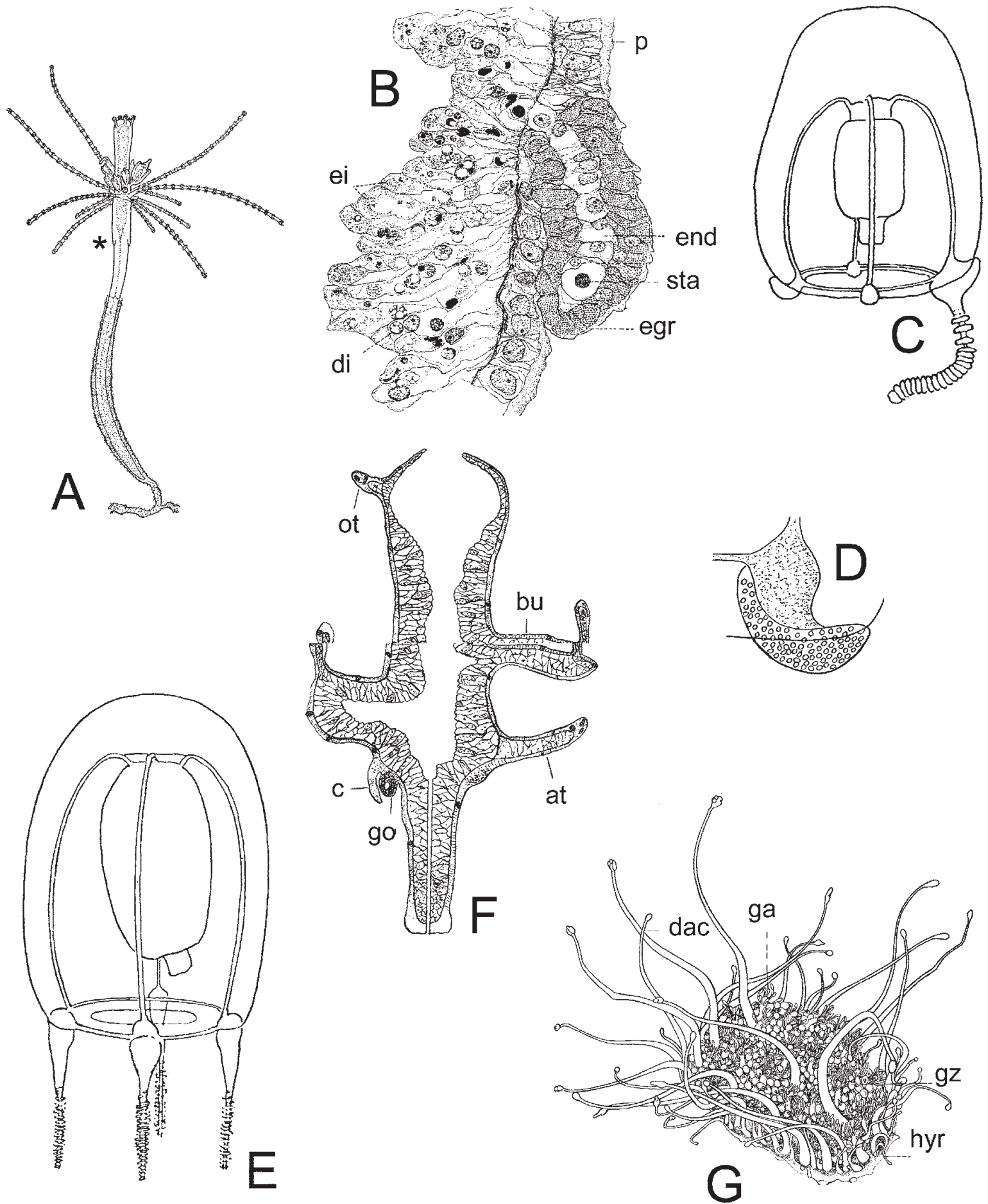

FIg. 54. - Anthomedusae. Capitata. Euphysidae. A to E: Euphysa: A to D: Euphysa aurata: A: hydroid; B: longitudinal histological section of the basal papilla and statocyst of a hydranth (see asterisk figure A); C: mature medusa; D: medusa, view of a non tentacular marginal bulb; E: Euphysa flammea fully-grown medusa; F: Siphonohydra adriatica diagram of a longitudinal section through a hydranth: left: radial, right: interradial. Paracorynidae. G: Paracoryne huvei: view of a mature colony (A after Rees, 1938; B after Bouillon and Grohman, 1990; C and D after Russell, 1953; E after Kramp, 1959a; F after Salvini-Pawen, 1966; G after Bouillon, 1975). at: aboral tentacle; bu: bud; c: process covering the gonophore; dac: dactylozooid; di: digestive inclusions; egr: ectodermal granulations; ei: excretory inclusions; end: endoderm; go: gonophore; ga: gastrozooid; gz: gonozooid; hyr: hydrorhiza; ot: oral tentacle; p: periderm; sta: statocyst. 

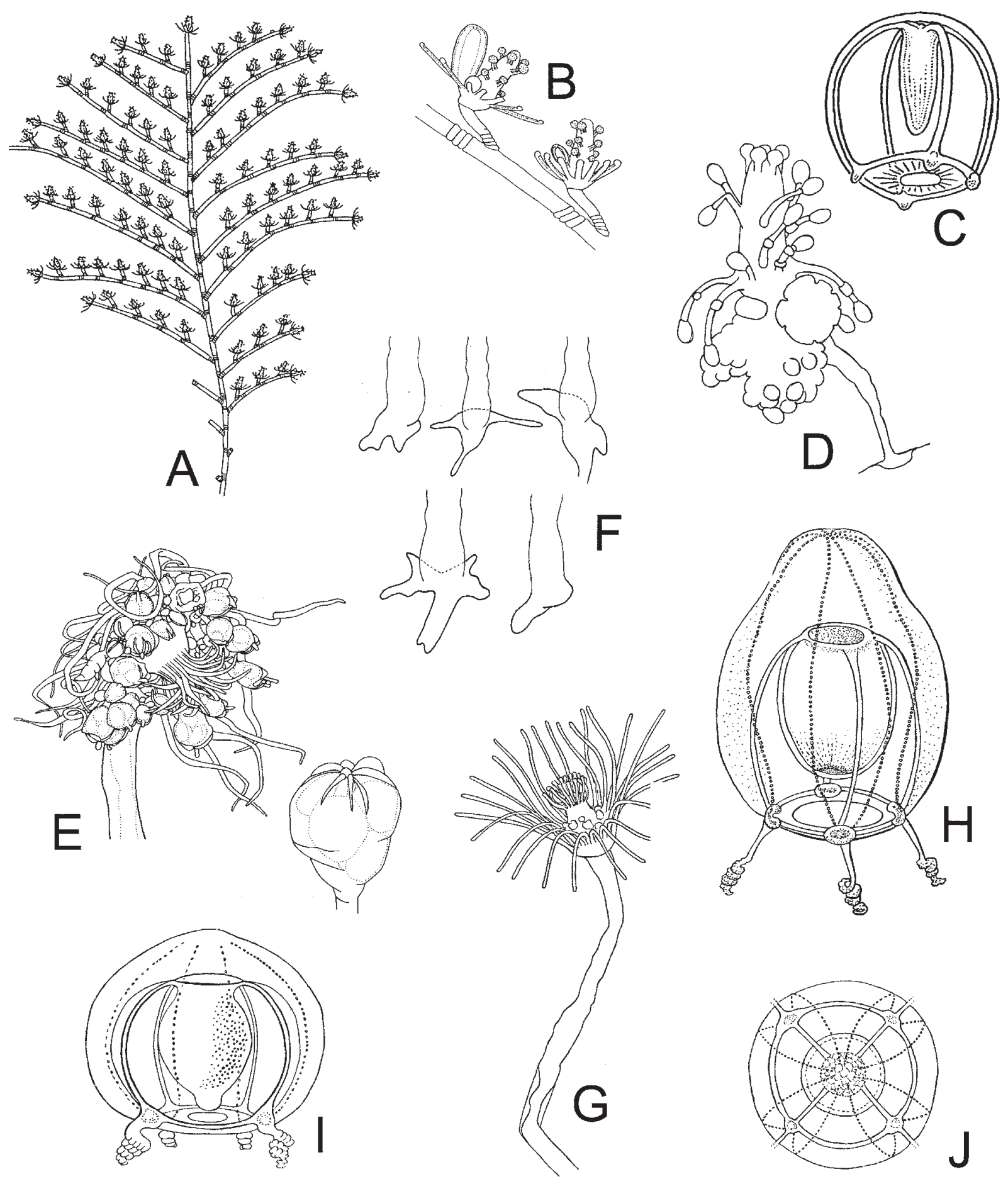

FIG. 55. - Anthomedusae. Capitata. Pennariidae. A to C: Pennaria disticha: A: portion of a colony; B: detail of branch with two hydranth; C: eumedusoid. Tricyclusidae. D: Tricyclusa singularis: hydranth with actinula larvae. Tubulariidae. E and J: Ectopleura: E and F: Ectopleura crocea: E: above left female hydranth with gonophores, below right detail of mature female gonophore, F: aboral ends of hydrocauli of newly-settled specimens showing the development of the stolons from the pedal disc area; $\mathrm{G}$ to J: Ectopleura dumortieri: G: hydranth; $\mathrm{H}$ and I: lateral view of mature medusae; J: apical view of an adult medusa (A and B after Schuchert, 1996; C after Kramp, 1959a; D after Bouillon, original; E and F after Petersen, 1990; G after Russell, 1953; H after Mayer, 1910; I and J after Rees, 1957). 

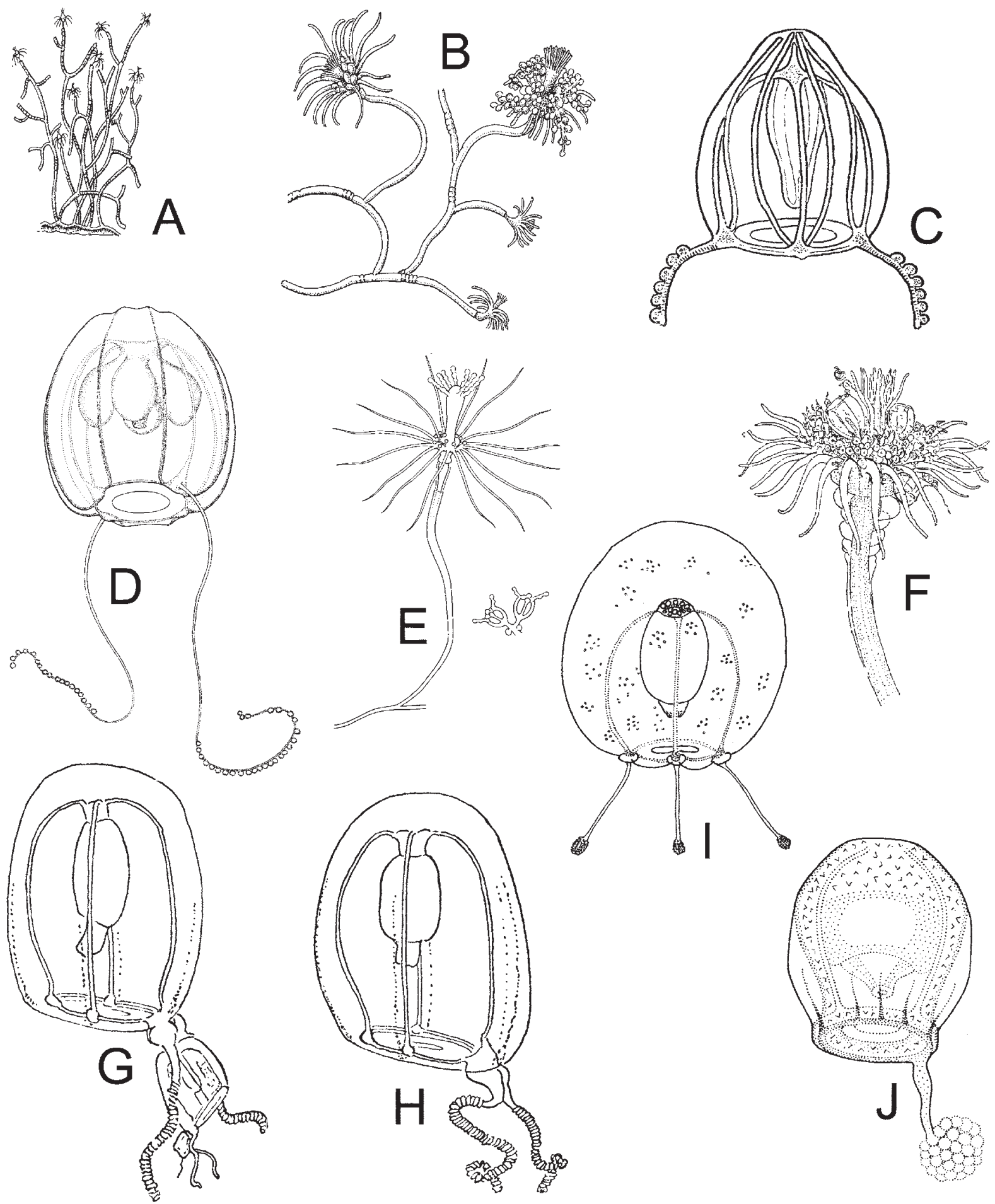

FIG. 56. - Anthomedusae. Capitata. Tubulariidae. A to E: Ectopleura: A and B: Ectopleura larynx: A: general view of a colony; B: detail of branches with hydranth and gonophores. C: Ectopleura minerva: adult medusa; D: Ectopleura sacculifera: fully-grown medusa; E: Ectopleura wrighti: left: hydroid, right: blastostyle with two medusa buds; F to $\mathrm{H}$ : Hybocodon prolifer: F: hydranth; $\mathrm{G}$ and $\mathrm{H}$ : medusae with and without medusa buds. I: Plotocnide borealis: mature medusa; J: Rhabdoon singulare: adult medusa (A and B after Cornelius et al., 1990; C after Mayer, 1910; D after Bouillon, 1978b; E after Petersen, 1990; F after Russell, 1953; G and H after Kramp, 1959a; I after Arai and Brinckmann-Voss, 1980; J after Vannucci and Soares Moreira, 1966). 

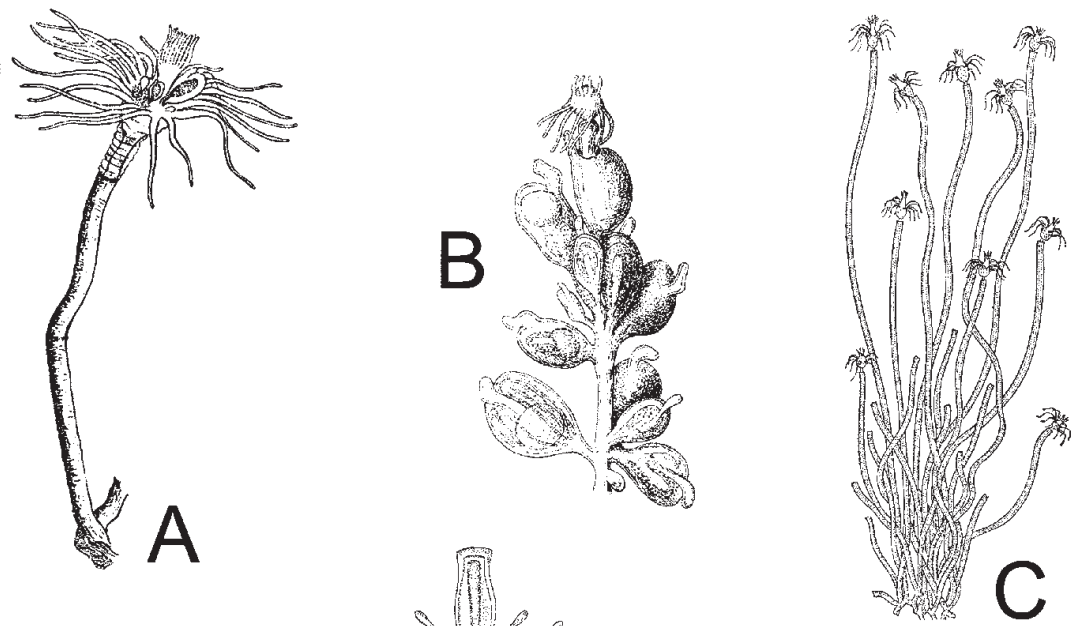

D
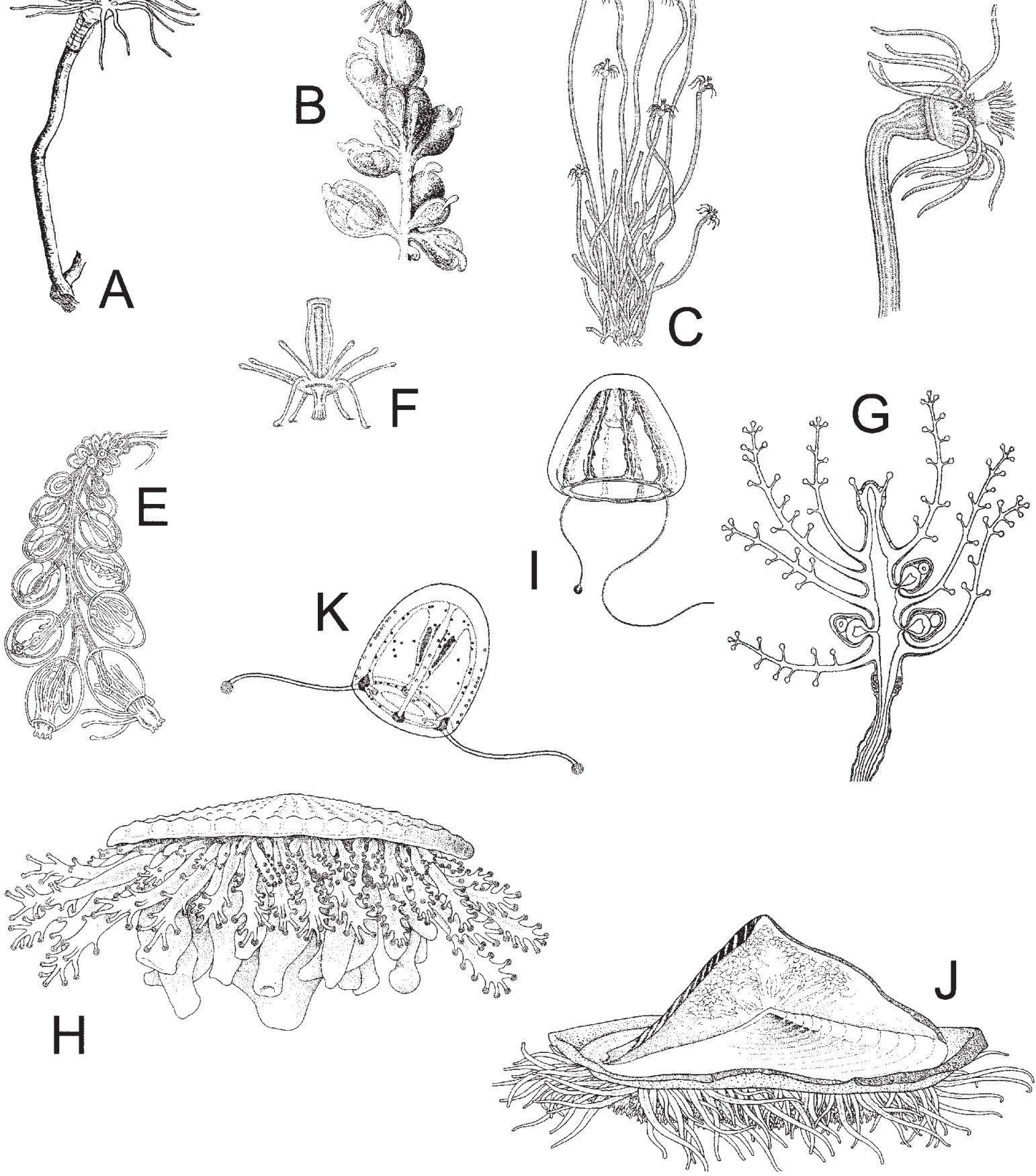

FIG. 57. - Anthomedusae. Capitata. Tubulariidae. A to F: Tubularia: A and B: Tubularia ceratogyne: A: hydranth, B: female blatostyle with an actinula escaping from a gonophore. C to F: Tubularia indivisa: C: portion of a colony; D: detail of a hydranth; E: cluster of gonophores of a female colony; F: actinula. Cladocorynidae. G: Cladocoryne floccosa: hydranth with gonophores. Porpitidae. H and I: Porpita porpita: H: polyp; I: medusa. J and K: Velella velella: J: polyp; K: medusa. (A to D after Leloup, 1952; E after Patriti, 1970; F after Pèrèz, 1920; G after Bouillon, 1995; H and J after Pagès et al., 1992; I after Bouillon, 1984d; K after Brinckmann-Voss, 1964b). 

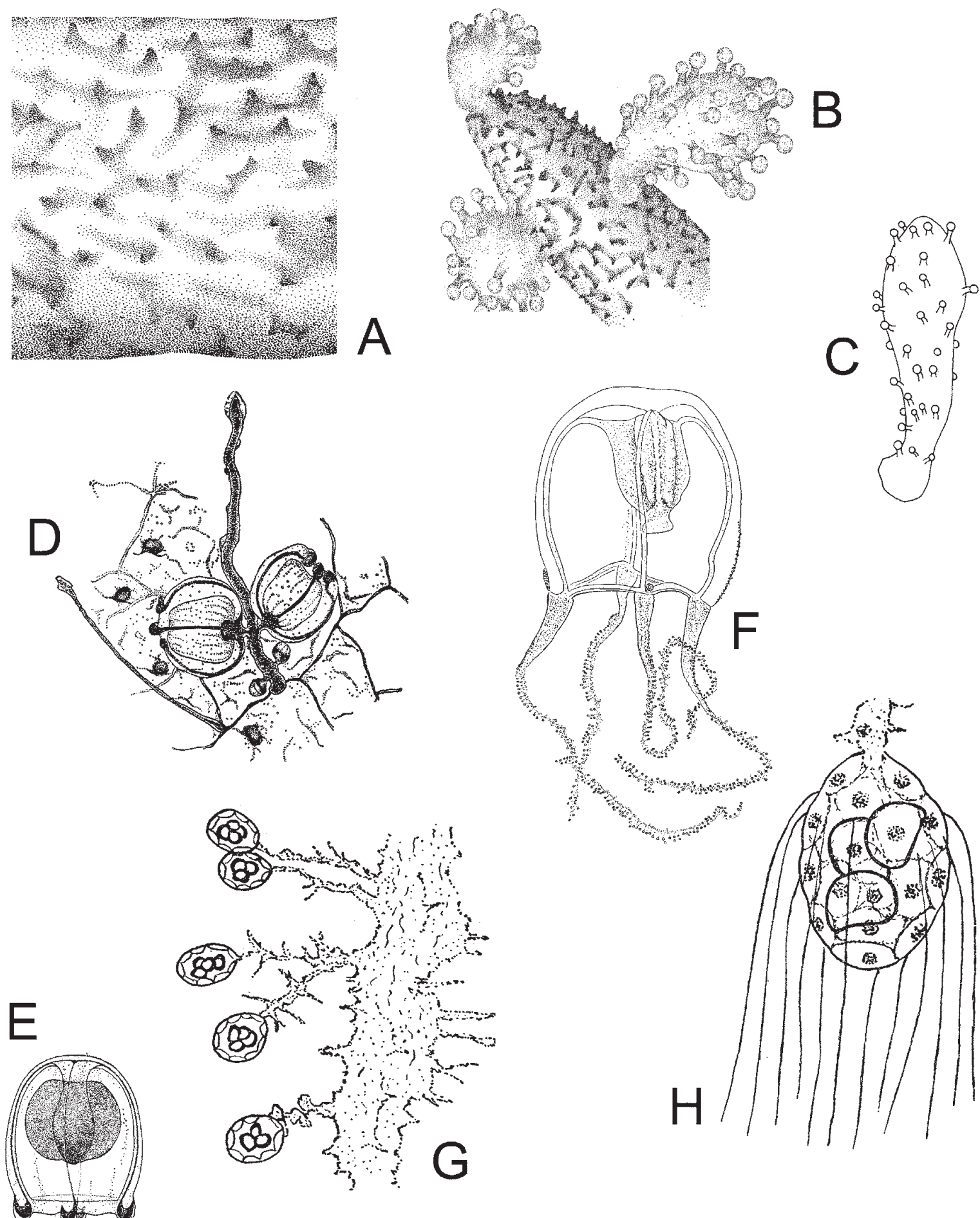

FIG. 58. - Anthomedusae. Capitata. Rosalindidae. A to C: Rosalinda incrustans: A: semi-diagrammatic drawing of a part of coenosarc and spines; B: detail of a portion of colony on a spine of Anamathia rissoana showing three hydranths; C: detail of a hydranth. Zancleidae. D and E: Halocoryne epizoica: D: general view of a part of colony living on a bryozoan host showing two polyps, one with medusa buds; E: newly released eumedusoid. F to H: Zanclea sp.: F: adult medusa; G: portion of a marginal tentacle with cnidophores; H: detail of a cnidophore (A and B after Vervoort 1966b; C after Petersen, 1990; D and E after Bouillon, 1995; F to H after Russell, 1953). 


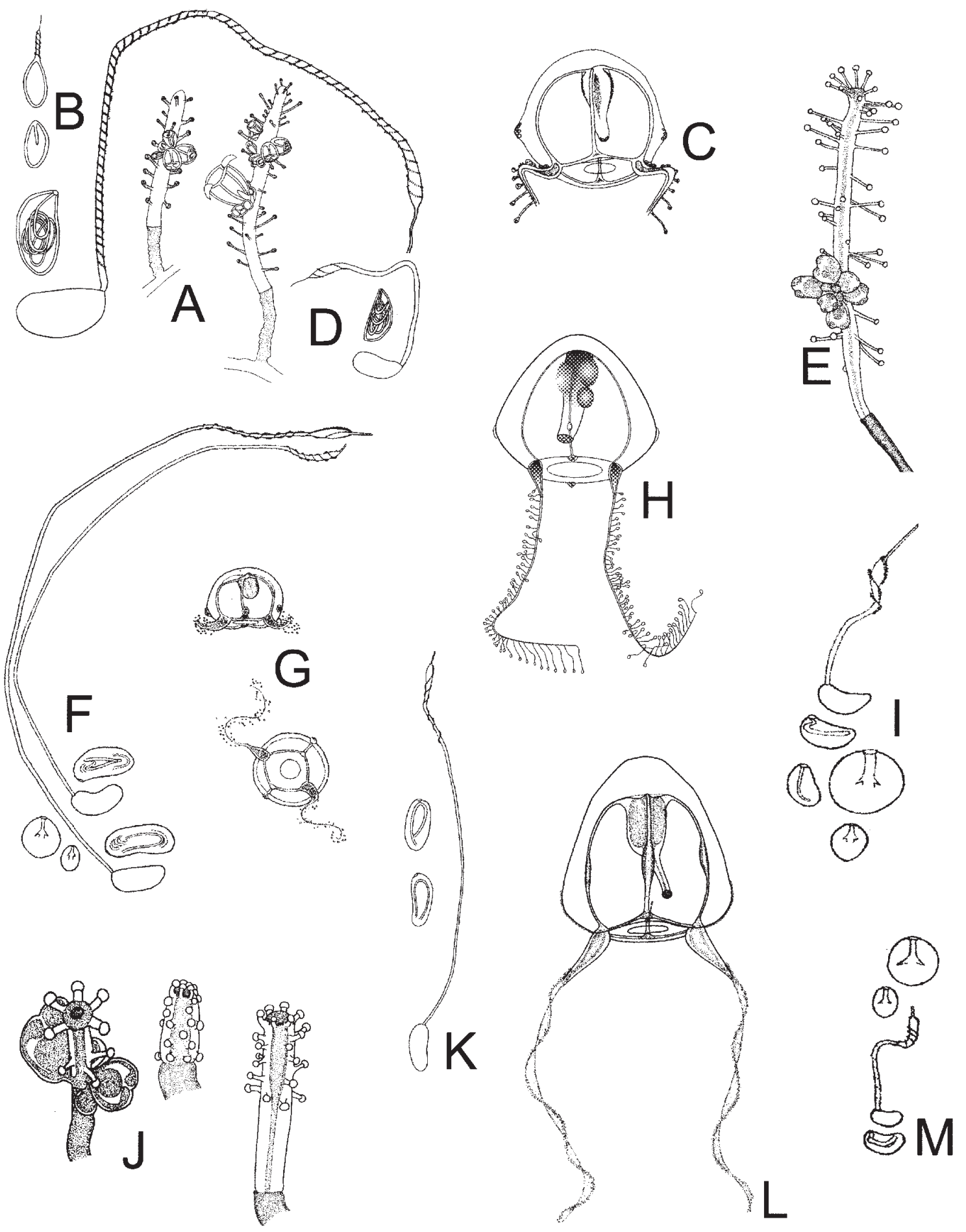

FIG. 59. - Anthomedusae. Capitata. Zancleidae. A to M: Zanclea: A to D: Zanclea costata: A: two hydranths with medusa buds; B: above left microbasic mastigophores, below left and at right macrobasic euryteles of hydranths; C: mature medusa; D: macrobasic euyryteles from medusan cnidophores. E to I: Zanclea giancarloi: E: hydranth with medusa buds; F: cnidome of hydroid comprising undischarged stenoteles of two sizes and discharged macrobasic euryteles of two types; G: newly released medusae; H: mature medusae I: cnidome of medusa comprising undischarged stenoteles of two sizes, discharged and undischarged macrobasic euryteles from cnidophores and undischarged microbasic euryteles from exumbrella. J to M: Zanclea sessilis: J: hydranth in different states of contraction, one with medusa buds; K: cnidocysts of the hydroid, stenoteles of two sizes, undischarged and discharged macrobasic euryteles; L: adult medusa; M: cnidome of the medusa, stenoteles of two sizes, undischarged and discharged macrobasic euryteles from cnidophores (all after Boero et al., 2000). 

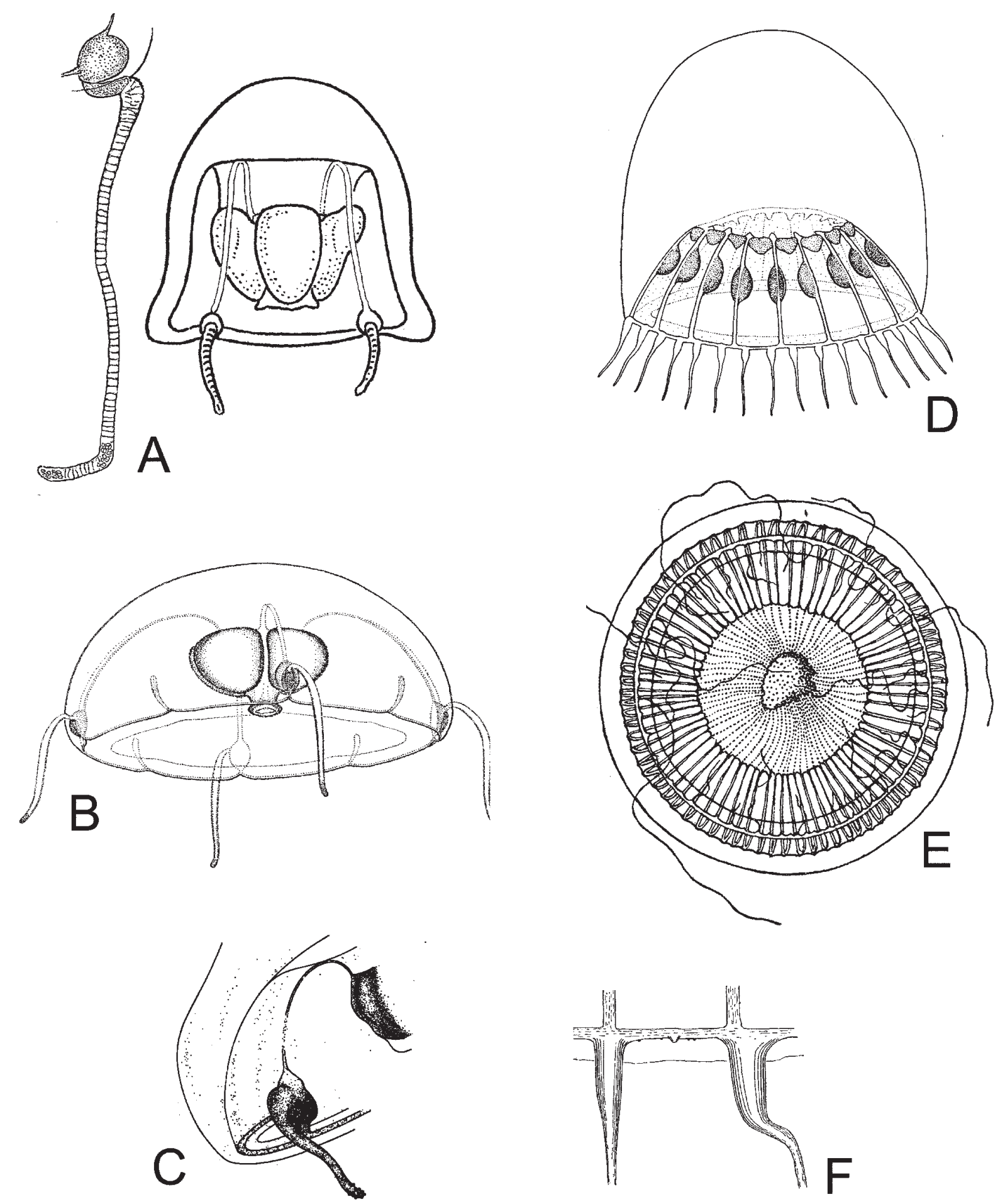

FIG. 60. - Laingiomedusae. Laingiidae. A: Fabienna oligonema: left marginal tentacle, right adult medusa; B and C: Kantiella enigmatica: B: mature medusa; C: detail of a tentacular bulb and tentacle. Leptomedusae. Aequoreidae. D to F: Aequorea: D: Aequorea conica: adult medusa; E and F: Aequorea forskalea: E: adult medusa; F: portion of umbrella margin (A slightly modified, E and F after Kramp, 1959a; B and C after Bouillon, 1978a; D after Pagès et al., 1992). 

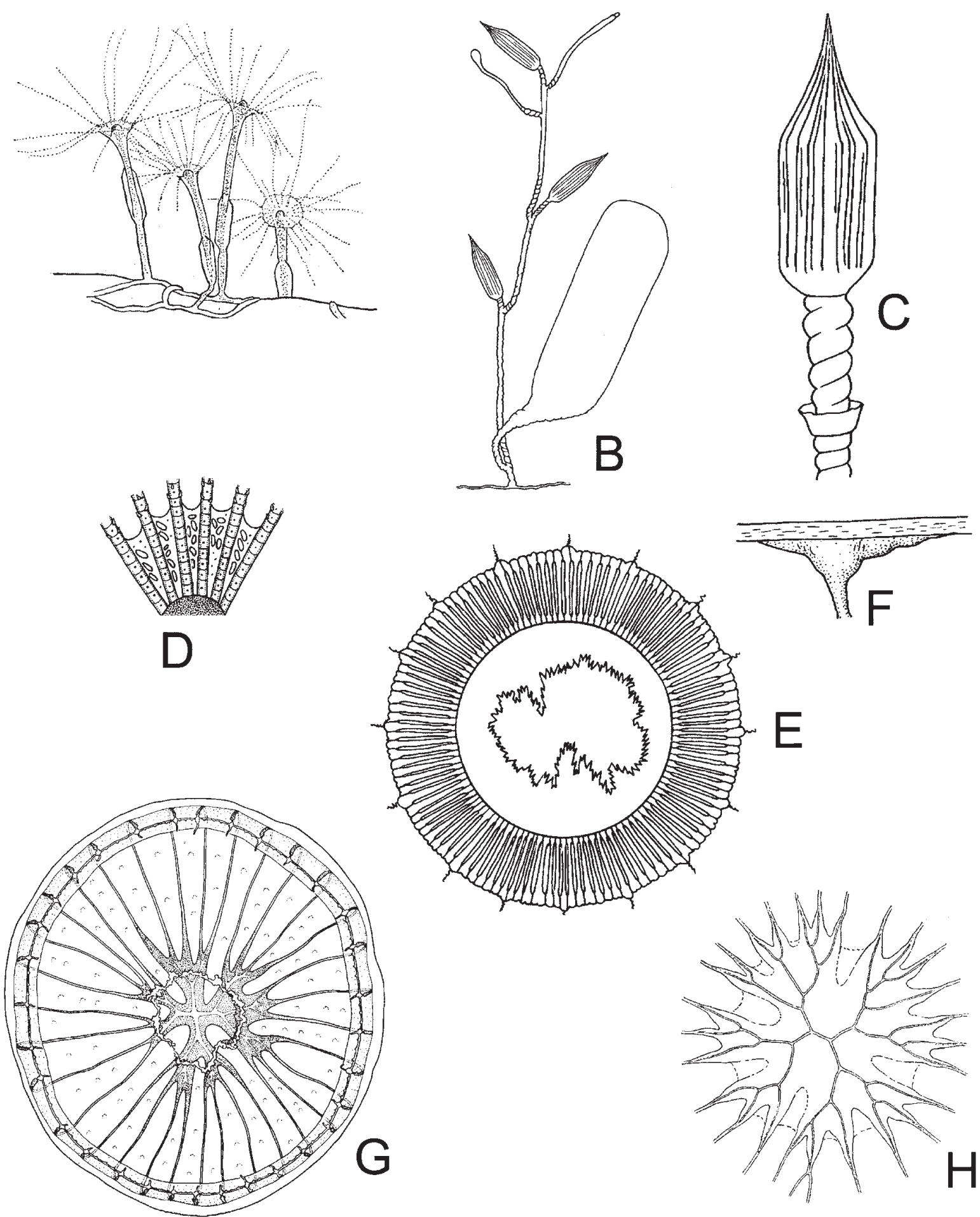

FIG. 61. - Leptomedusae. Aequoreidae. A to F: Aequorea: A to D: Aequorea spp. hydroid: A: portion of a colony; B: branch of a colony with a gonophore; C: hydrotheca; D: basal web between tentacles of hydranth; $\mathrm{E}$ and F. Aequorea pensilis: E. fully-grown medusa; F: portion of umbrella margin; $\mathrm{G}$ and $\mathrm{H}$ : Zygocanna vagans: G: oral view of an adult medusa; $\mathrm{H}$ : aboral view of the manubrium (A after Russell, 1953; B after Hincks, 1868; C after Cornelius, 1995; D after Rees, 1938; E and F after Kramp, 1959a; G after Pagès et al., 1992, H after Bigelow, 1919). 

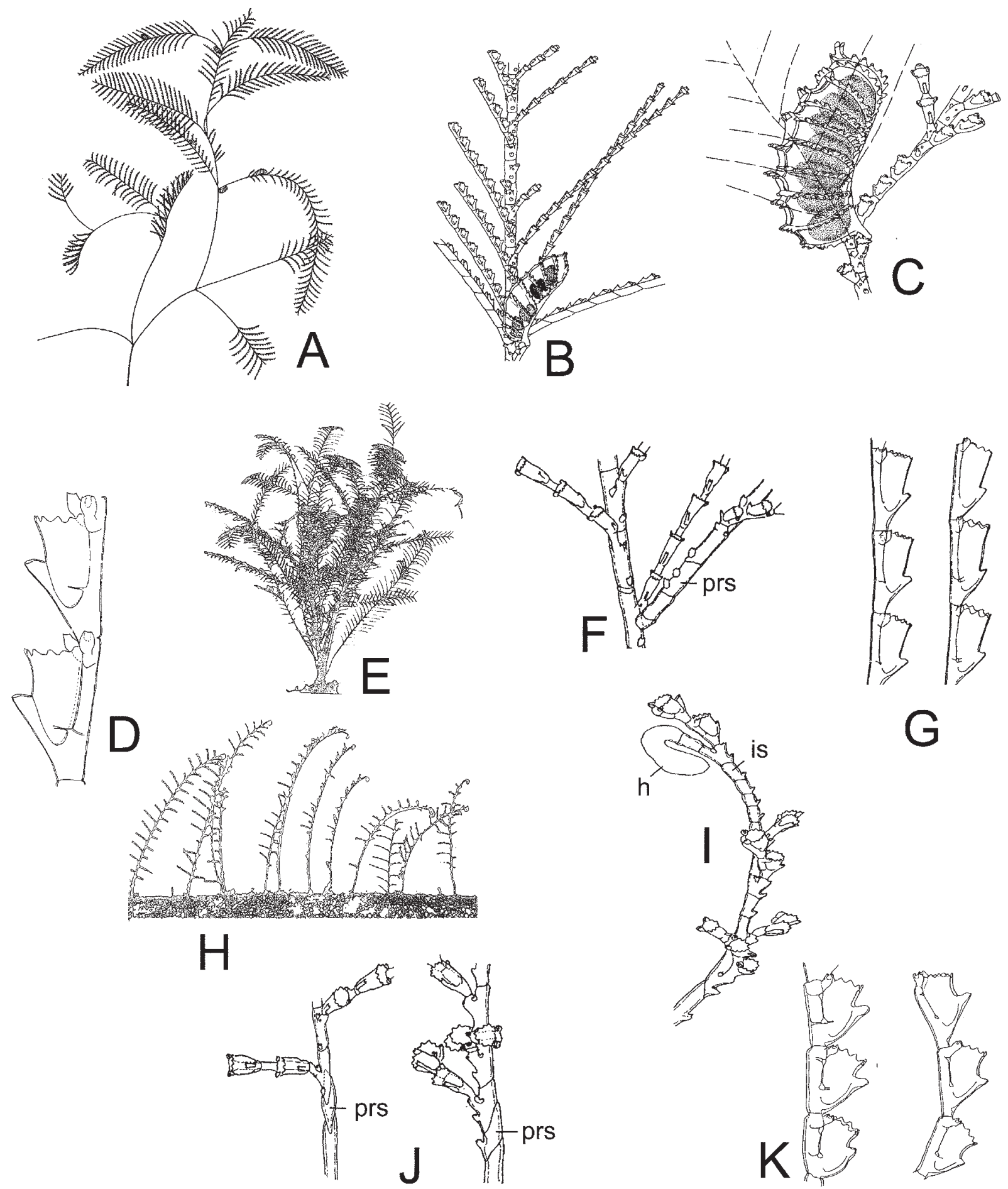

G
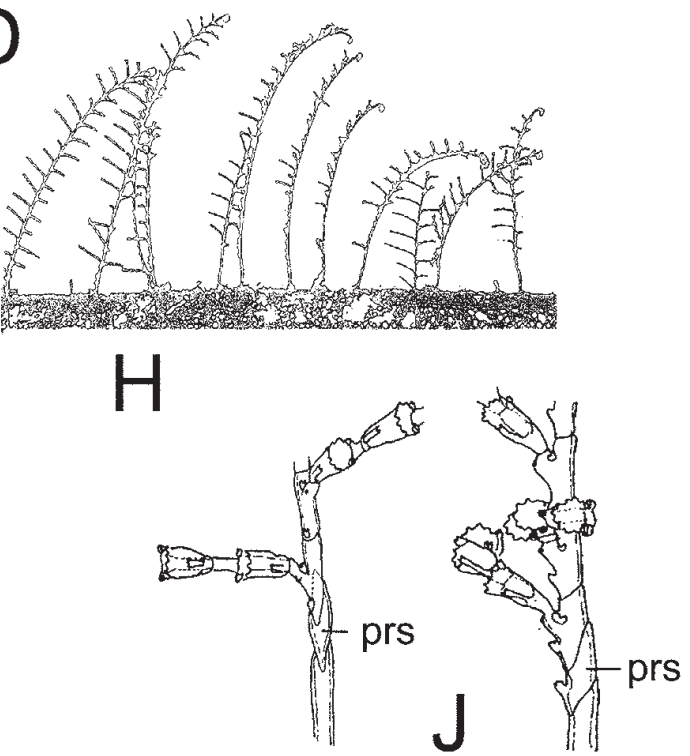

FIG. 62. - Leptomedusae. Aglaopheniidae. A to K: Aglaophenia: A to D: Aglaophenia acacia: A: general view of a colony; B: part of colony showing the insertion of corbula on hydrocaulus; $\mathrm{C}$ : detail of corbula on hydrocaulus; D: hydrotheca and associated nematothecae. E to G: Aglaophenia elongata: E: general view of a colony; F: part of branch with prosegments (prs); G: fragment of hydrocladia showing hydrothecae and associated nematothecae. $\mathrm{H}$ to K: Aglaophenia harpago: $\mathrm{H}$ : colony on Posidonia oceanica leaf bending backwards at slack water; I: apical region of hydrocaulus with hook (h) and intersegments (is); J: basal region of caulus, left frontal view, right lateral view (prs: prosegments); K: fragments of hydrocladia showing hydrothecae and associated nematothecae (A and D, after Medel and Vervoort, 1995; B, C, E to K after Svoboda and Cornelius, 1991). 

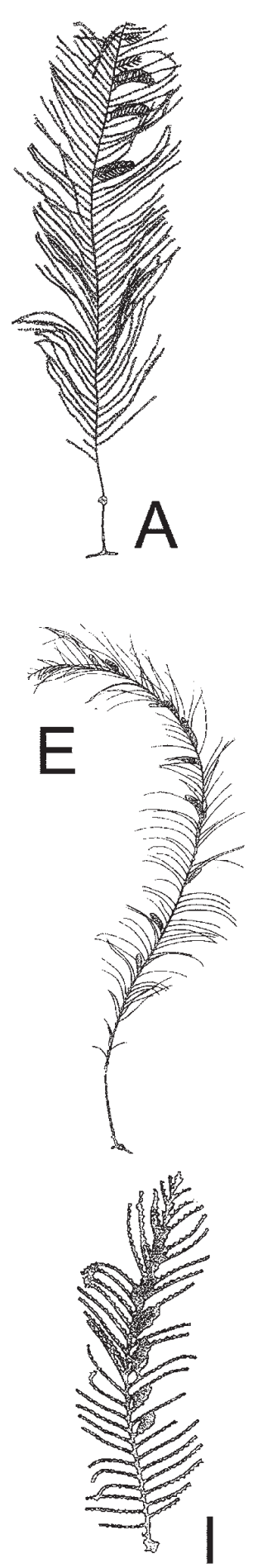
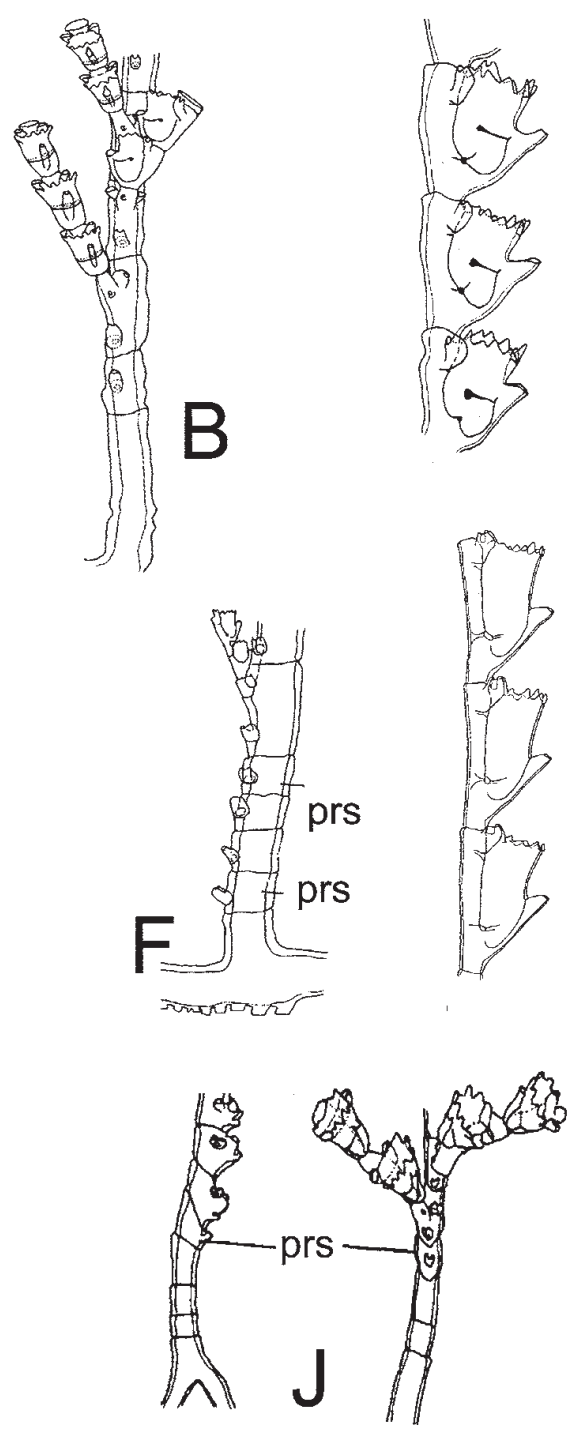

G
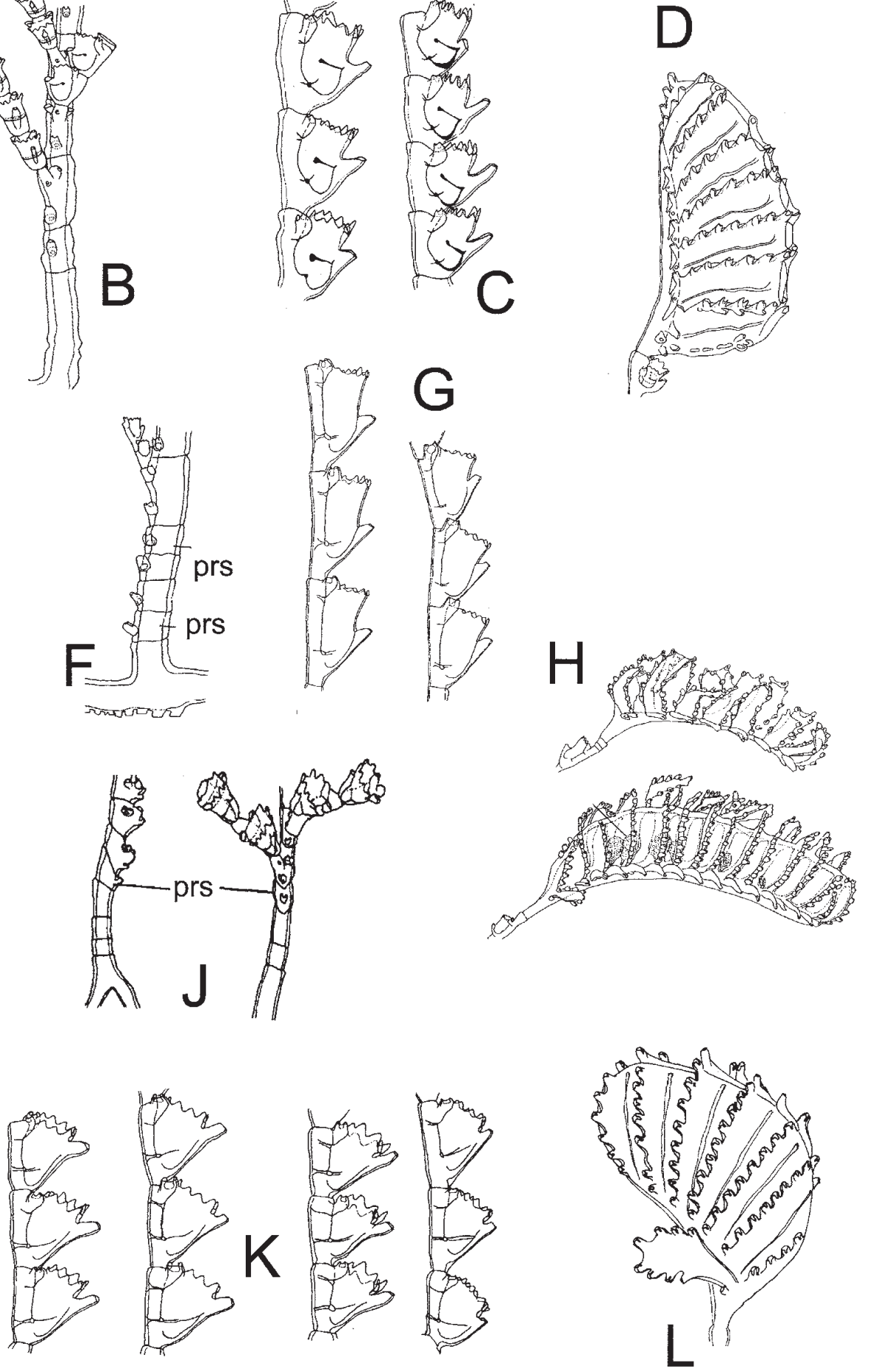

FIG. 63. - Leptomedusae. Aglaopheniidae. A to L: Aglaophenia: A to D: Aglaophenia kirchenpaueri: A: general view of a colony; B: basal region of hydrocaulus, showing prosegments and bases of hydrocladia; $\mathrm{C}$ : fragments of hydrocladia showing hydrothecae and associated nematothecae; D: male corbula; E to H: Aglaophenia lophocarpa: E: colony; F: base of cormoid with four prosegments (prs); G: fragments of hydrocladia showing hydrothecae and associated nematothecae; $\mathrm{H}$ : above fully-grown corbula with abnormally completely unfused ribs, below female corbula; I to L: Aglaophenia octodonta: I: general view of a colony; J: left: view of basal region of a caulus, right: end of a cladium (prs: prosegments); K: fragments of hydrocladia showing hydrothecae and associated nematothecae; L: female corbula (A to K after Svoboda and Cornelius, 1991; L after Medel and Vervoort, 1995). 

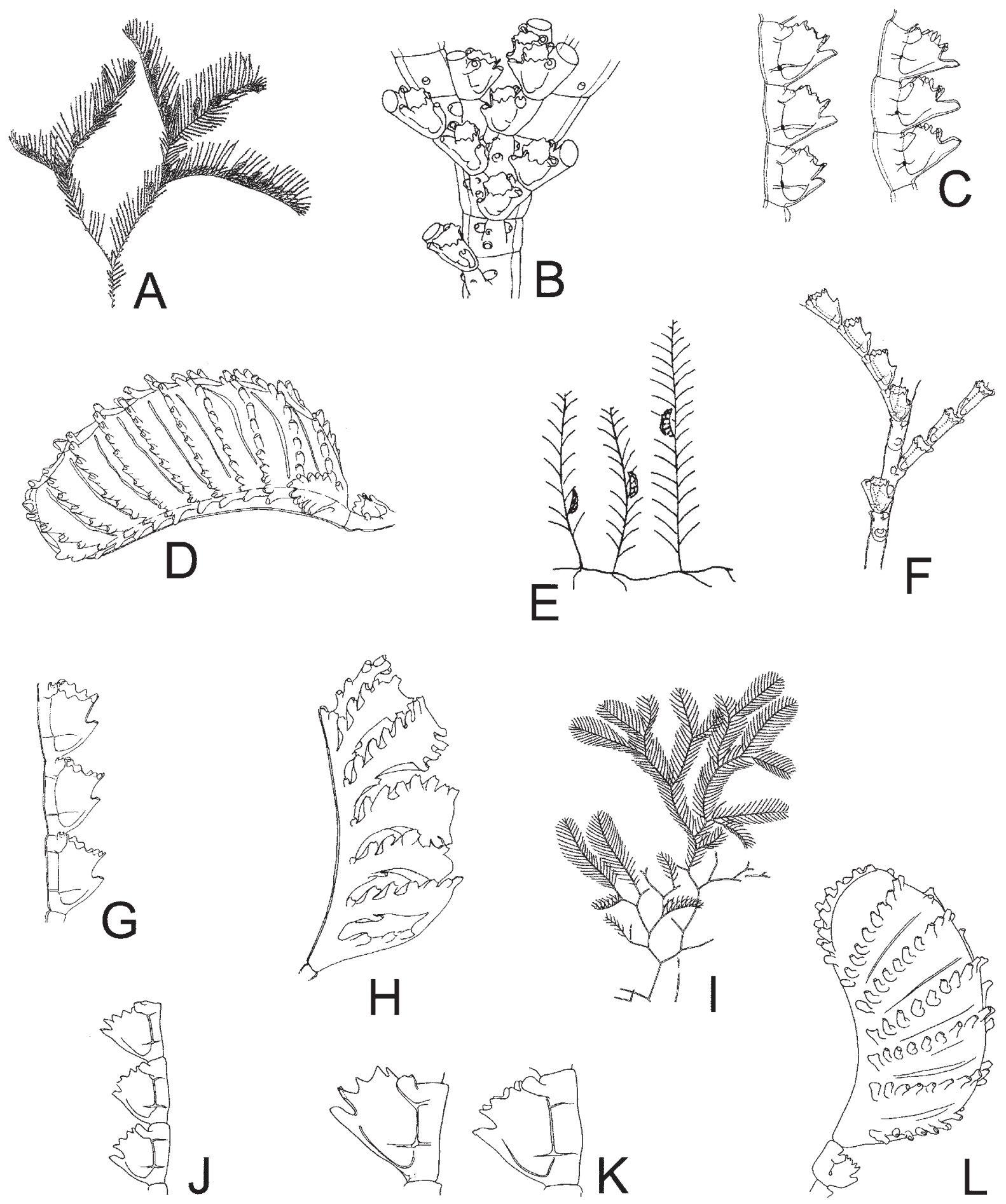

FIG. 64. - Leptomedusae. Aglaopheniidae. A to L: Aglaophenia: A to D: Aglaophenia parvula: A: general aspect of a colony; B: detail of fork of a dichotomously branched colony; C: fragments of hydrocladia showing hydrothecae and associated nematothecae; D: female corbula; E to H: Aglaophenia picardi: E: three colonies springing from same stolon; F: basal part of cormoid, frontal view; G: fragments of hydrocladia showing hydrothecae and associated nematothecae, H: male corbula; I to L: Aglaophenia pluma: I: general view of a colony; J: detail of hydrocladium; K: two hydrothecae and associated nematothecae; L: corbula (A to D after Svoboda and Cornelius, 1991 ; E, G and H after Medel and Vervoort, 1995; F after Ansín Agís et al., 2001; I after Bedot, 1919; J, K left and L after Cornelius, 1995; K right after Millard, 1975). 

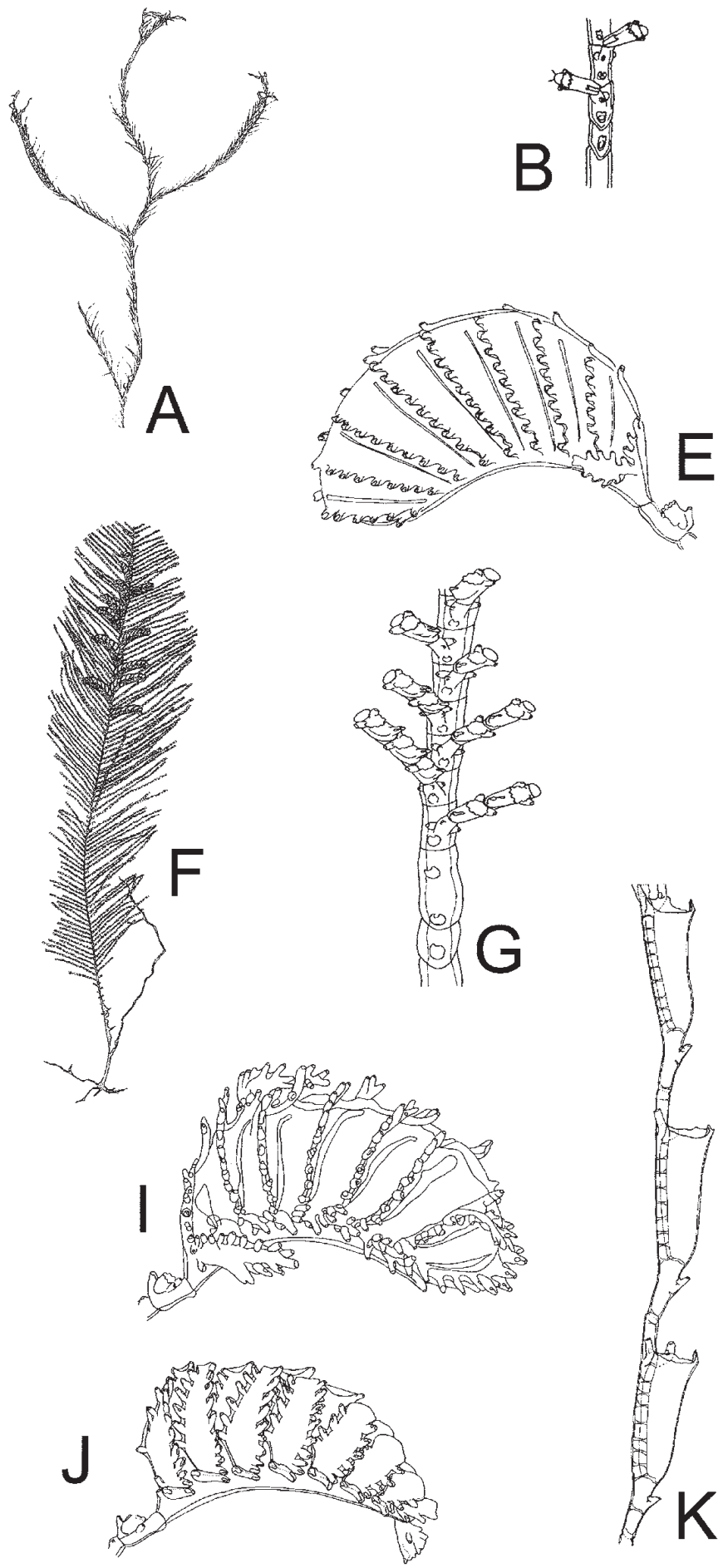
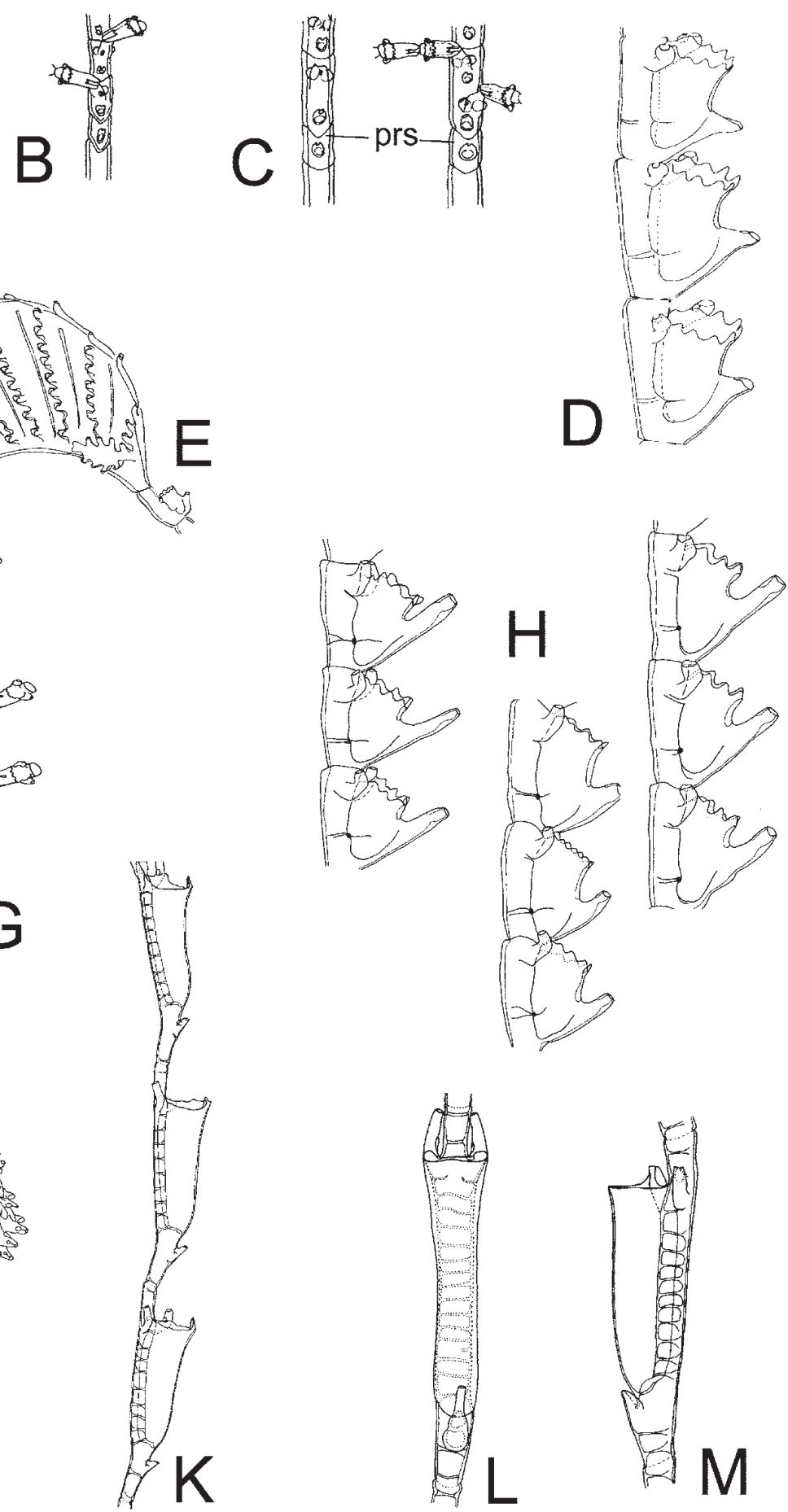

FIG. 65. - Leptomedusae. Aglaopheniidae. A to J: Aglaophenia: A to E: Aglaophenia tubiformis: A: general aspect of a colony, B and C basal parts of cauli (prs: prosegments), D: fragments of hydrocladia showing hydrothecae and associated nematothecae, E: female corbula. F to J: Aglaophenia tubulifera: F: whole colony, G: region of insertion of basalmost hydrocladia, including prosegments, $\mathrm{H}$ : fragments of hydrocladia showing hydrothecae and associated nematothecae, I: male corbula, J: female corbula. K to N: Cladocarpus: K: Cladocarpus multiseptatus: three hydrocladia internodes with hydrothecae and nematothecae, lateral view; L to N: Cladocarpus pectiniferus: hydrocladial internodes with hydrotheca and nematotheca (A and C frontal view, B lateral view) (A to C, F to J after Svoboda and Cornelius, 1991; D and E after Medel and Vervoort, 1995; K to N after Ramil and Vervoort, 1992a). 


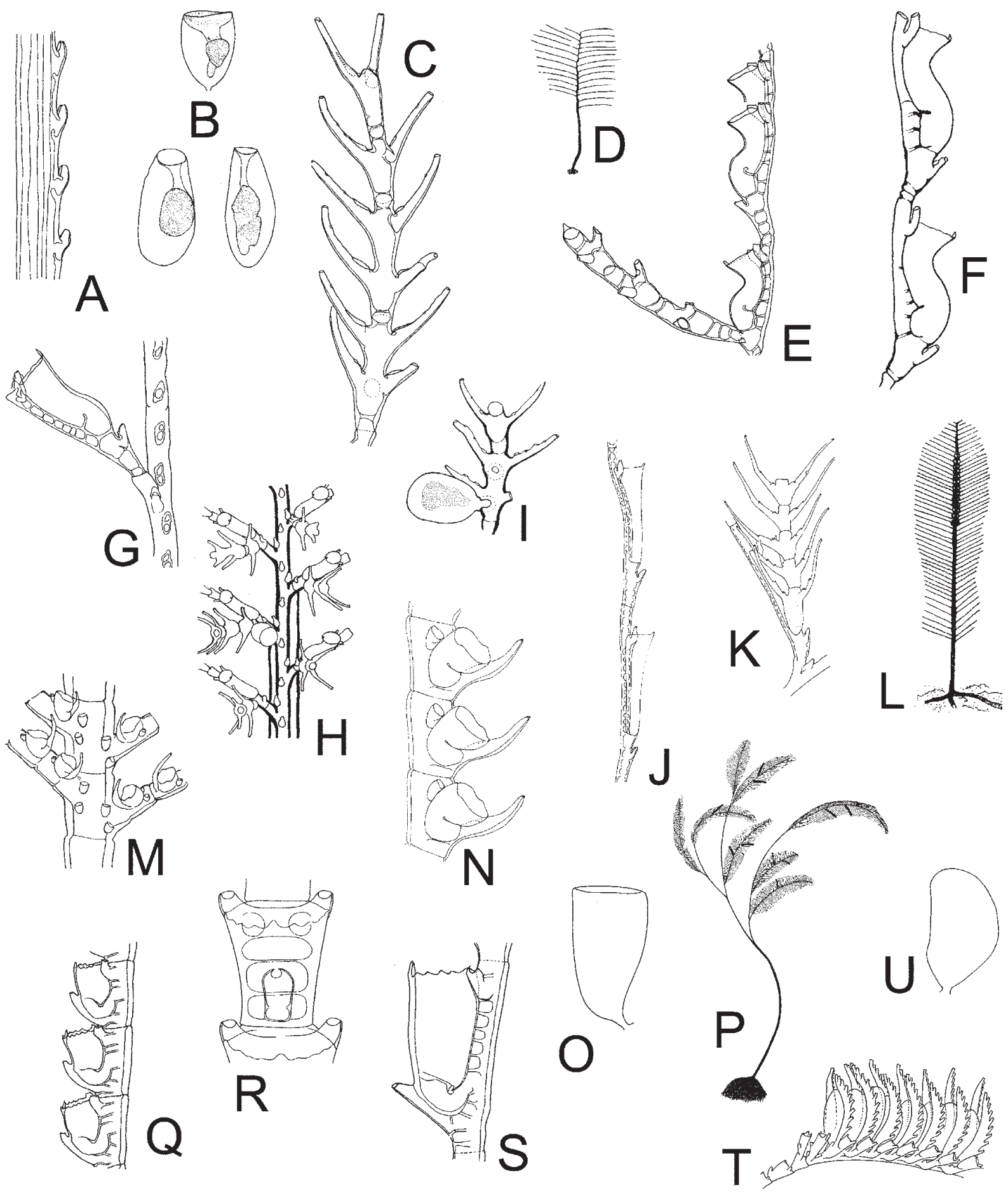

FIg. 66. - Leptomedusae. Aglaopheniidae. A to K: Cladocarpus. A to C: Cladocarpus pectiniferus: A: part of axis, lateral view; B: gonothecae; C: sterile phylactocarp view from above. D to I: Cladocarpus sinuosus: D: general view of a colony; E: two hydrocladial internodes with hydrotheca and nematotheca and a sterile phylactocarp, slightly oblique lateral view, F and G: details of hydrocladia showing hydrothecae and associated nematothecae; $\mathrm{H}$ anterior view of hydrocaulus showing a young phylactocarps and the origin of hydrocladia; I: young phylactocarp bearing a gonotheca. J and K: Cladocarpus tenuis: J: hydrocladium; K: phylactocarp. L to N: Gymnangium montagi: L: general aspect of a colony; M: part of main axis with four hydrocladia; N: three hydrocladial internodes with hydrothecae and nematothecae; O: gonotheca, P to U: Lytocarpia myriophyllum: P: general aspect of a branched colony; Q: part of hydrocladium showing hydrothecae and associated nematothecae; $\mathrm{R}$ and $\mathrm{S}$ : hydrothecal internodes with hydrothecae and nematothecae ( $\mathrm{R}$ frontal view, $\mathrm{S}$ lateral view); T: corbula; $\mathrm{U}$ : gonotheca removed from within corbula (A to C, E , S after Ramil and Vervoort 1992a); D, F, H to K after Millard, 1975; G and P after Gili et al., 1989; L to N after Medel and Vervoort, 1995; O, Q, T and U after Cornelius, 1995; R after Vervoort, 1972).

348 J. BOUILLON et al. 

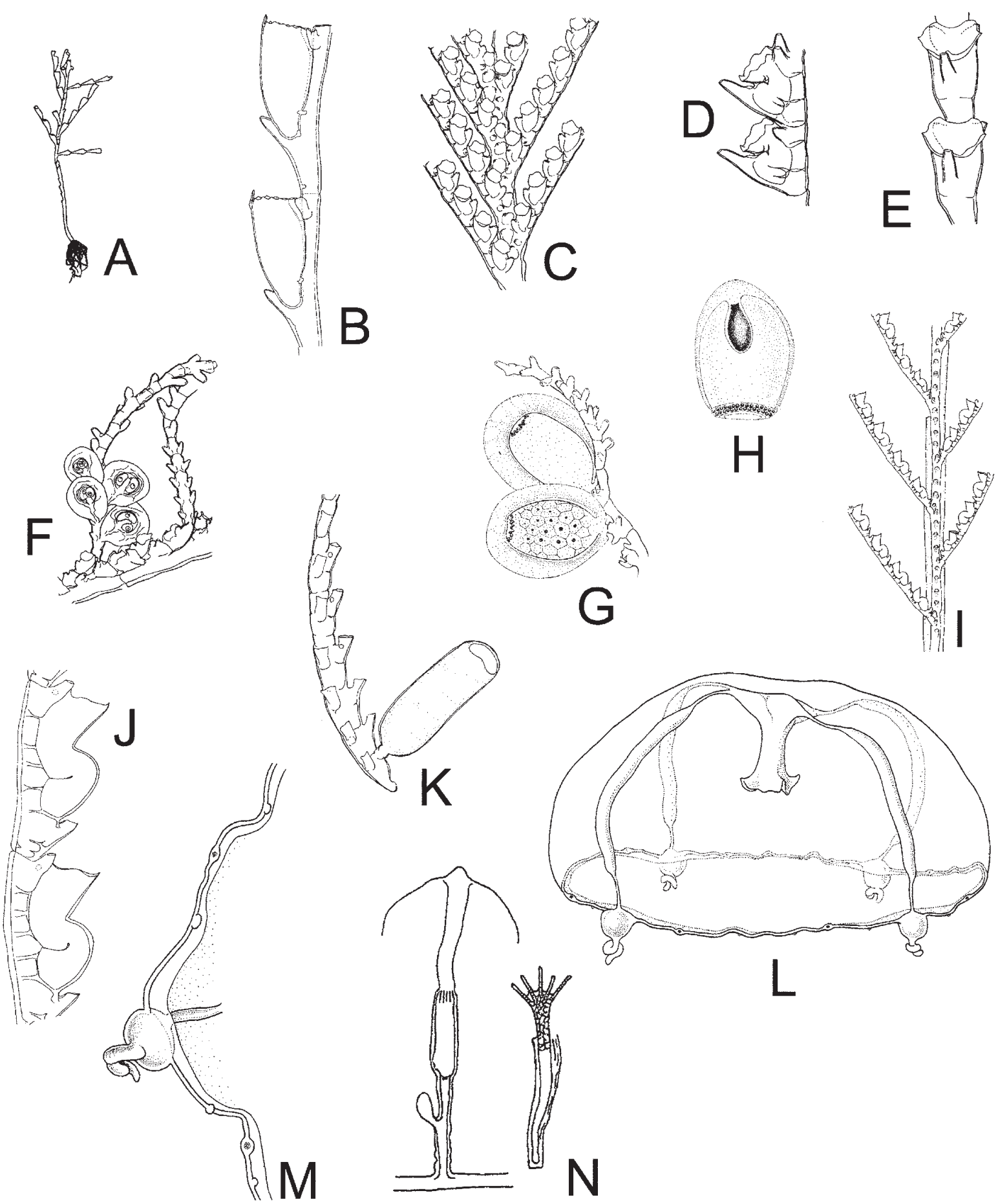

FIG. 67. - Leptomedusae. Aglaopheniidae. A and B: Lytocarpia distans. A: general aspect of a colony; B: two hydrocladial internodes with hydrothecae and nematothecae, lateral view; C to H: Macrorhynchia philippina: C: part of colony with origins of hydrocladia; D a part of hydrocladium in lateral view showing detail of hydrothecae and nematothecae; $\mathrm{E}$ : two hydrothecal internodes in anterior view; F: phylactocarps bearing female gonophores; G: phylactocarp with two gonophores; H: eumedusoid; I to K: Streptocaulus dollfusi: I: part of main axis with hydrocladia; J: two hydrocladial internodes with hydrothecae and nematothecae, lateral view; K: phylactocarp with a single gonotheca. Barcinidae. L and M: Barcino foixensis: L: mature medusa; M: portion of umbrella margin. Blackfordiidae. N: Blackfordia virginica: hydranths (A after AnsIn Agİs et al., 2001; B after Ramil and Vervoort, 1992a; C to F after Hirohito, 1995; G and H after Gravier, 1970; I to K after Medel and Vervoort, 1995; L and M after Gili et al., 1999; N after Valkanov, 1935). 

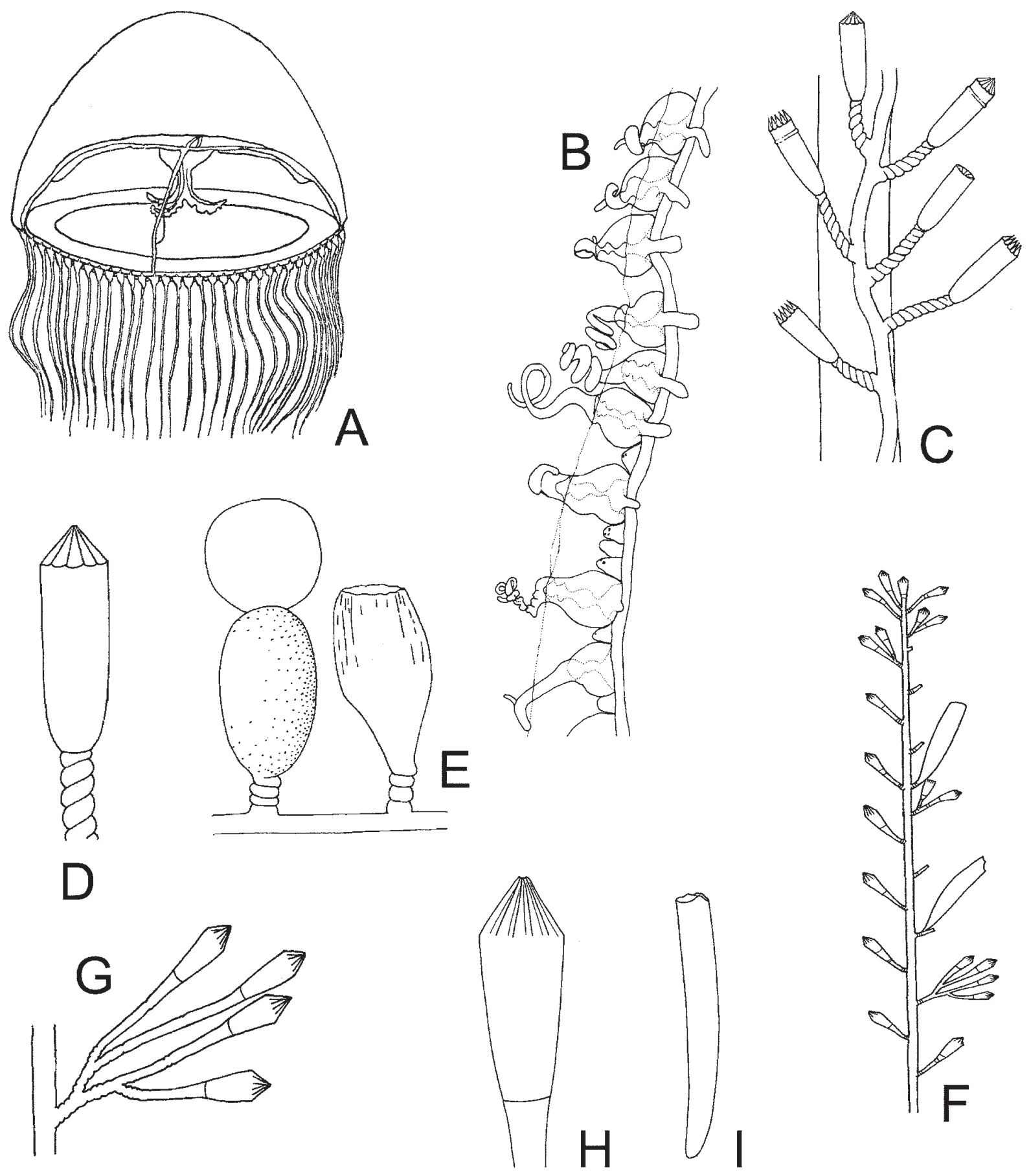

FIG. 68. - Leptomedusae. Blackfordiidae. A and B: Blackfordia virginica: A: fully-grown medusa; B: portion of umbrella margin. Campanulinidae. C to E: Calycella syringa: C: part of a colony (note sub-terminal annulus on some hydrothecae); D: detail of hydrotheca; E: two gonothecae, that on the left with an acrocyst. F to I: Campanulina panicula: F: general view of a part of a colony; G: panicle or group of hydrothecae; H: detail of hydrotheca; I: gonotheca (A after Kramp, 1959a, B after Moore, 1987, C to I after Cornelius, 1995). 

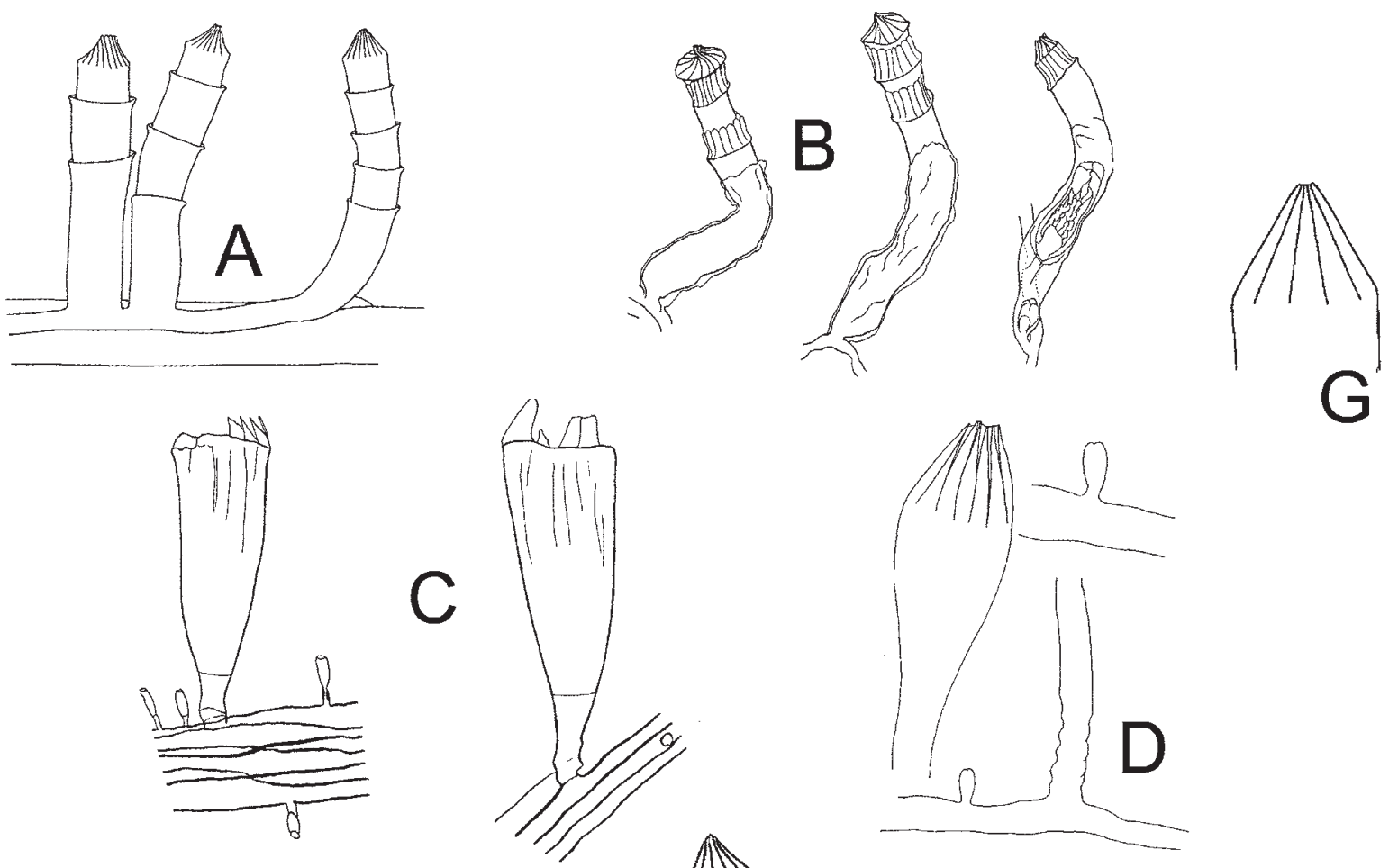

G
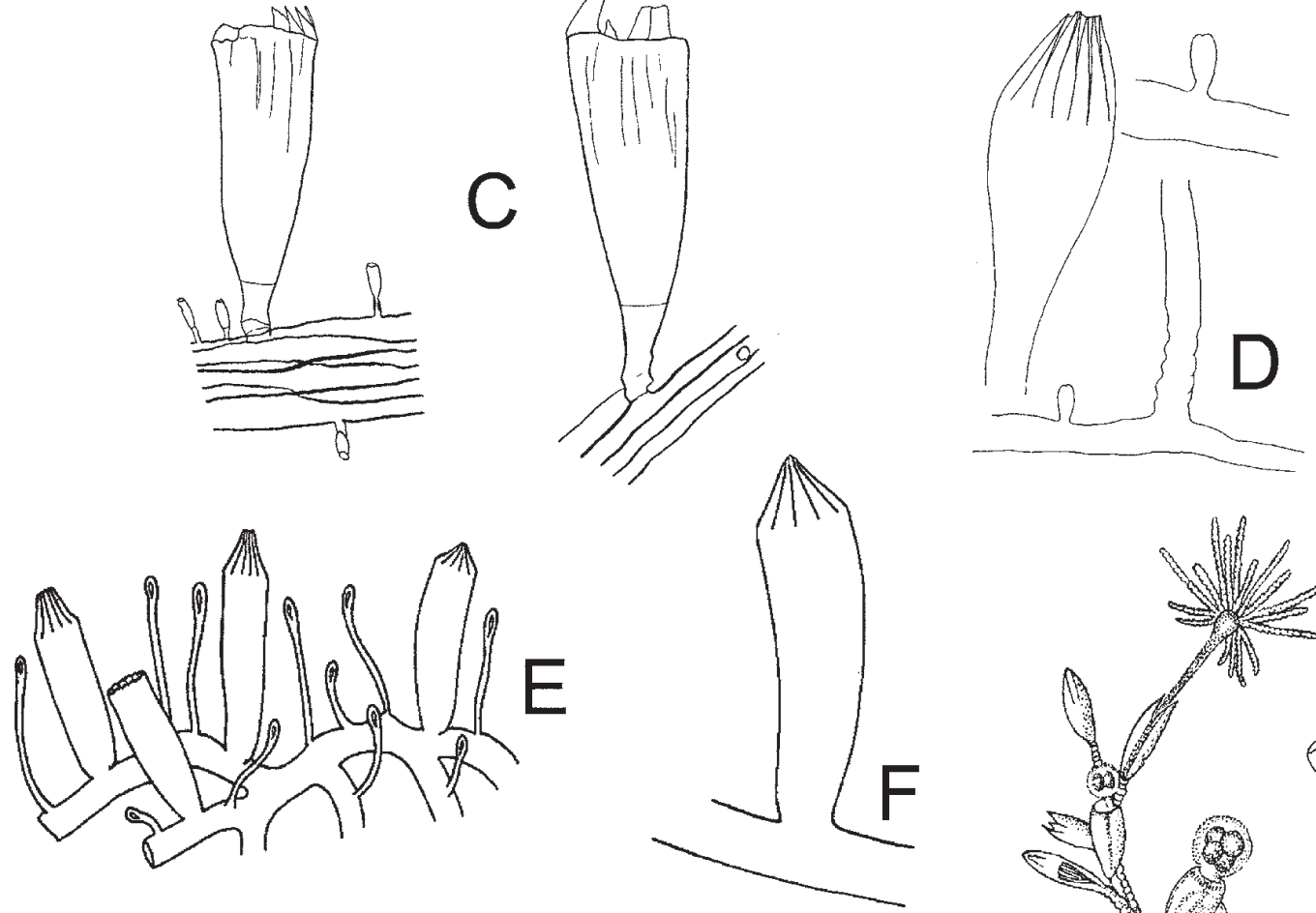

\section{(1)}
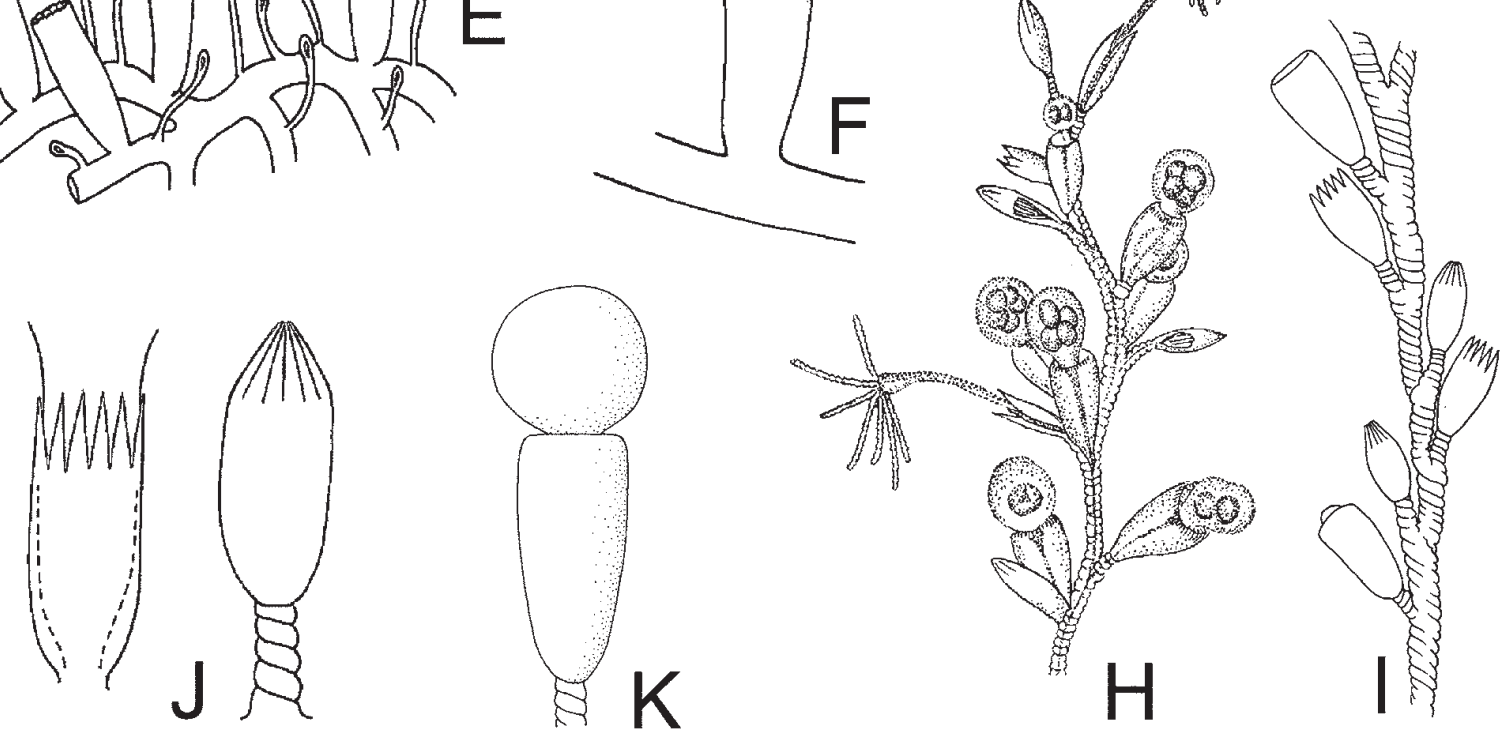

FIG. 69. - Leptomedusae. Campanulinidae. A and B: Cuspidella spp. hydroid general facies (note the horizontal ridges on the hydrothecae: "renovations" or growing lines): A: hydrotheca operculum without crease line, B: hydrotheca operculum with a crease line; C and D: Egmundella: C: Egmundella grimaldii: portions of stolons with hydrothecae and nematothecae; D: Egmundella valdiviae: hydrotheca and nematotheca. E to G: Lafoeina tenuis: E: part of a colony showing hydrothecae and nematothecae intermingled, F: detail of hydrotheca; G: detail of operculum. H to K: Opercularella lacerta: H: part of colony; I: portion of stem; J: two hydrothecae; K: gonotheca with acrocyst (A, E to G, I to K after Cornelius, 1995; B after Hirohito, 1995; C after Leloup, 1940b, D after Vervoort, 1966a, H after leloup, 1952). 

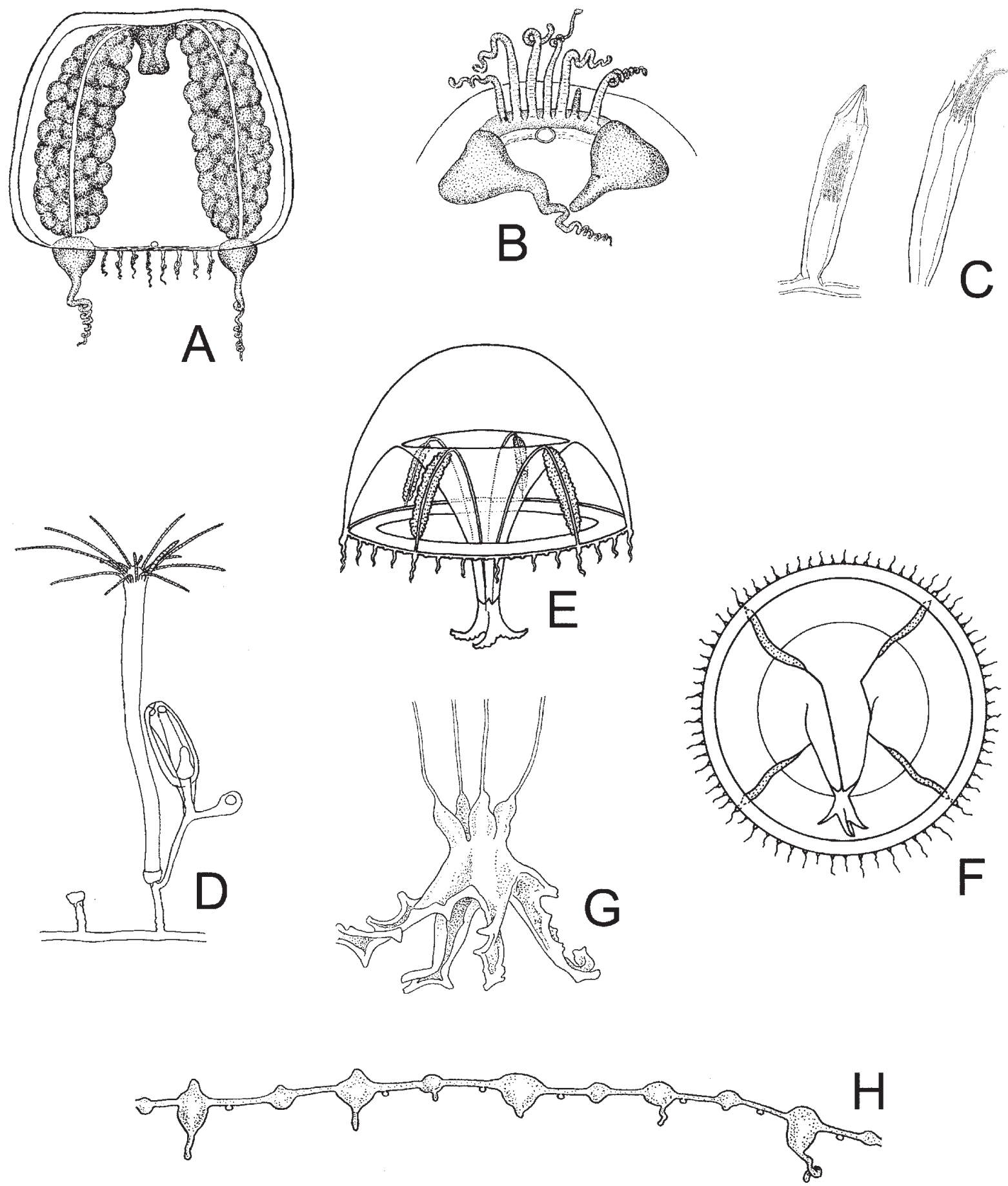

FIG. 70. - Leptomedusae. Cirrholovenidae. A to C: Cirholovenia tetranema: A: adult medusa, B: portion of umbrella margin; C: polyp. Eirenidae. D to $\mathrm{H}$ : Eirene viridula: D: hydroid stage with gonothecae; E and F: adult medusae; G: manubrium and four mouth-lips; $\mathrm{H}$ : detail of umbrella margin (A, B, E to G after Kramp, 1968; C after Brinckmann-Voss, 1965a; D after Cornelius, 1995; H after Russell, 1953). 

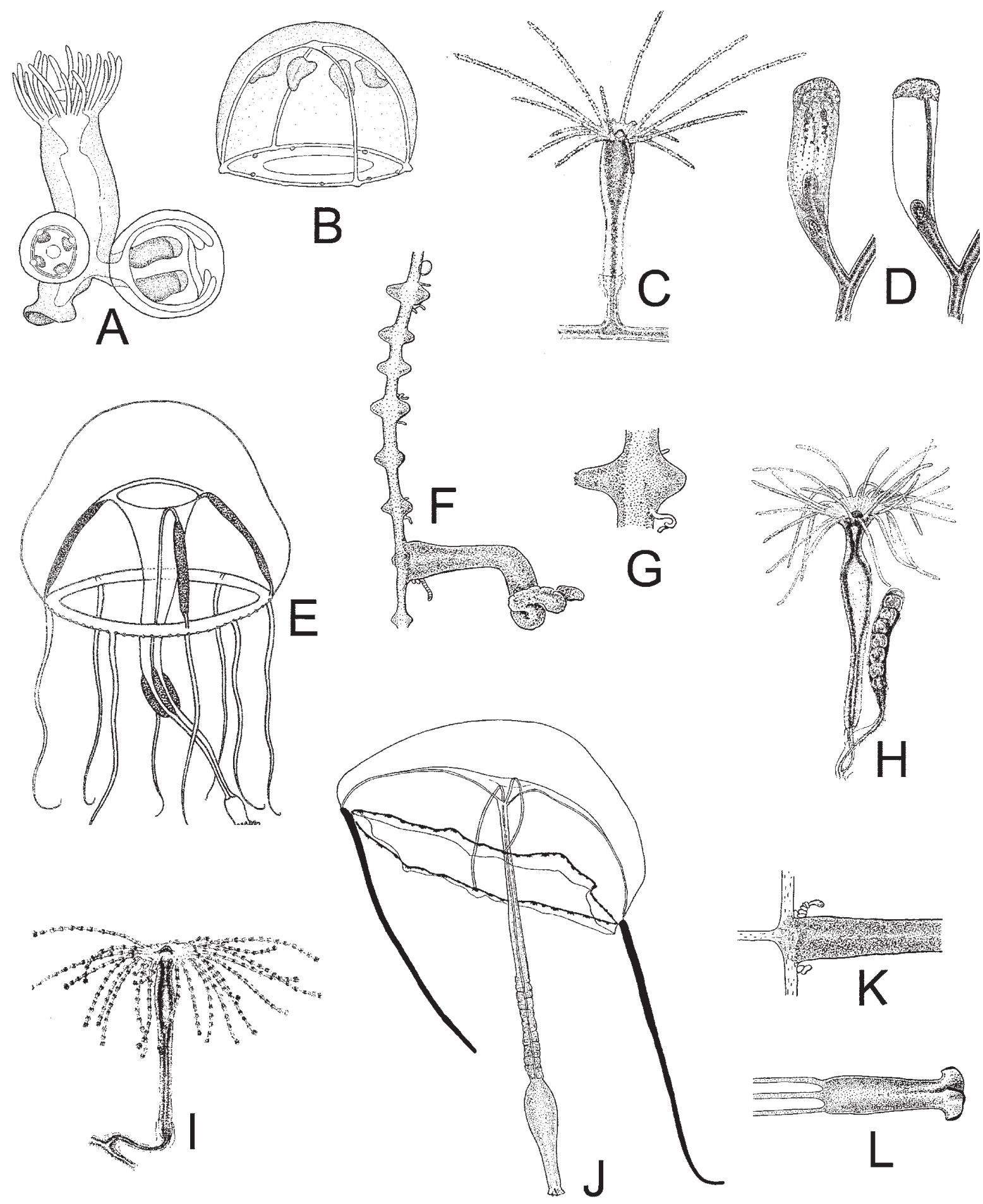

FIG. 71. - Leptomedusae. Eirenidae. A and B: Eugymnanthea inquilina: A: polyp with gonophore; B: eumedusoid; C to L: Eutima: C to G: Eutima gegenbauri: C: hydroid; D: gonangia before liberation of the medusae; E: adult medusa; F: portion of umbrella margin; G: non tentacular marginal swelling or warts, with lateral cirri and adaxial excretory papillae $\mathrm{H}$ to $\mathrm{L}$ : Eutima gracilis: $\mathrm{H}$ and $\mathrm{I}$ : hydranths: $\mathrm{H}$ : with gonangium. J: adult medusa; K: base of marginal tentacle with lateral cirri; L: manubrium and mouth (A and B after Morri, 1981; C and D, H and I after Russell, 1970a; E after Russell, 1963c; F and G, J to L after Russell, 1953). 

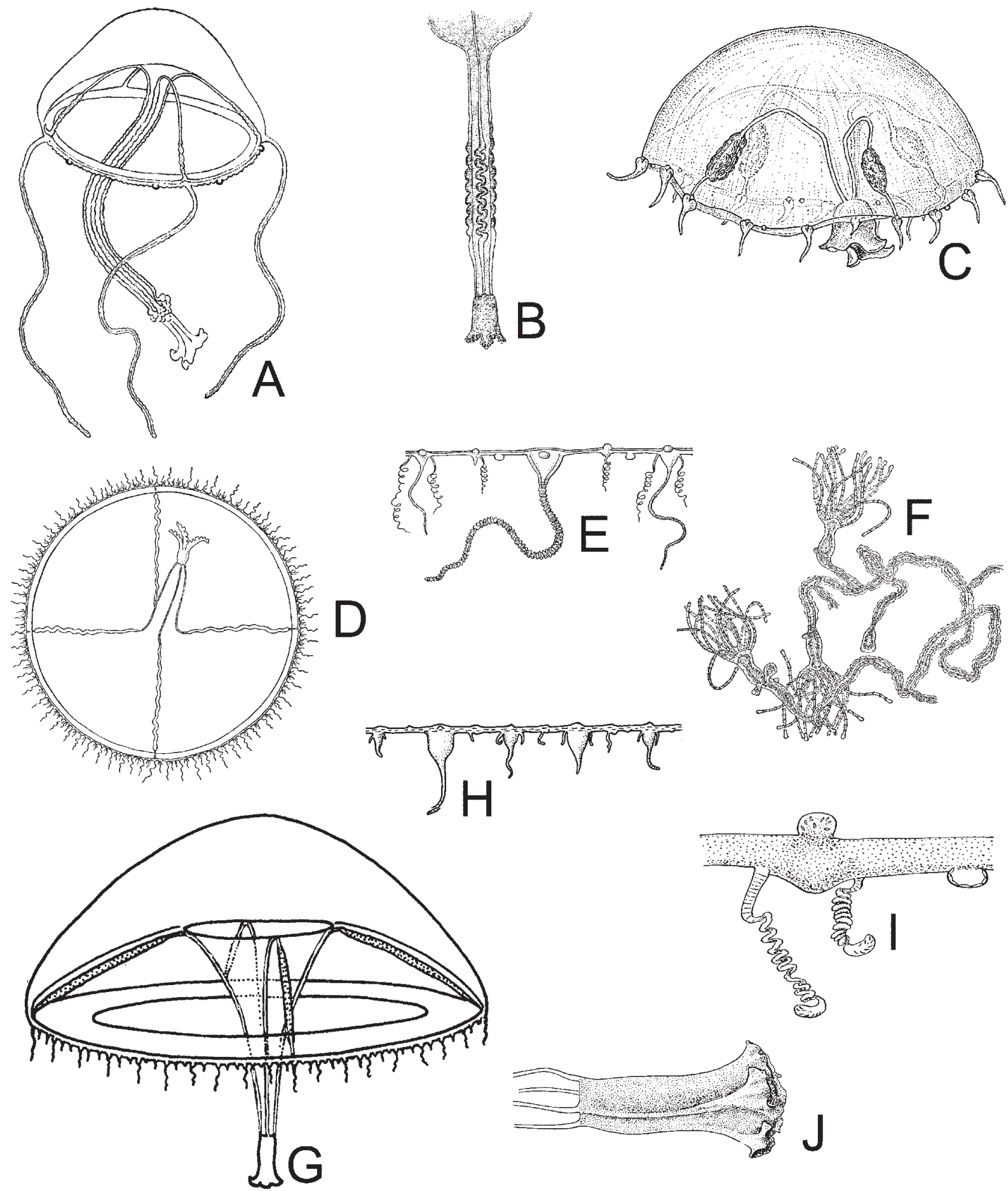

FIG. 72. - Leptomedusae. Eirenidae. A and B: Eutima mira: A: adult medusa; B: manubrium, gastric peduncle and gonads. C: Eutonina scintillans: mature medusa; D to J: Helgicirrha: D and E: Helgicirrha cari: D: mature medusa; E: portion of umbrella margin. F to J: Helgicirrha schulzei: F: hydroid colony; G: adult medusa; $\mathrm{H}$ : portion of umbrella margin showing marginal tentacles of two sizes; I: detail of margin showing the lateral cirri, statocyst and excretory papillae; J: manubrium and mouth (A after Kramp, 1933; B and C after Kramp, 1968; D and E after Mayer, 1910; F after Bouillon, 1971; G after Russell, 1963c, H to J after Russell, 1953). 


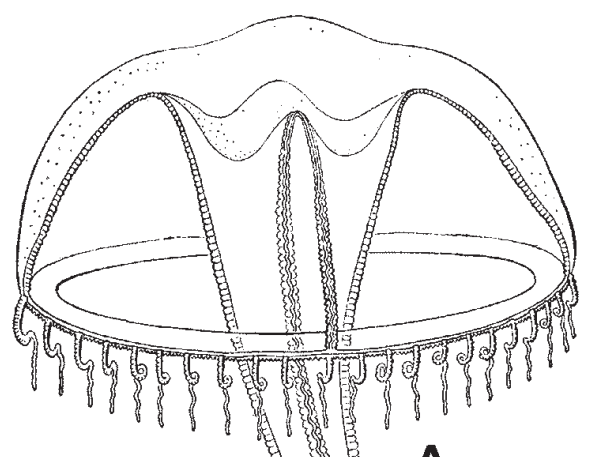

A
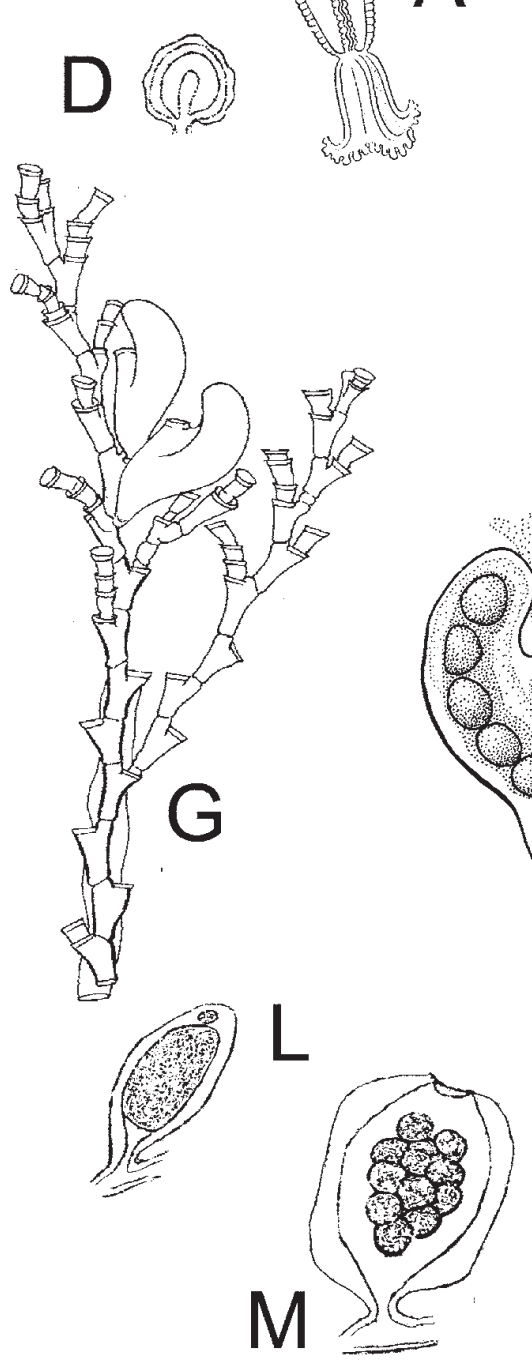
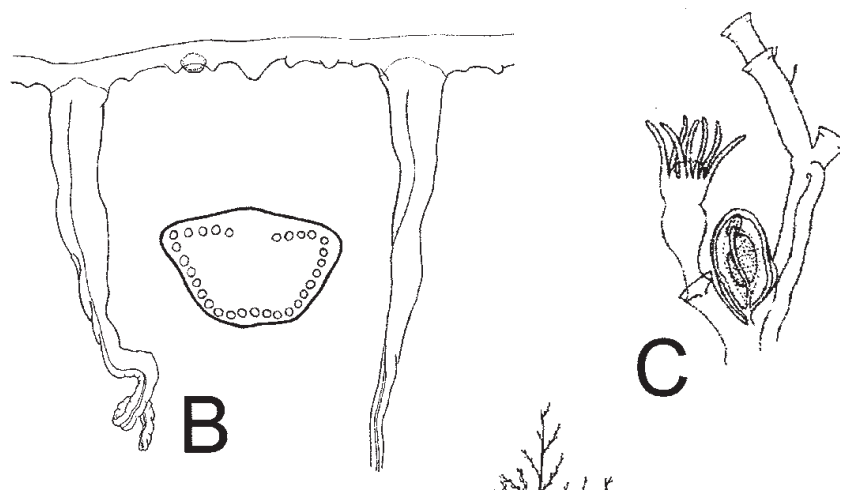

$\sqrt{3}$
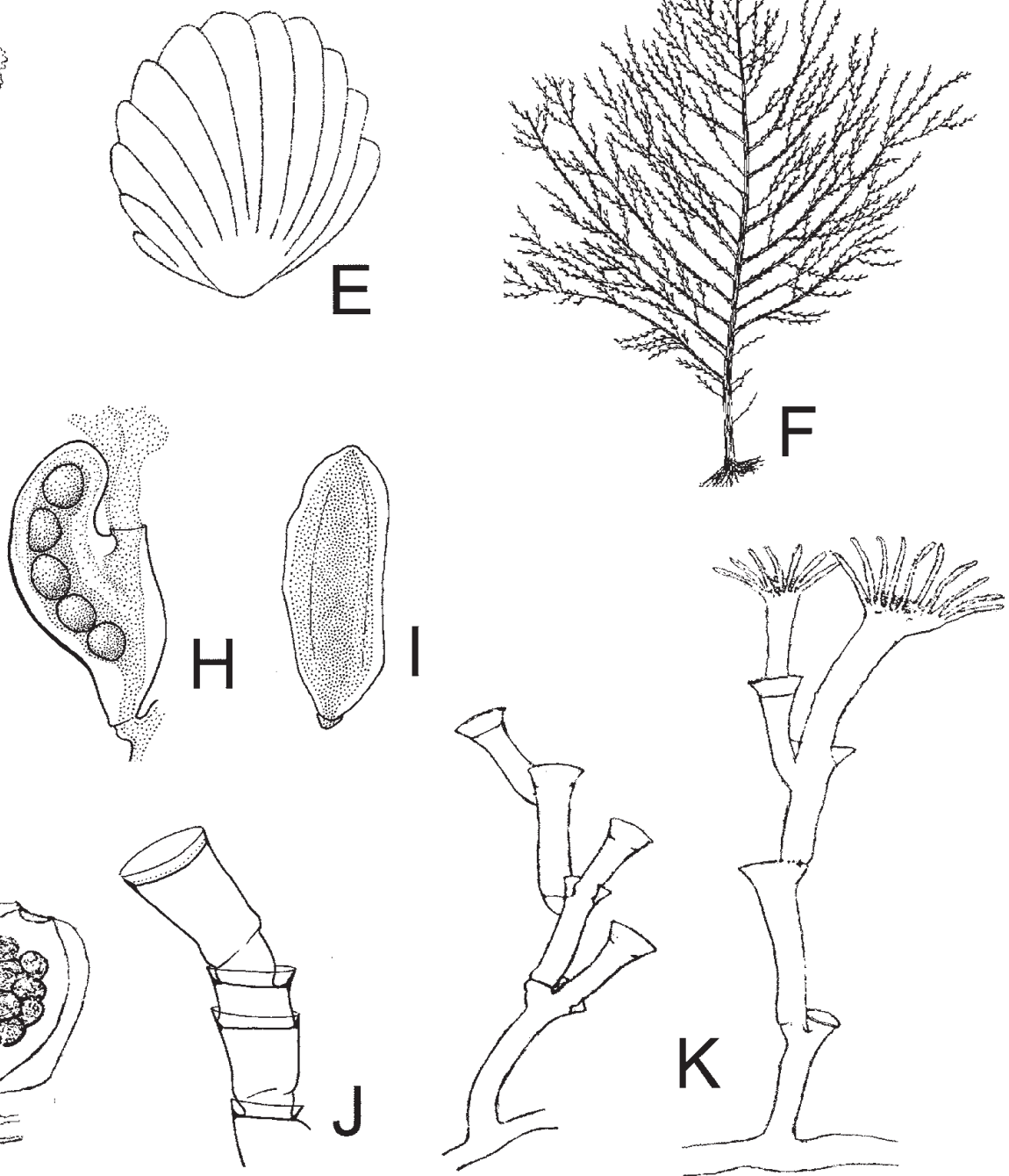

FIG. 73. - Leptomedusae. Eirenidae. A and B: Neotima lucullana: A: fully-grown medusa; B: part of umbrella margin and statocyst. Haleciidae $\mathrm{C}$ to $\mathrm{M}$ : Halecium: $\mathrm{C}$ to $\mathrm{E}$ : Halecium banyulense: $\mathrm{C}$ : hydrocladium with hydrotheca and gonophore; $\mathrm{D}$; young female gonophore; $\mathrm{E}$ : mature female gonophore. F to J: Halecium beanii: F: general aspect of a colony; G: stem with hydrothecae and female gonophore; H: female gonophore; I: male gonophore; J: regenerated hydrothecae; K to M: Halecium conicum: K: two type of stems; L: male gonophore; M: female gonophore (A after Kramp, 1959a; B after Petersen, 1990; C to E , K to M after Motz-Kossowska, 1911; F after Cornelius, 1995; G to J after Millard, 1975). 

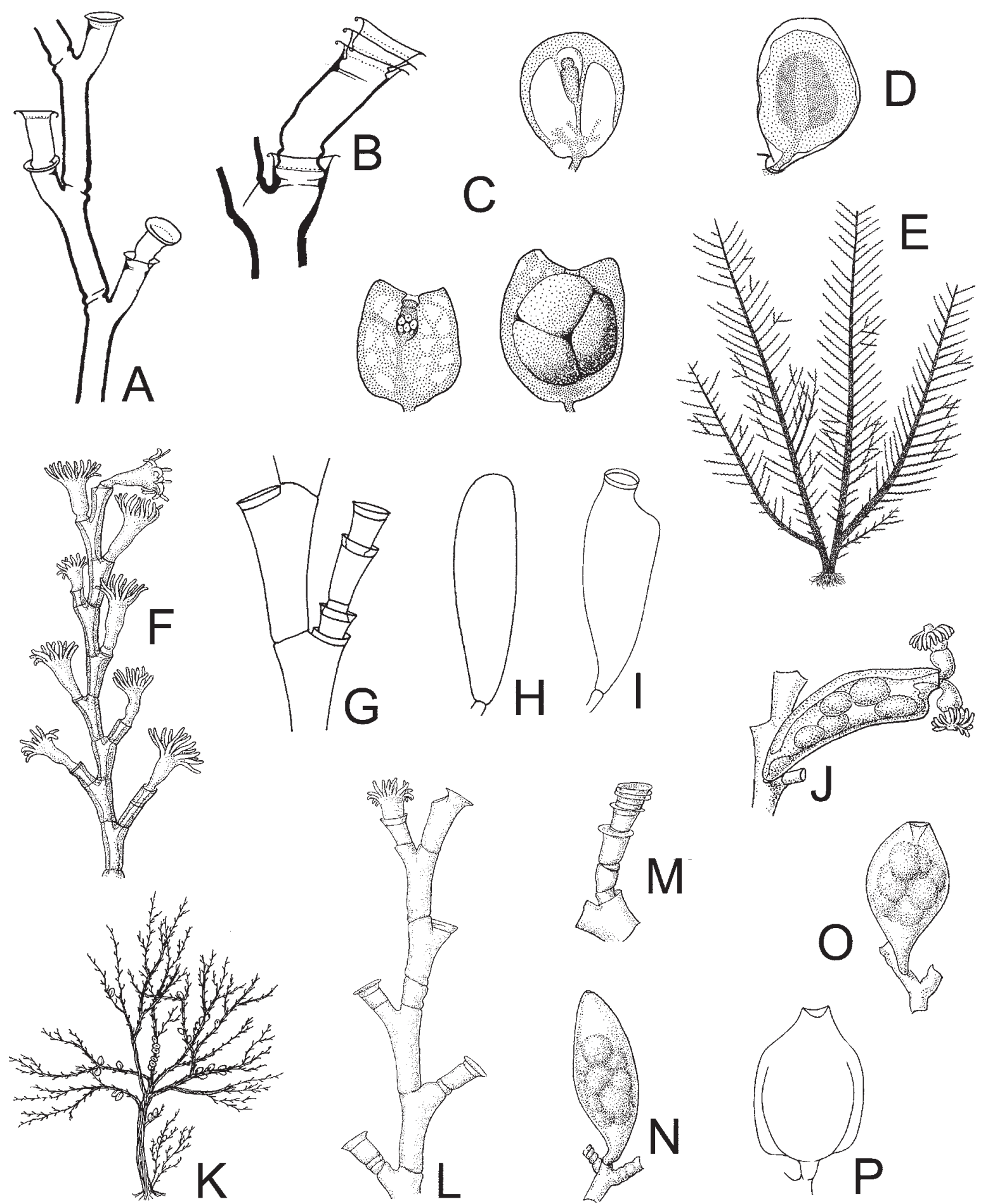

FIG. 74. - Leptomedusae. Haleciidae. A to C: Halecium delicatulum: part of stem from a small form; B: part of stem of a large form; C: female gonophores. D: male gonophore; E to J: Halecium halecinum: E: general view of a colony; F: hydrocladia with several hydranths; G: detail of a hydrocladial internodes; $\mathrm{H}$ male gonothecae; I and J: female gonothecae: J: with gonophoral polyps. K to P: Halecium labrosum: $\mathrm{K}$ : general aspect of a colony; L: portion of a hydroclade; M: hydrotheca with renovations; N: male gonophore; O and P: female gonophores (A to D after Millard, 1975; E, G to I, K and P after Cornelius, 1995; F and J, L to O after Cornelius et al., 1990). 


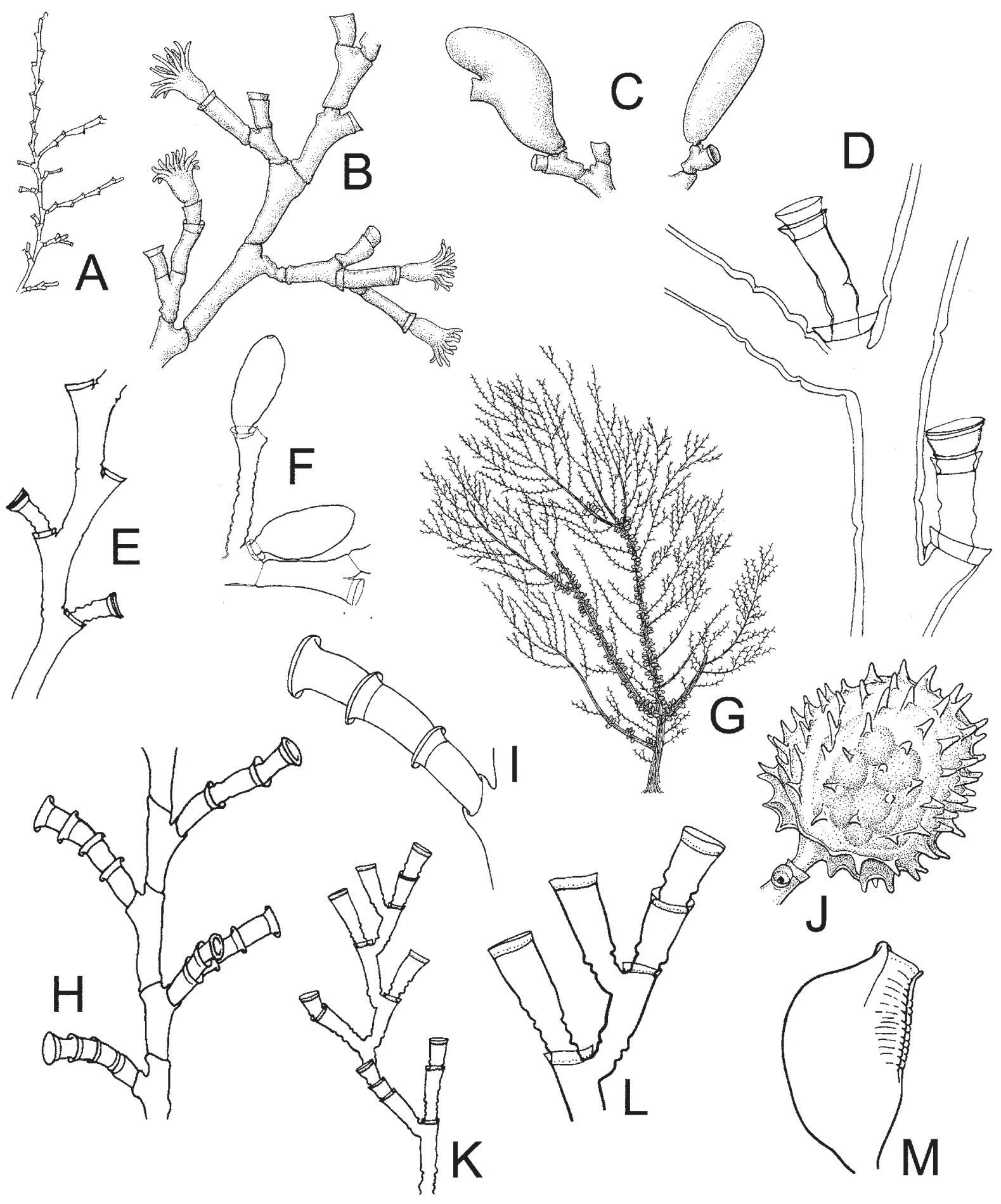

FIG. 75. - Leptomedusae. Haleciidae. A to D: Halecium lankesteri: A: part of a colony, B: detail of a branch; C: gonophores: left female, right male; D to F: Halecium liouvillei: D: part of axis with axillary hydrothecae and insertion of hydrocladium; E: hydrocladium; F: gonophores; G to J: Halecium muricatum: G: general aspect of a colony; H: hydrocladium, I: "chain" of renovated hydrothecae; J gonotheca. K to M: Halecium nanum: K: part of a colony; L: detail of a branch, M: female gonotheca (A to C , J after Cornelius et al., 1990; D and E after Medel and Vervoort, 2000; F after Ramil et al., 1998; G to I, K to M after Cornelius, 1995). 

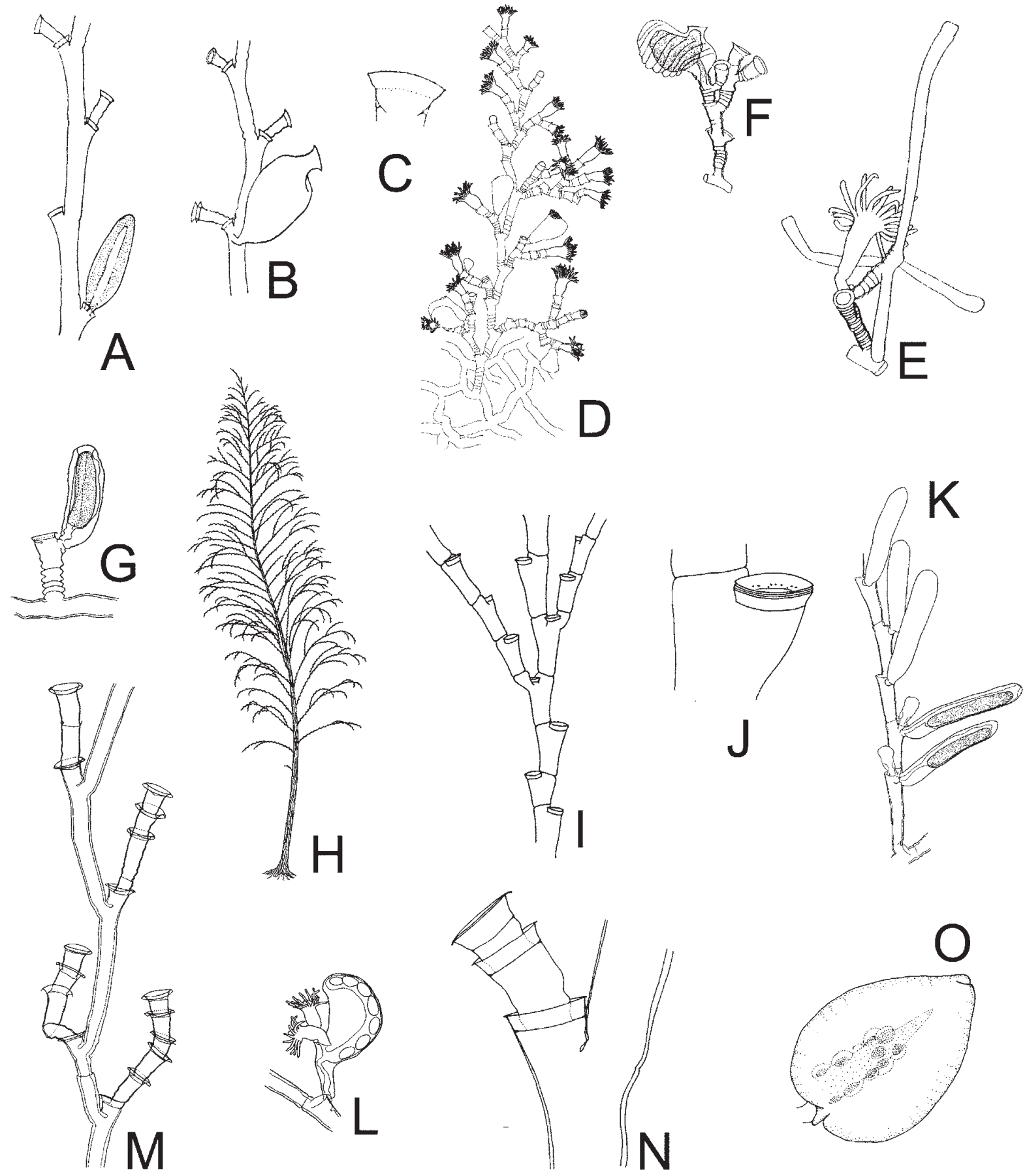

FIG. 76. - Leptomedusae. Haleciidae. A to C: Halecium petrosum: A and B: fragments of hydrocladia with hydrothecae: A: with male gonotheca; B: with female gonotheca. C: detail of hydrothecal rim; D to G: Halecium pusillum: D; part of colony with hydranths and female gonothecae; E: hydroid with planctonic propogules; F: hydroid with female gonotheca; G: hydrotheca and male gonophore and gonotheca; $\mathrm{H}$ to L: Halecium sessile: $\mathrm{H}$ : general view of a colony; I: detail of a branch of a colony; J: hydrotheca with renovated rim; K: part of branch with male gonophores; L: female gonophore; M to O: Halecium sibogae: M: portion of stem; N: hydrocladial hydrotheca; O: female gonotheca (A to C after Motz-Kossowska, 1911; D, G, K and L after Hirohito, 1995, E and F after Boero, 1981, H to J after Cornelius, 1995; M after Medel and Vervoort, 1995, $\mathrm{N}$ and $\mathrm{O}$ after Medel and Vervoort, 2000). 


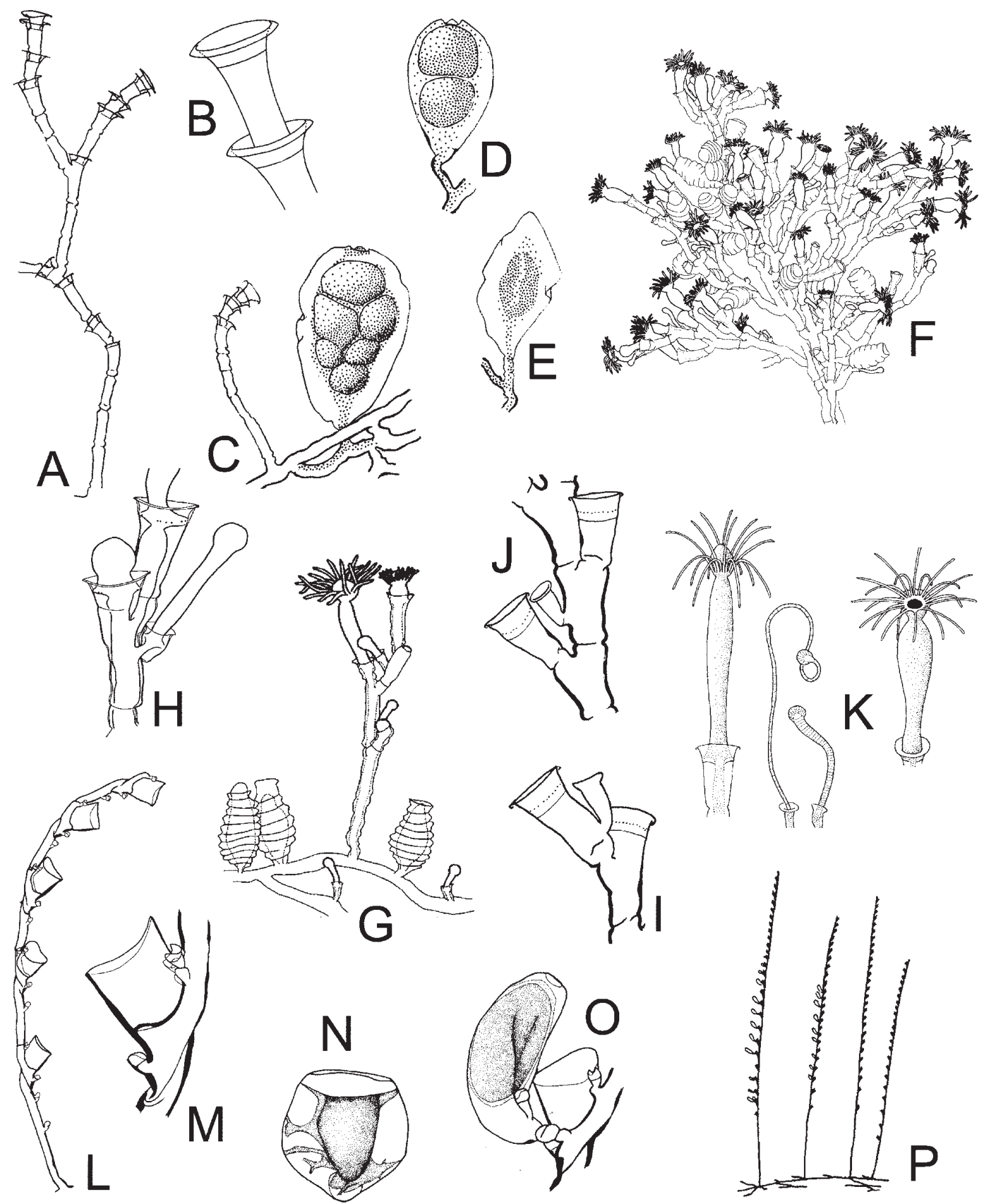

FIG. 77. - Leptomedusae. Haleciidae. A to E: Halecium tenellum: A: part of stem; B: detail of two hydrothecae; C and D: female gonophores; E male gonophore. F to K: Hydrodendron mirabile: F: part of male colony with hydranths and gonothecae; G: detail of part of a colony with gonothecae; $\mathrm{H}$ : nematotheca and nematophore with two hydrothecae; I and J: detail of parts of hydrocladia with hydrothecae and nematothecae; K: living hydranths and nematophores. Halopterididae. L to P: Antennella: L to O: Antnenella ansini: L: stem; M: hydroyhecate internode showing hydrotheca and nematothecae; N: female gonotheca; O: male gonotheca. P: Antennella secundaria: part of fertile colony (A after Cornelius, 1995; B to E, I to K after Millard, 1975, F to H after Hirohito, 1995; L, M and O after Peña Cantero et al. 2002; P after Schuchert, 1997). 

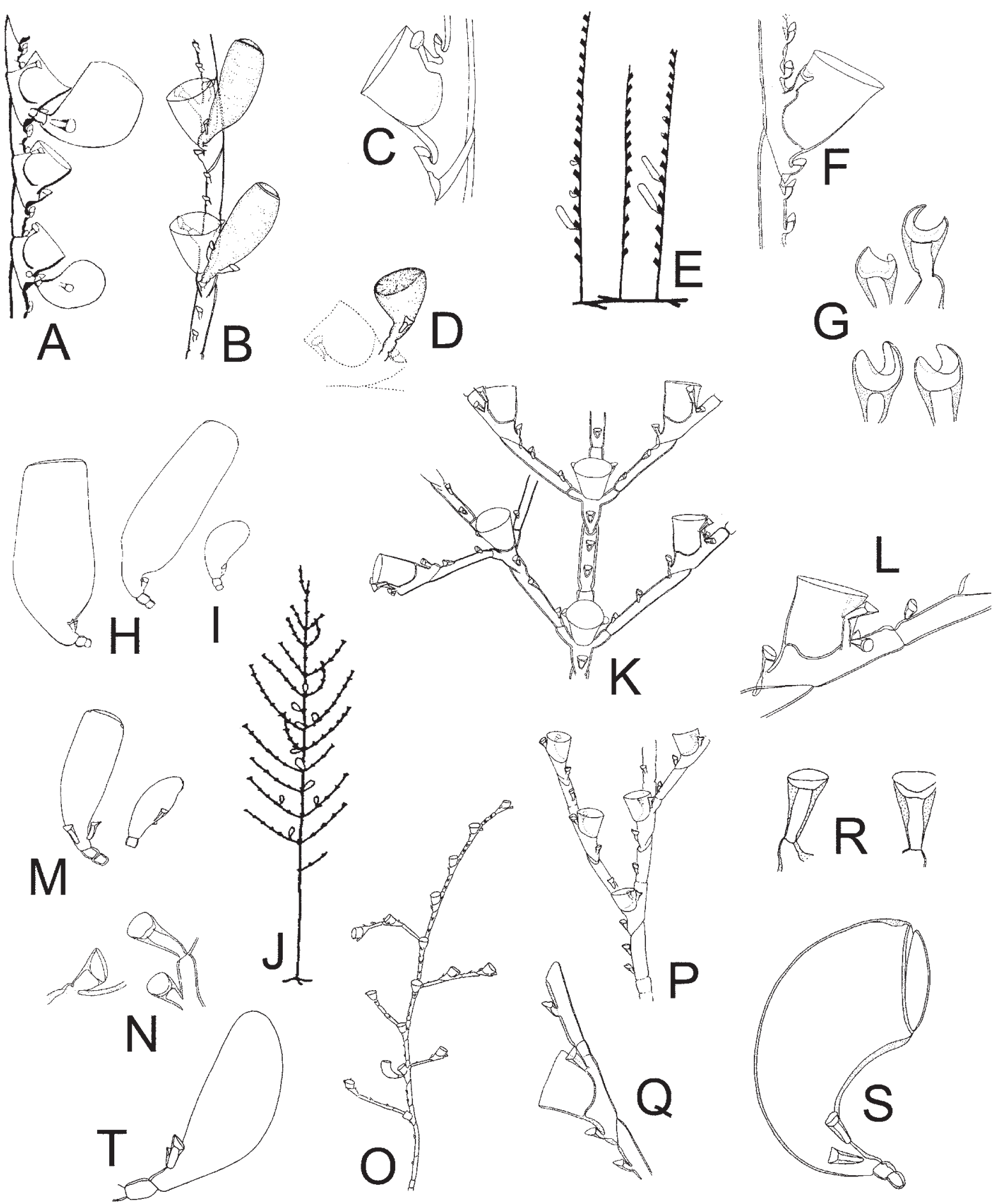

FIG. 78. - Leptomedusae. Halopterididae. A to D: Antennella secundaria: A: hydrocladium with proximal male and distal female gonotheca; B: part of axis with female gonothecae; C: internode with hydrotheca and associated nematothecae; D: male gonophore. E to I: Antennella siliquosa: E: part of fertile colony; F: part of stem with hydrotheca and associated nematothecae; G: several lateral nematothecae showing typical spanner-like shape; H: female gonotheca; I: male gonotheca. J to T: Halopteris: J to N: Halopteris catharina: J: normal plumose colony; K: part of caulus with opposite branched hydrocladia; L: part of hydrocladium with main segment and intersegment; M: gonothecae: left: female, right: male; $\mathrm{N}$ : left median inferior nematothecae, right pair of lateral nematothecae. O to T: Halopteris diaphana: O: plumose form of stem, P: part of axis with two hydrocladia; Q: part of hydrocladium with hydrotheca and associated nematothecae, R: lateral nematothecae, S: female gonotheca, T: male gonotheca (A after Millard, 1975; B to D, p. after Medel and Vervoort, 1995; E to N, O, q. to s. after Schuchert, 1997). 

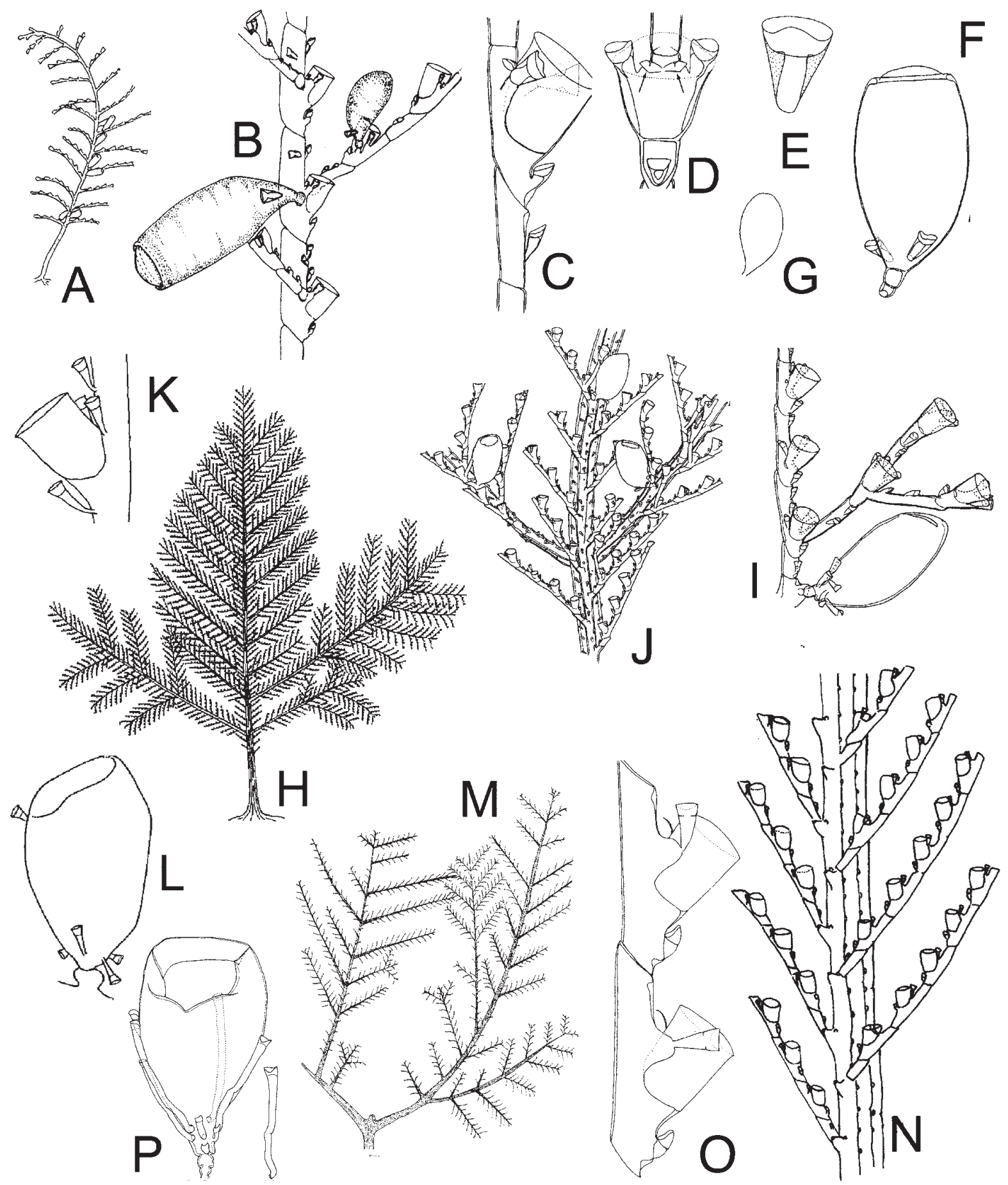

FIG. 79. - Leptomedusae. Halopterididae. A to G: Halopteris liechtensternii: A: single fertile plume; B: part of axis with hydrocladia and gonothecae; C: part of hydrocladium with hydrotheca and associated nematothecae; D: frontal view of hydrotheca showing pair of reduced nematothecae behind hydrotheca (arrows), E: above lateral nematotheca, below median inferior nematotheca; F: female gonotheca; G: male gonotheca. H to L: Polyplumaria flabellata: H: general aspect of a colony; I: detail of part of a colony with gonothecae; J: branched hydrocladia with gonotheca; K: hydrotheca and associated nematothecae; L: gonotheca. M to P: Pseudoplumaria marocana: M: part of a colony; $\mathrm{N}$ : detail of a fragment of colony; O: portion of hydrocladia with hydrothecae and associated nematothecae; P: male gonotheca and an isolated gonothecal nemathoteca (A, C to G after Schuchert, 1997; B, M to O after Medel and Vervoort, 1995; H, K and L after Cornelius,1995; I and J after Ansín Agís et al., 2001; P after Ramil and Vervoort, 1992a). 

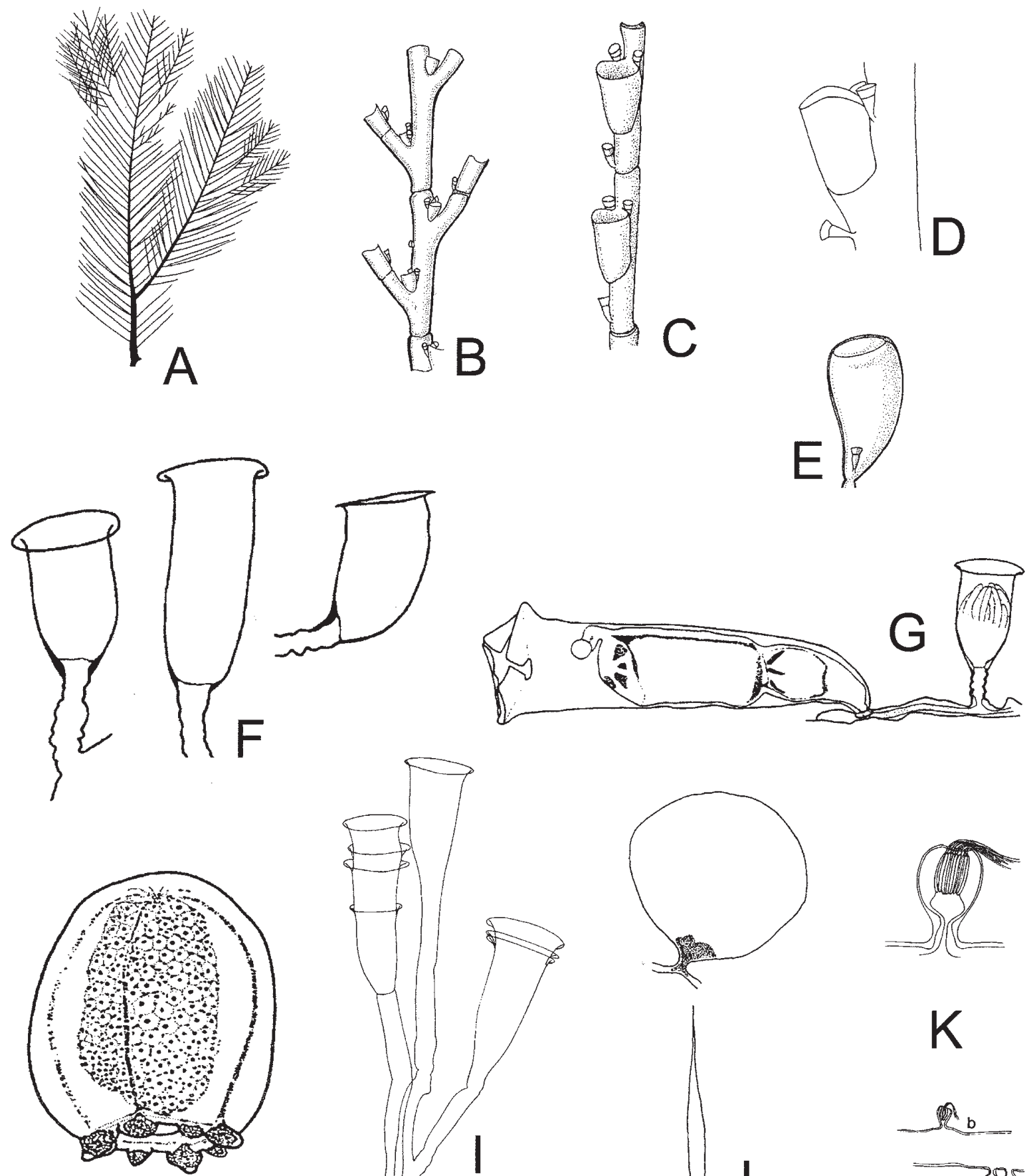

$\mathrm{H}$
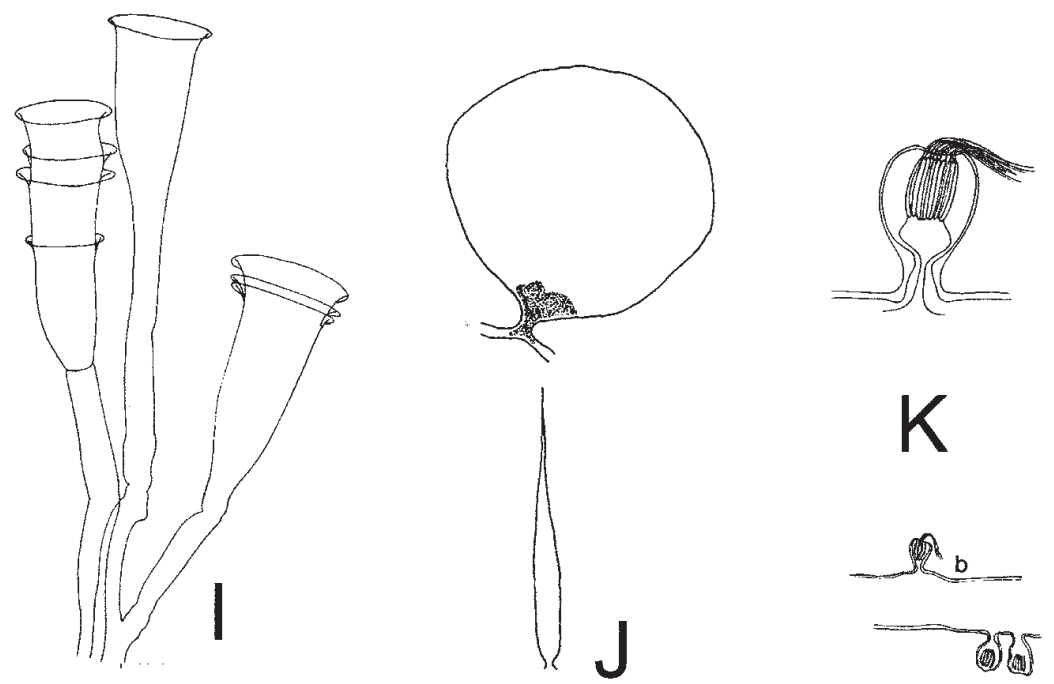

FIG. 80. - Leptomedusae. Halopterididae. A to E: Schizotricha frutescens: A: general vue of a colony; B: hydrocaulus with bases of hydrocladia, C: fragment of hydrocladia, D: hydrotheca and associated nematothecae, E: gonotheca. Hebellidae. F to H: Anthohebella parasitica: F: various aspects of hydrothecae, G: fragment of colony with hydrotheca and gonotheca containing two medusa buds, H: female swimming gonophore; I to K: Bedotella armata: I: part of rhizocaulomic colony with two renovated hydrothecae, J: gonotheca in frontal and lateral view, $\mathrm{K}$ : stolonal nematothecae (A to C, E after Cornelius et al, 1990; D after Cornelius, 1995; F to H after Boero et al., 1997; I and K after Ramil and Vervoort, 1992a; J after Álvarez Claudio, 1994). 


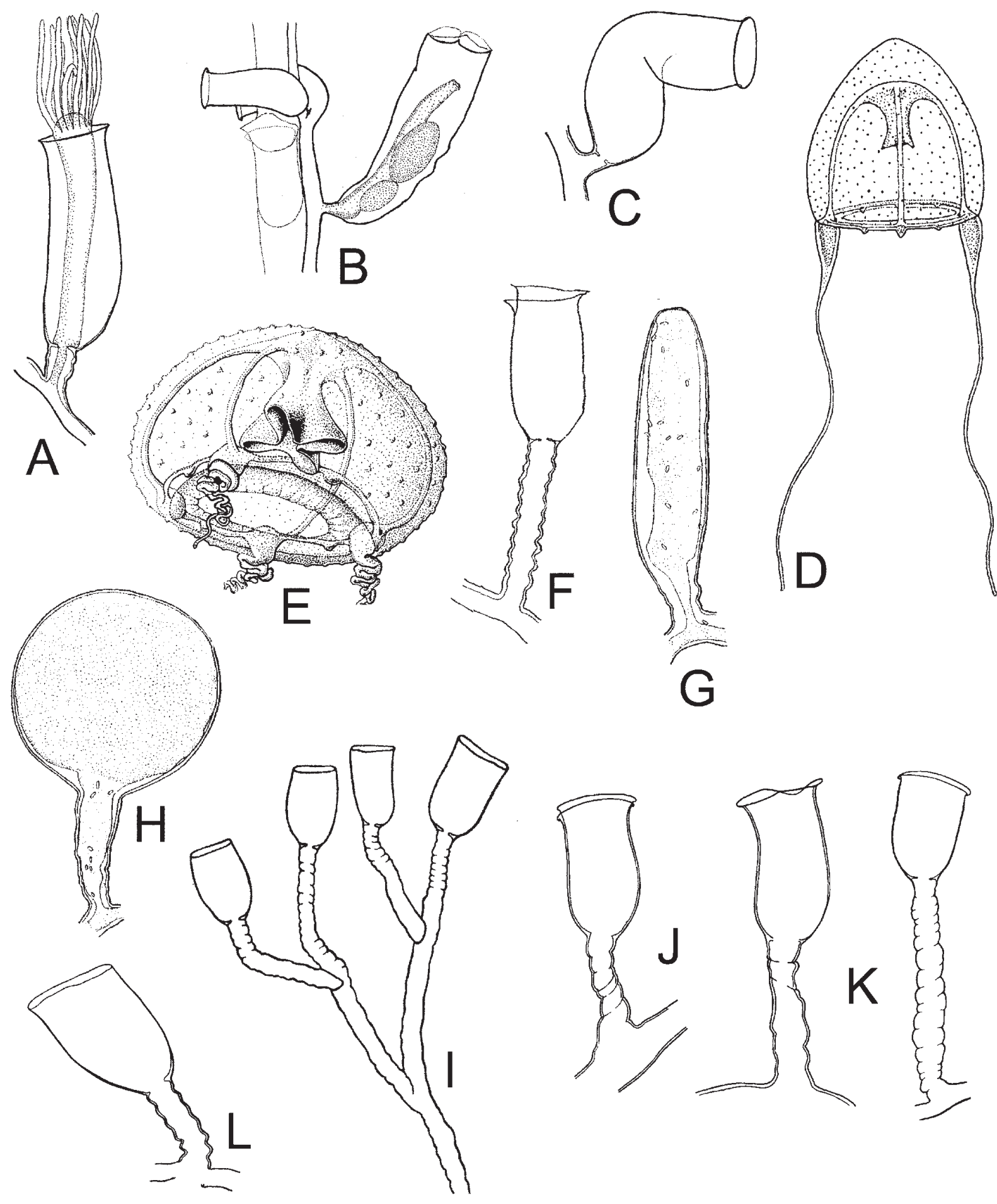

FIG. 81. - Leptomedusae. Hebellidae. A to E: Hebella scandens: A: straight hydrotheca, B: portion of fertile colony growing on a sertulariid, C: twisted hydrotheca, D and E: juvenile medusae. F to L: Scandia. F to H: Scandia gigas: F: hydrotheca, G: male gonophore, H: female gonophore; I to L: Scandia michael-sarsi: I: general view of a portion of a colony, J to L: various aspects of hydrothecae (A to D after Boero et al, 1997; E after Altuna Prados, 1996; F to H after Boero, 1981; I, K and L after Garcia-Corrales et al., 1979; J after Vervoort, 1959). 

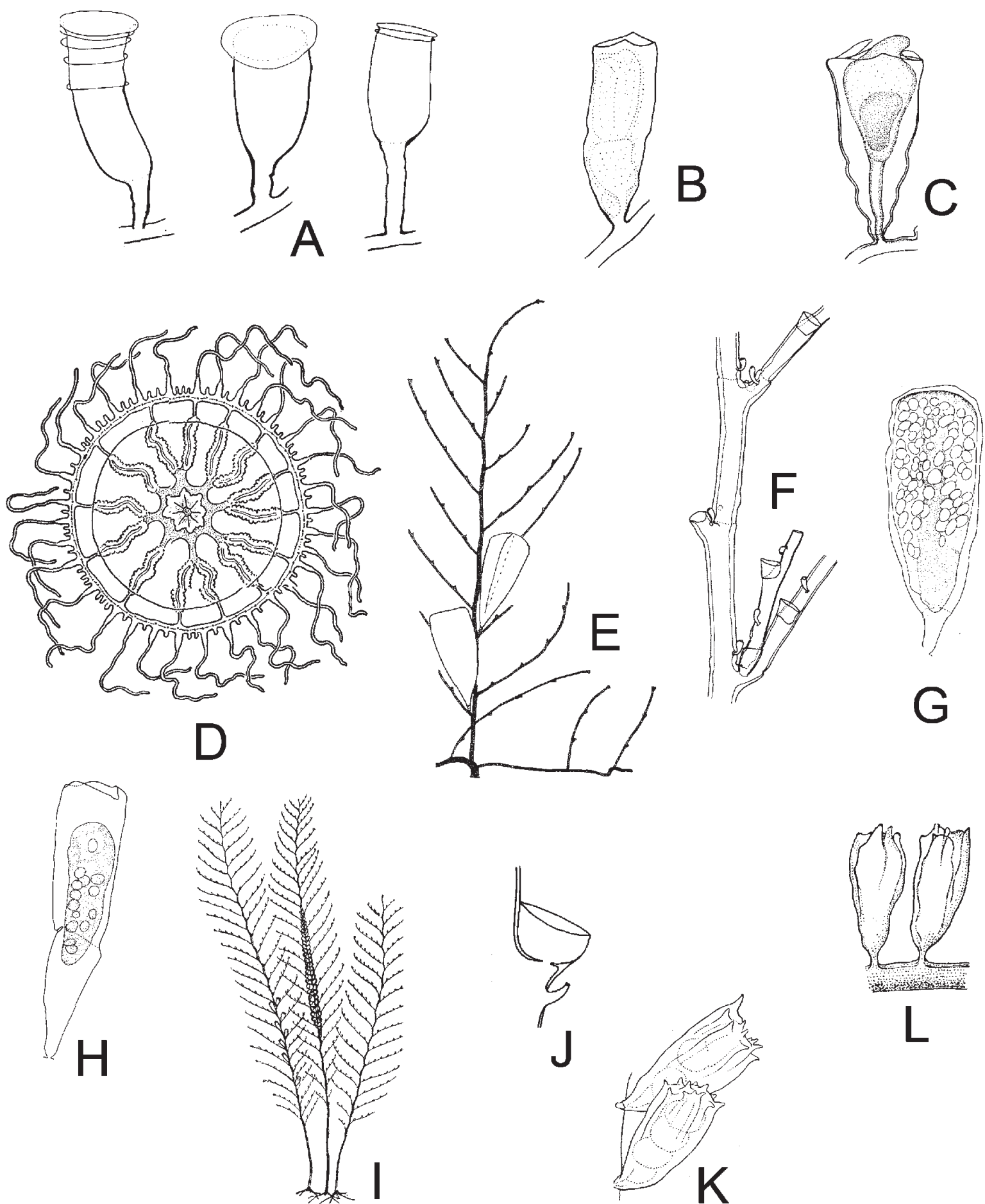

FIG. 82. - Leptomedusae. Hebellidae. A to D: Staurodiscus kellneri: A: lateral view of hydrothecae showing variation of form, length and perisarc development, B and C: gonothecae; D: adult medusa. Kirchenpaueriidae. E to L: Kirchenpaueria: E to H: Kirchenpaueria bonnevieae: E: fragment of colony with pinnate stem bearing gonothecae and hydrocladia, F: hydrocladia developping from axial apophysis, G: male? gonotheca, H: female? gonotheca; I to L: Kirchenpaueria pinnata: general view of a colony, J: hydrotheca and nematotheca, $\mathrm{K}$ and L gonothecae (A and B after Migotto and de Andrade, 2000; C after Boero et al., 1997; D after Kramp, 1959a; E after Millard, 1975; F to H after Ramil and Vervoort, 1992a; I, K and L after Leloup, 1952; J after Cornelius, 1995). 

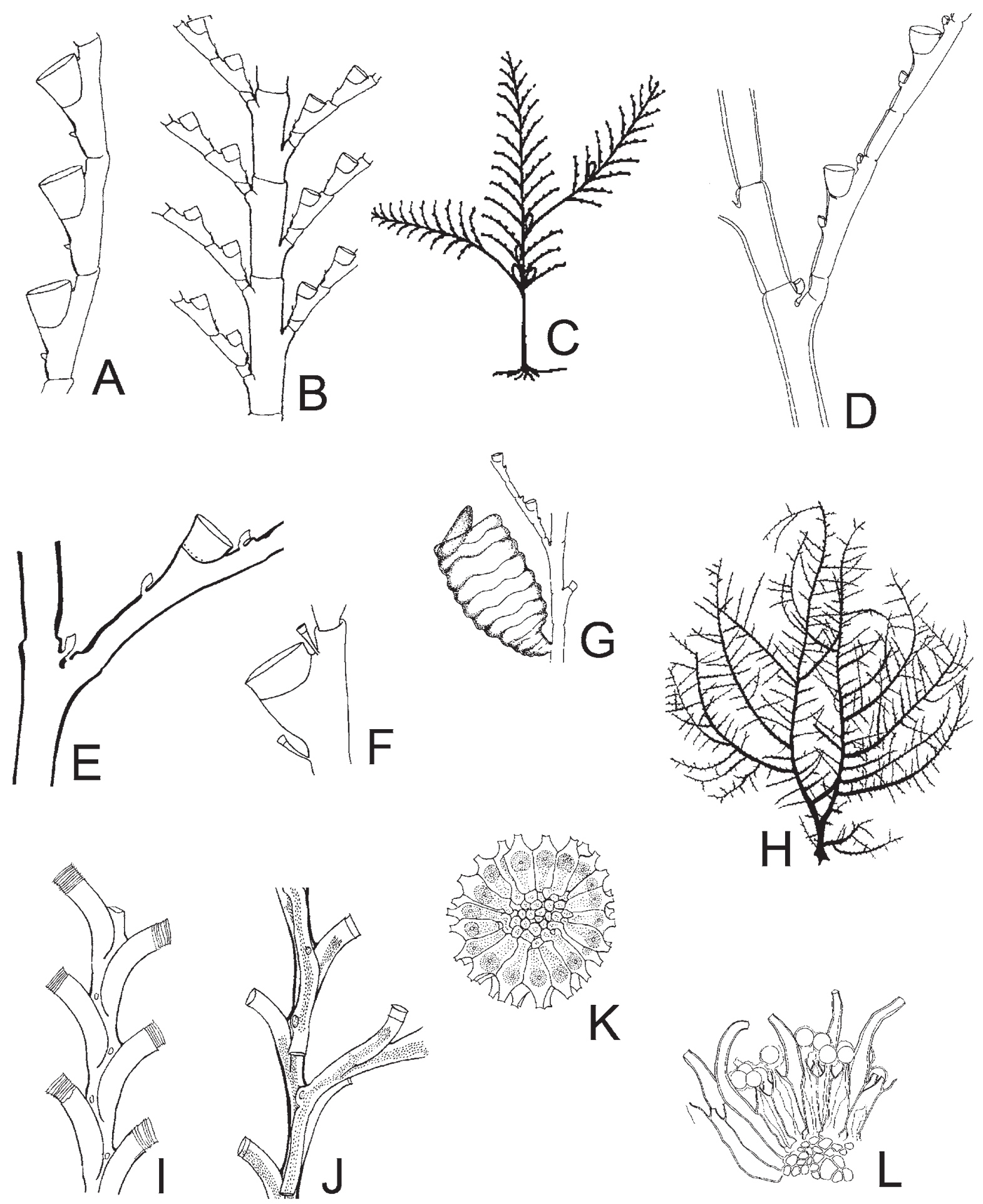

FIG. 83. - Leptomedusae. Kirchenpaueriidae. A and B: Kirchenpaueria pinnata: A: part of hydrocladium, B: part of stem with origins of hydrocladia; C to G: Ventromma halecioides: C: general aspect of a colony, D: monosiphonic part of axis with hydrocladia, E: hydrocaulus and part of an hydrocladium, F: hydrotheca with associated nematothecae; G: mature gonotheca. H to L: Lafoeidae. H to L: Acryptolaria conferta: $\mathrm{H}$ : colony, general view of heavy form, I: part of stem, J: portion of stem showing branching portions of peripheral tubes in position, K: coppinia with female gonothecae, L: cross section of a part of coppinia with female gonophores and modified hydrothecae (A and B, H to K after Millard, 1975; C and F after Cornelius, 1995; D and G after Medel and Vervoort, 1995; E after Calder, 1997; L after Hirohito, 1995). 

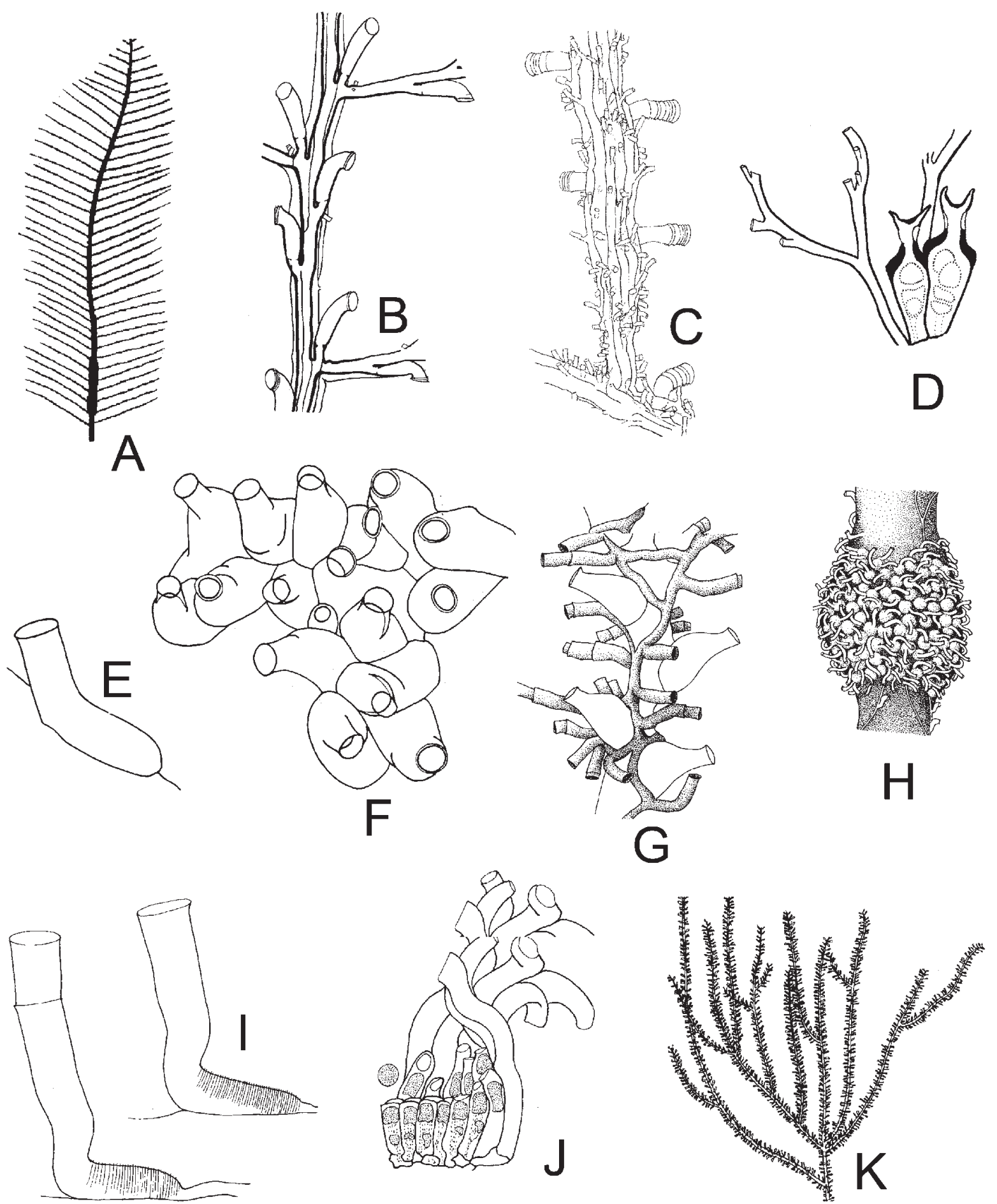

FIG. 84. - Leptomedusae. Lafoeidae. A to D: Cryptolaria pectinata: A: stem with basal coppinia, B: detail of stem from distal region to show axillary hydrothecae and origins of hydrocladia, C: detail of origin of a hydrocladium showing hydrothecae and nematothecae, D: part of coppinia showing female gonothecae and nematothecae; E to J: Filellum. E and F: Filellum disaggregatum: E: hydotheca, F: coppinia in dorsal view; G and H: Filellum serpens: G: general view of a colony, H: coppinia and a few hydrothecae; I and J: Filellum serratum: I: large hydrothecae, J: part of coppinia showing gonothecae and accessory tubes; K: Lafoea dumosa: general aspect of an erected colony, (A, B, D, I and J after Millard, 1975; C after Hirohito, 1995; E and F after Peña Cantero et al 1998; G, H and K after Cornelius, 1995). 

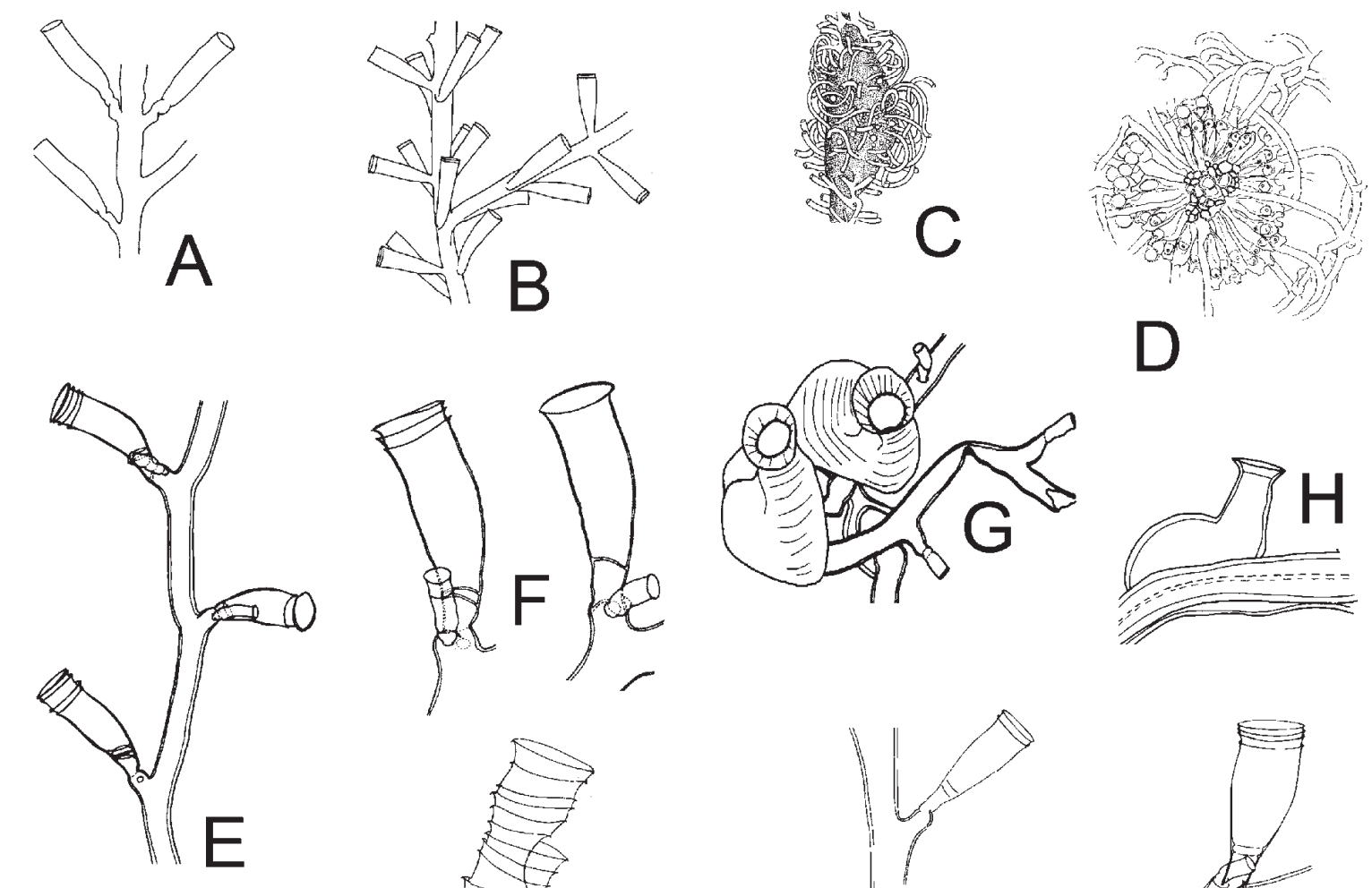

$\mathrm{D}$
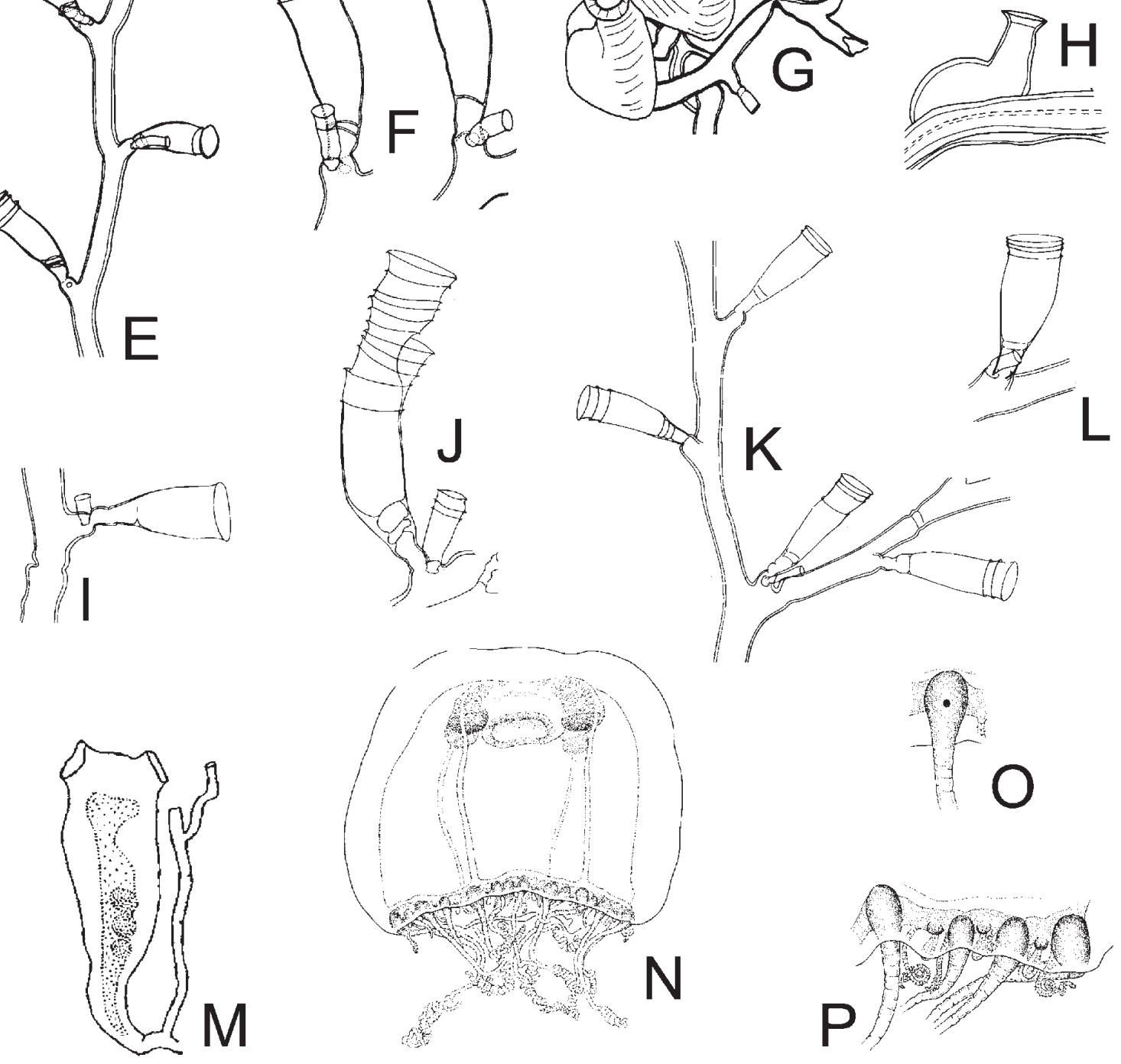

FIG. 85. - Leptomedusae. Lafoeidae. A to D: Lafoea dumosa: A: details of a branche of an erected colony with stalked hydrothecae, B: details of a branch of an erected colony with unstalked hydrothecae, C: coppinia and a few hydrothecae, D: cross section of a coppinia with female gonophores and tubular hydrothecae. E to M: Zygophylax: E to J: Zygophylax biarmata: E: monosiphonic part of stem, F: two hydrothecae and their associated nematotheca, G: two gonothecae and some nematophorous tubules isolated from coppinia, H: gonothecae (lateral view), I: part of nematophorous tubule with a nematotheca and a small hydrotheca, J: strongly renovated hydrotheca and renovated nematotheca; K to M: Zygophylax brownei: K: monosiphonic part of stem with two hydrocladia, L: two hydrothecae and nematothecae, M: gonothecae. Laodiceidae. N to P: Guillea canyonincolae: N: general view of a mature medusa, O: adaxial view of a marginal tentacle showing ocellus, P: abaxial view of umbrella margin showing cordylus and lateral spiral cirri (A to C after Cornelius, 1995; D after Hirohito, 1995; E to L after Ramil and Vervoort 1992a; M after Schuchert, 2001a; N to P after Bouillon et al, 2000). 

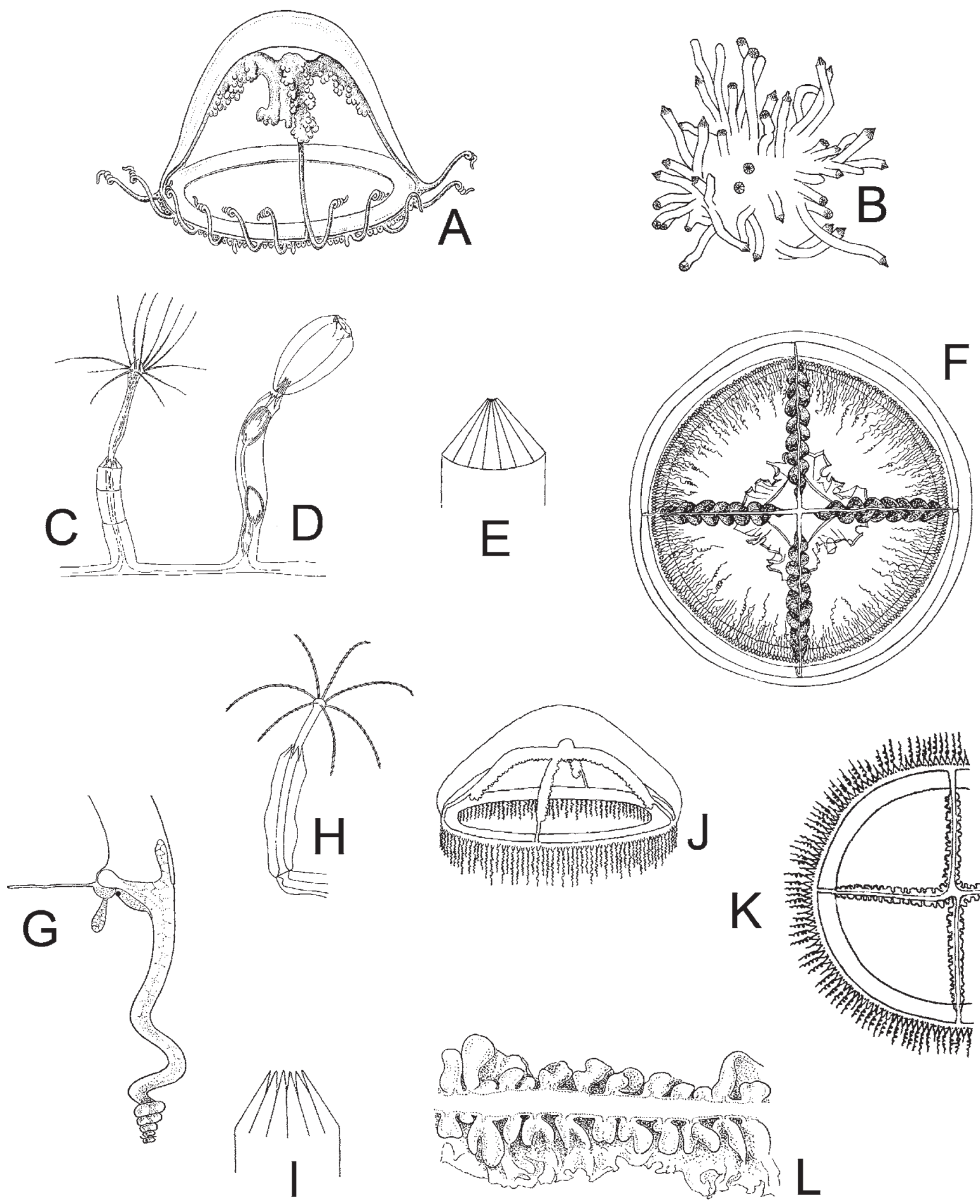

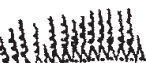

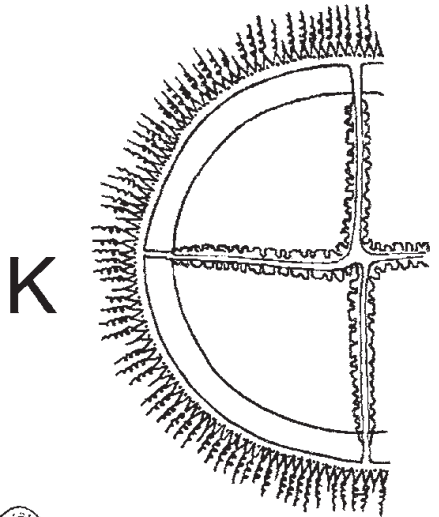

FIG. 86. - Leptomedusae. Laodiceidae. A to G: Laodicea: A: Laodicea fijiana mature medusa; B to G: Laodicea undulata: B: general view of hydroid colony, C: hydrotheca and hydranth with amphicoronate tentacles, D: a gonotheca with medusa buds and a young medusa just before release, E: diagram of closed operculum, F: fylly-grown medusa, G: adaxial view of marginal tentacle showing: ocellus, cordyli and endodermal processes; H to K: Staurophora mertensii: H: hydrotheca and hydranth, I: diagram of operculum, J: mature medusa, K: part of the umbrella of a fully-grown medusa, L: portion of mouth-lip seen from above (A after Kramp, 1968; B to E, H and I after Cornelius, 1995; F and K after Kramp, 1959a; G and L after Russell, 1953; J after Russell, 1963a). 

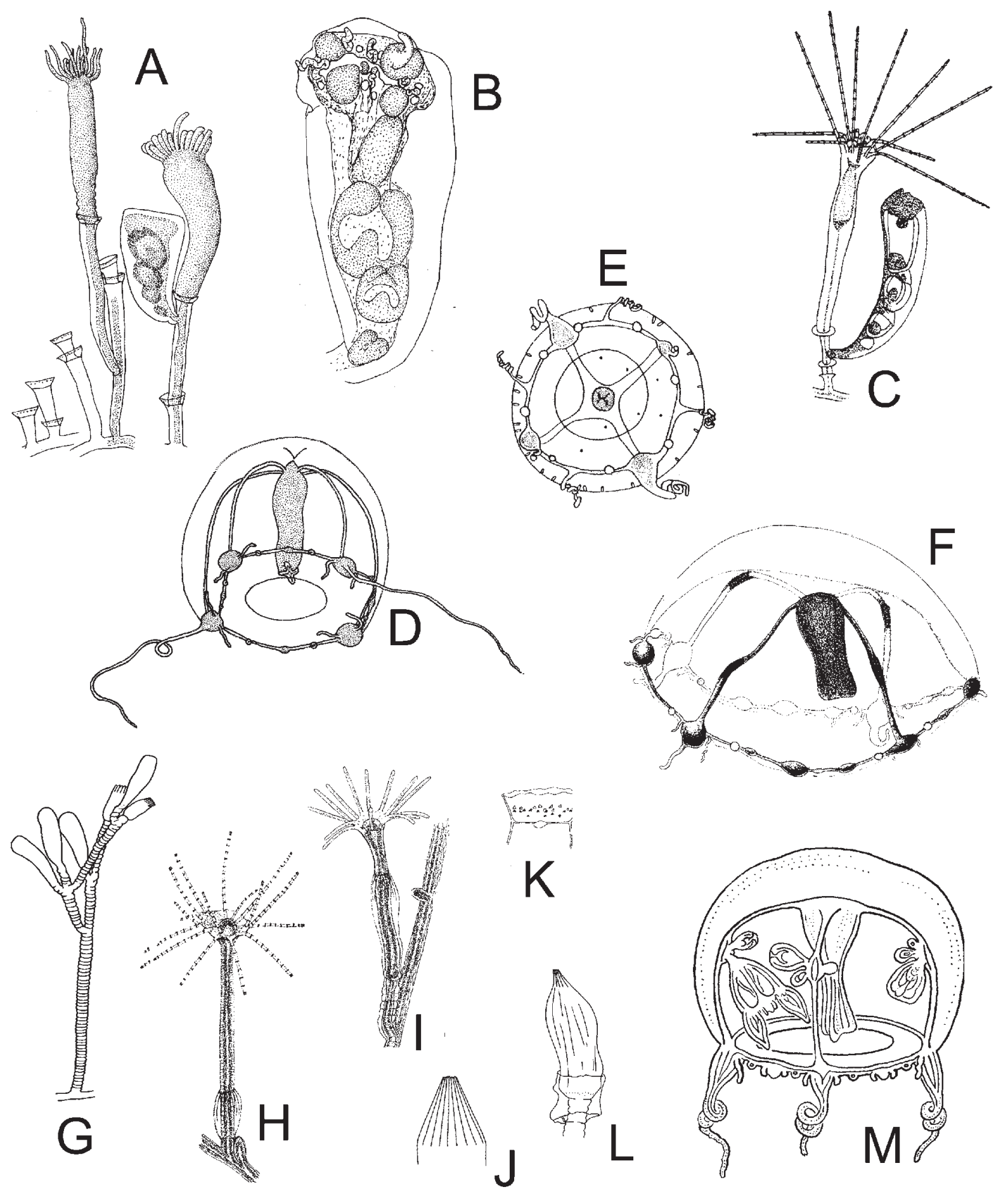

FIG. 87. - Leptomedusae. Lovenellidae. A to E: Campalecium: A and B: Campalecium cirratum: A: parts of colony with hydranths and gonotheca, B: gonotheca with medusa buds ready to escape; C to E: Campalecium medusiferum: C: hydranth and gonotheca with medusa buds, $\mathrm{D}$ : lateral view of juvenile medusa, E: oral view of juvenile medusa; F to M: Eucheilota: F: Eucheilota maasi: mature medusa; G to L various stages of hydroids of Eucheilota maculata: showing the regression of a lovenelliid type of hydrothecae to a haleciid type one: G: part of a juvenile colony, H: detail of a juvenile hydranth, I: fully developed hydranth with its complete loveneliid hydrotheca, J: operculum of a juvenile hydranth, K: remains of the hydrotheca of a fully grown hydranth, haleciid type, L: renovated hydrotheca with the remains of previous haleciid hydrotheca at base. M: Eucheilota paradoxica: medusa with medusa buds on radial canals (A and B after Millard and Bouillon, 1975; C to E after Boero, 1981; F after Neppi and Stiasny, 1913; G to K after Werner, 1968a; L after Cornelius, 1995; M after Kramp, 1959a). 


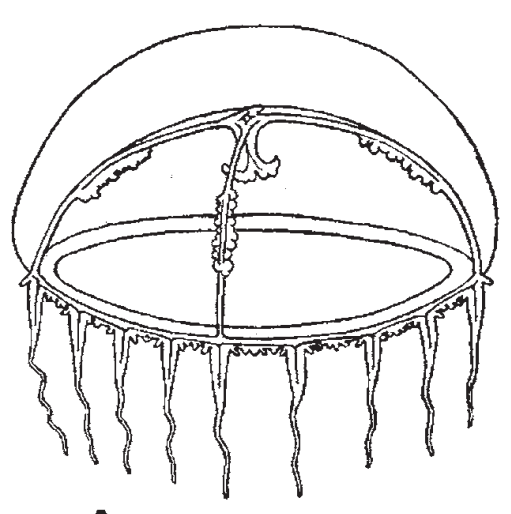

A
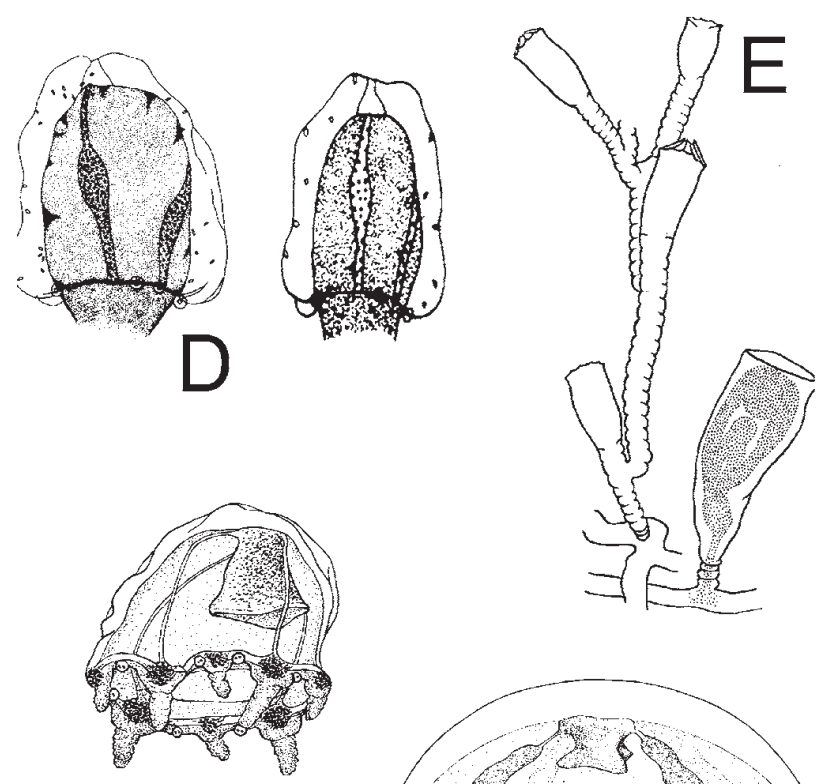

$\mathrm{H}$
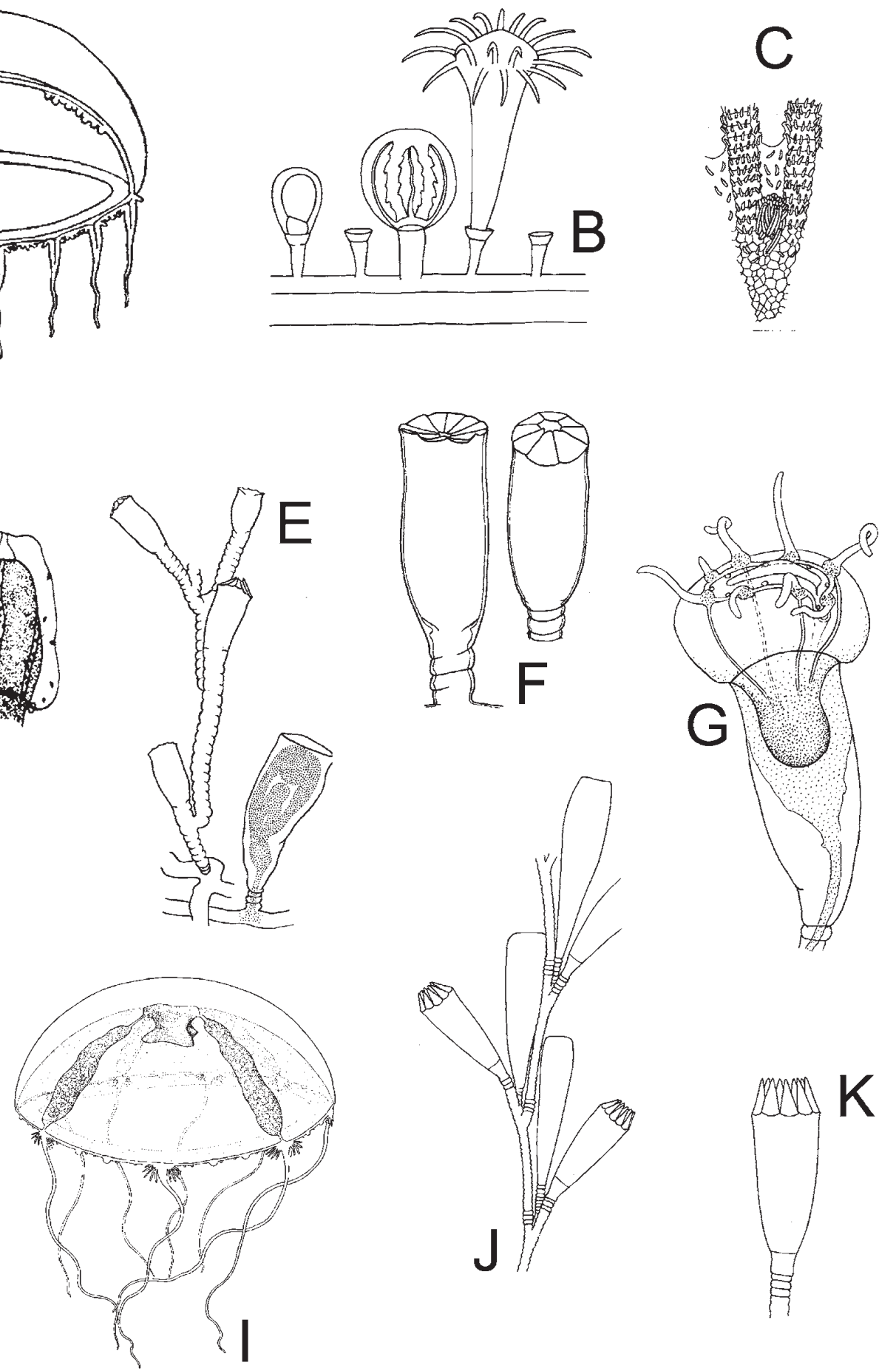

FIG. 88. - Leptomedusae. Lovenellidae. A: Eucheilota ventricularis mature medusa; B to D: Hydranthea margarica: B: part of colony with a hydranth and a medusoid, C: two tentacle bases with intervening web, D: male medusoids; E to K: Lovenella: E to H: Lovenella chiquita: E: part of colony with a branching stem and a gonotheca, F: two hydrothecae, G: young medusa escaping from gonotheca, $\mathrm{H}$ : newly liberated medusa; I: Lovenella cirrata: adult medusa; J and K: Lovenella clausa: J: part of a colony with hydrothecae and gonothecae, K: detail of a hydrotheca (A after Kramp, 1968; B, C, J and K after Cornelius, 1995; D after Boero and Sará, 1987; E to H after Millard, 1975; I after Pagès et al., 1992). 

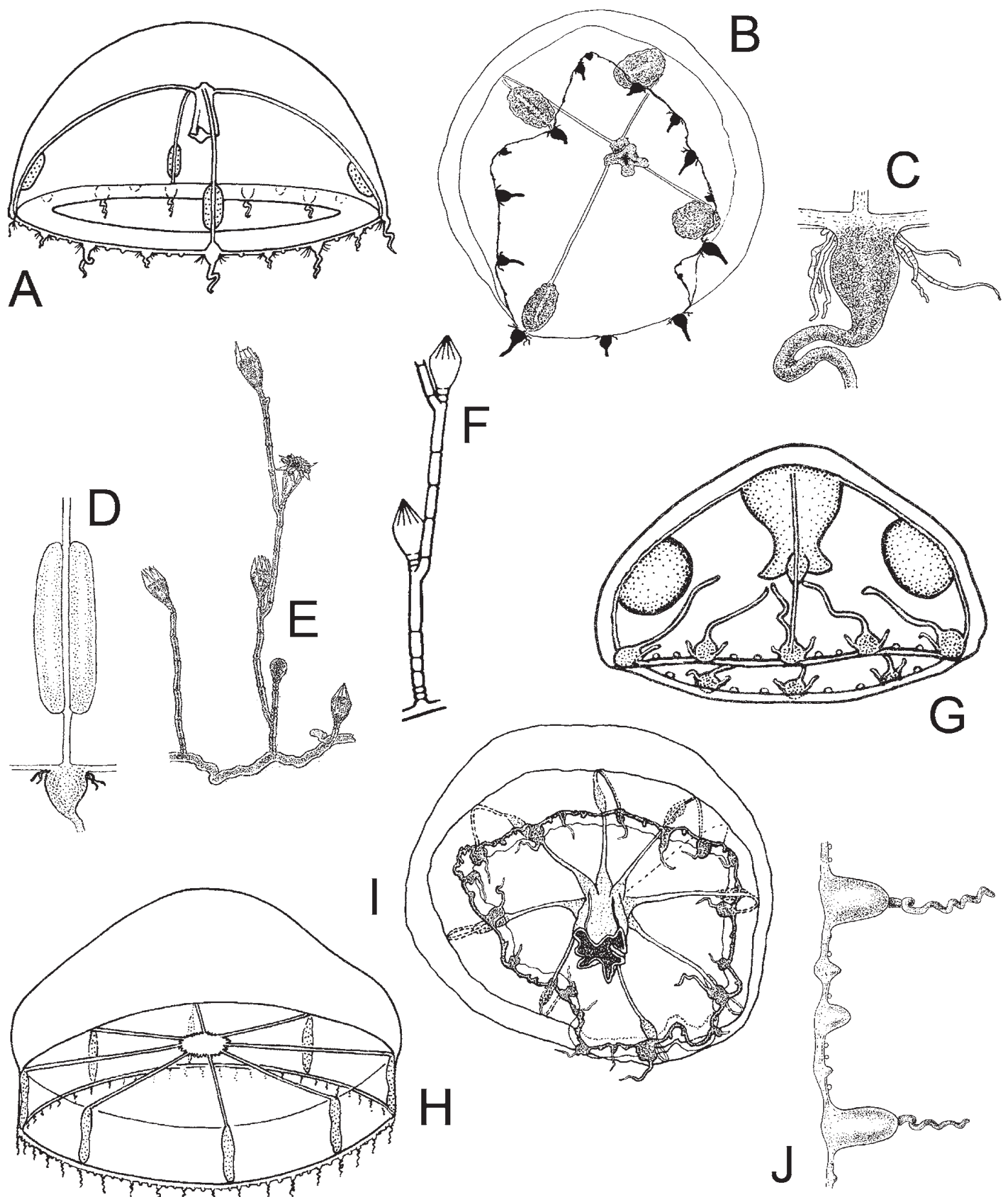

FIG. 89. - Leptomedusae. Lovenellidae. A to D: Lovenella clausa: A and B: mature medusae, C: detail of a marginal bulb and cirri, D: above subumbrellar view of the longitudinally divided gonad; E to G: Lovenella gracilis: E: portion of a colony, detail of a branch with hydrothecae, G: medusa. Malagazziidae. H to J : Octophialucium funerarium: H and I: two aspects of fully-grown medusae, J: portion of umbrella margin (A and H after Russell, 1963b; B to D, J after Russell, 1953; E after Huvè, 1952b; F and G after Calder, 1971; I after Gili, 1986). 


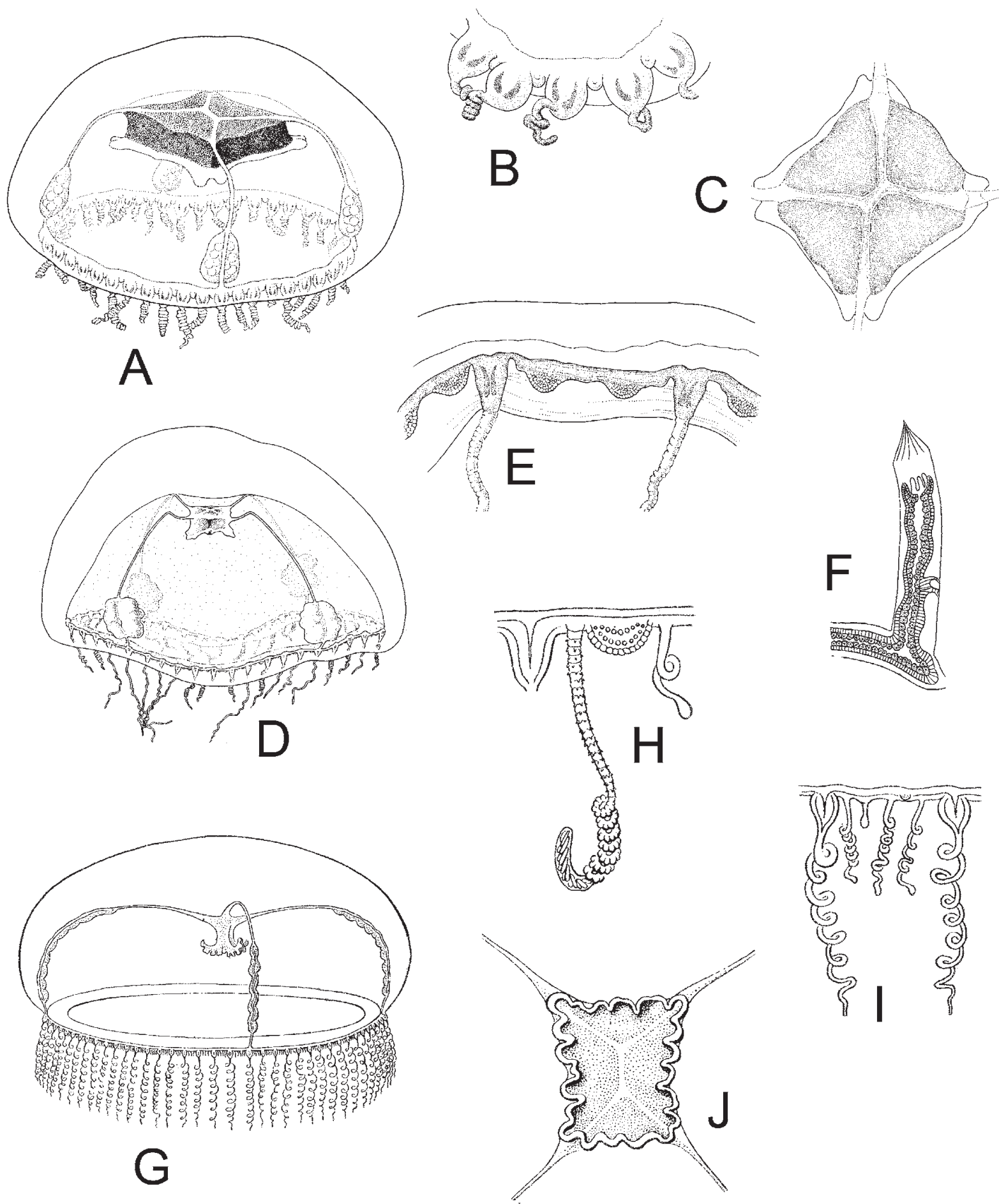

FIG. 90. - Leptomedusae. Mitrocomidae. A to E: Foersteria: A to C: Foersteria antoniae: A: adult medusae, B: detail of umbrella margin, C: aboral view of manubrium; D and E: Foersteria araiae: D: fully-grown medusa, E: portion of umbrella margin; F to J: Mitrocoma annae: F: hydranth, G: mature medusa, $\mathrm{H}$ and I: portions of umbrella margin showing cirri and statocysts, J: oral view of open mouth (A to C after Gili et al., 1998; D and E after Gili et al., 1999; F after Metschnikof, 1886; G to J after Mayer, 1910). 

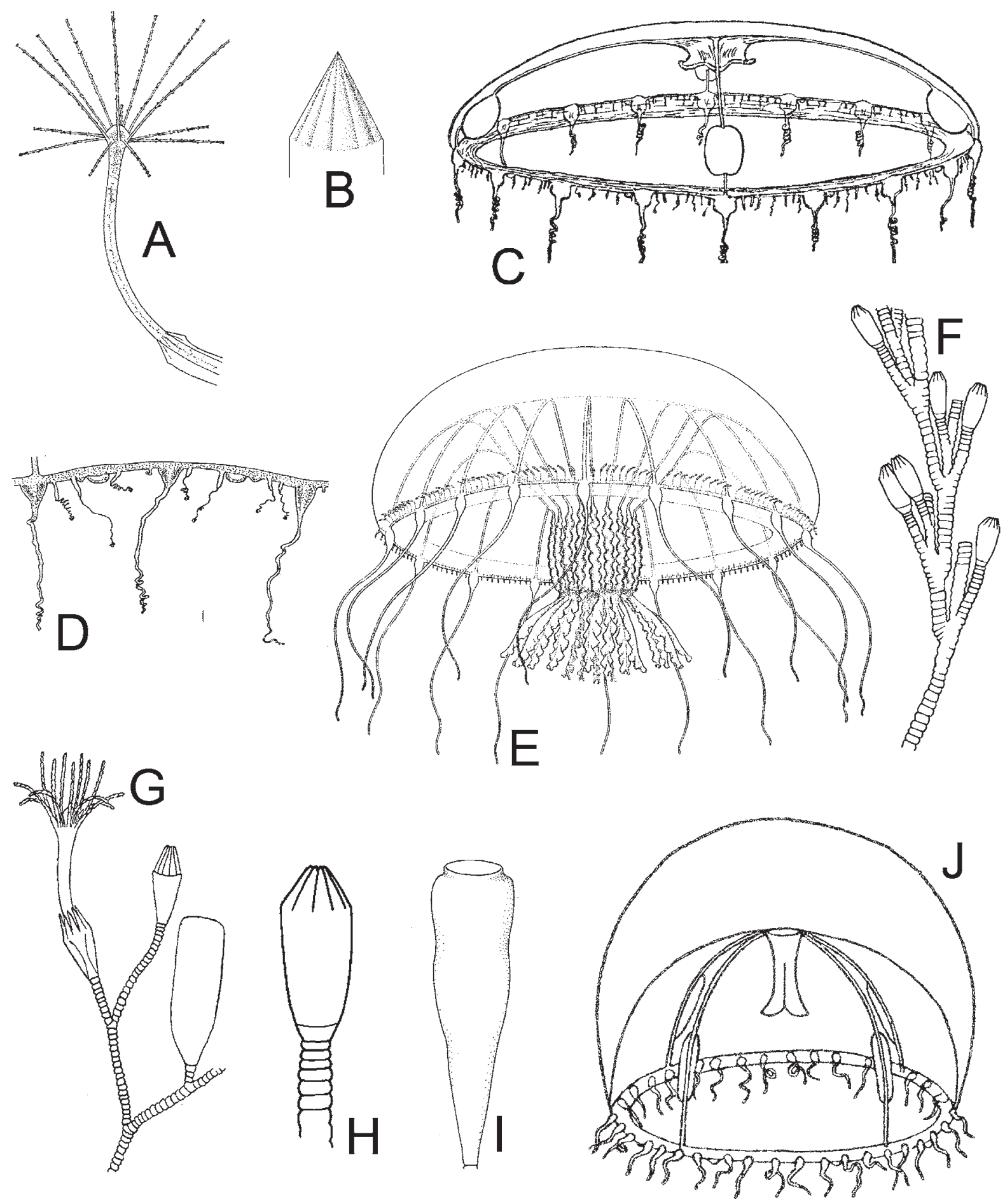

FIG. 91. - Leptomedusae. Mitrocomidae. A to D: Mitrocomella brownei: A: hydranth, B: diagram of operculum, C: fully-grown medusa, D: portion of umbrella margin. Orchistomidae. E: Orchistomella agariciforme: general view of an adult medusa. Phialellidae. F to J: Phialella quadrata: F: general view of a colony, G: detail of a branch with hydrothecae and gonotheca, opercula of hydrothecae with or without a crease line in the same colony, $\mathrm{H}$ : detail of hydrotheca with a pleated operculum without basal crease line, I: detail of gonotheca, J: fully-grown medusa (A, D, G after Russell, 1953; B, F , H, I after Cornelius, 1995, C, J after Kramp, 1959a; E after Bouillon, 1984b). 

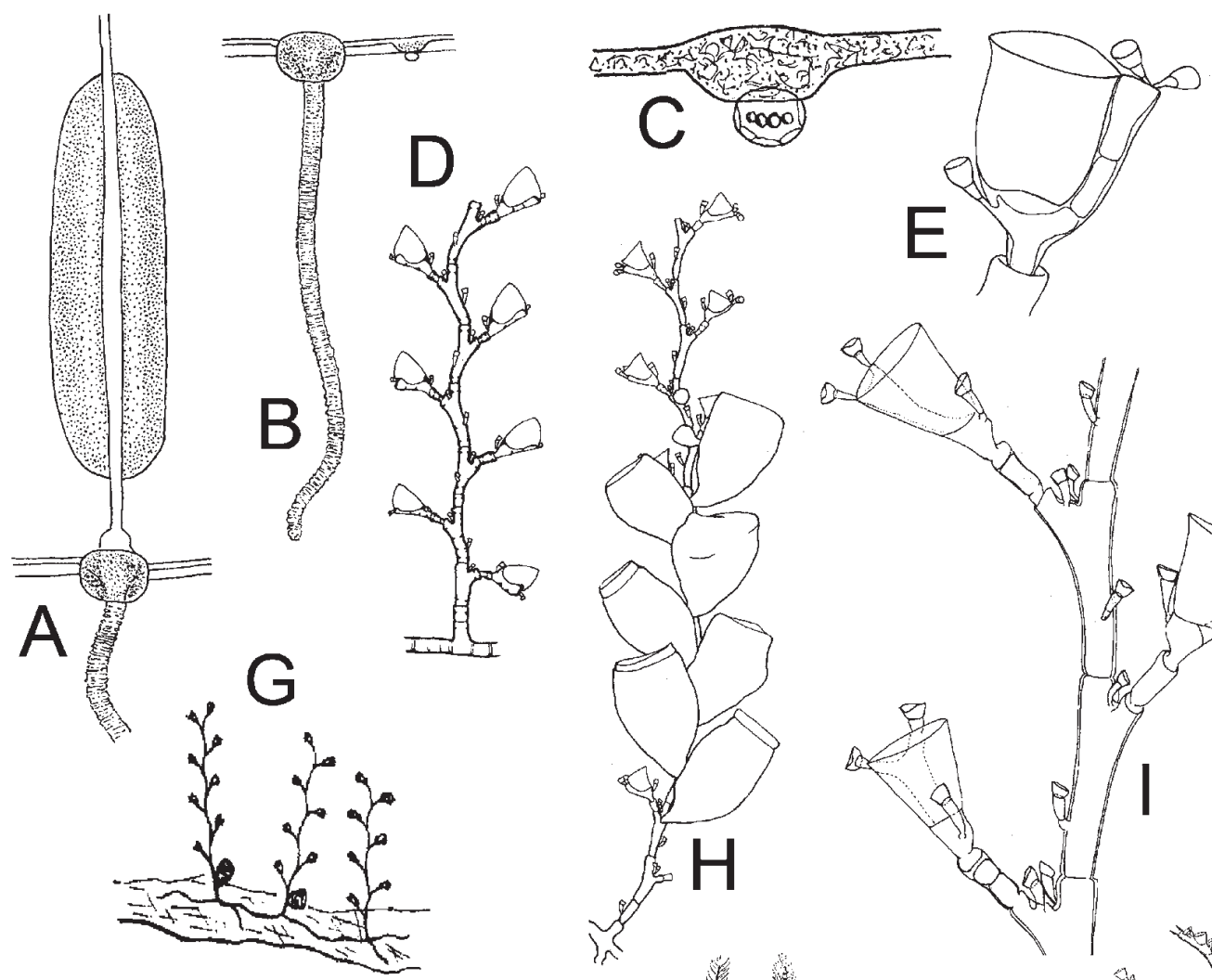

F
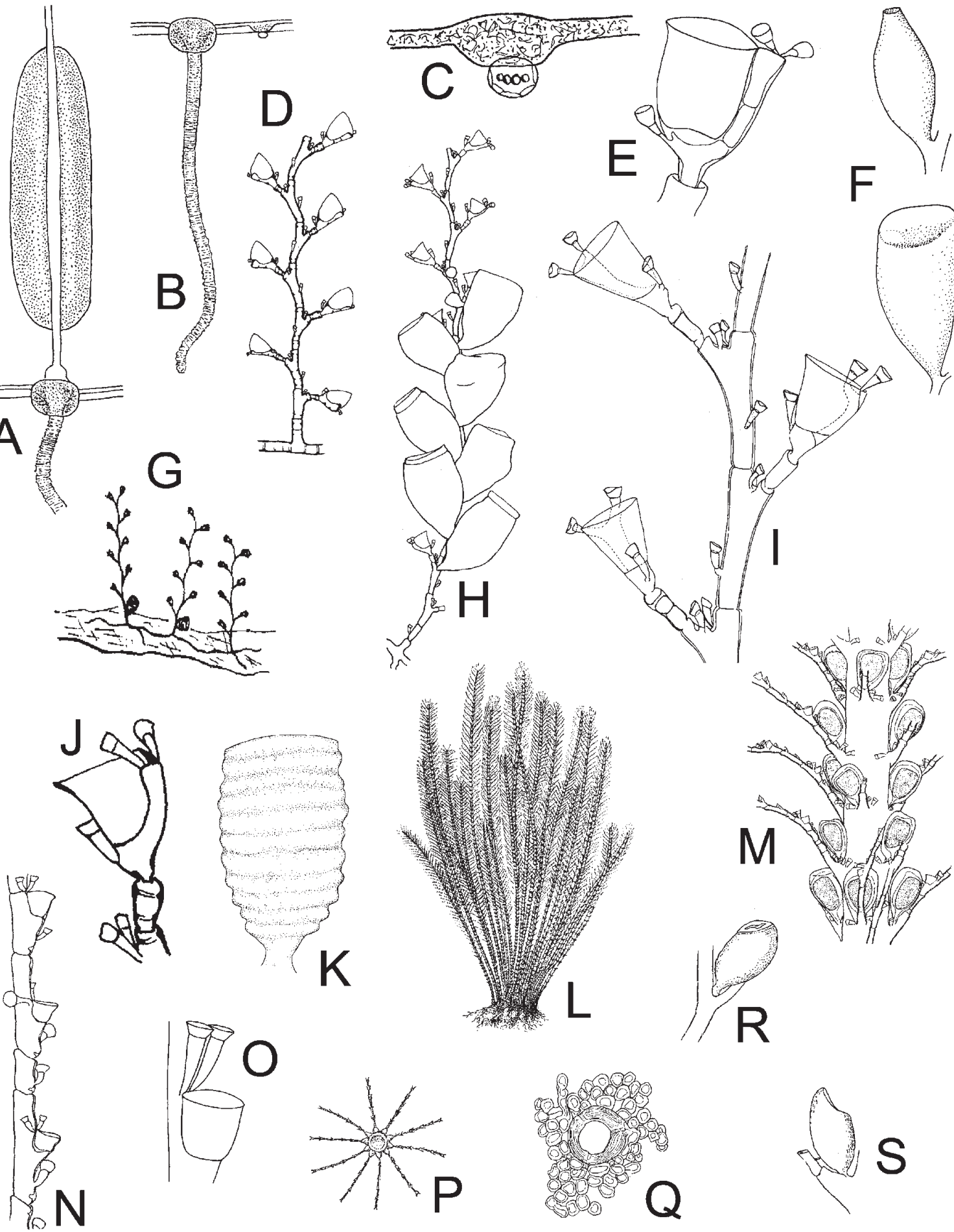

FIG. 92. - Leptomedusae. Phialellidae. A to C: Phialella quadrata: A: male gonad with the characteristic median groove, B: marginal tentacle and statocyst, C: detail of a statocyst with the typical cushion-like swellinig. Plumulariidae. D to K: Monotheca: D to F: Monotheca obliqua: D: detail of a branch, E: hydrotheca and associated nematothecae, F: above male gonotheca, below female gonotheca, G to K: Monotheca pulchella: G: three colonies rising from creeping stolon, H: stem with gonothecae, I: part of axis with three hydrocladia, J: part of hydrocladium with hydrotheca and associated nematotheca, K: detail of gonotheca; L to S: Nemertesia antennina: L: general view of a colony, M: upper part of stem with male gonothecae, $\mathrm{N}$ : detail of a hydrocladium, $\mathrm{O}$ : hydrotheca and nematothecae, $\mathrm{P}$ : transeversal section of a hydrocaulus showing arrangement of hydrocladia (number of rows not constant), Q: cross-section of a fascicled stem, R and S: gonothecae (A to C after Russell, 1953; D after Cornelius et al, 1990; E, F, O and P after Cornelius, 1995; G, I and K after Medel and Vervoort, 1995; H and J after Millard, 1975; L, N, R, S after Leloup, 1952; M, Q after Hirohito, 1995). 

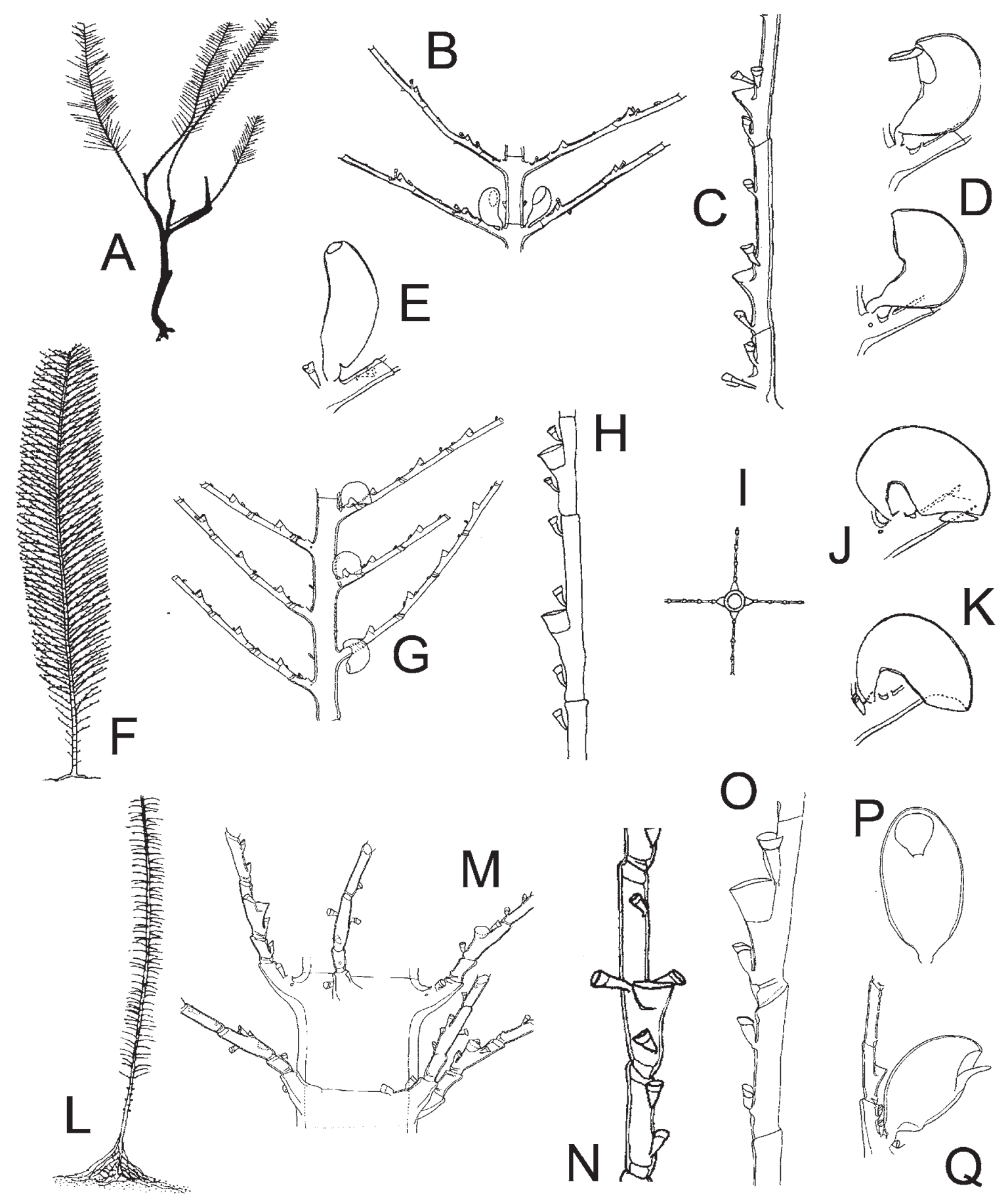

FIG. 93. - Leptomedusae. Plumulariidae. A to Q: Nemertesia: A to E: Nemertesia falcicula: A: general aspect of a colony, B: detail of a colony, C: part of hydrocladium, D: female gonotheca, E: male gonotheca; F to K: Nemertesia norvegica: F: general aspect of a colony, G: detail of colony, frontal view, $\mathrm{H}$ : hydrocladium, I: arrangement of hydrocladia (note just four rows), J and K gonothecae; L to Q: Nemertesia perrieri: L: general view of a colony, M: detail of a colony, frontal view, N: thecate internode with one supracalycine nematothecae, O: athecate and thecate internodes from hydrocladium, P and Q: gonothecae, frontal and lateral views (A to E, G, J, K, M, N, P and Q after Ansín Agis et al, 2001; F, H and I after Cornelius, 1995; L and O after Medel and Vervoort, 1995). 


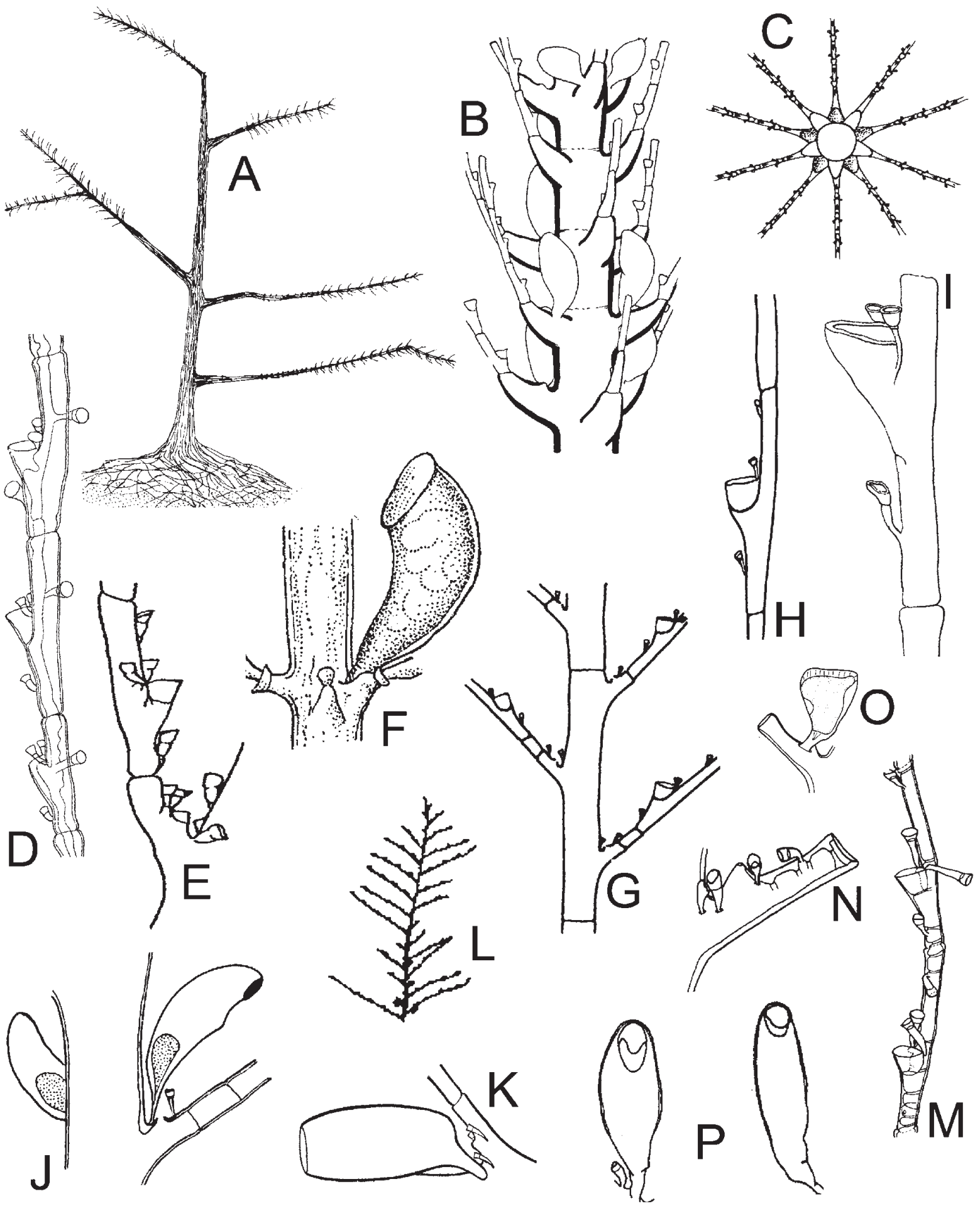

FIG. 94. - Leptomedusae. Plumulariidae. A to P: Nemertesia: A to F: Nemertesia ramosa: A: general view of a colony, B: part of stem with three hydrocladia per whorl and female gonothecae, C: arrangement of hydrocladia on hydrocaulus, D: detail of hydrocladium, E: hydotheca and associated nematothecae, F: gonotheca; G to K: Nemertesia tetrasticha: G: part of a colony, H: fragment of hydrocladium, I: hydrotheca and associated nematothecae, J: part of stem with gonothecae, K: detail of gonotheca; L to P: Nemertesia ventriculiformis: L: distal fragment of a colony, M: hydrocladial internodes, N: apophysis, O: young gonotheca, P: left: female gonotheca, right: male gonotheca (A after Medel and Vervoort, 1995; B after Millard, 1975; C after Cornelius, 1995; D, E and F after Leloup, 1952; G, H and J after Garcia Carrascosa et al, 1987; I after Meneghini, 1845, K after Stechow, 1919; L and p. after Ansín Agís et al, 2001; M to O after Ramil and Vervoort, 1992a). 


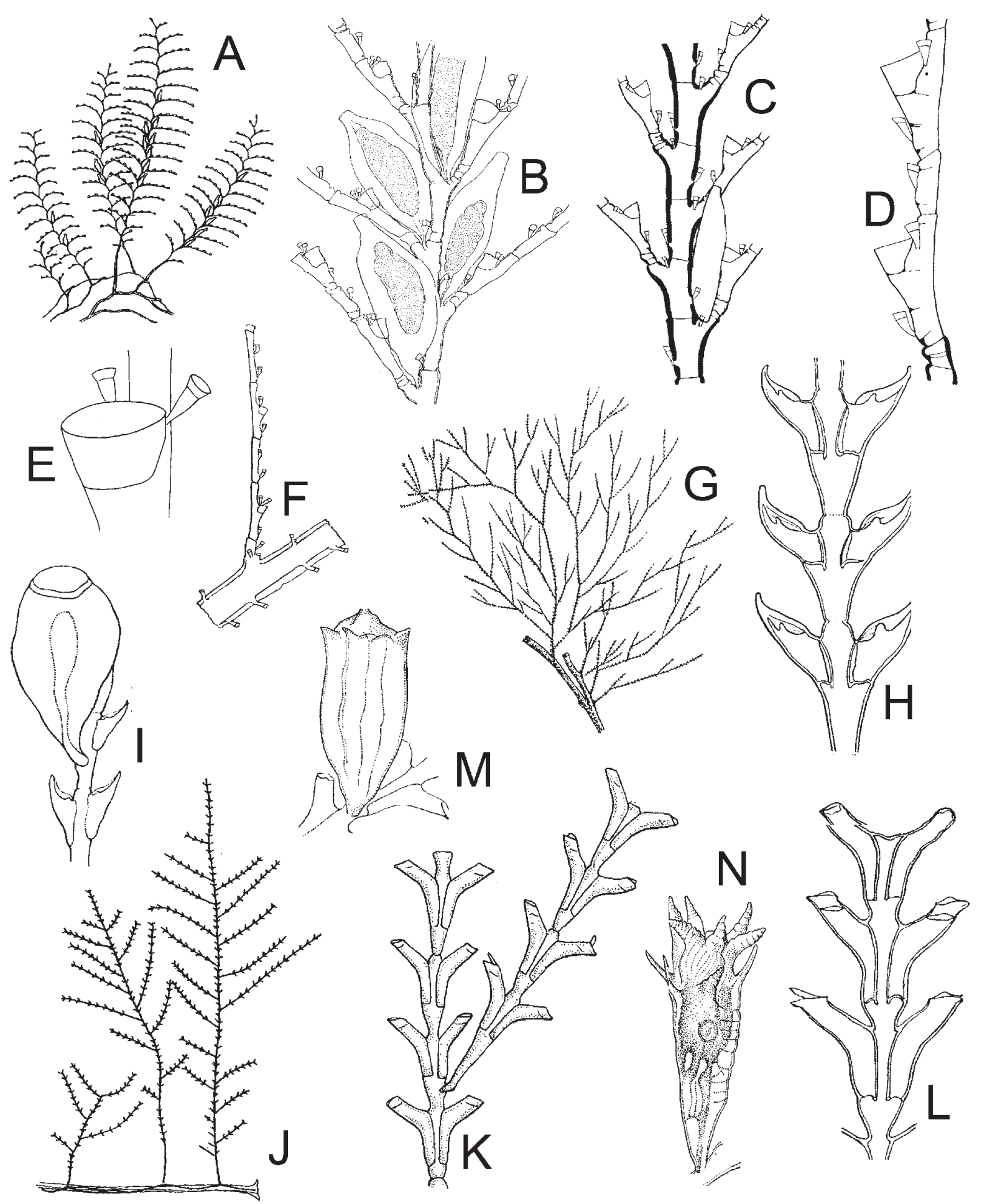

FIG. 95. - Leptomedusae. Plumulariidae. A to F : Plumularia. A to E: Plumularia setacea: A: general view of a colony, B and C: parts of stem showing origins of hydrocladia and gonothecae, D: detail of hydrocladium, E: hydrotheca and associated nematothecae, F: Plumularia syriaca: part of hydrocaulus and hydroclade. Sertulariidae. G to I: Amphisbetia operculata: G: part of colony, H: detail of a hydrocladium, I: gonotheca, J to N: Diphasia attenuata: J: part of a colony, K: portion of stem with hydrocladium, L: detail of hydrocladium, M: male gonotheca, N: female gonotheca (A and E after Cornelius, 1995; C and D after Millard, 1975; B, G to I, L to N after Leloup, 1952; F after Billard, 1931, J and K after Cornelius et al., 1990). 

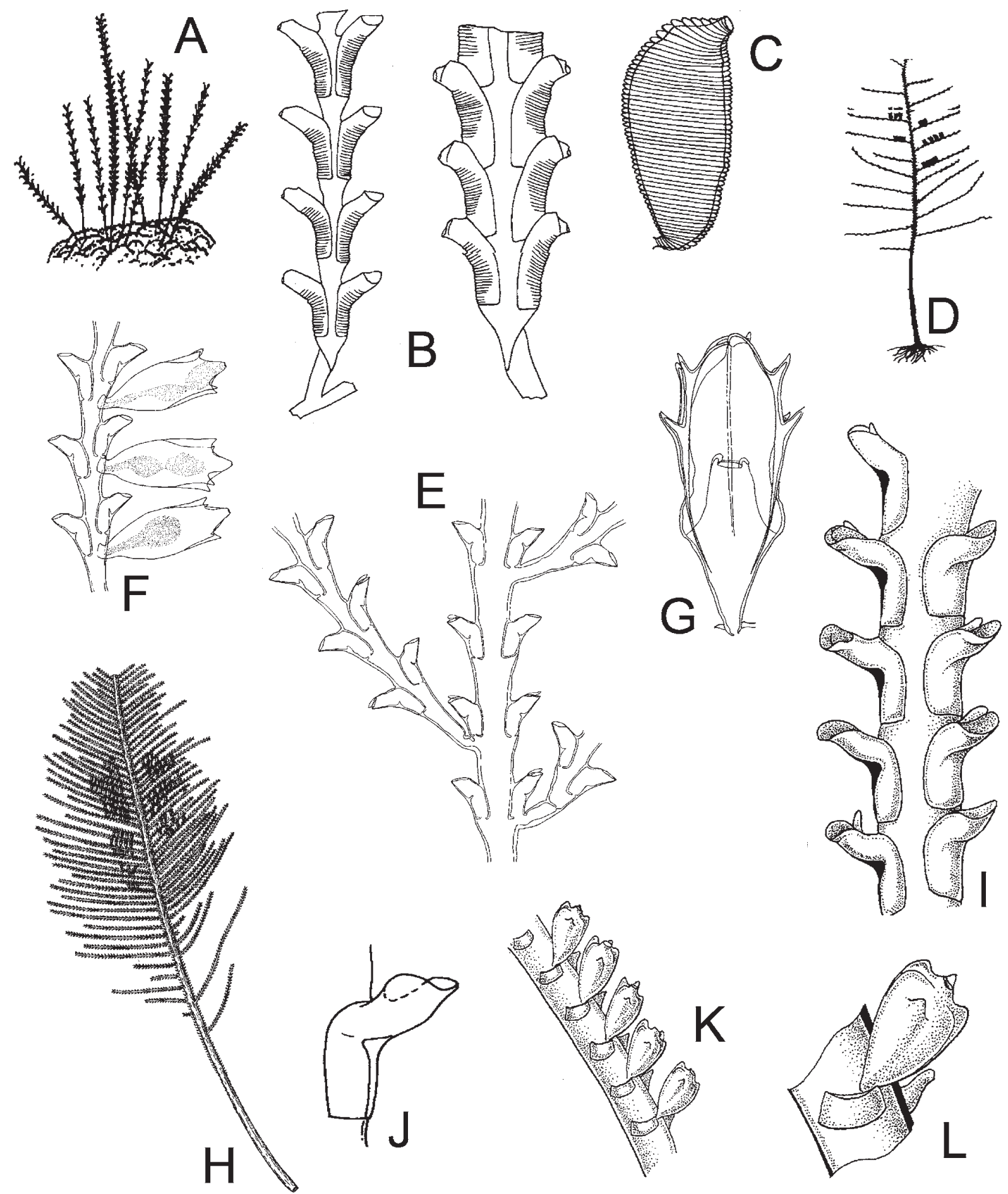

FIG. 96. - Leptomedusae. Sertulariidae. A to L: Diphasia: A to C: Diphasia delagei: A: general aspect of a colony, B: detail from stems of two different colonies, C: gonotheca, D to G: Diphasia margareta: D: view of a colony, E: part of stem with hydrocladia, F: hydrocladium with gonothecae, G: female gonotheca; H to L: Diphasia pinastrum: H: stem, I: detail of hydrocladium, J: hydrotheca, K: hydrocladium with gonotheca, L: detail of gonotheca (A to C, H and J after Cornelius, 1995; D to F after Gili et al, 1989; G after Ramil and Vervoort, 1992a; I, $\mathrm{K}$ and L after Cornelius et al., 1990). 


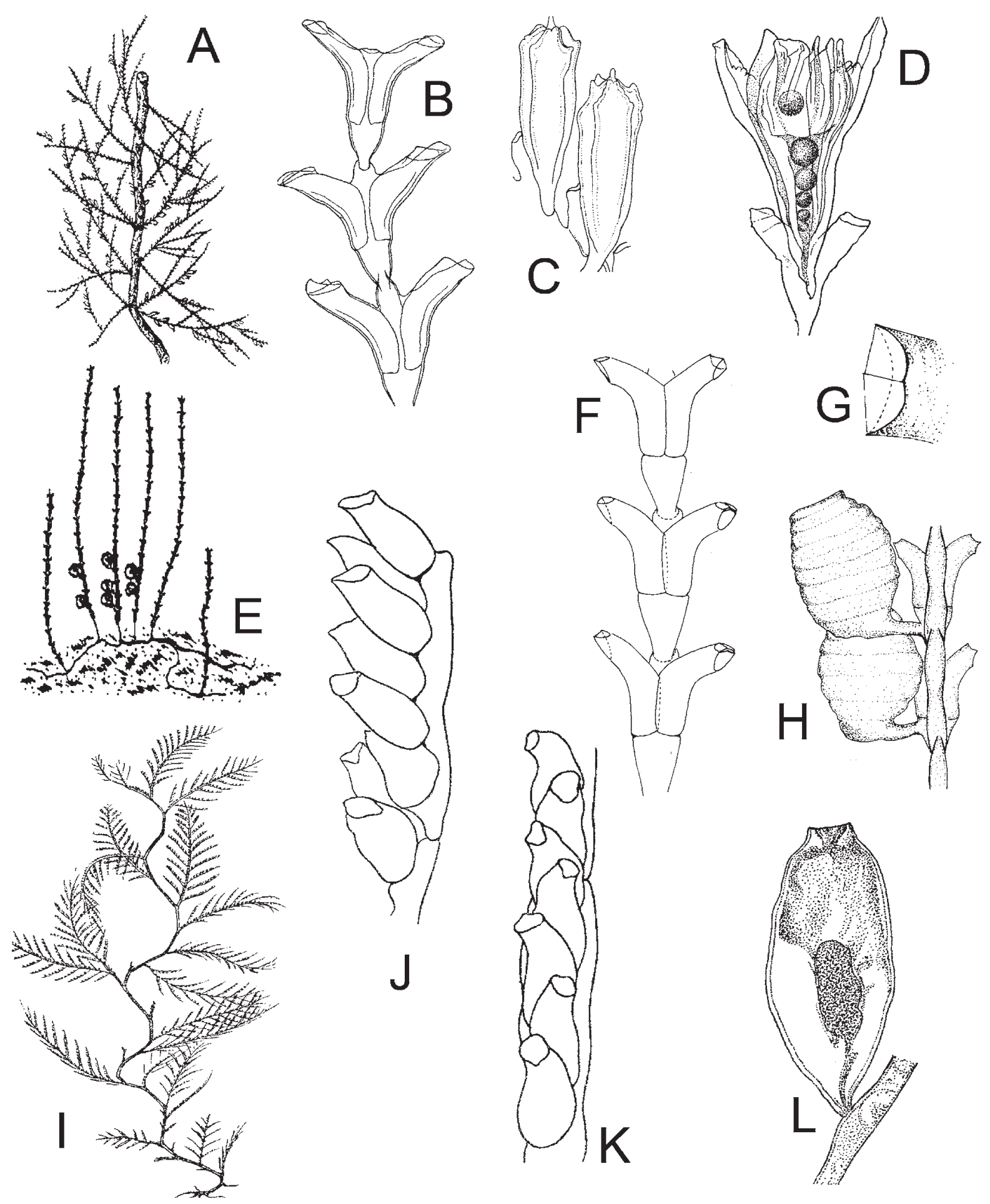

FIG. 97. - Leptomedusae. Sertulariidae. A to D: Diphasia rosacea: A: part of colony, B: hydrocladium, C: male gonotheca, D: female gonotheca; E to H: Dynamena disticha: E: colony, F: part of stem showing the hydrothecae, G: detail of operculum, H: stem with hydrothecae and gonothecae; I to L: Hydrallmania falcata: I: general view of a colony, J: lateral view of a hydrocladium, K: frontal view of a hydrocladium; L: gonotheca (A to D and I to L after Leloup, 1952; E to H after Medel et al., 1991). 


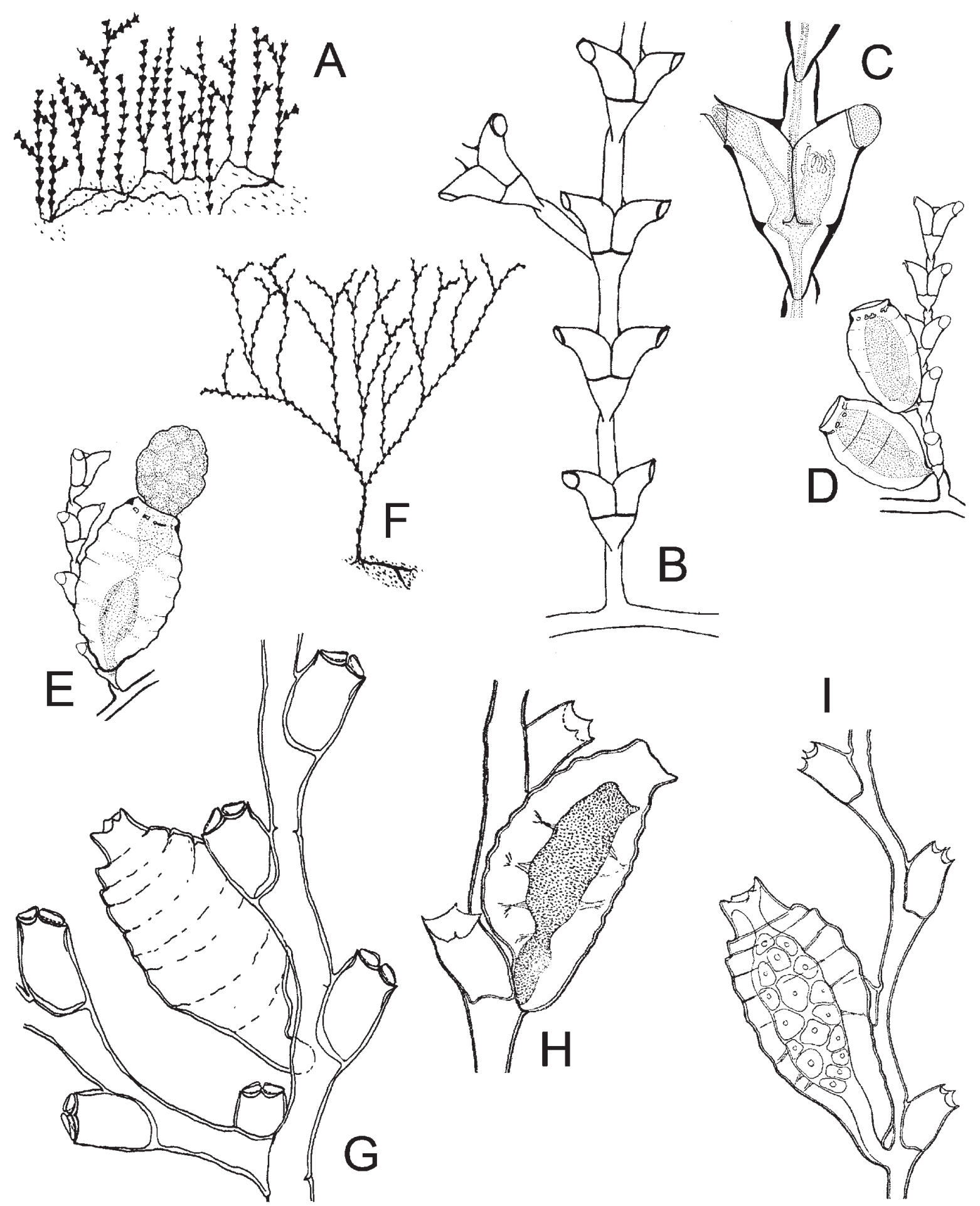

FIG. 98. - Leptomedusae. Sertulariidae. A to E: Salacia desmoides: A: general view of colony, B: detail of stem with a lateral branch; C: hydrotheca with hydranth and opercula; D: stem with male gonothecae, E: part of stem with female gonotheca and acrocyst; F to I: Sertularella crassicaulis: F: general aspect of a colony, G: detail of a stem with female gonotheca, H: male gonotheca; I: female gonotheca (A and B, F after Medel et al, 1991; C to E after Millard, 1975; G after Gili, 1986; H and I after Stechow, 1919). 

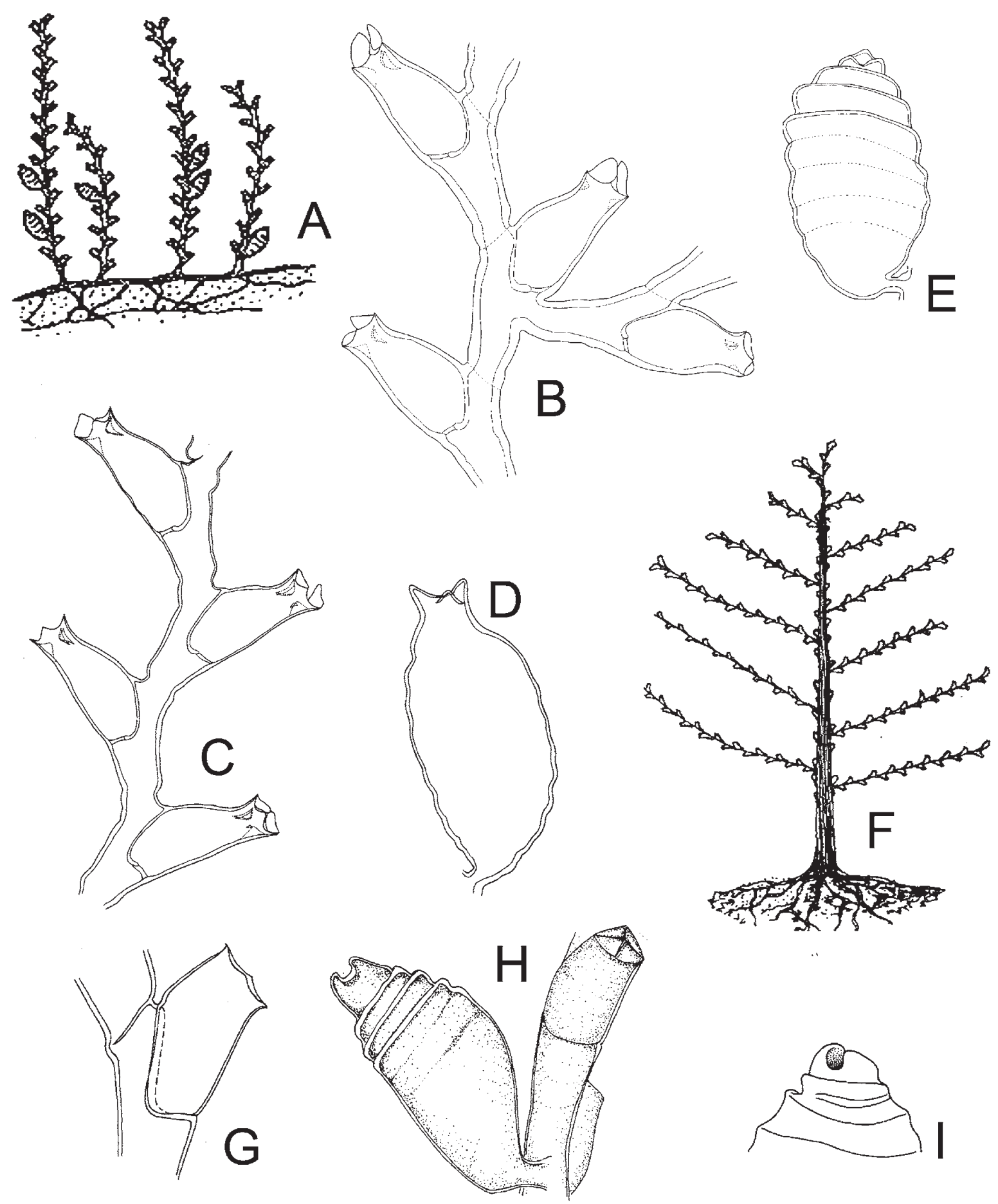

FIG. 99. - Leptomedusae. Sertulariidae. A to I: Sertularella: A to E: Sertularella ellisii: A: general view of a part of colony, B: detail of stem ramification, C: detail of stem and hydrothecae, D and E: detail of gonothecae; F to I: Sertularella gayi: F: general view of a colony;

G: detail of hydrotheca; H: gonotheca and hydrotheca; I: detail of end of gonotheca (A, G and I after Cornelius, 1995 ; B to D after Ramil et al, 1992a; E, F and H after Medel et al., 1991). 

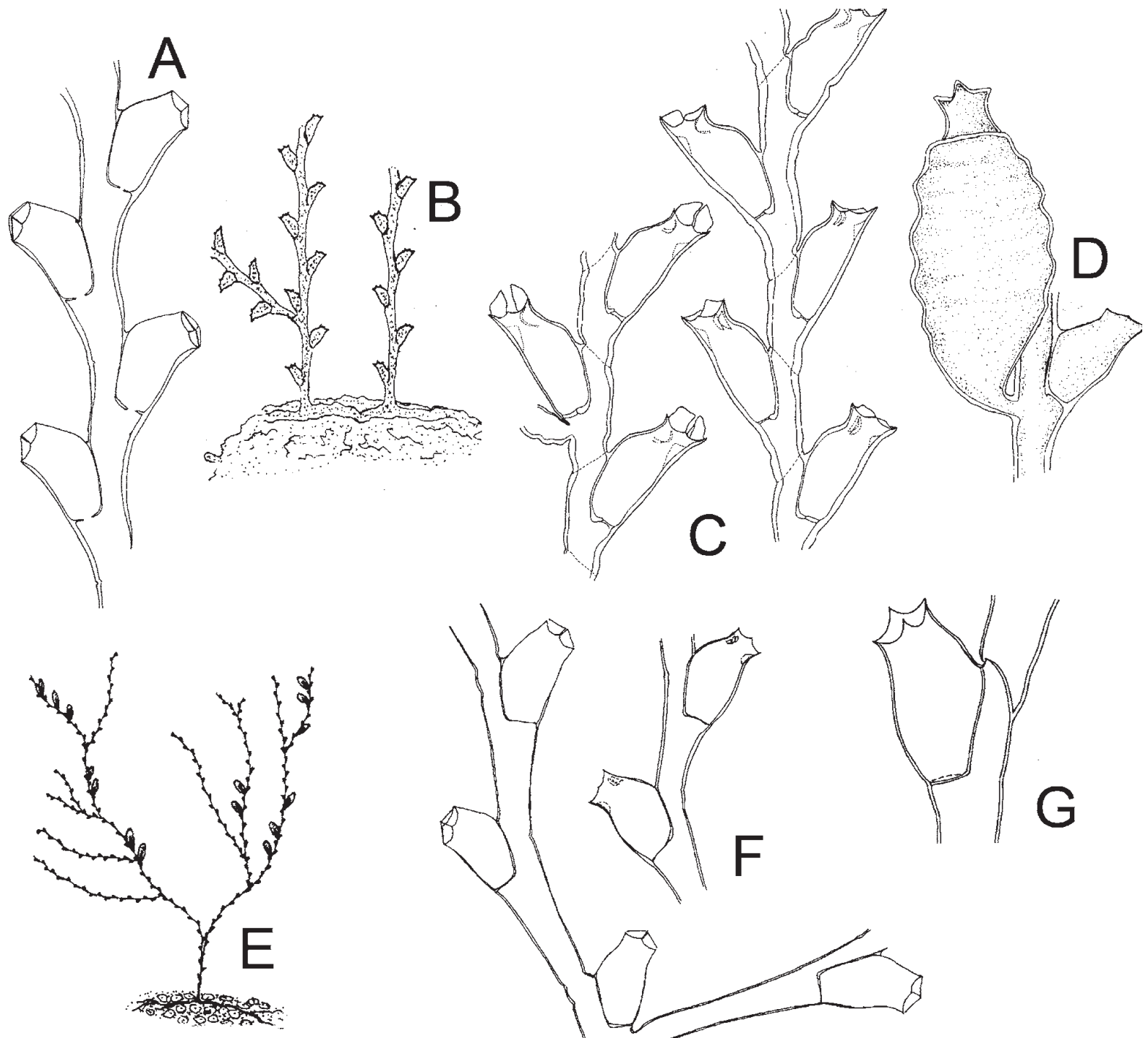<smiles>C1C[As]C1</smiles>
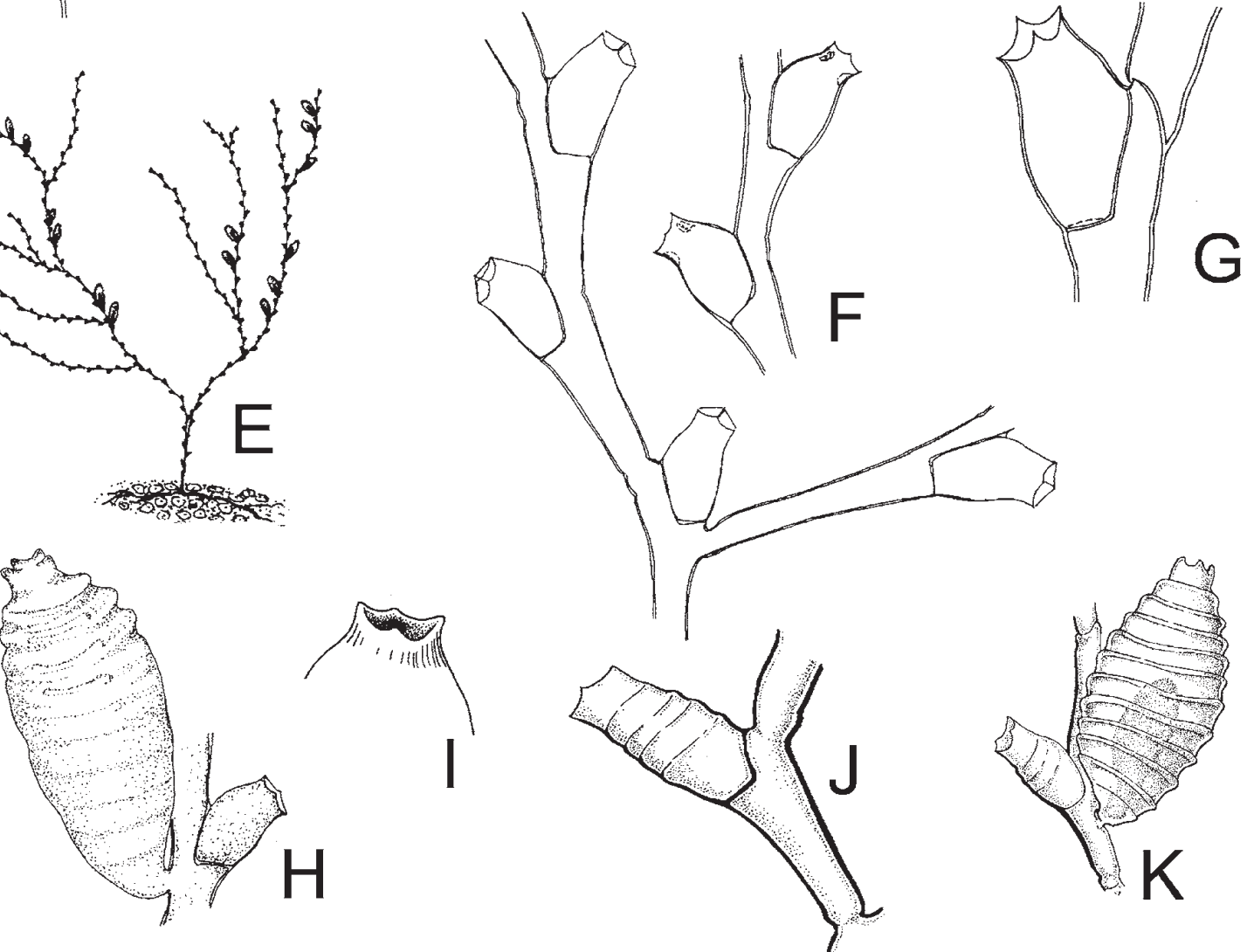

FIG. 100. - Leptomedusae. Sertulariidae. A to K: Sertularella: A: Sertularella gayi: detail of hydrocladia; B to D: Sertularella mediterranea: B: general view of a colony; C: parts of stem, left with ramification; D: gonotheca; E to I: Sertularella polyzonias: E: view of a colony, F: framents of colony; G: hydrotheca; H: gonotheca; I: detail of end of gonotheca; J and K: Sertularella tenella: J: hydrotheca; K: gonotheca (A, B, D to F, and $\mathrm{H}$ after Medel et al., 1991; C after Ramil et al., 1992a; G and I after Cornelius,1995; J and K after Cornelius et al., 1990). 

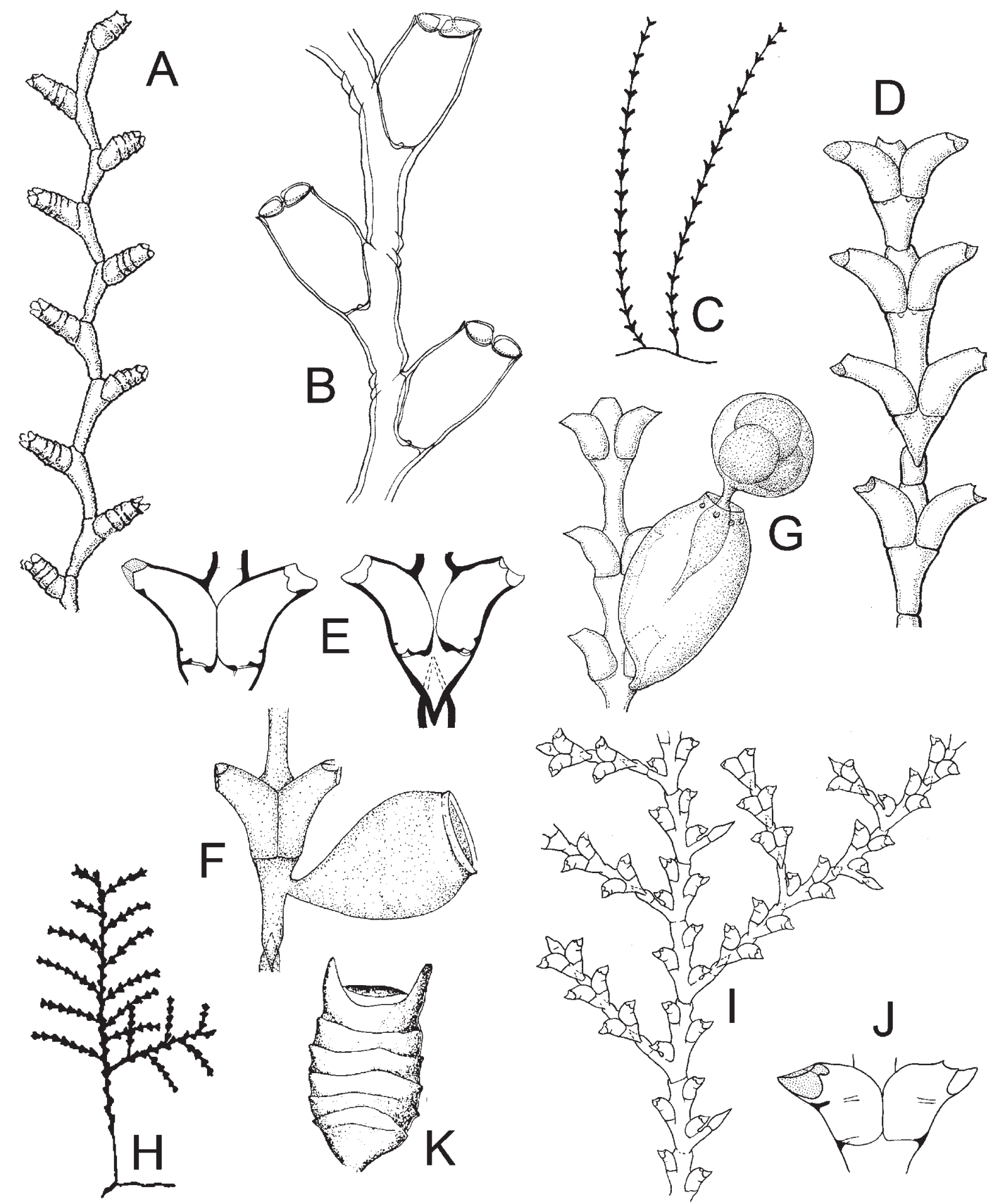

FIG. 101. - Leptomedusae. Sertulariidae. A to K: Sertularella: A: Sertularella tenella: stem; B: Sertularella cubica: branch; C to K: Sertularia: C to G: Sertularia distans: C: view of a part of colony, D: portion of stem, E: left: hydrothecae from middle part of stem, right: hydrotheca from lower part of stem with hinge-joint; F: gonotheca; G: part of branch with gonotheca and acrocyst; H to K: Sertularia marginata: $\mathrm{H}$ : fragment of a colony; I: pinnate stem showing origins of hydrocladia and one rebranching hydrocladium; J: hydrothecae; K: gonotheca (A, C, D and G after Cornelius et al., 1990; B after García-Corrales et al., 1980; E, I and J after Millard, 1975; F and H after Medel et al., 1991; K after Patriti, 1970). 

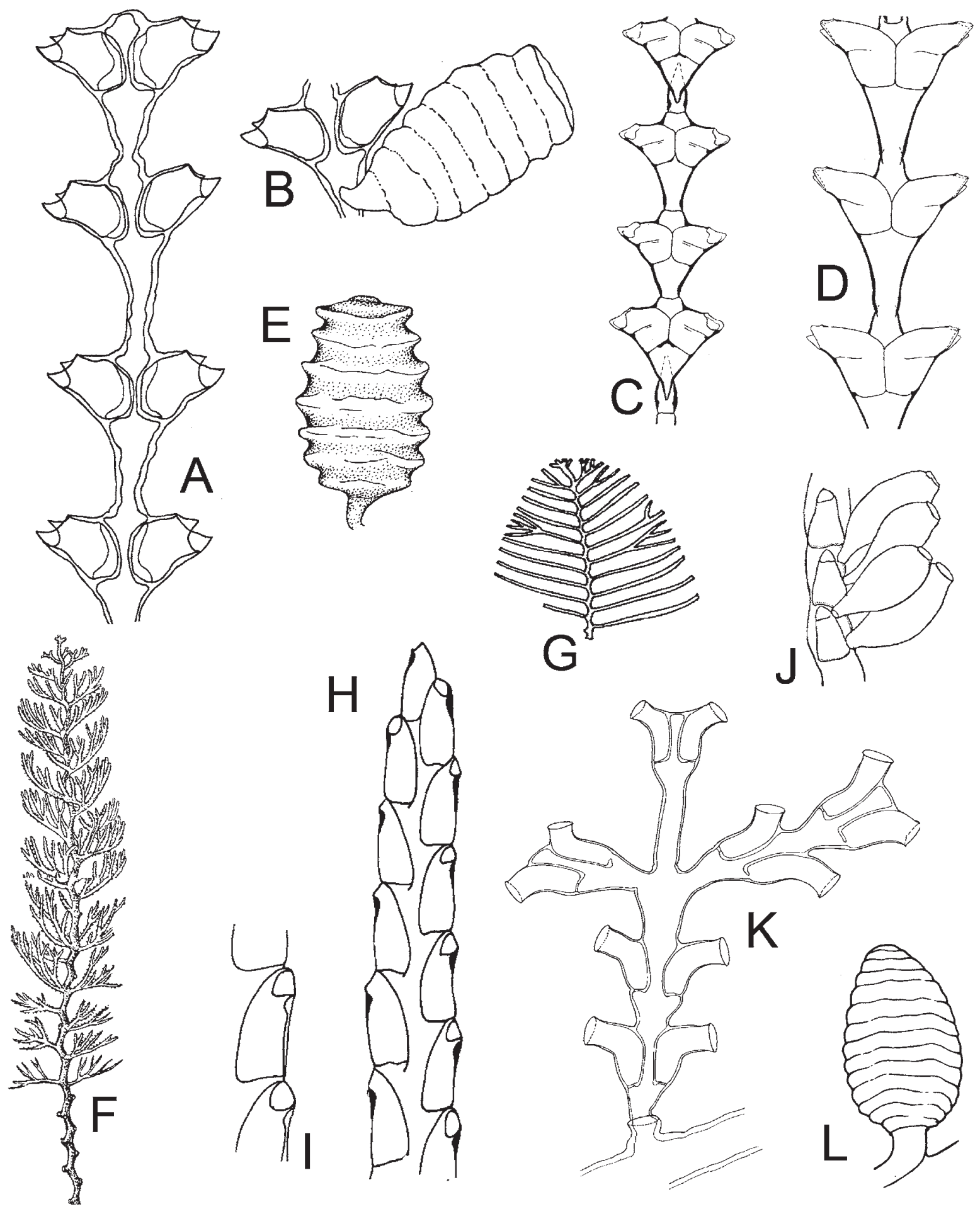

FIG. 102. - Leptomedusae. Sertulariidae. A to F: Sertularia: A and B: Sertularia perpusilla: A: part of stem; B: a gonotheca and two hydrothecae; C to E: Sertularia turbinata: C and D: different aspect of stems; E: detail of gonotheca; F to J: Thuiaria thuja: F: view of part of a colony, G: portion of young pinnate colony; H: detail of a hydrocladium; I: detail of hydrothecae; J: gonothecae. Syntheciidae. K and L: Synthecium evansi: K: part of colony showing hydrocladium with secondary ramication; L: gonotheca (A and B after Gili, 1986; C to E after Millard 1975; F and J after Leloup, 1952; G to I after Cornelius, 1995; K after Ramil and Vervoort, 1992a; L after Izquierdo et al., 1986). 

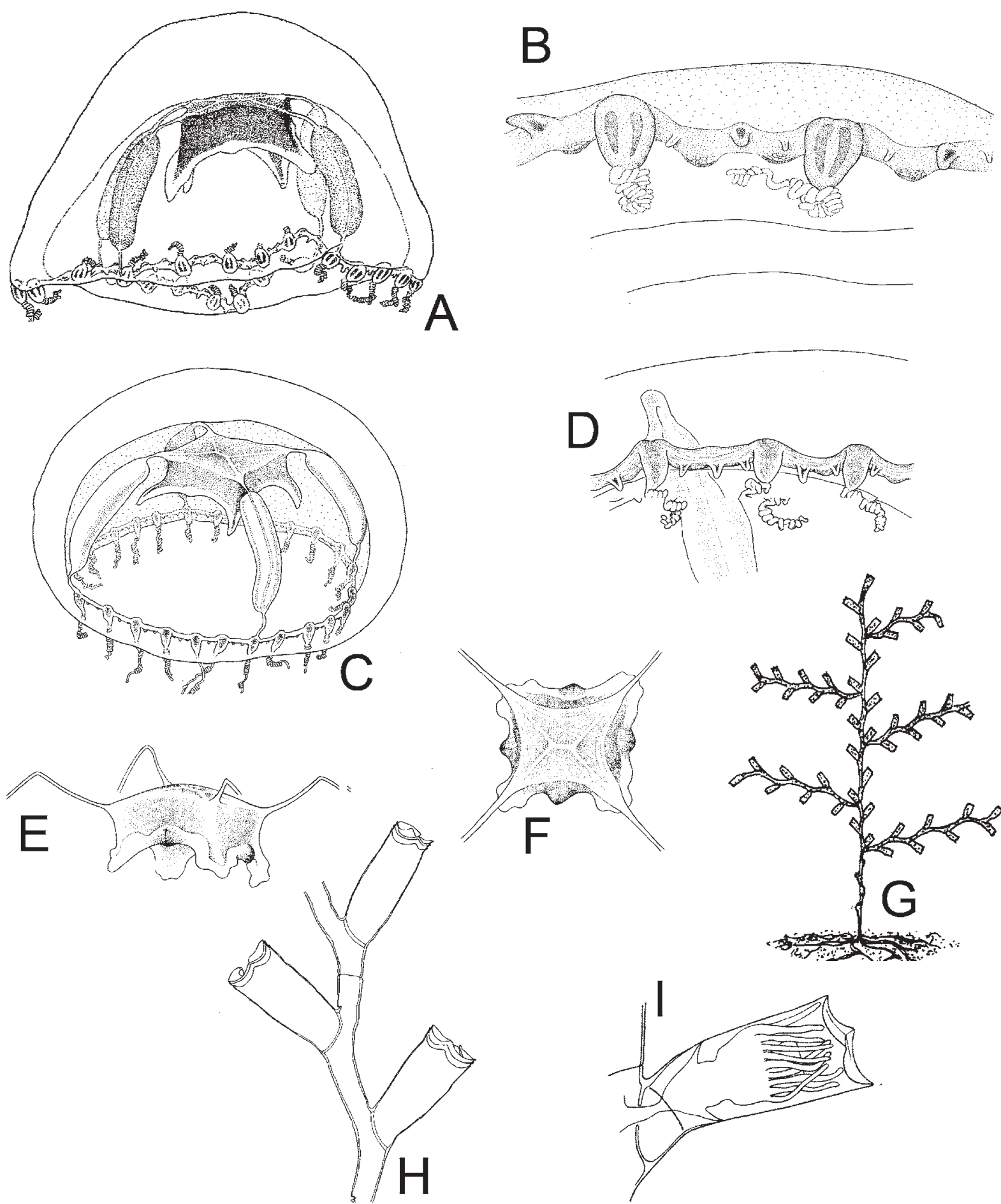

D
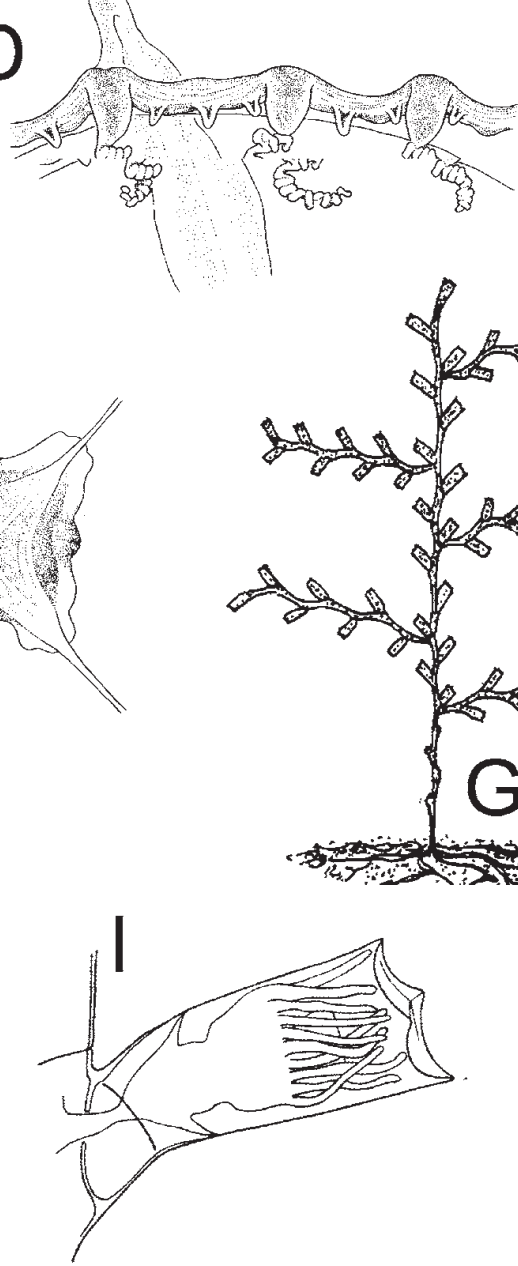

FIG. 103. - Leptomedusae. Teclaiidae. A and B: Parateclaia euromarge: A: fully-grown medusa, B: portion of umbrella margin; C to F: Teclaia rencicolae: C: adult medusa, D: portion of umbrella margin; E and F: details of manubrium, Thyroscyphidae. G to I: Sertullaroides cylindritheca: G: general view of a colony; $\mathrm{H}$ : fragment of axis; I: hydrotheca with hydranth showing the ectodermal annular fold (A and B after Bouillon et al., 2000; C to F after Gili et al., 1999; G after Medel and Vervoort, 1995; H after Ramil and Vervoort, 1992a; I after Vervoort, 1959). 

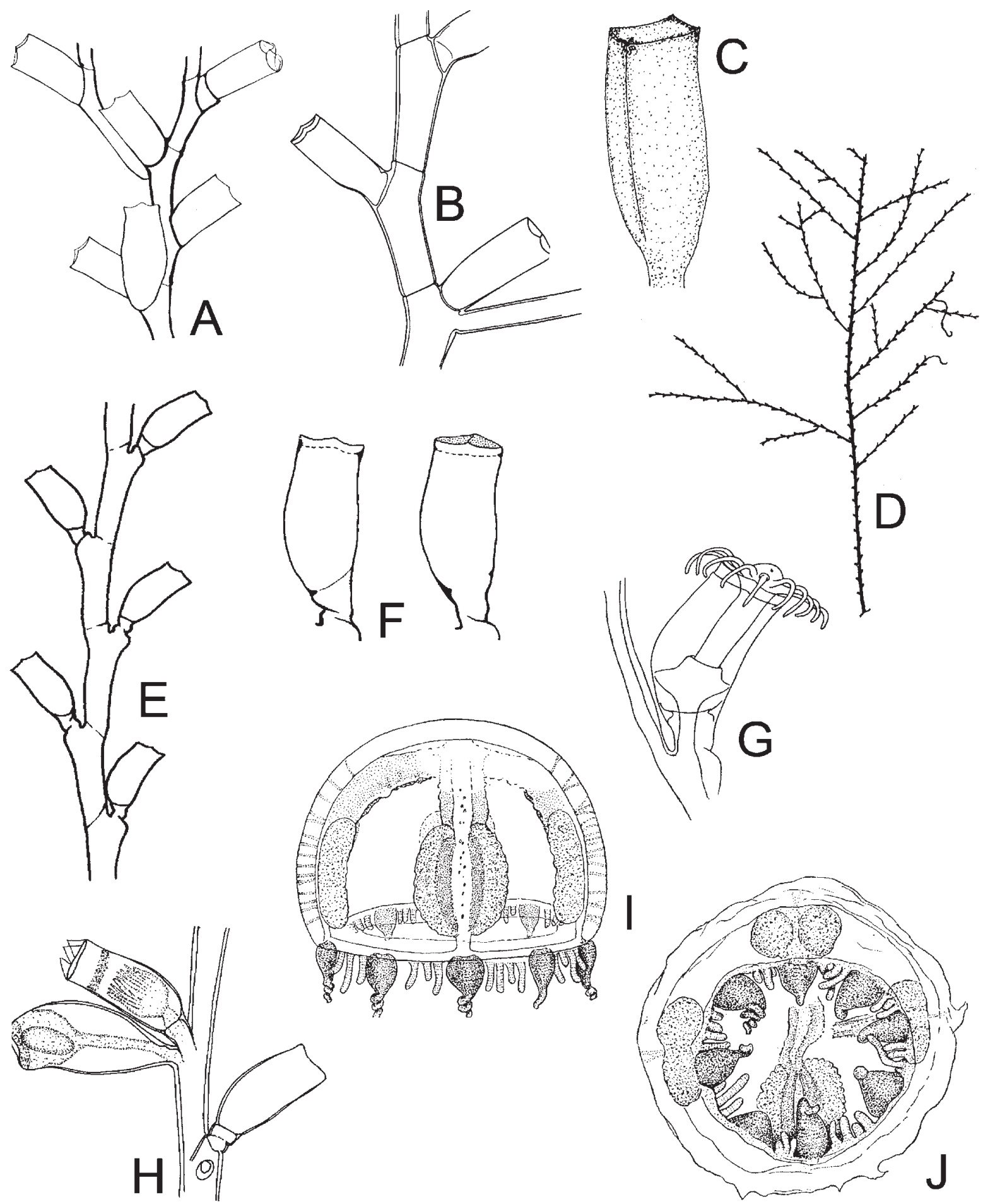

FIG. 104. - Leptomedusae. Thyroscyphidae. A to C: Sertullaroides cylindritheca: A: stem with hydrothecae and gonotheca, B: some internodes from the higher parts of a colony; C: gonotheca; D to G: Thyroscyphus fruticosus: D: general view of a colony; E: detail of a hydrocladium, F: hydrothecae; G: hydrotheca with expanded hydranth showing the ectodermal annular fold; $\mathrm{H}$ : internode with hydrotheca and gonotheca. Tiarannidae. I and J: Krampella dubia: fully-grown medusa, I: lateral view, J: oral view (A after Migotto, 1996; B after Vervoort, 1959; C after Medel et al., 1991; D to F after Millard, 1975; G after Vervoort, 1967; H after Watson, 2000; I and J after Russell, 1970a). 

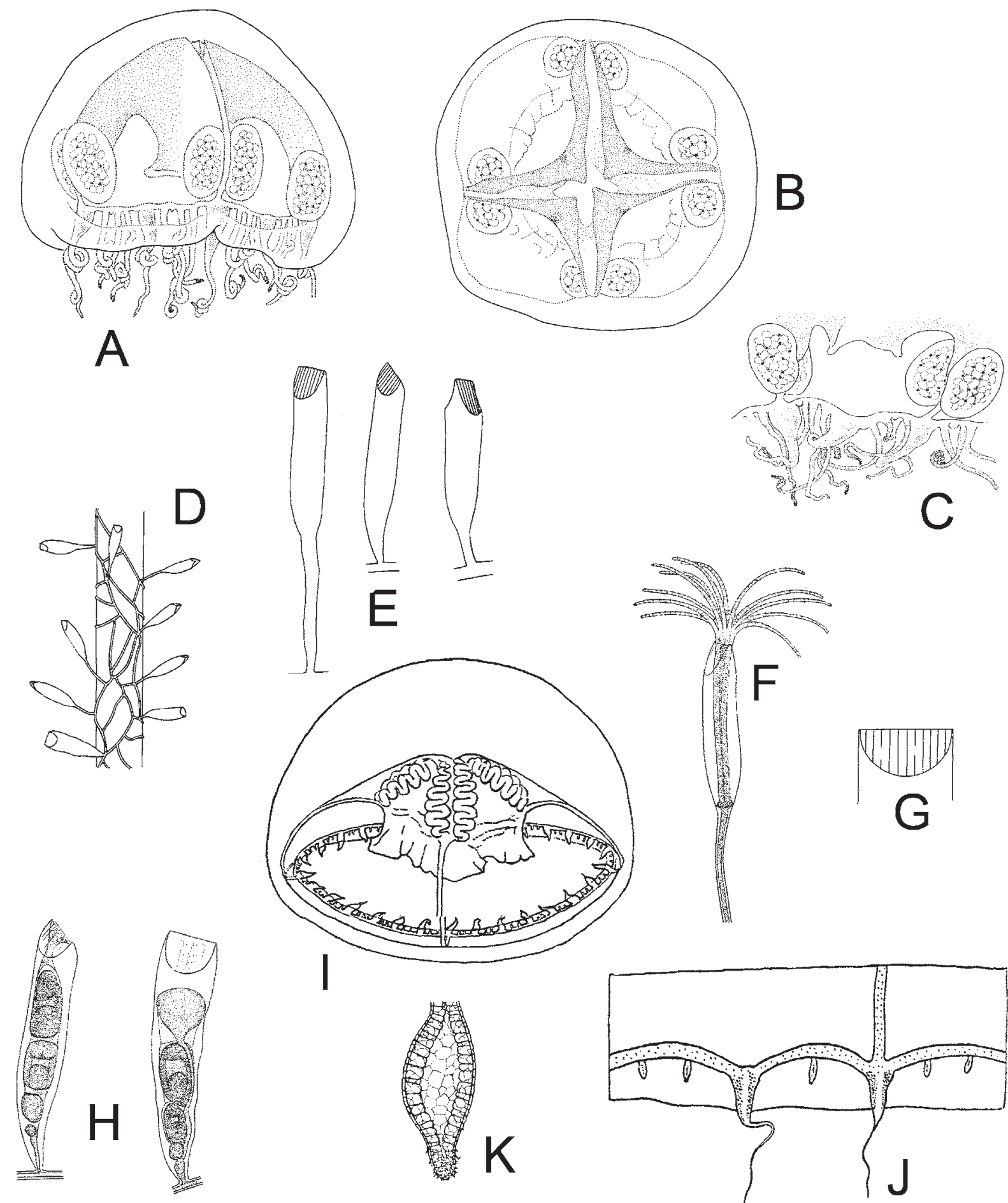

Fig. 105. - Leptomedusae. Tiarannidae. A to C: Krampella tardenti: A: lateral view of a fully-grown medusa, B: oral view of a fully-grown medusa, C: detail of exumbrellar margin and gonads; D to K. Modeeria rotunda: D: view of a part of colony, E: detail of hydrothecae: from left to right, with long peduncle, not stalked and shortly stalked thecae, F: fully grown hydranth, G: diagramatic representation of opeculum, H: two gonothecae bearing medusa buds, I: fully-grown medusa, J: portion of umbrella with marginal tentacles and cordyli, K: detail of a cordyli (A to C after Gili et al., 1999; D, E, G after Cornelius, 1995; F and H after Edwards, 1973b; I and J after Kramp, 1920; K after Kramp, 1919). 

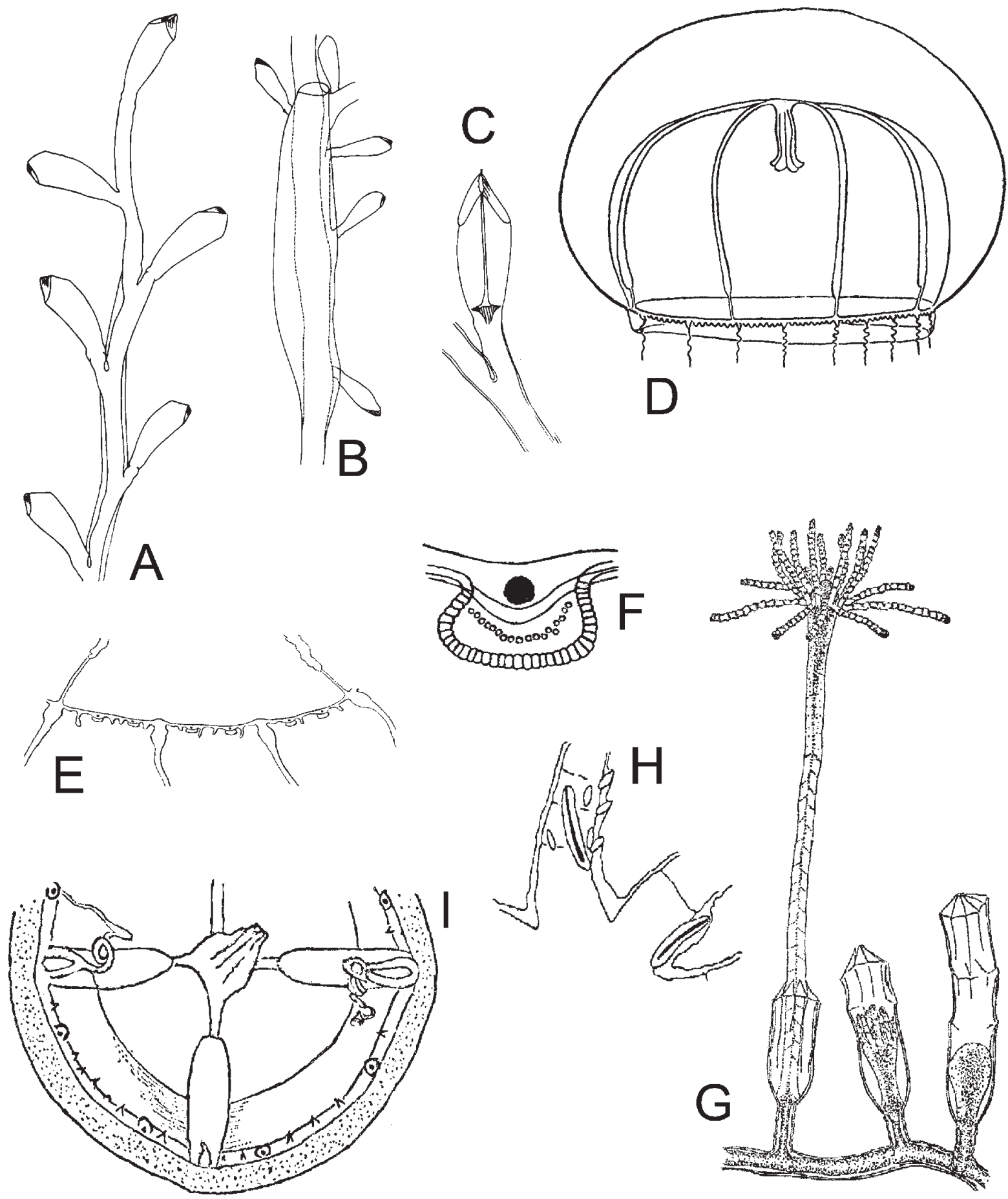

FIG. 106. - Leptomedusae. Tiarannidae. A to C: Stegopoma bathyale: A: distal portion of a colony, B: portion of colony with hydrothecae and gonotheca, C: detail of hydrotheca. Tiaropsidae. D to F: Octogonade mediterranea: D: adult medusa, E: portion of umbrella margin, F: open compound statocyst: $\mathrm{G}$ to I: Tiaropsidium mediterraneum: G: part of colony with expanded hydranth, $\mathrm{H}$ : detail of tentacular base showing the merotrichous isorhizae, I: half umbrella of mature medusa (A to C after Ramil and Vervoort, 1992a; D after Mayer, 1910; E after Pell, 1918; F after Trègouboff, 1957; $\mathrm{G}$ and $\mathrm{H}$ after Huvè, 1952a; I after Metschnikoff, 1886b). 

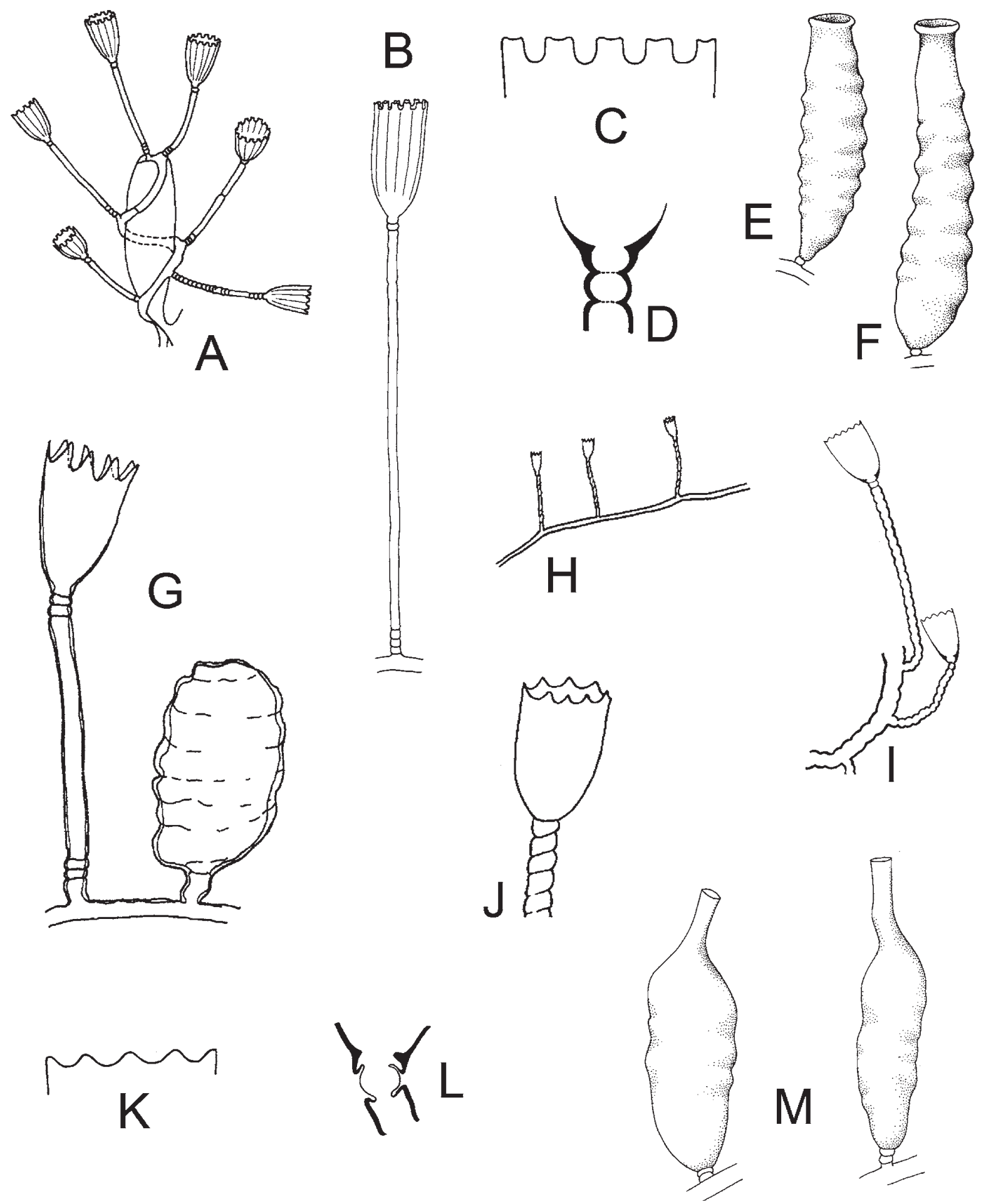

FIG. 107. - Leptomedusae. Campanulariidae. A to M: Campanularia: A to F: Campanularia hincksii: A: part of a colony on alga, B: single hydrotheca and pedicel, C: detail of hydrothecal rim, D: sub-hydrothecal spherule and basal chamber of hydrotheca, E: male gonotheca, F: female gonotheca; G: Campanularia raridentata: hydranth and gonotheca; $\mathrm{H}$ to $\mathrm{M}$ : Campanularia volubilis: $\mathrm{H}$ : detail of part of a colony, I: detail of hydrothecae and pedicels, J: hydrothecae, K: detail of hydrothecal rim, L: sub-hydrothecal spherule and basal chamber of hydrotheca; M: two gonothecae from same colony the one right sexed female on contents (A to F, H, J to M after Cornelius, 1995 ; G after Gili, 1986; I after Cornelius et al., 1990). 

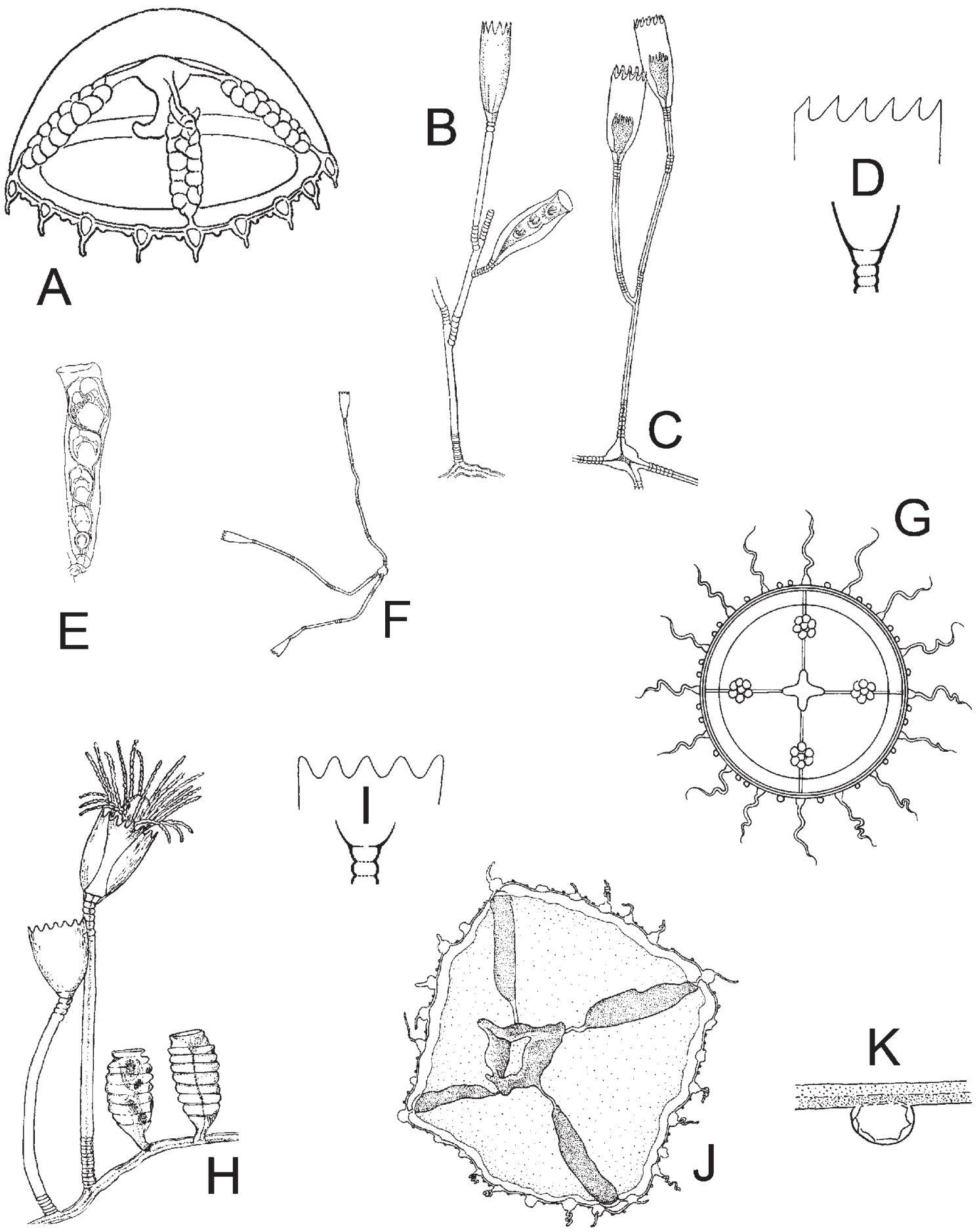

FIG. 108. - Leptomedusae. Campanulariidae. A to K: Clytia: A: Clytia discoidum adult medusa; B to G: Clytia gracilis: B: branch of fixed colony, C and F: branches of pelagic colonies, D: detail of hydrothecal rim and of basal chamber, E: gonothecae with medusa buds; G: mature medusa; $\mathrm{H}$ to K: Clytia hemispherica: $\mathrm{H}$ : part of hydroid colony with hydranths and gonothecae, I: diagrams of hydrothecal rim and of basal chamber, J: fully-grown medusa, K: statocyst (A after Kramp, 1959a; B, C, F after Leloup, 1952; D, G and I after Cornelius, 1995; E after Hirohito, 1995; H and K after Russell, 1953; J after Pagès et al., 1992). 

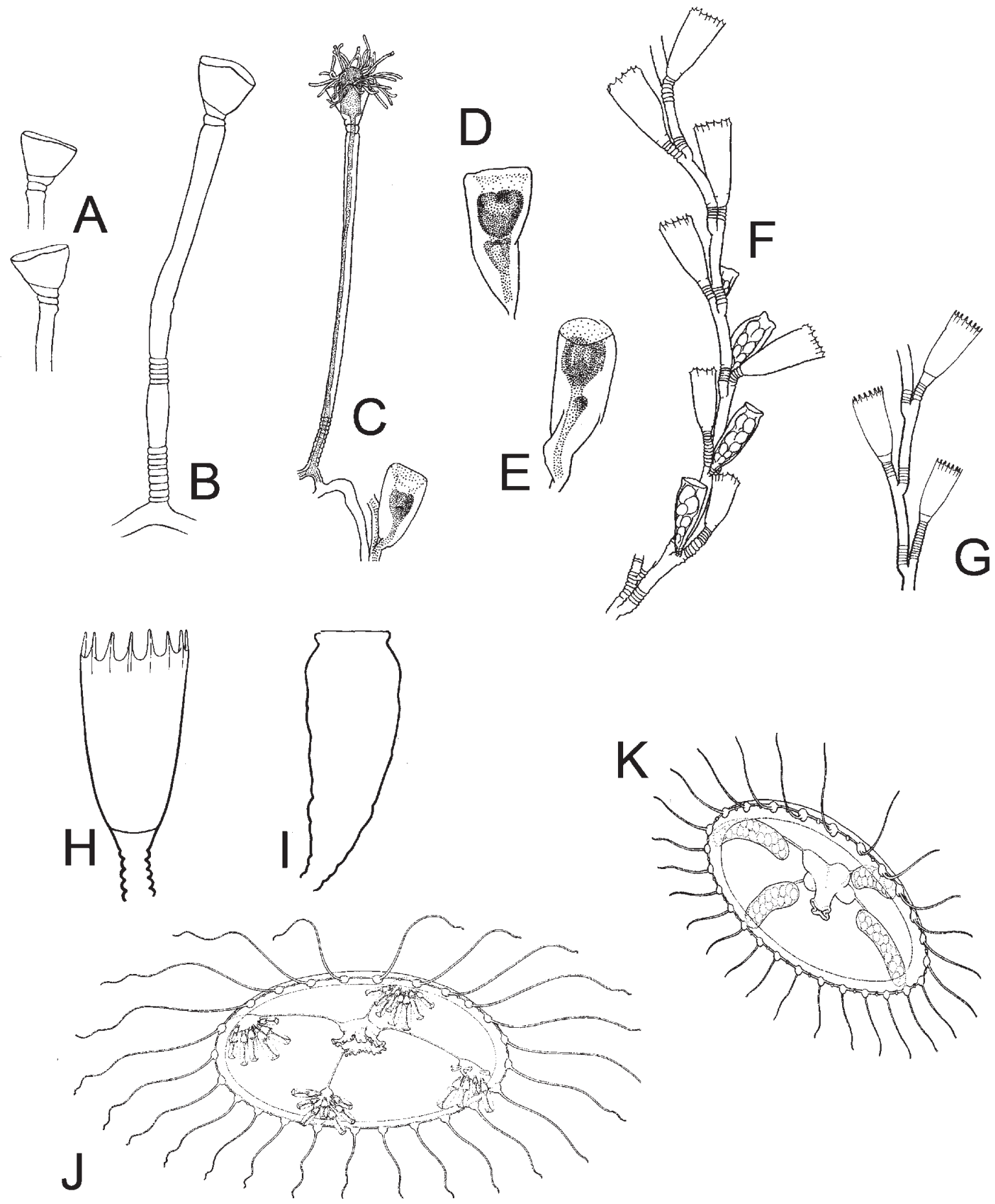

FIG. 109. - Leptomedusae. Campanulariidae. A to K: Clytia: A to E: Clytia hummelincki: A: detail of hydrothecae, B: hydrotheca and pedicel, C: hydrotheca, pedicel and gonotheca, D and E: gonothecae; F to I: Clytia linearis: F: part of stem with gonothecae, G: detail of part of hydrocaulus with hydrothecae, $\mathrm{H}$ : detail of hydrotheca, I: detail of gonotheca; J: Clytia maccradyi: fully-grown medusa with blastostyles; K: Clytia macrogonia mature medusa (A and B after Leloup, 1935; C to E after Millard, 1975; F after Hirohito, 1995; G to I after Calder,1991; J original after Bouillon; K after Bouillon, 1984a). 

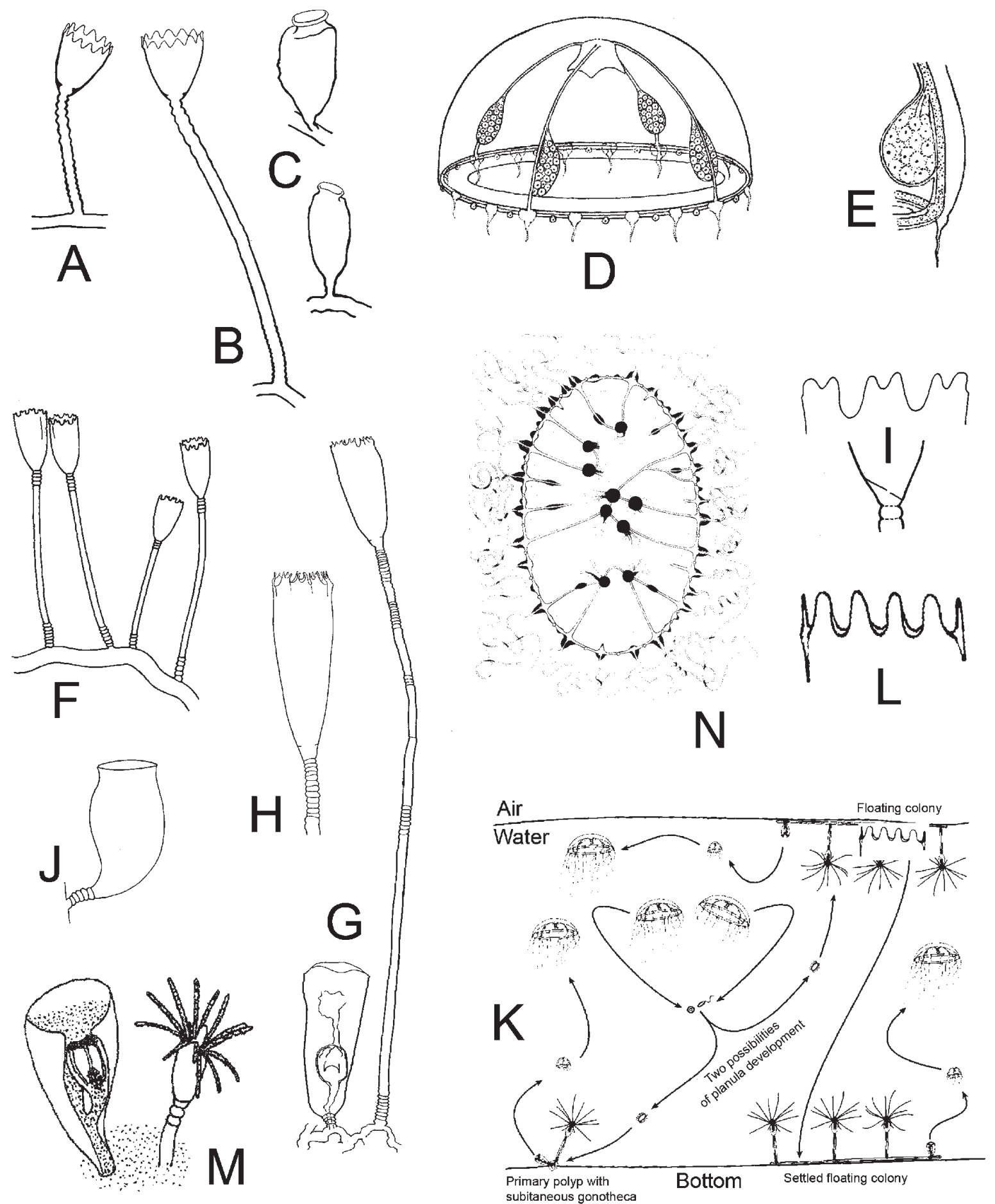

FIG. 110. - Leptomedusae. Campanulariidae. A to L: Clytia: A to E: Clytia noliformis: A and B: part of a colony; C: gonothecae; D: mature medusa, E: detail of gonad. F to J: Clytia paulensis: F: detail of a part of colony; G: enlarged part of colony with gonotheca; H: detail of hydrotheca; I: diagrams of hydrothecal rim and of basal chamber with oblique diaphragm; J: gonotheca. K to L: Clytia viridicans: K: alternative life cycle pathways involving planula settlement either on the bottom or on air-water surface; L: detail of hydrothecal rim. M and N: Gastroblasta raffaelei: M: hydroid and gonotheca embedded in a sponge; N: mature medusa (A to C after Calder, 1991, D and E after Vannucci and Ribeiro, 1955; F, I and J after Cornelius, 1995; G and H after Hirohito, 1995; K after Pagliara et al., 2000; L after Gravili et al., 2003; M after Boero, 1980b; N after Lang, 1886). 

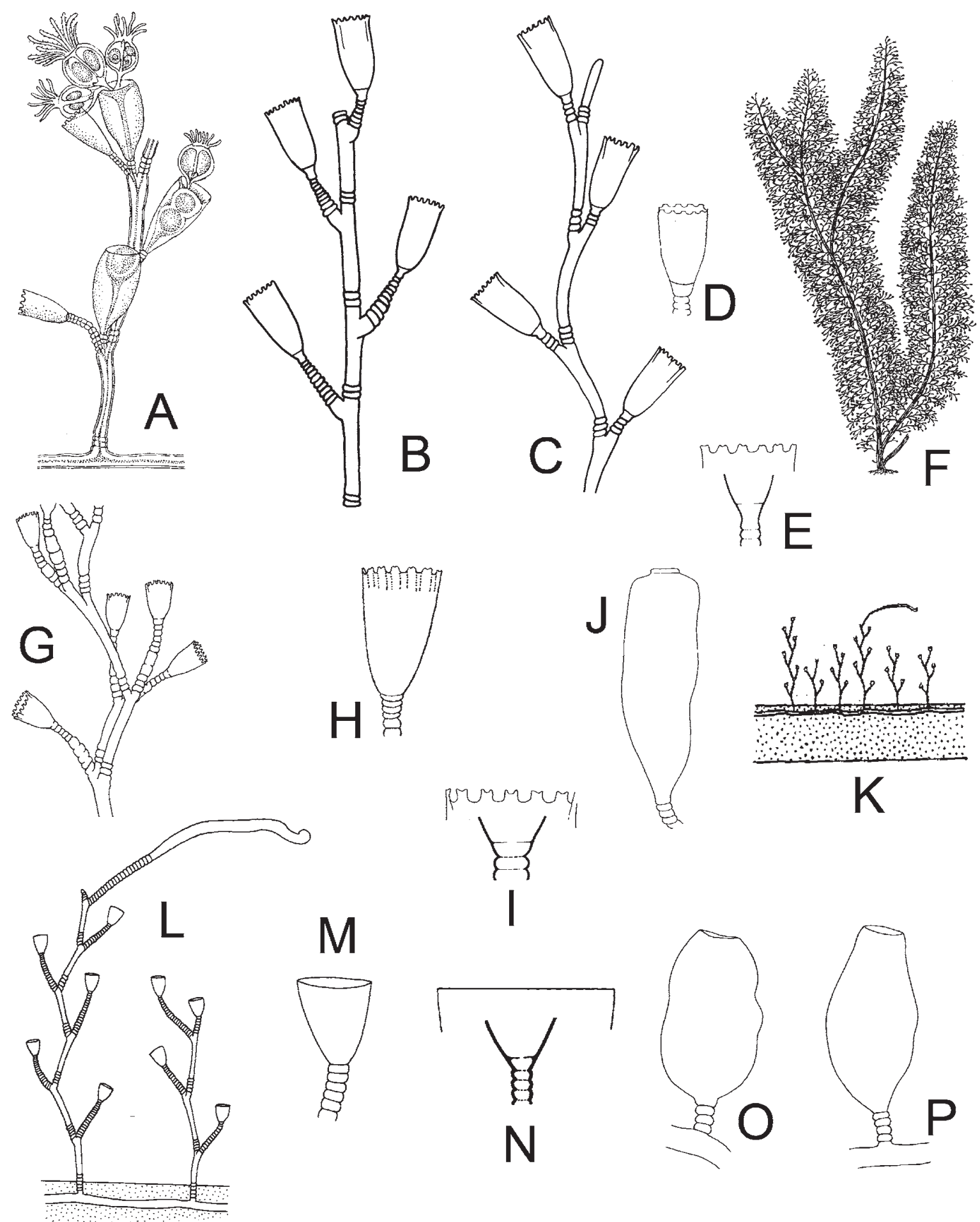

FIG. 111. - Leptomedusae. Campanulariidae. A to E: Gonothyraea loveni: A: part of colony with gonothecae and meconidiae, B: branch with straight internodes, C: branch with flexuose internodes, D: detail of hydrotheca, E: diagrams of hydrothecal rim and of basal chamber; F to J: Hartlaubella gelatinosa: F: general view of a colony, G: detail of hydrocladium, $\mathrm{H}$ : detail of hydrotheca, I: diagrams of hydrothecal rim and of basal chamber, J: gonotheca; K to P : Laomedea angulata: K: general aspect of a colony, L: detail of two branches of a colony, one ending in a tendril, M: detail of hydrotheca, N: diagrams of hydrothecal rim and of basal chamber,O: male gonotheca, P: female gonotheca (A and D after Leloup, 1952; B, C, E to P after Cornelius, 1995). 

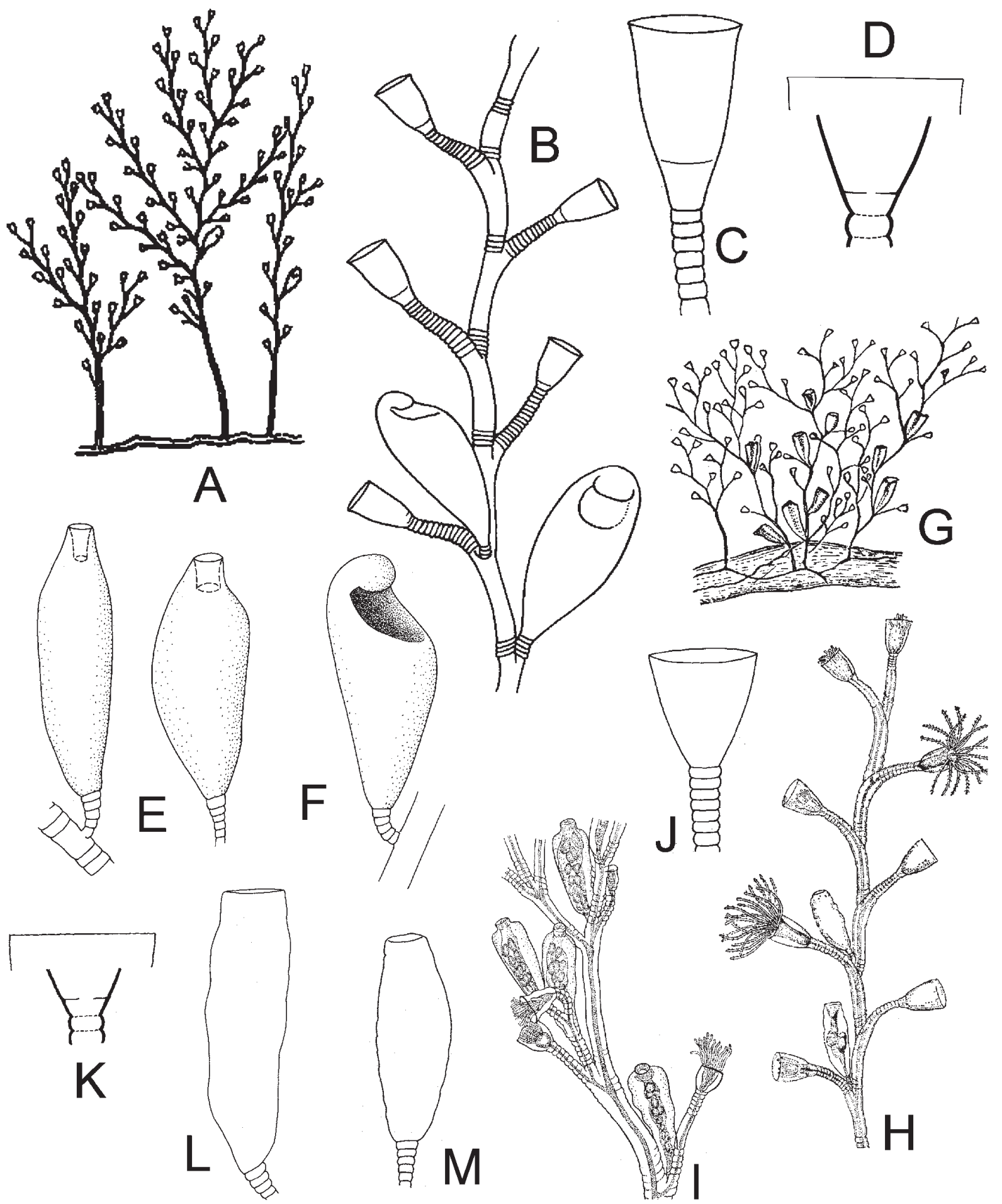

FIG. 112. - Leptomedusae. Campanulariidae. A to M: Laomedea: A to F: Laomedea calceolifera: A: a general aspect of a colony, B: detail of hydrocladia with female gonotheca, C: detail of hydrotheca, D: diagrams of hydrothecal rim and of basal chamber, E: two male gonotheca, F: female gonotheca; G to M: Laomedea flexuosa: G: general view of a colony, $\mathrm{H}$ and I: parts of hydrocladia, J: detail of hydrotheca, K: diagrams of hydrothecal rim and of basal chamber, L: female gonotheca, M: male gonotheca (a to F, J to M after Cornelius, 1995; G and H after Hincks, 1868; I after Leloup, 1952). 


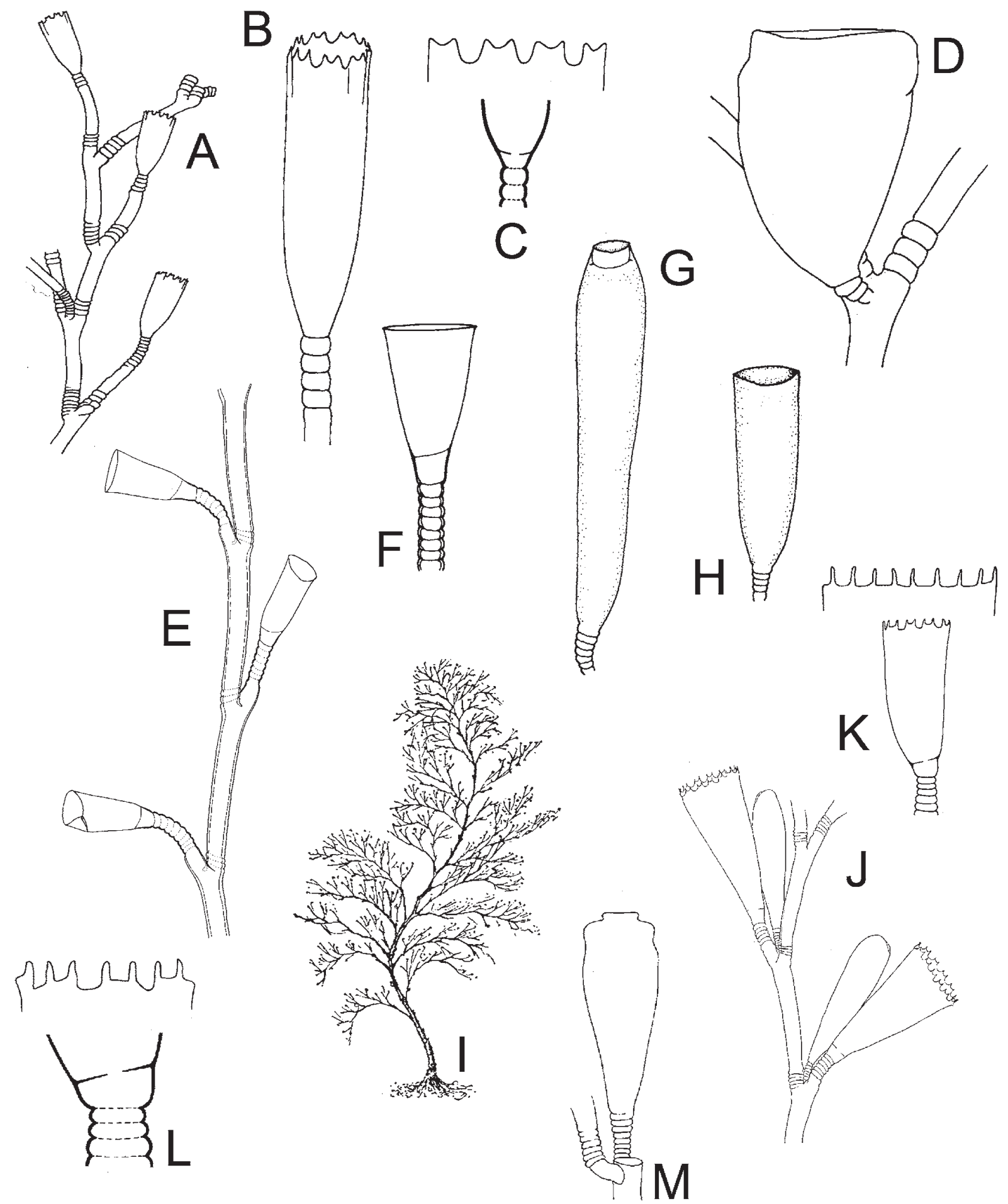

FIG. 113. - Leptomedusae. Campanulariidae. A to H: Laomedea: A to D: Laomedea neglecta: A: detail of a colony, B: hydrotheca, C: diagrams of hydrothecal rim and of basal chamber, D: gonotheca; E to H: Laomedea pseudodichotoma: E: monosiphonic part of axis, F: detail of hydrotheca, G: female gonotheca, H: male gonotheca; I to M: Obelia bidentata: I: general view of a colony, J: part of hydrocladium with hydrotheca and gonotheca, K: above: detail of hydrothecal rim with uniform cusps, below: detail of hydrotheca, L: above: detail of hydrothecal rim with bimucronate hydrothecal rim, below diagram of basal chamber, M: gonotheca (A to D, K to M after Cornelius 1995 , E after Ramil and Vervoort, 1992a; F to H after Medel and Vervoort, 2000, I after Leloup, 1952; J after Hirohito, 1995). 

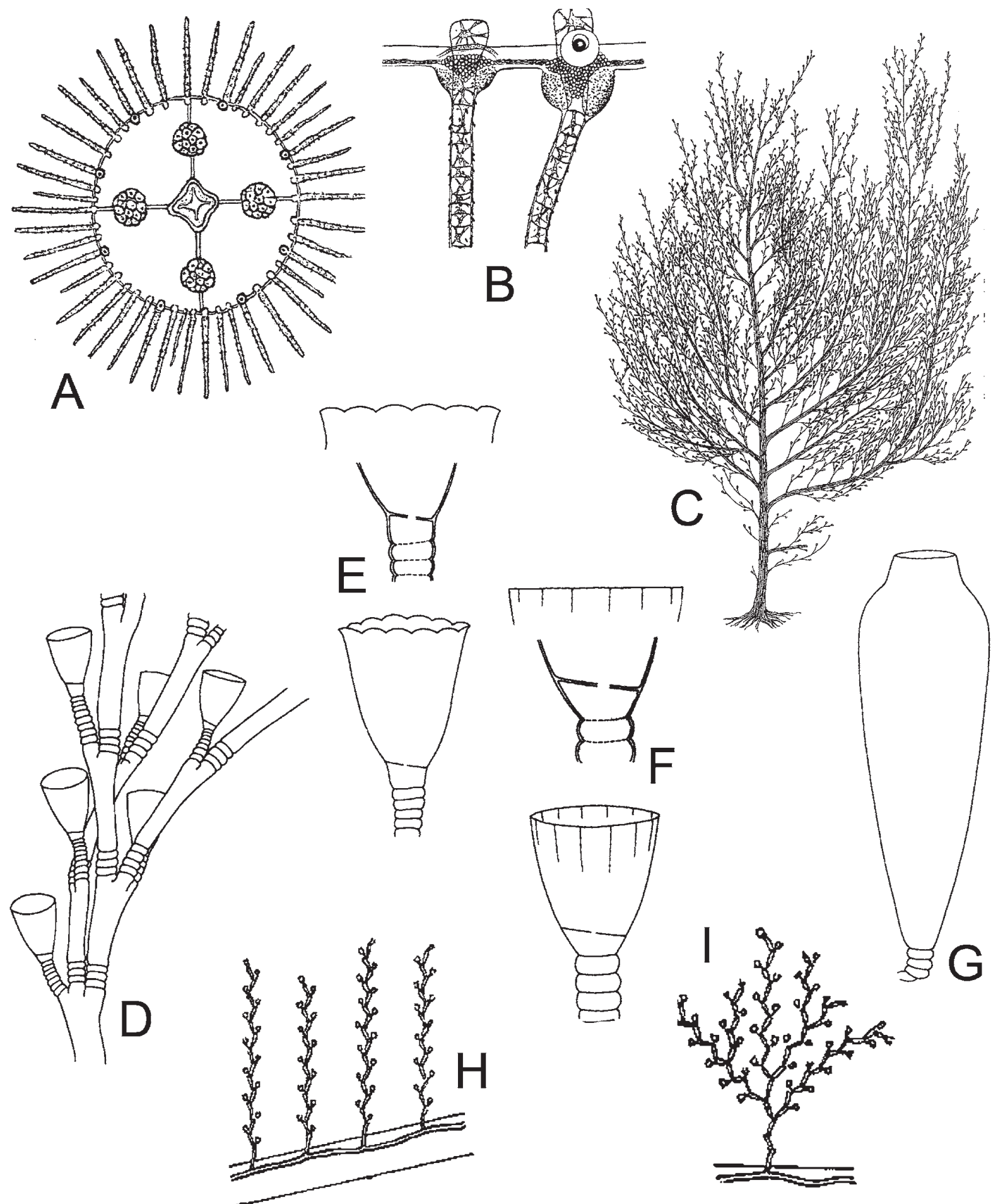

FIG. 114. - Leptomedusae. Campanulariidae. A to I: Obelia: A and B: Obelia spp. A: mature medusa, B: portion of umbrella margin showing the position of the statocyst at the base of the tentacular bulb; $\mathrm{C}$ to $\mathrm{G}$ : Obelia dichotoma: C: general aspect of a colony, D: detail of hydrocladial ramifications, E: below: hydrotheca with crenate rim, middle: diagram of basal chamber, above: diagram of hydrothecal rim, F: below: hydrotheca with even rim, middle: diagram of basal chamber, above: diagram of hydrothecal rim, G: gonotheca; H and I: Obelia geniculata: $\mathrm{H}$ : part of colony with erect unbranched stems, I: part of colony with erect branched stems (A and B after Kramp, 1959a; C to I after Cornelius, 1995). 

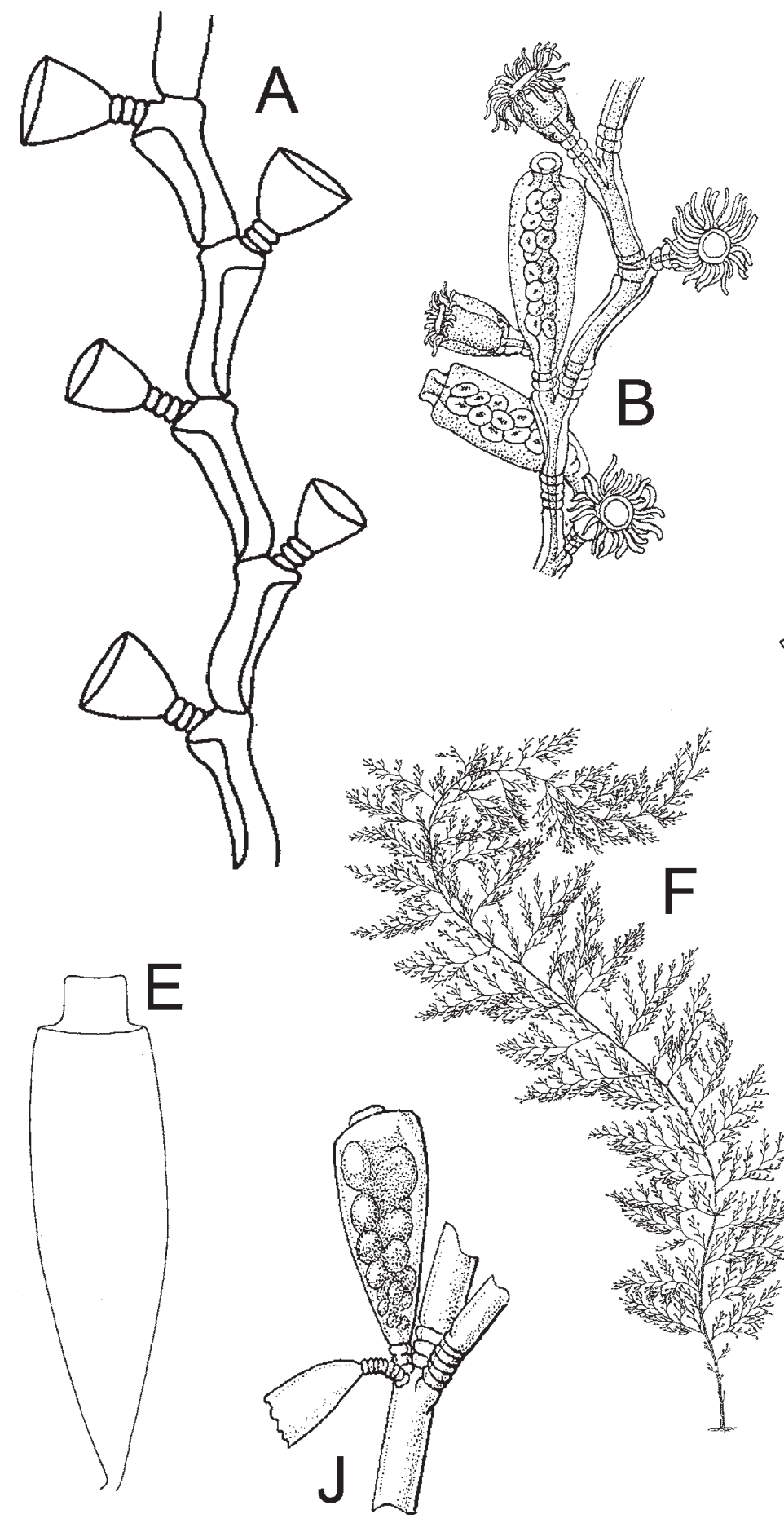
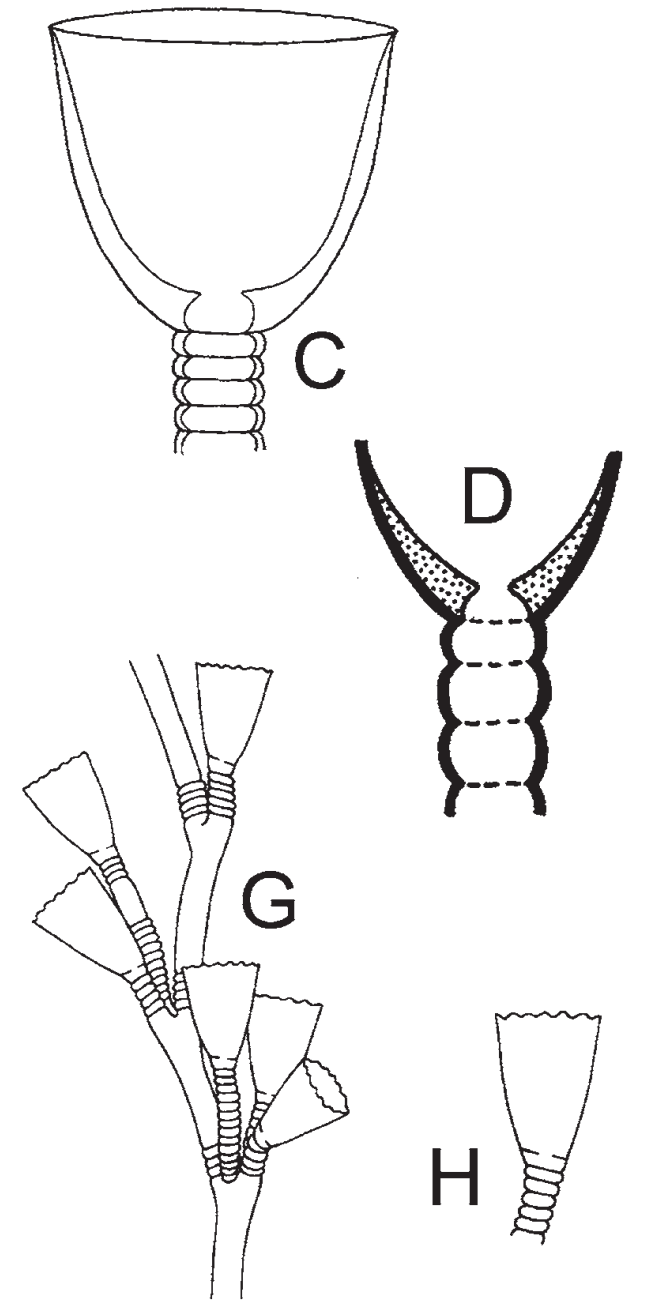

FIG. 115. - Leptomedusae. Campanulariidae. A to E: Obelia geniculata: A: detail of a part of stem, B: portion of stem with hydranths and gonothecae, C: detail of hydrotheca, D: diagram of basal chamber, E: gonotheca; F to K: Obelia longissima: F: aspect of a large colony, G: detail of a portion of branch, $\mathrm{H}$ : detail of hydrotheca, I: diagrams of hydrothecal rim and of basal chamber, J: fragment of stem with a hydrotheca and a gonotheca, K: gonotheca (A, C to H after Cornelius, 1995; B after Leloup, 1952). 

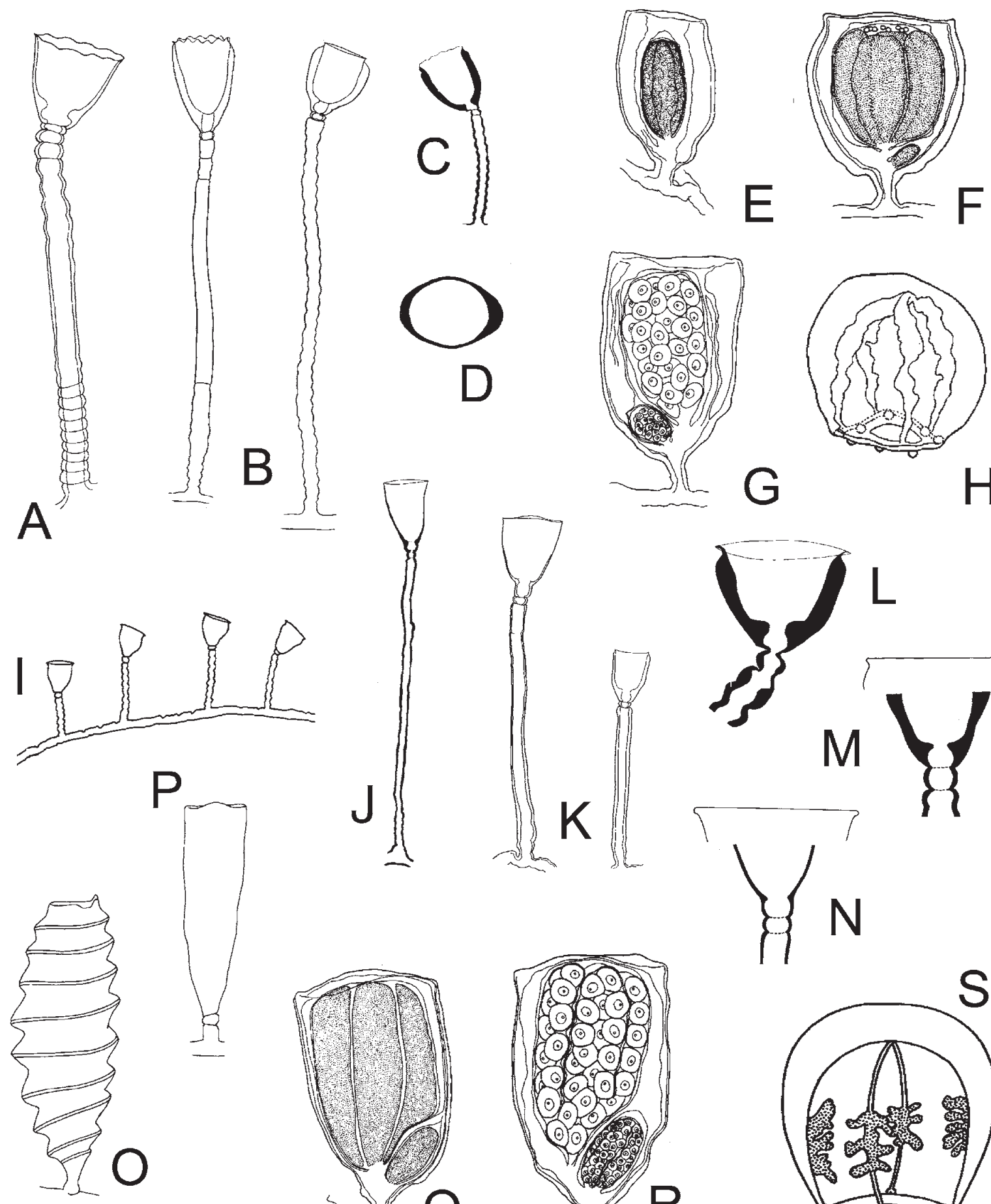

$\mathrm{H}$
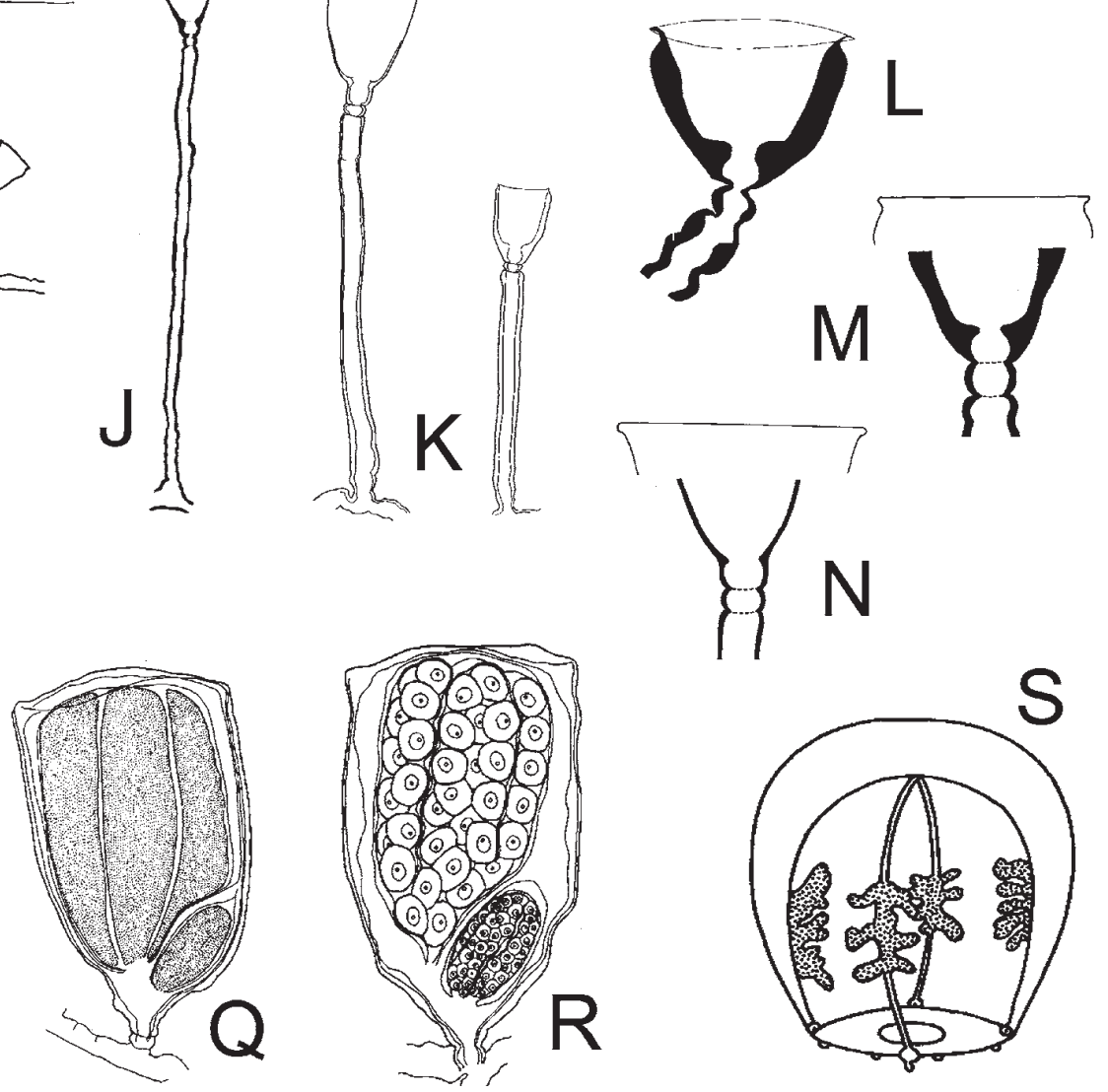

116. - Leptomedusae. Campanulariidae. A to S: Orthopyxis. A to H: Orthopyxis crenata: A and B: different views of hydrothecae and pedicels, C: detail of hydrotheca, D: transverse section of a hydrotheca, E: gonotheca with male immature gonophore, F: gonotheca containing male eumedusoid, G: gonothecae with immature female gonophore, H: spent female eumedusoid; I to S: Orthopyxis integra: I: general aspect of a part of colony, $\mathrm{J}$ and $\mathrm{K}$ : different aspects of hydrothecae and pedicels, L: detail of hydrotheca, M: diagrams of hydrothecal rim and of basal chamber of a thickened hydrotheca, N: diagrams of hydrothecal rim and of basal chamber of unthickened hydrotheca, O: grooved walled gonotheca, P: smooth walled gonotheca, Q: gonotheca with male gonophore, R: gonotheca with female gonophore, S: released eumedusoid (A after Medel and Vervoort, 2000; B, E to H, K, Q and R after Hirohito, 1995; C and D after Millard, 1975; I, M to P, S after Cornelius, 1995; J and L after Cornelius, 1982). 


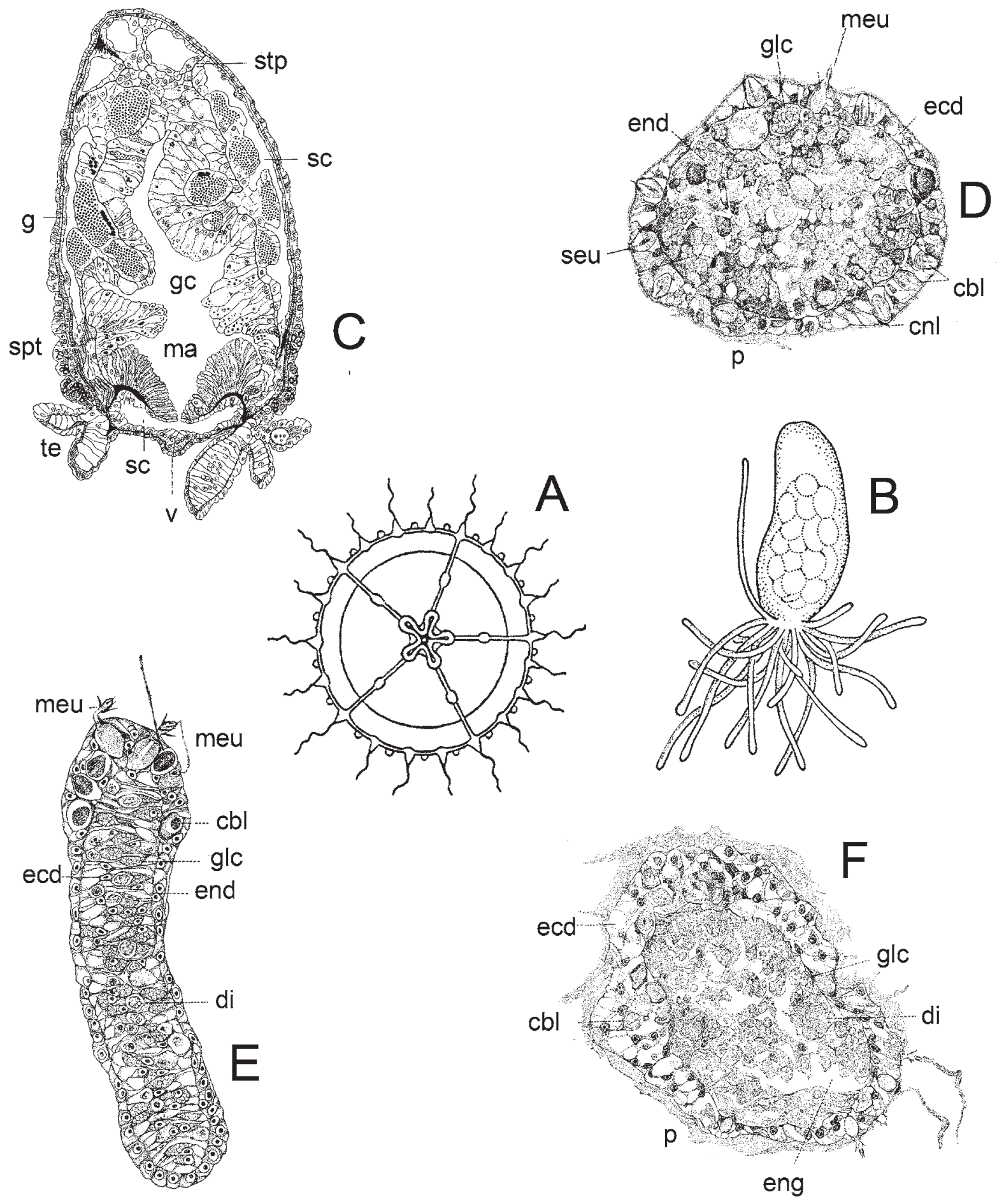

117. - Leptomedusae. Campanulariidae. A: Pseudoclytia pentata: mature medusa. Limnomedusae. Armorhydridae. B and C: Armorhydra janowiczi: B: medusa; C: longitudinal histological section of a medusa. Microhydrulidae. D and E: Microhydrula pontica: D: histological section of a polyp; E: histological section of a frustule. F: Rhaptapagis cantacuzenei, histological section of a polyp (A after Kramp, 1959a; B after Thiel, 1988; C after Lacassagne, 1968a; D to F after Bouillon and Deroux, 1967). cbl: cnidoblast; cnl: cnidocil; di: digestive inclusion; ecd: ectoderm; end: endoderm; eng: endodermal gap; g: gonads; gc: gastric cavity; glc: glandular cell, ma: manubrium; meu: microbasic eurytele; p: periderm; sc: subumbrellar cavity; seu: semiophoric eurytele; spt: septum; te: tentacle; v: velum. 

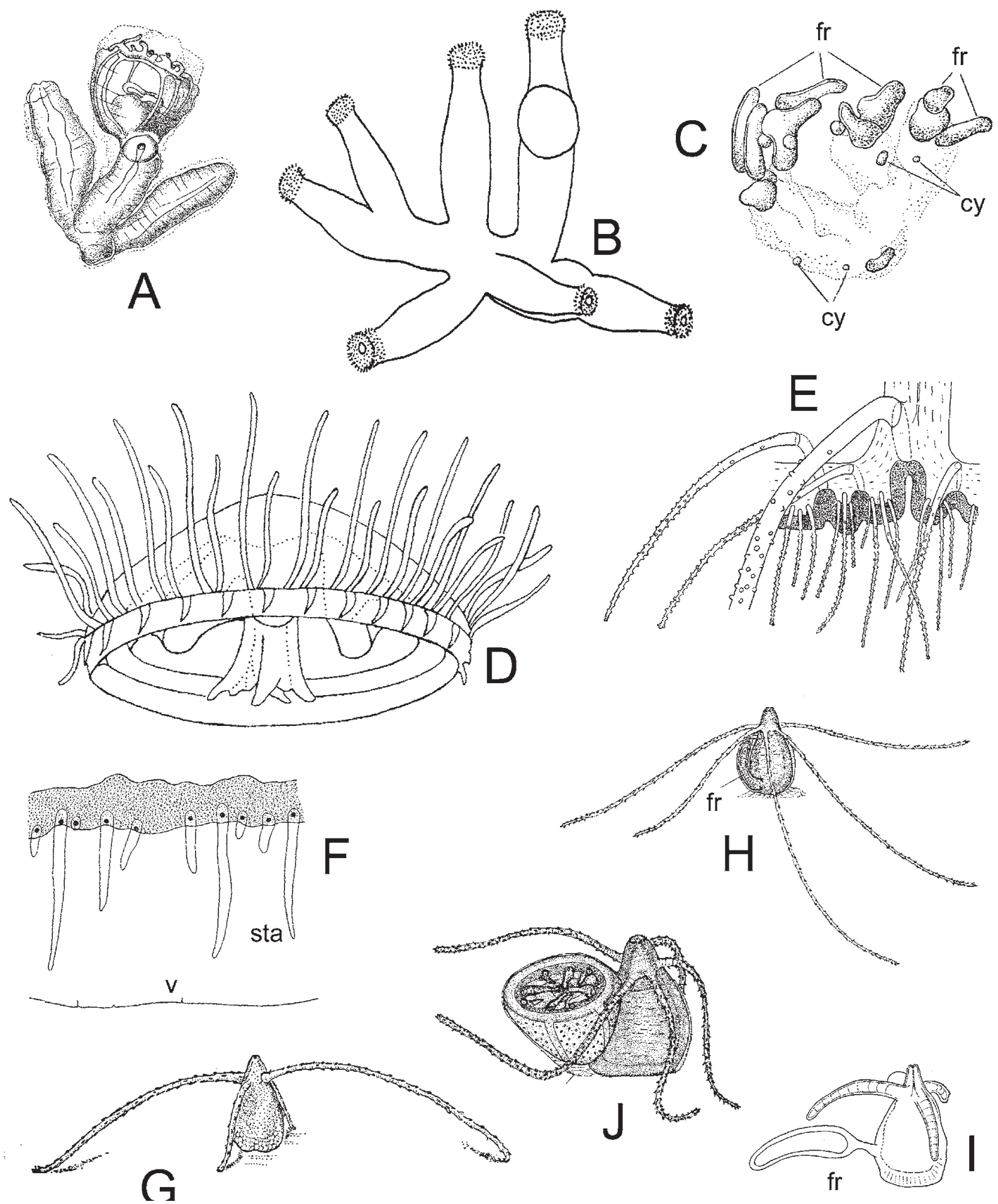

FIG. 118. - Limnomedusae. Olindiidae. A to F: Craspedacusta sowerbii: A and B: two aspects of polyp colonies with a medusa bud; C: a polyp colony reducing itself in frustules and resting stages or cysts; D: fully-grown medusa; E: portion of umbrella showing the marginal cnidocyst ring and tentacular roots; F: portion of the velum with the centripetal tubes of the statocysts. $\mathrm{G}$ to I: Gonionemus vertens: G: hydranth; H and I: two hydranths developing a fustule. J: hydranth with a medusa bud (A and C after Damas, 1939; B, E and F after Russell, 1953, D after Tardent, 1978; G and I after Leloup, 1952; H and J after Werner, 1984). cy: cyst; fr: frustule; sta: statocyst, v: velum. 

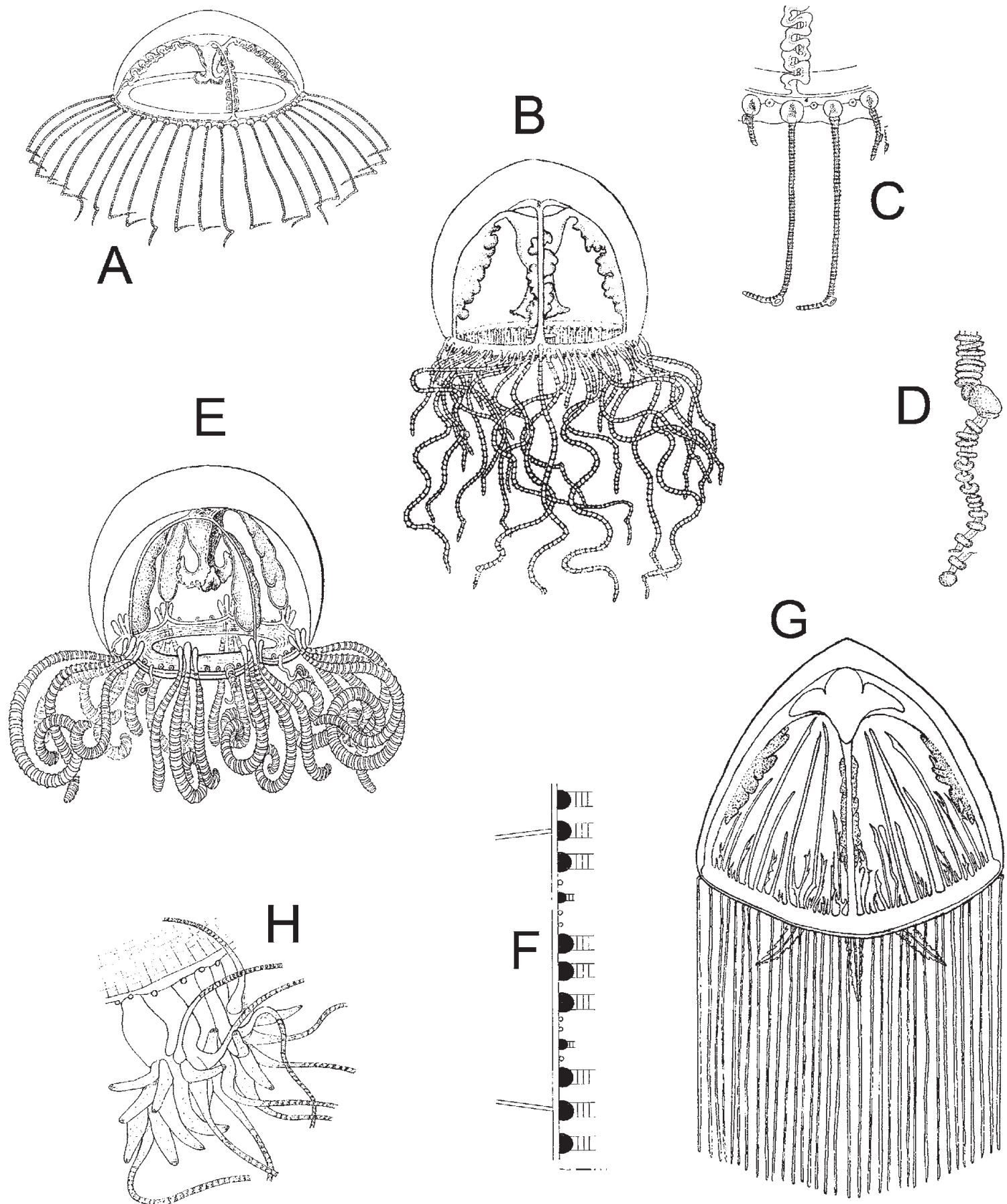

FIG. 119. - Limnomedusae. Olindiidae. A to D: Gonionemus vertens: A and B: fully-grown medusae, C: exumbrellar margin showing the statocysts, the adhesive pad and the sharply bended tentacular end, D: detail of the terminal end of a tentacle with adhesive pad; E and F: Gossea corynetes: E: mature medusa, F: schematic view of a portion of the umbrella margin sowing the disposition of the two types of tentacles and of the statocysts; G and H: Maeotias marginata (= M. inexpectata): G: whole medusa, H: portion of the umbrella margin showing the base of the oldest tentacles with the tips twitch of (A and C after Leloup, 1952; B and D after Russell, 1953; E after Mayer, 1910; F after Bouillon, 1978a; G after Borcea, 1929, H after Denayer, 1973). 

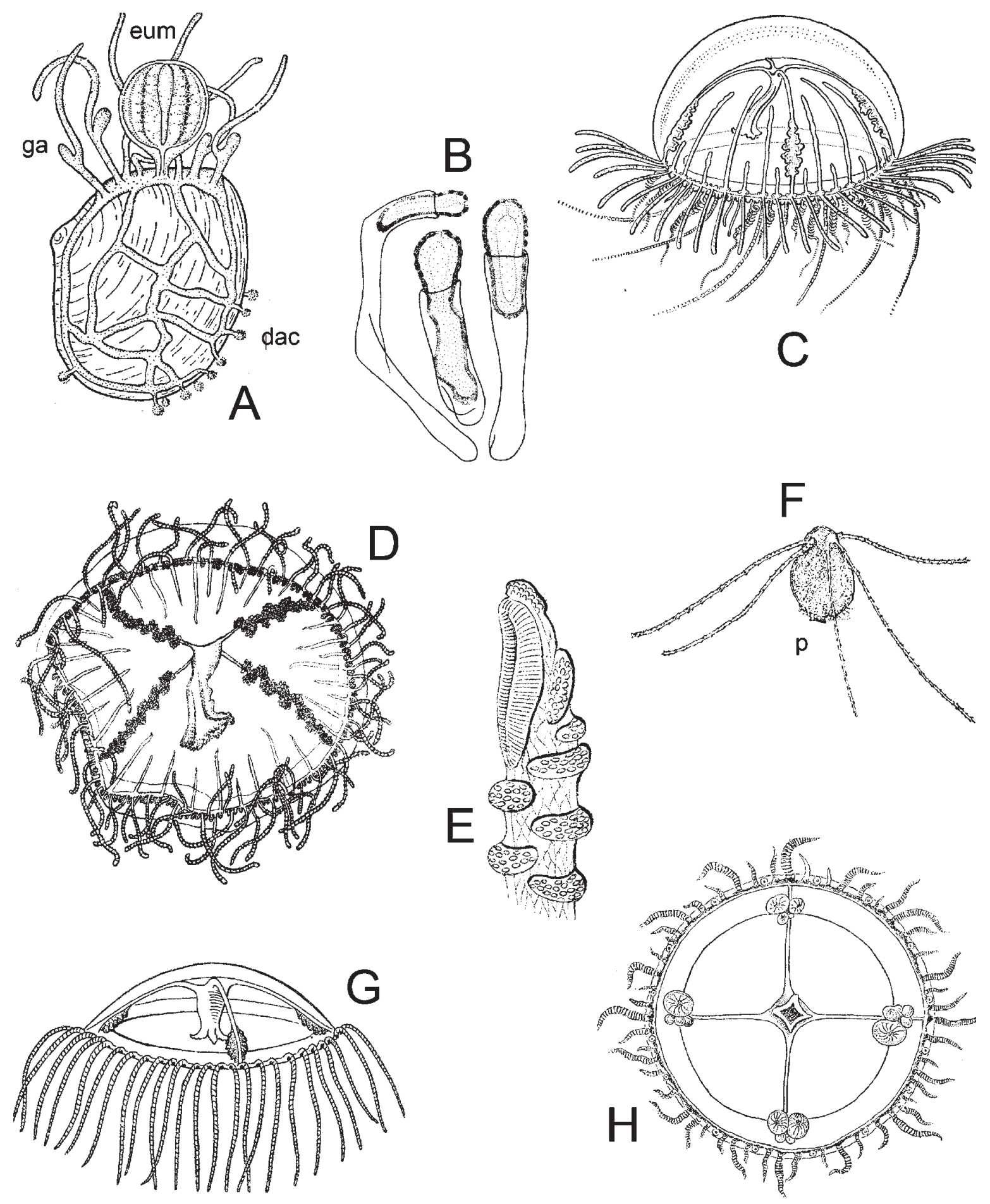

FIG. 120. - Limnomedusae. Olindiidae. A: Monobrachium parasiticum: colony with almost mature eumedusoid; B to E: Olindias phosphorica: B: hydroid, C and D: fully-grown medusae; E: adhesive pad on the aboral side of a primary tentacles. F to H: Scolionema suvaensis: F: polyp; G and H: adult medusae (A after Hand, 1957, B after Weill, 1936; C and G after Kramp, 1959a; D after Trègouboff, 1957; E and H after Mayer, 1910; F reconstruction after Goy, 1973). dac: dactylozooid; eum: eumedusoid; ga: gastrozooid; p: periderm. 

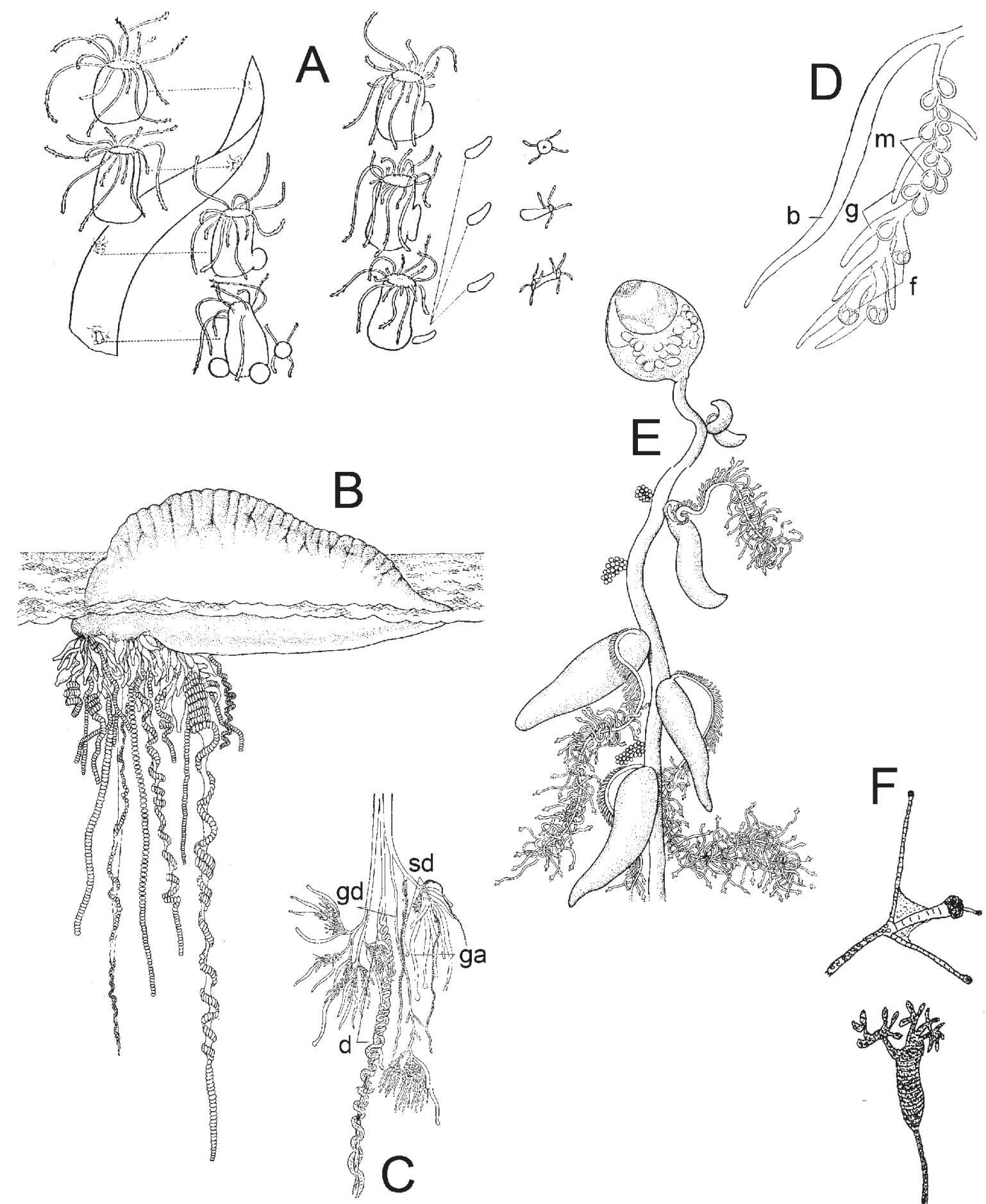

FIG. 121. - Limnomedusae. Olindiidae. A: Calpasoma dactyloptera: hydranths showing different stages of reproduction. Siphonophorae. Physaliidae. B to D: Physalia physalis: B: colony; C: cluster of persons from sexualy mature colony; D: small part of a gonodendron. Rhysophysidae. E and F: Rhizophyla filiformis: E: colony; F: tentilla (A after Matthews, 1966; B and E after Pagès and Gili, 1992; C and D after Hyman, 1940; F after Pugh, 1999). 

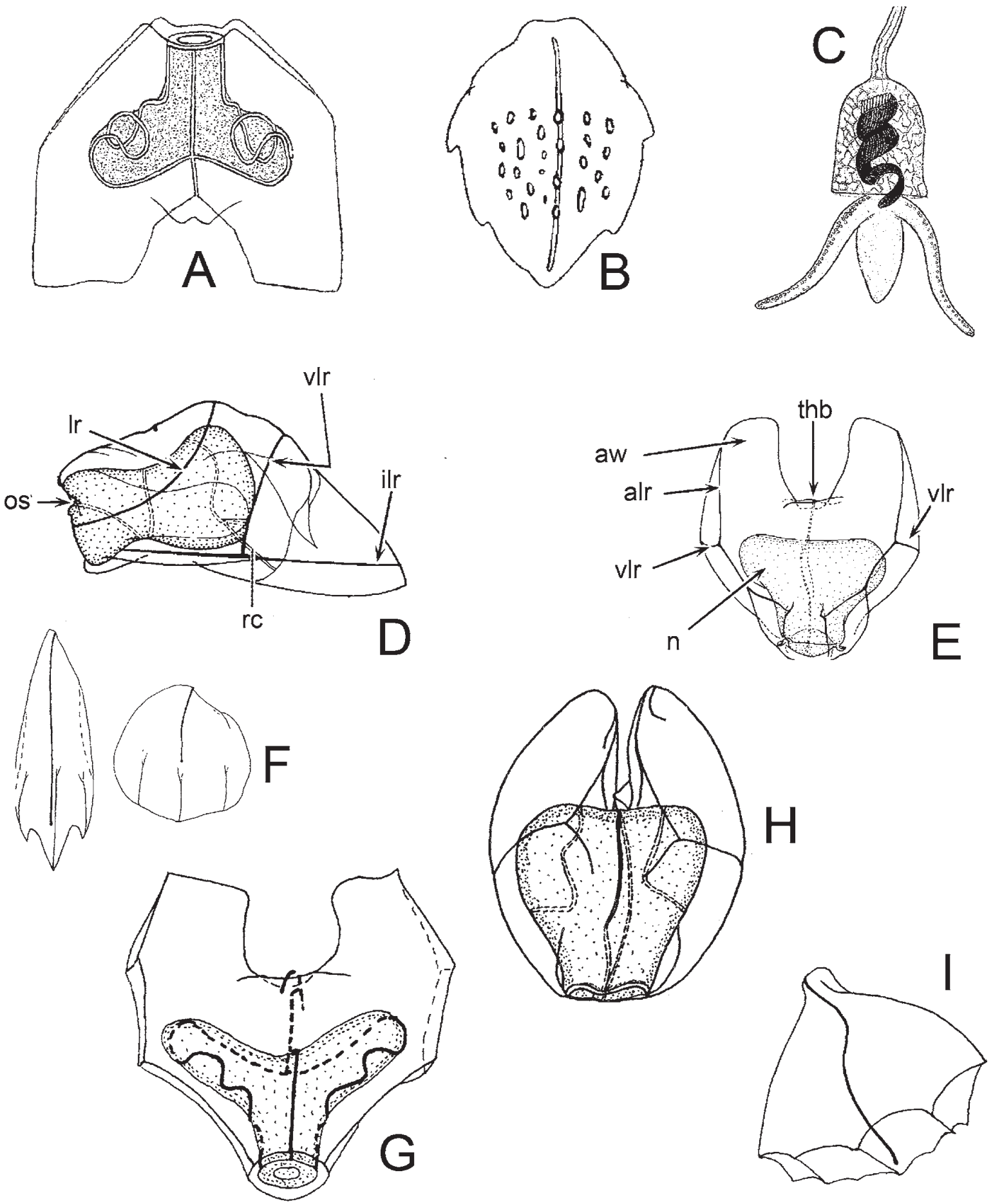

FIG. 122. - Siphonophorae. Agalmatidae. A to I: Agalma: A to C: Agalma clausi: A: nectophore; B: bract; C: tentilla. D to F: Agalma elegans: D: detail of a lateral view of a nectophore; $\mathrm{E}$ : detail of an upper view of a nectophore; F: bracts. G to I: Agalma okeni: $\mathrm{G}$ and $\mathrm{H}$ : upper and lateral view of nectophore; I: bract (A to C after Bedot, 1888; D to E after Totton, 1965; G and I after Pugh, 1999; H after Gili, 1986). alr: apico-lateral ridge; aw: apical wings; ilr: infra-lateral ridge; lr: lateral ridge; n: nectophore; os: ostium; rc: radial canal; thb: thrust block; vlr: vertical lateral ridge. 

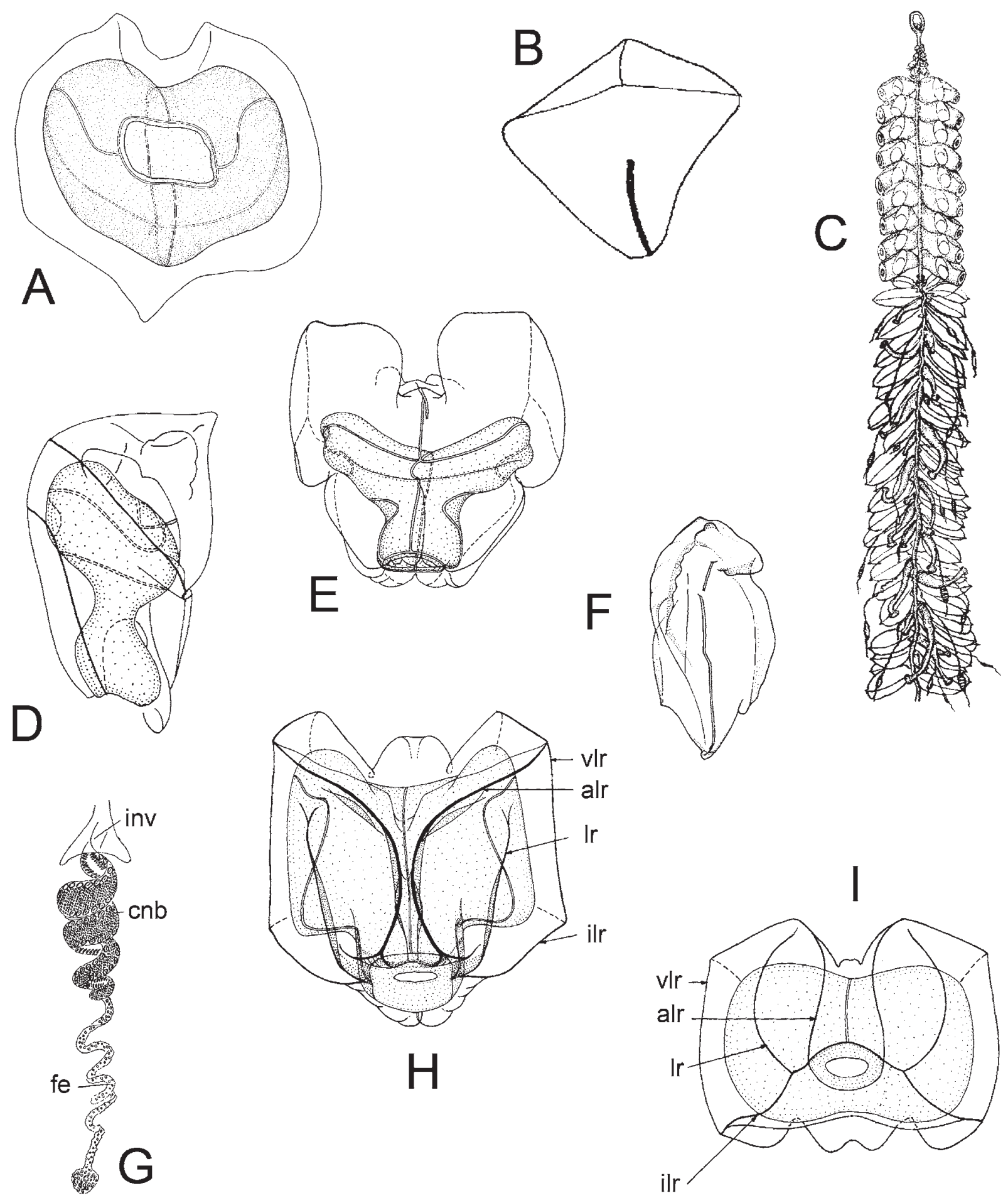

FIG. 123. - Siphonophorae. Agalmatidae. A to B: Cordalgama cordiformis: A: nectophore (ostial view); B: bract. C to G: Halistemma rubrum: C: polygstric stage; D: nectophore (lateral view); E: nectophore (from below); F: bract; G: tentillum. H and I: Lychnagalma utricularia: H: nectophore (upper dorsal view); I: nectophore (ostial view) (A after Pagès and Gili, 1992; C after Trègouboff, 1957; B, D to F after Pugh, 1999; G after Hyman, 1940, H and I after Pugh and Harbison, 1986). alr: apico-lateral ridge; cnb: cnidoband; fe: end of the tentillium filament; ilr: infr-lateral ridge; inv: involucrum; lr: lateral ridge; vlr: vertical lateral ridge. 

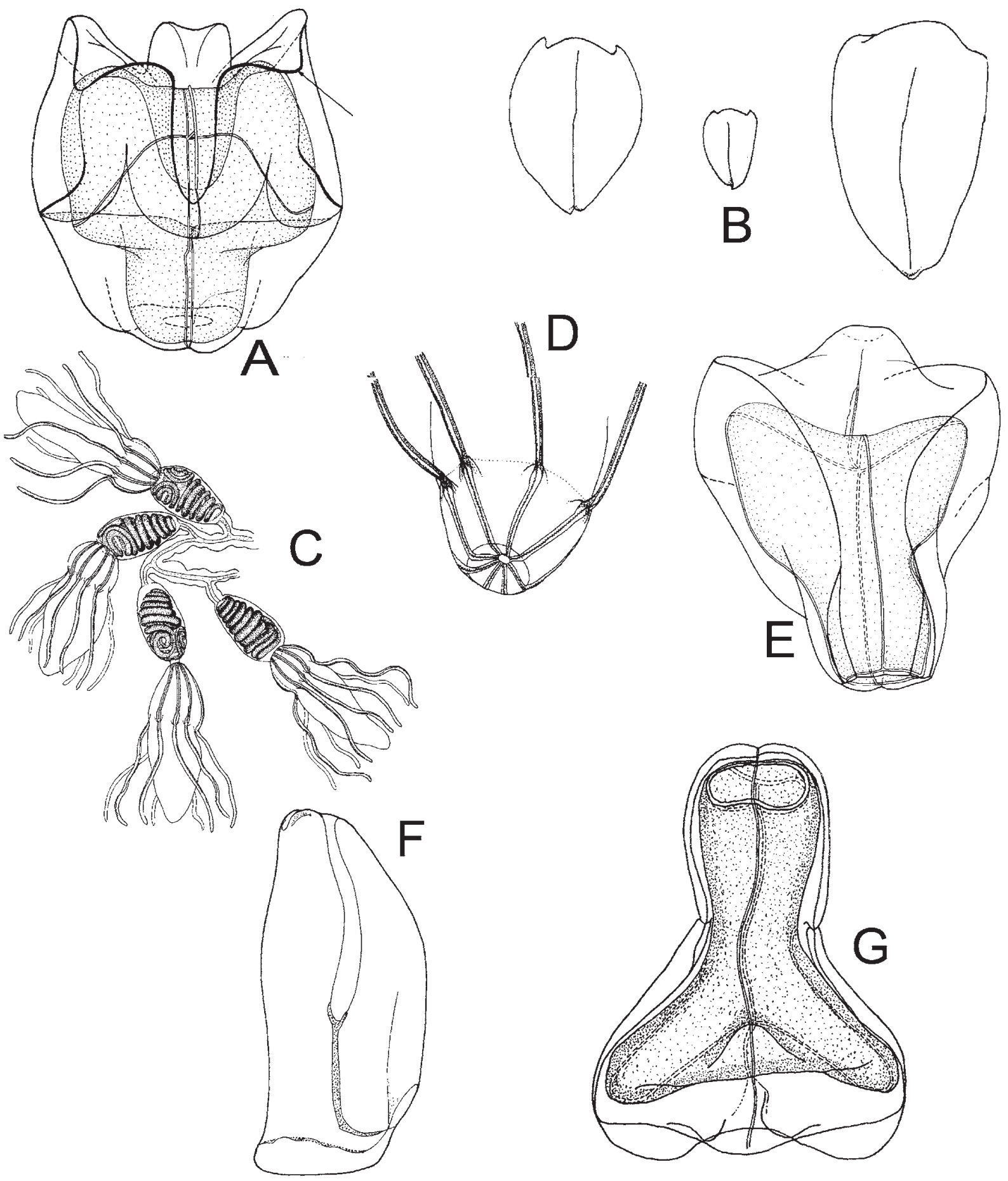

FIG. 124. - Siphonophorae. Agalmatidae. A to D: Lychnagalma utricularia. A: nectophore (lower ventral view), B: bracts (Lychnalgama spp.), C: general view of four tentilla, note the coiled cnidoband enclosed within the involucrum and the terminal vesicle, D: detail of base of a detached terminal vesicle showing the octoradial filaments. E to F: Marrus orthocanna: E: upper view of nectophore, F: lateral view of nectophore, G: bract (A to D after Pugh and Harbison, 1986; E and F after Pugh, 1999; G after Gili, 1986). 

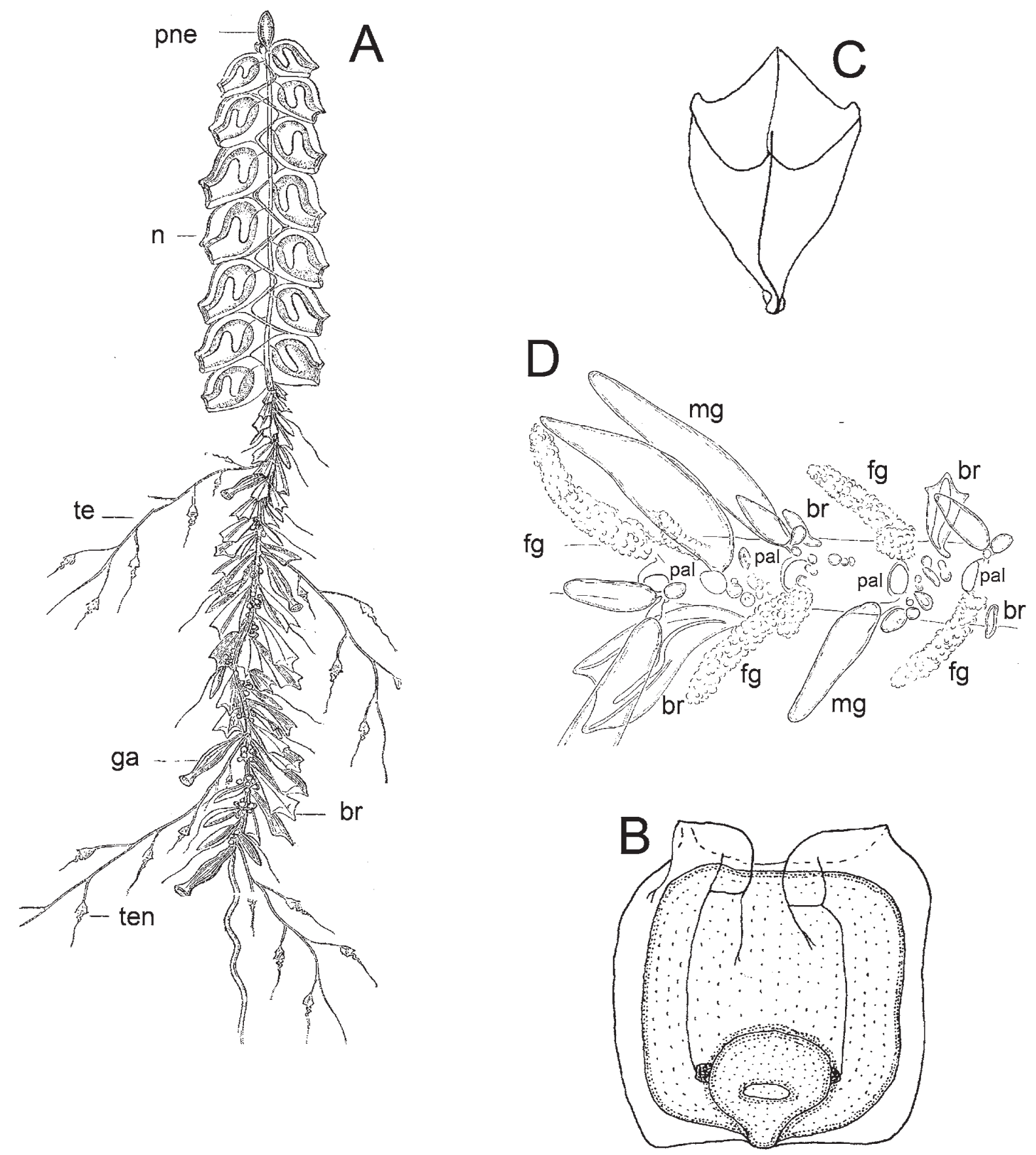

FIG. 125. - Siphonophorae. Agalmatidae. A to D: Nanomia bijuga: A: polygastric stage; B: upper view of nectophore; C: bract; D: part of an internode of the stem showing alternating male and female gonodendra arising from the base of a series of palpons. (A and D after Totton, 1965; B and C after Pugh, 1999); br: bract; fg: female gonophore; ga: gastrozooid; mg: male gonophore; n: nectophore; pal: palpon; pne: pneumatophore; te: tentacle; ten: tentilla. 

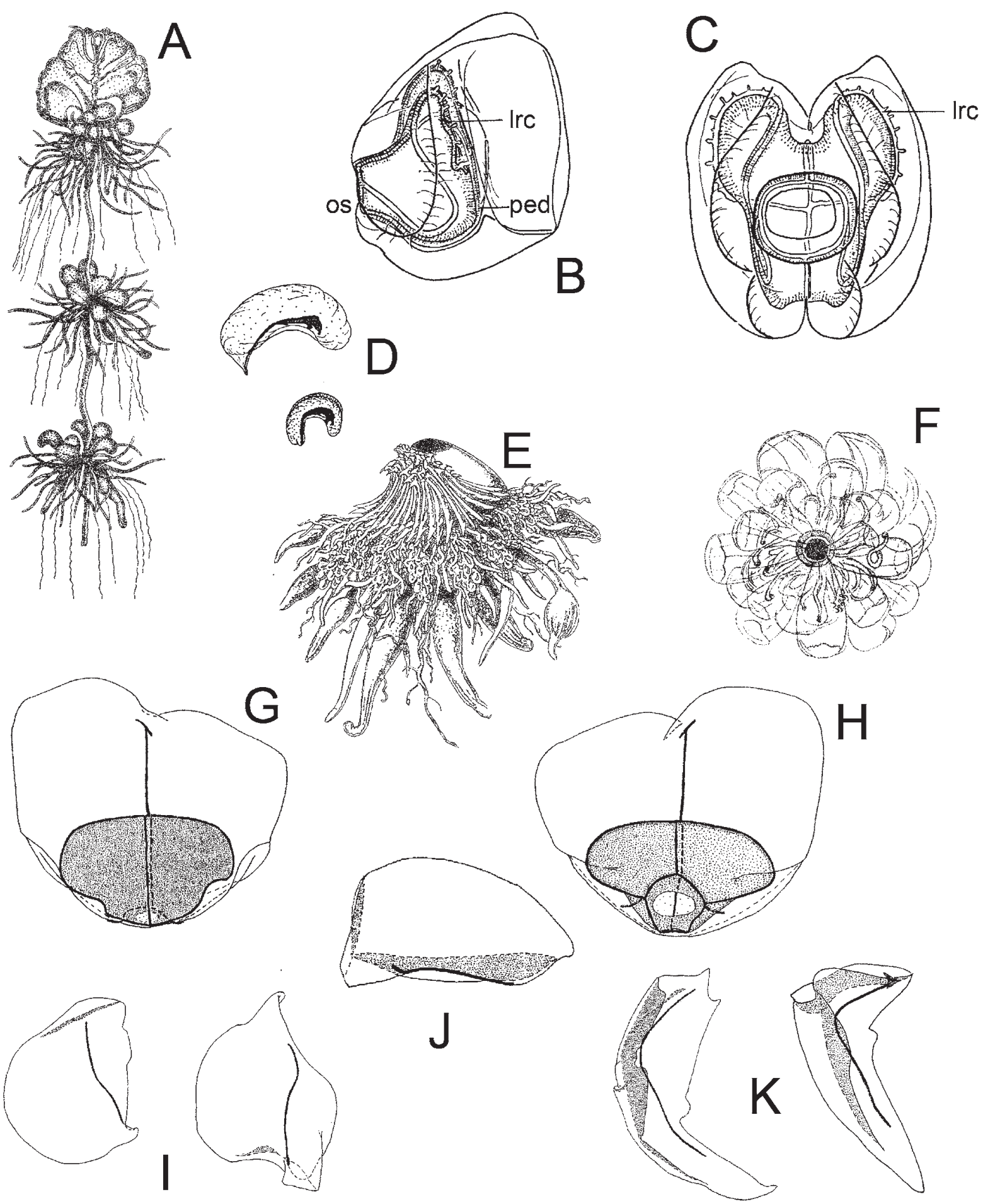

FIG. 126. - Siphonophorae. Apolemiidae. A to D: Apolemia uvaria: A: polygastric stage; B: nectophore (lateral view); C: nectophore (ostial view); D: bracts. Athorybiidae. E and F: Athorybia rosacea: E: polygastric stage (lateral view); F: dorsal view of a polygastric stage. Forskaliidae. G to K: Forskalia asymmetrica: G and H: inner and outer view of nectophores; I: inner and outer view of stem bratcs; J: inner view of bolster bract; K: inner view of knee-shaped bracts (A to D after Totton, 1965; E after Pugh, 1999; F after Trègouboff, 1957; G to K after Pugh, 2003). lrc: lateral radial canal; os: ostium; ped: peduncle. 

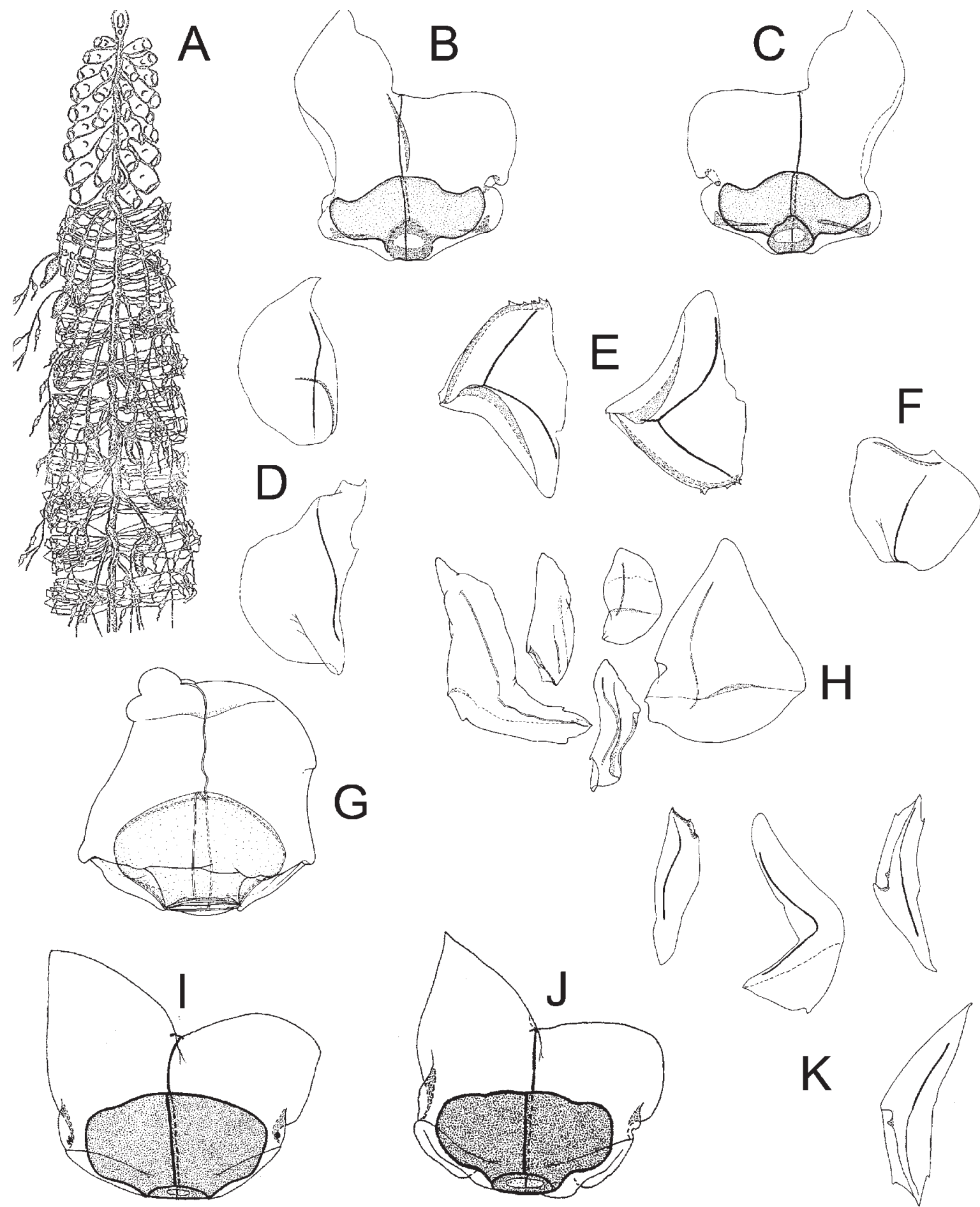

127. - Siphonophorae. Forskaliidae. A to K: Forskalia. A to F: Forskalia contorta: A: polygastric stage, B: nectophore (upper view), C: nectophore (inner view), D: stem bracts, E: knee bracts, F: third type of bract; G and H: Forskalia edwardsi: G: nectophore (upper view), H: variuos types of bracts; I to K: Forskalia formosa: I: nectophore (upper view), J: nectophore (lower view), K: various types of bracts (A after Trègouboff, 1957, B to F, I to K after Pugh, 2003; G and H after Kirkpatrick and Pugh, 1984). 


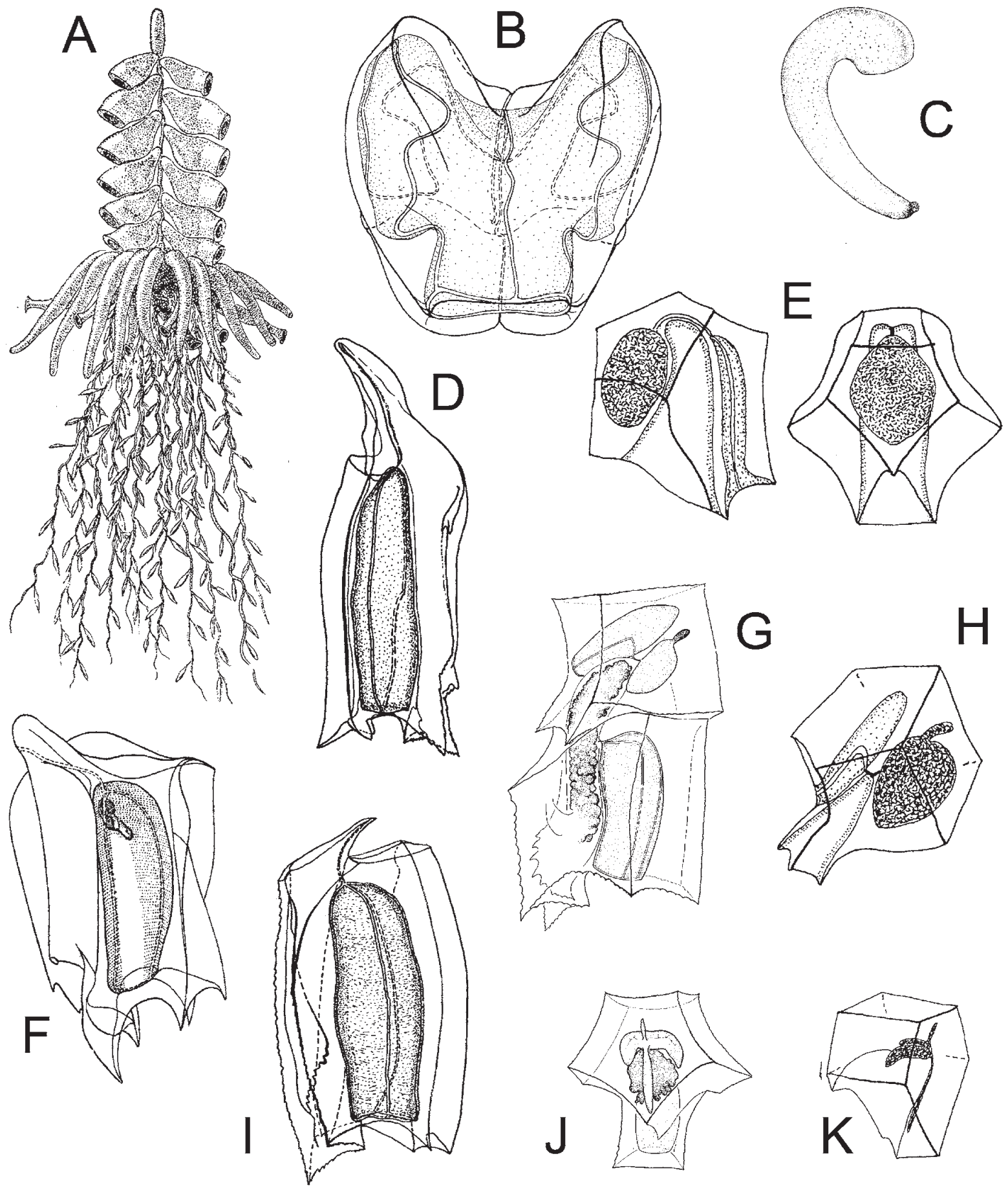

FIG. 128. - Siphonophorae. Physophoridae. A to C: Physophora hydrostatica: A: polygastric stage, B: nectophore (upper view), C: palpon Abylidae. D to F: Abyla haeckeli: D: posterior nectophore, E: ventral and lateral views of anterior nectophore, F: eudoxid; G to K: Abylopsis eschscholtzi: G: polygastric stage (lateral view), H: anterior nectophore, I: posterior nectophore, J: eudoxid, K: bract. (A to C after Kirkpatrick and Pugh, 1984; D and I after Gili, 1986; E, H and K after Pugh, 1999; F after Totton, 1965; G and J after Pagès and Gili, 1992). 
A
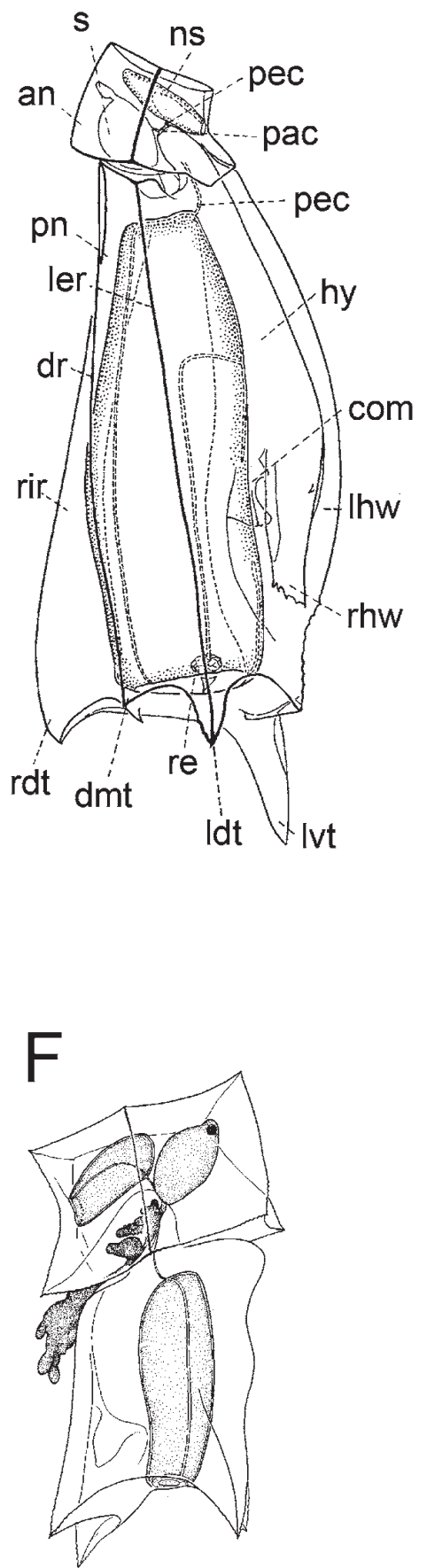
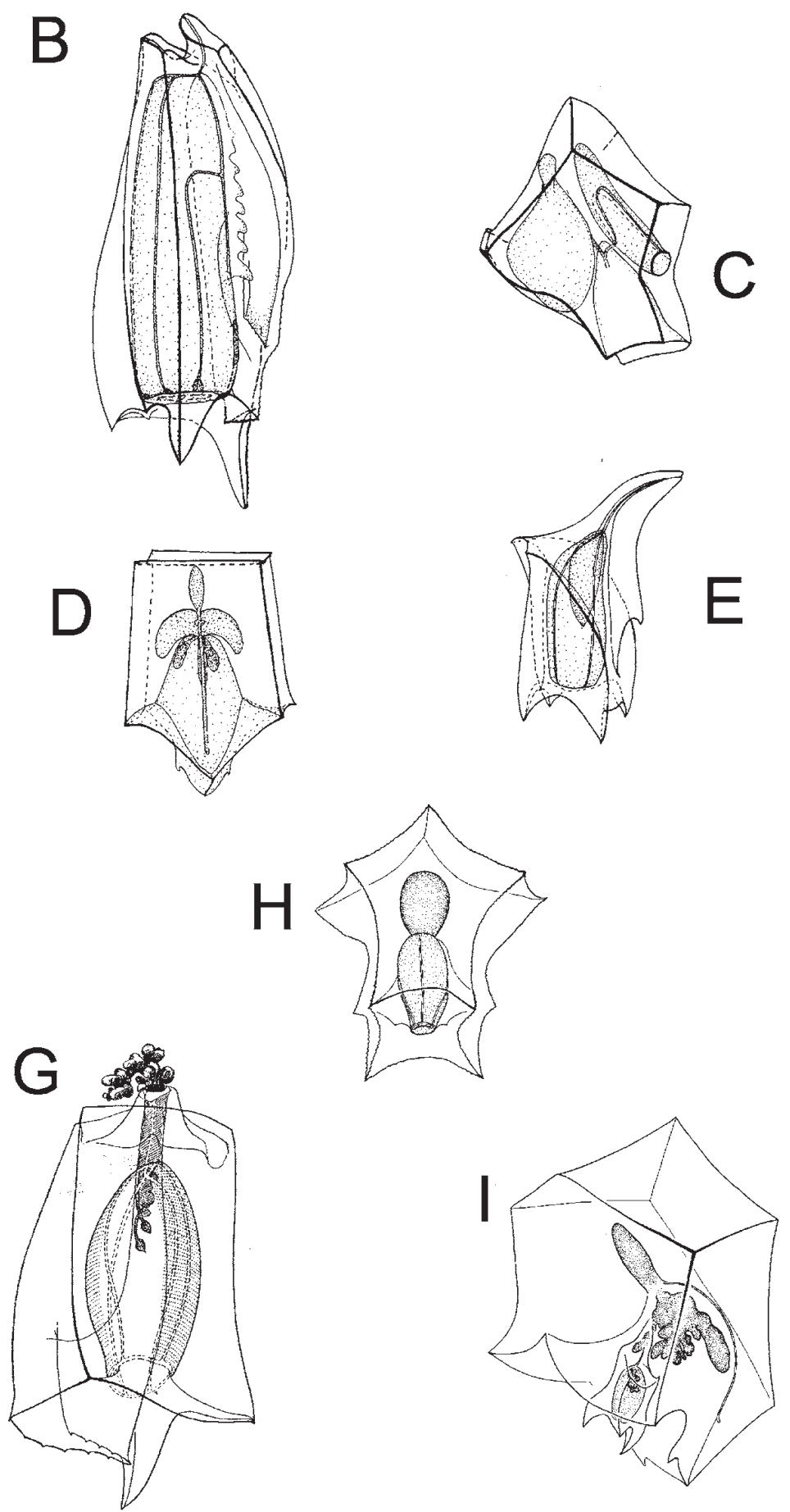

FIG. 129. - Siphonophorae. Abylidae. A to E: Abylopsis tetragona: A: polygastric stage; B: posterior nectophore; C: anterior nectophore; D: eudoxid bract; E: gonophore. F to I: Bassia bassensis: F: polygastric stage (lateral view); G: polygastric stage (dorsal view); H: anterior nectophore (dorsal view); I: eudoxid (latero-ventral view) (A and G after Totton, 1965; B to E after after Kirckpatrick and Pugh, 1984; F, H and I after Pagès and Gili, 1992). an: anterior nectophore; com: comb; dmt: dorso median tooth; dr: dorsal ridge; hy: hydroecium; ldt: left dorsal tooth; ler: left ridge; lhw: left hydroecial wing; lvt: left ventral tooth; ns: nectosac; pac: pallial canal; pec: pedicular canal; pn: posterior nectophore; rdt: right dorsal tooth; re: rete; rhw: right hydroecial wing; rir: right ridge; s: somatocyst. 

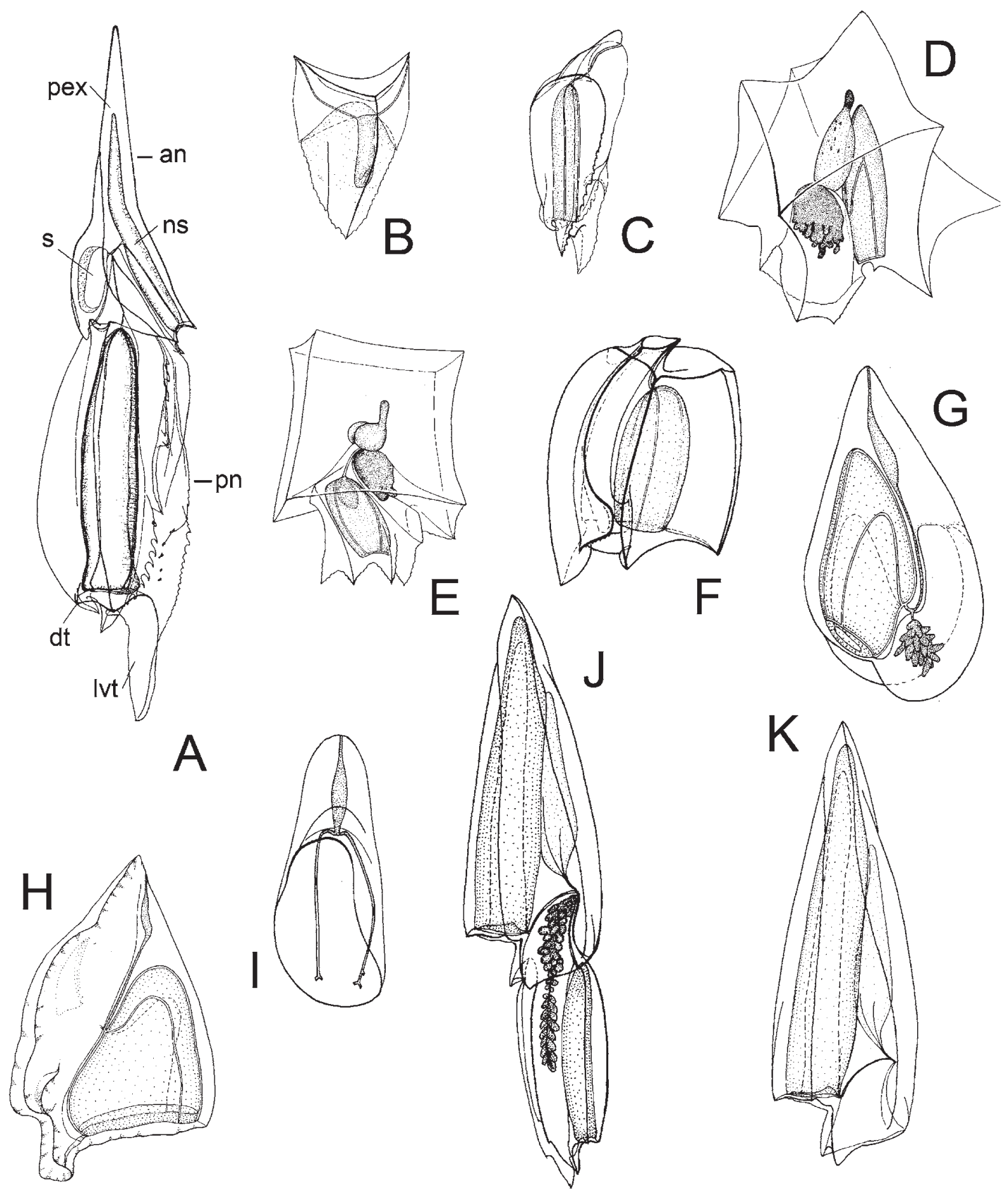

FIG. 130. - Siphonophorae. Abylidae. A to C: Ceratocymba sagittata: A: polygastric stage; B: eudoxid bract; C: gonophore. D to F: Enneagonum hyalinum: D: polygastric stage (lateral view); E: eudoxid bract (lateral view), F: gonophore. Clausophyidae. G to I: Clausophyes ovata: G: anterior nectophore; H: posterior nectophore; I: eudoxid bract. Diphyidae. J and K: Chelophyes appendiculata: J: polygastric stage; K: anterior nectophore (A after Totton, 1965; B, C, F to K after Kirckpatrick and Pugh, 1984; E, D, after Pagès and Gili, 1992). an: anterior nectophore; dt: dorsal tooth; lvt: left ventral tooth; ns: nectosac; pex: pyramidal extension; pn: posterior nectophore; s: somatocyst. 

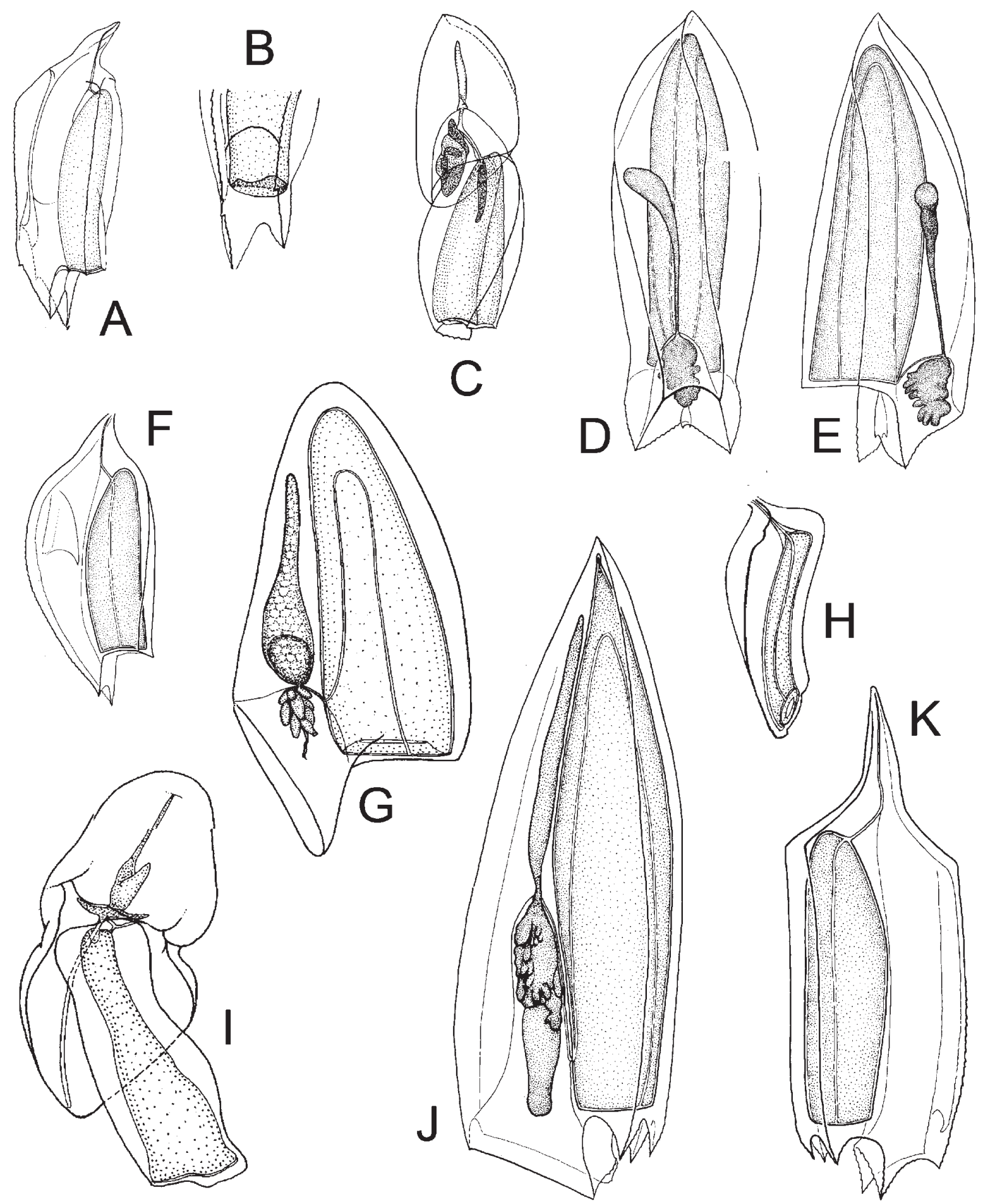

FIG. 131. - Siphonophorae. Diphyidae. A to C: Chelophyes appendiculata: A: posterior nectophore, B: detail of mouth-plate of posterior nectophore (dorsal view), C: eudoxid stage (dorsal view); D to F: Chelophyes contorta: D: anterior nectophore (ventral view), E: anterior nectophore (lateral view), F: posterior nectophore; G to I: Dimophyes arctica: G: anterior nectophore, H: posterior nectophore, I eudoxid stage; J and K: Diphyes bojani: J: anterior nectophore (lateral view), K: posterior nectophore (lateral view). (A, B, C, G to I after Kirkpatrick and Pugh, 1984; D to F, J and K after Pagès and Gili, 1992). 

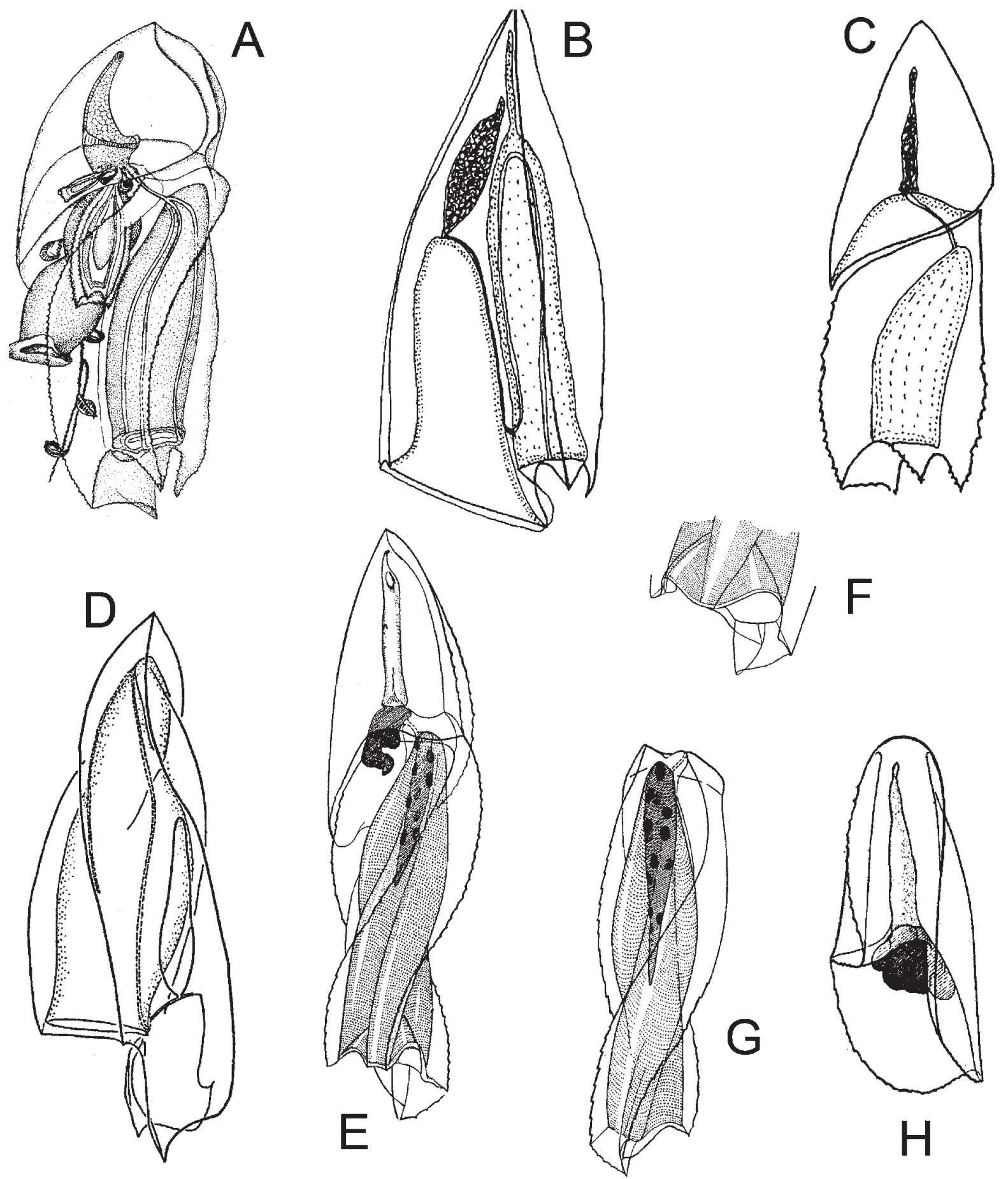

FIG. 132. - Siphonophorae. Diphyidae. A to C: Diphyes dispar: A: polygastric phase, B: anterior nectophore (lateral view), C: bract with gonophore; D to H: Eudoxoides spiralis: D: polygastric stage, E. lateral view of a whole animal, F: enlarged view of the base of figure $\mathrm{E}$ G: lateral view of a detached femelle gonophore, H: ventral view of the bract (A after Trègouboff, 1957; B and C after Pugh, 1999; D to H after Totton, 1965). 

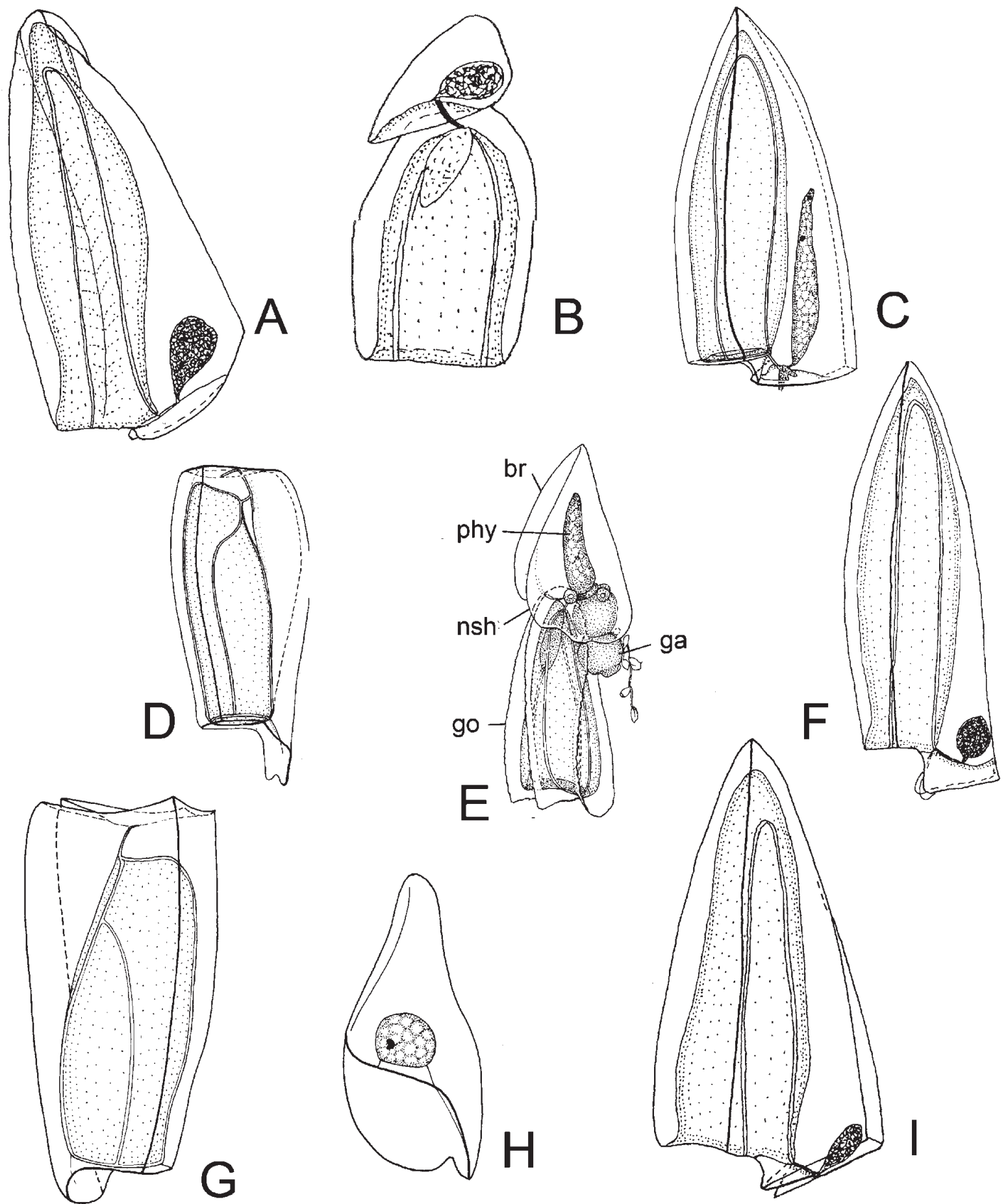

FIG. 133. - Siphonophorae. Diphyidae. A to I: Lensia: A and B: Lensia campanella: A: anterior nectophore (lateral view); B: bract with gonophore. C to E: Lensia conoidea: C: anterior nectophore; D: posterior nectophore; E: eudoxid stage (lateral view). F to H: Lensia fowleri: F: anterior nectophore; G: posterior nectophore; H: eudoxid bract (lateral view). I: Lensia hotspur: anterior nectophore (lateral view) (A, B and I after Pugh, 1999; C to H after Kirkpatrick and Pugh, 1984). br: bract; ga: gastrozooid; go: gonophore; nsh: neck-shield; phy: phyllocyst. 

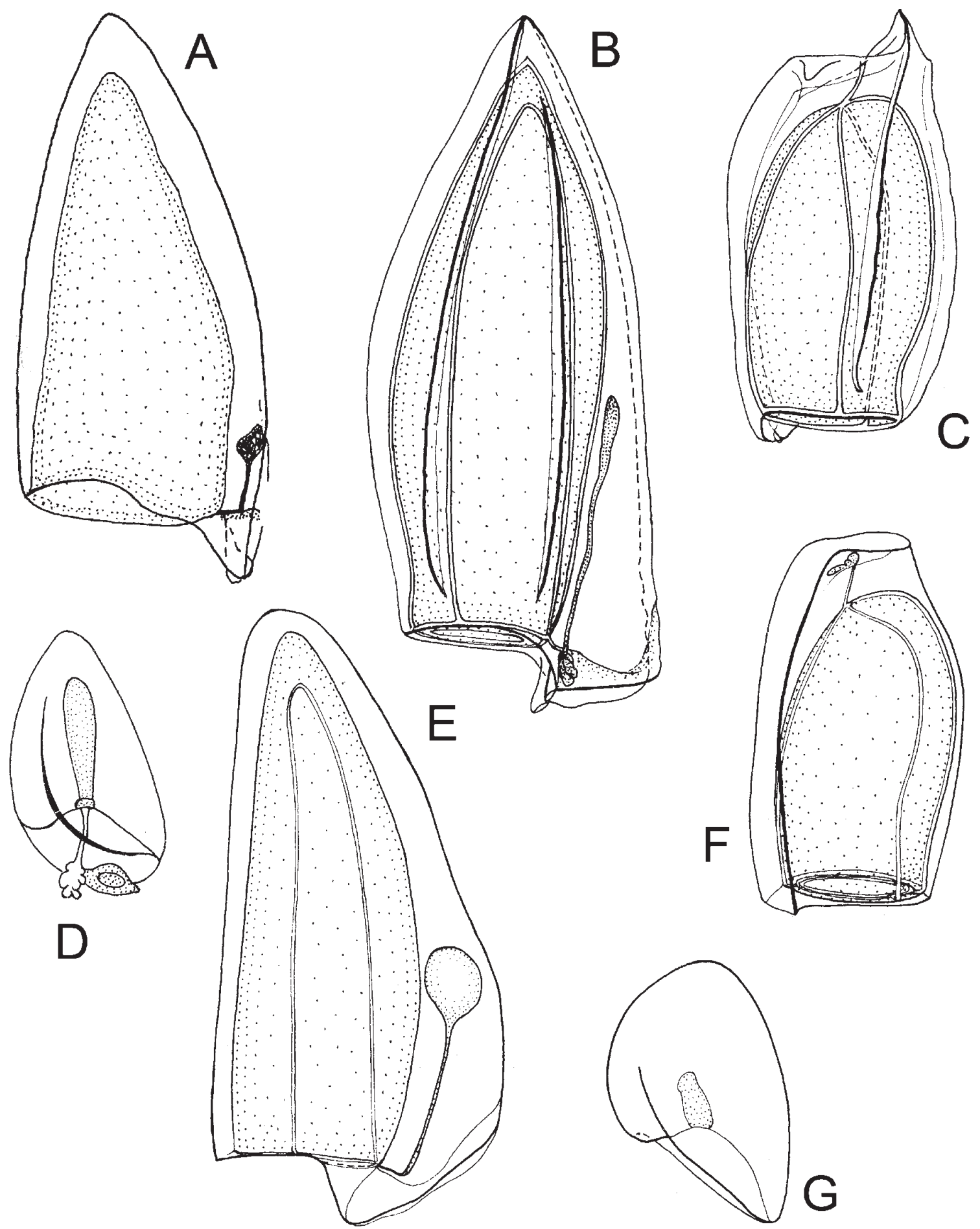

FIG. 134. - Siphonophorae. Diphyidae. A to F: Lensia: A: Lensia meteori: anterior nectophore (lateral view); B to D: Lensia multicristata: B: anterior nectophore, C: posterior nectophore, D: eudoxid bract (all lateral view). E to G: Lensia subtilis: E: anterior nectophore, F: posterior nectophore, G: eudoxid bract (all lateral view) (all after Kirkpatrick and Pugh, 1984). 

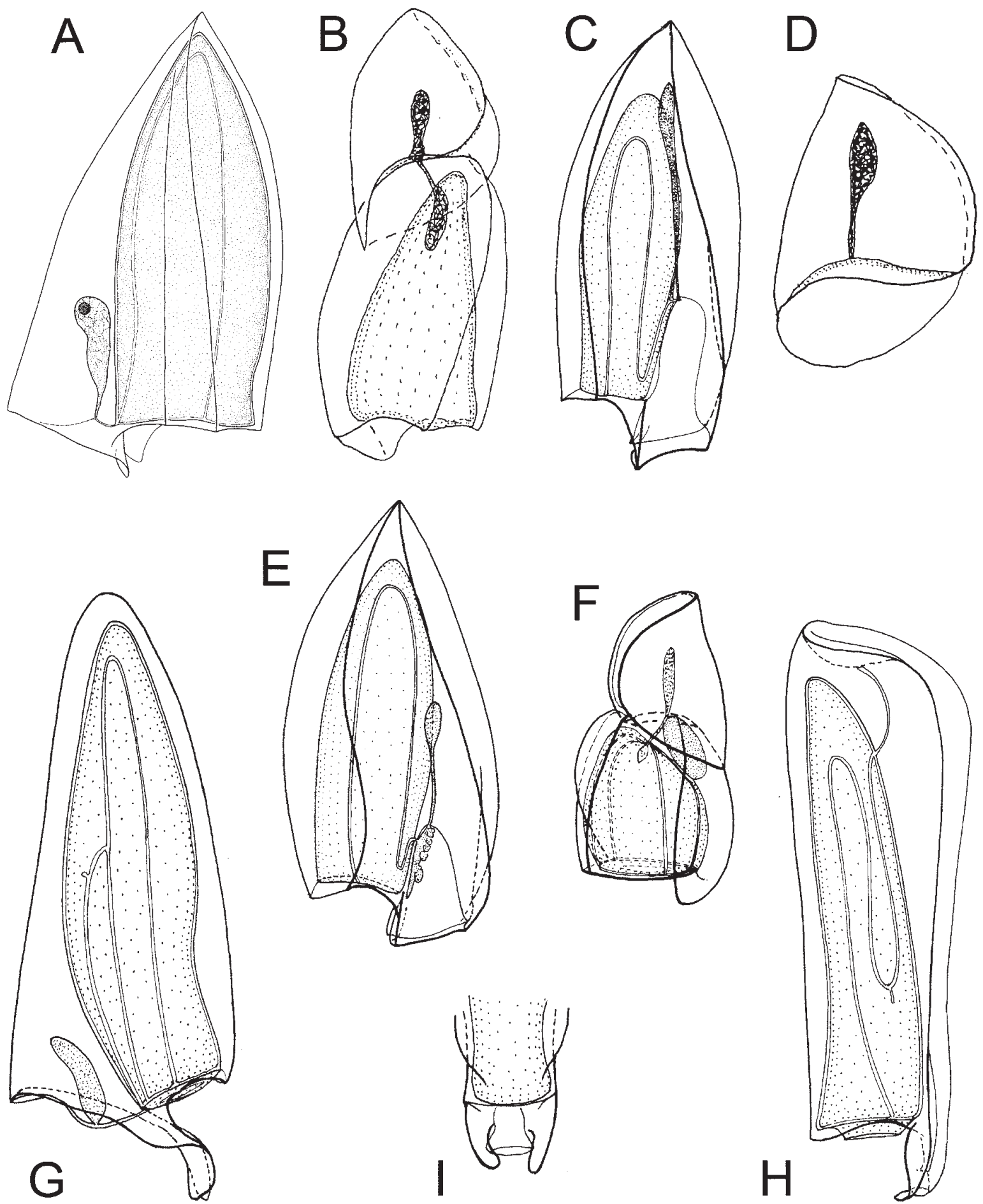

FIG. 135. - Siphonophorae. Diphyidae. A and B: Lensia subtiloides: A: anterior nectophore (lateral view), B: bract with gonophore; C to F: Muggiaea: C and D: Muggiaea atlantica: C: anterior nectophore (lateral view), D: bract; E: Muggiaea kochi: E: anterior nectophore, F: Muggiaea sp.: eudoxid stage (all lateral view); G to I: Sulculeolaria. G to I: Sulculeolaria biloba: G: anterior nectophore (lateral view), H: posterior nectophore (lateral view), I: mouth-plate, detail of H (dorsal view) (A after Pagès and Gili, 1992; B and D after Pugh, 1999; C, E, F to I after Kirkpatrick and Pugh, 1984). 

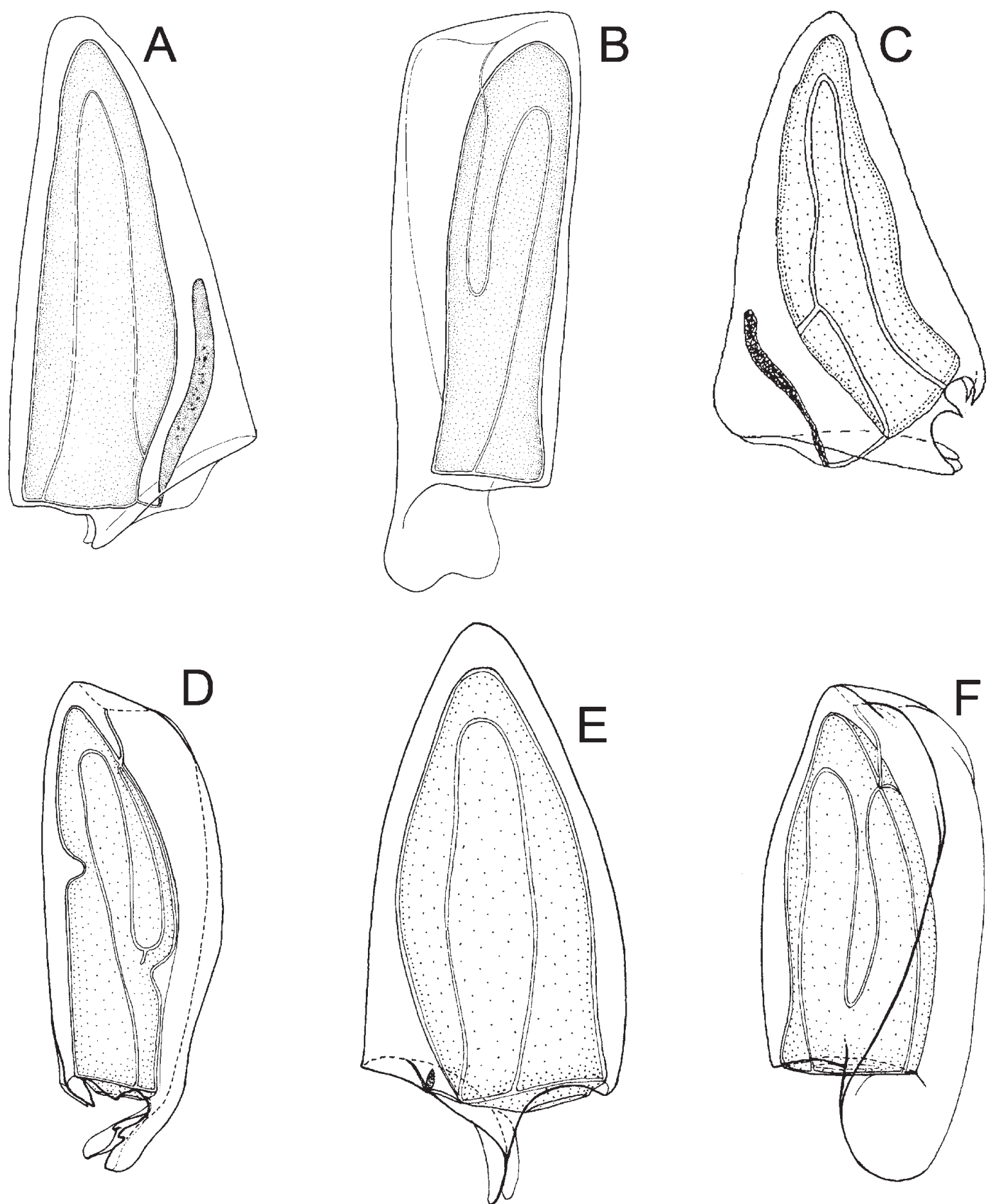

FIG. 136. - Siphonophorae. Diphyidae. A to F: Sulculeolaria. A and B: Sulculeolaria chuni: A: anterior nectophore, B: posterior nectophore (lateral views); C and D: Sulculeolaria quadrivalvis: C: anterior nectophore, D: posterior nectophore (lateral views); E and F: Sulculeolaria turgida: E: anterior nectophore, F: posterior nectophore (lateral views) (A and B after Pagès and Gili, 1992; C to F after Kirkpatrick and Pugh, 1984). 

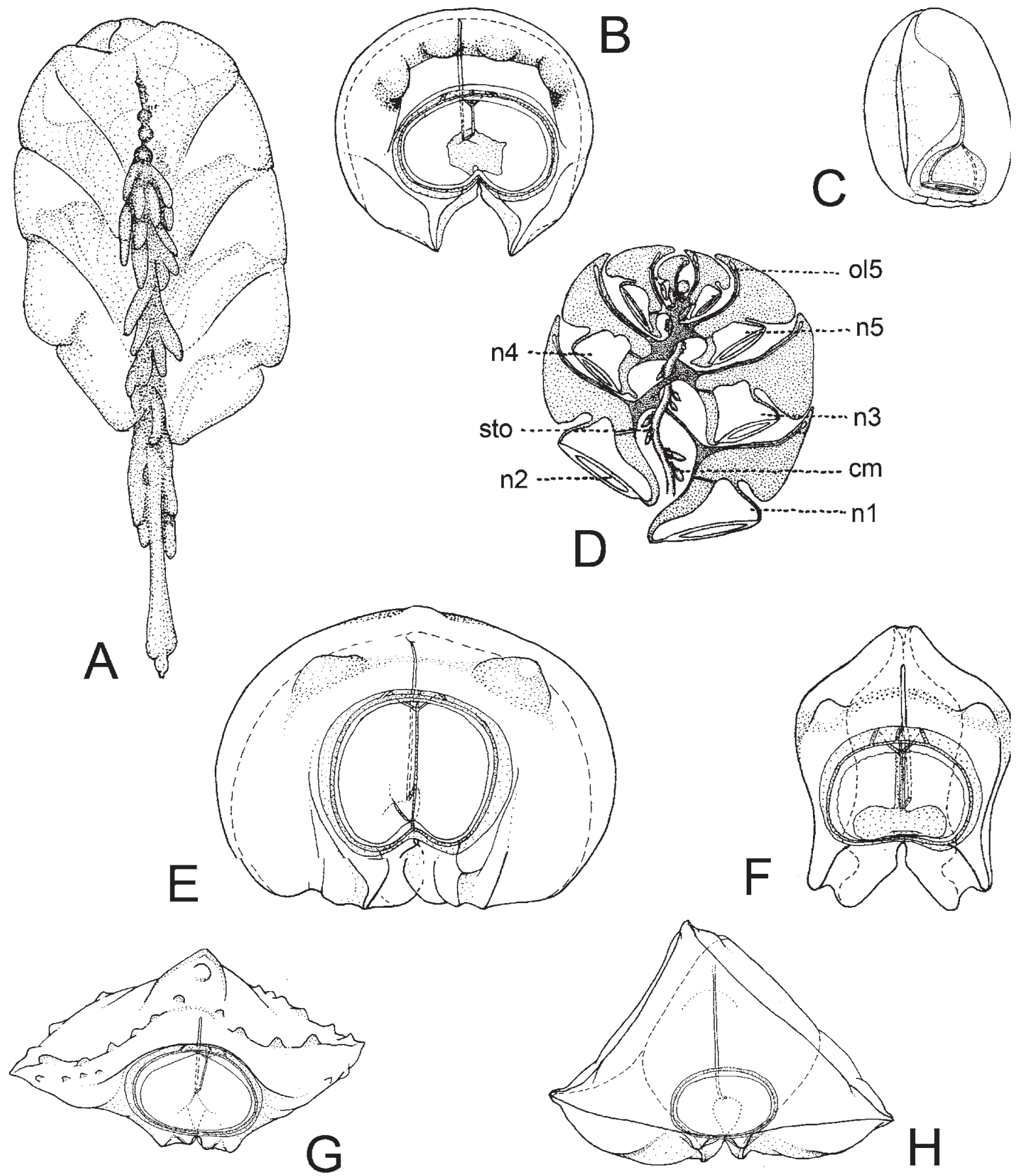

FIG. 137. - Siphonophorae. Hippopodiidae. A to D: Hippopodius hippopus: A: polygastric stage; B: definitive nectophore; C: larval nectophore; D: schema of the disposition of the nectophores in a colony. E to H: Vogtia: E and F: Vogtia glabra: E: definitive nectophore (dorsal view); F: young stage; G: Vogtia pentacantha: definitive nectophore (dorsal view); H: Vogtia serrata: definitive nectophore (dorsal view) (A to C, E to H after Kirkpatrick and Pugh, 1984; D after Trègouboff, 1957). cm: cormidia; n1, n2, n3, n4, n5: nectophores; ol5: oleocyte of nectophore; sto: stolon. 


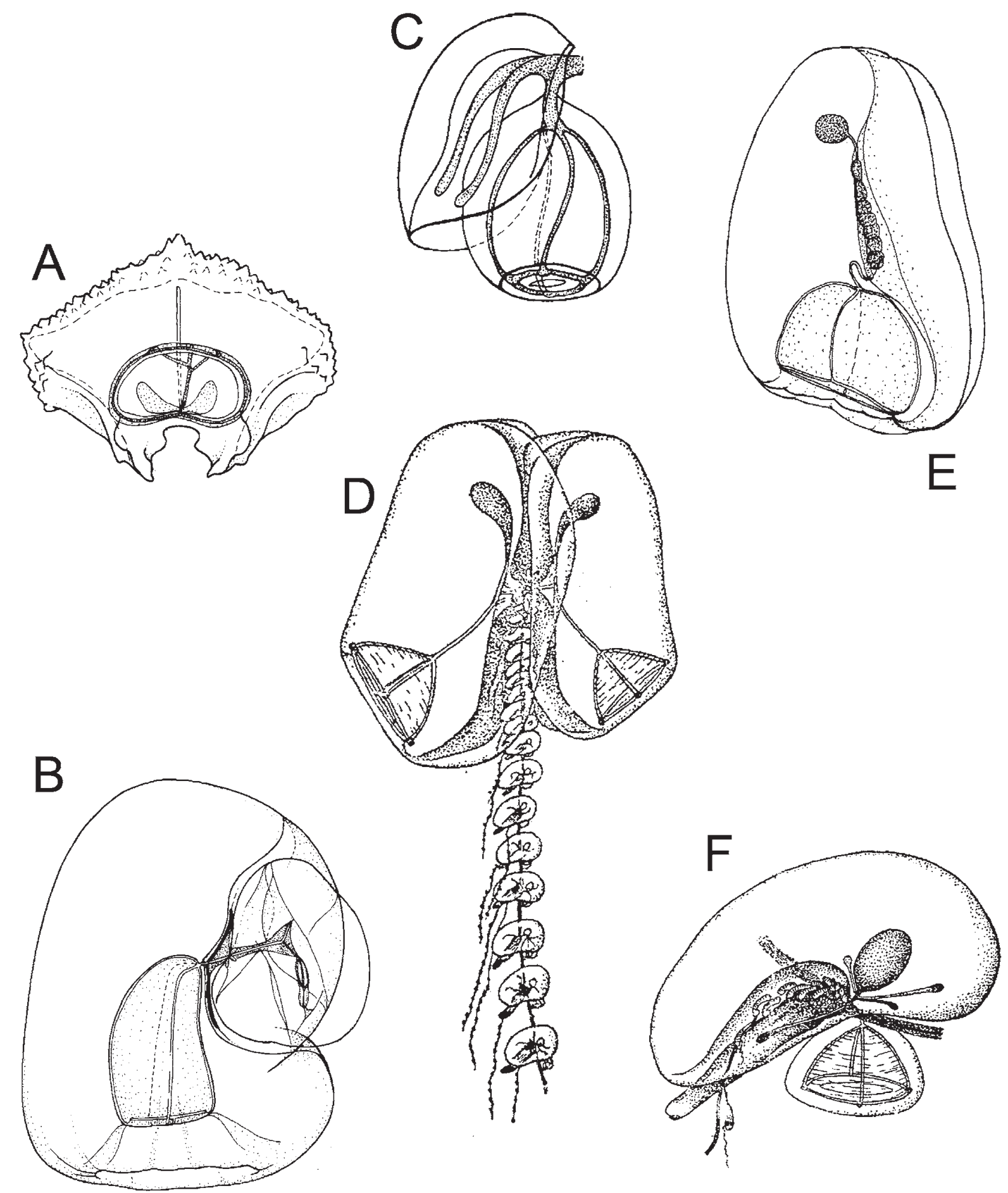

FIG. 138. - Siphonophorae. Hippopodiidae. A: Vogtia spinosa, definitive nectophore, (dorsal view). Prayidae. B and C: Amphicaryon acaule: B: nectophores of polygastric stage, C: eudoxid stage; D to F: Desmophyes annectens: D: polygastric stage, E: nectophore (lateral view), F: eudoxid bract with gonophore. (A to C, E after Kirkpatrick and Pugh, 1984; Dand F after Kawamura, 1915). 


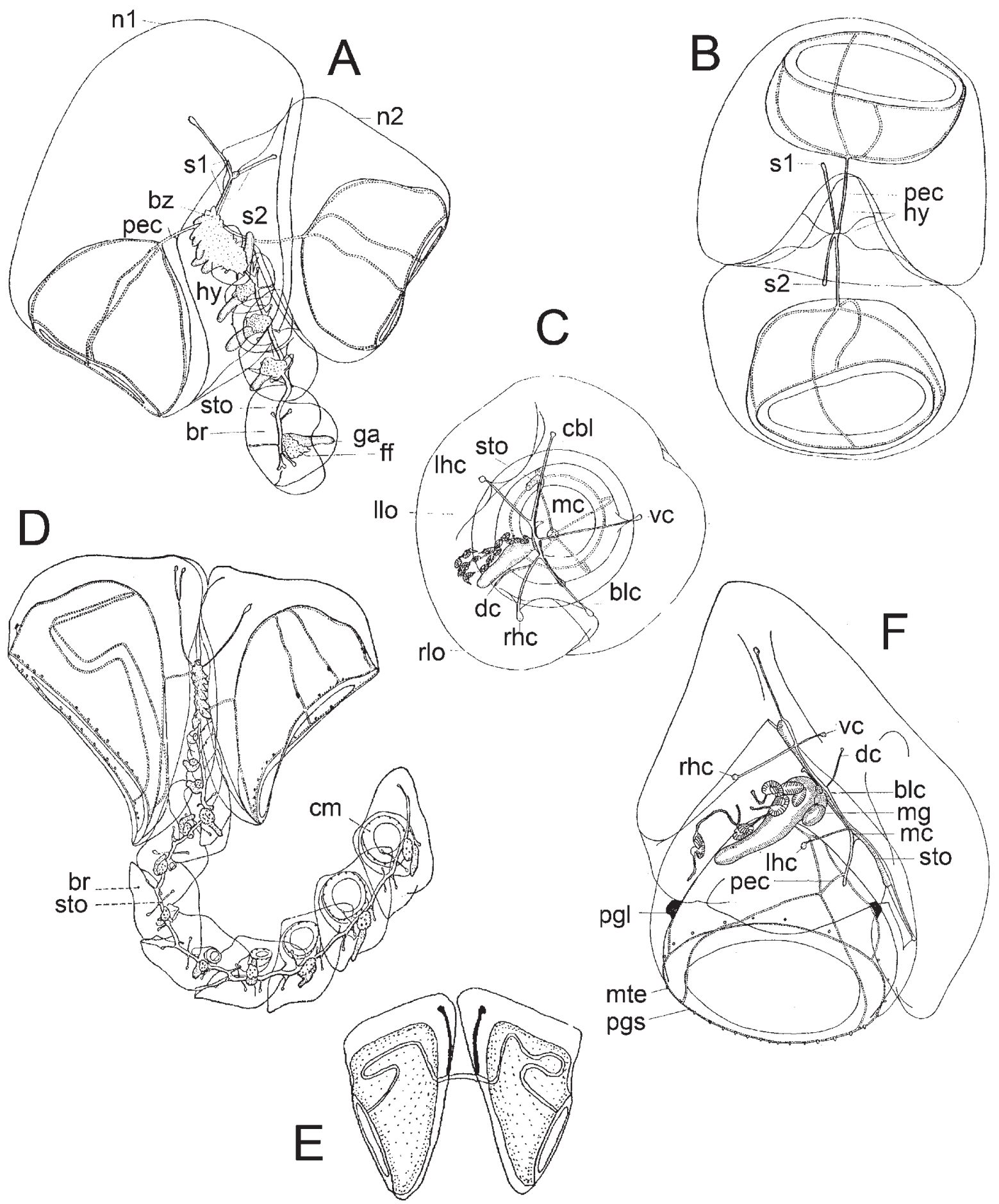

FIG. 139. - Siphonophorae. Prayidae. A to C: Desmophyes villafranca: A: polygastric stage; B: nectophores (apical view); C: cormidia (apical view). D to F: Lilyopsis rosea: D: polygastric stage, E: nectophore (lateral view); F: male cormidia detached of the stolon (A to c after Carrè, C 1969a; D to F after Carrè Cand Carrè D, 1995). bz: budding zone; br: bract; pec: pedicular canal; blc: bracteal longitudinal canal; dc: dorsal canal; rhc: right hydroecial canal; lhc: left hydroecial canal; cm: cormidia; vc: ventral canal; ff: fishing filament; ga: gastrozooid; $\mathrm{mg}$ : male gonophore; mc: mantel canal; vc: ventral canal; hy: hydroecium; llo: left lobe; rlo: right lobe; n1 and n2:nectophores 1 and 2; pgl: pigmentary lamella; mte: marginal tentacle; s1: somatocyst of nectophore 1; s2:somatocyst of nectophore 2; pgs: pigmentary spot; sto: stolon. 

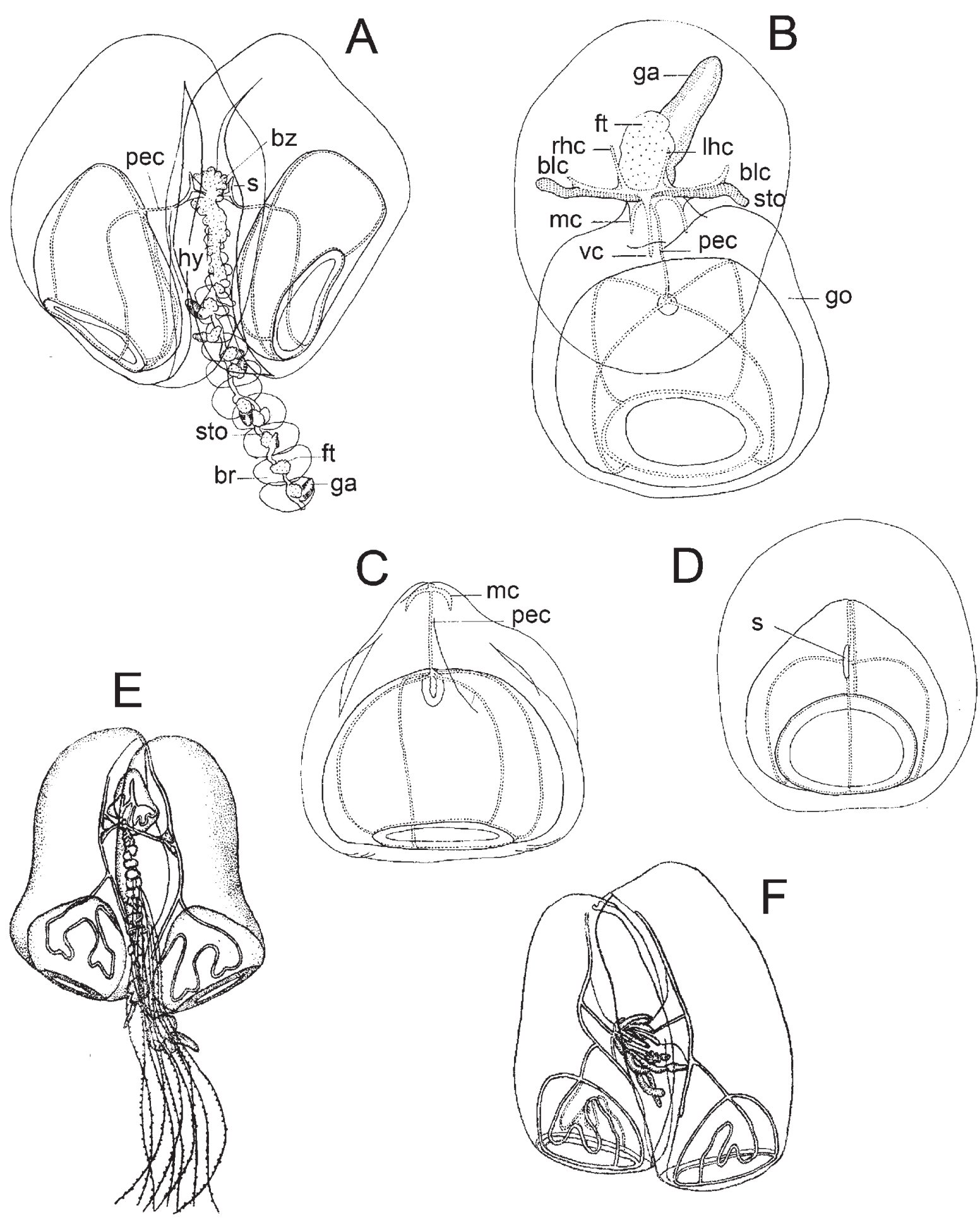

FIG. 140. - Siphonophorae. Prayidae. A to D: Prayola tottoni: A: polygastric stage; B: cormidia from below; C: gonophore (ventral view); D: nectophore (ventral view). E and F: Rosacea cymbiformis: E: young polygastric stage; F: two definitive nectophores (A to D after Carrè C, 1969c; E and F after Trègouboff, 1957). blc: bracteal longitudinal canal; br: bract; bz: budding zone; ft: fishing tentacle; ga: gastrozooid: go: gonophore; hy: hydroecium; lhc: left hydroecial canal; mc: mantel canal; pec pedicular canal; rhc: right hydroecial canal; s: somatocyst; sto: stolon; vc: ventral canal. 

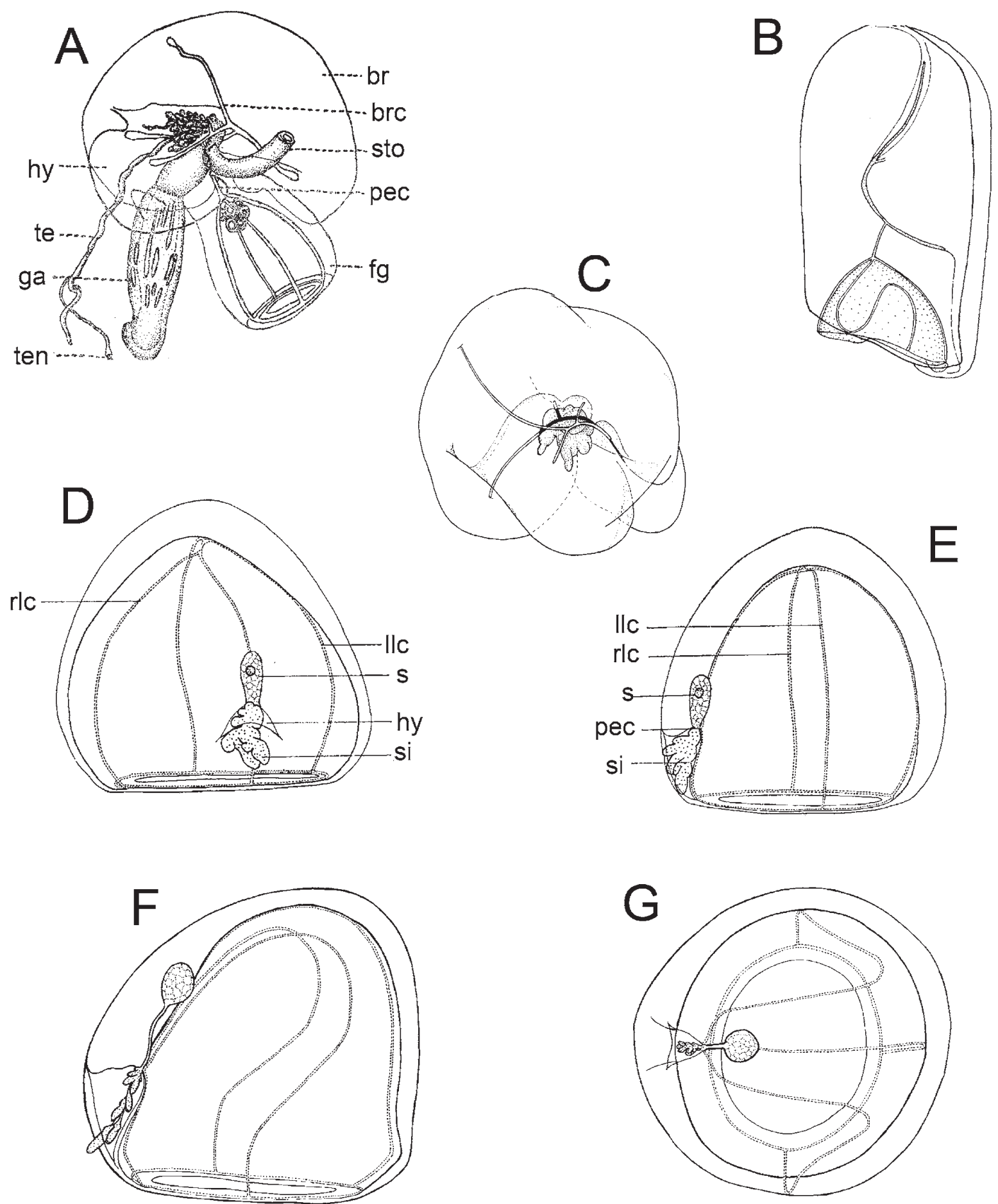

FIG. 141. - Siphonophorae. Prayidae. A to C: Rosacea: A: Rosacea cymbiformis: adult cormidia; B and C: Rosacea plicata: B: nectophore (lateral view); C: eudoxid bract (dorso-lateral view). Sphaeronectidae: D to G: Sphaeronectes: D and E: Sphaeronectes bougisi: nectophores; D: lateral view; E: ventral view. F and G: Sphaeronectes fragilis: nectophores: F: lateral view; G: apical view (A after Trègouboff, 1957; B and C after Kirkpatrick and Pugh, 1984; D and E after Carrè, 1968d; F and G after Carrè, 1968c). brc: bracteal canal; br: bract; fg: female gonophore; ga: gastrozooid; hy: hydroecium; llc: left lateral canal; pec: pedicular canal; rlc: right lateral canal; s: somatocyst; si: siphonosome; sto: stolon; te: tentacle; ten: tentillum. 

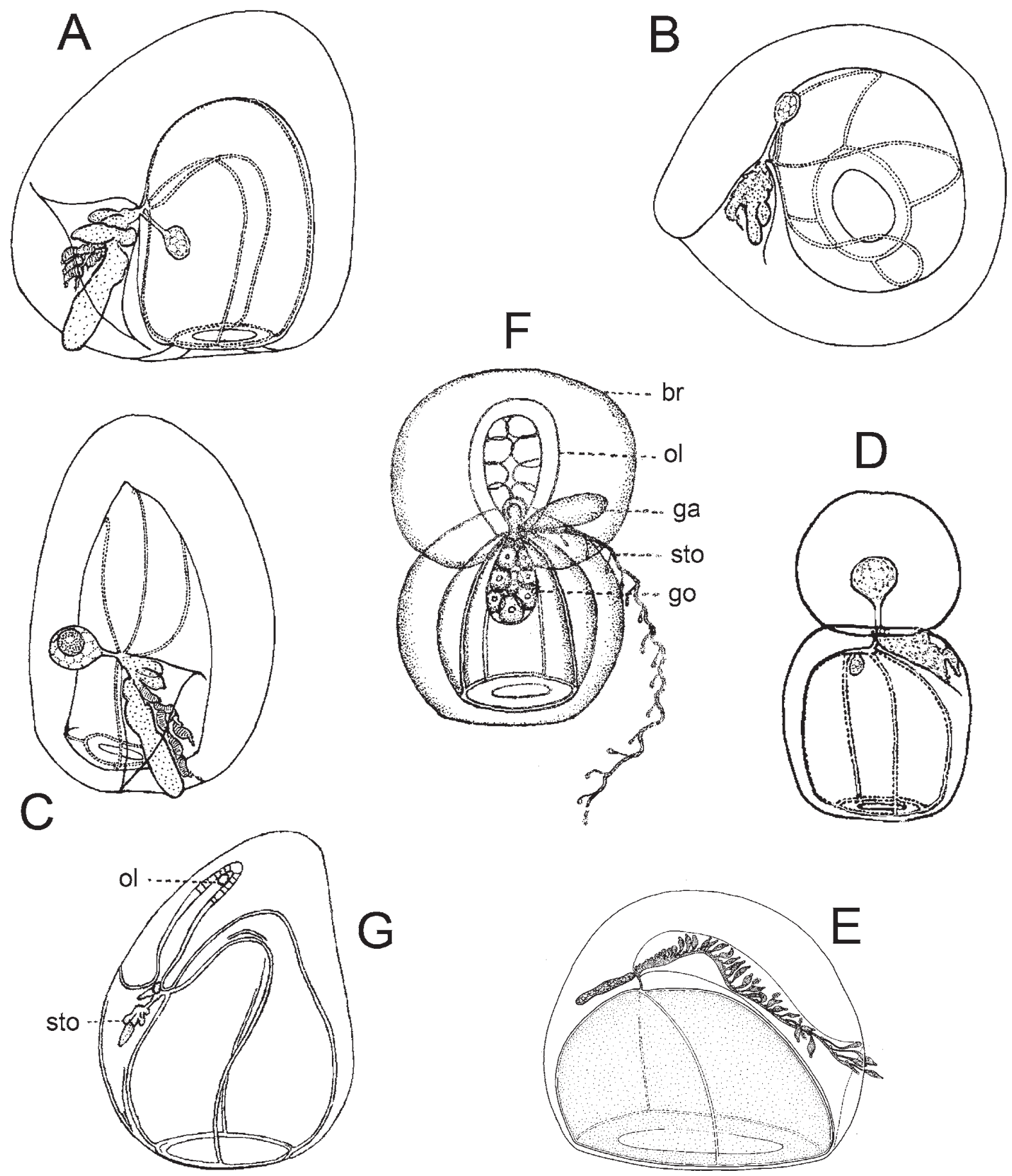

FIG. 142. - Siphonophorae. Sphaeronectidae. A to G: Sphaeronectes: A to D: Sphaeronectes gamulini: A to C: nectophores: A: lateral view; B: apical view: C: ventral view. D: eudoxia. E and F: Sphaeronectes gracilis: E: polygastric stage; F: eudoxid stage. G: Sphaeronectes irregularis: nectophore (A to D after Carrè, 1966, E after Pagès and Gili, 1992; F and G after Trègouboff, 1957). br: bract; ga: gastrozooid; go: gonophore; ol: oleocyte; sto: stolon. 

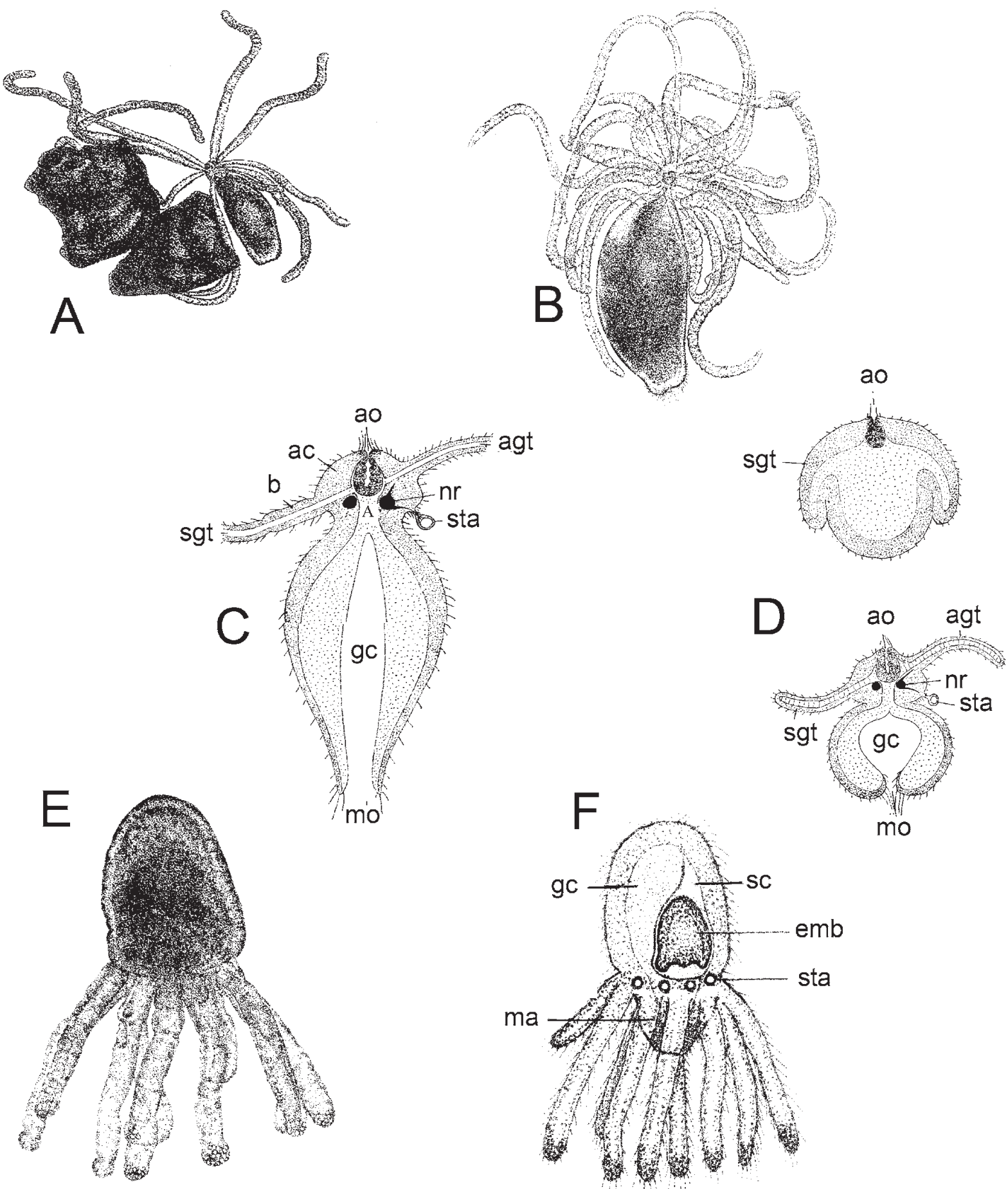

FIG. 143. - Actinulidae. Halammohydridae. A to D: Halammohydra: A: Halammohydra octopodides general view; B to D: Halammohydra schulzei: B: general view; C: structural organization; D: above young actinula, below halhydrula. Otohydridae. E and F: Otohydra vagans: E: general view; F: structural organization (A to E after Swedmark and Tesssier, 1966; F after Swedmark and Tessier, 1958c). ac: aboral cone; agt: tentacle of the aboral girdle; ao: adhesive organ; b: tentacular bulb; emb: embryo; gc: gastric cavity; ma: manubrium; mo: mouth; nr: nerve ring; sc: subumbrellar cavity; sgt: tentacle of the subaboral girdle; sta: statocyst. 


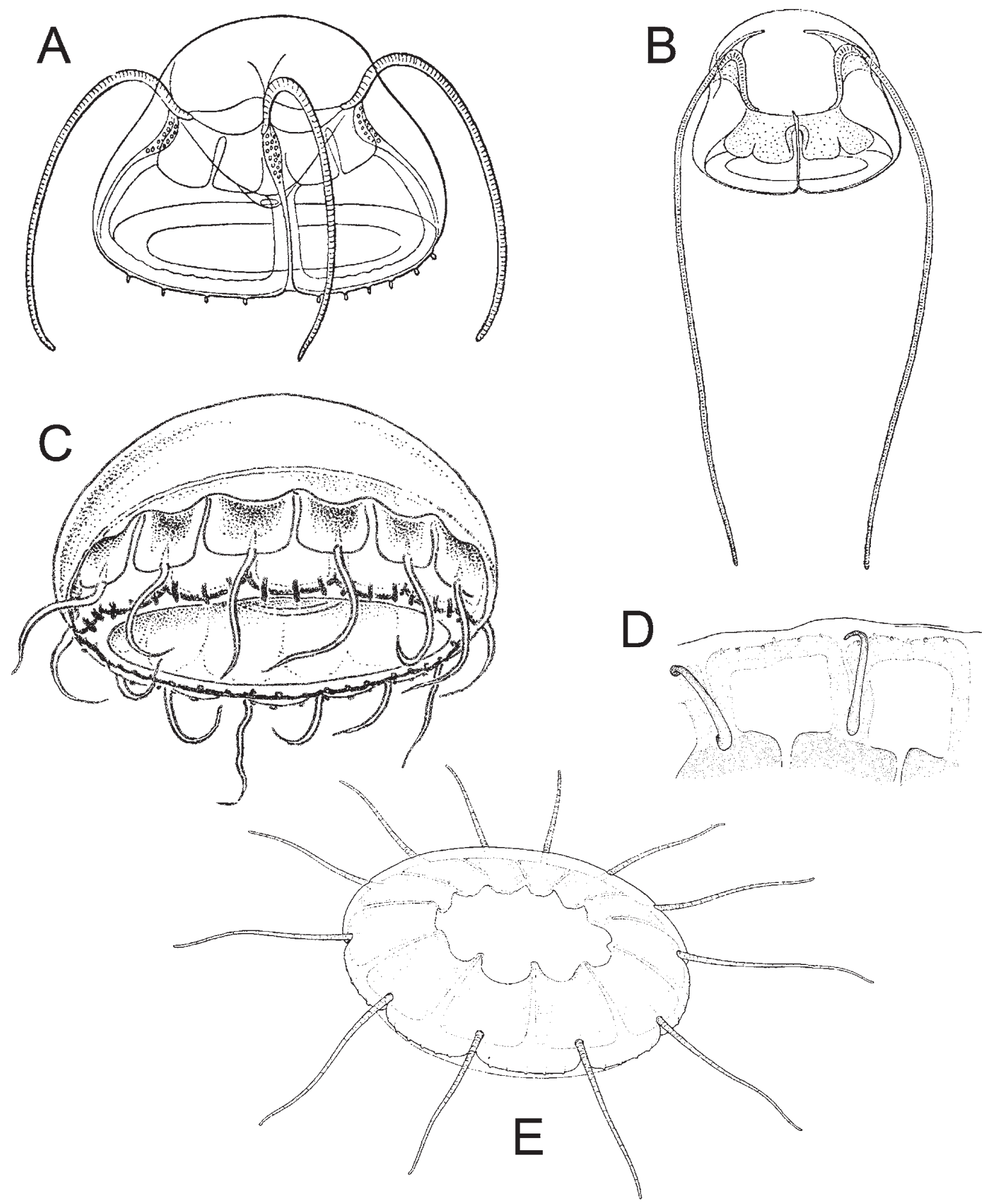

FIg. 144. - Narcomedusae. Aeginidae. A: Aegina citrea mature medusa; B: Solmundella bitentaculata fully-grown medusa. Cuninidae. C: to E: Cunina: C and D: Cunina globosa: C: adult medusa , D: portion of umbrella; E: Cunina octonaria mature medusa (A after Mayer, 1910; B and C after Kramp, 1959a; D after Gili et al., 1998; E after Bouillon, 1987). 

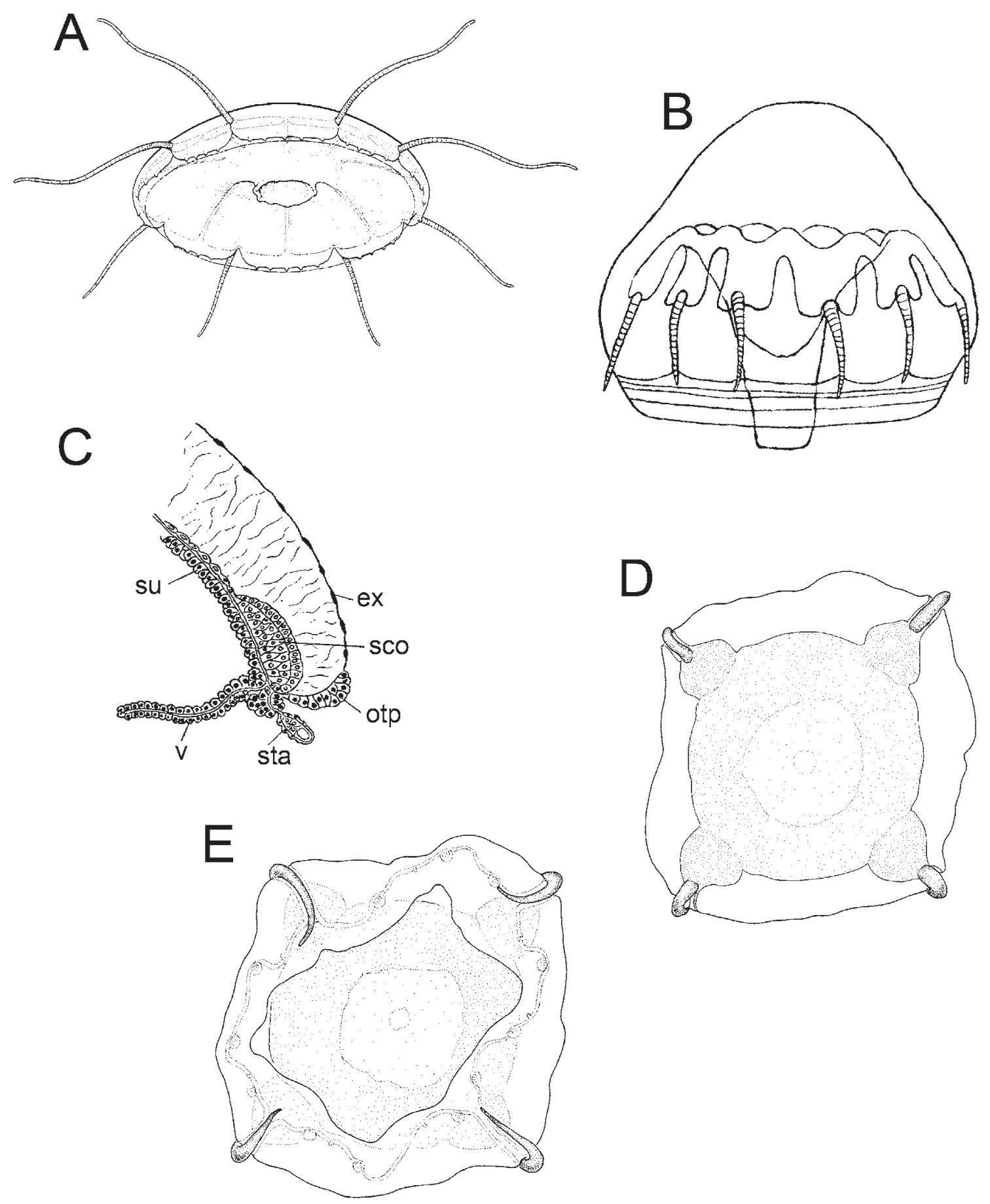

FIG. 145. - Narcomedusae. Cuninidae. A to E: Cunina: A: Cunina octonaria mature medusa; B and C: Cunina proboscidea: B: whole medusa; C: radial section through a statocyst and an otoporpae. D and E: Cunina simplex: D: aboral view; E: oral view (A after Bouillon, 1987; B and C after Mayer, 1910; D and E after Gili et al., 1998). ex: exumbrella; otp: otoporpae; sco: solid core replacing the ring canal; sta: statocyst; su: subumbrella; v: velum. 


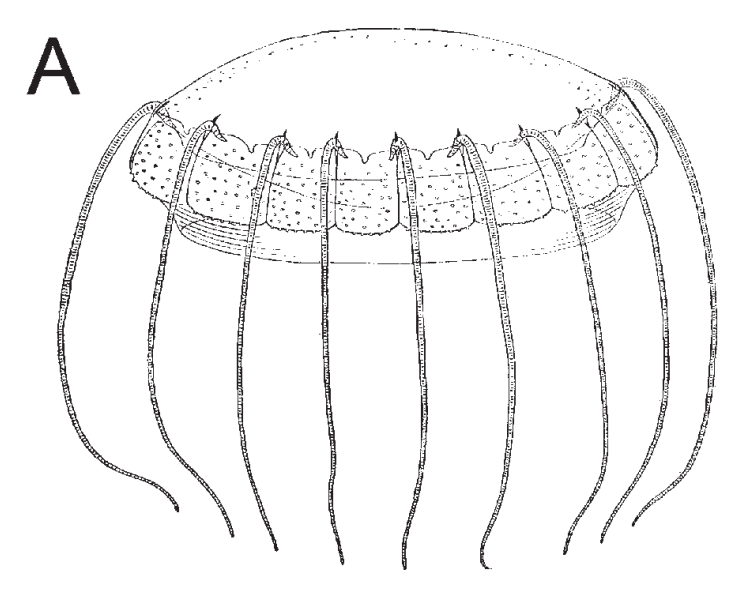

\section{B}
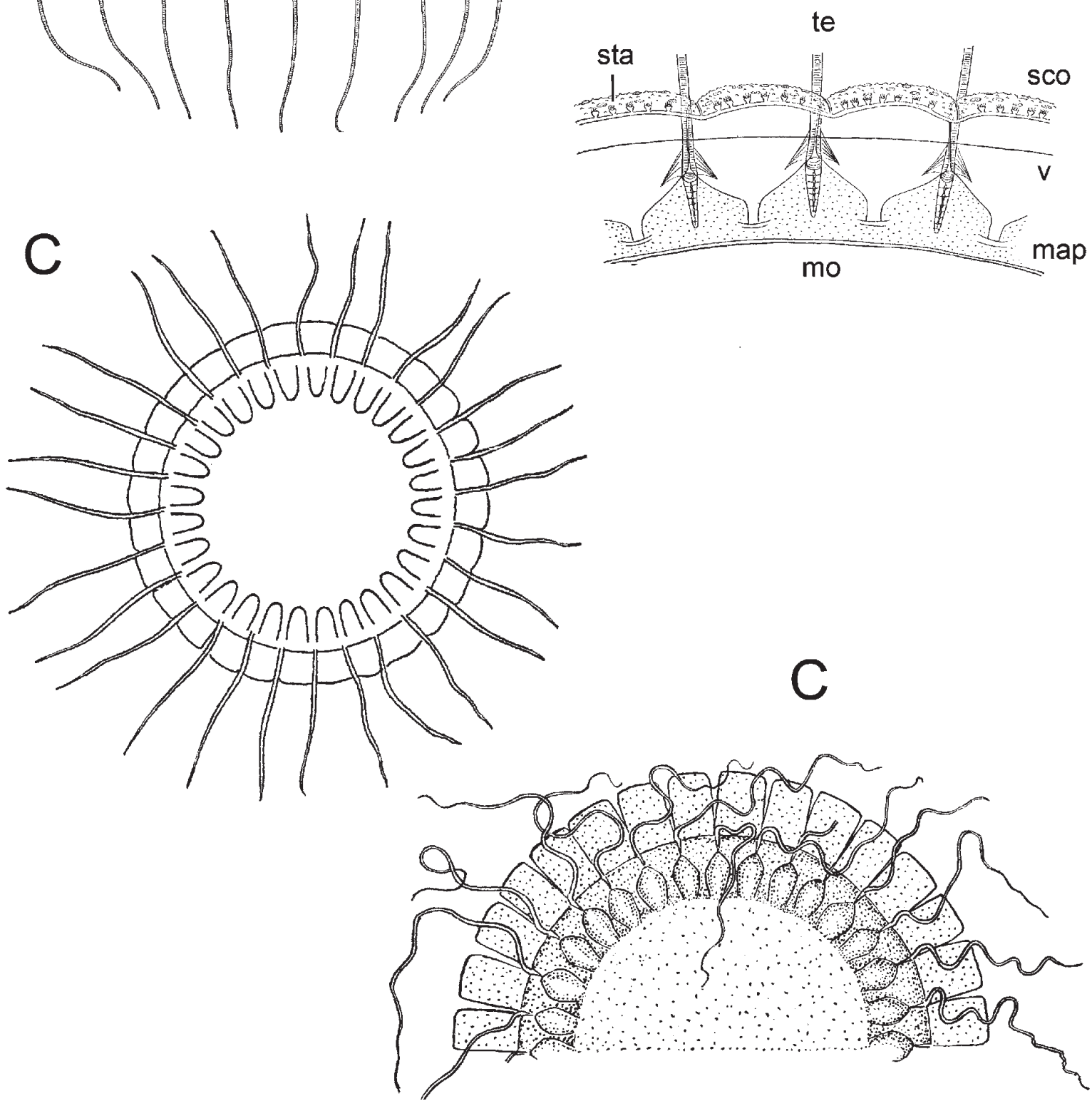

FIG. 146. - Narcomedusae. Cuninidae. A to D: Solmissus. A and B: Solmissus albescens: A: fully-grown medusa; B: portion of umbrella margin; C and D: Solmissus incisa: C: whole medusa; D: portion of umbrella (A and B after Mayer, 1910; C after Russell, 1953; D after Broch, 1929) ex: exumbrella; map: manubrial pouches; mo: mouth; otp: otoporpae; sco: solid core replacing the ring canal; sta: statocyst; su: subumbrella; te: tentacle; v: velum. 

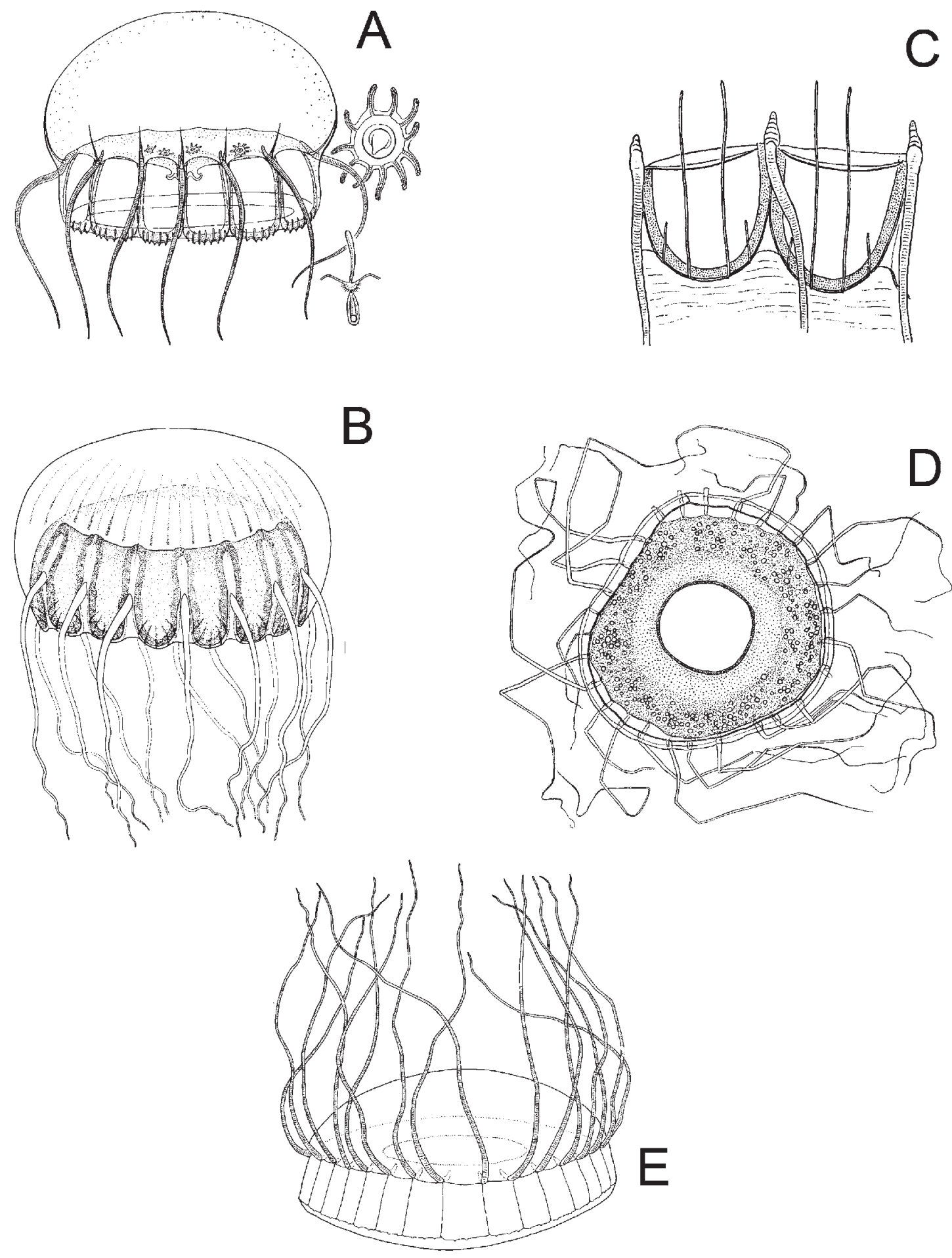

FIG. 147. - Narcomedusae. Solmarisidae. A to C: Pegantha: A and B: Pegantha rubiginosa: A: adult medusa with juveniles of first sexual embryonic generation inside manubrium, right above late stage of sexual development, below statocyst with otoporpae, B: portion of umbrella margin showing peronia and otoporpae; C: Pegantha triloba: adult medusa; D and E: Solmaris corona: D: oral view, E: lateral view of fully grown medusa (A and B after Mayer, 1910; D after Russell, 1953, E after Pagès et al., 1992). 

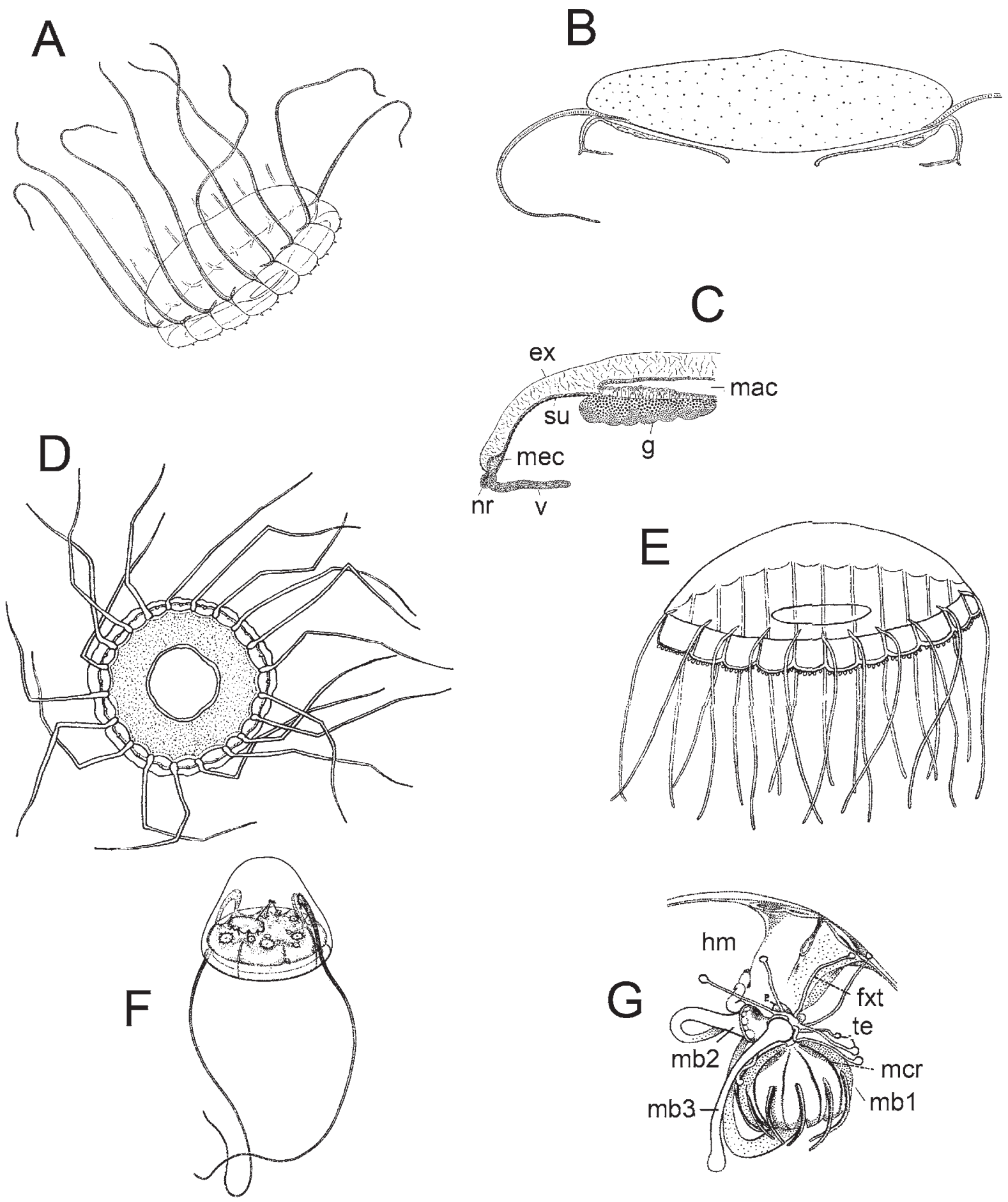

FIG. 148. - Narcomedusae. Solmarisidae. A to E: Solmaris: A to C: Solmaris flavescens: A: whole medusa; B: diagrammatic section of a medusa; C: detail of exumbrella. D: Solmaris leucostyla: fully-grown medusa; E: Solmaris solmaris: adult medusa. Narcomedusae development. F: Solmundella bitentaculata parasitized by Cunina peregrina at different stages of reproduction; G: different stages of development of Pegantha triloba parasitizing an Anthomedusae Pseudotiara tropica (A to C after Mayer, 1910; D after Gili, 1986; E after Trègouboff, 1957; F and G after Bouillon, 1897). ex: exumbrella; fxt: tentacles of the primary larval stage serving for fixation; g: gonad; hm: manubrium of the host; mac: manubrium cavity; mb1, mb2 and mb3: successive stages of medusa buds formed by the primary larval parasitic stage; mcr: median crests of umbrellar lobes of Pegantha triloba medusae buds; mec: marginal endodermal core; nr: nerve ring; pls: primary larval stage; su: subumbrella; te: tentacle; v: velum. 


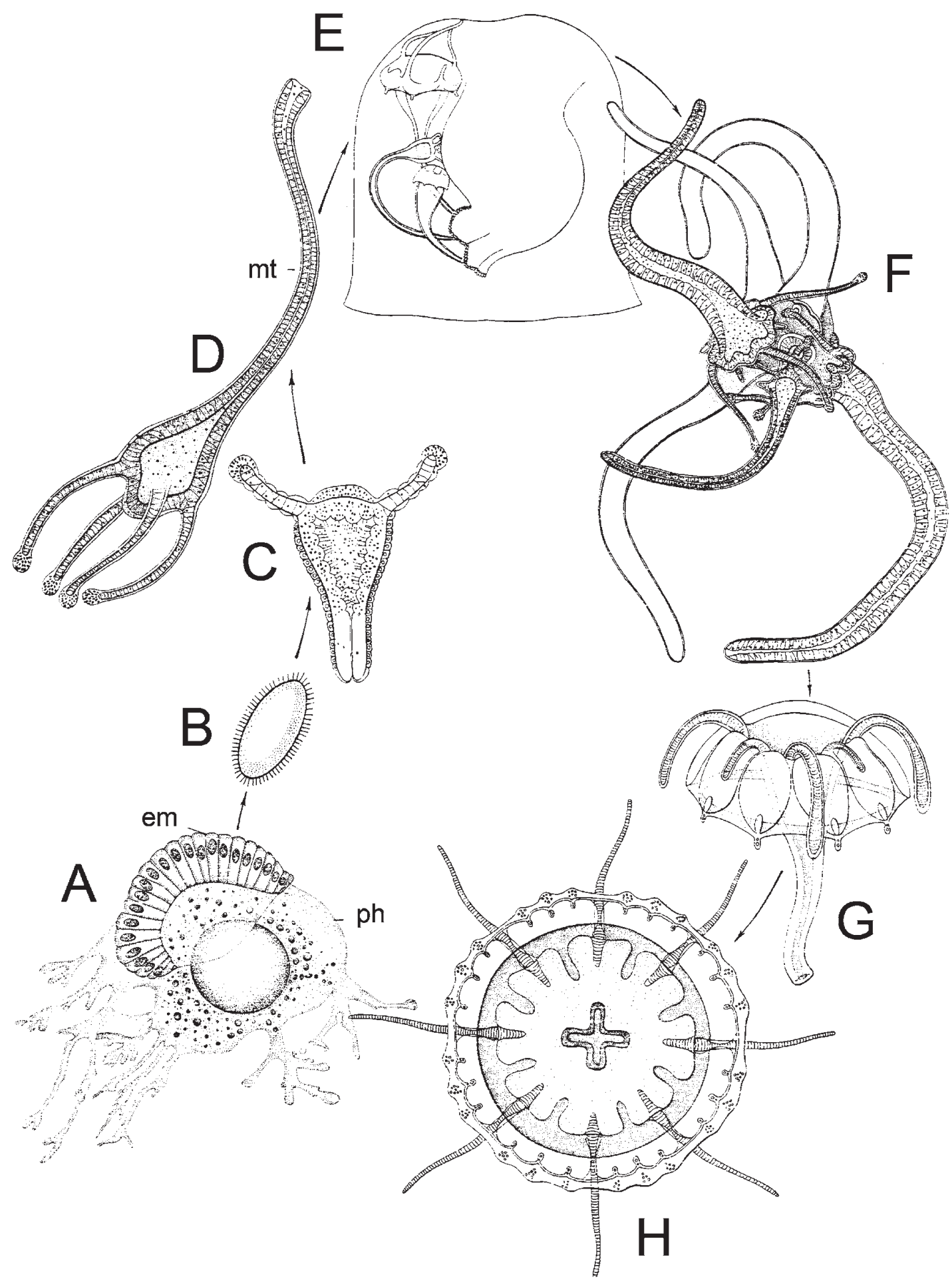

FIG. 149. - Narcomedusae development (continued). Development of Cunina octonaria parasitizing Turritopsis nutricula, Anthomedusae. A: Young embryo (Em), blastula, in his phorocyte developing in the gastro-vascular pouches of the Cunina mother, B: free planula stage; C: bitentaculate primary larvae issued from the planula, D: primary larvae with four tentacles and manubrial tube, ready to parasite its future host, E: primary larvae fixed by the tentacles on the subumbrellar ectoderm of the Turritopsis host, F: primary larvae budding of secondary larvae from their aboral end, G: young Cunina issued from a parasitic larvae, H: adult medusae from Cunina octonaria (copied from Bouillon, 1987) 

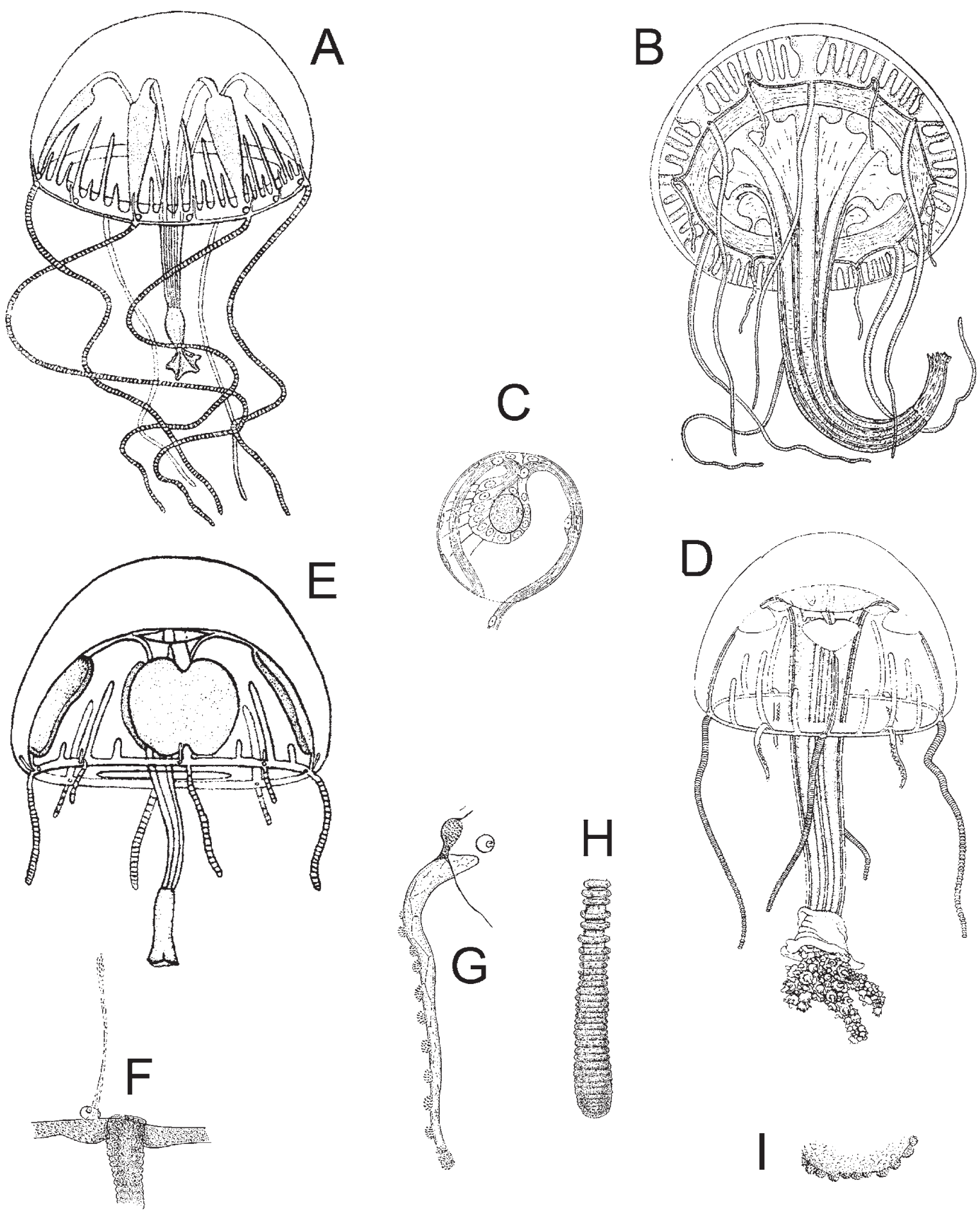

FIG. 150. - Trachymedusae. Geryoniidae. A to C: Geryonia proboscidalis. A and B: general view, C: statocyst. D to I: Liriope tretraphylla: D: adult medusa parasitised by Cunina octonaria: $\mathrm{E}$ : general view of adult medusa; F: base of a solid interradial marginal tentacle with a centripetal canal and statocyst: $\mathrm{G}$ : lateral view of a solid marginal tentacle showing a statocysts and the marginal cnidocyst ring of the umbrella; H: terminal portion of a hollow perradial tentacle; I: portion of margin of mouth-lip (A after Hyman, 1940; B after Trègouboff, 1957; C after Hertwig O and R., 1878; D after Bouillon, 1987; E after Trègouboff, 1957; F, G, H and I after Russell, 1953). 

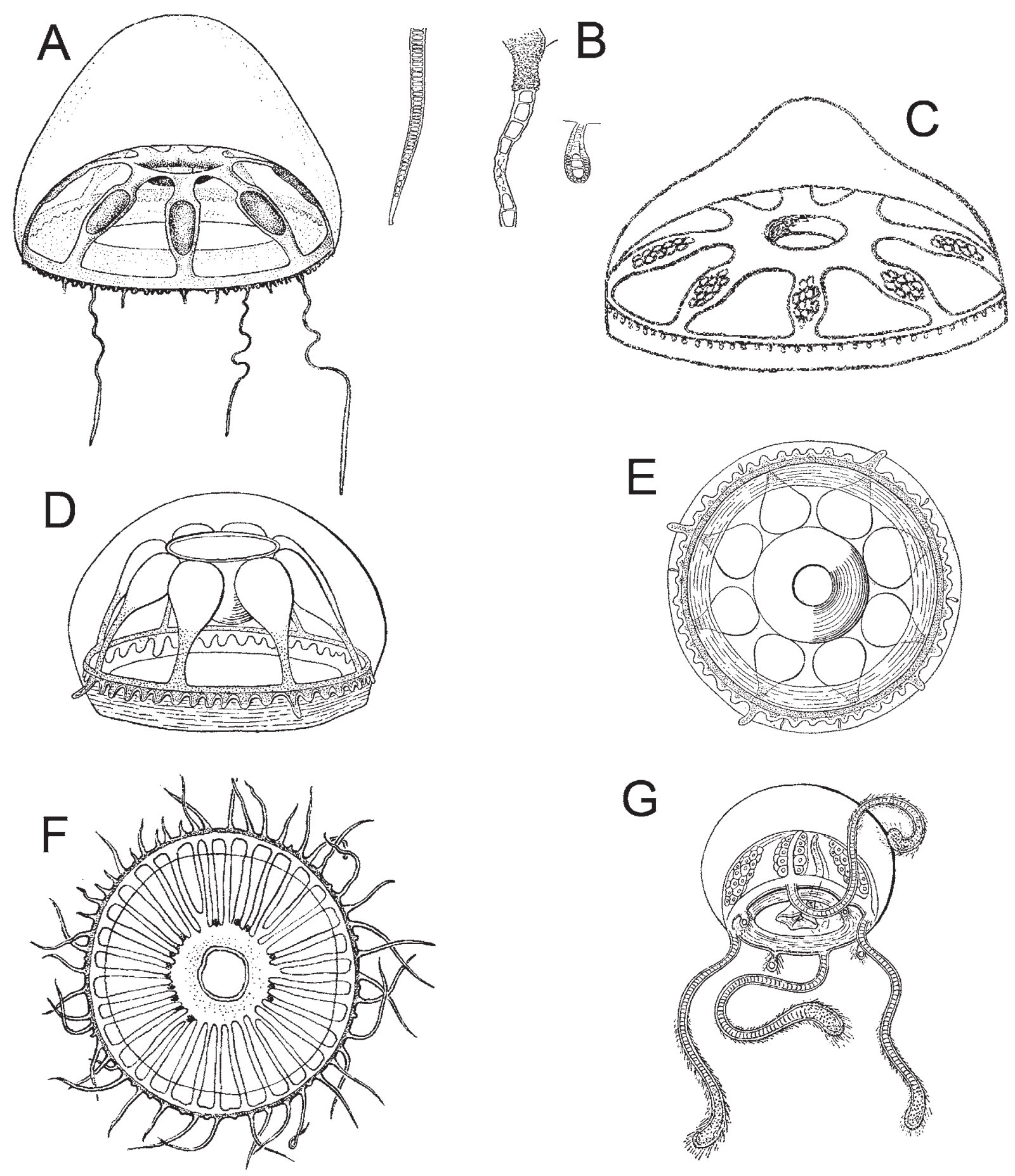

$G$

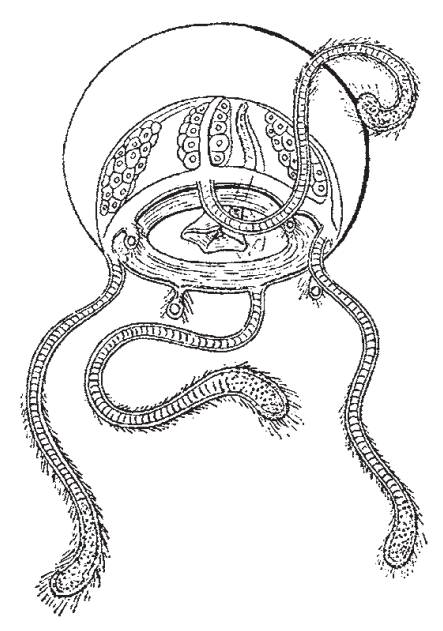

FIG. 151. - Trachymedusae. Halicreatidae. A to E: Haliscera: A and B: Haliscera bigelowi: A: fully-grown medusa, B: left: stiff distal end of marginal tentacle, middle: flexible proximal portion of marginal tentacle, right: statocyst; C: Haliscera conica mature medusa; D and E: Haliscera racovitzae: D: lateral view of mature medusa, E: oral view; F: Halitrephes maasi whole mature medusa. Petasidae. G: Petasus atavus fully-grown medusa (A, F and G after Kramp, 1959a; B after Russell, 1953; C, D and E after Mayer, 1910). 

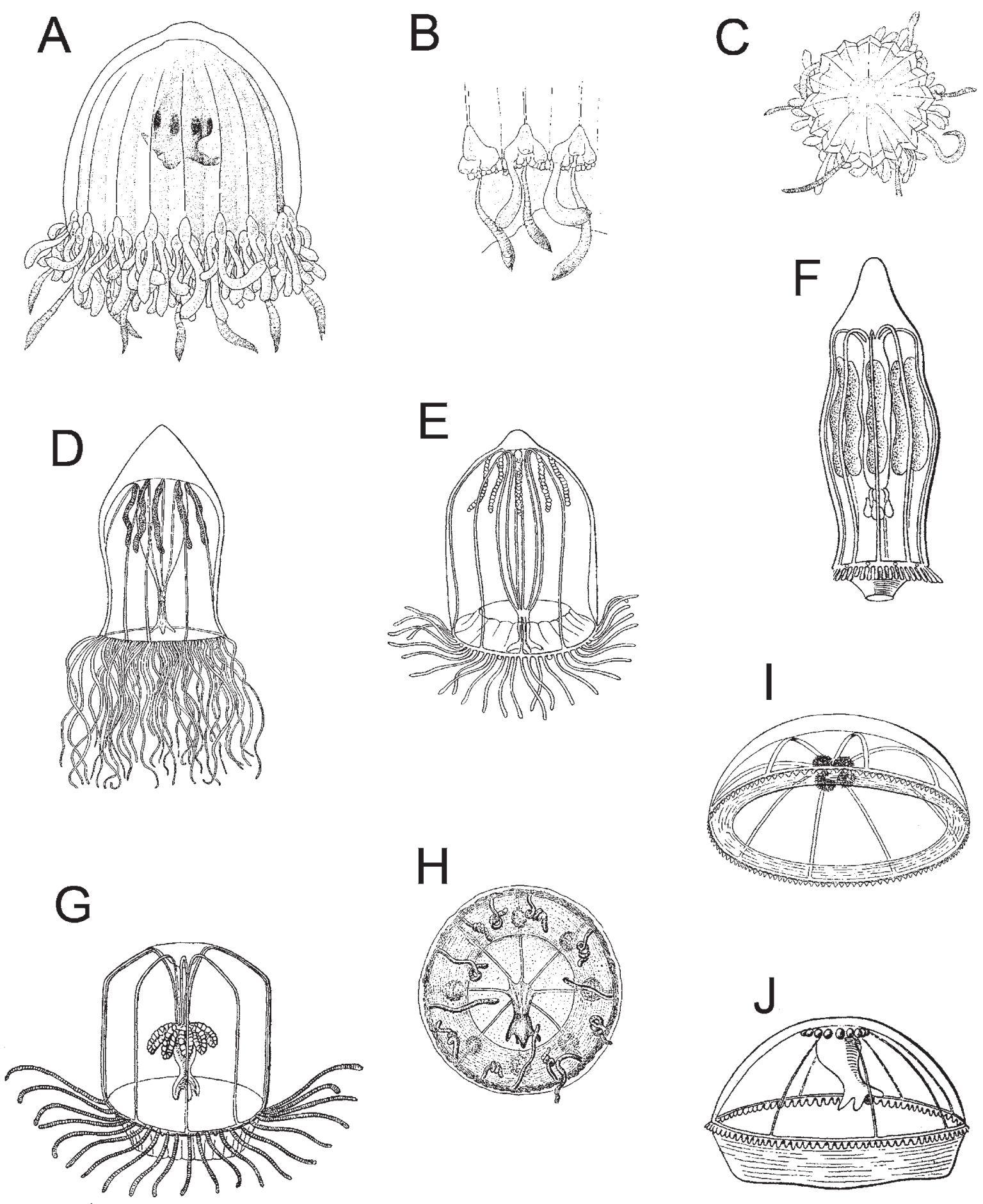

FIg. 152. - Trachymedusae. Ptychogastriidae. A to C: Ptychogastria asteroides: A: lateral view of an adult medusa, B: detail of marginal border, C: upper view of the umbrella of a juvenile specimen. Rhopalonematidae. D to F: Aglantha: D and E: Aglantha digitale: lateral views of adult medusae; F: Aglantha elata: fully-grown medusa; G: Aglaura hemistoma: mature medusa; H: Amphogona pusilla: adult medusa; I and J: Arctapodema ampla: fully grown medusae (A to C after Gili et al., 1999; D after Hyman, 1940; E after Broch, 1929; F to I after Kramp, 1959a; J after Mayer, 1910). 

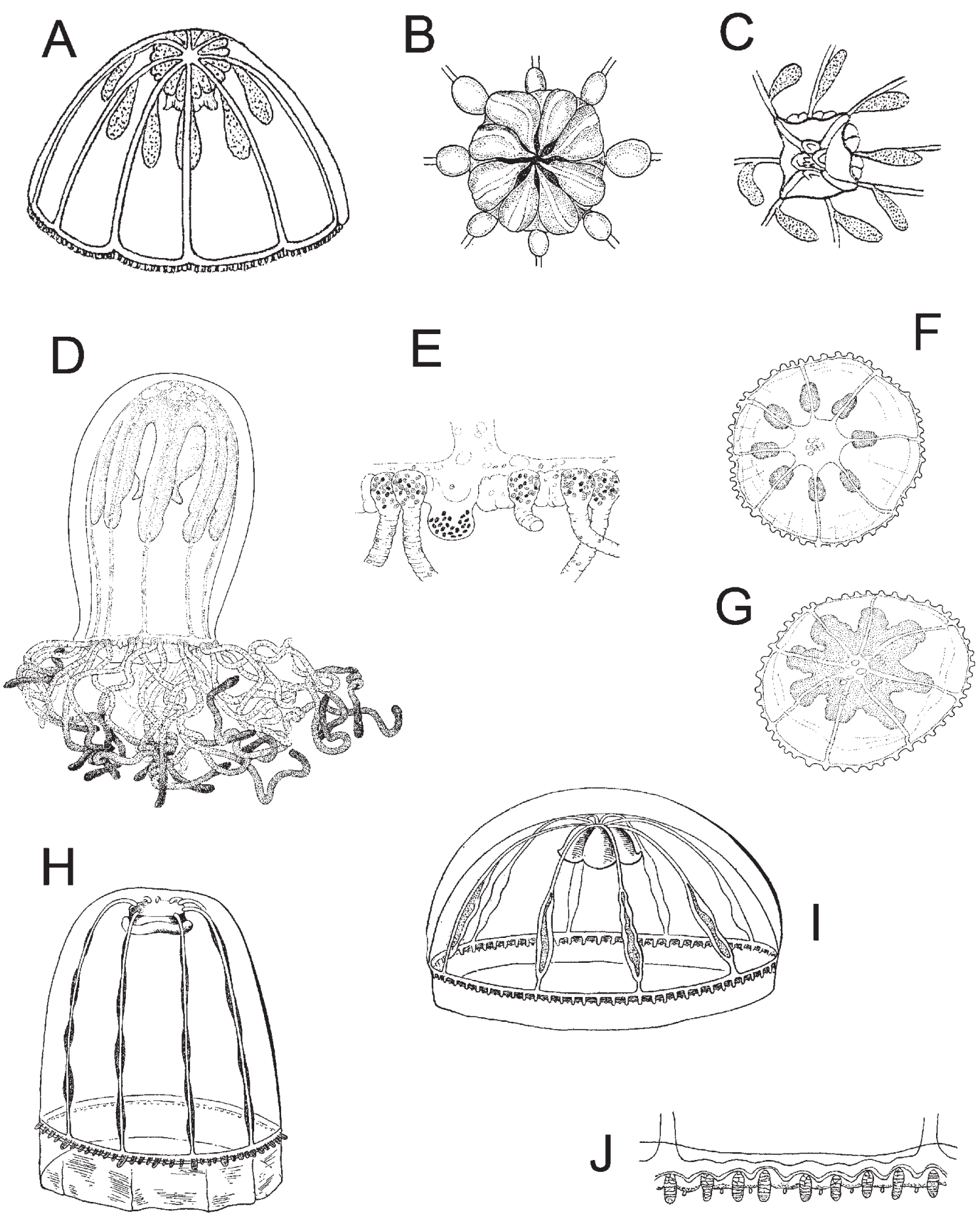

FIG. 153. - Trachymedusae. Rhopalonematidae. A to C: Arctapodema australis: A: lateral view of a mature medusa, B and C: aboral views of manubrium and gonads; D to G: Homoeonema platygonon: D: lateral view of mature medusa, E: detail of umbrella margin, F: aboral view of a juvenile specimen, G: aboral view of a mature specimen; $\mathrm{H}$ to J : Pantachogon haeckeli: $\mathrm{H}$ and I: aspect of two fully grown medusae, J: portion of umbrella margin (A and C after Vanhoeffen, 1913; B after Kramp, 1959a; D to G after Gili et al., 1998; H and I after Mayer, 1910; J after Russell, 1953). 

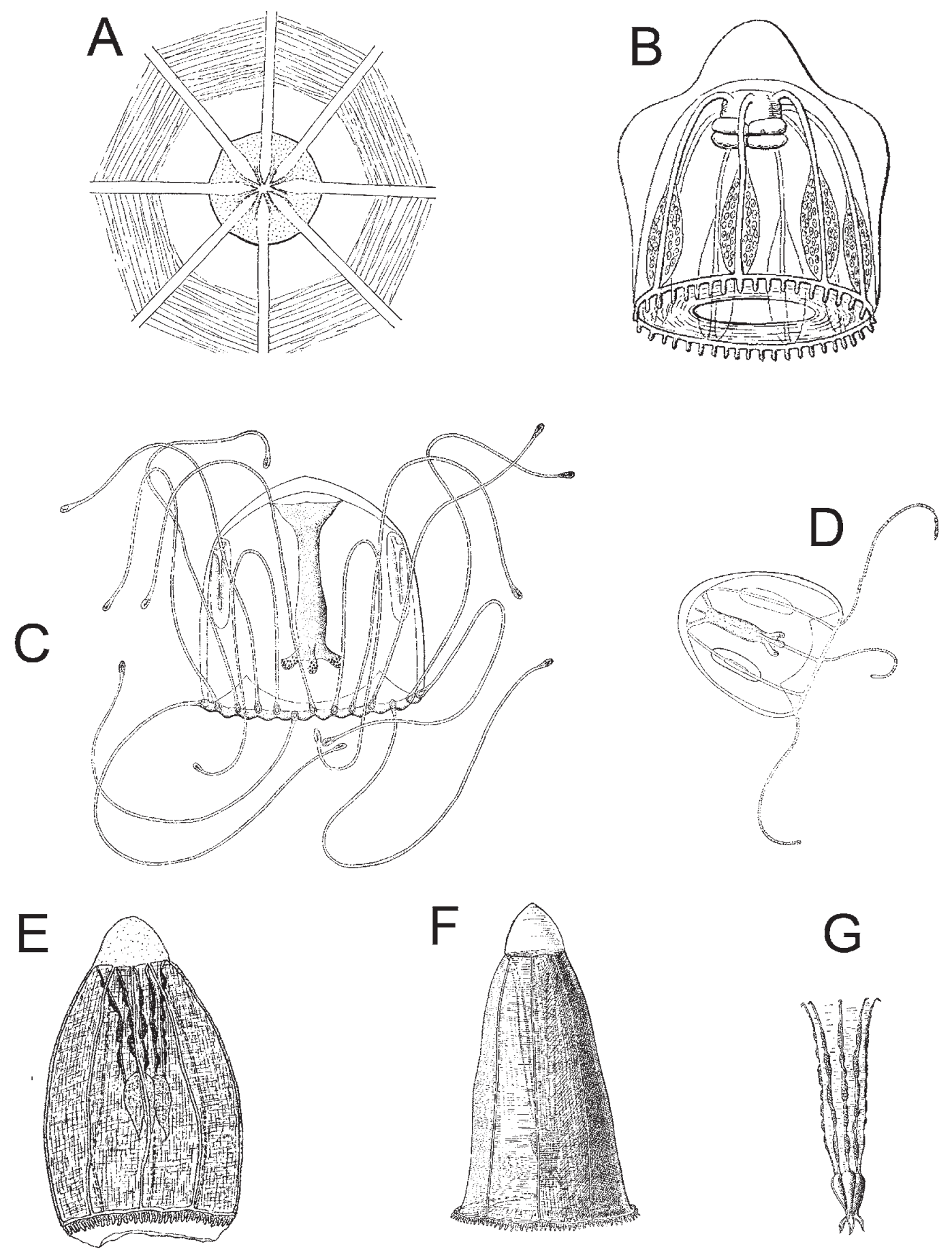

FIG. 154. - Trachymedusae. Rhopalonematidae. A: Pantachogon haeckeli: apical view of the summit of the umbrella showing the manubrium, the radial canals and the muscle fields; $\mathrm{B}$ : Pantachogon militare: fully-grown medusa; $\mathrm{C}$ and D: Persa incolorata: $\mathrm{C}$ : adult medusa, D: juvenile medusa; E to G: Ransonia krampi: E and F: lateral views of mature medusae, G: detail of manubrium (A after Russell, 1953; B, C and D after Mayer, 1910; E after Gili, 1986; F and G after Kramp, 1959a). 

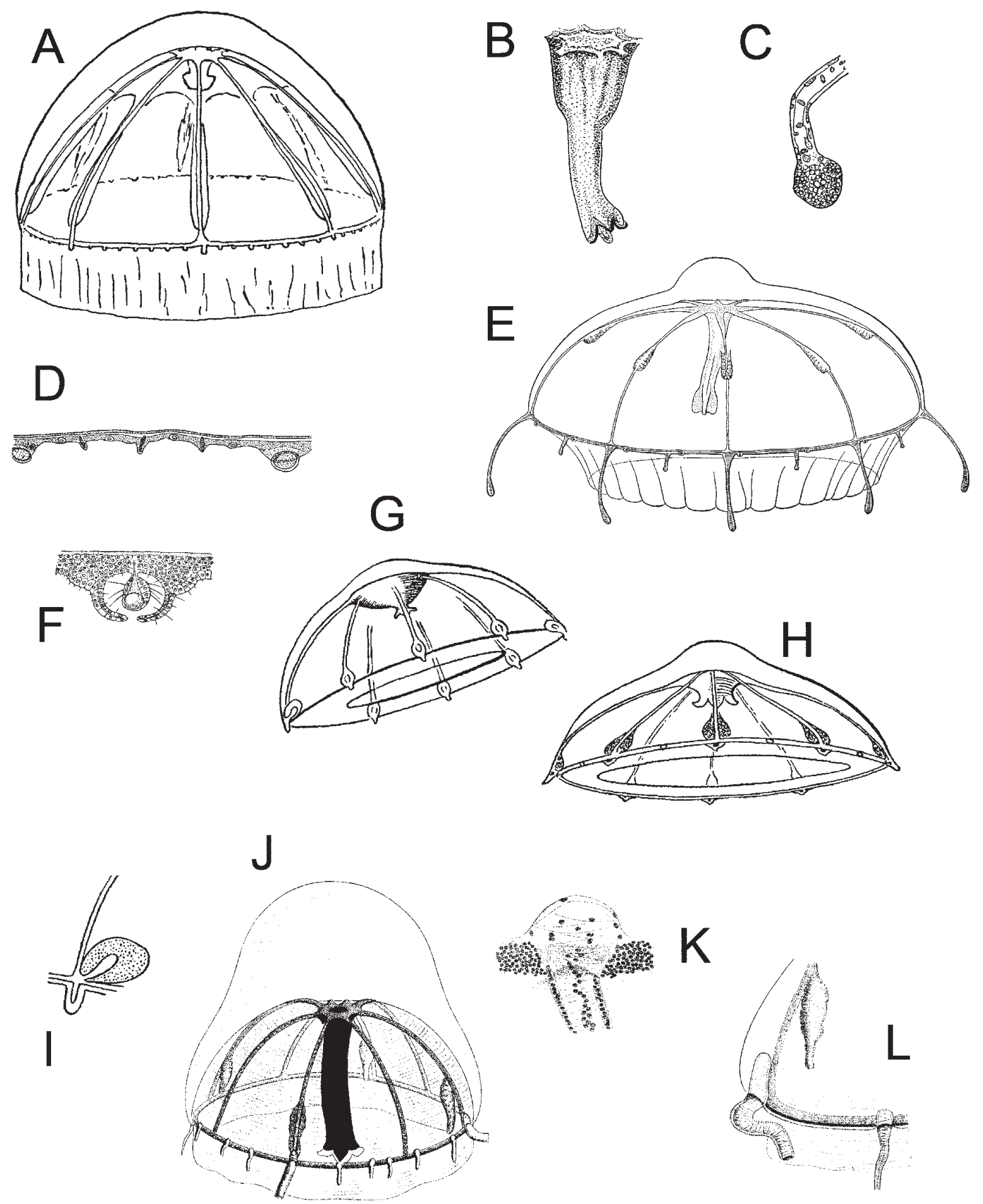

FIG. 155. - Trachymedusae. Rhopalonematidae. A to F: Rhopalonema. A to D: Rhopalonema funerarium: A: fully grown medusa, B: detail of manubrium, C: detail of interradial marginal tentacle, D: portion of umbrella margin; E and F: Rhopalonema velatum: E: mature medusa, F: statocyst; G to I: Sminthea eurygaster: G and H: lateral views of adult medusae, I: enlarged view of a gonad; J to L: Tetrorchis erythrogaster: J: fully grown medusa, K: base of a small tentacle with rounded endodermic tentacular root, L: side view of the umbrella showing the position of the a gonad and the endodermic tentacular root of a perradial tentacle (A to D after Russell, 1953; E, G to I after Mayer, 1910; F after Hertwig and Hertwig, 1878; J to L after Bigelow, 1909). 


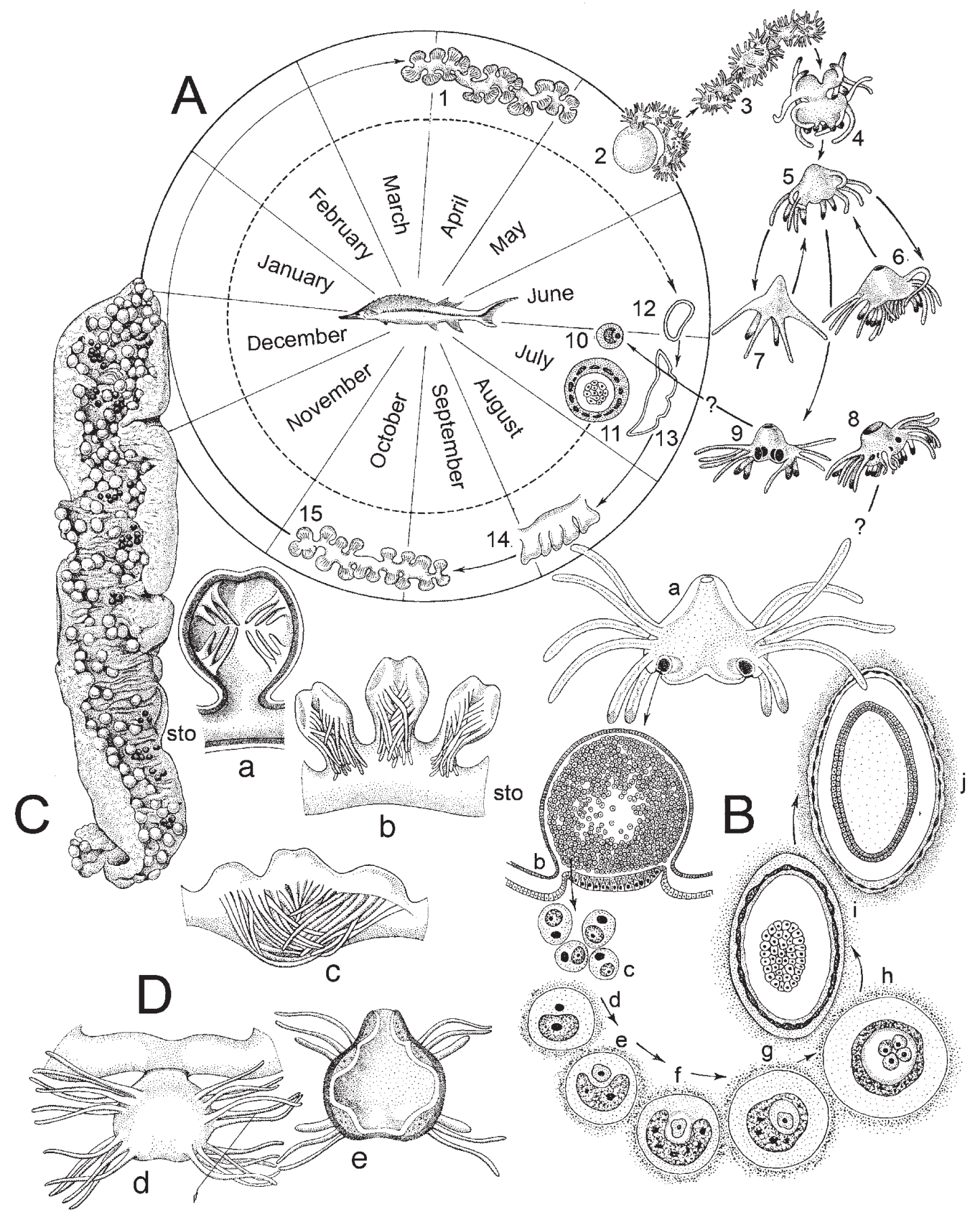

FIG. 156. - Polypodiozoa. Polypodiidae. Polypodium. Life cycle of Polypodium hydriforme internal parasite of Acipenserid fishes. A: general cycle: 1: reversed stolon prolifer; 2: stolon prolifer living an infected acipenserid egg; 3 : stolon prolifer in the water; 4: fragment of a stolon; 5: polyp with 12 tentacles; 6: polyp with 24 tentacles; 7: polyp with 6 tentacles; 8: female polyp; 9: male polyp; 10: binucleate cell parasite of an acipenserid oocyte; 11: morula encapsulated in the trophamion; 12: planula; 13: budding planula; 14: stolon prolifer without tentacles; 15: stolon prolifer reversed with internal tentacles. B: diagram of the formation of the trophamion: a: sexual medusa; b: gonad with binucleated cells; c: binucleated cells; $\mathrm{d}$ to g: binucleated cells parasite of a fish oocyte; h: segmentation of the embryo; i: morula stage inside the trophamion; j: planula stage inside the trophamion. C: ovary of an Acipenser, the large eggs are parasitised, the small ones are not. D: a to c: reversed buds with internal tentacles on a stolon prolifer (St.); $\mathrm{d}$ : stolon prolifer with external tentacles; e: medusae liberated from an infected fish egg (Redrawn from Bouillon, 1987).

438 J. BOUILLON et al. 